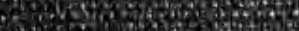








\section{HANDBUCH}

DES

\section{DEUTSCHEN UNTERRICHTS AN HÖHEREN SCHULEN}

BEGRUNDET VON

DR. ADOLF MATTHIAS

WIRKL. GEH. OBER-REGIERUNGSRAT

UND VORTRAGENDEM RAT IM PREUSS. KULTUSMINISTERIUM

\section{SECHSTER BAND}

GESCHICHTE DER DEUTSCHEN LITERATUR BIS ZUM AUSGANG DES MITTELALTERS

ZWEITER TEIL

DIE MITTELHOCHDEUTSCHE LITERATUR

I. FRUHMITTELHOCHDEUTSCHE ZEIT

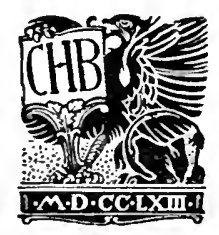

MÜNCHEN 1922

C. H. BECK'SCHE VERLAGSBUCHHANDLUNG

OSKAR BECK 


\title{
GESCHICHTE \\ DER \\ DEUTSCHEN LITERATUR BIS ZUM AUSGANG DES MITTELALTERS
}

\author{
VON \\ DR. GUSTAV EHRISMANN \\ O. PROFESSOR DER UNIVERSITÄT GREIFSWALD
}

ZWEITER TEIL

DIE MITTELHOCHDEUTSCHE LITERATUR

I. FRÜHMITTELHOCHDEUTSCHE ZEIT
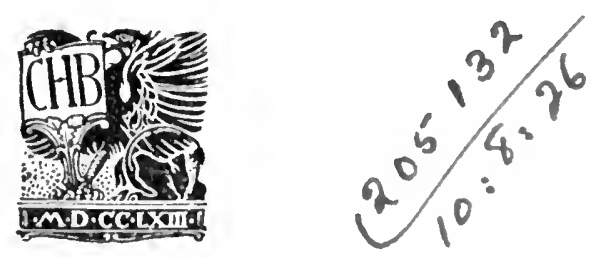

MÜNCHEN 1922

C. H. BECK'SCHE VERLAGSBUCHHANDLUNG

OSKAR BECK 


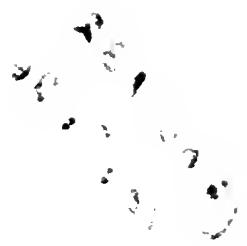

Germany 


\section{VORWORT}

$\mathrm{D}$ ie für das Handbuch des deutschen Unterrichts bestimmte Geschichte der deutschen Literatur bis zum Ausgang des Mittelalters (die altdeutsche Literatur) ist auf vier Bände berechnet. Der erste, 1918 erschienene Band ( $=$ Erster Teil), enthält die althochdeutsche, der hier vorliegende zweite die frühmittelhochdeutsche Zeit; die mittelhochdeutsche Blüte- und Spätzeit sollen als dritter und vierter Band folgen (Bd. II. III. IV $=Z$ weiter Teil).

Die Geschichte der altdeutschen Literatur, wie sie hier geplant ist, nimmt alle in deutscher Sprache utberlieferten Werke des althochdeutschen und mittelhochdeutschen Zeitraums auf. Sie ist aufgefaßt als „eine Geschichte des deutschen Schrifttums"1) oder auch als "ein Stück Entwicklungsgeschichte des geistigen Lebens" des deutschen Volkes. ${ }^{2}$ ) Sie fällt nicht mit dem Gebiet der altdeutschen Dichtkunst zusammen, sondern hat einen viel weiteren Umfang und betrifft verschiedenartige Wissenskreise.

Die leitenden Grundsätze sind im Vorwort zum I. Band angedeutet, sie sollen hier in ein System gefaßt werden.

Unter fünf Gesichtspunkten (Einstellungen) kann der Literarhistoriker seinen Stoff betrachten und danach seine Aufgabe einrichten. Aber jede dieser Forschungsweisen beleuchtet nur einen Teil des beobachteten Gegenstandes, zu einer allseitigen Erkenntnis kann nur ihre Vereinigung führen. Sie müssen also alle zusammen zur Erklärung angewendet werden. ${ }^{3}$ )

1) RiCH. HeinZEL, Kleine Schriften S. 417.

2) ERICH SCHMIDT, Charakteristiken I, 2. Aufl., S. 466.

3) Ueber Wesen und Methodik der Literaturgeschichte vgl. WilHelm Dilthey, Das Schaffen des Dichters, Bausteine zu einer Poetik, Philosoph. Aufsätze, Eduard Zeller gewidmet, 1887, S. 303-482, Das Wesen der Philosophie, Kultur d. Gegenwart Teil l Abt. VI, 1907, S. 1-71, Das Erlebnis u. die Dichtung, 1. Aufl. 1905, 7. Aufl. 1921; ERICH RothaCKER, Einleitung in die Geisteswissenschaften, 1920 (für den Germanisten bes. S. 190 ff.). - ERICH SснміDT, Wege u. Ziele der deutschen Literaturgesch., 1880, Charakteristiken I, 2. Aufl. S. 455-4i2; BERNH. TEN BRINK, Ueber die Aufgabe der Literaturgesch., 1891; W. WETZ, Ueber Literaturgesch., 1891; HUGO FALKENHEIM, Kuno Fischer u. d. litterarhistor. Methode, 1892; ERnst EIsTER, Die Aufgaben der Litteraturgesch., 1894; Elster, Prinzipien der Litteraturwissensch., 2 Bde., 1897. 1911; GuST. ROethe, Anz. f. deutsches Altert. 24 (1898), 225-242; Otto Behaghel, BewuBtes u. Unbewußtes im dichterischen Schaffen, 1906; Rud. Unger, Philosoph. Probleme in der neueren Literaturwissensch., 1908; ERICH SChMidT, Die litterar. Persönlichkeit, 1909, Reden zur Litt.-u.Univers.gesch., 191 1,S.1 - 20; Elster, Ueber d. Betrieb der deutschen Philologie an unseren Universitäten, Neue Jahrb. XXIV (1909), 540-548; OSKAR F. WALZEL, Analytische u.synthetische Literaturforschung, Germ.-rom. Monatsschr. 11 (1910), 257-274. 321-341 (s. auch WALZEL, Dic künstl. Form des Dichtwerks, Deutsche Abende III, 1919, S. 38 f.); RICH. M. MEYer, Alte u. neue Literaturgesch., Germ.-rom. Monatsschr. 11, 342-347; EduARD Wechssler, Ueber die Beziehungen von Weltanschauung 11 . Kunstschaffen, Marburger Beitr. z. roman. Philol. IX, 1911 ; R. Buchwald, Praktische Grundlagen u. Ziele der Lit.wissensch., Studien z. Lit.Gesch. für A. Köster, 1912, S. 248 ff.; BuClłWALD, Die Weltanschaumg in Kunstwerk, Germ.-rom. Monatsschr. V (1913), 417-425; LEVIN L. Schü CKING, Literaturgesch. u. Gesclunacksgesch., ebenda S. $561-577$; JuL. 
I. Die philologische Einstellung ist gerichtet auf das Tatsachenmaterial des Textes: 1. die Handschriften, kritische Herstellung des Textes, Erklärung einzelner Stellen; 2. die Sprache, die Mundart, zugleich zur Bestimmung der Heimat des Verfassers und der Zeit der Abfassung; 3. Sprachgebrauch: Syntax, Wortschatz, Stil; 4. die poetische Form: Metrik, Rhythmik und Melodik, Vortragsweise; 5. Inhaltsübersicht, Komposition; 6. Lebensgang und Kenntnisse des Verfassers; 7. Entstehung des Werkes, äußere Veranlassung, Besteller oder eigenes Erlebnis, Entwicklung des Werkes, Arbeitsweise, ältere und jüngere Bestandteile, Interpolationen; 8. Quellen des Stoffes, Parallelmotive, Nachwirkung.

II. Die historische Einstellung bringt den Verfasser in Beziehung zu seiner Zeit und seiner Umgebung (Milieu), versteht ihn als Kind seiner Zeit und seines Landes und reiht sein Werk ein in den Gesamtgang der Literaturgeschichte. Die philologische Methode richtet ihr Augenmerk mehr auf die Einzelheiten, das Detail, die historische auf den Zusammenhang der Dinge, der Kulturverhältnisse, ') jene verfährt mehr analytisch, diese mehr synthetisch. Beide haben das gemeinsam, daß sie ihren Gegenstand in seiner historischen Gegebenheit erklären, die drei folgenden Betrachtungsweisen suchen die immanenten geistigen Bedingungen zu verstehen. Es sind die drei philosophischen Einstellungen.

III. Die psychologische Einstellung dringt ein in die seelischen Grundbedingungen im schaffenden Künstler, Phantasie und Gefühl als die dichterischen Kräfte. Die psychol. Erklärung bildet die Grundlage für das Verständnis des Dichters und die geistige Entstehung seines Werkes (das Erlebnis).

IV. Die ästhetische Einstellung beobachtet die künstlerischen Formen und deren Gesetze. Die ästhet. Erklärung ist Kunstlehre, Poetik. Ihre Formgebiete sind: a. Die äußere Form. 1. Der Stil als Kunstsprache, die Poesie als Wortkunst, Stilistik; 2. die Metrik in ihrer künstlerischen Wirkung auf das Gefühl (das Ethos des Rhythmus, der musikalische und akustische Eindruck des Reims, der Alliteration, Klangfarbe und Lautsymbolik); 3. die Maßverhältnisse der Komposition (der künstlerische Aufbau, die Architektonik, Einheit in der Mannigfaltigkeit, Harmonie oder Formlosigkeit). Der Philologe beschreibt die Elemente des sprachlichen Ausdrucks (Grammatik, Syntax, Wortschatz), die Technik von Rhythmus und Reim, des Aufbaus,

Petersen, Literaturgesch. u. Philologie, ebenda 625-640, Der Aufbau der Literaturgesch., ebenda VI(1914), 1-16.129-152, zusammen: Literaturgesch. als Wissensch., 1914; PAUL MERKEr, Neue Aufgaben der deutschen Literaturgesch., 1921; EMIL ERMATINGER, Das dichterische Kunstwerk, 1921.

1) Kuno Francke, Die Kulturwerte der deutschen Lit. in ihrer geschichtl. Entwicklung, I. Bd. Die Kulturwerte der deutschen Lit. des MA.s. 
die ästhetische Betrachtung dagegen bewertet diese drei Beobachtungsgruppen nach ihrem künstlerischen Gehalt. - b. Die innere Form, die besondere Art und Weise, wie ein Dichter seinen Stoff auffaßt. Er kann ihn sachlich begreifen (objektive Anschauung) oder er kann seine eigene Stellungnahme zum Stoff mitwirken lassen (subjektive Ansch.): realistisch oder idealistisch, naturalistisch oder idealisierend, charakteristisch (ins Detail malend) oder typisch (die großen Gattungszüge), naiv oder sentimentalisch, humoristisch oder elegisch, komisch oder tragisch. Hierher gehören auch die Fragen nach der Folgerichtigkeit, Anschaulichkeit, Lebendigkeit und Tiefe des seelischen Geschehens, Bedeutsamkeit. Die Poetik behandelt ferner die Gattungen der Dichtkunst und gibt endlich Anleitung zum künstlerischen Verständnis eines Werkes, zu seiner Erklärung.

V. Die ethische und metaphysische Einstellung sucht den sittlichen und den Ideengehalt des Werkes zu ergründen. Der Dichter will mit den ethischen Zielen den Sinn des Lebens erschließen, der metaphysische Flug trägt ihn zu den obersten Mächten, zu Gott und dem ewigen Gesetz, zur reinen Form. Damit ist sein Werk Ideendichtung geworden.

Für eine gleichmäßige und umfassende Lösung der hierher gehörenden Probleme ist der Stoff der ad. Literatur nicht mannigfaltig und reichhaltig genug, das überlieferte Material ist für eine ausgiebige Untersuchung der historischen, psychologischen und ästhetischen Zusammenhänge zu gering. So fällt der größte Teil der Arbeit der philologischen Einstellung zu. Aber die ad. Literatur ist ein unmittelbarer und naturgemäßer Ausdruck ihrer Zeit und des Volksbewußtseins, sie ist ganz durchdrungen von den sittlichen Forderungen und den großen, zum Ewigen führenden Ideen: darum eröffnen die ethischen und metaphysischen Betrachtungen ein weites Feld bedeutungsvoller Ergebnisse, und darin beruht der hohe geistesgeschichtliche Wert auch dieser Periode der deutschen Literatur. Sie verbinden Mittelalter und neuere Zeit, denn die sittlichen Gesetze der Religion sind ewige Normen, und in veränderten Formen kehrt der ethische Idealismus wieder bei Kant und Fichte, Schelling und Schopenhauer, bei Schiller und Goethe.

Der Aufbau der ahd. und frühmhd. Litcraturgeschichte stellt sich in klaren Umrissen dar, die Wirkungszusammenhänge bewegen sich in einfachen Linien, erst in der mhd. Zeit werden die ineinander spielenden geistigen Kräfte mannigfaltiger und verwickelter. Dabei besteht cin wesentlicher Unterschied zwischen der geistlichen Literatır der ahd. und der frühmhd. Zeit. Haben sie auch das gleiche Ziel - die christliche Lehre zu verbreiten und im Volke zu fördern —, so sind doch die Wege, zufolge der politischen und kulturellen Grundbedingungen, verschieden. Die alıd. 
kirchliche Bildungsbewegung mußte noch einseitig rein elementar gerichtet sein auf die Belehrung des christlich $z u$ erziehenden Volkes, andrerseits galt es, eine nationale religiöse Dichtung zu schaffen (Heliand, Otfrid). Im Frühmhd. aber wurde der Fortschritt von der Elementarlehre zur Dogmenlehre, vom Religionsunterricht zur Theologie gemacht, und $z u$ der auf die Gesamtheit der Gläubigen berechneten religiösen Dichtung trat die ritterlich-religiöse Standesdichtung (Rolandslied).

Die Probleme der frühmhd. Literaturgeschichte sind durchsichtig, denn sie beruht in einer organischen Entwicklung: sie ist ein unmittelbarer kultureller Ausdruck der Zeitgeschichte. Diese aber ist bestimmt durch-den Kampf zwischen Kaisertum und Papsttum. Letzteres, politisch weit erfahrener und geschulter, kämpfte mit geistigen Waffen und sein Rüstzeug war die Gemütsmacht der Religion. Noch beherrschten, wie in ahd. Zeit, die Geistlichen das deutsche Schrifttum, die volkstümliche Laiendichtung hatte noch keinen Zugang, und während die religiösen Erzeugnisse durch die Klöster über das ganze hochdeutsche Sprachgebiet verbreitet wurden, blieb die Volksdichtung beschränkt auf die Spielleute, durch die sie meist mündlich oder in nur flüchtig skizzierten Texten, Hilfsmitteln für das Gedächtnis, weitergegeben wurde. Von wirklich im Volke lebenden oder gesungenen Liedern haben wir gar keine Kenntnis, aber um die Mitte des zwölften Jahrhunderts kam, jetzt zum ersten Mal, eine auch schriftlich weitergepflegte weltliche Literatur von weltlichen Dichtern auf, die Spielmannsepik, als der Vorlauf der bald zur reichsten Blüte gelangenden mhd. Heldendichtung.

Die herrschende Literatur der Zeit, die geistliche, ist also eine Ausstrahlung der maßgebenden Zeitgewalt und Zeitidee, der Hierarchie. Gleichlaufend mit dem kulturhistorischen Werdegang dieser Epoche bewegt sich die frühmhd. Literaturgeschichte. Die Entwicklung erfüllt sich geradezu mit historischer Gesetzmäßigkeit (d. h. nach Kausalgesetzen, nicht mit naturgeschichtlicher Gesetzmäßigkeit bezw. nach Naturgesetzen in positivistischem Sinn). Durch diese ebenmäßige Struktur unterscheidet sich die frühmhd. Literaturperiode von der ahd. Dort war die Entwicklung nicht zusammenhängend, sondern sprunghaft. Sie ging zwar ebenso Hand in Hand mit den geschichtlichen Wandlungen, aber diese selbst nahmen einen auf- und absteigenden, keinen geradlinigen Verlauf.

Auch innerhalb der frühmhd. Zeit selbst bewegt sie sich auf den durch die geschichtlichen Bedingungen gegebenen Bahnen. Am Anfang und Abschluß der geistlichen Literatur stehen die beiden Bearbeitungen des Hohen Liedes, jede in einer andern, in ihrer Zeit wurzelnden Anschauung: dort die dogmatische Heilslehre Willirams, hier die Mystik der S. Trudperter Um- 
dichtung, jene ein Abbild der neuen Geschlossenheit und Macht der Kirche, diese ein Einzelerlebnis der durch den heil. Bernhard erweckten Gemütsvertiefung.

Die geistliche Literatur der ahd. und frühmhd. Zeit war durchaus eine Wiederholung, zum großen Teil unmittelbare Übertragung der lateinischen, und auch die frei abgefaßten Werke bezogen aus ihr ihre Gedanken bis ins Einzelne in unmittelbarer Nachahmung. Mit den großen Epen der Geistlichen, dem Alexanderlied und Rolandslied, greift dann zum erstenmal der französische Einfluß als geschichtliche Triebkraft entscheidend in die Geschicke der deutschen Literatur ein und bestimmt dann gegen Ende des Jahrhunderts ihre Grundrichtnng, indem sie in der höfischen Kultur dem ganzen deutschen Geistesleben das hochmittelalterlich-romantische Gepräge verleiht.

Auf der Gesetzmäßigkeit der historischen Idee beruht der Sinn der frühmhd. Literatur und aus ihr heraus ist die Bedeutung der einzelnen Denkmäler $z u$ erklären. Und diese Idee war eine religiöse, die kirchlichen Gedankennormen gaben der Zeit die Richtung, nicht die staatlich-politischen, darum ist die Entwicklung der Literatur auch nicht beeinflußt durch die Regenten des Reiches, durch die Kaiser von Heinrich IV. bis auf Konrad III. Im Wirbel der ganzen Zeitströmung aber erheben sich die Kreuzzüge. Nach ihnen ist die Geschichte und damit auch die Literaturgeschichte der Periode orientiert. In den ersten Jahrzehnten, bis in das erste Drittel des 12. Jahrhunderts, ist sie rein geistlich. Sie stellt sich die Aufgabe, die neue Lehre von Clugny, die asketische, einzuführen und arbeitet mit dem herrschenden Zeitzweck daran, das Gemütsleben zur Weltverachtung zu bestimmen. Mit den Kreuzzügen wurden die Laien, das Rittertum, in den Dienst der herrschenden Kirchenidee gezogen, aber eben dadurch gewann dieser Stand eine starke sittliche Weltaufgabe und damit ein gesteigertes Gewicht. Sein individuelles Selbstgefühl wuchs, er wurde aus einem bloßen Material ein geistiger Faktor in der Weltpolitik. Die Erweiterung des kosmischen Gesichtsfeldes und der erzieherische Ungang mit den kulturell vorgeschrittenen Orientalen hoben ihn auf eine höhere Bildungsstufe. Ansätze zu feineren Formen sind bemerkbar, aus dem heimsässigen Bauernadel wird ein internationales Rittertum. Und nun ist es wiederum lehrreich, zu beobachten, wie organisch aus der Zeitgeschichte heraus sich die Literatur entfaltet: aus der Kreuzzugsidee entsteht eine ritterlich-weltliche Literatur, aber, wiederum bezeichnend, nicht der künstlerisch noch unfähige Adel, auch nicht der an alten Stoffen und alter Weise haftende Spielmann, sondern die Geistlichen tun den ersten Schritt dazu, in besonderer Absicht, die Anschauungen des aufsteigenden Ritterstandes mit ihren kirchlichen Ideen zu 
erfüllen: der Weltheros Alexander wird zu einem romantischen Fürstenideal umgedeutet und Anfang und Schluß der Reckenbiographie ist Weltentsagung. Das Idealbild aber eines Ritters, wie es die Kirche aufstellt und dem Adel vorhält, ist der christliche Ritter, sind Karl der Große und seine Paladine. Eine bedeutungsvolle Wandlung in der Technik bewirken diese ersten größeren Epen der Geistlichen: ihrem Vorgang folgen die Spielleute, sie erweitern das epische Lied zum umfangreichen Epos und es entsteht der mehr oder weniger höfisch stilisierte weltliche Spielmannsroman. Aber selbst dieser zeigt noch, wie stark das Laientum unter der Macht der kirchlichen Idee stand, denn die Tendenz ist hier zum Teil überhaupt noch legendenhaft-religiös (Oswald, Orendel) oder es sind doch geistliche Lichter oder Lichtchen aufgetragen (König Rother, Salman).

Damit ist auch das Stoffgebiet der frühmhd. Literatur umrissen. Wie im Ahd. herrscht der geistliche Kreis weit vor, dazu ist eine neue Form der Spielmannsdichtung getreten, aber schmerzlich zu beklagen ist der Verlust des alten epischen Liedes. Die Lyrik ist beschränkt auf das Marienlied, das deutsche Drama entwickelt sich aus den lateinischen Spielen erst im folgenden Zeitraum. Weltliche lehrhafte Dichtung steht vereinzelt (Merigarto), außer Zusammenhang; von der gewiß umfangreicheren praktischmedizinischen Prosa ist nicht eben viel erhalten.

Immer aber ist $z u$ berücksichtigen, daB das literarische Leben des deutschen Mittelalters sich nicht in der deutschen Sprache erschöpft, jedoch fällt die lateinische Literatur dieser Zeit außerhalb des Rahmens einer Geschichte des mhd. Schrifttums. Sie hat ihre eigenen Zusammenhänge, ihre eigenen historischen und ästhetischen Gesetze. Einige bedeutend in die Geschichte der deutschen Dichtung eingreifende Bewegungen der lateinischen Literatur werden den folgenden Abschnitt der LG. beschäftigen.

Geographisch, landschaftlich, richtet sich die Verbreitung der frühmhd. geistlichen Denkmäler ebenfalls nach der umwälzenden kirchlichen Neuerung, der cluniacensischen Reform. Nicht gab es mehr wie in der ahd. Missionszeit große geistige Mittelpunkte wie Fulda, St. Gallen, Reichenau, von denen Antriebe zum kulturellen Leben ausgingen, sondern die Regelung des Klosterlebens und die neuen Mönchsorden verbreiteten sich über ganz Deutschland und in Verbindung damit auch die literarischen Erzeugnisse, so daß diese geistliche Literatur keinen ausgesprochen landschaftlichen Charakter annahm (wie denn auch die einzelnen Gedichte der großen Sammelhandschriften verschiedenen Gegenden angehören). In Bamberg wirkte ein kräftiger Kirchenfürst für die Einführung der Reform, so entstand dort das erste Lied der neu erweckten Frömmigkeit, Ezzos Gesang. Am eifrigsten wurde die neue Verschärfung in Alemannien durchgeführt, ein 
Ausdruck dieser Askese ist das Memento mori. Literarisch sehr regsam waren die bairisch-österreichischen Klöster, so geht Innerösterreich voran mit der alttestamentlichen Erzählungsdichtung. Auch die Rheinlande lieferten ihren Beitrag, Thüringen ist an der Literatur dér Zeit nur wenig beteiligt, das sächsisch-niederdeutsche Sprachgebiet scheidet ganz aus.

Aber eine ganz neue Strömung kam vom Rheine her, die Spielmannsdichtung. Auch hier sind die historischen Kausalzusammenhänge deutlich: immer empfangen diese Gegenden zum ersten den Anstoß der benachbarten französischen Kultur.

Die Tradition beherrscht das christliche Bewußtsein, sie ist die charakteristische Anschauungsart, in welcher der mittelalterliche Mensch die Gedanken über Gott und die Welt erfaßt, theologisch ausgedrückt: die dogmatische Denkweise. Von dem Gesamtgeist ist der Einzelne abhängig, er steht ihm nicht gegenüber, er geht in ihm auf. Er ist nicht Individuum, sondern ein Glied der Masse. Der Autoritätsglaube hemmt die Eigenentfaltung. Aber er empfindet diese Entselbstung nicht als eine Beschränkung, er weiß nicht anders, der Eigenwille reagiert nicht, er agiert selbst unbewußt mit. Es fehlt das Individuationsgefühl, es ist eine Kirche, ein Typus, eine Gattung.

Aber doch ist jede Menschenseele ein eigen Ding und keine gleicht völlig der andern. Ist auch das geistige Glaubensleben in dieser Zeit unterschiedslos, so ist doch das Erleben dieses Geisteslebens beim einzelnen Menschen verschieden, je nach der Empfänglichkeit des Gemüts. Und da auch die Fähigkeit, diesem Erleben Ausdruck zu geben, bei dem einen größer, dem andern geringer ist, so erheben sich aus dem typischen Untergrund, wenn auch zuweilen nur undeutlich, lauter einzelne Abwandlungen, und es ist die Aufgabe der mhd. Literaturwissenschaft, die subjektiven Unterscheidungsmomente dieser Einzelerscheinungen aufzudecken. Aber in die Tiefen des individuellen Seelenlebens können wir nicht vordringen, es läßt sich bis zu einem gewissen Grade wohl eine literarische, aber nicht die volle menschliche Persönlichkeit aufbanen. Die frühmhd. Literatur ist also zum größten Teil, abgesehen vom weltlichen Epos, typische Religionsdichtung, und diese Dichter wissen inur das religiöse Massenleben auszusprechen, nicht aber ein in ihnen selbst entstandenes persönliches Erlebnis. Was sie in sich aufnelımen, ist aber doch nacherlebt, ist für sie doch erlebte Wirklichkeit. Auch das Märchenhafte, die wie ein Kinderparadies glänzende Herrlichkeit der himmlischen Stadt, ist geglaubte Wirklichkeit. Der Gefühlsgehalt dieser ubersinnlichen Erlebnisse kann je nach der Veranlagung des Individuums stark oder schwach sein, aber in dieser Zeit der ungeheuren Steigerung des Innenlebens, in der Angst um die Zn- 
kunft der Seele, muß die Gesamtgefühlslage eine sehr erregte, das religiöse Einzelerlebnis also ein ungemein affektreiches gewesen sein.

Die das Seelenleben der Periode beherrschenden geistesgeschichtlichen Bedingungen sind also das traditionell gebundene Denken des Mittelalters (die weitere Bedingung) und die cluniacensische Zeitbewegung (die engere Bedingung). Die cluniacensische Idee ist nur eine Verschärfung und Vereinseitigung der christlichen Tradition. Der Inhalt beider, der.Tradition und des Zeitbewußtseins, ist die christliche Weltanschauung. Alle geistlichen Schöpfungen des Mittelalters sind nur Einzelformen dieser allumfassenden theologisch-kosmischen Idee, des christlichen Dualismus, des Zwiespalts zwischen Welt und Gott, des weltgeschichtlichen Dramas mit den drei Akten Paradies, Sündenfall und Welt, Erlösung. Die ganze geistliche Literatur des Mittelalters ist eine Verbildlichung der Heilsidee und so vereinigen sich alle diese analytischen Formen, die mittelalterlichen religiösen Auswirkungen jeglicher Kunst, der Poesie, Musik, Architektur, Skuiptur in die letzte Synthese: Gott ist das höchste Gut. Dieses ist der mittelalterliche Formwille, der Stil, der gesetzmäßige Ausdruck dieser einheitlichen Weltanschauung. Die Gegenwart hat keinen Stil, sondern nur verschiedene Moden, weil sie keine einheitliche Grundanschauung über den Sinn und Wert des Daseins hat.

Der christliche Glaube ist Erlösungsreligion. Eine solche vollzieht sich in drei Stufen: Einheit mit Gott, Trennung von Gott, Wiedervereinigung mit ihm. Erlösung ist Wiederherstellung der Einheit zwischen Mensch und Gott, aus der Einzelheit zur Einheit, vom Individuum zum All. Der Grund zur Vereinzelung, zur Trennung und damit der Ursprung des Erlösungsbedürfnisses ist die Sünde. Die Sünde ist das Übel, darum lautet die siebente und letzte Bitte des Vaterunsers: und erlöse uns von dem Übel. Die Sünde, das Übel trennt uns von Gott. Das größte Elend des Menschen ist, Gott fremd zu sein, das größte Glück ist, Gott anhangen, Deo adhaerere (Augustinus). Wodurch wird die Einheit wiederhergestellt? durch den Glauben, der Glaube kommt aber nicht aus eigenem Verdienst, sondern ist eine Wirkung der Gnade, wird also durch einen magischen Akt Gottes in uns erweckt. Von der Sünde geht der Weg durch die Gnade zum Heil. Worin besteht das Böse? in der Sinnlichkeit, in den Begierden, im Körper, in der Welt. Darum mache dich los vom Leib, dem Lustgehäus der Leidenschaften, fliehe die Welt, die Herberge der Scheinfreuden.

Nach zwei Richtungen aber kann der Mensch den Blick lenken auf seiner irdischen Reise nach dem himmlischen Ziel: rückwärts auf die verwünschte Welt, von der er loskommen will, die ihn von Gott trennt, das ist die Weltverachtung, und die Stimmung der Seele ist pessimistisch; oder 
vorwärts auf das Ziel selbst, er kann das Glück der Gottesnähe schon hier in seinem verzückten Herzen spüren: das ist die Mystik, die unio mystica mit Gott. ') Zum Glauben tritt hier noch eine andere, noch innigere innere Kraft, der Glaube ist umwoben von einem magischen Glanze, der von der Liebe ausstrahlt und die Seele mit himmelsfreudigem Optimismus erfüllt. Der Glaube ist zunächst ein Akt der Erkenntnis, durch Belehrung im rechten Glauben kann der Weg zum Heil gezeigt werden, aber die Heilswahrheiten sind nicht nur mit dem Kopfe, sondern auch mit dem Herzen aufzunehmen; ganz durchdrungen sein von dem Gefühl der Seligkeit, Gott in sich zu tragen: das ist die Liebe, sie ist reines Gefühlserlebnis. Doch für beide, den finstern Weltflüchtling wie für den liebeerfüllten Mystiker, sind die Mittel zur Läuterung auf dem Lebensweg Askese und Buße, nicht tätige Arbeit im Dienste der irdisch-menschlichen Wohlfahrt. Wo gehandelt wird, geschieht es im jenseitig geistlichen Sinn und in kirchlicher Absicht, zur Selbststärkung im Glauben oder zur Bekehrung der Sünder und Heiden. Erst das ritterliche Laientum des folgenden Zeitraums hat seine diesseitige, rein menschliche Lebensaufgabe auch als einen sittlichen Lebenszweck erachtet.

1) E. NAGEL, Das Problem der Erlösung, 1901 ; Eugen Stamm, Das Problem der Er- 
INHALTSVERZEICHNIS.

Einleitung.

Allgemeine Voraussetzungen.

$\$ 1$. Die geistigen Grundbedingungen

$\$$ 2. Metrik und Vortragsweise. Stil.

$\$ 3$. Die Sammelhandschriften

\section{Die Literaturdenkmäler.}

\section{A. Geistliche Literatur.}

a) Das Hohe Lied.

$\S 4$. Willirams Paraphrase des Hohen Liedes

$\S 5$. Das St. Trudperter Hohe Lied

b) Das Dogma.

$\S$ 6. Ezzos Gesang

$\S$ 7. Summa Theologiae

$\$$ 8. Das Anegenge.

$\$$ 9. Hartmanns Rede vom Glauben

$\$ 10$. Der Scopf von dem lône

$\$ 11$. Das Paternoster

$\$ 12$. Von der Siebenzahl

$\$$ 13. Priester Arnold, Von der Siebenzahl

$\$ 14$. Deutung der Meßgebräuche

$\$ 15$. Von Esau und Jakob. Von den zehn Geboten

$\$ 16$. Alcuins Traktat De virtutibus et vitiis

$\$ 17$. Idsteiner Sprüche der Väter

c) Geistliche Epik.

I. Die Bibel.

$\S 18$. Genesis und Exodus

a) Das alte Testament.

$\$ 19$. Vorauer Bücher Mosis

$\$ 20$. Das Lob Salomons

21. Die drei Jünglinge im Feuerofen

$\$ 22$. Judith

$\$ 2$. Die jüngere Judith

$\$ 24$. Des Pfatfen Lamprecht Tobias

$\S 25$. Babylonische Gefangenschaft

$\S 26$. Makkabäer

b) Das neue Testament.

$\S 27$. Die Gedichte der Ava

$\$ 28$. Friedberger Christ und Antichrist

$\$ 29$. Von Christi Geburt

\$ 30. Priester Adelbrecht, Johannes Baptista

$\$ 31$. Baumgartenberger Johannes Baptista

$\$ 32$. Christus und Pilatus

$\S 33$. Wernher vom Niederrhein und der Wilde Mann

\section{c) Die letzten Dinge.}

\$34. Linzer Antichrist

$\$ 35$. Hamburger jüngstes Gericht

$\$ 36$. Himmel und Hölle

$\$ 37$. Das himmlische Jerusalem

$\S 38$. Vom Himmelreich

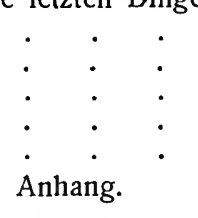

§39. Prosaische Bibelübersetzungen .

II. Legenden.

$\S 41$. Das mittelfränkische Legendar 
\$ 42. Der Trierer Silvester

43. Der Trierer Aegidius

$\$ 44$. Andreas

$\$ 45$. S. Veit

$\$ 46$. Albanus

$\$ 47$. Pilatus

48. Die heilige Margarete

$\$ 49$. Priester Arnolds Juliane

III. Jenseitsvisionen.

$\$ 50$. Visio S. Pauli

51. Patricius

$\$ 52$. Die Vision des Tundalus

$\$ 53$. Sanct Brandan

d) Die Heilsmittel.

l. Gebetliteratur.

a) Gebete.

§54. Frauengebet der Vorauer Hs., Gebete von St. Lambrecht, Muri, Engelberg, Upsalaer Frauengebete u. a., Messegesang

$\S 55$. Heinrichs Litanei

b) Sündenklagen.

§ 56. Milstäter Sündenklage

$\$ 57$. Vorauer Sündenklage

$\$ 58$. Rheinauer Paulus

59. Cantilena de conversione S. Pauli

$\$ 60$. Upsalaer gereimte Beichte

$\$ 61$. Rheinauer Sündenklage

II. BuB- und Sittenpredigt.

\$ 62. Memento mori .

$\$ 63$. Heinrich von Melk

64. Die Wahrheit

$\$ 65$. Trost in Verzweiflung

$\$ 66$. Vom Rechte

$\$ 67$. Die Hochzeit

$\S 68$. Melker Marienlied

e) Mariendichtung.

69. Arnsteiner Marienlied

$\$ 70$. Mariensequenz aus St. Lambrecht

$\$ 71$. Mariensequenz aus Muri

$\$ 72$. Marienlob

$\$ 73$. Drei Lieder von der Jungfrau vom Priester Wernher

$\$ 74$. Physiologus

$\$ 75$. Merigarto

$\$ 76$. Medizinische Literatur

\section{B. Weltliche Literatur.}

a) Weltliche Epik von geistlichen Dichtern.

$\S 77$. Das Alexanderlied des Pfaffen Lamprecht

$\$ 78$. Das Rolandslied des Pfaffen Konrad

79. Die Kaiserchronik vom Pfaffen Konrad

b) Das Spielmannsepos.

\$ 80. König Rother

$\$ 81$. Salman und Morolf

82. Oswald

$\$ 83$. Orendel

Zeittafcl, Ortstafel

Nachträge und Berichtigungen

Register 


\section{Erklärung der Abkürzungen.}

Ad. $=$ Altdeutsch

Ad. Bl. = Altdeutsche Blätter von HaUpt und HofFMANN, 1836. 1840.

ae. $=$ altenglisch.

afrk. $=$ altfränkisch.

afrz. $=$ altfranzösisch.

ags. = angelsächsisch.

ahd. = althochdeutsch.

Allg. d. Biographie = Allgemeine deutsche Biographie.

an. $=$ altnordisch

Anz. = Anzeiger für deutsches Altertum

BAECHTOLD = JAKOB BAECHTOLD, Geschichte der Deutschen Literatur in der Schweiz, 1892.

BARTSCH, Katal. = BARTSCH, Katalog der Handschriften der Universitäts-Bibliothek zu Heidelberg I.

Beitr. = Beiträge zur Geschichte der deutschen Sprache und Literatur.

Berl. Ak. = Jahresbericht über die Erscheinungen auf dem Gebiete der Germanischen Philologie.

Betl. SB. = Sitzungsberichte der kgl. Preußischen Akademie der Wissenschaften, philosoph.histor. Klasse.

Bolte-PolívkA = Anmerkungen zu den Kinder- und Hausmärchen der Brüder Grimm, 3 Bde., $1913 \mathrm{ff}$.

Braune LB $^{8}=$ Braune, Althochdeutsches Lesebuch, 8. Aufl. 1921.

BURDACH, Ackermann = BURDACH, Der Ackermann aus Böhmen. Vom Mittelalter zur Reformation, 3. Bd. 1. Teil 1917.

$\mathrm{C}_{\text {RUEL }}=$ CRUEL, Geschichte der deutschen Predigt im Mittelalter, 1879.

DIEMER, DGied. = DIEMER, Deutsche Gedichte des XI. und XII. Jahrhunderts, 1849

DIEMER, Gen. u. Ex. = DIEMER, Genesis und Exodus nach der Milstäter Handschrift, 1862.

DIEMER, KI. Beitr. = DiEMER, (Kleine) Beiträge zur älteren deutschen Sprache und Literatur, in den Wiener Sitzungsberichten 6 (1851) u. ff.

Diss. $=$ Dissertation.

DLZ. = Deutsche Literaturzeitung.

Du CANge-Favre = Du CANGE, Glossarium mediae et infimae Latinitatis, editio nova a LÉOPOLD FAVRE $1883 \mathrm{ff}$.

DWb. = Deutsches Wörterbuch von JACOB GRIMM und Wilhelm GRIMM.

EBERT $=$ Geschichte der christlich-lateinischen Literatur (1. Bd. in 2. Aufl.).

EHRISMANN, R. v. Ems = GuST. EHRISMANN, Studien über Rudolf v. Ems, Heidelberger Sitzungsberichte, philos.-histor. Klasse 1919, 8. Abhandl.

frühmhd. - frühmittelhochdeutsch.

Germ. Abh. = Germanistische Abhandlungen, hgb. von K. WEINHOLD und F. VoGT.

GervinUS = GervinUS, Geschichte der deutschen Dichtung 1. Bd., 5. Aufl. 1871.

Gesch. d. d. Lit. = Geschichte der deutschen Literatur.

GiEsEBRECHT $=$ Wilh. v. GIESEBRECHT, Geschichte der deutschen Kaiserzeit, 4. Aufl. Bd. 1 u. $2,1873.1875$.

Gött. gel. Anz. = Göttinger gelehrte Anzeigen.

Gött. Nachr. = Nachrichten von der K. Gesellschaft der Wissenschaften zu Göttingen, philol.histor. Klasse.

GraFF, Diut = GraFF, Diutiska, 3 Bde. 1826-1829.

GRAU = GuST. GRAU, Quellen und Verwandtschaften der älteren germ. Darstellungen des jüngsten Gerichtes, Halle 1908.

W. Grimm, DH. = Wilhelm Grimm, Die deutsche Heldensage, 3. Aufl. 1889.

W. GRIMM, ZGdR. = WILHelm GRIMM, Zur Geschichte des Reims, Abhandlungen der Kgl. Akademie der Wissenschaften zu Berlin (phil.-hist. Klasse) 1852 S. 521-713, einzeln S. $1-193$, wieder abgedruckt in: Kleinere Schriften von WILHELM GRIMM, Bd. 4, 125-336.

Gröbers Grundr. - Gtundriß der Romanischen Philologie, hgb. von GUSTAV GRÖBER, 1I. Bd. 1. Abteilung, 1902.

GRÜNEWALD = AUGUST GRÜNEWALD, Die lateinischen Einschiebsel in den deutschen Gedichten von der Mitte des 11. bis gegen Ende des 12. Jahrhunderts, Göttinger Dissertation 1908.

Grundr. = Grundriß.

HAHN, Ged. = K. A. HAHN, Gedichte des XII. und XIII. Jahrhunderts, 1839.

HARNACK, Dogm. = ADOLF HARNACK, Lehrbuch der Dogmengeschichte 3.Bd., 2. u. 3. Aufl. 1890. 
HaSs = ALBERT HaSs, Das Stereotype in den altdeutschen Predigten, Greifswalder Dissertation 1903.

Heidelberger SB. = Heidelberger Sitzungsberichte, philosoph.-histor. Klasse.

HofFMANN, Fundgr. = HofFmanN (VON FaLlerslebEN), Fundgruben, 2 Bde. 1830. 1837.

H. Lied oder HL. = Hohes Lied.

KAMPERS = FRANZ KAMPERS, Alexander der Große und die Idee des Weltimperiums, 1901.

KARAJAN, DSpr. = TH.G.V KARAJAN, Deutsche Sprach-Denkmale des zwölften Jahrhunderts, 1846.

Kch. = Kaiserchronik.

KELLE = KELLE, Geschichte der deutschen Literatur Bd. 2, 1896.

KELLE, Spec. eccl. = Kelle, Speculum Ecclesiae altdeutsch, 1858.

Kl. Schr. = Kleinere Schriften,

KrauS, DGed. = CARL KrauS, Deutsche Gedichte des zwölften Jahrhunderts, 1894.

KRAUS, Vom Rechte = CARL KraUS, "Vom Rechte* und "Die Hochzeit ${ }^{*}$, Wiener Sitzungsberichte Bd. 123 (1891), IV. Abh.

LachmanN, S. u. S. = LachmanN, Ueber Singen und Sagen, Abhandlungen der Akademie der Wissenschaften zu Berlin aus dem Jahre 1833 S. 105-122, wieder abgedruckt K1. Schr. S. $461-479$.

LB. = Lesebuch.

LC. = Literarisches Centralblatt.

LECOY = LECOY DE LA MARCHE, La Chaire française au Moyen âge, 1886.

LeITZMANN, Kl. geistl. Ged = LEITZMANN, Kleinere geistliche Gedichte des XII. Jhs., 1910.

v. D. LEYEN, Kl. Beitr. = FRIEDR. v. D. LEYEN, Kleine Beiträge zur deutschen Litteraturgeschichte im 11. und 12. Jahrhundert, 1897.

LG. = Literaturgeschichte.

LG I = EHRISMANN, Geschichte der deutschen Literatur bis zum Ausgang des Mittelalters, I. Teil 1918.

LiNSENMAYER = ANTON LINSENMAYER, Geschichte der Predigt in Deutschland von Karl dem Großen bis zum Ausgange des vierzehnten Jahrhunderts, 1886.

LitBl. = Literaturblatt für germanische und romanische Philologie.

MA. = Mittelalter.

ManitiUS = ManitiUS, Geschichte der lateinischen Literatur des Mittelalters, 1. Teil.

MaSSManN, Denkm. = Massmann, Denkmäler deutscher Sprache und Literatur, 1833.

MASSMANN, DGed. = MASSMANN, Deutsche Gedichte des zwölften Jahrhunderts, 1837.

md. = mitteldeutsch.

MEYER-BENFEY = MEYer-Benfey, Mittelhochdeutsche Uebungsstïcke, 2. Aufl. 1921.

mfrk. = mittelfränkisch.

mhd. = mittelhochdeutsch.

Mhd. Wb. = Mittelhochdeutsches Wörterbuch von BENECKE, MÜlleR, ZARNCKE.

mnd. = mittelniederdeutsch.

mnl. = mittelniederländisch.

MSD. $1^{3}$ bezw. $I^{3}=$ Móllenhoff und Scherer, Denkmäler Bd. I bezw. Bd. II, 3. Ausg. 1892.

MSF. = Minnesangs Frühling.

MOLLENHOFF, DAK. = MOLLENHOFF, Deutsche Altertumskunde.

Münch. SB. = Münchener Sitzungsberichte.

N.Jahrb. = Neue Jahrbücher für das klassische Altertum, Geschichte und deutsche Literatur.

Pal. = Palaestra, Untersuchungen und Texte aus der deutschen und englischen Philologie, hgb. von BRANDL, ROETHE und ERICH SCHMIDT.

Pauls Grundr. = Grundriß der Germanischen Philologie von HERManN Paul.

Elis. Peters = ElisABeth PETERS, Quellen und Charakter der Paradiesesvorstellungen in der deutschen Dichtung vom 9. bis 12. Jahrhundert, Germ. Abh. 48. Heft, 1915.

PIPER, Aelt. d. Lit. = PIPER, Die älteste deutsche Litteratur.

PIPER, Ep. = PIPER, Höfische Epik 3. Teil.

PIPER, GD. = PIPER, Die geistliche Dichtung, 1. u. 2. Teil.

PIPER, LB. = PIPER, Lescbuch des Althochdeutschen und Altsächsischen, 1880.

PIPER, Nachtr. = PIPER, Nachträge zur älteren deutschen Litteratur.

PIPER, Notk. = PIPER, Die Schriften Notkers.

PIPER, Spielm. D. = PIPER, Die Spielmannsdichtung, 1. u. 2. Teil, 3 Bde. o. J.

QF. = Quellen und Forschungen zur Sprach- und Culturgeschichte der germanischen Völker.

RAAB = KARL RAAB, Ueber vier allegorisclie Motive in der lateinisclien und deutschen

Literatur des Mittelalters, Jahresbericht des Landes-Obcrgymnasiums zu Leoben 1885.

Realencyklop. = Realencyklopädie für protestantische Theologie und Kirche, 3. Aufl.

Reg. = Register.

REUSCHEL, Weltgerichtsdicht. $=$ REUSCHEL, Untersuchungen zu den deutschen Weltgerichtsdichtungen des 11.--15. Jahrhunderts, Leipziger Diss. 1896. 
Rl. = Rolandslied.

$\mathrm{SA} .=$ Sonderabdruck.

$\mathrm{SB} .=$ Sitzungsberichte.

SARAN = SARAN, Deutsche Verslehre, 1907.

SCHADE, Cresc. = OSKaR Schade, Crescentia, 1853.

SCHADE, Decas = OSKAR SCHADE, Veterum Monumentorum theotiscorum Decas, 1860.

SCHADE, Geistl. Ged. = OSKaR SCHADE, Geistliche Gedichte vom Niederrhein, 1854.

SCHERER, D. Stud. = ScHERER, Deutsche Studien I, Wiener SB. 64 (1870), 283-355, auch als Sonderabdruck.

SCHRÖDER, Anegenge = EDWARD SCHRÖDER, Das Anegenge, QF. 44. Heft 1881.

SPECHT, Unterrichtswesen = FRANZ ANTON SPECHT, Geschichte des Unterrichtswesens in Deutschland, 1885.

SPROCKHOFF = PAUL SPROCKHOFF, Althochdeutsche Katechetik, Berl. Diss. 1912.

THALHOFER $1^{*}=$ THALHOFER, Liturgik, 2. Aufl. von Eisenhofer, 2 Bde. 1912.

UHLANDS Schr. = UHLANDS Schriften zur Geschichte der Dichtung und Sage, 1865-1873.

Verhandl. der Philol.-Vers. = Verhandlungen der Versammlung deutscher Philologen und Schulmänner.

VoGT, Grundr. = FrIEDR. VoGT, Geschichte der mittelhochdeutschen Literatur in PAULS Grundr. II, 1, 2. Aufl.

VOGT, edel = FRIEDR. VOGT, Der Bedeutungswandel des Wortes edel, Marburger Rektoratsrede 1909.

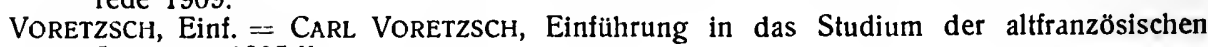
Literatur, $1905 \mathrm{ff}$.

WAAG, Kl. d. Ged. ${ }^{2}=$ Albert WAAG, Kleinere deutsche Gedichte des XI. und XII. Jahrhunderts, 2. Aufl. 1916.

WACKERNAGEL LB ${ }^{5}=$ WILH. WACKERNAGEL, Altdeutsches Lesebuch, 5. Aufl. 1873.

WACKERNAGEL LG $^{2}=$ WILH. WACKERNAGEL, Geschichte der deutschen Literatur, 2. Aufl. von ERNST MARTIN, 1. Bd. 1879.

Wackernagel, Ad. Pred. = Wilh. Wackernagel, Altdeutsche Predigten und Gebete, hgb. von MAX RIEGER, 1876.

WATTENBACH GQ. == WILH.WATTENBACH, Deutschlands Geschichtsquellen im Mittelalter, 2Bde., nach dem Reg. zit.

Wetzer UND Welte = Wetzer und Welte's Kirchenlexikon, 2. Aufl.

Wiener SB. = Wiener Sitzungsberichte, philosoph.-histor. Klasse.

Wilhelm, Denkm. = FrIEDR. WiLHELM, Denkmäler deutscher Prosa des 11. und 12. Jahrhunderts, Münchener Texte Heft VIII, 1914.

Wilhelm, Komm. = FrIEDR. WILHELM, Denkmäler deutscher Prosa des 11. und 12. Jahrhunderts, Kommentar 1. u. 2. Hälfte, Münchener Texte Heft 8, 1916. 1918.

WOLFSKEHL u. v. D. LEYEN $=$ KARL WOLFSKEHL und FRIEDR. v. D. LEYEN, Aelteste deutsche Dichtungen, 2. Aufl. 1920.

ZfdA. = Zeitschrift für deutsches Altertum.

ZfdPh. = Zeitschrift für deutsche Philologie.

ZfdW. = Zeitschrift für deutsche Wortforschung.

ZföG. = Zeitschrift für die österreichischen Gymnasien. 


\section{EINLEITUNG.}

\section{Allgemeine Voraussetzungen. ${ }^{1}$ )}

\section{$\$ 1$. Die geistigen Grundbedingungen.}

Die um die Mitte des elften Jahrhunderts in Deutschland wieder einsetzende Dichtung steht unter völlig veränderten Bedingungen. Eine neue Frömmigkeit war aufgekommen, in welcher der Zwiespalt zwischen Gott und Welt der absolut herrschende Gedanke war. Von kleinen Anfängen an reicht sie allmählich weit in die gesamte Christenheit hinein. Sie hatte ihren Ursprung in dem Kloster Clugny (bei Macon in Frankreich), das im Jahr 910 gegründet wurde und zwar mit dem $Z$ weck, die in der späteren Karolingerzeit lax gewordene Regel des heiligen Benedikt wieder in ihrer ganzen Strenge zur Geltung zu bringen. Ein asketischer Mönchsgeist ging von Clugny aus, besonders durch die Tätigkeit der Äbte Odo (927-942) und Odilo (994-1048), und verbreitete sich zunächst innerhalb der Cluniacenser Kongregation. Am Ende des zehnten Jahrhunderts aber war die Klosterreform in Frankreich allgemein geworden, hatte zunächst in Lothringen festen Fuß gefaßt und wurde von da aus nach Deutschland weiter getragen. Der Streit zwischen den fanatischen Sendboten der Weltabtötung und den alten behaglicheren Klosterbrüdern störte das friedliche Leben in vielen Klöstern (zu St. Gallen, wo die Reform um 1030 von lothringischen Mönchen eingeführt wurde, vgl. Bd. 1,436) und beschränkte den gelehrten Betrieb, besonders die klassischen, auf Grund der septem artes liberales gegründeten Studien. Die alten Sitze der wissenschaftlichen Bildung Fulda, St. Gallen, Reichenau, Freising und andere verloren mit ihrer Schulgelehrsamkeit auch ihren Ruhm. Die Reform war der auf dem Klassizismus beruhenden Wissenschaft des Triviums und Quadriviums, den sieben freien Künsten, geradezu feindlich gesinnt und ganz auf das praktische gottselige Leben gerichtet. Den stärksten Einfluß auf diese asketische Ausbildung des Mönchslebens gewann das Kloster Hirsau. Jedoch nicht nur die Klöster, sondern auch die Weltgeistlichkeit der Domstifte, die Chorherren, wurden mönchiscl reguliert, in Deutschland zuerst in Bamberg von dem Bischof Gunther um 1050.

1) Literatur für Theologic und Philosophie des MA.s: Jahresbericht für Theologie; UBERWEG-HeInZE, Grundr. d. Gesch. d. Philosophie 2. Tell 10. Aufl. 1919; HERM. Reuter, Gesch. d. religiosen Aufklärung im MA., 2 Bde. 1875. 1877 ; Herm. SchwarZ, Der Gottesgedanke in d. Gesch. d. Philosoplie, 1. Teil 1913.Lit.gesch. Spez. für die frühmhd. Zeit: KeLle, LG. Bd. 2; PIPER, Die älteste deutsche Lit. bis um d. J. 1050, Nachtr. Zur älteren d. Lit., Die geistl. Diclıtung des MA.s, 2 Teilc, Dic Spielmannsdichtung, 2 Teile; MULldinHOFu. Scherer, Deukn. 3. Ausg. 2 Bde. (MSD.); SCHERER, QF 1.7. u. 12. In wcitcrem Umfang: Deulsche Literafurgeschichle. II.
Uhlands Scluriften; Gervinus, Gescl. d. d. Dichtung, 5. Anfl. von Bartsch 1871; WACKERNAGEL, LG. 1. Bd., 2. Aufl. von Ernst Martin 1879; Kobersteins Grundr. 1.Bd., 5.Aufl. 1872 u. 6.Auf1. 1884 von Bartsch; GOEDEKEs Girundr. 1. Bd. 2. Aufl. 1884; SCHERER, LG. $1880 \mathrm{ff}$., 14. Aufl. von Edw. Schröder 1920; Gol.THER, Gesch. d. d. Lit. in Kiirschners D. NationalLit. Bd. 163, o. J.; VogT, Giesclı. d. mhd Lit. in Pauls Grundr. 11, 1, 2. Aufl. 1906; (jol.THER, Die deutsclıc Diclitung in MA. 1912; R. M. MeYer, Die deutsclıe lit. bis z. Beginn des 19. Jahrlı. 1916; VoGt, Gesch. d. d. Lit. von VoGt I. Kocı, 1. Bd. 4. Aufl. 1919. 
Die Glut der Frömmigkeit steigerte sich in der einmal von Sündenpein gequälten Menschheit zu leidenschaftlichem Erlösungsbedürfnis und den Weg zur Erringung der Gnade fand man in der äußersten Selbstverneinung. Die Cluniacenser und Hirsauer Askese genügte dem Entweltlichungsdrang nicht mehr, war auch zum Teil schon schlaffer geworden. Neue Orden wurden in diesem Gefühl der Heiligung gegründet, die wohl immer noch der Regel des heiligen Benedikt angehörten, aber neue, noch stärker auf Selbstabtötung zielende Gebote aufnahmen. Die Weltflucht wurde zur Tatsache. In einsame Gegenden, in die Wüste, zogen sich diese Mönche zurück wie Johannes der Täufer, um ein von der Verführung der Welt unbedrängtes Leben zu führen und allein Gott zu dienen.

Der älteste und strengste dieser Orden war der der Karthäuser, $\left.{ }^{1}\right)$ gestiftet 1084 vom heiligen Bruno (geb. in Köln, $†$ 1106) mit dem in einer wilden Schlucht bei Grenoble liegenden Kloster la Chartreuse. Ihr Leben war ständige Bußübung, eremitenartig schlossen sie sich in Einzelzellen ab, in völligem Schweigen verharrend. Das Ziel der Gedanken und deren dauernde Beschäftigung ist der Tod, darum ist memento mori ihre Losung und auch ihr Grußwort.

Von weitgreifenderer Bedeutung als die nur um ihr eigenes Seelenheil sorgenden Karthäuser wurde der Orden der Cistercienser. Ihr Stifter, der Burgundermönch Robert, entwich in eine Einöde bei Dijon (1098) und gründete das Kloster Citeaux. Jedoch suchten die Cistercienser, die sich als selbständiger Orden von den Benediktinern trennten, besonders auch in Deutschland, am wirksamsten gefördert durch den Bischof Otto von Bamberg (Bischof 1103-1139), werktätiges Christentum zu üben. Die Wissenschaft verschmähten sie wie die Hirsauer, aber sie wirkten volkswirtschaftlich fördernd in der Kultivierung des Bodens durch Ackerbau, Obst- und Weinzucht und gewannen mit ihren praktischen Bestrebungen zugleich einen starken erziehenden Einfluß auf das Volk. Ihre Frömmigkeit war milder und menschlicher als die der Karthäuser, ein durch die Mystik verklärter Wunderglaube mit dem schönsten Wunder, der holdseligen Erscheinung der Mutter Gottes. Hier wurzelte jene ausgeprägte Form der schwärmerischen Marien- und Frauenverehrung des Mittelalters. Ihren höchsten Ausdruck fand diese mächtige Glaubensinnigkeit in dem Werke und dem Wirken des heiligen Bernhard, der im Jahr 1113 in den Orden eintrat.

Auch unter den Stiftgeistlichen, den Kanonikern, entstand ein neuer, stärker mönchisch geregelter Orden, die Prämonstratenser, gegründet 1120 in Prémontré bei Laon von Norbert, einem fränkischen Geistlichen aus Xanten. Er wurde 1126 Erzbischof in Magdeburg, von da aus verbreitete sich der Orden besonders nach Niedersachsen und den wendischen Gegenden. Auch bei den Prämonstratensern stand das Idealbild der gebenedeiten Jungfrau und Gottesmutter im Mittelpunkt des Gottesdienstes.

1) KeLLE 2, 70-75. 283-286. 
In der Zentralisation des Mönchtums unter dem einen strengen Gedanken des Gehorsams und der Weltentsagung durch die Bewegung, die von Clugny ausging, erstarkte die gesamte Kirche, sie wurde zu einer geschlossenen Macht und das noch langhin in der ersten Hälfte des elften Jahrhunderts kraftlose Papsttum wurde fast plötzlich zur Spitze einer gewaltigen Hierarchie, der Gottesstaat auf Erden war befestigt und konnte bewußt den Kampf gegen den Weltstaat aufnehmen. Augustins Auffassung von der Weltgeschichte, $\left.{ }^{1}\right)$ die Gegenüberstellung der beiden Reiche, kam in ihrer strengsten Form zur Herrschaft: das Reich Gottes verlangte gänzliche Absonderung vom Reich der verachteten Welt, sein Geist ist Weltflucht, Askese ist die höchste Stufe der Gottesverehrung. ${ }^{2}$ ) Nur eine im Innern mächtig pulsierende Gemütsbewegung konnte solchen Umschwung bewirken. Es trat eine gemütserregte Zeit ein, das religiöse Bedürfnis war mächtig gesteigert und diese innere Energie schaffte große äußere Ergebnisse, sowohl auf dem politischen als auf dem wissenschaftlichen Gebiet: dort ist es der Triumph des mönchischen Gottesstaats über die Weltleute, des Papsttums über das Kaisertum, und als Folgeerscheinung die geistliche Kriegsfahrt des Christentums gegen das Heidentum in den Kreuzzügen, hier die neue christliche Wissenschaft, die Scholastik. In der zweiten Hälfte des elften Jahrhunderts beginnt das spezifische Mittelalter, jene Weltanschauung der Widersprüche.

Das Wunder soll nicht nur geglaubt, sondern vernunftgemäß bewiesen werden, die Frömmigkeit soll nicht nur bloß Sache des Glaubens, sondern zugleich des verstandesmäßigen Urteilens sein. Indessen ist die Vernunft, die das Wunderbare. erklären will, von der Realität eben dieses Wunderbaren schon von vornherein überzeugt. Somit dient die Vernunft a priori der Offenbarung, das Wissen dem Glauben, und die Beweise für die vernunftgemäße Einrichtung des Spirituellen werden mit den Sätzen der Logik, mit der dialektischen Methode geführt. Der Verstand soll das Übernatürliche, das Unbegreifliche begrifflich darstellen.

Und so lösen sich schließlich diese Widersprüche zwischen Vernunft und Glauben doch wieder in einer aprioristischen Einheit, denn es sind ja nicht gleichwertige Größen, der Glaube herrscht von vornherein und alle Spekulation dient schließlich dem Glauben. Der Glaube ist die Einheit.

1) Augustinus, De civitate Dei libri XXII; vgl. ERnSt BERnheim, Politische Begriffe des MA.s im Lichte der Anschauungen Augustins, DZs. f. Geschichtswissensch. I (1897), 1-23. 74 ; ders., Der Charakter Ottos v. Freising und seiner Werke, Mitteil. d. Instituts f. österr. Geschichtsforsch. 6,1-51; ders., Dic augustinische Geschichtsanschauung in Ruotgers Biograplıje des Erzbischofs Bruno von Kölı, Zs.d.Savigny-Stiftung Kanon.Abt.2, 299-335; ders., Mittelalterl. Zeitansclianungen T. 1, 1918; s. ferner EHRISMANN, Rudolfs v. Ems Weltchron., Einl. S. V.
2) Ein häufiger 'Titel für asketische Schriften und für die Verherrlichung des Mönchsideals ist 'De contemptu mundi' (sieculi). Zu den wichtigsten gehören i.unserm Zeitraum (11.Jh.) des Hermamus Contractus Carmen de cont. mundi (um 104t-1046), ZfdA. 13, 398 ff., und des Petrus Damiani Apologeticum de contemptu sacculi und De fluxa unundi gloria et sacculi despectatione (Migne 145, 251 - 291 bezw. $807-820$, s. anch Kelte, L.G. 2, 31. 260). Vgl. anch A. Frisybe, Das Memento mori in deutscher Sitte 11sw. 1909. 
Die Phantasie hat die Herrschaft, die Aufklärung ist die Dienerin der Phantasie. Darin liegt die Eigenart des mittelalterlichen Gemütslebens, in dem unerschütterlichen Glauben an Gott, das höchste Gut, in der idealisierenden Kraft, in dem himmelstrebenden Sehnen und dem seligen Sichversenken in die Tiefen der Mystik. Es ist ein magischer, von den Banden des Stoffes befreiender Idealismus.

Mit der Scholastik kam auch eine neue Bewegung in den Betrieb der Wissenschaft. Wohl hatten schon vorher berühmte Lehrer der Schule, an der sie wirkten, einen besonderen Glanz verliehen, aber die individuelle Bedeutung der Persönlichkeit kam jetzt viel mehr zur Geltung, wo die wissenschaftlichen Streitfragen öfentlich behandelt wurden und die Gelehrten als Lehrer zugleich ihre eigenen Systeme vortrugen. Zu Lanfranc nach dem Kloster Bec in der Normandie, zu Abälard nach Paris strömten die studierenden Kleriker von nah und fern. Es bildete sich ein freizügiger Studentenstand aus, die Vaganten, die fahrenden Schüler, die, oft von den Mimen kaum zu unterscheiden, die Lande durchwanderten, in den Klöstern, bei Prälaten oder weltlichen Herren einkehrten und mehr auf der freien Straße zu sehen waren als in den Hörsälen. In dieser gegenüber der Tradition der älteren Klosterschulen freieren Form des Lehrens und Lernens liegt der Anfang zü den Universitäten.

Mit der neuen Geistesbewegung aber trat Frankreich an die Spitze des christlichen Kulturlebens im Abendland. Von hier ging die neue Mönchsbewegung aus, die durch Abtötung des Fleisches den Sieg des Geistes erstrebte und durch Weltentsagung die Weltherrschaft gewann. ${ }^{1}$ ) Frankreich ist die Heimat der neuen Wissenschaft, der Scholastik,2) dorthin wandten sich auch diejenigen Gelehrten, die anderswoher stammten, wie Italiener und Deutsche. Frankreich ist aber endlich auch das Geburtsland der spezifisch mittelalterlichen Kunst, der gotischen Baukunst und der romantischen Poesie. Am Ende der althochdeutschen Zeit hatte Notker eine deutsche humanistische Wissenschaft begründet durch Vereinigung deutscher Eigenart mit klassischer Bildung, eine lateinische Dichtung deutschen Geistes begann zu entstehen mit dem Ruodlieb, aber es ist eine der tragischen Wendungen in der Geschichte des deutschen Volkes, daß in dem Moment, wo es seine Eigenart auch auf geistigem Gebiete kräftig zu äußern begann, die stärkere romanische Kultur die frischen Keime heimischen Wuchses erstickte. ${ }^{3}$ )

Die religiöse Spannung hat in Deutschland eine neue, die früh-mittelhochdeutsche Literatur hervorgerufen. Der an ihrer Spitze steht, Williram, hat es ausgesprochen als ein Zukunftsprogramm: es gibt viele, die sich genügen lassen an dem Studium der Grammatik und Dialektik und die heilige

\footnotetext{
1) HaRnack, Dogmengesch. 31.2, 298 f.; ZöCKLER, Askese und Mönchtum,2.Aufl.1897; s. unten H. v. Melk.

2) Scholastiker sind ursprünglich die doctores scholastici, die Lehrer der Schulfächer,
}

d. i. der sieben freien Künste in den Klosterschulen. Der Name wurde dann besonders auf die übertragen, die sich mitPhilosophie beschäftigten (UEBERWEG-HEINZE, Grundr. $2^{9}, 158$ f.).

3) ZfdPh. 36, 400. 
Schrift beiseite schieben, während man die Werke der Heiden (d. i. der klassischen Literatur) nur lesen soll, um zu erkennen, was für ein Abstand ist $z$ wischen Licht und Finsternis, Wahrheit und Irrtum. ${ }^{1}$ ) Die Beschäftigung mit den Alten soll also nur zum Dienste der heiligen Schrift betrieben werden, während Notker, am Abschluß der althochdeutschen Zeit, sein Lehrgebäude auf Grund harmonischen Zusammenwirkens antiker und christlicher Wissenschaft errichtete. Damit vertritt Williram die zweite von jenen beiden Richtungen, die sich im elften Jahrhundert etwa seit dem Beginn des zweiten Drittels schroff gegenüberstanden: auf der einen Seite die Dialektiker oder Philosophen, die die sieben freien Künste in den Vordergrund der wissenschaftlichen Betätigung stellten, auf der anderen die Theologen, die ausschließlich nur die Beschäftigung mit den religiösen Schriften gelten ließen, also ein Gegensatz zwischen einer mehr weltlichen und einer rein geistlichen Strömung. Gegen Ende des elften Jahrhunderts wendeten sich alle Kräfte der geistlichen Richtung $z u$, jedoch in der Weise, daß sie die Dialektik als Mittel benutzten, um das Dogma zu erklären und dadurch zu befestigen. Das ist die Scholastik. Die deutschen Kirchenschriftsteller allerdings blieben bis tief ins zwölfte Jahrhundert hinein einseitige Theologen, insofern sie die dialektischen Kunstgriffe bekämpften und nur die einfache Erklärung des Doginas, gestützt auf die Autorität, d. i. die Kirchenväter, pflegten. Besonders Otloh2) kehrt als reiner Theologe die Gegnerschaft gegen die Dialektiker stark heraus (Dialogus de tribus quaestionibus, Prologus, Migne 146, 60). ${ }^{3}$ ) Er stellt die saecularis scientia, philosophia mundana, sophia mundana den libri catholicorum, der lectio sancta, dem studium sacrae lectionis gegenüber (De doctrina spirituali Cap. XI -XIII, Migne 146, 270 A -D. 273 B.276 BC). Seine Feindschaft gegen die Wissenschaft spricht er unumwunden aus in dem Verse: Quo, rogo, subvertit te tanta cupido sciendi (Migne aaO.275 D). Der einflußreichste Vertreter dieser orthodoxen Partei war der Abt Wilhelm von Hirsau (1069-1091), der von der Philosophie ausging, dann aber einseitig die praktische Religionsübung vertrat und das Haupt der Klosterreformer wurde, hervorragend auch als Förderer der Kirchenmusik.

Die von der Scholastik aufgeworfenen wissenschaftlichen Probleme wie der Abendmahls- oder der Universalienstreit haben in die deutsche Literatur nicht eingegriffen, doch sind Leitsätze der führenden Scholastiker der Epoche, Anselıns, Hugos v. S. Victor, Abälards, Petrus Lombardus', auch hier eingedrungen, sofern sie dogmatische oder praktische Bedeutung hatten. Die in der frühmlıd. Literatur verarbeiteten theologischen Kenntuisse beruhen auf der Schulwissenschaft, wie sie Honorius Augustodunensis in seinen Kompendien und Abhandlungen zum Gebrauche für die Geistlichen zusammen'gestellt hat. ${ }^{4}$ )

1) Prolog zum HLied, s. unten.

2) LG. 1, Reg. S. 465 unt. Otlolı.

3) Scherer, Leben Willirams S. 289 Anm. 2.
4) Ueber scin Leben ist fast uichts bekanut Gewisse Spuren fultren nach Regensbury. Seine Schriften fallen in die Jalure 1110 bis 
Aber die vernunftgemäße Behandlung der Glaubenstatsachen, welche sich die Scholastik zur Aufgabe machte, konnte der Frömmigkeit nicht für die Dauer genügen. Die tiefe Sehnsucht des Herzens, der leidenschaftliche Drang zur Nähe Gottes kann nur gestillt werden in inniger Vereinigung mit ihm. Dann wird das Sehnen erfüllt im Schauen. Die Scholastik sucht das Göttliche nur vernunftmäßig zu begreifen, die Mystik dagegen kann es mit dem Gefühl leibhaftig in sich aufnehmen. Der Zustand, in welchem dieser Verkehr mit dem Göttlichen geschicht, ist die Kontemplation. Der Gegensatz $z$ wischen dem aktiven und dem kontemplativen, dem tätigen und dem beschaulichen Leben, wird stark betont. Der vollkommenste Akt jener Vereinigung aber ist die Ekstase. ${ }^{1}$ )

Auf die Durchdringung des wirklichen Lebens mit dieser in dem subjektiven Gefühle verankerten Frömmigkeit ist die linneißende Beredsamkeit Bernhards von Clairvaux (1091-1153) gerichtet (praktische Mystik). Er ist Prediger, auch in seinen geschriebenen Traktaten. Er erschüttert die geknechtete Seele, um sie zu befreien. Das Ablegen des Irdischen ist die Grundbedingung für die höhere Frömmigkeit, die Weltverachtung führt zur Befreiung. Die notwendige Seelenbeschaffenheit ist die Demut, das Ziel ist die Liebe. Es gibt aber vier Stufen der Liebe, sie führen vom Egoismus zu der mit der Gottesliebe verbundenen Nächstenliebe. In dieser höchsten Form der Liebe gipfelt die Ethik Sankt Bernhards. Seine religiöse Vorstellungswelt konzentriert sich um den gekreuzigten Erlöser, er ist das Bild der Hoheit in der Erniedrigung. Die schwärmerische Innigkeit der Mystik wird im Symbol erfaßt: Christus ist der Bräutigam der Seele. Christus und die minnende Seele ist das alte Kernmotiv der Mystik.

Gegenüber der auf das unmittelbare Leben wirkenden praktischen Frömmigkeit St. Bernhards steht die spekulative, in der dialektischen Methode mit der Scholastik verwandte Mystik Hugos von St. Victor (1097-1141). Charakteristisch für die Mystik ist eine stufenweise Vervollkommnung. Durch drei Stadien führt der Weg zur Erkenntnis Gottes: cogitatio (Vorstellungskraft des den Sinnen Zugänglichen), meditatio (begriffliches Denken), contemplatio (unmittelbare Anschauung). Es gibt drei Stufen der Frömmigkeit:

1150. Die wichtigsten sind: De imagine mundi, eine Darstellung des Weltbildes nach Geographie, Astronomie, Zeitrechnung und Geschichte; Summa totius de omnimoda historia, eine kurze Chronik von Karl Martell bis auf Lothar; Elucidarium, eine Zusammenfassung der Glaubensregeln (eine Summa theol.); Gemma animae, tuber die kirchlichen Gebräuche, eine Liturgik; Speculum ecclesiae, eine Predigtsammlung als Hilfsbuch für Geistliche; und exegetische Werke: Erklärung ausgewählter Psalmen und des hohen Liedes. Ueber ihn s. UEBERWEG-Heinze, Grundr. $2^{9}$, 179; MSD. I1 ${ }^{3}$, Reg. S. 483; KELLE 2, 92-94. 140 f. 158. 296 ff.; Jos. BACH, Dogmengesch. 2, 298-307; HaUCK, Kirchgesch. 4, 1.
2. Aufl. Reg. S. 1002 u. bes. S. 425 ff.; SCHERER, ZföG. 19 (1868), 567-578 u. Kl.Schr. 1, 607-617; SCHRÖDER, Anz. 7, 178 ff. u. Anegenge S. 57 ff.; CRUEL S. 128 ff.; LINSENMAYER, Reg. S. 487 u. bes. S. $194 \mathrm{ff}$.; KELLE, Wiener SB. 145 (1902) Abh. 8, 150 (1905) Abh. 3, 152 (1906) Abh. 2, 153 (1906) Abh. 5 ; Jos. ANt. ENDRES, Hon. Aug., Kempten u. München 1906; v. D. LEYEN, Dichtung u. bild. Kunst, SA. S. 14; FRZ. BÄUMKER, Das Inevitabile des Honor. Aug., Beitr. z. Gesch. d. Philos. d. MA.s 13. Bd. 6. H., 1915; Allg. d. Biographie 13, 74-78.

1) Hierzu s. bes. Heiler, Das Gebet, an vielen Stellen. 
die einfache Frömmigkeit derer, die nicht mit der Vernunft prüfen; die vernunftmäßige bei denen, die zum Glauben das Vehikel der Vernunft hinzubringen; die Frömmigkeit des reinen Herzens, wenn der Glaube im Innern gleichsam schon gekostet wird.

Der Mystik verwandt sind die Lehren Ruperts von Deutz († 1135). Seiner Glaubensinnigkeit ist Christus der Gottmensch der Mittelpunkt, die Menschwerdung ist der Zweck der Schöpfung, die höchste Stufe der Offenbarung, die Liebe, ist der treibende Grund zur Inkarnation.

Die frühmhd. geistliche Literatur ist durchaus abhängig von der lateinischen. Sie gibt der Überlieferung keine eigenen Wendungen, sie bringt die herrschenden Glaubensanschauungen dem populären Verständnis entsprechend, die Verfasser selbst sind nur rezeptive Köpfe, sind „Theologen“ im Sinne der Zeit und nicht geschult in den Künsten der Dialektik. Demnach kommen die schwierigen Spekulationen der Scholastik nicht in Betracht und die Grundlage für die Beurteilung der deutschen Dichtungen muß das festgelegte Dogma bilden.

Das Dogma in seiner einfachsten Gestalt ist das apostolische Glaubensbekenntnis. Dieses bildet den Grundstock des Systems des christlichen Glaubens. Die Disposition des Symbolums liegt allen Glaubenslehren und Dogmensystemen zugrunde. Es ist die Trinität, die Lehre von der Dreiheit in der Einheit, von Gott als Gott dem Vater, dem Sohn, dem heiligen Geist. Nach diesen drei Hauptartikeln zerfällt also die Glaubenslehre in drei Teile, in dem kirchlichen Lehrsystem aber geht diesen voraus eine Darlegung aller drei Personen als einer Einheit, d. i. des Wesens der Trinität. $\left.{ }^{1}\right)$ Die Zusammenfassung der Lehren des katholischen Glaubens wird seit dem zwölften Jahrhundert Summa genannt, eine theologische Summe, „Summa Theologiae“, oder mit spezieller Bezeichnung, eine Summa Sententiarum, wenn die Summe zugleich die Sentenzen, Aussprüche, der Kirchenväter und Kirclienlehrer enthält. Die älteste derartige dogmatische Zusammenfassung ist Augustins De Symbolo, das einfachste Beispiel für eine Summa Theologiae ist der heutige katholische Katechismus.

Der Grundplan des kirchlichen Lehrsystems oder einer Summa Theologiae ist also folgender (wobei jedoch eine streng gleiche Reihenfolge oder Einteilung der einzelnen Teilartikel in den mittelalterlichen Summen nicht eingehalten ist):

I. Von dér Trinität. $\left.{ }^{2}\right)$ Wesen und Eigenschaften der drei göttlicheı Personen in bezug auf die Dreiheit in der Einheit.

1) Die besondere Betonung der Trinität am Eingang des ganzen Systems stammt aus dem athanasianischen Glaubensbekenntuis.

2) Die Trinität ist dic Haupt- und Cirundlehre des Christentums, an selsärfsten ausgesprochen in dem Athanasianischen Syntbolum. Die drei gottlichen Personen, Vater, Soln, heiliger Geist, sind nur ein cinziger wahrer Gott. Die 1)reiheit ist eine Einheit von Ewigkeit her, der Soln ist vom Vater von Ewigkeit gezeugt, der heilige Geist ist von Ewigkeit von Vater und Sohn ausgehend. Keine der drei Personen ist größer als die andere. Die Eigenschaften der ürei Personen innerlablb der Einlseit sind gefabt in den Trintatsformeln: 1. Augustins Trinitits- 
II. Von Gott als dem Schöpfer Himmels und der Erde (Erschaffung der Engel, Fall Lucifers, Sechstagewerk, Erschaffung Adams und der Eva, Sündenfall; daran anschließend Ethik: die sieben Todsünden und Haupttugenden) (Schöpfung und Sündenfall).

III. Von Christus, dem Sohn, dem fleischgewordenen Wort, und von der Erlösung (das Leben Jesu) (Erlösung).

IV. Von dem heiligen Geist als der Kirche mit ihren Sakramenten und Dienern. Die letzten Dinge: Auferstehung des Fleisches und jüngstes Gericht und ewiges Leben (Heiligung durch die Kirche; Weltende und Ewigkeit).

In drei Stufen spielt sich die christliche Weltgeschichte ab: Einst war der Mensch mit Gott vereint im Paradies; durch die Verführung des Satans gerät er in Sünde und wird aus der Heimat in das Elend der Welt gestoßen; durch den Erlösertod Christi wird er wieder mit Gott ausgesöhnt und in die himmlische Heimat zurückgeleitet, die Unversöhnten aber sind der Hölle verfallen. So ist das Leben des Christen ein ständiger Kampf, ein Krieg gegen die Welt und gegen den Teufel. Die Einheit in diesem inneren und äußeren Zwiespalt und der Grundgehalt der ganzen christlichen Gedankenwelt ist 'Erlösung'. In dieses System läßt sich jedes geistliche, ja selbst jedes weltliche Literaturwerk des Zeitraums einreihen: der Dualismus zwischen Sinnen- und Geisteswelt, der in der Harmonie mit dem Göttlichen seine Auflösung findet. „Der Himmel hat sich der Erde vermählt“ Ezzo 11, 2.

Eine für die mittelalterlichen Glaubensvorstellungen charakteristische Anschauungsform christlicher Ideen ist die Symbolik. Die allegorische oder typologische Auslegung ${ }^{1}$ ) umrankt die einfachen Wahrheiten oft mit einer

formel lautet memoria, intelligentia, voluntas; memoria, die Erkenntnis seiner selbst, dieGesamtheit desBewuBtseinsinhaltes, die innere Erfahrung; intelligentia, Verstand, Urteilskraft; voluntas, Wille. Die Dreieinigkeit ist also psychologisch gefaßt: so wie die einheitliche Seele drei Funktionen hat, memoria, intelligentia, voluntas, so bilden auch die drei göttlichen Personen eine Einheit. Diese im Wesen des Geistes begrüundete Trinität ist für Augustin auch ein rein geistiges Bild. 2. A bälards Trinitätsformel hat die dreiFaktoren potentia, sapientia, charitas (statt charitas auclı amor oder dilectio oder bonitas), d.i. Macht, Weisheit (des Vaters und des Sohnes), Liebe oder Güte. Diese Eigenschaften der Trinität sind ebenfalls Augustin entnommen, sie sind aber von diesem nicht als Dreieinigkeitsformel zusammengefaßt, sondern an verschiedenen Stellen zerstreut. Sie wurden also vereinigt (von Abälard oder schon früher?) und wurden dann, weil verständlicher als die abstraktere Formulierung der Augustinischen Dreiheit, volkstümlich, so daß heute dem Vater die Werke der Allmacht, dem Sohn die der
Weisheit, dem heiligen Geist die der Liebe zuerkannt werden.

1) Siehe Bd. I, 148. - Die allegorische Methode ist ein Erzeugnis griechischer Dialektik. Plato und noch mehr die Stoiker suchten die Mythen der Volksreligion $\mathrm{zu}$ verbinden mit ihren philosophischen Ideen. Diese Methode der Vergeistigung des Sinnlichen wendete der jüdische Religionsphilosoph Philo von Alexandrien (zur Zeit Christi) auf das alte Testament an, in dessen Erzählungen er hinter dem einfachen Tatsachenbericht tiefere philosophische Gedanken fand. Das ältesteChristentum hatte das gleiche Bedürfnis, das alte Testament mit seinen neuen Anschauungen zu vereinigen, ja das alte Testament drängte geradezu darauf hin, indem die Propheten ja auf. den kommenden Messias und die Erlösung des Volkes hiudeuteten, ihn in erhabener Bildersprache verkündeten. Für den Christen ist das alte Testament die Erwartung, das neue die Erfüllung. - Eine übersichtliche Behandlung der Geschichte der typischen Schriftauslegung gibt HaNS VOLLMER, Vom Lesen und Deuten heiliger Schriften, Reli- 
überwuchernden Bilderfülle. Dic Typen des alten Testaments, Personen und Begebenheiten, werden auf christliche Verhältnisse gedeutet, die buchstäbliche Erzählung erhält einen tieferen, geistigen Sinn, indem sie nur ein Bild ist für eine christliche Wahrheit. Und viel weiter: die ganze christliche Kunst, der christliche Kultus ist Symbol;1) sind doch die Dinge der Sinnenwelt Offenbarungen Gottes im Bilde. Alles Irdische ist nur ein Gleichnis.

Das Mittelalter hat in Kunst und Wissenschaft das Erbe des sinkenden Altertums angetreten. So sind mit dem Christentum viele antike, in romantisches Gewand verhüllte Elemente ${ }^{2}$ ) den abendländischen Literaturen, auch der deutschen, zugeführt worden. Mit der Alexanderdichtung wurde der Weltherrscher des Spätgriechentums zu einem mittelalterlichen Romanhelden, in der wunderbaren Orientfahrt des Herzogs Ernst lebten, wie in Alexanders Ostfahrt, antike Reiseabenteuer und Märchen fort. Auf die Konzeption der spielmännischen Entführungssagen ist der griechische Apollonius von Einfluß gewesen, die römische Geschichte der Kaiserchronik beruht zum größten Teil auf Erzählungen und Fabelgeschichten des Altertums und in Physiologus wurde alexandrinische Naturwissenschaft christlich umgedeutet. Das Gesetz vom ununterbrochenen Zusammenhang der Kultur kommt immer wieder zur Geltung, auch geistliche Dichtgattungen des Mittelalters haben ihren Ursprung im Griechentum. Die Vorgeschichte und Jugend Jesu ist durch die apokryphen Evangelien der ersten christlichen Jahrhunderte poetisch erweitert worden; wie der kynische Asket im christlichen Gottesstaat sich zum weltentsagenden Mönch umbildete, so sind die Heiligen- und Märtyrerlegenden christliche Stilisierungen hellenistischer Wundererzählungen, der Aretalogien, und die Jenseitsvisionen gehen zurück auf griechische Hadesfahrten und Himmelsflüge.

Auch die bildende Kunst ${ }^{3}$ ) hat in diesem Zeitraum eine Wandlung erfahren. Der Höhepunkt des romanischen Baustils wird erreicht, die Rundbogenwölbung wird vollkommen durchgeführt, es entstehen die großen Dome von Speyer und Mainz, auch die Malerei entwickelt in sich eine ausgesprochen mittelalterliche Kunstform. In diesem Zeitraum treten die Beziehungen zwischen Literatur und bildender Kunst stärker auf als in der ahd. Periode, es mehren sich die Bilderhandschriften. Die lllustrationen dienen zum Schmuck, oft

gionsgeschichtl. Volksbïcher III. Reihe 9. H., Tübingen 1907.

1) WolfG. MENZEL, Clıristl. Symbolik, 2 Bde., 2. Aufl. 1856; Ferd. Piper, MythoIogie der cliristlichen Kunst von der ältesten Zeit bis ins 16. Jh., 2 Bde., 1847. 51; W. GrimM, Konrads v. Würzburg Goldene Schmiede S. XVIIIff.; ANSElm SALZER, Die Sinnbilder u. Beiworte Martens in der deutsclı. Lit. und lat. Hymnenpoesie des MA.s, Progr. Seitenstetten 1886-1893.

2) BURDACH, Verhandl. d. 44. Philol.-Vers. zu Dresden 1897 S. 28-31; KARL. BOHINSKI,
Die Antike in Poctik u. Kunsttheorie vom Ausg. d. klass. Altertums bis auf Goethe u. Willı. v. Humboldt I, 1914.

3) Siehe bes. PANZER, Diclıtung u. bild. Kunst des deutschen MA.s in iliren Wechselbezichungen, N. Jahrb. VII, 135-161; V. D. LEYEN, Deutsche Dichtung u. bild. Kunst im MA., Abliandl. fiir Franz Muncker 1916; BukDACi, Deutsclie Renaissance,DeutscheAbende IV, 2. Aufl. 1918 S. 15. 98; MAX HERrMANN, Forschungen zur deutschen Theatergesch. des MA.s 11. der Renaissance, 1913, wo iiberall weitere Literatur angegeben ist. 
mehr noch zur Erläuterung des Textes. Die Formen sind gebundenl, nicht frei schafft der Zeichner aus eigener Anschauung die Gestalten, sondern nach einem allgemein gültigen, traditionell überkommenen Schema. Personen und Gegenstände sind typisch erfaßt, es sind mehr Symbole als Wirklichkeiten. Die Zeichnungen der Milstäter Genesis sind Szenenbilder in geschickter Raumverteilung, oft in wohl abgemessenem symmetrischen Bau. Die Körper bewegen sich in schön geschwungenen Linien, was durch den Faltenwurf der Gewänder unterstützt wird. Das größte Gewicht aber ist auf die Wiedergabe innerer Vorgänge gelegt, sie bestimmen die äußere Haltung. Die Gebärdensprache beherrscht die Personendarstellung: in dem Ausdruck des Antlitzes, in der Haltung des Kopfes, vor allem aber in dem Deuten der Hände und der Finger will der Zeichner die Bewegungen der Seele dem Betrachter mitteilen. Diese Stilmittel sind spätantike, überall in der gleichzeitigen Malerei geltende Tradition. Die Natur ist nur symbolisch durch einen architektonisch-ornamental stilisierten Baum erläutert. Aber trotz der wenigen und sich immer wiederholenden Typen wird ein reiches Leben entfaltet. -Wir sehen die Menschen, in Alltagskleidung, bei häuslichen Verrichtungen, beim Essen, Trinken, Schlafen, beim Handwerk und im gesellschaftlichen Verkehr, im Haus, im Freien, Geburt und Tod. Im Gegensatz zu dem Volksleben in der Milst. Hs. stellen die Zeichnungen des Rolands liedes das heroische Rittertum dar, ritterliches Kostüm, Rüstungen, Waffen, Pferde, Kämpfe geben hier das charakteristische Gepräge. Der Physiologus der Milst. Hs. ist belebt durch die phantastischen Bilder einer symbolischen Tierwelt, hier treffen Wissenschaft und Kunst, Naturgeschichte und Literatur, Skulptur, Malerei, zusammen, um in spielender Märchenphantasie christliche Lehren in heiligen und höllischen Gestalten bildhaft zu verkörpern. - Gegenüber der einfacheren Zeichnertechnik der Milst. und der Roland-Hss. stellen die kolorierten, reichaus geführten Bilder der Hss. von Wernhers Marienleben eine höhere Stufe der Buchillustration dar. Es sind selbständige kleine Kunstwerke. Sie fallen schon in den Beginn des folgenden Zeitraums.

Mit der neuen Frömmigkeit ist die christliche Welt in eine neue Entwicklungsstufe eingetreten und die Literatur der Zeit mußte den neuen Geist zum Ausdruck bringen. Es trug aber dieses neue Menschheitsideal die Nötigung zur Ausdehnung in sich, denn der Universalgedanke ist jetzt die Triebkraft aller politischen und geistigen Strebungen. Die Weltherrschaftstendenz der Kirche forderte eine völlige Durchdringung der Gesellschaft mit ihren Forderungen, es mußte das ganze Volk in den Gedankenkreis des Christentums einbezogen werden. Die Welt zum Dienste Gottes zu erziehen, im Weltreiclı das Gottesreich vorzubereiten, das war die Aufgabe der Kirche. Mit der imperialistischen Reichsidee der sächsischen Kaiser war die deutsche Sprache gleichsam zu einem Volksdialekt heruntergesunken, die lingua latina hatte die lingua theotisca nun ganz auf dem geistlichen Gebiete verdrängt. Eine Vereinigung beider zu praktischen Klosterzwecken wurde von Notker er- 
strebt, aber zur selbständigen Berechtigung gelangte die Volkssprache erst damit, daß die Reformbewegung auch in Deutschland die Religion wieder zu einer neuen Gemütsmacht erhob. Alle Menschenseelen sollten mit dem Glauben durchtränkt werden. Darum wurde von nun an in viel umfassenderer Weise als je zuvor das Deutsche auch in der geistlichen Literatur gepflegt, die Bedeutung der Volkssprache ist anerkannt. Jetzt erst wird eigentlich Otfrids Forderung, Gottes Lob in deutscher Sprache zu besingen, voll und ganz verwirklicht.

\section{$\$ 2$. Metrik und Vortragsweise. $\left.{ }^{1}\right)$ Stil.}

Die Metrik und wohl auch die Vortragsweise der geistlichen ahd. Alliterationsdichtung stand, wie die weltliche, unter den Gesetzen der germanischen Epik, Otfrid und die ahd. Reimdichtung folgte dann im Rhythmus dem deutschen Sprachgeist, nahm aber mit dem Reim lateinisch liturgisches Formprinzip auf. Die frühmhd. geistliche Dichtung steht in keinem unmittelbar fortwirkenden Zusammenhang mehr mit der ahd., sondern ist eine Neuschöpfung der neuen Zeit, des Aufschwungs durch die cluniacensische Kirchenreformation. Diese Dichter waren geschult an der liturgischen, der kirchlichen Vortragsweise. Sie brachten ein neues Prinzip in Rhythmus und Vortrag, das des liturgischen Rezitativs, bezw. des liturgischen Sprechvortrags, ${ }^{2}$ ) und damit eine viel größere Freiheit der Senkungen. Sie behielten

1) Literatur s. LG. I, 69. 74; für das Frühmhd.: LACHMANN bei W.Grimm, GrafRudolf, 2. Ausg. S. 12-14; W. GRIMM, K1. Schr. 4, 164 ff. 231 . $310 \mathrm{ff} .330 \mathrm{ff}$; MSD. $1^{3}$, Vorw. XXXVII-XXXIX u. II $^{3}$ unter den einzelnen Denkmälern; SCHERER, QF 1 u. bes. QF 7 an vielen Orten; AMELUNG, ZfdPh. 3, 253-305; GeMOLL, Germ. 19, 35-44; WilmanNS, Der ad. Reimvers; ders., Anz. 23, 353 ff.; VoGT, Festgabe f. Hildebrand S. 150 ff.; HeUSLER, Zur Gesch. d. ad. Verskunst, Germanist. Abliandl. 8, bes. S. 55 -90; HiRT, ZfdA. 38, 304-333; HERTEL, Die Verse von mehr als 4 Heb., Marb. Diss. 1908; HABERMANN, Die Metrik der kl. ahd. Reimgedichte 1909; STEINMEYER, ZfdA. 21, 313; KOCHENDÖRFFER, ZfdA. $35290 \mathrm{f}$; ; SCHRÖDER, ZfdA. 52, 59; SCHRÖDER, Reimstudien 1 u. 11, Göttinger Nachr. 1918, 378-392. 407-428; Kraus, Verhandl. d. 42. Philol.-Vers. zu Wien, vgl. ZfdPh. 26, 400 f.; BoRINSKI, Die Antike in Poetik u. Kunsttheorie 1914, S. 43 u. Anm.; BRaune, Reim u. Vers, Heidelberger SB. 1916, 11. Abh.; Heusler, Der deutsche u. der antike Vers 1917; PAUL, Grundr. 11, $2^{2}, 63-65$; SARAN, D. Verslehre bes. S. 250 ff.; SiEvers, Rhythm. melod. Stud., 1912; ders., Metr. Stud.IV, Ablı. d. sächs. Ges. d. Wiss. Bd. 35, I u. H, dazu Blơmel, Anz. 40, 22-31, PANZER, ZfudUnt. 33 H. 10/11; BAEsECKE, Wissenschaftl. Forsclungsberichte III 1919, $116 \mathrm{ff}$. - KḰRAUS, DGed., WAAG, KI. d. Ged. unter den einzeinen Nummern sowic die betr. hier im Folgenden besprochenen poet. Denkmäler.

Lat. Kirchenlieder: MONE, Lat.Hymuen des
MA.s, 3 Bde. 1853. 54.55; DAniel, Thesaurus Hymnologicus, 4 Bde. 1855; KEHREIN, Kirchen- und religiöse Lieder aus dem 12. bis 15. Ji. 1853; G.M. Dreves und Clem. Blume, Analecta Hymnica medii aevi, 54 Bde. $1888-$ 1915; FERD. Wolf, Ueber die Lais, Sequenzen und Leiche 1841, bes. S. 84 ff.; JoH. KAYSER, Beitr. zur Gesch. und Erklärung der Kirchenhymmnen 1866; LÉON GAUTIER, Histoire de la poésie liturgique au moyen âge. Les tropes I. 1886; WILH. MEYER, Gesammelte Abhandlungen zur mittellat. Kythmik, 2 Bde. 1905; WILH. BÄUMKER, Das katholische deutsche Kirchenlied in seinen Singweisen von den frühesten Zeiten bis gegen Ende des 17. Jhs., 4 Bde. 1883-1911, mit erschöpfender Bibliographie in jedem Bande; HOFFMANN vON Fallersleben, Gesch. des deutschen Kirchenliedes bis auf Luthers Zeit, 3. Ausg. 1861 Phil. Wackernagel, Das deutsche Kirchenlied von der äłtesten Zeit bis zum Anfang des XVII. Jhs. 5 Bde., Leipz. 1864-1877. ThalhofEr, Liturgik", Das Breviergebet S.510-637; Prot. Realencyclop. ${ }^{3}$ Bd. 10, 410 ff.

2) Aus dem liturgischen Vortrag also stammen die iiberlangen Verse. Sie sind bis jetzt verschieden beurieilt worden. Aufgegeben ist Wackernagels "Reimprosa" (1.G. ${ }^{2}, 107 \mathrm{fi}$., $\mathrm{LB}^{+}$u. $\mathrm{LB}^{5} \mathrm{~S}$. Vlf.), da doch ein in gewissen Grenzen sich haltender Rhythmus nicht zu lemgnen ist. Man halt num allgemein dic Reimzeilen aluch für wirkliche Verse. Dabei scheiden sich bezuiglich der rhyllımischen Gliederung zwei Auffassungen: die eine ftilurt 
den Grundstock des deutschen Verses bei, das Gesetz der vier Hebungen (die guten Taktteile), aber sie gewährten den Senkungen (die schlechten Taktteile) noch größere Freiheit. Und eben in der rhythmischen Freiheit, also in der Unregelmäßigkeit, besteht das Charakteristische der frühmhd. Dichtung: die Senkungen übersteigen oft das normale Maß; aber auch umgekehrt, die Hebungen können von vier auf drei beschränkt werden. Der ahd. und mhd. Reimpaarvers hat folgende Takttypen:

d. h. der normale Takt besteht aus zwei Silben, einer Hebung und einer Senkung $\dot{x} \times$; er kann aber erweitert werden auf drei Silben, eine Hebung und $z$ wei Senkungen $\dot{x} \times x$ (selten drei Senkungen); er kann endlich an Silbenzahl auch gemindert werden und nur aus der Hebung bestehen, wobei diese aber lang sein muß $\frac{1}{x}$ (um die Zeitdaụer des normalzweisilbigen Taktes $\dot{x} \times$ auszufüllen).

Die frühmhd. Verse sind also durch schwere Senkungsfüllung sehr oft länger als die normalen Verse: es können 3, 4, 5, sogar 6, 7 und 8 Senkungen eintreten, besonders auch wird der Auftakt gelängt; sie sind manchmal auch kürzer, durch Fehlen von Senkungen oder einer Hebung. Danach entstehen vier Typen von Gedichten:1)

I. Das Gedicht enthält meistens normale Verse, normaler Typus. II. Das Gedicht enthält verhältnismäßig viele überlange Verse, gelängter Typus. - III. Das Gedicht enthält verhältnismäßig viele kurze Verse, gekürzter (gedrungener) Typus. - IV. Das Gedicht hat verhältnismäßig oft sowohl lange als kurze Verse, ungleicher Typus.

Die für den frühmhd. Versbau charakteristischen Typen sind: II. III. IV. Im Vortrag ist $z \mathfrak{u}$ unterscheiden:

A. der Rhythmus, die Tonstärke, die Akzentuation, Betonung, der Wechsel zwischen stärker und schwächer betonten Silben, Hebung und Senkung, die zusammen den Takt bilden. Dieser Wechsel kann sein: a) regelmäßig, die Takte sind also gleich in ihrem Maß (Mensur) gebaut, die Taktlänge ist gleich; oder b) unregelmäßig, frei, die Takte sind frei gebaut, verschieden in ihrem Maß.

strengen Rhythmus durch, also möglichst Einsilbigkeit der Senkung, wobei eben viele Aenderungen an der handschriftlichen Ueberlieferung nötig sind (so führten Müllenhoff und Scherer in MSD. die strengen Regeln Lachmanns ein und suchten möglichst normale vierhebige Verse herzustellen) und doch noch Verse von melır als vier Hebungen zugelassen werden müssen; die andere hält an dem Prinzip der vier Hebungen fest unter Annahme mehrsilbiger Senkungen (dic Lit. bei EBERHARDT, Beitr. 34, 1 ff., vgl. PAUL aaO.). Ueber die Entstehung der frei gebauten Zeilen herrschen bis jetzt zwci verschiedene
Ansichten: nach der einen sind sie Weiterbildungen sclion bei Otfrid vorkommender freierer Typen, nach der andern gehen sie unmittelbar auf die alliterierende Langzeile zurück. die jedenfalls noch längere Zeit auch nach Otfrid bestanden hat (vgl. WiLMANNS, Der ad. Reimvers u. Anz. 23, 353 ff.; Gemoll aaO.; Berger, Beitr. 11, 460 ff.; HeUSLER, Zur Gesch. d. ad. Verskunst S. 81 ff.). Aber ein historischer Zusammenhang ist mit beiden Systemen, dem otfridischen und dem alliterierenden, nicht nachzuweisen.

1) SARAN S. 254. 
B. die Modulation, Melodie, die Tonhöhe, der Wechsel zwischen höher oder tiefer betonten Silben, zwischen in der Tonleiter höheren oder tieferen Tönen.

Je nach der Melodie unterscheidet man:

a) Gesangsvortrag, mit ausgeprägter Melodie; die Absicht ist, künstlerisch zu wirken.

Gesangsvortrag mit $\alpha$ ) regelmäßigem Rhythmus besteht im Lied, im Hymnus; Gesangsvortrag mit $\beta$ ) unregelmäßigem, freiem Rhythmus besteht in der Sequenz (mit kunstreichen Maßen und Melodien), im Choralgesang, im liturgischen Vortrag der Psalmen, des Ave Maria, des Gloria in Excelsis, des Paternosters, des Symbolums, der Gebete, des Evangeliums, der Epistel, im Falle sie gesanglich vorgetragen werden. ${ }^{1}$ ) Gesangsvortrag mit freien Rhythmus (oder umgekehrt: unregelmäßiger Rhythmus mit Gesang) ist Rezitativ, bezw. im geistlichen Vortrag: liturgisches Rezitativ.

b) Sprechvortrag: Die Melodie hat kein selbständiges Interesse, die Tonbewegung ist auch im großen und ganzen geringer als im Gesangsvortrag, die Absicht ist bloß rhetorisch, oratorisch. Es gibt die verschiedensten Arten des Sprechvortrags, je nach der inneren Bewegung des Redenden, der Stimmung, dem Ethos, dem Zweck. Die gewöhnliche Sprechweise des Alltagsverkehrs kommt hier nicht in Betracht, sondern die liturgische. Hier ist der Vortrag ausdrucksvoller und mehr getragen. Sie findet statt in der Lectio, Lesung, ${ }^{2}$ ) der Predigt, und kann auch im Evangelium, in der Epistel und andern Prosastücken angewendet werden, wenn sie nicht gesanglich vorgetragen werden (meist Einzelvortrag). Dieser gehobene Sprechvortrag berührt sich dann wieder mit dem Rezitativ. ${ }^{3}$ )

Zur rhythmischen Gliederung ist noch zu bemerken: Der regelmäßige Rhythmus verläuft in gleichen Teilen, der unregelmäßige Rhythmus in un-

1) Jeder gesprochene bezw. geschriebene Satz kann melodisch vorgetragen werden, eine mathematische Formel, ein Gesetzesparagraph, eine Zeitungsannonce u. dgl.; so also auch Vaterunser, Glaubensbekenntnis, Evangelium, Epistel usw. - Ueber liturgische Musik (Kirchenmusik), bes. über den Vortrag s. THALHOFER $1^{2}, 249-297$, darin iiber Sprachmelodie und Sprachrliythmus S. 257. 266; Wolf, Ueber die Lais, bes. S. 97 ff.; Dom JosePH POTHER, Mélodies Grégoriennes, übers. von P. AmBROSIUS KIENLE: Der gregorian. Choral, Tournay 1881 , bes. S. 161 229: Peter Wagner, Einfiihrung in die gregorian. Melodien, 2. T. Neumenkunde, 2 . Aufl. Leipz. 1912; EMIL NikEL, Gesch. der kath. Kirchenmusik, I. Bd.: Gesclı. des gregorian. Chorals 1908, bes. S. 110-144. 257-268; Riemann, Gesch. d. Tonkunst; Norden, Dic antike Kunstprosa II, 841 ff.

2) Ueber den Predigtvortrag s. Lecoy DI: LA MARCHE aaO. S. $279 \mathrm{ff}$. Die Formel singen und lesen bezieht sich anf die zwielaclie
Weise des Vortragens, auf den liturgischen Gesangs-bezw. den liturgischen Sprechvortrag (Lectio), vgl. Jul. SCIWIETERING, Singen und Sagen, Göttinger Diss. 1908 S. 27 ff.

3) Man untersclicidet drei Arten von rezitativischer Singweise: 1. olne Stimmbewegung, ohne Modulation; die Stimme hält sich immer auf dem gleichen Ton; 2. desgleichen, nur die Abschnitte von Satzteilen oder Sätzen haberi Stimmbewegung, Melodie; 3 . der ganze Text hat mannigfaltige Stimmbewegung, reiche Melodie (Pothier-Kienle S. 199 ff.). Bei der ersten Art wirkt gerade dic Monotonie, bei der zweiten die Monotonie und besonders der darauf folgende melodische Abschluß, bei der dritten die reiche Melodie. Danach wäre ein monotones, ein tonreiches und cin aus den zwei Arten zusammengesetztes Rezitativ festzustellen. Das monotonc Rezilativ unterscheidet sich von den liturgischen Sprechvortrig gerade durclı dic Einförmigkeit des Tons, das tonreiche Rezitativ durch dic beabsichtigte kunstreiche Melodic. 
gleichen Teilen. Die mittelalterlichen Musikgelehrten nehmen drei Teilungen an: der kleinste Teil ist die melodische Silbe, das ist das Wort; dann folgt die melodische Neume (pars), mehrere Wörter, der melodische Satzteil; endlich: der melodische Satz, distinctio, Periode. - Der Schluß eines in sich fertigen Teils, die Pause (Punkt), wird oft länger gezogen mit verzögerter Bewegung, die Stimme klingt sanft aus, es ruht also auf dem AbschluB ein Schwerpunkt.

Aus dem lat. liturgischen Rezitativ bezw. dem liturgischen Sprechvortrag ist die große Freiheit der Senkungen in den Typen II. III. IV zu erklären.1)

In welchem Vortrag unsere frühmhd. Gedichte dargeboten wurden, ist im einzelnen schwer zu entscheiden. Gesungen wurde jedenfalls das Ezzolied, zum Gesang bestimmt waren auch die Marienlieder und Mariensequenzen. Alle übrigen Stücke (biblische Erzählungen und Legenden, gereimte Bußreden, $z$. B. Memento mori, Sündenklagen, die Litanei, dogmatische und allegorische Abhandlungen, auch die Predigten, sind wohl in gehobenem Sprechvortrag gehalten worden, der aber, wie erwähnt, mannigfache Abstufungen haben konnte. Der Rhythmus kommt dabei nur so weit in Betracht, als gesungene Lieder auch den regelmäßigen Versbau haben, während gesprochene sowohl in regelmäßigem Versbau als in den freien Typen abgefaßt sein konnten.

Die Grundstimmung jeglichen Vortrags, sowohl des Liedes als der Lectio um diese beiden als Vertreter des Gesangs- bezw. Sprechvortrags aufzustellen ist das Maß, das Maßhalten: "natürlich bleiben ist die höchste Kunst", so also auch im Choralgesang: „leidenschaftliche Aufregung widerspricht ihm ebenso wie Künstlichkeit und Effekthascherei“, „Einfalt und Anmut kennzeichnen die Vollkommenheit in der Ausführung des Choralgesanges. Alles Gesuchte und Gemachte, alles mehr oder minder Theatralische muß hier fern bleiben." 2 ) Das Maßhalten aber nicht nur im Gesange oder im gesprochenen Wort, sondern im ganzen äußeren und inneren Menschen, also auch in der Gebärdensprache, in den Bewegungen, der Mimik. Für den Vortrag der vulgären Predigt hat Honorius Augustodunensis ${ }^{3}$ ) die Regeln kurz zusammengefaßt in seinem Speculum ecclesiae am Schluß der Pred. in Septuagesima (Migne 172, 861. 862): „Wenn du eine Rede hältst, so sollst du nicht mit ausgestreckter Hand gleichsam die Worte dem Volk ins Gesicht schleudern; nicht mit geschlossenen oder auf den Boden gehefteten Augen, sondern mit aufgerichtetem Blicke da stehen; auch nicht den Kopf wie ein Unsinniger hin und her bewegen oder den Mund nach allen Richtungen verdrehen, sondern, wie die Rhetorik lehrt, mit geziemenden (ruhigen) Bewegungen (gestus) sprechen, die Worte ruhig und einfach aussprechen, das Traurige mit betrübter Stimme, das Freudige mit fröhlicher, das Herbe mit

1) Unter dem Einfluß dieser freien Vortragsweise können auch die kurzen Verse mit nur drei Hebungen zugelassen worden sein und ebenso die häufigen klingend aus- gehenden Verse von vier Hebungen.

2) Pothier-Kienle S. 21.

3) Siehe auch Hrabanus Maurus, De clericorum institutione III, 28 (Migne 107, $406 \mathrm{CD}$ ). 
scharfer, das Gewöhnliche mit leiser (nicht hervordringender) vorbringen. Die Zuhörer sollen viel mehr den Eindruck haben, die Dinge selbst mit Augen $z u$ schauen als dich $z u$ hören. " ${ }^{1}$ )

Die mittelalterliche Rhetorik (das ist Stilistik) ist eine unmittelbare Fortsetzung der lateinischen, Beredsamkeit und Kunst der sprachlichen Form sind in Italien auch nach dem Untergang des römischen Reiches weiter gepflegt worden. Die Gesetze des Stils haben hauptsächlich Augustin (De doctrina christiana IV, 10-26) und Isidor (Orig. Il, 6 ff.) dem Mittelalter überliefert. Die Grundlagen bilden die drei Stilarten (genera dicendi), die Cicero festgelegt hat:2) a) der niedrige (alltägliche, einfache) Stil, genus dicendi tenue, auch extenuatum, submissum, humile (Isidor); b) der mittlere Stil, genus dicendi mediocre oder temperatum, medium (Isidor); c) der erhabene Stil, genus dicendi sublime, auch grave, grandiloquum (Isidor). Diese drei Arten des sprachlichen Stils sind Ausdrucksformen für einen entsprechenden Inhalt, für das Gewöhnliche, für das Mittelmaß, für das Erhabene. Jede ist auch in einer bestimmten Absicht anzuwenden: der einfache Stil berichtet einfache Dinge und lehrt (docere); der mittlere Stil soll ergötzen (delectare); der erhabene Stil soll rühren (movere). Diese drei ethisch-rhetorischen Stilarten kann man auf jeden Gegenstand anwenden, je nach der Absicht zu belehren, zu ergötzen, zu rühren. Der erhabene Ausdruck aber hat seinen richtigen Platz, wenn die Rede zum Lobe Gottes dient. ${ }^{3}$ )

\section{\$3. Die Sammelhandschriften.}

Die Uberlieferung der frühmhd. Literatır ist im allgemeinen nicht ungünstig, da die geistlichen Schreiber dieser Zeit meistens leidlich gewissenhaft arbeiteten, so daß wirklich nachlässige Handschriften selten sind. Beeinträchtigt aber wird der Wert vieler Stücke dadurch, daß sie nur fragmentarisch auf uns gekommen sind. Von großer Wichtigkeit sind einige Sammelhss., in denen gerade mehrere der hervorragendsten Erzeugnisse des 11. u. 12. Jhs. enthalten sind.

I. Die Wiener Hs. $\left.2721,{ }^{4}\right)$ k. k. Hofbibliothek, Perg. kl. fol. 183 Bl., 2. Hälfte des 12. Jhs., stammt vielleicht aus Kärnten. Sie enthält: die Genesis Bl. $1 \mathrm{a}-129 \mathrm{~b}$, den prosaischen Physiologus Bl. 129b-158a, die Exodus Bl. 159a-183a. Die Genesis hat Bilder auf Bl. 1a -5 b, von da an ist für solche Raum gelassen, der Physiologus ist durchweg mit Bildern geschmückt, die Exodus ist nicht illustriert. Die Abschnitte beginnen mit größeren und farbigen Buchstaben. $\left.{ }^{5}\right)$

II. Die Milstäter Hs. K (nach ihrem Aufbewahrungsort Klagenfurt, oder $M=M_{\text {ilstat) }}^{6}$ )

1) Die Rhetorik des MA.s gründet sich auf die der Römer, vgl. EHRISMANN, Stud. über Rind. v. Ems.

2) Ebenda, bes. S. $23 \mathrm{ff}$.

3) Augustinus, De doctr. christ. 1V, 19; Isidor, Orig. aaO.; Hrabanus Maurus, De cleric. inst. III, 33.

4) HofFManns Verzeichnis Nr. V S. 3 f.; GrafF, Diut. 3, 22. 40; Hofmann, Fundgr. 2, 9 f.; Massmann, D. Ged. S. 158 f.; Diemer, Gen, u. Ex., Einl. S. 111; SCherER, QF 1 S. 1 f. 62-65; VOGT, Beitr. 2, 209; ERNST KossMANN, Die altdeutsche Exodus, QF. 57, 1886 , S. 2 f.; Kelle, LG. 2, 251.

5) GRAFF, Ditut. 3, 40; MSD. $11^{3}, 113 \mathrm{f}$. $\left.{ }^{6}\right)$ Karajan, D. Sprach-Denkm. des 12. Jhs., Wien 1846, S. V-X (dazu LeITZMANN, Anz. 34, 122); Jos. DIEMER, Genesis und Exodus nach der Milstäter Hs., Wien 1862, Einl. S. I-111; SCHERER, QF. 1, 4.62-65; 7, 3 ff. 21; Vogt, Beitr. 2, 209 f.; Kossuann, Exodus S. 3 f.; Kraus, Vom Rechte S. 2 ff.; Keli.e 2, 251; Bulthaup'r, Milstäter Genesis und Exodus, Palästra. 72, 1-12. - Dic Stïcke 1 und 3 sind von Diemer aaO., 2. 4. 5.6 Von KARAJAN aaO herausgegeben; iiber das Bruchst. vom himml. Jerusalem s. unten. Dic Bilder sind bei KaRAJAN (Physiologus) und DIEMER (Genesis), aber niclit koloriert, wiedergegeben. 
nach der Mitte des 12. Jhs. in Innerösterreich geschrieben, Perg. kl. okt. 167 Bl. einspaltig in unabgesetzten Versen, wobei jedoch die Anfänge der Abschnitte gekennzeichnet sind; die Blätter haben gegen das Ende durch Feuchtigkeit gelitten. Die Genesis und der Physiologus sind mit Bildern geschmückt, die Exodus nicht. Die Hs. stammt aus der ehemaligen Benediktinerabtei Milstat in Kärnten, kam nach 1598 an die Gesellschaft Jesu, wurde 1845 vom Verein für Geschichte und Landeskunde Kärntens in Klagenfurt (Kärntner Geschichtsverein) erworben. Sie enthält: 1 . die Genesis $1 \mathrm{a}-84^{\mathrm{a}} ; 2$. den gereimtẹn Physiologus $84^{\mathrm{b}}$ $101 \mathrm{a}$; 3. die Exodus $101^{\mathrm{b}}-135^{\mathrm{a}}$; 4. vom Rechte $135^{\mathrm{b}}-142^{\mathrm{a}}$; 5. die Hochzeit $142^{\mathrm{a}}-154^{\mathrm{b}}$; 6. die Milstäter Sïndenklage $154 \mathrm{~b}-164 \mathrm{~b} ; 7$. das Paternoster $164 \mathrm{~b}-167 \mathrm{~b} ; 8$. den Anfang

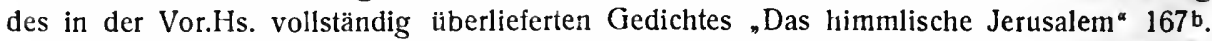

III. Die Vorauer Hs., $\left.{ }^{1}\right)$ Hs. des regulierten Chorherrenstifts zu Vorau in Steiermark Nr. XI, Perg. gr. folio 183 Bl., bald nach der Mitte des 12. Jhs. von einem Schreiber geschrieben (eine etwas jüngere Hand hat nur wenige Blätter ergänzt). Die Seiten sind zweispaltig, die Verse sind nicht abgesetzt, aber durch Zeichen, meist Punkte, markiert. ${ }^{2}$ ) Auch die Strophen sind nicht abgesetzt, ihr Anfang ist aber durch große Initialen bezeichnet. Die Hs. besteht aus zwei Teilen, deren zweiter erst später angebunden wurde. Der erste, der deutsche Teil, enthält auf Bl. 1 1a $-135 \mathrm{vb}$ die beriihmte Vorauer Sammlung deutscher Gedichte: I. die (Vor.) Kaiserchronik Bl.1ra-73vb; Il. Geistliche Gedichte des 11. u. 12. Jhs.: 2. die Bücher Mosis Bl.74ra_96ra (darin das Marienlob Bl. 93va_94ra); 3. die Wahrheit Bl. 96ra-96vb; 4. Summa Theologiae Bl.97ra_98va; 5. das Lob Salomons Bl.98va_ 99va; 6. die drei Jünglinge im Feuerofen und die ältere Judith Bl. 99va-100va (Nr. 4-6 haben die gleiche Orthographie); ${ }^{3}$ ) 7. die jüngere Judith Bl. 100va-108vb; 8. Vorauer Alexander Bl. 109ra-115va; 9. Gedichte der Ava (Leben Jesu, Antichrist und jüngstes Gericht) BI. 115va $-125^{\mathrm{ra}} ; 10$. (Vorauer) Sündenklage Bl. 125ra $-128 \mathrm{rb} ; 11$. Ezzos Gesang Bl. 128rb_ 129vb; 12. Priester Arnolds Loblied von der Siebenzahl zum Lob des heiligen Geistes (mit Laudate Dominum Bl. 133rb) Bl. 129vb-133vb; 13. das himmlische Jerusalem Bl. 133vb_ 135va; 14. Gebet einer Frau B1. 135va-135vb. - Der zweite Teil, lat., besteht aus den Gesta Friderici imperatoris Ottos von Freising (Buch 1 - Anfang von Buch 4), Bl. 136rb_-183vb.

Die Stücke sind, ohne Überschriften, in historischer Reihenfolge geordnet und zwar nach dem Plane einer christlichen Weltgeschichte. Die Kaiserchronik (Nr. 1) stellt die Ereignisse des Weltstaates dar, soweit derselbe im römischen Reiche, dem antiken und dem

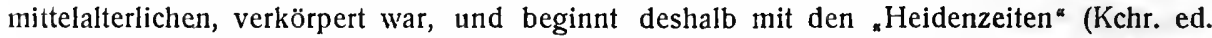
Schröder v. 43). Der Gottesstaat lindet seine Erscheinungsformen in den darauf folgenden geistlichen Stücken (Nr. 2-14). Der alte Bund umfaßt die Nr. 2-8 und reicht vom Anfang der Dinge, das ist Gott, und der Weltschöpfung, also von der Genesis, bis zum Ende des alten Testamentes, denn das Alexanderlied (Nr. 8) umfaßt das Weltreich Alexanders des Großen, auf diesem aber bauten sich die letzten Ereignisse des alten Testamentes auf, die Kämpfe der Makkabäer: den Zusammenhang deuten an.die Verse diz mugit ir wol hôren in libro Machabeorum Vor. Alex. $11 \mathrm{f}$. In die Zeit, die zwischen den Büchern Mosis und dem Alexanderreich liegt, fallen die Preislieder auf Menschen, die durch Weisheit und Gottvertrauen vorbildlich waren: Salomo, die drei Jünglinge, Judith (Nr. 5, 6, dazu 7). Nicht in

1) Die Hs. wurde gefunden 1841 von Diemer. Von ihm wurde der gesamte deutsche Teil der Hs. herausgegeben, und zwar die geistlichen Gedichte in: J. DiEmER, D. Ged. des XI. und XII. Jlis., Wien 1849, außer dem Voraucr Joseph (einem Teil der Bücher Mosis, B1. $78 \mathrm{rb}-87 \mathrm{vb})$, der in seinen KI. Beiträgen V.T. Nr. XX u. XXI, Wiener SB. 47 (1864), 636687 u. 48 (1864), 339-423 erschien; die Kchr. wurde vonDiemer gesondert hrsg. Wien1849.Beschreibung der Hs.: DIEMER, D. Ged.Einl. S. I-XII; M MASMANN, ZfdA. 2, 223-227;
SCHRÖDER, Kaiserchronik S. 3. 7 f.; Faksimile bei DiEMER, D. Ged. vor dem Titelblatt und vor S. 87 (Faks. des zweiten Schreibers), und bei SCHRÖDER Kchr. nach S. 8. Bestand und Zusammensetzung der Hs.: KonR. HOFMANN, Studien üb. d. Vor.Hs., Münch. SB. 1870, II, 183-196; MSD.II ${ }^{3}, 168$ f. 217f. 248 f.; SCHERER, QF. 1, 4. 7, 28-90; WAAG, Die Zusammensetzung der Vor. Hs., Beitr. 11, 77-158.

2) Vgl. Kraus, D. Ged. S. 103 Anm.

3) MSD I ${ }^{3}$ S. XXXII. $11^{3}, 217 \mathrm{f}$.; WAAG, Beitr. 11 , 109-119; Orthogr.d. Kchr.: SCHRÖDERS. $35 \mathrm{ff}$. 
den Zusammenhang gehören die außerbiblischen Stücke: das Marienlob (in Nr. 2), dieses gleichsam als Ersatz für die Weissagung Barlaams auf Christus eingeschaltet; die Wahrheit am Schluß der Bücher Mosis (Nr. 3); und darauf folgend die Summa Theologiae (Nr. 4), deren Inhalt sich an die Bücher Mosis immerhin insofern anschlieBt, als ihr Eingang von den ersten Dingen handelt, die aber ihren Platz hier darum gefunden hat, weil sie mit den folgenden $z$ wei, ebenfalls md. Nummern 5,6 ursprünglich eine engere Gemeinschaft bildete.

Der neue Bund beginnt mit der Geschichte Jesu, die bis zum jüngsten Gericht reicht (Nr. 9). Ezzos Gesang (Nr. 11) ist gleichsam eine kurze Zusammenfassung der Wundertaten Jesu. Nach den Taten des Sohnes folgt sinngemäß der Preis des heiligen Geistes (Nr. 12) und den Abschluß bildet die Herrlichkeit des Jenseits, des himmlischen Jerusalems (Nr. 13), das dem letzten Buch des neuen Testaments, der Apokalypse, entnommen ist. In diesen ganz folgerichtigen Aufbau eingeschaltet ist unmittelbar nach den Taten Jesu eine Sündenklage (Nr. 10), womit die schuldbeladene Menschheit in das Erlösungswerk Christi hineinbezogen wird. Ein Gebet (Nr. 14) beschließt den weltumspannenden Zyklus. - Was hier vom Gottesstaat gleichwie in einem lang hinrauschenden Epos, oft mit Ausmalung der Einzelheiten erzählt wird, ist in Ezzos Gesang als wie in einem epischen Liede kurz gedrängt zusammengefaßt: die Menschheitsgeschichte.

IV. Die Straßburg-Molsheimer Hs., ${ }^{1}$ ) einst Eigentum des Jesuitenkollegs zu Molsheim in Nieder-Elsaß, dann seit zirka 1820 in der ehemal. Straßburger Universitäts-Bibl. C.V. 16. 6. 40, Perg. kl. fol. $30 \mathrm{Bl}$. (zwei Bl., nach Bl. 8 und 14, fehlen), zweispaltig in unabgesetzten Versen geschrieben um 1187 (eine Randnotiz auf dem zum Pilatusgediclit gehörenden Bl. 29a unten bezieht sich auf die Einnahme Jerusalems durch Saladin 1187), ist bel der Belagerung Straßburgs im Spätsommer 1870 verbrannt. Inhalt der Hs.: Hartmanns Rede vom Glauben Bl. 1c-9b; die Litanei Bl. 9b-13c; Straßburger Alexander Bl. 13c-29a; Pilatus Bl. 29a_-30c (unvollendet). Die Sprache der Hs. ist suidliches Rheinfränkisch. ${ }^{2}$ )

V. Die Wiener Hs. $2696,{ }^{3}$ ) perg. kl. fol. 156 Bl. zweispaltig, stammt erst aus dem 14. $\mathrm{Jh}$. Sie ist in Österreich, wahrscheinlich im Dorotheenkloster in Wien, verfaßt und enthält von den in unsern Zeitraum fallenden Werken: Albers Tnugdalus und die Gedichte Heinrichs von Melk. Der Gesamtinhalt ist folgender: 1. Die Kindheit Jesu von Konrad von Fussesbrunnen $1 \mathrm{a}-40 \mathrm{~b} ; 2$. die Urstende von Konrad von Heimesfurt $40 \mathrm{~b}-69 \mathrm{a}$; 3. das Jüdel $69^{\mathrm{a}}-75^{\mathrm{a}} ; 4$. S. Katharinen Marter $75^{\mathrm{b}}-118 \mathrm{a} ; 5$. S. Servatius $118^{\mathrm{a}}-164 \mathrm{~b}$; 6. Heinrich von Melk, Erinnerung $165^{\mathrm{a}}-178^{\mathrm{b}}$; 7. Das Anegenge $179^{\mathrm{a}}-221 \mathrm{a} ; 8$. Albers Tnugdalus 221a-250b; 9. Die Warnung 251a-302b; 10. Heinrich von Melk, Priesterleben $303 a-307 b$.

Die frühmhd. Literatur ist zum größten Teil in Sammelwerken veröffentlicht. Es sind die in der Erklärung der Abkürzungen näher titulierten Werke: GRAFF, Diutiska; HofFMANN, Fundgruben; die Vorauer Hs.: Diemer, Deutsche Gedichte des XI. u. XIl. Jlis.; die Milstäter Hs.: Karajan, Deutsche Sprach-Denkmale des 12. Jhs., Diemer, Genesis u. Exodus; die Straßburg-Molsheimer Hs.: Massmann, Dentsche Gedichte des 12. Jhs.; dic kleineren Denkmäler: MÓllenhoff u. Scherer, Denkmäler; WAAG, Kleinere deutsche Gedichte des XI. u. XIl. Jhs.; Kraus, Deutsclie Gediclite des 12. Jhs.; LeitzManN, Kleinere geistl. Gedichte des XII. Jhs.; Wilhelm, Denkınäler deutscher Prosa des 11. u. 12. Jhs, u. Komınentare.

') Massmann, Denkm. 1828, S. 1-3; Massmann, D. Ged. S. Vil f.; KInzel, Lamprechts Alexander Einl. S. X1f. Die ganze Hs. ist abgedruckt in Maßmanns D. Gedichten 1. Tell; die Einzelausgaben s. unten bel den betr. Dichtungen.

2) v. BAHDER, Germ. 30, $388 \mathrm{f}$.

3) Grafl, Diut. 3, 398-404; Massmann, Deutsche Lileraturgeschichte. II.
D. Ged. 2,159 ; HorfanannsVerzeichnis S.2331; SChErer, ZföG. 19 (1868), 564 ff. I1. Kl. Sclir. 1, 617 ff.; Scuröber, Anegenge S. 2, ders. ZfdA. 45, $217 \mathrm{ff}$; ALBr. WAGNER, Visio Tnugdali, Einl. S. XLVI. Ueber die Sprache s. HAUPT, Ad. BI. 1, 236-238; HeInZEl., Heinrich v. Meli, Vorrede S. V f.; SPRENGER, Albers Tundalus S. 4-26. 


\section{DIE LITERATURDENKMÄLER.}

A. Geistliche Literatur.

Die geistliche Literatur der frühmhd. Periode ist von einem einheitlichen Gedanken getragen und jedes ihrer Erzeugnisse spiegelt diese Grundidee wider, welche ist: die Erlösung des Menschen vom Leiden der Welt oder die Vereinigung mit Gott; und die Macht des religiösen Bewußtseins der Zeit beeinflußt mehr oder weniger auch die weltliche Literatur. So entfaltet sich in der Gesamtheit der uns erhaltenen geistlichen Werke ein reich gegliedertes Bild von den Glaubensanschauungen der neuen cluniacensischen Frömmigkeit. Unter dem Gesichtspunkt des Erlösungswerkes ist darum auch hier im folgenden die Anordnung und Einreihung der einzelnen Stücke getroffen. Am Eingang steht mit Willirams Hohem Liede das Gottesreich auf Erden in seinem Verhältnis zum Erlöser (Christus und die Kirche). Dann folgen, von Ezzos Heilsgesang eingeleitet, die dogmatischen Dichtungen als Lehre von der Erlösung, darauf die geschichtlichen Tatsachen des Reiches Gottes (die Bibel, Legenden, Visionen), und dann die Stücke, welche in das Gebiet der Heilsmittel fallen: Gebete, Buß- und Sittenpredigten. Dann kommt in der Marienliteratur die Mutter Gottes als Erlöserin und zum Schluß die Naturwissenschaft mit dem Physiologus als tiersymbolische Heilsgeschichte. Mit Willirams Hohem Lied und Ezzos Gesang stehen am Anfang des Zeitraums zwei Werke, die den herrschenden religiösen Gedanken gleich von vornherein einen monumentalen Ausdruck verleihen.

\section{a) Das Hohe Lied.}

\section{$\S 4$. Willirams Paraphrase des Hohen Liedes.}

Kelle 2, 55-59. 279; PIPER, Ält. d. Litt. S. 446-453; BRAune, LB. ${ }^{8}$ Nr. XXIV u. S. 179 f. Ausg. (vgl. PIETsCH, ZfdPh. 9, 227 f.): Paulus Merula, Leiden 1598 (Leid. Hs.), [vgl. S. P. HAAK, Paullus Merula 1558-1607, Leidener Diss. 1901; J. PRINSEN, Tijdschr. voor nederl. Taal- en Letterk. 25 (1906), 182-188]; Schilters Thesaurus I, 1728 (Bresl. Hs.); HofFmanN (v. Fallersleben), Breslau 1827 (Bresl. u. Leid. Hs.); v. d. HAGEN, v. d. Hagens Germ. 4 (1841), 153-173, 5 (1843), 143-179 (Berl. [Lambacher] Hs.); SeEmülLer, Die Hss. u. Quellen von Willirams deutscher Paraphr. d. HL., QF. 24 und Krit. Ausg. (mit Glossar) QF. 28, dazu PIETsch, ZfdPh. 9, 227-240. 10, 214-227. - SCHERER, Leben Willirams, Wiener SB. 53 (1866), 197-303; Th. Wiedemann, Österr. Vierteljahrschr. f. kath. Theol. 3 (1864), 83-114; HeinR. Reichau, Will., Abt zu Ebersberg, Progr. Magdeb. 1877 (dazu Pietsch, ZfdPh. 9, 227 ff.).

Willirams Leben. ${ }^{1}$ ) Williram stammte aus einem vornehmen fränkischen Geschlechte, aus dem mehrere Kirchenfürsten des 11. Jhs. hervorgegangen

\footnotetext{
$\left.{ }^{1}\right)$ Scherer aaO., bes. S. 261 ff.; Reichau S. 5-25; SCHRÖDER, Gött. gel. Anz. 1910, 320. - Einige Hss, nennen ihn in der Uebersclirift des Prologs "Abt von Ebersberg" (Ebersbergensis Abbas, SeEMÜlLER, QF. 28 S. 1 Var.), die Hs. B aber hat Incipit praefatio Willirammi Babinbergensis scholastici Fuldensis monachi (die erste Zeile der Grabschrift lautet Fuldensis monachus Wilram de fonte vocatus), woraus aber immer noch nicht mit Sicherheit hervorgeht, daß Williram zu-
}

erst Scholasticus in Bamberg und dann Mönch in Fulda gewesen wäre, vgl. REICHAU S. 12 f.: der Titel Scholasticus kann vor monachus gestellt sein, weil er die speziellere Würde ist. Er kann auch als Mönch von Fulda eine Zeitlang Scholasticus in Bamberg gewesen sein, wie z.B.Ekkehard lV. innerhalb seiner Mönchzeit in S. Gallen einige Jahre Leiter der Schule von Mainz war, und dabei Fulda als sein Heimatskloster angesehen haben. 
waren. Ums Jahr 1020 wurde er dem Kloster Fulda übergeben und war eine Zeitlang Leiter der Schule des Klosters S. Michael zu Bamberg. Im Jahre 1048 wurde er Abt zu Ebersberg, einem nicht besonders wohlhabenden Kloster Oberbayerns, dessen Besitztum er bedeutend förderte. Bei Heinrich III. scheint er in Gunst gestanden zu sein, wie aus seinem Widmungsgedicht zum Hohen Lied an dessen jungen Sohn, Heinrich IV., hervorgeht (versus ad Regem). Große Unbefriedigtheit spricht aus der gedrückten Bitte, sie scheint aber bei dem jungen König keinen Erfolg gehabt zu haben. Sein Ehrgeiz strebte nach höheren Würden, aber er starb als Abt seines bescheidenen Klosters im Jahre 1085.

Über das Kloster Ebersberg und über Willirams Tätigkeit daselbst besitzen wir nähere Nachrichten durch die Ebersberger Chronik,1) die unter ihm zusammengestellt wurde, und durch den noch erhaltenen Codex traditionum (Gütererwerbungen) und den Libellus concambiorum (Tauschverträge) des Klosters, an denen er vielleicht als Veranlasser und als Verfasser der Vorrede mitgewirkt hat. ${ }^{2}$ ) Er war eine auf praktische Tätigkeit angelegte Natur und sorgte, da ihm ein größerer Wirkungskreis versagt war, eifrig für sein bedürftiges Kloster. In der Wissenschaft aber brachte er es zu dem ersehnten Ansehen. Er hatte in Fulda eine gute Schule durchgemacht und schrieb gewandt Latein. Seine kleineren religiösen Gedichte in Hexametern bezw. in Distichen sind formell geschickt, aber ohne innere Wärme. Besonders hervorzuheben sind die genannte Widmung an Heinrich IV. und die Grabschrift in Distichen, die er selbst verfertigte (Epithaphium Willirami abbatis). ${ }^{3}$ ) Auch in dem Prolog zum Hohen Liede verleugnet Williram nicht, daß der Ruhm auf ihn Eindruck machte. $\mathrm{Zu}$ der Bearbeitung der Cantica canticorum wurde er angeregt durch den großen Ruf, den Lanfranc als Lehrer und Gelehrter eben in diesen Jahren gewann, und von einem so beliebten und bedeutenden Stoffe wie der allegorischen Erklärung des Gesangs der Gesänge durfte er besonderen Erfolg erwarten, der denn auch eintrat. Aus der Erwähnung Lanfrancs läßt sich auch auf die Abfassungszeit seines Werkes schließen: Lanfranc begann seine Lehrtätigkeit 1059, im Jahre 1065 wurde Heinrich IV. mündig, so daß also das Jahr 1065 als runde Zahl für die Abfassungszeit angesetzt werden kann. ${ }^{4}$ )

Die Sprache von Willirams Übersetzung ist ostfrk.5) Die Orthographie

1) Ed. W. Arndr, Mon. Germ. Script. XX, $9-16$.

2) Scherer S.238-249; Reichau S.14-16; WATTENBACH, GQ. 2, Reg. unter Will, F. H. GRAF HUNDT, Das Cartular des Klosters Ebersberg, Abhandil. der Mitnch. Akad. XIV, 3 (1879), 115-196.

s) Beide abgedruckt in Schilters Thesaurus und in v. d. Hagens Germ. 5, $181 \mathrm{f}$., das Epitaph auch in Grarrs Dint. 3, 438 f.; bei ARNDT S. 16.

4) Scherer S. 256 weist das Widmungsgedicht in das Jahr 1069. Reicuau S. 7 nimmt als Erscheinungszeit von Willirans 11L. die Jahre 1059-1063 an, da Lanfranc bis 1063 die Schule zu Bec leitete.

$\left.{ }^{5}\right)$ MSD. $1^{3}$, Einl. S. XXX f.; Braune, Aldd. Gramm. ı. FRANCK, Alifränk. Gramm. passim; Pietsci, ZfdPl. 10,223 f. Holfeld, Die Merkmale des Ueberganges vom Alnd. zum Mhd. In der Deklination W.s, Progr. Guben 18!1; Clir. Aug. MaYer, Dic Flexion von Nomen und Verbum in W.s ahd. Paraphrase des HI.s, Progr. Cöln-Nippes 1907 (nach der Hs. C); E. BrodrüHrer, Beitr. zur Syntax W.s, Hallenser Diss. 1906. Der Wortschiatz In Seemilllers 
ist pünktlich, Sorgfalt hat er auch auf die Bezeichnung der Betonung verwendet, sein Akzentuationssystem verfolgt die Grundsätze Notkers. ${ }^{1}$ )

Willirams Werk besteht aus drei Teilen, dem lat. Vulgatatext, dem lat., in leoninischen Hexametern (Versus) verfaßten Kommentar, und dem deutschen, in lat.-deutsche Mischprosa übertragenen Kommentar. Die ursprüngliche Anordnung war dreispaltig, in der Mitte die Vulgata, links die lat. metrische, rechts die deutsche prosaische Auslegung. Den Grund zu dieser Einteilung gibt Williram im Prolog Z. 25-28 an (SEEmÜller, QF. 28 S. 2). Sie ist noch erhalten in den Hss. BCFGKN, die übrigen Hss. haben zwar ebenfalls die drei Teile, aber nicht mehr die dreispaltige Anlage, sondern, mit verschiedener Reihenfolge der drei Teile, quer über die Seite geschriebenen Text. ${ }^{2}$ )

Hss. $^{3}$ ) Die Überlieferung ist sehr gut, wir besitzen von keinem frühmhd. Denkmal so viele Hss.

Seemüller kannte 17 (bezw. mit dem von ihm nicht benutzten Veesenmeyerschen Bruchstück 18) Hss., davon 11 vollständig ( $\mathrm{B}$ CF G H I K L N O), 3 nicht ganz vollständig bezw. nur teilweise erhalten (DMP) und 3 nur kleine Fragmente sind (EQR), wozu er 4 verlorene nachweisen konnte. Alle die $17 \mathrm{Hss}$. mit Ausnahme von D (nur in Abdruck erhalten) sind Pergamentcodices des 11. oder 12. oder des frühen 13. Jhs.

A. Die Leidener Hs., ${ }^{4}$ ) der Leidener Williram (abgedruckt von Paulus Merula und bei HOFFMANN). Nach Seemüller gehört sie dem 11. Jh. an (vg1. SCHERER, Leben W.s S. 249-252), sie ist wohl die älteste aller W.-Hss. und stammt vielleicht unmittelbar aus dem Archetypus (PIETsCH, ZfdPh. 10, 214, setzt sie ins 12. Jh.). Jedoch bietet sie einen sehr freien Text, indem sie flüchtig und willkürlich abgefaßt und aus dem ursprünglich ostfrk. Dialekt in das Südmittelfrk. umgesetzt ist. ${ }^{5}$ - B. Die BreslauerHs., 11. Jh., abgedruckt in Schilters Thesaurus I und bei Hofrmann. - C. Die Ebersberger Hs., jetzt in München Cgm. 10, geschrieben in dem Kloster Willirams, 11. Jh. - D. Frehersche Hs., ${ }^{6}$ ) nur erhalten in einem teilweisen Abdruck bei GotTHARD VöGELIN, Uhralte verdolmetschung dess Hohen liedes Salomonis usw. (SeEmÜller S. 2 u. 66-74), Wormbs 1631. - E. Monseer Fragm. in Wien Nr. 12847, 11/2 Bl., 11. Jh. (GrafF, Diut. 2, 379 f.). - F. Pfälzische Hs. in der Vatikan. Bibl. zu Rom, 11./12. Jh. (vgl. BarTschs Katal. Nr. 334). - G. London, Brit. Mus., 12.Jh. (PRieBsCH, D. Hss. in England II, 12 f.). - H. Trier, 11./12. Jh. (AD. BECKER, Verzeichn. der Hss. d. Stadtbibl. zu Trier, H. 7). - I. München Cgm. 77, 11./12. Jh. - K. Kremsmünster, 11. Jh. L. Lambacher Hs. (Oberösterreich) in Berlin, 12. Jh. (abgedr. in v. d. HAGENS Germ. 4, $153 \mathrm{ff}$. 5, 143 ff.). - M. Stuttgart, 12. Jh. - N. Wien 2686 aus Ambras, 12. Jh. - O. Einsiedeln, 12. Jh. - P. Kaisersheimer Hs. in München Cgm 40, 11./12. Jh. - Q. Fragm. Zingerles, 11/2 Bl., 12. Jh. - R. Innsbruck, Univ.-Bibl., Fragm., 1 Bl. 12./13. Jh. — Erst nach SeEmÜLlezRS Ausg. bekannt bezw. wieder gefunden worden sind: Bamberger Hs. v. 1528 (РIETsCH, ZfdPh. 9, 232); Buxheimer Bruchstücke, aus Kl. B. bei Memmingen, Anf. 13. Jh. (W. Meyer, ZfdA. 28, 227-241); (Veesenmeyers Bruchst. vg1. Seemüller, QF. 24, 12 f.); Maihingener Hs.,

Glossar, QF. 28, 68-147 zusammengestellt, vgl. auch PIETSCH, ZfdPh. 10, 224-227.

1) PIETsCh, ZfdPh. 10,217f.; Paul Sievers, Pal. 57 S. 32 f.; HeInR, KrUSE, Die Accente in den Hss. von W.s Uebersetzung usw., Greifsw. Diss. 1913.

$\left.{ }^{2}\right)$ SeEmüller, QF. 24 S. 5 f. 28 S. VIII.

3) GrafF, Diut. 3 , 436 ff.; SeEmüller, QF. 24,1 -78 28. S.X-XIV; dazu PIETSCH,ZfdPh.
9, $231-238$

4) SeEmúller außer QF. 24, 2 u. 28, $\mathrm{X}$ bes. $24,63-66$.

5) Sprache des Leid. Williram: van Helten, Beitr. 22, 437-519; H.ENTHOLT, Straßb.Diss. 1897; M. THOMAs, Züricher Diss. 1897; s. auch BusCH, ZfdPh. 10, 168-204.

6) SEemÜller außer QF. 24,2 น. $28, \mathrm{XI}$ bes. $24,66-74$. 
die sog. Schöbersche Hs. (Seemüller, QF. 24, 13. 28 S. X; Pietsch, ZfdPh. 9, 233), vgl. Ernst Panten, Der Maih. W., Greifsw. Diss. 1908.

Die Hss. spalten sich in 3 Gruppen: 1. Y zu der alle Hss. gehören außer 2. D und 3. A; Y zerfällt wieder in die beiden Untergruppen $* \mathrm{C}$ u. $* \mathrm{~B}: \mathrm{C}^{*}=\mathrm{C}$ mit den unmittelbar daraus geflossenen Abschriften $\mathrm{J} \mathrm{KL}$ dazu $\mathrm{F}(=\alpha)$ und weiter $M$; $\mathrm{B}^{*}=\beta$ ) B mit der Abschrift $\mathrm{H}$, dazu $P,(E)$, u. $\gamma)=G+$ NO. Die für die Textkritik wichtigsten Hss. sind C, welche Seemuiller zugrunde legt (sie hat Korrekturen, die vielleicht auf W. zurückgelien); dann B; A ist von besonderem Interesse wegen des Dialektes, hat aber wegen der willkürlichen Behandlung des Textes nicht die Bedeutung, die ihr hohes Alter erwarten ließe.

Die große Zahl der Hss. - außer den erhaltenen Hss. besitzen wir noch Nachricht von mehreren verlorenen - beweist, daß W.s Werk im 11 . u. 12. Jh. sehr geschätzt und verbreitet war. In der Mitte des 12. Jhs. wurde der Text als Grundlage für das Trudperter Hohe Lied benutzt, mit dem 13. Jh. aber hört das Interesse für die geistliche Literatur der früheren mhd. Zeit auf, die Sprache, zumal die Mischprosa, galt als veraltet. Doch am Ende des MA.s fand W.s Paraphrase wieder Beachtung, wie die Maihingener Hs. von 1483 beweist, und als die wiederauflebende Wissenschaft des Humanismus sich auch der deutschen Vergangenheit zuwendete, wurde 1528 von Menrad Molther in Hagenau ein erster Druck veranstaltet, aber freilich in der Humanistensprache, denn der deutsche Teil wurde ins Lat. übertragen. ${ }^{1}$ ) Dann folgen 1598 der erste Druck des deutschen Textes nach der Hs. A von Merula und Marquard Frehers (1631) wissenschaftliche Vorarbeiten zu einer Ausgabe (SEEMÜLLER, QF. 24, 66-74), des Franciscus Junius Observationes in Willerami Abbatis Paraphrasin, Amsterdam 1655, und dann die Ausgabe von Schilter.

Willirams lat. Prologus ${ }^{2}$ ) in Cantica Canticorum, der in den meisten Hss. das Hohe Lied eröffnet, ist das wichtigste Zeugnis für die Lage der Wissenschaft am Übergang der ahd. in die frülımhd. Zeit und darum von großer Bedeutung für die Geistesgeschichte im 11. Jh. Er zerfällt in 5 Teile: I. Z. 1-24 Grund zur Abfassung des Werkes. II. Z. 24-28 Titulıs, d. i. Benennung des Werkes und Beschreibung der Einrichtung des Textes. III.Z. 29-38 Art der Bearbeitung: Ich habe nichts aus Eigenem hinzugefügt, sondern alles verschiedenen Kommentaren der heil. Väter entnommen und mehr auf den Sinn als auf den Wortlaut geachtet. Den Stil habe ich für die Worte des Sponsus und der Sponsa so gefaßt, daß er, wie es in der Bibel der Fall ist, so auch in den lat. Versen und im deutschen Text ein höheres Ansehen gewinnt. IV. Z. 38-41 Freudiger Stolz ïber die eigene Arbeit. V. Z.41-44, zum Schluß legt er sein Werk den Gelehrten zur Beurteilung vor, deren Besserungsvorschläge er gern befolgen werde.

In der Beurteilung der geistigen Strömungen, in der Williram hier mit bewußter Absicht die Begründung seiner Arbeit niederlegt, ist kurz und klar ausgesprochen, daß eine neue, Zeit angebrochen ist: an die Stelle der

2) Seemoller, QF, 24, 8; Pietsch, ZfdPh. 9, 227 f. 232.
2) Seemühler, QF. 28, 1 f.; Kelle S. 55 f.; REICHAU Absclunitt II. 
freieren Richtung, die, noch ein Nachklang der Renaissance des großen Karl, den Sinn für die Kunst des klassischen Altertums offen hielt (dialectica), sollte alleinherrschend die christliche Wissenschaft treten (ecclesiastica studia). Schroff werden sich entgegengesetzt Heidentum und Christentum, die alte humane Wissenschaft der septem artes liberales und die "divina pagina", das Wort Gottes mit den theologischen Schriften: sie verhalten sich wie Finsternis und Irrtum zum Licht und zur Wahrheit. Die beiden Reiche, die Notker noch vereinigen konnte, die Wissenschaft von der Welt und die von Gott, sind jetzt radikal getrennt, so zwar, daß jene überhaupt wertlos, ja schädlich ist. Die Humanität ist gegenüber dem Dogmatismus aufgegeben, die Dialektiker, die Philosophen müssen den Theologen weichen, zumal in Deutschland ist die Literatur ganz klerikalisiert. Dieser Übergang hat sich sogar in einem einzigen Manne vollzogen, dem bedeutendsten Lehrer der Zeit, Lanfranc, den sich Williram selbst zum Vorbild nimmt. Noch schärfer setzt er den schandbaren, lediglich weltlichen Spielen, Fabeln und Gesängen der Laien, den ludis et fabulis aut turpibus cantilenis, die diuina mysteria des alten und neuen Testamentes entgegen, welche die doctores lehren, $\$ 128$ (SEEMÜLlER S. 58).

Inhalt. In der Vermählungsallegorie ist der Kerngedanke der Religion überhaupt aufgenommen: die religio als „Verbindung“, als Verhältnis des Christen zu Gott; und es ist die Kirche als das Vereinigungsmittel aufgestellt, als Heilsinstitut, durch welches jene religio zwischen Mensch und Gott bewirkt wird. Das HL. ist damit eine Verherrlichung der Macht der Kirche, denn in ihrer Gemeinschaft kommt der einzelne Gläubige zum Heil seiner Seele. Wenn aber solch eine einzelne Seele sich nach der innigsten Vereinigung mit dem Allerhöchsten sehnt, so ist es gleich einem liebenden Umfassen, und das seligste Ineinssein, das völlige Aufgehen des eigenen Seins im andern geliebten Sein ist gleich einer irdisch-himmlischen Brautschaft. Dann ist es die Stimmung der Mystik, und so ist die Gemahelschaft der Seele mit Christus, Christus und die minnende Seele, Jesus der Seelenbräutigam, in den Zeiten gesteigerten religiösen Empfindungslebens das Leitmotiv der Mystik gewesen, der innerste Ausdruck des erotisch-spirituellen Ewigkeitsdranges. So kann die allegorische Bedeutung der Brautschaft im HL. in zwiefacher Weise aufgefaßt werden: entweder mehr intellektuell und dogmatisch als Christus und die Kirche, oder mehr sentimental und mystisch als Christus und die liebende Seele. W.s Allegorie ist ersterer Art, ja seine Paraphrase ist eine dogmatische Heilslehre. Es ist eine Summa Theologiae mit dem bestimmten Ziel der Erlösung, in der nur die einzelnen dogmatischen Sätze nicht systemgemäß ausgesucht und geordnet, sondern eben nach dem Verlauf des biblischen Textes des HL.s vorgetragen sind.

Entsprechend dem Grundgedanken der Allegorie, wonach Christus der Bräutigam der Kirche bezw. der christlichen Menschheit ist, bestimmt 
sich auch das Wesen Christi: er ist Gottmensch, ${ }^{1}$ ) deus et homo 88,3 . 89,4 . 93, $2 \mathrm{f}$; ; verus deus et verus homo $48,29 \mathrm{f}$. 33 , er vereinigt die beiden Naturen divinitas und humanitas 37,3-6. 81, 9. 82, 2f. 86, 4-6. 88, 7 f. 93, 11-13. 96, 6. 97, 5 f. 98, 5, vgl. 47, 7. 90,3. 92, 7. 8; gotes sun per naturam, speciosus forma prae filiis hominum 28,5 f., vgl. 23,3 f. $87,3-5$. Er war von Anfang an: verbum in principio apud deum, verbum caro factum 130, 9 f., er ist alpha et $\omega$, principium et finis 111,8; seine Menschwerdung, Leiden, Auferstehung, Himmelfahrt waren im alten Plan der Trinität vorausbestimmt 94, 8-10. Die ganze Paraphrase ist durchwoben von Zügen aus dem erlösenden Leben des Bräutigams von seiner Menschwerdung bis zur Herrschaft in der himmlischen Seligkeit. Die Hauptereignisse sind als eine kurze Biographie zusammengestellt $\$ 93$ u. 94 auch 35,6-10; im einzelnen: Geburt 23, 4. 26, 3. 35, 7. 36, 2. 93, 3-5. 125, 2f. 126, 6. 127, 2; 63, 4; 36, 3.5. 37, 3f.; Taufe 15, 6; Wunder 93, 11-13; Führung ins Land der Verheißung 15,3-7. 50,4-10. 135,6f.; Marter, Tod, Auferstehung und Wonne des Himmelreichs 20, 3 f. 63,5-7. 79, 8f. 93. 94; 52, 9; 53, 9-12. 53, 17-19. 119, 15. 136, 7; 122, 5-10. 149, 6. 99, 4 f.; 131, 8, vgl. 52, 19f. 24 f.; 32, 9 f. 54, 11 f. 88,13 f. 92, 11. 129. 133, 9. 136, 21, vgl. 114, 16f. $117,10.120,5-7.147,3-9 ; 52$. - Der Teufel ist der Verderber der Christenheit 51,18, der Verführer der Auserwählten; Christus bewahrt die Kirche gegen ihn 67, 5f., dazu 53,17-19. 136, 7 f.; die Gläubigen gegen den Teufel 89, 11; diePropheten und Apostel gegen den Teufel 84, 5 f.; die doctores und der Teufel s. nachher; mit dem Teufel zusammen sind die Ketzer Feinde der Kirche 51, 12. Die Kirche, Ecclesia, ist die Braut, sponsa, Christi, auch Schwester, soror et sponsa 74, 5. 77, 4 f. 130, 7 f. u. ö., frûintin (oft), Christus ist wine der Braut, der Ecclesia (oft), Vorstellungen, die einfach aus dem Bibeltexte stammen. Die Mutter der Ecclesia ist die Synagoge 11,3 . 48, 38. 136, $2 \mathrm{f}$., die humana natura $130,6 \mathrm{f}$; d durch die typologische Auslegung ist die caelestis Hierusalem 104, $7 \mathrm{f}$. Mutter der Kirche. In den $\$ \$ 11.12$ und $130-143$ wird dieses Verhältnis näher bestimmt: die Kirche zu Jerusalem ist die primitiva Ecclesia und mater ecclesiarum ${ }^{2}$ ) 11, 2 f. 137, $5 \mathrm{f}$. Die Juden, die Kinder der Synagoga, bekämpften dic Christen, vertrieben sie aus ihrem Lande und erregten eine Verfolgung usw. (persecutionem 11 u. 12). Der größere Teil der Juden hat Christus, da er die Synagoga am Kreuz. vom Tod der Sünde und von der Gewalt des Teufels erlöste, nicht anerkannt und die praedicatores Christi vertrieben zu den Heiden, daraus entstand die Ecclesia de gentibus 135. 136, dazu 137.141. 142. 143, vgl. 50 (in dero vocatione gentium 141, 9f.). Die Ecclesia catholica, obgleich sie zusammengesetzt ist aus verschiedengestaltigen Personen, ist doch eins im Glauben und im Geiste (vgl. 68,7-12), ihr Symbol ist die Taube, d. i.

1) SeEmÖLLER, QF. 24, 115-117. Die Bedeutung des HL.s als Ausdruck für die Person des Gott-Cliristus ist schon in der Lehre des Athanasius begrïndet, HaRNACK, Dogmen- gesch. $2^{2}, 23$

2) Ueber das allegorische Motiv der Ecclesia und Synagoga vgl. RAAB S. 12 Anm. 17. 
der heilige Geist 104; sie ist die congregatio justorum, fidelium 69, 3, vgl. 70,2 , ihre Angehörigen sind die Gläubigen, die fideles (oft), die spirituales filii 127, 7 f., sîne holdon 52, 10, 74, 6. 89, 5. 99, 7. 139, 4.

Durch die ganze Erklärung hindurch zieht sich die Verfassung der Kirche: $\left.{ }^{1}\right)$ sie ist gebildet durch zwei Stände der Gläubigen, die doctores und die auditores, die Lehrer und die Hörer, die Führer und die Untergebenen (= Geistliche und Laien): Uniuersitas fidelium, diu da constat ex bonis doctoribus et fidelibus auditoribus 105, $3 \mathrm{f}$., in den conventiculis der Kirche sind doctores, die andere stärken mit ihrer Lehre (doctrina), und auditores, die mit Einfalt (simplicitate) und vielerlei Tugenden (virtutibus) ihr Haus zieren 25; die doctores eröffnen dem Volk die Geheimnisse der Schrift und sind die Zierde der Christenheit, denn sie sind geschmückt mit dem Gold der Weisheit und mit den Edelsteinen der Tugenden 17 u. 18; die doctores besorgen das Nützliche für ihre Untergebenen, und die Gläubigen, auditores, hängen den doctores an $63,8-10$; die doctores als Lehrer, die auditores als die Lernenden auch 64,2-6 (auditores hier parvuli), 66, 4-11 (hier sind die auditores wieder geteilt in perfecti und infirmi), 55, 17-23 (doctores-populi), 56. 57.58 (doctores sind mediatores inter Christum et populum), 74, 12-21. 113 (die doctores sind hier praedicatores genannt), ferner 39, 10. 59. 114-118. 121-128. 141. 142. 144; mit geistlichen Waffen sind die sancti doctores Schützer der Ecclesia gegen den Teufel und die Ketzer (hereticos) 13, 5--9. 45. 51, 8-13. 116, 7-10. 120, 4. 141. 142, vgl. 114. 118. 120. Die doctores sind die Lehrer, in der Verkündigung des Evangeliums liegt also die Hauptaufgabe der Kirche, als ihr wichtigstes Heilsmittel wird die Predigt angeführt. Dagegen treten die Sakramente ganz zurück, Sünde und Buße werden nicht behandelt, überhaupt wird auf das innere Leben des einzelnen Menschen und auf sein Verhältnis zu Gott nicht eingegangen. Die doctores sind praedicatores und treffen darin mit den A p o steln und auch mit den Propheten zusammen: Mîn sponsus hât sîne Ecclesiam biderben agricolis beuolehan, prophetis, apostolis, doctoribus 144. 146, vgl. 12, 3 f. Die Apostel sind Freunde Christi 75, 2, sie waren praedicatores 40, 2f. 41, 2 f. 42, 2 f. 128, 2-10. Die Apostel und Märtyrer sind Stufen zur Wonne des ewigen Lebens 52, 25-29.

Den wahren Predigern stehen die falschen gegenüber: die Apostel predigten die Gnade des Evangeliums, die Vorsteher der Synagoge. befolgten das Gesetz fleischlich, die Lehren des Gesetzes sind nur ein Schatten der Wahrheit und der Gnade 41.42. Die Philosophen, Plato, Aristoteles, Sokrates, Pythagoras, lehrten die Weisheit dieser Welt, die Apostel und Pro-

1) Vgl. Honorius Aug., Expositio in Cantica cant. Kap. I, Vers 1, 2 (Migne 172, 361): Tota Ecclesia est quasi unum corpus, cujus caput est Christus, caput autem Christi Deus. Membra autem hujus corporis sunt diversi in Ecclesia ordines, oculi sunt doctores ut apostoli, aures oboedientes ut monachi, nares discreti ut magistri, os bona loquentes ut presbyteri, manus alios defendentes ut milites, pedes alios pascendo portantes ut rustici, mit Verweisung auf Ephes. IV, 12. V, 23, 1. Kor. XI,3. 
pheten bewachen den Staat Gottes 48, 13-27. 84, 5 f.1) Die Propheten verheißen die Ankunft Christi, Gesetz und Propheten sind die Verheißung, die Erfüllung ist das Evangelium 108. 109. Das alte und das neue Testament stehen im Gegensatz von lex und gratia, 2. 5. 6. 7. 65; vgl. 129.

Andere Glieder der Ecclesia sind die virgines des HL.s, die Jungfrauen, daz sint die sêla, die in der Taufe verjüngt sind und gekleidet mit dem Gewand der Unschuld 4, die guoten (heiligen) sêla, die da Hoffnung haben auf das himmlische Jerusalem 33, 4-7. 53, 5-11. 85, 3-7. 97, 2-4. 134, 3-10; die heiligen Seelen, die durchdrungen sind von Gottesminne 31,4-8; die reginae, die edelen sêla, die der sint sponsae regis aeterni $103,5-13 ;^{2}$ ) die reginae und adolescentuli, die keuschen Frauen und Jünglinge 104, 3 f.; die doctores und virgines, die continentes und conjugati, die Enthaltsamen und die Ehegatten, und alle, die keine schweren Sünden haben 61 .

Die Kirche erlebt drei Entwicklungszustände, die persecutio, die contemplatio, die praedicatio. Christus schützt die Kirche in den Verfolgungen und in den Wallungen der Versuchung, vgl. 9, 7. 106, $15 \mathrm{f}$; Christus läßt die persecutiones zu, damit die Tugenden der Kirche gestärkt werden 72.73; sie sind jetzt nicht mehr so hart wie am Anfang des Glaubens 76. Nachdem die Kirche ausgeruht von der Verfolgung, will sie um so mehr sich tüchtig zeigen in der Betrachtung, im Nachtwachen, Fasten, Almosengeben und den übrigen guten Werken 24. Aus der Einsamkeit der contemplatio tritt die Ecclesia in die Öffentlichkeit der praedicatio 79,3-5; Christus ermahnt sie dazu 77, -10 , ebenso $38,2-7$ (Predigt zum Dienst für die Brüder 84,12-15). Einmal ist die Zeit zu handeln, ein anderes Mal zur Betrachtung, tempus actionis - tempus contemplationis 38, vgl. 43, 5-8. 44,3-6. 47, 3-5. 49, 5-10. Da die Kirche sich entschließt zu dem Werk der Predigt, erhebt sie sich zu guten Werken 80, mit dem Gehorsam der Predigt nähert sie sich Christus 81; Predigt der Kirche ferner 54, 6f. 111, 2-4. 112, 4-6. 123, 3-5. 124, 3-5. 148, $12 \mathrm{f}$. 149,3-7. Auch die gute Seele ergibt sich der Betrachtung, dem Gebet, der Lectio, dem Wachen, Fasten, und gelangt nach der contemplatio zum Handeln im Zeitlichen 33. 134, 4-10. Die doctores sollen nach der contemplatio zur praedicatio schreiten und danach zur contemplatio zurückkehren 49,8-10. Praedicatio und bona opera also bilden die vita activa der Kirche und dazu kommt die arbeit, die Mühsale, die sie auf sich nimmt um die Leiden, die Christus um ihretwillen erduldete 48, 34-37. 76, 3. 79, 7-10. 120, 3-7, vgl. 119, 11-23.

Die Eigenschaften der Kirche sind die Tugenden, virtutes. Die Tugenden und die guten Werke sind nicht ihr eigenes Verdienst, sondern sie sind durch die Gnade verliehen 65,6-11.67, 9f. 69, 5-8. 107, 5-12; uber die Tugenden ferner 9, 8. 19, 4 f. 27, 4f. 50, 10. 106, 6f. 107, 16-19.

1) Vgl. Honorius Aug., Migne 172, $1085 \mathrm{f}$., wo auch die sponsa Cluristi dic Gemeinschaft der Gilabigen bedeutet.

2) Vocir, edel S. 33. 
135, 5-7. 136, 5. Die Apostel verbreiteten die Tugenden über die ganze Welt, zuerst auf die Märtyrer, dann an die Konventikel der Gläubigen 68, vgl. 128, 2-4; die doctores sind geziert mit den gemmis virtutum 17, 5-7; in der congregatione justorum erscheinen Tugenden aller Arten 69, $3 \mathrm{f}$.; die Holden Christi haben sie in ihren Gärten 74,6f.; die Kirche pflanzt sie ihren Untergebenen (auditoribus) ein 148, 3 f.; die Tugenden sind die Blüten, die guten Werke sind die Früchte (d. h. aus den Tugenden entstehen die guten Werke) 31,3f. Bildlich sind die Tugenden, in Ausdeutung betreffender Stellen des HL.s, aufgefaßt als Gewürze, köstliche Spezereien, Wohlgerüche: aromata, aromaticae arbores, nardus 19, $5 \mathrm{f}$. 69, 3-5. 11-19, unguentum 65, 6, als Kräuter des Gartens 67, $4 \mathrm{f}$., myrrha, thus, aromata universi pulveris pigmentarii 50,10-16, vgl. 74, 8-10, die pimentare, die de uuurzbette sazton, daz sint prophetae et apostoli 90,13f. Oft sind einzelne Tugenden der Kirche genannt: innocentia und castitas (meist zusammen) 38,3 f. 39, 9. 40, 3 f. 43, 5. 89, 6; virginitas 50, 10-16. 65, 9 f.; continentia 39, 8-10. 65, 9 f. 80,6; Demut 107, 13 f.; Freigebigkeit, Almosengeben, freiwillige Armut (gute Werke) 39, 8-10. 50,10-16. 65, 9 f. 74, 8 f. 80, 6 f. 91, 5f. 145, 7-10. Die Gebärden Christi in seiner menschlichen Natur sind mansuetudo, severitas, laetitia, tristitia 90,3-8. - Diese Tugenden des Christentums liegen zum Teil schon in der Allegorie von der Kirche als der verlobten Jungfrau, wie die castitas, innocentia, virginitas, sie sind dann erweitert worden $z \mathfrak{u}$ den Forderungen der Askese, continentia, mortificatio carnis, voluntaria amissio divitiarum, und damit ist die Tugendlehre von W.s HL. ausgesprochen cluniacensische Mönchmoral. Aber die Grundlage der Ethik bilden die drei christlichen Tugenden, fides, spes, caritas, wofür viele einzelne Stellen zeugen; und unter ihnen ist die caritas (dilectio), die Liebe zu Gott und zu den Nächsten, die eigentliche Quelle aller sittlichen Erhebung. Auch diese Grundlehre des Christentums ist in dem allegorischen Sinne des HL.s verborgen, denn die Idee desselben ist ja die Liebe zwischen Christus und der Christenheit. Aber die Erlösung kann allein nur durch die Gnade geschehen, sie verleiht die Tugenden, nur durch sie wird man von den Sünden gereinigt $88,15 \mathrm{f}$, mit seiner Gnade hat Christus die Kirche berufen, hat ihr Lehren und Verheißungen gegeben 46,3-6, und wenn sie ihm die Treue leistet, so gibt er ihr die Gnade, daß die Kaiser und die Könige und die Weltfürsten, die wie die Pardeln und die Löwen gegen sie eifern, die Spuren ihrer Füße anbeten und den Sündenschmutz hinwerfen und die Weltverworrenheit und sich bekehren zum christlichen Glauben $62,11-18$.

Quellen. ${ }^{1}$ ) W.s Paraphrase gehört als Expositio super Cantica Canticorum zu der Literatur des HL.s. Das HL. ist wie alle Bücher des alten

${ }_{1}^{1)}$ Literatur über die allegor. Bedeutung des HL.s: Realencyklop. ${ }^{3} 8$, 256-263; WeTZER u. Welte 6, $171 \mathrm{ff}$; HARNACK, Dogmengesch. $1^{2}, 525.2^{2}, 11-13$. 23; RAAB S. 11-19;
ARN. OpPEL, Das Hohelied Salomonis und die deutsche religiöse Liebeslyrik, Abhandl. zur Mittl. u. Neueren Gesch. H. 32, 1911. 
Testamentes in die allegorische Erklärung mit einbezogen worden, d.h. die jüdischen Überlieferungen wurden mit dem Plan des Christentums dadurch vereinigt, daß man dem historischen Inhalt des alten Bundes einen spirituellen Sinn als Hindeutung auf christliche Glaubensanschauungen unterlegte (typologische Auslegung). Schon im alten Testament ist auch außerhalb des HL.s die feierliche und festliche Vereinigung von Braut und Bräutigam ein häufiges Bild inniger Verbindung von Jehovah und dem Volk Israel. Im neuen Testament wird Jesus oft einem Bräutigam verglichen, Matth. 9,15=Marc. 2, 19 f., Luc. 5, 34 f., Luc. 12, 36, Joh. 3, 29, besonders aber im Gleichnis von den zehn Jungfrauen Matth. 25, 1-13;1) in der Apokalypse aber liegt unmittelbar schon der Kern der Allegorie von Christus und der Kirche: Et ego Joannes vidi sanctam civitatem Jerusalem novam, descendentem de caelo a Deo, paratam sicut sponsam ornatam viro suo 21,2 , ostendam tibi sponsam, uxorem agni 21,9, vgl. 19,7.8., der Geist und die Braut, spiritus et sponsa 22,17; das neue Jerusalem ist die neue Menschheit, die neue Kirche. Den Begriff der Kirche als einer mystischen Gemeinschaft der Gläubigen mit Christus, nach dem Bilde, daß die Kirche der Leib, Christus das Haupt ist, hat Paulus begründet, vgl. Eph. 1,22f. 4, 15. 5, 23; Kol. 1, 18. 2,9f., und auch er hat schon das allegorische Verlobungsmotiv von Christus und der Gemeinde, 2. Kor. 11, 2.

Maßgebend für die kirchliche Auslegung wurde der zum größten Teil verlorene Kommentar des Origenes, der das Verhältnis des Liebenden zur Geliebten, des Königs Salomo zu Sulamith, auf Christus und die christliche Gemeinde oder auch die Christenseele bezog, die nach der Vereinigung mit dem Herrn verlangt. Augustinus hat die Allegorie in den Psalm 44 gelegt, der sich selbst als ein Brautlied, canticum pro dilecto, ${ }^{2}$ ) bezeichnet. Enarr. in Ps. 44 (Migne 36, 493 ff.), vgl. auch Enarr. in Ps. 53, 2; Sermo 90, 6 (Migne 38, 562 f.). Und in dieser Auslegung des 44. Psalms durch Augustin, in welcher Christus als sponsus mit der Ecclesia als sponsa sich verbindet, sind auch schon die Grundgedanken für die späteren Kommentare des HL.s enthalten, wozu diese wahrscheinlich auch einiges aus Cassiodors Erklärung des 44. Psalms entnommen haben. In der deutschen Literatur ist dieser Psalm und somit die Allegorie von Christus und der Kirche zum erstenmal behandelt in der Übersetzung Notkers, der ja Augustins Kommentar und auch den Cassiodors benutzt hat. ${ }^{3}$ )

Williram hat als Quelle Haimos Kommentar zum HL.*) zugrunde gelegt (Migne 117, $295 \mathrm{ff}$.), der ein selbständig gearbeiteter, iibersichtlicher, aber

1) RAAB S. $11 \mathrm{f}$.

2) Epithalamium, nuptiale carmen ill der kirchlichen Literatur; cpithalamium auch im Psalmerikommentar Cassiodors am Scliluß von Ps.44 und danach in Notkers Uebersetzung (PIIPR, Notker 2, 173, 26f.: epithalamium, daz chit pritelob).
3) PiPfir 2, 167-173; ERnst Hlinrici, Dic Quellen von Notkers Psalmen, QF.29, 126 $-130$.

4) Sigebert von Gembloux legt diesen Kommentar dem Remigius von Auxerre bei, vgl. Manitius 1, 516: s. auch Rueinau S. 1. Die wichtigsten lat. Kommentare zun Ht. bis 
trockener Auszug aus Beda ist, unter seltener nochmaliger Beiziehung von Beda und den Kommentaren von Alcuin und Angelomus von Luxeuil (um 830). Er gibt den Inhalt Haimos ganz frei und nicht in bloßer wörtlicher Übersetzung wieder. Er verfolgt eigene Grundsätze und zwar sowohl hinsichtlich der Anordnung als der Darstellungsweise. Während Haimo der Reihe nach jedes Motiv eines Bibelverses erklärt und dann diese einzelnen Deutungen zu der daraus sich ergebenden Auslegung zusammenfaßt, uberträgt W. zuerst den Vulgatasatz ins Deutsche, dann bringt er die bei Haimo einzeln gegebenen allegorischen Auslegungen des Satzes zusammen in eine allegorische Erzählung. Dadurch sind die trockenen Aneinanderreihungen von Grundstoff und Auslegung zu einem mehr einheitlichen Vorstellungsbilde verwoben. Aber auch die äußere Anlage gestaltet er lebendiger, indem er über den Abschnitten die redenden Personen angibt, z. B. Vox Christi, Vox Ecclesiae, zuweilen auch Synagoga, meist mit erläuternden $\mathrm{Zu}$ sätzen, die besagen, zu wem oder ubber welchen Gegenstand gesprochen wird, während bei Haimo die Personenangaben innerhalb des fortlaufenden Textes eingeflochten sind. So tritt die Form eines dramatischen Dialogs stärker hervor, in dem die Rollen auch gleich äußerlich verteilt sind. W. also setzt ein literarisch-künstlerisches Prinzip an Stelle des didaktisch-praktischen Haimos. Die Darstellung hat damit an lebendigem poetischen Reiz gewonnen und man erhält aus der ganzen Art der Behandlung den Eindruck, daB W. ein wohlgeschultes Verständnis für die Form besaß, ohne jedoch den starken Empfindungsgehalt des Stoffes innerlich zu durchleben: die Zeit der Mystik war noch nicht gekommen. Durch die Bevorzugung der künstlerischen Technik hat die Ausführung an Klarheit verloren, da der ursprüngliche Wortsinn und die hinzugetretene Deutung nicht mehr so leicht zu scheiden sind; zuweilen allerdings kennzeichnet W. die allegorische Auslegung durch figuratur, significatur, bezeichenet. Man erkennt also bei Haimo und bei W. zwei verschiedene Absichten: jener will nur belehren, docere, W. will zugleich auch ergötzen, delectare. Das spricht er auch im Prol. Z. 34-38 aus: er wendet an den inhaltlich vornehmeren Stellen einen gehobeneren Stil an, majoris auctoritatis, und zwar den schönen Stil, ut... quivis legens ... delectabilius afficiatur. Er kürzt zumeist seine Vorlage und weiß dabei geschickt die Hauptpunkte des Sinnes herauszugreifen, er vereinfacht, stellt um, sucht Zusammengehöriges in engere Verbindung zu setzen, lauter Mittel, um die Rede zu glätten, die er zudem durch gewandten Satzbau in angenehmen Fluß zu bringen weiß.

Die Sätze des Bibeltextes sind völlig deutsch wiedergegeben, daran reiht sich die allegorische Auslegung in lat.-deutscher Mischsprache. ${ }^{1}$ ) Mit

zum Ende des 12. Jhs. s. bei Kelle 2, 57. 123 f., dazu noch Honorius Aug., Migne 172 , 347-496. 495-518; Jos. ENDRES, Honorius Aug. 1906 S. $26-28$. 58-61.
1) SCHERER S. 293 ff.; SEEMỨleR S.94-96; FrIEDR. JUNGHANS, Die Mischprosa Willirams, Berline: Diss. 1893, dazu SEEMÜLLER, Anz. 21, 225-228. 
der Anwendung dieses Stils folgt er Notker und überhaupt der Klostertradition.1) Aber es schwebte ihm ein anderes Ziel vor als Notker, denn nicht als Pädagog für die Schule wollte er wirken, sondern für die Geistlichkeit zur Förderung ihrer wissenschaftlichen Kenntnisse. Diese Mischung ist eine Gelehrtensprache, in welcher die wissenschaftlichen Begriffe auch in der Sprache der Gelehrten, also lat. ausgedrückt bezw. aus dem Original ubernommen wurden, die Begriffe allein oder mit den syntaktisch dazu gehörenden Wörtern der Umgebung. So haben die technischen Ausdrücke das ursprüngliche und gewohnte lat. Lautbild behalten und sind auch ihrer Würde entsprechend von dem übrigen, in der Volkssprache gegebenen Texte hervorgehoben. Lat. also sind die Hauptbegriffe, besonders die kirchlichen Wörter wie sponsus, ecclesia, synagoga, evangelium, doctores, praedicatores, auditores, und echt allegorische Wendungen wie contemplatio, spiritualis virtus, aurum sapientiae, gemmae virtutum, gleichsam Schlagwörter des allegorischen Inhalts. Mitbestimmend wirken auch dialektische Gründe der Symmetrie und des Parallelismus, so besonders wenn antithetische Begriffe durch lat. Wörter einander gegenübergestellt sind; oder rhetorische Gründe, indem besonders häufig Sätze oder Abschnitte lateinisch abgeschlossen werden. Zumeist ist ein rascherer Wechsel zwischen Deutsch und Lateinisch beab. sichtigt, wobei das Deutsche überwiegt, seltener binden sich längere deutsche Perioden ohne lat. Einmischung. Unter den Wortgattungen stellen die Substantiva als die hauptsächlichen Träger der Gedanken die meisten lat. Wörter, entweder alleinstehend oder mit den lat. Wörtern ihrer syntaktischen Umgebung. Andrerseits werden Vorstellungen aus der Profanwelt gern deutsch wiedergegeben, wie uilzhûs, hereberga 9,5, scâf, hereberga, sinen cortare 13, 6. 7.15, halsziereda 18, 1, trebon, trûbon, heilbrunno 21,3.10, affaltera, uualtholz, epfele 28,2.4, in den steinlocheron unte in den heggeholeron 43, 13, disk, stega, lineberga, des diskesideles 52, die oft aus der am Kopf des betr. Kapitels stehenden deutschen Übersetzung des lat. Vulgatatextes wieder aufgenommen sind.

Aus dem glühenden Liebeshymnus ist in der theologischen Literatur ein allegorisch ausgeklügelter Traktat geworden. Aber so unverwüstlich ist in seiner Verzückung dieses Liebeslied, daß sein berückender Zauber auch die starre Hülle der typologischen Methode durchbricht. Später ist der Gedankenkreis durch die Weihe der Mystik noch erhoben worden, hinausgeführt uber die Leidenschaft der irdischen Sinnenwelt in das Reich der ewigen Liebe. Und auch in der Auslegung des Ebersberger Abtes briclit da und dort ein Abglanz durch von der großen Seligkeit, die die Menschheit mit dem Erlöser vereinigt.

$\$ 5$. Das St. Trudperter Hohe Lied.

Kelle 2, 123-126. 325 f.; Piper, Ält. d. Litt. S. 453 f. - Ausg.: Jos. HAupt, Wien 1864 (Hs. A), dazu Zarncke, LC. 1864, 114 f., BeCh, Germ. 9, 352-370. - SCherer, QF. 7, 74. 12,

1) LG. I, Reg. S. 464 unter Mischprosa. 
19. 74 Anm. 76-78, u. ZfdA. 20, 198-205; Seemóller, QF. 24, 13f.; W. Walther, Die deutsche Bibelübersetzung des MA.s 3, 530 ff.; HAYNER, Beitr. 3, 491-523; VICT. MÜLler, Marburg. Diss. 1901, dazu LitBl. 1902, 280 f.; NAumann, Ad. Prosaleseb. S. $1-3$.

Hss.: ${ }^{1}$ ) A, die Haupths. Wien 2719, Perg. 13. Jh., mit schlechter Orthographie, flüchtigem Text und vielen späteren Nachträgen bezw. Verbesserungen von mehreren Händen (sieben bis neun). Am Schlusse der Hs. stehen die Worte: „Iste liber est sancti Trudperti martyris" von einer Hand nach 1300. Die Hs. befand sich also einmal in dem Kloster S. Trudpert im Münstertal im badischen Schwarzwald bei Freiburg. Der Dialekt ist, besonders im Eingang, etwa im ersten Viertel der Hs., vorherrschend alemann., von da an überwiegend bair. Die Vorlage von A scheint bair. gewesen zu sein, der Schreiber aber war wohl Alemanne, der im Laufe der Arbeit die Orthographie seiner bairischen Vorlage immer genauer kopierte. ${ }^{2}$ )

B. Das Hardenbergsche Fragment, zwei Perg.Bl. des 12. Jhs., jetzt im Germ. Museum zu Nürnberg Nr. 42518, bair. Dialekt. ${ }^{3}$ ) Der Text ist viel besser als der von-A.

a) München, Cgm 4479,4) vom J. 1509, eine sprachlich modernisierte und im Text stark abweichende Bearbeitung, bair., befand sich laut einer Notiz auf der Innenseite des Einbanddeckels im J. 1592 in einem Franziskanerinnenkloster in München; davon zwei Abschriften,

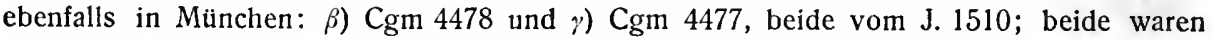
einst in dem gleichen Kloster wie $\alpha$ und alle drei sind höchst wahrscheinlich auch in diesem geschrieben worden.

C. Einige Stellen, etwa 50 Zeilen, sind in den alemann. (schweiz.) Traktat von dem Palmbaum aufgenommen worden. ${ }^{5}$ )

Die Heimat des Denkmals ist nicht mit voller Sicherheit zu bestimmen. Die Hss. B und $\alpha$ weisen nach Baiern, A war in S. Trudpert, ist aber vielleicht auch in Baiern geschrieben worden. Alemann. jedoch ist die häufig vorkommende Redensart gesach in Got, wonach doch alemann. Ursprung des Werkes wahrscheinlich ist. - Der Verfasser war ein Geistlicher, ${ }^{6}$ ) geschrieben hat er sein Werk für Nonnen, ${ }^{7}$ ) also ist es jedenfalls nicht in dem Mönchkloster S. Trudpert entstanden. ${ }^{8}$ )

1) V. MÜLLER S. 6-43.

2) V. MÜLLER S. $80 \mathrm{ff}$. vंerlegt die Heimat des Trudperter HL.s nach Baiern wegen der bair. Hss. B und $\alpha$, auch für A nimmt er bair. Ursprung an. Wegen der Mischung alemann. und bair. Formen hält er eine Gegend Baierns nahe der schwäbischen Grenze für das engere Entstehungsgebiet. So wäre also diese Mischung die Wiedergabe einer wirklich gesprochenen Mundart: dann aber muißte diese Mischung doch gleichmäßig durch die ganze Hs. durchgeführt scin, auch können in ein und derselben Sprechgemeinschaft Doppelformen wie râwe und ruowe oder schol bei sonstigem sol u. a. nicht nebeneinander hergehen. Diese alemann.-bair. Mischung ist nicht sprachlich, sondern orthographisch zu beurteilen: es sind zwei Schreibsysteme, d.h. ein alemann. und ein bair. Schreiber waren an der Hs. bezw. an einer ihrer Vorlagen beteiligt. Vgl. Wilhelm, Denkm. d. Pr. 8, Komm. II, $140 \mathrm{f}$.

3) ZACHER, ZfdPh. 9,420-422.11,416-418; SteinMEyeR, Berl. JB. 1901 S. 70-72.

4) Kollation von V. MÜlLer, ZfdA. 46,360380. $\alpha, \beta, \gamma$ sind zuerst bekannt gemacht

worden durch W. WALTHER aaO.

5) WaCkernagel-Rieger, Ad. Pred. S. 134 $-149.453 \mathrm{f}$.

$\left.{ }^{6}\right)$ ScHerer hält eine bair. Frau für die Verfasserin, QF. 12, 19.76, ZfdA. 20, 198; dagegen BECH, Germ. 9, 356; Hayner S. $491 \mathrm{ff} . ; \mathrm{V}$. MÜlLER S. $73 \mathrm{f}$.

$\left.{ }^{7}\right)$ Anreden an Nonmen s. Scherer, ZfdA. 20, 198 f.; V. MÖ́lLER S. 75-80.

8) Scherer, ZfdA. 20, 199. Der Herausgeber der Hs. A, Jos. HAUPT, hat unter unzureichenden Erwägungen angenommen, das Werk sei im Kloster Odilienberg bezw. Hohenburg bei Straßburg (wonach es früher das "Hohenburger" Hohe Lied genannt wurde) unter den Aebtissinnen Rilindis und Herrad (um 1150-1167 bezw. 1167-1195) verfaßt worden. Scherer sucht wegen der Erivähnung des heiligen Rupert den Ursprung in Baiern (dagegen HAYNER S. 503-505) und wegen des am Rande Bl. 47, 2 geschriebenen Namens Othilia Beziehungen zu einem Ottilienkloster. Einen Zusammenhang zwischen Hohenburg (Odilienberg) und Baiern findet er in der Person der Aebtissin Rilindis, welche um 1150 aus dem Kloster Bergen bei Neuburg im Bis- 
Willirams HL. ist stark benutzt. ${ }^{1}$ ) Aus ihm sind größtenteils die Schriftworte der Verse entnommen, jedoch nie ganz wörtlich, sondern es besteht ein Streben nach stilistischer Abrundung und sachlicher Klarheit. Im Wortschatz sind ältere, seltenere oder dem Verfasser nicht beliebte Wörter durch gebräuchlichere ersetzt. Innerhalb der jeweils auf die Bibelverse folgenden Auslegung ist der sinnspringendste Unterschied die bedeutende Einschränkung der Mischprosa. Die Einrichtung ist also derart, daß die Bibelverse zuerst lat. stehen, dann ins Deutsche übersetzt sind; darauf folgt die Auslegung, mit nur vereinzelten lat. Worten, meist sind die lat. Sätze oder Ausdrücke übersetzt oder in verwandte Gedanken übertragen. Die Benutzung W.s ist in der Auslegung sehr verschieden: etwa ein Drittel der W.schen Bibelverse ist unberücksichtigt geblieben, in den übrigen Teilen finden sich stellenweise nur leise Anklänge, dann aber auch wörtliche Entlehnungen. Aber die Leitgedanken und die Tendenz beruhen auf einer ganz andern Seelenstimmung. In dem St. Trudp. HL. hat die große gemütserhebende Bewegung der Mystik des 12. Jhs. einen ungemein charakteristischen Ausdruck gefunden: wie das Gefühlsleben aufs äußerste gespannt ist, wie das Natürliche und das Übersinnliche verschwimmt in dem einzigen Sehnen nach der Vereinigung mit dem Göttlichen, wie dieses Sehnen leibhaftes Erlebnis wird in der süßen Umarmung des himmlischen Bräutigams, in dessen Kuß die selige Welt versöhnt wird init ihrem Erlöser, da die heitere Sonne des ewigen Lichtes leuchtet in die finstere Kammer der im Elend irrenden Seele (6, $22 \mathrm{ff}$.$) . Es ist das erste Buch der deutschen Mystik, und was$ dieser wonnigliche Brautgesang $(6,28)$ verkündet, das ist auch der Geist der späteren deutschen Mystik. Von W.s Auslegung, die die Bedeutung der Kirche als allgemein christliche Heilsgemeinschaft zum Gegenstand hat, unterscheidet sich das St. Trudp. HL. eben dadurch, daß es die mystische Erfassung der göttlichen Liebe durch die Liebe innerhalb des klösterlichen Lebens lehrt. Damit ist auch die liebende Braut nicht mehr so sehr, wie -bei W. die Kirche, die Gesamtinstitution der Gläubigen, als vielmehr entweder Maria oder die einzelne menschliche Seele. So sagt der Verfasser selbst: die Gemahlin ist die heilige Christenheit und zuvorderst die Gottesmutter und eine jegliche reine Seele 43,1 f., ${ }^{2}$ ) und im Eingang nennt er auch nur zwei Vermählungen, einmal die zwischen dem höchsten Gott und der demütigsten Jungfrau: in ihr hat er uns Menschen alle geküßt 10, 16-11,4; und dann die, in der des armen Sünders Seele in Einheit mit Gott gelangt nach vollkommener Bekehrung und Reue 11, 29-32. Diese

tum Eichstäit nach Hohenburg berufen wurde; vgl. dagegen bes. KeLLE S. 125 f. 325 f. Hayner setzt unser HL. im Anschluß an die Hs. A nach $\mathrm{S}$. Trudpert, woher es den seither iibHchen Namen "St. Trudperter HL." hat. Hier sei daran erinnert, daß in jenen Jalıren ebenfalls ein lat. Kommentar zum HL. von einem Geistlichen für ein Nonnenkloster ab- gefaßt wurde, nämlich die Commentaria super Cantica Canticorum vols Wolbero, Abt von S. Pantaleon in Köln (i 1167) für die Bencdiktinerinnen in issula Rheni, Migne 195 , $1001-1272$, s. KELLE S. 124.

1) V. MUULLER S. $44-57$.

2) LÖBNER, Die Hocluzeit S.6f.; RAABS.111i.; V. MÜLLLR S. $58-61$. 
beiden Brautschaftsverhältnisse haben ihre Grundlage in der Bibel, denn die heilige Jungfrau ist die auserwählte Mutter des Gottessohnes und auf die menschliche Seele wird die Braut in einzelnen Stellen des alten und neuen Testamentes gedeutet (s. oben Williram S. 27).

Die dogmatische Grundlage des S. Trudp. HL.s ist die Trinität, und zwar ausgedrückt in den beiden herrschenden Formeln, der Augustinischen und der Abälardischen. Gleich auf den beiden ersten Seiten werden sie festgesetzt: memoria (mit der Glosse gehuht), ratio, voluntas 1, $17 \mathrm{f}$., und gewalt, wîstuom, güete 2, 18-21. Das Verhältnis der Braut zum Bräutigam wird gestellt auf die Verbindung der drei Augustinischen Seelenkräfte (die zugleich die Funktionen der dreieinigen Gottheit sind) mit den drei Abälardischen Wesenheiten der drei göttlichen Personen: in der menschlichen Seele sollen sich die drei Kräfte memoria (gehuht, die Selbsterkenntnis, die innere Erfahrung seiner selbst, das Bewußtsein seines eigenen Seins), intelligentia (vernunst), voluntas (wille) im Verein mit den drei göttlichen Tugenden geloube, gedinge, minne erheben $\mathrm{zu}$ den drei Äußerungen des göttlichen Wesens, zu der Macht (gezwalt) des Schöpfers, der Weisheit (wîstuom) des Erlösers, der Güte (güete) des heiligen Geistes 13,4-12. Kunstreich wie hier sind die beiden Trinitätsformeln untereinander und zugleich mit den drei göttlichen Tugenden verschmolzen auch 95, 4-19 und 97, 8-15. In 130, 32--132, 30 sind die Eigenschaften der drei Personen weiter ausgeführt und in Beziehung zu den sieben Gaben des heiligen Geistes gebracht. Verbunden auch sind die beiden Trinitätsformeln 18, 25-29 und 52,30-53, 21, nur die Formel Abälards als Erklärung des Wesens Gottes steht $117,30-32$; vgl. ferner $12,29-13,3.60,8$ f. 102, 22-25. 110, $10-13.129,19-22$.

In der Allegorie von der Hochzeit ist entsprechend dem Dogma von der Trinität Gott der Bräutigam, Gott als Gesamtwesenheit. Dogmatisch kann Gott in dem Brautschaftsverhältnis auch in seinen drei Äußerungsformen eintreten, d. h. der Bräutigam kann aufgefaßt werden als der Vater, der Sohn und der heilige Geist, so wie es in der Eingangsstelle von der brûtlouft 13, 4-12 dargelegt ist; zumeist aber ist die nähere Bestimmung der Person des Bräutigams offen gelassen. Was aber dem Trudp. HL. seinen ganz eigenen Charakter verleiht, das ist die besondere Art der Brautallegorie als Nonnenmystik; denn es ist ein Spiegel der keuschen Mägde, der Klosterfrauen, was gegen den Schluß selbst als Zweck angegeben wird. An diesem Buch sollen die Bräute des allmächtigen Gottes ihren Spiegel haben 145, $14 \mathrm{f}$., und unmittelbar am Ende, 147,25-148,6: an dieser Schrift sollst du erkennen die Bräute des allmächtigen Gottes usw. Sie vor allem sind gemeint unter den juncfrouzven, die sêle, die sich Christus vermählt, ist die keusche Nonne, ihr ist der Seelenbräutigam bestimmt. Die geistliche Hochzeit ist im Sinne des Kreises, für den diese Auslegung des HL.s verfaßt wurde, die Vermählung der Nonne mit dem himmlischen Bräutigam, sie ist die Jung- 
frau oder die Braut (brût), die Gemahlin (gemahele, chone), die Freundin (friundinne) Gottes. Sie haben nie mit Sinnenlust geküßt, dieses Küssen preßt nicht den leiblichen Mund, sondern den geistigen Willen der Liebenden aneinander, dieses Umfassen geschieht nicht mit den umschlingenden Armen, sondern mit den heiligen Gedanken, mit welchen man Gott zu allen Zeiten umfängt. Das Ziel der sehnenden Seele ist die Ruhe in Gott, dessen irdisches Abbild ist Salomo der Friedenskönig (rex pacificus) 41, 6 f. u. ö. Aber in der Liebesglut des alttestamentlichen HL.s empfand die Überspannung des Gefühlslebens ein religiös-sinnliches Reizmittel, denn im Zeitalter der Kreuzzüge und der Askese genügte die Frömmigkeit nicht mehr in der naiv gläubigen Hingabe an Gott oder im Streben nach rein geistiger Wahrheit, sondern die Empfindung der Gottesnähe wollte man mit den Sinnen und mit dem Körper spüren. Die Gott essen, sind seine Freunde und am liebsten sind ihm die, die von seiner übermäßigen Süßigkeit trunken sind, die in Gott verwandelt werden 66,5-20. "Gott schmecken" ist jetzt zu einem symbolischen Ausspruch der Mystik geworden 20, 13f. 65, 18. 93, 31 f., vgl. 121, 12. 138, $1 \mathrm{f}$. Der höchste Zustand aber dieser sinnlich übersinnlichen Leidenschaft ist die Liebeserfüllung, die erotische Ruhe in der Umarmung des Bräutigams. Ein schönes Bild ist 134, 27-135, 1, wie die Seele durch die Wüste der Verbannung in das Reich des Vaters geführt wird, wo sie die ewige Liebe des Bräutigams besitzt. Erregter sind andere Liebesszenen. In dem Brautkuß der lieiligen Jungfrau ist die selige Welt versöhnt mit Gott 7, 5-18. Liebeskrank ist die Seele nach dem gemahele 74, 1-75, 4 . In sein Gemach geleitet sie der König 18,7, das ist die höchste Freude, sie fliehet alles Leiden und alle Sünden, sie fliehet auch gute Arbeiten, Venien und Weinen und selbst das Gebet, sie wird mit Ruhe gestillt werden in der süßen Bewegung Leibes und der Seele 18, 30-34, vgl. 66, $23 \mathrm{f}$., vgl. ferner 136, 12 f.; 125, 5-10, vgl. 138, 20-25; 41, 26-28. Zum Seelenfrieden und zur Gemeinschaft mit Gott glaubte man zu gelangen, indem man dem Körper Keuschheit auferlegte und den Geist zur üppigsten Sinnlichkeit reizte.

Für das Gemütsleben der Mystik, aber auch für die Dogmatik und Psychologie derselben, ist das S. Trudp. HL. ein bedeutsames Denkmal. Der grundbildende Glaubenssatz ist, wie oben erwähnt, die Lehre von der Trinität, die sich zuerst in dem Schöpfungswerk, dem anegenge, offenbart, Prolog 2,17-4, 34. Aber das Transzendente ist für den Mystiker ein Objekt des Gefühlslebens und durch das höchste und äıßerst subjektive Gefühl gelangt man zur Erkenntnis Gottes, das ist die Liebe, und die Grundlehre ist am Ende des Buches ausgesprochen: iz ist ain lêre der minnichlichen gotes erkennusse 145, $12 \mathrm{f}$.

Aus diesem Gedanken gehen alle einzelnen Sătze dieser Lehre hervor, in ihn münden sie ein, er ist das Ein und das All der mystischen Weltan schauung. Seine sinnliche Darstellung ist die Vermählung der menschlichen Seele mit der Gottheit, das natürlichste Gefilhl, die Liebe, ist es, die 
sie mit der Idee des Übersinnlichen vereint. Die drei Personen der Trinität werden im Gefühl der Liebe erfaßt, in der Hoffnung auf den Bräutigam erfüllt sich das irdische Sehnen. Im Speziellen ist Gott der Schöpfer, der die Welt aus Güte erschaffen hat $8,10 \mathrm{ff}$. Christus ist wahrer Gott und wahrer Mensch 16,1 f. 21, 15-17. 28, 29f.; von den drei Personen trägt er allein menschliche Gestalt, in der mystischen Vorstellung ist er vor den $z$ wei andern der menschgeschaute Bräutigam; seiner warten die klugen, ihn versäumen die törichten Jungfrauen; sein Bild als eines lichten Engels schwebte der leibentsagenden und liebesehnsüchtigen Nonne als der göttliche Geliebte vor; er ist der Heiland, der durch seine Liebe die Welt und die im Elend schmachtende Seele erlöst hat. Weil aber die Liebe die allherrschende Macht ist, so wird auch die dritte Person der Dreieinheit stark hervorgehoben, der heilige Geist, denn er ist die Wesenheit der Liebe. Mit ihm beginnt dieses geistliche "Gespräch", Prolog 1, 1 ff.: Wir wollen reden von der obersten Liebe, der größten Gnade, der ruhevollsten Sußigkeit, das ist der heilige Geist, mit seinen heiligen Gaben bringet er alles Gute 2, 34-3,14. 3, 14-28. 5, 1-13; seine Gnadengaben sind die letzten Heilsverheißungen des Buches 128, 12-33. 145, $28 \mathrm{ff}$ : was ist unsere Seele? das ist unser Gemüt (muot), worinnen Gott gerne ist. Was ist aber das. Auge? Das ist unsere Vernunft (vernunstlich ratio), mit der wir Gott sehr fröhlich und sehr liebevoll (vil minneclichen) sehen und in uns leiten. Nun meinen etliche, daß die Seele in dem Leib sei: das weiß niemand. Der Leib ist eine giftige Kotmasse (aiterhaftez hore): daran seht ihr der Seele Kraft, daß sie ihn so herrlich erhöht.

Auch ein Stück mystischer Psychologie ist in die Erklärung des HL.s. eingeschaltet, und zwar am eingehendsten 128, 12-33, wozu 129, 19-22 zu ziehen ist, und 141, 20-142, 7: Wenn der Mensch Furcht und Reue hat und schmerzlich zu weinen vermag, so hat Gott die Seele unter sich und hat sie in Besitz genommen als sein Erbe; wenn der Leib und die Seele Freude haben in der Süßigkeit des heiligen Geistes, so hat die Seele Gott in sich gezogen, so daß sie nimmer geschieden werden weder mit Liebe noch mit Furcht 128, $26 \mathrm{ff}$. Nun wollen wir sehen, was das Haubt unserer Seele ist: das ist unser Wille, der lenkt unsere Seele wie das Haubt alle Glieder. Unsere Vernunft (vernunst) ist das Herz, unsere Selbsterfahrung (gehuht) sind die Füße und die Beine 129, 19 ff. Entsprechend dem Augustinischen Primat des Willens steht dieser hier obenan. Aber umgekehrt ist. $141,20 \mathrm{ff}$. die Vernunft das Haubt, die den Willen leitet, der Wille sind die beiden Füße (die eine Willenstätigkeit, die sich auf die Bedürfnisse des Leibes, die andere auf die der Seele richtet). Dieses Verhältnis zwischen Vernunft und Willen nähert sich der Ansicht Hugos v. St.Victor. ${ }^{1}$ ) Deine Selbsterfahrung (gehuht) ist ein Buch, in das du deine Gedanken einmalst oder einschreibst.

1) Summa sent.III Kap. 8, Migne 176, 101 C, vgl. Ostler, Die Psychologie des Hugo v. St. V. S. 164 . 
Sie können nütze und gut sein, dann lebt deine Seele mit Gott; sind sie aber von der Welt, dann scheidet Gott von ihr, das ist ihr Tod. Das Wesen der Vernunft wird bestimmt 43,6-15: Was der Mensch wirkt oder schafft, das bildet sich wieder in seinen Gedanken. Wer die Wiederbildung (Schaffung des Ebenbildes) getreulich und innig an Gott kehrt, das ist Vernunft. Vernunft also ist getreue Vorstellung Gottes in der Seele. Dazu 118, 10-14: So rein deine Vernunft (gezvizzede), so rein ist dein Herz und so rein vermagst du Christus (Gott) zu sehen und $\mathrm{zu}$ erkennen. Also ist die höchste Kraft der Seele die reine Erkenntnis Gottes.

Einzelne dieser psychologischen Bestimmungen kehren zerstreut im Texte wieder: das Vereintsein Gottes und der Seele 117, 29 f. 128, 25 f., vgl. 7, 16-18. 23,1-9. 31, 25. Gott geht aus durch die Pforte unseres Mundes, er geht ein durch die Pforte unserer Augen, unserer Ohren, er wohnt in unserem Herzen 125,31-126,10. Gott hat uns zu seinem Bilde geschaffen, daß unsere Seele sein Siegelbild (insigele) sei 8, 10-14, vgl. 141, 20 f. (gebraeche), 35, 18-20. 72, 27 f.; deine Seele soll ein Spiegel sein, da du deinen friedsamen König und deinen lieben Gemahl innen siehest 93, 27-29.

Ganz durchwoben ist dieses HL. von dem Preis der Mutter Gottes. Der wonnigliche Brautgesang wird erhoben zu Ehren des höchsten Bräutigams und der heiligsten Braut, die geküßt ist mit dem Kusse, welcher Welt und Gott versöhnt 7,4-18. Zuerst will der Verfasser von der heiligen Mutter sprechen 14, 4 f. Für sie ist das Buch angefangen 139, 25-140, 4, sie ist vollkommen in den Tugenden und in jeder Heiligkeit. Darum ist sie in ihrer Keuschheit und Demut (vgl. 7, 15. 8,21-27. 32, 31 f. 36, 18 f. u. 32. $41,17-22$. 51, 14-29. 54, 16-20. 56, 32-57, 2) das Vorbild für die Jungfrauen, die kommen wollen $\mathrm{zu}$ dem königlichen Brautbett der Liebe Gottes 140,10-15. Sie hat die Jungfrauen erzogen, die Christi Gnade begehrten, $\mathrm{daß}$ er ihnen reines Leben gibt und viele Tugenden und seine volle Liebe; die hat sie ihm zu Bräuten, zu Gespielen, zu lieben Freundinnen erzogen $16,9-17$ und weiter bis 18,6 .

In dem S. Trup. HL. ist das Sittlichkeitsideal geistlicher Jungfrauen dargestellt, das die Seele mit Gott verbindet. Tugendlehren erfüllen das ganze Werk. Es sind die Tugenden der Klosterschwestern, derer „die diese Welt verschmähen " und allen Trost an Gott haben und der Welt tot sind 51,7-10, die sich enthalten von dem üppigen Leben 72, 9 f., die dem Fleisch und der tötlichen Welt entsagen 90, 5-13, die ihr Magdtum oder ihre Keuschheit rein bewahren und williglich verschmähen die Reichtümer der Welt und ihren Leib unterwerfen dem langen Kampf und der cmsigen Arbeit geistlichen Lebens durch die süße Minne, so wie Agnes und Cäcilia, Lucia und Agatha und viele andere 16,18-17,11. Demut und Keuschheit, Geduld und Gehorsam sind die vornehmsten Tugenden der Weltentsagnng und des Gotterringens 33, 15 f. 35, 22-24. 42, 6-11. 50,2-23. 53, 7-9. 59, $5-12$. 59, 26-60, 3. $70,12-24$. 84, 14-21. 90, 22 f. 91, 10-93, 13. 100, 
$\left.1-5.108,2 .{ }^{1}\right) 109,25$ f. 116, 25-29. 117, 1-28. 118, 33-119, 10. 123, 31-124, 16. 139, 14. 140, 10-15.

Eine dreifache Dreizahl.von Pflichten ist 35, 18-27 aufgestellt: gute Gedanken, Worte und Werke, das ist Gehorsam, Geduld und Demut, Glaube, Hoffnung und Liebe. Grundbedingungen für das sittliche Leben sind also auch die drei göttlichen Tugenden, die größeste unter ihnen ist die Liebe, die Liebe $z \mathfrak{u}$ Gott und dem Nächsten: das allerbeste Gut ist das minnende Herz, alle Tugenden zergehen außer die Minne 89, 19-90, 4, vgl. 18, 10-13. 29, 3-20. 35,23 f. $74,25-75,4$. 79, 4-80, 3. 84, 29-32. 90, 30-91, 9. 109, 22-24. Die drei sittlichen Handlungsarten, gute bezw. böse Gedanken, desgl. Worte, Werke sind außer 35, 18-27 noch geboten 53, 6 f. 23-28. 97, 3f. 134,8-17. Eine umfassendere Tugendreihe ist aufgestellt 16,9-17, 11: außer den drei göttlichen Tugenden und der Keuschheit, Demut, Verschmähung der. Welt werden hier gepriesen: kindliche Furcht, Gehorsam, beständige, gute Werke, reine Gedanken, lauteres Gewissen, Pflege der inneren Sinne, guter Wille, Langmut: diese Tugenden, die das reine Leben ausmachen, lehrte die Mutter Gottes; ferner 57, 25-58, 21, die ganze Partie 57, 21 - 75, 17 und das KapitelVI, 91, 10-106, 4 sind hauptsächlich den Tugenden des geistlichen Lebens gewidmet.

Diese Ethik ist also nicht auf dem System der sieben Haupttugenden aufgebaut - sie erscheinen nur im Kampf der Tugenden und Laster 114, 7-115, 2 -, vielmehr werden die Pflichten der Klosterleute gelehrt mit der Grundforderung von Armut, Keuschheit, Gehorsam. Oft ist auf das Klosterleben Bezug genommen: die Nonnen werden angeredet ir juncfrouwen, 2 ) das gaistliche leben 57, 22. 59, 3. 104, 8 u. ö. ist der Kreis, für die diese Sittengesetze gelten, die samenunge 58,26. 61,7f. 67,20, die samenunge gaistliches lebennes 92, 18 f., die saminunge der gotes irwelten 59, 24, ordenunge (Klostergemeinschaft) 67,27, dâa ze capitele sollen die Klostergenossen ein bußfertiges Leben führen $57,33 \mathrm{f}$, , in geistlicher $z u h t$ leben sie 59, 4. 75, 5-17. 100, 4, unter der maisterschaft 70, 12-21. 98, 11. 104, 13, vgl. 117, 33-118, 9, innerhalb der bruoderschaft 98, 11, in freiwilliger Armut 108, 9. 139, $23 \mathrm{f}$., mit ärmlicher Kleidung und geringer Speise 106, 16-19, vgl. 98, 12f.; in Fasten, Wachen und Beten 29, 23-25 (die guten Werke werden oft genannt; die sieben Horen 58, 13 f.), in gehorsame, mit guoter einmuote 59, 26-30, in ruhigem Gemüt (râtwiger muot 93, 20. 94, 14; fride ist häufig, dîn fridesamiu sêle 93, 32. 94, 1), in Sanftmut (mitewâre 93, 14-94, 10. 109, 4-110, 5), mit Schweigen (mit redelîcheme swîgenne 57,26). Das alles sind auch Gebote der Benediktinerregel und auf $\mathrm{S}$. Benedictus beruft sich der Verfasser selbst 59, 28. Aber es sind auch unwürdige Glieder in der Gemeinschaft, außer den Guten und den Besseren die Schlimmeren und die Allerschlimmsten (die guoten unde die bezzeren,

1) Der enge Weg des Gehorsams, vgl. Bened. Regel Kap. V De oboedientia.

2) V. MÜLLER S. $75-80$. 
die ubilen unde die allir wirsten 103,10-13, zu den beiden letzten Arten gehören die Hoffärtigen und Widersetzlichen, die wirderbruhtigen 104, 9 f.), die Empfindlichen und die im Wohlleben sind und die wollen, daß man ihnen schmeichle und die mit ihrem vornehmen Geschlecht prahlen 104, 17-22. Ein besonderes Laster ist das Murren, das geheime Lästern gegen die Obrigkeit, murmel 59,30. 134, 17, murmul $\hat{u} f$ die maisterscaft odir ûf die bruoderscaft 98,11 , und unnützes Geschwätz, mit murmurle unde mit unnutzeme chôsen 67,12f. (Benedikt. Regel Kap. V und VI). Unmittelbar eine lat. Bezeichnung der Benediktinerregel ist elatio 119, 3 (soviel wie superbia), vgl. auch ypochrisis 119,4. Andere, die der Teufel irre führt, sind die Fürwitzigen und die allem nachgehen, was sie anzieht, die an jeder Blume riechen und nach allen Dingen greifen und die, die keinen geordneten Willen, kein Maß haben 66,23-67, 28. Noch andere sind die Unstäten, die der Teufel von einer Statt zur andern treibt, die ihr Kloster verlassen und in eine Klause gehen oder Einsiedler werden 70,1-24 (vgl. Bened.-Reg. Kap. I). Und am Schluß des ganzen Buches wird den Nonnen je nach ihrem Verhalten gegen die Tugenden eine Note gegeben: die den Eifer haben, ein tugendhaftes Leben zu führen, sind Bräute des allmächtigen Gottes, die nur den Willen dazu haben, sind Jungfrauen, denen beides mangelt, sind Kebse 147, 25-148,6. Eine besondere Pflichtenreihe ist angeknüpft an die Erklärung der acht Seligpreisungen '109, 2-116, 2.

Nur durch Mühsal und Arbeit, durch Abtötung des Fleisches und gute Werke kann man vollkommen (durnaht) werden, was fleischlich Gutes den Vollkommenen und in der Gottesfurcht Starken geschieht, essen, schlafen, Leibespflege, auch schönes Wetter, Blumen, blühende Bäume in der Sommerszeit, das fliehen sie, weil sie wohl wissen, daß der Mensch zu nichts taugt als zum Arbeiten (d. i. "geistlich" arbeiten) 85, 9-22, vgl. 11, 19-28. 44, 20-24. 107, 27-30. 133, 10—28. Das tätige Leben, die Liebe zum Nächsten, ist dargestellt an Martha, das kontemplative (gaistliche), die Liebe zu Gott, an Maria 79,32-80, 25. Auch die Mühsale der Versuchung (bechorunge) dienen zum Guten, zur Besserung 104, 11. 110,30. 137, 24-31. 142, 12 f. $142,33-143,3$. Beati qui lugent ist der Spruch der Seligkeit für die weltverachtenden Gemüter, darum ist uns melır zu suchen Weinen als Singen 143, 24-29. Gott tröste sie, die diese Welt als eine Verbannung auf sich genommen haben ..., dainnen man mehr weinen muß als singen, denn da ist keine ganze Liebe als nur die Hoffnung, heraus zu kommen 107, 4-10, vgl. 106,5-107, 25. Mit königlicher Freude hat das Buch angefangen, es endet mit einem jammervollen Schmerze, es fing an mit einem königlichen Sange, nun geht es aus mit inniglichem Weinen 145,6-10. Vom Jubelgesang im Brautkuß zum Scheiden der treu Liebenden fühtt das HL., vom Osculetur me osculo oris suo zum Fuge a me, dilecte mi, aber diese Tränen sind süß 144,5-9, denn die Liebenden scheiden sich in ungetriibter Minne $145,11 \mathrm{f}$, , und diese süßen Tränen kräftigen dic Braut zum Kampf gegen 
die Welt und der Bräutigam vergißt der Braut nicht in diesem Elend 143, 31-145, 5. Das ist die tristitia coelestis. Mit dieser Seligkeit der Tränen ist zum erstenmal in deutscher Sprache die empfindsame Stimmung durchgebrochen, und die solche Empfindung hat, ist die schöne Seele. Schön ist die Braut, die wahre Treue, ein wahres Herz und ein ruhiges Gemüt hat. Friedsam ist sie und trägt in sich den König des Friedens, so wird Gott geeinbart mit seiner Gemahelen; da ist die Seele schön und ihre Zierde ist Güte und Sanftmut 93,14-94, 10. Das ist das frühste Bild der schönen Seele im Deutschen; harmonisch ist sie in sich und gütig gegen die Menschen.1)

In der ganzen Auffassung der ethischen Forderungen wird ein Wertunterschied geltend gemacht $z$ wischen der weltlichen und der geistlichen Sittlichkeit. Gleich von vorneherein wird der Standpunkt festgestellt: Wir geistlîchen mennisken sprechen mit rehte von deme geiste 1, $3 \mathrm{f}$. Die Christenheit zerfällt in weltliche und geistliche Menschen 101, 14-102,3. Der Glaube der Geistlichen muß größer sein als der der Weltlichen, Gott mutet ihnen mehr zu 139,6-13, sie besitzen also die höhere Vollkommenheit. Aber doch ist die Lehre, die hier den Klosterleuten vorgetragen wird, ein Strebeziel für alle Menschen (57, $22 \mathrm{f}$.).

Die Grundbedingung für das tugendhafte Leben ist die unterschidunge, die Fähigkeit, Gutes und Böses zu unterscheiden. Sie ist die muoter aller tugende 71, 2-7, vgl. 16, 22 f. $\left.{ }^{2}\right)$ 57, 32 f. 116, 5-12; danach müssen auch die Oberen (maisterschaft) die Behandlung der Mönche einrichten 104,12-16. $\mathrm{Zu}$ jeglichem Tugendhaftsein gehört der gute Wille von seiten des Menschen 12, 18-28. 13, 22-14, 2. 42, 10. 53, 11. 57, 29. 59, 5. 9 f. $72,19.84,19$ f. 124, 6-12. 147, 30; aber wie alles Gute, kommt auch der Wille von Gottes Gnade $96,1.7$ f. u. ö. Gott lehrt die Tugend 108, 33-109, 2, er führt uns aus der Schlechtigkeit zur Tugend 18,16 f.; Maria lehrt die drei göttlichen und damit verbundene Tugenden $16,18-27$.

In der Mystik des HL.s führt die völlige Hingabe der Seele, die Erhöhung des inneren Lebens, die Steigerung der sittlichen Persönlichkeit zu Gott, in der Liebe wird die Erkenntnis Gottes erfüllt. Die Urempfindung und der Urgedanke ist die Liebe: „Das Buch fing an mit einem Kusse der Freundschaft und nun scheiden sie sich mit einer vollkommenen Liebe, denn es ist eine Lehre der Liebeserkenntnis Gottes" 145, 10-13. Der symbolische Ausdruck dafür ist die Brautschaft Gottes mit der Seele. Dagegen findet sich das Bild von der Vermählung Gottes mit der Kirche, das allegorische Motiv Willirams, nur selten. Doch aber be-

1) Ein weltliches Abbild der geistigen "schönen Seele", der mystischen edelen sêle, ist daz edele herze bei Gotfrid v. Straßburg: s. VoGT, edel S. $10 \mathrm{ff} .31 \mathrm{ff}$.

$\left.{ }^{2}\right)$ si lêrte si des vesten gedingen unde underschidunge unde unruomelîchiu werch, gehôrsame [unde] stâtigiu werch. unruomelîch, das sonst nicht belegt ist, würde unprahlerisch, also soviel wie demuitig bedeuten. Vermutlich ist der willige, nicht murrende Gehorsam darunter $\mathrm{zu}$ verstehen, vgl. $50,19 \mathrm{f}$, 59, 29 f. und Bened.-Reg. Kap. V De oboedientia. 
schränkt sich das geistige Leben nicht auf die persönliche Frömmigkeit, sondern es wird auch stark die Bedeutung der kirchlichen Gemeinschaft für die Befestigung des Glaubens hervorgehoben, besonders in ihren Gliedern, wie bei W., den Patriarchen, Propheten, Evangelisten, Boten, Heiligen, Märtyrern, Lehrern 16, 32 f. 17,7 f. 39,3 f. 42, 18-44, 14. 47, 15-49, 5. $53,2-4.73,19$ f. $80,29-83,28.102,12$ f. 103,14 f. $140,26-29$; auch hier sind einander gegenübergestellt Meister und Untertanen, Hörer und Lehrer $48,8,28$ f. $55,8-17.62,1-3.143,6$.

In diesem Werke ist es doch in der Hauptsache auf starke Gemütswirkung abgesehen. Dazu stehen dem Verfasser auch die sprachlichen ${ }^{1}$ ) Mittel zu Gebote. Er hat eine umfassende Beredsamkeit, bis zum höchsten lyrischen Schwung erheben sich die hymnischen Lobpreisungen, glühende Liebesworte beseligen diesen heiligen Minnesang, mit rhetorischer Kunst fesselt der Dichter das Interesse der Hörer, er tritt zu ihnen in persönlichen Verkehr, häufig gebraucht er predigtartige Formeln, Fragen, Aufforderungen. Der Stil ist nach dem Inhalt verschieden, einfacher in den didaktischen und dozierenden Teilen, gehoben in den lyrischen und steigert sich dann zuweilen $z \mathfrak{u}$ dramatischer Lebendigkeit. Eine strenge Gliederung und bestimmte Anordnung des Stoffes ist in den Kommentaren des HL.s ausgeschlossen, im St. Trudp. HL. gruppieren sich aber doch die Gedanken nach zwei Grundmotiven: Kap. I $(1,1-27,4)$, II $(27,5-37,28)$, III $(37,29-46,15)$ behandeln mehr die himmlische Ehe, Maria und die Gemahlschaft der Seele, Kap. IV (46, 16-63, 26), V (63, 27-91, 9), VI (91, 10-106, 4), VII (106, $5-126,28)$, VIII $(126,29$ bis gegen den Schluß) mehr die Tugenden des geistlichen Lebens; gegen das Ende treten Maria und der heilige Geist in den Vordergrund.

Ein neuer Geist ist mit dem St. Trudp. HL. in der deutschen Literatur eingekehrt, aus der Tiefe der Seele heraus dringt ein sehnsüchtiges Verlangen nach einer nur geahnten unaussprechlichen Schönheit. Nur mit dem Gefühl kann sie erfaßt, nur unter dem süßesten Bilde innigster Seelengemeinschaft kann sie vorgestellt werden. Es ist der Geist der Mystik, der durch den heiligen Bernhard erreicht wurde, und am nächsten verwandt in der Literatur der Zeit ist unser Werk wohl seiner Ermahnung an die geistliche Schwester, De modo bene vivendi ad Sororem. Beide verfolgen die Zwecke praktischer Mystik, wenngleich, besonders in dem dentschen Werk, auch dogmatische Spekulation mit einbezogen ist. Aber die Empfindungen in dem deutschen Werke sind weicher, schmelzender, sinnlicher. Der große Lehrer des zwölften Jahrhunderts, der doctor mellifluus, war zur höchsten Stufe menschlicher Gotteserkenntnis gelangt, der deutsche Mönch war nur auf dem Wege dahin. Ihm blieb allein das Sehnen.

i) BECH S. 365-370; V. MỨlLER S. 83-87; ARN. Pieritz, Die Stellung des Verbums im
König Rother mit Bericksichtigung des St. Trudp. HL.s, Greifsw. Diss. 1912. 


\section{\$6. Ezzos Gesang.}

\section{b) Das Dogma.}

Kelle 2, 7-21. 99. 240-250. 302; PiPER, GD. 1, 37-54, Nachtr. S. 245. 371, Höf. Ep. 3, 715. - Ausg.: Erster Abdr. des Vor. Textes: Diemer, D. Ged. S. 317-330, Anm. S. 77-82, Einl. S. XLVII-XLIX u. LVII-LXIl (Übersetzung), DiemER, Beitr. VI. Teil, Wiener SB. 52 (1866), 183-202. 427-469, Wiener SB. 55 (1869), 271-331, dazu ScherER, ZföG. 19 (1868), 735-743 u. Kl. Schr. 1, 588-597; erster Abdr. des StraBburger Textes: K. A. BARACK, Ahd. Funde, ZfdA. 23, 209-216, Ezzos Gesang von den Wundern Christi u. Notkers Memento mori in phototyp. Facs. der Straßburger Hs., 4 Tafeln, Straßburg 1879, dazu Steinmeyer, Anz. 5, 431 f.; MSD Nr. 31 u. I[ ${ }^{3}, 168-188$, dazu WilmanNS, Gött. gel. Anz. 1893, 535-537, KraUS, ZföG. 45 (1894), 134, WunderLich, ZfdPh. 26, 112 f. (zur 1. Aufl.: Bartsch, Germ. 9, 59 f.); Braune, LB. ${ }^{8}$ Nr. 43 u. 200 f.; WaAG, KI. d. Ged. ${ }^{2}$ S. 1-16 u. Einl. S. XI-XIX. - Schade, Geistl. Ged. S. XXIII-XL u. Decas S. 30-36; KonR. Hofmann, Münch. SB. 1871, 293-328; Scherer, QF. 12, 28-30; Wilmanns, Ezzo's Gesang von den Wundern Christi, Bonner Univers.-Progr. 1887; JoHN Meier, Beitr. 16, 67-74; Heinr. Giske, Germ. 28, 89-98; Friedr. Weidling, Germ. 37, 69-74; W. Metrin, Die Composition des Ezzoleichs, Diss. Halle 1892; ders., Philol. Studien, Festgabe für Sievers S. 277 ff.; Kelle, Die Quelle von Ezzos Gesang, Wiener SB. 129 (1893), I; JoH. BaPt. KralLINGer, Der Ezzoleich, Progr., München 1894/95 (gemeinverständl.); v. D. LEYeN, Kl. Beitr. S. 9-40, dazu LC. 18971078 f., Reuschel, Lit.Bl. 1898, 178-180, UhL, ZfdPh. 32, 271 f.; WOLFSKEHL u. v. D. LEYEN S. 156-177. 224 f. - Beiträge zu einzelnen Stellen: MULLENHOFF, ZfdA. 19, 493 f.; SCHRÖDER, ZfdA. 47, 72. 55, 40.

Hss. V (A), die Vorauer Hs., s. oben S. 16. S (B), Straßburger Hs., ${ }^{1)}$ Universitäts- und Landesbibl., Cod. germ. Nr. 278, 2V, $155 \mathrm{Bl}$. fol., 11. Jh., aus dem oberschwäbischen Kloster Ochsenhausen bei Memmingen, enthält Teil 3 u. 4 von Gregors Moralia in Job. Am SchiuB des dritten Teils, auf der ursprünglich leeren Rückseite des Blattes 74, sind in 23 Zeilen 76 Verse des Ezzoliedes eingetragen, die den ersten 132 Versen von V entsprechen, von einer Hand des 11./12. Jhs.

Beide Hss. sind Abschriften, ein gemeinsames fehlerhaftes Original ist nicht nachzuweisen. $S$ hat die ältere Fassung bewahrt (abgesehen von den beiden letzten Wörtern des V. 132). Die Überlieferung ist gut und nur durch wenige Schreibfehler gestört. ${ }^{2}$ ) Stark ändert dagegen V.3) Viele Wörter sind verschrieben, dazu ist mit dem ursprünglichen Wortlaut sehr frei verfahren durch Einschaltung von Wörtern (Attribute) und willkürliche, gutes Alte verwischende Änderungen.

Der Hauptunterschied zwischen $\mathrm{V}$ und $\mathrm{S}$ liegt in der Erweiterung des Stoffes, indem in V drei neue Strophen eingefügt sind: Str. I (in MSD), die Eingangsstrophe, gibt eine Mitteilung über die historische Entstehung des Gedichtes. Str. III u. IV vervollständigen den biblischen Bericht von der Schöpfungsgeschichte: Str. III Verleihung des guten Sonntags [gehört dem Zusammenhang nach erst hinter das Sechstagewerk, also erst hinter 3, 12] und Erschaffung des Menschen aus acht Teilen; Str. IV Erschaffung des Weibes und des Paradieses mit den vier Strömen. Der Verfasser dieser Zusatzstrophen besaß viel geringeres Talent als der ursprüngliche Dichter, sein Stil ist hölzern, durch häufige Wortwiederholungen ${ }^{4}$ ) und steife Aufzählungen

1) Die Hs. wurde aufgefunden 1878 von K. A. Barack.

$\left.{ }^{2}\right)$ Steinmeyer, MSD. II ${ }^{3}, 184$.
3) Steinmeyer, ebda S. 187.

4) Steinmeyer, ebda. 
(Str. III u. IV). Außer diesen ganzen Strophen I. III. IV ist noch ein Zusatz von $z$ wei Zeilen gemacht, II, in denen ein neuer Titel gegeben wird, die vier êwangeljon, ${ }^{1}$ ) der aber im Widerspruch steht mit der vorhergehenden echten Str. 1 und die daselbst gebrauchte Eingangsformel benutzt (Die rede die ich nû sol tuon = eine wâre rede vor tuon. ${ }^{2}$ )

Außer den vier Zusätzen sind keine andern mehr nachzuweisen, so daß also von da an in $\mathrm{V}$ der alte Textbestand gewahrt ist. ${ }^{3}$ )

Sprache der Hss.4) V hat entsprechend seiner Herkunft bairischösterreich. Dialekt. Sicher beweiskräftige Spuren anderer Mundarten finden sich nicht, doch ist $z \mathbf{u}$ bemerken, daß das umgelautete $\hat{a}$ zehnmal $e$, zweimal ae, einmal a geschrieben ist; bequam mit qu 2,7 könnte aus einer ostfränk. Vorlage stammen. $\left.{ }^{5}\right)-\mathrm{S}$ ist rein alemannisch. Es hat mit vollen Endsilbenvokalen ältere Sprachformen bewahrt, während diese in $\mathrm{V}$ fast durchweg zu $e$ abgeschwächt sind. - Ein Schluß auf die Heimat des Originals läßt sich aus diesen Anzeichen nicht ziehen. Die Sprache dieses Originals hatte noch volle Endvokale.

Die Verfasserfrage ist schwierig und nicht mit Sicherheit zu lösen, weil zwei verschiedene Berichte vorliegen, deren Zugehörigkeit $z u$ unserm Gedichte sogar nicht ganz außer allem Zweifel steht.

1. In der Vorsatzstrophe der Vor. Hs. (Str. I) wird mitgeteilt: der Bischof Gunther von Babenberg (Bamberg) trug seinen Pfaffen auf, ein Lied $z u$ dichten. Sie machten sich an die Ausführung, denn sie waren in den geistlichen Schriften bewandert. Ezzo schrieb den Text, Wille erfand die Melodie.

1) d. i. die evangelische Geschichte, das Leben Jesu, vgl. HARTMANNS Rede v. Glauben 1319 f.: wir lesen in den scriften der vier evangelisten; Otfrid III, 14, 1-4 thie scriptora fiari, thie scribent evangelion (die Wunder Christi); die Gesamtheit der christl. Lehre: Himmel u. Hölle 32 ; Kristes lêre und siniu wort... daz sint diu êwangeljâ Rudolf v. Ems, Barlaam ed. PfEIFFER 78, 23 ff. 83, $27 \mathrm{ff}$.

2) Vielleicht hatte der Abfasser dieser Inhaltsangabe die zwei Verse an den Rand bei Str. 1 geschrieben, von wo sie dann in einer späteren Hs. ins Innere des Textes gelangten.

3) Keiner der vielen sonstigen Ausscheidungsversuche ist überzeugend (SCHADE aaO. und in seinem ad. Lesebuch; SIMROCK in scinem Lesebuch; DIEMER, Wiener SB 52, 427-469; Giske aaO.; WilmanNS S. 15, vgl. aucl S. 21. 22. 24. 26; Kelle, Quelle voll Ezzos Gesang S. 31-39. Vor der Auffindung von $\mathrm{S}$ hat $\mathrm{K}$. HOFMANN die Einschibe I. II. III. IV nahezu, MÜllenhofF (MSD. 2. Aufl. S. 58 ff. u. 382 f.) zum Teil richtig erkannt. Nur eine größere Entstellung kann mit einiger Slcherheit begrïndet werden, und zwar in der von V. D. LEYEN S. 37 ff. beanstandeten Str. 25: in der symbolischen Aus- legung des Zuges der Israeliten durch die Wiiste werden Zum Schluß das Manna und das aus dem Felsen geschlagene Wasser beigezogen als Bilder für die Eucharistie (25, 9-12); dabei fehlt zu dem himelprôt die Bezugnahme auf den Leib Christi, und das Blut, das dem Trank aus dem geistlichen Felsen entspricht, wird verwechselt mit dem Blint des Osterlammes, von dem Str. 23 und 24 die Rede war, indem die Zeilen 23, 9. 10 wiederholt werden. Es scheinen also zwischen 25,9 und 25, 12 zwei eclite Zeilen zu felılen, die durch die jetzigen 11 und 12 verdrängt sind. - Die historische Entwicklung ist durch Str. 21 gestört, weshalb MULLENHOFF in MSD. (und nach ihm V. D. LEYEN S. 20) vielleicht mit Recht Str. 21 vor Str. 19 setzt (sclion DIEMER, Wiener SB. 52, 455. 457, dagegen MetTin, Diss. S. 22 f. 27 f.; R. BuchHolz, ZfdPh. 33, $141 \mathrm{f}$.). Jedoch ist oft in Gedichten iiber die Heilsgeschichte die historische Folge durchbrochen, z. B. wie in unserm Fall ebenso in des Prudentius Hymnus Da puer plectrum Str. 24 ff., Höllenfahrt vor dem Kreuzestod.

4) VoGT, Beitr. 2, 261 f.; WAAG, Beitr. 11. 139-141; J. MEIER, ebda 16,68 ff.; STEINMEYER, MSD $\left[1^{3}, 188\right.$.

s) Vgl. O. Mendius, Beitr. 27, 206 Anm. 2. 
Nachdem er die Melodie ausgearbeitet hatte, waren sie alle angelegentlich darum bemüht, Mönche zu werden.1)

Bisch of Gunther von Bamberg $\left.{ }^{2}\right)(1057-1065)$ war einer der leitenden Reichsfürsten in den letzten Jahren der Regierung Kaiser Heinrichs III. und während der Kindheit Heinrichs IV. Eine glänzende Persönlichkeit, aus hohem Stande geboren, mit schöner Gestalt begabt und leutseligen Sinnes vereinigte er die Tugenden eines geistlichen und weltlichen Herrschers. Denn er war gelehrt in der Theologie und klug in der Politik, er beförderte die Wissenschait und hatte seine Freude am deutschen Heldensang. ${ }^{3}$ ) Er erkannte die Forderungen seiner Zeit. Diese waren auf die Kräftigung der kirchlichen Ideen gerichtet. Dazu war die innere Festigung der Hierarchie die Grundbedingung. Er war der erste, der in Deutschland das lax gewordene Leben der Domgeistlichen wieder regelte. Wie die Mönche in den Klöstern in der Regel des heil. Benedikt bestimmte Vorschriften hatten, so waren auch die Kleriker der Kirchen, zumal der Domstifte, die Kanoniker, zu gemeinschaftlichem Leben innerhalb ihres Stiftes verpflichtet und zwar nach der Regel des Bischofs Chrodegang von Metz (Regula Sancti, Chrodegangi, um 750-755). Aber die Regel war im 10. u. 11. Jh. in Verfall geraten, die Kanoniker, meist vornehme Herren, lebten sehr frei, manche hatten sogar eigenes Vermögen, wohnten außerhalb des gemeinsamen Stiftes und hielten sich nicht an die Vorschriften im Essen und Trinken. Mit der Wiedererstarkung des kirchlichen Machtbewußtseins trat ein Wandel ein. Der Geist Clugnys, die Askese, in welcher das Klosterleben zur höchsten Form des Christentums wurde, drängte auch zur mönchischen Regulierung der Weltgeistlichen, der Kanoniker. Hildebrand, der spätere Papst Gregor VII., der Sieger im Kampf zwischen Welt und Kirche, war es, der auch diese Glieder des geistlichen Staates durch die neue Zucht dem neuen Geiste dienstbar machte. ${ }^{4}$ )

Das Bistum Bamberg, eine Schöpfung Heinrichs II. (1007), wurde, durch seinen Stifter mit reichen Mitteln ausgestattet, bald eine Pflegestätte geistlicher Kultur und Wissenschaft. Aus der Bamberger Schule ging hervor Anno, der als Erzbischof von Köln jahrelang die Geschicke des Reiches leitete; hier war Williram Schulvorsteher. Auch mit deutscher Literatur beschäftigte man sich hier, es entstanden das umfangreiche Formular von Bamberger Glaube u. Beichtes) und das Gedicht Himmel u. Hölle (s. unten). Außer

\footnotetext{
1) Diese Eingangsstrophe ist der Titulus bezw. Prologus (vgl. Conradi Hirsaugiensis Dialogus ed. G. SCHEPSS S. 23 f.); er enthält den Veranlasser des Werkes (Bischof Gunther), den Verfasser (Ezzo), die Quelle (ait buoch) und den Grund bezw. die Folge der Abfassung (duo ilten...). Die erste Strophe des Gedichtes selbst (Nût wil ich iu hêrron) gibt den Inhalt an, enthält also ebenfalls einen Teil des Prologs.

2) Giesebrecht $3^{4}$, Reg. S. 1286 u. bes.
}

S. 60 f.; Diemer, D. Ged. S. XLVIII f., Wiener SB. 55, 295 ff.; WilmanNs S. 4-8; Kelle 2, 14 ff. u. Anm.

3) Semper ille Attilam, semper Amalungum et caetera id genus portenta (Wundertiere, Bestien) tractat, GIESEBRECHT aaO. S. 1241 Nr. 3; Müllenhoff, ZfdA. 12,311; WilmanNS S. 5 Anm. 1.

4) Otto Hannemann, Die Kanonikerregeln Chrodegangs v. Metz usw., Greifsw. Diss. 1914.

5) LG. 1, Reg. S. 457. 
dem Dom (1012) wurden mehrere Stifte gegründet, von Gunther das Kollegiatstift St. Gangolph im Jahr 1063 und zwar mit Einführung der strengen Klosterregel. So wurden die bisherigen Canonici saeculares zu Canonici regulares, die nach einer Regel lebten. ${ }^{1}$ ) - Bald darauf wirkte in der Ostmark in demselben Sinne der Bisch of Altmann von Passau, ein Freund Gunthers. Alle Chorherrenstifter wurden dort nach der strengen Zucht reformiert, neue bis über die Mitte des 12 . Jhs. hinaus gegründet. Im Jahr 1163 entstand das regulierte Chorherrenstift Vorau in Steiermark. So lassen sich die Beziehungen Bambergs zu den österreichischen Klöstern verfolgen an dem Einfluß der Bischöfe Gunther und Altmann. Zugleich entfaltete sich eine noch viel folgenreichere Strömung zur Hebung der Frömmigkeit in den Klöstern des Schwarzwalds. Der Abt Wilhelm von Hirsau (1069-1091) knüpfte unmittelbar an die Mönchsordnung von Clugny an, durch die Energie dieses bis zum Fanatismus für seine reformierenden Ideen durchdrungenen Mannes verbreitete sich von Hirsau aus die strenge Ordnung des Mönchswesens über Schwaben und zugleich mit den von St. Blasien (im oberen Schwarzwald) ausgehenden Reformbestrebungen nach Baiern, Österreich, ${ }^{2}$ ) Ostfranken, Thüringen und Norddeutschland. Zu St. Blasien aber stand das Kloster Ochsenhausen im Allgäu in Abhängigkeitsverhältnis, ${ }^{3}$ ) die beiden Klöster also, aus denen die Hss. des Ezzoliedes stammen, gehören der neuen Sittenrichtung an, die in Bamberg so bedeutsam zum Ausdruck kam. Durch unser Denkmal aber ist bewiesen, daß der in der Mitte des 11. Jhs. anhebende Umschwung der Literatur in der größten Bewegung der Zeit begründet ist, in dem neuen kirchlichen Geiste, der den Sieg des Gottesstaates über den Weltstaat entschied. Darin liegt ein Teil seiner großen literarischen Bedeutung.

2. Die Vita Altmanni Kap. 3 (Mon. germ. Script. XII, 230) berichtet4) zum Jahr 1065: In jener Zeit ... verließen, von Schrecken erfaßt über die drohende Ankunft des jüngsten Gerichts, viele Leute aus dem Volke, aber auch Fürsten und selbst Bischöfe, ihre Heimat, ihre Verwandten und ihre Besitztümér und folgten, das Kreuz tragend, Christus. Ihr Führer war der Bischof Gunther von Bamberg, ein Mann ausgezeichnet durch Schönheit des Körpers und Weisheit des Geistes, in dessen Gefolge viele berühmte Männer, sowohl Kleriker als Laien, aus Ostfranken und Baiern sich befanden. Unter diesen ragten besonders zwei ausgezeichnete Kanoniker hervor, nämlich der Scholasticus Ezzo, ein Mann begabt mit jeglicher Weisheit und der Kunst der Rede, der auf ebendemselben Zuge ein Lied von den Wundern Christi in heimischer Sprache trefflich verfaßte (cantile-

1) Du CANGe-Favre 5, 451c.

2) St. Paul in Steiermark von St. Blasien aus gegründet, s. LG. 1, 251. - KONR. HOFMANN, aaO.

3) KeLLLe 2, 7 .

4) MSD II 3 , 181 f.; KelLe 2, 247; GIESEBRECHT S. 110 f. u. 1099 f.; DIEMER, D. Ged.
S. XLVIII und Wiener SB. 55, 271 f.; KoNR. Hofmann aaO. - Altmann war Bischof von Passau 1065-1091, die Vita ist verfaßt im Kloster Göttweih, das Altuann 1073 gegriundet hatte; und zwar unter dem Abt Chadalloh $1125-1141$. 
nam de miraculis Christi patria lingua nobiliter composuit); und Konrad, geschmückt mit jeglicher Wissenschaft und Beredsamkeit, der nachher in unserm Kloster der Probst der Kanoniker war. Sie begleitete Altmann, der Vertraute der Königin (Agnes, Witwe Heinrichs III). - Die Pilgerfahrt von 1065 war die erste, die gleich einem Kriegszug von Deutschland ausging, und ein geschichtliches Ereignis. An zwölftausend Pilger sollen daran beteiligt gewesen sein, von geistlichen Fürsten nahmen außer Gunther und Altmann teil die Bischöfe von Regensburg und Utrecht und als vornehmster Siegfried von Mainz. Der Auszug erfolgte im September 1064, die Wiederkehr war kläglich, im Sommer 1065 kamen die Übriggebliebenen nach Deutschland zurück. Gunther von Bamberg war auf der Heimreise am 23. Juli 1065 in Ungarn gestorben.

Zufolge der Einleitungsstrophe der Vor. Hs. war Ezzo Priester und Domherr in Bamberg unter Bischof Gunther, nach der Vita Altmanni scholasticus, d. i. in weiterem Sinne Gelehrter, in engerem Lehrer an einer geistlichen Schule. Der Name Ezzo begegnet mehrfach in Bamberger Urkunden und Kalendarien, ein dominus Ezzo, canonicus S. Petri et S. Georgii et prepositus ecclesie S. Jacobi i.J. 1100, kann der Dichter sein.1) Wille ist wahrscheinlich der spätere Abt von Michelsberg bei Bamberg, der 1082-1085 diesem Kloster vorstand.

Der Bericht der Vor. Strophe ist ungenau, doch ist sicher, daß nach diesen Angaben das Lied in Bamberg abgefaßt worden sein muß, da von der Kreuzfahrt nichts erwähnt wird. In diese aber verlegt die Vita die Entstehung des Liedes. Der Irrtum liegt offenbar beim Verfasser der Vita. Er schrieb mindestens $60 \mathrm{Jahr}$ nach der Pilgerfahrt und dem Tode Gunthers, ${ }^{2}$ ) nach Mitteilungen älterer Mönche. Ein Hauptgewährsmann für diese Göttweiher Tradition war gewiß jener Cuonradus, der die Kreuzfahrt mitmachte und später als Probst nach Göttweih berufen wurde. Die Chronik zeigt neine starke Hinneigung zum Märchenhaften und Mangel an ernstlichem Geschichtsstudium “. $\left.{ }^{3}\right)$ Der Irrtum des Biographen war indessen nicht allzu groß, wenn er meinte, das von den Pilgern gesungene (aber schon früher von Ezzo gedichtete) Lied sei auch erst gerade auf diesem Zuge verfaßt worden.

Ein zweiter fraglicher Punkt in der Vita Altmanni betrifft die Inhaltsangabe, die lautet "de miraculis Christi". Miracula bedeutet zunächst in engerem Sinne die Wunder, die Jesus unter dem Volk Israel vollbracht hat (Str. 14. 15), dann aber auch die wunderbaren Ereignisse seiner Geburt, seines Todes, der Auferstehung und Himmelfahrt. Der Biograph Altmanns hat also bei der Angabe des Inhalts nur den zweiten Teil, die evangelische Geschichte (Str. 9-30), berücksichtigt, der auch für die Kreuzfahrt wesentlich in Betracht kam.4)

1) DIEMER, Wiener SB. 55, 315 f.; MSD. $\mathrm{II}^{3}, 183$

2) MSD. $I^{3}, 183$
3) WattenBACH, Reg. unter Vita Altmanni.

4) Mira cula (vgl. HoffMANN v. FallersLEBEN, Gesch. d. d. Kirchenliedes S. 27 f.; 
Ezzo hat also das Lied auf Veranlassung des Bischofs Gunther in Bamberg gedichtet, unter Beiziehung der Vita Altmanni erfahren wir, daß es auf der Kreuzfahrt von 1064/65 gesungen wurde. ${ }^{1}$ ) Und für ein Kreuzzugslied war ja der Inhalt wohl geeignet, besonders von Strophe 17 an, zumal in Str. 27-29.

Der Grund der Abfassung des Gedichtes ist in der Vor. Eingangsstrophe nicht angegeben, wohl aber die Wirkung: duo ilten si sich alle munechan. Es sind die phaphen Gunthers von Bamberg gemeint, also Stiftsherren, nicht Klosterbrüder, Kanoniker des Domstifts St. Stephan oder des von ihm gegründeten Stiftes St. Gangolph. Sie nahmen mönchisches Leben an, d. h. die strenge Ordnung gemeinsamen Lebens der regulierten Chorherren, sie wurden aus canonici saeculares zu canonici regulares. Zur Feier dieser Reformierung ließ der Bischof das Lied von Ezzo dichten, von Wille komponieren. ${ }^{2}$ ) Der Verfasser der Vor. Strophe zieht den Vorgang in

D1EMER, Wiener SB. 52, 430. 55, 278-230; MSD. II ${ }^{3}, 182$; .KELLE 2, 20. 249). Wunder sind Zeichen, sind eine Wahrheit, die der gewohnten Anschauung neu, der Vernunft aber nicht entgegengesetzt ist (Augustinus, De civ. Dei XXII, 7, auch XXI, 5-8; das Wunder ist ein bei Aug. sehr häufig vorkommendes Thema, s. Miraculum im Register bei Migne 46, 438 f.). Sie sind geschehen, um Zeugnis zu geben für jenes eine große Heilswunder, welchem zufolge Christus mit dem Fleische, in welchem er auferstand, gen Himmel gefahren ist (De civ. Dei XXII, 8). Ein streng durchgeführter Unterschied zwischen miracula und dogmata, Glaubenssätzen, besteht nicht. Welt- und Menschenschöpfung sind Dogmen (KELLE aaO.), aber die Dogmata der Auferstehung und der Himmelfahrt sind doch als wunderbare Ereignisse anerkannt (Passionis miracula im Breviarium), die Geburt des von Ewigkeit gewesenen, eingeborenen Gottessohnes war immer ein Wunder im Sinne von Miraculum (Ezzo 11, 1, MSD. 10, 11 f.; Otfr. I, 17, 1 ff. 11, 3, 5 ff.; Walthers Leich 5, $30 \mathrm{ff}$., sein Kreuzlied 15, 9, 12; auch der Kreuzestod ein wunter Otfr.V,1, 10, vgl. auch V, 8, 47. 54; Walther 15,25 f.). Miracula sind also dic großen Offenbarungstaten Gottes und Christi, z. B. Prudentius in seinem Hymnus Omni Hora 3, I [ = gesta Christi insignia Str. 1,2], MoNe, Hymnen 1, 77 Str. 1; Summa Theol. 3, 1. In engerem Sinne miracula sind die Wunder Jesu, die er bei seinem Wandel unter dem Volk Israel vollbrachte. - Um das Wunderbare auch in den als Glaubenssätze geltenden Ereignissen des Weltgeschehens zu bezeichnen, wird das Wort mirabilia gebraucht, das also cinen erhabeneren Sinn hat als miracula; Gott ist der (ad)mirabilis Deus, der wunderliche Got, ipse mirabilis solus mirabilia fecit (Christus), Hrabanus Maur., De laud. S. Crucis II, 8, Migne 107, $273 \mathrm{~A}$. Es sind die unergriandlich hohen Werke.
1) DiEMER, Wiener SB. 55, 271 ff., bes. 319 HoFFMANN v. FALLERSLEBEN aaO., WACKERNAGEL, LG. Bd. 1, 1. Aufl. S. 86, 2. Aufl. S. 110 u. Kelle (s. auch K. HofmaNN, aaO. S. 293 ff.) nehmen zwei verschiedene Gedichte an, das in der Vor. Str. 1 gemeinte und die Cantilena de miraculis Christi der Vita Altmanni (nach Diemer wäre die Cantilena unser Ezzolied, das von Gunther veranlaßte Gedicht der Vor. Str. I wäre identisch mit der Summa Theol.). - In der Litgesch. trägt dasGedicht verschiedene Namen:DIEMER, D. Ged. S. XLVIIf. LVII. 317 ff. 'die vier Evangelien', aber Wiener SB. 52, 193. 427. 430. 55, 271 'Ezzo's Lied von dem (rechten) Anegenge'; WACKERNAGEL aaO. 'von dem Anegenge', LB. ${ }^{5}$ S. 325 'Rede von dem Anegenge' (die Cantilena hält er für das eigentliche Ezzolied und nennt sic 'Ezzos Lied von den Wundern Christi' LG. 1 aaO.); W. GrIMM, ZGdR., Kl. Schr. 4, 163. 231. 312: 'das ältere (alte) Ancgenge'; MSD aaO.: 'Ezzos Gesang von den Wundern Christi', ebenso WilmanNs u. KELLE, Wiener SB. 129 (LG. 2, 8: Ezzos Leich von den Wundern Christi), s. Wiener SB. 129 S. 42 ; Braune und WAaG 'Ezzos Gesang'; VogT, Gesch. d. d. Lit. 1', 75 'Ezzos Lied von Christus und der Welterlösung'.

2) DIEMER, Wiener SB. 55, 301; und bes. Wilmanns S. $6 \mathrm{f}$. - Der Zeitpunkt innerhalb der Fcier läBt sich nicht genau ermittelı. Wenn das Lied für den speziellen Akt der Beziehung der gemeinsamen Wohnung bestimmt war (WILMANNS aaO.), so wirde es in den Ritus der Kirchenkonsecration, der Kirchweihe, fallen. Aber die Gedanken, dic in diesem zum Ausdruck kommen, sind ganz. verschieden von denen unseres Liedes, die Lektionen und Hymnen bei der Feier der Dedicatio Ecclesiae sind von ganz anderer Symbolik getragen (Thalhofer ${ }^{2} 2,488-499$, auch 1, 691-693); des Honorius Predigten De dedicatione ecclesiae (Migne 172, 1099 - 
den Bereich des Wunders: die Wirkung des Gedichtes war es, die erst die Stiftsherren bestimmte, die strenge Regel anzunehmen.

Heimat des Gedichtes und Zeit der Abfassung. Nachdem die historischen Anzeichen erweisen, daß der Bamberger Mönch Ezzo der Verfasser war und das Lied auf der Kreuzfahrt 1064/65 gesungen wurde, ergibt sich als seine Heimat Bamberg und als Abfassungszeit etwa das Jahr 1060.

In halt. [Str. I, Vor. Hs., historischer Vorbericht]. Str. 1 Ei nl eitung, Inhaltsangabe: das Gedicht handelt von dem Anfang der Dinge und von der ganzen Menschheitsgeschichte. Teil I, Str. 2-8 Das alte Testament. a) Str. 2-4 Die Gottheit: Str. 2 der präexistente Christus das Licht, das Wort. Str. 3. 4 Gott der Ursprung der Dinge, daz anegenge, der Schöpfer. b) Str. 5-8 Die Menschheit: Str. 5 der Sündenfall. Str. 6-8 die Menschheit in der Finsternis; die Sterne, der Morgenstern. - Teil 11, Str. 9-29 Das neue Testament. a) Str. 9-21 die Geschichte Christi des Erlösers. b) Str. 22-26 Symbolik zum Erlösungswerk. c) Str. 27-29 das Kreuz. - Teil III, Str. 30 Schluß, Preis der Trinität.

Das Lied umfaßt das Weltgeschehen vom Anfang bis zum Abschluß. Weltgeschichte in christlichem Sinn ist Erlösungsgeschichte. ${ }^{1}$ ) Es ist das Erlösungswerk Christi: von Anbeginn ist der Gottessohn der Menschheit zur Gnade bestimmt (Str. 2. 8) und am Ende der Zeiten wird er uns als himmlischer König zu sich in sein Reich führen (Str. 28, 9 f.). Als Grundmotiv wiederholen sich die Gegensätze von Finsternis und Licht, Verbannung und Heimkehr, Kampf und Sieg. Über allem aber schwebt die Lichtgestalt des Erlösers mit dem Siegeszeichen des Kreuzes.

Christus ist als historische Persönlichkeit dargestellt. In den verschiedenen Entwicklungsstadien tritt dieser geschichtliche Christus in speziellen Erscheinungsformen auf: vor der Menschwerdung als das Licht, das Wort, der präexistente Gott, während des Lebens als der Heiland der Evangelien, nach seiner Erhöhung durch den Tod als Herr des Himmels, der Erde und der Hölle. Für die Menschen ist er einmal der Sündentilger (13) und einmal der Mittler (Versöhner) mit Gott (11). Die Menschwerdung ist ein vorbestimmter Akt der Gnade (2), die Gegensätze zwischen Sünde und Gnade, Dienst und Lohn sind nicht ausgesprochen. Der wesenbestimmende Zug dieses Christusbildes aber ist der Erlöser als Besieger des Teufels, und das ist die herrschende Vorstellung in der frühmhd. Literatur, überhaupt in der romanischen Stilperiode, wie sie denn auch in der kirchlichen Plastik der Zeit ein sehr beliebtes Motiv bildet und mit vielen der symbolischen Tiergestalten des Physiologus (s. unten) verbunden ist. Die Überwindung des Teufels geschieht durch das Kreuz und zwar in der hauptsächlich durch Gregor den Großen vertretenen, dër Würde des Gedankens nicht

11C8). Indessen paßt Ezzos Thema, die Heilsgeschichte, für jede kirchliche Gelegenheit, wie denn auch des Prudentius Hymnus $\mathrm{Da}$ puer plectrum omni hora, d. h. für den Vortrag zu jeder Hore, verfaßt ist.

1) "Und da nun die Erlösung des sündigen Menschen nach christlicher Anschauung den einzigen Sinn und Wertinhalt der Welt- geschichte und damit der gesamten außergöttlichen Wirklichkeit ausmacht, so erscheint die planvolle Reihenfolge der Offenbarungstaten Gottes als das Wesentliche in dem ganzen Ablauf der Weltbegebenheiten", WINDELBAND, Lehrbuch der Gesch. der Philosophie, 4. Aufl. S. 216. 
gerecht werdenden Erklärung als ein frommer Betrug, pia fraus, nach welcher Christus der Köder am Angelhaken ist, an dem der Teufel (der gir Leviathan 17. 27) durch List gefangen wurde. ${ }^{1}$ ) In symbolischer Auslegung des Passahlammes ist Christus das Osterlamm (23. 24. 25), das für uns geopfert wurde, ohne daß jedoch diese mystische Beziehung erweitert wurde zu der Theorie des Opfer- und Sühnetodes. Insofern in dem Zuge der Israeliten aus Ägypten nach Palästina die Heimkehr der Gläubigen in das Himmelreich vorgebildet war, ist Christus der Herzog, der Held, der sein Heer im Kampf gegen den Feind, den Teufel, in die Heimat zurückführt (26). Diese Auffassung von Christus als Helden und Heerführer ist germanischem Geist verwandt und wird auch durch die Bezeichnung herzoge wie auch durch die der Gläubigen als Dienstmannen des Himmelskönigs. (28) in volkstümlicher Weise ausgedrückt. Ebenfalls ein Anklingen an germanisches Wesen liegt in dem Begriff triuwe, die Christus als Eigenschaft beigelegt wird und die er lehrt (2.16), die aufopferungsvolle und wahrhaftige Hingabe an die durchs Leben Verbundenen, an den Nebenmenschen, an die Pflicht.

Die Quelle für Ezzo war das theologische Wissen seiner Zeit, das er völlig beherrscht, denn er war Scholasticus an einer der berühmtesten Domschulen und wird gepriesen als ein Mann ausgerüstet mit aller Kunst der Rede und allem Wissen. Der Boden, auf dem seine Dichtung erwuchs, war längst völlig vorbereitet. Es ist die kirchliche Tradition seit Augustin in der besonderen Beschränkung durch Gregor den Großen. ${ }^{2}$ ) Kein einziger Gedanke ist neu bei ihm, er hat sie alle vorgefunden. ${ }^{3}$ ) Den Stand der in Deutschland von der Mitte des 11. bis zur Mitte des 12. Jhs. herrschenden Theologie vertritt vor allen andern kirchlichen Schriftstellern Honorius Augustodunensis. Mit ihm hat denn auch Ezzos Gedicht viele Übereinstimmungen. Wie dieser wendet auch der Bamberger Scholasticus in ausgedehntem Maße die Methode der allegorischen Schrifterklärung an. Eine reich entfaltete Symbolik umrankt das Wunder des Erlösungswerkes. Der Dichter will reden von dem zvîstuom alsô manechvalt, der an den buochen stêt gezalt $\left(1,5\right.$ f.), $\left.{ }^{4}\right)$ d. i. die Weisheit

1) HARNACK, Dogm. $2^{2}, 174 \mathrm{f}$.

2) WILMANNS (S.8. 29) hielt die Evangelientexte von Welhnachten bis Ostern für die Quelle, im Anschluß an den kirchl. Gottesdienst dieses Quartals wäre also das Gedicht entstanden. Diese Ansicht ist aber wohl allseitig aufgegeben. Uebereinstimmungen zwischen dem Gedicht und der Perikopenfolge müssen sich notwendig aus der Gleichheit des Stoffes ergeben. Andrerscits sind die Abweichungen $z$ wisclien dem Lied lind den Predigttexten zalılreich, da jenes zum Teil weniger, zum Teil melır enthält als die betr. Evangelienstellen. - Nach Kelle ist Ezzos Gesang einAuszug aus HrabansKreuzeswerk (Wiener SB. aaO.; LG. 2, 8-11. 241), mit Ausnahme von 5 für unechıt erklärteu
Strophen. Aber auch hier ist die Uebereinstimmung durch die Gleichheit des Stoffes begrändet. Die Folge der Gedanken beweist, daß Ezzo nicht das Kreuzeslob des Hrabanus zur Grundlage hatte, denn er müßte sich die unsägliche Mühle genommen haben, dieStellen, die in der unübersichtlichen Masse von Hrabanus' Gedicht zerstreut sind, einzeln herauszulesen, um sie erst zu cinem planvoll zusammenhängenden Ganzen zu verarbeiten, da llrabanus sein Werk niclit historisch anordnete, sondern in freier Allegorie in 28 Kapiteln nach 28 liguren des Kreuzes. Vgl. V. D. LEYEN S. $12 \mathrm{ff}$.

9) $\mathrm{MSD} .11^{3}, 187 \mathrm{f}$.

4) In der Quellenangabe vizer genesi unde tizer libro regum 1,7 vertritt Genesis den 
des alten Testaments, die die Anfänge der Welt und der Menschheit umfaßt und zugleich die Heilstaten Christi vordeutet (Str. 6-9. 13, 1. 21, 1-6. Str. 22-26. 17, 9-14 u. 27, 3. 4). Zweimal wird ausdrücklich auf die geistige Auslegung hingewiesen: der Inhalt des alten Bundes ist nur ein Schatten der zukünftigen Dinge, die Wahrheit war zurückgehalten 24, 1-4, und das in geistigem Sinn zu fassende Israel, die Christenheit, Spiritalis Israel 26, 1. Auch Stellen des neuen Testamentes werden symbolisch ausgelegt $(12,11 \mathrm{f}$. 19, 7. 20,3). Endlich sind aber im christlichen Geistesgebiet zahlreiche Bilder entstanden, die nicht an biblische Überlieferung anknüpften; dahin gehören 11, 1 f. 21, 1 ff. Die meisten dieser Allegorien begegnen auch bei Honorius, $\left.{ }^{1}\right)$ besonders in seiner Predigtsammlung, dem Speculum ecclesiae: Einige der Predigten, wie De Passione Domini (Migne 172, 907 ff.), De paschali die (927 ff.), De inventione sanctae Crucis (zum Fest der Kreuzauffindung, 941 ff.), stehen auch im Stoff dem Lied nahe, denn ihr Gegenstand ist die Heilsgeschichte von der Schöpfung an und im Hauptteil ein Preis des Kreuzes in typologischer Sprache.

Auch die literarische Gestaltung des Erlösungswerkes, also die Komposition des Themas, war längst festgesetzt ${ }^{2}$ ) und Ezzo konnte auch hier an bekannte Vorbilder sich anlehnen. Am nächsten kommen dem Liede Hymnen und Sequenzen, die ebenfalls in gedrängter Kürze den Stoff in den Hauptpunkten zusammenfassen. An der Spitze steht der prachtvolle Hymnus des Prudentius (geb. 348) "Reich das Plektrum mir, o Knabe" (Da puer plectrum choreis ut canam fidelibus dulce carmen, Cathem. IX, Migne 59, $862-875 . .^{3}$ ) In diesen Grundgedanken bewegt sich ebenso das berühmte Carmen paschale des Sedulius (um 450). Der Zeit Ezzos besonders nahe stehen der Modus qui et Carelmanninc, ${ }^{4}$ ) der mit unserm Lied auch in Einzelheiten übereinstimmt, indem auch hier an den Anfang der Erlösungsgeschichte Christus als das Wort und als das die Finsternis ïberwindende Licht gepriesen wird (MSD Nr. 19, 8 f.) und auf Christus die vordeutenden Worte Jesaias 63, 1 tinctis vestibus de Bosra (V. 62) angewendet sind; und die in der Cambridger Hs. gleich darauf folgende Sequenz Grates usiae (ZfdA. 14, $476-479) .5$ )

Pentateuch, liber regum den zweiten Teil der Geschichtsbücher des alten Testaments. Den Kanon der biblischen Bücher hat Augustinus festgestellt in De doctrina christ. II, 8, wobei Genesis den ersten Teil der historischen Bücher des alten Testaments einleitet und die 4 Bücher der Könige an der Spitze des zweiten stehen.

1) Siehe die Anm. Diemers, Wiener SB. $52,427 \mathrm{ff}$., u. MÜLLENHOFFS in MSD. II ${ }^{3}, 169 \mathrm{ff}$.

2) Die Lehre von der durch das a. und $n$. Testament sich entwickelnden Erlösungsgeschichte hat für den populären Unterricht Augustinus festgelegt in De catechizandis rudibus Kap. $17-27$, ausführlich im 2 . Teil seines Gottesstaates.

3) Uebersetzt von Alex. BAUMgartner, Die lat. u. griech. Lit. der christl. Völker 3. u. 4. Aufl. S. $159-162$.

4) Siehe LG. 1, $354 \mathrm{f}$.

5) Die Entwicklung der Heilsgeschichte ist in der frühmhd. Literatur auch sonst noch behandelt: in der Summa Theologiae, in Hartmanns Rede vom Glauben, dem jüngern Anegenge. Aus der ags. Literatur ist besonders anzuführen die Einleitungspredigt Wulfstâns, da sie viele Parallelen zu dem hier besprochenen Thema enthält (ARTH. NAPIER, Wulfstan S. 6-20). 
Das Erlösungswerk Christi findet seine sieghafte Entscheidung durch den Tod am Kreuz, das Kreuz ist das Symbol des Heils. Darum wird in Liedern, die den Preis des Kreuzes singen, ${ }^{1}$ ) auch die Heilsgeschichte mit einverwoben, wie in des Venantius Fortunatus ( $\dagger$ um 600) Passionshymnus Pange lingua, wie in dem Planctus Bonaventurae de Christo2) oder in dem troparium "Nunc crucis alma cantet gaudia" ${ }^{3}$ ) oder in dem Nocturnenhymus de Pascha "Rex aeterne Domine“.4) Walther von der Vogelweide erzählt in seinem ersten Kreuzlied die Geschichte Jesu von der Geburt bis zum jüngsten Gericht, bei ihm wie bei Ezzo ist das heilige Land unser Erbe (Lachm. 16,30) und, spiritualistisch, der Anfang und Abschluß unseres Seins 16, 26-28 wie bei Ezzo 30,13 f.; im zweiten Kreuzlied Walthers wird Gott im Eingang als daz anbeginne (anegenge) angerufen (Lachm. 76, 24).5) Hrabanus Maurus aber hat in seinem eben erwähnten pedantisch gekünstelten und mühsam zusammengearbeiteten Werk De laudibus S. Crucis überhaupt die Summe des gesamten theologischen Wissens angehäuft unter der Symbolik der Kreuzesform. ${ }^{6}$ ) Ein deutscher Kreuzeshymnus also ist Ezzos Gedicht. Auch die Umrahmung im Eingang und Schluß hat ihre Entsprechung in der Hymnendichtung: Preis des Lichts ist das herrschende Motiv in den Morgenhymnen ${ }^{7}$ ) (hymni matutini, Laudeshymnen), ganz zu dieser Tageszeit passend, da das Licht die Finsternis durchbricht. Ein üblicher Hymnenschluß aber ist der Preis der Trinität, ${ }^{8}$ ) so auch in der letzten. Strophe, mit der der Gesang in die Klänge eines Lobgebetes ausströmt.

Stil des Inhalts. Der größte Teil des Inhalts entfaltet sich episch. Dazwischen fügen sich symbolisch-erklärende Stellen ein, manchmal erheben sich die Gedanken in dramatischer Lebendigkeit, in Anrufungen und Preisgebeten (2, 1-4. Str. 27, 1 f. u. 29, 1 f. Str. 28). Die Erzählung schreitet in einfacher Ausdrucksweise ungehemnıt vorwärts, bei den stärker interessierenden Teilen wird länger verweilt. Die Ereignisse werden jedoch nicht lediglich objektiv berichtet, sondern Dichter, Publikum und Menschheit werden mit einbezogen, sie handeln mit oder werden mit betroffen, denn sie sind ja Glieder der Erlösungsgeschichte. Es kommt also außer der dritten Person auch häufig die erste des Plural zur Anwendung (wir, uns, unser), wie im belehrenden und betrachtenden Stil der geistlichen Literatur, besonders in der Predigt. ${ }^{9}$ )

Der sprachliche Ausdruck ist feierlich, ohne starke Erregung, doch poetisch gehoben, wie es dem Inhalt geziemt; denn bei höheren Gegen-

1) Ueber Kreuzesdichtung im MA. s. OTto ZöcKLER, Das Kreuz Christi S. 221-244 11. $456-475$.

2) Mone, Hymnen 1 S. 150 ,

3) Ebda S. 147.

4) Dreves, Analecta Hymnica II S. 47.

s) Ezzo und Walther: WILMANNS, Leben Walthers, 1. Aufl. S. 138. - Ezzos Licd ist das erste Kreuzgedicht.

b) Sein umfangreiches Gedicht Acterne

Deulsche Literaturgeschichte. II. rerum conditor (600 Verse, Migne 112, 16091621) ist ebenfalls cine christliclic Weltgeschichte, von der Schöpfung der Engel bis zum jungsten Gicricht, aber nicht mit der ausgesprochenen Richtung auf das Kreuz.

7) THALHOFER 22 2, 592.

8) Ebda S. 553.

9) ZfdWortforsch. 2, 125 ff.; der "geistliche Universalplural* gehört zur Kirchensprache und bedentet die Menschen (alle). 
ständen, wo es sich um Gott und das Heil der Menschen handelt, soll Pracht und Glanz entfaltet werden. Und wo sollten die stilistischen und musikalischen Ausdrucksmittel weihevoller und wirksamer verwendet werden können als in dem Weltgeschichtsdrama, das von so starkem Stimmungswechsel bewegt ist, vom tiefsten Jammer der der Hölle verfallenen Menschheit an bis zum jauchzenden Glück der Erlösten, von der hoffnungsreichen Freude über die Geburt des Heilands bis zum schmerzvollen Mitleid mit seiner Todespein?

Der Dichter steht auf dem Boden der geistlichen Beredsamkeit, der Predigt. 1) Dieser Zusammenhang zeigt sich vor allem im Stil der Sprache. Er ist traditionell, die gleichen Gedanken und Bilder kehren ständig wieder, wir kennen sie aus den lat. Predigten und Abhandlungen, besonders. aus Honorius Augustodunensis, sie sind großenteils gewiß schon in der deutschen geistlichen Literatur vor Ezzo geläufig gewesen. ${ }^{2}$ ) Die weitgehendste Übereinstimmung zwischen dem Ezzolied und den geistesverwandten deutschen Denkmälern der Zeit zeigt die Sammlung von Wendungen in den Anmerkungen von $\mathrm{MSD} \mathrm{II}^{3}, 169 \mathrm{ff}$. und besonders S. $183 \mathrm{f.}^{3}$ )

Die Sprachmittel sind einfach. Die großen Gedanken sind in knappe Worte gefaßt. Der Dichter scheut, obgleich sein Wortschat $z$ nicht gering ist, doch Wiederholungen nicht:

anegenge 3 ,2. 3. 11 ; gescuofe $3,9.4,1.3$; lieht $7,2.3$; lêrt 7,5. 9. 16, 3. 7; irscein 8 , 1. 9, 4. 10; sunne 9, 6. 7; muoter 10,7.9; sanch-sungen 11, 5. 8; wuohs 13, 2. 5; machôt er 14, 4. 8; gab er den lîb 14, 5. 20, 8; triwe 16, 4. 5; erda 18,3.4; stuonten âz, irstuonten 18, 8. 10. 12. 20,6; magenchraft 19, 2. 20,11. 21,7; nam 19, 4. 11; grabe 20, 4. 6; lamp: gedanc 22,3 f. 23,5 f.; slahen 23,2 . 3. 5. 10; lamb $23,5.7$; daz ôsterlamp 24. 5. 25, 3; alterbelant, lant $25,6.7 .26,6.12$; este $27,5.7$; loben 30,2 . 3. Besonders liebt er gleiche Versanfänge und Versschlüsse (MSD $11^{3}, 177$ ).

Einen Anklang an die alte epische Sprache geben die Alliterationen,4) wie ligentes unte lebentes 3,8 ; in worten unt in werchen $3,12.16,8$, ferner 4, 12. 6, 5. 6,5 f. 6,8 . 6, 10. 8, 5. 8, 7. (8, 8). 8, 10. 9, 1 f. 10, 4. 10, 7. 10, 9 . 11, 4. 11, 5. 12, 12. 14, 4. 15, 5. 17, 1. 17, 9. 21, 7. 21, 8. 21, 10. 24, 9 f. 25, 9 f. 26, 8. 27, 9. 28, 6. 29, 11. - Eigentliche Formeln, wie Berufungen auf die Quelle, Anrede an die Zuhörer, werden in dem Liede nicht verwendet, denn es dient nicht wie die Predigt zu unmittelbarer Ansprache an das Publikum. Flickverse sind selten $(10,8.12,10)$, als Flickreimwort ist nur gote lop 17, 10. 29, 12 anzusprechen. Die Würde der Sprache wird erhöht durch die lat. Verse und Worte, die im Innern oder auch am Anfang. der Strophen in den deutschen Text eingestreut sind wie oft in der deutschen Dichtung dieser Zeit. Zitate aus der Bibel, aus kirchlichen Autoren oder aus.

1) MÜLlENHOFF, MSD. Il ${ }^{3}, 187$ f.; SCHERER, QF. 12, 26; SCHRÖDER, Anegenge S. 69; v. D. LEYEN, Kl. Beitr. S. 12; dagegen Kelle, LG. 2,21 .

2) Gewiß sind einige dieser traditionellen Wendungen von Ezzo als erstem aus dem Lateinischen ins Deutsche umgeprägt worden.
3) Siehe auch Diemer, D. Ged. Anm. S. 77 -82; SCHERER, QF. 1 u. 7 an verschiedenen Stellen; ROEDIGER, Anz. 1, 65 ff.; SCHRÖDER, Anegenge S. $72 \mathrm{f}$.; JoHN MEIER, Beitr. 16, 73 f.; MetTIN, Diss. S. 3 f.; KraUS, D. Ged. Reg. S. 275; v. D. LEYEN, Kl. Beitr. S. 28 ff.

4) B. Q. Morgan, Beitr. 38, 347. 
dem Gottesdienst: 2, 1. 5. 8, 11. 9, 9. 11,6. 12, 7. 19, 7. 21, 2. 26, 1. 4. 27, 1 . $29,1.30,4.1)$

Vers- und Strophengliederung. Meist sind die zwei Verse eines Reimpaares zu einer inhaltlichen Einheit zusammengefaßt, indem der Sinn der Periode mit dem zweiten Verse schließt. Die Strophe gliedert sich dann in einzelne Reimpaare, z. B. Str. 7. Die Sätze also sind dann parataktisch nebeneinander gestellt, ${ }^{2}$ ) nahezu ganze Strophen bestehen aus Parallelsätzen, die oft mit einförmig sich wiederholendem $d \hat{o}$ aneinander gereiht sind, was der syntaktischen Architektonik eine monumentale Kraft verleiht. Dieser Satzbau paßt zu dem Kunststil der Zeit, ${ }^{3}$ ) er hat die starre Gedrungenheit einer romanischen Krypta. Von den 30 echten Strophen des Liedes enthalten die meisten, nämlich 21, 12 Zeilen, und zwar Str. 3-9. 11 (nach der Hs. V). 14. 18-29; 8 Zeilen haben die beiden ersten Str. 1 u. 2; 10 Zeilen: Str. 10 (nach V); 14 Zeilen: 12 u. 13 (nach V) 15. 17. 30; 16 Zeilen: Str. 16.4) Jede Strophe ist eine in sich einheitliche und gegen die folgende Strophe mehr oder weniger deutlich abgehobene Gedankenreihe. Die Abschlüsse der Strophen sind nicht durch Verlängerung des letzten Verses markiert, immerhin sind doch manche Schlußverse etwas mehr gedehnt.5) In vielen Strophen steht gleich in den ersten Zeilen das inhaltgebende Wort: Str. 3: got; 4: Got; 5: der man; 6: Adam beviel; 7: sterne; 8: Baptista Johannes; 10: ein chint; 11: demo chinde; 12: Daz chint; 13: Antiquus dierum; 22: Ditze sageten uns $\hat{e} ; 24:$ Daz was allez geistlîch; 26: Spiritalis Israel; 27:O crux benedicta; 28: Trehtîn; 29: O crux salvatoris; 30: Unser urlôse ist getân. Besonders die lat. Eingänge bilden einen starken Sinneseinsatz.

Der Rhythmus ist ziemlich ebenmäßig6) (normaler Typus), Überfüllungen oder Kürzungen der Senkungen wiegen nicht schwer. Von den 182 Reimen sind (die Reime $\_\dot{x}$ als klingend gerechnet) 76 rein, 106 unrein (Assonanzen). Volle Flexionsvokale in den echten Strophen werden durch die Reime bezeugt in ca. 25 Fällen. ${ }^{7}$ ) Schwache Endsilben sind oft Träger des Reims; oft ist ein einsilbiges Wort mit der Flexionssilbe eines

1) Grönewald S. 7 ; Emil Henricı, Sprachmischung in älterer Dichtung Deutschlands, 1913, S. 38 f., wo noch andere frühmhd. Gedichte ausgezogen sind.

2) BEHAGHel, Beitr. 30, $431 \mathrm{ff}$.

3) Er ist aber nicht etwa erst aus diesem allgemeinen Stilprinzip der Zeit hervorgegangen, vielmehr entspricht er dem germanischen strengen Zeilenstil; $z u$ diesem vgl. Heusler, ZfdA. 57, 5 ff. und Hoops Reallexikon 1, 457 ff.; NeCkEL, Beiträge zur Eddaforschung an verschicdenen Stellen u. Germ.roman. Monatsschrift 5 (1913), $523 \mathrm{f}$.

4) Schade, Geistl. Ged. S. XXIII ff. I. DecaS S. $30 \mathrm{ff}$. gewinnt 686 zeil. Strophen; SiMROCK, Ahd. Leseb. (1851), SchaDE, Ad. Lesebuch (1862), Diemer, Wiener SB. 55, 320-323 u. K.
HofmANn, Münch.SB.1871,1,303 u.3r, 8 , stellen regelmäßige 12zeil. Strophen her; zu Giskes u. bes. MÜLLENHOFFS Einteilung s. STEINMEYER, MSD. 1[ ${ }^{3}, 185$ f.; R. BuchHolz, ZfdPh. 33, $141 \mathrm{f}$. - Die Stroplien des Liedes haben also ungleiche Zeilenzahl, wie d.meisten strophisch gebauten Gedichte der Zeit, vgl. LG. 1, 227 Ann. 3.

b) Vgl. VoGT, Beitr. 2, 257-261. -- Die cinzelnen Zeilen bilden dann nach der Terminologie der liturgischen Musik "melodisclıe Satzteile", das Reimpaar ist eine "melodische Periode“. Zur Verlängerung der letzten Verszeile inı liturgischen Gesang s. oben S. 14.

6) SARAN S. 252. 253.254.

7) VoGT, Bcitr. 2, 261 . 
mehrsilbigen gebunden, so daß Hauptton auf Nebenton reimt, z. B. hêrron: tuon 1,1 f.; bechom: gnâdon 2,7 f.; [be]chom: wâron 6, 9 f.

Vortragsweise. Ezzos Gesang ist das einzige mhd. Lied, dessen Komponist genannt wird, meist war sonst der Dichter zugleich auch der Schöpfer der Melodie. Wille konnte dieser keinen andern musikalischen Charakter verleihen als den in der Zeit herrschenden, das ist die gregorianische Ton$\operatorname{art}^{1}$ ) (s. oben S. 11 ff.). Diu wî̀se muß hier recht kunstvoll gewesen sein, da ihr Verfasser ausdrücklich mit Namen genannt wird. Der Rhythmus der Melodie wird, da der Versbau ziemlich regelmäßig ist, in annähernd gleichförmigen Takten sich gehalten haben, der Gesang trug also mehr die Art eines Hymnus als eines liturgischen Rezitativs. Er war wohl bestimmt, vom Chor gesungen $\mathrm{zu}$ werden (Choralgesang), nicht von einem Einzelnen. Im Prolog der Eingangsstrophe nennt sich nur ein Vortragender: $N \hat{u}$ wil ih iu hêrron eine wâre rede vor tuon, diese Strophe wurde wohl auch nur.von einem gesungen oder etwa im Epistelton rezitiert. Der Vortragende wendet sich hier an sein Publikum, es sind "Herren", das sind die geistlichen Herren des Bamberger Kapitels, für welches das Lied durch den Bischof Gunther bestimmt war. ${ }^{2}$ ) Die Vor. Hs. hat eine allgemeine Hörerschaft, auch Laien, ${ }^{3}$ ) im Auge, denn die Anrede iu hêrron ist in ize eben allen geändert, auch sind die nachträglich eingeschobenen Strophen III und IV populärer.gehalten. ${ }^{4}$ ) Das Lied wurde in dieser Fassung (Vor. Hs.) jedenfalls nicht mehr in der ursprünglichen, kunstreichen Melodie Willes gesungen, denn in der Vor. Hs. ist der Rhythmus etwas unregelmäßiger geworden durch die Einschiebung von Wörtern. Überhaupt ist die ursprüngliche Komposition Willes gewiß nicht so weit verbreitet gewesen wie der bloße Text Ezzos; meist waren wohl die Notenzeichen in den Handschriften weggelassen, wie ja die uns erhaltenen Abschriften $\mathrm{S}$ und $\mathrm{V}$ auch keine Neumen enthalten.

Ezzos Werk ist von der größten Bedeutung in der Entwicklung der deutschen Literaturgeschichte. Aus dem ganzen Zeitraum seit der ersten Hälfte des 10. Jhs. bis auf seine Entstehung, uber nahezu anderthalb Jahrhunderte hin, ist uns kein Gedicht in deutscher Sprache erhalten. Mit ihm beginnt für uns zeitlich die frühmhd. Dichtung, aber nicht nur dieses, sondern sie ist mit ihm auch wirklich begründet worden. Hier ist ein neues Thema in erhabener und vorbildlicher Sprache und in einer neuen Gedankenform zur Geltung gebracht worden. Zum erstenmal wird hier die ganze

1) Gottesdienstlicher Gesang in deutscher Sprache und der gregorianische Stil: THALHOFER $1^{2}, 286$.

2) V. D. LEYEN aaO. S. 39.

3) Es werden unterschieden Predigten für Geistliche u. Predigten für Laien, Ad clericos und ad populum, LECOY DE LA MARCHE S.206f.

4) Ueber die geringere Gewandtheit im Stil s. oben S. 40. Der ursprüngliche Dichter (S) deutet nur in großen Zügen die Hauptereig- nisse der Menschheitsgeschichte an, das ubrige einem geistlichen Publikum als bekannt voraussetzend, der Bearbeiter (V) dagegen verweilt bei den Einzelheiten der Schöpfungsgeschichte, wie ein Volksprediger, der der Laiengemeinde die biblische Geschichte erzählt. Auch die Mahnung zur Heilighaltung des Sonntags ist auf das Volk berechnet. 
geistige Menschheitsgeschichte, die gesamte Heilslehre, vom anegenge bis zur urlôse, in den bedeutungsvollsten Hauptzügen in Versen der Volkssprache verkündet; und hier ist zuerst diese Erlösungstat als ein Sieg des Lichtes über die Finsternis, des Gottessohnes über den Teufel dargestellt. Wie große Bedeutung dem Gedichte schon von seinen Zeitgenossen beigelegt wurde, ersehen wir aus der Einleitungsstrophe der Vor. Hs. und aus dem Bericht der Vita Altmanni, seinen starken Einfluß auf die folgenden Jahrzehnte zeigen die vielen Anklänge, die in Gedichten bis tief hinein in das 12. Jh., bes. bei der Ava, in der Vor. Genesis, der Summa Theologiae, der Wahrheit, $z \mathfrak{u}$ finden sind. ${ }^{1}$ ) So steht am Eingang dieser neuen Literaturperiode eine ihrer hervorragendsten Schöpfungen. Nirgends ist die geistige Idee des Erlösungswerkes so tief erfaßt und in so erhabenen Worten ausgesprochen.

\section{$\$ 7$. Summa Theologiae.}

Kelle 2, 135-141. 336-342; PIPeR, GD. 1, 65-75. - Ausg.: DiemER, D. Ged. S. 91-103 („Die Schöpfung“), Anm. S. 32-43 u. Einl. S. XLI und LII-LVI (Übersetzung), Faksimile der ersten Strophe (vor dem Titelblatt); dazu Kollation von PIPER, ZfdPh. 20, 481; MSD Nr. 34 u. $11^{3}, 202-223$; WAAG, Kl. d. Ged.2 S. 16-27 u. Einl. S. XIX -XXIV. - Diemer, KI. Beitr. XXIV, Wiener SB. 55 (1867), 285-295; SCHADE, Decas S. 36-39; KonR. HofMANN, Münchener SB. 1870, II, 183-196, 1871, I, 318-328; SCHERER, QF. 7, 54-56. 12, 33 f.; John Meier, Beitr. 16, 94; Kraus, ZföG. 45 (1894), 134 f.; Wunderlich, ZfdPh. 26, 113; v. D. LEYEN, Kl. Beitr. S. $40-56$.

Hss.: A. Vor. Hs. Bl. 97a-98c, von einer Hand des 13./14. Jhs. ist die Überschrift De sancta trinitate mit sehr kleinen Buchstaben unmittelbar über dem Anfang nachgetragen (DIEMER, Wiener SB. aaO. S. 291), die sich aber nur auf den Inhalt der beiden ersten Strophen bezieht. Der Text hat ziemlich viele zweifelhafte Stellen durch Verschreibung von Wörtern und Auslassung von Wörtern oder ganzen Zeilen (Zeilen fehlen sicher in Str. 12b und 23 und sehr wahrscheinlich in Str. 11). ${ }^{2}$ )

B. Die Hs. des Germ. Museums in Nürnberg 1966, perg. kl. fol., 12. Jl., enthält auf der sonst unbeschriebenen Rückseite des letzten Blattes, 122b, die Str. 27 unseres Gedichtes (MSD. II ${ }^{3}, 135$ f.). Die Strophe ist zuerst herausgegeben von MASSMANN in v. D. HAGENS Germania 10 (1853), 185, dann im Anz.f. Kunde d. d. Vorz., NF. 2 (1855), 80, und von BARTSCH, Germ. 7, $267 \mathrm{f}$. Der Text ist fehlerhafter als der in der Vor. Hs. - In der Suetonhandsehrift Cod. Gudianus 268, 11. Jh., der Wolfenbüttler Bibl. stehen auf Bl. 172 u. 173 am oberen und am rechten Seitenrand die 6 ersten Zeilen des Gedichtes, ebenfalts von einer Hand des 12. Jhs. (?), MAX IHM, Beitr. 26, 312. Das erste Wort, vor der ersten Zeile, ist probatio, der Eingang war also eine Schriftprobe.

Der ursprüngllche Diale kt ist theinfrk., ${ }^{3}$ ) ist aber stark mit baierischen Formen des Schreibers der Vor. Hs. (bezw. seiner österreich. Vorlage) gemischt. ${ }^{4}$ ) Die Heimat des Gedichtes ist also, zufolge der Sprache in der

1) Viele dieser Gleichungen sind gewi $\beta$ nicht unmittelbar dem Ezzoliede entnommen, sondern Gemeingut der geistlichen Sprache gewesen, bei nicht wenigen läßt sich aber doch unmittelbare Entlehnung mit ziemliclier Sicherheit nachweisen.

2) In MSD. sind verschiedene Stellen als Interpolationen ausgeschicden (s.MSD.II ${ }^{3}, 219$; WAAG S. XX), aber sie sind (außer keysir in 3,5$)$ nicht mit Sicherheit als unecht nacl1zuweisen. Die Str. $12^{\mathrm{b}}$ stört allerdings den
Zusammenhang, sie scheint aber doch von dem ursprianglichen Verfasser herzurïhren, ist also vielleicht ein spiterer Nachtrag. Dagegen fältt das Verspaar 3, $9 \mathrm{f}$. ganz aus dem linhalt und dem Stil heraus nud ist offenbar uneelit.

$\left.{ }^{3}\right)$ Dialekt und Orthographie: MSD. $11^{3}$, an verschiedenen Stellen von S. 202 ff. an, bes. S. 217 f. 249; WAAG, Beitr. 11, 109-119.

4) Die beiden Bruchstiicke B und C slud nicht sicher zu lokalisieren. B hat anl. bair. 
Vor. Hs., das rheinfrk. Gebiet. Der Verfasser war ein Geistlicher. Als Zeit der Abfassung kann der Anfang des 11. Jhs. angenommen werden.

Inhalt. ${ }^{1)}$ Die Uberschrift "Summa Theologiae", die Scherer in MSD. dem Gedichte gegeben hat (Diemer nannte es "Die Schöpfung ${ }^{4}$, D. Ged. S. 91 und sonst), ${ }^{2}$ ) umfaßt den Inhalt und bezeichnet zugleich die Gattung, zu welcher es in der theologischen Literatur gehört: es ist eine kurze Zusammenfassung der Glaubenslehre, ein in Verse gebrachtes Kompendium der Theologie.

I. Str. 1 bis Str. 4, 6 Die Trinität. Str. 1 Wesen Gottes: er ist der Vater ewig, der Urgrund alles Guten, hat den Teufel gebunden; seine Allmacht lenkt die Dinge von oben, hält sie von unten fest, erfüllt sie innen, umfaßt sie außen; er ist unwandelbar; sein Tun ist ohne Aufwand von Mühe. ${ }^{3}$ ) Str. 2 Die drei Personen sind eine Einheit, die Seele ist ein Beispiel für die Dreiheit in der Einheit (Augustinus De civ. Dei XI, 26 ff.), sie ist eins und hat doch in sich drei Wesenheiten: Vernunft, Gedächtnis, Wille (Augustinische Trinitätsformel: memoria, intelligentia, voluntas); die Dreiheit (5 f.) ist eine immerwährende Einheit; in bezug auf unsere Seele sind wir das Ebenbild Gottes $(6-10)$. Str. 3 Wesen Gottes: mit "Macht" und "Güte" vollbringt er alle Wunder (die erste und dritte Person in Abälards Trinitätsformel). Er ist allmächtiger König und gütiger Vater, diesen Eigenschaften entsprechen wir durch Furcht und Liebe. Str. 4, 1-6 Wesen des Sohnes. Gott schuf die Welt durch die Weisheit (die zweite Person. in Abälards Trinitätsformel); ${ }^{4}$ ) die Weisheit (sapientia Abälards) ist der Rat (intelligentia Augustins, die Vernunft, s. euch 2,4), der Sohn also war der meistir unde wercman, der Schöpfer und Vollender der Welt. -

II. Str. 4, 7 bis Str. $12 \mathrm{Schöpfung} \mathrm{und} \mathrm{Sündenfall.} \mathrm{4,} \mathrm{7-12} \mathrm{Erschaffung} \mathrm{der} \mathrm{Engel.}$ Str. 5. 6 Luzifers Fall durch den Übermut. Luzifer des Neides Vater (weil er. den Menschen beneidete, der nun an seiner Stelle von Gott bevorzugt wurde). Str. 7 Erschaffung des Menschen zur Ausfüllung der durch den Fall Luzifers und seiner Genossen entstandenen Lücke in den Engelchören. Str. 8 Schöpfung der Welt. Str. 9 Schöpfung der Kräfte des Menschen; hier sind es vier Kräfte nach Augustinus De civ. Dei V, 1i: vita essentialis und dazu die drei aristotelischen Seelentätigkeiten vita seminalis = anima vegetativa (Pflanzenseele), vita sensualis = anima sensitiva (Tierseele), vita intellectualis = anima rationalis (Menschenseele). Str. 10 Erschaffung der 5 Sinne aus den 4 Elementen (die Luft doppelt gerechnet, als höhere, superior, und niedere, inferior). Str. 11. 12 Sündenfall, unter dem Bilde eines $Z$ weikampfes als Gottesgericht, der Mensch unterlag, indem seine Begierlichkeit (concupiscentia) siegte. Teufel - der Gottes Sohn.

III. Str. 12b-17 Die Erlösung durch Christus. Str. 12b Adam - der Jungfrau Sohn. Str. 13 Erlösung des Menschen durch den zweiten Adan vermittelst der List (vgl. auch 14,6) mit dem Angelhaken und zugleich durch Loskauf. Str. 14-17 Kreuzestod und Kreuzessymbolik.

IV. Str. 18-30 Der heilige Geist. Str. 18. 19 Die Liebe = der heilige Geist: die Gottesliebe, Furcht und Hoffnung (Str. 18); die Nächstenliebe (Str. 19). Str. 20. 21 Der Dienst Gottes: alle Dinge dienen Gott; die zwei Leben: Gnade-Knechtschaft, Himmel-Hölle (Str. 20); selbst der Teufel dient Gott (Str. 21). Str. 22-27 Die Heilsmittel: die Taufe und das Blut Christi $=$ das Abendmahl (Str. 22); Grablegung, symbol. = Taufe ${ }^{\prime}$ (Str. 23); Auferstehung, Heilsmittel der Taufe und der Buße (Str. 24); Tugendlehre (Str. 25); nochmals die Buße (Str. 26); die bösen Werke, das sind die Werke des Leibes; die Seele ist die Braut

$c h$, eine Besonderheit sind die $h$ in $g h$ : ligham, ghut, ghewinnen, sh: shol (3mal), shu (3mal). In C ist $g g$ für $n g$, nach griechischer Schreibweise, bemerkenswert. B und C haben keine vollen Endungsvokale mehr.

1) Gliederung bezw. Stellenerklärung: DiEMER, D. Ged. Anm. S. 32-43; MSD. $11^{3}$, 202 ff. (Anordnung S. 220 f.); KonR. HoFmanN, Kelle, KraUs, v. D. Leyen aaO.
2) Siehe Diemer, Wiener SB. 55, $285 \mathrm{ff}$.

3) Augustinus, Migne 2, 302; Beda, Exegesis in Psalm. libr.Ps. 103, Migne 93, 1005 A.

4) Für die Summa Theologiae gilt noch die alte Trinitätsformel Augustins, s. Str. 2, 4; Macht und Güte werden dem Vater, die Weisheit dem Sohne zugeschrieben, getrennt wie in Honor. Aug. Elucidarium I, 2, Migne 172, 1111. 
Gottes, der Leib ist die Magd der Secle (Str. 27); Str. 28. 29. 30 die letzten Dinge. - Str. 31 Schlußstrophe: Preis des Gotterlösers.

Der Stoff ist in der üblichen Reihenfolge und Gruppierung einer theologischen Summe oder des Katechismus gegliedert und zwar läßt sich sehr gut die Einordnung in vier Teile durchführen, welche gemäß dem Symbolum zugrunde liegt und z. B. in der Musterdogmatik, in des Petrus Lombardus Sententiarum libri quatuor, eingehalten ist. Aber er ist nicht gleichmäßig bearbeitet. Manches ist weit ausgesponnen, während wichtige Bestandteile des christlichen Glaubensinhaltes nur flüchtig erwähnt werden. So fehlt das Paradies und der Sündenfall in der Art der biblischen Darstellung, die Geburt Jesu und damit die Inkarnation, die Taufe, überhaupt das Leben Jesu. Damit tritt Christus als Persönlichkeit zurück, wie es allerdings meist bei den Summen der Fall ist.

Dem Inhalt nach steht die Summa Theologiae in enger Beziehung zu dem Ezzolied. Beide umfassen die ganze religiöse Geschichte von Uranfang bis zum Ende der Welt, aber doch decken sie sich nicht völlig, vor allem ist die Tendenz beider Gedichte eine verschiedene: das Ezzolied ist eine Heilsgeschichte und eine Ereignisdichtung, der Inhalt wird durchlebt, die Summa Theologiae eine Glaubenslehre und eine Gedankendichtung, der Inhalt wird reflektiert. Dort bildet Christus der Erlöser den Mittelpunkt, am Beginn steht das uranfängliche Wort und am Schluß das Kreuz; hier durchdringt das Grunddogma der Christenlehre, die Trinität, die ganze Gedankenmasse, die Aussicht auf die Erlösung von der Sünde verleiht dabei dem lehrhaften Gehalt einen stärkeren Gefühlston.

Der Verfasser hat den Stoff sicherlich nicht selbständig zusammengestellt, er hatte als Vorlage eine kurze lat. Glaubenslehre, und zwar wahrscheinlich in poetischer Form.1) Er ist seiner Quelle jedenfalls genau gefolgt, aber er hat sie in vielen Fällen nur unverständlich wiedergegeben. Das liegt einmal in der Schwierigkeit der Übertragung vieler lat. Stellen und dann in der Kürze des Ausdrucks. Schon seine Vorlage mag eine knappe Fassung gehabt haben, ${ }^{2}$ ) die jedoch im lat. Ausdruck nicht leicht verständlich war. Der Dichter hat dann offenbar noch manche notwendige $Z$ wischenglieder ausgelassen. So z. B. ist 4, 1 ff. unklar, weil nicht gesagt ist, daß "wîsheit“ die Eigenschaft des Sohnes ist; Luzifer heißt, ohne Erklärung weshalb, des nîdis vatir 6,1 ; gibrist 7,2 kann sich unmöglich aus den Vorhergehenden ergeben; s. auch Str. 18.

Auch hier treffen wir viele jener in der damaligen Theologie allgemein gültigen Sätze wieder, die sich in des Honorius Aug. populärer Religionsdarstellung finden, ${ }^{3}$ ) doch ist in keinem Fall unmittelbare Entlehnung nach-

1) Für ein lat. Original sprechen Latinismen S. 57.

2) Der Hymnen- und Sequenzstil ist überhaupt gedrängt und inhaltreicl..

3) Honorius gibt das theologische Wissen, wie es iiberhanpt damals in den Kloster- und Domschulen gelehrt wurde. Diese Rénntnisse setzt auch die Summa Theologiae voraus. lrgendein näherer Zusammenhang zwischen beiden braucht also nicht zu bestehen. 
zuweisen ${ }^{1}$ ) und so findet sich für die Abfassungszeit des Gedichtes auch kein bestimmter Anhaltspunkt. In den ersten Jahrzehnten des 12. Jhs., etwa um 1120 - 30, wird es entstanden sein. Dazu paßt auch die Sprache der Reime. - Von der Mystik Hugos von St. Victor ${ }^{2}$ ) oder Bernhards von Clairvaux ist es nicht beeinflußt. Dazu fehlt schon die schwärmerische Gemütstiefe. Das mystische Motiv von der Seele als Braut Gottes ist zu einem allgemein geläufigen Bild geworden, und gerade an unserer Stelle $(27,1 \mathrm{ff}$.) ist nicht von der innigen Vereinigung des Menschen mit Gott die Rede, sondern von dem Dualismus von Seele und Leib und von den bösen Werken des Fleisches. Sêle in 2, 2.9 ist nicht die mystische Seele, sondern die des psychologischen Systems. Näher kommt dem Ziele der Mystik, dem Einswerden mit Gott, die Geleitung der Liebe zur Gotterkenntnis in Str. 18. Aber dieses Empfindungsmoment kommt nicht zur Geltung, es wird verdrängt durch die Reflexion, die zu der Allegorie von der knechtischen Furcht und der kindlichen Hoffnung ableitet. Gerade hier zeigt sich die Unfähigkeit des Dichters zum Sichversenken in das mystische Gemütsleben, denn er handelt nicht davon, Gott mit dem Gefühl zu erfassen, sondern ihn interessiert der Gegensatz von Furcht und Liebe (Hoffnung) nach 1. Joh. 4, 18. Der Verfasser hat übrigens hier seine Vorlage gar nicht verstanden, die Stelle ist durch Zusammenschweißung verschiedener Motive ganz verworren.

Stil. Die Summa Theologiae ist der Gattung nach ein Lehrgedicht. Hier liegt schon der Wesensunterschied gegenüber Ezzos Gesang, der viel mehr den Charakter eines Hymnus trägt. Beide Gedichte haben eine verschiedene Grundstimmung. Das Ezzolied will erheben, begeistern (movere), die Summa Theologiae will belehren (docere) wie ein theologischer Traktat. Dort ist die Darstellung anschaulich und lebensvoll, stellenweise dramatisch gesteigert; hier gedankenreich und schwerverständlich, in ebenmäßigem Verlauf einer Abhandlung bezw. Erzählung ohne poetischen Schwung, nur am Ende etwas gehoben.

Indes ist die Auffassungsart der Dinge keineswegs ins Abstrakte verflüchtigt, man kann zweierlei Partien unterscheiden, abhandelnde und erzählende. Der erste Teil (Str. 1-4,6) bespricht Glaubenssätze, der zweite (Str. 4,7-12) erzählt Schöpfung und Sündenfall, der dritte (Str. 12b-17) ist gemischt, erzählend und abhandelnd. Der vierte Teil (Str. 18-30) ist meist abhandelnd. Erkenntlich sind die beiden Darstellungsarten auch äußerlich an dem verschiedenen Gebrauch der Tempora, des Präsens oder des Präteritums. Auch hier, wie im Ezzolied, sind die Ideen großenteils in

1) Ueber Anklänge an Anselm von Canterbury s. SCHERER, QF. 7, 55 f. 12, 34. Die in MSD. $11^{3}, 202$ zu Str. $1,5-8$ gegebenen Belege aus Anselm und Abälard gehen auf Scotus Eriugena zurück.

2) Die Stellen, die Kelle S. 137 f. 139 u.
Anm. speziell mit Hugo von St. Victor in Beziehung bringt, haben eine weitere Verbreitung. - Ueber mystischen Gehalt in dem Gedicht SCHERER, MSD. II ${ }^{3}, 221$ f., QF. 7,54 f. 12,34 . 
Symbolik gekleidet und gerade die typologische Auslegung verdunkelt oft den Sinn. Die Ausdrucksweise ist ganz geistlich, es finden sich keine Erinnerungen an den epischen Stil wie im Ezzolied (außer der Formel sagin unde singin in den eingeschobenen Versen 3,9f.), denn die sonstigen zwei- oder mehrgliedrigen Wendungen sind durch den geistlichen Inhalt veranlaßt. ${ }^{1}$ ) Desgleichen sind die Alliterationen nicht als dichterischer Schmuck beabsichtigt, sondern sie sind ein zufälliges Ergebnis des zu verwendenden Sprachstoffes. Flickverse und Flickreime finden sich kaum, doch sind die Dreireime 9, 3.4.5 und 10,3.4.5 nur Verlegenheitsmittel, weil der Dichter' mit zwei Reimzeilen hier nicht auskam. Wortwiederholungen, die bei Ezzo so häufig sind, gehören nicht zum Stil des Gedichtes, auch kommen lat. Einschiebsel und Zitate nicht vor. Der Plural, für die gesamte Menschheit gebraucht, gehört notwendig zum geistlichen Stil. Als eine stilistische Sonderheit mag noch die Umschreibung der heiligen Person durch einen Relativsatz angeführt sein wie Der dir ist beidu got und mennischi $28,1=$ Christus, ferner 7, 1.24,5. Der Satzbau ist reicher gegliedert als im Ezzolied, die Hypotaxe ist weiter ausgebildet (vgl. 4, 9-12. Str. 11. Str. 17. 20,1-4. 29, 3-6). Parallelaufzählungen enthalten 1,5-8. Str. 9. Str. 10. Str. 25. Bemerkenswert sind die undeutschen Partizipialkonstruktionen: Part. präs. mit sein: sû ist . . dû dinc richtinti usw. $\left.1,5-8,{ }^{2}\right)$ sint woninti 2,6 , ferner 8, 8. 9, 13. 19, 4. 21, 7 f. 26, 8. 31, 6; Part. prät. sini hêrschaf gigebin ime durch guot 5,5; deutlich nachgeahmt einem lat. Text sind auch die substantivierten Partizipia mit den vlîgintin, suimmintin unde cresintin $9,10 \mathrm{f}$. statt mit den vogilin, fischin unde wurmin und besonders auch in der Wortstellung mit den volginti imo ginôzzin $5,10 .{ }^{3}$ )

Metrik. In der Hs. sind 25 10zeilige Strophen abgeteilt: 1. 2. 3. 5. 7. 8. 12. 13. 14. 15. 16. 17. 18. 19. 20. 21. 22. 24. 25. 26. 27. 28. 29. 30. 31, dazu kommen 3 Strophen $11.12^{\text {b }} .23$, in denen in der Hs. Zeilen fehlen, die aber höchstwahrscheinlich auch als 10zeilige zu rechnen sind; ergibt also. zusammen 2810 zeilige Strophen. 12 Zeilen haben Str. 4 und 6, 11 Zeilen hat Str. 10 und 13 Zeilen hat Str. 9. Da Strophen von ungleicher Länge für die strophischen Dichtungen der frühmhd. Zeit zuzugeben sind, so ist kein Grund vorhanden, an der Zeilenzahl irgendeiner Strophe zu ändern, zumal der Inhalt dazu keine Veranlassung gibt. ${ }^{4}$ ) Der Sinnschluß fällt mit dem Versschluß zusammen und zwar bilden meist ein, oft auch zwei Reimpaare eine in sich geschlossene Gedankenreihe. Der Rhythıus ist recht

1) Sonst wiederkehrende Ausdrücke s. außer in MSD. bei V. D. LEYEN, KI. Beitr. S. 54-56.

2) Die partizipialen Umschreibungen entsprechen dem possidendo, sustinendo, complectendo, implendo des Hymnus Alpha et $\Omega$ (MSD. II ${ }^{3}, 202$; Kelle 2, 336; Mone, Hymnen Bd. 1 S. 14).

$\left.{ }^{3}\right)$ Falls niclut die Hs. ursprüngliches imo volginti fehlerlaft umgestellt hat, vgl. MSD.
$\mathrm{II}^{3}, 205 \mathrm{f}$.

4) Die beiden SchluBzeilen von Str. 3 können uneclıt, jedoch an Stelle zweier anderer echten getreten sein. - MüLLENHOFF tilgt in Sir. 9 zwei Zeilen, so daß sie statt der liandschriftlichen 13 Zeilen nur 11 euthält. SCHADE und KONR. HOFMANN stellen 32 , 10zeilige Strophen her. 
frei, neben Versen von normalem Maß stehen andere mit vielen Senkungen (gelängter Typus); $;^{1}$ ) lange Verse befinden sich besonders am Strophenschluß. Die Reime sind weniger frei und altertümlich als im Ezzolied, die Zahl der reinen Bindungen ist viel größer, selten reimt ein einsilbiges Wort auf die schwache Endung eines mehrsilbigen. Weibliche Reime sind viel zahlreicher als im Ezzolied. Bemerkenswert ist das Vorkommen von Dreireimen (s. oben S. 57), ${ }^{2}$ ) die aber nicht als Strophenabschluß auftreten. Bestimmt ist das Gedicht nicht zum Chorgesang, sondern zum liturgischen, rezitativischen Sprechvortrag (Einzelvortrag).

\section{$\$ 8$. Das Anegenge.}

Kelle 2, 141-153. 342-356; PIPER, GD. 1, 239-249. - Ausg.: HAHN, Ged. S. 1-40. Scherer, ZföG. 19 (1868), 578 u. Kl. Schr. 1, 619 f.; QF. 12, 60 f., dazu Steinmeyer, Anz 2, 238; E. SCHRÖDER, Das Anegenge, QF. 44, 1881 (s. auch ZfdA. 26, 199 Anm. 35, 423, dazu SCHÖNBACH, DLZ. 1881, 1112; SteinMEYer, Anz. 7, 333; BartsCH, LitBl. 1882, 129 f.; LC. 1882, 1592); BaRTsCh, Beitr. 8, 494-505; TeUber, Öber die vom Dichter des Anegenge benutzten Quellen, Beitr. 24, 249-360.

Hs.: Wien Nr. 2696 (s. oben S. 17) Bl. 179a-221b; auf Bl. 178b steht Daz bůch heizzet daz anegenge.

Der Dialekt $\left.{ }^{3}\right)$ der Hs. und des Gedichtes ist österreichisch. Von einem Geistlichen wahrscheinlich in dem österreich. Donauland wurde etwa um 1160 das Gedicht verfaßt.

Inhalt. I. 1, 1-2, 19 Einleitung: Bitte zu Gott um Beistand bei dem Werke $(1,1-26)$; Inhaltsangabe: die Erlösung der Menschen vor dem Anfang der Dinge beschlossen (1,27-36); Rat für die tumben, man solle in die Geheimnisse Gottes nicht zu tief eindringen ( $1,37-59)$; Inhaltsangabe des Folgenden in sechs Punkten $(1,60-2,19$, vgl. 11, 60-78). - II, 2, 20-40, 3 Hauptteil: A. 2, 20-28, 2 Das alte Testament. a) 2, 20-4, 44 Schöpfung. 1. Vor der Schöpfung saß Gott in seiner Majestät $(2,20-38)$, Himmel und Erde, das Licht und alle Dinge schuf er dem Menschen zum Dienst (2,39-59); 2. Gott beschlieBt in der Trinität (Macht, Weisheit, Güte), ${ }^{4}$ ) um die Wonne nicht allein für sich zu haben sondern sie allgemein zu machen, die Schöpfung $(2,60-76)$, Erschaffung der Engel $(2,77-3,34)$, Gott beratschlagt mit Güte und Weisheit, die Weisheit rät ihm, alle Dinge und die Engel zu schaffen, das Sechstagewerk (3, 35-78); 3. Luzifers Fall $(3,79-4,44)$. b) 4, 45-11, 59 Di e Trinität. 1. Ihr Wesen $(4,45-6,42)$ : Vater, Sohn, Geist - gewalt, wîstuom, güete; 2. Der Anteil der drei Personen an der Ausübung der Macht 6, 43-7, 83): die Güte rät dem Vater, daß er die große Wonne nicht allein haben solle, darauf überträgt der Vater dem Sohn die Schöpfung Himmels und der Erde und der Geschöpfe. Nicht aus eigenem Bedürfnis haben die drei Personen das Schöpfungswerk getan, sondern auf daß wir glücklich würden; 3. Die drei Personen sind nur ein Gott, Beweise $(8,1-11,59)$. c) $11,60-14,12$ Die Erlösung. 1. Inhaltsangabe in fünf Punkten: Wie die Barmherzigkeit den Sohn trieb, unser Leid zu vertilgen, durch welche Schuld wir Gottes Huld verloren, weshalb er lieber zu unserer Erlösung den Tod duldete, als daß er Adams Fall verhinderte, weshalb die ungetauften Kinder in das Feuer kommen (11,60-78, vgl. 1, 60-2, 19); die darauf folgenden Punkte beziehen sich (mit Ausnahme von 12,11-40, wo auf die letztgestellte Frage geantwortet wird: die ungetauften Kinder hätten doch die Hölle verdient, wenn sie am Leben

1) SARAN S. 252-254; W. Grimm, ZGdR. S. 173 , Kl. Schr. 4, 312. SCHERER MSD. II ${ }^{3}$, 218-221 nimmt 4-, 5-, 6- und 7-hebige Verse an (dazu SteinMeyer ebda S. 220; WAAG S. XX f.).
2) VogT, Beitr. 2, 258.

3) SCHRÖDER S. 3-12; ZWIERZINA, ZfdA. 45,75 . 76. 407.

4) Siehe oben S. 7 f. 
geblieben .wären) auf das Thema: Warum hat uns Gott so geschaffen, daß wir den Sündenfall begingen, da er ihn voraussah und ihn hätte abwenden können? d) 14,13-25,63. Die bibl. Geschichte von der Erschaffung Adams bis $z u$ Noes Trunkenheit. Auf den Rat der Weisheit erschafft Gott Adam, Verbot des Obstes (14, 13-15, 38), Erschaffung der Eva (15, 39-16, 19), Sündenfall $(16,20-73)$, Verführung durch die Schlange, Verfluchung (16,74-19, 70) Adams Nachkommen, Kain und Abel $(19,71-22,28)$, Noe $(22,29-25,63)$. e) Gott kann nicht mit menschlichen Augen gesehen werden $(25,64-28,2)$. - B. 28, 3-40, 3 Das neue Testament. Weiter vom anegenge zu reden würde zu lang werden (28, 3-22). a) 28,23-30, 28. Die Beratung der vier Tugenden Gottes, Barmherzigkeit, Wahrheit, Gerechtigkeit, Friede, vor Gott über das Schicksal der Menschen: beschlossen wird die Erlösung des Menschen durch.den Gottessohn, der menschliche Armut annehmen und für die Menschen sterben solle. b) 30, 29-33, 22. Die biblische Erzählung von der Verkündigung der Geburt Jesu bis zu den drei Königen; das weitere Leben Jesu wird übergangen. e) 33,'23-35, 3. Die Sünden Adams und der Eva: sie sind aller Hauptsünden schuldig $(33,23-34,55)$; trotzdem erbarmte sich Gott $(34,56-35,3)$. d) $35,4-40,3$. D a s E r lösungswerk: Eva - Maria, Fluch - Segen, Geburt des Kindes (35, 4-36, 51), Adam Christus, Christus büßt die Sünden Adams, Hochmut - Demut $(36,52-78)$, Beispiele für Christi Demut: Geburt in der Krippe $(36,79-82)$, Versuchung $(37,1-38,9)$, seine Marter $(38,10-34)$, sein Kreuzestod $(38,35-58)$, Begräbnis $(38,59-62)$, durch Christi unschuldigen Tod hat der Teufel das Recht an die schuldigen Menschen verloren $(38,63-39,12)$, Höllenfalırt, Auferstehung, Himmelfahrt (39, 13-40, 3). - 111. 40, 4-13 Schlu B: Ermahnung an die Hörer oder Leser; Lob des Sohnes.

Die Bezeichnung "Anegenge“, die schon die Hs. als Titel des Gedichtes aufgenommen hat, gebraucht der Dichter selbst 28,9 und bezieht sie auf den ersten Teil des Werkes, so wie er auch im Eingang 1, 17-26 (vgl. auch 1,60 ff. 3,74 ff.) den Anfang der Dinge als Inhalt angibt. ${ }^{\text {) }}$ Zum Unterschied von Ezzos Lied, das nach seiner Angabe von dem anegenge handeln will, nennt man das spätere Gedicht auch das jüngere Anegenge.

Das Anegenge ist eine Erlösungsgeschichte, als solche will der Verfasser selbst sein Werk aufgefaßt wissen $(1,27-33.3,74.11,60 \mathrm{ff} .29,16 \mathrm{ff}$.). Der erste Teil, zwei Drittel des Gedichtes, enthält die Vorbedingungen zur Erlösung. Die Hauptpunkte sind hier: die Trinität in der Abälardschen Formel, von ihr ausgehend die Erschaffung aller Dinge, der Engel und der Menschen, beide mit Freiheit des Willens; von ihr voraus gewußt der Fall Luzifers und ebenso des Menschen, und vorausbestimmt die Erlösung. Im zweiten Teil wird, nach dem Beschluß der Menschwerdung durch die vier göttlichen Tugenden, ${ }^{2}$ ) das Erlösungswerk selbst entwickelt und zwar

1) SCHRÖDER S. 78.

2) Die vier Tugenden werden auclı als vier Töchter Gottes angesehen, wonach die hăufig im MA. begegnende Legende "Streit der vier Töchter Gottes" genannt wird. Der Ursprung liegt im Talmud im Anschluß an Ps. 84, 11 f. Misericordia et veritas obviaverunt sibi, institia et pax osculatae sunt. Veritas de terra orta est, et institia de coelo prospexit. Die m.alterl. Fassungen gehen auf St. Bernhards Predigt ln festo Annunclationis beatae Mariae virginis zuriack, die Personi- fizierung der Tugenden und ihre Deutung als Schwestern und Töchter Gottes ist bedeutend alter. Vgl.HEINZEL, ZfdA. 17.43-51; BARTSCH, Erlösung S. V1ll-XX1; SCHERER, ZfdA. 21, 414-16; Aug. HaktmanN, ZfdA. 23, 173189; Franck, ZfdA. 24, 389 f.; Kelle S. 146 f. 347; SCHRÖDER, ZfdA. 25, 128 f. 11. Anegenge S. 55 f. Burdach, Vom MA. zur Ref. S. 300 ff.; Teuber bes. 33.1 ff. Vollmer, Materialien zur Bibelgesclı. 1, 25; BERNIIEIM, Mittelalterl. Zeitanschaunngen S. 29 ff. 11. die Greifsw. Diss. von Heinr. ḰrÚger 1910, Fredirici 191\%, 
hauptsächlich in dem Gegensatz von Eva - Maria, Adam - Christus; die Erlösungstaten Christi sind als Bußen für Adams Sünden aufgefaßt. So sind die beiden Pole, Anfang und Ende der geistigen Menschheitsgeschichte, Sündenfall und Erlösung, zusammengehalten durch die Person des Sohnes und angeknüpft an die Trinität.

In dieser Ausführung ist das Anegenge eine Glaubenslehre in der Art einer Summa Theologiae, es ist also eine dogmatische Erlösungsgeschichte, denn die Entwicklung von Glaubenssätzen ist die Hauptaufgabe. Die historischen Tatsachen der Bibel werden nur zum geringeren Teil um ihrer selbst willen erzählt, vielmehr dienen sie meist der daran geknüpften dogmatischen Erklärung, wie z. B. die Taten und Leiden Christi unter dem Gesichtspunkt des Rechtshandels mit dem Teufel betrachtet werden,1) womit das Leben Jesu ganz unter den Zweckbegriff gestellt ist. Immerhin kommt die historische Grundlage der Bibel viel stärker zur Geltung als in den theologischen Lehrgebäuden der lat. Summisten. Man sieht, der Verfasser hat sich doch nicht losmachen können von der ihm naturgemäßen konkreten Anschauungsweise. Dies zeigt sich trotz allen scholastischen, intellektualistischen Spitzfindigkeiten: so gerät er vom Sündenfall an in ein langes Weitererzählen der Bibel; so hat er die Legende von dem Streit der vier Tugenden aufgenommen, die nicht zum Dogma gehört; und so hat er das unbegreifliche Geheimnis der Dreieinigkeit sich recht natürlich, d. h. sinnlich-menschlich vorgestellt, die ganze Darlegung der Trinität läßt dies durchspüren: es sind ihm eben doch drei Personen, die miteinander reden und beraten. Wenn die drei psychologischen Wesenheiten Gottes dramatisiert auftreten, dann ist die Vermenschlichung so weit getrieben, daß alle spiritualistische Illusion schwinden muß. Entsprechend dem dogmatischen Inhalt ist auch die scholastische Methode angewendet. 'Die Glaubenssätze werden als vernunftgemäß in Anspruch genommen: es werden wirkliche oder mögliche Einwände und Fragen widerlegt (2,37 ff. 49 ff. 6, 20 ff. 7, 2 ff. 9,19 ff. 10,68 ff. $14,56.15,64$ f. 16, 38 ff. 65 ff. 21,8 f. 23,64 ff. 26, 79 ff. 27,18 f. 39 ff. 34,51 ff. 39, 52 ff.); oder es wird gesagt, daß es so sein mußte, denn anders wäre es verkehrt gewesen (in Bedingungssätzen wie Got het im selben getân unreht, het er sô geschaffen sînen kneht 12, 1 ff.; ähnl. 12, 76 ff. 13, 2 ff. 13 ff. 14, 49 ff.). Aber es werden auch dem

TIRALLA 1916; s. auch Archiv 62 (1879) S.378.Die Begründung der Menschwerdung Christi (Cur Deus homo?) ist in die Form eines Rechtsfalles gekleidet: der Teufel hat ein Eigentumsrecht auf den Menschen, dieser kann darum nur durch ein rechtliches Verfahren ihm entzogen werden. Wenn Gott selbst für den Menschen stirbt, dann kann dér Teufel keinen Anspruch mehr auf seinen Knecht erstreben und das Recht ist ihm gewahrt. Der Tod Christi als eine Rechtshandlung im Interesse des Menschen gegen den Teufel ist eine der herrschenden Theorien über das Erlösungswerk und wird auch von Augustin vertreten, De libero arbitrio 3,10 .

1) Die Gerechtigkeit ist eine wesentliche Eigenschaft der Trinität, die göttlichen Entschließungen werden vom Rechtsbegriff geleitet: die Erlösung des Menschen $(28,23 \mathrm{ff}$. 34, 56 ff. 36,81 f.), die Schaffung der abtrünnigen Engel $(3,2)$, die Schaffung des dem Falle bestimmten Menschen (12, 1 ff. 12, 45 ff. 13, 2 ff.). 
Erkenntnisdrang Grenzen gesteckt: es ist unmöglich, ja schädlich, die Tiefe des Wunderbaren zu ergründen (1, $6 \mathrm{ff} .4,50 \mathrm{ff} .5,3 \mathrm{ff}$.), darum soll man sich hüten, zu tief $z \mathfrak{u}$ grübeln, $\left.{ }^{1}\right) \mathrm{d}$. h. in selbständigem Nachdenken über die Autoritäten hinweg auf den Grund dringen zu wollen $(1,37-2,19$. $11,56-59)$.

Offenbar hat der Verfasser von vornherein seinen Plan'2) nicht genau überschlagen, denn er erzählt die Geschichte von den Nachkommen Adams und von Noe so ausführlich, daß er plötzlich abbricht, weil die Rede zu lang werden könnte $(28,3$ ff). Andrerseits eilt er so rasch zu Ende, daß er zu einer Schilderung der letzten Dinge, der Seligkeit und der Verdammnis, die den notwendigen Abschluß der Heilsgeschichte bilden, gar nicht kommt und für das Schlußgebet nur einige dürftige Worte hat. Er beherrscht den Stoff nicht recht, daher mehrmalige Wiederholungen, die sich nicht ganz entsprechen: so die Schöpfung des Himmels, der Erde und der Menschen 2, 40 ff. 3, 35 ff. (vgl. 14, 18 ff.). 6, 5 ff.; die Erschaffung der Engel 3, 43 ff. u. 3, 79 ff. (s. auch 2, 78 ff.); die Anordnung der fünf Punkte des Programms in 11, 60 ff. ist nicht folgerichtig: zuerst die Erlösung und dann der Sündenfall (11, 60-64 gegen 11, $65 \mathrm{f}$.), die dazu gehörenden Erläuterungen von 12, 1 ff. stimmen nicht zu den fünf Punkten der Disposition; der Sündenfall 16, 20 ff. 33, 27 ff. 35, 1 ff.; Sendung des Gottmenschen 28, 28 ff. $36,52 \mathrm{ff}$.

Der Verfasser ist ein völlig unselbständiger Denker, dem es Schwierigkeiten machte, die begrifflichen Probleme klar zu fassen. Er hat alles aus Büchern und von seinen Lehrern. In vielen Zitaten bekräftigt er die Wahrheit seiner Darlegungen: er schöpft aus der Bibel (daz buoch 3, 53. 16, 17. 26, 17. 33, 9; diu schrift 20,11.21, 21. 25, 36, vgl. 22, $40 \mathrm{f}$; din alte $\hat{e}$ 1, 40. 44; einzelne Bücher: 11, 16. 26, 52 f. 27, 70-78. 30, 73. 32, 21 ff.; der buochstap, buochstabe, die buochstabe der Wortlaut der heil. Schrift 15, 77. 21, 24. 25. 66. 32, 23); er beruft sich ferner auf Augustin 4, 28, Gregorius d. Großen 27, 13; auf unbestimmte nicht biblische Bücher (8, 9 . 10,30. 12, 18 [u. vielleicht 12, 22]. 21, 22); auf einen Predigttext (letze, lectio) 23, 52; auf gelehrte Theologen 8, 16. 16, 4; auf seinen Lehrer 16, 47; auf ein Lehrbuch 27, $46 \mathrm{f}$. und wohl auch 27,38. Hauptquelle ${ }^{3}$ ) aber ist für ihn Hugo von St. Victor und zwar dessen systematisches Grundwerk De Sacramentis, weniger dessen Summa Sententiarum. Beeinflußt von diesen Lehrgebäuden und aus ihnen schöpfend hat der deutsche Verfasser seine gereimte Summa Theologiae zusammengestellt, auch die Methode mit den Fragen und Einwänden konnte er dort vorgefunden haben. Darauf eben beruht die eigenartige Stellung, die das Anegenge in der mhd. Literatur des 11./12. Jhs. einnimmt, daß es in umfassender Weise und mit scholas-

1) Eine in Predigten und Abhandlungen hăufige Warnung: s. SCHRÖDER S. 26 f. $59 \mathrm{f}$ KELLE S. 150 f. 352 f.
2) Komposition s. SCHRÖDER S. 77-84.

3) Schröner S. 39-68; Kelie S. 143 ff. 337 ff.; TEUBER aaO. 
tischer Methode den Glaubensinhalt auseinandersetzen will, wodurch es mehr als irgendeine andere Dichtung dieser Zeit einen theologischen Cha- rakter trägt. $\left.{ }^{1}\right)$ Aber freilich, ein geordnetes, einheitliches und vollständiges System ist nicht erreicht.

Beziehungen $z u$ deutschen Gedichten ${ }^{2}$ ) sind nicht zahlreich. Es finden sich Anklänge an die Wiener Genesis, an das Ezzolied und besonders an die Vorauer Sündenklage; sie können dem gedächtnismäßig überlieferten Sprachschatz entstammen. Verbreitet war das Anegenge nicht, es hat keinen Einfluß auf die weitere Literatur ausgeübt. ${ }^{3}$ )

Der poetische Gehalt des Gedichtes ist gering, die Sprache ist, besonders in den lehrhaften Teilen, eintönig und erhebt sich nicht über den Abhandlungsstil, denn es ist nur auf Belehrung, nicht auf Erbauung abgesehen. Immerhin gehörte schon eine sprachliche Schulung dazu, um dem schwierigen Inhalt eine verständliche Ausdrucksform zu verleihen. Auch im Stil $\left.{ }^{4}\right)$ zeigt sich der Gelehrte: er baut künstliche Perioden, oft unter Voranstellung der Nebensätze, in der Inhaltsangabe 11, 60-78 gehen 18 Zeilen vor dem Nachsatz vorher, in 1, 60-2, 19 sogar 28 Zeilen. Zum.Predigtund Vortragsstil gehören die vielen Formeln, Anreden an die Zuhörer, Bitten um Nachsicht, Fragen, Ausrufe, Quellenberufungen. Einen besonderen Ton bringen herein die obengenannten polemischen Zurückweisungen und Warnungen. Von einzelnen rein formalen Wendungen sind besonders zweigliedrige Ausdrücke, Parallelismus und Aufzählung häufig gebraucht. Lat. Worte kommen trotz des gelehrten Inhalts verhältnismäßig nicht viele vor. ${ }^{5}$ ).

Metrik. ${ }^{6}$ ) Die Verse sind normal gebaut, doch manchmal mit schweren Senkungsfüllungen oder umgekehrt mit fehlenden Senkungen. Die Reime sind oft ungenau, doch sind die Assonanzen meist leicht.

$\$ 9$. Hartmanns Rede vom Glauben (Credo).

Kelle 63-68. 281-283; PIPER, GD. 1,75-82. - Ausg.: Stellen vom Anfang und Schluß. in GRAFFs Diut. 1, 303-307 und HofFmanns Fundgr. 1, 256 f.; vollständig bei MASSMANN, D. Ged. S. 1-42; v. D. Leyen, Des armen Hartmann Rede vom Glouven, Germ. Abh. XIV, 1897, dazu Reuschel, LitB1. 1899, 160-164, SchröDER, ZfdA. 35, 419 Anm., Uhl, ZfdPh. 32, 263-271, ferner LeItZMANN, Beitr. 24, 206-220 und Erwiderung von v. d. Leyen, ebda 522-528. - Karl Reissenberger, Über Hartmanns Rede vom Glauben, Leipzig. Diss. 1871; Scherer, QF. 12, 36 f.; MART. Scheins, Ist Hartmann der Alte der Verfasser des Linzer Entecrist? ZfdA. 16, 157-164; v. D. Leyen, Kl. Beitr. S. 57 f.; John MeIER, Beitr. 16, 99; Elis. Peters S. 137 ff.

Hs: Straßburg-Molsheimer Hs. Bl. 1c -9b (Bl. 8 mit ca. 400 Versen fehlt).

Das Gedicht ist, wie die Reime beweisen, im mittelfrk. Dialekt ${ }^{7}$ ) ab-

1) SCHRÖDER S. 39.

SCHRÖDER S.69-77; KELlE S.152f. 355 f.

3) SCHRÖDER S. 89-91.

4) Zum Stil s. SCHRÖDER S. 24-39.84-86.

5) GRÚNEWALD S. 16. 424 .

6) SCHRÖDER S. 12-23; Gött. Nachr. 1918,

7) ReISSENBERger S. 21-39; v. D. LEYEN
S. 15-30; PAUL KÖHLER, Der zusammengesetzte Satz ... in des a. Hartm. Rede v. Gl., Berl. Diss. 1895; Jos. BRÜCH, Zur Sprache der Rede vom Gl. des Armen.H., Prager D. Stud. H. 17 (1910). - Zum Titel 'Rede v. Gl.' bezw. 'Credo': SCHRÖDER, Gött. Nachr. 1917 S. 162. 
gefaßt, in der Hs. aber ist derselbe nicht sehr ausgeprägt, der elsässische

- Schreiber ${ }^{1}$ ) hat stark normalisiert. Entstanden ist es um 1140-1150.

Inhalt. Der Einteilung liegt das nicänisch-konstantinopolitan. Glaubensbekenntnis zugrunde. Die einzelnen Sätze desselben sind lat. aufgestellt, ins Deutsche übertragen und durch andere, verwandte Gedanken erweitert. Oft sind diese Ausführungen an lat. Zitate, die fast durchweg der Bibel entnommen sind, angeknüpft. ${ }^{2}$ )

I. 1-60 Einleitung: Bedeutung des Glaubensbekenntnisses 1-24; Anrufung Gottes um Sendung des heil. Geistes 25-54; Angabe des Titels: di rede des geloubin 55-60. II. 61-3708 Hauptteil: Erklärung und Paraphrase des Symbolums: a) Gott 61-178. b) Christus 179-1641. c) Der heilige Geist 1642-3708 (1680-3630 die Räte des heil. Geistes, darin eine Sündenklage 1752-2369). - III. 3709-3800 SchluB: Gebet an Christus; der Verfasser.

Das Gedicht enthält viel mehr als bloß die Erklärung der Sätze des Symbolums, denn dieses ist durch die Erweiterungen zu einer Glaubenslehre, einer theologischen Summe ausgedehnt. Neben dem dogmatischen Stoff tritt sehr stark die Absicht auf praktische Belehrung hervor in der großen Ausdehnung der Sündenklage und der Räte des heiligen Geistes. Hier offenbart sich ein Hang zu strenger Askese, ein Kampf gegen Reichtum und Weltehre. In der Sündenklage zumal werden Beispiele gewählt von bekehrten Weltkindern: der Schächer, der Zöllner Petrus, Maria Magdalena, Afra, die ägyptische Maria, der ehrgeizige Theophilus; und die Seligen, die im Himmelreich belohnt werden, sind die, welche die Welt aufgegeben haben (2886), die im Kampf zwischen Geist und Fleisch (2988) Sieger blieben; die aus Überdruß an der Welt (3130) als Einsiedler in der Wildnis Ungemach leiden; die Eigen und Lehen (3168), Weib und Kind und Freunde verlassen, um im Kloster große Mühsal zu dulden; die Eigen und Erbe (3199) aufgeben und den Gotteshäusern spenden. Auch spielt der Teufel die große Rolle des Menschenverderbers, nicht genug tun kann sich der Dichter, um gegen diesen schlimmsten Feind loszuziehen (11. 491-494. 597-688.810-. 850. 861-880. 933-958. 1074. 1097. 1926-2001. 2720-2825. 3019 ff.). In volkstümlicher Weise ist dabei das Christentum aufgefaßt als ein Kampf gegen den Satan: ein Volkskampf wird gefochten, von St. Michael, von Christus selbst gegen den Drachen; aus dem Himmel ward er geworfen tief in den Höllengrund, da liegt er gebunden mit einer Kette $11 \mathrm{~m}$ den Hals und einem Ring durch die Nase (515-554).

Das rein dogmatische Element weicht überhaupt einer volkstümlich sinnfälligen Auffassung des Stoffes: Christus ist der Herr, die Jünger sind die Holden, die ihm dienen 873. 1183. 1269. 1379. 1431. 1477. 1970. 2092. 2220. 3072. 3122. 3154. 3717, er ist der Känpfer und Sieger 515 ff. 866. 1472. 3035 ff.; der Herrscher des Himmels in kaiserlicher Riistung mit Speer und Schwert $1461 \mathrm{ff}$. Die den Sieg über das Fleisch gewinnen, sind die

1) Schröder, ZfdA. 33, 104 Anm. (vgl. dazu WeEde, Diı Wârheil S. 96 f.).

2) GRÚNEWALD S. $21-25$ แ. 66 f. 
guten Knechte, die Christus, ihrem Fahnenträger, folgen (die christlichen Ritter (die ecclesia militans); sie werden empfangen von den Hausgenossen des Himmels (die ecclesia triumphans), Christus, der Kaiser aller Könige, ihr lieber Herr, richtet ihnen selbst das Mahl, setzt sie in die Bänke und reicht ihnen als Truchseß die Speisen und danach gibt er ihnen Gewand zur Kleidung 2988-3095; ferner die realistische Schilderung des Herrenmahles 981 ff., des Wohlstands der Reichen 2404 ff., des Eremitenlebens 3130 ff. Aber doch ist der Stil1) mehr rhetorisch als pathetisch, zu einer starken, von innerer Empfindung getragenen oder von der Wucht großer Gedanken eingegebenen Sprache erheben sich die Worte nicht, sie sprudeln ihm leicht hervor, aber sie strömen nicht kräftig, hier herrscht Redefülle ohne eigentliche Redekraft. Demgemäß zeichnet sich die stilistische Form aus durch viele Parallelausdrücke und -sätze, Aufzählungen, Antithesen, durch formelhafte und öfters wiederkehrende Wendungen und Verse, lauter Dehnungen des Inhalts durch Worte. Unmittelbar zu beobachten ist diese Verbreiterung des Sprachstoffs an den aus dem Lateinischen übersetzten Versen: die vier Punkte im Artikel vom Vater sind in acht Zeilen gedehnt, jeder Punkt in zwei Zeilen (67-74); ${ }^{2}$ ) die zwei Begriffe in $487 \mathrm{f}$. verteilen sich in der Übersetzung auf sechse (489-494), vgl. ferner 1109-1114. 1449-1460. 1544-1560.3)

Der Dichter ${ }^{4}$ ) nennt sich 3737 "ih arme Hartman". Er verstand Lateinisch, hatte sich mit der sapientia philosophorum (345), den sieben freien Künsten ${ }^{5}$ ) beschäftigt und besaß Kenntnisse in der Dogmatik, hatte also geistliche Bildung genossen. Die Art und Weise aber, wie er die Weltentsagung darstellt in Bildern aus der Legende und aus dem wirklichen Leben der Gegenwart, erweckt den Eindruck persönlicher Erfahrung. Wir glauben einen Mann sprechen zu hören, der selbst aus Weltleid Hab und Gut hergegeben, um im Kloster durch strenge Zucht und Entsagung die ewige Krone zu erringen. Da paßt auch die Bezeichnung, die er sich selbst beilegt: nicht Priester nennt er sich, sondern den "armen" Hartmann, den armen büßenden Sünder.

1) SchERER aaO.; Rödiger, Anz. 1, 67 f.; SCHEINS aaO.; REISSENBERGER S. 8 ff.; v. D. LEYEN S. 31 ff. 56-74. 119-158.

2) Man kann verfolgen, wie die 8 Verse zustande gekommen sind. Credo in unum Deum lieferte im Deutschen das Reimwort got; dazu ergab sich als Reim gebot; potrem omnipotentem ist wörtlich verdeutscht uater alemechtic; darauf reimt sich creftic; auf den himel unde di erden $=$ coeli et terrae reimte gwerden und zu der Uebersetzung von visibilium et invisibilium 'sichtic unde unsichtih' ergab sich der Pluralbegriff allir dinge gelich.

3) Das sind Beispiele für das allgemein übliche mhd. Uebersetzungsprinzip, das eben in meist überfluissiger Verbreiterung des fremden Originals besteht (s. unten beim Spielmannsstil). Der Dichter des Glaubens war übrigens geradezu gezwungen, den lat. Text im Deutschen auseinanderzuziehen, denn die vier Punkte in $61-63 \mathrm{z}$. B. konnte er gar nicht in vier Reimverse bringen.

4) Ueber die Person des Dichters s. ReissENBERGER S. 16-21; v. D. LEYEN S. 4 ff.; KELLE aaO. - Diemer hicit ihn für den Sohn der Ava, s. unten.

5) Philosophi sind die Gelehrten der septem artes (s. oben S. 5), hier die wîsen genannt (321. 347. 391. 409). Sie treiben die Wissenschaft, die vergängliche weltliche Weisheit, durh werltlich êre 420. Der Dichter rechnet sich $z u$ den tumben und $z u$ denen, die sich der unvergänglichen Weisheit von Christus hingeben. Auch in der dem Wessobrunner Gebet vorhergehenden Abhandl. wird nach der Erörterung der septem artes der Unterschied $z$ wischen dem weItlichen und göttlichen Wissen gemacht (LG. 1, 140). 
Sein Gedicht nennt er di rede des geloubin 58, uon deme heiligen gelouben 3738 (schon vorher hat er ein deutsches Werk geschrieben über das jüngste Gericht und die letzten Dinge 1622-1641). Es ist ein geistlicher Vortrag, er denkt sich einem Laienpublikum gegenüber, daher die unmittelbaren Anreden wie Vernemet waz man iu sage 13, Zo gote solt ir hoffen 55 , nu vernemet ze dîte dabî $65 \mathrm{u}$. a.; zur Belehrung der tumben will er sprechen (22), das sind die tumben leien im Gegensatz zu den wîsen pfaffen. Aber es ist keine für den liturgischen Gottesdienst bestimmte Predigt, die Gegenstände sind nicht predigtartig ausgeführt und das Ganze ist zu umfangreich angelegt. ${ }^{1}$ )

Der Inhalt setzt sich, wie immer in der frühmhd. Literatur, aus religiösen und fest formulierten Anschauungen der Zeit zusammen, aber eine unmittelbare $Q$ uelle ${ }^{2}$ ) scheint dem Dichter nicht vorgelegen zu haben. So gehört ihm die Verarbeitung des schon in gegebenen Motiven überlieferten Materials. Außer dem nicänisch-constantinopolitanischen Glaubensbekenntnis hat er die Bibel sehr häufig benutzt, kein anderes frühmhd. Gedicht enthält im Ver-. hältnis so viele lat. Zitate. ${ }^{3}$ )

Die Verse ${ }^{4}$ ) haben ziemlich gleichmäßigen, meist gedrungenen Bau und erweitern sich nicht zur Überlänge. Die Assonanzen sind nicht auffallend, schwache Flexionssilben sind nicht mehr reimfähig.

\section{$\S 10$. Ein Scopf.}

\section{(Der scopf von dem lône.)}

Ausg. Martin, ZfdA. 40, 305 ff.; Leitzmann, KI. geistl. Ged. S. 5-9. 30; Schröder, ZfdA. 41, 92-94.

Hs.: Colmar, Kreisarchiv, 12. Jh. (s. unten). Dialekt der Hs. elsäss. Das Gedicht ist in seinem ganzen Umfang erhalten, aber mit einigen Lücken. Der Dialekt des Gedichtes ist alemann., abgefaßt ist es um 1150 oder nicht allzu lange nachher. Der Dichter war ein Volkssänger, ein Spielmann, denn er nennt sein Werk am Schluß einen scopf.i)

Wie verschieden auch inhaltlich die einzelnen Teile sind, so läßt sich doch ein einheitlicher Plan erkennen, dessen Pole Anfang und Ende der Menschheit bilden. Es ist eine Menschheitsgeschichte in einzelnen Bildern: (Prolog II $\left.{ }^{a}, 1-6\right)$; Ursprung der Menschen und ihre Verschiedenheit (II', $\left.7-44\right)$; das schlimmste Laster: der Wankelmut, die Unstäte, Untreue (45-51), daran sich anschließend das Weib, ${ }^{6}$ ) die Ehe (II $\left.{ }^{b}, 1-\mathrm{III}^{2}, 3\right)$; der Mensch als Herr

1) Sichere Interpolationen sind nicht nachzuweisen, höchstens sind einzelne wenige Verse spăter eingefügt worden, vgl. REISSENBERGER S. 6 ff.; SCHRÖDER, ZfdA. 33, 104 Anm.; v. D. LEYEN nimmt stärkere Interpolationen an S. 31 ff. und Beitr. aaO.; dagegen LEITZMANN ebda aaO.

2) Kelle aaO.; V. D. Leyen S. 92 ff.

3) GRÓnEwald aaO.-Parallelen zurKaiserchron. und bes. zum Rolandslied s. bei V. D. LEYEN S. 9 ff.; anderes ebda S. 82 ff. $119-158$.

4) W. GRImM, ZGdR., Kil. Schır. 4, 169;
AMELUnG, ZfdPh.3, 269 ff.; V. D. LeyenS.6-8. 15-34. 45-55; BrüCH aaO.; SCHRÖdER, Gött. Nachr. 1918, 424 f. SARAN S. 254.

$\left.{ }^{5}\right)$ LG. 1, 64 u. Reg. S. 467. - Die Bezetchnung "D.sc. von demlone" stammt von dem Herausgeber Martin, aber das Belohnen (nit den Himmelreich lil c 4. 6. 43. 44, vgl. Elis. PETERS S. $137 \mathrm{ff}$.) ist ein selbstverständlicher und ganz nebensächlicher Zng.

6) Vgl. Franz Brietzmann, Die böse Fram Pal. 42 , S. 143 f. 160. 
der Welt (4-56); die Handlungen, die zum Himmel führen, an Beispielen; die wichtigste Tugend, die Mildtätigkeit, und die Buße (III ${ }^{b}, 1-$ Schluß).

Auch dièses Gedicht umspannt Zeit und Ewigkeit, aber welch ein Unterschied zwischen dem Scopf und dem Gesang des Scholasticus Ezzo! Die ganze Weltgeschichte ist dort zum Jenseits bestimmt und errungen wird dieses durch die Flucht vor der Welt, der Spielmann aber steht fest auf dem Erdboden: der Mensch ist der Herr der Welt; in der Ehe entfaltet sich die Sittlichkeit; die edeln Kinder, die ins Himmelreich, das Land des Adels (edilente 36) kommen, und die von ihnen abgesonderten der Magd sind für den fahrenden Mann nicht bloß theologische Kategorien, sondern Standesunterschiede der bitteren Wirklichkeit; die Freigebigkeit (diu milte) ist für ihn die höchste Tugend, die ins Himmelreich führt, und sein Idealheiliger ist St. Martin, der Ritter, der dem Gehrenden seinen Mantel schenkt.

Spielmännisch ist auch der Stil, mit einer gewissen Nachlässigkeit: Reime und Sätze kehren oft wieder, ${ }^{1}$ ) auch gleiche Reime hintereinander: vier IIa 45-48, sogar fünf III ${ }^{b} 31-35$; Reime guot : tuot bezw. muot kommen zehnmal vor: II 45 f. 46 f., II ${ }^{b} 12$ f. 18 f. 40 f. 44 f. 52 f., III 10 f. 22 f. II 9 f., sehr häufig sind die Reime ân:ân, ât:ât. - Im Satzbau herrscht Parataxe, benachbarte Sätze sind oft von gleichem Bau, auch anaphorisch. Epitheta sind selten angewendet und ausdruckslos; von zweigliedrigen Verbindungen auch nur die allergewöhnlichsten: man unde wib III $^{\mathrm{b}} 36$. III 32 . 33 , wib oldir man II 4 , arm oldir rîh $\mathrm{III}^{\mathrm{e}} 41$, roubete unde brande III 9 , fròde unde wirtscaft III 49 , dazu das sonst seltenere eben unte gnuc III $49 ;^{2}$ ) im Stoff begründet sind die III ${ }^{a} 16-42$ vorkommenden Doppelglieder. Übergangsformeln: II ${ }^{\mathrm{a}} 45$. II $^{\mathrm{b}}$ 13. III 8 . 59, auch III $^{\mathrm{b}} 33$. Zum Volkston paßt auch die Vorliebe für bildliche Vergleiche: II ${ }^{\mathrm{a}} 48-50$. II $^{\mathrm{b}} 18-21.48-57$. III $48 \mathrm{f}$. III $19-28$. Lateinisch ist dreimaliges sanctus in III 52 und euuangelio III $4 .{ }^{3}$ ) Charakteristische Merkmale des germanisch-epischen Stiles treten nicht auf, es fehlen Synonyma und Alliteration.

Die Reime sind zum größten Teil rein, Assonanzen kommen fast nur bei klingendem Ausgang vor. ${ }^{4}$ ) Die Verse sind im allgemeinen normal gebaut, sie neigen eher zur Kürze als zur Länge.

Das Stück hat eine besondere literarische Bedeutung, weil es das älteste mhd. spielmännische Lehrgedicht ist. Geistliche und weltliche Fragen, die im Interessegebiet des Volkes liegen, werden laienverständlich behandelt und kehren zumeist in der späteren Lehr- und Spruchdichtung wieder.

\section{$\$ 11$. Das Paternoster (Auslegung des Vaterunsers).}

Kelle 2, 128-131. 328-331; PIPER, GD. 2, 90 f., Nachtr. S. 251-253. 283-285. Ausg.: MSD. Nr. 43 u. I1 ${ }^{3}, 256-265$; zuerst von MoNE, Anz. f. Kunde d. d. Vorz. 8 (1839), 39-44 (Hs. A); KarajAn, D. Sprach-Denkm. S. 67-70 (Hs. B); WAAG, Kl. d. Ged. ${ }^{2}$ S. 43-52

1) MARTIN S. 310 .

2) SCHRÖDER, ZfdA. 41, 93.
3) GRÚNEWALD S. 26.

4) MARTIN S. $310 \mathrm{f}$. 
u. Einl. S. XXXV-XXXVIII. - BARTSCH, Germ. 9, 64-66; SCHERER, QF. 7. 21. 12, 54; RÖDIGER, ZfdA. 33, 423; KRAUS, ZföG. 45 (1894), 139-142.

Hss.: A. Universitätsbibl. zu Innsbruck (aus Kloster Stams) Nr. 652, Perg., $4^{0}$, Fragmente verschiedenen Inhalts. Unser Gedicht (B1. 72a) steht mit der Siebenzahl und mehreren lat. bezw. deutschen Rezepten (B1. $\left.7^{\mathrm{b}}-79^{\mathrm{b}}\right)^{\prime}$ ) auf einer besonderen, einst selbständigen Lage und ist im 12. Jh. geschrieben. Der Dialekt des Innsbrucker Textes ist bairisch. - B. Milstätter Hs. Bl. 164b-167b. Der Text ist hier stark beschädigt und hat viele Lücken, deshalb miß A als Grundhs. gelten. Beide Hss. haben gemeinsame Fehler (MSD $11^{3}, 259$ ).

Das Gedicht wird um 1135-1145 in Kärnten verfaßt worden sein.

Im Volksglauben wird gewissen Zahlen eine besondere Bedeutsamkeit beigelegt. Eine solche "heilige“ Zahl ist die Sieben. Im alten Testament ist sie eine typische Zahl und im Anschluß an die jüdische Tradition kommt sie in der Apokalypse Johannes zu reichlicher symbolischer Verwendung: sieben Gemeinden 1, 4 u. ö.; sieben Geister vor dem Stuhl Gottes 1, 4. 4, 5; sieben Leuchter 1, 12 u. ö.; sieben Sterne 1, 16. 20; das Buch mit den sieben Siegeln 5, 1 ff.; das Lamm mit sieben Hörnern und sieben Augen 5, 6; sieben Engel 8, 2 ff., mit sieben Posaunen 8, 2. 10, 7; ferner: 10, 3. 4; 12, $3 ; 13,1 ; 15,1.8 .21,9 ; 15,7.17,1.21,9 ; 17,9,11$. Das Christentum, dessen Gedanken in symbolische Form gekleidet sind, nahm auch diese symbolische Zahl auf und maßgebend war auch hier Augustinus: er brachte eine Anzahl von typologischen Siebenergruppen des neuen Testamentes miteinander in Verbindung. Solche sind: die sieben Bitten des Vaterunsers, die sieben Gaben des heil. Geistes, die sieben Seligpreisungen (d. h. die acht wurden auf sieben beschränkt, der Übereinstimmung wegen), die sieben Hauptsüıden, denen gegenüber die sieben Haupttugenden traten; andere Siebenzahlen sind: die sieben Sakramente, die sieben Siegel, d. i. die sieben Stationen des Lebens Jesu; die sieben letzten Worte Christi am Kreuz, die sieben Schmerzen Mariä u. a. So war der Septennarius der numerus perfectus, die vollkommene Zahl. Besonders nahm die Mystik seit Bernhard von Clairvaux und Hugo von St. Victor diese Zahlensymbolik ${ }^{2}$ ) auf. In der allegorischen Auslegung ist die Heptade, ein numerus mysticus, eines der häufigsten Motive. Die Siebenzahl also gab reichlich Gelegenheit, verschiedenartige geistliche Lehrsätze analogisch miteinander zu verbinden, und einer ausgesprochen symbolischen Literatur wie der der mhd. Frühzeit war dieses Thema innerlich wesensverwandt.

Auch unser Gedicht ist ein Zeugnis solcher assoziativer Denkweise, die dem Inhalte nach fernliegende Vorstellungsreihen durch äußere Gleichheit der Zahlen in einen inneren Zusammenhang zu bringen suclit - allerdings

1) J. V. ZINGERLE, Germ. 12, 463-469; Wilhelm, Denkm. d. Pr. Nr. XI 11. XII, das Innsbr. Arzneibuch u. d. Innsbr. Kräuterbuch.

$\left.{ }^{2}\right)$ Realencykl ${ }^{3}$ 18, 310 ff.; KELLE 2, 126 ff. 165 ff. 326 ff. 362 ff.; MSD $11^{3}, 261-265$; Eucherius, Migne 50, 770; Isidor, Migne 83, 179-200; Beda, Migne, 90, 694; Hrabanus Maurus, Matthäuskommentar (Migne 107, 817, vgl. Kraus aaO.); Drogo († 1138, Migne 166. 1553-1558); Bernlı. v. Clairvaux (Migne 183, 688 f. 1034. 184, 574. 1114-1118); Hingo v. S. Victor bes. in den Traktat De quinque Septents (Migue 175, 405-414, ferner ebdil 176, 114-116. 177. 371-373). Zöcki.er, Tugendlehre d. Cliristentuns S. $99 \mathrm{ff}$. 
oft nur durch gewaltsame und weither geholte Analogien -, denn die Zahl sieben ist eben der letzte Grund für diese Ideenverbindungen. Ausgegangen wird von den sieben Bitten des Vaterunsers, denn diese Siebenzahl ist die würdigste in der christlichen Lehre und die Auslegung der petitiones des Paternosters gehört $\mathrm{zu}$ den notwendigen katechetischen Anforderungen.1)

Mit den sieben Bitten sind in Einklang gebracht die sieben Seligpreisungen (Matth. 5, 3-9), in umgekehrter Reihenfolge; sie gehören zum Stand der Vollkommenheit auf Erden. Dann die sieben Gaben des heiligen Geistes (Jes. 11, 2 f.): sapientia, intellectus, consilium, fortitudo, scientia, pietas, timor Dei; in unserm Gedicht ebenfalls in umgekehrter Anordnung (wie Augustin): Gotes vorhte 7, 4; nâch dem vrônem gebote (Frömmigkeit) 9, 4; verwizzenhait 11,6 ; sterche 13,5 ; rât 15,1 ; vernunst 17,9 ; rê̂stuom 19,3 ; sie sind Hilfsmittel des Geistes zur Erlangung der Vollkommenheit. Die sieben Siegel, d. i. Lebensstationen Christi, ebenfalls in umgekehrter Folge: Gericht 7, 5; Himmelfahrt 9, 3; Auferstehung 11,4; Begräbnis 13, 3; Kreuzigung 15, 5 f.; Taufe 17, 5; Geburt 19, 11. Endlich werden symbolisch sieben Patriarchen, Vertreter des alten Testaments angeführt, als Beispiele für die betr. christlichen Eigenschaften, die in den sieben Bitten, Seligpreisungen, Gaben ausgesprochen sind, ebenfalls in umgekehrter Chronologie: David 7, 9; Moses 9, 10; Jakob 11, 9; Isaak 13, 9; Abraham 15, 9; Noe 17, 8; Adam 18, 10. $\mathrm{Zu}$ einem lat. Schema, das nach dem in der Hs. folgenden Gedicht von der Siebenzahl steht, sind die Namen der fünf Siebenzahlen unseres Gedichtes, die auch größtenteils schon den betr. Strophen überschrieben, sind, in sieben Zeilen der Reihenfolge nach, also als Inhaltsangabe, zusammengestellt. Auch die Anfangsworte der in den Strophen zitierten Bibelstellen sind lat. an der betr. Stelle beigeschrieben. ${ }^{2}$ )

In halt. I. Der Eing ang des Gedichtes, Str. 1-5, bezieht sich auf das Verhältnis zwischen den Menschen und Gott und zwischen den Menschen unter sich: Str. 1 Die Weisheit Gottes, Christus, lehrt uns Liebe zu Gott und Gottesfurcht. Er ist Gott und Herr, er ist aber auch unser Vater, wir sind die Kinder. Str. 2 Er hat uns das Vaterunser gegeben, die sieben Bitten. Sieben sind auch die Gaben des heiligen Geistes. Str. 3 Aufzählung der sieben Gaben. Str. 4 Was ist Gottesfurcht? Str. 5 Da wir Kinder sind des Vaters, so sollen wir auch unsere Brüder lieben, so wie Christus uns geliebt hat [das sind die Grundlehren der christlichen Ethik, des praktischen Christentums: Gottesfurcht und Gottesliebe und Liebe zum Nächsten.] II. Der Hauptteil, Str. 6-19, ist regelmäBig schematisch geformt: je zwei dieser 14 Strophen bilden ein zusammengehöriges Paar, in der jeweils 1. Strophe wird der Reihe nach von je einer der sieben Bitten gehandelt, in der 2. von einer der sieben Seligpreisungen, der sieben Gaben, der sieben Siegel (Ereignisse aus dem Leben Jesu, diese sind hier nur kurz angedeutet), und der symbolischen Bedeutung von sieben Patriarchen, in der vorhin angegebenen Reihenfolge (nur Adam steht in der ersten Strophe des betr. Paares). Ill. Im SchluB, Str. 20, wird nochmals die Bedeutung der sieben Bitten wiederholt: die 3 ersten streben zur Vollkommenheit in der Trinität, die Hoffnung auf den Gerichtstag, die 4 letzten geben den Trost für das Elend des Lebens. Die Endgedanken also

1) Siehe LG. I Freisinger Paternoster und Weißenburger Katechismus.

2) MSD. II ${ }^{3}, 261 \mathrm{f}$. 
werden gelenkt auf das Hauptdogma der Dreieinigkeit und auf die menschliche Nichtigkeit gegenüber der im Jenseits zu erhoffenden Wesensvollendung.

Eine Fülle Gedanken sind verschlungen gleich Arabesken, die doch in wiederkehrenden Linien eine sinnvolle Ornamentik bilden, aus der einzelne Motive bedeutsam hervortreten. Die Grundidee ist die Erwerbung der Gerechtigkeit, der Vollkommenheit (durnahtichait 20,3); diese gibt der heil. Geist, er ist der Geist der Heiligung (d. i. die Vollkommenwerdung, Reinwerdung von Sünden), er verleiht diese innerliche Heiligkeit durch die Gnade (Gnade 4, 11. 6, 9. 9, 6. 15, 2) und seine sieben Gaben sind ebenfalls Mittel zur Heiligung. Er verleiht das Gnadenleben, er erweckt dem in Sünden erschlaffenden Menschen ein Sein, er bewirkt eine Wiedergeburt (das neue Leben in der Gerechtigkeit deuten an 5,2 ff. $6,12.8,9.11,4 \mathrm{f} .13,3 \mathrm{f}$. 16, 2-4. 19, 9 f.). Dann erlangen wir die Gotteskindschaft, wir werden aus Knechten des Herrn, die in der Furcht vor Strafe befangen sind, zu Kindern des Vaters, Gottesfurcht und Kindesliebe sind vereinigt (Str. 1 u. 4). Christus ist der Urheber unserer Heiligung, denn er hat uns die Gnade durch seinen Opfertod und durch die Taufe veriiehen $(6,4$ ff. 14, 10. 17, 5); Gnade und Geist machen uns sündenrein $(6,4$ ff.). - Das Ziel der irdischen Läuterung ist die Erlangung des Himmelreichs, des Gottschauens (Blick aufs Jenseits 2, 8. 5, 6. 7, 5. 9, 5. 11. 11, 10. 14, 4. 17, 12. 18, 5 ff. 20, 5). Der Dualismus zwischen Welt und Himmel $(18,4.19,2 \mathrm{ff}$ ), Teufel und Gott $(16,7 \mathrm{f}$. 17, 10 f.), Fleisch und Geist (10, 9 f. 11, 7 f.), Leib und Seele $(12,6$ f.) ist hier. ausgesprochen in dem Gegensatz zwischen dem Geist der Welt und dem heiligen Geist. Das ist ein Hauptpunkt in der Lehre Ruperts von Deutz, ${ }^{1}$ ) unser Gedicht ist also ein Ausdruck dieser die Zeit besonders bewegenden Frage nach der Heiligung durch den Geist.

Quelle. Die Gedanken des Gedichtes mit ihrer eigenartigen Verbindung sind also der kirchlichen Literatur der Zeit entnommen und wahrscheinlich hat dem Verfasser eine ganz ähnliche lat. Zusammenstellung vorgelegen.

Der Stil ist der eines Vortrags vor einem Publikum, und zwar begreift sich der Verfasser mit diesem zusanmen als die gesamte Christenheit, weshalb die 1. Person pl. durchgeht. Die Sprache ist einfach und verständlich, ohne viele Formeln $(1,12.4,1.12,4.9 .20,10)$; dreimal sind lat. Worte gebraucht. ${ }^{2}$ )

Metrik. 20 Strophen $z u$ je 12 Versen. $^{3}$ ) Keine starken Assonanzen; rührende Reime 4, $1.9(14,5)$. 14, 11. 15, 3. 19, 1.9. Die Verse sind von mittlerem Umfang, zuweilen aber über das Normalmaß-gelängt.

\section{$\$ 12$. Von der Siebenzahl.}

Kelle 2, 131-134. 331-335; PIPER, GD. 2, 92, Nachtr. S. 287. - Ansg.: MSD Nr. 44 u. II ${ }^{3}, 265-269$; erster Druck von MONE, Anz. f. Kunde d. d. Vorz. 8 (1839), 44-46; WAAG,

1) BACH, Dogmengesch. 2, 256 ff.

2) GRÜNEWALD S. 8.

$\left.{ }^{3}\right)$ Str. 4 hat 14 Verse, SchERER hat durch
Ausscheidung von V. 5. 6 die normale Zwölfzahl liergestellt, MSD. II ${ }^{3}, 259$. 
Kl. Ged. ${ }^{2}$ S. 52-55 u. Einl. S. XXXVIII f. - BARTSCH, Germ. 9, 66; Scherer, QF. 12, 54; KraUs, ZföG. 45 (1894), 142.

Hs: Universitätsbibl. zu Innsbruck Nr. 652 , B1. 74b-76a , folgt unmittelbar auf das Paternoster, mit der Überschrift De septem sigillis, die der ersten Strophe entnommen ist: mit insigilen siben 1, 6 .

Die Heimat des Gedichtes ist Österreich (MSD. II ${ }^{3}, 267$, zu Str. 6, 3.4), die Entstehungszeit fällt etwa um 1145-1155.1)

Während im Paternoster und in den sieben Gaben des heil. Geistes von der Ava die fünf Siebenzahlen planmäßig angeordnet und durch einen bestimmten Grundgedanken verbunden sind, haben wir hier nur eine Anhäufung vieler einzelner Fälle aus der Bibel und aus der Glaubenslehre. Ausgegangen ist von der Apokalypse, dem Buch mit 7 Siegeln, den 7 Augen des Lammes, das uns die Geheimnisse Gottes eröffnete (Str. 1).

Stil (zusammenfassendes 'wir'; Formel: 5, 4; lat. Worte) 2 ) und Metrik (rührende Reine 1, 9. 4, 3. 6, 5. 8, 1) sind behandelt wie im Paternoster. ${ }^{3}$ ) Es ist möglich, daß beide Gedichte von ein und demselben Geistlichen verfaßt sind.4) Es muß ihm eine lat. Quelle, eine nicht sehr abweichende Sammlung von Siebenzahlen, vorgelegen haben. - Die V. 4, 3 f. stehen schon aim Schluß der Geschichte von Josua in der Vor. Hsr (DiEmer, D. Ged. 69, 4-6).

$\$ 13$. Priester Arnold, Von der Siebenzahil zum Lobe des heiligen Geistes.

Kelle 2, 166-173.363-367; PIPER, GD. 2,97-99. - Ausg.: Diemer, D. Ged. S.331-357 ( „Loblied auf den h. Geist ${ }^{\text {) }}$, Anm. S. 82-87, Einl. S. XLIX f., dazu Kollation von PIPER aaÖ.; Herm. Polzer-van Kol, Sprache u. Dicht. H. 13, Bern 1913. - Scherer, QF. 7, 81-89. 12, 54. 64. 68. 78; Rödiger, Anz. 1, 88; SсHÖNBACH, Priester Arnolts Juliana (s. unten), bes. S. 459 ff.; SCHRÖDER, DLZ. 1883, 555-557; WAAG, Beitr. 11, 142-146; SChWIETERING, Singen u. Sagen S. 7.

Hs.: Vor. Hs. Bl. 129d-133d $(349,15-350,20$ sind von einem andern, aber gleichzeitigen Schreiber geschrieben). Der Text ist ziemlich fehlerhaft.

Der Dialekt ist bairisch, ${ }^{5}$ ) die Heimat des Dichters wahrscheinlich Steiermark oder Kärnten (Innerösterreich), ${ }^{6}$ ) Verfasser ist der Priester Arnold, der auch die Legende von St. Juliana dichtete, Zeit der Entstehung um 1130.

Auch dieses Gedicht ist nicht nach einem festen System gebaut unter Zugrundelegung einer bestimmten Siebenzahl wie das Vaterunser nach den sieben Bitten, die sieben Gaben von der Ava nach den septem donis; doch aber ist es nicht ein planloses Gemengsel zufällig zusammengeraffter Heptaden, ${ }^{7}$ ) denn auch hier können gedankenknüpfende Fäden ausgelöst werden,

1) MSD.II ${ }^{3}$, 269; SCHERER aaO.; KELLE aaO.

2) GRÜnewald S. 9.

3) KELLE S. 131.

4) In der Hs. hat das Gedicht 6 Absätze von 12 und einen von 22 Zeilen (der 6 . Abschnitt der Hs.). ScHERER stellt für das ganze Gedicht gleichmäßig zwölfzeilige Strophen dar, indem er jene 22 Zeilen des 6 . Abschnitts in zwei Strophen, Str. 6 u. 7, zerlegt, wobei er für Str. 6 Ausfall von zwei Zeilen

annimmt. Aber jene 22 Zeilen gehören inhaltlich und der Quelle nach zusammen, so daß sie wohl auch als ein strophisches Ganze zu gelten haben.

5) WaAG aaO.; Polzer-van Kol S. IX u. 59-92. 97-100.

6) Diemer S. XliX; Scherer, QF. 7, 89; SCHÖNBACH S. $486 \mathrm{f}$.

7) MSD. $11^{3}, 268$. SCHERER hat QF. 7, $81 \mathrm{ff}$. acht einzelne Stücke ausgeschieden, Frag- 
man kann die einzelnen Ideenassoziationen fast durchweg verfolgen und sogar literarhistorisch begründen. Gerade aber die freie Beweglichkẹit der im Bewußtsein haftenden Elemente, wo die Phantasie waltet und sich nicht an die Fesseln der Logik kehrt, ist der wesenhafte Zug mittelalterlichen Gedankenlebens.

Die Masse der Siebenzahlen in unserm Gedicht ${ }^{1}$ ) ist in folgender Kette aufgereiht: ${ }^{2}$ )

A. Eingang 333, 1-334, 14: Preis der Dreieinigkeit, insbes. des heil. Geistes. B. Hauptteil 334, 14-354, 7. Einl. 334, 14-28: die erhabene Zahl (sieben), der heil. Geist, Taufe, Dreieinigkeit. I.Erste Gruppe der Siebenzahlen 334, 29-341, 5: a) 334, 29-339, 12: die 7 Gaben des heil. Geistes, dazu zwei Haupttugenden: Gott und den Nächsten lieben; Abschwelfung: Jesus bringt den Aposteln den heil. Geist, der heil. Geist erscheint ihnen 338, 18-339, 12, beide Sätze stehen in Zusammenhang mit dem Vorhergehenden, denn sie stellen die Eingebung der Nächsten- und Gottesliebe dar. b) 339, 12-25 die 7 Bitten. c) 339, 25-341, 5 die 7 Siegel. II. Zweite Gruppe 341, 5-354, 7: a) die Siebenzahl in der Astronomie, diese umfaßt im m.alterl. Schulsystem der 7 freien Künste auch die Zeitrechnung ${ }^{3}$ ) und unter diesem Gesichtspunkt gehören fast alle folgenden Heptaden zur Wissenschaft der Astronomie. a) 341, 5-345, 9: 7 Himmel, 7 Sterne, 7 Sonnen, 7 Wochentage, die 7 Mondphasen als Symbole des menschlichen Lebensalters, ${ }^{4}$ ) dazu die 12 Zeichen des Tierkreises, die 7 Planeten. b) Abschweifung 345, 9-23: der heil. Geist als Deus septiformis. c) 345, 23-346, 26: allegorische Deutung der 7 Kirchen in der Apokalypse auf die 7 Teile des Menschen, auf das 7 tägige Fortschreiten des Kindes im Mutterleibe, ${ }^{5}$ ) die 7 Menschenalter. d) $346,26-347,26$ : die sieben freien Künste, die vom heil. Geist verliehen werden. e) 347, 26-349, 19: das Heranwachsen des Kindes, Gebote für die Eltern, den Pfarrer, gegen die Sünden, bes. gegen den Mord, 7 Gnadenmittel. f) 349, 19-352, 3: die bisherigen Heptaden betrafen das Menschenleben, die folgenden sind Siebenzahlen der Weltgeschichte:

mente, aus verschiedenen Gedichten $\mathrm{zu}$ sammengeschweißt. Auch POLZER-VAN KoL nlmmt an, daß die Dichtung nur zum Teil von Arnold herrühre (S. IX f. u. 101). SCHÖN$\mathrm{BACH}$ aaO. hat dagegen festgestellt, daß Sprachgebrauch, Versbau und Reime so gleichmäßig durch alle Teile des Gedichtes durchgehen, daß zu einer Zergliederung auf einzelne Verfasser keine Veranlassung gegeben ist; vgl. auch KELLE aaO.

1) Die Benennung "Von d. Siebenzahl" usw. stammt von MÜLLENHOFF, vgl. MSD. $11^{3}$, 269.

2) Inhalt:SCHÖNBACH S.472-478; POLZERVAN KOL S. Xlll f.

8) SPECHT, Unterrichtswesen S. 135-139. Die Berechnung der Zeiten konnte zugleich in der Arithmetik behandelt werden (LG. 1, $139 \mathrm{f}$ ).

4) Bedas De temporum ratione enthält dic Zeitberechnungen nacl dein Mondlauf, den Himmelszeichen, darauf die sechs Weltalter mit einer Geschichte der wiclitigsten Bcgebenheiten, abschließend mit denı jüngsten Gericht und der zukiinfligen Welt (Migne 90, 293-578). Hrabanus Maurus behandelt in seinem Liber de Computo Sonne, Mond, Sterne, Lebensalter (Migne 107, 669-728), Honorius Aug. in Buch 11,75 f. von De imagine mundi ebenso Himmelserscheinungen, Zeitrechnung, Lebensalter und Weltalter (Migne $172,156 \mathrm{f})$. Wilhelm v. Conches gibt in seiner Philosophia mundi B. Il einen kurzen Abriß der Astronomie, in B. IV u. a. über die Entstehung des Menschen, dabei über dic Bildung des Menschen im Mutterlcib Kap. 15, Migne 172, 90; diese Stelle ist dann mit einigen Aenderungen in den deutschen Lucidarius ïbergegangen, ed. HeIDLAUF, D. Texte des MA. Bd. 28, S. 29, 5-9; KARL SCHORBACH, Studien über d. deutsche Volksbuch Lucidarius, QF. 74, 164), über die Lebensalter (Kap. XXXVI, Migne Sp. 99), über die sieben Kïnste (Kap. XLI, Migne Sp. 100 f.); vgl. SchönBACH S. 483 f. In dem lat. Abriß der Geographie und der sieben Künste, der dem Wessobrunner Gebet vorangeht (s. LG. 1, 139 f.), stelien am Schluß unter De chronica die sieben Lebensalter in Verbindung mit den sieben Horen und vergliclien mit dem Stand der Sonne.

5) Nach dem dentschen lucidarius wird der Mensch in 40 Tagen geschaffen, darum muB, wer einen Menschen erschlägt, 40 ' lage sich reiligen (HEIDLAUF S. 29,9-11). Die Hereinzielnung des Mordes an dieser Stelle hat also in der Tradition ilıre Begriundung. Vgl. auch Polzer-VAN Kol S. $103 \mathrm{f}$. 
7 Zeichen bei Christi Geburt. g) 352,3-354, 7 : an die 7 Verwandtschaftsgrade werden angeknüpft die 7 Weltalter, darauf das 7. Leid des Menschen, der Tod. Himmel und Hölle. Memento mori. - C. 354, 8-355, 23: der Hymnus Laudate Dominum, es ist die letzte Siebenzahl, der Preis Gottes in den 7 Horen. Die Erzählung vom heil. Geist $(334,15$ f.) strömt aus in einen Hymnus auf den dreieinigen Gott. Dann folgt noch ein spezielles Lob des heil. Geistes 355, 24-356, 16. - D. SchluB 356, 16-357, 17: der Dichter nennt seinen Namen Priester Arnolth und das Thema seines Werkes. Gegen den Teufel, der die törichten Laien verführt, ${ }^{\text {) }}$ ) die Marter Christi und den Ostermittwoch zu beschimpfen. ${ }^{2}$ ) Gebet um Aufnahme in die himmlischen Chöre.

Der Dichter scheint nicht nach einer einheitlichen Vorlage gearbeitet, vielmehr die Masse der einzelnen Siebenzahlen aus seiner eigenen Kenntnis und wohl unter Zuhilfenahme mehrerer lat. Quellen, welche Heptaden da und dort zerstreut darboten, zusammengestellt $\mathrm{zu}$ haben. Das starke Hervorkehren der eigenen Person am Schlusse (356, 16 ff.) läßt auf eine gewisse Unabhängigkeit in der Behandlung des ganzen Stoffes schließen. Dann kommt die Gedankenfolge, sowohl die planmäßige als die willkürlich assoziativ ablaufende, zum größten Teil auf seine Rechnung. ${ }^{3}$ )

Seine theologischen Kenntnisse ${ }^{4}$ ) waren nicht unbedeutend, er bringt manche Einzelheiten bei, die sonst selten vorkommen. Aber auch aus deutschen Quellen hat er zusammengetragen,5) aus der Summa Theol.,.,dem Leben Jesu der Ava, der Milst. Sündenklage, dem Tobiassegen. Die Namensnennung 356, 16-19 (es fehlt in der Hs. ein Reim auf minne) ist der entsprechenden Stelle in Priester Adelbrechts Johannes Baptista nachgeahmt (248-252, Kraus, D. Ged. S. 23). ${ }^{6}$ ) Umgekehrt hat der Pfaffe Konrad im Rolandslied und in der Kaiserchronik eine Anzahl Verse aus unserm Gedicht entlehnt. ${ }^{7}$ )

Der lässigen Gedankenführung entspricht im Stil die bequeme Formulierung neuer Eingänge: alle Augenblicke begegnen Wendungen wie $N u$ wil ich iu sagen, dazwischen auch Quellenberufungen und Beteuerungen wie

1) Zweimal spricht der Priester Arnold von tumpen leigen, 348,27 u. 357 , 4, wo er solche Leute unmittelbar anredet. Er behandelt sie nicht besonders respektvoll: "Ihr könnt es wohl verstehen, wenn ihr es euch nicht verdrießen lassen wollt." Das Beispiel, das er dann anführt, ist aus dem wirklichen Leben gegriffen und auf den Horizont seiner Hörer berechnet. Er ist ein Volksredner, sein Werk eine Laienpredigt.

2) Der Mittwoch, der Tag Wôdans, ist noch heute im Volke ein Ungluickstag. Der "krumme" Mittwoch s. LEXER 1, 2191; DWb. 5, 2451 f.; Schweiz. Idiot. 3, 821 f.; E. L. RocHHOLZ, Deutscher Glaube u. Brauch im Spiegel d. heidn. Vorz. 2, 27. Der Dichter wendet sich hier gegen den Volksaberglauben.

$\left.{ }^{3}\right)$ Ueber den einheitlichen Verlauf der Erzählung in seinem Gedicht über die heil. Juliana s. unten.

4) DIEMER aaO. in den Anm.; SchöNBACH S. 479-486. - Vieles bietet Honorius Aug. in seinen populären Lehrbüchern De imagine mundi, Elucidarius, Gemma animae und besonders in seiner Pfingstpredigt (Migne 172, 959-966), mit der sich Arnolds Siebenzahl selbstverständlich berührt, da beide das gleiche Thema, Lob des heil. Geistes, behandeln. In dem Abschnitt von den sieben Zeichen bei der Geburt Christi 349, 19-352, 3 folgt Arnold der Predigt De nativitate Domini des Abtes Wernher v. St. Blasien (Migne 157, 185 ff.), vgl. Kelle S. 170. 365; POlZER-VAN KOL S. 104-110.

5) MSD II ${ }^{3}, 203.216 .269$ f.; DIEMER in den Anm. zu den betr. Stellen; POLzER-VAN KOL in den Varianten unter dem Text.

6) SCHERER, QF. 7, 89 nach Gervinus; KraUs, D. Ged. S. 116; dagegen Kelle S. 364.

7) DIEMER in den Anm.; SCHRÖDER, Kchr. Anm. zu 606; EMIL KeTTNER, ZfdPh. 9, 283 f.; RÖDIGER, Annolied S. 77 f.; POLZER-VAN KOL S. $48.104 .105 \mathrm{ff}$. 
334 , 14. 29. 335 , 8. 18. $337,10.338,4.340,19.341,5.20 .27 .342,15.345$, 23. 26. 29. 346, 15. 17. 21. 24. 347, 7. 348, 19. 26. 351, 13. 24. 352,3. 7.10.17.

Neben den belehrenden Partien mit ihrer siebenfachen Einteilung (oft aufzählend, z. B. mit aneinanderreihendem sô: 335,28 ff. 346, 3 ff. 346, $18 \mathrm{ff}$. 346, $29 \mathrm{ff}$.) finden sich auch paränetische mit gehobener Stimmung, Preisworte auf Gott und besonders auf den heiligen Geist (333, 12 ff. 334, 2 ff., vor allem aber im Laudate Dominum 354, 8-355, 23). Als in einem Lehrgedicht, das auf Vortrag berechnet ist, herrscht als Redeform der die Hörer bezw. die ganze Christenheit einbegreifende Gemeinschaftsplural. Einen besonders gelehrten Anstrich hat der Verfasser seinem Werke durch die Anfüllung mit lat. Zitaten und Kunstausdrücken verliehen. ${ }^{1}$ )

Metrik. Die Reime sind überwiegend rein, ${ }^{2}$ ) es finden sich aber einige schwere Assonanzen. Die Verse sind von ungleichem Umfang, nicht selten überlang.

Der Lobgesang auf den heiligen Geist 354, 8-355, 23 bildet die Krönung des ganzen Lobgedichtes und den notwendigen Abschluß. Er ist also nicht etwa nur ohne weiteren Plan hineingeflickt, aber er fällt durch seinen Inhalt, der einen in sich abgeschlossenen Hymnus bildet, aus der Umgebung heraus, Müllenhoff und Scherer haben ihn denn auch als ein selbständiges Gedicht, unter dem Titel Laudate Dominum, in den Denkmälern herausgegeben (Nr. 45 u. II $\left.{ }^{3}, 269-271\right){ }^{3}$ ) Da mit dem Aufschwung der Stimmung auch andere sprachliche Ausdrucksmittel als in dem sonst lehrhaften Gedicht sich einstellen mußten, so kann aus dem Stil nicht auf einen andern Verfasser geschlossen werden. Auch nicht aus der Metrik.4)

Der Hymnus besteht aus 7 Strophen, entsprechend der Siebenzahl. Str. 1 u. 2, der Eingang, sprechen von dem täglich siebenmaligen Psalmgesang der Horen, Str. 3. 4. 5. 7 vom Preis der einzelnen Teile der Schöpfung, Str. 6 vom Lob der Menschen und Engel mit den jubilierenden Instrumenten. Zugrunde liegt Ps. 148, mit dem Ps. 150 und Stellen aus dem Gesang der drei Männer im Feuerofen ${ }^{5}$ ) (von Daniel 3, 59 an) und Jes. 6, 2 f. (Apokal. 4, 8) verbunden sind; die Einführung der 7 Horen durch David in Str. 1.2 stammt aus Ps. 118, 164, dazu 1. Paral. 16, 40 (vgl. 2. Paral. 13, 11 ; Ps. 54, 18.6)

Die fünf ersten Strophen haben 10 Verse, die zwei letzten 8. Von Str. 3 an beginnen sie mit Nû loben (lobe wir) dich (dich trehtîn) aver sâa, außer Str. 5; damit zusammen hängt, daß das Reimwort auf $s \hat{a}$ in diesen Strophen auf $a$ ausgehen muß, d. h. ein lat. Wort ist. Die Schlußverse lauten von Str. 2 an abwechselnd laudate dominum de celis und laudate dominum in

1) Grónewald S. 17-19. Laudate Dom. ebda S. 9.

2) W. Grimm, ZGdR., K1. Schr. 4, 168.

3) Scherer, QF. 7, 82 f.; RöDiger, Anz. 1, 87 f.; SCHRÖDER, Gött. Nachr. 1918, 424.
4) SCHÖNBACH S. 459--470. 486.

5) In Dominical ad Laudes gehören Canticum trium puerorum und Ps.148 zum officium.

$\left.{ }^{6}\right) \mathrm{MSD} .11^{3}, 270 \mathrm{f}$. 
excelsis, welche beiden Sätze den 1. Vers von Ps. 148 bilden. - Das Vers$\mathrm{ma} B$ ist regelmäßiger als in dem vorhergehenden Teile Arnolds, überlange Verse begegnen nicht. Der Vortrag des Hymnus war gesangsmäßiger als der der lehrhaften Teile.

$\S 14$. Deutung der Meßgebrăuche.

Kelle 2, 174. 367; PIPER, GD. 2, 126. - Ausg.: Pfeiffer, ZfdA. 1, 270-284; Kelle, Speculum Ecclesiae S. 144-157; LeitzManN, Kl. geistl. Ged. S. 14-20. 30. - SteinMeYER, ZfdA. 24, 92 (Collation); Kraus, Vom Rechte S. 50-56. 88-96; SCHRÖDER, Anz. 17, 295297; Kraus, D. Ged. S. 148 f.

Hs.: München, Cgm. 39, aus Benediktbeuren, Perg., letztes Drittel des 12. Jhs. Innerhalb dieser Predigtsammlung (Ausg.: Kelle, Speculum Ecclesiae, München 1858, vgl. Petzet, Catalogus Tom. V, I, 2, Ausg. 1920 S. 66-68), an eine Predigt De virginibus angeschlossen, folgt, in nicht abgesetzten Versen, also sich von dem umgebenden Predigttext nicht abhebend, auf Bl. 132b-142a unser Gedicht. Der Text ist sehr fehlerhaft. - Wolfenbüttel, Pergamentdoppelbl., 14. Jh., geht von 120 bis $144 .{ }^{2}$ ) Der Text ist viel besser als in M, aber die langen Verse sind gekürzt.

Der Dialekt²) der Hs. und des Gedichtes ist wohl elsässisch, die Abfassungszeit ist um 1160 anzusetzen.

Inhalt. A. 1-78 Nach einer Warnung vor dem Teufel folgen Lehren für den Bearbeiter und Vortrager einer Rede. - B. 79-186 Allgemeines über die Messe: mit Demut wollen wir an sie herantreten 79-114; der Priester 115-130; der Teufel als Verführer zur Sünde 131-152; der Priester als Hirte der Gläubigen 153-186. - C. 187-336 die Kleidung des Priesters. - D. 337-524 der MeBritus.

Ein liturgischer Stoff ist hier in deutsche Verse gebracht, ${ }^{3}$ ) die einzelnen Punkte sind symbolisch ausgelegt und folgen in richtiger Anordnung aufeinander, aber nicht alle zur Messe gehörigen Stücke sind erörtert.

Trotzdem der Inhalt in Einzelerklärung zerfällt, ist die Ausführung doch nicht einförmig und die Sprache ist eindrucksvoll. Die Beschreibung der Kleidung und der Vorgänge ist in Handlung aufgelöst. Der Verfasser besitzt Anschauungskraft, er verweilt gerne bei Bildern, die dann selbständig für sich wirken: die Arbeit des Vogelstellers 9 ff.; der Hirte, der die Schafe behütet oder auch, wenn eines sich von den andern absondert, es mit dem Stab schlägt, daß ihm das Auge blutet oder von Tränen naß wird $161 \mathrm{ff}$. Er versetzt sich in das Gefühl des Helden, indem er den christlichen Ritter zeichnet, der den Volkskampf durchzufechten vermag gegen den schwarzen Meister (den Teufel) und ohne Wunden wieder zu seinem lieben Herrn zurückkehrt zum himmlischen Jerusalem $279 \mathrm{ff}$. Gott ist der liebe Herr, dem wir die Huld verletzen. Der Priester dient Gott, und er hat an ihm einen armen Dienstmann 348 ff. Hier bewegt sich der Dichter in dem Vorstellungskreis des Heldenepos. Besonders da, wo von dem Recht die Rede ist, steht die "Deutung der Meßgebräuche" dem Inhalt nach den Gedichten Vom Rechte und Von der Hochzeit nahe, aber die inneren Beziehungen, die gewiß

1) v. Heinemann, ZfdA. 32, 117 f.; Kraus, D. Ged. S. 149 Anm.

2) RÖDIGER, ZfdA. 20, 317 f.; SCHRÖDER aaO.; KraUs, D. Ged. aaO.
3) M.alterl. liturg. Literatur über Priesterkleidung u. Meßgebräuche s. bei KraUs, Vom Rechte S. 88-96. 
bestanden, liegen nicht klar. $\left.{ }^{1}\right)$ In der Moral des Gedichtes wird der Rechtsbegriff stark betont (100. 198. 200. 227. 255 ff. 280. 293 ff.). ${ }^{2}$ )

Die Benediktbeurer Predigtsammlung, in welche unser Gedicht von der Messe eingeschaltet ist, enthält auch andere liturgische Stücke. ${ }^{3}$ ) Es schließt sich unmittelbar an den vorhergehenden Sermo de virginibus dadurch an, daß es mit dem Teufel beginnt, mit dem jener aufhört.4)

Das Gedicht ist eine gereimte Predigt, denn es steht innerhalb einer zum Vortrag bestimmten Predigtsammlung; auch spricht der Verfasser selbst vom Predigen 30 und redet sein Publikum an $72-78$, das aus Laien besteht. ${ }^{5}$ )

Die Reime sind sehr unrein, viele allerdings sind in der Überlieferung der Hs. entstellt. Der Versbau gehört dem ungleichen Typus an, in dem Wolfenbüttl. Bruchst. sind die Verse auf das Normalmaß gebracht.s)

\section{$\$ 15$. Von Esau und Jakob. Von den zehn Geboten.}

Dürftige Überreste einer Hs. (München, Cgm. 5249 Nr. 26) vom Anfang des 13. Jhs., 10 verstümmelte Querstreifen von zwei Doppelpergamentbl., gefunden von Keinz, hgb. BARTSCH, Germ. 31, 57-66.

Die Sprache der Hs. ist obd., sie ist wohl in Baiern geschrieben, es finden sich jedoch md. Eigenheiten. Das Original ist in Mitteldeutschland entstanden, dafür sprechen die Reime iehen (=jên) : gên 20 f., mach: sprach 63. Als Entstehungszeit sind, den Reimen zufolge, die letzten Jahrzehnte gegen den Schluß des 12. Jhs. anzusetzen. ${ }^{7}$ )

Es sind $z$ wei verschiedene Stücke, $\left.{ }^{8}\right)$ die jedoch von dem gleichen Verfasser stammen, da sie in Sprache, Stil und Metrik ubereinstimmen. Man kann das erste Gedicht, 1-114, „Esau und Jakob" nennen nach der

1) KRAUS, Vom Rechte aaO.; SchröDER aaO.; VOGT, Lit.Bl. 1892 Sp. 146.

2) Wer Gottes Recht begeht, der siegt im Kampf 279 ff., denn er hat das Recht auf sciner Seite: das ist fatalistischer Rechtsbegriff, vgl. LG. 1, 124.

3) CRUEL S. 168.

4) Die Reihenfolge der Predigten von KELles Ausg. S. 130-158 stimmt mit der Anordnung in Honorins' Aug. Predigt De omnibus sanctis (Migne 172, 1013-1022, speziell 1017-1022) überein. In der Benediktb. Sammlung kommen zuerst 4 Predigten in communi: De quolibet sancto S. 130; De apostolis S. 137; De confessoribus S. 141; De virginibus S. 142, dann folgt unser Gedicht S. 144, dann De omnibus sanctis mit der Weihe des Pantheons in Rom. Honorius bringt nach dem Text über dic Jungfrauen usw. (Migne 172, 1017 ff.) eine Erweiterung, die beliebig vorgetragen oder weggelassen werden konnte (Sp. $1019 \mathrm{ff}$.), also an der entsprechenden Stelle, an der in der Benediktb. Samnlung unser Gedicht stelit; und den Schluß der Erweiterung des Honor. bildet die Allerheiligenpredigt mit der Weilıe des Pantheon. - In den V. 129 ff. naclı der Fassung des
Wolfenbilttl. Bruchst. ist der Grundgedanke jenes Sermo de virginibus ausgesprochen: dem aller hêrsten gomen (govmen Hs.) Wolfenbuittel 12 (fehlt in der Münch. Hs.) entspricht der brîtegome) des Sermo (KELLE S. $142 \mathrm{f}$ ), die gotes gimaheln sind die lit heil. gotes gemahelen des Sermo (S. 144), das hêre olevaz in Gedicht 143 (Wolf. V. 24) ist das liehtwaz mit dem Oel in Sermo (Kelle S. 142 f.). - . Der Verfasser der Predigten ist nicht auch zugleich der Dichter unseres poet. Stückes gewesen, dieses war niclit von vornherein mit der Predigtsammlung vereinigt; es hat eine andere schriftliche Tradition, da es viel fehlerhafter ist als der Text der Predigten. Aber die Gedanken des Gedichtes berihren sich manchmal mit denen der Predigten.

5) Lat. Wörter bei GRÜNEWALD S. 25.

6) RÖDIGER aaU.; SCHRÖDER aAO.; KRAUS, Vom Rechte S. 55; Scinde, Cresc. S. 52-54 (6zeil. Stroplien).

7) Vgl. Grünewald S. 11.

${ }^{8)}$ Die Anordnung voll Bartscly ist beibehalten, obgleich sie nicht ganz einwandfrei ist. Möglicherweise gehört das zweite Stück vor das erste. 
auf die zweite der uns erhaltenen Zeilen folgenden roten Überschrift De esav et iacob.

Inhalt: Die Geschichte von Esau und Jakob, Lea und Rahel 1-73, dann von Jakobs Söhnen und von Joseph 74-108 allegorisch ('Misticum' vor V. 35) ausgelegt. Der Gegensatz von Juden und Heiden ist gegeben in Jakob und Esau bezw. ihren Nachkommen 11-17. Jakob außerdem ist der in der Welt lebende und doch seine Seele bewahrende Mensch 45-48. Mit den Kindern der Lea und der Rahel stehen sich gegenüber die Juden und die Christen $30-34 ; 1$ ) Lea und Rahel bedeuten das aktive und das kontemplative Leben 18-29.35-66, womit beide Schwestern in demselben gegenseitigen Verhältnis stehen wie im neuen Testament Martha und Maria. Der Unterschied zwischen dem Leben der in Sorgen geschäftigen Welt und dem der inneren Beschaulichkeit ist ein Hauptmotiv der Mystik, deren ganzes Sein aufgeht in dem Kultus des religiösen Innenlebens. ${ }^{2}$ ) Die ganz verstümmelte mystische Deutung von Jakobs Kindern (Significacio super Abel 111-114) enthielt die Auslegung, daß Abel und Joseph die Unschuld und die Gerechtigkeit bezeichneten. ${ }^{3}$ )

Das zweite Stück, 115-222, überschrieben Von den zehen geboten (rot), beginnt mit einer selbständigen Einleitung 115-141 (Anrufung Gottes 115-125, das alte und das neue Testament 126-141). Der Hauptteil 142-206 enthält die Bestimmung der 10 Gebote. Die Lehre der einzelnen Gebote ist kurz angegeben, darauf folgt jeweils, soweit aus den abgerissenen Bruchstücken zu sehen ist, eine Hinweisung auf das zukünftige Leben. Nach der Behandlung aller Gebote kommt zum Abschluß eine längere Vermahnung auf den jüngsten Tag, auf Himmel und Hölle. Dann aber sind noch einige Verse über einen andern Gegenstand vorhanden, 207-222, sie handeln von Lucifers Fall. Ob dieses Thema noch mit dem vorhergehenden über die letzten Dinge in Verbindung stand oder einen ganz neuen Abschnitt bildete, ist bei dem unzusammenhängenden Bestand der Überlieferung nicht zu erschließen.

Die hier gemachte Einteilung der 10 Gebote in $3+7$, die erste und die zweite Tafel, die sich auf die Pflichten des Menschen gegen Gott bezw. gegen den Nächsten beziehen, ist die allgemein übliche in der Glaubenslehre. In den ersten 3 Geboten wird zugleich die Verehrung der Dreieinigkeit gelehrt, die übrigen bilden eine Siebenzahl, weil sich unser Leben und damit das Werk unserer Nächstenliebe in 7 Tagen abspielt, vgl. bes. Hugo v. St. Victor, De sacramentis lib. I pars XII Kap. 6.7.8 (Migne 176, 352-360, bes. 355 A B) und Summa Sententiarum Tract. IV Kap. 3-8 (Migne 176, $120-126)$.

1) Vgl. für diese Stelle bes. St. Bernhard, De modo bene vivendi Kap. 53; Appendix zu Hugo v. St. Victor De nuptiis II, 1 (Migne 176, 1213 f.); Honorius Aug. Spec. eccl. In festo Innocentium (Migne 172, $838 \mathrm{BC}$ ); In dedicatione Ecclesiae II (Migne 172, 1107).
2) Oder wie Synagoge und Ecclesia in Willirams HL.

$\left.{ }^{3}\right)$ Abel und Joseph stehen in Parallele, beide sind innocens und justus, PseudoHugo v. St. Victor, Migne 175, 640B. $652 \mathrm{~A}$. 
Aus dem Zustand der Überlieferung ist nicht zu ersehen, ob beide Stücke Teile ein und desselben Werkes oder zwei selbständige Gedichte sind. Die solenne Einleitung zu den "Zehn Geboten" spricht für die zweite Annahme; und ebenso die Verschiedenheit in der stofflichen Grundanlage, denn in „Esau und Jakob" wechseln erzählende mit lehrhaften Partien, da dieses Stück von der biblischen Geschichte ausgeht, während die "Zehn Gebote“ keinen erzählenden Untergrund haben, sondern nur aus dogmatischen Erklärungen bestehen. Was die fehlenden Teile enthalten haben, ist nicht mit Sicherheit zu bestimmen. Das ganze erste Gedicht, von dem „Esau und Jakob" ein Bruchstück ist, war wohl eine tropologische Auslegung der Genesis oder wichtiger Teile derselben, wobei der Schwerpunkt auf den mystischen Deutungen lag, während der biblische Text nur die Anhaltspunkte für die theologischen Erörterungen abgab, denn die erzählenden Partien sind ganz knapp gehalten und betreffen nur einzelne dogmatisch verwertbare Hauptstellen.

Metrik. Die Assonanzen sind nicht stark; voller Flexionssilbenvokal reimt in gebot: hangot $163 \mathrm{f}$. Mehrsilbige Senkungen begegnen nicht selten, aber keine schweren Senkungsfüllungen.

$\$ 16$. Alcuins Traktat De virtutibus et vitiis.

Kelle 2, 81. 289; PiPer, Ält. d. Lit. S. 460. - Ausg.: GrafF, Diut. 1, 281 -291, dazu Collation von SCHERER, ZfdA.21, 414; genaner bei PIPER, Notker II, Einl. S. I-lV, vgl. Bd. I, Einl. S. XCVI; und bei Wilhelm, Denkm. d. Prosa S. 33-37, Komm. I S. 70-79; Naumann, Prosaleseb. S.4-8. - Scherer, Anz. 1, 190 u. Kl. Schr. 1, 302, QF. $12,78$.

Hs.: München, Clm. 7637, 12. Jh., ist dic Notkers Vaterunser enthaltende Indersdorfer Hs. (s. LG. 1, 428), vgl. MSD. II ${ }^{3}, 403$; PIPeR aaO.; Wilheim, Komm. S. 70 f. An das Vaterunser schließt sich unmittelbar unser deutsches Stïck an, Bl. 46a-48a.

Es ist die prosaische Übersetzung der Kap. 1-9 von Alcuins Tractatus de virtutibus et vitiis (Migne 101, 613-619 A), ${ }^{1}$ ) mit Ausnahme des 5.Kapitels, unter den lat. Überschriften De Sapientia, De Fide, De Caritate, De Spe, De Pace, De Misericordia, De Indulgentia, De patientia, und bricht etwa mit dem ersten Drittel von De patientia ab, das 5. Kapitel, De lectionis studio, fehlt in der deutschen Übersetzung. $\left.{ }^{2}\right)$

Alcuin hat das Werk für den Grafen Wido von der Bretagne geschrieben als Handbuch zum täglichen Gebrauch (Migne 613 C-638 B), um daraus $z \mathfrak{u}$ lernen, was zu tun und $z u$ lassen sei. Es ist eine kurz gefaßte christliche Morallehre, begründet in dem System der Tugenden und Laster, besonders unter Beziehung auf die guten Werke (Kap. 16 f.), die Buße (Kap. 11-14) und auf die Pflichten eines-Regenten (Kap. 19-21). Die Über-

1) KARL, Werner, Alcuin 11. sein Jh. S. 32 f.; Ebert 2, 22; Manitius S. 283; Max Förster, Archiv 122 (1909), 257. 260 f. 129 (1912), 49.

2) Auf den deutsclien Text folgt in der Hs. der lat. (abgedruckt bei Graff u. bei Wilhelm im Konm.), der aucl das in deutsclien Text fehlende 5. Kap. enthält. Graff liell das
Werk fii einen lraktat Nortperts (der lieil. Norbert, Stifter des Prämonstratenserordens, + 1134) und nannte es Uebersetzung des tractatus Nortperti de virtutibus. Erst KELL.E aaO. Liat es als Alcuins Traktat erkannt, vgl. WHLELM, Komm. S. $71 \mathrm{f}$. 
setzung ist gewandt, sie hält sich stellenweise ziemlich genau an das Original, das sie zuweilen kürzt. Einige Male sind Reime angebracht. ${ }^{1}$ )

Die Hs. hat alemann. u. bair. Formen. Der Verfasser war wahrscheinlich Alemanne. ${ }^{2}$ )

\section{$\$ 17$. Idsteiner Sprüche der Väter.}

Der größere Teil der Bruchstücke gehörte einer jetzt verschollenen Hs. des 13. Jhs. in Idstein (Nassau) an, hgb. von KaRL Rотн, Bruchstücke aus Jansen des Eninkels gereimter Weltchronik, Anhang, München 1854 (über die Hs. K. Roth, Kl. Beitr., 1. H., München 1850, S. 35 ff.; MSD. II ${ }^{3}, 238$; Jellunghaus, ZfdPh. 15, 349); ein Blatt wurde später im Staatsarchiv zu Wiesbaden gefunden; hgb. von WiLH. MiethKe, ZfdA. 51, 102-106.

Eine Blütenlese von moralischen Aussprüchen aus den Kirchenvätern, Sententiae S. Patrum, zum größern Teil aus Gregors Werken, angeordnet nach dem Inhalt. Der Vers- und Reimtechnik nach sind sie in der ersten Hälfte des 12. Jhs. verfaßt worden, und zwar dem Dialekt zufolge im nördl. Rheinfranken oder im Moselfränkischen.

\section{c) Geistliche Epik.}

\section{Die Bibel.}

a) Das alte Testament.

\section{$\$ 18$. Die altdeutsche Genesis und Exodus.}

(Wien-Milstäter Genesis und Exodus.)

Kelle 2, 21-30. 251-260; Piper, GD. 1, 87-193. 194 f., 2, 294, Nachtr. S. 253-260. 371. - Ausg.: Wiener Hs.: GrafF, Diut. 3, 40-112 (Wien. Gen., nicht ganz vollständig); HofFMANN, Fundgr. 2, 9-101 (Wien. Gen. S. 9-84, Wien. Ex. S. 85-101), dazu Collation von PIPER, ZfPh. 20, 479 f.; MASSMANn, D. Ged. 2, 158 f. 235- 110 (Wien. Gen.), 326-342 (Wien. Ex.), dazu J. GRIMM, Besprechung von Hoffmann und Maßmann, Gött. gel. Anz. 1838, S. 549-551. 554 f. u. KI. Schr. 5, 280 f. 283; PIPER GD. aaO. (Wien. Gen. bis zum Tod Isaaks). Milstäter Hs.: Jos. Diemer, Genesis und Exodus nach der Milstäter Hs. hgb. I. II, Wien 1862 (Bd. 1 Einl. u. Text, Bd. 2 Anmerk. u. Wörtèrb.), dazu BarTsch, Germ. 8, 247-252, BECH, ebda 466-482, DiEmer, ebda 482-489, BARTSCH, ebda 9, 213-217 (zur Textkritik und zum Wortschatz), PIPER, Nachtr. S. 253-260 (Verbesserungen zu Diemers Text); ERnst Kossmann, Die ad. Exodus, QF. 57, dazu Vogt, LC. 1886, 629-631, PNiower, Anz. 13, 1-11, Schröder, DLZ. 1886, 1338 f., v. BAHDER, Lit.BI. 1886, 446-449. - DIEMER, KI. Beitr., Wiener SB. 55 (1867), 331-337; K. Hofmann, Münch. SB. 1870, 2, 183-196; Scherer, QF. H. 1 u. H. 7, 3-7. 12, 44-51; RöDIGER, ZfdA. 18, 263-280; VoGt, Beitr. 2, 208-317, dazu Rödiger, ZfdA. 19, 148-154, Vogt, Beitr. 2, 586-592; PNIOWer, Zur Wien. Gen., Berl. Diss. 1883, dazu Vogt, Lit.Bl. 1885 Sp. 5-8; PNiower, Der Noe der Wien. Gen., ZfdA. 29, 26-47; ders., Der Abraham der Wien. Gen., ebda 30, 1.50-175; ders., Die Abfassungszeit der ad. Exodus, ebda 33, 73-97; Johannes Joachim, Zur ad. Gen., Berl Diss. 1893; Harry Petersen, Deutsche Altertümer in der Wien. Gen., Gött. Diss. 1897; Stephan GrudzińSKI, Der Vocalismus und Consonantismus der "Wien. Gen.", Progr. Kremsier 1901, dazu DollmaYr, ZföG. 53 (1902), 845 f.; Vict: Dollmayr, Die Sprache der Wien. Gen., QF. 94, dazu JellineK, ZföG. 55 (1904), 418-421, LC. 1904, 105 f. (zur Sprache auch ZwierZINA, ZfdA. 45, 281; Vogt, Beitr. 45, 460-463); EmIL Kreibich, Über die Wien. u. Milst. Hs. der Genesis, Progr.

1) WiLhelM, Komm. S. 79.

2) Ebda S. $77 \mathrm{f}$. 
Tetschen 1904, dazu Dollmayr, ZföG. 56 (1905), 853 f.; Fritz Bulthaupt, Milst. Gen. u. Exod., Pal. 72, dazu GieraCh, DLZ. 1913, 1386f, Behaghel, Lit.Bl. 1914, 381 f., Moser, ZfdPh. 46, 294 f.; Alfred Weller, Die frühmhd. Wien. Gen., Pal. 123, dazu rez. Archiv 134, 453 f., VoGT, CB. 1915, $1277 \mathrm{f}$.

Hss.: Die Wien-Milstäter Genesis und Exodus sind in der Wiener Hs. 2721 (W) und in der Milstäter Hs. (M od. K) (s. oben S. 15) erhalten. $M(K)$ ist eine iiber ein halbes Jahrhundert jüngere Bearbeitung von $W,{ }^{1}$ ) die den Sinn zwar wenig antastete, aber mit dem Grundtext doch ziemlich frei verfuhr, indem sie sprachliche und technische Altertümlichkeiten, veraltete Formen, Wendungen und Reime und ungebräuchlichere Redensarten durch neue und gewöhnlichere ersetzte und ein reineres Metrum herstellte. Aber durch Korrigieren wurde zuweilen der alte Text verschlechtert und durch Kleinigkeiten, wie Umstellungen von Worten, Vereinfachung des Satzbaues, direkte Rede statt indirekte, die Ausdrucksweise alltäglicher gemacht. ${ }^{2}$ ) Die Änderungen sind nicht überall gleich stark, am Anfang des Ganzen und des Joseph sind sie durchgreifender.

Der Joseph ist sowohl in der Wien-Milstäter (WM) als auch in der Vorauer (V) Genesis überliefert. Das Verhältnis dieser drei Hss. des Joseph ${ }^{3}$ ) ist der Art, daß W und $M$ wieder auf eine gemeinsame Vorlage zurückgehen, also WM $-\mathrm{V}$. Als Hs. verdient $\mathrm{W}$ den Vorzug, $M$ hat auch hier stark modernisiert, $V$ hat viele Flüchtigkeitsfehler.

Inhalt der Genesis: I. Schöpfung und Sündenfall, Hoffm. 10, 1-23, 17: Einleitung 10, 1-5; Erschaffung der zehn Engelchöre, Lucifers Sturz, Beschluß Gottes, den Menschen zu schaffen, um den gestürzten Engelchor zu ersetzen 10,6-12,5; Schöpfung von Himmel und Erde (das Sechs-Tagewerk) 12,6-13, 2; Erschaffung des Menschen 13, 3-16, 14; das Paradies 16, 15-17, 35; Erschaffung des Weibes 17, 36-18, 11; Sündenfall und Verstoßung 18, 12-23, 17. II. Kain und Abel 23, 18-27, 5. III. Noe 27, 6-29, 35: Sintflut 27, 6-28, 24; Noes Trunkenheit, Entstehung der Stände 28, 25-29, 18; Sprachverwirrung 29, 19-29, 35. IV. Abraham 29,36-36, 14. V. Isaak und seine Söhne 36,15-52, 18. VI. Joseph in Ägypten $52,19-84,20$.

Die frühmhd. Genesis ist eine freie Übertragung des ersten Buches Moses. Ihm folgt der Dichter ohne stärkere Verletzung der grundsätzlichen Überlieferung, doch hat er den biblischen Text vielfach umgestaltet durch Weglassung oder Zufügung (I) von Stoffteilen, durch religiös moralisierende Erläuterungen (II) und durch Übertragung alttestamentlicher Darstellung in die Auffassungsweise seiner Zeit (III).

1. Weggelassen ist vieles Nebensächliche wie die Kämpfe Abrams Kap. 14, Abraham und Abimelech Kap. 20. 21, 22-34, die Kinder Heths und Ephron Kap. 23; und besonders die Geschlechtsregister 4, 17-24. Kap. 5. Kap. 10. 11, 10-32. 25, 1-7 u. 12-18. Kap. 36. 46, 8-27; aber aucl die Zerstörung von Sodom und Gomorra mit Lots Flucht 18, 16-33 u. Kap. 19, wie denn auch die Episode von Juda und Thamar wegen ihres verfänglichen Inhalts ausgeschieden ist ${ }^{4}$ ) Kap. 38. Vieles auch ist gekürzt, wie dic Verheißungen des Herrn an Abraham Kap. 13 u. 17, an lsaak 26,1-5, an Jakob 35, 1-15; Isaak in Gerar 26, 6-26.

1) DiEMER, Gen. u. Ex., Einl. S. IV-VI; SCHERER, QF. 7, 3 f.; VOGT S. 210-230; 271 -273; Bulthaúpt bes. S. $17-19$.

2) Bulthaupt S 148-162.

a) Vogt aaO.; Diemer, Gen. u. Ex. Bd. 2 , $52 \mathrm{f}$; SCherer, QF.7, $45 \mathrm{f}$; K Kelle S. 118. $320 \mathrm{f}$.
4) Bcim Strafgericht iiber dic bciden Städte kam die Gerechtigkeit Gottes in Frage. Un1erfalurene konnten sich diesen Fall nicht erklären, deshalb wolıl ist der biblische Bericht nicht aufgenomunen worden, vgl. Otloch, Dialogus de tribus quaestlonibus Kap. XIX, Migne 146, 84-86. 
Weniger die Ausschaltungen als die Zutaten und Erweiterungen beeinflussen die Darstellung. Sie sind verschiedenen Ursprungs. Besonders im 1. Teil, doch auch im 2. und 3., sind außer der Vulgata Nebenquellen benutzt. Größere Fülle und poetischen Schwung hat der deutsche Verfasser der lat. Genesisdichtung des Alcimus Avitus ( $\dagger$ als Bischof von Vienne 523) entnommen, ${ }^{1}$ ) die aus fünf Büchern besteht, zumeist dem ersten und zweiten Buch. Manchmal sind es mehr nur Anregungen oder Motive im allgemeinen; wie besonders bei dem Wunderwerk der Schöpfung und bei der Versuchung, zuweilen aber auch unmittelbare Entlehnungen.

So z. B. stammt die der menschlichen Natur glücklich abgelauschte Schilderung von Evas Zweifel, ob sie der Lust zum verbotenen Obste folgen solle 19, 1 ff., aus Avitus (Migne 334A); hier fand der Dichter auch die Verfluchung Chams mit der Entstehung der Stände 29, 11 f. (352 AB); das verlorene Magdtum der Erde 26, 1 f. (340C) und einzelne ausmalende Züge, so $13,5 \mathrm{ff} .=$ Migne $327 \mathrm{~A} ; 13,25 \mathrm{f} .=326 \mathrm{~A} ; 16,20 \mathrm{ff} .=329 \mathrm{D} .330 \mathrm{CD}$, vgl. $326 \mathrm{C} ; 17,38 \mathrm{f} .=327 \mathrm{~B} ; 18,20=332 \mathrm{D} ; 19,36-39.21,33-40.23,31-40=339 \mathrm{~B}$; $28,21-24=356 \mathrm{ABC}$. Bei einigen ausgedehnten Schilderungen sind außer Avitus noch andere Quellen benutzt, so für 13,32-15,34 (Migne 326 AB) des Lactanz De opificio Dei u. Isidors Etym. XI, 1 (oder des Hrabanus Maurus De Universo VI, 1); 16, 23-35 (vgl. Migne $326 \mathrm{C})=$ Isidor Etym. XVII, 8-11 (Hrab. XIX, 8); 26, 10-25 (vgl. Migne 326A. 328A) $=$ Isidor Etym. XI, 3 (Hrab. VII, 7). Mit diesen Einlagen ist ein dem biblischen Stoffe fremdes Element hereingekommen: Anthropologie, Ethnographie, Botanik, die sich aber an das Schöpfungswerk und die Erzählung von den ersten Menschen ohne Zwang anschlossen. Die Teile IV, V und VI des deutschen Gedichtes sind von Nebenquellen wenig beeinfluBt. Manche Motive, wie die gegensätzliche Charakterisierung Esaus und Jakobs, finden sich in des Hrabanus Maurus Kommentar zur Genesis, aber dieser hat seine Werke selbst wieder aus anderen zusammengeschrieben. ${ }^{2}$ )

II. Der Dichter hat seinem Werke eine besondere, eine lehrhafte T endenz verliehen, denn er knüpft an den biblischen Bericht, wo ihm der Inhalt gelegen scheint, christlich religiöse Betrachtungen und Ermahnungen an. ${ }^{3}$ ) Die biblische Geschichte soll nicht nur Erbauung, sondern auch Belehrung gewähren, soll Fundamentstücke der christlichen Moral enthalten. Die Grundpfeiler sind Sünde und Gnade, Gott hat die Gnade, die Gegensätze werden vermittelt durch die Buße. Das ist die sittliche Lebensaufgabe: von der Sünde durch die Buße zur Gnade, die erfüllt wird in der ewigen Seligkeit. Die in den drei ersten Teilen ausgesprochene moralische Tendenz hat der deutsche Dichter in das Werk hineingelegt. Die Stellen sind zahlreich: 11, 15. 12, 37. 22, 5. 22; 21, 20-24. 33-40. 22, 27--23, 5. 23, 31-24, 20. 26, 3-6.40-42. 35, 41-36, 14; die Taufe sündentilgend 20, 29. 28, 21-24.4)

1) Migne 59, 323-368; DiemER, Kl. Beitr. aaO.; SCHERER, QF. 1, 11 ff.; VOGT, Beitr. 2, 289-292. 311 f.; Kelle S. 252-258; Weller S. 42-86; Osw. Zingerle, Der Paradiesgarten der ad. Genesis, Wiener $\mathrm{SB} .112$ (1886), 785-805; R. v. FisCHER-BENZON, Ad. Gartenflora, Kiel 1894, dazu Hoops, LitBl. $1897,223-225$.

2) DIEMER, Kl. Beitr. aaO.; SCHERER, QF. 1, 52-57; Weller S. 80-83. Die lat. Kom- mentare zur Genesis vor Hrabanus Maurus und Walahfrid nennt Kelle S. 21 f. 25. 251 f. 258 f. Die Quellen für die Entlehnungen des deutschen Dichters sind noch nicht vollständig nachgewiesen.

3) WELLER S. 5-21. 190-192.

4) Gottes Gnade beim Sündenfall ist auch das Thema der ersten Kapitel von Otlohs Dialogus de tribus quaestionibus, Migne $146,61 \mathrm{ff}$. 
Die Erlösung allerdings ist erst durch die Menschwerdung und den Kreuzestod Christi möglich geworden, der sündlose Gott hat Adams Fall getilgt 23,11-17. Ein massiver Teufelsglaube herrscht in dem Gedichte.1) Der Teufel ist der Erzbetrüger, die Sünde kommt von ihm. Das Urlaster ist der Hochmut, mit Lucifer hat er angehoben: an ime huob sich allerêst ubermuot 11, 14 (vgl. 11, 19), der Fall des schönsten Engels geschah durch Übermut, da er seinen Stuhl über den Thron Gottes setzen wollte 11, 25 (= Jes. 14, 12-14); er wollte wie Gott sein im Hochmut 17, 6. 14. 26, 38. Sein Abbild, der Antichrist, kommt vom Neid 43, 14 f.; auch er will im Hochmut Gott sein 80, 4. 18 f. Dem Menschen, der der Welt lebt, die Demut aufgibt und in Hochmut und Herrschsucht nach Ehren strebt, schleicht der Teufel nach 80,6-13. Durch Hochmut, der sie zu dem Bau des Turmes trieb, gingen Noes Nachkommen zugrunde. Die Lust (concupiscentia) reizt Eva zum Apfelbiß 19, 7, vgl. 18, 10. Aus Neid verführte der Teufel den Menschen zur Sünde 18, 12 ff. 26, 32 ff., zur Wollust, zum Hochmut, Habgier, Neid, Zorn (das sind 5 Todsünden), zu verschiedenen Lastern 20, 29-21, 30. Jederzeit sind wir bereit, uns mit Wollust, Neid, Hochmut und mit Habgier (4 Todsünden) zu beflecken 23, 45. 24, 2. Kain ist ein Beispiel des Neides und des Zornes, durch den Brudermord entstand der Neid und $\mathrm{HaB}$ unter der Menschheit 25, 24-33; Cham ein Typus des verhöhnenden Spötters 28, 25-29, 18. Von Seth stammen die Kinder Gottes, von Kain die Kinder Belials, des Teufels 26, 26-45.

Zwischen zwei Mächten steht der Mensch, auf der einen Seite der Teufel mit der Verführung zur Sünde, auf der andern Gott mit der Gnade. Von der Beichte hängt es $a b$, welcher von beiden er zufällt. Der Schwerpunkt des moralischen Handelns ist für den Christen in die Beichte gelegt. Ihre Bedeutung für das kirchliche Leben des 11. und 12. Jhs. ist uns durch die umfangreiche deutsche Beichtformelliteratur bezeugt.2)

Am Schluß des ganzen Gedichtes setzt wieder ein langes geistliches Stück ein, diesmal eine allegorische Auslegung, der Segen Jakobs 77, 30-82, 40. Daß das hier Ausgesprochene einen tieferen Sinn habe, ein tiefiu rede 78,2, darauf machen die wiederholt eingestreuten technischen Ausdrücke bezeichinet, bizeichinheit, bizeichinunge aufmerksam $(78,4.5$. 11. 79, 2. 43. 80, 1. 36. 81, 5). Diese Symbolik am Schluß umfaßt die gcsamte Erlösungsgeschichte in der Entwicklung von Christi Geburt zumn Tod, weiter zum Antichrist, jüngsten Gericht und Himmelreicls. Die einzelnen Stufen sind auf einzelne Söhne Jakobs verteilt. Der Mittelpunkt aller Gedanken ist Christus als Überwinder des Teufels 78,18 f. 32-40. 80, 36-42. $82,28 \mathrm{f}$. So ist die geistige Weltgeschichte auch in der Wiener Genesis aufgefaßt in der Form des romanischen Kunststils als Kampf des guten und bösen Prinzips mit dem Sieg des Guten. 
Auf den Segen folgt der Tod Jakobs 82, 40-83, 20 und hier nimmt der Dichter noch einmal Gelegenheit, auf die Bedeutung der Beichte hinzuweisen: wer den Teufel überlistet, daß er mit Beichte und Buße Gottes Treue sucht, der hat mit Abraham die ewige Ruhe, mit Isaak Freude, mit Jakob die Anschauung Gottes und kann wohl sagen, daß es ihm gut gegangen sei.

Nun läßt sich die innere Entstehung des religiösen Gehaltes, den der Dichter in die biblische Überlieferung hineingelegt hat, überblicken. Es ergibt sich ein doppelter Ursprung: die Lehre von der sündentilgenden Beichte, von der Gnade und vom Teufel stellt er aus eigenem Zutun in den Mittelpunkt der christlichen Glaubenstatsachen; dagegen bei der tropologischen Auslegung des Jakobssegens ahmt er einen Kommentar nach, in dessen Inhalt er aber eben jene eigene Grundansicht über Beichte und Teufel einflicht.

Der Dichter spricht die einfachsten religiösen Gedanken aus, er will moralisch wirken, nicht wissenschaftlich, für das Volk, nicht für die Gelehrten. Den Kindern hat Gott gegeben, was er den Weisen und Schlauen verborgen hat, den Kindern ist die Gnade geoffenbart 78, 7-11, die gelehrte Auslegung des Kommentars zum Segen über Juda nennt er eine tiefe Rede, die wohl niemand ganz ergründen könne 78,2-4. Dogmatische Schwierigkeiten vermeidet er. Über die Dreieinigkeit und das Meßwunder spricht er nur in wenigen und zudem nicht besonders klaren Worten 13, 27-31. 28, 14-20. Marienverehrung kommt nicht zum Ausdruck; von sante Marie wird nur gesagt, daß die reinen Jungfrauen bei ihr sind 20, $40 \mathrm{f}$, daß Christus der Magd Sohn ist 80, 22.

III. Den biblischen Stoff hat der deutsche Dichter in volkstümliche Auffassungsweise ${ }^{1}$ ) übertragen, Menschen und Dinge sieht er als Erscheinungen seiner Umgebung: das ist eine Umbildung der inneren Form, eine realistische Stilisierung des Vorstellungs- und Empfindungslebens. Es ist zugleich auch eine Änderung der Erzählungsart: der Inhalt der einzelnen Szenen ist meistens zusammengezogen, ${ }^{2}$ ) selten gedehnt; das Tempo der Darstellung ist rascher geworden, jedoch sind in die einzelnen Bilder kleine, ausprägende Sonderzüge hineingezeichnet, die der Erzählung eine schärfere Gliederung verleihen und sie kräftiger ausmalen. Die Abtönung des biblischen Kolorits zum m.alterl. deutschen ist die tiefliegendste Umwandlung, an die Stelle des alttestamentlichen Pathos, das der Ausdruck ist ewig gültiger Werte und einer großen und furchtbaren Weltgeschichte, ist volkstümliche Einfachheit getreten, welche die Weit sieht mit natürlich menschlichem Empfinden in dem engeren Rahmen der eigenen Zeit. Die hebräische Genesis ist zu einem deutschen geistlichen Epos geworden. ${ }^{3}$ )

1) Vgl. die Diss. von Petersen.

2) Kürzungen: Weller S. $87 \mathrm{ff}$.

3) Auf der Verständlichmachung, vulgarisatio, beruht ïberhaupt diese freiere Uebertragungsmethode in der ahd. und mhd. Literatur. Otfrid hat sie befolgt wie Hartmann v. Aue, vgl. SCHÖTZE, Beitr. zur Poetik Ot- frids, bes. S. 56 ff.; Albert Hass, Das. Stereotype in den ad. Predigten, Greifswald. Diss. 1903. Es ist die in literaturgeschichtl. Abhandl. mit unrecht sog. "psychologische Vertiefung “, s. EHRISMANN, ZfdPh. 36, $516 \mathrm{f}$. 45, 306, Studien über Rudolf v. Ems S. 77 f. 
Der Grund zu dieser geistigen Umschaffung liegt nicht allein in der dichterischen Eigenart des deutschen Geistlichen, sondern zugleich in dem Gesetze, das ihm bei seiner Arbeit vorschwebte: es ist eine Regel der Predigt, das Vorgetragene dem Verständnis und dem Herzen des Hörers oder Lesers näher zu bringen. Darum also auch mußte er in die biblische Geschichte so viel von seiner Zeit und von seiner eigenen inneren Erfahrung hinein legen, weil es zur Aufgabe des Predigers gehörte. Und somit ist der tiefste Ausgangspunkt für die Umformung des biblischen Stoffes in dieser bestimmten Art in letzter Hinsicht Stilisierung im Sinne der Predigt.

Diese Umformung läßt sich beobachten 1. an kleinen Einschaltungen und 2. an ganzen Szenen.

1. Gern knüpft der Dichter kurze Beobachtungen an den Bibeltext an, allgemein gültige Erfahrungen ${ }^{1}$ ) wie: Adam lebt nach Ehebrauch mit seinem Weibe, so wie man es hierlands und dortlands pflegt 23, $19 \mathrm{f}$.; als Abraham 175 Jahre alt wurde, mußte er den Weg gehen, den wir alle gehen werden, wie alt wir auch werden mögen $35,36 \mathrm{f}$; ; was geschehen soll, das kann niemand abwenden, Menschenstreben hilft nicht viel, wenn es nicht Gottes Wille ist 36, $43 \mathrm{f}$; ; viel gewährte Gott Joseph, außer daß er ihn, wie es seine Sitte war, versuchte, ob er an ihm nicht zweifle 56, 16-18. Häufiger noch sind Beziehungen auf Zustände und Gebräuche der Gegenwart: es ging ihnen (Adam und Eva) wie jetzt manchen Seelen, die vom Reichtum in Armut kommen 24, 42 f.; die Sitte (die Beschneidung) ist noch heute unter dem jüdischen Volke 31, 35, vgl. 48, 19; aus den Standesanschauungen der Zeit heraus kommt die Mißachtung der Kaufleute als Betrüger 32, 41-44, desgl. der „Kaltschmiede“ (Hausierer)2) 31, 22-30; eine unmittelbar historische Anspielung wird beim vierten Finger, dem Ringfinger, ${ }^{3}$ ) gemacht: der König hat die Sitte, damit (mit dem Ring) das Bistum demjenigen Priester anzuverloben, den er zu einem Herren machen will 14, 15 f., worunter die Belehnung der Bischöfe und Äbte durch den Kaiser mit dem Ring verstanden ist (vgl. die Belehnung Josephs mit der höchsten Reichsgewalt $61 ; 11-17=$ lat. Gen. 41, 42). Die Gesellschaft, in der sich der Dichter bewegt, besteht aus Rittern und Bauern (Bauernleben s. unten "Das Recht"), helede und riter sind die Patriarchen mit ihrer Umgebung. $\left.{ }^{4}\right)$

2. Wo sich Gelegenheit gab, hat der Dichter die uberlieferten Szenen in seinem Sinne umgearbeitet. Er konnte dabei alte biblische Motive verwenden, sofern sie in dem gleichzeitigen Volksepos wirksam waren, wie Brautwerbung, 33, 35-35, 23, Gelage 31, 40-32, 1. 35, 5-8. 47, 1 f., Empfang, Abschied, ${ }^{5}$ ) Totenklage 33, 32-34. 83, 26-84, 18, vgl. 35, 34 f. Ein gutes Beispiel, wie der Dichter den biblischen Stoff in seine Anffassung iibertragen hat, gibt die Werbung Eliesers um Rebekka 34,1-35, $23=$ Gen. 24, 1-61. Die

1) WELLER S. 192-194.

2) SCHERER, QF. 1, 24-26.

3) WELLER S. 45.
4) Kelle S. 29; Petersen S. 13 ff.

5) Empfang und Abschied s. WeLler S. 176 $-178$ 
Änderungen hängen zumeist mit der Umbildung der alttestamentlichen Brautwerbung in eine altdeutsche zusammen. In der Bibel werden die Ereignisse geleitet von der wunderbaren Fügung Gottes, die der Weg des Knechtes zu Rebekka als der künftigen Stammutter des jüdischen Volkes lenkt, im deutschen Gedicht bestimmt Abraham schon von vornherein Rebekka als Braut seines Sohnes und gibt genau deren Angehörige an 33, 35 ff. (gegenüber Gen. 24, 4). Die Abendzeit, wenn die Weiber Wasser am Brunnen holen Gen. 24, 11 ist für deutsche Sitte die Stunde, da man das Vieh zur Tränke treibt 34, 4. Statt 10 Kamelen werden nur 2 beladen 34, 1 (Gen. 24, 10), weil der Umarbeiter nur die Beladung mit Kleinodien meint. ') Empfangsszenen gehören zu den typischen Motiven der volkstümlichen Epik: bei der Begrüßung Eliesers 34, $27 \mathrm{f}$. fallen die orientalischen Gebräuche weg. Eine Zufügung des Dichters ist wieder die Anpreisung der Heirat, daß es Rebekka gut gehen werde, wenn sie Isaak nähme 34,35 (vgl. 35, 16);2) ebenso die Frage der Angehörigen an Rebekka, ob sie dem Knecht in ihr eigenes Heim folgen wolle $35,15 \mathrm{f}$., womit ausgesprochen ist, daß sie durch das Verlöbnis in eine andere Sippe übergeht und eigenen Besitz erhält. Im Stil des Volksepos ist es, wenn das Gelage mit Behagen geschildert wird 35, 5-8. Nach m.alterl. Sitte werden der die Heimat verlassenden Braut dienende Jungfrauen mitgegeben 35, $17 \mathrm{f}$, , und hinzugefügt wird als Grund, daB ihr die Abreise nicht zu schmerzlich werde. Es ist ein bewegtes Abschiednehmen der Tochter aus dem Elternhaus; und die Klage 35, 20 ist ebenfalls ein volksepischer Zug. ${ }^{3}$ )

Schon die biblische Genesis hat starke Gefühlsakkorde, die deutsche Übertragung hat dieselben noch gesteigert. Wie dort treten sie nur bei bestimmten Gelegenheiten ein, jedoch häufiger und in größerer Stärke. Es sind einzelne Momentäußerungen, die Kunst, die Gefühlsuntertöne durch die ganze Erzählung der Menschenschicksale mitschwingen zu lassen, ist noch auf lange hinaus nicht entdeckt. Es gehört überhaupt zum inneren Stil des deutschen Volksepos, das Empfindungsleben zu Geltung kommen zu lassen, und so hat der deutsche Dichter, wo er Gefühlsmomente in der Bibel vorfand, diese meistens erweitert, oft aber hat er auch unabhängig von der Vorlage neue hinzugetan. Weitaus am meisten Empfindungsgehalt hat schon in der Bibel die Erzählung von Joseph. Es ist eine rührende Familiengeschichte, in der der hebräische Dichter durch starke Gemütsbewegungen die Handlung dramatisch belebt.

Stimmungserregende Motive im deutschen Volksepos sind besonders

1) Zwei Saumtiere sendet auch Erec seinem Schwiegervater, Hartm. Erec 1812 ff.; drei Saumtiere mit Silber und Gold: Fleckes Flore 2671.

2) So suchen die hunnischen Gesandten das Widerstreben Kriemhildens gegen die Heirat mit Etzel zu beschwichtigen, Nibel. (Bartsch) 1239-41. - Die Schönheit der Re- bekka wird durch Vergleich mit den Jungfrauen ihrer Umgebung hervorgehoben $34,13 \mathrm{f}$. (Gen. 24, 16): so leuchtet Kriemhild an Schönheit vor ihren Frauen, Nibel. (Bartsch) 283.

3) Stimmung beim Abschied: Trauer, Weinen, Nibel. (Bartsch) 69 f. 1091. 1286. 1291. 1710 f.; fröhlicher Abschied 701; Trauer und Freude 1522, 3. 4 . 
Abschied und Totenklage. Die Totenklagen ${ }^{1}$ ) sind überhaupt die sentimentalen Einschläge im volkstümlichen sowohl wie im höfischen Epos, es sind die Gelegenheiten, bei welchen die Dichter die stärksten inneren Erregungen zur Äußerung bringen können, und darum gehören sie zum herkömmlichen Motivenschatz der Erzählungsliteratur. Die Klage um die Toten war gebotene Sitte bei den Hebräern und den Germanen. Der deutsche Dichter hat die Stellen der biblischen Genesis - Abraham klagt um Sara Gen. 23, 2, Joseph um Jakob 50, 1, die Ägypter um Jakob 50, 3 - ebenfalls aufgenommen 33, $32-34.83,21-24.83,26 \mathrm{f}$, wobei er in $33,33 \mathrm{f}$, wie häufig in den späteren deutschen Gedichten, nachher den Klagetrost folgen läßt mit dem aktuellen Hinweis sô tuot unser igelîch sô ime gescihet samelîch. Selbständig ohne Anregung durch die Bibel hat er beigebracht die tägliche Klage Isaaks an seiner Mutter Grab 35, 34 und die Klage Jakobs und seiner Söhne um Isaak 52, 8-102) zu Gen. 35, 29, die allgemeine Klage um Joseph 84, 18 (man chlagit) zu Gen. 50, 25, besonders aber die erschütternden Worte des Dichters beim Tode der Rahel 51, 31-42 zu Gen. 35, 19 f.: er tritt gleichsam selbst vor den vom Unglück Zerschmetterten und statt ihn zu trösten, malt er ihm die Größe des Verlustes aus und läßt ihn die ganze Ohnmacht seines Jammers fühlen. Es ist eine unbarmherzige Leichenpredigt. Doch mit einem einfachen, aber wahrhaft ergreifenden Zug schließt diese Trauerszene: als der leidgebeugte Mann von dem Grabe nach Hause kam, nahm er sein kleines Kind auf seinen Arm, Benjamin, die Waise, seinen Liebling 51, 43-52, 3.

Auch offizielle Empfangsszenen ${ }^{3}$ ) gehören zum stehenden deutschenMotivenschatz, aber nicht zum biblischen, der Dichter hat sie demnach auch ohne Veranlassung seiner Vorlage angebracht und zwar in den üblichen Formeln (wole empfâhen, willekomen heizen): 34, 27 (Gen. 24, 32). 47, 1-6 (Gen. 32, 6). 66, 28 (Gen. 43, 27). 70, 27 (Gen. 45, 16 ff.). 73, 14 (Gen. 47, 1 ff.). $\left.{ }^{4}\right)$ Dagegen sind Wiedersehens- und Erkennungsszenen ${ }^{5}$ ) mit den stereotypen Gebärden des Umhalsens, Küssens, Weinens nicht deutsch, der Dichter hat sie aber aus der Vorlage getreu aufgenommen, z. T. unter wörtlicher Wiederholung: 41, 31-34. 35-38 (Gen. 29, 11-13). 48, 30-32 (Gen. 33, 4). 66, 36-40 (Gen. 43, 30). 70, 19-24 (Gen. 45, 14). 72, 20-22 (Gen. $46,29)$. - Joseph ist eine empfindsame Natur und der Dichter kehrt diese zarte Seite seines Wesens noch mehr hervor (vgl. 57, 40-42. 58, 2. 14. 35 f. 59,5 f. 63,38 f. $66,36-40.84,1$; die väterliche Licbe Jakobs zu Benjamin 52, 1 f. 62, 27 f. 63, 7; zu seinen Söhnen 71, 36. 75, 26; Klage der Bruder 67, 38-40). Ist in den vorhergehenden Fällen die Stimmnng schon im hebräischen Gemütsleben vorgezeichnet, so läßt der geistliche Dichter aus

1) s. LG. I, Reg. S. 468, auch ZfdPh. 36, $397 \mathrm{f}$. aaO.
3) Weller S. 176 f.; PANzer, Hilde-Gudrun S. $31 \mathrm{ff}$.

4) Weller S. $175 \mathrm{f}$.

s) Weller ebda. 
eigenem Empfinden ohne Anlehnung an die Bibel den Schmerz der Betroffenen zum Ausdruck kommen, wo momentanes Unglück über sie hereinbricht: so die Klage des im Elend verkauften Knaben Joseph 55, 1-4 (Gen. 37, 28), das Weinen des Kindes Benjamin, da es nie mehr seinen lieben Vater sehen werde 67, 41 f. (Gen. 44,13). Das sind Klänge aus dem deutschen Volksepos, der Geistliche aber flocht sie ein, weil er damit Rührung bei seinen Hörern erzielen konnte. Denn das gehört auch in eine Predigt. - In Joseph aber hat der deutsche Dichter außerdem einen besonderen Typus seiner Zeit dargestellt, nämlich den Edelmann. Die biblische Geschichte gab hierzu nur die äußeren Lebensereignisse, seine hohe Ehre und fürstliche Stellung am Hofe, die Umdeutschung in ihrer vergegenwärtigenden Tendenz verleiht dem Helden der Erzählung aber auch die entsprechende Persönlichkeit: sein ehrenhafter Sinn wird gerühmt, sein feiner Anstand, sein sittsames Gebaren, seine Mäßigkeit, seine Schönheit und Makellosigkeit 55, 30 f. 56, 6-18. 81, 37-82, 6 .

Die Rührung der Freude ist viel seltener als die des Schmerzes: die Brüder küssen freudig Simeon, als er ihnen wiedergegeben wird 66,23 , in Freuden kehren sie mit Benjamin $z \mathfrak{u}$ ihrem Vater zurück 71, 14-19; beide Stellen sind unabhängig von der Bibel. 71, 35-40 entspricht, lebhafter ausgedrückt, Gen. 45, 27 f.

Schließlich liegt auch oft in der mehr formal stilistischen Ausdrucksweise eine leise Nuancierung des Gefühlslebens, so wenn bei dem redeeinleitenden sprach ein Adverbium steht, wie er sprach wile minnechlîchen 69, 30 oder uil riuwechlîchen 39, 28, wil âmerlîchen 39, 38, uile gezogenlitchen 47, 31, ferner $39,24.48,13.34 .40 .71,17$; oder beim Gebrauch von zärtlichen Epitheta: uater mîn der guote 38, 26, mîn sun guoter 40, 22, vgl. 71, 18; trût bei kint: trût chint mîn 38,42 u. ö., liep bei vater, muoter, barn u. a. ${ }^{1}$ )

Die realistische Gegenwartsschilderung wird zu einem Kulturbild, wo der Dichter aus dem Landleben schöpft. In harter Arbeit bewirtschaften die ersten Menschen nach ihrer Vertreibung aus der Herrlichkeit des Paradieses den kärglichen Boden, gerade wie ihre späten Enkel, die österreichischen Bauern des Mittelalters 24, 26-25, 10 und "wie manche, die vom Reichtum in Armut gekommen sind" 24, 42 f. Ausführlich schildert der Dichter die Arbeit um die Lebensmittel in Feld und Garten. Kain schafft Sommer und Winterum die Ernährung, Abel geht den langen Tag in der Sonne und hütet die Lämmer: eine Bauernfamilie, deren beide Söhne so grundverschieden sind, jeder in seiner Art sein Tagewerk tuend. Derselbe Gegensatz zwischen dem kräftigen, draußen im Leben schaffenden Menschen und dem beschaulichen, in den Zelten wohnenden ist dargestellt an Esau und Jakob 36, 29-37, 4.2)

1) Weller S. 143-147.

2) Das aktive und das kontemplative Leben, 
Die Sprache ${ }^{1}$ ) ist einfach, ohne rhetorische Stilisierung und ohne besonders hervortretende Eigentümlichkeiten. Zwillingsformeln, Epitheta, Anapher, formelhafte Wendungen und Sätze werden mit Maß gebraucht, stehende Beiwörter sind nicht gerade häufig, aus dem Lat. sind einige Kirchenwörter und Eigennamen entnommen.2) Im Satzbau wechseln Parataxe und Hypotaxe. ${ }^{3}$ )

Die Wien-Milstäter Genesis steht mit den Lektionen des kirchlichen Gottesdienstes in Beziehung: in der Vorfastenzeit, die vom Sonntag Septuagesimae bis zum Dienstag vor Aschermittwoch reicht, und am II. und III. Sonntag der darauffolgenden Fastenzeit ist die Lesung der Genesis vorgeschirieben. ${ }^{4}$ ) Die ersten Kapitel derselben stehen in innerem Zusammenhang mit der Bußzeit durch den Sündenfall, hier liegt der Ursprung der Sünde und damit des Bußbedürfnisses. Daraus erklärt sich, weshalb in der deutschen Genesis die Buße das religiöse Thema bildet.

Das Gedicht war zum Vortrag bestimmt, worauf die, allerdings nicht häufigen, Anredeformeln deuten, zumal es gleich mit einer solchen beginnt: $\mathrm{Nu}$ fernemet mine liebe, ich wil in aine rede fore thon. ${ }^{5}$ ) Es wurde also in einzelnen Lektionen ${ }^{6}$ ) vorgelesen, und zwar wohl hauptsächlich vor Laien. Die ursprünglichen Lektionen, die jeweils auf die einzelnen bestimmten Tage fielen, lassen sich nicht mehr abteilen. ${ }^{7}$ )

Der Verfasser war ein Klostergeistlicher, vielleicht ein Kanoniker, ${ }^{8}$ ) er war geübt im Predigen und die Ausdrucksformen der Predigt hat er auch der Sprache seines Gedichtes zugrunde gelegt. Von der Predigt hat er die Vorzüge der Technik, des Aufbaus und der Gliederung, der Regehaltung der Aufmerksamkeit durch lebhaften Fortgang der Erzählung und durch Wirkung auf das Gemüt. Das alles ist gelernte Kunst, ist Form, Stil, nicht angeborene, besondere dichterische Begabung. Eine ausgeprägte künstlerische und menschliche Persönlichkeit läßt sich darum aus dem Werke nicht auslösen, aber es offenbart sich hier eine maßvolle Natur, die das Menschliche mit menschlichem Verständnis beurteilt und nicht mit leidenschaftlichem Übereifer asketisch verdammt. ${ }^{9}$ )

1) Ueber den sprachlichen Stil s. WELLER S. 87-237; BulthaUPT S. 116-144. 148162 ; GotTH. KRÖMER, Die Präpositionen in Gen. u. Ex., Beitr. 39, 403-523.

2) Weller S. 187 f.; Grünewald S. 9 f.

$\left.{ }^{3}\right)$ "Wiederholung ", s. BEHAGHEL, Beitr. 30, $431-564$.

4) SCHRÖdER, ZfdA. 26. $199 \mathrm{f}$; über die Septuagesimalzeit vgl. MAR'TIN GEBERT, Vetus Liturgia Alemannica, St. Blasien 1776, II et IIl pars p. 938 ff.; Thalhofer 2, 595-60l; Amalarius (Presbyter in Metz um 820), De ecclesiasticis officiis lib. I, I Cap. 1, Migne 105, 993 ff.; RUPERT V. DEUTZ, De divinis officlls lib. IV Cap. 1-6, Migne 170, 87-93.

8) Weller S. 186.

6) Man kann diese Absclnnitte "Reim- lektionen " nennen, SCHRÖDER aaO.

7) In der Vorfastenzeit, die 17 Tage dauert, an deren jedem eine Lektion stattfindet, werden die Kapitel 1-14 der Genesis gelesen; denen entsprechen im Gedichte die Verse vom Anfang bis 30,29 , das sind 825 Langverse (1650 Verse). Die etwaige Anzahl der deutschen Lektionen kann man aber nicht bestimmen, da man nicht weiB, ob an jedenı dieser 17 Tage je eine Lektion vorgetragen wurde.

8) KELLE S. 27 ff. 259 f.

9) Vogt S. 267 ff. 288 ff. ; Scherer, QF. 1, 7 ff., s. auch 12, 44-49, hat aus Ungleichmäßigkeiten der Belıandlung und Bearbeitung, aus Schwankungen des Stils und der Metlıode (S. 9), 6 Verfasser erschlossen, wobei das 
Seine Heimat hat der Verfasser in Österreich, vielleicht in Kärnten. Dorthin weisen die Sprachformen.1) Für die Abfassungszeit²) gibt die Anspielung auf die Laieninvestitur 14, 15 f. einen Anhalt: gegen diese erließ Gregor VII. zum erstenmal auf der Synode zu Rom 1075 ein Verbot, vor diesem Jahre wird also das Gedicht entstanden sein, auch die Sprache und die noch sehr freie Reimkunst sprechen für diese Ansetzung. Die Metrik ${ }^{3}$ ) zeigt die Freiheiten des 11 . Jhs. Die Reime sind sehr altertümlich, oft stark unregelmäßig, tieftonige Silben sind leicht Träger der Bindung. Auch dreifache Reime kommen vor. Große Bewegungsfreiheit herrscht ebenso im Rhythmus, die Verse sind ungleich gebaut, besonders häufig überlang.

\section{Exodus.}

Hss. ${ }^{4}$ ): Die Wiener Hs. ist am Schluß nicht vollständig, sie enthält nur Vulg. Kap. 1 $-8,17$, es fehlen die in der Milstäter Hs. vorhandenen Verse DIEMER $138,9-138,35$, bei Kossmann 1401-1454, vor allem aber die ganze Schlußpartie von Diemer 139,11, bei Kossmann von 1480 an, also ca. 1887 Verse, d. h. über die Hälfte. W und $M$ sind gute Abschriften ein und derselben Vorlage, $M$ hat in der Exodus den Grundtext nicht modernisiert wie in der Genesis. Zwischen der Wien-Milstäter Exodus und dem das gleiche Gebiet umfassenden Vorauer Moses finden nur lose Beziehungen statt, ein sicherer Beweis dafür, da $\beta$ der eine der beiden Dichter das Werk des andern gekannt habe, ist nicht erbracht.

Der Dialekt ist der gleiche wie der der Genesis, die Heimat des Gedichtes ist also ebenfalls Österreich, wahrscheinlich Kärnten. Aber die Abfassungszeit ${ }^{5}$ ) fällt um einige Jahrzehnte später, etwa um 1120 , denn die Verskunst ${ }^{6}$ ) ist weiter vorgeschritten, das Gesetz der vier Hebungen ist eingehalten, mit den Freiheiten allerdings der frühmhd. Zeit, so daß auch überlange Verse, besonders am Schluß von Absätzen, selten zu kurze, vorkommen. Die Reime stehen auf einer jüngeren Stufe als die der Genesis, die Freiheiten in der Assonanz sind geringer und tieftonige Silben sind nicht mehr so leicht Träger des Reimes. Der Verfasser war ein Klostergeistlicher.

Der Inhalt umfaßt die ersten 15 Kapitel der Exodus, d. i. den Auszug der Kinder Israel bis zum Lobgesang Moses nach dem Untergang der Ägypter im roten Meer. Den Eingang bildet ein Prolog mit Inhaltsangabe $1-10^{7}$ ) und Bittgebet an Gott um Verleihung der Dichtkunst durch

erste Stïck wieder in zwei Lektionen zerfällt. Ihm folgen RöDIGER, der für Schöpfung und Sündenfall zwei verschiedene Verfasser annimmt, und PNIOWER aaO. Die Einheit hat Vogt durch exakte Untersuchungen bewiesen; s. auch KELLE und WELLER aaO. An ihr wird wohl jetzt kaum mehr gezweifelt werden.

1) SCHERER, QF. 1, 64 f. 12, 44; Vogt S. 230 -240. 261-266; GRUdzIŃSKI, DOLlMAYR, Kreibich, Bulthaupt (S. 19-95) und oben.

2) DIEMER, Gen. u. Ex., Einleit.S. VI ff., Scherer, QF. 1, 59-61; Vogt S. 261 ; Kelle S. 27. 259 .

3) W. Grimm, ZGdR., Reg. S. 333; VoGT
S. 217 ff. $230-261.587-592$; RÖDIGER aaO. DOLLMAYR S.47-109; BulthauPT S.96-116. 144-147; SCHRÖDER, Gött. Nachr. 1918 S. 422 f.; SARAN S. 254 .

4) DIEMER, Gen. u. Ex., Einleit. S. I ff.; SCHERER, QF. 1, 70-77. 7,6 f.; VOGT, Beitr. 2, $271 \mathrm{ff}$; KosSMANN S. $2-5$; BulthauPT S. $1-18$.

5) PNIOWer, ZfdA. 33, 73-97.

6) W. GrimM aaO.; SChERER, QF. 1, $71 \mathrm{ff}$. 7, 6 f.; VOGT S. 273-284; KOSSMANN S. 6-18; SCHRÖDER, Gött. Nachr. 1918, 424.

$\left.{ }^{7}\right)$ Die Zahlen beziehen sich auf die Ausgabe von Kossmann. 
Sendung des heiligen Geistes (Anrufung $11 \mathrm{f}$., Bitte 12-20. 29-34, Begründung 21-28). Ihm entspricht am Schluß ein Epilog mit dem Dank an den heiligen Geist für die Gewährung der Bitte 3303-3316. Der Hauptteil zerfällt in 3 Stücke: 1. Bedrückung der Israeliten, Vorgeschichte Moses, Moses und Aarons Berufung 35-938; 2. die Verhandlungen mit Pharao und die zehn Plagen (die hier aber auf neun vermindert sind, da die dritte und vierte vereinigt wurden) $939-2750$; 3. der Auszug 2751-3302.

Quelle ist eine Bibelhs., die aber von der Vulgata an etwa einem Dutzend Stellen abweicht. ${ }^{1}$ ) Erweiternde Zusätze sind häufig, Kürzungen seltener, ${ }^{2}$ ) doch ist der Inhalt der Bibel dadurch wenig geändert. Die Übersetzung ist nicht frei von Mißverständnissen und Fehlern. Wie der Dichter der Genesis hat auch der der Exodus die Bibel in geistlich-epischem Sinne stilisiert, in der Art der Übertragung aber weicht er von jenem ab. Er steht dem biblischen Text nicht so frei gegenüber, sondern folgt ihm Schritt für Schritt, wobei er das dort Gesagte breiter und umständlicher ausdrückt. Bei der Übertragung des alttestamentlichen Stoffes in die Verhältnisse seiner Zeit hat auch er epische Motive aufgenommen, wie den Empfang 389-398. 889-892 u. 901 ff., einen Abschiedssegen 831-834, Totenklage 2680-2706. Am stärkten aber kommt der mittelalterliche Geist zum Ausdruck in der Freude am kriegerischen Leben. Moses wart ein degen lussam 425; die Israeliten sind die hêrren 135. 2940, die gotlieben hêrren 3021; manche sind von adele geborn 127, hêrlìche chnehte 129, sî sint guote chnehte, geturren wole vechten $95 \mathrm{f}$. Sie sind eine adelige Kriegerkaste, die in der Gefangenschaft zu Knechtsdiensten erniedrigt wird; schließlich erlangen sie wieder die Freiheit und es entsteht der Krieg zwischen den zwei feindlichen Heeren, dem israelitischen und dem heidnischen (swarze môre 3043. 3060. 3256). Moralisch sind sie in Gegensatz gestellt: die Juden unternehmen die Fahrt ohne jeden Übermut 2928, der Heiden Prahlerei dagegen war groß 3075-3077, vgl. 3038; als aber das Meer sie umringt, da geraten die vermessenen Helden in Furcht 3222. Mit diesem jähen Wechsel von Hochmut und Fall hat der geistliche Dichter die Verderblichkeit der Superbia, des Urlasters Satans und seines Geschlechtes, der Heiden, wirksam gekennzeichnet. Das Motiv aber der Ausrüstung und das große Interesse für den Glanz der Waffen und die Herrlichkeit ritterlicher Erschęinung liat or dem damaligen Heldenepos entnommen: $\left.{ }^{3}\right)$ in solcher Pracht läßt das Rolandslied Freund und Feind, Roland und die Heiden, auftreten 3279-3368 (Bartsch) und das Endurteil über die Heiden ist ebenfalls: sic führten großen Übermut 3361 ff. - Aber auch die Kröten, Läuse und Heuschrecken der Plagen werden als in das Land fallende feindliche Heerscharen aufgefaßt; sie fechten gegen den mächtigen König Pharao für den erhabenen Himmelskönigy 1360-1362, besetzen das Land 1375. Der Dichter wendet dabei das Mittel

1) KossmanN S. 24-32.

2) VogT S. 312-314; Kossmann S. 40 ff.

3) Vgl. Vogt S. 285 f.; PNiower, ZfdA. $33,80 \mathrm{ff}$. 
der negativen Schilderung an und gibt wiederum eine Ausrüstungsbeschreibung. Die Kröten werden Helden genannt 1384. 1408-1416, die Läuse sind wilde Gottesritter 1482, die die Beleidigung Gottes rächten 1494, gute Wiegande, schnelle Helden waren die Heuschrecken 2175-2180. Diese verritternde Personifizierung der Kleinkreatur ist ein glücklicher Kunstgriff, um das Vorstellungsinteresse zu reizen. Das gleiche Kunstmittel, durch eine negative Veranschaulichung die positive Tatsache $z u$ heben, wendet der Dichter bei der Errettung der israelitischen Knaben an: daß die Ammen die Kinder vor der Vernichtung. behüteten, stellt er an dem Bilde einer Walstatt vor Augen: der Rabe brauchte hier keinen blutigen Schnabel zu bekommen, die Geier konnten wohl ihr gieriges Schnappen lassen, der graue Wolf brauchte nicht dahin zu laufen noch die Hetzhunde mit hungerigem Munde 157-164. Dieser frühmhd. ritterliche Stil kam in der Kreuzzugsepik (Rolandslied, Alexanderlied) zur Blüte, aus dieser Literaturströmung heraus ist die Verritterung in der deutschen Exodus zu erklären und die dem Dichter vorschwebenden Helden sind nicht nur Ritter im allgemeinen, sondern es sind im speziellen Kreuzritter, es sind Gottesritter.

$\mathrm{Zu}$ Gefühlsäußerungen der Trauer und der Freude gibt die Bedrückung und die Befreiung der Juden schon in der Bibel Gelegenheit. Sie sind in dem deutschen Gedicht häufiger und stärker: 453-456. 511. 925. 1051 ff. 1095-1098. 1739-1748. 3274; Totenklage Pharaos und der Ägypter 2680-2706; Klage der ertrinkenden Ägypter 3268. Das Mitleid der Ammen 153-156, die Vaterfreude Moses $421 \mathrm{f}$. haben in der Bibel keine Entsprechung.

Die Exodus hat nur den Zweck, die Tatsachen der Bibel zu erzählen, nicht auch, durch dieselben $z u$ belehren, ${ }^{1}$ ) eine besondere religiöse Auffassung hat der Dichter in die Überlieferung nicht hineingetragen, wie dort ist Gott der Herr, der menschlich in die Geschichte seines Volkes eingreift. Den Hymnus Moses 3289-3296, der das Ende der ganzen Erzählung bildet, benutzt der Dichter, um eine Schlußmoral anzuknüpfen: so wollen auch wir tun, damit wir aus diesem Elend heim zum himmlischen Jerusalem fahren 3297-3302. Dieses aber ist eben der mystische Grundgedanke des Auszugs aus Ägypten (vgl. oben S. 47 Ezzo).

Der Sprachstil2) ist einfach und nicht gewandt, die Sätze reihen sich parataktisch aneinander, oft durch dô eingeleitet. Zweigliedrige Ausdrücke sind häufig, ebenso predigtartige Anrede-, Beteuerungs- und Quellenformeln. Die Anredeformeln weisen darauf hin, daß das Gedicht zum Vortrag bestimmt

1) Die allegorische Auslegungsweise war dem Dichter nicht unbekannt, denn er macht einige Male entsprechende Anspielungen (KOSSMANN S. 81): 602. 2490. 2797-2802 (Vogt S. 312; PNiower, ZfdA. 33, 76 f.). Der Grund, weshalb der Dichter die allegorische Methode vermeidet, liegt wohl darin, daß er zu einem weltlichen Publikum redete, dem er solche Schwierigkeiten nicht zutrauen durfte, vgl. Alanus de Insulis, Summa de arte praedicatoria, Migne $210,184 \mathrm{C}$ : Minoribus decet in parabolis loqui, majoribus revelare mysteria regni Dei.

2) SCHERER, QF. 1, 74 ff.; KosSMANN S. 56-76, auch 51-55; BEHAGHEL, Beitr. $30,431 \mathrm{ff}$. 
war, und zwar vor Herren, denn für deren Interessenkreis paßt der ritterliche Aufputz und die Anrede mîne hêrren. Lat. Wörter kommen nur am Anfang und Ende vor, öftèr aber lat. Flexionen in Eigennamen. ${ }^{1}$ )

\section{$\$ 19$. Vorauer Bücher Mosis.}

Kelle 2, 110-119. 309-321; Piper, GD. 1, 88. 193 f. 195-199. - Ausg.: Diemer, D. Ged. S. 1-85, Anm. S. 3-31, Einl. S.XXXIX ff., dazu Kollation von Piper, ZfdPh. 20, 474 -479; der Abschnitt über Joseph ist von Diemer nicht in seiner Ausgabe der Vor. Hs. abgedruckt (vgl. daselbst S. 32 und Einl. S. XL), sondern nachgeliefert als "Geschichte Josephs in Ägypten“" in seinen Beitr. Teil V Nr. XX u. XXI, Wiener SB. 47 (1864), 636-687, 48 (1864), 339-423; neu hgb. von PIPER "nach der Wiener und der Vorauer Hs.", ZfdPh. 20,257-289. 430-474. - SCHEEER, QF. 1, 4-6. 57 f. 7, 42-51. 12, 56 f.; MSD. 1133, 248. 258 Anm.; RÖDiger, Anz. 1,69-72. 75-78; WAAG, Beitr. 11,93-105; AlB. MÜNSCHER, Marburger Diss. 1908.

Hs.: Vorauer Hs. B1. 74a-96a. Der Text der Bücher Mosis ist nicht sorgfältig, er enthält viele Schreibfehler und Lücken. ${ }^{2}$ ) Zwei Pergamentbl. des Vorauer Moses (= DiEMER 57, 23-66, 8), 13. Jh., befinden sich im Linzer Museum. ${ }^{3}$ ) Die Geschichte Josephs ist auch in der Wien. u. Milst. Gen. enthalten.

Das ganze Werk besteht aus fünf Teilen: I. Die Vorauer Genesis, B1. $74^{\mathrm{a}}-78^{\mathrm{b}}$, DiEMER S. $3,1-31,30$.

Schöpfung des Himmelreichs und der zehn Engelchöre, Lucifers Fall 3, 1-5, 8; Erschaffung der Erde, der Sterne, von Sonne und Mond, des Paradieses 5, 8-6, 10; Erschaffung von Adam und Eva 6,10-7, 19; Sündenfall 7, 19-9, 26; Verstoßung aus dem Paradies 9, 26-10, 29; Kain und Abel 10, 29-11, 19; Adams Nachkommen 11, 19-12, 4; Noe, Sintflut 12, 4-13, 28; Noes Trunkenheit, Entstehung der Stände 13, 28-15, 9; Sprachverwirrung 15, 10-24; Abraham 15, 24-19, 21; Isaak 19, 21-21, 13; Esau und Jakob 21, 13-24, 17; Jakob 24, 17-31, 30.

Der Dichter kannte die Wiener Genesis, ${ }^{4}$ ) wie aus einer Reihe sprachlicher Übereinstimmungen hervorgeht. Sie lag ihm als Muster einer Bibelübersetzung vor, er hat aber seinen Text unabhängig von ihr gestaltet, ja man kann an einzelnen Stellen, die das gleiche Thema behandeln, beobachten, daß er absichtlich eine andere, eigene Fassung wählte. Es sind zwei verschiedene Behandlungen des Vulgatatextes: während der ältere Dichter den überlieferten Inhalt mit Ausnahme weniger Partien beibehält, läßt der jüngere viel mehr Stoffteile aus und zicht die beibehaltenen zusammen, stellt um, trennt $\mathrm{Zu}$ sammengehöriges leichter als jener. Die einzelnen Bilder sind viel magerer, es fehlen die belebenden Kleinzüge, wenngleich auch hier zuweilen kurze Zusätze gemacht sind. Die Darstellung ist starrer, unbeholfener.

Aus der Anschauung seiner Zeit betrachtet auch dieser Dichter die alttestamentlichen Begebenheiten. Manchmal findet auch er volkstümliche Töne, dahin gehört die Gebetsformel Ich wil dich wîsen in daz paradîse 7, 14f., oder im Segen Isaaks dîneme vihe unde din(er) fruht deme ne wirret hagel

1) Kossmann S. 55; Grönewald S. 10.

$\left.{ }^{2}\right)$ Sprache: WaAg aaO.; MÖNCHER S. 13 -74 .

3) Mone, Anz. f. Kunde d.d. Vorzeit 8, 431 f.; LAMBEL, Germ. 7, 230-235; DIEMER, Wiener SB. 55 (1867), 286; SCHERER, ZföG. 19 (1868),
738 u. K1. Schr. 1, 592.

4) PNIOWER, Zur Wicner Genesis (Diss.) Anliang S. I-V; KELLE S. 113. 315; MONSCHER S. 126-140; SCHERER, QF. 1, 4-6. 57. 7, 42. 12, 56; RODDIGER aaO. S. 69; Wang, Beitr. 11, 93; Vogt, Beitr. 2, 209 ff. 
noch suht 22,22-24. Auch läßt er sein Gefühl da und dort mitsprechen: Noe weinte, sein Herz tat ihm weh, als er die durch die Flut vernichtete Erde sah, und Gott tröstete ihn 13,12 ff. - Mit tränenden Augen nimmt Rebekka Abschied von ihrem Sohne 24, 6 f.; traurigen Herzens empfiehlt sie ihn Gott mit innigem Gebet, da schieden sie sich im Schmerz, sie sahen sich niemals wieder 24, 14-17. - Die Klage Jakobs am Grabe der Rahel 31,16 - 24 hat der Dichter der Wiener Genesis entnommen (51, 31 ff.), aber stark gekürzt, auch das Zerstörungswerk des Todes hat er nicht so schonungslos aufgedeckt und hier ist er menschlich teilnahmsvoller als der ältere Dichter. Seine einfachen Worte gehen in ihrer schlichten Wahrheit zu Herzen: hier liegt alles mein Lieb, es spricht nicht mehr zu mir, das allerschönste Weib, ich Armer, wär ich vor ihr gestorben! - In einem kleinen Naturbilde vereinigt er 5, 8-7, 19 mit poetischer Sprache, die an die lat. Dichtung seiner Zeit und an den Minnesang anklingt, die Dinge der Erdschöpfung, die in der biblischen Genesis 1, 6-30 in Variationen mehrfach wiederkehren.1) Aber solche Fälle subjektiver Schattierung sind nicht stark genug, um dem Ganzen eine persönliche Färbung zu verleihen, und im allgemeinen muß man sagen, daß dieser Dichter den anheimelnden Ton des Volksmäßigen und Gegenwärtigen nicht getroffen hat. Man vergleiche als Beispiel wiederum die Brautwerbung Isaaks 19, 22-21, 3: schon der Umfạng ist viel geringer, nur die Hälfte des Wiener Textes, und wie trocken ist die Erzählung, fast bis zur Unverständlichkeit beschnitten! Man sieht, die ganze Geschichte soll möglichst rasch abgemacht werden.

Das gesamte, Bücher Mosis genannte Werk der Vor. Hs. hat eine ausgesprochen lehrhafte Tendenz, die historischen Tatsachen der Bibel werden zugleich in ihrer Bedeutung für das Dogma dargestellt. Es ist also die Methode der allegorischen Schrifterklärung angewendet, biblische Stellen werden in ihrer Bedeutung für die Heilsgeschichte erläutert. In der Genesis macht sich das allegorische Element nicht übermäßig stark geltend. Im Unterschied von der Wiener Genesis, welche mit Buße und Beichte auf das praktische Christentum gerichtet ist, sind die geistlichen Bezüge hier vielmehr dogmatischer Art. Der ältere Dichter knüpft an den Bibeltext moralische Mahnungen, der jüngere allegorisch mystische Auslegungen. ${ }^{2}$ ) Jener ist der Prediger, der sich an das naive Verständnis der Laien wendet, dieser der Theolog, der auf tieferes Wissen, auf Geistliche, absieht. Die Dreieinigkeit ist die Grund- und Anfangslehre des christlichen Dogmas, und so ist dies auch der theologische Kerngedanke in der Vor.Genesis: die drei obersten Engelchöre sind die drei Bestandteile der Trinität, auf Weisheit, Güte, Macht gerichtet 3, 17-19, ${ }^{3}$ ) Weisheit, Güte, Macht stürzen Lucifer 4, 23-25; die

1) Die Schönheit des Waldes, die Vögel in demselben, die grünende Erde, die wonniglichen Blumen: vgl. z. B. Cambridger Lieder Nr. 27. 28. 29. 32 , ZfdA. 14,490 ff., R. M. MEYER ebda 29, $195 \mathrm{ff}$., und viele Lieder der
Carmina Burana.

2) Die Auslegungen sind also in der Wien. Genesis moraliter, in der Vor. Genesis mystice oder spiritaliter, vgl. LG. I, 178.

3) Einzelne Engelchöre werden in ver- 
-drei Engel, die Abraham besuchen, sind die sancta Trinitas 16, 24; die Dreiteilung der Gottheit übertragen auf die menschliche Seele ergibt die drei Kräfte virnunst (ratio), gehuht (memoria), wille (voluntas) 8,6-8; als Schöpfer wird Gott allein genannt 3,1 ff. Wie schwächlich ist diese spiritualistische Verflüchtigung der Gottesvorstellung gegenüber der trostreichen Lehre der Wiener Genesis von dem Gott der Gnade!

Auch sonst sind theologische, in der alttestamentlichen Genesis nicht enthaltene Beziehungen eingestreut: 9, 6. 10,2f. 17, 14; 7, 22-8, 2. 10, $1 \mathrm{f}$. 5-16. 19-25. $25-29$. 11, 21 ff. 12,1 ff. 12,4 ff. 15, 27 ff.; 13, 28-15, 9. 16, 8f. 19. 18, 21 f.; 17, 29-18, 4. 18, 27-29. 29, 20-30,6. Diese Belehrungen und Erklärungen sind Gemeingut der mittelalterlichen Theologie, eine spezielle Quelle, aus der die Vor.Genesis unmittelbar geschöpft hätte, ist nicht nachzuweisen. ${ }^{1}$ )

Der Stil ist der der einfachen Erzählung. In der Satzverbindung herrscht Parataxe vor, oft mit Aneinanderreihung mit dô oder durch anaphorische Pronomina; die Nebensätze sind meistens temporal mit $d \hat{o}$ oder relativ verbunden. Epitheta sind spärlich verwendet und nur die typisch gebräuchlichen, zweigliedrige Formeln sind beliebt. Häufig stellt sich die Beteuerung ze wâre, daz ist wâr, ich sage dir ze wâre ein, besonders als Notbehelf für den Reim. Formelhafte Quellenberufungen sind selten. ${ }^{2}$ ) Neue Personen werden oft durch eine kurze, allgemein gehaltene Charakteristik eingefühtt: $4,15.11,20.12,4.15,27.16,11.19,5.21,24$. Individuell erfaßt ist der jugendliche Jakob als ein frommer Hirtenknabe: er kam selten aus dem Zelt seiner Mutter, da innen lernte er die stuße Gottesminne, da hütete er seine Schafe; Gott kam selten aus seinem Sinne 21, 29-22, 4. ${ }^{3}$ )

II. Joseph in Ägypten, B1. $78^{\mathrm{b}}--87^{\mathrm{a}}$, Ausg. von Diemer und Piper s. oben in der Literaturangabe. Der Joseph der Wiener Hs. ist unverändert in die Vor. Hs. aufgenommen worden, der Text der Wiener Hs. ist besser als der an Flüchtigkeiten, seltener an überlegten Änderungen reiche der Vor. Hs.4) Der größte Teil, PIPER 1-2064, ist rein erzählend, der Schluß von 2065 an, der Segen Jakobs, ist gedeutet auf Christus' Erlösungstod, den Antichrist, das Himmelreich.

III. Vorauer Moses, Bl. 87 ${ }^{d}$-93 $3^{c}$, Diemer S. 32, 1-69, 6. Die Behandlung des Bibeltextes ist noch viel freier als in der Genesis, sowohl hinsichtlich der Auswahl als der Anordnung der stofflichen Elemente. Der größte

schiedenen Büchern des alten und neuen Testaments genannt. Hieronymus, Ambrosius und Augustinus (Enchiridion 58, De civitate Dei B. 11 u. 12) haben dic Lelire von den Engeln begründet, die Rangabstufung der himmlischen Hierarchie in den neun Chören hat ihren Ursprung in des Dionysius Areopagita (5. Jh.) De coelesti Hierarchia c. 6 u. wurde bes. durch Isidors (Etymologicn VII, 5) System zum festen Bestand der Kirchenlchre.
1) Benutzung von Ruperts v. Deutz De Trinitate et operibus ejus nimmt KELLE S. 110 -113 u. Anm. an; vgl. MUNscher S. 140 ff.

2) MÚNSCHER S. $113-115$.

3) Lat. Wörter s. Grunewald S. 10. Sprachliche Parallelen zu Joseph und Moses: MÜNSCHER S. 151 - 153; zu andern Gedichten : Diemer, Alim. S. 3 ff.; Scherer, QF. 7, 43 f.; KELLE S. $315 \mathrm{f}$.

4) VoGT, Beitr. 2, 210-230. 
Teil gehört der Exodus an, nämlich $32,1-62,2$, dann folgt $62,3-14=$ Num. $21,6-9 ; 62,14-26=$ Ex. $17,8-13 ; 62,26-63,4=$ Num. 13,1 ff.; $63,4-27=$ Jos. 2,$1 ; 63,27-66,8=$ Num. 13,24 ff. 14,1 ff. ; 66, $9-15=$ Num. 20, 12 f.; $67,15-69,6=$ Jos. 1. 3. 4 . 6 (gekürzt). ${ }^{1}$ ) Das Verhältnis zwischen Erzählung und Auslegung ist im Vor. Moses ein anderes als in der Genesis. Die Exodus hat schon an sich ein geringeres episches Gepräge und nur wenige Höhepunkte in der Handlung; in der Vor. Bearbeitung aber überwuchert die Belehrung die biblische Überlieferung auf breite Strecken: Moses Stab ist das Kreuz 35, 8-18; die zehn ägyptischen Plagen sind gewisse Klassen von Sünden 38,6-40,14; das Osterlamm ist Christus und sein Tod 41,19-42, 27; das Manna ist der Leib Christi im Abendmahl 50, 6-20; die Stiftshütte ist die Christenheit 55, 24-26, die einzelnen Teile sind die einzelnen Glieder der Gemeinschaft der Heiligen 58, 10-60, 21; die eherne Schlange ist Christus 62, 8-11; s. ferner 35, 18-29. 43, 19-44, 26. 48, 16-49, 2. 49, 3-18. 49, 18-50, 5. 50, 20-30. 50, 30-52, 3. 60, $21-61,3$. 61, 3-22. 61, 22-62, 2. Die stärkste Verchristlichung aber der alttestamentlichen Religionsanschauung liegt in dem Gottesbegriff: aus dem strafenden Judengott ist der Gott der Liebe des Evangeliums geworden, an Stelle des Fluches, den der Herr über das Volk ausspricht Ex. 32, 33-35, setzt der Dichter die Segensworte des Evangeliums Matth. 22, 37-40, die das Grundgebot des Christentums enthalten, die Liebe zu Gott und dem Nächsten 55, 11-19. Damit ist die Gottesvorstellung im Vor. Moses gekennzeichnet: es ist die gleiche wie in der Vor. Genesis, die Menschen sind Gottes Kinder 36,5-8. 13-16. 18 f.; Gottes ist die Gnade 55, 12.

Der Vor. Moses enthält nach der Erzählung von Moses in Ägypten den Auszug der Israeliten und schließt ab mit der Eroberung Kanaans, allegorisch gedeutet ist dies die Rückkehr der Menschen aus der Verbannung in der Welt zum Heimatland im Himmel. Dieser Grundgedanke ist behandelt in $43,19-44,26$ und 49,3-50, 5 (vgl. auch 37, 1-6). Um dieses Hauptmotiv gruppieren sich dogmatische Auslegungen: Christus und das Kreuz, das Meßopfer, die Taufe, die Trinität, und moralische: Verhalten der Menschen in der Christenheit, Sünden, Ermahnung zur Beichte und Buße, Hinweisung auf Gnade oder Verdammnis. Somit ist die alttestamentliche Geschichte im Vor. Moses zu einem christlichen Kommentar geworden und zwar hat der Verfasser hier das Werk Ruperts von Deutz De Trinitate et operibus ejus. vor Augen gehabt (vollendet 1117). Mehrere Deutungen, besonders auch die Verdrängung des rächenden durch den gnädigen Gott, finden sich dort ähnlich, aber allerdings nur in allgemeinen Zügen. Auch hier, wie in der ganzen Bearbeitung, ist der Dichter recht selbständig verfahren.2)

Sehr häufig sind Formeln des geistlichen Vortrags. ${ }^{3}$ ) Gedanken- und Sprachstil sind also unterschieden in der Genesis und dem Moses der

1) MSD. II ${ }^{3}, 248$; MÜNSCHER S. 120 ff.

$\left.{ }^{2}\right)$ KELLE S. 114 f. 316-319; MÜNSCHER

S. $140-144$.

3) MÜNSCHER S. 112-114. 115. 
Vor. Hs.: dort herrscht die epische Anschauung und die erzählende Darstellungsweise, hier überwiegt die lehrhafte Durchdenkung mit predigtartigem Ausdruck. In dem mehr formellen Sprachgebrauch, in der Syntax, in dem Gebrauch der Zweigliedrigkeit, des Epithetons, lat. Wörter,1) lassen sich beim Vor. Moses keine maßgebenden Sondermerkmale gegenüber der Genesis feststellen.

Gegen Ende greift die Erzählung noch auf das Buch Josua über 67, 15-69, 6, denn der Verfasser hatte die Absicht, mit der Besitzergreifung des Heimatlandes durch die Israeliten abzuschließen. Die Raab-Episode (63, 4-27, Josua Kap. 2) ist schon vorausgenommen und mit der erstmaligen Aussendung der 42 Kundschafter vereinigt worden. Die typologischen Auslegungen hören hier auf. Der Dichter eilt zum Schluß. Moses' Ende wird rasch abgetan 66, $16 \mathrm{ff}$,, der Dichter muß es verschweigen, er will es in Latein sagen. Dann führt er einige Sätze De obitu Moysis an, sie stammen aus der apokryphen Himmelfahrt des Mose, Adscensio oder Assumptio Mosis. $\left.{ }^{2}\right)$ Gibt der Sinn mit der Eroberung Jerichos einen natürlichen Haitepunkt, so ist doch die Darstellung jäh abgebrochen. Unmittelbar darauf 69, 6 folgt das Marienlob mit der Weissagung von der Geburt Jesu.

Zwischen dem Vor. Moses und der Wien-Milst. Exodus, die beide demselben biblischen Buch entstammen, bestehen nur geringe Beziehungen; der Verfasser mag das ältere Gedicht gekannt haben, ist aber nicht von ihm beeinflußt. ${ }^{3}$ ) Die Gedankenbezüge gehen auf die Dreieinigkeit, auf die Gaben des heil. Geistes, auf Glaube, Hoffnung, Liebe, auf geistliche Tugenden und auf den Weg der in der Welt Wandelnden zu Gott 82, 8-84, 26. Die Stiftshütte mit ihrem Inhalt ist auch im Vor. Moses als Grundlage zu geistlicher Auslegung gemacht 58,7-62,2, aber hier sind es andere Gegenstände und andere Deutungen. Die allegorische Partie wird rasch abgebrochen mit den Worten nu lâze wir die rede stân von disen selben dingen 84, $20 \mathrm{ff}$. Kurz wird zurückgekehrt auf die Lagerung der Israeliten 84, 26 und in eiliger Hast mit ein paar zusammengerafften Worten geschlossen. Die letzten Zeilen sind verstümmelt.

IV. Marienlob, B1. 93e - $94^{a}$, Diemer S. $69,6-72,8$, s. unten.

1) Grónewald S. 10. - Sprachl. Parallelen zur Genesis und zum Joseph s. MONSCHER S. 151 f.; zu andern Gedichten: DIEMER, Ann. S. $15 \mathrm{ff}$.; SCHERER, QF. 7, 48.

2) DIEMER, Anm.S. 24-26; über die Himmelfahrt Moses s. EMIL ScHÜRER, Gesch. d. jüdischen Volkes Im Zeitalter Jesu Christi 111 ${ }^{3}$, 213-222; Burdach, Faust u. Moses, Berl. Ak. 1912 S. $361 \mathrm{ff}$. - In dem aus dem Buch Josua (vgl. auch Josephus B. IV Kap. V1II, 46 ff.) entnommenen letzten Stiick 67, 15-69, 6 wird der Held, der vorher Josue hieß $(65,1 \mathrm{f}$. $66,4)$, Jesus genannt $(67,18.24 .68,4.9 .29)$. Daraus braucht man nicht auf $z$ wel verschiedene Verfasser zu schließen (RödigEr, Anz.
1,77; WAAG S. 103 f.). Jesus kommt für Josue in der Bibel oft vor (Sirach 46, 1; Hab. 4, 18; 1. Mach. 2, 55; 2. Mach. 12, 15; Apostelgesch. 7, 45; Hebr. 4, 8), es ist die Form des Josephus, unser Verfasser aber konnte sie aus der Ascensio Mosis haben, wo sie Regel ist, auch Ruperts v. Deutz' Kommentar konnte mitgewirkt haben, wo Josue auf Jesus den Heiland interpretiert wird, Migne 167, 10011005; vgl. Jesus der Goles genanne DIEMER 68, 29 f. (Zu 68, 4-7 vgl. den Jordansegen, I.G. I, 103).

3) PNiower, ZfdA. 33, 73 ff.; MÜnscielk S. 132 ff. 
V. Balaam, Bl. 94a-96a, Diemer S. 72, 8-85, 3. a) Balaam und Balach 72, 8-25; Balaams Eselin 72, 26-75, 10; Balaam und Balach 75, 11-76, 4. b) Die israelitischen Stämme 76, 4-78, 17; die Stiftshütte 78, 17-84, 26. c) Schluß, Balaams Segenswunsch 84, 26-85, 3. Auch dieses V. Stück ist zusammengesetzt aus epischen und didaktischen Partien, die sich aber hier nicht durchschlingen, sondern gesondert gehalten sind. Dem Ganzen liegt Num. 22-24, die Erzählung von Balaam, zugrunde, die sehr frei behandelt ist. ${ }^{3}$ ) Das Ringen des guten Mannes mit dem störrigen Vieh liest sich wie eine komische Heldenballade. Mit sichtlichem Wohlgefallen verweilt der Dichter bei dem ins Burleske gezogenen Vorgang, den ernst religiösen Hintergrund der biblischen Darstellung außer acht lassend.

Der zweite Teil (b) ist die Aufzählung und die Lagerung der israelitischen Stämme in freiem Anschluß an die Balaamepisode Num. Kap. 22, 41. 24, 2. 5. 6 u. Kap. 26 sowie an Num. 2,3-33. An die Leviten als Hüter der Stiftshütte und Bundeslade (Num. 1, $49 \mathrm{ff}$.) ist eine Beschreibung des Inhalts der Stiftshütte angeknüpft $(78,17-84,26)$. Die Dinge werden dann geistlich gedeutet und diese Auslegungen haben vereinzelt eine Ähnlichkeit mit Ruperts von Deutz Erklärung.

Es ist ein seltsames Stück, zur Hälfte weltlich, zur Hälfte geistlich. Die Weissagung, die dem heidnischen Propheten sein Ansehen verschaffte, Num. 24, 17, ist ausgelassen, dafür bei Aarons Gerte die Hindeutung auf die jungfräuliche Geburt Num. 17, 1 ff. beigebracht.

Die sprachliche Ausdrucksweise weicht etwas ab von der in der Vor. Genesis und dem Moses. Am deutlichsten tritt das zutage in der Aneinanderreihung der Sätze, wo die einleitenden dô wenig gebraucht sind. Vortragsformeln, etwas anders gewendet als im Moses, ${ }^{1}$ ) sind häufig, wie denn viele Wendungen und Sätze zur Ausfüllung oder zum Reimen dienen, besonders in der Aufzählung 76, 12 ff., z. B. patriarchis: daz ist gewis 13 f., und so 76,20 f. 21 f. 23 f. 26 f. 77,4 f. ${ }^{2}$ )

Metrik. ${ }^{3}$ ) In den Reimen der Genesis und des Moses herrscht noch große Freiheit, nicht viel unter der Hälfte sind unrein, schwachtonige Nebensilben sind oft Reimträger, doch sind ganz schwere Assonanzen gemieden. Der Versbau ist mittlerer Art, ganz kurze oder überlange Verse sind selten.

1) MÜNSCHER S. $113 \mathrm{f}$. 115 . Lat. Wörter: GRÜNEWALD S. 11.

2) Manches in Sprache und Inhalt erinnert an das Marienlob (MÜNSCHER S. 152): gleich der Eingang mit Wîlent Barl. 72,8 wie Marienl. in MSD. Str. 1, 1, auch 2,5; Ausfüllung zweier Verse durch zwei Wortpaare: suoze oder siure, genuoge oder tiure 78, 28 f. - tiuren unde guoten, edelen unde fruoten Marien1. 3, 3 f.; irkennen : nennen 78, $30 \mathrm{f}$ - - genennet: irkennet Marienl.3, $5 \mathrm{f}$; sich pflegen 81, 22 f. (und Moses 41, 19) - Marienl. 3, 12. Ähnliche Motive: lilie 83, 26, lilium (im Reim) 82,7. 83, 17 - Marienl. lilje 3, 5, lilium (im Reim) 5, 11 (als Symbol der Unscluuld 83, 19 - der Demut Marieni. 5, 13); berehaft 82, 23. 83, 26 - Marienl. 4, 2; Aarons. gerte 79, $20 \mathrm{ff} .-$ gerte von Yessê Marien1. 2, 3. 6. 5, 1; diu gerte bezeichenet unser frowen $80,18 \mathrm{f}$. - Diu gerte bezeichenet di magt Marienl. 4, 1 ; des geistes gebe 82, 24 f. -- mit sibenvaltiger gebe Marienl. 3,11, di siben gebe 4, 5; wuocher auf Christus bezogen 80,19-Marienl. 2, 13; ir einbornen $\operatorname{sun} 80,19 \mathrm{f}$. - Marienl. 4, 3 .

3) MÜNSCHER S. $75-i C 9.145 \mathrm{ff}$. 
Einige Male kommen Dreireime vor. Ein grundsätzlicher Unterschied besteht in der Metrik zwischen Genesis und Moses nicht; Barlaam und Marienlob haben regelmäßigere Verskunst (weniger schwere Endsilbenvokale, im Prozentsatz mehr reine Bindungen, gleichmäßigeren Rhythmus). Der Joseph als ein fremdes Stück ist hier natürlich auszunehmen.

Die Frage nach der Entstehung und der Einheit des Ganzen läßt sich mit Sicherheit nicht entscheiden. Unterschiede konnten zwischen der Vor. Genesis und dem Moses nachgewiesen werden in der Quellenbenutzung, in der Tendenz (größere oder geringere Neigung zur lehrhaften Auslegung) und im Stil (besonders im Formelwesen). Danach sind zwei Bearbeiter wahrscheinlich. Aber es ist doch nicht ganz in Abrede zu stellen, daß Ausweichungen wie die angegebenen auch bei ein und derselben Persönlichkeit möglich sind. Selbst Formeln, spontane Stilelemente, die sich mehr mechanisch, absichtslos einstellen, können doch abhängig sein von dem gesamten Stilcharakter. Rhetorische Formeln ${ }^{1}$ ) wie die im Moses sind da mehr geeignet, wo der Dichter als Prediger oder Lehrer auftritt, also im lehrhaften Stil, wie eben im Moses, weniger in einem gedrungen-epischen Stil wie in der Genesis. Könnten nun aber auch die Vor. Genesis und der Vor. Moses in solcher Hinsicht Werke ein und desselben Mannes sein, so sind sie doch in der geistigen Auffassung und im Formelgebrauch derart unterschieden, daß sie als zwei getrennte Geistesschöpfungen zu betrachten sind. Der Barlaam weicht in Denkweise, Sprache und Metrik doch von den beiden großen Teilen, der Genesis und dem Moses, stärker ab, so daß man für ihn einen andern Verfasser annehmen muß.2)

Die Vor. Bücher Mosis sind demnach zu beurteilen als eine Kompilation verschiedener Stücke, in denen von Mönchen ein und desselben Klosters ${ }^{3}$ ) die alttestamentliche Genesis und Exodus zum Zweck typologischer Erklärung übertragen wurden. Die einzelnen Verfasser standen also untereinander inVerbindung. Die Zusammenstellung sollte nicht zu umfangreich werden, daher die Kürzungen. Es scheint, daß die Zeit zur Herstellung beschränkt war, daher der plötzliche Abbruch beim Tode Moses (daz muze wir

1) Es gibt $z$ weierlei formelhafte Wendungen: 1. ep is cheFormeln, Wiederkehr der gleichen oder ähnlichen Worte, wenn die gleichen Gedanken wieder auftreten (Gedankenassoziation); sie sind durch den epischen Stoff bedingt, z. B. liute unde lant, riter unde frouten, der edele kunic, helde kalene unde guot; 2. rlietorische Formeln, Vortragsformeln, die nicht durch den Stoff bedingt sind, sondern nur rednerisch eingeschaltet werden, so dic Wahrheitsbeteuerungen: ze wâre, für wâr ich it daz sage; Quellenberufungen: als uns daz buoch seit; Erlăuterungsformeln: daz bezeichnet; Uebergangsformeln: nn wil ich it sagen, na muget ir horen, zugleich als Aufforderung:

Deutsche Literaturgeschichte. II. nù vernemet! Die epischen Formeln eignen mehr der Erzählung, die rhetorischen Formeln mehr der Belehrung, doch können natürlich die epischen Formeln auch in didaktischen Stïcken und umgekehrt vorkommen.

2) SchERER, QF. 7, 42-51 liat als erster fünf verschiedene Verfasser aufgestellt und hat die Genesis wieder in drei Teile geteilt; MÜNSCHER S. $152 \mathrm{f}$. gelangt auf Grund seiner eingehenden Untersuchungen ebenfalls zu fuinf Verfassern; WAAG aaO. S. $101 \mathrm{ff}$. hảlt an einem Urlucber fest.

$\left.{ }^{3}\right)$ Alle Stìcke stammen aus demselben Kloster, denn die Orthographie ist durchaus einheitlich, vgl. WAAG aaO. 
uirdagen 66,25$)$ und bei der Einnahme Jerichos, ebenso wie am Schluß des Balaam (lange tvâle hân ich getân 84, 25). Dies war wohl auch der Grund, weshalb der Joseph einfach aus der Wiener Genesis abgesćhrieben wurde. Der erste Dichter ubertrug die Genesis, und zwar ließ er den epischen Gehalt vorherrschen. Dann wurde der Joseph aus der Wien. Genesis angefügt, zu der allegorischen Absicht paßte er deshalb, weil schon in dieser Vorlage der große Abschnitt vom Segen Jakobs ein tiefiu rede (ed. PIPER S. 458 v. 5551) mit Bezeichnung war, d. h. Ausdeutung auf den christlichen Glauben. Ein anderer Klosterbruder als jener Verfasser der Vor. Genesis fuhr fort mit dem Moses und verlieh diesem stärkeren allegorischen Gehalt. Von einem dritten Arbeitsgenossen wurde das Marienlob angeschlossen. Unter den vorhergehenden Auslegungen war keine von der Geburt Christi. Maria ist nur kurz erwähnt im Moses 60,11; nicht einmal der brennende und sich im Feuer doch nicht verzehrende Busch Moses 34, 28 ff., der eines der gebräuchlichsten Symbole für die unverletzte Geburt durch Maria ist, wird als solches benutzt. In einer Zeit, in welcher der Preis der heiligen Jungfrau für die Poesie gleichsam entdeckt wurde, konnte in einem typologischen Kommentar die magdtumliche Geburt nicht fehlen. Das ist der Grund für die Aufnahme der eben durch das Marienlob dargestellten Prophezeiung des Jesaias. Im Balaam ist von einem vierten Mitarbeiter eine Episode aus dem 4. Buch Moses nachgetragen worden. Das entspricht dem kompilatorischen Charakter des Werkes. Der Verfasser kannte den Vor. Moses, ${ }^{1}$ ) denn er hat seine Stiftshüttensymbolik nach ihm eingerichtet: er bringt nur solche Punkte, die bei jenem nicht vorkommen. Er kannte auch das Marienlob, wie die oben angeführten sprachlichen Anklänge wahrscheinlich gemacht haben. Dadurch wird es verständlich, weshalb die religiös wichtigste Stelle der ganzen Balaamgeschichte, die Verkündigung Christi Num. 24, 17, in der Vorauer Bearbeitung ausgelassen ist. Der Grund, weshalb überhaupt dieser Nachtrag mit Balaam gemacht wurde, liegt wohl in der Berühmtheit des heidnischen Propheten, besonders in dem Wunder seiner redenden Eselin. Der spirituellen Tendenz des ganzen Werkes folgend mußten aber auch belehrende Auslegungen gebracht werden. Die Prophezeiung Balaams war schon im Moses vorweg genommen, so griff der Dichter zu der geistlichen Erklärung der Stiftshütte, die er, allerdings nur auf Umwegen, an die Lagerschau Balaams anknüpfen konnte.

Die allegorische Schrifterklärung des ganzen Werkes zusammen ergibt das Dogma in seinen Hauptzugen: die Genesis enthält mit der Trinität, Engel und Teufel, Schöpfung, Sündenfall und Verstoßung (die Welt als Verbannung) den Anfang des christlichen Dogmas. In der Entwicklung der christlichen Glaubenslehre folgt dann die Erlösung durch Christus und die Erlangung des Himmelreichs: dieses ist dargelegt im Joseph. Der Moses

1) RöDIGER, Anz. 1, 69. 
enthält eine Reihe Einzelstücke, außer dem Kreuz, dem Tod Christi, dem Aufgeben der Weit, die schon in den beiden vorhergehenden Teilen erklärt wurden: das Abendmahl, die Taufe, Beichte, die Christenheit, Sünden, Tugenden. Im Lobgesang wird die jungfräuliche Geburt dargestellt, im Balaam nochmals die Dreieinigkeit und der Weg zu Gott. Man erkennt, daß ein einheitlicher Plan die Auslegungen durchzieht. Im einzelnen herrscht Freiheit und Manchfaltigkeit, was bei der Entstehung der Kompilation selbstverständlich ist, aber das Ganze ist eine Glaubenslehre, eine christliche Menschheitsgeschichte vom Anbeginn des Weltplans in der Dreieinigkeit bis zum Ende, ebenfalls in den drei Personen, in Gott. Dieser Ideenverlauf ist natürlich nicht künstlich beabsichtigt, sondern er ergibt sich naturgemäß aus dem Stoff, der spirituell erklärt wird, aus dem Inhait der biblischen Genesis und Exodus und deren herkömmlicher Auslegung, nur daß zur Erreichung einer gewissen Vollständigkeit in den dogmatischen Hauptzügen einige Male nachgeholfen wurde, wie besonders bei der Einschaltung des Marienlobs und dem Schluß des Balaam. - Abgefaßt ist die Kompilation der Vorauer fünf Bücher Mosis in einem österreichischen $\left.{ }^{1}\right)$ Kloster und zwar sind, unter Berücksichtigung besonders des Reimgebrauchs, die Jahre $1130-1140$ anzunehmen. $\left.{ }^{2}\right)$

$\$ 20$. Das Lob Salomons.

Kelle 2, 119-121. 321 - 323; Piper, GD. 1, 207-214. - Ausg.: Diemer, D. Ged. S. 105 114, Anm. S. 43-46, Einl. S. XLI f.; MSD. Nr. 35 u. $1 l^{3}$, 223-230; WAAG, Kl. d. Ged. ${ }^{2} 27-35$ u. Einl. S. XXIV-XXIX. - Schade, Decas S. 43-45; Bartsch, Germ. 9, 62 ff.; Konr. Hofmann, Münch. SB. 1871, 553-557; Scherer, QF. 7, 56. 12, 40 f., ZfdA 22, 19-24; WAAG, Beitr. 14, 573-579; John MeIER, Beitr. 16, 95; Kraus, Anz. 17, 20 ff., ZföG. 45 (1894), 135-138; Wallner, Beitr. 43, $181 \mathrm{ff}$.

Hs.: Vor. Hs. B1. 98c-99c, mit verschiedenen Fehlern und kleineren Lücken.

Die Heimat des Gedichtes ist das rheinfrk. Sprachgebiet, als A b fassungszeit $^{3}$ ) ist das erste Drittel des 12. Jhs. anzusetzen. Der Verfasser war ein Kleriker, er verstand Lateinisch.

Die Quelle für das deutsche Gedicht ist die biblische Erzählung von Salomo, 3. Reg. 3-10 bezw. 2. Paral. 1-9 (und zwar hauptsächlich Paral.), die unter sich ziemlich übereinstimmen. Ob der Dichter den Text schon in der gleichen gekürzten Form, wie er jetzt überliefert ist, lat. vorfand und nur ins Deutsche frei übertrug oder ob er selbst den vorliegenden Inhalt unabhängig von einer lat. Fassung aus der Bibel auszog, ist ungewiB. Behandelt hat er solche Punkte, die die Zeit interessierten.

Inhalt (die Reilenfolge der Str. nach der Hs, und nach WAAG.). I. Einleitung Str. 1: Das Licht der Welt, $\left.{ }^{4}\right)$ der allwissende Gott, also die zweite Person der Trinität, die Weisheit,

1) Im Donautal: SCHERER, QF. 1, 58. 12, 56 (das Marienlob in Kärnten, QF. 7, 49); in Kärnten: RöDIGER aaO. S. $68-70$.

2) SCHERER setzt den ersten Teil der Vor. Genesis schon um 1115 an, QF, 7, 74f. 12,
56; nach 1117 , den Vollendungsjaht von Kuperts v. Deutz De operibus: KELLLE S. 112 f. $314 \mathrm{f}$.; MÜNSCHER S. $145 \mathrm{ff}$.

s) MSD. ${ }^{3}$ S. XXXIX.

4) Mit der lat. Anfangszeile Inclita lux 
wird als Beistand zur Abfassung des Gedichtes angerufen.") 11. Hauptteil Str. 2-19: a) Str. 2. 3. 4 Salomos Wahl zwischen Reichtum und Weisheit nach 3. Reg. 3, 5-13 bezw. 2. Paral. 1, 7-12. b) Str. 5. 5b. 6. 7 An Stelle des bibl. Tempelbaus ist eine Geschichte von Salomo und einem Drachen gesetzt (Str. $5^{b}$ ), die Beschreibung des Tempels und der GefäBe (Str. 6 . 7) ist aus 3. Reg. 6,15 ff. und 7,38 ff. (bis 7,50 ) bezw. 2. Paral. 3,3 ff. und 4,6 ff. zusammengezogen, die Priester sind 2. Paral. 8, 14 entnommen. Die im alten Testament folgende Tempelweihe sowie die Beihilfe Hirams ist übergangen. c) Str. 8-15 Die Geschichte der Könlgin von Saba ist besonders ausführlich erzählt, hier wollte der Dichter ein Bild von Salomos Reichtum und glänzender Hofhaltung geben, denn solche Schilderungen waren ganz im Geschmacke der Zeit. Er benutzt als Grundlage 3. Reg. 10, 1-21 bezw. 2. Paral. 9, 1-20: die Königin kommt mit Schätzen, 3. Reg. 10, 1. 2. 10 bezw. 2. Paral. 9, 1.9 (Str. 13); sie sieht die Einrichtung von Salomos Hof, den Tisch, die Speise, die Diener, 3. Reg. 10, 5 bezw. 2. Paral. 9, 4 (Str. 10. 11) unter Beiziehung von Cant. Cantic. 3, 9 f. ${ }^{2}$ ) (zu Str. 10) ${ }^{3}$ ) und 3, 7 f. (zu Str. 11). ${ }^{4}$ ) Dem Dichter aber ist es darum zu tun, Salomos Pracht weiter auszuführen, er sagt darum ein Mehreres äber die Hofbeamten (Str. 8. 9. 11) in Anlehnung an 3. Reg. 4, 7. 27 und fügt den Thron und die Tischgeräte dazu, die in der blblischen.Erzählung erst später erwähnt sind (Str. 8. 9) aus 3. Reg. 10, 18 f. bezw. 2. Paral. 9, 17 f. und 3. Reg. 10, 21 bezw. 2. Paral. 9, 20. Mit dieser Vorwegnahme hat er die Schilderung von Salomos Reichtum in einen einheitlichen Zusammenhang gebracht. Es blieb nun noch übrig, auch die Weisheit des Königs, die die Königin an dieser Stelle preist, 3. Reg. 10, 4. 6-8, auch 23, bezw. 2. Paral. 9, 3. 5-7, dazu auch 12, zu berühren: dieses tat er mit der in der Hs. folgenden Str. 12; am Schluß erwähnt er hier noch kurz Salomos Heeresmacht in Jerusalem, nach 3. Reg. 10, 26 bezw. 2. Paral. 9, 25. Jetzt endlich konnte er mit der Königin von Saba weiterfahren; dieses geschieht mit Str. $14.15=3$. Reg. 10, 6-8. 13 bezw. 2.Paral. 9, 5-7. 12. Der Abschnitt, die Königin von Saba und Salomos Reichtum und Weisheit, ist also nach einem bewuBten Plane gearbeitet. d) Str. 16. 17.18 In der allegorischen Deutung von Salomo und der Königin auf Christus und die Kirche, der Dienstmannen auf die Bisclıöfe folgt er einer bekannten Allegorie. e) Str. 19 Der Friedenskönig stammt aus 1. Paral. $22,7-9.5$; So gipfelt das Gedicht in einer Verherrlichung der Kirche mit den Bischöfen und des Fürsten als eines Friedensherrschers. III. SchluB Str. 20: Bitte zu Gott um Verleihung des himml. Jerusalems. ${ }^{6}$ )

Eine besondere Betrachtung erheischt die Geschichte von Salomo und dem Drachen, ${ }^{7}$ ) Str. $5^{b}$. Sie ist nicht der Bibel entnommen, sondern ist eine jüdische, talmudische Sage. ${ }^{8}$ ) Die unmittelbare Quelle für den deutschen

mundi beginnt das Gedicht wie ein Hymnus: mit lux, lumen, auch inclitus, werden of formelhafte Hymnen- bezw. Sequenzeneingänge gebildet.

1) Vgl. das Gedicht De Heinrico LG. I, 231.

2) SCHERER, QF. 7, 56; dâ bâch bezieht sich also auf das HL.

3) Vgl.Williram ed. SeEMÜLLERS.21 Kap.52; ferculum Cant. 3, 9 wird auch bei Honorius Aug., Migne 172, 406 D. 408 D dem mensa gleichgesetzt.

$\left.{ }^{4}\right)$ Williram S. 20 Kap. 51.

5) Vgl. auch Honorius Aug., Migne 172, 404 B. 407 A. 1099 C.

6) MÜLLENHOFF in MSD. macht Strophenumstellungen $z$ wischen Str. 7 u. 15: seine Reihenfolge gegenüber der Hs. ist Str. 7. 13. 10. 8. 9. 11. 12. 14. $15 \mathrm{ff}$. Er vereinigt die drei Strophen der Königin von Saba (seine Str.
13. 14. 15), aber sie sind in der Bibel ebenfalls getrennt. Die Beziehung des Pron. sa 14, 1 auf Ein kunigin 13, 1 ist allerdings nach dem langen $Z$ wischenraum von fünf Strophen für den Hörer oder Leser nicht recht verständlich, vom Standpunkt des Dichters aus aber begreiflich, denn er wußte bel der Konzeption wohl, um wen es sich handelt. Der Vor. Text ist gewiß manchfach entstellt, aber bei Annahme von Lücken kommt man über Vermutungen nicht hinaus (vgl. WAAG, 2. Aufl. S. XXV11).

i) SCHERER, ZfdA. 22, 19-24. Es ist eine ätiologische (b.egründete oder begründende) Sage, es soll begründet werden, weshalb der Tempel ohne Eisenwerk gebaut wurde (3. Reg. 6, 7); Kelle 2, 121.

8) VOGT, Salman S. XLIX ff. $213 \mathrm{ff}$. 
Text ist unbekannt. Der Dichter führt als Gewährsmann Hieronymus an, der habe die Wundergeschichte in den Buche archely gefunden $\left(5^{b}, 1 \mathrm{ff}\right.$.): damit sind die Antiquitates des Hieronymus Egyptius (um 300 v. Chr.) gemeint. ${ }^{1)}$ Gegen die Würde der alttestamentlichen Auffassung von Salomo, seinem Tempelbau, seiner fürstlichen Größe und Weisheit, hebt sich dieser groteske Beitrag zur Geschichte des großen Königs ab wie ein Spielmannsscherz von einem ernsten Epos und ist vielleicht einer burleskeren deutschen Ballade entnommen, und man hält die Szene wohl nicht mit Unrecht für interpoliert. ${ }^{2}$ ) Der Stil ${ }^{3}$ ) gibt keinen entscheidenden Anhalt, die Verse sind im allgemeinen kürzer, die Strophen länger als sonst. Lat. Formen hat auch der Interpolator, die wohl aus einer lat. Vorlage stammen (libano 40.57, cisternam 18 , dagegen verdeutscht dî cisternin 12 ; aber archely $5=$ Archaeologia spricht nicht für besonderes Verständnis des Lat.). Der Grund aber, weshalb der Interpolator an Stelle der biblischen Darstellung vom Tempelbau dieses seltsam profane Märchen setzte, ist die Freude am Wunderbaren (ein michel wundir $5^{\mathrm{b}}, 3$, michilis wundiris gimach 8 ). Außerdem enthielt es die im volkstümlichen Epos beliebte Figur des Drachen und das echt spielmännisch-populäre Motiv, die Trinkerfreude des Wurmes; zugleich war die Überlistung des Trunkenen ein Beispiel für die Weisheit des gefeierten Königs (er ded sô wî̀slîchi 5", 16. 36. 52). Durch solche Popularisierung des biblisch würdevollen Stoffes wollte der Bearbeiter auf das Interesse eines volkstümlichen Laienpublikums wirken.

Den Kerngehalt des Gedichtes bildet Salomo in seinem Reichtum, seiner Weisheit, seiner Friedensliebe, als ein Vorbild weltlichen Königtums, und zugleich symbolisch als ein Abbild Gottes des allmächtigen Weltschöpfers und Himmelskönigs, insofern er den Tempel erbaute und einen glanzvollen Hof hielt, und Christi des Herrn der Kirche und des Bräutigams der Seele, vermittelst seiner Beziehungen zu der arabischen Königin. ${ }^{4}$ ) Die religiöse Stimmung kommt besonders in den Eingangs- und Schlußstrophen zur Geltung, geistlich ist auch die Allegorie.

Der Stil ist episch, also formelhaft: Einfacher Satzbau, der oft parallel verläuft. Wiederkehrende Wendungen: $\left.{ }^{5}\right) 3,4-20,4 ;\left[3,10=5^{\text {b }}, 49\right] ; 4,1 \mathrm{f} .=$ 12,1 f. $; 4,6=5,8\left[5^{b}, 29\right] ; 4,9$ f. $=12,6$ f. [ $\left[5^{b}, 3=5^{b}, 8 ; 5^{b}, 15\right.$ f. $=5^{b}, 51$ f. $; 5^{b}, 40$ $=5^{\mathrm{b}}, 57 ; 5^{\mathrm{b}}, 41 \mathrm{f} .=5^{\mathrm{b}}, 63 \mathrm{f}$. $] ; 7,10=19,9 ; 9,1=11,1 ; 13,5 \mathrm{f} .=15,3 \mathrm{f}$. $; 15$, $1=20,1 ; 17,1=18,1 ; 16,1=17,2=18,2$. Bekannte Formeln: $\left[5^{b}, 1\right.$

1) Kelle 2, 121.322f. Hieronymus v. Kardia s. Handb. d. klass. Altertumswissensch. Vli, 2, $159 \mathrm{f}$.

2) MSD. 1132, 224-226; SCHERER aaO.; K. HofmanN aaO.; WaAG, 2. Aufl. S. XXV; dagegen 1. Aufl. S. XX. H.Schammberger, Zum Ged. 'Lob Salomons', Leipz. Diss. 1910, sucht auf Grund der rhythmischen Melodik das Gedicht verschiedenenVerfassern zuzuweisen.
3) Wunderlich, ZfuPh. 26, 113.

4) Salomos Tempelbat ist Gegenstand für dic Predigt der Kirchweihe, zur Feier der Dedicatio Ecclesiae; teilwcise almlichen Inhalt wic unser Gedicht hat die Predigl bei SchönBaCH, Ad. Predigten Bd. 3, Nr. 4 a S. $98 \mathrm{ff}$.

5) Kraus, Zfö. aaO. S. 136. 
die Einleitungsformel ein hêrro hîz (vgl. MSD. II ${ }^{3}, 230$ f. 234)]; 10, 1. 17, 1. 18,$1 ;\left[5^{\mathrm{b}}, 55 \mathrm{f}\right.$. hat Parallelen in altdeutschen Wurmbesegnungen]. Epische Epitheta: duirir wîgant 5,1 ; ferner $\left[5^{b}, 14.25.\right] 6,8.7,4.11,3.13,5$ f. 15 , 3 f. 19, 6, dî guldînin crônin 6,6. Ein Lieblingsadjektiv ist michel 3, 4; 4,$6 ; 5,6.8$; [5, 3 . 8. 23. 29.] 6. 2. 8, 1. 11, 10. 13, 3. 20, 8; hyperbolische Epitheta: 3, 9. [5 $\left.{ }^{b}, 20\right]$. Zweigliedrige Ausdrücke: 2, 7. 4, 8. 6, 7. 8, 5. 13, 4. $13,6=15$, 4. [5 b 19 (20)]. Lat. Wörter: 1,1 . [5, 18$] .6,7.8 .12,10.13$, 4. 17, 2. 6. 18, 10. 19, 10.1) - Die Stimmung des sprachlichen Ausdrucks ist gleichmäßig und erhebt sich nirgends zu gesteigerter Empfindung. ${ }^{2}$ )

Metrik. ${ }^{3}$ ) Fast die Hälfte der Reime ist rein, auffallende Assonanzen kommen nicht vor. Volle Endungsvokale sind selten: 5, 5. 5, $8\left[5^{\text {b }}, 18\right] 7$, 9. [16, 6]. Die Verse haben ziemlich ebenmäßigen Rhythmus. Zu bemerken sind scaz:opes 13, 3 f. und gibot : pacificus 19, 9 f., mit lat. Reimworten. Die Strophen sind meistens 10zeilig,4) 8 Zeilen haben Str. 12.13.15; die Strophen der Drachenerzählung sind länger, sie haben 14. 20. 16. 16 Zeilen; so teilt die Handschrift durch große Initialen ab.

$\$ 21$. Die drei Jünglinge im Feuerofen.

Kelle 2, 6 f. 240; PiPer, GD. 1, 215-222. - Ausg.: Diemer, D. Ged. S. 117-119, Anm. S. 47, Einl. S. XLII; MSD. Nr. 36 u. II $^{3}$, 230-234; WAAG, K1. d. Ged. ${ }^{2}$ S. $36-38$ u. Einl. S. XXIX-XXXV (Nabuchodonosor); SCHADE, Geistl. Ged., Einl. S. XL-XLVIII. - BARTSCH, Germ. 9, 63 f.; K. HofMANN, Münch. SB. 1871, 557 ; SCHERER, QF. 12, 41 ; RÖDIGER, ZfdA. 33, 422 f.; John MeIER, Beitr. 16, 95; Kraus, ZföG. 45 (1894), 138 f.

Hs.: Vor. Hs. B1. 99c-100a mit einigen Fehlern und einer Lücke in Str. $3 .^{5}$ )

In bezug auf Dialekt und Orthographie, Heimat, Zeit und Verfasser gilt dasselbe wie für die Summa Theologiae und das Lob Salomons Gesagte.

Inhalt. $\left.{ }^{6}\right)$ I. Einleitung Str. 1: Vor Christi Geburt, in der Heidenzeit, waren die Israeliten es, die Gott bekannten. II. Hauptteil Str. 2-8: Str. 2. 3 Nabuchodonosors (Nebukadnezars) Götzendienst; Str. 4-7 die Marter der drei Jünglinge; Str. 8 Bekehrung der Heiden, Erlösung der Jünglinge. Die zwei letzten Zeilen, dié auf Str. 8 folgen, sind unecht und erst von einem Schreiber nachträglich zugefügt (nach Daniel 4, 28 ff.).

Quelle ist Daniel Kap.3. Der Verlauf der äußern Handlung ist annähernd beibehalten, aber die innere, die ethische Richtung ist geändert: aus der biblischen Erzählung ist eine christliche Märtyrerlegende geworden. Die drei Männer sind todesmutige Bekenner des Christenglaubens, der König ist der heidnische Wüterich, der sie zu grausamster Marter verurteilt. Aber die Kraft des Glaubens und die Hilfe Christi schirmt sie, ihr unerschütter-

1) GRÜNEWALD S. $7 \mathrm{f}$.

2) Die V. 16, 8-10 stimmen überein mit Rol. 9050-52, MSD. II 230.

3) Saran S. $253 \mathrm{f}$.; Schammberger aaO.

- 4) Zu Str. 9 s. Kraus aaO. S. 135 f. MÜllenHOFF und SCHERER nehmen 20 10zeilige Strophen an, wobei sie das Drachenstiick ausscheiden; SCHADE bekommt ungefähr (circiter) 26 Zehnzeiler, K. HofMaNN deren 25 ;
WAAG teilt der Hs.entsprechend 24Strophen ab.

5) SCHERER hält die Ueberlieferung für stark verdorben durch einen Interpolator und gibt darum in MSD. einen stellenweise bedeutsam geänderten Text. Es leiten ihn dazu seine rhythmischen Grundsätze (Verse von 4 Hebungen, keine zu schweren Senkungen).

6) Strophenbezifferung nach MSD. 
licher Gottesmut zwingt selbst die Heiden zur rechten Überzeugung und zur Bekehrung. Von diesem christlichen Standpunkte aus erklären sich die Abweichungen gegenüber der historischen, das ist der biblischen Auffassung: die christlichen Glaubenszeugen predigen von Gott $(4,6)$, ihre Lebensaufgabe ist es, die Heiden zu bekehren, und sie gelingt ihnen; die drei Bekenner des alten Testamentes dagegen können wohl für ihren Glauben sterben, aber die Gegner nicht von ihrer Irrlehre zur Wahrheit bekehren. Und andererseits ist der König kein blöder Tyrann, sondern ein wahrheitsempfänglicher Mensch, der Wandel seiner Gesinnung besteht aber doch nicht in der Bekennung, sondern nur in der Duldung des andern Glaubens. In dem alttestamentlichen Stoff sah das Mittelalter gläubige Männer, die in der dunklen Zeit des Heidentums schon vor der Erscheinung des Erlösers den wahren Gott verkündigten und ihr glaubenstreues Heldentum glich so ganz einem Märtyrerwunder: das ist der Grund, weshalb er aus der Fülle des bewegten alttestamentlichen Lebens wieder werbende Kraft für die Christenheit gewann.1)

In Stil und Metrik besteht kein prinzipieller Unterschied gegenüber dem Lob Salomons. Charakteristische Formen wie Wiederholungen $(7,7 \mathrm{f} .=$ 8,7 f.), zweigliedrige Ausdrücke $(6,6)$, Formeln $(2,1)$, epische Epitheta (1, 8. 2, 2. 7, 6. 12. 8, 6), lat. Sätze $\left(7,14\right.$ f.), $\left.{ }^{2}\right)$ begegnen im Verhältnis seltener (das Gedicht umfaßt etwa nur ein Drittel der Verszahl vom Lob Salomons).

Die Hs. bezeichnet durch große Initialen 7 Abschnitte zu 12. 12. 8. 8. 16. 16. 10 Zeilen (im dritten Abschnitt Lücke). ${ }^{3}$ )

\section{$\$ 22$. Judith (die ältere Judith).}

Kelie 2, 5 f. 239 f.; Piper GD. 1, 215-22. - Ausg.: Diemer, D. Ged. S. 119-123, Anm. S. 47 f., Einl. S. XLII; MSD. Nr. 37 und $11^{3}, 234-237$; WAAG, Kl. d. Ged. ${ }^{2}$ S. 38-43 u. Einl. S. XXIX-XXXV; SChADE, Geistl. Ged., Einl. S. XL-XLVIII. - BARTSCH, Germ. 9, 64; K. Hofmann, Müncl. SB. 1871, 558-561; Scherer, QF. 12, 41; John Meier, Beitr. 16, 95; Kraus, ZföG. 45 (1894), 139; Sievers, Prager deutsche Stud. 8; V. Teuber, Die m.alterl. Ged. von d. Judith, Progr. Kommotau 1906; Wallner, ZfdA. 41, 76; ders., Beitr. 43, $181 \mathrm{ff}$.

Hs. Vor. Hs. Bl. 100a-100c. Der Text schließt sich ohne Unterbrechung in gleicher Zeile und ohne durch großen Anfangsbuchstaben als ein neues Stück kenntlich gemacht zu sein an das vorhergehende Gedicht von den drei Jünglingen an. ${ }^{4}$ )

1) Symbolische Bedeutung der tres pueri z. B. im Speculum Eccl. des Honorius Aug., Migne 172, 905 BC. $1082 \mathrm{~A}$; cin Bild der Gerechten beim jüngsten Gericht: Alcuin de Trinitate, Migne 101, 53, s. anch Sp. 485; im griech. Physiologus: STRZYGOWSKi, Byzantin. Archiv H.2, Reg. S. 128. Die drei Jünglinge werden oft in Gebeten angerufen als Beispiele, wie Gott die Bittenden erlöst.

2) GRONEWALD S. 8.

3) In MSD. sind 8 Strophen angenommen. SCHADE aaO.führt scine6zcilige Strophe durcl.

4) Die Hs. macht fälschlich einen Abschnitt vor den beiden letzten, unechten Zeilen des Gedichtes von den drel Jiinglingen. Diefalsche Abteilung wird dadurclı entstanden scin, da $B$ jenc beiden Schlußzeilen, MSD. Nr. 36, Str. 8 , $11 \mathrm{f}$., in einer früheren $\mathrm{Hs}$. von einem Schreiber an den Rand notiert waren, dann von cinem folgenden Abschreiber in den Text hincingetragen wurden, wobei dieser dic richtige Ábteilung verfchlte. - SCHERER trennt in MSD. zwci Gedichte, die drei Jünglinge und die Judith. DiEMER machte, der Hs. entsprechend, kcine Trennung und faßte beide Gedichte zusammen unter dem Titel ,Gesclichte der Judith nach älterer Bearbcitung* (S. 115), iiltere Judith. K. HOFMANN und ihm folgend WAAG, Beitr. 11,116-119 und in seiner Ausgabc, belassen ebenfalls die Einheit und geben den Gesamttitel "Nabuchodonosor". 
Zu Überlieferung, Dialekt, Orthographie, Heimat und Zeit s. das vorhergehende Gedicht.

Inhalt. I. Einleitung Str. 1. 2: Holofernes der Gottesfeind. Il. Hauptteil Str. 3-11b: a) 3-6 Holofernes belagert Bathania (Bethulia); b) 7-11b die Tat der Judith. Der SchluB fehlt, das Gedicht bricht unvollendet ab.

Quelle ist das biblische Buch Judith, und zwar mit Kap. 1.2.4.6.7. 8. 10. 12. 13, aber der Dichter scheint den Text der Bibel nicht unmittelbar benutzt $z \mathfrak{u}$ haben. In der Entwicklung der Handlung weicht das deutsche Gedicht außer starken Kürzungen nicht ab, wohl aber in vielen Einzelheiten, die besonders in der zweiten Hälfte, von Str. 8 an, die Gesamthaltung beeinflussen: Holofernes sieht die Judith herankommen Str. 8, 1-9, 4, während in der Bibel die Knechte sie ihm zuführen, ohne daß er sie vorher erblickt hatte Kap. 10, 11 ff.; im Gedicht wünscht Judith das Hochzeitsmahl Str. 9, 5-10, 4 und macht den Holofernes trunken, in der Vorlage sind diese Ereignisse eine Fügung Gottes Kap. 12, 8, Holofernes verlangt selbst das Mahl Kap. 12, 10 und kommt durch übermäßige Fröhlichkeit Kap. 12, 20 in den verhängnisvollen Zustand; Judiths Gebet Str. 11, 3-8=Kap. 13, 6 f.; die Engelserscheinung.in der letzten Strophe $11^{\mathrm{b}}, 1 \mathrm{ff}$. ist eine Zutat des Dichters gegenüber Kap. 13, 8 ff. - Kleinere Änderungen: der Name der Stadt, Bathania Str. 3, 8 gegen Bethulia (Bethania war dem Dichter aus der Lebensgeschichte Jesu bekannt); aus dem Hohepriester Eliachim in Jerusalem Kap. 4, 5. 11 ist der Bischof Bebilîn der belagerten Stadt geworden Str. 6, 11; der Name der Dienerin Abra ist in Âvi verdeutscht; die Belagerung von Bethulia dauert in der Bibel zwanzig Tage Kap. 7, 11, im Gedicht mêr danni ein jâr Str. 4, 2, die Frist bis zur Übergabe in der Bibel fünf Tage Kap. 7, 23. 25, im Gedicht drei Tage Str. 6, 14.

Das deutsche Gedicht ist für die Entwicklung unserer Literaturgeschichte von ganz besonderer Wichtigkeit: es ist eine der wenigen volkstümlichen Balladen, die wir aus ahd. bezw. mhd. Zeit besitzen ${ }^{1}$ ) und damit ein Muster für den Stil eines epischen Volkslieds aus der mhd. Frühzeit; zugleich aber auch ein Beispiel für die Methode bei der Übertragung eines biblischen Stoffs in ein deutsches Spielmannsgedicht, und zwar das einzige Beispiel hierfür, denn die ältere Judith ist das einzige echte geistliche Spielmannslied. Der fremde Stoff ist in die deutsche Anschauungswelt umgeformt, darauf beruhen die meisten der oben angeführten $\mathrm{Ab}$ weichungen von der alttestamentlichen, jüdischen Erzählung. Deutsch ist das Lokale, eine Bischofsstadt, ${ }^{2}$ ) eini burch 3, 7, deren Herr, der biscof, den deutschen Namen Bebilîn hat, die Bewohner sind die Bürger, burgâri 6, 10, an deren Spitze der burcgrâvi steht 6,1. Mit dem Bischof als dem Herrn über Krieg

\footnotetext{
1) Das Hildebrandslied s. LG. I, $115 \mathrm{ff}$. , der Segen Ad equum erræhet S. 110, die Tänzer von Kölbigk S. 239 ff. - Ueber das Wesen des epischen Liedes s. unten Spielmannsdichtung.
}

2) Bethulia zu einer Bischofsstadt zu machen wird der Dichter veranlaßt worden sein.durch die in der Bibel vorhergehende Nennung Jerusalems und des Hohepriesters Kap. 4. 
und Frieden verhandeln die Bürger und zwar in einem viel weniger anspruchsvollen Ton, als ihn die Einwohner gegen den weltlichen Vorgesetzten in der biblischen Überlieferung anschlagen Kap. 7, 12 ff.: dort verlangen sie unter Vorwürfen von dem obersten Beamten oder Fürsten Ozias die Übergabe und dieser, zur Verantwortung gezogen, bittet sie um Geduld und Aufschub, im deutschen Gedicht dagegen sind die Bürger die Bittenden und die um Fristgewährung Ersuchenden. Zum deutschen epischen Stil gehört die Wechselrede zwischen den Gegnern, Holofernes und dem Burggrafen, ein Kampfgespräch (gelf, s. LG. I, Reg. S. 459), die typische Zahl 3 statt 5 $(6,14)$ und die Hyperbel mêr danni ein jâr $(4,2)$. Die Geschichte von Judith und Holofernes ist $\mathrm{zu}$ einem kleinen Spielmannsroman umgedichtet: ein König sieht ein schönes Weib vor seinen Palast, er will sie zur Frau haben, sie aber ist gekommen, um Rache zu nehmen für ihr Volk und um ihn zu töten. Sie nimmt seine Werbung an, aber es ist nur eine List: bei dem Mahl, das sie ihn zu rüsten bittet, macht sie ihn trunken und schlägt dem Schlafenden das Haupt ab. ${ }^{1}$ ) Unter dieser Voraussetzung erklären sich die Umänderungen im Gedicht. Zunächst paßte für die rasche Entwicklung eines epischen Liedes der Umweg nicht, daß Judith zuerst von den Wächtern gesehen wird; gleich mitten in die Haupthandlung hinein strebt die Erzählung, die Wächter müssen als dienende Nebenpersonen hinter der Hauptperson, dem Fürsten, zurücktreten. Damit fällt auch die List weg, mit der sich Judith in das Lager hereinzumachen weiß Kap. 10, $12 \mathrm{f}$. Ein echt germanisches Sagenmotiv aber ist es, dem Gegner beim Gelage die Sinne $z \mathfrak{u}$ berauschen, um den. Sinnlosen betrügen oder beseitigen zu können, darum mußte Judith, nicht Holofernes, die Mahlzeit anregen. Und wiederum ist die Darstellung eines Gelages im heimischen Epos beliebt, deshalb ist über das Brautmahl, bei dem die fürstliche Wirtin selbst den Wein schenkt²) und alle bis auf den letzten Mann an der Bank ${ }^{3}$ ) volle Humpen haben, einiges Behagen verbreitet. - Eine besondere Technik wird dann in der letzterhaltenen Strophe angewendet: die blutige Tat der Judith wird nicht unmittelbar erzählt wie in der Bibel, sondern wir erfalıren sie aus dem Munde eines Engels, der ihr im Namen Gottes verkündigt, wie sie sie ausführen soll. Die Handlung ist also hier, echt germanisch, in einer Rede weitergefuhrt. - Verwirrung ist in der Person der beiden Heiden eingetreten: sie sind gleichsam zu einem Menschen verschmolzen, Str. 1, 3-2, 6 gehören eigentlich dem Nabuchodonosor, nicht dem Holofernes zu, 9, 8. 11, 1 wird

1) Ganz ähnlich ist das Ende Atlis in der altnordischen Nibelungensage: den vom Mord ihrer Brtider heimkehrenden Gatten lădt Gudrun zum Mahle, sỉe reicht den Männern den Trunk und erschlägt den trunkenen Atli (Atlakvipa Str. 33 ff.). Attila im Rausch von einem Weibe aus Rache erschlagen: W. Grimm, D. Heldensage ${ }^{3}$ S. 9 f. Zu einer weiteren Szene gestaltet Ekkehard in seinem
Waltharius manufortis $276 \mathrm{ff}$. (s. LG. I, $384 \mathrm{ff}$ ) die auf Attila angewandte List des Trunkenmachens und ihre Folgen; vgl. auch Biterolf $12634 \mathrm{ff}$.

2) Vgl.Beowulf 611 ff. 1169 ff. 1980 ff. 2020 f.; Atlakvipa aaO.; andere Stellen s. bei WeINHOLD, Altnord. Leben S. 461 ; ders., Deutsclie Franell $2^{2}, \mathbf{Y} 23 \mathrm{f}$.

3) Andere Betspicle MSD. $\|^{3}, 235$. 
Holofernes, der herzogi $(1,1)$, kunic genannt und in Str. 6 werden vom Burggrafen beide angeredet, während seine Antwort doch nur dem Holofernes gelten kann. $\left.{ }^{1}\right)$

In einer Spielmannsdichtung geht der religiöse Gehalt nicht tief, in unserm Lied ist denn auch nichts zu spüren von der Glaubensstärke der alttestamentlichen Erzählung: in dieser stellt Judith den Verlauf ihres Unternehmens Gott anheim Kap. 9, 18, in dem Gedicht dagegen leitet sie selbst durch ihre Schlauheit ihr Geschick. Die gegebene religiöse Voraussetzung ist der Kampf zwischen dem Christentum und dem Heidentum oder zwischen Christus und dem Satan wie in dem gleichzeitigen Gedicht von den drei Jünglingen und wie im Rolandslied des Pfaffen Konrad. Die spezielle Idee ist ausgesprochen in den Versen 11,5-8: Erlösung der Gläubigen von den Heiden, und mit dieser schließt auch der uns erhaltene Text der Vor. Hs. 11 ${ }^{\text {b }}, 21$. Es ist die Stimmung der Kreuzzüge. Verkörpert sind die beiden Gegensätze in dem Heiden Holofernes, für den der Dichter das Stichwort hat "der streit widir goti gerni“, und in der guten Judith, "dî zi goti wol digiti".

Die glaubenseifrige Großtat der Judith war dem MA. ein sympathischer Stoff, sie ward viel gepriesen, in Prosa und in Versen: Judith ... omnium ore usque hodie laude digna triumphat rühmt Honorius Aug. von ihr (Spec. eccl., Migne 172, 896 D) und zählt sie unter den alttestamentlichen Vorbildern auf (Migne ebda und Sp. 1070 A-C. 1082 A). Ein lat. Gedicht, Versus de Judit et Holofernem, ist uns in mehreren Hs., leider nur unvollständig, erhalten. ${ }^{2}$ ) Es folgt ganz der Bibel und in der Vergleichung des deutschen Gedichtes mit diesem lat. zeigt sich aufs einfachste der Unterschied zwischen spielmännischer und geistlicher Behandlung: es ist die Umkleidung des historischen Stoffes in ein alltägliches Gewand.

Das Gedicht ist in reinem Spielmannsstil abgefaßt, ein wahres Muster für eine volkstümliche Ballade: ein geradliniger Verlauf, ohne Abschweifung und Nebendinge, gesagt ist nur, was zur Sache gehört, gegenständlich, sinnfällig. Es interessieren aber nur die Tatsachen der Handlung, daher keine Schilderung, weder der Menschen noch des Milieus oder der Natur, keine Reflexion, keine Stimmung, die Personen werden nicht charakterisiert, sie handeln triebhaft, sie erwecken Teilnahme nur durch ihre Taten, doch geben manchmal kurze Formeln, wenn sie auch rein mechanisch gesetzt

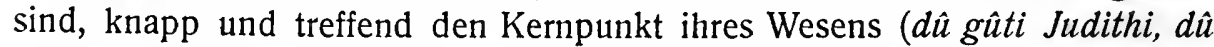
$z i$ goti wol digiti, Oloferni, dî burc habit er gerni). Klar sind die gegebenen, hervorspringenden Tatsachen, aber auf die Zusammenhänge kommt

1) Der Grund $z u$ diesem Zusammenwerfen ist nicht sicher zu erkennen, sehr wahrscheinlich lautete die Stelle 6, 3-8 in der Judith ursprünglich anders und erst ein späterer Vortrager oder Schreiber hat diese Verse aus den drei Jünglingen dafür eingesetzt. Dann hätte der Dichter nur Str. $1,3 \rightarrow 2,8$ von $\mathrm{Na}$ buchodonosor auf Olofernes übertragen und in 9,8 und 11,1 diesem den Titel kuninc beigelegt, welch letzteres deshalb um so leichter geschehen sein konnte, weil ihm überhaupt eine Scheidung der beiden Personen nicht deutlich im BewuBtsein lag.

2) Du MÉRIL, Poésies pop. lat. antérieures au XII. s. S. 184 f.; E. DÜMMLER, ZfdA. 23, 266-268 u. 262f.; GRÖBERS Grundr. II, 1, 173. 
es nicht an, die bleiben der Auffassung der Hörer überlassen, soweit sie sich darum kümmern, denn dieses Publikum verlangt gar keine im Innern begreifliche und folgerichtige Entwicklung, sondern eben nur fesselnde Momente. Darum stehen die größten Unmöglichkeiten ruhig nebeneinander. Holofernes spricht - zu wem ist nicht gesagt - , es antwortet der Burggraf, an den die Rede gar nicht gerichtet ist und von dem sie auch gar nicht gehört werden konnte: der Dichter macht hier ein Kampfgespräch, weil ihm die Gelegenheit dieses ihm geläufige epische Mittel darbietet. Die eine der Hauptpersonen, Holofernes, wird in der Exposition eingehend vorgeführt, wie denn überhaupt die vorauszusetzenden Umstände reichlich ausgebreitet werden (Str. 1-4), da die biblische Vorlage dazu den Stoff abgab. Aber die Nebenpersonen, der Burggraf und der Bischof, und dann die andere Hauptperson, die Judith, werden gar nicht vorgestellt, sondern treten unmittelbar in die Handlung ein.

$\mathrm{Zu}$ dieser naiven Auffassung des Stoffes paßt auch der Sprachstil. Die Formensprache ist einfach, der Ausdruck ergibt sich dem Dichter spontan aus den angeschauten Dingen und zielt auf unmittelbare Wirkung.

Vorherrschende Parataxe, in Parallelbau 4, 5-8. 5, 5-8. 6, 15-18 (antithetisch). 9, 3. 4. 11, 1. 2 u. 3. 4. Forfführung mit $d \hat{o}$, schr oft im Strophenanfang: $3,1.4,1.5,1.6,1.9 .7,1$. 8, 1. 9, 5. 13. 10, 1. 6. 12. 11, 3. 11b, 1. 3. Ausruf 9, 2. Formeln (MSD. II', 233): 1,$1 ; 4,1$. 7, 4. 10, 5. $9 ; 4,2.6,14 ; 2,8 ; 5,1$ f. 8,1 f. 10,12 f. (vgl. 1,1 f. 9,13 f.); 7,1 f. 9,5 f. 10 , 6 f. 11 b, 5 f. Wörtliche Wiederholungen $3,1.6,11 ; 8,5.10 ; 9,11 \mathrm{f} .=10,1 \mathrm{f}$.; $10,6=10,9$;

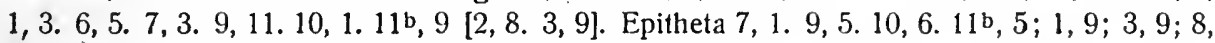
5. $10 ; 8,3 ; 11,5.11 \mathrm{~b}, 2 ; 11,7 ; 3,2$; volkstüml. Kampfwörter: wiglichi, vrabillichi $11 \mathrm{~b}, 13$ f. (s. MSD., Varianten). Hyperbeln 1, 3. 2, 7. 7, 5.

Bemerkenswert ist, daß keine lat. Worte vorkommen. Einen verhältnismäßig großen Teil des Gedichtes nehmen die Redeverse ein, nämlich nahezu die Hälfte, in der Geschichte der Judith für sich gesondert machen sie sogar mehr als die Hälfte aus. - Für den Stimmungsausdruck gilt dasselbe wie bei den drei Jünglingen.

Metrik. ${ }^{1}$ ) Rein reimt fast die Hälfte der Verse; voller Endungsvokal ist gebunden in man: lernan 1, 3 f.; [Judithi: digiti 7, 1 f. 9, 5 f. 10, 6 f. 11b. 5 f., aber Juditha: Bathania 3, 8 f. $]^{2}$ ) - Die Absätze bezw. Strophen haben nach der Hs. folgenden Versbestand: Str. 2-5 und 11: 8 Zeilen, Str. 6-8: 10 Zeilen, Str. 9 und 10: 14 Zeilen, Str. 1: 16 Zeilen, Str. 12 endet mit Dreireim bei 21 Zeilen, aber der eigentliche Schluß fehlt. ${ }^{3}$ )

Im Vorhergehenden sind von vornherein die drei Jünglinge und die Judith als zwei getrennte Gedichte angesehen worden. Es ist die Art des deutschen epischen Liedes, einen in sich abgeschlossenen und für sich wirken-

i) W. GRIMM, ZGdR., Kl. Schr. 4, 163. 214; SARAN, S. 254.

2) In MSD. ist 3,9 für unecht erklärt.

3) SCHADE aaO. führt auch hier seinc 6zeilige Strophe durch; SCHERER in MSD. teilt Abs. 1 der Hs. in 2 Strophen und zieht die Abs. 5 u. $6(=$ MSD. Str. 6$)$ in einc Strophe zu- sammen unter Annahme starker Interpolation; den letzten Abs. (11b) erklärt er für unecht. SIEVERS nimmt aaO. aus rhythmisch-melodischen Gründen ein ursprïngliches Gedicht von 12 8zciligen Strophen an, das nacls. träglich durch verschiedene lnterpolationen crweitert worden sei. 
den Stoff zusammengefaßt darzustellen. Jedes der beiden historischen Lieder umfaßt einen in sich abgegrenzten Ausschnitt aus der alttestamentlichen Geschichte. Auch in der m.alterl.-lat. Dichtung gab es solche biblische Einzelgedichte, wie z. B. die oben angeführten Versus de Judit et Holofernem und die in der ZfdA. 23, 268 ff. darauf folgenden Gedichte von Hester und Mardocheus und De Diuite et Paupere zeigen. Die weitere Frage ist nun, ob beide Gedichte auch verschiedene Verfasser haben. Die Verskunst ist die gleiche, aber die Sprachbehandlung nicht: das Gedicht von den drei Jünglingen hat den einfachen Erzählerstil, die Judith trägt ausgesprochen spielmännischen Charakter. Jedenfalls sind also zwei stilistische Typen festzustellen. Nun ist es ja nicht ausgeschlossen, daß ein und derselbe Verfasser je nach seinem Bedarf unter bestimmten Gründen zwei verschiedene Stilarten anwendet. ${ }^{1}$ ) Aber eben ein Grund für verschiedene Sprachgebung liegt in dem Stoff nicht vor, die drei Jünglinge hätten ebensogut in spielmännischem Gewande dargestellt werden können wie die Judith. Also wird man wohl, wie zwei verschiedene Gedichte, so auch zwei verschiedene Verfasser anzunehmen haben. Der Dichter der Judith war also ein rheinischer Spielmann, ${ }^{2}$ ) der Ton seines Gedichtes ist weltlicher gestimmt als der der beiden vorhergehenden Stücke.

In den drei biblischen Dichtungen ist der Stoff jeweils in besonderer Weise aufgefaßt: das Lob Salomons ist eine didaktische Allegorie; darin die Drachengeschichte eine Wundererzählung, ein Märchen; die drei Jünglinge sind eine Legende, die Judith ist ein heroisch-episches Lied.

$\$ 23$. Die jüngere Judith.

Kelle 2, 155 f. 356 f.; Piper, GD. 1, 204-206. - Ausg.: Diemer, D. Ged. S. 125-180, Anm. S. 48-57, Einl. S. XLII. - Scherer, QF. 7, 56-59. 12, 69; Jos. PIRIG, Diss. Bonn 1881, dazu Vogt, Lit.B1. 1882, 173 f., Steinmeyer, Anz. 7, 332 f.

Hs. Vor.Hs. B1. 100c-108d.

Der Dialekt des Gedichtes in der Hs. ist bair.-österreich., mit wenigen alemannischen Formen. ${ }^{3}$ ) Seine Heimat ist doch wohl Österreich; entstanden ist es um 1140.

Inhalt. Erzählt wird die Geschichte der Judith. Voran geht eine längere Einleitung 127, 1-128, 19, die in drei Teile zerfällt: 1. Empfehlung des Werkes 127, 1-6. 2. Polemik gegen die äbelwollenden Kritiker (nîdore, spottere) 127,6-16. 3. Sittliche Lehre des Gedichtes mit Angabe des Inhalts: das hebräische Volk ist ein Beispiel dafür, daB Gott die beschützt, die seiner Lehre und seinen Geboten gehorsam sind, wie Gott an diesem schwachen Weibe bewiesen hat 127, 16-128, 19.

Der biblische Text und das deutsche Gedicht entsprechen sich folgendermaßen: Vulg. Kap. $1=128$, 20-132, 28; Kap. $2=132$, 28-138, 13; Kap. $3=138,14-140,14$; Kap. $4=$ $140,14-143,6$; Kap. $5=143,6-147$, 13; Kap. $6=147$, 13-150, 22; Kap. $7=150$, 22-155, 27 ; Kap. $8=155,27-160,22$; Kap. $9=160,22-161,1$; Kap. $10=161,2-164,13$; Kap. $11=$ $164,13-167,7$; Kap. $12=167,7-170,6$; Kap. $13=170,6-174,1$; Kap. $14=174,1-176$, 22 ; Kap. $15=176,23-179,17$; Kap. $16=179,17-180,29$.

Die Quelle ist eine Vulgatahs., die von der Itala beeinflußt ist. Der Dichter folgt der Bibel Schritt für Schritt, ohne dogmatische oder allegorische

1) Vgl. „Die geblümte Rede“, Beitr. 22, 322.

2) MSD. $\mathrm{II}^{3}, 237$.

3) WAAG, Beitr. 11, 119-122. 
Belehrungen, jedoch mit den Freiheiten des geistlichen Übersetzerstils: er verlängert den Text oder verkürzt ihn zuweilen, das heißt er verwässert ihn. Der oft knappe Bibelstil erforderte wohl zum Verständnis der Zuhörer, die mit den alttestamentlichen Verhältnissen nicht vertraut waren, ein näheres Eingehen auf den Gegenstand und eine gemächlichere Auseinandersetzung; aber die Zutaten des Dichters gehen allzusehr ins Breite und sind oft nur langstielige, aber geringhaltige Umschreibungen einfacher Grundgedanken. ${ }^{1}$ ) Er schafft mit einem geringen Material von Vorstellungen und Worten. Persönlichen Ausdruck, wie etwa der Dichter der Wien-Milstäter Genesis, hat er seinem Werke nicht $z u$ verleihen gewußt, ${ }^{2}$ ) es fehlt auch jene Teilnahme an den Menschen und ihren Schicksalen, die die Erzählung mit Wärme durchdringt.

Man sieht die Arbeitsweise des Dichters: er verweilt bei epischen Motiven und führt sie in der herkömmlichen Stilisierung aus.

So hat er in Artaxersis und Nabuchodonosor den Typus des heidnischen Königs gezeichnet, so benutzt er die kurzen Worte vom Untergang Arphaxads durch Nabuchodonosor: pugnavit contra Arphaxad et obtinuit eum Vulg. 1, 5 zu einer Schlachtschilderung 130, 15-26. Und wiederum kann man hier seine Unselbständigkeit beobachten: er findet nur altbekannte Wendungen und bringt es zu keinem belebten Sclulachtenbild. Er hält sich sklavisch an das, was die Bibel ihm bietet, nach den zwei Punkten pugnavit contra Arphaxad und obtinuit eum ${ }^{3}$ ) gliedert er seine Auseinandersetzung in Kampf 130, 15-20 und Niederlage 20-26. Dann wird im Anschluß an die Ortsangabe Vulg. 1,6 noch einmal auf den Kampf zurückgekommen und die Örtlichkeit umständlich auseinandergesetzt 130, 26-131, 13, dazu bedarf er zuerst dreier Flickverse als Uberleitung 130, 26-30; das Wort uelt, für den Sinn notwendig (in campo magno Vulg.), ruft dann den Vers mit dem Reimwort gezelt hervor, die Ubersetzung von circa Euphraten et Tigrin erfordert dann wieder drei Zeilen 131, 2-5. Schleppend entwickelt sich die Ratsversammlung 133, 4-27 = Vulg. 2, 2-4, mit ungeschickter Wiederholung von dreimaligem gereit sin 133, 14.21. 26, zweimaligem geuiel wol 20. 23.

Seltener hat der Dichter den Bibeltext gekürzt, und dann am unrechten Orte. Er hat keinen Sinn für die Überzeugungskraft des Gebetes, mit dem Judith den Beistand Gottes erfleht (Kap. 9), noch für die Glaubensstärke, die aus ihrem Triumphlied spricht (Kap. 16, 1-21); er übergeht dies einfach: ihr Gebet war sehr groß, Gott möge sie behüten, denn kein Gott ist ohne dich, Herr Gott erhöre mich 160, 24-161, 1. 179, 17-20. Was er dazu getan hàt, um den fremden Stoff in seine Zeit zu übertragen, wie etwa die obengenannte Schlachtschilderung, ist nicht viel. Selbstverständlich sind die ritterlichen Standesbezeichnungen wie uorrten, herzogen unde grâuen gebraucht, 133, 6. 175, 24 ff., denn das sind einfach Übersetzungen von majores natu, duces, principes, so auch manige helde $133,8=$ bellatores Vulg. 2, 2, doch nur zweimal riter 153, 9. 163, 27 und einmal holden 146, 13; oder kriegerische Ausdrücke, die zu dem epischen Stil gehören, wie helde 133, 8. 147, 15, manigen helt balt 130, 14, ähnlich 174, 23, manigen chơnen man 134, 26, des michel(n) hers chraft 135, 25, des hers schal 135,

1) Vgl. Pirig S. 5 f. 35 ff.

2) Das Wenige dieser Art s. bei PIRIg S. $33 \mathrm{f}$.

3) Vielleicht enthielt seine Vorlage noch die Angabe, daB Arphaxad im Kampfe fiel, PIRIG S. 36. 
12, ähnl. 133, 24, walblìt 130, 19, uolchwîch 131, 9. 137, 26, wî̀chgeserwe $151,22.175,8.179,27$ u. a. $\left.{ }^{1}\right)$ In der Beschreibung von Judiths Kleidung $161,5-22=$ Vulg. 10, 3 nennt er die vestimenta jucunditatis nicht unpassend brûtgwant, denn das Brautkleid ist das Festgewand der Frau;2) die Sandalen, induitque sandalia pedibus suis, erwähnt er nicht, weil sie nicht zu der typischen Ausstattůng der deutschen Frau gehören.

Gegenüber den hervorragenderen Werken biblischer Epik, der Wien-Milstät. Genesis, den Vor. Büchern Mosis, auch der Exodus, deren Verfasser dem überlieferten Stoffe eigene Gedanken und eigenes Leben einzugeben verstanden, stellt die jüngere Judith eine geringwertigere Schicht der Bibelübertragungsliteratur dar. Dem entspricht auch die äußere Form, Stil und Metrik. Der sprachliche Ausdruck ist ungewandt, die vielen ausfüllenden formelhaften Verse und erzwungenen Reime zeigen zur Genüge die Not, die der Verfasser bei der Übertragung des lat. Textes hatte. ${ }^{3}$ )

Ebenso ist die Metrik ${ }^{4}$ ) beschaffen, unbeholfen in Reim und Versbau. Die Reime fallen nicht mehr auf Flexionssilben, sind aber unverhältnismäßig oft unrein, nicht selten finden sich Dreireime. Die Verse sind ungleich gebaut.

Der Verfasser war ein Geistlicher, dēnn er kannte die Bibel und verstand Lateinisch. Er hat das liet $(128,1.19)$ für ein Laienpublikum gedichtet, denn er erzählt nur Tatsachen, und diese in anspruchsloser Form, geht aber nicht auf den tiefern Sinn ein. Er rechnet nicht nur auf ritterliche Hörer, denn er richtet seine rede $(127,3.128,18)$ an die lieben lutte 1.

Das ältere und das jüngere Gedicht von der Judith sind Vertreter der zwei verschiedenen Gattungen der erzählenden Dichtung, des epischen Liedes und des Epos, also zweier Stilarten, des gedrungenen Stils und des breiten Stils. Das epische Lied läßt die Höhepunkte der Handlung scharf hervortreten, das Epos nivelliert; jenes stellt Ereignisse dar, dieses Situationen. Beide Dichter, der spielmännische und der geistliche, fassen den geistigen Gehalt von verschiedenem Standpunkt aus auf, für jenen ist die Geschichte der Judith der Kampf des Christentums gegen das Heidentum, für diesen ein Beispiel des Schutzes, den Gott den gläubig Gehorsamen verleiht.

$\$ 24$. Des Pfaffen Lamprecht Tobias.

Abgedruckt und besprochen von Herm. Degering, Beitr. 41, 528-553; Faksimile bei VoGT u. Koch, LG. 4. Aufl. 1, 84. - Wallner, Beitr. 43, 199-208.

Hs.: Bruchstücke einer Pergamenths. vom Ausgang des 12. Jhs. in Berlin, 2 Bll., in sehr fehlerhaftem Texte.

Inhalt: A. 1-29 Einleitung. 1-6 Anrufung Gottes, 7-10 der Name des Verfassers, 11-29 Gehalt des Gedichtes: Belehrung den Guten und den Bösen. B. 30-274 der erhaltene Hauptteil bis zum Schluß des Bruchstücks handelt nur von der Frömmigkeit und den Taten des alten Tobias.

1) Scherer, QF. 7, 57 f.; PIRIg S. 27 f. 39 ff.

2) SCHERER aaO., vgl. mhd. bratlachen (bei Wolfram), ein feines Gewebe, das nicht nur von der Braut getragen wird, HEYNE, Körperpflege u. Kleidung bei den Deutschen S. 220.
3) PIRIG S. 45-50. Lat. sind häufig die Flexionen bei Eigennamen, PIRIG S. 15 f.; GRÜNEWALD S. 11.

4) SCHERER, QF. 7, 58 f.; PIRIG S. 59-76; SCHRÖDER, Gött. Nachr. 1918, 424. 
Der Verfasser nennt sich am Eingang seines Werkes V. 7 der paffe Lambrecht. Es ist der Dichter des Vorauer Alexander. Das Bild von Lamprechts Persönlichkeit hat sich durch die vor wenigen Jahren erfolgte Auffindung dieses von ihm herrührenden geistlichen Gedichtes, einer predigtartigen Legende, bedeutsam erweitert. Tobiaslegende und Vor. Alexander haben den gleichen Dialekt, moselfrk. ${ }^{1}$ ) Auch im sprachlichen Ausdruck finden sich zahlreiche Berührungen. ${ }^{2}$ ) Aber doch bestehen zwischen beiden Gedichten nicht unerhebliche Verschiedenheiten, sowohl in der äußern wie in der innern Form. Im Tobias sind die Verse weniger ungleichmäßig gebaut, der Prozentsatz der unreinen Reime ist geringer, auch assonieren sie weniger stark. ${ }^{3}$ ) In der Darstellung machen sich zwei verschiedene stilistische Auffassungen geltend: im Alexander spricht der Volksdichter, im Tobias der Geistliche, der Prediger. Dort ist Fülle und Leben, die Kraft der Persönlichkeit kommt zum Ausdruck, eine fortlaufende Handlung wird erzählt in Zeitfolge, durch Temporalsätze mit dô, alsô. Demgegenüber ist der Ton im Tobias trocken, monoton, lehrhaft berichtend, es fehlen die dramatisch wirksamen Fragen, einmal begegnet ein Ausrufsatz (ozvî 234), selten werden zweigliedrige Formeln gebraucht. ${ }^{4}$ )

1) DEgERING S.543-547; WALLNER S. $200 \mathrm{f}$.

2) Uebereinstimmungen, die auf ein und denselben Verfasser deuten: Anna was sin wif genant Tob. 168 (vgl. auch 147. 199) = Philippus was sin vater genant Vor. Al. 10, Mennes was ein herzoge genant 1239 (vgl. auch 381. 815. 1391); durch Meden lant, dar der engel sint wart gesant Tob. $145 \mathrm{f} .=$ Mêdinrich ist noch daz selbe lant, dar der engel mit Tobia wart gesant AI. 1461 f.; unde sich also besath Tob. $266=$ unt si sich an dem besatten Al. 453; dar na over unmanigen tach: gelach Tob. $169 \mathrm{f} .=\mathrm{Al} .557 \mathrm{f}$. (vgl. auch 481); mortere, beim Bauwerk (des werkes 209) verwendet Tob. $213=$ Al. 709 (werch 708); Alse Thobias zu sinen dagen quam daz usw., Tob. $155 \mathrm{f}$. = unt bin alsô chomen ze minen tagen, daz Al. $351 \mathrm{f}$; daz er gewan : man Tob. $151 \mathrm{f}$. = Al. $525 \mathrm{f}$; ; dar na hiez er alle $(z)$ irslan die da gote weren underdan Tob. $241 \mathrm{f}$. = unt wurden ine undertan, er hiez si alle an daz crúce slahen Al. $653 \mathrm{f}$.; vast (= veste) : gebrast Tob. $193 \mathrm{f}$. (s. Degerings Anm.) = Al. 675 f. Neptalym und Zabulon und, nach Degerings Besserung, Naason werden Tob. 43 f., im Al. 687-690 genannt; auf Tobias in Medenreich wird angespielt in Al.1461 f. (Meden lant Tob. 145); Zitate aus Salomo: Tob. 187 f., Al. 20.62. Die Formeln im Tobias sprechen wenigstens nicht gegen gemeinsame Verfasserschaft: ich sage uch 129 ist auch im Al. häufig, daz buoch saget uns Tob. $122.224=\mathrm{Al} .36 .1396$ (vgl. 1529); Nu vernemet Tob. $135=$ Al. 155; nu ne weiz ich Tob. $261=\mathrm{Al}$. 748; Formeln mit man, mach men horen Tob. 78 (vgl. 218) $=\mathrm{Al}$. man saget 1321 , vgl. 1329; Hir mulgeter (verstan) Tob. $117=$ muget ir (wol hôren) Al. 11; Eingangsformel mit Einführung des Helden: dar umbe ich doch des began Tob. 36 (vgl. 30. 232) = umbe den ich is began Al. 60 (die Straßburger Hs. hat umbe den ich diser rede began 64, Tob. stimmt also, wie $z \mathrm{u}$ erwarten war, mit V gegen S). Einige formelhafte Wendungen mit quit 34.186 , verstan 117 , gescriven 160 kommen in V nicht vor, wohl aber in S, z. B. 2367. 5241. 4924, was auf dem Inhalt beruhen kann und keineswegs engere Beziehungen vom Tobias zuS anzunchmen benötigt.

s) Einige "Reimbesonderheiten" bei DEGERING S. 545; J. VorstIUS, Die Reimbrechung im frühmhd. Alexanderliede, Marburger Diss. 1917; vgl. auch WALLNER S.' 201.

4) Der Tobias wird vor dem Alexanderlied verfaßt sein (anders WALLNER S. 20i), denn die Erwähnung von Naason, Neptalim und Zabulon im Al. 687-690 stammt doch wohl aus Tob. $43 \mathrm{f}$. Naason konnte Lamprecht nur aus Vulg. Tob. 1, 1 kennen, da dieser Ort sonst nirgends in der Bibel erwähnt wird. Naason und Neptalim hat er aus jenem Verse der Vulg. entnommen, Zabulon aus Eigenem hinzugefügt (vgl. KINZEL, Lampr. Alex. Anm. zu 687. 689 u. 690, S. 433). Die im Tob. verstiummelte Stelle scheint zu besagen: Neplithalim und Zabulon stifteten Naason, womit Lamprecht Nephthalim als Person, Solnn Jakobs, auffaßte, während er später in Alexander richtig Nephthali (ex civitate Nephthali Vulg.) als "Neptalimlant " ibersetztc. Das lnteresse Lanprechts fiir die Tobiasgeschichte zeigt ihre Erwahnung Al. $1461 \mathrm{f}$. 
Die Quelle für das Gedicht ist im wesentlichen das alttestamentliche Buch Tobias, wie Lamprecht selbst angibt (in testamento 32). Außerdem nennt er das Buch der Könige (in libro regum 160) bei der Behauptung, Salmanassar sei aus Israel vertrieben worden und geflohen: hier liegt aber eine Verwechselung vor, nicht Salmanassar, sondern Sennacherib floh (vgl. 253), die betr. von Lamprecht zitierte Stelle müßte 4. Reg. 19, 36 sein (reversus est, vgl. Jesaias 37, 37 egressus est et abiit et reversus est Sennacherib, von. einer Flucht spricht nur Tob. 1, 21 (cum reversus esset rex Sen. fugiens a Judaea - V. 254-256 bezieht sich auf Jesaias Kap. 36-39). ${ }^{1}$ ) - Die Bemerkung uber den Umfang von Ninive 224-227 ist des propheten buoch entnommen (Jonas 3, 3). Zitiert ist ferner Salomo 186-188, gemeint ist wahrscheinlich der Leitspruch von der Gottesfurcht principium sapientiae timor domini Prov. 9, 10. Aber Lamprecht ist in der Benutzung des biblischen Buches Tobias sehr frei verfahren. Aus diesem stammen folgende Partien des Gedichtes (dazu einiges aus dem 4 . Buch der Könige): $46-50=$ Liber Tobiae $1,2.11 ; 55 \mathrm{f} .=1,5 ; 61=1,2.11 ; 65-74=1,12 ; 75 \mathrm{f} .=1,4$; $117-129=1,14 ; 123=1,16 ; 125-134=1,6.7 ; 135-143=1,17$; $144 \mathrm{f} .=1,16 ; 147=3,7 ; 155 \mathrm{f} .=1,9 ; 159-162=1$, 21 (4. Reg. 19, $36) ; 163=1,11 ; 164-166=1,13 ; 168=1,9.175-192=1,19.20$; $\left.186-188=1,10^{2}\right)(=$ Prov. 9,10$) ; 193 \mathrm{f.}=1,2.8 ; 233-238=1,18$; $239=1,22 ; 241-244=1,21 ; 250-252=4$. Reg. 19, 35, Jesaias 37,36; $254=4$. Reg. 19, 13 ff.; $256=$ Jesaias 37,36 f.; $257-260=1,21 ; 261-268$ $=1,21.2,2-9 ; 269 \mathrm{f} .=1,24$. Die Reihenfolge der biblischen Erzählung ist also nicht genau eingehalten. Ungeschickt ist die Umstellung innerhalb der Verse 135-174, da hierdurch Verwirrung in den örtlichen Vorstellungen eingetreten ist: die Geldleihung an Gabel in Medien, dann die Hochzeit, die in Israel stattfand, dann erst die Wegführung des Tobias nach Ninive und nun endlich der Name seines Weibes und die Geburt seines Sohnes.

Die biblische Überlieferung ist stark ausgedehnt durch kürzere Erläuterungen, z. B. die Arbeitsmühsale der Juden 53 f: $58-60$, das Schweinefleischessen 65-68 (vgl. 83), Sennacheribs Zug gegen Juda 245-248; mehr noch durch theologische und historische Zusätze: geistlichen Inhalt hat der ganze Eingang 1-45, christliche Moral lehrt die Anfangsbetrachtung der Erzählung von Tobias' Leben 97-116, ein Beispiel für Glaubensfestiǵkeit enthalten die Verse 78-92. Eine geschichtliche Abschweifung ist angebracht gelegentlich der Stadt Ninive, deren Stiftung durch Ninus mit darauf folgendem babylonischen Turmbau und schließlicher Gründung von Trier 197-230 erzählt wird. Hier trifft Lamprechts Tobias mit dem Annolied zusammen, das die Erbauung Kölns zurückführt auf die älteste Städtegründung, die Ninives durch Ninus, Annol. 121 f. $147-151 .{ }^{3}$ ) Die Zusätze beruhen auf

1) Statt Ezechielis 254 1. Ezechiasis, statt irbat 256 1. irbart(e), zu erbarn kund tun.

$\left.{ }^{2}\right)$ V. 190 ist $\mathrm{zu}$ lesen selen gerede $=$ sêl- gercete.

3) In dem Abschnitt von der Gründung Ninives berühren sich die beiden Dichtungen 
dem Einfluß der Predigt. 1) Mit den Erweiterungen ist im Tobias die gleiche Technik wie im Alexanderlied befolgt.

Erhalten ist in den Bruchstücken nur das erste Kap. des Buches Tobias. Der Umfang, den das ganze Gedicht mochte gehabt haben, läßt sich aus den überlieferten Versen nicht abschätzen, da sich aus ihnen nicht ersehen läßt, wie Lamprecht die eigentliche Geschichte des Tobias behandelt hatte, ob der biblischen Vorlage folgend in ruhig ausmalender, von $Z$ wiegesprächen und Gebeten durchwobener Erzählung oder rasch fortschreitend in knappsten Berichten. Für das letztere Tempo spricht die Anlage des auf uns gekommenen Anfangsteiles, der in kurze in sich geschlossene Abschnitte gegliedert ist. ${ }^{2}$ )

Stark betont ist der moralische Gehalt. Gute Lehre zu geben ist der Zweck des Gedichtes, Lamprecht spricht es selbst in der Einleitung aus: daz roret manege gude sachen 12 , und macht auch weiterhin durch formelhafte Anreden, wie sie an die Gemeinde in der Predigt üblich sind, auf tugendhaftes Verhalten aufmerksam: Hir mvgeter gode dinc verstan 117, $N v$ vernemet eine dogent groz 135 . Hervorgehoben wird die Frömmigkeit, das Festhalten an Gottes Gebot (die [rechte] ê) 74. 92. 106; im Glauben stark bleiben 193 f., vgl. 78 ff. 125 ff., und das Wohltun: sus vordethe er daz er gewan, diz svlen merken die riche man 151 f., vgl. 129 ff. 135 ff. 177 ff.; der Gottesfürchtige vergißt keine Güte 188 ff.; unrechten Gewinnes soll man sich entziehen $28 \mathrm{f}$, nach Himmlischem soll man seinen Sinn richten $175 \mathrm{f}$.

Nach Beda, Interpret. in librum Tobiae (Migne 91, 923-938), den Hugo v. S. Victor benutzt (De mysteriis, quae continentur in libro Tobiae, Migne

außerdem noch in dem Verweis auf Jonas, den der Fisch nach Ninive trug, Tob. $224 \mathrm{f}$. = Annol. 152, und in der Bestimmung der Größe von Ninive, Tob. $226=$ Annol. 148 f. Aber doch scheint Lamprechts Darstellung von der des Annoliedes unabhängig zu sein, denn bei ihm stiftete Assur den Turm zu Babel 199-201, im Annolied 157 ff. aber Nimrot, was mehr zu dem biblischen Berichte stimmt, da Nimrot Urheber des babylonischen Reiches war (Gen. 10, 10). Der Gründer von Ninive war nach der Bibel Assur (Gen. 10, 11), nach des Hieronymus Chronik Ninus, so auch im Annolicd und im Toblas (und meist in der mittelalterl. Weltgeschichte, vgl. Honorius Aug. De imagine mundi, Migne 172, $166 \mathrm{f}$.; Rudolf v. Ems in seiner Weltchronik vereinigt beide Annahmen V.1064 - 1069.3386-3391.34043409). Als Stifter von Trier, der Tob. $229 \mathrm{f}$. ein kint (Naclıkomme) des Ninus genannt wird, galt nach den Gesta Trevlrorum Trebeta, der Stiefsohn der Semiramis (vgl. MASSMANN, Kchr. 3, 398 f., Rudolf v. Ems Weltchr. 3601 3626, aucli in der Ursperger Chronik, Migne

Deutsche Literaturgescinichte. 11.
154, 505. 6 f. Anm.; s. auch WALLNER S. 206 f 1) Vgl. HASS an verschiedenen Stellen; Cruel desgl., bes. S. 134 ff.; EhrismanN, ZfdPh. 45, 306 und Studien über Rudolf v. Ems S. $73 \mathrm{ff}$.

2) Sie sind noch verdeutlicht durch Ueberschriften oder ursprüngliche Randschriften (bezw. Vorschriften) der Abschnitte. Indessen sind wolıl nur die zwei lat. sicher echt, der Titel des ganzen Werkes "Liber Tobie" und die Inhaltsangabe vor 97 , die aber vor 30 gehört. Die deutschen Ueberschriften, die alle den Namen Tobias enthalten (Thobi vor 77, Van Thobien 117. 135, [Van] Thobias 175. 197. 231; dic Vulgata hat nur Tobias, in der hebräischen und griechischen Fassung und in der Itala heißt der Vater Tobi, der Solın Tobias), riilıren vielleicht erst von einem Schreiber lier, demn der Dichter selbst würde wolıl den Inhalt des Abschnittes iber Ninive, in den gar nicht von Thobias die Rede ist, niclst mit "Thobias" angezeigt luaben (vor 197), hätte autclı die Geschichte des tungenannten israclitselicu Mannes 79 nicht dem Thobias zugeschrieben (vor 77 ). 
175, 737-744), ist das Buch Tobias uberreich an Beispielen und Ermahnungen eines moralischen Lebens (maximis vitae moralis et exemplis abundat et monitis (Beda 923 C), vornehmlich aber sind durch Tobias in der geistlichen Symbolik Glaube und gute Werke, eben jene auch in Lamprechts Gedicht hervortretenden sittlichen Forderungen, dargestellt: ipse serviebat Deo fide recta et operibus justis (Beda $923 \mathrm{D}$ ). Zu den guten Werken gehört das Begraben der Toten, daher Augustinus auf Tobias verweist in seinem Liber de cura pro mortuis gerenda (Migne 40,595), vgl. auch Hrabanus Maurus (Migne 109, $812 \mathrm{C}$ ). Besonders als Beispiel für Almosengeben wird Tobias zitiert (Honorius Aug. Spec. eccl., Migne 172, 888 B. 1082 A; Hugo v. Trimberg, Renner 20861 ff.). Zusammengefaßt sind die vorbildlichen Eigenschaften in der Präfatio des Mathaeus Vindocinensis: Tobiam decorat elemosyna, latria, firma spes, illaesa fides, exsequialis honor (Migne 205, 933). Des Ambrosius Erläuterung des Tobiasbuches (Migne 14, 759-794) ist gegen den Wucher der Reichen gerichtet (vgl. Lampr. 152-154). Immerhin gehört das Buch Tobiäs zu den im Mittelalter weniger bekannten Schriften des alten Testamentes. Eine lat. Tobiade in Distichen mit schwülstiger Rhetorik verfaßte der eben genannte französische Geistliche Matthaeus Vindocinensis um 1200,1) ein französisches Reimgedicht von Tobias' Leben Guillaume le Clerc de Normandie am Anfang des 13. Jhs., ${ }^{2}$ ) beide in freiem Anschluß an die Vulgata. Volkstumlich geworden aber ist die Gestalt des Tobias im Tobiassegen, zu dem jener eine Punkt der Erzählung, die Aussendung des Sohnes (Tob. 4, 22.5, 4), die epische Einkleidung abgab. ${ }^{3}$ )

In der Alexanderdichtung hatte Lamprecht die Aufgabe, eine Heldenlaufbahn zu schildern. Er konnte ihr gerecht werden, denn der epische Stil bot ihm dazu die Kraft der Worte. Das Tobiasbuch aber ist eine naive Familiengeschichte und fromme Legende. Wird er auch die Wärme der Sprache gefunden haben, um dem Idyll den herzgewinnenden Ton, der Gottbegeisterung den hymnischen Flug zu verleihen? Nach den Bruchstücken des Eingangs haben wir Grund daran zu zweifeln. Über eine äußerliche Wiedergabe des Stoffes mit belehrenden Zusätzen ist er hier nicht hinausgekommen und man vermißt die Frische der inneren Teilnahme am Stoff.

\section{$\S 25$. Babylonische Gefangenschaft.}

Ausg.: Mone, Anz. f. Kunde d. d. Vorz. 8 (1839), 55-58, genauer von v. Kraus, ZfdA. 50, 328 ff.; LeitzmanN, KI. Ged. S. 10-12. 30. - SCherer, QF. 7, 88. 12, 64; Kraus, D. Ged. S. 112 f.

Hs.: Pergamentbl. im Besitz des Stiftes St. Paul in Kärnten aus Maria-Saal. Es gehörte wahrscheinlich zu einer andern Hs. als die mit ihm gefundenen Bruchstücke aus Maria-Saal des Joh. Bapt. und des S. Veit, denn es ist zweispaltig und von anderer Hand geschrieben.

Das Gedicht wird wohl im bairisch-österreichischen Sprachgebiet ent-

1) ED. MÜLDENER, Göttingen 1855; Migne 205, 925-980; vgl. DEGERING S. 553.

2) RoB. ReINSCH, La vie de Tobia, Archiv
Bd. 62 (1879), 375-396

3) Siehe Bd. I, $112 \mathrm{f}$. 
standen sein (aus den Reimen ergibt sich kein sicherer Anhalt für die Mundart), und zwar um 1140.

Die eigentliche Fastenzeit beginnt mit dem Sonntag Quadragesima, vierzig Tage vor Ostern (Fastenzeit). Die erste Stufe der Vorbereitungen reicht vom Sonntag Septuagesima bis zum Aschermittwoch (Vorfastenzeit, Septuagesimalzeit). Mit Septuagesima fängt die liturgische Bußzeit an, das Alleluja wird nicht mehr gesungen (Depositio des Alleluja). Die 70 Tage der Septuagesimalzeit entsprechen nach der typologischen Auslegungsmethode den 70 Jahren der babylonischen Gefangenschaft des Volkes Israel. ${ }^{1}$ ) Die Gefangenschaft bedeutet diese Welt der Sünde. Durch Buße gelangen wir aus der Verbannung der Welt in die Heimat, das himmlische Jerusalem: das ist das Thema der Predigt am Sonntag Sept., vgl. des Honorius Aug. Sermo Dominica in Sept., Migne 172, 851 ff. bes. 854 D. 855 A B. 856 A, ferner Sacramentarium Kap. 1 u. 17, Migne 172,737-739. 755; S. Bernhards Sermo in Sept. I; Hildebert v. Tours, Sermo in Sept., Migne 171, 419 ff.; von den mhd. Predigten besonders die des Speculum Ecclesiae (KelLE S. 44-47).

Dies ist auch der Inhalt des deutschen Gedichtes, nur daß die Gefangenschaft hier nicht diese Welt bedeutet sondern den künftigen Tod 12, das lange Weh, große Qual, die Hölle 119-127. Der Zweck ist, zur Buße zu mahnen. Weil wir Christen sind, brauchen wir nicht die lange Buße $z \mathfrak{u}$ bestehen, die siebenzig Jahre, sondern nur siebenzig Tage 82-107.

Der Stil mit der die Zuhörer einschließenden 1. Person Pluralis wir und den Anredewendungen ist predigtartig und stark formelhaft: $42.53 .71 \mathrm{f}$. 89. 97. 99. 101. 103, Berufung auf den Propheten ${ }^{2}$ ) (Jeremias) 28. 69. 116. Am Anfang fehlen Verse, jedoch, wie es scheint, nicht viele, ob auch am Ende, ist ungewiB.

Die Reime sind sehr unrein, freilich ist der Text auch oft entstellt; altertümliche Bindungen mit vollen Nebensilben kommen nicht vor. Die Verse sind von mittlerer Länge, zuweilen kurz oder länger, aber nicht überlang.

$\S 26$. Makkabäer.

Ausg.: Gust. SchмidT, Die Hss. der Gymnasialbibl. Il, 26-28, Progr. des Halberstädier Dom-Gymn. 1881; BarTsCH, Germ. 28, 267-271; KRAUs, D. Ged. S. 25-29 u. 147-157; Kelle 2, $388 \mathrm{f}$.

Hs.: Zwei Bruchstücke eines Pergamentblattes in der Halberstädter Dombibliothek, Anf. des 13. Jhs.

Dialekt der Hs. und des Gedichtes (Heimat): südrheinfrk. Abfassungszeit des Gedichtes: um 1160. Die Bruchstücke umfassen 1. Macc. 13, 16-32. Der biblische Bericht ist sehr in die Länge gezogen, denn er ist in dem mhd. Erzählerstil dargestellt: zwei Dritteile des Gedichtes bestehen aus Rede. $\mathrm{Zu}$ predigtartiger Moralisierung ist willkommene Gelegenheit gegeben bei dem aufruhhrerischen Usurpator Tryphon (99 ff.). Erweiternde Erklärung mit wande 5 .

Der Dichter sieht die Ereignisse und die Personen mit den Augen seiner Zeit: volkstümlich aufgefaßt ist Tryphon als der ungetreue Dienstmann (111 in der Herstellung von Bartsch), populär christlich ist sein Abfall ein Werk des Teufels. In echt epischer Weise wird ausführlich die Toten-

1) Septuagesimalzeit vgl. oben S. 87. Das $\mid$ SciönnACH, Ad. Predigten 3, 42, 15. Alleluja nider legen, vgl. So man alleltita leit, ") GioünEwald S. 19. 
klage (33 ff.) gehalten mit den typischen Motiven, den Ausdrücken des Schmerzes, der Rache und den beschwichtigenden Schlußworten des Trösters. Es ist aber auch der ganze Vorgang schon an sich so verwandt deutscher Heldensage: Simon schickt dem verräterischen Tryphon als Geiseln für das Leben seines Bruders Jonathan dessen beide Söhne, aber der Treulose läßt sie töten und den Vater dazu. Simon hatte die Untat vorausgesehen und sein Volk vorher gewarnt, wie Hagen seine Herren, und er hat, wie Hagen, als Endergebnis die frostige Genugtuung: $i z$ ist irgangin als ih e sprah (67 in Bartschs Wiederherstellung). Aber doch ist von dem Trotz der germanischen Helden in dem Gedichte wenig zu spüren: der deutsche Umdichter hat in die rein historischen Tatsachen der biblischen Erzählung sein subjektives Empfinden hineingetragen, die strengen Formen des alttestamentlichen Heroismus sind in die weiche Stimmung mittelalterlich-romantischer Sentimentalität verhüllt.

Einige lat. Worte sind zum Teil aus dem biblischen Text übernommen.1)

Metrik: leichte Assonanzen. Kürzere Verse wechseln mit mittellangen. b) Das neue Testament.

$\$ 27$. Die Gedichte der Ava.

Kelle 2, 156-161. 357-360; PIPER, GD. 1, 223-238. - Ausg.: Hoffmann, Fundgr. 1, 127-204 (Hs. G); Diemer, D. Ged. S. 227-292, Anm. S. 65-74, Einl. S. XIV-XXXVI. XLIV (Hs. V); krit. Ausg. nach V und G: PIPER, ZfdPh. 19, 129-196. 275-321. - W. GRIMM, ZGdR. S. 37-39 u. K1. Schr. 4, 165-168; HAuPT, ZfdA. 15, 265; Scherer, QF. 1, 57. 7, 64-77. 12, 57; RöDIGER, Anz. 1, 65 ff.; AD. LanGGUTH, Untersuchungen über die Gedichte der Ava, Budapest 1880 (dazu Steinmeyer, DLZ. 1880, 296 f.).

Hss.: V, Vor. Hs. Bl. 115c-125a; G, Görlitzer Hs., Bibl. d. Oberlausitzischen Gesellsch. d. Wissenschaften in Görlitz Nr. 10, perg. 40, $56 \mathrm{Bl}$. zweispaltig, 14. Jh., in abgesetzten Versen, mit 29 Bildern (20 davon sind veröffentlicht von PIPER GD.aaO.); die Gedichte stehen Bl. 1r-24r, darauf folgt das Evangelium Nicodemi Bl. 24v - 56v. ${ }^{2}$ ) Beide Hss. haben österreich. Dlalekt, ${ }^{3}$ ) beide enthalten kleinere Lücken (in V ist außerdem ein Bl. nach Bl. 116 ausgeschnitten, $=$ PIPER S. 154, 405-668) und nicht unwesentliche Versehen, aus denen hervorgeht, daß sie von einer gemeinsamen fehlerhaften Hs. abgeleitet sind. Die Görl. Hs. ist eine modernisierende Bearbeitung des alten Textes, abgefaßt in der Absicht, die Reime reiner zu machen und das Versmaß zu glätten. ${ }^{4}$ ) Sie enthält außerdem am Anfang noch ein Stück von 446 Versen mehr als die Vor. Hs. (Johannes Baptista).

Am Schluß des Werkes nennt sich die Verfasserin Ava (dieser Schluß, PIPER S. 317, 393-406, fehlt in der Görl. Hs.), die Mutter zweier Söhne, deren einer aus der Welt geschieden ist; sie haben ihr den Inhalt des Buches erklärt (395), sie waren also Geistliche. Der Name Ava ist im 12. Jh. nicht unbekannt, für unsere Dichterin kommt aber besonders in Betracht eine Notiz der Melker Annalen, die auch in verwandten österreichischen Klosterchroniken wiederkehrt:5) MCXXVII. Ava Inclusa obiit, dazu in jenen andern

1) GRÜNEWALD S. 11.

2) Beschreibung von $G$ bei HofFmanN S. 127 f.; PIPER, ZfdPh. 19, 317 f.; LANGGUTH S. 7 f.; Helm, Das Evangelium Nicodemi von Heinr. v. Hesler, Bibl. d. Lit.Ver. Bd. 224 S. VIIl f.
3) LANGGUTH S. 16-18. 27-35; WAAG, Beitr. 11, 129-135.

4) LANGGUTH S. $18-27$.

5) DIEMER S. XIV f.; SCHERER, QF. 7, 76 f.; KeLLE 2, 360 . 
Chroniken (auch in dem Necrologium von Melk) noch das Datum des Todes: VII. bezw. VIII. Id. Febr. Die Erwähnung des Todestages dieser Frau in den Melker Annalen, die sonst mit solchen Angaben sparsam sind, läßt schließen, daß diese inclusa (eine in einer Einzelzelle nach strenger Regel lebende Klausnerin) in jenen Gegenden eines hohen Ansehens genoB und sie wird in der Tat unsere Dichterin gewesen sein. ${ }^{1}$ ) Danach wäre die Abfassung des Buches vor das Jahr $1127 \mathrm{zu}$ setzen. Ava ist die erste Dichterin in deutscher Sprache, deren Name uns überliefert ist. Ihre Klause lag wohl am ehesten in der Nähe des Klosters Melk an der Donau in Niederösterreich. Da sie aber von ihren Kindern spricht, so lebte sie einst in der Welt und hat sich erst später als Büßerin in die Einsamkeit zurückgezogen. Kärglich nur sind die Mitteilungen, die sie am Ende ihrer Arbeit über sich macht: sie enthalten die Verfasserangabe, „dizze bich dihtôte zweier chinde muter", dazu als letzte Worte "daz ist Âva "; ferner die Personen, die ihr die Quelle überlieferten, ihre Söhne, die „sageten ir disen $\sin ^{\text {"; }}$ und endlich die Bitte an die Leser, den verstorbenen Sohn in ihr Gebet aufzunehmen und dem lebenden, der noch in den Mühsalen der Welt schwebt, ${ }^{2}$ ) und ihr selbst, der Mutter, Gottes Gnade zu wünschen. Aber diese einfachen Zeilen sagen noch viel, viel mehr; es spricht nicht nur die Verfasserin eines frommen, gottseligen Werkes, es offenbart die Mutter in natürlicher Menschlichkeit ihre innersten Gedanken, und die sind bei den Söhnen, bei dem toten und bei dem lebenden. Tiefe Sehnsucht liegt in den einfachen Worten: „Es war eine große Freude unter ihnen, der Mutter waren die Kinder lieb, der eine ist von der Welt geschieden." Solche Äußerungen rein menschlichen Empfindens hören wir so selten aus der deutschen Literatur jener Zeit. ${ }^{3}$ )

Das Werk der Ava umfaßt das Leben und Wirken Jesu von seiner Geburt bis zu den letzten Dingen und läßt sich in folgende Abschnitte teilen: I. Das Leben Jesu (PIPER S. 140, 1-196, 1692 u. S. 275, 1693-299, 2418); II. Der Antichrist (S. 299, 1-303, 118); III. Das jüngste Gericht mit Hölle und Himmelreich (S. 304, 1-316, 392); darauf folgt das Schlußwort der Dichterin (S. 317, 393-406). Das in der Görl. Hs. vor dem Leben Jesu enthaltene Gedicht von Johannes dem Täufer (PIPER S. 129, 1-140, 446) ist ein selbständiges, in sich abgeschlossenes Stück, ${ }^{4}$ ) kann aber immerhin

1) Dagegen Kelle S. 160 f. - Das Stuick von den 7 Gaben setzt Beziehungen zu Hugo v. St. Victor voraus. Dieses Thema tiberhaupt ist von der Mystik stark gepflegt worden, es ist also höchst wahrscheinlich, daß hier Einwirkungen Hugos und Bernliards v. Clairvaux auf das deutsche Geistesleben vorliegen. Dann aber wurde Avas Werk nicht wohi vor 1127 entstanden seln können, sondern erst etwa in die Jahre zwiscien 1130 und 1140 fallen, und die 1127 verstorbene Ava inclusa könnte nicht die Verfasserin sein.
2) Vgl. Otfrid I, 18, 23. 27.

3) DIEMER hat aus den geringen Andeutungen weitgehende Schlïsse gezogen: die beiden Söhne scien Hartmann, der Dichter der Rede vom Glauben, und Heinrich von Melk, denen er dann nocl eine große Zahl der frillımhd. Dichtungen beilegt (S. XVIXXXVIII); doch DIEMER, Wiener SB. 48 (1864), Ant1. zu 1166

4) Die Stellung dieses Gediclutes von Johannes d. Täufer zu dem Hauptwerk, dem Leben Jesu, ist nicht ganz klar. Erzälnlt wird 
als Vorgeschichte zu dem Leben Jesu gelten. - Auch der Text selbst hat an einigen Stellen Eingangs- oder Abschlußworte: nach der Versuchung, als Jesus in die Öffentlichkeit tritt und den Grund zur Christenheit legt, stehen die Formeln dâ mit sî div rede verendet 526 und $N \hat{v}$ geb vns got die sinne 527; die Erörterung der sieben Gaben des heiligen Geistes beginnt mit Nô sculen wir bellinden 2269 und endet nû sprechen wir âmen 2418; das jüngste Gericht wird eingeleitet durch $N \hat{u}$ sol ich rede rechen PIPER 304, 1 und mit Amen, PIPER 316, 392 wird das ganze Werk abgeschlossen.1)

Es reihen sich Szenen an Szenen, meist in sich abgeschlossen, in ruhiger, manchmal auch dramatisch belebter Erzählung, zum Teil über den Umfang der biblischen Vorlage ausgedehnt. Ausführlich sind behandelt z. B. die Versuchung 463-525; die Berufung der Jünger 527-616; der Blindgeborene 981 - 1092; die Kreuzigung mit den Kreuzesklagen 1587-1722; die Höllenfahrt 1731-1782.2) Nur flüchtig dagegen sind erwähnt Johannes als Prediger in der Wüste S. 152, 353-362 und der darauf folgende Bethlehemitische Kindermord 363-372; die Heilungen 923-936; Lazarus' Erweckung 10931098; die Grablegung 1723-1730. Sehr zurück tritt Jesus als Lehrer; Bergpredigt und Gleichnisse sind übergangen, nur die letzten Lehren beim Abendmahl mit dem Gebot der Liebe werden herangezogen 1273-1344. Am liebsten aber verweilt die Dichterin bei den büßenden Frauen: die Sünderin, die beim Gastmahl des Pharisäers ihm die Füße wäscht 837-922; Maria, die Schwester der Martha, die zu des Herrn Füßen sitzt 951-980, die ihn mit Balsam salbt 1125-1142; die Ehebrecherin, der Jesus die Sünden vergibt 1189-1230; ihre Lieblingsgestalt aber ist Maria Magdalena 1693-1702. 1807-1826. 1863-1866. In den Weltfrauen, denen Christus ihre Sünden vergab, in Maria Magdalena, die zur Büßerin geworden, mochte die Klausnerin ihre eigenen Vorbilder gesehen, aus der Gnade, die der Herr ihnen gewährte, eigenen Trost geschöpft haben.

die ganze Lebensgeschichte des Täufers, zusammengestellt aus den Evangelien, dabei die Verkündigung Mariae (79-158). Stil und Versgebrauch weichen nicht wesentlich von dem Hauptgedicht $a b$, doch sind von 1 bis 280 verhältnismäßig viel mehr Flickverse gebraucht als im Leben Jesu (17. 31. 52. 57. 70. 80. 255. 280, alle mit dem Verbum sagen; ferner man list 207. 211. 221, wir lesen 233). Indessen liegt darin noch kein zwingender Grund, dieses Vorstück der Ava abzusprechen, da es ihr möglicherweise bei seiner Abfassung noch an Versübung fehlte. Jedenfalls bestehen zwischen dem Görl. Johannes und dem Leben Jesu nähere Bezieliungen, Versentsprechungen, Gleichungen im Ausdruck, Zusammentreffen gleicher biblischer Partien, aber wie die gegenseitige Beeinflussung aufzufassen ist, liegt nicht klar.

1) W. Grimm aaO. schließt aus den riihrenden Reimen, die im Leben Jesu häufiger vor- kommen, daß dieses nicht von der Ava verfaßt sei. Weiter geht SCHERER, QF. 7 aaO., indem er sechs Gedichte unterscheidet: I. Im Leben Jesu: 1. Johannes d. Täufer (Görl. Hs.). 2. Christi Geburt bis zur Versuchung (PIPER $140,1-158,526)$, dieses besteht aber wieder aus zwei Hälften, deren zweite mitten in der Erzählung von den drei Königen $(150,273)$ beginnt. 3. Die Stiftung der neuen Kirche $(158,527-294,2268)$; diese drei Gedichte haben drei verschiedene Verfasser. Il. Der Ava gehören nur die drei letzten Stücke an: 4. Frau Ava von den Gaben des heil. Geistes $(294,2269-299,2418)$; 5. Ava vom Antichrist $(299,1-303,118) ; 6$. Ava vom jüngsten Gericht $(304,1-316,392)$. Die eingehenden Untersuchungen über Sprache und Metrik von LANGGUTH haben eine solche Zerstilckelung nicht bestätigt; vgl. auch SCHRÖDER, Anegenge S. 69 u. ŻfdA. 50, 312; WAAG aaO.

2) SCHRÖDER, Anegenge S. 54. 
Das Leben Jesu der Ava ist ein Beispiel dafür, wie man zu ihrer Zeit die biblische Geschichte des neuen Bundes auffaßte. DerBericht der Evangelien wurde nicht lediglich einfach wiedergegeben, sondern es wurden. Erweiterungen eingestreut. Seltener natürlich sind dies ganze Themata wie hier die Klagen am Kreuze 1693 - 1722, der Empfang Christi im Himmel 20392112, die 4 Evangelisten 2203-2268 und unmittelbar darauf die 7 Gaben des Geistes 2269-2418, beide letzten Stellen in AnschluB und in innerem Zusammenhang mit der Ausgießung des heiligen Geistes; sehr häufig aber Einschaltungen einzelner oder auch mehrerer Verse, die den Gedanken in irgendeiner Weise erweitern: dogmatisch erläuternd oder begründend 11-14. 377 f. 447-456. 466-469. 482-484. 530-532. 1591-1600. 1649-1658. 1727-1730. 1783-1790 (darin die Abälardsche Trinitätsformel Macht, Weisheit, Güte). 2081-2114; nähere Bestimmung einer Person: 202. 208. 578. 580. 582. 594-604. 812. 1562; typologisch (allegorisch): 169-180. 262-282. 300-304. 445-456. 1664-1670; ermahnend: 297-299. 1692. 2105-2112. Es gehörte aber zur Kenntnis von Christi Wirken nicht nur sein Erdendasein, sondern auch die Vollendung der Dinge durch ihn als Weltrichter, daher an die Erzählung der Evangelien noch der Antichrist und der jüngste Tag mit Verdammnis und Seligkeit angeschlossen werden.

Quellen für die Geschichte Jesu sind durchaus die Evangelien und die Apostelgeschichte, nur kurze Einzelheiten sind aus sonstiger Tradition geschöpft, ebenso beruhen die Angaben über das Weltende auf dem der Zeit geläufigen Wissen. ${ }^{1}$ ) Gesondert jedoch $z u$ betrachten ist der Einschub von den sieben Gaben des heiligen Geistes (2269-2418). Dieser steht in engem Zusammenhang mit der Abhandlung De quinque Septenis des Hugo von St. Victor ${ }^{2}$ ) und die Übereinstimmung ist so weitgehend, daß an einer Abhängigkeit der Dichterin von Hugo nicht zu zweifeln ist. In dem deutschen Gedicht werden der Reihe nach die 7 Gaben aufgezählt; verbunden damit sind 7 Seligpreisungen, zugleich sind die 4 Elemente hineinverflochten, die Erde mit dem Geist der Gottesfurcht 2279, das Feuer mit dem der Güte 2298, das Wasser (nezzede) mit dem der Weisheit 2308, die Luft mit dem der Tapferkeit 2324. - Hier auch treffen wir, und zwar zum erstenmal in der deutschen Literatur, wirklich mystische Empfindung in dem Ausdruck "Gottes Weisheit schmecken, das ist_eine unaussprechliche Süßigkeit “ 2365 f., vgl. Sapientia namque a sapore dicitur: cum mens gustu internae dulcedinis tacta ... Hugo v. S. Victor, Migne 475, 110 B.

Der Stil ${ }^{3}$ ) ist der denkbar einfachste, ohne jeglichen rhetorischen Schmuck, schlicht werden die Dinge erzählt oder die Gedanken entwickelt. An manchen Stellen aber spricht sich die innere Teilnahme der Dichterin in bewegteren

1) Zur Quelle des jüngsten Geriehts s. LANGGUTH S. 131-133; REUSCHEL, Weltgerichtsdicht. S. 37-40; El.IS. PETERS S. $78 \mathrm{ff}$.

2) Migne 175, 405-414; s. auch den Stammbaum der Tugenden Migne 176, 1010. - AL.13.
LiEbNFr, Hugo v. St. Victor 278-282. Vgl. auch den dem Bernhard v. Clairvaux zugeschriebenen Sermo de septem gratiis seu donis Spiritus sancti V. $306-308$.

3) LANGGUTH S. $68-105$. 
Worten aus, so besonders in den Kreuzesklagen 1693-1722, die schmerzerfüllte Maria Magdalena am Ostermorgen 1863 ff. -- Der Einförmigkeit des Vortrags entspricht das parataktische Satzprinzip. Zeitliche oder logische Folge wird oft anaphorisch in starrer Nebeneinanderreihung aufgebaut mit immer sich wiederholenden dô oder sô, das dann einer Aufzählung der einzelnen Gedanken nahekommt. ${ }^{1}$ ) - Formeln sind nicht allzu zahlreich, es sind meist Verweisungen auf die Quellen oder Übergangsphrasen (als ich ez vernomen hân, als ez hie geschriben stêt), seltener Wahrheitsbeteuerungen (daz ich iu sage daz ist wâr). Auffallend viele Formeln sind im jüngsten Gericht vertreten, davon können aber V. 22. 32. 90. 143 auf Bindungen mit dem durch den Stoff gebotenen tage beruhen (vgl. auch 98 . 106. 128); die andern Flickverse sind V. 117. 203. 298. 344. 359, stehen also überhaupt gegen den Schluß des ganzen Werkes. Alliterationen kommen vor, sind aber zufällig und wirken in der Formensprache nicht mit. ${ }^{2}$ )

Als Leser-oder Hörerkreis denkt sich die Dichterin Leute höheren Standes, also Adlige oder Geistliche, da sie 297 (PIPER S. 150) die Anrede an ${ }_{\text {"Herren" }}$ richtet (lieben mîne hêrren). ${ }^{3}$ ) Durch den Inhalt bedingt ist ein Unterschied in der redenden Person: im Leben Jesu richtet sich der Numerus nach dem redenden Subjekt, in den abliandelnden Teilen von den vier Evangelisten (2203 ff.) tritt oft die 1. Pers. Plur. wir, wir Menschen, ein.

Eine Besonderheit in diesem Gedicht sind die genauen Zeitangaben in der Erzählung: eines mânôdes zit 101, an dem êrsten tage 163, wierzẹch tage unde naht 309, ferner 336. 366. 369. 382. 387. 421. 431. 434. 547. 617. 643. 736. 1093. 1123. 1189. 1232. 1435. 1463. 1505 f. 1681, 1684. 1731. 1807. 1810. 1867. 1881. 2021. 2137. 2143. 2179.4) - Häufig sind lat. Wörter und Sätze eingestreut, davon viele reimend. ${ }^{5}$ ) Mehrere Verse hat Avas Buch mit andern deutschen Gedichten gemein:6) mit dem Ezzolied, der Summa Theologiae, den Büchern Mosis, Himmel und Hölle, dem Melker Marien-

1) Sô und dô: LangGuTh S. 69-72.

2) LANGGUTH S. 34 f.

3) SCHERER, QF. 7, 68. Da unmittelbare Wendung an das Publikum außer hier nicht ersichtlich ist, so ist die Dichtung wohl nicht als Predigt aufzufassen.

4) Vgl. Reuschel S. 38 f.

5) LANGGUTH S. 23 f. 95 f.; GRÜNEWALD S. 12-14. - SCHRÖDER hat ZfdA. 50, $312 \mathrm{f}$. aufUebereinstimmungen $z$ wischen lat. Phrasen in der Ostermorgenszene 1899. 1904. 1925 mit der lat. Osterfeier aufmerksam gemacht. Solche bestehen auch zwischen Joh. d. Täufer und dem Benediktbeurer Weihnachtsspiel, SCHMEller, Carmina Burana ${ }^{2}$ S. 85: alle gratia plena ... Maria PIPER S. 131, 99 f., spiritus sanctus 122 , ecce concipies et paries filitum 125, ecce ancilla domini 157, dazu im Leben Jesu Magnificat PIPER S. 144, 96. Ferner Leben Jesu u. Benediktb. Ludus paschalis: Ingressus Pylatus $1017 \mathrm{f} .=$ Carm.
Bur. S. 95, eamus $1362=$ Carm. Bur. S. 101, Jesum Nazarenum ...ego sum $1419 \mathrm{f} .=$ Carm. Bur. S. 101, crucifige eum $1558=$ Carm. Bur. S. 104, Raboni $1904=$ Rabboni auf dem neugefundenen Blatte d. Carm. Bur. bei WILH. MEYER, Fragmenta Burana Taf. 15 u. S. 144. Es sind Schlagworte aus dem Bibeltexte, die auch in den Predigten verwendet wurden. Ob Ava bei ihrer Aufnahme von lat. geistlichen Spielen beeinflußt wurde, ist fraglich, da solche lat. Zitate im Leben Jesu auch an Stellen vorkommen, die nicht Gegenstand lat. Dramen waren. Anders in dem Gedicht "Christus und Pilatus": dieses beruht gerade auf den Textworten eines Passionsspiels (s. unten).

$\left.{ }^{6}\right)$ Diemer Anm. S. 65 ff.; ders., Gen. u. Exodus, Vorrede S. VIII-X; SCHERER, QF. 7, 66 f. 73.75 u. QF. 12, 57; RöDIGER, Anz. 1, 66 ff.; Kelle S. 158-160. 358-360; LANGGUTH S. 123-130; SCHRÖDER, Reimstud. II, 408. 423. 
lied. Es können unmittelbare Entlehnungen sein oder Reminiszenzen aus dem allgemeinen, gedächtnismäBig aufbewahrten Formelschatz.

Dem (kunstlosen) äußern Gewand des Stils entspricht auch die Metrik. ${ }^{1}$ ) Die. Verse sind im Normaltypus gebaut, in der Mehrzahl sind die Senkungen nicht stark überfüllt, doch treten nicht selten darunter auch lange Verse auf. Auch auf die Reime hat die Verfasserin offenbar nicht besonderes Interesse verwendet; Assonanzen bilden die Mehrzahl der Bindungen, rührende Reime werden nicht vermieden.

Die Wirkung des Buches auf die zeitgenössische Literatur scheint nicht bedeutend gewesen zu sein. Die Übereinstimmung der V. 37 f. im Görl. Johannes (= Leb. Jesu 461) mit Heinrichs Litanei Fundgr. 2, 226, 30 f. ${ }^{2}$ ) beruht wohl auf gemeinsamer Quelle. Doch hat das Gedicht von den 15 Zeichen vor dem jüngsten Tag (ZfdA..1, 117-126) einige Verse aus dem Abschnitt über die 15 Zeichen in Avas Gedicht entnommen. ${ }^{3}$ )

Ava war keine große Dichterin, aber eine gläubige Frau, die warm und innig die Geschichte des Heilands in ihr Herz aufgenommen und das Sehnen einer erlösungsbedürftigen Seele in sich selbst erlebt hat.

\section{$\$ 28$. Friedberger Christ und Antichrist.}

Kelle 2, 79. 288; PIPER, GD. 1, 60 f. - Ausg.: Weigand, ZfdA. 7, 442-448 und vollständiger ebda 8, 258-274; MSD. Nr. 33 u. II ${ }^{3}$, 197-201; PIPER, Höf. Ep. 3, 715-721 (Abdruck der Hs.). - Schade, Decas S. 16 f.; Bartsch, Germ. 9, 61 f.; Scherer, QF. 12, 35; SCHÖNBACH, ZfdA. 33, 367 ff.; RöDIGER, ebda 419-422; BEHAGHEL, Lit.Bl. 1892, 331; JOHN MEIER, Beitr. 16, 96; v. D. LEYEN, K1. Beitr. S. 56-61.

Hs.: Bruchstïcke einer Pergamenths. des 11./12. Jhs. auf der Universitätsbibl. zu Gießen, aus der Burgpfarrbibl. zu Friedberg in der Wetterau, 9 Bl. (A-1), von denen zwei, F u. G, fast vollständig, die andern nur an einzelnen Stellen bezw. als Falzstreifen erhalten sind. Das ganze Gedicht hat ursprünglich etwa 1100 bis 1200 Verse enthalten.

Der gröBte Teil der Bruchstücke enthält Teile aus dem Leben Jesu (Aa, $\left.1-H^{b}, 22\right)$, nur die letzten erhaltenen 23 Zeilen (Ia und Ib) handeln vom Antichrist.

Der Titel "Christ und Antichrist" gilt nur für die uns überlieferten Bruchstücke, das gesamte Gedicht dagegen war ein Leben Jesu von der Geburt bis zu den letzten Dingen und zum jüngsten Gericht. Die Erzählung des Lebens Jesu folgt in einfacher Wiedergabe der Bibel, wobei der Kreuzestod, die Auferstehung ${ }^{4}$ ) und die Himmelfahrt stärker ausgeführt gewesen zu sein scheinen als das Wirken Jesu auf Erden. Der Antichrist ist ebenfalls in der gewöhnlichen Auffassung wiedergegeben. ${ }^{5}$ )

Die Symbolik ist in der Hauptsache an den Anfang verlegt und unterbricht die Darstellung nur wenig, doch sind Begründungen und Erweiterungen zum biblischen Text eingeschaltet: $\mathrm{E}^{\mathrm{a}}, 15 \mathrm{ff}$; $\mathrm{E}^{\mathrm{b}}, 18 \mathrm{ff}$; F $\mathrm{Fa}, 18 \mathrm{ff} .28 \mathrm{ff}$.; $\mathrm{F}^{b}, 44$ ff.; Ga, 98 ff.; Gb, 123 f.; $\mathrm{H}^{\mathrm{a}}, 146$; $\mathrm{H}^{\mathrm{a}}, 155$ f.; $\mathrm{H}^{\mathrm{b}}, 9 \mathrm{ff}$. In der Ein-

1) LANGgUTH, passim, bes. S. 25-30; SCHRÖDER, Gött. Nachr. 1918, 408. 423.

2) SCHERER, QF. 7, $65 \mathrm{f}$.

3) LANGgutil S. $130 \mathrm{f}$.

4) Die Erscheinungen Jesu nach seiner Auferstehung nelimen viele Verse in Anspruch.
Hicr ist die Technik der Legenden nachgeahmt, wo nacl dem Heinngang des Heiligen oft Wunder erzälılt werden, die er wälırend scines l.ebens oder nich seinem Tode gewirkt hat.

5) Siche die Literatur in MSD. $11^{3}, 201$. 
leitung ist also der Erlösungsgedanke an die Spitze des Ganzen gestellt: der Sieg Christi über den Satan (sein menschlicher Leib war der Köder für den Teufel, am Kreuz ward der neidige Leviathan gefangen), der Heiland als Lichtbringer und als das uranfängliche Wort. Jedoch durchtränkt die Idee nicht das ganze Gedicht wie in Ezzos Lied, vielmehr ist diese nur an den Anfang gestellt, getrennt von der einfach historischen Erzählung des Lebens Jesu. Anlehnung an das vorbildliche Werk spricht aus einigen Stellen: $A^{a}$, $3=$ Ezzo 17, 11 f.; $A^{\text {a }}, 6=$ Ezzo 27, 3 f.; Ea 15 f. u. Fa, 12 f. =Ezzo 18, 11 f.; $\mathrm{E}^{\mathrm{b}}, 16-20=$ Ezzo 20,7 ff. 25, 6. 26, 2; $\mathrm{H}^{\mathrm{b}}, 10=$ Ezzo $11,4$.

Die Heimat des Gedichtes ist zugleich die des Fundortes der Hs., also die Wetterau, darauf deuten die Reime $s a ̂ n=s a ̂ h e n: g a ̂ n \mathrm{G}^{b}, 111.129$; an : gevân 135; besonders aber die Orthographie, die jedenfalls die Mundart des Entstehungsortes wiedergibt, da sie ganz rein und ohne fremde mundartliche Beimischung ist, die etwa auf eine andere Ursprungsgegend hinwiese. Als Abfassungszeit wird man etwa die Jahre 1120-1130 anzusetzen haben.

Die Reime bezw. Assonanzen fordern keine auffallend schweren Endungsvokale. Die Versfüllung ist ziemlich ebenmäßig, selten begegnen ganz kurze Verse, überlange gar nicht. ${ }^{1}$ ) Zum Stil: Quellenberufungen $\mathrm{G}^{\mathrm{a}}, 76 . \mathrm{H}^{\mathrm{a}}, 144$; lat. Worte sind nicht selten. ${ }^{2}$ ) Wiederholt sind die beiden Verse $E^{a} 15$ f. durch $F^{a} 12 f .{ }^{3}$ ) Parallelstellen zu andern Denkmälern s. in MSD.; SCHÖNBACH, ZfdA. 33, 367 f.; V. D. LEYeN S. $59-61$.

$\S 29$. Von Christi Geburt.

Kelle 2, 79. 288. - Ausg.: SchÖNBACH, ZfdA. 33, 350-373; KRAUS, D. Ged. S. 3-6 u. 71-77, dazu RöDiger, Anz. 24, 61; John MeIER, Beitr. 16, 96; JellineK, ZfdA. 43, 392; WALlNER, Beitr. 43, 178 Anm. 1.

Hs.: Universitätsbibl. zu Innsbruck, Bruchstücke, vier Pergamentstreifen $12^{\circ}$, aus der ersten Hälfte des 12. Jhs., Anfang und Ende des Gedichtes fehlen.

Der Dialekt der Hs. und des Gedichtes ist mittelfrk., dieses ist in oder in der Umgegend von Köln um 1120-1140 entstanden.

Der Titel mit der Beschränkung auf die "Geburt" Christi ist von Schönbach dem Gedichte gegeben worden, weil die Hauptereignisse unserer Bruchstücke gerade diesen Gegenstand betreffen. Das ganze Gedicht war als Erlösungsgeschichte gedacht, darauf gehen die "Vorzeichen" V.44, bedeutende Momente aus dem alten Testament als Hinweisungen auf die künftige Erfüllung durch Christus: Rückkehr der Israeliten aus Ägypten 1-5, die Erhöhung der Schlange durch Moses als Bezeichnung für den Sohn Gottes, den wahren Arzt 6-19; die Verbannung der Juden durch Nabuchodonosor und ihre Rückkehr in ihr Erbland 20-43; zuletzt David als der weltliche Stammvater des Geschlechtes, aus dem Jesus in geistlicher Weise kam 44-63, das steht in libro generationum. ${ }^{4}$ )

Dann folgen die Ereignisse des neuen Testaments aus dem Leben Jesu,

1) Amelung, ZfdPh. 3, 276.

2) GRÜNEWALD S. $14 \mathrm{f}$.

3) Ueber den Dreireim Ga, 90-92 s. MSD. $\mathrm{II}^{3}, 200$.

4) Das ist das Ev. Matth., vgl. Matth. 1, 1; Leben Jesu der Ava, PIPER, ZfdPh.19, 292.2216. 
mit der Darstellung im Tempel bricht das Fragment ab. Alles ist kurz dargetan, das Gedicht war jedenfalls nicht umfangreich.

Es ist Durchschnittsarbeit. Der Stil ${ }^{1}$ ) oft unklar, mit Wiederholungen, mit den üblichen Formeln und lateinischen Wörtern. ${ }^{2}$ ) Ebenso bietet die Metrik ${ }^{3}$ ) sowohl in der Reimbildung (etwas mehr als ein Drittel genau) als im Versbau (ziemlich gleichmäßige Verse, nicht überkurz oder überlang) nichts Bemerkenswertes. Seine Unselbständigkeit zeigt der Verfasser in einer sogar für jene Zeit auffallenden Abhängigkeit von der damaligen Dichtersprache. Fast das ganze Gedicht besteht aus herkömmlichen Wendungen, das Ezzolied ist geradezu ausgeschrieben, viel ist aus dem Friedberger Christ und Antichrist entlehnt, wohl auch das Jesusleben der Ava und das Melker Marienlied sind unmittelbar benutzt worden. ${ }^{4}$ )

\section{$\$ 30$. Priester Adelbrecht, Johannes Baptista.}

Kelle 2, 163. 361; PIPer, GD. 1, 238 f. - Ausg.: Mone, Anz. f. Kunde d. d. Vorz. 8 (1839), 47-51, dazu BarTsCh, Germ. 12, 86 f.; Kraus, D. Ged. S. 15-23 u. S. 111-134, dazu WUnderlich, ZfdPh. 28, 258. - SCherer, QF. 1, 67 f. 12, 49. 69; Gust. VomberG, Drei Bruchstücke einer poetischen Bearbeitung des Lebens Johannes des Täufers aus dem XII. Jh., Marburger Diss. 1875; v. KRAus, ZfđA. 50, 328 ff.; SchröDER, Gött. Nachr. 1918, 427. Hs.: Bruchstücke aus Maria-Saal, s. oben Babylon. Gefangenschaft. Der Anfang und ein Stück in der Mitte (Herodias und ihre Tochter) fehlen,

Heimat(Dialekt)des Gedichtes ist Kärnten, Abfassungszeit umı $1120-1130 .{ }^{5}$ ) Der Dichter Adelbrecht nennt sich 252: ein priester hiez adelbreth.

Der biblische Stoff, der den Evangelien, bes. Luc. und Matth. entstammt, ist in Legendenform gebracht. Damit hängen alle Änderungen zusammen, die biblischen Stellen wurden bedeutend erweitert durch Ausmalung geschichtlicher Züge, durch nähere Erklärungen, religiöse Betrachtungen; darum liegt auch der Schwerpunkt auf dem Märtyrertum, der Kerkerszene mit der Hinrichtung $172 \mathrm{ff}$. Unbiblisch ist die Versenkung des Hauptes in einen Brunnen (nach dem Beispiel anderer Martyrien) 200; die Totenklage $217 \mathrm{ff}$. Das Wirken des Täufers wird an das Ende gestellt $236 \mathrm{ff}$., wie in einer Heiligenlegende. In Taufe und Bußpredigt besteht seine Aufgabe, und so wird er am Schluß angerufen als Führer aller Büßer, meister unde noget 259 ff., er soll unser Fürsprecher sein am jüngsten Tage, helfâre 262, loget 266. Das Gedicht gipfelt in dem Gedanken der Buße: in der Tat wird Johannes der Täufer oft in Beichtformeln als Beichtempfänger angerufen (MSD. Nr. 94, 3. 95, 30. 96, 40. 97, 41).6) So ist er, dem kirchlichen Heiligenkult entsprechend, auch hier der Typus des Bußpredigers, des Asketen. Dieses heiligen Mannes Diener und Knecht (253 f.) will der Priester Adelbrecht sein. Er hat ein Laienpublikum vor Augen, denn er spricht zu guten

1) SCHÖNBACH S. 363.

2) Grónewald S. 14.

3) SCHÖNBACH S. 36! f.

4) MSD. $1^{3}, 101$ Anm. u. $11^{3}, 174$ f. 183; SCHÖNBACH S. 363-373; KKRAUS S. $71-77$.

5) Kraus S. 116.

6) Johannes derTăufer ist unter allenHeiligen hier der vornehmste, der Fijhrer der Propheten (Mattl. 11,9-11, Luc. 7, 26-28), der oberste der Märtyrer und einer der wirksamsten Fürsprecher der Beichtenden, vgl. auch die Litanei $447-569$, bes. 450 f. 552 f.; KELLE, Spec. eccl. S. 90; Baungartenberger Jol. Bapt. 25 ff. 
luten 226. - Einfacher Erzählerstil, durchzogen von bloßen Füllversen und Formeln (50.74.111. 114.127-133.139. 167. 177.226 f. 231,1) lateinisch ist nur der Schlußvers.

Benutzt sind Rolandslied und Kaiserchronik. Versparallelen finden sich auch mit der Legende vom heil. Veit. ${ }^{2}$ )

\section{$\$ 31$. Baumgartenberger Johannes Baptista.}

Kelle 2, 163. 361 ; Piper, GD. 1, 238 f.. - Ausg.: GrafF, Diut. 3, 277-279; Hoffmann, Fundgr. 2, 139-141, dazu Mone, Anz. f. Kunde d. d. Vorz. 8 (1839), 51; Kraus, D. Ged. S. 12-15 u. 101-111. - SCHERER, QF. 12, 68 f.; VomBERG, Drei Bruchstücke usw.; SCHIFFMANN, ZfdPh. 35, $88 \mathrm{f}$.

Hs.: Fragm., Öffentl. Bibl. zu Linz, stammt aus dem Kloster Baumgartenberg an der Donau, Perg., 1. Hälfte des 12. Jhs. $8^{\circ}$. Erhalten sind nur sechs Abschnitte (die die Hs. selbst am Rande mit römischen Ziffern, VII-XII, numeriert), 77 Verse, das ganze Gedicht enthielt ca. 200-250 Verse.

Verfaßt ist es in der Heimat der Hs., also in Baumgartenberg oder der dortigen Gegend, und zwar um 1130 (vor der Kaiserchronik, da diese die V. 1-4 aufgenommen hat). Im Mittelpunkt steht Johannes der Täufer und zwar als der Prophet auf der Scheide zweier Zeiten, ${ }^{3}$ ) des alten und des neuen Bundes, als Vertreter der neuen Wahrheit und Vorläufer des sündentilgenden Erlösers. Die geistige Seite des Täufers also ist Gegenstand der Bruchstücke und auf ihr lag wohl auch der Schwerpunkt des ganzen Inhalts. Da der Verfasser sicher diese Gedanken nicht aus eigenem Wissen zusammengestellt hat, so ist als Quelle eine lat. Vorlage für das Gedicht vorauszusetzen. Denn ein Nachschreiber ist er: aus dem Ezzoliede hat er 5-9 entnommen $=$ Ezzo 14, 9. 10; 15, 7. 8.11; dagegen sind andererseits Verse der Kaiserchronik aus seinem Gedicht entlehnt: $1-4=$ Kchr. 40474050; vgl. 705 f. 17834) (wenn nicht beide aus gleicher Überlieferung schöpften). Der Stil ist einförmig in der Aufzählung 27-35. Metrisch sind $\mathrm{zu}$ bemerken überlange Verse bei kurzen (ungleicher Typus), wodurch sich der Versbau von dem des Priesters Adelbrecht unterscheidet, ${ }^{5}$ ) Dreireim 45-47.

Die drei Dichtungen von Johannes dem Täufer sind verschieden in der innern Form: der Görlitzer Joh. Bapt. der Ava gibt einfach die Erzählung der Evangelien wieder ( $N \hat{v}$ sule wir mit sinnen sagen von den dingen, Piper, ZfdPh. 19, 129), der Priester Adelbrecht hat die biblische Darstellung zu einer Legende verarbeitet, im Baumgartenberger Gedicht ist geistiges Wesen in seiner theologischen Bedeutung erfaßt.

1) Ueber „rekapitulierende Parenthese " vgl. KRAUS S. $119 \mathrm{f}$.

2) Kraus S. 113-116.

3) Vgl. Augustinus Sermo 293; Sermo de Sanctis 20; Honorius Aug., Gemma animae IV Kap. 47 (Migne 172, 706). Zu 50 vgl. Honor. Aug. Spec. eccl., Migne 107, 966 D: hunc (i. e. Redemptorem) iste praesentem digito de- monstrando asseruit : es ist die in der typologischen Malerei dem Täufer häufig beigelegte Deutegebärde, des gegen Jesus ausgestreckten Zeigefingers der rechten Hand. 4) Diemer, D. Ged. Anm. S. 80; Kraus S. 105 f.; Kelle S. 361; MSD. 11 ${ }^{3}, 175$; SCHRÖDER, Kchr. S. 58; VOMBERG S. 22 ff. 5) VOMBERG S. $57 \mathrm{ff}$. 


\section{$\$ 32$. Christus und Pilatus.}

Ausg.: Bartsch, Germ. 4, 245 f.; Kraus, D. Ged. S. 62-64 u. 246--249. -- Scherer, QF. 12, 35; v. KraUs, ZfdA. 50, $333 \mathrm{f}$.

Hs.: Pergamentdoppelbl. vom Ende des 12. Jhs., verloren.

Der Dialekt ist der von Thüringen, hier ist auch die Heimat des Gedichtes; ${ }^{1)}$ Entstehungszeit: Ende des 12. Jhs. ${ }^{2}$ )

Der Inhalt bewegt sich hauptsächlich in Gesprächsform. Die einzelnen Redeabschnitte haben als Kernsatz ein lat. Zitat aus den Pilatusszenen der Evangelien, ${ }^{3}$ ) diese lat. Sätze sind sofort ins Deutsche übersetzt mit der einleitenden Formel daz spricht. Der ganze Aufbau von Rede und Gegenrede ist dramatisch wirksam, die Anklage der Juden dreht sich um die eine Frage: dieser will sich zum König machen. Darum ist treffend an den Anfang die Anrede "aue, rex iudeorum" 8 gesetzt und, gegen die Bibel, dem Pilatus in den Mund gelegt.

Diese dramatische Gestaltung des Stoffes hängt mit dem Ursprung des Gedichtes zusammen. Es steht in naher Beziehung zu dem Benediktbeurer Passionsspiel, dem Ludus paschalis sive de passione Domini der Carmina Buranat) (13. Jh.). In der Pilatusszene dieses Benediktbeurer Passionsspiels ${ }^{5}$ ) kommen sechs der sieben lat. Zitate des deutschen Gedichtes fast wörtlich vor (es fehlt nur sanguis eitus ... 50); doch in etwas anderer Anordnung, denn das lat. Drama ist nicht so folgerichtig aufgebaut. Die Jesus betreffenden Stellen des lat. Werkes fehlen in den deutschen Fragmenten, sie hatten in der Lücke zwischen Bl. A und B ihre Entsprechungen. Auch der Gebrauch, die lat. Bibelworte sofort von der deutschen Übersetzung folgen zu lassen, weist auf das geistliche Schauspiel.6)

Man kann nun die Arbeitsweise des deutschen Dichters beobachten: er hat als Gerüste die maßgebenden Bibelstellen benutzt - außer den lat. zitierten noch andere: $1.11 \mathrm{f} .24 .33 \mathrm{f} .35-43.61-64-$ und hat den biblischen Text unnötig und mit dürftigen Worten erweitert und verdeutlicht: 3-7 Empfang Jesu durch Pilatus mit der fehlerhaften Behauptung, Jesus sei wieder nach Jerusalem gekommen; andere überflüssige Erweiterungen: 22 f. 27-29. 49. 57.62; Hindeutungen auf die Zukunft: 53 f. 60; Vergleiche: 10. 46; Flickformeln: $18=48,19.40 .41 .64$.

Wie weit ausgedehnt das ganze Gedicht war, ist aus unsern Bruchstücken schwer zu schließen, jedenfalls bildete die Pilatusszene nur eine Episode. Vermutlich erstreckte sich der Inhalt nur auf die Leidensgeschichte, ent-

1) Kraus S. 246.

2). Die Hs. soll nach BARTSCH ans dem Ende des 12. Jhs. stammen. Nach Reimgebrauch und Spraclie könnte man das Gedicht auch erst in das 13. Jh. heruntersetzen.

3) Die Bibelstellen sind verzeichnet bei KRAUS S. $62-64$ in den Varianten. Sie sind den Ev. Matth., Luc. und Joli. entnommien.

4) Schmeller, Carmina Burana ${ }^{2}$ S. 95-107; W. Meyer, Fragmenta Burana passim (bes.
S. $64 \mathrm{f}$.). -- Die Quelle des deutschen Gedichtes scheint eine dem Benediktbeurer Texte des Ludus paschalis verwandte, doch ältere Fassung (12. Jl.?) gewesen zu sein; ferner steht die kleine Benediktbeurer Passion (W. MEYER Tafel 5-7 und S. 122-124).

5) Schmeller S. 102-104.

6) Wackernaget, LG. 12, 397 Anm. 5.4; GRÜNEWALD S. 15 f. 
sprechend dem Gegenstand eines Passionsspiels, vielleicht mit einer frühere Ereignisse im Leben Jesu enthaltenden Einleitung. Das entspräche dem Umfang des Benediktbeurer Oster- bezw. Passionsspiels.

Sprache und Verskunst sind ganz mittelmäßig. Der Stil ist schon durch die eben vorgebrachten Einschiebungen und Einflickungen gekennzeichnet. Die Verse sind ungleich gebaut, neben kurzen stehen sehr lange. Die Reime sind vom Standpunkt der Mundart aus rein; häufig sind Bindungen auf Fremdwörter, dreimal kommt der Reim pylatus : dus (sus) vor (25. 35. 55).

Eine literarische Bedeutung kommt dem Stücke damit $z u$, daß es das fast einzige Beispiel in der mhd. Literatur ist für Einwirkung des Dramas auf die erzählende Dichtung.

\section{$\$ 33$. Wernher vom Niederrhein und der Wilde Mann.}

Zusammen zu nennen sind diese zwei Dichter: ihre Werke, die in ein und derselben Hs. stehen, sind sich in Inhalt und Form sehr ähnlich, so sehr, daß man beide früher für ein und dieselbe Person hielt.

Kelle 2, 134 f. 198 f. 205 f. 335 f. 380. 384; PIPER, GD. 2, 26-28. 114 f. 117. - Ausg.: W. GRIMM, Wernher vom Niederrhein, Göttingen 1839; KARL KöHN, Die Gedichte des Wilden Mannes und Wernhers vom Niederrhein, Schriften zur Germ. Philol. 6. H., 1891, dazu Leitzmann, Archiv 88, 410 ff.; Kraus, Anz. 19, 54-69; Behaghel, LitB1. 1894, 147 f. SCHERER, QF.12, 122 f. Textkritische Beiträge: W. Grimm, ZfdA.1, 423-428; PFEIFFER, Germ.1, 223-233; Conr. Hofmann, ebda 2, 439 f.; v. Bahder, ebda 30, 396-399; Sprenger, Beitr. zur deutschen Philol., J. ZACHER dargebr., S. 121-146; JoHN MErer, Beitr. 15, 334-336.

Hs.: Die Werke beider Dichter sind ïberliefert in der Hs. Cod. I. $81 \mathrm{der} \mathrm{kgl}$. Bibliothek in Hannover, ${ }^{1}$ ) früher, laut Randbemerkung auf der ersten Seite v. J. 1455, im Karthäuserkloster zu Köln, k1. 80, perg. 13. Jh. Die Hs. enthält auf Bl. 94a-133a die vier Gedichte des Wilden Mannes: ${ }^{2}$ ) 1. Veronica, B1. 94a-105a, 2. Vespasianus 105b-110a, 3. Von der Girheit 110a-117a, 4. Christliche Lehre 117a-121a. Darauf folgt nach vier Zeilen des Schreibers (Wunsch für seine Seligkeit) das Gedicht Wernhers vom Niederrhein "Die vier Rädèr " B1. 121a-133a. Der Schreiber hat auf Bl. 137a und 137b in 51 kunstreichen Versen eine Nachschrift persönlichen Inhalts angefügt, ${ }^{3}$ ) worin $\mathbf{u}$. a. gesagt ist, daß er ein junger Mann (KöHN 3) namens Henrich sei (38) und das Buch auf Veranlassung einer Frau Bele geschrieben habe (26f.). Der ïberlieferte Text hat außerordentiich viele Fehler, die von einem unsorgfältigen Schreiber, aber nicht erst unmittelbar von dem unserer Handschrift, herrühren.4)

Die Sprache ${ }^{5}$ ) beider Dichter ist mittelfrk., aus der Gegend von Köln oder mehr rheinabwärts; es finden sich aber darin Spuren einer südlicheren Mundart, bes. im Dentalstand ( $t$ für mfrk. $d$ ).

Wernher vom Niederrhein.

Der Verfasser nennt sich im letzten Vers 69: Dit dihte (dithe Hs.) der phaffe Wernhere; seiner Heimat entsprechend wird er in der Literatur-

1) MASSMANN, v. d. Hagens Germania 1, 170-177; W. GRIMM, Vorrede S. III-VIII; KöHN, Einl. S. VII -X; NÖRRENBERG, Beitr. 9, $412-421$.

2) Ueberschriften hat die Hs. nur vor der Veronica: Dit ist Veronica und vor den „Vier Rädern": Di vier schiven. Die Benennungen der andern drei Gedichte rühren von W. GRIMM her.

3) W. GRIMM S. IV-VI; KöHN S. VIII-X.

4) Die textkrit.Lit.bis 1891 verzeichnet KöHN, Einl. S. XXXVII f.; ferner bei KRAUS aaO.

5) Ueber die Sprache s. SPRENGER aaO. $121-130$; KöHN S. X-XVIII, aber dazu KRAUS und BEHAGHEL aaO; vgl. ferner NÖRRENBERG aaO. 
geschichte W. vom Niederrhein genannt. Das Gedicht ist in der Hs. überschrieben Di vier schiven (so auch am Rand bei 87), d. h. Die vier Scheiben oder Die vier Räder (mhd. schîbe Scheibe, Kreis, Rad).

Inhalt. Das Gedicht ist eine Allegorie. I. Einleitung 1-24, der ethische Gedanke ist entnommen aus Eph. 3, 17-19: die Liebe als erstes Menschengebot, die alle Weiten durchdringt, die Tiefe, die Breite, die Länge, die Höhe, und das Erlösungswerk Jesu als weltumfassende Liebestat. Klar ist die große Idee von der welterlösenden Liebe Jesu nicht durchgeführt, es verschlingen sich die allegorischen Gebilde: die vier Dimensionen werden mit den vier Enden des Kreuzes in Verbindung gebracht (von den [der Hs.] vier Enden bel 24, vgl. auch 26). - II. Hauptteil 25-660. Die Bibelstelle, welche allegorisch gedeutet wird: die vier Räder des Wagens Aminadabs HL.Vl, 11.1) Diese vier Räder und die vier Enden des Kreuzes bedeuten die vier hauptsächlichen Liebestaten des Erlösers: Geburt, Tod, Auferstehung, Himmelfahrt. - III. 661-690. Den Schlu B bildet eine neue Vierzahl, vier Straßen, von denen aber nur drei, die Breite $=$ Liebe Gottes, die Länge $=$ Nachsicht Gottes in der Sündenvergebung, die Tiefe $=$ Hölle, ausdrücklich genannt sind, während die Höhe (= Himmel) in dem Wunsch der letzten Verse (685 ff.) inbegriffen ist, Gott möge uns bei sich, also im Himmel, eine Stätte verleihen.

Formal ist das Gedicht ein wissenschaftlicher Traktat, in dem die schlichte Erzählung der Evangelien vermittelst der versinnbildlichenden Methode durchwoben ist mit Vergleichen aus dem alten und dem neuen Testament, aus dem Physiologus oder aus dem alltäglichen Leben. Die Art, in welcher die beiden Gedankenreihen, die historischen Ereignisse des Lebens Jesu und die darauf bezogenen Bilder, miteinander verbunden werden, ist wesentlich verschieden von der Symbolik des Ezzoliedes: in jenem mächtigen Kirchengesang sind die Bilder selbstwirkende Tatsachen, in der gelehrten Abhandlung Wernhers werden sie ausdrücklich als Bilder, als Vergleiche angeführt und oft eingeleitet durch die kennzeichnenden Worte dat bizeichinit, dat is. Das ist die gelehrte Methode und ihr entspricht der Stil überlaupt. Der Satzbau ist hypotaktisch, z. B. bes. 203-244. Anaphorische Reihen bilden die Sinnbilder Mariens 249-262, ferner 79-86. $147 \mathrm{f}$. Schematisch regelnden Schulgeist beweisen Gegenüberstellungen wie 399-404. $478 \mathrm{f}$. 629-632, vgl, auch 365 f. 530. Stilistisch ist dieser Abhandlungston einfach und schmucklos gehalten, aber stark formelhaft. Nicht gerade häufig sind Paarglieder: 47. 64. 73. 280. 283-286. 307. 361. 486. 514. 548. Sehr oft sind Formeln an die Hörer eingestreut: 17. 21. 25 f. 29. 52. 78. 109. 115 f. 127. 265 f. 315. 374. 426. 441 f. 444. 447. 459. 499. 661. Beziehungen auf die eigene Person: 87-89. 96. 271. 419. 569. 665; 118. 664; 203. 264. 267. 534; 444. Quellenberufungen: 158. 382 f. Hervorhebende Bemerkung: 607. Bibelstellen werden im lat. Urtext zitiert und meist unter Einleitung von dat quîd ins Deutsche übersetzt. ${ }^{2}$ )

Metrik. ${ }^{3}$ ) Reinheit der Reime ist Regel, die nicht gerade häufigen un-

1) Kelle S. 335 f.; KöhN S. 87 f.; Kraus S. 64; ferner Hrabanus Maurus, Migne 107, 210; Honorius Aug. Expositio in Cant., Prol., Migne 172, $353 \mathrm{AB}$; Alanus, Anticlaudianus, Migne 210, 519 ff.; Williram ed. SEEMOLLER
\$ 108 S. 48 f.; S. Trudperter HL. ed. Jos. HAUPT S. 102, $5 \mathrm{ff}$.

2) GRUNEWALD S. $19 \mathrm{f}$.

3) PlitifFer S. 224 f.; KöHN, Einl. S. XVIllXXVII. 
genauen Bindungen entsprechen dem sonstigen Gebrauch in der mittelfrk. geistl. Dichtung seit der 2. Hälfte des 12. Jhs. Die Verse haben ungleichen Betonungstypus, jedoch ohne allzu starke Überschreituug des Mittelmaßes.

\section{Der Wilde Mann.}

Der Dichter nennt sich der wilde man 1 u. 587, Girh. 161; Christl. Lehre 100 „de wilde“. Er war, wie Wernher vom Niederrhein, aus dem nördlichen Mittelfranken und zwar vermutlich ein Fahrender, der sich gelehrte Kenntnisse erworben, vielleicht einmal eine Klosterschule besucht hatte. Die Bezeichnung "der wilde Mann" hat wohl die Bedeutung eines Personennamens. $\left.{ }^{1}\right)$ Er wird um 1170-1180 die uns vorliegenden Gedichte verfaßt haben. Die vier Stücke sind im Stoff sehr verschieden. 1. Veronica ist eigentlich ein Leben Jesu von der Geburt bis zur Himmelfahrt, woran sich noch die Ausgießung des heiligen Geistes anschließt. Die Darstellung ist gleichsam in einzelnen Bildern gegeben, indem die Hauptereignisse, Taufe, Passion, Kreuzigung, Auferstehung, Gang nach Emmaus, Erscheinungen Jesu, Himmelfahrt, besonders ausgeführt sind. In gleicher Weise ist episodisch zwischen Geburt und Taufe 89-196 die Geschichte der Veronica erzählt: Ein Weib hieß Veronica, sie folgte Jesu aus Liebe nach. Sie brachte Lucas ein Tuch, darauf er das Antlitz des Herrn setzen sollte. (Der Heiland trocknete sein Gesicht in einem Tuche, das ihm Veronica, ein ihm in Liebe anhangendes Weib, bei der Mahlzeit reichte. In diesem Tuche prägte sich sein Antlitz ab.) Mit einem Schreiberreim $659 \mathrm{f}$. schließt das Gedicht in der Handschrift ab. Darauf folgt 2. mit dem historischen Einsatz Ein wounder $z u$ Rôme giscach, das Gedicht von Vespasianus, das eine Fortsetzung der Veronicalegende bildet. Der Kaiser Vespasianus, der an einer bösartigen Krankheit leidet, wird dadurch geheilt, daß er das Bildnis Jesu auf dem Tuche, das ihm Veronica bringt, an sein Gesicht drückt. Darauf zieht er mit seinem Sohn Titus ubers Meer und züchtigt die Juden für das, was sie an Jesus getan. Jerusalem wird zerstört, die Judenschaft uber alle Welt zerstreut.

Die beiden Gedichte Veronica und Vespasianus gehören zusammen, die Legende ist auf beide verteilt in der Weise, daß die Entstehung des Christenbildes dem ersten, die Heilung des Kaisers dem zweiten zufällt, getrennt ist ihr Inhalt durch das Leben Jesu seit der Taufe. Sie sind auch vom Verfasser als zwei selbständige Stücke beabsichtigt, denn das erste hat mit 653-658 einen besonderen Abschluß, der vom Schreiber der Handschrift noch mehr hervorgehoben wurde durch seine Verse mit "Amen".

1) Derartige Namen kommen seit dem Ende des 12 . Jhs., besonders aber im 13 . Jh. auf und waren anfangs noch nicht $\mathrm{zu}$ festen Geschlechtsnamen geworden. Sichere Schlüsse auf die Eigenschaften oder auf das Leben ihrer augenblicklichen Träger lassen sich nicht aus ihnen ziehen. Einschlägige Beispiele, wie Uolricus dictusWildenman, verzelchnet PFEIFFER S. 225. Aehnliche Namen trugen besonders Fahrende und bürgerliche Dichter, z. B. der wilde Alexander. 
Die Veronicalegende ist die "Sage vom Ursprung der Christusbilder" ${ }^{1}$ ) Sie ist in verschiedenen Fassungen erzählt worden. Unsere Zeugnisse reichen bis ins 8 . Jh., älter aber, schon im 4 . Jh. überliefert, ist die ursprünglichere Legende von Abgarus, dem König von Edessa, von welcher die Veronicalegende eine Abzweigung ist. Nur in einigen Fassungen ist der Gegenstand, in dem sich Christi Gesicht abprägt, ein Handtuch, in anderen reicht Veronica ihm, da er zum Kreuzestod geht, ihren Schleier, um sich den Schweiß abzutrocknen (das Schweißtuch der Veronica). Die Kaiserchronik enthält 690-1110 ebenfalls die Veronicalegende. Der kranke Herrscher ist dort Tiberius, Veronica ist das blutflüssige Weib, das Jesus nachfolgte, die Entstehung des Bildes, also der Inhalt des Gedichtes Veronica, fehlt ganz. Was in der Kaiserchronik erzählt wird, entspricht also dem Vespasianus des Wilden Mannes.

Die beiden andern Stücke sind rein geistlichen Inhalts. 3. Von der girheide, wie das dritte Gedicht von W. Grimm überschrieben wurde nach V. 21, ist eine christliche Morallehre, in der der Dichter nach einer Einleitung mit der Bitte un Beistand des heiligen Geistes und Angabe des Zwecks seines Werkes (1-20) heftig gegen die Habsucht kämpft (girheit), dazwischen auch stark gegen den Übermut, auch gegen den Hochmut der Besserwisser, der Spötter (255-272), unter Vorhaltung der höllischen Zukunft $(21-44$ und besonders am Schluß 340-371). Seine Predigt ist belebt durch Beispiele aus der Bibel (160), aus der Geschichte (Jugurtha 73-82), aus Natur und Leben (21 ff. 175-246. 255-272.273-291 [vgl. auch 13-17]²) 333-339). Demut, Geduld und Barmherzigkeit sind die Heilmittel zum ewigen Leben (bes. $375 \mathrm{ff}$.): es sind die Lebensbedingungen der Unterdrückten und die besonderen Pflichten der Herrschenden, die der Dichter lehrt, auch er einer der vielen Prediger, die eintreten für die Armen gegen den Übermut und die Unbarmherzigkeit der Reichen.

4. Die "Christliche Lehre" beginnt mit dem Schauen Gottes, das ist das Volk Israel, das von Moses mit dem Stabe, das ist Maria, durch das rote Meer geführt wurde. Der erste Teil lehrt in Bildern die unbefleckte Empfängnis: von der barmherzigen Magd kam der Heiland, der uns am Kreuz getröstet hat $(1-114)$. Ein Übergang, Beati qui audiunt, selig der das Wort Gottes gerne hört (115-142), weckt die Aufmerksamkeit und führt zum zweiten Teil (143-222), den Tugenden. Die erste ist die Weisheit, ohne die man keine Tugend haben kann (143-168). Wir können sie aber nur gewịnnen, wenn wir den Glauben lieben (trûree 169-182), den Weg der Demut betreten (ôtmîdicheit. 183-194) und Barmherzigkeit (195-217) haben. Die Lehre schlicßt mit dem ewigen Leben: dahin führt die Weisheit.

1) W. Grimm, Die Sage vom Ursprung der Christusbilder, Kl. Schr.3, 138-199; K. PEARSON, Die Fronica, Straßburg 1887; MASSMANN, Kchr. 3, 573-590; SCHÖNBACH, Anz.
2, 162 ff. 199 ff.; PIPER, Höf. Ep. 3, 724; s. Buscus Legendar u. Pilatusiegende; STRAucr, Enikel S. 379. 427.

2) Vgl. KRAus S. 59 . 
So verknüpfen sich Anfang und Ende des Gedichtes in dem Gedanken der Ewigkeit.

Ein einheitlicher Geist zieht durch die vier zum Teil so verschiedenartigen Gedichte: es ist die Lehre der Demut und der Barmherzigkeit, z. B. Ver. 239. 370. 616; Vesp. 39. 183. 218; Girh. 1. 47. 67 f. 84.185 f. 203 f. 237. 252 f. 273. 319. 379. 381. 402. 405; Christl. Lehre 99. 186. 195. 205. 208 210. Dazu eine Demut der eigenen Person: zwar gehört es zur äußeren Form der Geistlichkeit, seine Unwertheit zu zeigen in Gebärden und in Worten, da die humilitas ein Grundgebot des Christentums und am meisten des Mönchtums ist, aber wie dieser Mann von sich redet, das scheint doch einen persönlichen Grund $z u$ haben: er sagt selbst, er kenne die Bücher (die heiligen Schriften) nicht Ver. 4.57; er nennt sich einen gebrechlichen Menschen Girh. 2; er hat noch nicht die rechte Richtung fürs Leben gefunden, immer war er der Sünde verfallen (er hat immer unter die scharfen Dorne gesät), mit Leidenschaft, mit innerer Unsicherheit hat er gelebt Girh. 161--167; immer hat er um die Eitelkeit der Welt geworben Ver. 54, vgl. 492. Aber er fühlt sich zum Lehrer berufen: Ver. 49-62. 653-658, Girh. 1-20. 161-167, vgl. Christl. Lehre 56-61. 100 f. 115-142. Er war ein Volksprediger. Seinen Mangel an Bibelkenntnis verrät er oft: die Königin von Saba nennt er Austri (Regina austri Matth. 12, 42; Luc. 11, 31) Ver. 25 und Christl. Lehre 143; Ezechias hieß die Sonne still stehen Ver. 34-38; das Weib folgt Jesu 89 f. und Jesus predigt vor den Jüngern 135, eh er getauft wird $197 \mathrm{ff}$. Jesus barg sich auf einem hohen Steine 218; die Gläubigen folgen ihm auf den Berg Syon 307 f., dann erst wird er an die Säule gebunden und mit Dornen gekrönt 309 ff.; das Vaterunser lehrt er unmittelbar vor der Himmelfahrt $603 \mathrm{ff}$.; Unklarheit besteht über die Auffahrt Christi und die Anrede "Viri Galilei“.

Die Sprache des Wilden Mannes trägt kein besonderes Gepräge, so wenig wie die Wernhers vom Niederrhein. Der Satzbau ist etwas einfacher als bei Wernher, besonders in den erzählenden Partien eher parataktisch als in Nebensätzen ausgedehnt. Die größere sprachliche Gewandtheit Wernhers kann man besonders beobachten, wenn man die Darstellung der Wunder Gottes in den Vier Rädern mit jener des Wilden Mannes Ver. 7-46 vergleicht.

Innerhalb der vier Gedichte des Wilden Mannes selbst besteht ein verschiedener Stimmungston: in den erzählenden Partien ist er anders als in den belehrenden, demgemäß haben Veronica und Vespasianus historischen Stil, die Girheit und die christliche Lehre didaktischen. Anschaulich und in naiver Realistik sind einige Szenen in der Veronica dargestellt, gleichsam Genrebilder, wie der Besuch Jesu bei Veronica 171-196; die Grablegung 399-442; der Gang nach Emmaus und das Mahl daselbst 481-542. Die Geschichte von der Fahrt ins heilige Land und der Eroberung der heiligen Stadt ist zeitgemäß und entspricht dem höchsten Interessekreis der Kreuzzüge. Hierin steht Vespasianus in der Reihe der Spielmannsgedichte 
des 12. Jhs. Auch einzelne Motive gehören in die volkstümliche Epik: die Rüstung über Meer 47-52. 221-233; die Meerfahrten 63-70.131.143-159; Ankunft und Empfang 162-174; königliche Ratsversammlung 221 ff.; höfische Bestandteile 115 f. 132. 141. 174; Zahlenangaben 2. 232 f. Der Stil ist aber nicht spielmännisch, es sind nur wenige Formeln: Ver. 107. 239. 258; Vesp. 266; keine stereotypen Epitheta. Wortpaare sind nicht selten: Ver. 6. 25. 44. 77. 95. 114 f. 119. 121. 147. 220. 261. 398. 429. 485. 523. 529. 552. 559. 601. 649; Vesp. 9. 17. 51. 70. 123. 162.163.178. 222.244. Der Ton der beiden geistlichen Gedichte ist lehrhaft. Hier findet sich das zusammenfassende uns der kirchl. Gemeinschaft. Girh, hat noch am meisten Anredebezw. persönliche Formeln: 9. 12. 18. 21. 125. 143. 175. 222. 239. 333; Wortpaare: 18. 19. 33. 47. 61. 85. 101. 104. 111. 147. 155. 157. 205. 250. 253. 314. 321. 322. 369. 375. 381.402; Fragen: 345 -348 (mit ei). 76. 125 f. $175-$ 178. 299. 308. 330. 397. 401. Nur weniges Einschlägige enthält die Christl. Lehre 101. 117. 143. 180; 97. 99. 104. 112. 129. 132. 211. 217. Lat. Zitate ${ }^{1}$ ) mit deutscher Erklärung hat der Wilde Mann im Verhältnis weniger als Wernher: Im Reimgebrauch besteht zwischen beiden Dichtern insofern ein kleiner Unterschied, als Wernher etwas mehr unreine Bindungen hat, besonders konsonantische. Im Versbau gelten dieselben Freiheiten. ${ }^{2}$ )

Endlich ist die Frage nach dem Verhältnis beider Dichter zu berühren. W. Grimm war geneigt, beide für ein und dieselbe Person zu halten; der Pfaffe Wernher habe sich den Namen 'wilder Mann' beigelegt, um damit seinen Mangel an Kenntnissen ${ }^{3}$ ) anzudeuten. Pfeiffer zuerst hat zwei verschiedene Dichter erkannt und zwar aus den Reimen. ${ }^{4}$ ) In der Tat aber gleichen sich die geistige Auffassung, das Temperament, die sprachliche Form, der Dialekt, das metrische Gewand bis in Einzelheiten. Der Wilde Mann hat mehrmals gleiche Motive wie Wernher: Mariä Verkündigung Wernh. 173-202, Christl. Lehre 81-88; Marter und Kreuzestod Wernl. 281 ff., Ver. 293 ff.; Adam und Eva Wernh. 320-328, Ver. 226 f. 244-249. 265-272. 351-362; Bileams Eselin Wernh. 204, Ver. 16 f.; das rote Meer Wernh. 205 f., Christl. Lehre $5 \mathrm{ff}$.

Besonders kommt hier die Himmelfahrt in Betracht, Wernh. 545-574,5) Ver. 597-629, denn hier wird es aus der Darstellungsart des Wilden Mannes sehr wahrscheinlich, daß er Wernher wirklich gekannt hat; die Felıler gegen die biblische Überlieferung rühren eben daher, daß er die Schilderung seines Vorgängers nicht recht verstand. Das Verhältnis zwischen beiden ist also der Art, daß sich der Wilde Mann Wernher zum Vorbild genommen hat, woraus sich die große Ähnlichkeit der beiderscitigen Werke erklärt. Bei allen Gleichartigen aber finden sich doch auch trennende Zïge: Wernher ist ein gelehrter Geistlicher, der Wilde Mann dagegen ist nicht einmal bibelkundig.

1) GRÜNEWALD S. 27. 29.

2) PfEIFFER aAO.; KÖHN S. XVIII-XXVII; SCHIRŐDER, Gött. Nachir. 1918, 424.

3) Ausg. S. Vli f.
4) PFeiffer S. 224 f.; die Fälle sind aber doch zu wenig beweiskräftig.

5) KrRaus S. 67 f. 
Er redet von seiner Persönlichkeit, er bekennt seine Unzulänglichkeit, besonders im Eingang der Veronica und der Girheit (im Autorenprolog) spricht er von sich; Wernher dagegen stelit sich ganz zurück, nur seinen Namen nennt er in der letzten Zeile seines Gedichtes. Die formalen Kriterien des Stils ergeben deutliche Unterschiede, besonders im Satzbau und im Formelwesen. $\mathrm{Zu}$ einer eingehenderen Wertabwägung beider Dichter reichen ihre uns erhaltenen Werke nicht hin. Aber es zeigt sich doch Wernher als der gelehrtere und formgewandtere, der Wilde Mann als der vorstellungskräftigere.

\section{$\$ 34$. Linzer (Gleinker) Antichrist.}

c) Die letzten Dinge.

KeLLE 2, 164-166. 361-363; PIPER, GD. 1, 61 f. - Ausg.: Gefunden 1834 und hgb. von Hoffmann, Fundgr. 2, 104-134. - Mart. Scheins, Ist Hartmann der alte der Verfasser des Linzer Entecrist? ZfdA. 16, 157-164; SCHERER, QF. 1, 69. 12, 35 f.; AUG. WUNDRACK, Marburger Diss. 1886; Reuschel, Weltgerichtsdichtungen S. 10-14, dazu ZwIERZINA, Anz. 23, 199 f.; SChröDER, ZfdA. 47, 289 f. (Textkrit.); SCHRÖDER, Die Heimat des Linzer Entechrist, Gött. Nachr. 1918, 340-346; Elis. PETERS S. 139.

Hs.: Öffentl. Bibl. zu Linz, Perg., Anfang des 13. Jhs., stammt aus dem aufgehobenen, um 1121 gegründeten Benediktinerkloster Gleink (Gleunk) im Trauntal.

Die Orthographie der Hs. ist obd. (bair. und alemann. Merkmale lassen sich feststellen, ohne besonders hervorzutreten) mit starkem rheinfrk. Einschlag. Das Original scheint alemannisch gewesen zu sein. Um 1170 scheint es, den Assonanzen zufolge, entstanden zu sein. ${ }^{1}$ )

Der Inhalt ist im Gedicht selbst durch Überschriften angegeben. Sie betiteln die drei eschatologischen Teile: I. De anticristo, Elia et Enoch (106, 1-126, 38). Il. De signis XV. dierum ante diem iudicij $(127,1-129,32)$. III. De aduentu christi ad ivdicivm $(129,33-134$, 42); in diesem letzten Teil sind am Schluß auch die Hölle $(133,26-134,6)$ und der Himmel $(134,7-42)$ behandelt.

Der Verfasser zitiert oft die Quellen, am häufigsten nennt er die Apokalypse des Johannes: 110, 41. 111, 38. 112, 33. 115, 32. 116, 15. 125, 24. 126, 6. $(134,9) .134,21$, Paulus führt er an 109, 24 u. 125, 4 (Thessal.), 130, 7 (1. Kor.), David (Psalmen) 129, 33, Jeremias (der wîssage) 115, 25, Daniel 126, 33, in dem evangelio 124, 13 (124, 25. 130, 11), Hieronymus 108, 16. 110,2 . 127, 1, Beda 126, 4. Vieles schöpft er auch sonst aus den biblischen Schriften, ohne sie zu nennen. Die Grundlage aber für den I. Teil, den Antichrist, bildet Adsos Liber de Antichristo; die Reihenfolge der Darstellung Adsos ist nicht streng eingehalten, wahrscheinlich hat dem Dichter noch ein anderes lat. Werk vorgelegen, dem er genauer gefolgt ist. Nicht so ausführlich wie der Antichrist sind die beiden nächsten Teile, die 15 Zeichen und das Gericht, behandelt, in denen die allgemein bekannten Tatsachen mitgeteilt werden. Durch die Methode, die Schriftstellen lat. $\left.{ }^{2}\right)$ mit darauf-

1) WUNDRACK S. 6-17; REUSCHEL aaO.; ZWIERZINA aaO.; SCHRÖDER, Gött. Nachr. aaO. weist auf alemann. Ursprung hin. Die Orthographie des handschriftl. Textes hat Aehnlichkeit mit der des Friedberger Christ und Ant., der betr. md. Schrejber hat also wohl der Wetterau angehört. Simeliche 122, 7. 125,17 findet sich in Herborts Troj. Krieg 1155, vgl. BECH, Germ. 5, 502.

2) Siehe die Anmerkungen von HofFmanN unter dem Text seiner Ausg.; WUNDRAÇK S. 37-49; GRÜNEWALD S. 15. 
folgender deutscher Übersetzung oder Erklärung zu zitieren, verleiht er seiner Darstellung den Charakter eines wissenschaftlichen Traktats; ja, jeder der Teile ist von vornherein unter solchen Gesichtspunkt gestellt, indem sie durch Nennung von Autorităten (Paulus, Hieronymus, David) eingeleitet werden.

Der Dichter ist in der Behandlung der Sprache geschult, seine Ausdrucksweise ist zwar einfach und nicht stark rhetorisch, aber fließend in wechselndem Satzbau und selten unterbrochen durch unangebrachte Flickphrasen oder Notreime. Er denkt sich als Lehrer seinem Publikum gegenüberstehend, daher gebraucht er Formeln wie won dil wil ich beginnen von dem entecriste sagin, die not wil ich nivt verdagin 107, 14-16, und fügt öfter ähnliche Anrede- und Übergangswendungen ein, z. B. 114, $26 \mathrm{f}$. 117,9 f. 25 f. 118,37 f. $119,2.120,41.121,9.31 .122,30$ f. $127,4.129$, 38. Sie gehören zum Stil der Predigt' ${ }^{1}$ oder der Traktate.

Die Verse haben ungleichen Umfang, kurze (die die Mehrzahl bilden) wechseln mit langen. Unter den 593 Reimen sind etwa 100 ungenau. ${ }^{2}$ )

$\S 35$. Hamburger jängstes Gericht.

Kelle 2, 166. 363; Piper, GD. 1, 62-65. - Ausg.: Lappenberg, Anz. f. Kunde d. d. MA. 3 (1834), 35-38; Hoffmann, Fundgr. 2, 135-138; Wackernagel, LB. ${ }^{5}$ Sp. 331-334; PiperaaO.; Leitzmann, Kl.Ged. S. 12f. 30; Wilhelm, Komm. I, 46; Meyer-BenfeY2 S. 12-14.SCHERER, QF. 12, 35; REuSChEL, Weltgerichtsdichtungen S. 5 f., dazu ZWIERZINA, Anz. 23, 199; GRAU, Darstellungen d. jüngsten Gerichtes S. 52. 283--286.

Hs.: Öffentl. Bibliothek zu Hamburg, Doppelbl., Perg. 13. Jlı., kl. $8^{0}$. Bruchstück, Anfang und SchluB fehlen.

Der Dialekt ist rheinfrk., die Orthographie aber ist stärker rheinfrk. gefärbt als im Linzer Antichrist. Abfassungszeit etwa 1140-1150.

Das Bruchstück enthält die Erscheinung Jesu beim jüngsten Gericht, das Urteil, die Scheidung nach rechts und links, die Klagen der Verdammten. ${ }^{3}$ )

Es spricht hier eine andere Persönlichkeit als im Linzer Antichrist, dort legt der Gelehrte nach wissenschaftlicher Methode die Ereignisse klar, hier erschüttert ein Bußprediger die Gemüter durch die Ausmalung des unentrinnbaren Gerichts und der hilfesuchenden, rettungslosen Verzweiflung der Verworfenen. Die Macht des Wortes steht ihm zu Gebote, unmittelbar andringend durch Fragen, Ausrufe, Notschreie. Aber auch sanfte Töne weiß er anzuschlagen, vom Vater, der die lieben Kinder einlädt zu den himmlischen Gnaden. Er kennt die Wirkung der Rhetorik: durch Wiederholungen gewinnt er in gehobenen Momenten verstärkte Akkorde, bei der Berufung der Seligen mit den Willkommsworten: cumint mine vil libin kint4) 136, 40 u. 44 (Hoffmann) und bei der Verstoßung der Teufelskinder 137, 14 f. 11. 138, 12 f. (vgl. auch 136,27 ff. u. 137, 7 f.). ${ }^{5}$ )

1) Der Antichrist als Predigithema: KELLE, Speculum eccl. S. 171 ff. -- Zum Stil s.WundRACK S. 29-37; SCHEINS aaO.

2) WUNDRACK S. $17-29$; SCHIRÖDER, Gött. Nachr. S. 341.
3) Nahe steht eine Predigt des PsendoChrysostomos, GraU aaO.

4) Vgl. OTFRID V, 20,67 i. Quemet...liabun druta mine.

3) Scherer aaO.; Reuschel aaO 
Das Gedicht fordert zur Beichte auf $(136,22-27)$ und zum rechten Leben $(136,21.138,11)$. Die Vorstellung des Gerichts versetzt in eine dazu geeignete Stimmung. Vielleicht war es überhaupt bestimmt, bei der Beichte vorgelesen zu werden, so wie Himmel und Hölle sich an die Bamberger Beichte anschließt und wie in einer Predigt des deutschen Speculum ecclesiae nach der Aufforderung zur Buße das jüngste Gericht vorgetragen wird.'1) So wird auch unser Gedicht nur die letzten Dinge, außer dem Gericht vielleicht noch etwas vom Antichrist und dann das Leben der Seligen und Verdammten in Himmel und Hölle umfaßt haben, nicht wohl aber war es ein vollständiges Leben Jesu bis zum Abschluß der Dinge.

Metrisch gehört es zu dem ungleichmäßigen Typus wie der Linzer Antichrist, hat auch ähnlichen Reimgebrauch. Der Vortrag aber verlangt mehr Leidenschaft und dramatische Modulation.

\section{$\S 36$. Himmel und Hölle.}

Kelle 2, 49 f. 272-275; PiPer, GD. 1, 25-31. - Ausg.: Reuss, ZfdA. 3, 443-445; HaUpT, Monatsber. d. Akad. d. Wissensch. zu Berlin 1856, 568-580; MSD. Nr. 30 u. IIs, 158-164; WaCKernagel, LB. ${ }^{5}$ Sp. 333-336; Piper, Leseb. d. Ahd. u. As. S. 192-195; PIPER, Notker 3, XIX-XXI; v. Steinmeyer, Kl. ad. Spr. S. 153-155; Wilhelm, Münch. Texte VIII S. 31-33, Komm. H. 8 I. Hälfte S. 59-70. - Schade, Decas S. 9-15; SCHERER, QF. 12, 27 f.; LUPPE, H. u. H., Jahresber. d. Kieler Realschule 1876/77 (s. dazu MSD. II', 164); WOLFSKEHL u. v. D. LEYEN S. 82-97. $218 \mathrm{f}$.

Hs.: München, Cod. lat. 4460 Bl. 111b-114a, gehörte ursprünglich dem Dominikanerkloster in Bamberg. Himmel und Hölle folgt unmittelbar auf Bamberger Glaube und Beichte, mit der nächsten Zeile beginnend und von derselben Hand geschrieben. Es steht überhaupt mit dieser in engstem Zusammenhang und es ist wahrscheinlich, daB ein und derselbe Geistliche beide Stücke verfaßt hat. ${ }^{2}$ )

In stärkstem Gegensatz sind die Freuden des Himmelreichs und die Qualen der Hölle dargestellt, Hoffnung und Furcht suchen ein Bild der Seligkeit und der Verdammnis. I. 1-115: Die himmlische Gottesstadt ist durchleuchtet vom Glanz Gottes (1-12); die Stadt ist gebaut aus Edelsteinen und aller Kostbarkeit: das ist das Heer der Heiligen, der Gottesfreunde, die die vier Evangelien erfüllt haben in steter Befolgung der Gebote der Tugend (13--34). Die Straßen sind rotleuchtendes Gold: das bedeutet, daß da herrschen Minne (minna), Weisheit (wîstuom), Wohlwollen (wolewille) - das ist die Dreieinigkeit (35-40). Die himmlischen Erben und die drei göttlichen Tugenden Liebe (minna), ${ }^{3}$ ) Hoffnung (gedinge), Glaube (gelouba), die die Stadt bewohnen $(41-58)$. Da dienen die Engel mit ihrem Jubelsang (59--68). Da ist die Wohnstatt aller Griaden, des Friedens, der Erkenntnis, der Wissenschaften (69-80). Da ist die Überfülle alles Guten, zuletzt das allerhöchste Gut, das Schauen Gottes $(81-113)$. So ist das Himmelreich einerseits beschaffen (114 f.). II. 116-190: In der Hölle ist

1) KELLE, Speculum eccl. S. 175.

2) Bd. I, 316-320.

3) Minna bedeutet Erinnerung, also ergibt sich die Augustinische Trinitätsformel "Me- moria, intelligentia, voluntas", jedoch ist in dem Beisatz wole- zu wille der Begriff der Güte eingeschlossen, also die dritte Person, der heil. Geist, durch Abälards Formel beeinfluBt. 
Tod ohne Tod, Jammer und Klage, Pech und Schwefelstank, schwelende Flamme und feuriger Dampf, schreckliche Finsternis, peinigende Strafe ohne Rast, Qual ohne Unterlaß, Heulen und Zähneklappern, Wehschreie, unsägliche Marter, immer neuer Schmerz ohne Erbarmen, Schmutz und Fäulnis, der Kerker, das Schatzhaus aller Unwonne, Toben der Teufel, wütiger Zorn und böser Wille zur Verdammnis den Erben der Höile in Ewigkeit. So ist das Höllenreich andernteils beschaffen.

Ein bemerkenswerter Unterschied besteht zwischen der Schilderung des Himmels und der Hölle. Jene, viel umfassender, entwickelt sich in fortlaufender Gedankenreihe aufsteigend von der äußeren Beschreibung der Gottesstadt $(1-40)$ zu den Bewohnern, den Erben des Himmelreichs und den Engeln, damit zugleich zu der Dreieinigkeit und den drei göttlichen Tugenden (41-68), dann weiter durch die geistigen Güter, Friede, Gnade, Gotterkenntnis usw. und durch die himmlischen Freuden zu der höchsten Wonne, dem höchsten Gut, dem Schauen Gottes (69-113). Umschlossen ist die ganze himmlische Herrlichkeit durch die Person Gottes (am Anfang $1 \mathrm{ff}$. und am SchluB 991) ff.). Aber die himmlische Stadt hat zugleich geistige Bedeutung, also ist auch hier die Erzählung von allegorischer Deutung durchschlungen: die Edelsteine sind die Heiligen, die Männer Gottes(19-26); die Grundmauern sind die Gottesfreunde, die die Lehren der vier Evangelien erfüllen (27-34); das Gold der Straßen bedeutet (daz meinet 37) die Trinität $(35-40)$; die goldene Schönheit der Stadt, wie das durchsichtige Glas, sind die göttlichen Tugenden der Himmelsbewohner, die vor ihrer aller Augen klar liegen. - Die Schilderung der Hölle dagegen bewegt sich nur in dem einen Gedanken an ihre qualvolle Pein, auch ist keine allegorische Auslegung eingeflochten. Damit hat auch der Stil verschiedenen Bau: beim Himmelreich ist er mannigfaltiger, stellenweise erzählend, mit hăufigem satzeinleitenden $d \hat{a}$ und Abwechslung in den Prädikatsverben, bei der Hölle bloß aufzählend mit nur einmaligem Prädikatsverb (dâ ist 117) und darauf folgenden aneinander gereihten durch nähere Bestimmungen erweiterten Substantiven.

Die eschatologischen Vorstellungen ${ }^{2}$ ) vom Leben der Seligen und der Verdammten nach dem Tode gehören zu den bewegenden Ideen des Urchristentums. In leuchtendem Glanze, festgebaut ragt die Gottesstadt, das himmlische Jerusalem in der Zukunftsverkündigung der Johannesapokalypse $(21,10 \mathrm{ff}$.$) , wo dereinst die Knechte Gottes sein Angesicht sehen werden$ (22, 3 f.), welche Stelle der Schilderung von der himmlischen gotes burg (1) in unserem Gedichte zugrunde liegt. Die älteste christliche Ausmalung des Aufenthalts der Seligen und det Verdammten gibt die Petrusapokalypse im 2. Jh. nach Christıs. Derartige Schilderungen, besonders des Paradieses, sind zumal in den ersten Zeiten des Christentums sehr häufig. Den Ab-

1) Wineskaft, drîtscaft, hier Freundschaft zwischen den Sellgen und Gott.
2) Siche Einleitung S. 8; ELIS. Peters S. $63-78$ und unten Visionen. 
schluß des großen Weltgebäudes, das Augustin in seinem Gottesstaat errichtet hat, bildet die Auseinandersetzung über die beiden Städte, die Stadt des Teufels und die Stadt Gottes (De civ. Dei Buch XXI u. XXII).1) Jene ist die Fortsetzung des irdischen Weltstaates, diese des schon auf Erden begründeten Gottesstaates. Auf die Beschaffenheit der Hölle geht Augustinus im einzelnen nicht ein, es ist ein Ort der Pein, des Feuers und des quälenden Durstes, und auch die Gottesstadt ist nicht in das glänzende Sinnenbild der Apokalypse gekleidet: es ist ein Ort der Geistigkeit, es ist eine Glückseligkeit, in der die hienieden verborgenen Dinge, die Gute Gottes und die Schönheit seiner Schöpfung, dem vernünftigen Sinne geoffenbart werden; wahrer Ruhm, wahre Ehre, wahrer Friede wird dort sein, unablässige Wonne und nichts wonnevoller als der Gesang zur Verherrlichung der Gnade Christi, und als Endziel das Schauen Gottes (bes. Buch XXIII, 30). Diese vergeistigte Gottesstadt konnte das anschauliche Denken und sinnliche Begehren des MA.s nicht befriedigen. Das ahd. Gedicht Muspilli (LG. I, 141-150) gibt die einfach volkstümlichen Vorstellungen über Himmel und Hölle $(1-30)$, Otfrid besingt das himmlische Reich in einem langgezogenen Preislied als eine Idealwelt ohne Sorgen mit allen Wonnen und ewiger Sußigkeit, schönem Gesang, Gesundsein ohne Tod, als ein Märchenland von Lilien- und Rosenblüte und Wohlgeruch, und als die süßeste Freude das Schauen des Herrn; im Gegensatz zu den Himmelsfreuden stehen hier nicht die Höllenqualen, sondern die Mühsale des irdischen Tränentals (Buch V Kap. 23). Am nächsten kommt unser Stück dem lat. Hymnus Ad perennis vitae fontem, der unter den Gedichten des Petrus Damiani steht. ${ }^{2}$ )

Es ist nun begreiflich, weshalb die Beschreibung der Hölle an Umfang und Ausführung hinter der des Himmelreichs zurücksteht: schon die Apokalypse enthüllt nur die Herrlichkeit der himmlischen Stadt, Augustinus geht auf Einzelheiten der Hölle nicht ein, Otfrid spricht gar nicht von ihr und der Hymnus handelt in 20 Strophen "de gloria Paradisi“ und in nur 8 "de poenis inferni"; einige Hss. enthalten die Hölle überhaupt nicht. ${ }^{3}$ )

Die Verbindung zwischen Himmel und Hölle mit der Bamberger Beichte erklärt sich daraus, daß die Tugenden den Weg zum Himmel bereiten, die Laster den zur Hölle. So sagt Honorius Aug. in seiner Predigt In conventu fratrum (Migne 172, 1088 A:4) Porro Rex noster misertus suos quondam milites per præcipicia viciorum ad interitum ruere, misit Filium suum eos ad amissam miliciam per callem virtutum reducere. Das Thema dieser Predigt überhaupt ist der Weg vom Vaterland ins Exil, von Jerusalem nach Babylon, vom Leben zum Tod. Nach der Einleitung folgt eine Aufzählung

1) Vgl. auch De symbolo III Kap. 12.

2) Der Hymnus ist in mehreren Hss. überliefert, war also verbreitet und beliebt, er wurde sogar Augustinus zugeschrieben; s. KELLE aaO.; DANIEL, Thesaurus 1 S. 118. 3 S. 141 ff.; DU MÉRIL, Poésies pop. lat. antérieures au XII. s. S. $131-135 ;$ MONE,
Hymnen 1 S. 422-425; ERDMANN, Otfrid, Var. zu V, 23 u. Erläut. S. 479; ELIS. PETERS S. 65 ff.; Wilhelm, Komm. S. 61 ff.

3) Die Pariser Hs. bei Du MÉRIL, die Karlsruher bei MONE.

4) Siehe LG. I. 318-320. 
der Tugenden, das sind die Pfade der Gerechten, welche zu dem Mahl der Seligen führen (1090 CD); dann der Laster, die Wege des Bösen, welche zur Gemeinschaft der Teufel führen, dem Pfuhl des Feuers und Schwefels (1092 B). In der darauf folgenden Predigt In conventu populi (Sp. 1093-1100) werden die Laien belehrt über den Welt- und den Gottesstaat, über den Gegensatz der Bürger Babylons und Jerusalems, daß wir hier auf Erden in der Verbannung leben unter lauter Übel und daß wir zur Hölle eilen, deren Grausen dann beschrieben wird. ${ }^{1}$ )

Die Abfassungszeit des Stückes wie die der Bamberger Beichte ist nicht genau festzustellen. Durch die strenge, weltflüchtige Reform wurde der Blick noch mehr auf das Jenseits gerichtet, man erwartete für das Jahr 1000 den Weltuntergang und das jüngste Gericht. Aus solcher Stimmung werden beide hervorgegangen, also in der zweiten Hälfte des 11. Jhs. entstanden sein. Auch ist das Abhängigkeitsverhältnis von des Honorius Predigten nicht klar, die Beichte und 'Himmel und Hölle' einerseits, Honorius andererseits können unabhängig voneinander aus einer andern Quelle oder aus dem allgemeinen Wissen der Zeit geschöpft haben. Die Heimat der Beichte und von 'Himmel und Hölle' ist sehr wahrscheinlich Bamberg, worauf die Sprache am ehesten weist.

In der bisherigen Forschung stand längere Zeit das Problem der Form obenan: ist das Stück in reimlosen, vierhebigen Versen oder in Prosa abgefaßt? ${ }^{2}$ )

Ein Vergleich mit der Bamberger Beichte ergibt, daß Himmel und Hölle den gleichen rhythmischen Charakter trägt, $\left.{ }^{3}\right)$ daß es demnach als ein Prosawerk anzusehen ist. ${ }^{4}$ ) Der Grund, weshalb man leicht vierhebige Kola lesen

1) Vgl. WaCkernagel, Ad. Predigten S.324. Auch Hermannus Contractus (Mönch im Kloster Reichenau, $\dagger$ 1054) in seinem Opusculum diverso metro conpositum (a. 1044-46) führt nach einer Geißelung der Laster den Sündhaften zur Hölle, deren Qualen beschrieben werden (E. DÜMMLER, ZfdA. 13, 408-430) und vorher zeigt er den Weg zu den Freuden des ewigen Reichs, der in einem heiligen Leben besteht (S. 396 V. 393 ff.). Vgl. auch Hamburger jüngstes Gericht, oben S. 133.

2) HAUPT aaO, u. MSD. $l^{3}, 159$ erklärt es für ein Gedicht in dem gewöhnlichen Maße der vier Hebungen und macht dazu auf die Reime und Alliterationen aufmerksam, , aber da keine Regel wahrzunehmen, so ist weder Reim noch Alliteration beabsichtigt, und damit steht das Gedicht einsam in der altdeutschen Dichtung da ${ }^{\text {". Richtiger nennt es }}$ Wackernagel (L.G. $1^{2}, 108$, s. auch Ad. Predigten S. $324 \mathrm{f}$.) "poctische Prosa " (doch ist WACKERNAGELS "Reimprosa" keine literarische Gattung, vgl. PAUL, Grundr. II, 2, 2. Aufl. S. 64; RÖDIGER, ZfdA. 30, 84 f.; NORDEN, Die antike Kunstprosa S. 760 ff.; WiL.1. MEYER, Gesammelte Abliandl. II, Reg. S. 386; Ders.,
Carmina Burana S. 165; WILHELM, Komm. S. 65 ff.); FICKER, Wiener SB. 73, $200 \mathrm{ff}$; Paul PERDRIzet, Etude sur le Speculum humanae salvationis, Paris 1908 S. 3 ff.; und STEINMEYER, MSD. $\mathrm{Il}^{3}, 162-164$ (vgl. auch v. STEINMEYER, Kl. ahd. Spr. S. 155; BARTSCH, Germ. 9, 67 f.; LC. 1882, 1593; SCHRÖDER, Götting. Nachr. 1917, 172; SCHÖNBACH, ZfdA. 48, 97) zeigt, daß man auch in der Bamberger Beiclite, die gewiß Prosa ist, längere Partien mit älınlicher Kolabildung zu vier Hebungen lesen kann. - DaB die Kola für die Zeitgenossen als vierhebige Verse gelten konnten, erbellt aus der Aufnahme der V.99. 101-104 in das jiingste Gericht der Ava. Vgl. MSD. $11^{3}, 159$; DIEMER, D. Ged. Anm. S. 73 zu 291, 9; Scherer, QF. 7, 75; Rödiger, Anz. 1, 66; WilhelM, Komm. S. 68.69 .

3) Siche Steinmeyer, vorige Anm.

4) Auch in der Hs., die sehr genaue Interpunktion hat (wie die Bamberger Beichte), sind die Punkte nicht nach rliythmischen Versprinzipien gesetzt, sondern nach dem Sinn der Sätze bezw. Satzglieder. Starke Absätze begimnen mit großen Anfangsbuchstaben. 
kann, wenn man darauf abhebt, liegt im Stil: weitaus die meisten Kola sind Wörter oder Wortverbindungen, die mit noch etwaigen Formwörtern zusammen vier Hebungen ergeben, und zwar 1. zusammengesetzte Wörter, z. B. noh des mânskîmen 3 ; und daz eingehellist 21 ; daz rôtlohezônte golt 36; der himelmeregriezzon 16; 2 . Epitheton 1 )+Substantiv: der unendige tag 11; diu sichere râtwa 90 ; oder beides zusammen, Epitheton und zusammengesetztes Wort: ediler geistgimmon 15; der wundertiuro bîmentstank 63; 2. Substantiv+Genitiv, dâ ist daz gotes zorftel 10; Siu ist in goldes scôni 41; oder noch ein Epitheton dabei, aller gnâdône bû 70 ; oder ein zusammengesetztes Wort und Genitiv und Epitheton: der burge tiure lieht$f a z$ 12, daz suozze gotes wunnelob 61. Dieselben stilistischen Formen, zusammengesetzte Worte, Epitheton + Substantiv, Substantiv + Genitiv, sind nun auch in der Bamberger Beichte häufig angewendet, daher die Möglichkeit, in beiden Stücken leicht vierhebige Verse herauszubringen.

Damit sind auch die Grundformen des Stils festgestellt, und die Kunst der Sprache: sie besteht in dem Wortreichtum. Häufig sind auch Stabreime, sie ergaben sich wohl meist ungesucht, immerhin mochte der Verfasser eine straffere rhythmische Gliederung und die Alliteration mit künstlerischer $\mathrm{Ab}$ sicht verwendet haben, um der Prosa ein gehobeneres Pathos zu verleihen. Dagegen sind die Assonanzen gewiß immer zufällig. ${ }^{2}$ ) - Die kurzen markigen Sätze, die überwältigende Fülle der Ausdrücke für die leuchtende Glückseligkeit wie für den dumpfen Jammer halten das Gemüt in Spannung, obgleich sie immer nur ein und denselben Gegenstand variieren. Aber die Gedanken sind nicht Eigentum des. Dichters, er fand die Motive vor in der reichen eschatologischen Literatur seiner und der früheren christlichen Zeit.

\section{$\$ 37$. Das himmlische Jerusalem.}

Kelle 2, 122 f. 323 f.; PIPER, GD. 2, 99-113. - Ausg.: Diemer, D. Ged. S. 359-372, Anm. S. 87-95, Einl. S. I; PIPER aaO.; WAAG, K1. d. Ged. ${ }^{2}$ S. 55-70 u. Einl. S. XL-XLV, zur 1. Aufl. Kraus, Anz. 17, 23 f. 33. - Scherer, QF. 7, 89 f., auch S. 21. 12, 68; Walth. Ehrentraut, Leipz. Diss. 1913; Elis. Peters S. 87 ff.; Wilhelm, Komm. S. 69.

Hs.: Vorauer Hss. B1. 133b-135c. Das Gedicht war auch in der Milstäter Hs. enthalten, aber vorhanden sind nur noch einige verstückte Worte aus dem Anfang, V. 2-8, die sich am vermoderten Ende der Hs. Bl. 167b an das Paternoster (s. oben S. 67) anschließen. ${ }^{3}$ )

Der Dialekt ist bairisch.4) Das Gedicht ist um 1140 im inneren Österreich entstanden.

1) Sehr häufig ist, wie in den Beichten, das Attribut al.

2) SCHADE aaO.; HAUPT aaO. und MSD. $11^{3}$, 161 f.; B. Q. MORGAN, Beitr. 38, 343-353. Ein altes Gedicht aus der alliterierenden Periode, wie Morgan annimmt, kann nicht zugrunde liegen, weil die stabreimenden Wörter und Begriffe großenteils nicht jener frühen Zeit angehören; auch sind viele von den S. 345347 (s. auch S. 353) notierten Versen nicht nach ahd. bezw. german. Prinzip gebaut; endlich würde damit das Denkmal ganz von der Bamb. B. losgelöst werden. Vgl. HaNS NAUMANN, Notkers Boethius, QF. 121, 92; WILHELM aaO. S. $65 \mathrm{ff}$.

$\left.{ }^{3}\right)$ KARAJAN, Sprach-Denkm.S.70 Z.22-24.

4) SCHERER, QF. 7, 89 f.; WAAG, Beitr. 11, 146-153; WILHELM, Komm. S. 45; auffallend häufig kommen Mittelvokale (Gleitlaute) bei $1 \mathrm{r} \mathrm{m} \mathrm{n} \mathrm{w} \mathrm{und} \mathrm{Kons.} \mathrm{vor,} z$. B. cheleine gelas 185; burech 44; semal 462; sene $(=$ snê $) 265$. - Der Priester Arnolt als Verfasser: SCHRÖDER, Kchr. S. 92 Anm. 2; RöDIGER, Annol. S. 78. 
Inhalt. ${ }^{1}$ ) A. Einleitung 1-48 (nach $\mathrm{WAAG}^{2}$ ), darin Angabe der Quelle: die Apokalypse des Johannes Evangelista 21-48. - B. Hauptteil 49-443. a) 49-127 Beschreibung der Stadt: die Ausdehnung 49-60; die 12 Tore 61-110; das Innere 111-127. b) 128-429 die 12 Edelsteine an der Stadtmauer. c) 430-443 Umfang der Stadt. - C. SchluB 444-473 Epilog an das Publikum: gegen die weltliche Dichtung 444-455; die zwei Wege, der schmale, der zum Himmel, der breite, der zur Hölle führt 456-473.

Das Gedicht ist eine Allegorie. Die himmlische Stadt in der Darstellung der Apokalypse 21,2-25 wird ausgelegt auf religiöse Verhaltungsweisen der Menschen. Die Deütung der Edelsteine speziell schließt sich an Apokal. 21, 18-20 an. Diese Stelle bildet den Ausgangspunkt für die m.alterl. Steinbücher, Lapidarien, also für die Mineralogie bezw. näher: für die Edelsteinkunde. Auch die Steine, wie die Tiere des Physiologus, haben mystische Bedeutung. Eine unmittelbare Quelle des Gedichtes ist nicht aufzufinden, wahrscheinlich ist der Verfasser bei seiner Zusammenstellung frei verfahren und nicht einer Vorlage sklavisch gefolgt. Möglich ist, daß er im Allgemeinen einen Apokalypsekommentar benutzt hat. In der Auslegung der Steine hat das Gedicht viel Übereinstimmung mit einem dem Marbod v. Rennes († 1123) zugeschriebenen Prosatraktat und besonders mit des Hugo v. Folieto De bestiis et aliis rebus. $\left.{ }^{2}\right)$ Der Text der Apokalypse ist sehr frei behandelt, viele Punkte sind überhaupt nicht verwendet, die Reihenfolge ist nicht genau eingehalten. Es entsprechen sich im großen und ganzen: die Einl. 1-48 und Apokal. 21, 2. 9. 10; die Stadt und die Tore 49-127 (dazu 430-443) u. Apokal. 21, 12. 17. 21. 23. 25; die Edelsteine 128-429 u. Apokal. 21, 18-20.

Die allegorische Absicht des Gedichtes tritt auch im sprachlichen Ausdruck immer und immer wieder zutage durch das formelhafte bezeichenen (auch diuten), der lehrhafte Ton wird gleich in den Eingangsworten angeschlagen. Zum Gebrauch des Lat. gaben besonders die Namen der Steine Gelegenheit. $\left.{ }^{3}\right)$

Einige Verse sind, z. T. wörtlich, in die Kaiserchronik übergegangen: $23-26=$ Kchr. $5615-23 ; 397$ f. $=$ Kchr. 13679 f., vgl. $455=$ Kchr. 6.4)

1) Ehrentraut S. 31-33.

2) Marbods Werke bei Migne Bd. 171. DIEMER hält Marbods Traktat (abgedruckt in seinen D. Ged. Anm. S. 89-92) für die Quelle des deutschen Gediclites, während KELLE aaO. unmittelbaren Zusammenhang mit der genannten Abhandlung des Hugo v. Folieto annimmt (Migne 177, $115 \mathrm{ff}$,, als Appendix zu Hugo v. St. Victor); dagegen EHRENTRAUT S. $10-30$. $42-55$. Eine weit ausgedehnte allegorische Erklärung der coclestis Jerusalem ist in der ebenfalls als Appendix in Hugos v. St. Victor Werke aufgenommenen mystischen Schrift De Claustro animae lib. IV, $20 \mathrm{ff}$. eingeflochten, die wohl auch Hugo v. Folieto zum Verfasser liat (Migne 176, $1159 \mathrm{ff}$.). EHRENTRAut weist S. 30-41 auf Beziehungen zum Thema der Dedicatio ecclesiae hin. Das Gedicht ist eine allegorische Aus. legung (V. 2 f.), die vor einer Versammlung vorgetragen werden konnte, aber nicht eine Kirchweihpredigt. Die Veranlassung zur Abfassung liegt in der Beliebtheit des Gegenstandes, das ist die Schilderung der Herrlichkeit der himmlischen Wohnungen, das Interesse für die Edelsteine und ihre allegorische Auslegung, und ïberhaupt auch für das Buch der Apokalypse. Wenn das Gedicht zur Feier der Kirchweihe bestimmt gewesen wäre, dann müßten siclıgewisscAndcutungen darinfinden, auch Bitten an Gott wie in dem von EHIRENTRAUT zitierten HymmusUrbs beata Hierusalem (DREves, Analecta hymuica II Nr. 93, auch in dem daselbst vorhergehenden Hymnus Nr.92).

3) GRÚNEWALD S.19. Formeln s. belEHRENTRAUT S. $89-103$.

4) ScIIröder, Kchr. S.92. Ucber die Aelınlichkeit zwischen Versen des himunlisclicn 
Die Reime enthalten keine altertümlichen Assonanzen. Die Reimzeilen fehlen zu 97. 155. 429. Die Verse haben zumeist normalen Rhythmus, dazwischen erscheinen lange Verse, verhältnismäßig besonders häufig am Schluß von Absätzen. ${ }^{1}$ )

$\S 38$. Vom Himmelreich.

Kelle 2, 102 f. 305; Piper, GD. 2, 122. - Ausg.: Schmeller, ZfdA. 8, 145-155; Rud. Hävemeier, Daz himilriche, Gött. Diss. 1891; Meyer-Benfey² S. 1-11; LeITZmann, Kl. d. Ged. S. 20-27. 30. - Scherer, QF. 12, 101 f., dazu Steinmeyer, Anz. 2, 240; Scherer, D. Stud. 1, 14; Schullerus, s. Germ. Jahresber. 1893 S. 207; WaAG, Kl. d. Ged. ${ }^{2}$ S. V Anm.

Hs.: München, Clm. 9513, Perg., aus dem Kloster Oberaltaich in Niederbaiern, am Rande von 15 Seiten geschrieben.

In Dialekt und in Sprache sowie in der Orthographie, ja in den Schriftzeichen stimmt der Text mit der Windberger Psalmenübersetzung (s. LG. II, 2. Teil) überein, der Verfasser war demnach ein Mönch des Klosters Windberg (bei Straubing in Niederbaiern), der Schreiber ebenfalls ein Angehöriger desselben. ${ }^{2}$ ) Dort ist das Gedicht um 1180 entstanden.

Inhalt. ${ }^{3}$ ) A. Einleitung 1-64. 1. 1-36 Die Eigenschaften Gottes. 11. 37-64 die drei Reiche (1. Firmamentum, das Reich der Engel; 2. Die Erde, die untere Welt, terra morientium; 3. die obere Welt, terra viventium). - B. Hauptteil 65-303. I. Das dritte Reich, das Himmelreich, Herrlichkeit der seligen Burg 65-107. II. Die schöne Iris, der Regenbogen; Einfluß der Elemente; symbol. Bedeutung: Iris = Friede 108-192. Ill. Die Seligen im Himmelreich, das Schauen 193-245. IV. Das Leben im Himmelreich, Schilderung durch Negation: die irdischen Arbeiten und Mühen gibt es dort nicht..., es gibt nicht Hitze noch Frost, es wird nicht gesponnen noch gewoben usw. 246-303. - C. SchluB 304-378. I. Gebet zu Gott 304-320. Il. Aus der Apokalypse der Thron Gottes, die 24 Alten, diese als unsere Fürsprecher $321-378$.

Daz himilrîche (65) ist eine apokalyptische Dichtung. Zugrunde liegt die Apokalypse Johannis (Johannis revelatio 26), bes. Apok. 21, $10 \mathrm{ff}$., auch 7, 16 f. (das himmlische Jerusalem) und 4, 4 ff. (die 24 Alten); der Regenbogen stammt aus 4,3 f. Auch aus den Psalmen ist einiges entlehnt, der Eingangsvers $1=$ Ps. 47, 2 nach dem Windberger Text.4) Den Stoff scheint der Dichter selbst zusammengestellt $z u$ haben, im Anschluß an die genannten und andere lateinische Quellen und aus seinem Schul- und literarischen Wissen $\left.(122.132 .139) .{ }^{5}\right)$ Die beim Regenbogen entfalteten natur-

Jerusalem und solchen der mhd. Legende vom Bischof Bonus und des Wiener Servatius s. Kraus, D. Ged., Einl. S. VIII f. Anm., dagegen RöDIGER, Anz. 24, 61.

1) W. GRIMM, ZGdR., Kl. Schr. 4, 168; Konr. HoFmanN, Münch. SB. 1871, 561; SCHERER, QF. 7, 89; VoGT, Beitr. 2, 258; die Reime s. EHRENTRAUT S. 89-103. Die rhythmisch-melod. Methode wendet EHRENTRAuT S. $96-98$ u. $104-106$ auf unser Gedicht an, vgl.dazu SiEvers, Zur ält. Judith, s. oben S.107.

2) Schmeller aaO.; HÄVEMEIER S. 8-18; SCHRÖDER, ZfdA. 50, 391. Ob der Verfasser des Gedichts vom Himmelreich identisch ist mit dem der Psalmenübersetzung, ist nicht ganz sicher. - Interpunktion: KRAus,

\section{Ged. S. 103 Anm. 1.}

3) Die Zeilenzitate beziehen sich auf HÄVEMEIERS Ausg.

4) Die Quellen gibt Hävemeier an S. 20 u. 31 f. - Elis. Peters S. $101-108$.

$\left.{ }^{5}\right)$ Die ganze Stelle 126 ff. ist nur ein Bekenntnis der Bescheidenheit und gehört zum Stil eines geistlichen Autors. Darum ist aus diesenWorten nicht mit Sicherheit zu schließen, daß der Dichter noch zur Zeit der Abfassung des Gedichtes Klosterschüler gewesen sein mußte, der ein Specimen seiner Kenntnisse geben wollte (STEINMEYER aaO., dagegen HÄVEMEIER S. 19 f.). Gegen eine Schularbeit spricht schon die formelle Gewandtheit, die sich in der Beherrschung der Sprache zeigt. 
wissenschaftlichen Kenntnisse hat er von seinem Lehrer empfangen (139). Sie entsprechen der scholastischen Naturlehre seiner Zeit. $\left.{ }^{1}\right)$

Ganz eigenartig ist die Darstellung des Himmelreichs. Die selige Stadt wird von jeher nicht nur als eine Fülle der Schönheit und Freude gedacht, sondern auch als ein Freisein von Leiden, schon Apok.21, 4: „Und Gott wird abwischen alle Tränen von ihren Augen, und der Tod wird nicht mehr sein, noch Leid, noch Geschrei, noch Schmerzen wird mehr sein;" ferner "Sie wird nicht mehr hungern noch dürsten, es wird nicht auf sie fallen die Sonne oder irgendeine Hitze“ 7,16. Die "negative Schilderung" 2 ) wird zur stilistischen Formel durch die Fassung des Caesarius von Arles bezw: der pseudoaugustinischen Predigten Ad fratres in eremo Nr. 65 u. $67 .{ }^{3}$ ) Sie ist dann Gemeingut der kirchlichen Sprache geworden und findet sich in der ahd. Literatur im Muspilli 14 f., bei Otfrid I, 18, 9 ff., V Kap. 22 und bes. Kap. 23 als Gegensatz zwischen dem "hier" und dem Himmelreich; dann öfter in frühmhd. Gedichten, z. B. in Himmel und Hölle 85 f. 93-98. Die durch die Tradition gegebenen Motive hat unser Dichter in platt naturalistischer Weise ins Alltägliche umgeformt, was fast grotesk absticht gegen den überirdischen Spiritualismus der himmlischen Wohnungen. An Stelle des biblischen Bildes nec cadet super illos sol neque ullus aestus Apok. 7, 16, das z. B. bei Hrabanus Maurus schon in den einfach prosaischen Bericht ibi nulla frigoris, nulla ardoris asperitas ${ }^{4}$ ) abgeblaßt ist, hat er den Vorgang des Einheizens: "man legt nicht Block noch Stock ins Feuer." Das Motiv satietas sine fame ${ }^{5}$ ) macht er klar durch Aufzählung verschiedener Speisen und Getränke und deren Zubereitung, und schließlich ist bei ihm das ganze Leben der Seligen eine requies sine labore, ${ }^{6}$ ) eine selida âno sorgûn ${ }^{7}$ ) dadurch, daß die Bewohner der himmlischen Herrlichkeit keine Arbeit verrichten und nicht zu sorgen haben für ihr Tagesgeschäft. Aber in diesem Bilde des häuslichen Gewohnheitstreibens steckt doch ein tieferer Sinn: die irdischen Bedürfnisse, die die menschliche Gebrechlichkeit auferlegt, reichen nicht in die Regionen, wo die gewandlosen Leiber vom ewigen Licht umflossen sind. Es ist die Erfüllung dessen, was der Mönch im Klosterleben, da es seinem von der Natur gebundenen Körper nicht völlig erreichbar ist, doch anstrebt: Abstreifung alles Irdischen in völliger Bedürfnislosigkeit.

Eigenartig ist auch die Sprache, und ist der Versbau, von welchem jene bedingt ist. Die langen Zeilen begünstigen eine Dehnung der Sätze und des sprachlichen Stoffes. Der Satzbau ist hypotaktiscl, außer in den Aufzählungen: auch Parallelsätze verwandten Inhalts begegnen niclit selten. Erweitert wird der Inhalt durch mehrgliedrige Wendungen, wie michil unde

1) KarL Werner, Die Kosmologie und Naturlehre des scholast. MA.s mit spezieller Beziehung auf Wilhelm von Conches, Wiener SB. 75 (1873), 309-403.

2) STEINMEYER aaO.

3) Cruel, Pred. S. 15-17; MSD. II $^{3}, 32 \mathrm{f}$.
4) Erdmann, Anm. zu Otfrid V, 23, 135 ff. (S. 307).

5) Cruel S. 17

6) Cruel aaO.

7) Muspilli 15 
lobelich 1, sint beschirmit, sint gefirmit alter unde jugende 16, ferner 4. 5.13 usw.; auch mehr als zwei Glieder, z. B. $37 \mathrm{ff}$. Besonders der Preis Gottes 1-44 und hierin wieder 33-44 sind in solch gehobener Sprache abgefaßt. Auch Alliteration wird nicht selten angewendet. Die Vorliebe für Synonyma und Parallelismus kann befördert worden sein durch den Psalmenstil, zumal die Windberger Interlinearversion häufig zwei oder mehrere Übersetzungen für ein und denselben Ausdruck bietet. Oft finden sich lateinische Worte, Zitate, technische Ausdrücke, zumeist im Reim, ${ }^{1}$ ) hier zugleich als rhetorischer Schmuck. Die Ausdrucksweise ist gewandt und im Wortschatz anschaulich. Anredeformeln werden nicht gebraucht, das Gedicht ist nicht als Predigt gedacht.

Einzigartig ist auch die Metrik. ${ }^{2}$ ) Der gelängte Typus ist durchgefuhrt und besteht in allen Versen. Senkungssilben sind es meist mehr als eine, am häufigsten zwei, auch drei und sogar vier oder fünf; auch. schwerere Ableitungssilben körnen in mehrsilbige Senkungen fallen. Gewöhnlich haben die Verse vier Hebungen, es kommen aber auch sichere fünf Hebungen vor; das Reimgeschlecht, ob männlich oder weiblich, kommt dabei nicht in Betracht, die weiblich endenden Verse (\lrcorner $x)$ sind, weitaus die häufigsten; für viele Verse endlich ist die Hebungszahl zweifelhaft. Die vierhebigen Verse sind meist dipodisch gegliedert. Vierhebige Verse: 2. 3. 4. 9. 10. 16 . 18. 25. 30. 51 usw.; fünfhebige Verse: 37. 38. 39. 40. 269. 270. Diese beiden Typen sind durch die logische Betonung als vierhebig oder fünfhebig gesichert, sie enthalten vier bezw. fünf unbestreitbar sinnstarke Wörter bezw. haupttonige Silben. - Die Reime sind fast durchweg rein. Einen besonderen Schmuck bilden innere Reime, z. B. sint beschirmit, sint gefirmit alter unde jugende 16, ferner 45. 210, und zwei Paare in 38; Zäsur und Endreim 17.

\section{Anhang.}

\section{$\$ 39$. Prosaische Bibelübersetzungen}

sind aus diesem Zeitraum nur sehr spärlich erhalten. Eine rheinfrk. Interlinearversion der Psalmen (2 Perg.doppelbl. im Staatsarchiv zu Wien, 1. Hälfte des 12. Jhs., SchÖNBACH, ZfdA. 45, 177-186) geht wohl auf ein Original des 11. Jhs. zurück. Auch die Bruchstücke einer alemann. Evangelienübersetzung (Perg., in München u. Wien, um 1200, KeINZ, Münch. SB. 1869, I, 549; Jos. Haupt, Germ. 14, 440-466; Tomanetz, ZfdPhil. 257-285) setzen

1) GRÜNEWALD S. 26.

2) W. GRIMM, ZGdR. Reg. S. 332; HÄVEMEIER S. $1-8$; E. HERTEL, Die Verse von mehr als vier Hebungen in der frühmhd. Dicht., Marburger Diss. 1909 S. 73. Das Eigenartige im Versbau besteht darin, daß die in frühmhd. Gedichten häufig vorkommenden langen Verse hier durch das ganze Gedicht durchgeführt sind und außerdem einen oft überhaupt außergewöhnlichen
Umfang bis zu 17, 18, 19 Silben erreichen; und ferner in der Verwendung fünfhebiger Verse. Der Versbau ist also aus dem frühmhd. Prinzip abzuleiten und nicht eine Nachahmung des lat. Hexameters (HAUPT, Von dem ubeln Weibe S. 77, dazu Hävemeier S. 1). Möglich wäre allerdings, daß der Dichter zu der Anwendung und Durchführung der langen Verse durch das Vorbild lat. Gedichte veranlaßt worden ist. 
ein älteres Original voraus. Ans Ende des 12. Jhs. oder in das 13. Jh. fallen die Interlinearversion des 88. Ps. (Hs. Graz, SснӧnвACH, ZfdA. 20, $144 \mathrm{ff}$.) und die 2 Doppelbl. einer (alemann.?) interlinearen Psalmenversion im Kloster Schlierbach (Mariasaal) in Österreich ob der Ens (Schiffmann, ZfdA. 43, 220-226). 'Die Windberger und Trierer Psalmen, deren Hss. ebenfalls erst am Ende des 12. Jhs. geschrieben sind, sollen im folgenden Bande dieser LG. besprochen werden.

\section{Legenden.1)}

Die Heiligenlegende ist die Heldensage des Gottesstaates. Wenn die Helden der Welt kämpfen für Ruhm und Ehre, so streiten die Diener Gottes gegen die Feinde der Kirche und gegen deren Oberhaupt, den Erzfeind, den Teufel. Aber ihre Waffen sind nicht die zerstörbaren aus Erz und Riemenwerk, sondern das Schwert des Geistes und der Schild des Glaubens. Ihre Heldentaten verrichten sie nicht in selbsteingreifendem, wegebahnendem Handeln, sondern in standhafter Ertragung von Leiden und in geduldiger Entsagung. Sie sind Helden des Leidens.

Der Ursprung det Märtyrerlegende liegt in der Geschichte, in den Qualen und dem Sterben der zahllosen Blutzeugen der Christenverfolgungen.

Die Mönchslegende ist eine Übertragung der griechischen Wundererzählungen, der Aretalogie, auf die Anachoreten der alten Kirche.

Das Neue Testament berichtet nichts von den Lebensschicksalen der Personen, die zu Jesus in Beziehung standen. Hier setzte ergänzend die sagenbildende Phantasie ein und schuf die Apostel-und andere einschlägige Legenden, und vor allem die höchste Blüte der Heiligenliteratur, die Mariendichtung.

Im gesamten kirchlichen Leben wirkt die Legende als ein wichtiges Mittel zur Erbauung und Belehrung, als Vorbild frommen, gottergebenen Lebenswandels. Der Heiligenkult mit Predigt, Gebet und Hymnen erstreckt sich über alle Tage des Jahres, mit der Verehrung der Heiligen als Schutzpatrone und Fürsprecher war die Legende allgemein ins Volk gedrungen. Die Heiligengeschichte vertritt gleichsam die Stelle der Novelle in der christlichen Literatur und bildet damit in derselben cinen eifrig gepflegten $Z$ weig.

Aus den erhaltenen Legenden der frühmhd. Zeit, wenn auch ihre Zahl im Verhältnis zu der gesamten der Acta Sanctorum beschränkt ist, läßt sich doch ein Überblick über die Gattung gewinnen. Jedes Denkmal vertritt einen besonderen Typus: Das mittelfränk. Legendar ist eine ganze Sammlung, Andreas ist der heilige Apostel, Silvester der heilige Papst und Be-

1) Zur Legendenlit.vgl. bes.: ERNST Lucius, Die Anfänge des Heiligenkults in d. christl. Kirche, Ttibingen 1904; LuDwIG ZÖPF, Das Heiligen-Leben im 10. Jh., Leipz.u. Berl. 1908; R. Reitzenstein, Hellenist. Wundererzăhlungen, Leipz. 1906; WiLhelm, Deutsche
Legenden u. Legendare, Leipz. 1907; PAUL. MERKer, Studien zur uhd. l.egendendiclitung, Leipz. 1906; BuRdach, Dresd. Philol.-Versamml. 1902 S. 29; Ders., Vom MA. zur Ref. $\mathrm{I}, 1,21 \mathrm{ff}$. 
kehrer, Veit der Märtyrer der Christenverfolgungen, Anno ist der heilige Bischof, Aegidius der heilige Einsiedler und Abt, Albanus ist der heilige Büßer, Pilatus eine Gestalt aus der Umgebung Jesu; das weibliche Märtyrertum ist vertreten durch Margaretha und Juliana.

\section{$\$ 40$. Das Annolied.}

Kelle 2, 105-107. 307 f.; PIPER, Spielm. D. 2, 1-13, Nachtr. S. 243 f., Höf. Ep. 3, 712 . Ausg.:1) Ältester Druck: MarTinus OpITIUs, Incerti poetae rhythmus de Sancto Annone, Dantisci 1639; dann folgen die Ausgaben von SchILTER, Thesaurus I, 2, BODMER u. BRElTINGER, Zürich 1745, HeGEwISCH, Deutsches Magazin Bd. 1 u. 2, Hamburg 1791, GoldDMANN, Leipz. u. Altenbg. 1816, KarL Roth, München 1847 (dazu K. Roth, Kl. Beitr. Bd. II, 207 f.), BeZZenberger, Quedlinbg. u. Leipz. 1848, Kehrein, Frankfurt a. M. 1865. Die gulltige Ausg. ist die von Röbiger, Mon. Germ. hist. Script. vern. lingua Tom. I, pars II, Hannover 1895, S. 63-132 u. 139-145, dazu C. Kraus, ZföG. 47 (1896), 226-236, Wilmàns, Anz. 23, 346-357, SchÖNBACH, DLZ. 1897, 1614 ff., RosenhaGEN, ZfdPh. 30,.271--280. Übersetzungen: ALB. STERN, Reclams Universalbibl. Nr. 1416 (1881); WoLFSKEHL u. v. D. LEYEN, S. 142-155. 222-224. - HERDER, Andenken an einige altere deutsche Dichter II, 2. Brief (1793); Massmann, Kchr. 3, 263-278; Holtzmann, Der Dichter des Annoliedes, Germ. 2, 1-48; HeINR. WelZHOFER, Untersuchungen über die deutsche Kchr., München 1874, S. 22--31; SCHERER, QF. 12, 21. 30 f.; Ders., Rolandslied, Kchr., Rother, ZfdA. 18, 298-306; EMIL KeTTNER, ZfdPh. 9, 257-337; Wilmanns, Uber das Annolied, Wilm. Beitr. H: 2, 1886, dazu SeEmÜller, ZföG. 38 (1887), 372-380, VoGT, LitBl. 1887, 5-7, KETTNER, ZfdPh. 19, 321-338; ZARNCKE, Berichte d. Sächs. Gesellsch. d. Wissensch. 1887, 283-305; SCHRÖDER, Kchr. S. 50 f. 64 f. 438; SEEMÖLlER, ZfdA. 42, 322-338.

Uberlieferung. ${ }^{2}$ ) Das Annolied ist nur noch erhalten durch den Druck, den Martin Opitz 1639 in Danzig kurz vor seinem Ende herausgab;3) die zugrund gelegte Hs. selbst ist verloren, sie war, den Sprachformen nach, in der 2. Hälfte des 12. Jhs. abgefaBt; Opitzens Wiedergabe ist nicht ganz genau. Aus derselben Hs., allerdings mit stark von Opitzens Druck abweichender Orthographie, stammen die in dem Werke de Literis et Lingua Getarum sive Gothorum des niederländ. Gelehrten Bonaventura Vulcanius, 1597 (gest. als Professor zu Leiden 1615), abgedruckten Verse $19-74 .^{4}$ )

Der Dialekt der Hs. ist mittelfrk., genauer wohl moselfrk., die Herkunft des Gedichtes aber läßt sich aus den Reimen wegen der starken Assonanzen nicht so bestimmt lokalisieren. Ein Mittelfranke ist der Dichter jedenfalls gewesen. ${ }^{5}$ )

In halt. Das Gedicht zerfällt in zwei Hälften: A. Der historische Teil 1-560. I. Prolog 1-18. Il. Historischer Abriß vom Weltbeginn an bis auf Anno 19-560 (Einleitung 19-38).B. Die Legende 561 - 878. I. Einleitung 561 - 580. II. Annos Leben 581-772. III. Die Wunder nach seinem Tode $773-878$.

Das Annolied ist das erste zeitgeschichtliche und zeitbiographische Werk in deutscher Sprache, der Held der Legende, der Kirchenfürst und all-

1) Siehe K. ROTH S. XIII-XXXIV; RÖDIGER S. $66-73$.

2) HofFMann, Fundgr. 1,249-256; RöDiger S. $63-66$, dazu S. 66 ff.

3) Am 12. Juli 1639 widmete Opitz seine Ausgabe dem Danziger Bürgermeister Cirenberg, am 20. Aug. starb er an der Pest; ZARNCKE aaO. S. $283-293$.

4) KRAus aaO. S. $227-231$.

5) Ueber die Sprache und Heimat des
Schreibers und des Dichters s. HoltzManN, Germ. 2, 38 ff.; MSD. II ${ }^{3}$ s. Reg. S. 476; HeINZEL, Gesch. der niederfrk. Geschäftssprache S. 356-365; BRAUNE, Beitr. 1, 1 ff.; KeTtNer, ZfdPh. 9, 305-337; WilmanNS, Ueb. d. Annol. S. 89 ff. u. Anz. 23, 351-353; SCHRÖDER, Kchr. Einl. S. 51; RÖDIGER S. 8895; ZWIERZINA, ZfdA. 45, 281 ; EbERHARDT, Beitt. 34, 13-15. 
mächtige Lenker des Staates, ist nicht nur als wundertätiger Heiliger, sondern als eine hervorragende Erscheinung der Geschichte aufgefaßt. Das Zeitliche aber ist erweitert zur Menschheitsentwicklung, das Leben des einzelnen .Mannes zu einer allgemein gültigen Menschheitsform. Auf dem allumspannenden Hintergrund der Weltgeschichte ${ }^{1}$ ) ist sein Bild abgehoben, an der Weltanschauung des MA.s, dem Widerstreit zwischen Diesseits und Jenseits, wird er gemessen, der lebenvernichtenden Macht des Heidentums wird er gegenübergestellt als ein Kämpfer für den Dienst Gottes zum ewigen Dasein. Solche Grundgedanken ziehen sich durch das ganze Gedicht, als Leitmotiv sind sie in der Einleitung an die Spitze gestellt: die zerstörenden Taten der nationalen Welthelden und die rettenden Wunder des Heiligen durch den Herrn, das Leben in der irdischen Verbannung und die Ewigkeit 1-18. Am Anfang der geistlichen Weltgeschichte steht der Dualismus alles Seins, der Gegensatz zwischen der körperlichen und geistigen Welt, den Gott bei der Schöpfung in die Dinge gelegt, aus beiden Substanzen besteht der Mensch als dritte Welt 19-38.2) Mit dem Sündenfall hebt das Reich des Teufels an, die Sünde ist Störung der göttlichen Weltordnung. Der Teufel führt die fünf Weltalter vor Christi Geburt zur Hölle. Christus hat seine Macht vernichtet, durch ihn beginnt die Herrschaft des Kreuzes 39-96. Der zweite, der historische Abriß 121-560 gibt in rascher Folge von Kriegen und Reichs- bezw. Städtegründungen einen Überblick über die Entwicklung des Weltstaates mit.Hinleitung auf deutsche Verhältnisse. .Einzelne, die Geschichte bestimmende Heroen treten hervor. Den Anfang machen Ninus, der Tyrann, der erste Eroberer und zugleich der erste Burgenbauer, Semiramis die Städtegründerin; es folgen die vier heidnischen Weltreiche, dabei der wundersüchtige Alexander (der wunterlîche $A l .326)$; die vier deutschen Stämme, von denen die Franken und ihre Städte mit besonderem Interesse behandelt werden; Cäsar der Kriegsheld, als Begründer der römischen Weltmacht Augustus: da wird Christus geboren, ein neues Königreich entsteht, dem die Welt alle weichen muß (533 f.), der Gottesstaat Sankt Peters im Zeichen des Kreuzes. Und nun geht der erste Teil (A), der Weltgeschichte und Weltanschauung in ihren Grundztigen, im Dualismus, vorführt, über in den zweiten, die Legende, indem dem großen Helden der alten, heidnischen Welt, Cäsar, die besseren Streiter, die heiligen Bekehrer, die gegen die Sünde kämpfen lehıren, die Kölner Bischöfe, entgegengestellt werden, unter denen Sankt Anno hervorleuchtet wie der Hyazinth im goldenen Fingerring 561-576. Mit dem Verhalten Annos in diesem Zwiespalt der zwei Welten beginnt der legenda-

1) Ueber die mittelalterl. Weltgeschichtsschreibung s. Einl. S. 1 ff. und unten Kehr.

2) Hier wirkt Scotus Eriugena ein, der in seinem Werke De divisione naturae (Migne 122, 439 ff.) das ontologische Problem in ähnlicher Weise auffaßt; er schöpfte aus

Deutsche Literaturgeschichte. II. griechisehen Kircheniehrern (vgl. 36 Annol.), die er häufig zitiert. Unmittelbarer Einflub der Griechen auf den Dichter des Annoliedes, wie ZARNCKE aaO. 293-298 vermutungsweise andeutet, ist nicht wahrscheinlich. 
rische Teil (B 561-878), der ganz der Verherrlichung des einen Mannes gewidmet ist: beiden Pflichten wußte er gerecht zu werden; ein echter Herrscher sowohl in weltlichen Dingen als im Gottesdienst ging der Bischof Anno vor Gott und vor den Menschen (Staat und Kirche, als Reichsverweser und als Bischof), in Wahrheit ein gerechter Fürst 577-596. Indem so Anno in sich Körperwelt und Geisteswelt vereinigt, ist er der Typus der Menschheit, entsprechend der eingangs aufgestellten Ontologie (19-38); insofern er beide in harmonischer Weise in sich ausgleicht, ist er der Typus des vollkommenen Menschen. Und als solcher ist-er denn auch in dem legendarischen Teil dargestellt, ausgestattet mit den Tugenden eines Geistlichen und eines Fürsten: ein Löwe an Kraft gegen die Hohen, ein Lamm gegen die Armen, ein Schützer der Witwen und Waisen, in Predigt und Beichte gottselig und den Menschen ein Wohlgefallen, barmherzig, ein gerechter Richter. Das alles sind allgemeine Eigenschaften, die der ablichen typischen Personenschilderung des MA.s entnommen sind. Da die Kunst, die Persönlichkeit zu charakterisieren durch Hervorhebung einzelner Züge, noch kaum entdeckt war, ist ein Idealbild gezeichnet, wie es von jedem Bischof entworfen werden konnte: der historische Anno, der ehrgeizige Emporkömmling, die rücksichtslos in die Weltgeschichte eingreifende Herrennatur, ist er nicht. Bestimmte, greifbare Punkte für das äußere Leben geben jedoch die eingestreuten historischen Tatsachen, die sich an seine Reichsverweserschaft knüpfen. Als eine schwere Prüfung empfindet er die Anfechtung der Kölner und seine Vertreibung, die Schrecken der Kriege, die das Reich unter Heinrich IV. zerfleischten, betrübten ihn, den Friedensfürsten, in den Tod. Den einzigen Flecken, der sein reines Gewand beschmutzte, die Feindschaft mit den Kölnern, beseitigte er durch seine großmütige Gnade $733 \mathrm{ff}$.

Auch die Legende zerfällt in die beiden Regionen, auf die Taten in der Welt 577-696 folgt, beginnend mit den Visionen der göttlichen Wonne, das Leben im Geiste 697--878. Nach dem langen Gang durch die Geschichte der Welt und die Erdenspanne des Kölnischen Bischofs kehrt das Lied wieder zum Anfang zurück: Leib und Seele, Fleisch und Geist $(=23 \mathrm{ff}$.) scheiden sich, vom menschlichen Elend geht der Weg in das ewige Paradies 759-770 (vgl. $17 \mathrm{f}$.); daran wird die Mahnung angeschlossen, an das Ende zu denken $771 \mathrm{f}$. $(=7)$, und Anno wird als Vorbild aufgestellt $(=15$, wie am Anfang der Lebensbeschreibung 577-579), indem er uns anspornt, ihm auf dem Wege zum Himmel nachzufolgen 773-788. Die Wunder, die im Prolog angedeutet sind (10-14), werden jetzt erzählt 785-852. In dem Heiligen äußert sich die Kraft Gottes: wie Moses das Volk zu dem allerbesten Lande brachte, so führt er süß an Handen zu dem schönen Paradieseslande. So ist die Menschheitsgeschichte durchschritten von der Schöpfung durch das Heidentum zum Christentum bis auf den Helden des Preisliedes, den ins himmlische Jenseits geleitenden Bischof Anno von Köln. 
Dieser Geschichtsauffassung liegt der Dualismus von Körper- und Seelenwelt und dessen Äußerung als Weltstaat und Gottesstaat zugrunde. Die augustinische Geschichtsidee von den beiden Staaten bildet die ideelle Grundlage des historischen Teiles (A).

Quellen. ${ }^{1}$ ) Die beiden Hälften haben verschiedenen Ursprung. Wie die Grundlage für den geschichtlichen Teil beschaffen war, ist nicht klar erkenntlich. Es scheint, daß dem Dichter die Hauptzüge der historischen Entwicklung nach einem gedrängten $A b r i ß$ bekannt waren, in welchem die einzelnen Tatsachen nur kurz tabellenartig verzeichnet standen, die er dann aus verschiedenen Quellen und auch aus seinem eigenen Wissen ergänzte.

Am Anfang der christlichen Weltgeschichtsschreibung steht Ninus schon bei Hieronymus und als Urheber der Kriege ${ }^{2}$ ) in Augustins De civ. Dei IV Kap. 6 (nach Justinus), danach in der weitverbreiteten Weltgeschichte seines Schülers Orosius (a. 417/18), auch in Isidors Etymol. XVIII Kap. 1, 1.3) Die vier heidnischen Weltreiche behandelt dann Orosius, allerdings in anderer Fassung, ebenfalls im Zusammenhang mit Ninus an einer zweiten Stelle, B. II Kap. 1. 2. 3. Der Dichter des Annoliedes hat die vier Weltreiche an den Traum Daniels in der Bibel (Dan. Kap. 7)4) in der Auslegung, die Hieronymus gegeben, angeknüpft. Die historischen Beziehungen Cäsars $z u$ den deutschen Stämmen und die Ursprünge werden nach dem MA. bekannten, uns im einzelnen nicht vollständig nachweisbaren gelehrten Sagen erzählt. - Die Bekehrung der Franken durch die drei Heiligen ist den Gesta Trevirorum entnommen. Diese lagen dem Dichter nahe, da sie fränkische Geschichte und in engerem Sinne die einer benachbarten fränkischen Stadt behandeln. ${ }^{5}$ ) Auf sie weisen, außer der zuletzt genannten Stelle, die V. 275-278) hin, auch die V. 495-518 setzen rheinische chronikalische Notizen voraus. Den Bericht aber das mazedonische (griech.) Weltreich schmückte er durch Abenteuer aus der Alexandersage aus (207-236), ebenso suchte er die Phantasie der Leser anzuregen durch die Geschichte Trojas und des Ulixes (350 ff.), die er nach Virgils Aeneis bezw. dem Kommentar des Servius in den Abschnitt über die Franken aufnahm.

Der größte Teil der historischen Erzählung (A), der Abschnitt 179-518, findet sich auch in der Kaiserchronik 287-660, dazu $57 \mathrm{f}$. Sehr häufig stimmen die Verse wörtlich überein oder lassen doch gemeinsamen Ursprung erkennen. Der Verfasser der Kchr. hat das Annolied benutzt bezw. ausgeschrieben.7)

Einen ganz anderen Ursprung hat der zweite Teil des Gedichtes, die Legende (B). Das Leben Annos hat zuerst, in gedrängter Darstellung,

1) Siehe bes. Einleitung zu Bezzenbergers Ausg.; ZaRnCKE aaO. S. 298 ff.; WilmanNS, Annol. S. 10-64; O. Carnuth, Germ. 14, 74-81; PhIL. KohlmanN, Beitr. 35, 554-567.

2) Ninus 1st auch der erste Städtegründer (Hieronymus aaO., Annol. $121 \mathrm{ff}$.). In dem universalistischen Zug der m.alterl. Weltgeschichtsbetrachtung ist es begründet, dai bel den Volkern und Städten auf ihren Ursprung zurückgegangen wird. Gerade das Annolied berichtet hauptsächlich von der Urgeschichte, von Reiclıs- u. Städtegründungen: Ninus stiftet Ninive $121 \mathrm{ff}$., Scmiramis Babilonie $153 \mathrm{ff}$; die Herkunft der vier deutschen Stămme 281 ff.; Gründung elner griechischen
Troia, von Padua, Alba, Rom, Xanten 373 ff., Augsburg, Colonia Agrippina und Aufzälilung anderer rheinischer Siädte 481-517. Geschichte und Geographie sind hicr verbunden.

3) RöDIGER, Anm. Z11 V. 125.

4) Franz Kampers, Alex. d. Gr. u. die ldee des Weltimperiums in Prophetie u. Sage, Stud. 11. Darst. aus d. Gebiete d. Gesch. Bd. 1 H. 2. 3 S. $13-15$.

5) Massmann, Kclir. 3, 303 ff.; WattenBACHS GQ., Reg.

6) Wilmanns, Annol. S.51; ZaRnClie S.304; SCHRÖDER, Kiclir. S. 65 f.

7) Die Quellenfrage ist ein Hauptproblem in der Forschung des Annolieds, bes. 
Lambert von Hersfeld in seinen Annalen beschrieben (abgeschlossen im J. 1077), die, wie das Lied, mit einem kurzen Abriß der Weltgeschichte von der Schöpfung an beginnen. Auf Lambert beruht die umfangreichere, weitschweifige Vita Annonis, die im Jahre 1105 von einem Mönche des Klosters Siegburg verfaßt wurde. Mit ihr hat das Lied einige wörtliche Anklänge gemein und steht jedenfalls in Beziehung zu ihr, sei es daß es unmittelbar aus ihr schöpfte oder daß beide ein und dieselbe Vorlage hatten. Die Vita ist mönchisch engherzig, für Klosterleute bestimmt und hat den ausgesprochenen Zweck, durch Erzählung der Wunderkraft und Prophetengabe ihren frommen Helden als Heiligen zu erweisen und weithin bekannt zu machen, 1 ) um dadurch den Ruhm ihres Klosters zu erhöhen.

Für die Abfassungszeit des Liedes sind zwei feste Daten gegeben, das Vollendungsjahr von Lamberts Annalen 1077 und die Niederschrift der Vita 1105, welche jene Annalen voraussetzt. Eine sichere Entscheidung ist bis jetzt nicht erreicht worden. Wir müssen uns begnügen zu sagen, daß es zwischen ca. 1080 und 1110 entstanden ist. ${ }^{2}$ )

das Verhältnis $z$ wischen Annol. und Kchr. (die verschiedenen Ansichten s. bei RöDIGER S. 80-88). Gegenwärtig werden die drei folgenden Möglichkeiten vertreten: BEGEMANN, Verhandl. der 30. Philol.-Versamml. in Rostock 1876 S. 120 ff. (Germ. 20, 501; ZfdPh. 7, 102), ebenso KetTNER, ZfdPh. 9, 266-296. 19, 321 If., JOHN MEIER, Beitr. 16, 97, SEEMÜlLLE, ZfdA. 42, $322-338$ und RÖDIGER aaO, nehmen an, daß Annol. und Kchr. aus einer gemeinsamen Vorlage, einer älteren deutschen Chronik, geschöpft habe; SCHRÖDER, Anz. 7, 191, Kchr. S. 65, WilmanNS, Annol. S. 10-64, Anz. 23, 347 ff., SEEMÜlLER, ZföG. aaO., Kraus aaO. S. 232 f., RosenHAGEN, ZfdPh. 30, 271 ff. u. VoGT, Grundr. II², 169 dagegen erklären, die Kchr. habe unmittelbar das Annol. benutzt; SCHRÖDER setzt dabei jedoch ein älteres, ausführlicheres Annolied voraus, das unser erhaltener Annotext und die Kchr. vor sich hatten. - Die Kchr. enthält zwei umfangreichere, nicht im Annolied stehende Zusätze: 1. Die Gründung der festen Plätze und darauf die Einnahme Triers durch Cäsar 379-454, die auf 398 des Annolieds folgen (vgl. dazu VoGT, ZfdPh. 26, 551), und 2. die Erzählungen von Augustus $605-642$ linter 482 des Annolieds. Für beide Fälle ist es sicher, daß sie nicht dem ursprünglichen Text angehören, wie ihn das Annolied bietet, sondern daß sie die Kchr. erst nachträglich eingeschoben hat. Das zweite Stück ist der Siebenzahl des Priesters Arnold entnommen, darauf weist die Kchr. selbst hin mit den Worten daz liet kundet uns daz 622, sô wir daz buoch hôren sagen 626 . Beide Stiucke aber unterscheiden sich im Stil von dem Annol., und zwar ganz deutlich im Formelgebrauch. Es zeigt sich dabei, daß das
Annol. und die Kchr. nicht etwa eine gemeinsame Vorlage haben, denn diese köınte doch nicht die zweierlei Stilarten durcheinander gehabt haben. Die Kchr. hat das Lied un mittelbar ausgeschrieben und hat zur Ergänzung andere Quellen beigezogen, nämlich Arnolds Siebenzahl, besonders aber die Gesta Trevirorum, wie MASSMANN 3, 303 ff. für einige Stellen nachgewiesen und WILMANNS aaO. befestigt hat. Sie hat also mit den Gest. Trev. gerade diese selbe Quelle wieder benutzt, die schon dem Annolied bekannt war. Dafür spricht auch der Gebrauch des Namens Julius (selten Cesar, Julius Cesar, vgl. Julius, qui dicebatur Caesar, Gesta Trev., MASSMANN S. 320) in der Kchr., während das Annol. nur Cesar hat. Die Ursprünglichkeit des Annol. läßt sich auch noch an einigen kürzeren Stellen nachweisen, wozu jedoch hier nicht der Ort ist.

1) HoltzmanN, Germ.2, 14-16; KetTneR, ZfdPh. 9, 296-304. 19, 327 ff.; WILMANNS, Annol. S. 66; RöDIGER S. 101-112. Ueber die Vision Annos: Elis. Peters S. 135.

2) Die Meinungen über die Abfassungszeit schwanken, s. RÖDIGER S. 98-101. 'LACHMANN (Kl. Schir. 1, 468. 520) und nach ihm MASSMANN 3, 262, und BEZZENBERGER S. $10 \mathrm{ff}$. setzten das Gedicht um 1183, das Jahr der Aufhebung der Gebeine des Heiligen (Anno wird im Liede unter den 15 Fällen, wo der Name vorkommt, 12mal sent, seint [sanctus] genannt, außer 589 u. 821 , einmal heilig, den heiligen bischof Annen 13. Dagegen sprechen aber von vornherein Sprache und Reimgebrauch(SCHADE, Cresc. S.17ff.). Wie SCHADE (vgl. schon fruher HofFMANN, Fundgr. 1, 251) und nach ihm HoLTZMANN (der Lambert von Hersfeld für den Verfasser hält) Germ. 2, 1 ff., 
Das Annolied, das mit seinem Stoffe in der Gegenwart wurzelt, will auch den Zeitinteressen dienen. Der Verfasser eröffnet den Prolog mit dem Zweck seines Werkes: er streitet gegen die weltliche Dichtung ${ }^{1}$ ) und stellt den Helden des Volksepos ein geistliches Musterbild entgegen. Es ist das alte Mittel im Ringen der Kirche gegen die Kinder der Welt, wiederum bekämpft der Klerus die Volkssänger, die Spielleute, mit ihren eigenen Waffen ${ }^{2}$ ) wie in den Anfangszeiten des geistlichen Epos, als Otfrid durch sein großes Evangelienwerk die heidnischen Lieder verdrängen wollte. ${ }^{3}$ ) Und der Mann, den der Dichter dem Volke im Heiligenscheine vorstellte, war in der Tat ein gewaltiger Kämpfer, dessen Kraft die Menschen der Zeit selbst und am eigenen Leib verspürten; er war ein Recke an Ruhm und großer Kühnheit, der vor denen der Dichtung nicht zurückstand. Keinen Geringen führte der Mönch gegen die Spielleute ins Feld, sein Held hatte auch im geistlichen Gewand die Eigenschaften, selbst dem unbändigen Adel Bewunderung einzuflößen..4)

Vollends heroisch aber und in ritterlichem Geiste aufgefaßt ist der historische Abriß. Lange Stellen desselben konnten geradezu in einem Heldenepos stehen. Kriegerisch mußten die Bilder sein, in welchen der Dichter die Wirren des Weltstaates vorführte, den er der Legende entgegensetzt. Damit wurden die Kämpfe des Ninus, der Germanen, Cäsars geradezu Beispiele dafür, wî̀ snelle helide vâhten 3 , für jene Heldendichtung also, die er für unzeitgemäß erklärt. Er gewann damit das Interesse des ritterlichen Publikums, läßt aber doch keinen $Z$ weifel daran, daß diese Kriegs-

dann MÜLlenHOFF, MSD. $I^{3}$ Vorrede S. XXXIX und SCHERER, QF. 12, 30 erklären sich für den älteren Termin um 1080 unter den Neueren WiLMANNS, der genauer das Jahr I077/78 erschließt (Annol. S. 89-91) und im $\mathrm{Zu}$ sammenhang mit ihm VogT, Grundr. ${ }^{2}{ }^{2}, 168 f$., SEEMÖLLER,ZföG. aaO.; ferner RÖDIGER (S.98), KraUs (S. 235), Rosenhagen (S. 280); dagegen für den jüngeren Termin, 1105 oder die darauf folgenden Jahre, KETTNER, ZfdPh. 9, 304 f. 19, 337 f., ZARNCKE S. 299. 304 , SCHRÖDER, Kchr.S. 51, vgl. Anz. 7, 191, KELlE S. 105, KohlmanN, Beitr. 35, 558 f., LeITZMANN, Beitr. 36, 395 f. WILMANNS führt Anzeichen dafuir auf, daß das Annolied nicht direkt von der Vita abhängig sei, sondern $\mathrm{da} B$ beiden eine ältere, uns verlorene Vita vorgelegen habe (s, auclı RöDIGER aaO.), aber der Beweis ist nicht sicher erbracht; auch nicht durch die Erwägung, daß zwei im Charakter so verschiedene Werke wie das Lied und die Vita aus derselben Gemeinscliaft zu derselben Zeit (S. 90) hätten hervorgehen können, denn gerade die verschiedene $\mathrm{Ab}$ siclit, die Wirkung auf Geistliche in der Vita, auf Lalen bezw. Ritter im Liede, konnte die Verschiedenheit in der inneren Auffassung bedingt haben. Solange wir keinen sicheren
Beweis für friihere Entstehung haben und eine ältere lat.Vita nicht wirklich nachgewiesen ist, bleibt die einzige Tatsache für die Zeitfrage das Verlıältnis des Liedes zu der uns erlaltenen Vita von 1105 . Und dieses spricht allerdings, da dann das Lied aus dieser Vita entlchnt sein muB, für 1105 oder die nächsten Jahre als Abfassungszeit des Annoliedes.

1) Die 6 Eingangsverse sind stilistisch formelhaft; auch inhaltlich sind sie verwandt mit der ersten Strophe des Nibelungenliedes: die zerstörten Freundesbande und der Untergang mächtiger Könige ist eben das Thema der Nibelungensage.

2) SCHERER, QF. 12, $18 \mathrm{ff}$

3) Siehe LG. I, 177.

4) Indem Anno als vorbildliche Pcrsönlichkeit gezeichnet wurde, ist das Gedicht 211 einem Panegyricus auf den Heiligen geworden. Zugleich war das Lob seines Bischofssitzes damit gegeben. Zu den ribmenden Worten uber Kölı (97-120, vgl. 517 f.; doch der Tadel ilures Aufstandes 659 ff. 757 f.) mochte der Dichter nocli durch die Absicht mit veranlaßt worden sein, anf die Stimnung der Kölner zu wirken; vgl. hierzu bes. WILMANNS, Annol. S. 7.53. 91 f. 94 f.; ZARNCliE S. 300. 303 f.; RÖDiger S. 81 f. 
taten geringer sind als die Kämpfe gegen die Sünde im Dienste Gottes (561-566).

Ein Landsmann seines Helden, ein Mittelfranke, war auch der Verfasser. Köln, der Bischofssitz Annos, und Siegburg, seine Lieblingsstiftung, sind die beiden Orte, auf die sich das Hauptinteresse des Gedichtes erstreckt. In Köln - eher als in Siegburg, das mehr zurücktritt wird es abgefaßt worden sein. Der Dichter, ein Mönch oder Stiftsgeistlicher, besaß eine nicht gewöhnliche Belesenheit und war geschult, die menschlichen Dinge von dem großen theologischen Standpunkt einer Geschichtsidee aus zu betrachten. Er war mehr Gelehrter als Künstler, mehr Nachahmer als Selbstschöpfer, er besaß wohl dichterisches Empfinden, aber keine eigentlich selbständige Ausdrucksfähigkeit. In den kriegerischen Partien des ersten Teiles ist er abhängig von dem nationalepischen Stil, von da hat er die Schilderung von Ausrüstungen und Waffen $125 \mathrm{ff} .297 \mathrm{ff}$. 417 ff., die Darstellung des Krieges zwischen Cäsar und Pompejus 415-462, der Verheerung Deutschlands 675-696; der zweite Teil, die Legende, bewegt sich in den Formen der lateinischen geistlichen Literatur.

Es liegt etwas von der Kraft der Heldendichtung in der Erzählung von den Weltereignissen, und kräftig ist auch die Sprache ${ }^{1}$ ) in ihrer Einfachheit, ohne sich zur Leidenschaft zu steigern. Ein besonderer Schmuck sind die zahlreichen Bilder und Vergleiche, welche den Verlauf der Erzählung phantasievoll beleben: einige der schönsten gerade sind entlehnt: 435-438 aus Virgil, $449-458$ aus Lucan, $773-780$ aus 5. Mos. 32, 11. Die meisten Abschnitte sind durch einen abschließenden Gedanken markiert: Hinweisung auf die Zukunft 60. 152. 479 f. 810; gegenwärtiger Zustand 96. 630.646; eintretende Zustände 674.696. 712; religiöse Abschlüsse 74, ferner 108. 534. 771 f. 838. 852, dazu das Ende des ersten Abschnittes $17 \mathrm{f}$. und des letzten 878; Resultat kriegerischer Unternehmungen 279 f. 294. 319 f. 345 f. 398. 462; andere Schlüsse 37 f. 119 f. 518.595 f. 613 f. 757 f. 787 f.

Die formalen Stilmittel beherrscht der Dichter, seine Ausdrucksweise ist fließend, doch sucht er nicht durch besondere Sprachkunst zu wirken. Der Satzbau ist überwiegend hypotaktisch, besonders mit relativen und temporalen ( $d \hat{o})$ Anknüpfungen; Aufzählungen in mehrfachen Parallelgliedern begegnen an passenden Stellen. Zweigliedrige Ausdrücke werden mit $\mathrm{Ma} \beta$ verwendet, ebenso Formeln. Gerade im Gebrauch der Formeln und formelhaften Verse zeigt der Verfasser eine gewisse Beherrschung des Sprach- und Wortschatzes, denn er haftet nicht starr an dem geläufigen Material. Weitaus die meisten Formeln kommen im ersten Teil vor, Be-

1) Zum Stil vgl.HoltzManN, Germ. 2, 42 ff.; MSD. $1^{3}, 188$; SCHERER, QF. 12, 31; WILMANNS,Annol.S.94 f.; SEEMÖLLER aaO.S.334337; BEHAGHEL, Beitr. 30, 43 I ff. (bes. S.559f.); ZWIERZINA, ZfdA. 45, 281 Anm.; GRÜNEWALD

S.32. - Kraft, Würde, moralische Schönheit, die Komposition, den Stil rühmt Herder (aaO.) an dem Gedichte und nennt es ein pindarisches Loblied. 
rufungsformeln, mit denen sich der Dichter auf die Quellen seines weltgeschichtlichen Berichtes bezieht. Dagegen in der Legende braucht er solche wissenschaftliche Beglaubigungen nicht, da er deren Stoff nicht aus Büchern, sondèrn aus dem Leben entnahm.

Metrik. $\left.{ }^{1}\right)$ Reim und Versbau sind mit ziemlicher Freiheit behandelt. Mit der Prozentzahl der Assonanzen und deren Stärke steht der Reimgebrauch noch auf der älteren Stufe der frühmhd. Reimkunst. Etwa ein Drittel der Bindungen ist unrein. Der Reim kann noch auf schwachtonige Flexionssilben fallen (über man, gewan : -an vgl. SCHRÖDER, Kaiserchr. S.65; RöDIGER S. 83 f.). Die Verse haben in der Mehrzahl mittleren Versbau, doch leicht mit zweisilbigen Senkungen; dazwischen dehnen sich manche zur Überlänge.

$\S 41$. Das mittelfrănkische Legendar.

Kelle 2, 200. 382; PiPer, GD. 2, 85. - Ausg.: Hugo Busch, ZfdPh. 10, 129-204. 281-326. 390-485. 11, 12-62; ders., Beitr. z. d. Phil., Julius Zacher dargebr., Halle 1880, 277-292, dazu Rödiger, Anz. 6, 221-227, Zarncie, LC. 1867 Nr. 50; C. v. Kraus, Mhd. Ubungsbuch S. 1-17 u. 239 f. - SCHERER, QF. 7, 39-42. 12, 39 f.; RÖDIGER, Anz. 1, 72 ff.; John MEIER, Beitr. 16,96; Kraus, D. Ged. S. 260-268.

Hss.: Bruchstücke dreier Hss.: I. 6 Pergbl. 12. Jh., Universitätsbibl. in Halle, hgb. von SCHADE, Fragmenta carminis theodisci veteris, Königsberg 1866 (Habilitationsschrift) $(\mathrm{H})$; 4 Pergbl., Dombibl. in Halberstadt (Hs), abgedruckt von Busch, ZfdPh. aaO. Die von SchadE und von BARACK herausgegebenen Blätter wurden früher unter dem Titel „Schade-Baracksche Fragmente“ zusammengefaßt. $\mathrm{H}$ und $\mathrm{Hs}$. gehören ein und derselben Handschrift an. II. 3 Pergbl., etwas jünger als HHs, Donaueschingen, hgb. von BARACK, Germ. 12, 90-96 (D). 11I. 2 Pergbl., Halberstadt, hgb. von Busch, Beitr. f. Zacher aaO. (Br). ${ }^{2}$ )

Det Dialekt ${ }^{3}$ ) von 1 (HHs) (hier häufige schwache $o$ ) und III (Br) ist mittelfrk., der von II (D) obd., Dialekt des Gedichtes mittelfrk. Abfassungszeit ca. 1130-1150.

Inhalt. ${ }^{4}$ ) 1. Schöpfung und Sündenfall; 2. Johannes der Täufer (1 u. 2: Busch, Beitr. f. Zacher aaO.); 3. Veronilla (ZfdPh. 10,134 ff. V. 1-149); 4. Petrus (150-238); 5. Mariae transitus $(239-312)$; 6. Schicksale der Apostel (313-419); 7. Heilige (420-466); 8. Zerstörung Jerusalems $(467-528)$; 9. Kreuzauffindung $(529-593) ; 10$. Heraclius u. Cosdras (594-691); 11. Himmel und Hölle (Beweis, daß es zwei Himmel und zwei Höllen gibt), unter Beiziehung des armen Lazarus (692-764). Die Anordnung ist im großen und ganzen historisch, den Rahmen bilden die Schöpiung mit Adam und dem Sündenfall ${ }^{5}$ ) am Anfang und Hölle und Himmel am Schluß.

1) MSD. II ${ }^{3}, 113$; KETTNER, ZfdPh. 9, 320 326; RÖDIGER S. 95-98; WILMANNS, Anz. 23, 353-356; SeEMÜller, ZfdA. 42, 322 lf.; G. EBERHARDT, Beitr. $34,1-100$ (fiuhrt die Grundsătze der Sprachmelodik von SIEversSARAN durch; dazu HABERMAnN, Metrik d. kl. ahd. Reimgedichte S. 192 f.). - SCHADE wandte Cresc.S.16 ff. 11. Geistl. Ged. S.XLVIII ff. selne Theorie von der sechszeiligen Strophe auf das Annolied an.

2) Daß diese zwei Blätter mit den andern zusammen zu dem mfrk. Legendar gehören, hat Kraus aaO. bewiesen. RödIGER, Anz. 24,64 .
3) Busch 10, 168-204. 281-326. 390-405 und Beitr. f. Zacher S. 285-288; BeHAGHEL, Schriftsprache u. Mundart S. 29; SCHRÖDER, ZfdA. 42, 111; Heimat: JoHn MEIER, Beitr. $16,97$.

4) Sielie Veronica, oben beim Wilden Mann.

5) Vielleicht ist daran die Legende vom Kreuzesholz angekniipft gewesen. - Aehnlichen Inhalt und Reihenfolge liat die Allerlieiligenpredigt in des Honorius Aug. Speculum eccl., Migne 172, 1014-1019 bezw. 1022: Gott als Schoópfer der Welt (1014 D), Maria (die Erzengel), Adam (und dic Patriarclien), (die Proplieten), Johannes d. Tauler, Schick- 
Quellen der ganzen Sammlung waren lateinische Einzellegenden, die der deutsche Dichter zusammenstellte: eine Veronicalegende, ${ }^{1}$ ) die Petrusund Paulusakten des Marcellus und Pseudo-Abdias, Melito de transitu S. Mariae, ein Martyrologium (für die Schicksale der Apostel), die Acta S. Judae Quiriaci (für die Kreuzauffindung), das Chronicon Reicherspergense (für Heraclius und Cosdras); keine bestimmte einheitliche Vorlage ist für den Schluß von Himmel und Hölle zu ermitteln, ebenso nicht für den Anfang, Adam und Johannes den Täufer, der zumeist der Bibel folgt.

Der Verfasser hat plump gearbeitet, er hat sich im allgemeinen eng an seine Überlieferung gehalten, hat sie aber nicht selten verwirrt, auch Widersprüche hineingebracht: er hat die einzelnen Stücke meist ohne Übergang äußerlich aneinandergestellt, so daß $\mathfrak{u}$. a. die gleichen Personen in einem Abschnitt wieder auftreten, nachdem sie in einem vorhergehenden schon gestorben sind. ${ }^{2}$ ) Er zitiert einige Male Gewährsmänner: Paulus 416, Lucas 528, Johannes ewangelista Br.76, Miletus (Melito) 239, Arator 327, Sedulius 451 ; die beiden letzten passen aber nicht, er hat also offenbar die betreffenden Werke gar nicht gekannt. Einige Male sind kurze dogmatischerklärende Abschweife gemacht. ${ }^{3}$ ) Und so ist auch die Darstellung dürftig, meist wird nur trocken berichtet, ohne Stimmung. Die Ausdrucksweise mit den häufigen Wiederholungen, den hölzern gebauten Satzgefügen ist sehr ungelenk; das Verbum sagen erscheint alle Augenblicke, ${ }^{4}$ ) z. B. zwischen 43 und 80 zehnmal, zwischen 529 und 574 elfmal. Formelhafte und Flickverse sind im Verhältnis nicht übermäßig zahlreich. Lat. Worte5) kommen oft vor, sie sind aus dem betr. lat. Original entlehnt; deutsche Präpositionen mit falschem lat. Kasus verbunden 581. 582. 590, s. auch 243. 433. Lat. Konstruktionen begegnen z. B. 347 f. 360. 429. 431. 470.6)

Metrik. ${ }^{7}$ ) Etwa die Hälfte der Reime sind Assonanzen, darunter aber nur wenige starke. Die Verse sind im Umfang recht verschieden, das Gedicht hat also rhythmisch ungleichen Typus.

\section{$\S 42$. Der Trierer Silvester.}

Kelle 2, 105. 306; PiPer, GD. 2,31. - Ausg.: RöDiger, ZfdA. 22, 145-209; Kraus, Mon. Germ. Tom. I pars II, D. Chroniken 1895, S. 1-61 u. 133-138, dazu SсHÖNBACH, DLZ. 1897, 1614 ff., Rosenhagen, ZfdPh. 30, 271. - BaRTsch, Germ. 26, 57-63; LeitzMANN, ZfdA. $52,387 \mathrm{f}$.

Hs.: Trierer Stadtbibliothek, $\left.{ }^{8}\right) 4$ Pergbl., kl. $4^{0}$, vom Ende des 12. Jhs., enthalten Bruch-

sale der Apostel, Märtyrer, Bekenner usw.; am SchluB: Aufnahme in den Himmel. Latein. „Sammelhandschriften von ähnlicher Beschaffenheit“" s. SCHÖNBACH, Anz. 2, 201.

1) SCHÖNBACH, Anz. 2, 199-201.

2) Busch 11, $55 \mathrm{ff}$.

3) KRAUS, D. Ged. S. 264 . - Vielleicht hatte der deutsche Dichter schon eine lat. Kompilation vor sich (RöDIGER, Anz. 6, 224); dann würden die Mängel, wenigstens teil- weise, dieser zur Last fallen, nicht erst dem deutschen Bearbeiter.

$\left.{ }^{4}\right)$ BusCH 10, 408.

5) GRÜNEWALD S. $28 \mathrm{f}$.

6) Zum Stil s. KRAUS S. 263 f.

7) BusCH 10, 405-423 u. Beitr. f. Zacher S. 288-292; RÖDIGER, Anz. 6, 225-227; KRAUS S. $260-262$.

$\left.{ }^{8}\right)$ STEINMEYer, ZfdA. 21, 307 ff.; Kraus S. $2 \mathrm{f}$. 
stücke des Ägidius, des Silvester ${ }^{1}$ ) und des Floyris. ${ }^{2}$ ) Der Trierer Silvester foigt auf den Ägidius. Vieie Einzelstellen sind verstümmelt.

Dialekt der Trierer Hs. ${ }^{3}$ ) mhd. Normalorthographie mit mundartl. Formen; diese sind hessisch, also nordrheinfrk. Der Dialekt des Dichters ist ebenfalls md.4) Zeit der Abfassung nach 1150, einige Jahre nach der Kaiserchronik. ${ }^{5}$ )

Inhalt: Die Silvesterlegende erzählt die Heilung Kaiser Konstantins vom Aussatz durch den Papst Silvester, die Einführung des Christentums, die Verteidigung desselben durch den Papst gegenüber den Gelehrten der Juden und Heiden auf einer dazu berufenen Synode, endlich die Bekehrung der Helena, der Mutter Konstantins.

Sie ist in der Kaiserchronik enthalten, ${ }^{6}$ ) V. 7806-10633, und der Trierer Silvester ist nichts anderes als eine Umdichtung dieses Stückes. Die aus der Kchr. aufgenommenen Verse (es sind 502) hat der Verfasser zum größeren Teile mehr oder weniger umgeformt, wobei er die Reime meist bestehen ließ, selten hat er Verse der Kchr. durch andere ersetzt; zuweilen hat er längere Partien ausgelassen, auch Verse umgestellt. Zu der Kchr. hat er noch eine lat. Vita des Heiligen hinzu benutzt, mittels derer er den Text wiederum erweiterte. Einiges, aber Unwesentliches, unnötige Verdeutlichungen, hat er selbst beigebracht. ${ }^{7}$ ) Durch diese Änderungen und Zusätze ist die Darstellung matter und breiter geworden und hat viel von der lebendigen Erzählungsart der Kchr. verloren. Lat. Worte sind selten. ${ }^{8}$ ) Die Trierer Bruchstücke reichen bis in die Disputation und entsprechen den V. 7806-8679 der Kchr. Die Einleitung des Trier. Silv., 1-32, ist den V. 3-14 und 27-42 der Kchr. entnommen.

Die Verse ${ }^{9}$ ) haben rhythmisch ungleichen Typus; der Umdichter hat die Art seiner Vorlage, der Kchr., sowohl im Versbau als im Reimgebrauch nachgeahmt.

\section{$\$ 43$. Der Trierer Aegidius.}

Kelle 2, 199. 380; Piper, GD. 2, 28-31, Höf. Ep. 3, 724. - Ausg.: Rödiger, ZfdA. 21, 331-412 (mit Faksimile von Steinmeyer); mit Besserungen hgb. von BARTSCH, Germ. 26, 1-57, dazu RöDıger, ZfdA. 26, 240 f. - JOHN MEyer, Beitr. 16, 97.

Hs.: Bruchstücke der Trierer Stadtbibl., zu der gleichen Hs. gehörig wie der Trier. Silv.

Eine leichte Überarbeitung des Trierer Ägidius ist enthalten in einer zweiten Hs., einst in Höxter: Pergbl. vom Ende des 12. Jhs. (nur $130 \mathrm{~V}$. gegen $1720 \mathrm{~V}$.

1) Jetzt verschollen, s. AD. BECKER, Die d. Hss. der Stadtbibl. zu Trier, 19i2, Reg.

2) Trierer Floyris s. LG. 1I, 2. Abt.

8) RÖDIGER S. 396-399 น. ZfdA. 22, 179 181; Kraus S. 38-43. Der Stand der Dentalen $z$. B. ist normalmiıd., nicht rheinfrk., außer $t$ in dit (gegen $z$ in daz) in den zum Trier. Silv. gehörigen Teilen der Fragm. (nur in den vom Überarbeiter des Trier. Silv. herrlihrenden Versen, KRaUS S. 43; im Trier. Ágidius kommt das Wort nicht vor). Jenes dit entscheidet fur hesslscisen Dialekt.

$\left.{ }^{4}\right)$ Vielleicht mittieres Rheiufrk., vgl. den
Reim warheit: geit 486 bci Fehlen sonstiger mfrk. Formen.

5) Kraus S. 44.

6) Siehe unten Kchr.

7) Zur Quellenfrage und dem Verhältnis zur Kchr. S. RÖDIGER S. 181-209; VOGT, ZfdPh. 26, 560-562; Kraus S. 3-38; SchÖNBACH aaO.; SCHRÖDER, ZfdA. 27, 80, Kchr. S. 42. 60 f. 224 Anm. zu 7806. 439.

8) ZWierzina, ZfdA. 45, 281 Anm.; GrüeWALD S. 29.

9) RÖDIGER S. 170-179. 
der Trierer Hs.), hgb. von J. GRImm, Arch. f. Gesch. u. Altertumsk. Westphalens 1 (1826), 73-80 u. Kl. Schr, 6, 364-370; Hoffmann, Fundgr. 1, 246-249. Der Schreiber war ebenfalls ein Mitteldeutscher, wohl auch aus Hessen, wie der Schreiber der Trierer Hs., aber das Dialektische tritt bei ihm noch mehr zurück. $\left.{ }^{1}\right)$

Der Trierer Ägidius stammt, wohl, soweit man aus den Reimen Schlüsse ziehen kann, aus dem mittleren rheinfrk. Gebiet. ${ }^{2}$ ) Abgefaßt wurde er um 1160. Wenig später entstand, wohl in derselben Gegend, die Höxtersche Überarbeitung.

Inhalt. Der heilige Ägidius, aus reichem Hause $z u$ Athen, wandte sich schon in der Jugend der Lehre Gottes zu. Er landete auf einer Reise in Südfrankreich (7. Jh.). Hier, in dem Gebiet von Arles und Nîmes, lebte er in öder Gegend als Einsiedler in frommem Gebet. Eine Hindin nährte ihn. Einst kamen die Jäger des Königs Flavius in die Waldwüste. Sie verfolgten die Hirschkuh. Sie flieht zur Höhle des Einsiedlers. So wird er entdeckt. Der König baut ein Kloster in der Nähe, Ägidius wird Abt. Den König Karl von Frankreich heilt er von schwerer Schuld, viele Wunder vollbringt er. In einer Sommernacht, dominica nocte (Sonnabend), kam ihm die Botschaft von Gott, daB er in das ewige Reich fahre. Seine Seele wird von Engeln in den Himmel getragen.

Überliefert ist in unsern Bruchstücken der größte Teil der Legende. Der Anfang ist verloren, aber bald setzen die Fragmente von Höxter ein, sie enthalten die Bekehrung bis zum Entschluß des Heiligen, sich ganz Gott $\mathrm{zu}$ weihen. Die Trierer Bruchstücke beginnen mit seinem wohltätigen Wirken in Südfrankreich. Größere Lücken finden sich innerhalb der Trierer Blätter nicht, wohl aber sind viele einzelne Stellen schadhaft.

Quelle ist die lat. Legende der Acta Sanctorum zum 1. Sept. Der Dichter hat den Stoff stark erweitert durch Begründungen, religiöse Betrachtungen, Gebete; Ausmalung von Personen und Situationen. In oftmaliger Häufung gleicher Gedanken schreitet die Erzählung nur langsam vorwärts, aber sie ist aus einem bloßen Tatsachenbericht in poetische Darstellung erhoben und es entfaltet sich ein anschauliches Gesamtbild: der fromme Mann, in sich abgeklärt, fern von den Menschen, eins mit seinem Gotte. Aber er kann sich dem Leben nicht entziehen, aus der stillen Gottesnähe wird er in die Welt geführt. Er kommt an den Hof des Königs und an den des Papstes, immer Demut im Herzen. Über dem Ganzen liegt ein friedvoller Ton. Mensch und Gott und Natur sind gleichgestimmt in dem Waldidyll, in das das romantische Märchen von der ernährenden Hindin eingeflochten ist $\left.(310 \mathrm{ff} .)^{3}\right)$

Der Stil ist, auch in dem Höxterschen Bruchstück, einfach,4) der Verfasser beherrscht die Worte, will aber nicht durch sie wirken. Der Satzbau ist hypotaktisch. Zweigliedrige Ausdrücke sind häufig, doch ist der Stil nicht eigentlich formelhaft. Statt des persönlichen Pronomens her steht für Ägidius

$\left.{ }^{1}\right)$ Pron. er für das in den Trierer Bruchstücken herrschende her; umbe für umme.

2) Siehe Kraus, D. Gied. S. 148.
3) Carl Pschmadt, Die Sage von der verfolgten Hinde, Greifswalder Diss. 1911 S. $59 \mathrm{f}$.

4) RÖDIGER S. 404-407. 
sehr oft eine Umschreibung wie der guote man, der gotes holde. Lat. Wörter sind nur vereinzelt. ${ }^{1}$ ) Die Erweiterungen und Zusätze im Stoff und die Umschreibungen sind Eigenschaften des Predigtstiles.

Von den Reimen ${ }^{2}$ ) ist nur ein Viertel rein, Assonanzen herrschen also stark vor. Die Verse sind ziemlich normal gebaut, mehr der Kürze sich nähernd; lange Verse sind selten. Reime und Versbau sind in dem Höxterschen Stück besser als im Trierer Ägidius.

\section{$\$ 44$. Andreas.}

Kelle 2, 199. 381; Piper, GD. 2, 51. - Ausg.: Lambel, Germ. 12, 76-80, dazu ZföG. 24 (1873), 178 Anm.; Kraus, D. Ged. S. 64-67 u. 250-259. - SChERER, QF. 12, 40.

Hs.: Pergbl. des 12. Jhs., ehemals in der Bibl. des Grafen Czernin in Petersburg in Böhmen, jetzt verschollen. Der Text ist nur trümmerhaft erhalten, der Anfang fehlt. Dialekt: mitteldeutsch; Zeit der Abfassung: zweite Hälfte des 12. Jhs.

Inhalt: Der Apostel Andreas, in Patras (Achaia) vor Gericht gezogen, wird umgekehrt ans Kreuz geschlagen. Nach einer Heidenpredigt stirbt er.

Quelle ist eine lat. Andreaslegende, die am nächsten stehende Fassung ist enthalten in den Virtutes Andreae des Pseudo-Abdias. ${ }^{3}$ ) Der Stil der Erzählung ist einfach (Legendenstil); lat. Verse sind ein gestreut. ${ }^{4}$ ) Die Assonanzen sind nicht auffallend, die Verse ziemlich regelmäßig gebaut.

$\S 45$. S. Veit.

Piper, GD. 2, 51-53. - Ausg.: Mone, Anz. f. K. d. teutschen Vorz. 8, 53 ff.; Kraus, D. Ged. S. 24 f. u. $134-147$, und ZfdA. 50, 328 ff.

Hs.: Bruchstücke aus Maria-Saal s. Reg.

Die Sprache der Hs. ist obd., ohne ausgeprägte Merkmale (ch im Anl. 1. 17. 26. 41. 43.60) und mit nur sehr wenigen vollen Endsilbenvokalen (hersan 27, marteroten 28, dieses im Reim). Da auch die Reime keinen Anhaltspunkt geben, so ist die Heimat des Gedichtès nicht näher zu bestimmen denn als Baiern oder Alemannien. Abfassungszeit ca. 1170.

Inhalt: Christenverfolgung Diocletians und Maximians, die Kindheit des Heiligen. Mit der Taufe Velts bricht das Fragm. ab.

Die Quelle des Gedichtes ist unbekannt. Die Feier des Heiligen fällt auf den 15. Jan. ${ }^{5}$ ) Erwähnt wird er in der Kchr. 6464. 69 als Helfer gegen die fallende Sucht, dabei stimmen die V. 6469 ff. der Kchr. nahe zum Schluß der lat. Legende des heil. Veit. - Einfacher Legendenstil, darin Verfasser-, Einleitungs- und Beteuerungsformeln 12. 25. 36. In den Reimen begegnen keine außergewöhnlichen Assonanzen; die Verse sind ziemlich regelmäßig gebaut.

\section{$\$ 46$. Albanus.}

Kelle 2, 199. 381; Piper, GD. 2,5 f. - Ausg.: LachimanN, Über drei Bruchstïcke niederrheln. Ged. aus d. 12. und ans d. Anfange d. 13. Jhs., Berl. Akad. d. Wissensch. 1836 (Berlin 1838), 159-190 u. Kl. Schr. S. 519-547; Kraus, D. Ged. S. 41-45. 197-217. - Haupt, Historia Albani martyris. Monatsber. d. Berl. Akad. 1860, 241 ff.

1) GRÖNEWALD S. 29.

2) RÖDIGER S. 382-396.407-412; SCHRÖDER, Gött. Nachr. 1918, 427.

8) KRAUS S. $250--253$.
4) Grünewald S. 28.

5) Passion des Heiligen in den Acta Sanctoriun zum 15. Juni, p. 1021 ff., Kreaus S. $134-136$. 
Hs.: Berlin, Ms. germ. quart. 665, Perg.doppelbl. (aus der Bibl. Meusebachs), erste Hälfte des 13. Jhs.

Inhalt. Die Albanuslegende') ist die christliche Ödipussage. Ein Kaiser nimmt nach dem Tode seiner Frau seine eigene Tochter zur Ehe. Das Kind, Albanus, wird im fernen Ungarlande mit kostbaren Kleidern und Kleinodien ausgesetzt. Der König von Ungarn nimmt den Findling an, setzt ihn, da er kinderlos ist, zum Erben ein und läßt ihn, nachdem er zu einem trefflichen Jüngling herangewachsen, krönen. Er kommt an den Hof des Kaisers und gewinnt dessen Tochter zur Frau, heiratet also, ohne es zu wissen, seine Mutter; die zugleich seine Schwester ist. Die Kostbarkeiten, die Albanus einst bei seiner Aussetzung beigegeben worden waren, enthüllen den unbewußten Frevel. Die Unseligen reinigen sich durch Buße. ${ }^{2}$ )

Alle Legenden haben als ethische Bedingung den Kampf des sittlichen Menschen gegen böse Mächte. Zumeist sind es äußere Feinde, die Heiden, oder auch gefährlichere, der Teufel, Verführer, die die Lüste des Herzens anreizen. Diese Märtyrer stärkt der Glaube und die Hand des Allmächtigen führt sie zum Sieg. Hier aber, in den Erlebnissen des Albanus, gibt es keine Wundertaten und Folterqualen, sondern es ist eine Tragödie des menschlichen Herzens. Hier ist es ein Ringen mit der eigenen Schuld, und diesen armen verworrenen Seelen bleibt nichts als die Gnade Gottes. Sie können das himmlische Reich nicht erkämpfen durch Heldentaten, sondern sie können es nur erbüßen. Und das ist der religiöse Grundgedanke, der auch in unsern Bruchstücken zum Ausdruck kommt in den Worten gnâde 69. 73. 81. 88. 106, bezzeren inde bekêren 93. - Die Berliner Blätter enthalten zwei Abschnitte aus der ganzen Legende: 1. 1-60 Das Findelkind wird von dem König von Ungarn aufgenommen und zum Erben eingesetzt, wächst zum Jüngling heran, wird gekrönt; 2. 61-118 Die Tochter des Kaisers entdeckt diesem, daß Albanus ihrer beider Sohn ist.

Der Grundstoff ist eine weltliche Geschichte, eine Novelle, die zur Legende erst wird durch die religiöse Schlußwendung. So ist auch die Darstellung reiner Erzählungstil, lebensvoll, leidenschaftlich gesteigert bei seelischer Erregung, frei fortschreitend, nicht gebunden in typische Formeln und belastet durch Flickverse. Es ist eine neue stilistische Technik, die der höfischen Zeit. Dagegen die Vers-und Reimbehandlung hat noch nicht die RegelmäBigkeit der höfischen Dichtung. Die Reime sind allerdings überwiegend rein, aber Assonanzen, wenn auch leichte, sind doch nicht selten. Die Senkungen sind oft stark überfüllt, dadurch sind viele Verse überlang. ${ }^{\mathbf{3}}$ )

1) GREITH, Spicilegium Vaticanum S. 159 f.; REINHOLD KÖHLER, Germ. 14, 300-304 u. K1. Schr. 2, 184-189 (s. dazu auch die Vergogna Legende, ebda S. 190-203); PAUL, Gregorius (große Augabe), Halle 1873,S.XVf.; W. CREIZENACH, Beitr. 2, 199 ff. (Sage von Judas Ischariot); AD. SEELISCH, ZfdPh. 19, 408; SCHÖNBACH, Ueber Andreas Kurzmann, Wiener SB. 88 (1878), 865-872. - Statt Albanus erscheint auch die Namenform Albinus. Von dem Mainzer Heiligen, dessen Fest am 21. Juni gefeiert wird, und dem gleichnamigen Protomartyr Englands (22.Juni) ist der Held unserer Legende zu unterscheiden, wird allerdings auch mit dem ersteren verwechselt (KRAUS S. 198 Anm. 1).

2) In der von HAUPT aaO. herausgegebenen Fassung ist damit des Greuels nicht genug: dort begehen die Alten wieder einen Inzest und der Sohn lädt noch die Schuld des Elternmordes anf sich.

3) Überlange Verse in den mfrk. Dichtungen s. Annolied. 
Quelle ist die lateinische Vita oder Passio S. Albani des Transmundus, der zwischen 1170 und 1190 Kanzleibeamter des römischen Stuhles war. Das deutsche Gedicht ist wahrscheinlich nach 1186 entstanden. ${ }^{1}$ ) Seine Heimat ist, dem Dialekt zufolge, das moselfränk. Gebiet. ${ }^{2}$ )

Die Inzestsage war in verschiedenen Fassungen verbreitet. Als Gregoriuslegende ist sie zu großer literarischer Bedeutung gelangt. ${ }^{3}$ )

\section{$\S 47$. Pilatus.}

Kelle 2, 199. 381; PIPER, GD. 2, 21-26. - Ausg.: Mone, Anz. f. K. d. d. Vorz. 4 (1835), 434-446; Massmann, D. Ged. S. 145-152 u. Vorw. S. VlI f.; WeInHOLD, ZfdPh. 8, 253-288; MüllenhofF, Ad. Sprachpr. 3. Aufl. (1878), 101-107. - SCherer, QF. 12, 123; SPRenger, ZfdPh. 7, $3 € 8$ (Textkrit.); SteinMeyer, Münch. Mus. 3, 155 ff.; WOLFSKEHL und v. D. LeyeN S. $130-141.222$.

Hs.: Straßb.-Molsh. Hs. (s. oben S. 17) Bl. 29a-30c. Das Bruchstück beginnt mit dem Anfang des Gedichtes und enthält nur einen kleinen Teil der ganzen Legende.

Orthographie der Hs.: normal-mhd. mit md. Färbung. Der Dialekt des Gedichtes ist hessisch. Abfassungszeit zwischen 1170 und 1180.

! nhalt der Pilatuslegende. Der König Tyrus van Mainz nahm, da er auf der Jagd übernachtete, eine Magd namens Pyla zu sich, die Tochter des Müllers Atus. Des Tyrus und der Pyla Sohn ist Pilatus, so genannt nach seiner Mutter Pyla und seinem Großvater Atus. Am Hofe seines Vaters erzogen, tötet er seinen Stiefbruder. Er wirá nach Rom geschickt zu Julius Cäsar, wird aber, da er einen Königssohn erschlagen, zur Strafe nach Pontus geschickt (daher Pontius Pilatus, der pontische Pilatus). Herodes beruft ihn nach Judäa. Der Kaiser von Rom, der von einer schweren Krankheit befallen ist, sendet einen Boten an Pilatus, daß er ihm Christus zur Heilung schicke. Aber der Herr lebt nicht mehr, dagegen bringt Veronica das Schweißtuch dem Kaiser, der dadurch Genesung findet. Pilatus wird zum Tode verurteilt, er bringt sich aber vor der Hinrichtung selbst um. Sein Leichnam wird in den Tiber geworfen, dort àber veranlaßt er Sturm und Ungewitter. Dann wird er nach Vienne gebracht und endlich in einen See hoch in den Alpen versenkt (lokalisiert an dem Berg Pilatus).

Das deutsche Gedicht beginnt mit einer längeren Einleitung (Weinhold 1-176) allgemeinen Inhalts: a) über Sprache und Dichtkunst: die Schwierigkeit der Behandlung der deutschen Sprache $(1-18)$, der von Gott zum Dichten verliehene Sinn $(19-65)$; b) religiöser Übergang zum Hauptteil: Preis der Gottesmutter (66-142), von ihrem Sohn, von seinem Tod und von dem, der ihm den Tod veranlaßte, Pilatus (143-176). Die Geschichte des Pilatus bricht da $a b$, wo Herodes ihn nach Palästina kommen läßt.

Die Sage von Pilatus ${ }^{4}$ ) war im Mittelalter in sehr vielen Fassungen verbreitet, als selbständige Legende oder eingeschaltet in geistliche Werke, die

1) KRAus S. $200-209$

2) Kraus S. $209 \mathrm{f}$.

3) Siehe LG. II, 2. Abt.

4) Ueber die Pilatussage (und zugleich uber die Veronicalegende) handeln: W. GRIMM, Die Sage vom Ursprung der Christusbilder, Abh. d. Akad. d. Wissensch. zu Berlin 1842, 121-175 u. K1. Schr. 3, 138-199; MassMANn, Kchr. 3, 594-621. DU MÉrIL, Poésies populaires du moyen âge, Paris 1847, S. $315-$
368; W. Creizenacil, Legenden und Sagen von Pilatus, Beitr. 1, 89-107, dazt1 HEINZEL, ZföG. 25 (1874), 163 1. Kí. Scirr. S. 275 f., SCHÖNBACl, Anz. 2, 149-212 (die einzelnen Fassungen s. bei SchönBACI! S. $167 \mathrm{ff}$.); Borinski, Anz. 15, 222 f.; S7rauch, Enikels Weltchron. S. 379; ALFR. HiEINkICII, Johannes Rothes Passion, Germ. Ablı. 26. H.S. 59-100; Steinmeyer aaO. 
ihrem Stoff nach auch von Pilatus handeln mußten, lat. in Versen und in Prosa, altengl., altfranz., häufig in mhd. Denkmälern (auch niederrh. und mnd.), meist in Verbindung mit der Veronicalegende. - Die Quelle des deutschen Dichters war, wie er selbst angibt, lateinisch (177).

Inhalt und Darstellung tragen die Art eines Rittergedichtes, religiöse Empfindung spricht, soweit unser Bruchstück reicht, nirgends mit. Aber die Auffassung des Stoffes ist noch nicht höfisch, Pilatus ist der gewalttätige, streberhafte Egoist, an dem der Fluch haftet, überall, mit oder ohne Willen, Böses zu stiften. Schon als Knäblein ist er unbändig: er wächst also im Gegensatz zur höfischen zuht heran. Sein Charakter wird indirekt durch seine Taten geschildert und die ganze Persönlichkeit ist gut herausgearbeitet, wie denn der Dichter anschaulich und lebensvoll zu erzăhlen weiß. Der Stil1) ist im Grunde einfach, der Satzbau überwiegend parataktisch; die dann und wann begegnenden Inversionen verleihen ihm einen natürlichen Ausdruck. Und doch ist er rhetorisch gefärbt, die häufigen Tautologien, Synonyma und $\cdot$ zweigliedrigen Formeln sind beabsichtigte Sprachmittel. Vor allem aber ist die Einleitung $(1-176)$ ein stilistisches Kunstwerk, denn sie ist in der geblümten Rede abgefaßt und zwar ist sie wohl das erste Beispiel für diese in der mhd. Literatur. ${ }^{2}$ ) Solche Blümungen sind z. B. $11-13.19-30.36 .54 .57$ f. $72-79.136 \mathrm{f}$; seltene Reimwörter 5. 7. 9. 75. 77. Der ganze Ton ist hier manieriert. Auch im übrigen Text kommen manchmal seltenere Worte und seltenere Bindungen vor.

Das Gedicht steht also stilistisch am Eingang der höfischen Kunst. Und ebenso metrisch, denn die $\operatorname{Reime}^{3}$ ) sind rein und Assonanzen sind ausgeschlossen, die Verse sind, wenn auch nicht gewandt, so doch nach dem Prinzịp der vierhebigen Reimpaare gebildet.

$\$ 48$. Die heilige Margarete.

Kelle 2, 199. 382; PIPER, GD. 2, 18-21, Nachtr. S. 334-346, Höf. Ep. 3, 724; VoGt, Beitr. 1, 263-287.

Die Margaretenlegende ist uns in verschiedenen Fassungen erhalten, die alle nicht mehr dem Frühmhd. angehören, zum Teil aber doch ein älteres deutsches Gedicht aus dem Ende dieses Zeitraums voraussetzen.

Der Inhalt ist typisch für Frauenlegenden. Die Heilige hat heidnische Eltern, aber sie ist im Herzen Christin. Sie soll einen heidnischen Großen zum Herrn nehmen, aber sie hat sich Gott ergeben. Darauf die Ausmalung der Martern, die sie glaubensfreudig und sieghaft über sich ergehen läßt; ihr Tod; dazwischen auch oft die Bändigung des

2) WEINHOLD S. $270 \mathrm{f}$.

2) Die geblümte Rede ist die mit "Redeblumen ", flores rhetoricales, versehene Stilmanier, eine hyperpoetische Schmückung durch gesuchte und geschraubte Ausdrücke und Bilder und durch seltene Reimwörter, s. Ehrismann, Beitr. 22, 313 ff., ZfdPh. 33,
395 ff. u. 42, 490, Germ.-roman. Monatsschr. 1, 664 ff., Stud. über Rudolf v. Ems S. 57-78; OTTO MORDHORST, Egen von Bamberg und "die geblümte rede“, Berliner Beitr. zur germ. u. rom. Philol. Nr. 43, SINGER, Wolframs Stil, Wiener SB. 180 (1916), 4. Abhandl. S. 6 ff.

3) SCHRÖDER, Gött. Nachr. 1918, 427. 
Teufels. - Margarete ist eine der am meisten gefeierten Heiligen $\left.;^{1}\right)$ sie findet besonders Verehrung als Helferin in gesegneten Umständen.

Sante Margareten Marter. ${ }^{2}$ ) Hss.: Universitätsbibl. zu Prag XVl. G. 19, ${ }^{0}$, 15. Jh.; Stiftsbibl. zu Klosterneuburg, 15. Jh. ${ }^{3}$ ) Der Eingang, 1-60 der Prager Hs. bei BARTSCH, fehlt, ebenso der Schluß von 621 an. Der Dialekt der Hss. und des Gedichts ist österreichisch.

Das Gedicht ist in der uns erhaltenen Gestalt eine starke Umarbeitung einer Vorlage, die noch zum Teil in Assonanzen, etwa um 1160 oder 1170, verfaßt worden sein mag. Darauf können einige altertümliche, unreine Reime hinweisen.4) Der Bau der Verse wechselt, erreicht jedoch nicht Überlänge. ${ }^{5}$ )

$\$ 49$. Die heilige Juliane (Priester Arnolds Juliane).

Kelle 2, 173. 366 f.; PIPER, GD. 2, 80 f., Nachtr. S. 277. - Ausg.: Schönbach, Wiener SB. 101 (1882), 445-536, dazu SChröDER, DLZ. 1883, 555-557; BARTSCH, Germ. 28, 257-267; SPRENGER, Germ. 30, 75-78.

Hs.: Universitätsbibl. zu Graz 39/59, $8^{\circ}$, dieselbe, welche Heinrichs Litanei und die Gebete einer Frau enthält (s. unten; ZfdA. 18, 82 ff.); das Gedicht ist auf Bl. 26a-65a von einer Frauenhand im 14. Jh. eingetragen. Die Orthographie ist unsicher, der Text sehr verderbt.

Der Dialekt der Hs. und des Gedichtes ist bairisch-österreich. Entstanden ist es in der 1. Hälfte des 12. Jhs.

Der Verfasser nennt sich V. 5: ez was ein êwart, Arnolt was er genant, also ein Priester Arnolt. Ob er der gleiche ist wie der Dichter der Siebenzahl (s. o. 70 ff.) ist wahrscheinlich, kann jedoch nicht mit völliger Sicherheit behauptet werden..$\left.^{6}\right)$

Inhalt (Schema wie in der heiligen Margarete). I. 1-12 Einleitung. II. 13-185 Julianas Leben als Christin. III. 186-225 Marter. IV. 226-509 Sie bindet den Teufel, der sie im Kerker zur Weltlust verführen will. V. 511 -628 Weitere Martern und Enthauptung. Aulesius ertrinkt im Meer.

1) Ueber die Verbreitung der Legende s. VoGT aaO.

2) BARTSCH, Germ. 4, 440-471. 7, 268-270.

3). J. M. WAGNER, Germ. 6, 376-379.

4) BARTSCH S. 460 ff. Unreine Reime läßt die Volksdichtung immer zu. Das Ohr und der Sprachsinn empfinden es dabei nicht, wenn der Gleichklang nicht vollkommen ist, zumal bei den Liedern, die gesungen werden. Diese unreinen Reime (jïngerer Assonanzentypus) in den Dichtungen nach der Zeit, in der die Assonanzen stilgemäß waren, also nach dem Ausgang des 12. Jhs., unterscheiden sich von jenen älteren der frübmhd. Zeit besonders dadurch, daß volle Endsilbenvokale im Reime nicht mehr vorkommen (doclı -ott, part. präs. -unde, sind noch lange zu treffen). Meist besteht die Unreinheit dann in der Verschiedenheit der Konsonanten bei Gleichheit des reimtragenden Vokals, z. B. haben: tragen, binden : singen, kam : an, mal: jâr; überschüssige Konsonanten, bes. $n$ : geben:lebe, witzen:Criste, immer : singe, wange: ander; $i: u: k i n d e:$ sunde, $i: i u: z i t e n$ : bediutèn. Aus diesem Grunde kann z. B. die von SCHÖNBACH, Zs. 17, 85-141, hgb. Cliristophoruslegende wegen der Masse von konsonantischen Assonanzen gegenüber ver- schwindend wenigen vokalischen nicht auf ein Original des 12. Jhs. zurückgehen.

5) Auch mehrere der anderen Fassungen der Margaretenlegende haben verstreut unreine Reime, aber keine solche, die für eine Herkunft aus dem 12. Jh. sicher beweisen (einige altertümliche Assonanzen finden sich in Sand Margreten piiechlein, Haupt, ZfdA. 1, 152-193). Immerhin ist es möglich, daß es i m 12. Jh. ein oder mehrere deutsche Margaretengedichte gab, die noch lange auf die Behandlung der Legende nachwirkten. Sente Margareten Passie (Schade, Geist!. Ged. S. 71-99) hat mit der von BARTSCH herausgegebenen Sante Margareten Marter die V. $61-80$ (= Eingang der Passie 1-20) gemein, mit Weglassung der unrein gereimten V. $71 \mathrm{f}$. (BARTSCH) und Ersetzung derselben durch rein gereimte $19 f$. Der Eingang, $B$ ARTSCH $1-60$, fehlt auch hier wic in der Kklosterneuburger $\mathrm{Hs}$. $\mathrm{Zu}$ den verschiedenen Fassungen $s$. VOGT aaO.

6) SchÖNBACH aaO. sucht die Identität nachzuweisen, doch haben die Reime in der Siebenzahl ein reineres Gepräge, s. POLZERVAN Kol, Priester Arnolds Ged. von der Siebcuzalil S. XI. 
Quelle ist eine lateinische Julianalegende, die uns in der genau entsprechenden Gestalt nicht vorliegt. Der Stil ist nicht ungewandt, Hypotaxe ist dem Verfasser ganz geläufig. Der Sprachgebrauch ist der stereotype der geistlichen Dichtung der Zeit; daher viele Parallelen mit andern Werken $\mathrm{zu}$ finden sind. ${ }^{1}$ ) Die Verse sind ungleich lang (ungleicher Typus). Etwa ein Sechstel der Reime sind unrein. ${ }^{2}$ ) Mehrmals kommen Dreireime vor. ${ }^{3}$ ) Über die Legende von der Veronica vom Wilden Mann s. oben S. 128 f.

\section{Jenseitsvisionen. ${ }^{4}$ )}

Während die zahlreichen Darstellungen von Himmel und Hölle das Leben der Seligen und der Verworfenen nur in allgemeinen Zügen geben, schildern die Jenseitsvisionen die Freuden und Peinen der einzelnen Seele, und zwar in dem Rahmen einer Fahrt, die ein Sterblicher in die beiden Welten macht. Die ältesten dieser phantasievollen, in die Tiefen der Qual und die Höhen der Wonnen dringenden Zukunftsausmalungen sind geknüpft an die Namen von Aposteln, die erste und zugleich wohl das Muster für die folgenden ist die griechische Petrusapokalypse aus der ersten Hälfte des 2. Jhs. n. Chr.; später, erst am Ende des 4. Jhs., entstand, von ihr beeinflußt, die ebenfalls ursprünglich griechische Paulusapokalypse, die für die abendländischen Literaturen weitgreifende Bedeutung erlangte: sie wurde ins Syr., Lat., Altfranz., Mittelengl. und Mhd. übertragen. Im 12. Jh. ent-

1) SсHÖNBACH S. 75-94.

2) In der Siebenzahl nicht ganz ein Zehntel.

3) SCHÖNBACH S. 456; BARTSCH aaO. -

Das Gedicht von der Sieberizahl kennt keine Dreireime.

4) Die christliche Auffassung von dem Wesen und den Arten der Visionen hat Augustinus festgesetzt im 12. Buch von De Genesi ad Litteram. Zwei ältere m.alterl. lat. Jenseitsvisionen finden sich in Gregors Dialogen IV Kap. 36 und in Bedas Kirchengesch. V, 12. Die wichtigste ist die Visio Wettini von Walhfrid Strabo, WatTEnBaCH, GQ. unter Walahfr., andere Visionen s. ebda im Register Bd. 2; EBERT 2, 148 ff.; MANITIUS 1, 308 f. - Lit.: Realencyklop. 6, 568 ff.; WETZER u. Welte 1,917 ff.; BERNHEIM, M.alterl. Zeitanschauungen S. 63 ff.; KAMPERS, Alexander d. Gr. u. die Idee des Weltimperiums; R. KNOPF, Die Zukunftshoffnungen des Urchristentums, Religionsgesch. Volksbücher 1. Reihe 13. Heft; VOSSLER, Dante II, 1,743 ff.; G. v. Zezschwitz, Das m.alterl. Drama vom Ende des röm. Kaisertums, Leipz. (1877); C. FRITZSCHE, Die lat. Visionen des MA.s bis zur Mitte des 12. Jhs., Roman. Forsch. 2, 247-279. 3, 337-369; EMIL PeTERS, ebda 8, 361-364; G. NECKEL, Studien zu den germ. Dichtungen vom Weltuntergang, Heidelberger SB. 1918, 7. Abh.; G. GRAU, Quellen usw. des jüngsten Gerichtes; SсHÖNBACH, Ueb. Hartmann v. Ane S. 149 ff.; VoGT, Ueb. Sibyllen Weis- sagung, Beitr. 4, 48-100; REUSCHEL, Weltgerichtsdichtungen; CAROLINE MICHAELIS, Quindecim signa ante judicium, Arch. 46 (1870), 33-60; G. NöLlE, Die Legende von den 15 Zeichen vor dem jüngsten Gerichte, Beitr. 6, 413-476 (vgl. ZwierzINA, Anz. 23, 200); Elisabeth Peters, Quellen der Paradiesesvorstellungen usw.; FRIEDR. RANKE, Der Erlöser in der Wiege, München 1911; WILHELM, Thomaslegenden S. $40^{*}-42^{*}$; GEORG Voss, Das jüngste Gericht in der bildenden Kunst des früheren MA.s, Leipz. Diss. 1884; KARL W. Chr. SChmidT, Die Darstellung von Christi Höllenfahrt in den deutschen und den ihnen verwandten Spielen des MA.s, Marburger Diss. 1915; BuRDaCH, Ackermann S. 316 f.; Poeschel, Das Märchen vom Schlaraffenland, Beitr. 5, 389 ff.; ERICH SCHMIDT, Charakteristiken 22, 53-73; BoLTE-PoLf́VKA Nr. 158, Bd. 3, 244-258; WAGNER, Visio Tnugdali S. VI f.; LANGGUTH, Ava passim, bes. S. 130-133. - Visionen der frühmhd. Lit. sind die Visio S. Pauli, Visio Tundali, ein Abschnitt in der Patriciuslegende, dazu die kurze Erwähnung der Jenseitsfahrt des irischen Königs Echu in der Patric.-Leg.; s. ferner El. PETERS aaO.; die Hölle auch bei H. v. Melk (Heinzel S. 43.48 f. 126 f.), im Muinch.Oswald 2958-3021, Wien.Osw.1272-1309; vgl. Visio Fulberti, Du MÉRIL, Poés. pop. ant. bes. S. $217 \mathrm{ff}$. 
standen dann in Irland die phantastischen Jenseitsbilder des Purgatorium S. Patricii und der Visio Tundali, die Vollendung zur Erhabenheit eines Weltgedichts aber fand der Stoff von den Fahrten ins Jenseits in Dantes Göttlicher Komödie.

Die Darstellung der Zustände im Jenseits enthält schon in sich einen ethischen Sinn, eine Bestimmung des irdischen Lebens, eine Aufmunterung oder eine Warnung, und zwar den Grundgedanken der christlichen Moral: lebe so, daß du der Hölle mit ihren Schrecknissen entgehst und die Herrlichkeit des Himmelreichs erwirbst. Dieses Ziel wird erreicht durch die Buße. So stehen diese Dichtungen in Zusammenhang mit der Beichte. Diese Verbindung ist auch unmittelbar $z u$ sehen an der Verwandtschaft des Gedichtes "Himmel und Hölle" mit den Bamberger und Wessobrunner Beichtformularen, und die Paulusvision schließt mit der Bekehrung und der Erlangung des Himmelreichs. Dieser Zweck ist schon in der Visio Pauli ausgesprochen: Et in illa anime peccatorum puniuntur, qui non egerunt penitenciam post peccata commissa in hoc mundo. ${ }^{1}$ ) Dieselbe religiöse Lehre ist auch in der Visio Tundali und im Purgatorium S. Patricii niedergelegt. ${ }^{2}$ )

\$50. Visio S. Pauli") (von der Zukunft nach dem Tode und S. Paulus).4)

Kelle 2, 193 f. 379; PIPer, GD. 2, 11 f., Nachtr. S. 267. - Ausg.: Karajan, DSpr. S. IX u. 107-112; Kraus, D. Ged. S. 35-41. 182-197 u. Anz. 23, 114.1. - Scherer, QF. 7, 22-27, dazu Rödiger, Anz. 1, 71; Herm. Brandes, Visio S. Pauli, Engl. Stud. 7, 34-65; Ders., Visio S. Pauli, Halle 1885, bes. S. 42 ff.; Eus. Peters S. 108 ff.; Handb. der klass. Altertumswissensch., Griech. Lit. 2, 2. Aufl. 1913, S. 1016 ff.

Hs.: 2 Pergamentbl. vom Ende des 13. Jhs., einst im Besitz von Karajan, dann verschollen, jetzt in Wien Nr. 19813. Der Text ist ziemlich fehlerhaft.

Die Hs. hat md. und bair. Dialektformen, die Reime sprechen für ind. Heimat des Gedichtes, die bair. Formen stammen von einem bair. Schreiber her. Zeit: um 1150.

Inhalt: A.Vonder Zukunft nach dem Tode: Der Anfang des Gedichtes fehlt. 1, 1-63 Die Seele der Bösen wird vom Teufel empfangen, Schilderung der Hölle und Qual der Seele. Der Engel der Bräutigam, der die Braut, die Seele in sein Haus führt (s. unten Hochzeit). - B. S. Paulus. Zwischen A und B ist eine größere Litcke. Das Fragment B cnthält Stücke aus dem Fegfeuer. I. 1-12. Der Engel führt Paulus. Die 4 Flüsse des Paradieses. II. 13-80 Die unfruchtbareı Bäume am Tor der Burg. 111. 81-89 Der Honigfluß. Hier briclit das Fragment ab.

Der Ursprung der Paulusvision liegt in den Worten des Apostels von seiner Entzückung bis in den dritten Himmel 2. Kor. 12,2-4. Quelle des deutschen .Gedichtes ist eine lat. Fassung der Visio S. Pauli. ${ }^{5}$ )

1) BRANDES S. 75, 14 f.

2) Andere Tendenzen, die erbauliche und die politische (ELIS. PETERS bes. S. $112 \mathrm{f}$.), kommen für die deutschen Visionen nicht in Betracht.

3) Die Gedichte ïber die Bekehrung des Paulus, der Rheinauer Paulus und die Conversio S. Pault, s. unten.

4) KarAJAN faßte sie riclitig als cin GeDeutsche Literaturgeschichte. II. diclit (S. Paulus), MÜlleniofF und Scherer (s. QF. 7, 22) nalimen zwci gesonderte Gedichte an, KRAUS hat ilire Einlieit Wahrscheinlich gemacht. Oben ist in Titel die Trennung beibehalten, weil bis auf die Untersuclungen vou KRAUS MULLENHOFFs und ScHERERS Scheidung ziemlich allgemein ancrkannt war.

$\left.{ }^{5}\right)$ Ueber die Vis. Lazari und ilır Verhalt- 
Stil. Die Sprache ist in der "Zukunft", wie in allen Schilderungen von Himmel und Hölle, dramatisch bewegt, in der Vision des Apostels einfach erzählend. In jenem Teile sind lat. Sätze eingestreut. ${ }^{\text {) }}$ Die Verse bewegen sich im Mittelmaß. In den Reimen finden sich einige stärkere vokalische Assonanzen, mehr in dem $z$ weiten als in dem ersten Teil.

\section{$\$ 51$. Patricius.}

Kelle 2, 195 f. 379 f.; Piper, GD. 2, 13. - Ausg.: Keinz und Bartsch, Germ. 31, 66-74; Kraus, D. Ged. S. 30-35. 157-182; R. Verdeyen en J. Endepols, Tondalus' visioen en St. Patricius' vagevuur I, s'Gravenhage 1914; H. J. E. Endepols, Patrlcius. Die Hijstorie van Sunte Patricius Vegevuer. Naar en Berlijnsch Hs. uitgeg., Groningen 1919. Ders., Museum XXVII (1921), Nr. 7.

Hs.: München Cgm. 5249 Nr. 38, Perg., Anf. 13. Jhs., 8 z. Teil sehr kleine Ausschnitte.

Der Dialekt des Gedichtes ist alemann., Abfassungszeit: um 1160. Patricius ist der berühmte Apostel Irlands (S. Patrick), gestorben 464, sein Festtag ist der 17. März. Quelle ist eine lat., in Irland entstandene Vita des Heiligen.

In unser Bruchstück fallen einige.seiner Wundertaten. Die erste Geschichte ist die Erweckung des toten Königs Echu, der dem Heiligen berichtet, was er von dem Glücke der Seligen und von den Strafen der Gottlosen gesehen. ${ }^{2}$ ) Das bekannteste Stück der Legende, S. Patricii Fegefeuer, $\left.{ }^{3}\right)$ Purgatorium S. Patricii, die Erzählung der Reinigung eines adeligen Wüstlings im Fegefeuer, ist in dem Bruchstück nicht enthalten. - Die lat. Quelle ist durch belebende Züge erweitert. Über die Reimkunst und Rhythmik des Gedichtes läßt sich bei dem übeln Zustand der Bruchstücke nichts Bestimmtes sagen.

\section{$\$ 52$. Die Vision des Tundalus.}

Kelle 2, 194 f. 379; PiPER, GD. 2, 6-11, Höf. Ep. S. 724. - Ausg. des mfrk. Tundalus: LaChMANN, Über drei Bruchstücke S. 159-190 u. Kl. Schr. S. 519-547 (Berl. Bruchstücke); Fr. Grimme, Beitr. 13, 340-358 (Grimmes Bruchstücke); Kraus, D. Ged. Nr. XI, S. 46-62. 217-246 (krit. Herstellung unter Benutzung von den Berliner und Grimmes Bruchstücken). - Ausg. von Albers Tnugdalus: HaHN, Ged. S. 41-66; beide zusammen, der mfrk. Tundalus und Albers Tnugdalus, hgb. von ALBR WAGNER, Visio Tnugdali, lat. und altdeutsch, Erlangen 1882, dazu ERNȘT VolGt, Anz. 8, 350-368. - MÜllenhofF, ZfdA. 13, 575; HAupt, ebda 15, 2.58 f. (Textverbesserungen); SpRenger, Albers Tundalus, Diss. Halle 1875; Ders. Germ. 22, 264-272, Alber v. Regensburg und die Eneide ebda 27, 287 f., Konjekturen ebda 35, 404-406. 37, 414; Scherer, QF. 12, 94 f., D. Stud. 1, 14; SCHröDER, ZfdA 52, 190-192 (Lesarten und Kritik); Euss. Peters S. 108 ff.; Verdeyen en ENDEPOlS s. oben \$51.

Es gibt zwei mhd. Tundalusdichtungen:

1. Der mittelfränkische (Lachmann: niederrheinische) Tundalus.

Hs., Bruchstücke: 1. Berlin Ms. germ. quart 642, Doppelpergbl., 13. Jh., V. 1-175 (KRAUs), früher in Meusebachs Bibliothek; 2. drei Doppelpergbl. in Grimmes Besitz, gehörten zur

nis zur Vis. Pauli s. MAX VoIgT, DLZ. 1920, 316. - Zwei deutsche Prosafassungen der Vis. Pauli des 15. Jhs. bei Brandes S. 4245. $81-88$.

i) GRÜnewald S. 27. - Zukunft 63, aus Ps. 33, 22, stelit auch im Rolandsl. 7700;
$64=1$ der Milst. Sündenkl.

$\left.{ }^{2}\right)$ Das war also eine Jenseitsvision; vgl. BAEsecke, Münch. Oswald S. 368.

3) Vgl. KöPKE, Passional (s. LG. II, 2. Abt.) S. $234,75-240,96$. 
gleichen Hs. wie die Bruchstücke 1 und beginnen da, wo diese aufhören. Die Überlieferung ist nicht gut. Erhalten sind die Verse 1-508, der Gesamtumfang belief sich wohl auf etwas über 2000 Verse.

Der Dialekt des Schreibers ist hessisch (Nassau), der des Gedichtes mittelfrk. ${ }^{1}$ ) Zeit der Abfassung um 1180-1190. Der Name des Verfassers kommt in den Bruchstücken nicht vor. Er war jedenfalls ein Geistlicher. Seiner lat. Vorlage (Visio Tnugdali) gegenüber verhält er sich ganz unselbständig, er folgt ihr genau; nur von Zeit zu Zeit hat er einen überflüssigen Vers eingeschoben, um einen Reim zu gewinnen. Lat. Zitate sind häufig. ${ }^{2}$ ) Die Verse erstrecken sich oft über das normale Maß hinaus, unreine Reime sind selten.

2. Albers Tnugdalus.

Hs.: Wien Nr. 2696 (s. oben S. 17); Hoffmanns Verzeichn. S. 27-30.

Die Sprache des Gedichtes ist bairisch. ${ }^{3}$ ) Der Verfasser macht Angaben über sich und sein Werk: In der Einleitung $(22-74)$ wird berichtet: ein irischer Ritter hatte die Vision im Jahr 1149 (richtiger 1148) (22-43); ein Mönch hörte sie aus dessen eigenem Munde erzählen und brachte dann den Bericht davon in das Nonnenkloster S. Paul in Regenburg, dort schrieb er die Geschichte (lateinisch) nieder (44-62), veranlaßt durch drei Frauen (Klosterfrauen) Otegebe, Heilka und Gîsel (67-74), er, der Verfasser (Alber), hat sie verdeutscht (63-66). Am Schluß nennt er seinen Namen, Alber, 2185, er war Priester 2184, Veranlasser zu seinem Werke war bruoder Kuonrât ze Winneberge $2150 \mathrm{f}$., das ist das Prämonstratenserkloster Windberg zwischen Regensburg und Straubing.4) Dort war also Alber Mönch, Konrad war wohl ebenfalls Mönch, vielleicht derselbe, der 1191 Abt wurde. ${ }^{5}$ ) Ähñliche Mitteilungen über die Quelle enthält der Prolog der lat. Visio, hier erfahren wir auch den Namen des Mönches, Marcus, sicherlich ${ }^{6}$ ) eines Iren, der das Mysterium aus barbarischer Sprache (d. i. aus dem Irischen) ins Lateinische übertrug (Wagner S. 4, 5-7); als Auftraggeberin wird jedoch nur eine Äbtissin G. (Gisela, Äbtissin von S. Paul) genannt (S. 3, 1 f.). ${ }^{7}$ )

Die lat. Visio Tntigdali (Tundali), Prosa, ${ }^{8}$ ) vom Frater Marcus $11 m 1150$

1) Kraus S. $217-220$.

2) GRÜNEWALD S. 28.

3) Sprenger, Diss. S. 5-32; Scherer, D. Stud. 1, 14; Zwierzina, ZfdA. 44, 111. 45, 73. $407 \mathrm{f}$.

4) Windberger Psalmen, s. LG. II, 2. Abt.

b) Sprenger aaO. S. 52-57; Wagner S. XLVII ff.; Steinmeyer, Allg. d. Biogr. 1, 219; SCHRÖDER, ZfdA. 50, $391 \mathrm{f}$.

$\left.{ }^{6}\right)$ Von der Mitte des 11. bis ins 13. Jlı. war der Verkehr.zwischen irischen Mönchen und deutsclıen Klöstern wieder besonders rege. Im Jahr 1076 wurde in Regensburg das spătere S. Jakobskloster gegrïndet und von hier aus entstanden noch verschiedene andere Klöster, in Wiirzburg, Niirnberg, Eichstätt, Wien und dann weiter in Scliwaben und
Mitteldeutschland. Sic wurden "Schottenklöster" genannt, die Mönchic "Schottenmönche", von Scotus, das den Schotten und den nahverwandien Iren bezeichnet; H. ZIMMER, Preuß. Jahrb. 59, Jan. bis Juni 1887 , $27-59$, bes. S. 49 .

7) SCHRödER aAO.

8) SCHADE, VisioTnugdali, Königsberg 1869 ; WAGNer, Einl. S. IX-XXVIll u. $1-56$. Das lat. Gedicht, in 1601 Hexametern. ist abgeclruckt S. 57-110, dazı Einl. S. XXIXXXXIX; limil Peters, Die Vision des Tumgdalus, Progr. Bertin 1895, S. $10 \mathrm{ff}$ - Dic lat. Hss. Iraben die Namenform Tundatus, Tnuerdialus, Tungdalus oder anch noch ander Varianten. 
-1160 abgefaßt, ist in sehr vielen Hss, und auch in Drucken erhalten. Von ihrer großen Beliebtheit zeugt ihre Verbreitung: sie wurde in viele Volkssprachen übersetzt. ${ }^{\text {) }}$

Inhalt. I. Einleitung 1-178: Prolog mit Angabe der Quelle und det Veranlasserinnen derselben (1-74); Bericht über Irland und über Patricius (75-178). - II. Haupteil, Die Vision 179-2146: Person des der Weltlust ergebenen Ritters Tnugdalus, sein Scheintod, Wiedererwachen nach drei Tagen, er wird Mönch (179-342). Die Erlebnisse seiner vom Leib getrennten Seele a) in der Hölle (343-1444); b) im Himmel (1445-2130); c) Aufforderung zur Buße (2131-2146). - III. Schluß 2147-2192: Veranlasser und Verfasser des deutschen Gedichtes.

Vom Grauen in der Tiefe zur höchsten Wonne führen die Zukunftsbilder der Verdammten und der Seligen, vom Sündenreich der mit den. Hauptlastern Beladenen in die Hierarchie der Heiligen. Hier hatte die irische Phantastik einen geeigneten Stoff gefunden und die christlichen Jenseitsvorstellungen ließen sich leicht vereinigen mit den irischen Volksmärchen vom Totenreich. Im mhd. Roman von Lanzelot wird eine düstere Landschaft geschildert, der verworrene Tann, das Land ohne Wiederkehr: wer dahin gelangen will, muß gefahrvolle Proben bestehen; die Geschichte des Königs Cormac, die in der Visio Tundali erzählt wird, ist sehr ähnlich der vom Gralskönig Anfortas in Wolframs Parzival:2) so berühren sich die irischen Visionen mit den Artusepen, deren Grundbestandteile ebenfalls großenteils irisch-keltischen Ursprungs sind.

In- der Visio Tundali hat die Seelenreise ins Jenseits noch eine ganz besondere Tendenz erhalten: ein leichtsinniger Ritter ist es, der die furchtbaren Gesichte hat, und die Wanderung ins Höllenreich ist ihm als Strafe auferlegt, wie in der Patriciuslegende die Seele des Adeligen tatsächlich die Pein des Fegefeuers durchkostet. Hier ist also die Schilderung der nach dem Tode drohenden Schrecknisse als Bußmittel für die vornehmen Herren benutzt.

In der Behandlung des Stoffes verfährt Alber ziemlich selbständig, $\left.{ }^{3}\right)$ d. h. er überträgt frei, aber mit den üblichen Grundsätzen: er macht verdeutlichende Zusätze und wird dadurch ausführlicher, seltener läßt er Vorhandenes aus. Die starke, oft fürchterliche Phantasie seines Vordermannes sucht er zu mildern; er ist umständlicher und zahmer als jener; auch muß er sich oft mit Flickversen behelfen, um eine reimende Zeile zu gewinnen. Ist also das deutsche Gedicht eine Abschwächung gegenüber der lat. Quelle, so ist es doch auch in seiner einfacheren Sprache noch wirksam.4).

Die Verse ${ }^{5}$ ) sind normal gebaut. Assonanzen sind häufig, aber nicht schwer. ${ }^{6}$ )

\footnotetext{
1) V. D. HAGEN, Mus. f. ad. Lit. u. Kunst 1 , 561 f.; WAgner S. V-VII, Anglia 22, 452462; VoIGT S. 367.

2) Ehrismann, Beitr. 30, 19 f. 26.48 f.
}

3) WAGNER S. LI-LXXI.

4) Lat. Worte im Text s. GRÖNEwald S. 32.

5) SPREnger, Diss. S. $32-36$.

') Sie fallen unter den ,jüngeren Asso. 
Eine Bußfahrt an gefährliche Schreckensörter und bei gequälten Sündern ist auch das deutsche Gedicht von S. Brandans Seefahrt. Insofern ist es dem Ideenkreise des Tundalus verwandt, jedoch mit dem Unterschied, daß der Schauplatz nicht das Jenseits ist, sondern das Weltmeer. Zugleich aber entspricht der Stoff auch der Wanderlust der-Kreuzzugszeit, dem romantischen Zug nach der Ferne, nach fremden Menschen und Ländern. In dieser Hinsicht folgt es der gleichen Zeitströmung, welche die fabelhaften Orientfahrten Alexanders und des Herzogs Ernst zum Ausdruck bringen.

\section{$\S 53$. Sanct Brandan.}

PiPER, GD. 2, 13-18, Nachtr. S. 267, Höf. Ep. 3, 724. - Ausg.: CARL SchröDer, Sanct Brandan, Ein lat. und drei deutsche Texte, 'Erlangen 1871. - MoNE, Anz. f. K. d. t. Vorz. 1839, 255-258; KARL SCHRÖDER, Germ. 16, 60-74; H. SUChiER, Bölmmers Roman. Stud. 1, 559-563; G. SCHIRMER, Leipz. Habil.Schrift 1888; WilH. Meyer, Die Überlieferung der deutschen Brandanlegende I. Der Prosatext, Gött. Diss. 1918 (mit vollst. Literaturangabe S. 10-18), dazu Görze, LitBl. 1919, 82 f.; Elis. Peters S. 146 ff.

Hs.: Berlin Ms. Germ. Oct. 56, Perg., 14. Jh. Nach 607 ist eine größere Lücke.

Der Dialekt der Hs. ist ein temperiertes Mitteldeutsch, stark ausgeprägte lokale md. Formen begegnen nicht. Der Dialekt des Gedichtes ist ebenfalls md. ${ }^{1}$ ) Es ist erst im 13./14. Jh. abgefaßt, aber die deutsche Brandanlegende darf doch schon der frühmhd. Periode zugeteilt werden, weil dieses md. Gedicht auf ein älteres Original von ca. 1150 zurückgeht.

Inhalt. I. Einleitung, Prolog 1-16: Anrufung Gottes. II. Hauptteil 17-1924: Brandan liest ein Buch mit seltsamen Wundern, findet sie unglaublich und wirft es ins Feuer. Zur Strafe gebietet ihm Gott, daß er neun Jahr die Wunder des Meeres suchen solle (17-72). Er rüstet ein Schiff aus, fährt ab (73-138). Nun beginnt die Abentenerfahrt zu den Meereswundern: Drache (139-164). Fisch, auf dessen Rücken ein Wald wächst (165-226). Das Meerweib; die Insel der gepeinigten Unbarmherzigen (227-290). Lebermeer; Magnetberg; Kloster der von einer Taube aus dem Paradies gespeisten Mönche (291-355). Der auf einer Felsenklippe büßende König (356 -426). Der glühende Berg, die Pein der Sünder (427-454). Die finstere Insel mit dem goldenen Saal; einer seiner Mönche stiehlt darin einen Zaum (455-514). Insel der Seligen (515-556). Das finstere Land (557-616). Magnetberg; die Teufel streiten mit S. Michael um die Seelen der mit dem Tode Kämpfenden (617-660). Ein Siren singt sie in Schlaf; Brandan holt seine Kapuze, die ins Meer gefallen, unter Anfechtung vieler Teufel $(661-806)$. Burg mit zwölf Chören; Wunder der Meerestiefe (807-849). Der Mönch auf dem scliwimmenden Rasen (850-935). Judas auf dem glühenden Stein (936-1092). Das Land "multum bona terra“ (1093-1244). Die neutralen Engel, verwandelt in Menschen mit Schweinskopf, Kranichhals usw. (1245-1417). Ein schreckliclıcr Fisch hält sie gefangen (1418-1455). Sie werden aus der Festankerung von dem Zwerg Botewart befreit (1456-1630). Der getaufte Heidenkönig Johannes (16311694). Der kleine Mann auf dem Blatt im Meer (1695-1758). Der alte Richter in der prächtlgen Kleidung (1759-1814). Die Ruickkehr (1815-1924). - Ill. Schlußgebet (1925-1934).

In Irland waren im 7./8. Jh. Seefahrtsgeschichten, ${ }^{2}$ ) Imrama (Imram, das Umherrudern, die Seefahrt), sehr beliebt und gehörten zu den wichtigsten Vortragsstoffen der Erzälıler. Die Sagenbestandteile waren zum Teil irische

nanzen-Typus", s. oben S. 159 Anm. - ZWIERZINA, ZfdA. 45, 407 f.; SCHRÖDER, Gött. Naclır. 1918, 424.
1) Zur genaueren Bestimmung der Heimat des Gedichtes s. W. MEYER S. 122 f.

2) ZiMMER, ZfdA. 33, 144-220. 257-338. 
Schiffermärchen, denen wohl zuweilen wirkliche Erlebnisse irischer Seefahrer und Einsiedler zugrunde liegen mochten. Anderes entstammte der irischen Mythologie, dem Glauben an das Totenreich mit den Gefilden der Wonne und der Strafe, an die terra repromissionis, das Land der Verheißung. Vorbild und Veranlassung zur literarischen Gestaltung der Imrama war die Meerfahrt des Aeneas in Virgils Aeneis B. 3-5. Die angesehenste Seeabenteuerfahrt war die Seefahrt Maelduins, Imram Maelduin. Übertragen wurde die Sage auf den gefeierten irischen Heiligen S. Brendanus $(† 576$ oder 577, sein. Festtag ist der 16. Mai) schon im 9./10. Jh. So entstand im 11. Jh. eine irische Erzählung von Brendans Meerfahrt, der Imram Brenaind, die von dem Imram Maelduin ganz abweicht und überliefert ist in einer lat. Übersetzung des 11. Jhs., der Navigatio Sancti Brendani. $\left.{ }^{1}\right)$ Diese wurde die Quelle für die engl. und franz. und andere volkssprachliche Übersetzungen. Die wichtigsten deutschen Fassungen aber gehen auf eine daneben laufende, mehr weltlich gerichtete Brandanerzählung zurück. ${ }^{2}$ ) Die deutsche Quelle für die deutsche Brandanliteratur ist ein mittelfränk. (mfrk.) verlorenes Originalgedicht des 12. Jhs. (um 1150). Aus diesem sind unabhängig voneinander geflossen das mitteld. Gedicht (md., 13./14. Jh.) und das mittelniederländ. Gedicht ${ }^{3}$ ) (mnl., 13. Jh.), sowie die hd. Prosa ${ }^{4}$ ) (das Volksbuch, darin noch viele, meist unreine Reime enthalten sind, 14./15. Jh.; das mittelniederd. Gedicht ${ }^{5}$ ) aber (nd., 14. Jh.) geht vom md. Gedicht aus.

In der Navigatio S. Brendani fährt der Heilige aus, um die terra repromissionis zu suchen; die vielen Wunderdinge, die er sieht, sind andere als die in unserem Gedichte: am Ende gelangt er in der Tat zu dem ersehnten Land. In den Fassungen dagegen, denen unser Gedicht angehört, muß Brandan die Reise auf Gottes Befehl als Strafe für seinen mangelnden Glauben unternehmen, das Land der Verheißung ist nicht sein Ziel, vielmehr die Wiederkehr nach Hause, die ihm erst gelingt, nachdem er gesehen, daß die Wunder, die er bezweifelte, Wirklichkeit waren. Hier sind die Erscheinungen, die ohne Plan oder Steigerung aufeinander folgen, ungeheuerlich und fabulös, auch possenhaft; es ist eine gefahrenreiche und peinvolle Reise für den gestraften Gottesmann. In der Navigatio ist das Erlebte viel maßvoller, die Fahrt ist gleichsam ein fortgesetzter Gottesdienst; so liegt in dieser Auffassung eine viel größere Ruhe.

1) C. SCHRÖDER S. 1-36.

2) Deutsche Uebertragungen der lat. Navigatio sind die Uebersetzung des Münchener Arztes Dr. Johannes Hartlieb 1488; die Legende im niederd. Passional, zum erstenmal gedruckt in Lübeck 1488; aus dem obd. Basler Druck (1511) übersetzte sie Gabriel Rollenhagen in seinen Wunderbarlichen Reysen (1603). - Aus einer verlorenen deutschen Bearbeitung schöpfte der Verfasser des Wartburgkrieges seine verworrenen Kenntnisse. C. SCHRÖDER S. VII-X; W. MEYer S. 125 Anm. 2.
3) MARTIN,ZfdPh.1,162;i. SCHRÖDER,Germ. 16, 60-74; G. KALFF, Geschiedenis d. nederl. Letterk. 1, Groningen 1906, S. 54 f. u. 61 f. Das niederl. Gedicht ist ausführlicher als das mitteld. und weicht auch in Einzelheiten ab.

4) C. SCHRÖDER S. 161-196; W. MEYER S. 21-122; Reime in der Prosa: ebda S. 123125.

5) Abgedruckt bei PAUL JAK. BRUNS, Romant. u. andere Gedichte in altplattdeutscher Sprache, 1793 , S. $159-216$; und bei C. SCHRÖDER S. 125-160. Es ist kürzer als das md. Gedicht und weicht im Text stark ab. 
Mit den märchenhaften Meeresabenteuern ist der Reiseroman Brandans eine mittelalterliche Odyssee; und auch beide, der griechische Held und der christliche Mönch (in der Fassung der lat. Legende), schauen auf ihren Irrfahrten in der Ferne ein seliges Ziel, jener seine Heimat und sein langverlassenes Weib, dieser die Gefilde der Wonne. Ein Lied des Heimwehs ist im Grunde auch die mönchische Odyssee. - Der Stil ist nicht gewandt, in den Reimen sieht man oft die Not, die der Dichter mit der Sprache hat. Der Satzbau ist parataktisch, formelhaft ist die Sprache nicht. Die Reime haben mitteldeutsche Eigentümlichkeiten. Sie sind nicht sorgfältig, doch nicht assonierend. Die Verse sind normal gebaut, aber ohne rhythmisches Gefühl und mit den mitteldeutschen Freiheiten. ${ }^{1}$ )

\section{d) Die Heilsmittel.}

\section{Gebetliteratur. ${ }^{2}$ )}

a) Gebete.

Die Gebete sind die einfachsten Erzeugnisse innerhalb der volkstümlich geistlichen Literatur, unmittelbar kommt in ihnen der christliche Glaube so zur Geltung, wie ihn die Kirche das Volk lehrte, und dessen Stimmung ist: Unterdrückung des Lebensgefühls. Darum erkennt sich der Betende als ein Leidwesen, geplagt von Ängsten, umringt von Feinden und Gefahren, und es ist ihm versagt, sich mit eigener Kraft aus diesen Nöten zu retten. Hilfe kann nur durch die göttliche Gnade geschehen. Dazu hat die Kirche die Mittel, die Gnadenmittel, unter denen dem Laien am leichtesten das Gebet sich bietet. - Noch schwerer aber als die äußere quälte ihn die innere Drangsal, das Schuldgefühl. Der Mensch ist zerknirscht von dem Bewußtsein seiner Verworfenheit, verängstigt durch die Furcht vor dem Teufel, allein die Gnade kann ihn aus diesen Seelenpeinen erretten. Zwischen Sünde und Gnade schwankt das schuldbehaftete Gewissen. Aus dem Schuldgefühl sind diese Gebete hervorgegangen, eingegeben vom Erlösungsbedürfnis. So ist diese Literaturgattung ein Zeugnis für die mächtigste Strömung der Zeit, die Askese, und für deren politische Idee, die Herrschaft des Mönchtums.

Die Bitten, deren Erhörung erfleht wird, sind an Zahl und Inhalt und Umfang verschieden. Es können wenige sein oder auch recht viele, um geistige oder um materielle Güter. Hinsichtlich des Zwecks können die Bitten gerichtet sein entweder auf Verleihung eines Gutes oder auf Befreiung von einem Übel. Man bittet un Erhörung des Gebets, um Fürbitte, Gnade, Erbarmen, Trost, Hilfe, um Schutz gegen Feinde, gegen Verleumdung, ${ }^{3}$ ) um Erlösung von Sünden, von Ängsten und Nöten, von der Sünden-

1) SchröDER, Gött. Nachr. 1918, 408.

2) Texte und Kommentar mit Literaturangabe bei WiLHELM, Denkmäler deutsclier Prosa d. 11. u. 12. Jhs., Münch. Texte H. VIII (1914) und dazu Kommentar 2. Hälfte, H. 8
(1918). - Algemeines liber das christliclie Gebet: THALHOFER, Liturgik ${ }^{2}$ u. bes. FRIEDR. Heiler, Das Gebet, 2. Aufl. München 1920; B. BARDO, Deutsche Gebete, Freiburg 1918.

s) Diese Klagen stammen aus den P'salmen 
und Todesangst, von allem Übel, von Versuchung; um Hilfe gegen den Teufel, um ein gutes Ende, um Bestehen vor dem jüngsten Gericht, um Bereitschaft zum Himmelreich; ferner um Verleihung von Tugenden, von Frieden, um Stärkung des Herzens und Sinnes zur Aufnahme Gottes.

Notwendige Eigenschaften eines Bittgebets sind 1. Anrufung und 2. Bitte; in den christlichen Gebeten tritt aber häufig, in den hier zu besprechenden gewöhnlich, noch ein 3. Bestandteil hinzu, die Begründung; manchmal wird auch eine Empfehlung eingeflochten.

Angerufen werden Gott der Vater, der Sohn, der heilige Geist, die gesamte Trinität, die Fürbitter: Maria, die Engel, die Heiligen. Mit der Anrede können Eigenschaften und Handlungen des Angerufenen verbunden sein, welche dann schon zugleich an sich eine Begründung enthalten. Bei den angerufenen Personen werden Gründe aufgeführt, weshalb der Betende auf Erhörung hofft, er beruft sich auf ihre Eigenschaften, Taten, Erlebnisse, ihre Verdienste (merita), oder er erinnert, ermahnt sie daran (Berufung, Erinnerung, Ermahnung), führt sie als Beispiele auf.

Als Formeln der Bitte werden verwendet: (ich bite dich) durch oder $b \hat{\imath}$, hilf mir durch, ich mane dich, gedenke, gehuge, selten ich lobe dich; bei Beispielen alsô-alsô, z. B. so wie du Daniel aus der Löwengrube erlöstest, so löse mich ...

Die Empfehlung wird eingeleitet durch die Formel ich bevilhe mich, mînen lîp, mîne sêle etc. dir, an (in) dîne gnâde etc.

Mit dem Grundplan der drei Bestandteile treten die Gebete in enge Beziehung zu den Beichtformeln, auch dort Anrufung Gottes und heiliger Fürbitter und Bitte um Nachlassung der Sünden.

Ganz erfüllt ist das Gemüt des Betenden von seinem persönlichen Leidenszustand, deshalb enthalten diese Stücke fast durchweg nur Bitten, es sind Bittgebete. ${ }^{1}$ ) Nur zuweilen vorübergehend wird eine Lob-oder Dankesäußerung an die angerufene Person eingeflochten oder es wird als Preisgesang ein lateinischer Psalm empfohlen.

Die Bedeutung, die in der christlichen Kirche dem Symbol zukommt, zeigt sich auch in diesen Gebeten: die Gedanken und Worte sind begleitet

(angustiae, tribulationes der inimici), bes. aus den 7 Bußpsalmen (Ps. 6. 31. 37. 50. 101. 129. 142), die in den liturgischen Tagzeiten gebetet wurden oder an allen Freitagen der Fastenzeit. Vgl. sacrificium Deo spiritus contribulatus, cor contritum et humiliatum non despicies in Ps. 50, 19, dem Psalm des Miserere; und bes. Anselms v. Canterbury 1. u. 3. Gebet (Migne 158, 855 ff. 865 ff.). - Der These: "Schutze mich vor der Gewalt und den Verleumdungen meiner Feinde " wird andernorts gegeniubergestellt die antithetische Parallele „und verkehre ihre Zunge und ihr Herz in Liebe und in freundliche Gesinnung zu mir", und noch weiter: "die mir schaden wollen, die mache mir untertan". So im ersten Gebet der Hs. von Muri (Wilhelm 73, 6-11. $74,24-27$. 33-36). Ganz weltlich gewendet ist dieser Wunsch in dem zweiten Morgensegen derselben Hs.: hute si ich in allir der welte gimuote alse ir herze in ir pluote...daz ich inen allen si alse lieb. (WILHELM 94, 659-663; vgl. SCHERER, QF. 12, 90 f.; LG. I, 114).

1) Ueber die Einteilung in Lob-, Dankund Bittgebete s. LG. I, 324. - Ueber Gebetsstil: HASS, Das Stereotype usw. 
von zeremoniellen Handlungen, für welche oft innerhalb der einzelnen Gebettexte Anweisungen gegeben werden.

Einfach und volksverständlich wie der Inhalt ist auch die sprachliche Ausdrucksweise in diesen Gebetsformularen. Monoton fließt die Rede fort unter häufigen Wiederholungen, Aufzählungen und Formeln. Eine Sonderstellung nehmen die Morgengebete und Reisesegen ein. Hier lebt der Geist der alten Besegnungen weiter. $\left.{ }^{1}\right)$ Anselms hohe, aus ergriffenem Herzen kommende Sprache klingt auch noch in der Übersetzung des ersten S. Lambrechter Gebetsstückes nach.

In die prosaischen Gebete sind zuweilen gereimte (assonierende) Satzschlüsse eingeschaltet, so in den Morgen- bezw. Reisesegen der Hs. von Muri (Wilhelm S. 77, 150-168 und bes. 94, 661-96, 680; ferner in den S. Lambrechter Gebeten (Rödiger, ZfdA. 30, 84), und auch sonst (WilHelm, Komm. II, 159. 165. 167. 173. 192).

\section{$\$ 54$. Frauengebet der Vorauer Handschrift u. a.}

Prosagebete, seltener gereimte, sind uns aus dem MA., bes. aus dem 13. und 14. Jh., in großer Anzahl erhalten, ${ }^{2}$ ) wenige auch aus dem 12.3)

Ein gereimtes Gebet einer Frau enthält die Vorauer Hs. als letztes Stück, Bl. 135v; der Schluß fehlt (Kelle 2, 188. 377); gedruckt bei Diemer, D. Ged. S. 373-378, Anm. S. 95, Einl. S. L f. - Scherer, QF. 7, 90; LangGuTh, Ava S. 6). Es ist gerichtet an Gott, am Anfang und in den letzten erhaltenen Worten erfleht die Betende Rettung. Aus tiefer Not, aus weltlichen Bedrängnissen ruft die Frau zu Gott um Schutz und Hilfe gegen ihre Feinde, die Rache dem höchsten Richter anheimstellend. Geistliches Sehnen ist nur einmal ausgesprochen, da wo sie um die Gnade bittet, nicht des ewigen Todes sterben zu müssen. Sie beruft sich zuerst auf Susanna, denn diese ist ein Beispiel für lïgnerische Anklage; dann auf Maria und die Geburt Jesu, auf den Kreuzestod Jesu; auf St. Michael, den ritterlichen Engel und Schirmherrn; auf Tobias, den der Engel Gabriel aus seiner Entmutigung erlöste; auf Johannes den Tăufer, den größten der Heiligen; endlich auf die Auferstehung Christi.-Die Orth og r a p h i e weist auf bair.-österreichische Heimat des Gedichtes. ${ }^{4}$ ) DieVerse ${ }^{5}$ ) sind von ziemlich gleichmäßiger Ausdehnung, die Assonanzen bieten nichts Auffälliges.

In Innerösterreich geschrieben wurden auch die St. Lambrechter Meßgebete (KELLE 2, 188. 377). - Ausg.: Diemer, D. Ged. S. 379-383, Anm. S. 95 f., Einl. S. XVII f. XXVIII. LI (Hs. A), dazu PJPer, Nachtr. S. 286 f.; SchönbaCh, ZfuA. 18, 82 (Hs. A). 20, 168-173 (Hs. B) u. S. 189 (Hs. A); Rödiger, ZfdA. 30, 84 f.; LANGguth S. 6 f.; Wilhelm S. 96-103, Komm. II, 185-193; Wilhelm, Münch. Mus. 2, 238; Naumann, Ad. Prosaleseb. S. 12-16. A u. B, zwei Perg.Hss. aus der zweiten Hälfte des 12. Jhs. in Graz (Univers.Bibl.) aus St. Lambrecht [vielmehr aus Seckau $\left.{ }^{6}\right)$ ]: A, Grazer Hs. von Heinrichs Litanei Bl. $36^{\mathrm{a}}-43^{\mathrm{b}}$; B, Grazer Hs. 40/7 Bl. 67a-72b. Für die St. Lambrechter Gebete ist es nachweisbar, daß sie aus dem Lat. übersetzt sind. Der lat. Text ist in der Hs. von Muri entlalten (abgedruckt bei PIPER, Nachtr. S. 349-351). Es sind zwei verschiedene Stïcke anzunelınen:

1) LG. 1, 105-107. 112-114.

2) $\mathrm{Da}$ und dort eingetragen in mhd. Hss. oder auch gesammelt in Gebetbiichern, wortiber die Hss.kataloge Auskunft geben, so der von SCHMELLER für die Münch. Hof- u. Staatsbibl., Reg. Bd. I, 622, und der nene Kat. von PETZET; von BARTSCH fü die Heldelberger Un.-Bibl.Reg. S. 219; v. HEINEMANN, Wolffen- bittler Hss. I. Abt. Ill Reg. S.252, II. Abt. VReg. S. 398; LÄNGIN, Karlsruher Hss. Reg. S. Vi; PriebsCII, Hss. in England I Reg. S. 349.11, 336.

3) LG. l, Reg. S. 459.

4) WAaG, Beitr. 11.153 f.

s) W. GRIMm, ZGdR., KI. Schr. 4, 168.

6) Eichler, Zentralbl. f. Bibl. 35, 59-64. 
1. Diemer 379, 1-380, 28 (Wilhelm 96, 1-98, 47), ein Meßgebet, ist eine Übersetzung des Schlusses von Anselms v. Canterbury Oratio XXIX ${ }^{1}$ ) (Migne 158, 924 f.), im lat. Text der Hs. von Muri bei PIPER, Nachtr. S. 349 Sp. a [S. 84v Z. 9] bis Sp. b [S. 86r Z. 11]; 2. Diemer 380, 29-383, 19 (Wilhelm 98, 49-102, 122 bezw. 103, 131, bei PIPER S. 349 Sp. b [S. 86 Z. 12]-351 Sp. b [S. 91r Z. 17]. Im deutschen Text fehlt ein Stück des Innern, der SchluB weicht ab. Dieses 2. Stück ist ein Frauengebet für die Messe. Es zerfällt in drei Teile, die in der Hs. B und im lat. Text durch Überschriften bezeichnet sind. - Eingestreut sind Reine, bes. in $\mathrm{B}$.

Eine größere Anzahl von Gebeten enthält das Gebetbuch von Muri (Kelle 2, 46. 270; 188. 377; Diemer, D. Ged. Einl. S. XXVIII; WaAG, Kl. d. Ged. ${ }^{2}$ S. CX. - Ausg.: GrafF, Diut. 2, 291-297; Wackernagel, Ad. Pred. Nr. 76-90, S. 216-228. 285-288; PIPER, Nachtr. S. 318-352 [Abdruck der ganzen Hs.], dazu StEIN MEYER, Anz. 24, 323-325. - MSD. II ${ }^{3}, 253$ f. 286. 288; SCherer, QF. 12, 115 f.; Langguth aaO.; Wilhelm S. 73-96, Komm. S. 159173). Die Hs., 12. Jh., gehörte dem Kloster Muri in der Schweiz (Kant. Aargau), seit 1841 im Kloster Muri-Gries bei Bozen. ${ }^{2}$ ) Sie enthält auch die Mariensequenz von Muri (s. unten). Der Dialekt ist alemannisch. Die 16 Stücke sind für Frauen bestimmt. ${ }^{3}$ ) Das letzte Stück besteht aus zwei Morgensegen, deren erster auch sonst in Variationen vorkommt, worunter der Kölner Morgensegen. ${ }^{4}$ ) Die Engelberger Gebete sind Mariengebete in einem lat. Gebetbuch des Klosters Engelberg, 12. Jh. Sie entsprechen den im Gebetbuch von Muri enthaltenen Mariengebeten (Stück 15). Kelle 2, 188. 377. - Ausg.: GrafF, Diut. 2, 288-291; WACKERNAGEL Nr. 73. 74 S. 213-216. 284 f.; Wilhelm. S. $87-$ 93, Komm. S. 177-179. - Diemer, D. Ged. Einl. S. XXVIII; BARTSCH, Germ. 18, 71; STEPH. BEISSEL, Gesch. d. Verehrung Marias S. $131 \mathrm{f}$.

Nur wenige Zeilen umfaßt das $Z$ üricher Gebet einer Frau (Nonne) an Gott ùm Behütung der Keuschheit des Leibes und der Seele (WACK. Nr. 75 S. 216. 253-255; WiLHElM S. 64, Komm. S. 153 f.).

Inhaltreich, besonders wegen des auf die Gebete folgenden gereimten Meßgebetes, des sog. Messegesanges (s. unten) ist die Benediktbeurer Sammlung geistlicher Ratschläge und Gebete. Hs.: München $\mathrm{Clm}$. 4616, 12./13. Jh. (s. MSD. II', 271). Ausg. der Gebete und des Messegesanges: Schmeller, ZfdA. 8, 114-119; PIPER, GD. 2, 122-126; WiLhELM S. 104-107, Komm. 193-196 (ohne den Messegesang). Zunächst werden der Reihe nach zehn Engel mit Namen aufgezählt, die man bei gewissen Gelegenheiten des Tages im Gedächtnis haben soll (WILH. 3-26), dann folgen Ratschläge ubber gute Werke; darauf Anweisung zu einem Bittakt um Erlösung aus Sorgen mit Kerzenstiftung und mit Gebeten zu den Gliedmaßen des Gekreuzigten.

Dem 12. Jh. gehören noch an die theinfrk. Vatikanischen Gebete einer Frau in einem lat. Breviarium, Cod. Vat. lat. 4763 (GREITH, Spicilegium Vaticanum (1838) S. 68-71; Wilhelm S. 69-73, Komm. S. 156-159): 1.2. 3. drei Gebete an Gott und Maria, lat. u. deutsch, Variationen ein und desselben Gebetsformulars (Wilhelm Z. 1-55); 4. ein Mariengebet $(56-70)$; 5 . ein lat. Gebet vor dem Kreuz, mit deutschen Anweisungen an die leidenden Gliedmaßen Christi:5) der Betende wendet sich zu dem Antlitz des Gekreuzigten, zu der Brust, zur rechten Hand, zur linken Hand, zu den Füßen $(91-129)$; 6. Anweisung bei der Kerzenweihe (130-150) mit lat. Preisgedicht auf Christus mit lat.-deutscher Anweisung.

1) DIEMER, Wiener SB. 28 (1858), 135-138.

2) Kelle, Anz. 23, 114; STEINMEYER aaO.

3) Die einzelnen Stücke s. bei WiLHELM (Text u. Komm.). 288 .

$\left.{ }^{4}\right)$ Zum zweiten Segen vgl. MSD. II ${ }^{3}, 286-$

$\left.{ }^{5}\right)$ Bestimmend für die Gebete undHymnen, die in der Folgezeit Anflehung der Glieder des Gekreuzigten zum Gegenstand hatten, ist der mit Unrecht dem heil. Bernhard zugeschriebene Liederzyklus des "PassionsSalve " (Migne 184, 1319 ff.), dessen letztes Stück, "Salve caput cruentatum *, die Quelle für Paul Gerhardts "O Haupt voll Blut und Wunden ${ }^{*}$ wurde (vgl. Herm. PETrich, Paul Gerhardt, Gütersloh 1914, S. 209-211). 
Eine Anweisung für die Seelmesse befindet sich in ciner Hs. der Züricher Stadtbibliothek Cod. 171, Ende des 12. Jhs., alemann. (Wilhelm S. 107, Komm. S. 196 f.

Teile eines Gebetbuches sind auch die Upsalaer Frauengebete (hgb. von H.J. Psilander, ZfdA. 49, 363-375; Wilhelm, Komm. S. 173-177; vgl. Sprockhoff S. 83-85), 4 Perg.doppelbl. der Univers.-Bibl. zu Upsala, aus der Domkapitularbibl. zu Olmütz stammend, geschrieben um 1200, nördl. bairisch-österreich. Dialekt. Darunter vier Reimgebete: 1. an Johannes Ev. $(368,1-13)$; 2. an Magdalena $(369,14-370,69)$, eine Sündenklage (worin V. $42-58$ eine ziemlich wörtliche Übersetzung des Eingangs von Anselms v. Canterbury 74. (73.) Gebet (Migne 158, 1010); 3. an den heil. Michael $(372,116-126)$; 4. an Johannes den Täufer (127-135). Diese Versgebete haben einige Male Anklängc an die Vorauer Sündenklage. Prosagebete sind gerichtet an Petrus (70-115), Maria (136-180) und Jesus (181-210).

Ein schlichtes Maricnlob in kunstlosen Versen enthält die Grazer Hs. 42/93, das eine Frau in schlechtester Orthographie wohl aus dem Gedächtnis aufgezeichnet hat (SCHÖNBACH, ZfdA. 20, 154-156). Ebenfalls noch im 12. Jh. geschrieben sind die vier unbeholfenen Verse eines Ave Maria in zwei andern Grazer Hss. des 12. Jhs. (SCHÖNBACH, ZfdA. 18, 160. 20, 156).

In dem gereimten sechszeiligen Mariengebet der Münch. Hs. Clm. 19463 (12. Jh., BarTsCH, Germ. 24, 297) wird die frowe gebeten in der Art einer höfischen Dame des Minnesangs.

Die Klagenfurter Gebete (Sündenklagen) s. unten. Über die sog. spätbair. Sündenklage s. SPROcKHofF S. $82 \mathrm{f}$.

Die nịedergeschriebenen Gebete sind wolıl zunächst für die Geistlichkcit bestimmt, und zwar, zum Teil wenigstens, nicht nur zum Einzelgebrauch, sondern auch um vor der Versammlung vorgelesen zu werden. Die Mehrzahl sind Frauengebete für Nonnen. ${ }^{1}$ ) Der Grund mag darin liegen, daß die Mönche, die ja auf der Klosterschule Lateinisch lernten, der Gebete in deutscher Sprache nicht bedurften. ${ }^{2}$ )

Die drel Teile der Grundform, „Anrufung “, „Begründung“, „Bitte“, sind nicht überall leicht zu erkennen. Der nicht notwendige Bestandteil der Begründung fehlt zuweilen. Der Umfang der Gebete ist sehr verschieden; das Züricher Gebet umfaBt nur wenige Zeilen. In den längeren Gebeten sind die drei Teile untereinander gemischt. Im Muri-Engelberger Mariengebet (WilHELM 86,534-616) ziehen sie sich durch das ganze Stück, so daß sich einzelne selbständige kleinere Gebete auslösen lassen; ebenso in den vorher in der $\mathrm{Hs}$. von Muri stehenden Mariengebeten (WiLhELM 77, 169-79, 254).

Wie Gebete verschiedenen Inhalts in gebundene Form gebracht werden, so anch solche zur Messe, dem wichtigsten Teil der Liturgie. Jedweden religiösen lnhalt fassen die Geistlichen, um ihm durch den Schmuck des Reims und des Rhythmus ein gehobeneres Anschen zu verleihen, in poetische Form. So wurden auch die Worte und Gedanken der Wandlung in gebundener Rede dargestelit. Diese Meßgebete fallen in den Kanon der Opferhandlung, wo sie die vorschriftlichen Zeremonien begleiteten. Der Priester spriclit sle im stillen, er spricht sie für sich und zugleich für die Gemeinde, denn cr ist der Dolmetscher ihrer Gefühle. ${ }^{3}$ )

1) SCHÖNBACH, ZfdA. 20, 192.

2) Wenn sich lat. Stücke auch in Frauengebetbüchern finden (z. B. in der Hs. von Muri), so ist dabei zu erinnern, daß auch manche Nonnen lat. verstanden. Es konnten solche lat.Texte aber auclivor der versanumelten Kongregation vorgebetet werden, ohne Riicksicht auf etwalge Nichtkenntuis des Lat. aul seiten der Zuhörer.

$\left.{ }^{3}\right)$ Gesungen wurden diese Gebete nicht, deshalb kann die Bezeichnung "Messegesang" irrefíhren: die deutsche Spracle wurde niclit zum Gesangsvortrag bei der offiziellen Meßliturgie gebraucht. $\mathrm{Ob}$ jemals die uns erhaltenengereinten Wandlungsgebete bei einer Messe anch wirklich von einen Prlester in stillen - gesprochen wurden, ist zweifelhaft. Zunäclist sind es literarische Erzengnisse; wieweit sie fïr den praktischen Gebrauch bestimunt waren, ist unsicher. Manclie Worte in diesen Gebeten sind numittelbare Wiedergabe lat. liturgischer Formeln, so der 
Das gereimte Benediktbeurer Meßgebet (der sog. Messegesang).

Kelle 2, 173. 367; PIPER, GD. 2, 125 f. - Ausg.: K. Roth, Denkmäler S. XII. 46 f. ("Lied an Gott den Vater"); Schmeller, ZfdA. 8, 117-119 ("Gesang zur Messe"); MSD. Nr. 46, $11^{3}, 271$ f. ("Messegesang "); PIPER aaO.; WAAG, Kl. d. Ged. ${ }^{2}$ S. 170-173 u. Einl. S. CV f. SCherer, QF. 12, 102; Ders., D. Stud. 1, 14.

Hs.: Benediktbeurer Gebetsammlung, s. oben S. 170. Der Dialekt des Gedichtes ist wie der der Hs. bairisch. Abfassungszeit noch im 12. Jh.

Inlıalt. A. 1-48 Anrufung Gottes (1-4), Erklärung des Meßopfers. - B. 49-72 Begründung (Von ditu), Berufung auf Christi Marter. - C. 73-94 Bitte an Gott_(Verlih 73, ouch bite wir dich 77) unter Berufung auf das heilige Opfer.

Die Reime sind mit Ausnahme weniger leichter Assonanzen meist rein, aber sehr unbeholfen (sieben Reimpaare mit hait, sieben auf persönl. bezw. possess. Pronomen). Die Verse haben normalen Bau.

Ein ähnliches, aber kürzeres gereimtes Meßgebet ist erhalten in einer Hs. des Benediktinerstiftes S. Peter zu Salzburg, 12./13. Jh. Der Schreiber war wohl zugleich Verfasser des Gedichtes (hgb. in Mones Anz. f. K. d. t. Vorz. 7 (1838), 236 f., und von STEINMeyer, ZfdA. 17, 425-427). Stark betont ist das Gefühl der Sündhaftigkeit und darum das Verlangen nach Erbarmen, so daß das Ganze einer Sündenklage nahekommt (vgl. clage 12). Die Verse reimen nahezu rein und sind normal gebaut. Am Schluß steht ein dreifacher Reim.

Der Schluß in Freidanks Bescheidenheit 181, 10-21 ist ebenfalls ein Meßgebet, die Überschriften der Hss. $M$ und $R$ weisen selbst darauf hin. Die 12 Verse sind auch einzeln in Hss. erhalten: in einer Fuldaer aus Weingarten aus dem 12./13. Jh., wo am Rande die Anweisung steht, das Gedicht soll in der stillen Messe gesprochen werden (STEINMEYeR, ZfdA. 18, 455 f. 19, 103 f., vgl. 340); auch in einer St. Florianer Hs., 15. Jh. (LAMBel, Germ. 21, 347. 22, 384). Auch in diesen beiden Hss. sind die Verse als Schlußgebete verwendet, in der Weingarten-Fuldaer Hs. stehen sie nach dem Psalm 100, also am Ende des zweiten Psalmbuches, in der St. Florianer Hs. am Ende des St. Florianer Steinbuchs (LAMBEL, Das Steinbuch, Heilbronn 1877, S. XXV-XXIX u. 95-125).

Der massive Teufelsglaube der Zeit kommt wuchtig zum Ausdruck in einem Trierer Reimspruch (drei Reimpaare), in dem einer in Christi Namen den abtrünnigen Teufel, den Christ gefesselt, mit der Keule totschlagen will. Gelinder ist ein aus einem Satze von Gregors Moralia übersetzter ebenfalls Trierer Teufelsspruch in zwei Reimpaaren (v. STEINMEYER, Kl. ahd. Spr. S. 399 f.; PRIEBSCH, Beitr. 38, 341 ff.).

\section{$\S 55$. Heinrichs Litanei.}

Kelle 2, 176-182. 370-373; PiPER, GD. 2, 95 f., Nachtr. S. 285 f. - Ausg.: Graff, Diut. 1, 307 f. (Anfangs- u. Schlußverse der Straßburg-Molsh. Hs.); Hoffmann, Fundgr. 1, 257 (desgl.), Fundgr. 2, 215-238 (Grazer Hs.); MAsSmanN, D. Ged. 1, 43-63 (Litanîe, Straßburg-Molsh. Hs.); v. Kraus, Mhd. Übungsbuch S. 19-53. 240 f. (beide Hss.) - W. Grimm, ZGdR., KI. Schr. 4, 169 ff.; VoGT, Beitr. 1, 108-146; RÖDIGER, Die Litanei und ihr Verhältnis zu den Dichtungen Heinrichs v. Melk, ZfdA. 19, 241-346; SCHERER, QF. 1, 64. 7, 65 f. 12, 67; Ders., D. Stud. 1, 6; SchöNBACH, ZfdA. 20, 189-193; BeCH, Germ. 22, 41 f.

Hss.: G, Grazer Hs., Universitätsbibl. zu Graz Nr. 1501 (39/59), 80, 12. Jh., aus St. Lambrecht, ${ }^{1}$ ) enthält lat. und deutsche Frauengebete (s. oben die St. Lambrechter Gebete), auf B1.70a-105b unser Gedicht. - S, Straßburg-Molsheimer Hs., s. oben S. 17.

Eingang mit der Anrufung Gottes: Suscipe sancte Pater, omnipotens eterne Deus, wo Gott als der Allmächtige und der Vater gedacht ist wie Benediktb. Meßgebet MSD. Nr. 46, 1 f.; suscipe = enphâhe 7; dann die göttliche und menschliche Substanz Jesu als Gemeinschaft $z$ wischen ihm und uns 9 ff. (vgl. F. X. ScHMID, Kultus der christkathol.
Kirche 2, 168 f.); der kollektive Plural des Predigers, der seine Person und zugleich die Gemeinde umfaßt (Schmid S. 176). Im Sinne der Gemeinde gesprochen sind 57 f., wo diese Gott durch den Priester um Annahme des Opfers bittet.

1) Vielmehr aus Seckau, s. EICHLER aaO. S. $49 \mathrm{f}$. 
$\mathrm{G}$ mit 950 Versen ist die ursprüngliche Fassung, $\mathrm{S}$ ist eine um 518 Verse vom Verfasser selbst erweiterte Redaktion von 1468 Versen. $G$ hat auch in den gemeinsamen Partien weitaus den besseren Text und ist sorgfältig, während S häufig entstellt ist. ${ }^{1)}$ Der Dichter nennt sich in G 237, 19 Heinrich den Gottesknecht (dînen scalch Heinrîchen); er war jedenfalls ein Geistlicher, wohl Mönch und zwar, dem Dialekte zufolge, in einem österreichischen (wohl oberösterreich.) $\left.)^{2}\right)$ Kloster. S spricht nur allgemein von dem Urheber des Gedichtes, orthabe dirre getihte 1457. S, die in fränk. Dialekt umgeschrieben ist (Gegend von Mainz), nennt also den Dichter nicht, aber es wird ein Abt Engelbrecht angeführt 890, der ihn zur Abfassung der betreffenden Stelle veranlaßt habe. In Engelbrecht findet man den öfter in Urkunden genannten Engelbertus, Propst des Klosters St. Florian in Oberösterreich seit $\left.1172(1172-1203),{ }^{3}\right)$ oder den Abt Engelbrecht von Obernburg in Steiermark, der 1173 urkundlich belegt ist. ${ }^{4}$ ) Demnach fällt die Abfassungszeit des ursprünglichen Gedichtes zwischen 1160 und 1170 , die in S überlieferten Erweiterungen folgten dann kurz nach 1172 oder 1173. Den Namen hat der Dichter selbst gegeben: letanie Fundgr. 237, 25, letania Massmann 1461.

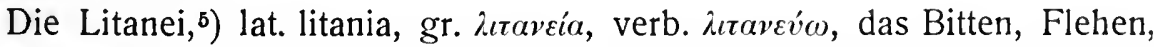
ist ein Bittgebet zu Gott um Erbarmen. Gesprochen wird es vom Priester, dem das Volk mit Kyrie eleison antwortet. Dieser Ruf Kyrie eleison, Herr erbarme dich, ist die Grundlage der Litanei, daran schlossen sich dann weitere Anrufungen an Heilige an und später wurde in der Allerheiligenlitanei der Umfang sehr ausgedehnt, indem eine große Anzahl heiliger Personen mit einbezogen wurde. Die Litaneien, die verschiedenartigen Ursprungs sind, wurden gebetet an gewissen Feiertagen und Festen mit Prozession, bei kirchlichen Umzügen, Bittgängen (daher rogationes) und auch bei liturgischen Handlungen. In der herrschenden, der Allerheiligenlitanei, ist eine bestimmte Reihenfolge eingehalten: Anrufung Gottes um Erbarmen, der Heiligen um Fürbitte; Aufzählung der Gründe; zum Schluß nochmaliges Rưfen um Erhörung und Erbarmen (die Aufzählung der Gründe fehlt in manchen Formularen). So besteht das Ganze aus einer Reihe in sich nicht verbundener Anrufe und Einzelsätze. Die lat. Formulare wurden dann in Gedichtform gebracht und mit einigen poetischen Strichen verbrämt.6) Das

1) Vergleichung der Hss. bei VoGT S. $108 \mathrm{f}$. 115-130; RÖDIGER S. $242-279$.

2) Ueber die Sprache der Hss. und des Dichters: VogT S. 109-115; RÖDIGER S. 279 -283. - Daß der Dichter ein Oesterreicher war, wird auch dadurch wahrscheinlich, da $B$ in der Straßburger Erweiterung der österreich. Heilige der Passauer Diözese Coloman (fälschılich Columban 806. 825. 897) so eingehend verherrlicht wird. - DIEMER hielt den Dichter für eins mit Heinrich von Melk, D. Ged. Einl. S. XVIff., bes. S. XXXI-XXXIII; dazu s. bes. RÖDIGER S. 279-324. 343-346. 3) VoGt S. 141-144; KELle S. 180 f. 372 f.

4) Rödiger S. $338-340$.

5) Wetzer u. Welte: 7, 2101-8; ThalHOFER $^{2} 1,316$ ff.; FR. X. SCHMID, Liturg. 1,313 -315; Vogt, Beitr. 1, 130 ff.; SCHÖNBACH S. 189 ff.; KELlE S. 174 f. $368-370$.

6) Bcispiele für in.alterl. Litancien: MARTĖNE, De antiquis Ecclesiae ritibus, 1, 552 ff.; MARTENe, Tractatus de antiqua Ecclesiae Disciplina S. 629 ff.; MABnllon, Vetera analecta S. 168 f. (Vogt aaO.; Kelle aaO., 
deutsche Gedicht ist ein weiterer Fortschritt: aus bloßen einzelnen Rufen der Gemeinde wurde ein erbauliches in einzelne in sich abgeschlossene Gebete gegliedertes Gedicht, das schließlich in das allgemeine Gebet ubergeht.

Der Inhalt ist in $G$ durch lat. Überschriften gegliedert. Er zerfällt in A. Anrufungen 1-1290 (MassmanN), B. Bitten 1291-1468.

Die ältere Litanei in $G$ enthält weniger Heilige als die jüngere in $S$ und zwar nur solche der römischen Litanei, während die neuzugekommenen von $\mathrm{S}$ in die röm. Litanei nicht aufgenommen waren, aber in der Passauer Diözese verehrt werden, besonders der heil. Coloman, ein irischer Pilger, der auf der Wallfahrt nach den heiligen Orten in Niederrösterreich erschlagen (13. Okt. 1012)1) und später als Landespatron Österreichs verehrt wurde. In S sind dazugekommen die Anrufung der Trinität (173-196), des Apostels Johannes (618-661), des heil. Blasius (746-805), Columban - Coloman (806-897), Nicolaus (898-947), Egidius (948-977), der heil. Margarete (1005-1035), Maria von Magdala (Maria Magdalena, 1096-1242). ${ }^{2}$ )

In der ursprünglichen Anlage, die in $\mathrm{G}$ erhalten ist, sind bei den Heiligengruppen immer zwei Vertreter ausgewählt, für die Apostel: Petrus und Paulus, für die Märtyrer: Stephanus und Laurentius, für die Jungfrauen: Agnes und Cäcilie, nur bei den Bekennern tritt zu Gregor und Martin noch als Führer Hieronymus. Am Schluß der einzelnen Gruppen werden dann die betreffenden zwei Heiligen zusammen angerufen.

Die Schlüsse von Abschnitten werden meistens durch lat. Zeilen oder Worte ${ }^{3}$ ) ausgezeichnet, die dem Gebrauch der lat. Litaneien entnommen sind (wo es Responsorien, gemeinsame Anrufungen des Volks oder des Priesterchores an die vorher berufenen Personen sind): kyrie eleison 216, 36 am Schluß der Anrufung Gottes und pater de celis 217, 25, ferner 218, 43. 223, 21. 224, 27. 227, 17. 228, 25. 229, 13 (deutsch); von da an nur Bittformeln ohne Namen: 230, 21. 232, 4 (deutsch). 235, 37. 237, 32.

Der Stili) ist der eines Gebetes, der unmittelbare Ausdruck innerer Erhebung, manchmal recht lebhaft durch Fragen oder Anrufe; und selbst die aus Cen lat. Litaneien oder aus den Beichten stammenden Aufzählungen witkon hier wie Ausströmungen einer erregten Seele, die sich in dem Ausdruck ihrer Empfindungen nicht genug tun kann. Ganz erfüllt ist ^der Flehende von seiner Verworfenheit und seiner Heils- und Hilfsbedürftigkeit. Aber diese ergreifenden Worte kommen nicht aus der Redekunst des Dichters, sondern sie sind ihm nur eingegeben durch die Sprache der Kirche.

hier auch Predigten über die Litanei). Gereimte Litaneien: Hrabanus Maurus, Migne 112, 1629-1632. St. Gallener Litaneien von Hartmann, Migne 87,32, Ratpert ebda S.39f., Notker Balbulus ebda S. 42; aus dem 10. Jh. auch die Litanei bei Migne 138, 1081-1090. In der liturgischen Litanei sind die Bestandteile getrennt, zuerst die Namen der Angerufenen, dann die Bitten und Begründungen.
1) Vogt S. 139 f.; Kelle S. 179. 372 f. Er ist mit dem älteren und beriłhmteren heiligen Columban ( $\rightarrow$ 618) verwechselt, der unter den Fürbittern der röm. Litanei steht.

2) Heinzel, H. v. Melk S. 104 f.

3) VOGT S. 131 ff.; alle lat. Worte bei GRÜNEWALD S. 21.

4) Vogt S. 126 f.; Rödiger S. $311-324$. 
Sehr frei ist die Rhythmik,1) es wechseln kurze mit überlangen Versen. Die Reime enthalten keine starken Assonanzen, überhaupt ist in G nur etwa ein Siebtel unrein.

\section{b) Sündenklagen.}

Die religiösen Grundgedanken der Sündenklagen sind die der Beichte: Sündengefühl und Erlösungsbedürfnis; sie äußern sich im Bekenntnis der Schuld und.Erflehung der Gnade. Sündenklagen ${ }^{2}$ ) sind Beich tgebete, durch die poetische Form, in welche die meisten gekleidet sind, ist eine besondere literarische Gattung geschaffen worden. Sie sind nicht wie die Beichtformulare zu offiziell kirchlichem Gebrauch bestimmt und weichen auch inhaltlich von jenen in einigen Zügen ab; doch bilden die Beichten in Gehalt und Form die Grundlage und damit lassen sich die Sündenklagen auch inhaltlich und formell aus diesen ableiten. Wie die Beichtformeln sind die Sündenklagen dreiteilig: $\left.{ }^{3}\right)$

1. der Empfängerformel in der Beichte, die zugleich eine Anrede ist, entspricht in der Sündenklage die Anrufung;

2. der mittlere Teil enthält in den Beichten und in den Sündenklagen das Sündenbekenntnis;

3. ein Hauptbestandteil des Beichtschlusses, die Versicherung der Reue, gehört auch zum Schlußteil der Sündenklagen. In der Beichte erscheinen in diesem 3. Teil außerdem die Bitte um Fürsprache, seltener die Bitte um Ablaß (Sündenvergebung) und vereinzelt die Begründung: die Bitte um Sündenvergebung ist im Schluß der Sündenklage ein Hauptzug, Bitte um Fürsprache und Begründung (Berufung) sind hier nicht an diese letzte Stelle gebunden. Der bedeutendste Unterschied in der Stoffverteilung bei Beichte und Sündenklage besteht darin, daß Eingang und Schluß dort nur aus wenigen Worten bestehen, wogegen der mittlere Teil, die eigentliche Beichte, d. i. das Sündenbekenntnis, weit vorherrscht, während in der Sündenklage die drei Teile etwa gleichwertig behandelt sind. Der Grundriß der Sündenklagen stimmt also im großen und ganzen zu dem der Beichtformeln, aber im Gegensatz zu dem knappen Stil der Beichten ist der Grundstoff durch Erweiterungen und Wiederholung bedeutend angefüllt. Verhältnismäßig stark ausgedehnt sind die Anrufungen mit Bitten um Gnade und Erhörnng und

1) Zur Metrik: W. Grimm aaO.; VogT S. $113-115$. 126. 142; RÖDIGER S. 276-279. 283 -311; GotTFr. DütSCHKE, Die Rhytlımik der Litanei, Hallenser Diss. 1889; SCHRÖDER, Gött. Naclir. 1918, 424; SARAN S. 254.

2) "Klagen"; Klage hat zunächst den Sinn von plangere, plorare, lamcntatio, lamentum (vgl. Lamentum poenitentiale Mon. germ. Poet. lat. medii aevi IV, II, 770) seine Sünden betranern, beweinen, iiber seine Sïnde Klage anstimmen, welıklagen; dann aber auch = accusare, accusatio "sich wegen seiner Sünden vor Gott anklagen" (vgl. De accusatione hominis erga deum ebda III, 1, 729), deutsch rüegen, oft in der Milst. Sündenklage; klagen und rilegen nebeneinander Milst 324-329 Der miner sunden ist sò vil, der ich dir nu chlagen wil. . mu wil ich mich selben ruogen $\dot{b}$ mich min wideminne ruogen beginne, klagen ist hier identisch mit rilegen. Sindenklage ist lamentum peccatorum oder poenitentiac. Im lat. querela und im mlat. lamentatio sind ebenfalls beide Bedeutungen, welklagen und anklagen, vereitnigt (lamentatio auch actio, calnmmia, DU CANGE.FAVRE 5, 17).

3) Siehe LG. I, 298 ff., bes. S. 300-302. 
die Begründungen (Berufungen), durch welch letztere ein erzählendes, biblischhistorisches Element in die lyrischen Gefühlsergießungen hereinkommt. In der Bedeutung, die den Anrufungen (Bitten um Erhörung und Gnade) und den Berufungen zukommt, stimmen die Sündenklagen mit den Gebeten überein, von denen sie sich aber, hierin mit den Beichten zusammengehend, durch die Wichtigkeit des Schuldbekenntnisses mit der unbedingten Hervorhebung der Sündhaftigkeit trennen, das in Beichten und Sündenklagen ein notwendiger Bestandteil ist.

Der Zentralpunkt der Sündenklage ist das Miserere, d. i. Ps. 50, 3 (Luthers Ps. 51)1) als liturgisches Gebet: Miserere mei Deus secundum magnam misericordiam tuam. Die von den Qualgedanken der Schuld gepeinigte Seele fleht $\mathrm{zu}$ ihrem Gott um ein reines Herz und einen neuen rechten Geist, daß sie wieder Trost erlange in ihrer Zerschlagenheit. In diesem Psalm sind ausgesprochen die leitenden Gedanken und Empfindungen der m.alterl. Sündenklagen: Anrufung Gottes und Bitte um Gnade, Trost Ps. 50, 3. 13. 14; Bekenntnis der Sündhaftigkeit im allgemeinen 5. 6. 7; Reue 19 (cor contritum et humiliatum); Bitte um Sündenvergebung 3. 4.9. 11. 12. 16; Berufung 3 (secunđum magnam misericordiam tuam et secundum multitudinem miserationum tuarum). Die betreffenden Ausdrücke sind denn auch Gemeingut der lat. Sündengebete: peccatum, iniquitas, malum, misericordia, miserere, delere, liberare, lavare, mundare, cor mundum, cor contritum. - Dem 50. Psalm (V. 17) gehört auch die liturgisch gewordene Bitte um Verleihung der Gabe zu reden an: Domine, labia mea aperies, welche die Vorauer Sündenklage einleitet.

Denselben Inhalt wie die deutschen Sündenklagen haben die lat. Poenitentialgedichte, aber sie sind von einem viel stärkeren Geist erfüllt und nicht so formlos im Umfang und Aufbau. Des Sachsen Gottschalk Miserere2) ist das ergreifende Bekenntnis einer ruhelosen, von dem Leiden der Sünde gepeinigten Seele. Er, der Knecht Gottes, wie sein Name Godescalk besagt, ist seinem Herrn, der ihn von der Sklaverei befreite, abtrünnig geworden, er hat den schwersten Frevel des Germanen begangen, den der Untreue. - Allzu gekünstelt in der Form sind einige alphabetische (die Verse der Reihe nach mit den Buchstaben des Alphabets beginnende Abecedarien) lat. Pönitenzgedichte der Karolingerzeit: ${ }^{3}$ ) des Paulinus von Aquileja Versus confessionis de luctu poenitentiali, ein "rithmus luctuosus"; De accusatione hominis erga Deum; Versus de poenitentia; Lamentum poenitentiale..

1) Der 50. Psalm ist einer der 7 Bußpsalmen (s. oben S. 168) und zwar der vierte. Insofern die Sündenklagen in naher Beziehung zu dem 50. Psalm stehen, haben sie also die Eigenschaften eines psalmus poenitentialis und wurden wohl bei ähnlichen Gelegenheiten vorgelesen wie diese, vgl. THALHOFER ${ }^{2} 2,627-629$ u. Reg. 2, 661.
2) Mon. Germ. aaO. III, I, 729-731. Ueber Gottschalk vgl. HAUCK, Kirchengesch. Bd. I, Reg.; HaRnaCK, Dogmengesch. Bd. 3; Beitr. $35,238$.

3) Mon. Germ. aaO. III, I, 147 f. IV, II, 484-486. $486-489$. $602-604.605$ f. 770 -783 . 
pro indulgentia peccatorum. Die ganze Glut der Askese strömt aus Petrus Damianis Rhythmus poenitentis monachi;1) eine Leidenschaft, welche von Marbods von Rennes Oratio poenitentis saepe lapsi ${ }^{2}$ ) nicht erreicht wird. Die lat. Reugedichte überragen die deutschen Sündenklagen weit an geistigem Gehalt. Es zeigt sich auch in ihnen der Abstand zwischen der deutschen und der lat. geistlichen Literatur der Zeit. Die höchste Bildung, die jenen Generationen erreichbar war, ist in der Kirchensprache niedergelegt, die Volkssprache, das Deutsche, ist das einfache Gewand einfacher Gedanken. Die lat. Versus poenitentiae sind auch nicht die Quellen der deutschen Sündenklagen, unmittelbare Vorbilder sind für diese überhaupt nicht nachgewiesen. Es sind Eigenschöpfungen von Mönchen, die von den aligemein gültigen religiösen Anschauungen ihrer Zeit aus die bekannten Stoffteile in volksmäßiger Auffassung zu gereimten Gedichten verarbeiteten.

\section{$\S 56$. Milstäter Sündenklage.}

Kelle 2, 184-186. 375; PIPER, GD. 1, 85 f. - Ausg.: Karajan, DSpr. S. 45-67 (unter dem Titel „Vom verlorenen Solın“), dazu PIPER, Nachtr. S. 250 f. (Kollation); RöDIGER, ZfdA. 20, 255-323 (kritische Ausgabe). - Scherer, QF. 7, 19-21. 12, 67, dazu Rödiger, Anz. 1, 70-.72.

Hs.: Milstäter Hs. (s. oben S. 16) Bl. 154b-164b. Der Text ist sehr verstümmelt. ${ }^{3}$ )

Abgefaßt wurde das Gedicht wahrscheinlich im ale mann. Sprachgebiet, ${ }^{4}$ ) und zwar vor der Vorauer Sündenklage, da die Reime und der Stil älteren Charakter tragen, also etwa $z$ wischen 1110 und 1130.

Inha1t ${ }^{5}$ ) I. Anrufung Gottes 1-277 (RöDiger). a) 1-52 Preis Christi, Gottes, Bitte an die Dreieinigkeit um Erhörung. b) 53-100 Bitte um Erhörung mit Griinden, Berufung auf Maria, den verlorenen Sohn. c) 101-277 Furcht des Sünders vor Gott wegen seiner Allwissenheit $(101-143)$, wegen seines Urteils am jüngsten Gericht, Hölle, Himmel (144277). - II. Sündenbekenntnis, Beichte 278-632 (die eigentliche Sündenklage, rluegen 301. 327. 349 usw.). a) 278-291 Bitte um Gnade. b) 292-345 Bekenntnis der Sündlıaftigkeit im allgemeinen. c) 346-632 die einzelnen Sünden, Sünden der Körperteile (dazwischen bei den Siunden des Herzens ein kleiner Lasterkatalog 448-473). - HI. Bitte um Erhörung und um Sündenvergebung, Rene, Berufungen 633-864. a) 633-641 Das Sïndenbekenntnis (chlage 633) ist beendigt, Bitte um Erlösung aus Not. b) 642--668 Berufungen auf Lazarus, Christi Höllenfahrt. ${ }^{6}$ ) c) $669-700$ Bitte um Erhörung (669), um Gnade (670), um Sündenvergebung

1) Migne $145,971 \mathrm{f}$

2) Migne 171, 1669. - Siehe ferner KRAUS, Vom Rechte S. $85-88$.

3) Textbesserungen s. BARTSCH, Germ. 7, 278-284; RÖDIGER S. 282-303; WALINER, ZfdA. 39, 8; LeITZMANN, Anz. 34, 125.

4) RÖDigEr, Anz. 1, 71. Die Reime geben keine Entscheidung. In Frage kommen können nur das Alemann. und das Bair. Für das Alemann. spricht folgende Erwägung: der Rheinauer Paulıs, der 129 Verse nit der Milstätter Sündenklage gemein hat (s. Inten S. 180), weist nur alemann. und gar keine Spur, von bair. Formen auf. Die Milst. Hs. ist allerdings bair., kann aber trotzden eine alemann. Vorlage gelıabt laben, wenigstens spricht nichts dagegen. Das Alemann. jener

Deutsche Literaturgeschichie. II.
Zeit hat eben keine so ausgeprägten Merkmale wie das Bair. Man kann also wohl Bairisclies in einer sonst alemann. Hs. erkennen, aber nicht so leicht Alemannisches in einer bair.

5) Vgl. RÖDIGER S 319 f.; SPROCKHOFF S.78f.

6) Die sinngemäBe Reihenfolge der Verse ist in der Hs. geslört, . 642-668 gehören linter 768. denn sie bilden mit 769 ff. zusammen die Berufungen. Ferner enthält die fälschlich hinter 641 gestellte Berufung anf Lazarus und Christi Höllenfahrt dieselbe Birte wie die Berufung auf die drei Jünglinge 769 796, nămlich um Befreiung von der Hölle (664. 772. 796), sie geliören also eng zileinander. Endlich pal3t der Anschluß von $669-768$ an 641 gut, besser als $642-668$, 
(675). Berufung auf Christus (687-700). d) 701-732 Bekenntnis der Reue (703), Bitte um Gnade (726). e) 733-768 Bitte um Sündenvergebung (735. 747), der gute Hirte (749-768); Reue (762). f) 769-854 Berufungen: auf die drei Jünglinge 769-796, auf Daniel (dieser auch als Fürbitter angerufen 797-819, auf die Ehebrecherin 820-864.

Die Verse 642-668 und 769-864 sind auch im Rheinauer Paulus und zwar in einer ursprünglicheren Fassung enthalten (s. unten S. 180). Daraus ist zu schließen, daß die ganze Milst. Sündenkl. das Original in vielen Einzelheiten geändert hat.

Ob der Verfasser das Gedicht, das nur aus bekannten Zügen besteht, in irgendeiner Quelle schon so verarbeitet vorgefunden hat oder ob er es selbst zusammenstellte, ist nicht zu entscheiden.

Im Stil ${ }^{1}$ ) herrscht Parataxe vor, daher auch die vielen Weiterführungen mit $s \hat{o}, n \hat{u}$ und die häufigen Aufzählungen (32 ff. 113 f. 119 ff. 151 ff. $156 \mathrm{ff}$. 165 f. 226 ff. 406 ff. 458 ff. 488 ff.). Lat. Ausdrücke²) sind mehrfach .eingestreut. Parallelen zu andern frühmhd. Gedichten begegnen natürlich auch hier, aber ohne Beweiskraft für gegenseitige Beeinflussung. ${ }^{3}$ ) Mit der Vor. Sündenkl. trifft die Milst. schon wegen des gleichen Inhalts öfter zusammen. ${ }^{4}$ )

Die Verse ${ }^{5}$ ) sind ziemlich gleichmäßig gebaut und ohne überlange Senkungen. Im Reimgebrauch treten starke Assonanzen auf und beschwerte Flexionsendungen. Dreireime sind öfters am Schlusse von Abschnitten angebracht. ${ }^{6}$ )

\section{$\$ 57$. Vorauer Sündenklage.}

Kelle 2, 182-184. 373 f.; Piper, GD. 1, 83-85. 2, 294. - Ausg.: Diemer, D. Ged. S. 293-316 ("Loblied auf die Jungfrau Maria“), Anm. S. 74-77, Einl. S. XLIV-XLVII, dazu Kollation von PIPER aaO.; WAAG, Kl. d. Ged. ${ }^{2}$ S. $141-167$ u. Einl. S. XCl-CIll. - SCHERER, QF. 7. 77-81. 12, 38, dazu RöDIGer, Anz. 1, 71 f.; SCHRöDER, Anegenge S. 73-76; ANT. MÜller, Breslauer Diss. 1887, dazu WAAG, Lit.Bl. 1889, 245-247; SchröDER, Heimat und Überlieferung der Vor. S., ZfdA. 35, 417-434.

Hss.: Vorauer Hs. Bl. 125a-128b. Der Text leidet an oft schwer verständlichen Entstellungen. ${ }^{7}$ ) Die ersten 13 Zeilen stehen auch auf dem letzten, aufgeklebten Blatt der Hs. Nr. 73 des Cisterzienserklosters Zwettl in Österreich. ${ }^{8}$ )

Die Sprache ${ }^{9}$ ) des Vor. Textes ist bair.-österreich., mit md., von einem rheinfrk. Schreiber herrührenden orthographischen Einmischungen (bes. $d$ für $t$ ). Der Verfasser war ein österreichischer Geistlicher, der etwa um die Mitte des 12. Jhs. dichtete.

denn mit 641 schlieBt die Bitte um Lösung von Not (der Sünde) und 669 enthält die gleiche Bitte um Befreiung von Sünden (s. auch unten Rheinauer Paulus).

1) RÖDIGER S. $311-313$.

2) Grönewald S. 20.

3) SChERER, QF. 7, 21; RÖDIGER S. 282-302 und Anz. 1, 66 ff.; Kraus, Vom Reclite S. 57

4) Kelle aaO.; A. MÜller, Vor. Sündenkl. S. $8 \mathrm{f}$.

s) Zur Metrik s. RÖDIGER aaO., bes. S. 313 -319 .
6) RöDiger S. 311 .

7) Textbesserungen von DJEMER, D. Ged. Anmerk.; Kraus, Anz. 17, 29-31. 33 f.; SCHRÖDER, ZfdA. 35, 417 ff.; WAAG, Einleit. zur 2. Aufl.

8) HofFmann, Fundgr. 1, 260; Diemer, D. Ged. Einl. S. XLV; SCHRÖDER, ZIdA. 35, $417 \mathrm{f}$.

9) SChERER, QF. 7, 78 f.; WAAG, Beitr. 11, 135-139; SCHRÖDER, Anegenge S. 74; A. MÜller aaO. S. 32-58; SCHRÖDER, ZfdA. 35, 417 ff.; JohN MEIER, Beitr. 16, 95. 
Inhalt. $\left.{ }^{1}\right)$ I. Anrufung 1-290 (WAAG $\left.{ }^{2}\right)$. Anrufung Gottes 1-7, der heil. Maria 8-290.II. Sündenbekenntnis (die eigentl. Sündenklage) 291-557. - Ill. Bitte um Sündenvergebung 559-728. - IV. Schlußgebet an Gott 729-858.

Ob der Verfasser den Inhalt, der nur aus`bekannten Zügen besteht, in irgendeiner Quelle schon so verarbeitet vorgefunden hat oder ob er ihn selbst zusammenstellte, ist nicht zu entscheiden. ${ }^{2}$ )

Der Stil ist einfach und ohne Schmuck. Der Satzbau ist nicht streng architektonisch abgemessen, wie etwa im Ezzolied, sondern die Linien gehen ineinander über (Hakenstil). Die Sätze erstrecken sich oft über eine Reihe von Zeilen durch An- und Einfügung von Nebensätzen, die Hypotaxe also ist Satzstil, im Unterschied von dem Milst. Gedicht, das durch die Parataxe einen altertümlicheren Eindruck macht als das Vorauer (z. B. Vor. Sündenkl. 14 - 23. 5862.77-83. 122-129. 227-239.328-336). Im Wortschatz sind einige selten belegte Wörter zu bemerken wie zurmgarte 71 , chelgîtechheit 76 , chintamme 86, behwelle 164. 354, whoftal 241, heilbringe 249, choufchneht 638 , brustslôz 755; daz halmel vor ziehen 401. Lat. Worte sind selten. ${ }^{3}$ ) - Parallelen $z u$ andern frühmhd. Gedichten sind häufig nachzuweisen. ${ }^{4}$ ). Benutzt ist das Gedicht von dem Dichter des Anegenge.

Unterschiedlich von der Milst. Sündenkl. hat der Versbau ${ }^{5}$ ) ungleichen Rhythmus, doch sind die Längenabstände nicht sehr stark. Die Anzalıl der Assonanzen ist verhältnismäßig groß.

Die beiden Gedichte, die sich in dem gleichen Gedankenkreis bewegen, sind doch in der Gestaltung der Formen und in der Erfassung des Stoffes verschieden. Wie der Satzbau, so ist überhaupt die ganze Darstellungsweise in der Milst. Sündenkl. straffer. Während in dem Vor. Stück die Gedanken stellenweise weitschweifig hingezogen sind, auch die Motive öfter und in verschiedenen Abschnitten wiederkehren, sind dort die einzelnen Stoffteile schärfer abgegrenzt. Man erkennt darum auch bei dem Milst. Gedichte die Zusammensetzung des Ganzen deutlicher. In die Anrufung Gottes am Anfang ist eine lange Aufzählung seiner Eigenschaften aufgenommen 32-52, wie in Heinrichs Litanei $41 \mathrm{ff} .149 \mathrm{ff}$; dann heben sich wieder heraus die Geschichte vom verlorenen Sohn 71-100, der Psaln 138 mit $111-135$, die Schilderung des jüngsten Gerichtes, von Hölle und Himmel 196-277, dann die Beichte 277-632, die Berufungen 642-864. So nacl allem ist das Milst. Gedicht anschaulicher als das Vorauer: es hat auch mehr erzählen-

1) Anklänge an Beiclıtformeln s. A. MÖLl.ER aaO. S. 4-6; SPROCKHOFF S. 79-81.

2) Honorius Aug. fülırt in sciner Predigt In annuntiatione Mariae (Migne 172, $905 \mathrm{ff.}$ ) ebenfalls die drei Jijnglinge, Daniel und dic ägyptische Maria als Beispiele an (SCHRÖDER, Anegenge S. 74 [s auch S. 54 Anm.] u. ZfdA. 35,423 ; A. Müll.er aaO S. 7-9), aber da $B$ der Dichter der Vor. Sundenkl. jene Predigt benutzt hätte, ist dadurch nicht erwiesen (Kelle aaO.).
3) GRÜNEWALd S. 20.

4) Diemer, Ein]. S. XLV f u. Annı. S. $74-$ 77; SCHERER, QF. 7 aaO ; die Uebereinslim11ungen mit Ezzos l.ied (SCHRöDER, Anegenge S. $74-76$ u. ZfdA. 35, 423) können zufällig sein (KElle, LG. 2, 183. 374).

b) Zur Melrik des Gedichtes s. W. Grma, ZGilR., Kl. Sclır. 4, 168; ScHERER, Q1'.7 aaO.; A. MÜller S. 9-32; SCHIRÖDER, ZfdA. 35 , 419 ff. 434 . 
den Stoff, während jenes mit Bitten, Klagen und Betrachtungen überfüllt ist; hier ist der Gesamtton mehr episch, dort mehr lyrisch. - Auch in der Auswahl der religiösen Gegenstände unterscheiden sie sich: der Dichter der Milst. Klage wendet sich ganz an Gott, der der Vor. ist durchdrungen von dem Marienideal; in dem Sündenbekenntnis hält sich jener nicht an die offiziellen Beichtformulare, denen dieser, stellenweise fast wörtlich, folgt. Eigentümlich aber ist der Vor. Sündenkl. die Hereinziehung des Teufels,1) dessen in den Beichten nicht gedacht wird: mit einem langen Gebet um Schutz gegen den verwünschten Hund schließt das Gedicht, das mit dem Preis der Jungfrau begonnen hatte. So steht der Mensch zwischen den Mächten des Glaubens und des Unglaubens.

\section{$\$ 58$. Rheinauer Paulus.}

Kelle 2, 186 f. 375 f.; PIPER, GD. 2, 117 f. - Ausg.: Graff, Diut. 2, 297-301 (vom Anfang bis 137), s. dazu HoffmanN, Fundgr. 1, 260; HaupT, ZfdA. 3, 518-523, dazu Sreinmeyer, Anz. 6, 11); PIPer, Höf. Ep. 3, 726 f.; Kraus, D. Ged. S. 7-12.77-101. - LachMANNS Briefe an Haupt, hgb. von J. Vahlen, Berlin 1892, S. 124; ScHERER, QF. 7, 20 f.; RÖDIGER, ZfdA. 20, 203 ff.; BaECHTOLd S. 79 u. Anm. S. 23; SPROCKHOFF S. 79.

Hs.: $\left.:^{2}\right)$ Kantonsbibl in Zürich Nr. 77, 10. Jh., aus dem Kloster Rheinau, nur Bruchstücke, nachträglich von einer Hand des 12. Jhs. eingeschrieben auf dem ersten und letzten Blatt, Bl. 1a u. 53b. Die Sprache der Hs. ist alemann1. ${ }^{3}$ )

Das Fragment umfaßt den Schlußteil des ganzen Gedichtes und besteht aus zwei verschiedenen Stücken: 1.1-129 sind die Berufungen der Milst. Sündenkl. (= Milst. 769-796. 642-668. 797-864). Beide Fassungen, die Milst. und die Rhein., sind, obgleich sie stellenweise sehr auseinandergehen, doch nur als zwei Hss. ein und desselben Werkes anzusehen $(M=$ Milst., $\mathrm{RP}=$ Rhein. Paul.). Der Text von RP ist altertümlicher ${ }^{4}$ ) und lebensvoller als der von $M$, andrerseits sind in RP die beiden ersten Berufungen 1-31 u. $32-58$ fälschlicherweise umgestellt, ${ }^{5}$ ) es entsprechen sich RP $1-31=M$ $769-796$, RP 32-58=M 642-668, RP 59-129=M 797-864). - 2. Das zweite Stück, das Ende des Gedichtes, umfaßt nur 26 Verse, also ein Sechstel des ganzen Fragments. Nur sie enthalten etwas über Paulus: es wird erzählt, daß er nach Aufsagung von Glauben und Beichte getauft und sein früherer Name Saulus in Paulus geändert wurde; er hat die Stelle des Judas unter den Aposteln eingenommen und ist Lehrer der Heiden geworden.

Über die Beschaffenheit des ganzen Gedichtes können bei dem geringen Umfang des Rhein. Bruchstücks nur Vermutungen geäußert werden. Da die Erzählung des Schlußteils nur kurz ist, das zur Sündenklage Gehörende, die Berufungen, dagegen einen großen Raum einnimmt, so ist es wahrscheinlich, daß alles über Paulus Gesagte in dem verlorenen Teile nur knapp dar-

1) SPROCKHOFF S. 81.

2) Kraus S. 77 f.

3) KRAUS S. $79-81$.

4) RöDiger, ZfdA. 20, 303 ff.

5) Mit dem lat Zitat [O] rex angelorum M 642, RP 32 und der Bitte um Erhörung setzt der Schlußabschnitt der Berufungen ein; an die Höllenstrafe $M 664 \mathrm{f} .=$ RP 51 schließt sich unmittelbar die hizze der Hölle M 772, RP 4 an; auch gehört in der Reihenfolge der Berufungen zuerst die auf Christus M 642668 , RP $32-58$ und dann erst die auf die drei Jünglinge $M 769-796$, RP $1-31$. 
gestellt, die Beichte aber, wie in der Milst. Sündenkl., recht ausgedehnt war. Wieviel von dieser auch im Rhein. Paulus stand, ist nicht $z u$ ermessen. Dann werden die Ereignisse bei der Bekehrung des Apostels den Anfang und den Schluß, gleichsam die Rahmenerzählung, gebildet haben, der Hauptteil in der Mitte kam dem katechetischen Inhalt $\mathrm{zu}^{1}$ ) (außer der Beichte bezw. der Sündenklage war auch wohl das Glaubensbekenntnis behandelt, vgl. RP 132).

Die Frage, ob ein und derselbe Verfasser die Berufungen (bezw. die Sündenkl.), die der RP mit $M$ gemeinsam hat, und die Pauluserzählung, die nur im RP enthalten ist, dichtete, ist wohl kaum zu entscheiden, da die Verszahl der letzteren zu gering ist. Stil und Metrik ${ }^{2}$ ) sprechen nicht dagegen.

Die Heimat des Gedichtes ist das alemann. Sprachgebiet, als Abfassungszeit sind die gleichen Jahre anzusetzen wie für die Milst. Sündenkl., auch wenn der Verfasser der Schlußerzählung ein anderer gewesen sein sollte als der der Berufungen.

$\$ 59$. Cantilena de conversione Sancti Pauli.

Ausg.: Martin, ZfdA. 40, 305 ff.; Leitzmann, Kl. geistl. Ged. S. 9 f. 30; SChröder, ZfdA. 41, 92-94; Ders., Gött. Nachr. 1917, 162.

Hs.: Colmar, Kreisarchiv, Bruchst. des 12. Jhs. (s. oben § 10); lückenhaft, der SchluB fehlt. Dialekt der Hs. elsässisch. Dialekt und Heimat des Gedichtes: das alemann. Sprachgebiet; Abfassungszeit etwa 1150.

Der Inhalt dieses Bruchstücks ist hier schon im Titel angegeben; daß es ein Bekehrungs- und Bußgedicht ist, das besagen auch die Worte wie wir uns bikêren Mart. IIc 17, ${ }^{3}$ ) ze buoze Ile 53 , und die lat. Bußworte Hell me misero II ${ }^{\mathrm{d}} 27$, tu mihi miserere $\mathrm{II}^{\mathrm{d}} 49 .^{4}$ ) Es ist eine Aufforderung zur Bekehrung und Buße und enthält I. II ${ }^{e} 16-39$ die Mahnung, daß wir uns bewahren in diesem Leben in Aussicht auf unsere Hinfahrt; II. IIc $40-$ II $^{d} 26$ eine Darlegung des jüngsten Gerichts; III. II $27-50$ Schuldbekenntnis und Bitte um Erbarmen (tu mihi miserere); IV. II ${ }^{d} 51-56$ Begründungen. Erhalten ist nur der Anfang von der großen Sünderin, es folgten noch weitere Berufungen, der letzte leserliche Buchstabe $\mathrm{H}=$ Herro leitete eine solche anaphorisch ein wie IId 51 .

Von Paulus, über dessen Bekehrung das Gedicht zufolge der Überschrift handeln soll, ist in dem Bruchstück nicht die Rede, die betreffenden Verse müssen also in dem nicht erlaltenen Schluß vorgekommen sein. Wie in Anselms Oratio und im Rheinauer Paulus sind auch hier Bekehrung und Schuldbekenntnis mit dem Apostel Paulus verknüpft, und wie die Zukunft nach dem Tode durch die Visio Pauli ebenfalls mit dem Apostel in Verbindung gebracht ist, so enthält auch unsere Cantilena einen Abschnitt

1) Möglicherweise wurde die Sündenklage deshalb mit dem Apostel in Verbindung gebracht, um ihr eln stärkeres Anselıen zu verleihen.

2) RÖDIGER S. 305 ff.; KRAUS S. 78 f.
3) Das Wort bekêren ist in der Hs. nicht erhalten, aber dic Konjektur, die schon Martin genacht hat, sicher richtig.

4) Grönewald S. 27. 
über die letzten Dinge, das jüngste Gericht. Eine Bußpredigt ist die S. Pauler Predigt in conversione sancti Pauli (25. Januar), ${ }^{1}$ ) die am Schluß ebenfalls bekêren, buoze, tegedinge (gerihte) als Grundgedanken hat.

Die Reime bezw. Assonanzen entsprechen der Zeit von ca. 1130-1150. Der Versbau ist normaler Typus. Cantilena ist das Stück überschrieben, weil es in Versen abgefaßt ist und also für liturgisch-melodischen Vortrag bestimmt war.

Paulus ist der Typus des bekehrten Sünders, ${ }^{2}$ ) ein Muster wahrer Bekehrung den Büßern; sein Fest, Conversio Pauli, feiert die Kirche am 25. Jan. (Pauli Bekehrung). In der Erzählung dieser Umwandlung aus einem Verfolger der Christen in einen Verkändiger Christi (Apostelgesch. Kap. 9) liegt der Grund dazu, daß Paulus eine Sündenklage in den Mund gelegt werden konnte. ${ }^{3}$ ) Hier ist der Schritt getan vom Unglauben zum Glauben, von der Sünde zur Buße, den jeder Beichtende tut. Paulus selbst bekennt sich als den vornehmsten der Sünder, er selbst hat eine ergreifende Sündenklage gesprochen in 1. Tim. 1, 9-15 und er selbst hat in Galat. 5, 19-21 eine. Anzahl von Hauptlastern zusammengestellt, die in die m.alterliche Beichtliteratur übergingen.

Unter den Fürbittern besaß Paulus, wie Petrus, die Gewalt, die Sünden zu behalten und zu erlassen.4) ${ }^{\circ}$ Der Tag seiner Bekehrung erinnert den Christen an die Hoffnung auf Gnade und ermahnt ihn zur Reue.5) - Eine Sündenklage, dem Heiligen vorgetragen, ist das 45. (72.) Gebet Anselms von Canterbury. ${ }^{6}$ ) Ein Schritt weiter ist.es, wenn nun die Sündenklage dem Apostel selbst in den Mund gelegt wird, und der ist in dem Rheinauer Gedicht getan. Damit ist die biblische Erzählung in die Auffassung und die Sitten des Mittelalters versetzt: Paulus spricht, bevor er sich taufen läßt, Glaube und Beichte, er klagt seine Sünde (RP 131-134). ${ }^{7}$ ) Seine Bekehrung wird aufgefaßt wie eine christliche Taufe. Die einzelnen Motive der Schlußerzählung sind alle der Tradition entnommen, hinzugetan aus Eigenem hat der Verfasser nichts. ${ }^{8}$ )

1) Jeirteles, Ad. Predigten aus St. Paul
S. $5-7$.
2) Paulus als Jenseitsfahrer s. oben Visio S. Pauli.

3) KRAUS S. 81.

4) Vgl. Litanei, Massmann S. 51, $601-604$.

5) S Bernhard, Sermo 1 in Conversione

S. Pauli; JeitTeles, Ad. Pred. S. 7.

6) Migne $158,975 \mathrm{ff}$.

7) Das ist der volkstümlich-legendarische Paulus. der Durchschnittstypus des populären Heiligen (ein gereimtes deutsches Gebet mit dieser Auffassung s. bei MONE, Hymnen 3, 85). Die herbe Größe des augustinischen Paulus war dem Volk nicht faßbar. - In das Breviarium Romanum aufgenommen wurde Augustıns Sermo 279, Migne 38, 1275 ff., (vgl. SCHÖNBACH, Ad. Predigten 3, 197 f. 390); ähnlichen Inhalt hat Sermo 176, Migne 38, 945 ff.; diese Predigt wird noch heute am Fest der Bekehrung Pauli vorgetragen. Augustinus hebt den Gegensatz zwischen dem Saulus und dem Paulus, dem Wolf und dem Lamm, stark hervor, um die Gnade Gottes in um so hellerem Lichte erstrahlen zu lassen. Den scholastischen Paulus findet man in der Legenda aurea des Jacobus a Voragine (GRAESSE, Jacobi a Voragine Legenda aurea, 3. Aufl., Vratisl. 1890, S. 133 f).

$\left.{ }^{8}\right)$ V. 139 der milte s. Paulus: bei Augustinus ist Paulus die Charitas eigen (Migne 35, 2089. 37, 1923), für das Mitlelalter ist er der barmherzige Tröster in Sündennöten. V. 140 f. Gottes Gnade. s. Kraus, Anm. zu V. 140 auf S $100 . \quad$ V. 142 irwelitiz gotis uas $=$ vas electionis, Apostelgesch. 9, 15 u. 
Im Lebensbild des Apostels Paulus traten dem Mittelalter zwei Ereignisse von besonderer Wichtigkeit entgegen, die zu legendarischen Hauptzaggen wurden: seine Bekehrung und seine Vision ${ }^{1}$ ) (Conversio S. Pauli und Visio S. Pauli). Die Bekehrung des Paulus ist ein Symbol der Buße, für die Herstellung des richtigen Verhältnisses zwischen Mensch und Gott; die Vision aber, das Gesicht der jenseitigen Dinge, öffnet dem Menschen dell Blick auf seine Zukunft in der Ewigkeit. Mit Sünde und Buße, mit der Ausmalung der höllischen Qualen und der himmlischen Freuden, beschäftigt sich gerade vornehmlich die Phantasie dieses mönchischen Geschlechtes, und so liegen in der Conversio und der Visio S. Pauli die beiden Pole des Menschengeschickes inbegriffen: hier die Sünde, dort die Strafe, hier die Buße, dort die Seligkeit.

\section{$\$ 60$. Upsalaer gereimte Beichte.}

Kelle 2, 187. 376. - Ausg.: v. BAHDER, Germ. 31, 99-104; WAaG, D. Ged. ${ }^{2}$ S. 167-169 u. Einl. S. ClV f. - Sprockhoff S. 76--78; HautKaPpe, Ad. Beichten S. 59 ff.

Hs.: Upsala, Ende des 12. Jhs. Der Schluß fehlt.

Die Sprache ist rheinfrk. mit mittelfrk. Einschlag. Abfassungszeit um 1150. Das Gedicht, auch Upsalaer Sündenklage genannt, ist eine gereimte Beichte, streng nach der Einrichtung eines Beichtformulars: voran geht die Abschwörungsformel; von der Beichte ist erhalten: I. die Empfängerformel 2-4; II. der größte Teil der Sündenaufzählung 5-Schluß.2)

Die Reime sind ibberwiegend unrein (21 assonierende gegen 10 reine Reime), die Assonanzen sind aber nicht schwer. Die Verse sind frei gebaut, öfters überlang.

\section{$\$ 61$. Die (prosaische) Rheinauer Sündenklage.}

Ausg.: WilHelm, Denkm. S. 64-69, Komm. S. 154-156.

Hs.: Zwei Doppelbl. der Züricher Kantonalsbibl., 2. Hälfte des 12. Jhs., losgelöst von einem Kodex des Klosters Rheinau. Anfang und Schluß fehlen.

Die Sprache ist alemann. Der größte Teil der Sätze hat gleichen Bau. Sie beginnen anaphorisch mit der Anrufung hêrro oder mit ich manon dich, auch mit nû bit ich, enthalten Begründungen (Berufungen) und oft auch noch Bitten. Daß das Stück unter die Sündenklagen zu rechnen ist, ergibt sich schon aus den Schlagworten: mih blvtigun sundârun 6, rizva 8, mih firborginun sundârun 10 f., ferner 11.17 f. 21 f. 71 f. 87. 88. 107. 109. 122 . 133-135. 154. 158. 164. 165, besonders auch abe nemen (Ablaß gewähren) 136 und (ih) chlagon dir 72. Weder am Anfang noch am Schluß des Bruchstïcks scheint viel zu fehlen. Mit 173 beginnt die Bitte um Aufnahme in die himmlische Schar.

Kraus aaO. - V. 144 Paulus als Apostel Ersatz für Judas und V.146 Paulus als Heidenbekehrer sind stehende Zïge in der m.alterl. Prulusliteralur. Fast alle diese Motive gehören zu der liturgischen Feler der Conversio Pauli im Breviarium Romanum.

1) _Die Visio S. Pauli s. oben S. 161.
2) Die Upsalacr poetische Beichte stehi nicht in unmiltelbarer Bezichung zu einer der prosaisclien Beicliten (V. BAHDER aaO.), doch ist sie unter die Gruppe A zu stellen (L.G. 1, 313). Zu der Untergmupe Y gehört sic nicht. 
Sündenklagen sind auch die beiden von SсHÖNBACH, ZfdA. 48, 87-98 (vgl. SPROckHoff S. 85) aus einer Klagenfurter Hs. des 12. Jhs. herausgegebenen, in Versen abgefaßten fragmentarischen Klagenfurter Gebete (Klagenfurter Sündenklagen). Es sind drei Stücke, von denen das erste und letzte in Versen $\left(1^{\mathrm{a}}\right.$ und $1^{\mathrm{b}}$ ), das mittlere (1b. $2^{\mathrm{a}}$ ) in Prosa abgefaßt ist. $\left.{ }^{1}\right)$ Für die Heimatsbestimmung gibt die Sprache keine sicheren Anhaltspunkte. Der Apostel Jacobus scheint der Schutzpatron des Bittenden oder ein besonders angesehener Heiliger seines Klosters bezw. seiner Diözese gewesen zu sein.

Die Magdalenenklage in den Upsalaer Frauengebeten s. oben S. 171.

In Hartmanns Rede vom Glauben (s. S. 63) ist im Abschnitt vom heiligen Geist als dem Bewirker der Sündenvergebung eine Sündenklage angefügt, ${ }^{2}$ ) bei MASSMANN 1752-2369, enthaltend I. 1768-1827 Sündenbekenntnis, II. 1828-1842 Bitte um Sündenvergebung, III. 1843-2369 Berufungen.

\section{Buß-und Sittenpredigt.}

\section{$\$ 62$. Memento mori.}

Kelle 2, 31 f. 260 f.; PiPer, GD. 1, 31-36. - Ausg.: K. A. Barack, s. oben S. 40; MSD.

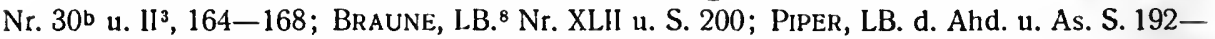
195: PiPer, Notker 1, 863-868 u. Einl. S. XCV. - Steinmeyer, Anz. 5, 431 f.; Scherer, ZfdA. 24, 426-450; BARTSCH, LitB1. 1880, 13 f.; BehAGHEL, ebda 1881, 235; F. SEller, ZfdA. 25, 188; H. Herzog, Germ. 30, 60-63; BaEchtold S. 76-78 u. Anm. S. 23; LeitZMANN, Beitr. 16, 533-536; Wilmanns, Gött. g. A. 1893, 535; Kraus, ZföG. 45 (1894), 133 f.; Wunderlich, ZfdPh. 26, 113; O. Mendius, Beitr. 27, 205 f.; Paul Habermann, Die kleineren ahd. Reimgedichte S. 78-96 u. 167-193; WOLFSKEHL u. v. D. LEYEN S. 98-109. 219 f.

Hs.: Straßburger Hs. des Ezzoliedes S. 154b. 155a, fortlaufend in nicht abgesetzten, jedoch durch Punkte getrennten Versen mit großen Initialen am Anfang der Strophe.

Die Bezeichnung "Memento mori“ rührt von dem ersten Herausgeber Barack her.

Der Dialekt ${ }^{3}$ ) ist alemann. und in der Orthographie recht gut und ziemlich regelmäßig ausgeprägt. Das Gedicht ist wahrscheinlich in der östlichen Schweiz entstanden und zwar in der 2. Hälfte des 11. Jhs., um 1070. Der Verfasser war ein Geistlicher. Am Schluß steht ein Schreiberzusatz, das Reimpaar fro so mozint ir wesin iemer, daz machot allein noker. Das letzte Wort ist der Name Noker, welche durch Assimilation des $t$ an das $k$ entstandene Form für Notker in schweizerischen Quellen schon seit dem 9. Jh. vorkommt und im 11. und 12. öfter belegt ist. Es ist wohl der Name des Dichters, aber die Stelle ist nicht recht verständlich. ${ }^{4}$ )

1) Die Verse 31-38 gehören doch wohl init den folgenden $40-72$ zu einem Gebet zusammen (SPROCKHOFF nimmt zwei Gebete an). Gott als Schöpfer angerufen im fünften Bußpsalm, Ps. 101, 26, vielleicht ist 37 eine freie Wiedergabe von Ps. 101, 24 f. Ihm steht der Mensch gegenuiber als ein Teil der Schöpfung ( 34 u. 56) : diese gedankliche Einheit spricht ebenfalls für Zusammengehürig$k: t$ von $31-38$ mit dem Folgenden.
2) DIEMER, Beitr. V, Wiener SB. 48 (1864) Anm. zu 1166 (s.oben S. 117 Anm.3); SCHERER QF. 7, 21.

3) SCHERER S. 431.437 ff.; MENDius aaO.

4) BARTSCH und BEHAGHEL aaO.; SCHERER S. 430-433; Braune S. 200; Herzog aaO. Den rechten Weg hat Bartsch eingeschlagen mit seinem Hinweis auf Rudolfs von Ems Alexander: ez hât ouch nâch den alten siten ein Lampreht getihtet. Dann hat ein die 
Inhalt. $\left.{ }^{1}\right)$ Der Grundgedanke ist: Wir müssen alle einmal von dieser Welt fahren, darum sollen wir immer bereit sein und dementsprechend leben. I. Str. 1-6 die Nichtigkeit der Welt. So schnell vergeht der Mensch, wie ein Schlag der Augenwimper. II. Str. 7-15 die Gebote des Lebens: Nächstenliebe (Str. 7. 8); das Recht: ihr habt zweierlei Recht, das eine für euch, das andere für die Armen (Str. 9. 10.11). Glücklich ist der für die lange Fahrt vorsorgt, daB er bereit ist, wenn der Todesbote kommt (Str. 12.13). Die gute Anwendung des Reichtums (Str. 14. 15). - Ill. Str. 16-18 Gleichnis von einem Wanderer, der unter einem Baum einschläft und seinen Weg versäumt: der Mensch, der sich zu lange in der Welt aufhält (Str. 16. 17). Anklage der Welt: Jâ dâ vil ubeler mundus, wie betriugist tû uns sus! (Str. 18). - IV. Schluß: Trohtîn, chunic hêre, nobis miserere! (Str. 19).

Das Gedicht ist eine Anspraclıe, die ein Mönch an Laien hält (wî́b unde man 1, 1), eine Bußpredigt, wie des Heinrich von Melk Erinnerung an den Tod, über die Weltminne ${ }^{2}$ ) im Geist der cluniacensischen Askese. Übereinstimmend damit geht ein sozialer Zug durch mit der Richtung gegen die, die das Weltglück besitzen, gegen die Reichen: alle Menschen stammen von einem Mann ab (Str. 7. 8); die Armen werden in Schutz genommen gegen die, die das Recht ungerecht auslegen ${ }^{3}$ ) (Str. 10. 11); die Reichen sollen ihren Besitz zu guten Werken verwenden (Str. 14. 15). Ermahnt wird mit diesen drei Punkten zur Nächstenliebe, zur Gerechtigkeit und zu den guten Werken, also gerade zu solchen gemeinfördernden Aufgaben, die in der sozialen Tendenz begründet sind. Damit gehen diese priesterlichen Lehren nicht auf in selbstquälerischer Weltflucht, sondern sie spornen an zu praktischer Lebensgestaltung. Diese Richtung aufs Handeln ist begründet darin, daß die Predigt für Leute bestimmt ist, die im wirklichen Leben stehen, und nicht für weltabgesonderte Mönche. Das Publikum also, das der Redner im Auge hat, besteht hauptsächlich aus reichen, angesehenen Leuten. Schon die gereimte Form erhebt die Predigt über das Gewöhnliche und verleiht ihr einen vornehmen Anstrich.

Die Sprache ist äußerst einfach und ohne stilistischen Sclımuck, keine zweigliedrigen Formeln werden angewendet, keine Epitheta. Der Bau in

hervorhebende Bedeutung, gleich „jener bekannte, berühmte", wofür im DWB. $3,132 \mathrm{f}$. mhd. Beispiele angegeben sind (dazu auch: Die vursten lobeten dô geliche ainen Hainrichen Kaiserchron. 16142 f.: Walther v. d. Vogelweide 82, 18 einen wunderlichen Gêrhart Atzen; UHLAND, Volkslieder Nr.74 B Str. 30 (S. 151) Und wer ist der uns das liedlein sang? ein Adelger ist ers genant. Ueber das 'auszeichnende ein' s. außerdem Hildebrand, Vom deutschen SprachunterrichtS 230-232;BRAUNE, Beitr. 11,518-527. 12, 393-395. 13, $586 \mathrm{f}$. Der Sinn ist dann: das machte alles jener berülımte Notker, und damit wäre das Gedicht von dem Verfasser dieser letzten beiden Zeilen dem Notker Labeo zugeschrieben, allerdings zu Unrecht (Scherer aaO.). Der Inhalt des Gedichtes paßt zul dem der Hs., in welche es eingelragen ist, zu Gregors Kommentar Moralia in Job, der von der Nichtigkeit der Welt handelt. Notker hatte diese ins Deutsche (LG. I, 439) übersetzt, vielleicht mag eine Erinnerung an dieses Werk Notkers bei dem Schreiber des Zusatzes mitgespielt haben. Der Wunsch des immerwährenden Frohseins bezieht sich auf die ewigen Freuden des Hinmelreichs.

1) Genaue lnhaltsangabe bei ScHERER S. $427-430$.

2) Bainberger (ilaube u. Beiclite, MSD. I 304 Z. 194. De contempt11 mundi, KELLE 2, 31.260.

3) Dasselbe Eintreten fiir die Handlabung des Reclits wie in Muspilli 68-72 (LG. l, 146) und in dem Gedicht vom Rechte (Scilerer, ZfdA 24, 448 f.). Die Predigt gelıört zu den sermontes ad status (LECOY DE la MARChE S. 207. 276 f. ; LinsenMAYER, Reg. S. 489), den an gewisse Sıände gerichteten, vgl. Honorius Aug. Spec.ecel.Sermo generalis: Ad judices, ad diviles (Migne 172, $863 \mathrm{f}$; KRAUS, „Vom Rechite* S. 57 f.). 
Hauptsätzen, die Parataxe, wird hier besonders merkbar, da auch nebensätzliche Gedankenteile, Bedingungs- und Einräumungssätze, parataktisch gegliedert sind: $1,5.7 ; 2,5 ; 4,7 ; 7,7 ; 15,3 ; 17,8 ; 17,11 ; 18$, 5. Ein Beispiel für die einfachste Art der Erzählung ist Str. 16, wo die Entwicklung des Vorgangs fast nur in einer Aneinanderreihung der sich folgenden Ereignisse besteht. - Charakteristisch für den Predigtstil ist die unmittelbare Ansprache an die Hörer durch die 2. Pers. plur., wozu auch die 1. Pers. plur. tritt als Zusammenfassung von Redner und Publikum. Rhetorisch berechnet sind die Ausrufe: 2,$8 ; 3,5$ f.; 10, 1 f.; 12,$1 ; 16,8 ; 17,13 ; 18,1$ f.; 19, 1 f.; Beteuerung 14, 8. Kräftig ist die Sprache nicht, nichts hat sie von einer zerinalmenden Bußpredigt, die dem verworfenen Menschen sein Sündenelend in diesem irdischen Jammertal vorhält. ${ }^{1}$ ) Aber doch ist sie nicht unwirksam, ${ }^{2}$ ) eindringlich wird immer und immer wieder die eine Warnung wiederholt, sich vor der Eitelkeit der vergänglichen Welt zu hüten. Der I. Teil, 6 Strophen, bewegt sich um diesen einen Gedanken, oft nur in Variationen oder sogar mit den gleichen Worten: $1,4=2,2.6,1 ; 1,3=2,3 ; 1,5=2,5$; ferner 3,3 f. $=11,3$ f.; 3,7 f. $=17,9$ f.; $7,2=8,1 ; 10,3=19,6$, auch 17, 2 . Lat. Worte sind eingeflochten 18,$1 ; 19,2$ (auch $4,1 \mathrm{Hs}$ !). ${ }^{3}$ ) Überhaupt erfahren Sprache und Gedanken am Schluß, Str. 18.19, eine fühlbare Steigerung.

Im Reimprinzip ${ }^{4}$ ) (Assonanzen, volle Endsilbenvokale) steht Memento mori dem Ezzolied nahe und ist altertümlicher als die Summa Theologiae. Der Versbau in seinen Verhältnissen von Hebung und Senkung ist ziemlich ebenmäßig, d. h. die Verse haben mittleren Umfang. Alle Strophen haben 8 Zeilen außer Str. 8 der Hs. ( 8 u. 9 in MSD.) mit 10 Zeilen und Str. 175) mit 14 Zeilen, die aber wohl beide entstellt sind. Demnach hat das Gedicht wohl nur 8zeilige Strophen gehabt. ${ }^{6}$ )

$\$ 63$. Heinrich von Melk.

Kelle 2, 84-98. 293-301; PIPER, GD. 1, 235 Anm. - Ausg.: Erinnerung an den Tod: MassmanN, D. Ged. 2, 343-357 u. Vorw. S. 159-161, dazu J. GRImm, Gött. g. A. 1838, 553-559 u. Kl. Schr. 5, 282-286 (Nachtrag zu Massmann von 38 Versen); J. Diemer, Beitr. XVl, Wiener SB. 18 (1856), 271-310; Einleitungs- u. Schlußverse bei GrafF, Diut. 3, 401; Hoffmann, Fundgr. 1, 257-259. Priesterleben: Haupt, Ad.Bl. 1, 217-238; Einleitungs- und Schlußverse bei Graff, Diut. 3, 403 f. Beide Gedichte: Hernzel, Heinrich

1) Es mangelt an unmittelbar persönlicher Wirkung, die das Gewissen des einzelnen Hörers aufpeitscht. Im Temperament liegt der Unterschied $z$ wischen der Sprache dieses Dichters und der Heintichs v. Melk.

*) Die Rede gehört ihrem Zweck entsprechend $\mathrm{zu}$ der Stilart des Erregens, movendi, und hier ist die Absicht, durch. Vorwürfe und Beschwörung Erschütterung hervorzubringen (Hrabanus Maurus, De Clericorum institutione Lib. III Cap. 28, Migne 107, 406 C D).

3) GRÜnewal.d S. 7.

4) Zur Metrik s. Scherer u. Steinmeyer, MSD. II $^{3}, 167$ f.; SCHERER, ZfdA. 24, 433 ff.;
SARAN S. 252-254; HABERMANN aaO.

5) 17, 8 f. dannan obinan (Hs!) heißt "von da nach oben", vgl. dannan hin obnen, DWb. 7, 1072, also: wenn ihr von da nach oben kommt, da müßt ihr ablassen. 17, $8 \mathrm{f}$. ist die Erklärung $z$ der Parabel 16, 7 ,wenn er dann vom Schlaf sich ethebt" usw. und hat den Sinn: wenn ihr von euerm verschlafenen, gleichgültigen Hinzögern (vertvelit 17,4 ; es ist die Todsünde der acedia) wieder obenauf kommt, so müßt ihr da bleiben, könnt euern Weg nicht weiter fortsetzen.

${ }^{6}$ ) Scherer u. Steinmeyer aaO.; Braune LB. ${ }^{8}$ S. 200; LEITZMANN aaO. 
v. Melk, 1867 (Hauptwerk ïber H. v. M.), dazu Scherer, ZföG. 19 (1868), 564-579 u. K1. Schr. 1,604-620. - DiEMER, Beitr. XIV. XV. XVl, Wiener SB. 18 (1856), XVIII. XIX, ebda 28 (1858); SChERER, QF. 12, 64-66; Rödiger, ZfdA. 19, 24 i ff.; Wilmanns, Der sogen. Heinr. v. Melk, Bonn 1885, dazı Schröder, DLZ. 1886, 885 ff., SEEMüller. ZfdPh. 19, 369-378 u. ZföG. 38 (1887), 372 ff.; OtTomar LoREnZ, H. v. M., der Juvenal der Ritterzeit, Halle 1886, dazu SeEmöllé, ZfdPh. 20, 123-126, KochendörfFer, ZfdA. 35, 187-204. 281 315; SCHRÖDER, ZfdA. 45, 217-223. 419; Kelle, Untersuchungen über das Offendiculum des Honorius, sein Verhältn. zu ... den deutschen Gedichten Gehugede u. Plallenleben, Wiener SB. 148 (1905) Nr. 4; Tн. BaunacK, Xenia Nicolaitana, Festschrift, Leipz. 1912, S. 109-128; Ders. ZfdA. 54, 99-116 u. 57, 49-94.

Hs. Wien 2696 (s. oben S. 17). Es sind zwei Gedichte, beide in der Hs. ohne Uberschrift. Im ersten (Bl. 165a $-178^{\text {b) }}$ gibt der Dichter selbst sein Thema an: daz ich von des tôdes gehugde eine rede fur bringe 2 f. (vgl. V. 444), wonach das Gedicht „Erinnerung an den To d" genannt wird. $\left.{ }^{1}\right)$ Innerhalb des Textes, Bl. 170b, steht eine neue Inhaltsangabe von dem gemäinem lebene (V. 450), womit cin neuer Teil der „Erinnerung “ beginnt. Im $z$ weiten Gedicht fehlt der Eingang, nach seinem Inhalt wird es genannt „Priesterleben $n^{*}$ oder "Pfaffenleben" (Bl. 303a--307b). ${ }^{2}$ ) Am Schluß dieses zweiten Gedichtes steht daz buch heizzet daz gemeine leben. ${ }^{3}$ )

Die Sprache ist österreichisch.4) Der Dichter nennt sich am Ende der Erinnerung in der Anrufung Gottes Häinrîchen dînen armen chnecht und schließt in sein Gebet ein den abt Erchennenfride 990 f. Nirgends ist ein sicherer Anhalt gegeben, um des Dichters Persönlichkeit näher zu bestimmen, die Verskunst aber ist noch die freiere der frühmhd. Zeit, etwa um die Mitte des 12.Jhs. Damals war ein Erkenfried Abt des Klosters Melk (1122-1163). $\left.{ }^{5}\right)$ Ihn wird also wohl der Dichter gemeint und zu seinem Kloster zu Melk wird er gehört haben. ${ }^{6}$ )

1) SCHRÖDER, Gött. Nachr. 1917, 162.

2) GrafF, Diut. 3, 401.403 f.; Hoffmanns Verzeichnis S. 26 f. 31 ; HoffmanN, Fundgr. 1, 257-259; SCHERER, KI Schr. 1, 617-620; Hugo Herzog, Anz. 15. 217; SCHRÖDER, ZIdA. 45, 217-223. 419. Daß beide Gediclite von ein und demselben Verfasser herrühren, ergibt sich aus der Uebereinstimmung in Inhalt und Form; im Priesterl. 386-393 zitiert er außerdem unter Berufung auf eigene Verfasserschaft seine Verse aus derErinn. 181186 (zwei verschiedene Verfasser nelımen an KOCHENDÖRFFER, ZfdA $35,187-2 C 4$, KELLE 2, 95 f., GRUNEWALD S. 26; dagegen BAUNACK, ZfdA 54, 99 ff. 57, 80 ff.). HEINZEL hielt die 42 Verse nach 884 in der Erinn. und die 9 Verse nach 315 im Priesterl. fiir eingeschaltet (S. 135 f. u. 153).

3) Vgl. Scherer, Ki. Schr. 1, 618.

4) RŐDIGER aaO. S. 279-283; ZWIERZINA, ZfdA. 43, 79 .

5) LaChMANN, KI. Schr. S. 331; Wilmanns S. 2 ff.; Kelle 2, 88. 294.

6) Das Iebensvolle Bild, das Hianzes von ihm entworfen hat, ist von der naclifolgenden Forschung in den Hauptziigen anerkann t worden (vgl. auch DIEMER, KI. Beitr. XIV; Scherer aaO.; O. Lorenz aaO., bes. S. $34 \mathrm{fI}$.; BAUNACK, ZfdA. 54, 113 ff.). Erimn. 225 reclmet sich Heinrich zu den Laien: Dar âf hab wir läien ein archwân. KOCHENDÖRFFER S. 308 ff. lıält diese Stelle für eine "fingierte Aeußerung der Gemeinde" (S. 312), aber es ist aus dem Zusammenhang nicht sicher nachzuweisen, daß hier die Gemeinde redend oder einwerfend gedacht ist. Er war also wohl Laienbruder im Kloster Melk. Er muB schon vorher eine umfassendere Bildung besessen haben. was so viel heißt als: er muß höherem Stande angchört haben, denn nur als Adliger oder Rilter konnte er ein solclies Wissen erreichen. Ein gewölnnlicher frater conversus, ein ursprünglicher Arbeiter, Bauer, Handwerker, der nach seinem Eintritt ins Kloster dic profanen Gesclıäfte verrichtete, war er niclit (vgl. Du CANGe-Favre 2, 547 unter "Conversio"; Buch der Riigen, ZfdA. $2,25 \mathrm{f}$ ). Vielmehr gelıörte er wohl zur kílasse der Oblati oder Donati, jener Laien, besonders Adliger, die sich und das llurige oder einen größeren Teil ilırer Giiter einem Kloster übergaben, jedoch noch in der Welt leben konnten (i) Cange-Favre $6,11-13$ ). Im Priesterl. $452-477$ stellt er sich als Verklindiger von Gottes Wort den Priestern, also den Weltgeistlicuen, gegenibber unter Bernfung auf die Bibel: „Der junge Daniel hat die alten jüdisclıen Priester tiberführt, also sollen die 


\section{Inhalt der Erinnerung. $\left.{ }^{1}\right)$}

I. Einleitung 1-34: "Ich will eine Rede halten von der Erinnerung an den Tod wcltlichen Leuten, da sie sich leider auf den Tod nur säumig vorbereiten." - II. Hauptteil 35-1023. A. Vom allgemeinen Leben (vgl. 450). Die allgemeine Sündlıaftigkeit 35-454. a) Gebrechen der Geistlichen 35-263 $\alpha$ ) Im allgemeinen 35-98; $\beta$ ) Gebrechen der Priester $99-186 ; \gamma$ ) Gebrechen der Mönche $187-242 ; \delta$ ) Schluß, über die Priester und Mönche 243-263. - b) Gebrechen der Laien 264-397 a) Die ungerechten Richter 264-271; $\beta$ ) das Ritterleben: Hoffart 289-397; dazwischen Hoffart der niederen Weiber 319-340. - c) Pfaffen und Laien sind lasterhaft 398-434 a) Die Habsucht Roms, Machtgeliust geistlicher Fürsten, die Reichen und die Armen 398-422; $\beta$ ) Laster aller Stände 423-434. - d) Ubergang zu B 435-454. - B. Erinnerung an den Tod 455-1028. a) Vergänglichkeit des Lebens, darum gedenke des Todes 455-482. - b) Elend des Lebens 485-558. - c) Häßlichkeit des Todes 559-635. - d) Schrecken nach dem Tode 636-1028 a) Mahnung zur rechtzeitigen Buße 636-662; $\beta$ ) der Sohn am Grabe des Vaters, die Pein des Vaters im Fegfeuer, Warnung für den Soln $663-884 ; \gamma$ ) Christus selbst warnt $885-910 ; \delta$ ) Hölle und Himmel 911-1028. - III. Schluß 1029-1042 Gebet 2u Gott.

Der Dichter selbst hat durch einen Übergang 435-454 die beiden Teile $A$ und $B$ ausdrücklich getrennt, $A$ ist für sich ein Gedicht oder ein Gedichtteil, liet: den Abschluß dieses ersten Teiles bezeichnet er mit den Worten hie welle wir enden ditz liet 447 ; das Bisherige handelte von dem gemäinem lebene 450, im Folgenden soll die Rede sein von dem tôde 452; es ist die Mahnung an den Tod: Nû gedench aber mensch dînes tôdes 455 .

\section{Inhalt des Priesterlebens. ${ }^{2}$ )}

Der Anfang fehlt. 1-8 Warnung vor der ewigen Strafe. Von da an ist das Thema des Gedichtes die Unzucht der Priester (Weltgeistlichen) 9-746. a) Die Priester, die die Merischen lehren sollen, sind nicht gewissenhafte Warner (Wartleute) vor dem Teufel 9-48. b) Schlemmerei und Buhlerei der Priester 49-249, dabei zwei Szenen: der Fremde, der um Einla $B$ in das Pfarrhaus bittet, wird nicht aufgenommen $69-89$, Gelage beim Pfarrer $90-110$; Salomo als Beispiel, wie die Weiber den Mann von Gott abziehen 136-162. - c) Das

Priester auch ihm, dem Dichter, erlauben, Gottes Wort zu reden; die (dumme) Eselin hat den Propheten Bileam das Wort Gottes gelehrt, darum darf es die Priester nicht verdrießen, wenn ich, ein Sünder, dies tue. Niemand kann mir es verwehren, daß ich von Gott sage, was ich weiß, mögen sie darüber auch in $\mathrm{HaB}$ und Neid geraten. Gott hat wohl auch noch irgendwo einen Dienstmann, dem dies wohlgefällt und der nach meinen Worten einen sichern Standpunkt gewinnt." Ein "monachus" hätte seine Kenntnisse vom Wort Gottes den Weltgeistlichen gegenüber wohl nicht so minderwertig dargestellt $(\mathrm{zu}$ Bileams Eselin vgl. HEINZELS Anm. S. 146 f.), und suntere 457 konnte er sich nennen als einen, der noch mit der Welt in Verbindung war und nicht durch die Priester- oder Mönchsgelübde völlig dem geistlichen Stande angehörte (zu V. $467 \mathrm{vgl}$. LECOY DE LA MARCHE S. 27: Befürchtungen vor der Eifersucht der Weltgeistlichen wegen des ungeheuren $\mathrm{Er}$ folges, den die Predigt der Franziskaner und Dominikaner im 13. Jh. hatte).
Zur Zeitbestimmung des Gedichté ist übrigens $z \mathfrak{u}$ bemerken, daß auch die Bußpredigten des 13. u. 14. Jhs. denselben lnhalt hatten, z. B. das Buch der Rügen, der Renner (vgl. auch CRUEL S. 269-277). Selbst die Ruicksicht auf die "Frauen(Weltfrauen)" findet sich im Buch der Rügen, ZfdA. 2, 89 f., und Rudolf v. Ems im Barlaam 294, 35-298, 10 und Hugo v. Trimberg im Renner Ausg. d. Lit.Vereins 12281 ff., gehen nach vorherigem Tadel in ein hohes Lob der Frauen über; demnach kann aus der Schonung, die Heinrich gegen die Frauen übt, kein SchluB auf etwaige ritterliche Herkunft gezogen werden (HEINZEL S. 17). Allgemein wurde, und mit Recht, die Annahme von WILMANNS zurückgewiesen, Heinrich habe in Ungarn um 1360 gedichtet (SEEMÜLLER aaO., LORENZ aaO., SCHRÖDER aaO., KOCHENDÖRFFER S. $281 \mathrm{ff}$.).

1) Heinzel S. 8-10; Wilmanns S. 53 f.

2) Diemer, Kl. Beitr. XV, 40-45; SCHERER aaO.; Heinzel S. 10 f.; Baunack, ZfdA. 57, $77-80$. 
Meßopfer 250-436. Es fordert reine Hände; das Opfer selbst wird nicht unrein, wenn es auch von unreinen Händen gereicht wird. - d) Beispiele aus der Bibel 437-515: Daniel und die unkeuschen jüdischen Priester 437-486; die drei Arten der Seligwerdenden: Noe - die die Kirche lenkenden (guten) Geistlichen, Daniel - die Enthaltsamen, Job die Ehelichen, diesen gegenüber die Hurer 487 - 515. - e) Das rechte Priesterleben 516 - 562. - f) Unkeuschheit und Simonie 563-618. - g) Die geistliche Obrigkeit und die Priester 619-642 (die Priester sollen keine weltliche Arbeit treiben, der Feldbau soll ihnen verboten werden). - h) Gegen die Pfaffendirnen 643-746.

Die Hauptzüge des Stoffes sind nach einem bestimmten Plane geordnet, aber innerhalb der engeren Teile bewegen sich die Gedanken ziemlich frei, bisweilen willkürlich. Infolge davon kommen mehrfach Wiederholungen vor oder es sind gewisse bevorzugte Motive besonders weit ausgesponnen. In der Darstellungsweise wechseln gegenständliche Partien, wie Erörterungen der bösen Zustände, der sündigen Handlungen, der Strafen, mit paränetischen Partien, wie Ermahnungen, Warnungen, Klagen und Anklagen. Während das zweite Gedicht, das Priesterleben, nur von den Priestern spricht, greift das erste weiter und erstreckt sich über Priester und Laien, über Leben und Tod.

Schontungslos enthüllt Heinrich die Gebrechen der Bevorrechteten, die dem Volk als höhere Wesen gelten mußten. Hoffart und Habsucht (superbia und avaritia) sind die Hauptlaster der Ritter, die Priester sündigen in Unzucht, Schlemmerei und Habgier (luxuria, gula, avaritia), die Mönche durch Klostersünden, die in der Mönchsregel (Benediktinerregel Kap.4) gerügt sind. Aber nicht nur durch Brandmarkung der Laster, sondern viel wirksamer durch das Schreckgespenst des.Todes') und der Verdammnis mahnt er die hoffärtigen und geilen Sünder zur Bekehrung: "Gedenke, Mensch, deines Todes, gedenke der Worte Hiobs 'kurz sind meine Tage, mein Leben ist wie der Wind, wie ein Wasser, das dahin streicht'; gedenke deines Schöpfers in der Jugend, ehe dein Staub wieder zur Erde wird" (Erinn. $455 \mathrm{ff}$.). „Armer Mensch, du brüchiger Lehmklotz, mit Schmerzen und Wehschreien hat dich die Mutter geboren zu großem Leiden, nackt und ohne Hemd bist du zur Welt gekommen, zur Armseligkeit bestimmt. Mit Schrecken ist der Mensch geboren, mit Schrecken muß er zergehen" (Erinn. 485 ff.). - Das ganze Leben ist eine fortgesetzte Sorge (Erinn. 511 ff.), der Leib ein Opfer aller möglichen Krankheiten und Verstümmelungen (Erinn. 544 ff.). - „Tritt an die Bahre des Gatten, du edle Frau, betrachte ihn genau, deinen lieben Mann, sieh, ob er noch so fröhlich mit den Augen gegen dir zwinkert! Wo sind seine müBigen Reden, mit denen er der Hoffart der Franen schmeichelte? Sieh, wie die Zunge in seinem Munde liegt, die so wohlgefällige Liebeslieder sang! Wo ist sein Kinn mit dem wolılgepflegten Bart? Wie liegen die Hände kläglich, mit denen er dich licbkoste und unfing! Wo sind die Füße, die so höfisch mit den Franen einherschritten? Schau

1) Siche oben S. 185 Memento mori; Freybe, Das Memento mori S. 205-210; EL. Petrers S. 137 ff.; BURDACH, Ackermann S. 310 . 
ihn an: gebläht ist sein Leib wie ein Segel, übel fährt Geruch und Dunst aus dem Leichentuch" (Erinn. 597 ff.). Und noch Schauderhafteres bekommt der edle und reiche Jüngling zu schauen, wenn er den Stein vom Grabe seines Vaters lüftet (Erinn. 663 ff.). ${ }^{1}$ )

Alles ist hier Sünde, und alle Sünde kommt aus der Weltlust. Schönheit und Schmuck des Lebens, die feine, rücksichtsvolle und freundliche Bildung des Rittertums, sie ist Eitelkeit und Hoffart, nichts als vergänglicher Schein. Arme und Reiche, Pfaffen und Bauern, Kaufleute, Edeldamen und Ritter (Erinn. 420 ff.) sind allzumal Sünder; der Sohn trachtet nach dem Besitz des Vaters (Erinn. 274 ff.), undankbar ist er und bekümmert sich nicht um dessen Wohl (Erinn. 867 ff.); keine Treue und Ehre gibt es zwischen Herrn und Knecht (Erinn. 286 ff.). Die Welt ist das ärgste Elend. Darum „Gedenke des Todes". Der Schluß aller menschlichen Weisheit ist memento mori.

Und doch, völlig gleichgültig gegen die Meinung der Menschen ist auch dieser Eiferer nicht. Zweimal bittet er, man möge ihm nicht zürnen, daß er die Wahrheit sage (Erinn. 438 ff., Priesterl. 641 ff.). Er verschweigt auch nicht, daß es rechtschaffene Priester gibt (Priesterl. 516 ff.). Und auch auf die Frauenverehrung nimmt er Rücksicht: obgleich er das Leben der Damen wie das der Ritter got widerwertic nennt (Erinn. 291, vgl. auch 427-429), so will er doch nichts Übles von ihnen sagen (Erinn. 341, s. auch 318), um sofort den armen Weibern eine Scheltrede zu halten.

Beide Gedichte sind Strafreden, Bußreden. ${ }^{2}$ ) So wie Heinrich haben viele im Mittelalter das moralische Gewissen der Menschen aufgerüttelt, gewiß nicht alle mit der gleichen gewaltigen Beredsamkeit. Er hat doch nur die herrschenden Ideen ausgesprochen. Sie gipfeln im Mönchtum. Dieses ist die höchste Form des christlichen Lebens, die Verwirklichung von Augustins Gottesstaat, und das Ziel ist: „in dieser Welt tot sein“ (Erinn. 194). Das ist die Askese, und sie wird gefordert auch vom Weltklerus und selbst den Laien zur Nacheiferung empfohlen. Dann ist das Ideal, das gottgefällige Leben, überall in der Menschheit erreicht. In Wirklichkeit aber herrscht der Abfall von Gott: omnes declinaverunt Ps. 13, 3. 52, 4 (Erinn. 12--15). Dieses wirkliche, das abgefallene Leben stellt der Dichter dar, so wie es ist, d. h. er spricht die wôarhäit (Erinn. 439, Priesterl. 645).

Ein Bußprediger ist Heinrich, ein schonungsloser Fanatiker, der die Sünde in den innersten Schlupfwinkel verfolgt und der auch nur die Sünde im Menschen sehen will. Er hat nur kalte Bitterkeit, nirgends Milde und Verzeihung, und keine schmerzliche Regung über das Sündenunglück läßt er vernehmen, in dem die Menschheit versunken ist; er hat keine Ge-

\footnotetext{
1) Mit diesen düsteren Bildern vom Verfall des Fleisches gerät das Gedicht in den Bereich der Visionen von der Zukunft des Leibes und der Seele. Vgl. auch besonders Hartmanns Rede vom Glauben 2370 ff. $2512 \mathrm{ff}$.
}

2) Leichenpredigten S. LECOY S. 222; CRUEL S. 237; LINSENMAYER, Reg. S. 488. Lat. Strafgedichte der Carmina Burana: SCHMELLER Nr. 17. 64. 68 a. 71.72 .73 .73 a. 86. 93.170. 171. 171 a. 192.199. 
meinschaft mit diesem Leiden, er selbst steht außerhalb dieser Gesellschaft. Sein einziger Zweck ist, Abscheu vor der Sünde und Furcht vor der Strafe zu erwecken. Er ist ein gewaltiger Prediger gegen die Sünde und für die Askese; einer der furchtbarsten unseres deutschen Mittelaiters, er ist ein Meister der Strafpredigt, er besitzt in höchstem Maße die Kunst, durch die Worte $\mathbf{z u}$ erschüttern, starke Erregungen hervorzurufen (movere, flectere). Ihm steht eine lange Stufenfolge von Wirkungsmitteln zur Verfügung, die sich steigern von der Ironie über die Schwächlinge, dem Spott auf die Erbärmlichkeit des Menschendaseins zum Hohn, der wie Schadenfreude sich anhört, wenn er den jähen Glückswandel des Reichen zergliedert, und zu leidenschaftlichem Zorn auf die Gemeinheit und Schlechtigkeit. $\left.{ }^{1}\right)$

Und leidenschaftlich wie der Mensch ist seine Sprache,2) lebhaft und bewegt, immer sollen die Zuhörer in Atem gehalten werden, daher er sich oft unmittelbar an das Publikum oder an die Angegriffenen wendet. Dazu dienen: Ausrufe, besonders mit owê, z. B. Owê armill phaffhäite (Erinn. 35), owê dirre cläglî̀che sterbe (Erinn. 636), oder Armer Mensch, brœder läim (Erinn. 483); rhetorische Fragen an die Zuhörer oder Leser, Antworten, die den Hörern oder Lesern in den Mund gelegt werden, Anreden an diese oder an den Menschen überhaupt, z. B. Nî̀ gedench aber mensch dînes tôdes (Erinn. 455); Aufmerksammachung auf das Folgende, z. B. noch hoeret einen andern sturmschal (Erinn. 264). Daneben finden sich natürlich auch die traditionellen Formeln der Wahrheitsbeteuerung oder Berufungen auf die Quelle.

Neben der Lebendigkeit ist die Anschaulichkeit eine zweite Bedingung der Bußpredigt. Dem Redner verleiht die eigene innere Erregung unwillkürlich eine Steigerung des sprachlichen Vermögens, die Gedanken nehmen dem volkstümlichen $Z$ weck entsprechend konkrete Gestalt an, die Ausdrucksweise wird metaphorisch, z. B. dill iriwe ist gärlîch erslagen (Erinn. 272), mûzzechäit unt muo singent nicht eine wî̀se (Priesterl. 230 f.); die einfache Versinnlichung kann dann auch zı Bildern oder Vergleichen erweitert werden. Noch eindrucksvoller wird der Ton durch Hereintragung des wirklichen Lebens. Der Priester, der Geld verdient durch Nachlaß von Sünden, führt Rechnung über diese Einkünfte; er nimmt eine Feder und ein Büchlein und schreibt seinem Weib eine Pergamenturkunde (blochvel), das ist "das Haupt-

1) Der Dichter setzt das ideale gottgefällige Leben voraus und stellt ihm die Wirkliclıkeit gegenüber. Er ist "von dem ldeale lebhaft durchdrungen " und will "gliihenden Unwillen gegen moralische Verkehrtheit erzeugen ": das ist die Art der Satire, wie sie Schiller in seiner Abhandlung Ueber naive und sentimentalische Dichtkunst bestimmt, und mit Recht nernt daher SCHERER Heinrich von Mclk den ersten deutschen Satiriker, dessen Namen wir kennen (aaO. S. 64); er legt ilım noch bestimmter die Bezeichnung "Juvenal der Ritterzeit" bei, was insofern zutreffend ist, als der Diclıter die Gebreclıen als Laster zornig straft und nicht, wie Horaz, als lächerliche Verkehrtheiten menschlich begreift. Eine engere Gleiclistellung aber des m.allerl. mit dem antiken Aulor wiirde auf Abwege fiilıren, vgl. KochendörFFLR S. 310 f.

2) Ueber Heinriclıs Stil s. HEINZEL S. 1-3. 12-14; RÖDIGER S. 311-324; KOCHENDÖRFFER S. 200. 311 ff.; LORENZ S. 71 ff.; BAUNACK, ZfdA. 57, 85 ff.; 'PAUl, KÖH.ER, Der zusamnengesetzte Satz in den Gediclıten H.s v. M. und in des arm. Harmann Rede v. Gl., I. Teil, Dic Temporalsälze, Berliner Diss. 1895. 
buch, in das die einlaufenden Sündengelder eingetragen werden " ${ }^{1}$ ) 641 . ff. Dramatisch in Wechselrede verläuft die Szene im Pfarrhof mit dem um Herberge bittenden Wanderer (Priesterl. $69 \mathrm{ff}$.), plastisch gestaltet sind die beiden Darstellungen vom toten und vom verwesenden Ritter (Erinn. $597 \mathrm{ff} .663 \mathrm{ff}$.). Überall hier ist das Leben in seiner Tatsächlichkeit beobachtet, das Gelage des Priesters wird nicht geschildert, sondern in seinem Verlaufe erzählt (Priesterl. 95 ff.); die armen und doch hoffärtigen Taglöhnerinnen sieht man auf den Gassen und in den Kirchen geputzt aufsteigen wie Herrentöchter (Erinn. $319 \mathrm{ff}$.); man sieht den Leichnam auf der Bahre liegen, und die Zurüstung, und wie sich die Verwandten versammeln (Erinn. $566 \mathrm{ff}$.); und lebendig steht vor uns die Pfaffendirne in ihrer modehaften Scheineleganz, wie sie sorgsam die Handschuhe überzieht, Handtüchlein und Spiegel anlegt, um sich einen neuen Liebhaber einzufangen (Priesterl. 689 ff.).

Einzelne Stilformen: der Satzbau ist oft lässig, der natürlichen Umgangssprache folgend. Zuweilen sind es längere Perioden, dann auch gedrungene Kola, je nach der rhetorischen Temperamentslage. Anapher, Asyndeton, Polysyndeton und besonders häufig zweigliedrige Verbindungen werden angewendet. Wortspiele: gebosern oder gibezzern Priesterl. 368 u. a.

Lat. Zitate ${ }^{2}$ ) sind es nur wenige, in jedem der Gedichte vier. Einige sind an passender Stelle angebracht: omnes declinaverunt im Eingang der Erinnerung (V. 12) ist das Leitmotiv der Strafpredigt; des beginne wir in nomine domini Erinn. 454 leitet zum zweiten Teil der Erinnerung über; mit in secula seculorum schließt dieser und das ganze Gedicht; das ironische Sprichwort Priesterl. 67 f. schließt drastisch die vorhergehende allgemeine Erörterung ab.

Endlich aber ist doch die Frage aufzuwerfen: sind diese Gedichte auch wirklich in dieser Form vorgetragen worden, sind es Predigten gewesen vor einer lauschenden Menge? Die Verse Erinn. 435-454 sprechen dagegen: der Dichter gibt den beiden "Liedern" einen besonderen Namen und meint ausdrücklich, ,swaz wir von dem tôde wellen sagen, daz vindet ir geschriben hie $b \hat{\imath}^{\imath}$, er rechnet also auf Leser. Das Priesterleben zudem kann gar nicht für eine öffentliche Predigi bestimmt gewesen sein, denn vor was für einem Publikum hätte dieser Stoff als Predigt vorgetragen werden sollen? Die stilistischen Formen sind der Predigtsprache entnommen, ${ }^{3}$ ) wie das überhaupt in der frühmhd. Dichtung üblich war. Die Gedichte waren also zum Lesen bestimmt oder zum Vorlesen in einer engeren Gemeinschaft; einige Partien, wie die Erinnerung an den Tod 455 ff., mochten sich auch ganz besonders zum öffentlichen Vortrag eignen.

Die beiden Gedichte zeugen von theologischen Kenntnissen: Beda (Priesterl. 325), Honorius Aug. und Gerhoch von Reichersperg und vielleicht

1) Heinzel S. 151; Wilmanns S. 61; KOCHENDÖRFFER S. 199; buochvel Mhd. Wb. II, 2, 492a Z. 12. III, 294a; LEXER 1, 387.
2) GRÜNEWALD S. 26.

3) KOCHENDÖRFFER S. 311. 
einige andere kirchliche Schriftsteller sind nachzuweisen, ${ }^{1}$ ) in der Bibel war der Verfasser wohl bewandert. Die ganze Tendenz seiner Dichtung beruht auf jener Strömung der Weltverachtung, die seit der Mitte des 11. Jhs. auftrat und besonders im 12. Jh. mächtig wurde. ${ }^{2}$ ) Ein Unterschied in der Beiziehung der Autoritäten besteht zwischen Erinnerung und Priesterleben. Die Zitates) in dem ersten Gedicht sind Lehrsätze, die den Inhalt leiten, $11 \mathrm{f}$. 456-482 aus den Psalmen, Hiob, Sirach, $840-842$ aus Paulus' Brief an die Epheser 5, 5, bezw. an die Kolosser 3, 5. Im Priesterleben dagegen nehmen die Berufungen auf die Bibel (bezw. auf Beda) eine bedeutsanere Stellung ein. Gleich im Eingang des Gedichtes wird die Pflicht des Priesters vorangestellt nach Ezechiel 33, 2-8: er soll als Wartmann auf hoher Zinne stehen, um sein Volk gegen den Ansturm der Feinde in Bereitschaft zu halten $17 \mathrm{ff}$. Weiterhin dienen die Zitate zu unterschiedlichen Zwecken: es sind Lehrsätze 136 ff. aus Sirach, 529 f. aus Malachias; Beispiele: Joel 115-117, Salomo 140-146, David und Urias 236-243, Judas 302-315. 355 - 360, Susanna und David 445-464, Balaam 469-472, Noah, Daniel, Hiob 494-504 (nach Ezechiel 14, 14 bei Gregor, Beda, Honorius u. a.); Beweise für dogmatische Sätze: Paulus 172-218. 286-289, Beda 316336, 1. Könige 2, 25. 341-346; der Abschnitt über die Messe ist in der Erinn. 161-186 eine einfache Erklärung, im Priesterl. 367-436 dagegen eine weitläufigere theologische Erörterung und Unterweisung.

Das Priesterleben hat also einen gelehrteren Charakter; das liegt in der Bestimmung des Gedichtes, das auf die Geistlichen wirken soll, während die Erinnerung das "allgemeine" Leben und den Tod betrifft, also die Gesellschaft insgesamt.

Durch die starke Verwertung des wirklichen Lebens kommt den beiden Gedichten große sittengeschichtliche Bedeutung ${ }^{4}$ ) zu. Unmittelbar die Literaturgeschichte berührt die Zeichnung des höfischen Ritters (Erinn. 597 ff.), zu dessen feiner Bildung es gehört, die Frauen zu preisen und Liebeslieder (troutliet 612) wohlgefällig zu singen. Da die Abfassungszeit des Gedichtes um 1160 anzusetzen ist, so liegt hier der älteste historische Beleg für den mhd. Minnesang vor. ${ }^{5}$ )

Metrik.6) Die Erinnerung hat weniger als ein Viertel, das Priesterleben etwa ein Siebtel unreine Reime, ohne schwere Assonanzen, hier auch kommen am Schluß von Abschnitten 16mal Dreireime vor. Die Verse haben

1) Heinzel S. 20. Damit ist freilich niclit erwiesen, daß er die betreffenden Quellen auch unmittelbar selbst benutzt habe, die Stellen gehören eben $\mathrm{zu}$ dem kirchlichen Zitatenschatz, LORENz S. $61 \mathrm{ff}$.

2) DiEMER, KI. Beitr. XV, 53 ff. 11. Anm., XVIII, 127 ff., HeinZEL S. 42-49; KeLLE LG. 1,82-84. 91-96. 289-293. 295-301; Kelle, Wiener SB. aaO.; BURDACH, Ackermann S. $309 \mathrm{ff}$.

.) Siehe Heinzed zu den betr. Stellen.

4) Heinzel in der Einleitung, bes. S. 4 ff.;

Deutsche Literaturgeschichte. II.
Wilmanns S. $6 \mathrm{ff}$; Baunack, ZfdA. 54, $113 \mathrm{ff}$

5) Ueber etwaige Bezielunngen von Veldekes Eneide und Heinrich v. Melik s. BeHaghel, Eneide S. CLXXIX f.

6) W. GrImM, ZGdR. Reg. S. 332. 334; HeINZEL S. 14 f. VoGT, Beitr. 1, 142; RöDIGER S. 283-311; SCHRÖDER, Anegenge S. 20 ff. Wilmanns S. 4 f.; KOCHENDÖRFFER S. 197-200; BAUNACK, ZfdA. 57, 80 ff.; SARAN S. 252-254. 
verhältnismäBig ebenen Rhythmus, doch ist im Priesterleben eine Neigung zur Längung $\mathrm{zu}$ beobachten.

\section{$\S 64$. Die Wahrheit.}

Kelle 2, 98-101. 301-304; PiPer, GD. 2, 94 f. - Ausg.: Diemer, D. Ged. S. 85-90, Anm. S. 31 f.; WAAG, Kl. d. Ged. ${ }^{2}$ S. $135-141$ u. Einl. S. LXXXIII-XC; EDUARD WEedE, Kieler Diss. 1891, dazu RődiGER, Archiv 88, 408 f., KRAUS, Anz. 18, 399-401; WUNDERLICH, ZfdPh. 25, 402 f.; Scherer, QF. 7, 51-54. 12, 63 f.; PIPER, ZfdPh. 20, 480 f. (Kollation); SCHRÖDER, ZfdA. 46, 392 (Textkritisches); MÜNSCHER, Bücher Mosis, passim.

Hs.: Vorauer Hs. Bl. 96a-96d. ${ }^{1}$ ) Der Dialekt ist bairisch. ${ }^{2}$ ) Das Gedicht betitelt sich selbst diu wârrheit (Daz liet heizet diu wârrheit WAAG 151). Es ist in Österreich verfaßt, etwa um 1150.

Inhalt. Das Gedicht ist eine Bußpredigt, beruhend auf dem Dualismus zwischen dem gegenwärtigen Leben, der Verbannung, und der Zukunft, dem Himmelreich, unserer Heimat, $z$ wischen dem ewigen Tod der Hölle und der Gnade des Paradieses I-26. Der Teufel führt zur Hölle 45-58, Christus in das Heimatland 59-78. Aufforderung zur Bekehrung, sie führt zum ewigen Leben 79-134. Höhepunkt der Bußpredigt: Warnung vor der Verzweiflung, keine Sünde ist so schwer, daß sie nicht durch Buße gesühnt werden könnte 135-150. Gott vergütet uns unsere Reue 151-170. Wir aber sündigen fortwährend an unserm Leibe ${ }^{3}$ ) und viele müssen zur Hölle fahren 171-183.

Der Dichter faßt im Predigtstil seine Zuhörer ${ }^{4}$ ) zusammen als "wir alle", als die Menschheit gegenüber Gott und dem Teufel und spricht auch unmittelbar zu seinem Publikum in der üblichen Anredeformel (mîne) vil lieben 27. 93. 121. 157, in leicht faßlichen Gleichnissen (62 ff. $94 \mathrm{ff.} 103 \mathrm{ff}$. $141 \mathrm{ff}$. ), in volkstümlicher Anschauung (das Treuverhältnis mit Dienst und Lohn zwischen Christus und den Menschen 86-102). In kunstloser Rede ohne lat. Floskeln, mit vielen bequemen Formeln und ohne starke Gedankenausprägung entfaltet er sein Predigtthema. Oft berührt er sich mit andern Gedichten, ${ }^{5}$ ) er ist weder in der Form noch im Stoff originell.

Assonanz gehört noch zum Reimstil, Flexionssilben können noch auf haupttonige Silben gebunden werden. Die Verse haben ungleiche Länge.")

\section{$\$ 65$. Trost in Verzweiflung.}

Piper, GD. 2, 126 f. - Ausg.: Docen in MaBmanns Denkm. S. 80-82; WaCKernagel, LB. ${ }^{5}$ S. 429-432; Meyer-Benfey Nr. 4 S. 19-21; LeitzmanN, Kl. geistl. Ged. S. 27--30. --

1) In DiEmers Abdruck von den vorhergehenden Büchern Moses nicht getrennt, erst von WACKERNAGEL, LG. $1^{1}$ S. $273\left(1^{2}, 349\right)$, als selbständiges Gedicht unter dem Titel "Himmel und Hölle" behandelt. Die Benerınung 'diu wârlieit' stammt von MÜLLENHOFF, Denkm. 1. Aufl. S. 390 (MSD. $11^{3}, 248$ f.); dagegen SchwiETering, Singen u. Sagen S. 12 f. 35 (vgl. SCHRÖDER, Gött. Nachr. 1917 S. 162).

2) WEEDE S. 29-43; WAAG, Beitr. 11, $105-109$.

$\left.{ }^{3}\right)$ Putzsucht und Kleiderluxus sind Auswüchse der Hauptsünde Luxuria; in der Bamberger Beichte sind sie unter die Vana gloria, eine Abart der Superbia, gebracht: in losser ubercieride, in wâttiuride MSD. Nr. 91, 134 (viell. auch in ubergivazzide unter Superbia $Z .123)$, ebenso in der Wessobrunner Beichte I, MSD. Nr. 90, 106 (96). - In des râtes 180 heißt rât 'Vorrat', = von einem solchen Gerät, Aufwand (wie vorher, 17I ff., in Gewand und Schuhwerk getadelt wurde), will ich für meine Person Abstand nehmen.

4) Es ist wohl ein gemischtes Laienpublikum vorauszusetzen, dafür spricht die Art der Formeln: arme unde riche 5, junge joh alte 7 , wîp unde man 173, auch das Fehlen lat. Wörter.

5) Parallelen bei Diemer, Anın.; MSD. I $^{3}$, 183; SCHERER, QF. 7 aaO.; WEEDE S. 16-28; KraUs aaO.; Kelle aaO.

6) WEEDE S. 44-59; über Dreireim s. WEEDE S. 50-52; WAAG S. LXXXV. 
Scherer, ZfdA. 20, 346-355, QF. 12, 102-106; SchönBACH, Über Hartmann von Aue S. $396-403$; v. D. LEYEN, K1. Beitr. S. $73-82$.

Hs.: Bruchstïck, zwei zusammenhängende Oktavblätter vom Ende des 12. Jhs., im Jahr 1813 in Privatbesitz in Memmingen, seitdem verschollen. Der ursprüngliche Umfang des Gedichtes läßt sich schwer bestimmen; am Eingang scheint wenig verloren zu sein.

Der Dialekt ist obd., die Hs. ist einigen wenigen Formen zufolge wohl in Baiern geschrieben. Dort oder in dem benachbarten Alemannischen wird auch das Gedicht verfaßt worden sein, etwa $1 \mathrm{~m} 1180$.

Inhalt. ') Es sind die Gedanken des Menschen, der zwischen Welt und Gott gestellt ist, die Kämpfe der nach Befreiung aus den Banden der leiblichen Bedingtheit und den Wirrnissen der Leidenschaften ringenden Seele. Auf der christlichen Grundanschauung vom Dualismus von Leib und Seele beruht diese asketische Moral. Die Lehre des Dichters $\left.{ }^{2}\right)(1-8)$ ist: Kampf gegen den Leib und die Begierden (9-31), mit dem Preis der Armut (32-47); und Kampf gegen das Herz (48-141). Vergebens will er der Welt entsagen, Verzweiflung ergreift ihn ob seiner Ohnmacht, von allen Heiligen verlassen glaubt er sich der Hölle verfallen (142-165) - da geschah ihm ein großes Glück. Hier bricht das Fragment ab. Wir hören die Bekenntnisse einer Persönlichkeit, die den schweren Weg vom Begehren zum Entsagen zurückgelegt hat und dabei bis zur Grenze der Trostlosigkeit gelangt ist. Stark ist dieser Mensch in der Selbstüberwindung, freudig gibt er den Reichtum hin, leicht bezwingt er das Behagen des Leibes, aber gegen die unselige Herrschaft der Begierden des Herzens kann er sich nicht selbst helfen, kein Fürbitter und nicht die lnbrunst des Gebetes. Der letzten hoffnungslosen Not ist er verfallen, dem Zweifel. Da kam die längst entschwunden geglaubte, die Rettung. Wir erfahren das Heil nicht mehr, aber welches Glück konnte ihm anders geschehen sein als die Gnade? Die Gnade Gottes, die ihm den Weg der Buße zeigt. ${ }^{3}$ )

Es ist eine Mönchspredigt, besonders eindringlich und wirksam dadurch, daß der Kampf gegen die Gefahren des Herzens als eigenes inneres Erlebnis (Ichform) vorgetragen wird. Als Predigt gibt sich das Gedicht zu erkennen durch die Anreden 15. 28 f. 132. 167. Der Redner versetzt sich in die Gedanken seiner Zuhörer 5 ff. 9 ff. 32 ff.

Die Sprache des Gedichtes wirkt ergreifend bei aller Schlichtheit. Die Metrik in ihrer Reimnot ist kunstlos. Die Reime sind fast rein, mit Ausnahme von sieben (oder sechs?) Fällen überschüssiger Konsonanz (6-[oder 5] mal $\mathrm{n}, 1 \mathrm{mal} \mathrm{t}) ;^{*}$ ) Dreireim findet sich $19-21$, ein lat. Reimpaar 70 f. ${ }^{5}$ )

1) Scherer, QF. aaO.; V. D. LEYeN aaO.

2) Das scheint der Inhalt des verstümmelten Eingangs V. $1-8$ zu sein, vgl. v. D. LEYEN S. 74 .

3) Dieselben Lelıren gibt Hartmann v. Aue: im armen Heintich zeigt er die Nichtigkeit der Welt, im Eingang des Gregorius das Verderbenbringende des $Z$ weifels, und ein Kampf der psychologisclien Faktoren des Leibes und des Herzens bildet den Inhalt seines Biichleins, hier jedoch in weltlich höfisclıem Sinne gewendet. Auch einzelne Züge kehren bei ihm wieder, ja dle Anklänge sind so stark, daß man an unmittelbaren Zusammenhang denken kann. Aber wahrseheinlich hat doch Hartmann unser Gedicht niclit direkt benutzt, vielmehr schöpften wohl beide aus gleicher Quelle, einem weitverbreiteten Ablandlungsund Predigtthema iiber die Abkehr von der Welt. Vgl. Scherer, ZfdA. 20, 352 ff.; W. Wackernagel, Der arme Heinricli, ligb. von TOISCher S. 14-16, neu ligb. von ERNST Stadler, 1911. S. 17 f.; Herm. Seegers, Neue Beiträge zur Textkritik von Hartnianns Gregorius, Kieler Diss. 1890, S. 32-34; SchÖNBACH, Ueber Hartmann v. Aue aaO.; v. D. LEYEN, KI. Beitr. aaO.

4) SCHerer, ZfdA. 20, 351 f.; SCHÖNBACH S. 398 f.; v. D. LEYEN S. 74.

5) Zwei lat. Stellen kommen vor, s. GRÚNEWALD S. 27. 
Die Verse sind noch ungleichmäßig gebaut, neben regelmäßigen Vierhebern begegnen viele mit silbenreicheren Senkungen.

$\$ 66$. Vom Rechte.

Kelle 2, 206. 384; Piper, GD. 2, 86 f., Nachtr. S. 281 f. - Ausg.: Karajan, DSpr. S. 3-16; WAAG, Kl. d. Ged. ${ }^{2}$ S. 70-87 u. Einl. XLV-LVI, zur 1. Aufl.: Kraus, Anz. 17, 24 f. - SCherer, QF. 7, 7-14. 12, 53 f.; KRAuS, ,Vom Rechte" und „Die Hochzeit", Wiener SB. 123 (1891), IV. Abhandl., dazu SCHRÖDER, Anz. 17, 287-301, VoGT, LitBl. 1892, 145147, KOCHENDÖRFFER, DLZ. 1892, 1241, JelLINEK, ZföG. 44, 372; LöBNER, ZfdPh. 25, 560563; SCHRÖDER, ZfdPh. 28, 423. 29, 223; HANISCH, Leipz.Diss. 1909/10.

Hs.: Milstäter Hs. Bl. 135b-142a. Der Text ist gut überliefert. - Der Dialekt der Hs. ist innerösterreichisch, in Kärnten vermutlich ist auch das Gedicht entstanden; allerdings sind einige sprachliche Eigentümlichkeiten mehr im Alemannischen belegt.") Es ist, den Reimen zufolge, wohl um 1130-1150 abgefaßt worden.

Inhalt. I. Einleitung 1-12. Gott ist ein gerechter Richter, darum soll sein Knecht (der Mensch) das Recht lieben. - II. Hauptteil 13-523. A. Die drei Rechte (Pflichten) 13-344. Aufzählung: Treue (18 f.), Gerechtigkeit (20-23), Wahrhaftigkeit (24 f.). a) Die Gerechtigi eit 34-185. Das Verhalten des Menschen (hie 34) gegenüber dem göttlichen Recht ( 1 ff.), drei Arten menschlichen, d. i. falschen Rechtes: 1 . jeder handelt wie er will $(36-39), 2$. jeder sieht nur auf seinen Vorteil $(40-43), 3$. jeder will so viel Recht haben als er Macht lat (44-47). Recht und Macht im Gegensatz (48-67). Die Gerechtigkeit wird dargestellt an dem Verhältnis von Herr und Knecht, Bild vom Ausroden eines Waldes (68185). Ubergang zur Treue (186-194). b) Die Treue 195-238. Lucifer als übermütiger Knecht Gottes (196-216). Gleichheit vor dem Recht (217-238). c) Die Wahrhaftigkeit 239-344, Gegensatz: die Lüge. Die Macht der Wahrheit (Gottesurteil des heiBen Eisens (239-266); die Lüge soll man nicht weiter verbreiten (267-276); fremde Schande nicht weiter verbreiten (277-302). Nachtrag: (303-344): der Geiz Wurzel alles Úbels (303320); der Herr soll dem Knecht mit gutem Bcispiel vorangehen (321-344). - B. Die Rechte (Pflichten) verschiedener Stände 345-523. a) Pflichten der Ehegatten 345-386. b) Pflichten in der Familie 387-416. c) Pflichten des Priesters 417-523 (dazwischen Abschweifung 450-497 Gott sieht das Recht an). - IIl. Schl u B 524-549. Die drei Ordnungen $(r e h t)$ des menschlichen Lebens: geboren werden, sterben, auferstehen.

Für das Verständnis des Gedichtes ist es zunächst notwendig, den Begriff von "reht" festzustellen. Mhd. reht bedeutet sowohl Recht als Pflicht, das Recht, das mir von seiten anderer zukommt und die Pflicht, die ich andern zu leisten habe. Das Recht aber ist nach der Lehre der Kirche von Gott eingesetzt. Hier sind fast durchweg Pflichten gemeint, darum ist das Gedicht eine Morallehre. Eingeschärft wird die Pflicht, treu bezw. hilfsbereit zu handeln (triuwe 18, bonitas); (ge)reclit bezw. auch gesetzmäßig $\mathrm{zu}$ handeln (reht 20, justitia);3) wahrhaftig zu sein (gewore sin 24, veritas). Es wird vorgetragen: die Pflicht des Herrn gegen den Knecht, ihm nicht gewaltsam sein Recht (seine Rechtsansprüche) vorzuenthalten (34-185); der Herr als Vorbild des rechten Handelns für den Knecht (323344); Pflicht des Knechtes (195-216); Herr und Knecht sollen gleicherweise das Recht erfüllen $(217-238) ; 4)$ Pflicht in der Ehe $\left.{ }^{5}\right)(345-372)$;

2) Scherer aaO.; Kraus S. 4-6. 96-98; VoGT, Lit.Bl. aaO. u. Beitr. 2, 266 f.; SCHRÖDER aaO. S. 289 ff., Gött. Nachr. 1918, 423; LErrzMANN, Anz. 34, 122 ff.; VoGT, Beitr. 45, $459 \mathrm{ff}$.

3) Die Definition der Gerechtigkeit 20-23 stammt aus Matth. 7, 12 .

4) Vgl. Kchr. 1390 ff.

5) 351 ff. $=$ Matth. 18, 20; 357 f. = Gen. 2, 24, Matth. 19, 5 , Marc. 10,7 . 
Gebot der ehelichen Treue (407-416); Pflichten des Priesters (417 ff.), des guten Nachbarn (440-449); ein Akt des positiven Rechts (jus, judicium) ist das Gottesgericht des heißen Eisens (239-266).

In andern Fällen hat reht die Bedeutung von ordo, Ordnung, Einrichtung, richtige Verfassung, richtiger Zustand. Gott ist der oberste Richter (3. 89. 157. 303. 347 ff. 380. 400. 454 ff. 523. 536 ff.), er hat das Recht, die Moralgesetze gegeben, die zehn Gebote und das Gebot der Liebe (lex Dei, 5-12), er hat die Weltordnung eingerichtet (gotes ordenunge).

$\mathrm{Zu}$ der göttlichen Ordnung gehören die Stände:') die Gesellschaft gliedert sich in die Geistlichen und die Laien, welch letztere sich trennen in Herren und Knechte, die entweder unter sich im Dienstverhältnis stehen oder als Mann und Weib im Familienband. Zu der göttlichen Weltordnung gehört auch die Einrichtung des Menschen in Fleisch und Bein und Seele, diese ist daz dritte reht (379), der dritte nach göttlicher Ordnung eingesetzte Bestandteil des ganzen; gehört ferner die Einrichtung der Ehe, in welcher das Kind daz dritte reht ist (399), der dritte von Gott angeordnete Bestandteil, denn es ist daz reht, die Bestiminung des Menschen (404), Erde und Himmel $z u$ bevölkern. Die bedeutsamste Ordnung aber ist die des menschlichen Lebens von der Geburt zum Tod und zum wieder neuen Leben (524-539 driu reht). ${ }^{2}$ )

Die drei Rechte (Pflichten) der ersten Hälfte (A) sind nicht in derselben Reihenfolge, wie sie angekündigt waren (18.20.24) abgehandelt, denn zuerst wird von der Gerechtigkeit gesprochen (34-185), dann erst von der Trene (186-238). Ihr Wesen wird darin gefunden: daß jeder den an'dern schützen soll in aller Not (186-188): das ist das germanische Treuverhältnis zwischen dem Herrn und dem Dienstmann oder Knecht, die Pflicht der gegenseitigen Hilfeleistung. In dieser Grundbedingung des Altruismus trifft der germanischnationale Begriff der Treue zusammen mit dem christlichen der Nächstenliebe, der charitas. ${ }^{3}$ ) Die Gerechtigkeit, justitia, besteht darin, daß man jedem

1) Den Unterschied der Stände hat Gott eingesetzt. Er kommt in der Predigt zur Geltung aus praktischen Grïnden, denn es ist Regel, daß sich der Kanzelredner nach dem Verständnis seiner Hörer richten soll (Augustinus, De catechizandis rudibus Kap. 15). Das sind die Sermones ad status, die Predigten für gewisse Stände, Standesreden, die gerichtet sind an Kleriker oder Laien, an Arme oder Reiche, Herren und Knechte, an Firsten und Richter, Priester und Mönche, Soldaten, Kaufleute, Bauern, Elıeleute, vgl. KRAus S. 57 f.; LECOY DE LA MARCHE S. $206 \mathrm{ff}$. 276 f. ; Linsenmayer, Reg. S. 489; Honorins Aug., Sermo generalis, Migne 172, 861-870, und danach KELLE, Speculum ecel. S. 168171; Alanus, Summa de arte praedicatoria Kap. 39-47, Migne 210, 184-195 (bes. 185). HILDEBERT richtet in seinen Sermones de diversis viele Stücke an die Geistlichen (Migne 171, $751 \mathrm{ff}$.).

2) Das Recht in der göttlichen Weltordnung stellt lebendig dar Walther v. d. Vogelweide in seinem zweiten Reichssprucl,, LACHMANN $8,28-9,15$ (zu diesem vgl. Burdach, Walther v. d. Vogelweide. S. 135 ff.). - Ordenunge 9,9 daselbst hat nicht den gewichtlosen Sinn von "Einrichtung, Lebensweise“, sondern die liefe, ethisclie Bedeutung voll der alle Wesen durchdringenden von Gott bestimmten Gesetzliclikeil, die von dem dentschen Volk miBachtet wird.

$\left.{ }^{3}\right)$ Bonitas vertritt oft die Stelle von claritas, so als Bezcichnung der dritten Person in der Abälardschen Trinitätsformel; die Variation Gewalt Weislseit Trene in einem Gedichte des 14. Jtıs. : Jos. HAUPT, Wiener SB. 69, $144-$ 146, s. MSD. $11^{3}, 257$ Anm.; Kraus S. 102 f. 
das Seine gibt, die Wahrhaftigkeit, veritas, hat als sündhaften Gegensatz die Lüge, mendacium. Die drei gehören nach der Kirchenlehre $z \mathfrak{u}$ den Eigenschaften Gottes. $\left.{ }^{1}\right)$ Hugo v. S. Victor stellt sie in dem Kapitel de Charitate seines Sakramentenwerkes zusammen: Deus bonitas est et justitia et veritas (De Sacr. lib. II pars XIII Cap. VI, Migne 176, 529 CD) und überträgt sie auf den Menschen. Nicht nur die Reihenfolge der drei Rechte ist gestört, sondern die Trennung ist auch innerhalb der drei Abschnitte nicht durchgeführt: die Gerechtigkeit (die Pflicht, gerecht zu handeln), die eigentliche Vertreterin des Rechtes, geht als Grundzug auch durch die Partien der Treue und der Wahrhaftigkeit. Auch ist der Inhalt des zweiten Teils schon im ersten berührt, indem das Verhältnis von Herr und Knecht béhandelt wird. Am Anfang und am Ende des Gedichtes aber steht der Preis des gottgesetzten Rechtes.

Die symbolische Zahl drei ist hier auf das Recht angewendet: drei Rechte 14, die drei falschen Rechte 36. 40.44; Gott der dritte in der Ehe von Mann und Frau 353 ff.; die Seele, das Kind das dritte Recht 379. 399; der Priester, der Lehrer der zwei Eheleute $417 \mathrm{ff}$; d die drei Pflichten des Priesters 511; die drei Ordnungen des Lebens $524 \mathrm{ff}$.

Aus der Bedeutung des Gegenstandes erklärt sich die Entstehung des Gedichtes. In der Bibel ist die Gerechtigkeit eine der höchsten sittlichen Mächte, im alten Testament ist sie die vorherrschende Eigenschaft Gottes, im neuen ist die bessere Gerechtigkeit das Ziel des neuen Menschen. Die Justitia, Platos $\delta \iota x a \iota \sigma o v v \eta$, ist im Moralsystem des Mittelalters eine der Kardinaltugenden, die Kirche, das Heilsinstitut, ist zugleich ein Rechtsinstitut, seit Augustin ist der rex justus²) der Idealfürst, Recht und Pflicht sind die

1) Gerechtigkeit und Wahrheit sind nach der m.alterl. Morallehre nahe verwandte Tugenden. In dem Hugo v. S. Victor zugeschriebenen Traktat De fructibus carnis et spiritus gehört die veritas zum Gefolge der justitia (Migne 176, 1003 und Stammbaum Sp. 1010). - Justitia ist nach Thomas' v. Aquino Summa Theologiae 2, 2 Quaestio 58 Art. 1 suum unicuique tribuere, veritas est pars justitiae Quaestio 109 Art. 3, das erste der veritas entgegengesetzte Laster ist mendacium Quaestio 110 Art. 1-4. Insofern die justitia den Menschen richtet auf Beziehungen zu andern, gehört in ihr Bereich auch die charitas: Justitia dirigit hominem sufficienter in his, quae sunt ad alterum und (nach Augustinus) justitia est ... dilectio Dei et proximi Quaestio 58 Art. 8, quae scilicet est communis radix totius ordinis ad alterum. Alanus de Insulis stellt seiner Predigt De dilectione proximi den Bibeltext über die Gerechtigkeit Matth. 7, 12 voran. Barmherzigkeit, Wahrheit, Gerechtigkeit sind drei der vier Töchter Gottes, s. oben S. 59 Anm. 2. Auch nach der neueren Ethik sind die drei Tugenden wesensverwandt. Im Wohlwollen lassen sich zwei Seiten unter- scheiden, die Gerechtigkeit und die Nächstenliebe (PAulsen, System der Ethik, 2. Aufl. 1891 S. 496); und die Wahrhaftigkeit kann man als eine Form des Wohlwollens ansehen, man kann auch an ihr zwei Seiten unterscheiden: "du sollst nicht lügen " und , diene dem Nächsten mit der Wahrheit" (S. 556). Aber die Grundlage für die Zusammenfassung der drei Rechte (diu driu reht) ist in der Morallehre Ciceros enthalten; fides $(=$ triuwe) und veritas (= geware $\sin$ ) Teiltugenden der justitia sind, De officiis I, 7, 23: Fundamentum autem est iustitiae fides, id est dictorum conventorumque constantia et veritas. Für das Mittelalter vgl. die Moralis philosophia, Migne $171,1007 \mathrm{ff}$. und danach WERNER v. ELMENDORF, ZfdA. 4, 301, 601 ff., (warheit und trûwe unter den Tugenden der Gerechtigkeit), die mit V. 237 beginnen. Vgl. EHRISMANN, ZfdA. 56, 142, auch ebda 49, 428 f.

$\left.{ }^{2}\right)$ BERNHEIM, Mittelalterl.Zeitanschauungen 1, 35 ff. und die Greifsw. Diss. von GotTFRIED HERZFELD 1914, LEONHARD FREDERICH 1914, Hugo TIRALla 1916 und besonders HEINR. KRUGGER, Was versteht Gregor VII. unter Justitia usw., 1910. Gregor 
bestimmenden Normen im täglichen Leben. Klagen gegen die ungerechten Richter, gegen die Reichen und Mächtigen, die das Volk bedrücken, sind in der Literatur des Mittelalters stereotype Motive, in Traktaten und Predigten wird über die Justitia gehandelt. ${ }^{1}$ )

Der Verfasser hat ländliche Zustände im Auge: Bauern sind der Herr (meister) und der Knecht, die zusammen den Wald ausroden, und der Nachbar (gemare 440), der dem andern Rind und Knecht zum Pflügen leiht; durch das Dorf geht die Lüge. So spricht auch Honorius Aug. in seiner Predigt Ad agricolas (Migne 172, 866 f.) zu den Landleuten vom Acker. ${ }^{2}$ ) Der deutsche Dichter befolgt also die Regel, daß der Prediger sich in den Interessekreis seiner Hörer versetzen soll: für eine Landbevölkerung, Herren und Bauern, ist seine Rede berechnet. Auch die Aufgaben der Priester gegenüber der Gemeinde legt er dar, sie sind Lehrer (420. 426. 436. 504. 506) und Vorbild (429. 439. 500 ff. 505. 518) für die Laien, diese haben die Pflicht, ihnen zu gehorchen (516-519); die gleichen Gedanken äußert Honorius in dem ersten Stück seines Sermo generalis, das von den Priestern und der Gemeinde handelt (Ad sacerdotes, Sp. 861-863).

Das Gedicht Vom Rechte ist also eine volkstümliche Predigt oder Rede uber Pflicht und Recht, der Titel wäre genauer "von göttlichem Recht und menschlicher Pflicht", oder, in weiterem Sinne, "von göttlicher Ordnung und menschlichem Leben ". ${ }^{3}$ ) Als eine Ansprache an ein Publikum kennzeichnet es sich durch die Aufforderung am Schluß: nû sprechet alle Âmen.

Die Gedanken seines Gedichtes hat der Verfasser der Theologie seiner Zeit entnommen, vor allem der Predigt; eine unmittelbare Quelle, die er übertragen hätte, ist nicht vorauszusetzen. Einige Stellen aus der Bibel hat er benutzt. ${ }^{4}$ ) Bezüglich der deutschen Literatur zeigen sich Berührungen mit den in der Vorauer Hs. überlieferten Gedichten, besonders aber mit dem folgenden Gedichte von der Hochzeit. ${ }^{5}$ )

Der Dichter ist Prediger und Lehrer, nicht Gelehrter, ${ }^{6}$ ) er will auf einen volkstümlich auffassenden Zuhörerkreis wirken und gebraucht dazu eine einfache, ungeschminkte Sprache ohne gelehrte, dogmatische Anspielungen. Sein $\mathrm{Stil}^{7}$ ) ist nicht gewandt, aber anschaulich und kraftvoll. In bildlichen Ausdrücken, Gleichnissen, Parabeln, die aus dem Leben geschöpft sind, macht er den Stoff verständlich ${ }^{8}$ ) (76 ff. 84. 120 ff. 267. 319 f. 448 f. 505.

VII. brachte den Rechtsbegriff in dem Organismus und in der Politik der Kirche auf die Höhe seiner Bedeutung.

1) Vgl. die Predigten S. Bernhards Serno in Epiphania, Sermones de diversis XIX u. XXI; dle Musterpredigt in des Alanus de Insulis Summa de arte praedicatoria Kap. 19 (Migne 210, 149-151); die Stellung des Rechtes im Anegenge und in den MeBgebrăuchen s. unter diesen Denkmälern.

2) Die Vergänglichkeit des Besitzes wird von unserm Dichter $76 \mathrm{ff}$. ähnlich ausgemalt wie von Honorius aaO. Sp. 866 B.

3) So VoGT, Pauls Grundr. II ${ }^{2}, 168$ u. Lit.Bl. aaO.

4) Kraus S. $57-62$.

5) Kraus S. 42-57. 98-105.

6) Ueber die Person des Dicliters s.ScHERER, QF. 7, 13 f.; HeInzEL, Heinrich v. Melk S. $44 \mathrm{f.;} \mathrm{KRAUS} \mathrm{S.} 8 \mathrm{ff}$.

7) KRAUS S. $7-18$.

8) Dies entspricht der Vorschrift fiir Prediger, daß man zu den Jingeren (und jedenfalls aucl zu den geistig Einfachern) gleichnis- 
507 ff.; 114 ff. 143 ff. 468 ff.; 98 ff. 125 ff. 243 ff. 440 ff.); durch Äußerung eigener Teilnahme an dem Erzählten erweckt er das Interesse der Hörer (98. 101. 204. 250 ff. 261. 287. 306. 354. 462); durch immer wiederkehrende Betonung des Wortes "Recht" zwingt er die Aufmerksamkeit auf den Kernpunkt des Themas, besonders in den Formeln Nieman ist sô hêre sô daz reht zewâre (1 f. 239 f. 321 f. 345 f.) am Anfang neuer Abschnitte, oder [Dâ] kêren aber an daz reht 67.124. 163 nach Abschweifungen vom Hauptgegenstand. Er hat eine bestimmte Disposition für den Inhalt, aber er bindet sich nicht streng an sie, sondern läßt die Gedanken leicht nach unwillkürlichen Assoziationen ablaufen, unbekümmert um den notwendigen inneren Zusammenhang. Er scheut Wiederholungen nicht, gleichgültig gegen die äußere Form gebraucht er öfter die nämlichen oder ähnliche Wendungen und Reime. Formeln sind nicht gerade häufig (68. 104. 219. 223. 241. 248. $342)$; lat. Wörter meidet er ganz. Der Satzbau ist hypotaktisch, darin zuweilen parallele Sätze mit oder ohne Konjunktion kräftig hervortreten.

Metrik.1) Nahezu ein Fünftel der Reime sind unrein, ohne auffallende Assonanzen. Es begegnen Dreireime (13 ff. 439 ff.). Der Rhythmus ist verschiedenartig, der Umfang schwankt zwischen kurzen und langen Versen.

$\$ 67$. Die Hochzeit.

Kelle 2, 206. 385; PiPer, GD. 2, 87-90. - Ausg.: Karajan, DSpr. S. 19-44, dazu PIPER, Nachtr. S. 282 f. - BARTSCH, Germ. 7, 278; WAAG, K1. d. Ged. ${ }^{2}$ S. 87-123 u. Einl. S. LVI-LXXIX, zur 1. Aufl.: KRAUS, Anz. 17, 25-29. - HAUPT, ZfdA. 15, 264 (Konjekturen); SChERER, QF. 7, 14-19. 12, 52 f.; Heinr. LöbNer, Berl. Diss. 1887; Kraus, Vom Rechte, s. oben S. 196, und die dazu gehörenden Besprechungen von SCHRÖDER, VoGT, KOCHENDÖRFFER, Jellinek, LÖBNER; LeitZMAnN, Anz. 34, 122-125.

Hs.: Milstăter Hs. Bl. 142a-154b. Für die Sprache, Herkunft und Zeịt der Abfassung gilt das gleiche wie für das Gedicht Vom Rechte, KRaUs S. 6 f.

Inhalt. I. Einleitung 1-146. Inhaltsangabe 1-6; Gleichnis vom Go!dschmied und dem Schmuck, das Gold ist die Weisheit 7-64; das Wort Gottes²) und der Glaube; Gegensätze: Heiden und Christen; der gute Knecht, der Gottesstreiter, und der nicht gute Knecht, der in Hochmut Fechtende; die Hölle und Abrahams SchoB 65-144. - II. Ha up tteil 145-1078 Die Parabel von der Hochzeit des Herrn vom Gebirge mit dem Edelfräulein im Tale. a) Die Erzählung 145-324. Im Hochgebirge hat ein Landesherr seinen Sitz. Ein Teil seiner Knechte empörte sich, er warf die Ungetreuen in den Kerker in einem grausigen Abgrund 145-193. Da war ein schönes Tal, aller Lieblichkeit voll, da wurde ein schönes Mädchen geboren aus edlem Geschlechte, voll Güte, Demut und Schönheit 194-207. Der Herr wirbt um sie durch seine Boten, die Verwandten stimmen zu, der Herr vermählt sich ihr. Sie steht in strenger Hut 208-244. Eine $z$ weite Botschaft wird gesandt: die Braut solle sich rüsten und schönes Brautgewand anlegen 245-258. Brautfahrt des Herrn mit seinen Rittern, die Braut wird gebadet, in weiße Gewänder gekleidet, mit Goldschmuck behangen 259-284. Das Brautgeleite, junge Ritter, bringen sie unter Ge-

weise reden soll: Minoribus autem decet in parabolis loqui, Alanus De arte praedicatoria Kap. 39, Migne 210, $184 \mathrm{C}$.

1) W. GRIMm, ZGdR., K1. Schr. 4, 165; KRAUS S. 39 f.; HANISCH aaO. (Vortragsform, Rhythmik); H. sucht aus Gründen der Versmelodik spätere Einschaltungen aus dem ur- sprünglichen Gedicht, dem „Ur-Recht“, auszusondern.

2) Den Schatz nicht vergraben, eine bäufige Mahnung in der christlichen Lehre, vgl. ROETHE, Reimvorreden des Sachsenspiegels S. 104-107; EHRISMANN, Stud. über R. v. Ems S. 4 Anm. 4. 
sang in die Heimat des Bräutigams 301-314. Mit dem Zug kommen müde Leute, Fahrende, die im Weintrinken ihres Leides vergessen. Da ist das beste Hochzeitsmahl, das je ein Mann feierte 315-324. b) Die Auslegung 325-1078. Das Hochzeitsmahl bedeutet die Macht Gottes 325-338. Bräutigam und Braut bedeuten den heiligen Geist und den Menschen (die Seele). Die großen Ehrungen der Braut bedeuten die hohe Auszeichnung, die dem kleinen Kinde zuteil wird, da es durch die Taufe mit Goit vermählt wird: der Verlobungsring ist soviel wie das Taufgewand 339-358. Der Brautbote bezeichnet den Priester 359-374. Die Verwandten im Rate der Braut sind die Sakramente 375-378. Die vornehmen Abgesandten des Bräutigams (s. $268 \mathrm{ff}$.) bedeuten den Gerichtstag 379-406. Das Himmelreich, Beschreibung der himılischen Stadt 407-481, Lehren für den Reichen 482-509. Parabel von dem Mann, der unter seine Knechte 5 Talente verteilte (Matth. 25, 14 ff.) und die Ausdeutung auf die 5 Sinne 510-569. Das Bad der Braut bedeutet den Vogel Phönix, die Reinigung von den Sünden 570-602. Die Fahrt mit den Brautgeleitern bezeichnet die Menschen; wenn einer hier fällt oder zuriickbleibt, soller sich an den Priester wenden um Rat 603-616. Die drei Beichten, die kupferne, silberne, goldene 617-694. Der Goldschmuck der Braut bedeutet die Seele, die Prägung darinnen die wahre Llebe 695-702. Wer die Beichte getan hat, der kann freudig vor dem Gerichte stehen 703-707. Man soll sich vorsehen, wenn der wahre Bräutigam kommt; die Wunden Christi, der Fall des Hochmuts, das jüngste Gericht 708-775. Das weiße Gewand der Braut bedeutet, daß wir weiß wie Schnee werden müssen (rein von Sünden), ehe wir ins Himmelreichkommen 776-785. Die leuchtende Schönheit der Braut bedeutet die heil. Jungfrau 786-799. Der Brautgesang deutet an, daß der Priester Gott lobsingen soll 800-805. Die auf die Braut wartenden Leute bedeuten die 5 Weltalter 806-811. Die folgenden Verse bis 1078 bilden zusammen eine Erlösungsgeschichte: Fall der Engel 812-817; der Pelikan als Symbol des erlösenden Gottes; die Engel, Schöpfung Adams 818-853; Stationen aus dem Leben Jesu 854-1050. ${ }^{1}$ ) Die Heermuden Leute sind die 12 Apostel und Märtyrer 1051-1060. Die bimmlische Hochzeit 1061-1078. - III. Schlußgebet 1079-1088.

Die Erzählung bildet die in sich abgeschlossene Geschichte von der Brautwerbung und Hochzeit eines vornehmen Herrn. Ein Vorbericlit geht voraus: der Herr hatte einen Aufstand seiner Knechte niedergeworfen. Einmal ist die Erzählung durch eine allegorische Erklärung unterbrochen (236-244). Die Allegorie (325-1078) mit den einzelnen Auslegungen folgt im großen und ganzen der Entwicklung der Parabel (der Erzählung). Die beträchtlichste Abweichung ist die, daß die 1. Auslegung des Hochzeitsmahls (wirtschaft), das in der Erzählung den Abschluß bildet (320-324), in der Allegorie am Anfang steht (Gottes Macht 325-338): das Erzählungsmotiv ,wirtschaft' hat unmittelbar die Auslegung der ,wirtschaft' nach sich gezogen. ${ }^{2}$ )

Der Grundplan der Erzählung ist in der Allegorie durchgefïlırt, ja einzelne Schlagworte sind unmittelbar herübergenommen. Der Verfasser hat also einen bestimmten Entwurf verfolgt; daß er die Ordnung der Erzähfung nicht genau

1) SCHRÖDER, Ancgenge S. 54 Anm.

2) Die Motive der Allegorie und dic Erzählung entsprechen sich etwa folgendermaßen: $325-338=320-324$. Briut und Brăutigam, das Hauptmotiv der Erzählung, wird in der Allegorie 339-346 ansgelegt [In 236-244 wird die allegorische Erklärnng schon innerhalb der Erzählung gegeben].
$347-358=226-235.359-374=245-258$. $375-378=222$ f. 379 ff. $=259-272.482 \mathrm{ff}$. vgl. 290 t1. $296.602=279.603-616=$ $297.691-694=282$ f. $695-702 \quad 283.776$ $-780=280.790-799=297-299.800$. $805-301-306.806-811-307$ f. $812-817$ $=148$ เ1. $166-189.878-891=216-219.1051$ $-1060=315-318.1061-106.1=320-324$. 
einhielt, liegt an dem Mangel an systematischer Methode, die er so wenig wie die meisten seiner Zeitgenossen beherrschte. In viel höherem Maße tritt die Freiheit oder Nachlässigkeit in der ungleichen Ausdehnung der einzelnen Teile hervor. Man kann in dieser Beziehung zwei Arten von Auslegungen unterscheiden, kurze und einheitliche, dagegen lange mit Abschweifungen. Danach gliedert sich die Allegorie folgendermaßen. 1. Kurze Auslegungen innerhalb 325-378: die Macht Gottes (325-338); der heil. Geist und die Seele (339-346); die Taufe (347-358); Priester (359-374); Sakramente (375-378). 2. Auslegung mit Abschweifung innerhalb 379-509: der jüngste Gerichtstag (379-406), das Himmelreich (407-509). 3. Abschweifung 510-707: die 5 Sinne (510-569 ohne Anschluß an die Erzählung), ') Sündenreinigung (570-616), die 3 Beichten (617-694), Reue und Abschluß der Beichte (705-707); die 4 Punkte gehören alle zur Beichte. 4. Auslegung mit Abschweifung 708-775: jüngster Gerichtstag. ${ }^{2}$ ) 5. Kurze Auslegungen 776-811: Sündenreinigung (776-785), Jungfrau Maria (786799), Priester (800-805), die heimwarten liute (806-811). 6. Abschweifung: Erlösungsgeschichte 812-1078, ist durch vorübergehende Anklänge mit der Erzählung verbunden $(812-817.878-891)$ und lenkt am Schluß in diese ein $\left.(1043-1078) .^{3}\right)$

Die erklärenden Partien gehen demnach weit über den Inhalt der Erzählung hinaus. Der Verfasser hatte die Absicht, der Allegorie einen umfassenderen, aber doch ganz bestimmten Lehrgehalt zu geben: es ist der Erlösungsgedanke der alle Deutungen durchzieht, denn sie handeln vom jüngsten Gericht und vom Himmelreich (von der Hölle 162 ff. 536 ff. 612 ff. 760 ff. 806 ff. 812 ff. 960-1050), von der Beichte als Heilsmittel zur Selig. keit (durch sie gelangt man in den Himmel: 508 f. 560. 705. 780, der Priester ist der Helfer in der Beichte: 359 f. 607 ff. 631 ff. 655 ff. 680 ff. 800 ff.; Gott als êtwarte 730); das letzte Viertel des ganzen Gedichtes bringt uberhaupt die gesamte Erlösungsgeschichte vom Sturz der abtrünnigen Engel bis zum Eingang der Seele in die ewige Herrlichkeit; ${ }^{4}$ ) und was dem denkenden

1) An die Erzählung 158-161 erinnern die Verse 510-513. Die Prüfung der 5 Sinne des Leibes und der 5 Sinne der Seele gehört zur Vorbereitung auf die Beichte, vgl. Parzival 488, 26 f. u. ZfdA. 49, 442.

2) Also werden zwei Ereignisse auf das jüngste Gericht bezogen, einmal die Sendung der Leute zur Braut unter 2 und hier unter 4 die Einholung der Braut.

3) Die langen Auslegungen mit Abschweifungen enthalien also ganz bestimmte Themata, nämlich einmal das jüngste Gericht und das Himmelreich (Abschw. 2 u. 4), diese Teile gehören zur Geschichte der Erlösung, gehen also mit Abschw. 6 zusammen; und dann die Beichte (Abschw. 3), unter welche aber auch Teile der Erlösungsabschnitte fallen, nämlich 482-509 (Werke der Barmherzigkeit und
Pflichten gegen die Kirche), 776-785(Sündenreinigung), 740-753. 912-944 (HochmutDemut); auch der Priester ist als Beichtvater und Seelenrat aufgefaßt (359 ff. 631 ff. 659 ff. 688 ff., vgl. auch $73(\eta)$. Die kurzen Auslegungen umgekehrt betreffen solche Themata, die in einer Erlösungsgeschichte zuriücktreten können und nicht notwendig zur Beichte gehören.

4) Die einzelnen auf die Erlösung gerichteten Gedanken sind durch das ganze Gedicht verwoben, die Heilsgeschichte, jüngstes Gericht. Himmel, Beichte und Priester, Glaube und Recht, und stehen in greifbarer Verbindung mit der Erzählung von der Hochzeit des himmlischen Herrn mit der erlösten Seele, so daß Interpolationen nicht auszulösen sind. Es ist eine Sammlung einzelner Motive, die 
Geiste in Symbolen verständlich gemacht wird, das spricht im Schlußgebet das Herz aus in schlichten, aber aus der Tiefe quellenden Worten: "Beschirme uns Gott vor der kranken Hölle und mache unsere Seele gesund, daB er unser Vater werde und wir als Kinder in sein Reich kommen." Der Idee des Erlösungswerkes, das sich in jenen Grundgedanken entwickelt, entspricht auch die Erzählung in ihren Hauptlinien: der Bräutigam im Gebirge ist Gott im Himmel, die Braut im Tale die menschliche Seele (später die Jungfrau Maria 790-799. 880-891); er sendet seine Leute zu ihr auf die Fahrt: Gott sendet die Menschen zum jüngsten Gericht; die Braut badet und schmückt sich, so reinigt sich die Seele von Sünden in der Beichte; er führt die Braut zur Hochzeit in sein Reich wie Gott die Seele in den Himmel.

Nun aber steht "die Hochzeit" in engem Zusammenhang mit dem Gedicht Vom Rechte, sowohl formal in Einzelheiten des sprachlichen Ausdrucks als inhaltlich, und hier zwar eben hauptsächlich durch die Betonung des Rechtsbegriffs, denn auch hier werden die menschlichen Handlungen unter den Gesichtspunkt des Rechts gestellt. Das Recht aber ist hier ganz ausgesprochen der Wille Gottes, der rechte Glaube, das rechte Christentum, das christliche Leben. Die Gerechten sind die, die immer Gottes Willen taten, sie werden aus der Hölle erlöst $\left.(1037-1040) ;^{1}\right)$ der gute Knecht ist der Christ (91), der den neuen Bund hält (95-100), der das (Gottes) Recht liebt und gegen die Hölle kämpft, der Gottesknecht, der Gottesstreiter (101144); unter seine Knechte, die ihm mit Recht (mit dem Glauben) dienen, verteilt der Herr seinen Reichtum $(510-513)$; die guten Knechte bringt Gott zu ihrem Recht, in die himmlische Zelle (1043-1050); wir sollen die rechten Wege gehen $(522-557)$; der rehte und der guote bessert seinen sündigenden Nächsten (395-397); der Reiche soll dem Unrecht wehren (504); wenn wir recht wandeln, werden wir erhabener als die Engel (846849); der Demütige, der sich um das Recht (den Glauben) erniedrigt, wird erhöht werden (943 f.). Auch der Bräutigam in der Parabel ist der guote kneht, der gute Ritter: er heiratet umbe daz reht einen Erben zu gewinnen (210-212), einen Rechtsnachfolger (vgl. daz chint daz ist daz dritte reht Vom Rechte 399); er vermählt sich die Braut nach Sitte und Recht (224 f.); der herre hat die ungetreuen Knechte (173), die nicht dem Rechte gemäß

unter einer Konzeption begriffen sind. Auch die formellen Kriterien, Sprache und Verskunst, lassen keine fremde Hand erkennen (Interpolationen nehmen an SCHERER, QF. aaO., LŐBNER S. 21-40, KRAUS S. 18-38, SCHRÖDER aaO., dagegen VoGT, Lit.BI. aaO.).

1) Es gibt drei Arten von Gerechten; 1. die melit tun als Gottes Gebote vorschreiben, die perfecti, das sind Märtyrer, Mönclie, Jungfrauen; 2. die Gottes Gebote erfüllen ohne Klage, die justi, dazu auch die justi aber imperfecti, die Eheleute, Honorius Aug.
Elucidarium III, 2, Migne 172, 1157; Lucidarius ed. Heidlauf $\$$. 59 f.; EhrismanN, ZfdA. 56, 152 ff. Diese Ordnung der Gerechten schlieBt sich unmittelbar an dic unten zitierte Stelle über das Brautgeleite an; hier ist also schon das Gereclitsein mit unsęrer Parabel verbunden. Und in dem Eingang deszweiten Prologs zur Expositio in Cantica Cant. des Honorius ist der lıöchste Schmuck der Secle der Gehorsam gegen das göttliche Gebot, also wiederum eine Verbindung des Gerechtseins mit der Sponsusparabel. 
handelten (165 Scheidung der guten und unrechten Knechte Vom Rechte $11 \mathrm{f}$.) in die Hölle verstoßen $(162-189)$; er ist der rechte Meister (Herr) des Feindes, den er in den Abgrund verstieß (1000 ff.); Gott ist der gerechte Richter (734). Die Braut erlangt das Recht, das am jüngsten Tag besteht (1075 f.).

Wie. im Rechte kommt auch in unserm Gedicht der soziale Sinn des Christentums zur Geltung: die Menschen sind gleich vor Gott, über Arme und Reiche kommt das Gericht (383-394); alle wollen gleicherweise zu der himmlischen Pforte (421-430. 431-436); alle will Gott erhöhen (840853); dem Reichen werden besonders die Lehren der Barmherzigkeit und christliches Leben eingeschärft ( $\left.{ }_{4}^{4} 82-509\right)$; der Arme soll beten, arbeiten und zu Gott guten Willen haben (562-569). Der Reiche kümmert sich nicht um den Armen, freilich fügt sich auch der Arme nicht dem Reichen, aber der Reiche hat auch mehr Verantwortung: er soll sich des Armen erbarmen (860-877); ein langer Kampf geht durch die Welt, der der Hochmütigen gegen die Armen, aber am jüngsten Tag wird Gott den Hochmut zu Fall bringen (740--753). Wie alle Prediger, und wie das Evangelium selbst, steht auch unserer auf Seite der Armen.

Die Bedeutung des Priesters für das Heil des Laien hebt auch der Dichter der Hochzeit hervor: hier ist er der Beichtvater, im Recht ist er Lehrer und Vorbild. Bilder aus dem Bauernleben bringt auch der Dichter der Hochzeit: sie sehen sich vor in der Ernte und richten sich ein nach der Witterung (417 ff.), sie helfen den früheren Tagelöhnern reuten (423 ff., vgl. Vom Rechte $98 \mathrm{ff}$.). Andere gleiche Vorstellungen in beiden Gedichten: Gott als gerechter Richter (Vom Rechte 3 f., Hochz. 734); Bestrafung Lucifers (Vom Rechte 206 ff., Hochz. 162 ff. 812 ff. 1007 ff.), die Menschen sind Gottes Kinder $(303.538=411$ f. 1069), Gottes Knechte (5. 12.66-95. 96-146. $380=1043-1050)$; Adam als der erste Mensch (460 f. $=850-852.1019 \mathrm{f}$ ); das Weib schmückt sich (411 f. = 15 ff., als Braut 251 ff. 280 ff.), die Verwandten geben es dem Manne $(413=222 \mathrm{f}$.) mit rechtsgültiger Vermählung (395 f. $=226$ f.).

Die Sprache erinnert auf Schritt und Tritt an das Gedicht Vom Rechte durch gleiche Wendungen, Verse, Reime, der Stil bewegt sich in ähnlichen Formen.1) Da auch Versbau und Reimkunst ${ }^{2}$ ) übereinstimmen (die "Hochzeit" hat etwas mehr unreine Reime), so wird man beide Gedichte ein und demselben Verfasser zuschreiben müssen.

Unser Gedicht von der Hochzeit gehört mit der Allegorie vom Seelenbräutigam zur m.alterl. Literatur des Hohen Liedes, ${ }^{3}$ ) die in Deutschland

1) Kraus S. 19-22. 23-38; Beziehungen zur Deutung der Meßgebräuche wie im Gedicht Vom Rechte und zufällige Uebereinstimmungen mit andern Gedichten ebda S. $42-57.105-126$. Lat. Worte s. GRÜNEWALD S. 26.
2) W. GRImm, ZGdR. K1. Schr. 4, 165; KRAUS S. 6 f. $40-42$. 55.

3) Die Quellen: RAAB, Allegor. Motive S. 15 f.; LöBNER S. 2-8; KRAUS S. 62-85. Aus dem Vorstellungskreise des Physiologus stammen $580 \mathrm{ff} .818 \mathrm{ff}$. 
mit Willirams Paraphrase beginnt. Eine unmittelbare $Q$ uelle ist nicht nachgewiesen, ähnliche, zum Teil kürzere Darstellungen der mystischen Hochzeit haben Wernher von S. Blasien in seinen Deflorationes (Migne 157, 1194) und Honorius Aug. in dem zweiten Prolog seiner Expositio in Cantica Cant. (Migne 172, 353 f.); näher steht dessen Predigt auf Dominica XX in seinem Speculum Eccl. (Migne 172, 1063-1065; hier ist es die Parabel von der Hochzeit des Königssohns, Matth. 22, 1-14); ferner Hildebertus Cenomanensis in seinem Sermo 105 (Migne 171, 822 ff.); und die dem heil. Bernhard zugeschriebene Parabel De Christo et Ecclesia (Migne 183, 767 ff.). ${ }^{1}$ ) Die Erlösungsidee liegt schon in der Parabel von Christus dem Seelenbräutigam begründet, aber eine solche Zusammenfassung zahlreicher Auslegungen und Erweiterung zu einer umfangreichen Lehre von der Erlösung ist uns sonst nicht überliefert. Der Dichter kann schon eine lat. Predigt oder Abhandlung dieser Art vor sich gehabt haben, vielleicht aber hat er auch nur einen Grundstock von Motiven vorgefunden. $Z$ u diesen gehörten dann die Erzählung mit dem Sturz der unrechten Knechte und der Hochzeit und die kürzeren Auslegungen; die Einleitung, die Erweiterung allegorischer Deutungen $z \mathfrak{u}$ den längeren Auslegungen, die durchgehenden Belehrungen über den Erlösungsweg, die Tendenzen auf das "Recht" wären dann vom Verfasser in seine Quelle hineingebracht worden. Aber auch diese Gedanken hat er alle schon in der theologischen Literatur irgendwo vorgefunden. Im Gedicht Vom Rechte hat der Verfasser dem bäuerlichen Stande die irdischen Pflichten und die Gottesordnung auf Erden vorgehalten, in der "Hochzeit“ entfaltet er Reichen und Armen die ganze Menschenerlösung. Die das Recht, die göttliche Ordnung, in diesem Leben befolgen, sind Gotteskinder und sie werden gesegnet in des Vaters Reich eingehen (Vom Rechte 538-545); und die Rechten und Guten, die hier Gottes Willen getan haben, gehen mit der Braut und erlangen als die gesegneten Kinder das Recht der Braut, das Reich des Vaters (Hochzeit 1065 ff.). Der Abschluß ist in beiden Gedichten gleich: es ist die trostreiche Gewißheit, daß wer das göttliche Recht und Gottes Willen tut, in die himmlische Herrlichkeit eingehen wird. Und ein versöhnungsvoller Zug geht durch beide Gedichte: nicht sind die beiden Welten getrennt durch eine unüberbrückbare Kluft, über die nur jenem

') Den Brautzug mit Gesang cnthält des Honorius Elucidarium lib. III, 1 (Migne 172, $1157 \mathrm{~A})$, von wo aus er in den deutschen Lucidarius uibergegangen ist (HeIdLAuF S. 59). Da das Elucidarium das verbreitetste Schullehrbuch war, so wird auch die Brautzugsszene bei der Geistlichkeit wolıl bekannt gewesen sein. Sie kommt auch in der Zukunft nach den Tode vor, V. 76-94. Die Fassung der Zukunft nach dem Tode ist nicht aus der Hochzeit direkt entnommen (ScliEkER, QF. 7, 26; LOBNER S. 40; KRAUS, D. Ged. S. $76-94$ [S. 37 f.] u. S. 190), denn sie hat cin
Motiv mit Honorius gemein, das in der Hochzeit fehlt: der Bräutigain ist der Engel $76 \mathrm{f}$. sicut sponsus ... ita .. angelus bei Honorius, und dazu Zukunft. Der engel . . Der si schol belivten $74 \mathrm{f} .=$ angelus sui costus Hon. .; in der Hochzeit bedentet der Gesang den Priester 800-805. Beide deutschen Gedichte aber weichen zusammen von der ursprünglichen Parabel, wie sie hier bei llonorius und sonst überliefert ist (KRAUS, Von Rechte S. 67), darin ab, daß an Stelle des einen Sängers (der Engel, oder David) das Brautgeleite den Hoclizeitsgesang singt. 
hinausgeholfen werden kann, der sich ganz von der Verdorbenheit der Welt löst, dem in der Askese sich verzehrenden Mönche; sondern das Leben hat, so wie seine Pflichten auch seine Rechte, und Gott ist auch bei den treuen Ehegatten. ${ }^{1}$ ) Vollends aber, wie sollte die Seele, die der Herr schon hier sich als Braut auserwählt, das Gefühl heillosester Verworfenheit in sich tragen, da sie die Hoffnung auf dereinstige unlösliche Gemeinschaft mit Gott durch das schuldvolle Leben geleitet? Hier weist ein Priester den Menschen auf ihren Wegen die Bahn zum Himmel und er tut es wie ein Seelsorger, der selbst in dem armen Leben lebt, nicht wie ein Mönch, der in der Weltentsagung schon eine höhere Stufe der Geistigkeit erlangt hat.

Aus dem Leben gegriffen sind auch die epischen Elemente in beiden Dichtungen: die rodenden Bauern, das heiße Eisen, die guten Nachbarn im "Recht" sind Genrebilder aus der Gegenwart, zu einer Novelle ausgemalt ist die Hochzeit. Die einzelnen Hauptzüge sind schon in der geistlichen Parabel enthalten, sie sind in das Kostüm der Zeit übettragen. Losgelöst aus den religiösen Bezügen ist es eine Verlobungsgeschichte, ist es jenes beliebteste Thema der Volks- und Spielmannsdichtung. ${ }^{2}$ )

\section{e) Mariendichtung.}

Schon in den Anfängen des Christentums genoß die Mutter des Herrn nach natürlich menschlichem Empfinden eine besondere Verehrung. ${ }^{3}$ ) Ihrer Person bemächtigte sich bald das Dogma, in den Theologenstreiten des

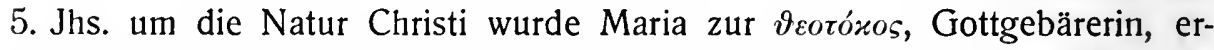
klärt, als Mutter des Gottsohnes (Nestorianischer Streit, Synode von Ephesus 431). Ambrosius in seinem Wirken für das Nonnentum stellt Maria als Vorbild der Jungfräulichkeit dar, Augustinus aber legte den Grund für das abendländische Mariendogma, indem er die Mutter des sündlosen Gottsohnes für sündlos erklärte. Die Weiterentwicklung in der Vergottung der Mutter Gottes ging dahin, daß Maria schon im Mutterleib für geheiligt erklärt wurde (Paschasius Radbertus 831), um die Mitte des 12. Jhs. kam das Fest der "unbefleckten" Empfängnis") auf (um 1140 in Lyon; ältere Marienfeste sind: Mariä Reinigung, 6. Jh.; Mariä Himmelfahrt, 6. Jh.; Verkündigung,

1) Heinzel, Heinr. v. Melk S. 44.

2) Von sittengeschichtlichem Interesse ist die Darstellung der Vermählungsgebräuche, Vermählung und Hochzeit in der ad. Literatur s. LG. I, 346 f. u. Nachtr. S. 454; KAUFFMANN, $\mathrm{ZfdPh} .42,129 \mathrm{ff}$.

3) Zur Geschichte des Marienkultus s. Realenzyklop. $12^{3}, 309-336$, wo Literatur angegeben ist; $u$. bes.: STEPH. BEISSEL, Gesch. der Verehrung Marias in Deutschland während des MA.s, Freiburg i. B. 1909; ERNST LuCIUS, Die Anfänge des Heiligenkults (s. oben S. 143 Anm.) S. 420-504. 512-522; L. PfannMÜLLER, Frauenlobs Marienleich, QF. 120;
A. Kober, Zur Gesch. d. d. Mariendichtung, ZfdUnterr. 28, 595-619. 691-700; Ders., Gesch. d. religiös. Dichtung i. Deutschl. 1919; AD. Mussatia, Stud. zu den m.alterl. Marienlegenden, Wiener SB. 113 (1883), 917-994. 115 (1885), 5-92. 119 (1889), IX. Abt.; KARL BENRATH, Zur Gesch. der Marienverehrung, Theol. Stud. u. Kritiken 59, 1-94. 197-267; WECHSSLER, Kulturproblem des Minnesangs S. 299 ff. $434 \mathrm{ff}$.

4) Festum conceptionis Beatae Virginis Mariae immaculatae, aber auch Festum immaculatae conceptionis B. V.M., deutsch kurz "Mariä Empfängnis", am 8. Dez. 
7. Jh.; Geburt, 7.Jh.), trotz vieler Gegner, u. a. auch des heil. Bernhard. Aber das Dogma allein hat die steigende Erhöhung der Mutter des Herrn nicht bewirkt: aus dem Innern der Volksseele kam die elementare Liebe $z \mathfrak{u}$ ihr, die der verlorenen Menschheit den Erlöser geboren, und ebenso unmittelbar entspricht dem Volksbewußtsein die poetische Verklärung der Gottesmutter zur Himmelskönigin, deren Macht und Herrlichkeit weit die Engel und Heiligen und Märtyrer ubberstrahlte. Und wem sollte die arme Seele in ihrer Not sich vertrauensvoller nahen können als ihr, der Schmerzensreichen, die selbst die größte Not erfahren mußte, als sie am Kreuz aufschaute zu ihres Sohnes Tod, sie die göttliche und doch so ganz menschliche Mutter. Da man die Heiligen als Fürbitter anrief, mußte ihre Hilfe die mächtigste sein, denn konnte der Sohn, der Heiland und Himmelskönig, der Mutter eine Bitte versagen? So wirkten die Gelehrten und das gläubige Volk zusammen, um dem Marienkultus eine Bedeutung zu verschaffen wie dem der drei gött. lichen Personen selbst.

Mit aller Schönheit und Lieblichkeit schmückte das dichtende Gemüt der Gläubigen die Reine, die Demütige, die Barmherzige, das Süßeste und Herzlichste will man ihr sagen, die verborgensten Schmerzen ihr anvertrauen. Zum menschlich göttlichen Ideal ist die heilige Jungfrau der katholischen Christenheit geworden, „selber die Kirche, die göttliche, stellt nicht Schöneres dar auf dem himmlischen Thron; Höheres bildet selber die Kunst nicht, die göttlich geborene, als die Mutter mit ihrem Sohn." Die eigentlich populäre Marienverehrung beginnt mit der Hebung des religiösen Lebens und der Steigerung des Empfindens im 11. Jh. Der Samstag wurde der allerseligsten Jungfrau geweiht mit dem Officium beatae Mariae Virginis in Sabbato, alle Christen sollten es wenigstens jeden Samstag beten, in den Klöstern sollte, wie besonders Petrus Damiani forderte, täglich neben dem kanonischen auch das Marianische Officium gehalten werden. ${ }^{1}$ ) Die neuen Mönchsorden, die Cisterzienser und noch mehr die Prämonstratenser, erkoren die Himmelskönigin ganz vornehmlich zu ihrer Schutzheiligen, neu gestiftete Kirchen und Klöster wurden ihr geweiht und vielfach auch nach ihr benannt. Die Mącht der Mutter Gottes im religiösen Leben steigerte sich besonders seit dem 13. Jh. im offiziellen Gottesdienst und in der Dogmenbildung sowohl als im Volksglauben. Nene Feste traten zu den alten. Außer dem Vaterunser und dem Glaubensbekenntnis sollten die Gläubigen nun auch das Ave Maria (den englischen Gruß) beten (Synode zu.Paris 1198), die Eltern und Paten wurden verpflichtet, es ihre Kinder zu lehren (13. Jh.), und im 13. Jh. kam der Brauch auf, es im Anschluß an das Paternoster zu sprechen. ${ }^{\text {) }}$

Dieses stete Wachsen der Marienverehrung seit dem 11. Jh. äußert sich auch auf dem Gebiet der Literatur. Schwärmerisch preist Petrus Damiani, der leidenschaftlichste Verkündiger der neuen Frönmigkeit, jene Frau, welche

1) THALhOFER 2 2, 249.616-627.

2) THALHOFER 2 1, 306 if., wo auf Berthold v. Regensburg verwiesen ist (PFenfFer 1, 44, 10 f. $125,22-24.424,19$ f.). 
in unsern Herzen den ausgezeichnetsten Rang einnimmt, die die Fülle der Süßigkeit hat, deren Geist süßer ist als Honig (Sermo XI, De annunciatione beatissimae virginis Mariae, Migne 144, 557-563), und der heil. Bernhard widmet der "Jungfrau" Maria, der Virgo Deipara, eine Reihe von Predigten, in denen er sie darstellt als jungfräuliche und demütige Gottesmutter, anknüpfend an die Verkündigung des Engels, „Missus est Gabriel“, beim Fest der Annunciatio, und als Regina Coeli bei dem der Assumptio. S. Bernhards Biograph Johannes Eremita erzählt, daß der Heilige, da er als apostolischer Legat 1147/48 in Speier weilte, am Marienaltar die Antiphone "Salve regina" von Engelstimmen singen hörte und sie dem Papst Eugen übermittelt habe, damit sie als Gesang in den Kirchen eingeführt werde. ')

Die Bibel selbst enthält nur spärliche Nachrichten über die Mutter Jesu und doch mußte es ein Bedürfnis der Gläubigen sein, etwas zu wissen von dem Leben dieser verehrungswürdigsten Gestalt. Da setzte die Phantasie ein, doppelt geschäftig in einer wundersüchtigen Zeit. In den apokryphen Evangelien wird viel Menschliches, Anekdotenhaftes besonders von dem Knaben Jesu und seiner Mutter erzählt.

Das Wunderbare ist der Bereich der m.alterl. Heiligenbiographie, die größten und seltsamsten Wunder aber wurden von der Allerheiligsten erwartet. Besonders im 13. Jh. entstanden zahllose Marienlegenden, die in der Literaturgeschichte ein eigenes Gebiet ausmachen. Am schwungvollsten jedoch ist die Marienverehrung im Liede ausgesprochen. In der griechischen Kirche, in der der Kult der Gottgebärerin überhaupt ursprünglich heimisch war, entstand eine umfangreiche Marienlyrik, erst später und langsam folgten lat. Hymnen. Die ältesten haben die jungfräuliche Geburt noch nicht als alleinigen Gegenstand, sondern als Teil der Advent- oder Weihnachtsfeier, so der ambrosianische Hymnus "Veni redemptor gentium" (Adventlied), die Weihnachtslieder des Sedulius "A solis ortus cardine" und des Venantius Fortunatus "Agnoscat omne saeculum"; auch des Sedulius Verse in seinem Carmen paschale "Salve, Sancte parens", die in das römische Meßbuch aufgenommen wurden. Eigentliche Marienlieder sind bis zur Einführung des Marianischen Officiums nicht häufig und wieder ist es Petrus Damiani, der hier vorangeht (seine Marienhymnen bei Migne 145, $933 \mathrm{ff}$., darunter das tägliche Officium Marianum Sp. 935 ff.). In den folgenden Jahrhunderten entwickelte sich dann eine sehr umfangreiche lat. Marienlyrik, Lieder auf Marienfeste und Andachten über Kirchengebete, Dank-, Bitt- und Loblieder an Maria. ${ }^{2}$ ) $\mathrm{Zu}$ den gefeiertsten Mariengesängen gehören der Hymnus "Ave maris stella" (9. Jh.) und die Marienantiphone "Salve regina" ${ }^{\text {" }) ~(11 . / 12 . ~ J h .) . ~}$

Es hatte sich zur Bezeichnung und Verherrlichung der Maria eine eigene poetische Sprache aus biblischer Übertragung und allegorischer Schrift-

1) Kelle 2, 76, $286 \mathrm{f}$.

2) MONE, Hymnen Bd. 2; DREwEs, Analecta Hymnica, in verschiedenen Bänden.
3) Daniel, Thesaurus Hymnol. 1, 204-206. 2,321 ff.; PHIL. WACKERNAGEL, Das d. Kirchenlied 1, 103; ThaLHOFER ${ }^{2} 2,572 \mathrm{f}$. 
erklärung gebildet, ${ }^{1}$ ) die in der Literatur und auch in der Liturgie angewendet wurde. $\left.{ }^{2}\right)$ Die biblischen Bilder stammen meistens aus dem hohen Lied, wie Mond, Sonne, Morgenröte, Blume, Lilie, Rose, Myrrhe, Narde, Zimmt, einige auch aus Sirach 24, $17 \mathrm{ff}$; Stern, besonders Meeresstern, ${ }^{3}$ ) Gemma (mhd. gimme, Edelstein), sind öfter im alten Testament vorkommende bildliche Bezeichnungen.

Die Mariensymbolik gehört zu der allgemeinen typologischen Methode der Auslegung des alten Testaments, das ist die allegorische Erklärung. Diese Symbole wurden zumeist schon von der griechischen Patristik gebildet (4./5. Jh.). Auf die Abstammung der Muttergottes wurden gedeutet: der Stern Jakobs, 4. Mos. 24, 17 „Orietur stella ex Jacob“; das Reis (Rute, Gerte) aus der Wurzel Jesse, Jes. 11, 1 „Et egredietur virga de radice Jesse“; auf die unverletzte Jungfrauschaft der Dornbusch Moses, 2. Mos. 3, 2 ff., weil der Busch mit Feuer brannte und doch nicht verzehrt ward (das Tertium comparationis ist das Unverletztbleiben); der beschlossene Garten, hortus conclusus, den Gott selbst behütete, in dem die Frucht Jesus inne wuchs, Hoh. Lied 4, 12 ff.; die beschlossene Pforte, porta clausa, durch die allein Gott einging, Ezech. 44, 2; das Fell Gedeons, Richt. 6, 37: der Tau, der auf das Fell niederfiel, bezeichnet den Tau des heiligen Geistes, mit dem Maria begossen wurde; Aarons Stab, der Blüten trug, ist die Jungfrau, die als Frucht Jesus hervorbrachte; das häufige Bild, daß die Sonne durch das Glas hindurchscheint, ohne es zu beschädigen (Sonne scheint durch ganzes Glas), wurde schon von den griechischen Kirchenvätern gebraucht (vgl. SAlzer S. 73 f.). Urchristlich ist die Gegenüberstellung der Maria, die der Menschheit den Erlöser gebar, gegen Eva, die die Sünde brachte, sowie schon der Paulinische Gegensatz von Christus zu Adam.

Mit einer Fülle von Beiworten schmückt die Liebe und Verehrung die Gottesmutter und gebenedeite Jungfrau noch außerdem: sie ist Mutter und Jungfrau, Kaiserin und Königin des Himmels, der Engel, das Licht und der Spiegelglanz, die Himmelsspeise und der Rosengarten, Viole und Zeitlose, Lavendel, Muskatblume, jeglicher Edelstein. Solche Preisworte sind zum Teil Eigenschaften, die dem Dogma entsprechen, andere sind dem Physiologus oder Lapidarius entnommen, viele sind spätere poetische Motive der Poesie des 13./14. Jhs.

Die ersten Jahrzehnte des 12. Jhs. brachten diesen Überschwang der Symbolik in die Mariendichtung, in den früheren Hymnen waren die Bilder nur vereinzelt und maßvoll, der Schwerpunkt lag auf der Person Jesu. Auch Petrus Damiani wendet sie spärlich an in seinem Officium (Migne 145, 935-937), stärker aber in seinem Rhythmus de S. Maria virgine (ebda

1) W.Grimm, Gold. Schıniede,Einl.;AnSELM SAlzER, Die Sinnbilder und Beiworte Mariens in der deutschen Lit. und lat. Hymnenpoesie des MA.s, 7 Programme des Ober-Gymn. zu Seitenstetten, 1886. 1E88. 1889. 1890. 1891. 1892. 1893 , s. auch MSD. $1 i^{3}, 251$ f. u. in den
Anmerkungen zu den in MSD. aufgenommenen Mariengedicliten.

2) Eine Anzahl solcher allegorischer Bilder enthält das Mariauische Officium.

$\left.{ }^{3}\right)$ Siehe bes. Salzer S. 411 Anm. 
S. 937-939). Man muß sich immer vergegenwärtigen, daß das lat. Kirchenlied zum Gesang bestimmt war. Gesungen wurde das Lob Gottes und der Heiligen und von Instrumenten begleitet, mit der Musik findet der Dienst Gottes die höchste Weihe. Eine reiche, großartige Formensprache wurde geschaffen und entwickelte sich besonders seit dem Aufkommen der Sequenzen. ${ }^{1}$ )

Unterschieden werden die lat. Kirchenlieder der Form nach als Hymnen und Sequenzen, ${ }^{2}$ ) jene mit gleichgebauten, diese mit ungleichen Strophen, die oft in zwei gleiche Hälften zerfallen, .und sehr künstlichen Verssystemen. Danach teilen sich auch die Marienlieder ein in Marienhymnen und Mariensequenzen.

Der Stil der Marienlieder ist in der Hauptsache hymnisch, d. h. es sind Preisgesänge zur Verherrlichung der Mutter Gottes. Die Motive sind überaus mannigfaltig, aber sie wiederholen sich immer und bewegen sich in einigen wenigen Gedankenkreisen: Eigenschaften der Mutter des Erlösers und der Himmelskönigin, Ereignisse ihres Lebens, besonders die jungfräuliche Geburt und die Verkündigung durch Gabriel und hiermit die Fülle der Sinnbilder und Beiwörter, in denen das Marienwunder verkleidet dargestellt ist. Meist macht eine Bitte an die heilige Jungfrau den Abschluß. Aber das kirchliche Lied ist zur Ehre der heiligen Personen bestimmt und darum nehmen die Teile, welche die Bitte enthalten, einen bei weitem geringeren Raum ein als die dem Lobpreis dienenden. Der Stil ist gedrängt, die Gedanken sind knapp ausgedrückt und folgen sich rasch, so daß viel Vorstellungsgehalt mit geringem, aber bedeutungsvollem sprachlichem Material ausgedrückt wird. - Unter dem Einfluß der Marienverehrung bei den Cisterziensern und Prämonstratensern entstand etwa seit dem 3. oder 4. Jahrzehnt des 12. Jhs. nach dem Vorbild der lat. eine deutsche Marienlyrik. Die uns erhaltenen Denkmäler sind nicht unmittelbar Nachahmungen lat. Vorbilder, sondern sie haben in Stil und Inhalt manches Eigentümliche.

\section{$\$ 68$. Melker Marienlied.}

Kelle 2, 78. 287; PIPeR, GD. 1, 290-293, Höf. Ep. 3, 723. - Ausg.: B. Pez, Thesaurus anecdot. nov. tom. I pars 1, 415 f.; Hoffmann, Fundgr. 2, 142-144; W. WackernaGel, Ad. Lesebuch 3. Ausg. (1859), 163-166; Jos. Strobl, Wien 1870, dazu SCHerer, ZföG. 21 (1870), 187-193 u. Kl. Schr. 1, 597-603; MSD. Nr. 39 u. II ${ }^{3}$, 244-248; WAAG, Kl. d. Ged. ${ }^{2}$ S. 173-176 u. Einl. S. CVI-CVIII; v. D. LEYEN, KI. Beitr. S. 62 ff.; WOLFSKEHL u. v. D. LEYEN S. 110-119. 221. - SCherer, QF. 12, 55 f.; Kraus, ZföG. 45 (1894), 139; Beissel S. 114 ff.

Hs.: Bibl. des Klosters Melk Cod. J 1. Das Marienlied wurde um 1140-1150 eingetragen. Rechts neben dem Liede stehen Noten, wohl erst aus dem 15. Jh., die wahrscheinlich nichts mit ihm zu tun haben.

Das Lied ist um 1140 in einem Kloster des österreich. Donautals entstanden. ${ }^{3}$ ) Es ist ein Chorgesang in 14 sechszeiligen Strophen, deren jede durch den Refrain Sancta Maria abgeschlossen wird.

\footnotetext{
1) WILHELM MEYer, Fragmenta Burana quenzen, u. bes. S. 84. S. $166 \mathrm{ff}$.

$\left.{ }^{2}\right)$ Siehe LG. I, Reg. unter Hymnen, Se- 459 ff.

3) MSD. I3 S. XXXIX; VoGT, Beitr. 45,
} 
In einer Fülle von Bildern wird Maria gepriesen als die jungfräuliche Mutter des Gotteskindes und in vielen anderen Eigenschaften voll Herrlichkeit, so daß sie von großem Glanz umflossen ist. Es ist die typische Mariendarstellung dieser m.alterl. Lyrik: nicht ein Heiligenbild, in dem die einzelnen Züge $z \mathfrak{u}$ einer schönen, erhabenen oder rührenden Menschengestalt zusammengefügt sind, sondern es ist eine Häufung von Motiven aus dem allegorischen Bilderschatz, entsprechend der typologischen Behandlungsweise der Kirche.

Eine durchgehende Ordnung ${ }^{1}$ ) besteht nicht bei dieser Methode der Aneinanderreihung einzelner gegebener Teile, doch schließen sich gewisse denkgemäße Assoziationsgruppen zusammen. In dem Melker Liede sind die drei ersten Strophen inhaltlich und formal gleich: drei Szenen des alten Testamentes werden erzählt, Aarons Mandelstab, Moses' Feuerbusch, Gideons Lammfell, und werden am Schluß jeder Strophe auf die jungfräuliche Geburt gedeutet. Str. 4 enthält nicht nur eines, sondern vier Bilder; Str. 5-8 gehören zusammen: der Stamm, aus dem Maria erwuchs ${ }^{2}$ ) und die Geburt des Erlösers; Str. 9. 10 und 11, 1-4: wieder eine Bilderaufzählung und zwar aus dem hohen Lied und aus Sirach außer 9, 1 f. (Ezechiel 44, 1 f.); Str. 11, 5-13, 2: Eva-Maria, Tod und Leben; 13, 3-14, 4 nochmals kurze Bilder und Preiswerk, die in der letzten Strophe (14) auf den Himmel deuten und übergehen in den Schluß mit der Bitte um Beistand an Ende 14, 5 f.

Der Inhalt des Melker Liedes steht dem Sermo in Annunciatione S. Mariae des Honorius Aug. sehr nahe (Migne 172, 901-908), fast alle seine Motive finden sich hier, so daß die Predigt wohl die Quelle des Liedes gewesen sein kann. ${ }^{3}$ )

Die Formung der Gedanken entspricht doch nicht völlig dem knappen Stil eines lat. Hymnus, ${ }^{4}$ ) wo sie rasch, oft Zeile für Zeile, wechseln, sondern sie geht in der Mehrzahl der Strophen ins Breite, mehr episch und erklärend wie im Stil einer Predigt, was zumal in den drei ersten Strophen lervortritt, die ja in dem Sermo des Honorius wahrscheinlich ihren Ursprung liaben. Das deutsche Melker Marienlied ist also in der Form nicht die genaue Übertragung eines lat. Hymnus. Die Sätze allerdings sind kurz, in Parataxe aneinandergereiht, die sprachliche Architektonik also ist einfach und kraftvoll wie in den Hymnen und wie im Ezzolied. Mehrere der Sinnbilder sind in ihrer lat. Form angeführt. ${ }^{5}$ )

1) Scherer, ZföG. aaO., QF. 12 aaO.; s. auch MSD. Il $^{3}, 248$; STEINMEYER, ZfdA. $20,127$.

ע) SPREnger, ZfdPh. 26, 285.

3) Die drel in dem Liede weiter ausgeführten Beispicle Str. 1 2. 3 sind die gleichen wic in der Predigt (Sp. 904 A-D), hier nur in der Reihenfolge Moses, Aaron, Gideon (auBer diesen dreien hat Honorius nur noch das Bild vom Manna); an die Erzählung schlleßt sich auch hier jeweils die Auslegung an. Wie in Liede folgt dann auch in der Predigt die Abstammung der Maria und zwar entspricht Hon. 904 D der Str. 6 und 4, wälirend die Entsprechung von Str. 5 erst am Schlaß der Mariensymbole Hon. $906 \mathrm{~A}$ angebracht ist. Von Str. 7 an kommen nur noch einzelne ancls in der Predigt enthaltene Motive vor: Str. 9, 1 = 1 Hon. $905 \mathrm{~A}$; Sir. 11, $6 \mathrm{ff}$. vgl. Hon. $903 \mathrm{~A}$ B; Str. 13, 3 vgl. Hon. 9031 ).

4) Vgl. FHRISMANN, Beitr. 3.t, $177 \mathrm{ff}$.

5) GRÜnEWALD S. 8. 
Die Verse ${ }^{1}$ ) sind ziemlich regelmäßig, die Strophen hatten immer die gleiche Melodie, denn sie sind gleichförmig gebaut. Unter den Reimen finden sich noch einige stärkere Assonanzen.

\section{$\S 69$. Arnsteiner Marienlied.}

Kelle 2, 75-77. 286 f.; PIPER, GD. 1, 82 f. Nachtr. S. 245-250, Höf. Ep. 3, 721. Ausg.: Benecke, ZfdA. 2, 193-199; MSD. ${ }^{3}$ Nr. 38, II $^{3}, 237-244$; PIPER, Nachtr. aaO.; WAAG, Kl. d. Ged. ${ }^{2}$ S. 124-134 u. Einl. S. LXXIX-LXXXIIl. - Scherer, ZföG. 19 (1868), 736 u. KI. Schr. 589 f., QF. 12, 37 f.; Jellinghaus, ZfdPh. 15, 345-358; SCHRÖDER, ZfdA. 47, 124; v. D. LEYEN, KI. Beitr. S. 62 ff.; WOLFFSKEHL u. v. D. LEYEN S. 120-123. 221 f.; BEISSEL S. 114 ff. 213.

Hs.: $\left.{ }^{2}\right)$ Staatsarchiv zu Wiesbaden, vorher im Zentralarchiv zu Idstein, aus dem ehemaligen Marienkloster (Prämonstratenserabtei) Arnstein an der Lahn stammend, Ende des 12. Jhs., ein Psalterium, enthält Bl. $129^{\mathrm{b}}-135^{\mathrm{b}}$ unser Gedicht.

Das Lied ist gedichtet von einer Frau (123. 219, vgl. auch 156 ff.), einer Nonne, ist also in einem Nonnenkloster für geistliche Frauen entstanden. Der Dialekt paßt zu Arnstein, wo sich die Hs. einst befand. Er ist rheinfrk., ${ }^{3}$ ) Arnstein liegt an der Grenze des Rheinfrk. und Mittelfrk., aber entstanden ist das Gedicht nicht in Arnstein selbst, denn dieses war ein Mönchkloster. Graf Ludwig von Arnstein hatte seine Burg im Jahre 1139 in ein Kloster zu Ehren der Maria und des heiligen Nikolaus umgewandelt, das er selbst mit einer Anzahl seiner Ritter bezog und mit Prämonstratensermönchen besiedelte.4) Vielleicht war die Verfasserin Insassin eines der Nonnenklöster, die von Arnstein aus gestiftet wurden. ${ }^{5}$ ) Um 1150 wird das Gedicht verfaßt worden sein. ${ }^{6}$ )

Inhalt. Das Gedicht zerfällt in zwei Teile: A. Die Mariensymbolik 1-77, erzählendbelehrend, enthält sechs Bilder für die Magdgeburt. - B. Der zweite Teil, das Mariengebet $78-325$, beginnt und schließt mit einer Lobpreisung der Maria 78-119 u. 292 bis Schluß. Zwischenhinein fallen die Bitten 120-291. Diese spricht die Betende zuerst für sich selbst 120-225 (lch-Gebet, ich, mig armez wîf), die persönliche Bitte beginnt und schließt mit der Eigenschaft der Mutter Maria als Fürsprecherin ${ }^{7}$ ) bei ihrem Sohn (124-131. 222225), dann für alle armen lûde (reuigen Sünder 262) 226-279 (Wir-gebet, uns), zum Schluß für die ihr persönlich Nahestehenden (die mîne sunderholden 281) 280-291.

Gegen den Schluß steigert sich die seelische Ergriffenheit der betenden Frau, gehobener werden die Worte der Verehrung für die himmlische Gnadenmutter von der Stelle an, wo sie um Erbarmen fleht für alle die Armen, die in der Verbannung der Trösterin dienen und sie von Herzen lieben (226ff.), und der Schluß (292 ff.) klingt aus in ein hymnisches Preislied der Königin, der milden, der süßen, der gnädigen Maria. In planmäßigem Aufbau entwickeln sich die großen Gedankenzüge, während die Einzelmotive nicht in strenger Ordnung gebunden sind. ${ }^{8}$ ) Die Verse der Symbolik bis 63, eben

1) SARAN S 257.

2) MSD. $11^{3}, 237$ f.; Jellinghaus S.345-347.

3) K. WAGNER, ZfdM. 1921, 137 f.

4) MSD. 11,241 ; WatTENBaCH, GQ. Reg. unter Arnstein. K. RoTH, K1. Beitr. I H. 1 S. 38, H. 8 S. 152 .

5) KeLle 2, $76 \mathrm{f}$.

6) MSD. S. XL.

7) Vgl. die Marienbitte der Vor. Sündenkl.

\section{$11-290$ (14 ff. 283 ff.).}

$\left.{ }^{8}\right)$ Eine ähnliche Anlage wie das Arnsteiner Marienlied hat das gereimte Officium De conceptione s. Mariae virg. (Hs. 12. Jh.) MONE $2,8-12$, vgl. auch ebda S. $355-357$ (12. Jh.). - In der allgemeinen Bitte und dem Lobgebet am Schluß 226-325 kehren Gedanken des Salve regina wieder: ad te suspiramus gementes et flentes in hac lacrimarum valle - 
jene, welche die reich ausgeführten Bilder enthalten, haben eine stärkere rhythmisch-melodische Ausprägung als die übrigen, näherten sich also mehr dem Gesangsvortrag, und bei dieser gesteigerten Formgebung inhaltsschwerer Gedanken mag das Beispiel lat. Sequenzen vorbildlich gewesen sein, aber ein wirklich voll melodisch gesungenes Lied oder ein Leich war das Gedicht nicht, ${ }^{1}$ ) dem widerspricht der Inhalt des Teils B. Es ist ein gereimtes Lob- und Bittgebet an Maria. Von der Art der lat. Hymnen und Sequenzen entfernt es sich völlig, denn der erste, kleinere Teil, hat zwar hymnischen Inhalt, aber die breite Ausführung der Symbole widerspricht dem knappen Hymnenstil, und der größere zweite Teil ist bis auf den Schluß ein Gebet. Es war verfaßt für Nonnenklöster, vermutlich zur gottesdienstlichen Feier an Marientagen, war also nicht bestimmt zur Andacht für eine einzelne Person, sondern zum Vortrag im Kloster, rezitiert von einem Chor oder vielleicht auch von einer einzelnen Klosterschwester. ${ }^{2}$ ) Auch trägt die Versform keine Anzeichen eines Leiches, denn die Absätze haben keine korrespondierende Gliederung und die Verse weichen von dem normalen Reimpaargebrauch nicht ab. Aber die erhabenen Bilder der Jungfrauschaft sind in schwungvolleren rinythmischen Sätzen vorgetragen, was dadurch erreicht ist, daß eine Reihe aufeinanderfolgender Sätze mit dreisilbigen Takten (zweisilbigen Senkungen) gebildet sind. $\left.{ }^{3}\right)$ Sie haben also den gelängten Typus des Vierhebungsverses, während die übrigen (von 64 an) normal gebaut sind.

Der Stil ist einfach, ohne besondere Kunstformen. Einige Male kommen gleichgebaute Sätze und anaphorische Verse vor. Für die Wortstellung bemerkenswert sind Hauptsätze wie meinet dầ ruode dig, heilig meidîn 43 mit reiner ${ }^{4}$ ) Anfangsstellung des Verbums. Lat. Worte sind eingeschaltet. ${ }^{5}$ )

$\$ 70$. Mariensequenz aus St. Lambrecht.

Kelle 2, 47 f. 271; PiPer, GD. 1, 301 f., Nachtr. S. 267. - Ausg.: Diener, D. Ged. S. 384 u. Anm. S. 96; MSD. Nr. 41 u. $11^{3}, 251-253$; WAAG, Kl. Ged. ${ }^{2}$ S. 176 f. u. Einl.

wir weinen unde sâften ... in dirre dale helden 242. 246; oculos ad nos converte kêre daz din ouge 266; post hoc exilium uns ellenden 233; exules Evae-Eva hat uns in des Teufels Gewalt verfällt $238-240$; $\mathrm{O}$ clemens, o pia, o dulcis virgo Maria-Milde, genêdige, suoze Marîe $312 \mathrm{f}$. (vgl. MSD. $1^{3}$, $240 \mathrm{f}$.); Benedictus fructus ventris tui 324 (Jesum nobis.. ostende-daz ig niloze scowen den unsen lieven hêrren 198 f.).

1) Vgl. SaRAN S. 254 f. 287.

2) Der Annahme, daß wenigstens die rhythmisch bewegteren Verse der Symbolik 1-63 gesungen wurden, widersprechen dic anf 63 folgenden, noclı zum symbol. Teil gehörenden Verse $64-77$, die in den gleichen Versmaß abgefaßt sind wie das Gebet B. Auch die Formeln In der buoche lese wir 32, Oug saget uns alsus 44, Man liset ouch ander... 74 gehören eher in gesprochene Rede.

3) Aehnliche Verse mit dreisilbigen Takten kommen auch sonst versireut in fritlimlid. epischen Gedichten häufig genıg vor, hier jedoch sind sie in der Absicht, rhythimisch zu wirken, gehäuft und gewiß hat der Gebrauch von Daktylen im lat. Kirchenlied (. $\mathrm{gl}$. die Sequenz von Muri) hier in diesem speziellen Fall dazu die Veranlassung gegebell. - Da Verse mit zwei Senkungen eełit germanisch sind, so kann die Bezcichnung Daktylus (MSD. 11 ${ }^{3}, 241-244$, vgl. ZfdA. 18, 159), abgeselien davon, daß sie nur fïr quantitierende Takte von der form - $-W$ gilt, die unrichtige Vorstellung erwecken, ais ob tiberlaupt ein unmittelbarerZusammenlaang dieser rhythmischen Form mit der klassischen Prosodie bestiinde, vgl. Heusler, Zur Gesclichte d. ad. Verskunsi, Germ. Ablı. 8, S. 711 ; PAUL, Grundr. 1I, 22, 81 f. 132; SARAN S. 254. $286-289$ u. dic daselbst angefiilırte Literafur.

4) Vyrl. Braune, Forsel. z. d. Pliilol., Festgabe fiïr HiLdebrand S. $34 \mathrm{ff}$.

5) Grünewald S. 8. 
S. CVIII f.; SCHERER, QF. 12, 68; v. D. LEYEN, Kl. Beitr. S. 62 ff.; WALLNER, Beitr. 43, 176178 (Conjecturen); BeISSEL S. $114 \mathrm{ff}$.

Hs.: Graz, Universitätsbibl. Nr. 287, aus dem Stift St. Lambrecht in Steiermark, ${ }^{1}$ ) perg., B1. $8^{\mathrm{b}}$, von einer Hand des 12. Jhs. mit der Beischrift Seqñtia. Das Gedicht ist um 1150-1160, vielleicht in St. Lambrecht, entstanden.

Inhalt. 1. Str. 1. 2. 3 Anrufung der Gottes Mutter mit Lobpreisung und mit Bitte um Erhörung (14). II. Str. 4. 5. 6. 7 Maria die Gottgebärerin. Der dritte Teil, der nochmalige Anrufung bezw. Bitte an Maria um Erhörung oder Fürsprache enthalten haben mußte, fehlt. ${ }^{2}$ ) Verfaßt ist das Lied zur Feier von Mariae Verkündigung. ${ }^{3}$ )

Die 3 ersten Strophen sind Übertragung der 2 ersten Strophen der lat. Sequenz Ave praeclara maris stella; ${ }^{4}$ ) aus dem Original sind die lat. Reimwörter stella: exorta, porta: aperta in das deutsche Gedicht herübergenommen. Die 4. Strophe entspricht teilweise der 3. Strophe der lat. Sequenz (die alten vater dîn $\hat{e}$ wunschten und prophetae $21 \mathrm{f}$. = priores desideraverunt patres et prophetae), doch ist das Motiv von der Abstammung aus Jesse weggelassen und dafür das Symbol von dem Mandelstab Aarons eingesetzt, welches in der 3. Strophe der lat. Sequenz angedeutet ist (divini floris amygdalum). Von der Strophe 5 an hört die Übereinstimmung des deutschen Gedichts mit dem lat. auf. - Unter den hier zusammengehörenden Marienliedern folgen das Melker Marienlied und die Sequenz von St. Lambrecht am reinsten dem lat. Stil, denn der hymnische Teil überwiegt hier bei dem St. Lambrechter Gedicht, wenigstens soweit der erhaitene Text reicht, ganz das Element der Bitte, und Gebetsteile sind überhaupt nicht hineingetragen.

Die Sprache hat einen besonderen Schmuck durch die lat. Reimwörter (V. 1. 2. 3. 4. 5. 22 [die wissagen Hs.] 32.33).5)

In der Geschichte der deutschen Verskunst nimmt das Gedicht eine besondere Stelle ein, indem hier zum erstenmal die lat. Sequenzform nachgeahmt ist. ${ }^{6}$ ) Die 3 ersten Strophen entsprechen auch im Bau den 3 ersten metrischen Gesätzen des lat. Gedichtes: Str. 1 mit 3 Versen ist $=$ Str. 1 der lat. Sequenz, Str. 2 und 3 mit je 6 Versen sind $=$ den beiden Halbteilen der lat. Str. 2. Unter den folgenden Strophen des deutschen Gedichtes ist die sechste durch lange Verse ausgezeichnet: sie bildet einen Höhepunkt in der Stimmung, denn in ihr ist der Beschluß der Gnade Gottes zur Sendung Gabriels ausgesprochen. Sonst sind die Verse meist von normaler Ausdehnung außer dem längeren Vers 28 und dem überlangen 15 f. am Abschluß der Str. 3. Die Betonungsweise des ganzen Gedichtes ist mehr sprechtaktartig, rezita-

1) Aus Seckau: Wallner, Beitr. 43, 176; zu den St. Lambrechter Hss. s. oben S. 169. 172.

2) Dieses ist der gewöhnliche Abschluß der Marienlieder älınlichen Inhalts, meist ist der Hinweis auf Verleihung des Himmelreichs mit der Bitte verbunden; zuweilen wird auch Christus angerufen.

$\left.{ }^{3}\right)$ Lieder zu MariäVerkündigung und Christi Geburt s. bei Mone, Hymnen 2 Nr. 343-391 S. $31-90$. Die Sendung Gabriels enthalten
Nr. 355. 357. 363. 375. 391; vgl. auch die Glossenlieder über d. engl. Gruß Nr.392-403.

4) MONe 2 Nr. 555 S. 355-359; Daniel, Thesaurus Bd. 2, 32-34. Die lat. Sequenz wird dem Hermannus Contractus von Reichenau $(\rightarrow 1054)$ zugeschrieben, sie ist in der ersten Hälfte des 11. Jhs. verfaßt; MSD. $I^{3}, 252 \mathrm{f}$.

5) GRÓnewald S. 8.

6) PAul, Grundr. II, 22, 132. - Ueber die ,Sequenzen' s. LG. I, 352 f. 
tivisch, als rein musikalisch. Darum sind auch die umfangreichen Verse mit vier Hebungen $z u$ lesen und als überlange mit schweren Senkungsfüllungen anzusehen. In $29 \mathrm{f}$. entstehen durch die Verlängerung daktylische Takte. Die Reime gehen meist paarweise, nur Str. 1 und 6 haben Dreireim. Die vorkommenden Assonanzen sind leicht.

\section{$\S 71$. Mariensequenz aus Muri.}

Kelle 2, 46 f. 270 f.; Piper, GD. 1, 302-305, Höf. Ep. 3, 723. - Ausg.: LachmanN, Rhein. Mus. Bd. 3 (1829), 425-429, Kl. Schr. S. 330-334; Wackernagel, LB. ${ }^{3}$ S. 259-262; MSD. Nr. $42,1^{3}$ u. 253-256; PIPER, GD. aaO.; WAAG, Kl. d. Ged. ${ }^{2}$ S. $178-180$ u. Einl. S. CIX-CXI. - SCherer, QF. 12, 115 f.; BAeChtold S. 78 u. Anm. S. 23 f.; v. D. Leyen; KI. Beitr. S. 62 ff.; WolfSKehl u. v. D. Leyen S. 124-129. 222; BeIsSEl S. 114 ff.

Hss.: A. Hs. der Gebete von Muri (s. S. 170), obd., mit der Überschrift Sequentia de s. Maria. A abgedruckt bei Graff, Diut. 2, 294-296, dazu Hoffmann, Fundgr. 1, 259; Piper, Nachtr. S. 329-331. Die Sequenz leitet eine neu beginnende Sammlung von Mariengebeten ein. - Ba und Bb, obd., zwei Abschriften in zwei Bibliothekskatalogen des Klosters Engelberg aus dem 18. Jh., deren Originalhs., ein Engelberger Meßbuch, verschollen ist. Ba schließt mit Z. 50, Bb mit Z. 38. Abgedruckt bei BARTSCH, Germ. 18, 49 f. - C. München Clm. 935, 12 u. 13. Jh., das sog. Gebetbuch der heil. Hildegard (lat. Gebete, die der heil. Hildegard zugeschrieben werden), ${ }^{1}$ ) enthält auf S. 70 das Gedicht von $Z .40$ an in mfrk. Mundart, abgedruckt bei Keinz, Münch. SB 1870, 2, 113 f.; PIPER, Höf. Ep. 3, 723.

Da die Reime dialektlos sind, bieten sie keinen Anhaltspunkt für die Heimatsbestimmung des Gedichtes, doch ist es höchst wahrscheinlich in der Schweiz entstanden; und zwar gegen Ende des 12. Jhs., da die Technik die Regeln der Blütezeit voraussetzt. ${ }^{2}$ )

Inlialt. 1. Str. 1. 2: Anrufung der Maria mit der Bitte um Verlcihung dichterischer Beredsamkeit. - Il. Str. 3. 4. 5: Maria Jungfrau und Mutter, dazwischen v. 17-20 Bitte (Hilf) mit Begründung. - IlI. Str. 6-9: Bitte (Begründung Str. 6), Fürbitte beim Sohn Str. 7. 8, Bitte um Hilfe am Lebensende Str. 9.

Auch die Sequenz von Muri folgt nicht dem gewöhnlichen Schema der lat. Marienlieder, denn die Erzählung von der Mutterschaft mit der Verkündigung (Str. 3. 4. 5) und das Bittgebet (Str. 6-9) überwiegen stark über den eigentlich hymnischen Teil mit dem Preis der Eigenschaften der Gottesmutter (Str. 1. 2), der nur gleichsam die Einleitung bildet. Symbolisch ist überhaupt nur weniges in dem Gedicht, ausgeführte Allegorien fehlen ganz. Gerade dadurch wirkt es unmittelbarer, der Gesamteindruck ist mehr der eines inbrünstigen Gebets als eines poetisch ausgeschmückten Preislieds. Eine innere Wärme zieht durch diese andachtsvolle Poesie, die besonders in den Bittversen zum Ausdruck kommt. Die St. Lambrechter Sequenz hat solches nicht erreicht, der äußere Schmuck der Symbolik kann das nicht ersctzen.

Ebenfalls unter dem Einfluß der lat. Sequenz Ave praeclara ist das Gedicht entstanden, schon gleich der Eingangsvers zeigt es; aber sonst hat es in lnlialt 1nit jener nichts gemein. Der deutsclie Dichter, erfüllt von seinem eigenen Erleben, schaut mit inneren Augen das rührende Bild der Mutter mit dem Kinde und in vertrauensvollem Gebet fleht er zu ihrer Barmherzigkeit." Solche persönliche Ergriffenheit spricht nicht aus dem lat. Gedicht,

1) JOHN MEIER, Bcitr. 16, 95.

2) Sicle LACHMANN aaO. 
das sich vielmehr in der glänzenden Rhetorik der Marienlieder entfaltet. Jedoch hat der Verfasser der deutschen Sequenz die gefeierte Melodie der lat. Ave praeclara angenommen ${ }^{1}$ ) und die Versform seines Gedichtes danach gebildet. Die Betonung der einzelnen lat. Verse hat er möglichst nachgeahmt, er hat aber verstanden, sie dem deutschen Formempfinden anzupassen. Dabei zieht sich ein musikalisches Lieblingsmotiv durch die Gesamtmelodie, das ist der Vers von fünf Hebungen mit weiblichem Ausgang (bezw. von sechs Hebungen, deren letzte nebentonig ist), derselbe Vers also, der den Abschluß der Spervogel- und der Kudrunstrophe bildet. Er kommt selbständig vor V. 49. 53, und mehrfach als zweiter Teil in Verbindungen: so ist V. 2 ein achthebiger Vers, bestehend aus einem Dreiheber und einem weiblich endenden Fünfheber. V. 6. 7 bezw. 11. 12 sind zusammengesetzt aus einen männlich ausgehenden Vierheber und dem Fünfheber; hier sieht man zugleich deutlich die Absicht des Dichters, den dem deutschen Formgefühl zusagenden Fünfhebungsvers mit weiblichem Ausgang an Stelle eines anderen lat. rhythmischen Satzes zu bringen (indutum carne ducis in orbem Str. 2, 8. 9 bezw. 14. 15 der lat. Sequenz, jamb. Dimeter + adonischer Vers). Das ganze System der deutschen Str. 6 gründet sich auf diesen Fünfheber: in 49.53 erscheint er allein, in $50.54=3+5$ Heb., das ist die vierte Langzeile der Kudrunstrophe, $52.56=2+5 \mathrm{Heb}$. Sechshebungsverse wechseln mit Dreihebern in Str. 4, sehr künstlich ist Str. 5 gebaut mit Wechsel von zwei-, drei-, vier-, fünfund achthebigen Versen. Das ganze Gedicht schließt mit einem Satz von zehn Hebungen. Dactylen kommen vor 15. 19. 34. 42. 43, vgl. Mone 40-32 bezw. $50-52 ; 65.66$ vgl. Mone 86-90. Mit dem Mariengedicht von Muri ist somit eine deutsche Sequenz geschaffen, deren Kunstform dem Wesen der lat. Sequenzen entspricht, aber doch von deutschem rhythmischen Gefühl getragen ist.

Die Reime sind rein. Sie sind paarweise gebunden. Die Strophen sind von ungleicher Länge, von 2 bis zu 16 Versen. Der ganze Bau der Sequenz ist sehr kunstvoll, ihm muß auch eine reiche Melodie entsprochen haben.

\section{$\S 72$. Marienlob.}

Kelle 2, 77 f. 287; PiPer, GD. 1, 300 f., Höf. Ep. 3, 723. - Ausg.: Diemer, D. Ged. S. 69, 6-72, 8, Anm. S. 26 f. u. EinI. S. XXXIV u. XL, dazu Collation von PIPER, ZfdPhil. 20, 478; MSD. Nr. 40 u. II ${ }^{3}, 248-251$. - SCHERER, QF. 7, 49. 12, 68; RöDIGER, Anz. 1, 68; WAAG, Beitr. 11, 101-105; v. D. LeYen, Kl. Beitr. S. 62 ff.; MÜNSCHER, Marburger Diss. 1908; BEISSEL S. $114 \mathrm{ff}$.

Hs.: Vorauer Hs. Bl. 93c_-94a, mitten im fortlaufenden Text ohne besondere Bezeichnung des Anfangs und des Endes. Es ist ein Teil der Bücher Mosis, ein selbständiges Gedicht ist es nicht gewesen; MülLENHOFF hat es in den Denkm. als ein Stück für sich herausgegeben. Es handelt von der Prophezeiung des Jesaias auf Christus, Jes. 11, 1 von der wunderbaren Geburt. Für die Lehre von den sieben Gaben des heiligen Geistes 3, 9-24 ist Jesaias 11, 2-3 die Quelle.

Die Auffassung des Stoffes ist von den im Vorhergehenden behandelten Marienliedern ganz verschieden: hymnisch ist nur die letzte Strophe, das

1) Lachmann aaO.; MSD. II $^{3}$ aaO.; A. Exempla Nr. 56; SARAN S. 258; Paul, Grundr. Schubiger, Die Sängerschule S. Gallens, II, 22, 132; Jellinghaus, ZfdPh. 15, 347. 
eigentliche Marienlob, der Hauptteil, ist eine Erklärung des Jesaiasspruches. Der Stil ist, außer in der letzten Strophe, didaktisch, nicht lyrisch, das kommt besonders zum Ausdruck in der Aufzählung 3,11-24 und in den Formeln 1, 21. 2, 4. 8. 3, 12.17. 20.1)

Metrik. ${ }^{2}$ ) Das Gedicht ist kein Lied, die Rhythmik ist nicht musikalisch, es sind Sprechverse, sie bewegen sich im mittleren Längenmaß. Die inhaltlich gehobene eigentliche Lobpreisung (Str. 5) ist ziemlich regelmäßig gebaut. Die Reime sind großenteils unrein, aber die Assonanzen sind nicht schwer.

\section{$\$ 73$. Drei Lieder von der Jungfrau vom Priester Wernher.}

Kelle 2, 200-204. 382-384; PIPeR, GD. 1, 249-260, Höf. Ep. 3, 723. - Ausg.: Oetter, Nürnb. und Altdorf 1802 (Berl. Hs.); HofrmanN, Fundgr. 2, 145-212 (Berl. Hs., s. auch 1, 242-244); Jul. FeifaliK, ${ }^{3}$ ) Wien 1860, dazu BarTsCh, Germ. 6, 117-123, auch BarTsCH, Herzog Ernst S. XXXII. - Scherer, QF. 12, 95-100, D. Stud. 1, 14; J. W. BRUINIER, Diss. Greifsw. 1890, dazu Karl KochendörfFer, Anz. 19, 137-150, JoHn MEIER, LitBl. 1892, 147-152; PAUL STEINHÄUSER, Wernhers Marienleben in seinem Verhältnisse zum „Liber de infantia sanctae Mariae et Christi salvatoris" nebst einem metr. Anhange, Diss. Rostock o. J. (1890), dazu KociuendörfFer aaO.; Sievers, Forsch. z. d. Philol, Festgabe f. Hildebrand S. 11-33 und Rhythmisch-melodische Studien S. 9-35; BeISSEL S. 117 ff.

Hss.:4) D. Berliner Hs.,5) Ms. germ. oct. 109, Perg. k1. 40, 91 Bl. mit 85 Miniaturen, vom Ende des 12. Jhs. Hgb. von Oetrer aaO. und Hoffmann aaO. Der Dialekt ist bair.-österreich.

A. Wiener Hs. Nr. 2743, ${ }^{\circ}$ ) Perg. kl. $4^{0}, 103$ Bl., von der Mitte des 13. Jhs., enthält: Die Manunge Marien (Mariengebete) Bl. 2a -7a, Wernhers Marienlieder Bl. 9a-74b, die Kindheit Jesu von Konrad v. Fussesbrunnen $74^{\mathrm{b}}-101^{\mathrm{b}}$, die fünf Manunge Marien lat. 101b 102b. Hgb. von FeIfaliK aaO. Der Dialekt ist bair.-österreich.

Bruchstücke: B. Docens Bruchst. (erstes Münchener Bruchst., Perg.blatt kl. $8^{0}$, 2. Hälfte des 13. Jhs., Ausg.: Docen, Aretins Beitr. z. Gesch. u. Lit. 7, 119-124; Docens Miscellaneen 2, 103-108; Hoffmann, Fundgr. 2, 213 f.; WaCkERnaGel, LB. ${ }^{5}$ S. 405-408; Keinz, Münchener SB. 1869, 296-298 (302 f.). Der Dialekt ist bair. oder alemann.

E. Nürnberg, Germ. Mus., ${ }^{2}$ ) Perg.blatt kl. ${ }^{0}$, Ende des 12. Jhs, Ausg.: Bartsch, Mones, Anz. f. Kunde d. d. Vorz. 1862, 112-115.

F. Augsburg, Stadtbibl., 4 Perg.blätter gr. 40, 12./13. Jh., Ausg.: Bened. Greiff, Germ. 7, 305-330.8) Der Dialekt ist bair. oder alemann.

C. Bruchslücke (ein Codex Diseissus), zusammen $24 \mathrm{Bl}$. und 21 Streifen, Perg. $8^{\circ}$, Anf. d. 14. Jhs.: $\mathrm{C}^{1}$ Hofbibl. Karlsruhe, 4 Bl., Ausg.: Mone, Anz. f. Kunde d. d. MA.s 7 (1837), 156-164; BaRTsCH, Germ. 12, 85 f. - C ${ }^{2}$ Berlin, Kgl. Bibl. qu. 1303, 18 Bl. und 14 Strcifen, Ausg.: BaRTsCH, Quellenk. S. 6-57. $-\mathrm{C}^{3}$ München (Zweites Münchener Bruchstück) 1 Doppelbl., Ausg.: KerNZ aaO. S. 298-305. - C ${ }^{4}$ Universitätsbibl. zu Breslau, 5 Streifen, Ausg.: Jos. KLAPPER, ZfdA. 50, 167-172, als zu Wernhers Marienliedern geliörig erkannt von VoGT, ebda 53, 381-384. - Die Bruchstücke $\mathrm{C}^{1}$ und $\mathrm{C}^{4}$ stamınen aus Einbänden

1) Lat. Wörter s. GRÜNEWALD S. 8.

2) MÚnscher S. 75 ff. - MÚll.enHoff hat in MSD. 5 gleiche Strophen zu 24 Zeilen abgeteilt, eine solche Regelung wird durch den Inhalt nicht erfordert und widerspricht den durch die großen Buclistaben bezeichneten Abschnitten der Hs.

$\left.{ }^{3}\right)$ Eine krit. Ausgabe mit Zugrundelegung von $D$ und Beiziehung aller liragmente fehlt noch.

4) Feifalik S. VIl ff., dazu Bartsch, Germ. 6, 117 ff.; SCHADE, Liber de lnfantia S. 7 f.;
BARTSCH, Beitr. Z. Quellenkunde S. 1 ff.; BRUINıER S. $1-35$; zur Berl. Hs. s. anßerden HoffManN aaO. S. $145 \mathrm{f}$.

5) Ueber die Miniaturen: Franz Kugler, De Werinhcro saec. XIl monacho Tegernseensi usw., Berol. 1831 u. Kl. Selır. 1, $12-37$.

6) PFEIFFER, Ger111. 5, 247; KochendörFFER, Kindheit Jesu, QF. 43 S. 4 i. S. V1l; Bruinier S. 3.

7) Vgl. Vogt, ZfdA. 53, 382 .

$\left.{ }^{8}\right)$ Vgl. Leitzmann, Beitr. 41, 378. 
von Büchern, die sich einst im Katharinenkloster in Nürnberg befanden. Der Dialekt von $\mathrm{C}$ ist thüring., aber die Vorlage war bair.

G. Drittes Münchener Éruchst., 2 Pergamentstückchen, Ende d. 13. Jhs., vgl. KEINZ aaO. S. 305-307, Ausg.: BarTSCH, Quellenkunde S. 58 f. Der Dialekt ist bair. Die 3 Münchener Bruchstücke B C ${ }^{3} \mathrm{G}$ sind vereinigt unter Cgm. 5249 Nr. 2.

Die Hss. zerfallen in 3 Klassen: die Bruchstuicke B C E F, die Berl. Hs. D und die Wiener Hs. $A^{1}$ ). Die 3 Gruppen stellen 3 Textstufen dar, B CEF enthalten die ursprüngliche Fassung des Gedichtes, also den Text des Originals, $=0$.

Inhalt (nach D, HoffmanN). Erstes Lied. Joachim und Anna 147, 1-162, 32. Einleitung 147, 1-149, 40: Anrufung der Mutter Gottes $(147,1-24)$. Persönliches Bittgebet an Maria $(147,25-148,6)$. Angabe der Quelle $(148,7-149,21)$. Gegen die übelwollenden Kritiker (149, 22 - 40). - Die Erzählung: Joachim, sein Geschlecht (149, 41$151,14)$. Verlobung mit Anna $(151,15-152,5)$. Wegen ihrer Kinderlosigkeit werden sie aus dem Tempel verbannt; Joachim flieht wegen der Kränkung in die Einöde (152, 6$153,6)$. Annas Kummer und Gebet $(153,7-154,24)$. Ein Engel verkündigt ihr die Geburt einer Tochter, von der der heilige Christ kommen werde; die Magd, die sie pflegen sollte, verläßt sie unter Beschimpfung $(154,25-156,5)$. Ein Engel verkündigt Joachim die Geburt einer Tochter und mahnt ihn zur Heimkehr $(256,6-158,40)$. Der Engel befiehlt Anna, ihren Gatten zu empfangen; das Wiedersehen $(158,41-159,35)$. Die Geburt Mariae (159, $36-160,36)$. Darstellung der dreijährigen Maria im Tempel; Lobgesang ihrer Mutter Anna $(160,37-161,29)$. Wir sollen die Frommen des alten Testaments anrufen, denn sie sind im Himmelreich den Engeln gleich $(161,30-162,32)$.

Zweites Lied. Von der Jugend der Maria bis zur Heimsuchung 162, 33182, 44. Einleitung 162, 34-163, 24: Mariengebet, Verfasser der Lieder 163, 1 f.; die Quelle: Matheus 163, 5. - Die Erzählung: Maria als Klosterschülerin im Tempel (163, 25-165, 29). Der Bischof Abiatar wirbt um sie für seinen Sohn, sie aber will Gottes Braut bleiben (165, 30-167, 20). Die Gertenprobe: Josephs Stab entschwingt sich die Taube, er lehnt die Vermählung mit Maria ab, nimmt sie aber in sein Haus auf $(167,21-172,24)$. Maria gehorcht Gottes Willen (172, 25-173, 39). Die Vermählung $(173,40-175,7)$. Joseph muß eine Reise machen, Maria und die Mägde arbeiten zu Hause, Spott der Mägde; Erscheinung eines Engels $(175,8-177,17)$. Erscheinung Gabriels, Maria empfängt das Kind; Menschwerdung Christi; die Weissagungen auf Christus. Der Dichter ist aber nicht fähig, die Herrlichkeit der Himmelskönigin in Worten auszusprechen. Gabriel zeigt Maria an, daß Elisabeth ein Kind gebären wird $(177,18-181,4)$. Die Heimsuchung $(181,5-182,44)$.

Drittes Lied. Von der Heimsuchung bis zur Heimkehr aus Ägypten 182, 45-212, 20. Einleitung 182, 45-184, 23: Inhaltsangabe: Heilkraft der drei Lieder; Gebet an die Jungfrau. - Mit 184, 6 beginnt nach nochmaliger Aufforderung an die Gläubigen und Wieđerholung des Inlıalts vom vorhergehenden Liede $(184,6-23)$ die Erzählung: Joseph kebrt nach Haus zurück; er ist betrübt über den Zustand Marias; er will fliehen; ein Engel klärt ihn auf $(184,24-187,31)$. Sie werden vor Gericht geladen, Maria soll als Ehebrecherin gesteinigt werden, sie reinigen sich durch die Wasserprobe $(187,32-191,17)$. Das Edikt des Augustus (191, 18-192,34). Joseph und Maria ziehen nach Bethlehem; Vision der Maria; die traurige und die freudige Schar $(192,35-195,8)$. Die bibl. Geschichte bis zur Heinkehr aus Ägypten mit symbolischen Erklärungen (195, 9-211,4). - Schluß: Warnung vor der Welt. Gebet zu Maria mit dem Ausblick auf die himmlische Seligkeit $(211,5-212,6)$. Erzählung von den Wundern, Tod, Auferstehung. Himmelfahrt und dem jüngsten Gericht (A 4469-4738, fehlt D). Angabe der Abfassungszeit (A 4809-4850, fehlt D). Inhaltsuibersicht iiber die drei Lieder $(212,7-20)$.

Der Dichter bringt mit Vorliebe literarische Angaben über sich und sein Werk. Im Prolog 148, 7 ff. gibt er einen kurzen Überblick über die

1) Das Bruchst. G gehört jedenfalls nicht zu der Bearbeitung, die durch A vertreten ist. 
Geschichte des Textes mit Angabe der Quellen, Matthäus als Verfasser des hebräischen Originals, Hieronymus als Übersetzer, um dann wieder auf sich als den Verdeutscher überzugehen. Seinen Namen nennt er am Eingang des zweiten Liedes: der pfaffe heizet Wernhere, der des lides began 163, $1 \mathrm{f}$., ausführlich spricht er über die Entstehung seines Werkes im Epilog (A, FEIFALIK 4809-4850, fehlt D). Er nennt sich hier nochmals: ein priester, Wernher geheizen; ein Priester namens Manigolt hat ihn auf den Stoff verwiesen und ihn in sein Haus aufgenommen, bis das Gedicht fertig war. Auch die Zeit gibt er an und zwar genau das Jahr 1172; und kurz darauf nochmals, unter chronikartiger Zitierung wichtiger Ereignisse (D 212, 7-13 und ausführlicher A 4851-4871). Der Dichter war demnach ein Weltgeistlicher, der um 1170 in Baiern, oder vielleicht in Augsburg, dichtete, und sein Gönner Manigolt kann Domgeistlicher gewesen sein. ${ }^{1}$ )

Die 3 Lieder $^{2}$ ) sind genau abgegrenzt, das 2. und 3. haben eigene Einleitung und eigenen Schluß, das 1. endet mit einer Bitte um die ewige Seligkeit. Der Dichter scheidet sie nochmals am Ende des Ganzen mit kurzer Inhaltsangabe eines jeden Liedes: Geburt der Jungfrau, ihre VerInählung, Geburt ihres Sohnes 212, 14-20.

Die von dem Dichter selbst in der Einleitung angegebene Quelle ist das apokryphe Pseudo-Evangelium Matthaei, Liber de ortu Beatae Mariae et infantia Salvatoris, a beato Matthaeo evangelista hebraice scriptus et a beato Jeronimo presbytero in latinum translatus. ${ }^{3}$ ) Doch hat er eine

1) Vgl. SCHRÖDER, Gött. g. A. 1884, 569; KOCHENDÖRFFER S. 144

2) Liet nennt er das ganze Gedicht gleich in der ersten Zeile: Eines liedes ich beginne 147,1 , und dann noch $3 \mathrm{mal}$ in der Einleitung: 148, 5. 15. 149, 29, ferner am Anfang und am Schluß des 2. Abschnitts 163, 2. 182, 43; am Anfang des 3 . Teils, 182, 45, bezieht sich liet nur auf den einzelnen $\mathrm{Ab}$ schnitt, nicht auf das Ganze, und desgl. ausdrücklich in A 2552 (fehlt D), 184 D, $6=$ $2579 \mathrm{~A}$ und am SchluB 212, 15. 17. $19=4872$. 4878. $4881 \mathrm{~A}$. Genauer faßt er alle $3 \mathrm{Ab}-$ schnitte als ditl driu liet zusanmen in der Einleitung zum dritten 183, 12 D, 2505 u. 2540 A (diu buchel driv 183, 21 D, 4816 A (felılt D);212, 14 D = 4870 A, diu geistlichen liet $4830 \mathrm{~A}$ (fehlt D). Vgl. Schwietering, Singen und Sagen S. 6 f. 13.

3) Die A p okry phen des neuentestamentes sind Jesuslegenden, Dichtungen über Lebensverhăltnisse des Herrn aus denZeitabsclutitten, die in den neutestamentlichen Schriften nicht oder nur kurz beluandelt sind. Sic sind entstanden aus dem frommen Bediirfuis, den Lebensgang des Heilands ganz und möglichst lückenlos zu besilzen. Das älteste apokryphe Evangelium ïber die Vorgeschiclite und die Jugend Jesu ist das griechische P rotev angelium Jacobi, dem Bruder des Ilerm zu- geschricben, das schon ins 2. Jh. fällt und weit verbreitet war. Das gnostische griechische Ev. Thomac ist nach dem Protevangelium das älteste; jünger ist das dem Evangelisten Matthaeus beigelegte lat. Ev. PseudoMatthaei (5. Jlı.), ferner das ursprünglich koptische Ev. De nativitate Mariae und das urspriinglich arabische Ev. infantiae arabicum. Sie alle wurden ins Lat. iibersetzt. Vgl. Realencyklop. 13, 653 ff. Ausgaben der apokr. Evangelien: THILO, Codex apocryphus novi Testamenti, 1832; CONSTANTINUS DE TISCHENDORF, Evangelia apocrypha, 2. Aufl. 1876; RoB. Reinsch, Die Psendo-Evangelien von Jesu und Maria's Kindlıcit in der roman. u. germ. Litcratur, 1879. Das Ev. Pseudo-Matthaei ist hgb. von SCHADE, Liber de infantia Mariae et Christi salvatoris ex codice Stutgart., Univ.schrift Königsberg 1869; bei THllo S. 339-400, TiSCHENDORF S. 51-112; vgl. auch Steinhäuser aaO. Die Hss. des PseudoMatth. weichen oft sehr voneinander ab. Das Ev. Pseudo-Matthaci wurde von Hrotsvitha in lat. Hexameter umgearbeitet (ed. PAUI. v. WintERFEI D, Hrotsvithile Opera S. 5-29, vgl. L.G. 1, 379), sie selbst allerdings nennt in der Uebersehrift als Quelle failschltich die Historia mativitatis . . . quann scriptan repperi sub nonine Sancti lacobi fratris 1)omini (vgl. SCHADE S. 6 f.). 
andere Textrezension als die in den uns erhaltenen Hss. überlieferte benützt und wohl auch noch aus andern Quellen geschöpft. Jedenfalls aber hat er den ihm gegebenen Stoff in freier Art behandelt, er hat ihn mit seiner Anschauungsweise durchdrungen und hat ihm sein Gemüt verliehen.1)

Das apokryphe Evangelium erzählt in einfacher Sprache die Tatsachen, läßt aber doch an gehobenen Stellen auch die inneren Bewegungen zur Geltung kommen, Wernhers Dichtung dagegen ist ein Preislied in sente Marien minne 147, 1, in dem die Handlung durchwoben ist mit lyrischen und belehrenden Partien, ausgestattet mit reichem Leben und einer Fülle von Empfindung. Anders als der Dichter der Wiener Genesis, der seine Auffassung nur in kleinen Einzelzügen ausprägt, dichtet vielmehr Wernher die Angaben seiner Quelle über Vorgänge und Personen zu ganzen Szenen und Charakteristiken aus und fügt viele erklärende und erbauende Stellen hinzu. Wo Pseudo-Matthäus Joachims Geschlecht nur mit den Worten angibt ex tribu Juda (TischendorF S. 54), hat Wernher 28 Verse uber die Frömmigkeit seiner Vorfahren, der Patriarchen 149, 41-150, 15. Im deutschen Gedicht ist Joachim dargestellt als das Musterbild eines geistlichen Übungen sich hingebenden Jünglings 150, 16-151, 14. Zu ihm ist Anna das Gegenstück, die gottselige Jungfrau 151, 19-29 (Tischendorf S. 55) und das Opfer Joachims wird ausführlich erzählt 152,6-20. Breit ausgeführt sind die Reden Josephs und Marias, in denen sie ihre Stimmung gegentiber der Vermählung ausdrücken $171,10-173,39$ (TischendoRF S. 69). Das darauf folgende Verlöbnis, das in der Vorlage ganz fehlt, ist hier doch in wenigen Worten geschildert 173, 41-174, 3. - Und in dieser Weise ist das deutsche Gedicht durchweg eine erweiterte Ausführung des lat. Originals. Neu hinzugekommen sind z. B. die Einleitungen und Schlüsse der drei Lieder, die sieben Wunder bei Christi Geburt, auch die Auslegungen biblischer Eigennamen $(150,21-23.151,39)$. Vor allem aber ist das Bild der Maria erweitert. Auch im Pseudo-Matthäus ist sie die unvergleichliche ob allen Frauen (TisCHENDORF S. 58), das Muster einer tugendhaften Jungfrau (S.6264), Wernher aber hat sie ins Überirdische, zur Himmelskönigin erhoben; jetzt erst besitzt sie göttliche Kraft, die die Sünden tilgt. Alle Schönheit und Lieblichkeit vereinigt der Dichter auf die himmlische Frau: sie war den Engeln so hold, daß sie bei den Blumen bleiben und ruhen wollte 150, $25 \mathrm{f}$; da stand sie wie die Blume, die an der grünen Wiese ihren lichten Glanz weithin ausbreitet 172, 39 f.; wie die Sonne leuchtete sie aus ihrem ganzen Geschlechte 163, 29; sie schritt über das Gefilde in Engelsbild 175, 3; sie ist die Lilie, die Himmelsrose, Stern und Edelstein, die Taube ohne Galle. ${ }^{2}$ ) Es sind zumeist die bekannten Sinnbilder, aber während sie in den älteren Marienliedern einzeln aneinandergereiht sind wie an einer Perlen-

$\left.{ }^{1}\right)$ Die einfach getreue Inhaltserzählung Uhlands, Schriften 2, 14 ff., läßt die Lieblichkeit dieser glaubensinnigen Wunderwelt getreu nachempfinden.

2) BRUINIER S. 206-208. 
schnur, sind sie hier wie Kleinode eingewebt in das Lichtgewand der Gottesbraut. Überhaupt ist Wernhers Gedicht in eine stärkere Stimmung getaucht. Er beobachtet die Ereignisse auf ihre Wirkung, die sie in der Seele der Menschen hervorbringen und verweilt bei den Empfindungen mit warmer und ausgiebiger Teilnahme. Echt deutsch ist das Bewußtsein von dem Wechsel der Gefühlswerte, die das Leben beherrschen, Freud' muß Leid, Leid muß Freude haben; wem je einmal Herzliebes zuteil ward, der kennt die Qual der Schmerzen, die das Herzeleid bereitet 209, $38 \mathrm{f}$. Wie im Nibelungenlied, wie liebe mit leide ze jungest lônen kan, so erfährt es Anna, nachdem ihr Gatte von ihr geschieden: ir frode wart gemisket mit leide 156, 5 (ir freude mischte sich mit weinen $630 \mathrm{~A}$ ); Gott aber verleilit dem Gatten nach der langen Prüfung nâh milen frơde 159, 35. Das ist die verschiedene Lebensauffassung der germanischen Volksseele und des Christentums: Leid ist das Ende in dem tragischen Schicksalsglauben des Heidentums, aber dem Christen wirft die erwartete himmlische Wonne einen erleuchtenden Strahl vorempfundener Seeligkeit in sein jammervolles Dasein.

Und diese hoffnungsfrohe Gewißheit ist bei allem Leiden auch die Grundstimmung des Gedichtes. Denn diese Heiligengeschichte ist so menschlich! Unverdiente Schmach und die Unbarmherzigkeit der Mitmenschen treiben Joachim von der Seite seines Weibes weg ins Elend; und der alternde Joseph, der mit dem Glauben an die Reinheit des ihm vermählten reinsten Wesens das Vertrauen zum Leben verloren hat, will heimlich seinem zerschellten Glück entfliehen. Aber auf Leid folgtFreude in diesen, auf die höclıste Freude, die Geburt des Erlösers, vorbereitenden Ereignissen: der Engel führt sie wieder zusammen, die sich lieb haben 156, $6 \mathrm{ff}$. 186, $34 \mathrm{ff}$. Anna, da der Engel ihr die Ankunft des Gatten verkündete, eilte durch das Stadttor auf eine Anhöhe, sie ging ihm entgegen, sie fiel ihm um den Hals, an seiner Hand ging sie, die Reine, Gute, küßte ihn mit frohem Herzen und empfing ihn innig wohl, wie Lieb Herzliebe soll 158, 41-159, 26. Auch der apokryphische Verfasser hat die Freude des Wiedersehens in schlichten Worten ausgedrückt, der deutsche Dichter aber empfand aus der ganzen Tiefe seines Gemütslebens heraus das Weh des Scheidens und die Wonne des Wiedersehens als starke innere Erlebnisse. Sie waren ihm selbst eigen, denn es waren elementare Gefühlszüge seines Volkes, und sind es noch heute: es ist die beseeligende, mit Schmerzen erkaufte Gnade, Glück und Leid in trenem Herzen zu bewahren. Die Poesie seiner Zeit hat auch schon Vorstellungen und Worte gefunden, un die Empfindung des Trennungswehs auszudrücken. Es ist ein Zug in der Stinmmungswelt des altdeutschen Minnesangs: Vil lieber frilunde scheiden $d a z$ ist schedelìch, swer sinen friunt behaltet, daz ist lobelîch (Der von Kürenberg, Minnesangs Frühling 7, 1-4), oder: Got sende si zesamene die gerne geliep wellen sîn $(9,11 \mathrm{f}$.), oder liep âne leit mac niht gesîn (DIETMAR voN EIST, ebda 39, 24), oder das Lied vom entflohenen Falken des Kürenbergers und Dietmars von Eist $(8,33 \mathrm{ff} .37,4 \mathrm{ff}$.). 
Anschaulichkeit und Kraft zeichnen die Darstellungsweise aus. Der Stil ist reich an Bildern und Vergleichen,1) die die Erzählung beleben. Schon die Verherrlichung der Maria bot deren eine Fülle. Andere sind dem Kriegsleben entnommen: die Gläubigen sind Gottesstreiter, die Heerschaten, die mit fliegenden Fahnen gegen den Lindwurm ziehen 148, 25 ff.; die dienen unter der Fahne der Jungfrau 160, 26. Wie die Ritter in den Volkskämpfen zu der Fahne strömen, so sollen wir zu dem Stern unsere Zuflucht haben, der das christliche Heer über der Sorgen Meer bringt aus des Teufels Banden $z \mathfrak{u}$ dem freudenreichen Lande, wo Gott selber ist, die Sonne, der Tag, die Wonne 184, $6 \mathrm{ff}$. (der Stern ist Maria, maris stella, die Sonne ist Christus, vgl. 147, 10. 16-18). Auch der in Sorgen lebt, ist ein Kämpfer: ihr (Anna) war als wie einem Manne, der unter einem Baum schlafend in schwerem Traum befangen liegt, der mit Mühe seinen Feinden entronnen ist und erwachend erkennt, daß alle seine Not verschwunden ist 155, $21 \mathrm{ff}$.

Der sprachliche Ausdruck ist gewandt, der Satzbau einfach, doch auch untermischt mit Perioden. Unter den stilistischen Mitteln treten die zweigliedrigen Formeln stark hervor, häufig sind auch parallele Ausdrücke und Sätze, ${ }^{2}$ ) nicht selten finden sich lat. Worte, $\left.{ }^{3}\right)$ Zitate, die manchmal aus der Vorlage stammen. Formelhafte Anreden an die Hörer sind maßvoll verwendet. Sie beweisen, daß die drei Lieder zum Vortrag bestimmt waren, besonders wohl zum Fest von Mariä Geburt, vgl. 160, 24 ff., dazu 161, $30 \mathrm{ff.}^{4}$ ) Zugleich aber sollten diese auch der Privaterbauung dienen und ihre heilsame Kraft bei Schwangerschaft ausüben 183, $12 \mathrm{ff}$.

Auffallend sind die Grundsätze der Metrik: während in der Reimtechnik die ältere Freiheit unreiner Reime herrscht - wobei die Assonanzen nicht mehr sehr stark sind -, ist der Versbau ziemlich regelmäBig wie in der klassischen Zeit. Die Schlußzeilen von Absätzen sind oft verlängert.5)

$D$, der Berliner, und $A$, der Wiener Text, sind Bearbeitungen des Originals $(\mathrm{O})$, und $z$ war fällt $\mathrm{D}$, die ältere Redaktion, um 1190, $\mathrm{A}$, die jüngere, ins 13. Jh.6) Für das ursprüngliche Gedicht (O) liegt die Überlieferung ${ }^{7}$ ) insofern nicht günstig, als die umfangreichsten Bruchstücke, die von $\mathrm{C}$, recht fehlerhaft sind, auch $E, F$ und $G$ sind nicht zuverlässig, dagegen ist $B$ gut.

Die ältere Bearbeitung ist durch $D$ gut vertreten, da diese Hs. recht sorgfältig ist, A dagegen, die jüngere Bearbeitung, ist sehr nachlässig. Der Verfasser von D steht auf dem Boden der neuen Reimkunst, die reine Bin-

1) BRUINIER S. $194 \mathrm{ff}$.

2) ZWierzina, ZfdA. 45, 281 Anm.

3) GRÜnEwald S. $30 \mathrm{f}$.

4) In der Predigt De Nativitate S. Mariae wurde die Geschichte von Joachim und Anna erzählt, vgl. Honorius Aug. Speculum Eccl, Migne 172, 999 ff.; Kelle, Speculum Eccl. S. $106 \mathrm{ff}$.

5) W. Grimm, ZGdR., Kl. Schr. 4, 172; Sievers, r.-m. Stud. S. $23 \mathrm{ff}$.; Bruinier S. $41-$ 81. 235 f.; STEINHÄUSER S. $53-67$; SARAN
S. 254; SCHRÖDER, Gött. Nachr. 1918, 407. 424. 428; BETHMANN, Palaestr 30,112.

6) Ueber das Verhältnis von Original, D und A untereinander s. bes. BRUINIER, STEINHÄUSER, SIEVERS. Ueber das Verhältnis von Konrad v. Fußesbrunnens Kindheit Jesu zu Wernhers Marienliedern s. KocHENDÖRFFER in seiner Ausgabe S. 36 ff. und SCHÖNBACH, ZfdA. 27, $65 \mathrm{ff}$.

7) BRUiNieR S. 12-40. 
dungen verlangt. Der $Z$ weck seiner Umarbeitung ist eben der, die Assonanzen des Originals möglichst zu beseitigen, immerhin ist noch mancher Reim unrein. Folgt der Bearbeiter D also in den Grundsätzen des Reimgebrauchs den neuen, strengeren Anforderungen, so ist es um so auffallender, daß er den Rhythmus freier, also archaistischer behandelt als das Original $(O)$ : dieses hatte verhältnismäßig regelmäßigen vierhebigen Bau, mit längeren Versen an Abschnitten, während D unbedenklich mehrsilbige Senkungen zuläßt. $\left.{ }^{1}\right)$ Mit der Umwandlung der Reime waren auch mehr oder weniger eingreifende inhaltliche Änderungen verbunden, aber auch ohne solche Gründe hat der Bearbeiter den alten Text umgestaltet. So kommt es, daß D vom Original (O) bedeutend abweicht. Der Umfang solcher völlig anders lautenden Textstellen kann 5 oder 10 oder auch mehr, etwa 30 Verse betragen. Auch ohne durch Umreimung veranlaßt zu sein verfährt der Bearbeiter ziemlich selbständig mit dem Versbestand. Er macht Zusätze, umfangreicher aber sind die Kürzungen, gegen den Schluß läßt er die ganze Partie von den Wundern Jesu bis zu den letzten Dingen weg (= A 4469-4738) und gleich darauf fehlt noch die Mitteilung über die Person des Dichters (= A 48094850). Der im Original poetisch gehobene und trostreiche Marienpreis C" 278-290 (BarTsCh, Ouellenk. S. 13 f.) ist in D 160, 28 f. auf anderthalb zusammengeflickte Verse beschränkt, ähnlich $C^{b}$ 1077--1085 gegen D 183, 37 f., Cb 1699-1712 gegen D 196, 31; ganz abgeschwächt ist auch die Erscheinung des Engels bei Joseph $C^{b} 1300-1314$ gegen D 186, 34 f.; ausgelassen sind ferner das Marienlob $\mathrm{C}^{\mathrm{b}}$ 1010-1032 (nach $\mathrm{D} 182,20$ ), und gleich darauf $C^{b} 1044-1063$ (nach D 183, 25), wo der Inhalt ähnlich ist wie in D 183, 21-25. Seltener als die Streichungen sind die Erweiterungen, z. B. die religiös gewendeten Zusätze 166, 4 f. (nach $C^{b} 655$ ), 184, 11-13 (nach $C^{b} 1123$ f.), 189, 25-27 (nach $C^{\text {b }}$ 1402). Auch durch Verschiebung des Inhalts ändert $\mathrm{D}$ : es läßt den Preis der Maria als der Himmelskaiserin $C^{b}$ 602-611 weg (D 164, 21), erweitert dagegen ihre klösterlichen Tugenden D 164, 29-33 (nach $C^{b}$ 627). Ein bestimmtes durchgehcr1des Prinzip liegt den Änderungen des Inhalts nicht zugrunde. Der poetische Wert des Gedichtes wird durch sie wenig berührt, zuweilen wird er etwas gehoben, zuweilen abgeschwächt. Solche Verschiebungen des seelischen Gehalts ändern die Stimmung z. B. an folgenden Stellen: D 153, 13-17 gegen $C^{b} 38-45$; D 159, 10-17 gegen C' $251-275$; D 185, 27-186, 10 gegen $C^{b} 1219-1255$. Der Dichter trägt das erhabene Bild der Maria als Himmelskaiserin in sich ( $C^{b} 863$ ff.): die Himmlische thront in Gottessaal, umgeben von den lobsingenden Propheten, Engeln und heiligen Jungfrauen; wir aber, wir Armen, liegen in der Not und wissen nicht, wenn uns der Tod ungewarnt erfaßt (auch D 180, 26 f.), darum sollen wir aus der Tiefe des

1) Vgl. Sievers S. 25. 33; S. zeigt auch, daß die Betonungsweise im $O$ und $D$ verschieden ist, indem $\mathrm{O}$ dipodischen, also volks- tïmlichen, D monopodischen Bau hat; s. auch MSD. $11^{3}, 161$. 
Herzens um Gnade flehen zu der Getreuen, daß sie alle Sachen aus dem Abgrund befreie durch die Ehre ihres Sohnes. Dem Bearbeiter dagegen $(179,26 \mathrm{ff}$.$) ist die Sorge um sich selbst das Nächste, ihm ist Maria vor$ allem die Mutter des Sohnes, durch dessen Gnade die büßenden Sünder dem Teufel entrissen werden, er schließt daran die ganz persönliche Hoffnung auf sein eigenes Seelenheil. Und nun stellt er sich selbst in Gegensatż zu seinem Vorgänger: er scheut sich, seine Sinne zu lenken auf die Geheimnisse vom Himmelreich, vom Hofstaat der Gottesmutter und von ihrer endlosen Erhabenheit 180, 1 ff. Damit hat er seine Grenzen selbst erkannt: dem Seelenaufschwung des alten Dichters hat er nicht folgen können, das zeigt auch die matte Nachahmung in den Schlußversen 180, $21 \mathrm{ff}$.

Bei weitem geringwertiger aber als $D$ ist die jüngere Bearbeitung $A$. Auch sie besteht in der Hauptsache in einer Glättung der Reime, die aber, wie in $\mathrm{D}$, nicht völlig durchgeführt ist. Das Versmaß erlitt, ebenso wie in D, weniger Eingriffe, jedoch wurden die langen Verse beseitigt. ${ }^{1}$ ) Der Text ist öfter gekürzt, meist infolge der Assonanzentilgung. Die Änderungen sind weniger durchdringend als in $\mathrm{D}$, dazu mechanisch und ohne Geschick vorgenommen. Der Bearbeiter hat kein poetisches Verständnis, und nicht das selbständige Urteil wie der von D.

\section{$\$ 74$. Physiologus.}

\section{Anhang: f) Naturwissenschaft.}

Kelle 2, 60-62. 280 f.; PiPer, Ält. d. Lit. S. 460-467 (der ält. Ph.), GD. 1, 200-204 (der jüngere pros. und der gereimte Ph.), 2, 294, Nachtr. S. 260 f., Höf. Ep. 3, 721 f. - Ausg.: 1. Der ältere Ph.: MSD. Nr. 82, II ${ }^{3}$, 408-411; v. STEINMEYER, KI. ahd. Spr. S. 124-134, dazu Seemüller, Gött. gel. Anz. 1918, 53 f., Ehrismann, Anz. 39, 30 f.; v. D. Hagen, Denkmale d. MA.s (1824) S. 50-56, dazu Kollation von GrafF, Diut. 3, 197 f.; HoffmanN, Fundgr. 1, 17--22; PIPer, Ält. d. Lit. aaO.; Braune, LB. ${ }^{8}$ Nr. 25 u. S. 180; Wilhelm, Denkm. S. 4-20, Komm. S. 13-52. 2. Der jüngere Ph.: Graff, Diut. 3, 22-39; Hoffmann, Fundgr. 1, $22-$ 37; Massmann, D. Ged. S. 311-325 u. 158 f.; Lauchert S. 280-299. 3. Der gereimte (Milstäter) Ph.: Karajan, Spr. D. S. 73-106 u. 32 Tafeln, dazu Kollation von PIPER, Nachtr. S. 260 f., Wilhelm S. 5-28, Komm. aaO. - Scherer, QF. 1, 1 f. 7, 4-6. 12, 50; KarL AHRENS, Gesch. d. sog. Physiologus, Progr. Plön 1885; M. Fr. MANn, Beitr. 11, 310-32ל; FrIEdr. Lauchert, Gesch. d. Physiologus, Straßburg 1889 (der Ph. im Deutschen bes. S. 116-120. 155-207. 280-299) u. Nachtr., Engl. Stud. 14, 127 f., dazu ERnst Volgt, ZfdPhil. 22, 236-242, MANN, Lit.Bl. 1890, 53-55 u. Engl. Stud. 14, 123-127 (s. auch 16, 296 f. 297-299), GASTON PARIS, Revue crit., nouv. série XXVII Nr. 24 p. 464-468, LC. 1890, 249; MANN, Zur Bibliographie des Ph., Anglia Beibl. 10, 274 ff. 12, 13 ff. 13, 18. ff.; A. L. Jelinek, ebda 13, 236 ff.

Der Physiologus ${ }^{2}$ ) ist das m.alterliche Lehrbuch der Zoologie. An keinem andern Werke offenbart sich der Begriff der Naturgeschichte, wie ihn das Mittelalter hatte, so schlagend wie hier: nicht das Wirkliche interessiert, sondern das Seltsame, das Wunderbare, aufgefaßt als Bild der Wunder des

1) Bruinier S. 42-81.

2) Zur Physiologus-Literatur s. besonders Laucherts Buch, PIPER, GD. und Höf. Epik aaO., Ahrens S. 2, MANn aaO., Wilhelm, Komm. S. 13 f. Einzelnes zur Gesch. des Ph.:
J. Victor CARUS, Gesch. d.Zoologie, München 1872; ZöCKLER, Gesch. d. Beziehungen zwisch. Theologie u. Naturwissenschaft, Abt. I, Gütersloh 1877; EDUARD KollofF, Raumers Histor. Taschenb. 4. Folge, 8. Jahrg. (1867), 177-269. 
Christentums. Hier ist die Tiergeschichte zur Glaubenslehre geworden, die Naturwissenschaft ist in den Dienst der Theologie getreten. Denn der Physiologus ist eine christlich-symbolische Schriftauslegung, in welcher die Eigenschaftèn der Tiere nicht an sich eine selbständige Bedeutung haben, sondern den richtigen Sinn erst erhalten durch Beziehung auf religiöse Vorstellungen. $\mathrm{Zu}$ einer theologischen Naturgeschichte wurde der Physiologus durch das Allheilmittel der Allegorie. Das merkwürdige Leben der Tiere wurde auf die Glaubenslehre ausgedeutet, wobei Christus als Überwinder des Teufels im Mittelpunkt steht. Neben den dogmatischen Auslegungen gehen moralisierende, in denen das Wesen der Tiere den Menschen als Spiegel vorgehalten wird. Jeder Artikel besteht aus zweierlei Bestandteilen, aus der Beschreibung und der allegorischen Anwendung, welche Theorie genannt wurde. Aufs engste verwandt durch den Stoff ist der Physiologus mit der Tierdichtung, ja er bildet einen Teil derselben und in der Tat hat er auch Einfluß auf die Gestaltung der Tierfabel und des Tierepos gehabt. ${ }^{1}$ )

Aristoteles hat die antike Naturwissenschaft begründet, aber auf der Höhe dieser biologischen Forschung blieb schon im Altertum die Zoologie nicht. Plinius (23-79 n. Chr.) in seiner aus zahllosen Einzelnotizen zusammengesetzten praktischen Naturbeschreibung, der Naturalis historia, wo auch fabulose Züge nicht fehlen, und Aelian (ca. 170--235 n. Chr.) in seinen zum Ergötzen geschriebenen Plaudereien $I_{\varepsilon \varrho i} \zeta \omega \omega \nu$ (De natura animalium), die ihrerseits manches aus Aristoteles entnahmen, hielten sich doch in ihren Beschreibungen vielfach an den Volksglauben und bezogen daher, besonders Aelian, mit Vorliebe merkwürdige Eigentümlichkeiten der Tiere. In der Freude an Raritäten übertraf sie aber die hellenistische Zoologie, der griechische Physiologus, der in der ersten Hälfte des zweiten Jahrhunderts in Alexandrien entstand. Dieses Lehrbuch trug schon vorhandenes Material zusammen, die Geschichten begegnen zum Teil bei Plinius, Aelian, auch schon bei Aristoteles, bei Herodot (der Phoenix II, 73, aber dort in anderer Fassung; die Viper III, 109), schöpfte auch aus ägyptischer Überlieferung und knüpfte zuweilen an biblische Stellen an. Das Wort Dvotóioyos bedeutet Naturforscher und findet sich zuerst bei Aristoteles, aber in der uns ethaltenen alten und m.alterl. Literatur ist Physiologus nicht als Titel des Buches aufgefaßt, sondern als Eigenname und man verstand darunter den Autor des Buches. Manche Hss. nennen auch einen bestimmten Verfasser: den Epiphanius, Basilius den Großen, Chrysostomus, Salomo; die lat. Übersetzung wurde dem Ambrosius zugeschrieben. Als Physiologus ist das Werk zum erstenimal von Origenes (a. 254) zitiert.

Die Anzahl der Tiergeschichten wechselte, man konnte einzelne hinzutun oder weglassen, da jede für sich eine abgeschlossene Geschichte war; aber auch die Texte selbst schwanken in einzelnen Sätzen. Die Zusammen- 
gehörigkeit der Hss. zu einzelnen engeren Gruppen bestimmt sich nach der Anzahl und der Reihenfolge der Artikel.

Der griech. Grundtext, in dem auch einige Beschreibungen von Steinen vorkommen, fand bald durch Übersetzungen die weiteste Verbreitung in den christlichen Literaturen und der lat. Physiologus wurde eines der bekanntesten Werke des MA.s, zumal er als Lehrbuch im Unterricht des Quadriviums gebraucht wurde. ${ }^{1}$ ) Sehr alt und wichtig sind die ältere syrische und die äthiopische Übersetzung, denen andere syrische, die armenische, die arabische folgten. Zahlreich sind die lat. Hss., die in zwei verschiedene Übersetzungen $A B$ und $C$ zerfallen; eine spätere kürzende Bearbeitung von $A B$ sind die Dicta Chrysostomi De naturis bestiarum (Pseudo-Chrysostomus), ${ }^{2}$ ) die im älteren und jüngeren deutschen Physiologus benutzt ist.

Der lat. Physiologus ist zum erstenmal erwähnt im Decretum Gelasianum um 600, in welchem er dem Ambrosius, der häufig auf Stellen daraus Bezug nimmt, zugeschrieben, aber als apokryph verworfen wird, welches Verbot jedoch nie zu praktischer Geltung kam. Entstanden ist er also jedenfalls nach dem Tode des Ambrosius (a. 397), wohl in der 1. Hälfte des 5. Jhs. (etwa zwischen 397 und 431). Auf ihm beruhen dann die Übersetzungen in die abendländischen Sprachen, ins Angelsächsische und Altenglische, ins Altfranzösische und Provenzalische, ins Deutsche und Isländische. Eine spätere lat. Bearbeitung (11. Jh.) mit 12 Artikeln in leoninischen Hexametern und andern Metren geht unter dem Namen des Theobaldus, der wohl italienischer Geistlicher war, und fand ebenfalls große Verbreitung. ${ }^{3}$ )

Die symbolische Zoologie des Physiologus entspricht der sinnbildlichen Denkweise der christlichen Weltanschauung. Leicht ließen sich diese Tiergeschichten im einzelnen als Lehren verwenden und so ist das Werk seit den Zeiten der griechischen Kirchenschriftsteller für die Verfasser wissenschaftlicher und erbaulicher Schriften eine Fundgrube gewesen, aus der gelegene Zitate oder Beispiele entnommen werden konnten. Unter den lat. Kirchenvätern haben ihn besonders Tertullian und Ambrosius, auch Hieronymus und Augustinus, mit Vorliebe dann wieder Gregor der Große benutzt. Für die deutsche Lit. ist zuerst Notker zu erwähnen, der für Ps. 101, 7.8 u. 103, 17 Bilder aus dem Tierleben einem Psalmenkommentar (dem ver-

3) Griech. u. lat. Texte s. bei LAUCHERT u. WILHELM; bes. zu berücksichtigen sind PITRA, Spicilegium Solesmense Bd. IIl, Paris 1885; MARTIN und CAHIER, Mélanges d'archéologie Bd. II-IV und Nouveaux Mélanges 1874; FRITZ HOMMEL, Die äthiop. Uebersetzung des Physiol., Leipz. 1877; E. PETERS, Der griech. Physiol. und seine oriental. Uebersetzungen, Berlin 1898; MaNN, Franz. Stud. V1 (1888), H. 2; REINSCH, Guill. le Cl., Le Best., 1890; E. Walberg, Le Bestiaire de Philipe de Thaün, Lund et Paris 1900; MANN, Anglia 7, $420 \mathrm{ff}$. -
Der Physiol. als Lehrbuch s. SPECHT, Unterrichtswesen S. 148 f.; VoIGT aaO.

2) G. HeIder, Physiologus nach einer Hs. des XI. Jhs., Arch. f. Kunde österreich. Geschichts-Quellen 5 (1850), 541 - 582 (vgl. auch 583 ff.); die Hs., mit Bildern versehen, befindet sich im Kloster Göttweih: sie enthält 27 Tiere, andere lat. Redaktionen führt MANN, Beitr. 11, 310-329 an; krit. Ausg. des lat. Textes von WilHELM, Komm. S. 17-44.

3) Migne 171, 1217-1224 unter den Werken des Hildebertus Cenomanensis. 
lorenen des Hieronymus) entnommen hat.1) Dann fanden in die Lit. des 12. Jhs. Physiologus-Motive Eingang. ${ }^{2}$ ) In dem Gedicht von der Hochzeit werden die Geschichten vom Adler (hier vermischt mit dem Phönix) und vom Pelikan als Beispiele angeführt (WAAG 580 ff. 818 ff.). In der Blütezeit der mhd. Lit. im 13. Jh. waren die Allegorien des Physiologus sehr beliebt. Ganze Abschnitte wurden in lehrhaften Gedichten aufgenommen, im Freidank, vgl. W. Grimms Ausgabe ${ }^{1}$ S. LXXXIIl ff.; in Hugos von Langenstein Martina ${ }^{3}$ ) an verschiedenen Stellen, in Hugos v. Trimberg Renner 19161 ff. $^{4}$ ) Erhalten hat sich als Gemeingut bis in unsere Zeit die Sage von dem sich im Feuer verjüngenden Phönix, und von der Treue der Turteltaube, die sich auf den dürren Ast setzt, wenn sie den Gatten verliert.5) Die wissenschaftlichen Kompendien der Naturgeschichte nehmen ebenfalls manche Züge aus dem Physiologus auf, so Isidor im 12. Buche seiner Etymologien und die drei "Physiologen" des 13. Jhs. ${ }^{6}$ ) Thomas von Cantimpré (De naturis rerum, zw. 1233 und 1248), Albertus Magnus (Physica, ca. 1260), Vincenz v. Beauvais (Speculum naturale, um 1250). Des Thomas Cantimpratensis Werk wurde ein Jahrhundert später von Konrad von Megenberg ins Deutsche übertragen.

Der Charakter der m.alterl. Kunst ist typisch und symbolisch. ${ }^{7}$ ) Solchen Bedingungen entsprachen die Tiergestalten des Physiologus und sie konnten in Skulptur und Bücherornamentik sowohl als Schmuck wie zum geistigen Ausdruck eines Werkes wirksam verwendet werden. So bildeten sie eine Stoffbereicherung der aus dem Altertum oder aus der Bibel stammenden plastischen Tiersymbolik und gehörten mit dieser zu den ornamentalen Bestandteilen des romanischen Stiles. An den Wänden und Portalen, den Pfeilern und Gestühlen der romanischen und frühgotischen Kirchen, noch lange in den Arabesken der Hss., verkündeten diese abenteuerlichen Gestalten dem Wissenden tiefe, mystische Wahrheiten, während sie uns in

1) PIPER, Notker II, 421 f. 437 f.; ERNST HENRICl, Die Quellen von Notkers Psalmen S. 22 (s. LG. I, 431).

2) KRAUS, Vom Rechte S. 77-79 mit vielen Belegen. Schr.

3) Dazu R. KöhleR, Germ. 8, 26 ff. u. K!.

4) Der Physiologus in der Predigt: CRUEL S. 256-258; LINSENMAYER S. 175 ff.

5) Wolframs Parzival 57, 9 ff.; weitere Beispiele in Martins Ausg. Bd. Il, $65 \mathrm{f}$.

6) CARUS S. $211-242$.

$\left.{ }^{7}\right)$ Zur Symbolik in der m.alterl. bildenden Kunst s. bes. Ferd. PIPER, Mythologie der christl. Kunst, Weimar 1847. 1851; WoLFG. Menzel, Christl. Symbollk, 2 'leilc, 2. Aufl., Regensburg 1856; Evans, Animal symbolism in Ecclesiastical Architecture, London u. New York 1895. Speziell zum Physiol. in d. bildenden Kunst s. Jos. STrzygowski, Der Bilder- kreis des griech. Physiol., Byzantin Archiv II, Leipzig 1889, und Byzantin Zs. 10, 218-222; K. Krumbacher, Gesch. d. byzantin. Lit., 2 Aufl. S. 874-877; Heider, Tiersymbolik; Carl Maria Kaufmann, Handbuch d. christl. Archäologie, 2. Aufl., Paderborn 1913 S.280ff.; M. Goldstaub, Verhandl. d. 41. Philol.-Vers. in Munchen 1891 S. 212-221; Derselbe, Philologus, Supplement-Bd. 8 (1901), $337-$ 404; Victor Schulze, Christl. Kunstblatt 39 (1897), 49-55; PANZER, Dichtung u. bildende Kunst des deutschen MA.s in ihren Wechselbezichungen, N. Jahrbiicher VIl (1904), 135 ff.; V. D. LeyEN u. SPAMER, Die ad. Wandteppiche im Regensburger Rathause, Regensburg 1910, S. 37 f.; V. D. LEYEN, D. Diclitung und bildende Kunst im MA., Festschrift f. FranZ MUNCKer. Mtinchen 1916, Soliderabdruck S. $7 \mathrm{f}$. 
ihren grotesken Formen ganz fremdartig und unverständlich sind. Aber auch vielen frommen, in Gott sich versenkenden Gemütern jener Zeiten waren die den Geist von der Andacht ablenkenden Fratzen ein Greuel und der heilige Bernhard klagt: „In den Klöstern vor den Gottesdienst pflegenden Brüdern, was sollen da jene lächerlichen Monstra, jene seltsam mißgestaltete Gestaltung und die Gestalt gewordene Mißgestaltung? was sollen dort die unflätigen Affen, was die wütigen Löwen, was die monströsen Zentauren, was die Halbmenschen, was die gefleckten Tiger, die kämpfenden Streiter, die trompetenden Jäger? (Epistola ad Guillelmum abbat. c. 12$\left.).{ }^{1}\right)$

Die deutschen Bearbeitungen des Physiologus.

1. Der ältere Physiologus (Reda umbe diu tier).

Hs.: Wien Cod. 223, Perg. 65 Bl. $4^{0}$, 11. Jh., Bl. 31a-33a, vgl. Hoffmanns Verzeichnis Nr. 373 S. 363; Steinmeyer u. Sievers, Ahd. Glossen 4, 630 f. Am Text der Vorlagewaren $z$ wei Schreiber ${ }^{2}$ ) beteiligt, der eine (A) schrieb Kap. 1-8, der andere (B) Kap. 9-12. A hat keine Tiernamen als Überschriften, wohl aber B. Auch die Orthographie ist in beiden Teilen verschieden (MSD. II ${ }^{3}, 411$ ). Der Dialekt ist alemann., aber in B sind rheinfrk. Spuren.

Entstanden ist das Original also wohl im alemann. Sprachgebiet in der 2. Hälfte des 11. Jhs.

Die deutschen Physiologi sind Übertragungen des lat. Pseudo-Chrysostomus. Der ältere enthält von den 27 Artikeln der lat. Vorlage nur 12 (von Land- und Wassertieren), ist also kein vollständiges Exemplar. Der erste Satz gibt die Einleitung mit Titel und Inhalt der ganzen Schrift: Hier begin ih einna rede umbe diu tier, uuaz siu gêslîho (geistlich) bezêhinen. Die der Reihe nach behandelten Tiere mit ihren Bedeutungen sind: Löwe $=$ Christus; Panther $=$ Christus; Einhorn $=$ Christus; Hydrus (Natter) $=$ Christus, ist Feind des Krokodils, d. i. des Todes und der Hölle; Sirenen und Onozentauren (halb Mensch halb Esel) bezeichnen den Feind (Teufel) und diejenigen die zwiespältig sind in Zunge und Herz; Hyäne = die weder ungläubig noch rechtgläubig sind; Onager (Wildesel) = Feind (Teufel); Elefant und sein Weib = Adam und Eva; Autula (Antilope) bezeichnet den Menschen, den der Teufel nicht betrügen kann; Serra (Sägfisch) den, der unstäten Sinnes ist; Viper = Juden; Lacerta lehrt den Christen, den Schöpfer zu suchen.

Die einzelnen Artikel sind mit Ausnahme des 1. u. 11. jeweils gleich gebaut: der 1. Teil enthält den Namen des Tieres und die Eigenschaften (mit dem Prädikatswort heizzit, heizzent), der zweite bringt die geistliche Bedeutung (bezeichenet, außer im 11. und 12. Art.). In Art. 1 und 11 sind drei Eigenschaften bezw. Arten des Tieres getrennt betrachtet.

Als Beispiel für die Technik des Physiologus, aber zugleich für die mystische Auslegungsweise überhaupt, ist in seinem systematischen Aufbau

1) Vgl. Kolloff S. 200 f.; LAUChert S. 208.

2) Nicht zwei verschiedene Verfasser, sondern nur zwei verschiedene Schreiber:v.STEIN-
MEYER, Kl. ahd. Spr. S. 133 f.; EHRISMANN, Anz. 39, $30 \mathrm{f}$. 
der Artikel über den Panther (2) lehrreich: „Ein Tier heißt Panther und ist sanftmütig und ist buntgestaltig und ist sehr schön und ist dem Drachen Feind. Dessen Lebensweise ist so beschaffen, wenn es satt ist, so legt es sich in seine Höhle und schläft drei Tage. Dann so steht es auf und läßt unmäßiges Gebrüll erschallen und bringt so süßen Geruch hervor, daß er alle Gewürze überduftet. Dann, wenn die Tiere fern und nahe die Stimme hören, so versammeln sie sich und folgen ihm wegen der Süßigkeit des Wohlgeruchs und der Drache wird so erschreckt, daß er für tot unter der Erde liegt. - Der Panther bezeichnet unsern Herrn, der alles Menschengeschlecht zu sich lud durch die Süßigkeit seiner Gnade. Er war sanftmütig, wie Jesaias sagte: Gaude et laetare, Hierusalem, quia rex tuus venit tibi mansuetus. Er war, wie der Panther, buntgebildet durch seine große Weisheit und durch die Wunder, die er vollbrachte. Er war schöner als je irgend jemand. Nachdem er gesättigt war mit der Pein und mit dem Spott und mit der Geisselung durch die Juden und er gekreuzigt war, da ruhte er in dem Grabe drei Tage, wie der Panther tat, und an dem dritten Tage da erstand er von den Toten und wurde das so offenbar gehört über alle diese Welt, und er überwand den Drachen, den großen Teufel." Abgebildet ist also im Panther das Dogma von der Gnade, der Lehre und den Wundern Christi, von der Überwindung des Teufels durch Leiden, Kreuzestod und Auferstehung. Auf diese Weise ist der Physiologus eine in Symbolen ausgedrückte Sammlung von Glaubenssätzen, welche das kirchliche Dogma bilden.

\section{Der jüngere Physiologus.}

Hs: Wien 2721, steht zwischen Wien. Genesis und Exodus, auf die Urgeschichte der Menschen also folgt die Geschichte der Tiere.

Der Dialekt der Hs. ist bair.-österreich. Die Heimat des Originals ist nicht näher zu bestimmen, doch wird es in Oberdeutschland um 1120 oder 1130 entstanden sein. $\left.{ }^{1}\right)$ Die Endungen sind in der Hs. schon fast ganz abgeschwächt.

Der jüngere Physiologus entspricht genau dem Pseudo-Chrysostomus, mit wenigen Ausnahmen Satz für Satz, enthält auch alle Tiere (in der Einleitung wird der Inhalt angegeben: das Buch erzählt won tieren uncle uon fogilen), nämlich 29 Nummern.

Die Fulica, Wilhelm S. 13, Komm. S. 24 f., gehört mit der vorhergehenden Hyaena zusammen, 6 u. 6a; Onager und Simia sind zusammengefaßt, WiLHelM S. 13, Komm. S. 25 $\left(7\right.$ u. 7 a). $\left.{ }^{2}\right)$ Die im alteren Phys. fehlenden Stäcke, die auf Lacerta folgen, sind: Hirsch, bezeichnet die Bußfertigen, ermahnt, daß wir dem Teufel nicht folgen und zu Christus fliehen; Dorcas, Caprea (Steingeiß), licbt die hohen Berge, d. i. Christus, der die Heiligen liebt;Fuchs = Teufel und Weltleute; Biber = Keuschheit $;$ Ameise $=$ die zelın klugen und törichten JungIrauen, dann die, welche Geistliches und Weltliches unterscheiden können, endlich die, welche Irrlehrer meiden; Igel $=$ Teufel; Adler $=$ Wiedergeburt durch die Taufe; Pelikan $=$

1) Naclı WILHELM, Komm. S. 45 f. „Schwäbische Arbeit in bayrischer Umsclirift".

2) Vgl. MANN, Beitr. 11, 324. 327
Lauchert S. 36 f.; Onager u. Simia sind schon im griech. Urtext vereinigt. 
Christus; Nachtrabe $=$ die Juden; Bläßhuhn $=$ die Gläubigen; Rebhuhn $=$ Teufel; Strauß $=$ wir sollen uns zu Gott kehren; Widehopf $=$ die ihre Eltern nicht ehren; Charadrius (deutsch als Lerche aufgefaßt) $=$ Christus; Phoenix $=$ Christus.

Da der ältere Physiologus das lat. Original stark ändert, ist die Darstellung in den beiden deutschen Werken sehr verschieden: das ältere ist knapp im Ausdruck und beschränkt sich auf die Wiedergabe der hauptsächlichen und notwendigen Tatsachen, das jüngere breiter und ausführlicher und kleidet, wie der lat. Pseudo-Chrysostomus, den Grundstoff in predigtartige Vortragsform. Inhaltlich besteht der Unterschied besonders darin, daß im älteren Phys. fast alle erklärenden und ermahnenden Zitate aus der Bibel und den Kirchenvätern ausgelassen sind. Eben durch diese, sowie durch Quellenberufungen (Physiologus zellit, man lisit von deme selben tiere, bes. bei den Zitaten, z. B. So chût dâûtd u. ä. und andere Formeln); endlich durch die verdeutlichenden, oft unnötigen Erläuterungen, z. B. uolgint deme tîere, suar iz ferit WILHELM S. 7, 10 gegen volgen im ält. Phys. MSD. 2, 6; der alte iacob 5, 3 - Jacob 1, 3; unser trehtin der heilige christ 5, 12 - unser trotin 1, 7 erhält der Stil den Charakter einer Predigt. So läßt sich der Zweck der beiden Übersetzungen dahin zusammenfassen: die ältere ist ein Lehrbuch für die Geistlichen - die Zitate sind lat. 1, 11 f. 2, 10 f. 8, 11 -, die jüngere ist zum Vortrag, auch vor Laien, bestimmt - die Zitate sind deutsch.

Der ältere Physiologus wurde in Reime umgesetzt, das ist die dritte deutsche Fassung:

\section{Der gereimte Physiologus.}

Hs.: Milstäter Hs., der Physiologus steht zwischen Milst. Genesis und Exodus. Die Beschreibungen sind durch Zeichnungen illustriert, die zum Teil dem Pseudo-Chrysostomus entnommen sind und entweder einzelne Tiere oder ganze Tierszenen darstellen. Die Umreimung der ursprünglichen Prosa mag zu dem Zwecke vorgenommen worden sein, um mit Genesis und Exodus zusammen eine fortlaufend einheitliche poetische Form $\mathrm{zu}$ schaffen. Sie fällt etwa zwischen 1130 und 1150.

Der Versmacher nahm für seine Reimerei die Prosa Satz für Satz vor, benutzte auch den Wortlaut selbst wo immer nur möglich, stellte um oder fügte, wo es eben nicht anders zu machen war, eigene Reimworte ein. Ebenso unverständig ist die Behandlung der Verse. Ihr Umfang schwankt. Häufig sind sie zu kurz, z. B. do sprach er 79, 5; wir birn ein 79, 9; Der wilde esel 83, 1; Div affine 83, 14; der ir wirt 84, 12; egedehsa 89, 26.1)

1) Man kann sein Verfahren Vers für Vers nachprüfen. Ganze Perioden sind wörtlich aus dem prosaischen Physiol. aufgenommen worden, wie KARAJAN $81,9-13=$ WILHELM $11,11-14$, wo die drei Reimpaare einfach auf folgende Weise gewonnen wurden: tiefallichen wurde als Bindung zu biswich in benutzt und hinter tiefallichen also das Reimpaar beendet, worauf mit dem zugehörigen Substantiv zierden ein neues Reimpaar begann; die $z$ weimaligen sint ergaben dann das zweite Reimpaar und das dritte stellte sich ohne viele Umstände ein,indem die letzten Worte deme tîeuale $z e$ rôbe $\mathrm{zu}$ dem rovbe des tiufils umgestellt wurden. Zum Reim genügten dem Bearbeiter die entferntesten Anklänge, schon irgendein schwaches $e(i, z$. B. iagent : chumet 74, $11 \mathrm{f}$; magede: chunne $74,19 \mathrm{f}$; uolgint : ferit 76 , 
In der Einleitung, die der Verfasser des gereimten Physiologus selbständig vorausschickt - sie fehlt in der deutschen Prosa-Vorlage -, richtet er die captatio benevolentiae an die Hörer und gebietet Ruhe mit der volkstümlichen Aufmerkformel so swiget uil stille. Außerdem ist der Titel angegeben phisiologus ist ez genennet, von der tiere nature ez uns zellet, übereinstimmend mit der Überschrift der Dicta Chrysostomi: ,De natura (naturis) animalium (bestiarum)'. ${ }^{1}$ )

Ein kleines Bruchstück eines assonierenden deutschen Physiologus, ganz kurz den Onozentaurus und das Einhorn behandelnd, findet sich in der Münchener Hs. Cod. lat. 17195, vom Ende des 12. Jhs. Es beruht vielleicht auf dem Milstäter gereimten Physiologus. ${ }^{2}$ )

$\S 75$. Mẻrigarto.

Kelle 2, 40-42. 266-268; PIPER, GD. 1, 54-60. - Ausg.: Gefunden 1834 und ligb. von H. HofFmanN: Merigarto, Bruchstück eines bisher unbekannten deutschen Gedichts aus dem XI. Jahrhundert, Prag 1834, und groBenteils wieder abgedruckt in HoFFMANNS Fundgr. 2, 1-8 (dazu J. Grimm, Gött. gel. Anz. 1838 S. 547-549 u. Kl. Schr. 5, 2i 9 f.); SCHADE, Decas S. 18-29; MSD. Nr. 32 แ. $11^{3}$, 188-197; WACKERNAGEL, LB. ${ }^{8}$ S. 317-320; BRAUNE, LB. ${ }^{8}$ Nr. 41 u. S. 200; PIPER, LB. S. 196-199. - Kelle, Serapeum 1868 S. 137 f.; Textkrit.: RöDiGER, ZfdA. 33, 417-419; Wood, Mod. Philol. 12 (1915), 495 ff.; GrienBerger, Beitr. $45,417-429$.

Hs.: Fürstl. Fürstenbergische Bibl. zu Prag, 2 zusammenhängende Pergamentbl., 11./12. Jh.

Der Titel merigarto kommt in den uns erhaltenen Bruchstücken nicht vor, er stammt von dem ersten Herausgeber Hoffmann, der das Wort J. Grimms Mythologie S. 754 (4. Ausg. S. 662 f.; vgl. auch Kl. Schr. a. a. O.) entnahm. ${ }^{3}$ ) Es ist $=$ der vom Meer umgürtete, meerumflossene Raum, Erdkreis, Welt.4) Da der Inhalt des Gedichtes von Erdkunde handelt, so ist die Bezeichnung nicht unpassend.

Die Bruchstücke sind Teile einer Erdbeschreibung und handeln von Gewässern. Die Grundlage dazu bilden Isidors Etymologien, wo in Buch XIII Kap. 12-22 über das Wasser, das Meer, Meerbusen, Ebbe und Flut, Seen, Flüsse und Überschwemmungen gehandelt ist.

$5 \mathrm{f}$; trohtines : christes 77, $9 \mathrm{f.;} \mathrm{kamre} \mathrm{:} \mathrm{ime}$ 77, 22 f.; schlechte Reime ferner 78, 14. 79, 2. 80,6 f. 80,13 f. 81,1 f. 82,10 f. $83,1.84,1$. 84,3 f. 84,14 f. 85,1 f. usw. Nicht hăufig ändert der Verfasser aus andern als aus Versgründen. Er wählt manchınal Worte, die ilım geläufiger sind oder angemessener dünken, z. B. statt michilen wistum 5, 1 schreibt er grozzen w. 74, 1 f.; der alte iacob 5, 3- der guote J. 74, 4; ferner gescepfide 5, 24 nature 75,5 ; in deme walde $5,8 \mathrm{f}$. - in dem tieffin walde 74,10 f. u. dgl.; das Verbum queden ersetzt er fast immer durch sprechen (außer 83, 10. 92, 10. 16. 96, 6. 100, 9, in $92,10.16 .100,9$ ist chovt chut chwit des Reimes wegen beibehalten worden).

1) Dei schopfpich hore wirz sagen 86,6 ist nur ein Flickvers des Reimes wegen auf: abe. Wenn unter schopfpuch wirklich eine bestimmte literar. Gattung gemeint ist, so muB es die Quellen, die Physiologusliteratur, bedeuten, die Bücher, welche die Tiererzählungen enthalten, die aber in diesem Falle nicht nur in poetischer Form abgefaBt zu sein brauchten, vgl. L.G. I, 64.

2) WilhelM, Komm. S. $46 \mathrm{f}$.

3) Es begegnet einmal im Ahd. im 8. Jh. in den Keronischen Glossen $=$ in etherium (caeleste), also $=$ Horizont Alıd. Glossen 1. 188. 189, 12, dann erst wieder im Fribmlıd.: Annol. (RÖDIGER) 447, Rol.l. (BARTSCII) 2942, Kchrr. (SCHRÖDER) 501. 6614.

4) Unir nuizen dáz tia érda daz nuázer limbegat, Notkers Bocthius I1, 45, PIPER, Notker $1,111,11 \mathrm{f}$. 
Im ersten Absatz (I), 1a, 1-20 wird erzählt, Gott hat die Erde vom Meer geschieden, hat sie aber doch nicht ohne Wasser gelassen, aus der Erde entsprangen Quellen, Seen, Flüsse; die Berge erhoben sich auf ihr. Die Schöpfung der Wasser und Berge durch Gott ist Ps. 103 entnommen, was der Verfasser selber andeutet, ${ }^{1}$ ) und bildet die Einleitung für das Folgende. Hier ist die Disposition gegeben, denn es wird nun von dem Meer, von Flüssen, von Quellen gehandelt, und zwar im Absatz $1 \mathrm{I}=1 \mathrm{a}, 21-1 \mathrm{~b}, 48$ vom Meer, De Maris Diue rs 1 tate: Verschiedenheit der Meeresfärbung, das rote Meer nach Isidor XIII, 14, 3, dazu XIII, 17, und Honorius Aug., De imagine mundi 1 Kap. 46 (Migne 172, 135). Dann De lebirmere: Das "Lebermeer", das geronnene Meer, mare concretum, in dem die Schiffe haften bleiben, liegt nach den Erzählungen der alten Geographen im nordwestlichen Meer Europas jenseits Britanniens. ${ }^{2}$ ) - Daran schlieBt sich der Ill. Absatz $=1$ b, 49-83 über Island, denn das Lebermeer wurde in die Nähe dieser Insel versetzt, die mit Thule (Thyle) für eins erachtet wurde. ${ }^{3}$ )

Die Nachrichten über Island verdankt der Verfasser des Gedichtes, wie er angibt, der mündlichen Mitteilung eines Geistlichen. Er kommt dabei auf persönliche Erlebnisse zu sprechen: „In der Heimat hatten wir zwei sich befehdende Bischöfe, auf der Flucht aus diesem Kriege kam ich nach Utrecht, da fand ich den sehr guten Reginpreht, einen erfahrenen Mann, ehrbaren Pfaffen" ; der erzählt ihm die Zustände Islands, die er dann hier wiedergibt $\left.\left(1^{b}, 65-83\right) .4^{4}\right)$ - Ebenfalls auf mündlicher Überlieferung (Daz ih ouh

1) Die ersten leserlichen Worte, MSD. $11^{3}$ S. 93 Var. vor V. 1, scheinen sich auf Gen. 9 , $11 \mathrm{zu}$ beziehen: neque erit deinceps diluvium dissipans terram, auf welche Stelle Cassiodor in seinem Psalmenkommentar zu Ps. 103, $9 \mathrm{f}$. verweist (Migne 70,731 B). Die darauffolgende Stelle (iz . . . louffit . . .) betrifftFlut und Ebbe, nach Isidor XIII, 18, 1; Honor. Aug. De imag. mundi 1 Kap 40.41 (Migne 172,133 D $134 \mathrm{~A}$ ).

2) Ueber das mare concretum s. MÜLLENHOFF D.AK. $1,410-425$ und MSD. $11^{3}$, 190-192. Fiir das MA. sind auch hier Isidors Etymologien Ausgangspunkt (unde et pigrum et concretum est eius [= Oceani] mare XIV, $6,4)$; vgl. ConR. HOFMANN, Münchener SB. 1865, 2, 1-19; BARTSCH, Herzog Ernst, Einl. S. CXLV-CXLVIII; DWb. 6, 463. Das Wort libermere, lebermeri begegnet zum erstenmal im Summarium HEINRICI (Ald. Gl. 3, 114, 7 ff. $=$ Mare mortuum), das aus lsidors Etymologien ausgezogen ist; dann folgt zeitlich die Beschreibung des ,lebirmere' in unserm Gedicht. - Das Lebermeer hat ähnliche Eigenschaft wie das tote Meer, mare mortuum, von dem erzählt wird, daß es nicht von Winden bewegt wird, da das Erdpech (bitumen) die Wasserbewegungen hemmt, wodurch alles Wasser zum Stehen kommt (Isid. Et. X1ll, 19, 3; Hon. Aug. De im. mundi 1 Kap. 50).

$\left.{ }^{3}\right)$ Ueber Thule s. MÖLlENHOFF MSD. $\mathrm{II}^{3}$, 190-193 u. D. AK. 1, 385-410; TH. THORODDSEN, Gesch.d.isländ Geographie, Uebersetzung von AUG. GEBHARDT, Leipzig 1897, bes. $1 \mathrm{~S}$. $54 \mathrm{f}$ Thile (Tyle) erscheint in der ad. Lit. in Notkers Boethius, PIPER S. 111, 32112,15 ; im Lanzelet (ed. HAHN) 7990-8015; in der Weltchron. Rudolfs v. Ems 2719-2741.

$\left.{ }^{4}\right)$ Auch der Ire Dicuil gibt seine anschau- liche Schilderung über Tile nach dem mündlichen Bericht einiger Kleriker (a. 795) und die Bemerkungen über die Fär-Oer nach der Mitteilung eines Priesters (G. PARThey, Dicvili Liber de mensvra orbis terrae, Berol. 1870, Kap. 7, 11-15, S. 42-44). Mit einer im MA. nicht gewöhnlichen Kritik nimmt er die geographischen Nachrichten über die Verteilung von Tag und Nacht auf der fernen Insel sowie über das Lebermeer (concretum mare) und über das Eismeer (congelatum mare) auf; vgl. A. LETRONNE, Recherches géographiques et critiques sur le livre De mensura orbis terrae par Dicuil, Paris 1814 , S. $130 \mathrm{ff}$. Ueber den irischen Mönch Dicuil (sein Liber de mens. terrae ist 825 vollendet) s. EBert 2, 392-394; MANitius 1, 647-653 u. Reg. S. 735. Adam v. Bremen (Domherr in Bremen um 1070) erwähnt in seinen Gesta pontific. Hammaburg. 4, 35 das brennende Eis und den Mangel an Brennholz (MSD. $\mathrm{Il}^{3}$, 193; Kelle S. 267) wie im Merigarto der Anonymus Leidensis das brennende Eis (über den Ân. Leidensis s. MANITIUS 1, 675-678 u. Reg. S. 727 f.). Notker aaO. beruft sich auf einige cosmografi, womit er vermutlich seiner Quelle folgt.

Die Nachrichten, die der Verfasser des Merigarto seinem Gewährsmann Reginpreht verdanken will, sind oberflächlich. Auch er erzählt von dem Holzmangel und von dem brennenden Kristall wie Adam von Bremen und der Anonymus und daß man dort der Wonne der Sonne entbehre; aber er redet trotzdem von dem Wohlstand und dem Vorrat zum Nutzen und zum Ergötzen. Reginpreht, ein êrhaft phaffo, war jedenfalls ein einfacher Priester, nicht Bischof, wie die 
hôrte sagan $\left.2^{\mathrm{a}}, 1\right)$ beruht der Bericht über den Fluß in Toskana, der den Absatz IV $=2^{a}, 1-42$ ausmacht. Die Quelle für dieses, wie es scheint historische Ereignis, ist unbekannt. - Der V. Absatz endlich $=2^{a}, 43-120$ enthält die Wunderkraft einer Anzahl von Brunnen (Quellen) nach Isidors Et. XIII, 13.1)

Das Gedicht steht in seiner literarischen Umgebung vereinzelt da: Erdkunde, in deutsche Verse gebracht, ein profaner Gegenstand aus dem Gebiete der Schulwissenschaft der sieben freien Künste. Aber doch sind die herrschenden Ideen der Zeit, die religiösen, hinein getragen, denn am Eingang steht Gott als Schöpfer, der die Dinge hervorgebracht hat, von denen der Verfasser lehren will. Die Kenntnis derselben hat er dem populären Wissen entnommen, dazu auch einiges vom Hörensagen beigebracht. Diesen Quellen entsprechend besteht seine Naturkunde aus einer Reihe einzelner Naturkuriositäten. Seinen naiven Standpunkt gegenüber den Erscheinungen der Fremde zeigt er in der Wiedergabe dessen, was er über Island gehört hat: da interessieren ihn materielle Fragen über den Reichtum und das Wohlbehagen auf der Insel und über das tägliche Leben und daß man mit Krystall kocht und heizt und daß das Scheit Erlenholz einen Pfennig kostet.

Für die Bestimmung der Abfassungszeit geben die persönlichen Andeutungen über seine Flucht einen gewissen Anhalt: ein Biscliofsstreit herrschte in Würzburg, wo im Jahr 1085 Bischof Adelbero von Heinrich IV. abgesetzt und Meginhart eingesetzt wurde. ${ }^{2}$ ) Auch die Sprache paßt zu dieser Annahme, so daß das Gedicht etwa um 1090 entstanden wäre. Sie hat zum meisten bairische Merkmale, ostfränkisch dagegen sind die $n$-losen Infinitive wese: wese $1^{\mathrm{b}}, 53 \mathrm{f}$. (substantiv. Inf.). Alemann. oder rhein- bezw. mittelfrk. Anzeichen sind keine darin, so daß als Heimat des Dichters das bairische oder ostfrk. Sprachgebiet angesehen werden kann.

Als Quelle hat der Dichter wohl eine prosaische lat. Kosmographie benutzt, die er stellenweise, wie es scheint, sehr frei in seine deutschen Verse übertrug. ${ }^{3}$ )

Dem didaktischen Inhalt entspricht der Stil, daher die Anrede des Lehrers im Vortrag Nû sage uuir zêrist 1 ${ }^{\mathrm{a}}, 21$, daz ist vone diu unt ih sag iu $2^{\mathrm{b}}$, 111 f. Häufig sind persönliche Formeln des Erzählers, Berufungen auf die

Randschrift De Reginperto epo lautet. Diese ist entweder überhaupt erst später abgefaßt oder $e \bar{p} o$ allein wenigstens ist erst späterer Schreiberzusatz (S. MSD. $11^{3}, 195$ f.).

1) Siehe auch Hugos v. TRIMBERG Renner $20151-20264$.

2) MSD. $\|^{3}, 196 \mathrm{f}$

3) Die Erzählung von seiner Flucht und der Begegnung mit Reginpreht in Utrecht inacht den Eindruck des persönlich Erlebten und kann deshalb wohl mit Recht, wie es MOLLENHOPF getan hat, zur Bestimmung der Abfassungszeit verwertet werden. Vielleicht hat er in seiner Vorlage schon eine ähnliche persönliche Mitteilung gefunden wie die von
Dicutl in seinem Liber De mensura orbis terrae beigebrachte und diese dann durch seine eigenen Erlebnisse ersetzt. - Zweifelhaft ist auch, ob der Dichter ein abgeschlossenes Lehrbiichlein der Erdkunde geschrieben hat oder nur einen Teil, etwa iiber die Gewässer und Winde. Die ersten der uns erhaltenen Verse, 1a, $1-20$, die mit Gott als Schöpfer cinsetzen und die Einleitung zum Folgenden bilden, könnten annehmen lassen, daB hiermit iiberhanpt die ganze Arbeit des Verfassers beginut. Aber sie köunen freilich auch nur der Aufang eines newen Abschnittes gewesen sein. 
Quelle u. dgl.: Daz ih ouh hôrte sagan, daz ni willih nieht firdagin 2a, 1 f.; ferner $2^{\mathrm{a}}, 42 ; 1^{\mathrm{b}}, 63 ; 2^{\mathrm{b}}, 71 ; 1^{\mathrm{b}}, 31.2^{\mathrm{b}}, 62.96(104) ; 2^{\mathrm{a}}, 67$; syntaktisch bemerkenswert sind asyndetisch aneinander gereihte Sätze wie Dâ gieng ein man, uuolt dâ bî giruouuan 2a, 21 f., ferner $1^{\text {a }}, 9$ f. 15 f. $2^{\text {a }}, 15$ f. 29 f. 35 ff. $\left.{ }^{1}\right)$

Die Verse sind kurz, in gedrungenem Typus, und bleiben mehrmals hinter dem Normalmaß zurück (stumpf endende Verse von drei Hebungen, sowohl mit dem Endtakt $\sim$ als $\left.\sim^{-} \cup\right){ }^{2}$ ) Die Reime bezw. Assonanzen entsprechen der frühmhd. Technik um 1100; volle Endsilbenvokale sind nicht häufig.

\section{$\S 76$. Medizinische Literatur. $\left.{ }^{3}\right)$}

Die wissenschaftliche Medizin-Literatur des MA.s hat ihren Ursprung letzten Endes in der Antike. Lateinische Arzneibücher wurden oft abgeschrieben und gingen unter berühmten Namen, wie des Plinius, Dioscorides, Hippocrates, Democrit, Apulejus, Placidus. Die ältesten erhaltenen verdeutschten Rezeptsammlungen stammen aus dem späteren 12. Jh.: das Innsbrucker und das $Z$ üricher Arzneibuch. Auch die Kräuterbücher dienen medizinischen Zwecken, es sind Kräuterrezepte, Aufzählungen pharmazeutischer Pflanzen und ihrer Heilkraft (Prüler und Innsbrucker Krăuterbuch). Ebenso galten die Edelsteine für heilkräftig, die 12 wichtigsten beschreibt das Prüler Steinbuch; die naturwissenschaftlich-medizinischen Lapidarien hatten pseudo-aristotelische Schriften zur Grundlage. Auch einzelne Rezepte sind uns aus dem 12. Jh. erhalten.

Neben diesen wissenschaftlichen (oder als wissenschaftlich geltenden) Heilmittelsammlungen und Rezepten bestand die abergläubische Volksmedizin weiter und auch eine Anzahl von Besegnungen sind aus der frühmhd. Zeit auf uns gekommen.

\section{B. Weltliche Literatur. $\left.{ }^{4}\right)$}

\section{a) Weltliche Epik von geistlichen Dichtern.}

Die weltliche Epik in deutscher Sprache, in der Form des epischen Liedes, lag bis in den Anfang des 12. Jhs. in den Händen der Spielleute, nun aber, etwa mit dem zweiten Jahrzehnt, griffen auch die Geistlichen auf dieses Gebiet über und suchten durch neue umfassende und zeitgemäße Stoffe besonders auf die ritterlichen Laien zu wirken. Geschult am Volksepos hatten sie den Stil desselben schon in biblischen Erzählungen angewendet

1) MSD. II ${ }^{3}, 192.194$.

2) W. GRIMM, ZGdR., Kl. Schr. 4, 310--312; SARAN S. $252-254$.

3) WILHELM, Denkm.8Nr.X-XIII.XV-XXV u. Komm. I u. II S. 79-153, vgl. Münch. Mus. 2, 365-367; PIPER, Nachtr. S. 262-266; PfEIFFER, Wiener SB. 42 (1863), 111-114. 118-127, dazu K. HofmanN, Münch. SB. 1870, I, $511-$
516; PRIEBSCH, Mod. Lang. Rev. 10, 203-221; SCHLECht, ZfdA. 46, 303-305; NAuMANN, Ad Prosaleseb. S. 11 f. - v. SteinmeYeR, Kl. ahd. Spr. 365-398; LG. 1, 96-115.

4) BURDACH, Zur Entstehung des m.alterl. Romans, Verhandl. d. 44. Philol.-Vers. zu Dresden 1897, 28-31. 
(vgl. Genesis, Exodus u. a.) und nun schufen sie auf dieselbe Weise umfassende Romane, in denen ritterliche Ideale verherrlicht und Musterbilder für die höfische Gesellschaft aufgestellt wurden: im Alexanderlied des Pfaffen Lamprecht ist in der Person des Königs, des mächtigsten Herrschers des Altertums, ein tapferer und hochherziger Fürst gezeichnet, ein Bild des guten weltlichen Regenten, dessen Größe aber doch nur von dieser Welt ist, da er von Ehrgeiz und Ruhmliebe erfüllt als Eroberer nur ein vergängliches Weltreich gründet. Ihm gegenüber ist im Rolandslied des Pfaffen Konrad in Karl dem Großen, dem erhabensten Herrn der Christenheit, der Idealfürst in kirchlichem Sinne dargestellt, der geistliche Ritter, der in demütiger Frömmigkeit das Reich Gottes auf Erden verwirklichen will. Mit der Geschichte Alexanders ist zum erstenmal ein antiker Stoff in deutscher Sprache behandelt worden. Hier sind die m.alterl. Anklänge nur hineingetragen; das Rolandslied, unmittelbar aus dem christlichen Geiste der Zeit entsprungen, ist der echte Ausdruck rein m.alterl. Romantik. Die beiden Gedichte bilden in der deutschen Literaturgeschichte einen Markstein, in ihnen ist der Schritt gemacht vom kürzeren, frei vorgetragenen Spielmannslied zum umfangreicheren Lese- (bezw. Vorlese)epos.1) Zugleich sind es die ersten Werke, die aus dem Französischen übertragen wurden und sie eröffnen somit den großen Einfluß, den Frankreich wie durch die Scholastik, so auch durch die Dichtkunst auf das deutsche Geistesleben im 12. und 13. Jh. ausübte. Beide Gedichte geben herrschende Ideen ihrer Zeit wieder: im Alexanderlied entfaltet sich, wie im Beginn der Kreuzzüge, eine Erweiterung des Weltbildes vom Abendland auf das Morgenland durch die Züge nach Osten, das Rolandslied vollends ist unmittelbar eine Darstellung des Kampfes zwischen Christentum und Heidentum unter der Falıne des Kreuzes, also eines Kreuzzuges.

\section{$\$ 77$. Das Alexanderlied des Pfaffen Lamprecht und seine Fortsetzung durch einen Ungenannten.}

PIPER, Spielm. D. 2, 116-182, Nachtr. S. 244. 370, Höf. Ep. 3, 713 f. 734; Einleit. zn OTTMANns Ubersetzung S. IX-LXVII - Ausg.: DiemER, D. Ged. S. 183-226, Anm. S. 57-65, Einl. XLII-XLIV (Vor. Hs.); MassmanN, Denkm. S. 16-75 und D. Ged. 1, 64-144 (Straßbg. Hs); Anfang und SchluB der Straßbg. Hs. bei GrafF, Diut. 1, 308-310, Anfang bei HofFmanN, Fundgr. 1, 211; Heinr. Weismann, Alexander, Urtext und Ubersetzung . . . Ubersetzung des Pseudo-Kallisthenes u. a., 2 Bde, Frankfurt a. M. 1850; die jetzt giiltige kritische Ausg. ist die von Karl Kinzel, Germ. Handbibl. VI, Halle 1884, dazu AuSFEld, LC. 1884, 1761-1763, PIPER, Lit.Bl. 1884, 458-460, Schröder, DLZ. 1885, 784-787, Wilmanns, Gött. gel. Anz. 1885, 291-303, RöDiger, Anz. 11, 257-281, SeElisch, ZfdPh. 17, 487-492; RichaRd Marla Werner, Die Basler Bearbeitung von Lambr. Al., Bibl. d. Lit.-Ver. Bd. CLIV, dazı KINZEL, ZfdPh. 14, 379-384. Ubersetzung: RICH. EduARD OtTMAnN, Halle a. S. o. J., Verlag Hendel, dazu Seller, ZfdPh. 31, 509 f., Ausfeld, Lit.BI. 1899, 369-371. - HoltzmanN, Der Dichter des Annoliedes, Germ. 2, 1-48; PreifFer, Germ. 3, 494 f. (Sprache); Bech,

1) Damit ist erwiesen, daß der Anstoß zur Schaffung des umfangreichen weltichen deutschen Epos, zuerst des von Geistlichen, dann des Spielmannsepos, von Frankreich ausgegangen ist. Eine nene und stärkere Einwirkung der franz. wellichen Epik erfolgte daun durch die Uebernalume des ritterlichhöfischen Romans. 
Germ. 30, 257-284 (Sprache und Textkritik); Scherer, QF. 7, 60-64. 12, 79-81, dazu RöDiger, Anz. 1, 78-87 (Reime, Sprache); HARczYK, ZfdPh. 4, 1-30. 146-173; R. M. Werner, Die Basler Bearbeitung von Lambr. Al., Wiener SB. 93 (1879), 7-122, dazu RÖDiger, Anz. 5, 416-425, KINZEL, ZfdPh. 14, 379-384; ANT. Miller, ZfdPlı. 10, 1-14; KINZEL ebda 14-89; ZACMER ebda 89-112; KINZEL ebda 11, 383-399, dazu ZACHER ebda 399-416; Kinzel ebda 15, 222-229. 20, 88-97. Heinr. CHristensen, Beitr. z. Al.sage, Progr. d. n. Gel. Schule zu Hamburg 1883, dazu KinZel, ZfdPh. 16, 118-123, BehaGHEL, Lit.-B1. 1884, 174 f.; ERdManN, ZfdPh. 17, 223-226; v. Bahder, Germ. 30, 385-396; BehaGHeL, Germ. 31, 121 f.; WaAG, Beitr. 11, 123-129; PAul Meyer, Al. le grand dans la litt. franç. du moyen âge, 2 Bde., Paris 1886, dazu Kinzel, Anz. 13, 223-231; C. Reblin, Progr. d. Gymn. zu Neubrandenburg 1889; AlwiN SchmidT, Ueb. d. Al.lied des Alberic v. Besançon, Bonner Diss. 1886, dazu SchröDER, DLZ. 1886, 1650, AuSFEld, Lit.-Bl. 1887, 313-315; Theod. HAMPe, Die Quellen der Straßburg. Fortsetz. von Lampr. Al., Bonner Diss. 1890, dazu KinZel, ZfdPh. 24, 255-258, Singer, Anz. 17, 197-204, Ausfeld, Lit.-BI. 1892, 5-7; Heynisch, Der Konjunktiv im Al.lied, Progr. d. Gymn. zu Meiningen 1890; H. Becker, Festschr. des Friedr.-Kollegiums zu Königsberg i. Pr. 1892 S. 93 ff.; Ders., Festschr. für Oskar Schade, Königsberg i. Pr. 1896 S. 1-26; KAMPERS, Idee des Weltimperiums (1901); Ders., Form u. Tisch der Madonna, Mitteil. d. Schles. Gesellsch. f. Volksk. 19 (1917), 72-189; ZwieRZina, Verhandl. d. 46. Phil.-Vers. in StraBburg 1902 S. 132-134 u. ZfdPh. 33, 426 f.; Wilmanns, ZfdA. 45, 229-244. 245-248. 49, 468. 50, 137-145; HeINR. Fuchs, Gießener Gymnasialprogr. 1907; LeitzMAnN, Anz. 34, 305; JoAChim Kunnt, Lampr. Al., Lautlehre usw., Greifsw. Diss. 1915, dazu Schröder, Anz. 39, 88; WAGNer, ZfdM. 1921, 130; JorIS VorSTIUS, Die Reimbrechung im frühmhd. Al.lied, Marburger Diss. 1917; WallnER, Beitr. 43, 199-219.

Hss.: V. Vorauer Hs., ${ }^{1}$ ) der Vorauer Alexander, Bl. 109a-115c. Der Dialekt ist, entsprechend dem Entstehungsgebiet der Hs., innerösterreich., mit vielen aus dem Original stammenden mittelfrk. Einmischungen.

S. $\left.{ }^{2}\right)$ Straßburger Hs. (Straßburg-Molsh. Hs.), der Straßburger Alexander, Bl. 13c-29a ; zwischen Bl. 14 und 15 fehlt ein Blatt, ca. 220 Verse. Der Dialekt ist rheinfrk., etwa aus der Gegend am Rhein und Main, und stimmt mit dem des vorauszusetzenden Originals Sx überein. $S$ ist sehr sorgfältig abgefaßt und hat den Text der Urhs. Sx gut bewahrt.

$\mathrm{B},{ }^{3}$ ) Basler Hs. E. VI. 26, Basler Alexander, (überarbeiteter, gekürzter und entstellter Text), Papierhs. aus dem Anfang des 15. Jhs., fol., $217 \mathrm{Bl}$. zweispaltig, in fortlaufenden Zeilen wie Prosa geschrieben, ist eine Weltchronik, in welche auf Bl. 22d-67c der Al. eingeschaltet ist (Bl. 1-14 ein Auszug aus Rudolfs v. Ems Weltchronik, Bl. 14-17 ein trojanischer Krieg, Bl. 22-67 Alexander, Bl. 67-179 die auf Alexander folgende Weltgeschichte nach der Repgauischen Chronik, römische und deutsche Kaisergeschichte bis auf Karl IV, Bl. 179 ff. von späteren Händen Notizen aus der Schweizer Gesch.). Der Dialekt ist alemann.

Inhalt nach $V$ u. S (KInZELS Ausg.). A. Prolog Lamprechts 1-34:4) Verfasser (1-4); Inhalt (5-12); Quelle und Art der Behandlung (13-18); Vanitas vanitatum (19-34; mit 19 beginnt die Übersetzung nach dem frz. Original des Alberich).

1) Beschreibung der Hss.: Kinzel, Ausg. S. XI ff. - Sprache der Hs. und Lamprechts: KInZeL, Ausg. S. LI f. XVII ff.; PfEIFFER, Germ. 3, 494 f.; SCHERER, QF. 7, 60 f.; RÖDIGER, Anz. 1, 78-87: BECH, Germ. 30, 257 ff.; v. BAHDER ebda 385 ff.; WAAG, Beitr. 11. 123129; ZWIERZINA, ZfdA. 44, 347. 45, 38; KUHNT S. 3-47. 102-106; DEgERING, Beitr. 41, 546.

8) Sprache: KINZEL, Beitr. z. d. Phil. Julius Zacher dargebracht, 1880, S. 25-70; Ausg. S. LII-LVII (moselländ); v. BAHDER, Germ. 30,385 ff. (westl. Grenze von Thüringen nörd- lich der Rhön); KuHNT S. 48-102. 102-106.

3) Beschreibung der Hs.: WACKERNAGEL, die ad. Hss. der Basler Universitătsbibl. S. 30-34; A. Bernouldi, Anz. f. Schwelz. Gesch. 13, 25 ff.; R. M. WERnER, Wiener SB. 93 S. 4 u. S. 48 Anm.; ZACHER, ZfdPh. 10, 89-93; KINZEL, Ausg. XII f. - Sprache: R. M. WeRnER aaO.S. $60-79$; KINZEL, Ausg. S. LVll, ZfdPh. 10, 50-53.

4) Die Zeilenziffern beziehen sich bis 1496 auf $V$, von da an auf $S$. 
B. Hauptteil: Geschichte Alexanders 35-7278.

I. Allgemeines: Alexanders Herrschergröße, Vergleich mit Salomo 35-70.

Il. Alexanders Jugend $71-558$.

III. Alexanders Kriegszüge 559-4751: a) gegen Darius bis zu seiner ersten Rückkehr nach Mazedonien $559 \mathrm{~V}-2128$ S (1533 SchluB von V); b) Alexanders Krieg gegen Darius von der Heimkehr bis zur Hochzeit mit Roxane 2129-4057; c) Der Krieg mit Porus 4058-4761.

IV. Alexanders Reisen in den fernen Orient 4762-7010: a) bei den bedürfnislosen Weisen in Occidratis 4762-4889; b) Brief über die Wunder Indiens 4890-6596 u. a. die Blumen- oder Waldschattenmädchen $(5157-5358)$, die im Sommer aus Blumenkelchen entsprangen, aber beim Beginn des Herbstes starben; die Königin Candacis am Weltende, die Amazonen (5511-6461); c) der Zug nach dem Paradies 6597-7010, an der Pforte mahnt ein alter Mann Alexander zur Demut (6871) und gibt ihm einen Stein (6932); Alexander gehorcht der Mahnung und kehrt um (6959).

V. Rückkehr nach Griechenland und Ende Alexanders 7(11-7278; ein alter Jude deutet ihm die Lehre des Steines: hüte dich vor Hoffart und Habgier, denn dereinst muBt du hinfahren und zur Erde werden (7153); Fürstenlehre (7207); Alexander regiert trefflich 12 Jahre und stirbt durch Gift; nicht mehr behielt er von allem, was er je errang, als von Erde ein Grab sieben FuB lang (7247).

C. Epilog 7279-7302: Mahnung zur BuBe und Gottesfurcht auf den Weg zum ewigen Leben.

Der Vorauer Al. (V) ist das unvollendete bezw. rasch abgebrochene Werk des Pfaffen Lamprecht, der Straßburger (S) und der Basler Al. (B) bilden eine Bearbeitung und Fortsetzung des ursprünglichen Werkes von Lamprecht (X). Dabei stellt der Basler Al. eine ältere Stufe dar, während der Straßburger Al. wiederum eine Bearbeitung von $\mathrm{X}$ ist $\left.(\mathrm{Y}) .^{2}\right)$ Das Verhältnis der drei Fassungen verzweigt sich also folgendermaßen $:^{2}$ )

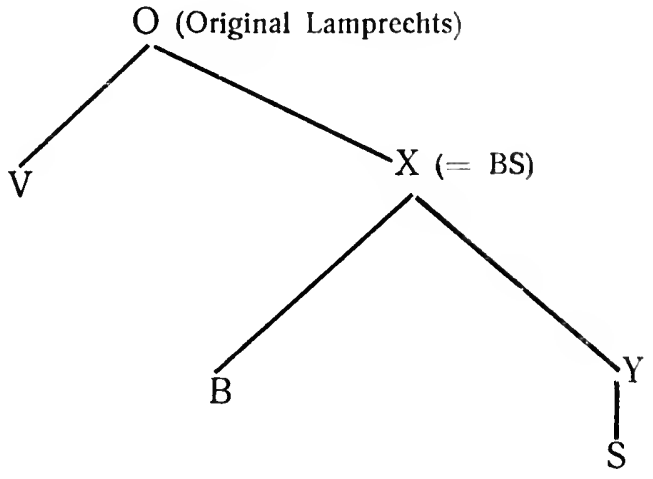

Lamprechts Werk fällt der Zeit nach vor das Rolandslied, etwa zwischen 1120 und 1130. Auch die Bearbeitung X liegt vor dem Rolandslied, Y ist etwa um 1160 abgefaßt.

1) Das Alexanderlied unserer Ausgaben rihrt also von zwel verschiedenen Verfassern her, vgl WiLMANNS, Gött. gel. Anz. 1885, 291 ff.; Alw. Schmidts u. HAMPES Diss. u. die betr. Rezensionen; SCHRÖDER, DLZ. 1885, 786; OTTMANN S. XXXVIII ff.; ZWIERZINA, Verhandlungen aaO.; EhrisMANN, ZfdW. 2, 142145; KunNT, Diss. S. $1 \mathrm{ff}$.
2) Sielıe Harczyk S. 1-30, dazu Ottmann S. L-LII Aum. 97; WERNER, WienerSB. 93, bes. S. 7-54, dazı KinZEl., ZfdPh. 14,379-384; KINZEL cbda $10,14-89$, ZACHER cbda S $89-$ 112; KINZEL cbda 11, 383-399. ZACHFR ebda S.399-416; KINZEL, Ausg. S.XXXII-XXXVIII; RÖDIGER, Anz. 5, 416-425. 11, 257-281; v.BAHDER a:IO,; CHRISTENSEN, Beitr. aaO., dazı 


\section{Der Vorauer Alexander.}

Als Verfasser ${ }^{1}$ ) des alten Werkes, das in der Vor. Hs. enthalten ist, nennt sich v. 4 der phaffe Lambret (= Lambrecht), der Schreiber der Schlußnotiz in V fügt dazu ein ehrendes Beiwort der gûte phaffe Lampret 1530. Er war also Geistlicher, von ihm rührt auch die Bearbeitung des Tobias her (s. oben $\$ 24)$. Seine Heimat war, wie sich aus dem Reimgebrauch erschließen läßt, das mittelfrk. (moselfrk.) Sprachgebiet. Gewissenhaft gibt Lampr. an drei Stellen seine Quelle an: es ist das welsche Lied des Alberich von Besançon (Alberîch von Bisinzo $13 \mathrm{~V}$, Elberîch von Bisenzûn $13 \mathrm{~S}$; Alberîch $19 \mathrm{~V}$, Elberîch $19 \mathrm{~S}$ ), und auf diesen Gewährsmann verläßt er sich vertrauensvoll 13-18 V. Beim Beginn der Erzählung von der Schlacht am Granicus nennt er ihn wieder und zwar als maister 1220 und seine Arbeit schließt er ab mit der Berufung auf die Darstellung des maister Albrîth 1529. Dieses altfranzösische Alexanderlied ist am Ende des 11. Jhs. in Tiraden (einreimigen, ungleichlangen Strophen) mit achtsilbigen Versen ver$\underset{f a ß t}{ }$. Erhalten ist uns nur der Eingang mit 105 Versen, $\left.{ }^{2}\right)$ die etwa den Versen $20-214$ des deutschen Gedichtes in V entsprechen.

KinZEl, ZfdPh. 16, 118 ff.; Reblin aaO.; OTTMANN S. XXIV ff. Die Bestimmung des Hs.verhältnisses hängt aufs engste zusammen mit der Frage: hat Lamprecht nur so viel gedichtet als in der Vor. Hs. steht oder hat er das ganze Al.lied verfaßt, bezw. hat Lamprecht selbst denVorauer Schluß gemacht oder ist er die Abfertigung eines Schreibers. Die ältere Ansicht, der Schreiber von $\mathrm{V}$ habe gekürzt, vertraten HolTzMANN, Germ. 2, $32 \mathrm{ff}$.; SCHERER, QF. 7,60 und ihnen folgend HARCZYK S. 1 ff.; WERnER, Wiener SB. 93, 50 f.; KinZEl, Ausg. S. XIV f., ZfdPh. 10, 46 f. 20, 88-97. 24, 255258; RÖDIGER, Anz. 11, 275 f.; SCHRÖDER, DLZ. 1885, 786 (vgl. dazu ZfdPh. 33, 427); WAAG, Beitr. 11, $127 \mathrm{f}$; BECKER S. 5; OTTMANN S. XXX ff.; Singer, Anz. 17, 197 ff.; PAul MeYer 2, 130 f. und Kap. VIl. WilMANNS hat, nachdem DiEMER, D. Ged. S. XLIl $V$ für den echten Lamprecht erklärte, zuerst Beweise dafür aufgestellt, daß das kurze Al.lied der Vor.Hs. uns die ursprüngliche Dichtung Lamprechts repräsentiert" (Gött. gel. Anz. 1885, 298 ff.) und später, ZfdA. 50 (1908) $144 \mathrm{f}$; ; von ihm wurden angeregt seine Schüler Alw. SchmidT, HaMPE und KuHNT; AUSFELD schloB sich nach einigem Schwanken an (Lit Bl. 1887, 314 f. 1892, 7. 1899, 370); ZWIERZINA aaO. (dem SCHRÖDER Zustimmt, s. Anz. 39, 88) und EHRISMANN aaO. brachten einzelne Merkmale für den Unterschied zwischen $\mathrm{V}$ und dem darauf in $\mathrm{S}$ folgenden Teile bei, VoRstius aaO. weist Verschiedenheit in der Reimbrechung nach; vgl. auch Wallner, Beitr. 43, 208 ff.; Vogt, Grundr. S. 172. - In der Auffassung des Verwandtschaftsverhältnisses gehen dic Meinungen auseinander, je nach der Stellung, die B zugewiesen wird. $\mathrm{B} \mathrm{V}$ gegen $\mathrm{S}$ nehmen an WERNER, Wiener SB. 93,7-60, Ausg. S. 1 ff: ; RöniGER, Anz. 5, 416 ff. 11, 257. 268. 276, dazuBEHAGHEL,Germ.31 ,121 f.; ChRISTENSEN, Beitr. S. 18 ff.; SCHRÖDER aaO.; BECKER S.9. B S gegen V: KINZEL, ZfdPh. 10, 48-50. 11, $385-395$. 14, 379 ff. 16. 121-123, Anz. 13, 229 ff., Ausg. S. XlIl-XVl; BEHAGHEL, Lit.Bl. 1884, 174 f.; WILMANNS aaO.; BEHAGHEL, Germ. 31, 121 f. läßt die Möglichkeit offen, daB alle drei Hss. auf die gleiche Vorlage zurückgehen, ihm folgt REBLIN S. 2. 27. - Das oben im Text gegebene Schema unterscheidet sich von dem von KINZEL und WiLMANNS, mit denen es in der Gruppierung der Hss. übereinstimmt, dadurch daß eine zweite Bearbeitung, $Y$, eingeführt ist und die beiden Hss. B und $S$ damit scharf voneinander abgehoben sind.

1) Verfasser: HoltzMANN, Germ. 2, 29 ff.; SCHERER, QF. 7,60 ff., SCHRÖDER, DLZ. aaO.; OTtManN S. XVll ff. XXIll. XXV.

2) Das Fragment, auf zwei leer gebliebenen Seiten einer Hs. des Curtius, wurde aufgefunden von PAul HEYsE und von ihm hgb. in , Romanische Inedita aus italienischen Bibliotheken', Berlin 1856, S. 3 ff. Textkrit. Ausg. von EDM. STENGEL, Marburg 1882. - Wie weit Alberichs Werk reichte, ist noch nicht sicher festgestellt. Trotz einigem was dagegen spricht, scheint es doch am wahrscheinlichsten, daß Lampr. von dem afrz. Original nicht mehr gekannt hat, als er selbst bis zum Abbruch seiner fortlaufenden Erzählung bietet, d. h. daß es mit der Heeressammlung des Darius abschloß $(1496 \mathrm{~V})$, worauf er dann seinen 
Bei der Ubertragung der französischen Quelle') hat Lampr. die übliche deutsche Methode angewendet, deren Grundzüge Erweiterung und Verdeutlichung sind. Sein Erweiterungs verfahren ist sehr einfach und es ist nicht schwicrig, seine Mittel $z u$ durchschauen. Es können rein äußerliche Gründe vorliegen: oft werden Zeilen des Reimes wegen eingeschaltet oder darum, weil sich ein Vers des französischen Originals nicht leicht in einen deutsclien pressen lieB, z. B. die Quelle enthielt das Wort Olimpias (Alb. 44), darauf stellte sich dem Obersetzer bequem der Reim was ein $91 \mathrm{f}$; sie die Mutter Al.s, war sor Alexandre, dic Schwester Al.s von Epirus (Alb. 41): leicht fand sich dafür das Reimpaar mûter: brâder $93 \mathrm{f}$. Ǎhnliche Dehnungen liegen in 44. 46. 53.75. 77 f. 86. 96. 115. 117.120.122. 125. 140. 146. 151. 160, von 163 und 177 die zweite Hälfte. Das sind zum großen Teil formelhafte Flickverse, $z u$ denen noch die Übergänge $103 \mathrm{f} .131 .155 \mathrm{kommen}$, wie auch 110 oder $128 \mathrm{f}$ Einige unter ihnen bringen zugleich eine kleine, aber unnötige stoffliche Zugabe. Oft ist nicht $z u$ unterscheiden, ob die Zusätze aus rein formellen oder aus inhaltlichen Gründen gemacht werden. Auch bei dieser $z$ weiten Art, den eigenen Erfindungen, die neue Motive zufügen, läßt siclı Lampr.s Arbeitsweise zumeist erkennen. Aus drei Vorstellungskreisen entnimmt er vornehmlich diese Erweiterungen: aus dem geistlichen Gebiete: 11 f. 24 (Zitat), 62-70 (Salomo) ; ${ }^{2}$ ) aus dem Kriegswesen: 85. 86. 88. 99-102 und innerhalb 199-214; aus der Technik der Personenschilderung: 48-50 (unde was der allerhêrste man), $57 \mathrm{f}$. 97-102 (zugleich aus dem Kriegswesen), 168-170; dazu kommen verdeutlichende Erklärungen: 25-28. 105-107. 134-137 und die persönliche Bemerkung 31-34. ${ }^{3}$ ) Selten trifft der umgekehrte Fall ein, daß Lampr. Verse Alberichs ausläßt: z. B. 64 f. 91 bei Alb. Einiges hat er falsch wiedergegeben. ${ }^{4}$ )

Auf Grund der stilistischen Ergebnisse muß man Lamprechts Verfahren handwerksmäßig nennen.

Alberichs Darstellung läßt ohne alles störende Beiwerk schlicht und einfach die Tatsachen sprechen gleichsam wie einen historischen Bericht, Lampr. hat durch die Methode der geistlichen Übertragungsweise dem knappen Ausdruck seines Vorgängers größere Fülle, eine gewisse, aber doch nur mäßige epische Breite verliehen. Wesentliches hat er nicht hinzugetan. ${ }^{5}$ )

zusammenfassenden Schluß anfügte. Vgl. bes. AlW. Schmidt S. 76 ff.; AUSFEld, Lit.-Bl. 1887, $313 \mathrm{ff}$; SINGER aaO.

1) PAUL MEYER, Alexandre le Grand 1, 1-15. 2, 69-10.1; STENGEL, Wörterbuch zu seiner Ausgabe S. 81-230. 254-256; Förster u. KoschWITZ, Afrz. Uebungsbuch ${ }^{2}$ S. 237 ff. Vergleichung von Lampr.s Text mit dem afrz. Bruchstück: ALFR. RochAT, Germ. 1, 273-290; HARCZYK S. 146 ff. ; OTTMANN Anm. 97 auf S. L-LI1; WilmanNS, Gött. gel. Anz. 1885, 292-298; KINZEL, Ausg. S. XXIX-XXXII. - Die Sprache ist franz - provenzalisch, d. h.aus dem Grenzgebiet des Provenzalischen. Vielleicht ist also nicht Besançon sond. Brian çon in d. Dauphiné Alberichs Heimat gewesen.

2) Alberich verleiht Al. dic höchste Stelle unter allen Königen, demgegenüber nimmt Lamprecht in ängstlicher Bibelgläubigkeit, indem er auf das Zeugnis der Regina austri verweist, Salomo als den unbestritten vorzliglichsten aus dem Vergleich mit den andern Herrschern aus. Dem Salomo aber stellt er Al. schon deshalb nach, weil er ein Heide ist.

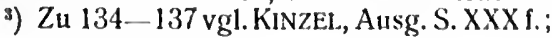

Wilmanns, Gött. gel. Anz. 1885, 295 f.

4) Bezeichnend für Lampr. Stellung zur klassischen Lit. ist es, daß er die Empfehlung der antiquitas, der Altertumsstudien, Alb. 7, unterdriickt (SINGER aaO. u. in "Mittelalt. u. Renaissance“, Sprache u. Dichtg. H.2 S. 46f.). Auch die Hist. de preliis bringt in ihrem Prolog eine Anpreisung der Lektüre klassischer Werke (ed. LANDGRAF S. 25 f.). Wie der Erzpriester Leo so gehört auch Alberich zt1 den Plilosoplien, die die Literatur des klassischen Altertums pflegten, im Gegensatz zu den dem weltlichen Wissen feindseligen Theologen (s. oben S. 5). Auch mit der Hochschätzung der septen artes zeigt siclı Alberich als Auhänger der klassizierenden Richtung.

s) Es ist anzunehmen, daB sich Lampr.s Verhalten gegen seine Quelle im weiteren Verlauf, naclı dem Abbruclı des afrz. Fragments, nicht wesentlich geändert hat. Die vorauszusetzenden Erweiterungen mögen besonders die Kampfschilderungen betroffen haben. Geistliche und gelelırte Zusätze sind eingesclialtet $473 \mathrm{ff} .6(1) 1.687 \mathrm{ff} .693 .797 \mathrm{ff} .1010 \mathrm{ff}$. 1015 ff. 1262 ff. [1321 ff.] 1396 ff. 1461 f. $1470 \mathrm{ff}$. 
Vieles aber hemmt den epischen Verlauf und schwächt die Wirkung ab. Aber er hat doch den Charakter des Originals nicht völlig verwischt und auch bei ihm tritt an vielen Stellen das Reckenhafte wuchtig hervor. Immer noch schreitet die Erzählung ohne längeres Verweilen vorwärts. Der Satzbau ist parataktisch, häufig unter fortführenden unde, temporale Nebensätze werden oft mit unde alsô eingeleitet. Die Gliederung ist noch starr, die einzelnen Szenen werden häufig ohne Übergänge durch formelhafte Einsätze aneinandergereiht, z. B. 103. 381. 411.703. Belebt wird der Vortrag durch Ausrufe mit $\hat{a}$ wie, $\hat{a}$ waz, $\hat{o}$ wê und Fragesätze, schleppend dagegen sind die vielen indirekten Reden und störend die blutleeren Flickverse. ${ }^{1}$ ) Zweigliedrige Ausdrücke sind mäßig gebraucht, die Epitheta spärlich und wirkungslos. $\mathrm{Zu}$ besonderem Schmuck dienen die Bilder und Vergleiche, zumal in den Schlachtschilderungen, in welchen überhaupt dieser epische Stil seinen charakteristischen Ausdruck findet. Frei sprach- und stilschöpferisch ist Lamprecht nicht, er steht ganz in Banne der Tradition.

Die metrische Form ${ }^{2}$ ) ist mit maßvoller Freiheit behandelt. Der Prozentsatz der unreinen Reime ist nicht groß, die Assonanzen sind leicht. Die Verse sind ungleich gebaut, mehrsilbige Senkung gehört zum rhythmischen Stil, weshalb lange Verse recht häufig sind.

Für den höfisch gebildeten Geschmack war Lamprechts Werk veraltet. Rud.v. Ems tadelt ihn in seinem Al. wegen der Ungewandtheit der Form: Verse und Reime, wohl auch die Worte, sind ungelenk und nicht gut zugeschnitten. ${ }^{3}$ )

$\mathrm{V}$ ist eine getreue Wiedergabe des Lamprecht'schen Originals, jedoch hat der Schreiber durch Verlesen oder Verschreiben einzelner Wörter, durch Auslassungen von Wörtern und ganzen Zeilen ziemlich viele Fehler gemacht. Einiges ist auch, wohl in einem der Vor. Hs. schon vorausgehenden Exemplar, neu hinzugekommen.

Der Basler Alexander.

Bist das Machwerk eines poesielosen Chronikschreibers, in dem der heroische Ton des Originals verroht und in die platte Alltagssprache herunter gezogen ist. Der ursprüngliche Text ist ganz willkürlich behandelt und stark gekürzt, alte epische Worte und Ausdrücke sind getilgt, die Assonanzen sind in reine Reime gebracht, wobei nach Belieben die Mundart mithelfen mußte; einzelne Verse fehlen, so daß ca. 330 Zeilen reimlos stehen. Die Regel der vier bezw. drei Hebungen wird angestrebt, überlange Verse werden meist durch Auslassung von Wörtern gekürzt, aber es blieben doch noch viele übrig. ${ }^{4}$ ) Der größte Teil der Änderungen fällt wohl dem Schreiber zur Last, dessen Vorlage, eine alemann. Handschrift aus der zweiten Hälfte des 13. Jhs., möglicherweise gar nicht schlecht war. Textkritisch ist B immerhin von Bedeutung,

\footnotetext{
1) HARCZYK, ZfdPh. 4, 15-18; EHRISMANN aaO.; ZWIERZINA, ZfdA 45, 281.

2) KUHNT S. 3-47; VORSTIUS, Reimbrechung; SARAN S. 253. 263; ZWIERZINA, ZfdA. 44, 43 Anm. u. S. 94; SCHRÖDER, Gött. Nachr.
}

1918,425 f. 428.

3) ZACHER, ZfdPh. 10, 96-98.

4) Ueber die Reime: WERnER, Wiener SB. 93, 56 ff.; KINZEL, ZfdPh. 10, 50-52. 
denn Stellen, wo B mit V übereinstimmt, können zur Verstärkung von V dienen und werfen Licht auf die Beschaffenheit von S, Gleichheiten mit $S$ gestatten einen Schluß auf die Bearbeitung X. Da aber B ganz unzuverlässig ist, so ergibt sich für die Herstellung von $X$ im einzelnen nur wenig, die Gesamtanlage der Bearbeitung aber läßt sich durch Vergleichung ihrer beiden Vertreter, $\mathrm{B}$ und $\mathrm{S}$, mit $\mathrm{V}$ im allgemeinen beurteilen: der (hier allein in Frage kommende) Lamprechtsche Teil erfuhr keine eingreifenden Wandlungen, ${ }^{1}$ ) die Haupttätigkeit für den Verfasser von X lag in der Vollendung des Gedichtes, in der Fortsetzung von Lamprechts Torso.

Am Anfang und ain Schluß hat B $(=X)$ Zusätze gemacht. $\left.{ }^{2}\right)$ An Stelle der rechtmäßigen Geburt Al.s und seiner Erziehung (1-236 V, 1--269 S) wird seine Herkunft von Nektanebus erzählt $(1-534$ B, Werners Ausg. S. 7-26, Kinzels Ausg. S.3-24), während Alberich und ihm folgend Lampr. entrüstet die lügenhafte Behauptung zurïckweisen, daß Al. dieses ägyptischen Gauklers Sohn sei $(71-77 \mathrm{~V})$. B nimmt damit die seit dem alten griechischen Roman in der Al.literatur immer wiederkehrende Sage auf, wonach Al. der Sohn des Ägypterkönigs Nektanebus ist, der in Abwesenheit des Philippus dessen Frau Olympias durch seine Zauberkünste berückt hatte. ${ }^{3}$ ) Erst mit der Bändigung des Bucephalus trifft $B$ wieder mit $V$ und $S$ zusammen. Das Vergnügen am Wunderbaren hat den Verfasser von $B$ auch veranlaBt, einige ans Ende von Al.s Orientfahrt fallende Abenteuer zuzufügen. ${ }^{4}$ ) Schon die Darstellung der Fahrt nach dem Paradiese weicht von der entsprechenden Fassung in $\mathrm{V}$ und $\mathrm{S}$ ab (4118-4246 B), ganz neu aber sind die darauf folgenden vier Stücke (4247-4729 B): 1. Die Taucherglocke (Al. läßt sich von seiner liebsten Freundin in einer Glasglocke an einer Kette ins Meer senken, um zu sehen, was Wunders darinnen sei. Da wirbt ein Mann um ihre Minne und sie wirft die Kette ins Meer, aber Ai. wird von den Wellen ans Land getragen) $4247-4280$ B. 2. Die Greifenfalırt ${ }^{5}$ ) (Al. will wissen,

1) Sie scheinen sich auf einzelne Reimund Versverbesserungen, auf einzelne Wortund Stiländerungen und kleine Zusälze zu beschränken, z. B. die Herstelıung des reinen Reimes vernomen:comen $\mathrm{SB}$ gegen geseit: nieht $279 \mathrm{f}$. $\mathrm{V}$; häufig sind in $\mathrm{SB}(=\mathrm{X})$ Reime auf lat. Dat. Si. o wie Dario: dô. Getilgt in $\mathrm{X}$ sind die Ausrufe $a$ zrie usw (vgl. KinZEL, ZfdPh. 10, 29.73), die liäufigen einleitenden Unt alsó (selten bloß Alsó) von V sind in SB (in B soweit dessen Text iibereinstimmt) durch das gelăufigere $D o ́$ ersetzt: in V 307 331. 337 365. 387. 393. 429. 741. 755. 839. 881. 1071.1195. 1307. 13431362 (Unde alse ist in S erhalten in $145 \mathrm{~S}=121 \mathrm{~V}$, $235 \mathrm{~S}=205 \mathrm{~V}, 297 \mathrm{~S}=258 \mathrm{~V}, 1578 \mathrm{~S}=1149 \mathrm{~V}$, $1645 \mathrm{~S}=1195 \mathrm{~V}, 2036 \mathrm{~S}=1497 \mathrm{~V}$ (vgl. 1037 S). -- Elne abscliließende Untersuclung uber die Beschaffenlseit von $\mathrm{X}$ fehlt noch.

3) HaRCZYK S. 146 148; KINZEL, Ausg. S. XV f., ZfdPh. 10, 54 f. 86-89; ZACHER ebda S. $103 \mathrm{ff}$; WERNER, WSB. S. 55-60. 117-122; Christensen S. 6 f.; PAul Meyer Bd. 2 Kap. V, dazu Kinzel, Anz 13, 226 f.

3) Die Nektanebussage ist wie der älteste Alexanderroman (Pseudokallisthenes) in Aegypten entstanden. Al. sollte damit als Nachkomme der ägyptischen Könige beglaubigt und die makedonisch-griechische Herrschaft in Aegypten als geselzlich bewiesen werden (Ncktanabis ll. regierte zur Zeit der Geburt Al.s und starb 341 v. Clir. in der Verbannung in Aethiopien, vgl. 55 B). Vgl. A. WiedemanN. Wochenschr. f. klass Phil. 34 H. 25 26; WeinireiCH, Der Trug des ^ek1.. 1911.

4) Teile in der Fortsetzung von Rudolfs v. Ems und Jansen Enikels Weltchronik, vgl. ZaCher, ZfdPliil. 10, 104 ff.; Srrauch, Ausg. von J Enıkel S. $368 \mathrm{ff}$. Die Quellen s. bei WERNER. WSB. 93, $117 \mathrm{ff}$.

5) Aucli in Seelentrost. - PANzer, N. Jahrb. $7(1504), 140 ;$ BURDACH, Ackermann S.268-272. 
wer im Himmel ist, auf einem von zwei Greifen getragenen Sessel fährt èr gegen den Himmelsthron, aber eine Stimme heißt ihn auf die Erde zurückkehren) 4281-4312 B. 3. Al.s Sonnenfahrt (Al. fährt zu den Bäumen der Sonne und des Mondes, eine Stimme verkündet ihm, daß ihn sein nächster Kämmerer vergiften werde) $4313-4345$ B. 4. Al.s Ende (seine Vergiftung durch seinen Vertrauten Jobas, sein Testament, Abschied von den Seinen, Beschreibung seiner Persönlichkeit) 4346-4729 B.

\section{Der Straßburger Alexander.}

Die zweite Bearbeitung, $\mathrm{Y}$, die durch die sorgfältige Hs. S gut vertreten ist, hat ohne tiefgreifende Änderungen des Inhalts ${ }^{1}$ ) mit dem ihr uberkommenen Grundtext Lamprechts sehr frei geschaltet in der modernisierenden Absicht, Versbau ${ }^{2}$ ) und Stil ${ }^{3}$ ) den Anforderungen der weitergescbrittenen Kunst anzupassen. Der Rhythmus des in V ubberlieferten Teiles ist geebnet, oft dadurch daß entbehrliche Worte, die den Vers beschweren, ausgeschaltet oder durch kürzere ersetzt sind, fehlende Senkungen sind ausgefüllt. Überlange Verse sind beseitigt: durch Teilung in zwei, wobei der neue Vers einen weiteren Reimvers nötig machte, oft unter Verwendung eines Wortes im Innern des ursprünglichen Langverses als Reimwort; oder durch Dehnung zweier langer Verse in vier kurze; leicht stellten sich hierbei Flickverse ein. Die selbständige Fortsetzung in $\mathrm{Y}$ ist von vornherein in regelmäßigen Versen angelegt. Dagegen war eine grundsätzliche Regelung des Reimgebrauchs in $\mathrm{Y}$ nicht beabsichtigt. Manches wurde zwar geändert. Schon in $\mathrm{X}$ sind unreine Bindungen gebessert worden, in $\mathrm{Y}$ wurden dann, oft durch leichtere Eingriffe, noch mehr gleiche Reime hergestellt; aber viele alte Assonanzen sind geblieben und in den von $S$ umgestalteten oder zugesetzten Versen sind wieder weitere neue hinzugekommen. Somit kann in dem $\mathrm{S}$ und $\mathrm{V}$ gemeinsamen Teile von einer Vermeidung der unreinen Reime nicht die Rede sein, und dementsprechend sind sie auch in der Fortsetzung bei $\mathrm{S}$ durchaus sehr häufig, nur gegen den Schluß nehımen sie ab. Ein Unterschied in der Art der Assonierung besteht zwischen den beiden Teilen von $S$ nur in wenigen unmaßgebenden Fällen. Zur Reimtechnik ist noch zu erwähnen, daß $\mathrm{S}$ im Verhältnis häufiger als $\mathrm{V}$ kleine, zum Reimen bequem sich eignende Wörtchen wie al, baz, daz, dâ, dô, vruo, zuo u. a. benutzt. $\left.{ }^{4}\right)$

Die ausgeprägteste Neuerung von $\mathrm{Y}$ aber liegt im Gebiete des Stils. Das bei den mhd. Umarbeitungen und Übersetzungen allgemein gültige Prinzip der Erweiterung zum Zweck des leichteren Verständnisses, durch Ausmalung und Begründung, hat auch der Bearbeiter $(\mathrm{Y})$ befolgt, er ist also auf dem Wege, den Lampr. einschlug, weitergeschritten, nur daß er die

1) ZACHER, ZfdPh. 11, $414 \mathrm{ff}$.

2) KINZEL, ZfdPh. 10,19 ff.; KuHNT aaO., bes. $\$ \$ 35$ u. 36 u. S. 106.

3) HARCZYK S. 11-30; ReBLIN S. 28 ff.;
HAMPE S. $79 \mathrm{ff}$.

$\left.{ }^{4}\right)$ ZWIERZINA, Verhandlung. aaO.; KUHNT S. 59 f. 
Überlieferung noch viel stärker umgestaltet und erweitert hat. Damit hat er den volkstümlichen epischen Stil zu dem der vorhöfischen Zeit entwickelt. Schon äußerlich ist diese Verbreiterung der Darstellung an dem größeren Umfang des in $\mathrm{S}$ mit $\mathrm{V}$ gemeinsamen ersten Teiles ersichtlich.

Solche Zusätze sind angebracht in Reden, z. B. 967-977. 1013-1022. 1635-1638. 1663-1666; in Kampfschilderungen u. dgl., z. B. 1035-1042. 1045-1048. 1169-1176. 125I f. 1311-1314. 1320-1324. 1357-1360. 1428 f. 1740-1749; bei Vorgängen des inneren Lebens, z. B. 330-333. 1029-1032 (oder hat hier V ausgelassen? vgl. B zur Stelle) 1073-1077. 1667-1670. 1695; als Belehrungen, 2. B. 69-77. 1418-1421 (Bibel), 2005-2010 (uber Armenien).

Zur Ausdehnung des Umfangs tragen auch jene Zerteilungen von längeren Versen in Versgruppen bei, die wegen Regelung des Rhythmus vorgenommen wurden. Wie dem Inhalt, so strebte der neue Stil auch der sprachlichen Form Abrundung zu verleihen. Statt einfacher Nebeneinanderstellung der Sätze werden verbindende Übergänge gewählt.

Oft tritt die vermittelnde und weiterführende Konjunktion dô mit lnversion des Subjekts ein, z. B. Man hiez daz ros thûn $261 \mathrm{~V}-D o ̂$ hiz man daz selbe ros leiten 300 f. S; Alexander steich $887 \mathrm{~V}$ - dô steich Alexander $1235 \mathrm{~S}$; Mennes der slûch Alexandern $1266 \mathrm{~V}$ do slâch doh Alexandren Mennes 1738 f. S, vgl. $291 \mathrm{~V}-341$ f. S, $323 \mathrm{~V}-378 \mathrm{~S}, 357 \mathrm{~V}-$ 421 f. S, 777 V - 1073 f. S. 837 V - 1159 S (1187 S). $1159 \mathrm{~V}-1593$ S, $1247 \mathrm{~V}-1724$ S; Haupt- und Nebensatz durch $d \hat{o}$ eingeleitet in S $1612(1175 \mathrm{~V})$. Umgekehrt hat auch S einleitendes $d \hat{\delta}$ von $\mathrm{V}$ fallen lassen, aus bestimmten stilistischen Gründen und bei stärkeren Satzänderungen, so z. B. $383 \mathrm{~S}-328 \mathrm{~V}, 492 \mathrm{~S}-417 \mathrm{~V}$ (zwei Hauptsätze von V in einen zusammengezogen), $1232 \mathrm{~S}-884 \mathrm{~V}$ (zur Vermeidung der Häufung von $d \hat{o}$, das auch in $\mathrm{S}$ 1229 und 1235 steht, $1648 \mathrm{~S}-1198 \mathrm{~V}$ (Satzänderungen wegen des Reimes), $1695 \mathrm{~S}-$ $1225 \mathrm{~V}$ (ebenso). Ein weiterer Scliritt über die Syntax von V hinaus ist die Bildung vors eingeschalteten Nebensätzen, z. B. unt nam die corône, die er mit samt ime dâ hete, sinnem fater ers âf sazthe $395 \mathrm{f} . \mathrm{V}-$ er sazte di crônen dô, die er Nicolâे hete geroubit, sinem vater af daz houbit $462-465 \mathrm{~S} ;$ vgl. $417-420 \mathrm{~V}$ und $493-495 \mathrm{~S} ; 1477-1479 \mathrm{~V}$ und 2017-202C S. In der Deklination der fremden Eigennamen') weicht der Verfasser von $\mathrm{S}$ insofern oft von $\mathrm{V} a b$, als er die lat. Kasusendungen statt der deutschen wählt: oft Dat. Si. Alexandro in S statt Alexander in V; Tyre 1015. $1025 \mathrm{~V}-$ Tyrus 1412. F430 S (1015 auch in B); Dat. Tyrin $806 \mathrm{~V}$, Tyre $1006 \mathrm{~V}-$ Tyro 1110. $1400 \mathrm{~S}$; die Panfilien $1455 \mathrm{~V}-$ Pamphilienser 1989 S; Acc. Philippus (wie Nom.) $257 \mathrm{~V}$-Philippum $296 \mathrm{~S}$; wie V 1478 uber Frigiam, aber mit falscher Konstruktion hat S 2018 sàzen in Frigiam (Reim: mant); Gen. $\mathrm{Si}$. auf is: Alexanders in V, Alexandris in S (mehrmals), Salemones $20 \mathrm{~V}$ - Salemonis 20 S, Gen. Philippus 237 V - Philippis 270 S. $\left.{ }^{2}\right)$

Die aus dem ersten, mit $\mathrm{V}$ gemeinsamen Teile von $\mathrm{S}$ erschlossenen Stilmerkmale finden sich ebenso im 2. Teile, wo $\mathrm{S}$ unmittelbar aus den lat. Quellen ubersetzt, nur daß bei dem viel größeren Umfang und dem veränderten Stoff gewisse Ausdrucksmittel neu oder stärker auftreten können. ${ }^{3}$ ) -

1) KinZEL, Beitr. z. d. Pliil. S. 65-67; OTTMANN S. XLI f. Anm. 77.

2) Weitere Lit zum Stil von V und S: zum Wortschatz: HARCZYK, ZfdPh. 4, 25 ff.; Flickverse: WERNER, WSB. S. 10 f. (in V), HAMPE S. 79 ff. (in S). Wiederholung: BEHAGHit, Beltr.30,431 ff.; Parallelen zum ganzen Lied gibt KINZEl in den Anm. seiner Ausg. Lateinisches:
Ottmann S. XX f. Anm., Grónewald S. 33. Ueber die Anredeformen (Du und lhr im Lampreclitschen Teil, Du in der Fortsetzung) s. ZfdW. 2, 142-145. Konjunkliv im Al lied: HEYNISCH aaO.; zu $\mathrm{S}$ im allgemeinen: REBLIN S. $35 \mathrm{ff}$.

$\left.{ }^{8}\right)$ z. B. Formeln, zweigliedrige Ausdrutcke; auch hiertiber fehlen noch Untersuchungen. 
Der vorhöfische Stil von $S$ und somit von $Y$ ist, wenn man das Urteil zusammenfassen will, zwar fließender als der volkstümliche von $\mathrm{V}$, aber weniger kraftvoll. Der Verfasser beherrscht die Sprache nicht unbehindert, er hat, weil er mehr Eigenes bietet als Lampr., auch noch schwerer mit der Formung $z \mathfrak{u}$ ringen und nimmt allzuoft Flickverse $z \mathfrak{u}$ Hilfe oder wiederholt leicht in kurzen Abständen den gleichen Ausdruck und die gleichen Reime. Allerdings erlangt er im Verlaufe seiner Arbeit größere Gewandtheit.

Der ungenannte Verfasser von $Y$ war Geistlicher. Seine Heimat war Rheinfranken, seine Tätigkeit am Al.lied fällt um 1160. Er zeigt Vertrautheit mit den lat. Sprachformen und gelehrte Kenntnisse, ') indem er theologișche, schon in V vorkommende Stellen wie S $23 \mathrm{f}$. $69 \mathrm{ff} .1413 \mathrm{ff}$. $2005 \mathrm{ff}$. erweitert sowie eigene Zitierungen ${ }^{2}$ ) wie $2305 \mathrm{ff}$. $4024 \mathrm{ff}$. neu bringt.

Der Vor. Al. schließt mit 1533, die letzten 4 Verse 1530-1533 rühren von einem Schreiber her, nicht von Lampr. selbst, denn der Abfasser redet von diesem als von einer andern Persönlichkeit: nach der Ansicht Alberichs und Lampr.s habe hiermit der Stoff seine richtig zugemessene Abgrenzung (mâze) gefunden. Aber auch der vorhergehende Ausgang des Vor. Textes 1497-1529 fällt, durch seine Kürze, aus dem Ton der Gesamterzählung heraus, es ist ein nur durch äußeren Zwang gebotener, eilig zusammengeraffter, überstürzter Abschluß, in welchem die auf die vorhergehende Erzählung von Al.s Leben und Taten folgenden weiteren Ereignisse, das $\mathrm{Zu}$ sammentreffen der beiden Heere in Mesopotamien (1497-1510), die große Schlacht (1511-1517) und die Erschlagung des Darius $\left.{ }^{3}\right)$ durch Al. (15181528) summarisch berichtet werden. Die Frage ist nun: hat Lampr. seine Arbeit mit 1496 abgebrochen und selbst diesen gewaltsamen Schluß 1497-1529 an die vorher ungehemmt verlaufene Erzählung angehängt oder hat Lampr. die ganze Al.geschichte bis zu ihrem tatsächlichen Ausgang gedichtet, wie sie in S vorliegt, und nur ein Schreiber hat mit 1496 das Weiterschreiben aufgegeben und den viel größeren folgenden Teil durch die notdürftige Schlußübersicht 1497-1529 ersetzt? Mit andern Worten: ist Lampr.s Arbeit Fragment geblieben oder ist nur der Text der Vor. Hs. fragmentarisch? Es läßt sich nachweisen, daß Lampr. das zusammenfassende Schlußstück 1497-1529 selbst verfertigt und also den Text nur bis hierher geführt hat [Lampr. = $1-1528 \mathrm{~V}]$ und daß umgekehrt die darauf beginnende Fortsetzung in S (2038 ff. S) von einem andern Verfasser stammt. Jenes Schlußstäck von $\mathrm{V}$ ist nämlich großenteils zusammengesetzt aus Versen, die in dem echten Text Lampr.s vorkommen. ${ }^{4}$ )

Die abgekürzte Schilderung dieses Völkerkampfes am Schluß von V hat der Fortsetzer $S$ benutzt bei seiner Darstellung der Schlacht von Arbela,

1) Reblin S 35 f.; ZACHer, ZfdPh. 11, 414 . Indessen ist nicht sicher zu entscheiden, wie vieles dem Bearbeiter $X$ zuzuschreiben ist.

") ZACHER ebda 11, $399 \mathrm{ff}$.
3) ALW. SCHMidT S. 81 f.; AUSFELD, Lit.BI. 1887, 315: OTTMANN S. XXXIX Aum. 72.

4) Vgl. WeRnER, WSB. S. 51-54; KINZEL, Ausg. S. 464. 
die eben in dem Krieg zwischen Al. und Darius der Entscheidungskampf, der eigentliche volkwîc, war und die auch Lampr. bei seinen Schlußversen im Sinne hatte. 1)

Quellen der drei Fassungen. ${ }^{2}$ ) Dem afrz. Gedicht Alberichs und ihm zufolge dem Vor. Al. liegt hauptsächlich Julius Valerius zugrunde, daneben die Historia de proeliis (s. unten), und $z$ war nicht in der ursprünglichen Gestalt, sondern in der Rezension des Orosius; 3 ) für die Belagerung von Tyrus wurde Curtius beigezogen. Der Fortsetzer S (bezw. genauer: Y, der Verfasser der Grundlage der Hs. S) ${ }^{3}$ ) arbeitete nach der alten Niederschrift der Historia, nach einem Text, der der Münchener Hs. der Historia nahe verwandt war; $\mathrm{B}$ gehört zur Redaktion $\mathrm{S}(\mathrm{SB}=\mathrm{X})$, gibt aber die Vorgeschichte (Nektanebus) und die Abenteuer Al.s gegen das Ende (Taucherfahrt usw.) nach einer deutschen Quelle, welche der überarbeiteten Fassung der Historia folgte. ${ }^{4}$ )

Nun liegen aber die Verlältnisse bei den Quellen der Al.geschichte keineswegs so einfach. Einmal weichen die Hss. der lat. Bearbeitungen, so besonders bei der Historia, oft beträchtlich voneinander $\mathrm{ab} ; 5$ ) außerdem hat es gewiß noch viele lat. und auch einige französische und deutsche Versionen gegeben, die wir gar nicht kennen; endlich aber ubertragen die Bearbeiter des deutschen Al.liedes ihre Vorlage mit Freiheit und nicht wörtlich, auch haben sie sicher gar nicht selten außer ihren Hauptquellen noch stellenweise andere Berichte aufgenommen, so geht die Belagerung von Tyrus in Alberich-Lamprecht auf Curtius zurück, die Episode von den Blumenmädchen ${ }^{6}$ ) und die von Candace haben Beziehungen zu einem französischen Al.roman, ${ }^{7}$ ) Gründe genug, daß unsere Kenntnis von dem Ursprung des in unserem Al.liede enthaltenen Stoffes vielfach Lücken aufweisen muß. Indessen läßt sich das Verhältnis zu der Überlieferung beim Fortsetzer S leichter durchschauen als bei Alberich-Lamprecht, denn beide verhalten sich ver-

1) Der Nachweis, daß Lamprechts Arbeit mit dem Schluß des Vorauer Al. aufhörte und daß die Darstellung der Schlacht von Arbela in $\mathrm{S}$ dem nicht widerspricht (KINZEL. Ausg. S 227 f., vgl. WERNER, WSB. S. 50; KinZEL, ZfdPh. 20,97; HAMPE S. 36 f. 104 ff.; SiNGtR S. 199) wird an anderer Stelle versucht werden.

2) KINZEL, Ausg. S. XXXVIII-LI, ZfdPh. 15, 222-229; BECKER, Zur Al.sage S. $93 \mathrm{ff}$; Singer S. 197 ff. Hauptsächl. für V und S: HARCZYK S 146-173; KINZEL, ZfdPh. 20, 88-97; ReBLIN S. 30; AUSFELD, Lit.Bl. 1892, 5-7. Speziell zu V: ALW. SchmidT aaO, dazu AuSFELD, Lit.BI. 1887, 313-315. Hauptsăchl. zu S: HARCZYK S. 21 ff.; MILLER S. I14; Zacher, ZfdPlı. 11, 413 ff.; HAMPE aaO., dazu KinZel, ZfdPlı. 24, 255 ff.; Ausfeld, Lit.BI. 1899, 369-371; SingER aaO. S. 197 ff. und WSB. 180 (1916), 4. Abhandl. S. 124. Hauptsăchl. zu B: WERNER, Ausg. S. 3 f..
WSB. 80-122, dazu Kinzel, ZfdPh. 14, 379 ff.; Christensen, Beitr. S. 15 ff., dazu KinZel, ZfdPh. 16, 118-121; KinzeL, Ausg. S. Xlll ff.

$\left.{ }^{3}\right)$ Orosius-Rezension: Ausfeld, Festschr. d. badischen Gymnasien zum Heidelberger Univers.-Jubiläum 1886 S. 385-405.

${ }^{4}$ ) Siche unten S. 249

5) Hinsichtlich ilırer Stellung zu deu Liss. der Historia teilen sich die deulsclıen Romane in zwei Gruppen: von der ursprijnglichen Fassung abliängig sind der Fortsetzer von $S(Y)$ und $B$, soweit es mit $S$ zusammenhängt, sowie Hartlieb; von der Orosiusrezension die andern: V, B (soweit es mit V zusammenhängl), Rud. v. Ems, Ulrichı v. Esclıenbach, Babiloth, Seifried und der Große Al.

6) Vgl. bes. KinZEl, Ausg. S. 497; HAMPE S. 46; Becker, Zur Al.sage S. $11 \mathrm{ff}$.

7) Wilmanns, ZfflA. 45, 229. 245. 
schieden gegen ihre Vorlagen: Alberich behandelt sie sehr frei, der Verfasser der Fortsetzung dagegen schließt sich ihr enge an.

Fast die gesamte Alexanderliteratur des Mittelalters entstammt dem griechischen Al.roman, dem sog. Pseudokallisthenes,1) der um 200 vor Christus in Alexandria entstand und dem Philosophen Kallisthenes zugeschrieben wird, einem der Begleiter Al.s auf seinem Zuge in den Orient. Der wirkliche Verfasser, dessen Name nicht bekannt ist, war ein Grieche aus Alexandrien, ${ }^{2}$ ) der mit geringer eigener Bildung und ohne geschichtliche Kenntnisse das Leben Al.s dem Volke darstellte, auf Grund historischer und mündlicher, sagenhafter Überlieferung und mit eigener bloß aufs Unterhaltende und Abenteuerliche gerichteten Erfindung.

Der historische Al, dessen Taten schon die Zeitgenossen fabelhaft ausschmückten, ist hier zu dem Helden eines Volksbuches geworden und in diesem Bilde dauerte er fort als Lieblingsgestalt der Erzählungsliteratur im Morgen- und im Abendlande.

Dem MA. wurde wie alle griechische Literatur so auch die Geschichte Al.s in lat. Ubersetzung zugänglich gemacht. $Z$ wei lat. Al.romane sind die hauptsächlichen Vermittler gewesen:

1. Die älteste lat. Übersetzung ist die nur in drei Hss. überlieferte des Juli us Valeri us,") Julii Valerii Res gestae Alexandri Macedonis, um $300 \mathrm{n}$. Chr. Ein kürzerer Auszug aus dem vollständigen Julius Valerius, Julii Valerii Epitome, vor dem 9. Jh., ist in einer größeren Anzahl von Hss. erhalten. $\left.{ }^{4}\right)$

2. Die für die abendländischen Bearbeitungen der Al.sage wichtigste Quelle - noch mehr als Julius Valerius - ist die Historia de preliis des Archipresbyter Leo (Neapel, 950, schrieb 941 u. $944 \mathrm{im}$ Auftrage seiner Herren, zweier Herzöge von Capua, in Konstantinopel den griech. Text ab), in vielen Hss., auch noch in Drucken des 15. Jhs. verbreitet (zwei stark verschiedene Hauptgruppen: I ursprüngl. Text, bes. Bamberger Hs. B, Münchener Hs. M; 11 bedeutend erweitert), die ziemlich freie Übersetzung eines den älteren

1) Seit dem 15. Jh dem Kall. zugeschrieben, vorher unter Aesops Namen oder anonym. Ausg.: C. MülleR, Paris 1846; H. MEUSEL, Leipzig 1871; die grundlegende Untersuch. ung ist: JUL. ZACHER, Pseudokallisthenes, Halle 1867; AUSFELD, Zur Kritik des griech. Al.romans, Progr. Bruchsal 1894, dazu BECKER, ZfdPh. 28, 379-382; AuSFELD, Wer griech. Al.roman, nach des Verfassers Tode hgb. von WILH. KROLL, Leipzig 1907. Uebersetzung bei WeISMANN, 2, 1 -224 und AUSFELD, Al.roman S. 30-213. Vgl. ferner WiLH. HERTZ, Aristoteles in den Al.dichtungen des MA.s; die Sage vom Giftmädchen, Ges. Abh. S. 1 155. 156-277 (aus den Abhandl. d. Münch. Akad. d. Wissensch. 19 (1890) H l u. 20 (1893) H. 1 ; ERWIN ROHDE, Der griech. Roman, 2. Aufl. Leipz. 1900 S. 197 ff.; EDUARD SCHWARTZ, Fünf Vorträge über den griech. Roman, Berlin 1896 (bes S. $65-102$ ); R. REITZENSTEIN, Hellenist. Wundererzänlungen, Leipzig 1906 (u. a. S. 16); J. STRZYGOWSKI, Byzantin. Archiv H. 2, 107. 109; KROLL, Der griech. Al.roman, Augsburger (Münchener) Allgem. Zeit. 1901, Beil. 74; BuRDACH, Beriiner SB. 1918, 1016; HILKA, Studien zur Al.- sage, Roman. Forsch. 29, 1-30; Ders., Jahresber. d. schles. Gesellsch. f. vaterld. Kultur 1907 (dazu Strecker, Anz. 33, 96), Progr. des Gymn. zu Breslau 1909, Festschr. d. schles. Gesellsch. f. Volksk. 1911, 188 ff., Mitteil. d. schles. Gesellsch. f. Volksk. 1914, 80 ff., Arch. 1918, 319 ff., vgl. Festschr. d. schles. Philologenvereins $191 \mathrm{l}, 151 \mathrm{ff}$; BOLTE-POLívKA 1, 510 ff. 2, 394 ff. (Wasser des Lebens); MaRTin Schanz, Gesch. d. röm. Lit. 4. Teil S. $47-51$, Handbuch d. klass. Altertumswissenschaft ${ }^{2} 8$. Bd., 4. Teil, 1. Hälfte.

2) AUSFELD S. 237 ff.; früher wurde als Entstehungszeit ca. das Jahr $200 \mathrm{n}$ a ch Christus angenommen.

3) Ausg.: BERnh. KüBLER. Leipzig (Teubner) 1888; ZACHER, Pseudokall. S. 32-48; AUSFELD, Griech. Al.roman S. 10-12; WEISMANN 2, 225-284 (Inhaltsangaben und Auszüge), s. SCHANZ aaO.

4) Ausg.: ZACher, Halle 1867; O. WAGner, Leipz. 1901 ; vgl. ZACHER, Pseudokall. S. 105107; G. G. ClLlıÉ, De Julil Valeril Epitome oxoniensi, Diss. Straßburg 1904, vollstăndig De duabus Julii Valerii epitomis. 
Rezensionen des Pseudokall. angehörenden Textes. Aus der Historia schöpften mehr oder weniger fast alle zeitlich folgenden m.alterl. Bearbeitungen der Al.sage (die deutschen bes. aus der zu II gehörigen, aus der Weltchronik des Orosius erweiterten Orosius-Rezension). ${ }^{1}$ )

Behandlungen einzelner Teile von Al.s Leben:

3. Iter ad Paradisum, Al.s Zug zum Paradies. Schon in jüngeren Hss. des Pseudokallisthenes sucht Al. vergeblich nach dem Lande der Seligen und nach dem Brunnen der Jugend; die Erzählung aber, daß er zu den Pforten des Paradieses gelangte, ist rabbinischtalmudischen Ursprungs. ${ }^{2}$ )

4. Das Itinerarium Alexandri, um 300 (Al.s Kriegszüge nach Arrians Anabasis und Julius Valerius).

5. Der Brief Alexanders an Aristoteles über die Wunder lndiens (in zwei lat. Versionen erhalten, die auf zwei verschiedene griechische, letzten Endes aus Pseudokallisthenes geschöpfte Ausschnitte zurückgehen. ${ }^{3}$ )

6. 7. 8. Drei Berichte über die Brahmanen, ebenfalls aus griechischen Quellen übersetzt: 1. Briefwechsel Al.s mit Dindimus, dem König der Brahmanen. $\left.{ }^{4}\right)$ 2. Commonitorium Palladii (P. lebte ca. 363-430 n. Chr.), eine kleine Abhandlung über Indien und die Brahmanen. ${ }^{5}$ ) 3. Dindimus tiber die Brahmanen, $\left.{ }^{6}\right)$ kurzer Traktat ähnlichen Inhalts.

9. Ein lat. Abecedarius (Gedicht, dessen Verse bezw. Strophen bezügl. der Anfangsworte alphabetisch sich folgen) erzählt im Volksstil einige Wundertaten Al.s (Hs. Verona, 9./10. Jh.).

In der Blütezeit des Rittertums, weiches den griechischen Eroberer zum Muster eines Heldenkönigs idealisierte, entstand das künstlerisch bedeutendste Denkmal der lat. Al.literatur: die Alexandreis des Gualterus de Castellione (Walther von Châtillon oder von Lisle), ein Epos in Hexametern, verfaßt 1170-1175, mit Benutzung von Curtius, von des Justinus Chronik und der Historia. Der klassische Stoff ist hier in ein klassisches Gewand gekleidet. In erhabenem Stil, vertraut mit den römischen Dichtern und mit freischaffender Phantasie hat der christliche Verfasser auch den antiken Geist, besonders durch Verwendung der Mythologie, zu erreichen gesucht, ist aber freilich hier nur bis zum Allegorisieren gelangt. ${ }^{8}$ )

Etwa 60 Jahre später hat in Unteritalien Quilichinus von Spoleto, eine Historia Alexandri in Distichen verfaßt (um 1236, mit Benutzung der Hist. de preliis), mit geringerem Wissen und Vermögen als Walther v. Châtillon, aber doch mit Verständnis und in guter Sprache. ${ }^{9}$ )

1) Ausg.: nach der älteren Rez. (B u. $M$ ): GUST. LANDGRAF, Erlangen 1885, dazu AusFELD, ZfdPh. 18,493-498; nach der jüngeren Rez.: OsW. ZINGERLE, Die Quellen zum Al. des Rud. v. Ems, in Anhange: Die Historia de prellis, Germ. Abh. IV; vgl. ZACHER, lter ad P. S 8 ff.; Pseudokall. S. 108-112; AUSFELD, Progr. Donaueschingen 1883, dazu O. ZiNGERLE, Anz. 10,321-326; Ausfeld, OrosiusRez. usw., dazu KinZel, ZfdPh. 16, 123-126, Ausfel.D ebda 17, 108 f.; Christensen, Beitr. S. 1 ff., dazu KINZEL, ZfdPh. 16, 118-123; KINZEL, Zwei Rezensionen der Vita Alexandri Magnil interprete Leone archipresbytero Neapolitano, Progr. des Berliner Gymn. zum Grauen Kloster 1884. dazu RÖDIGER, DLZ.1884, 902, AUSFELD, LC. 1884.531: KINZEL, ZfdPh. 17, 98-108; Ausg. S. XVII-XXIX; MaNITIUS I, 529-531; SCHANZ aaO.

2) Ausgabe: ZACHER, Regimont 1859; in KINZELS Ausg. unter dem Text S 357 ff., vgl. S. XLVIII-LI; ElIS PETERS S. 35 f. Eine gut stillsierte lat. Erzählung von Neptanabus und Al.s Kindheit: (Hs. Erfurt 1447-67) HiLKA,
Festschr. z. Jahurhundertfeier der Universität zu Breslau, 1911 S. 188-198.

3) FRIEDR. PFISTER, Kl. Texte zum Al.roman, Heidelberg 1910 S. VIII-X, wo weitere Lit.; ZAÇHER, Pseudokall. S. 165 ff.; Ausgabe: KÜbler S. 190-221; HilKA, Zur Al.sage, Progr. Breslau 1909.

4) Ausg.: Kübler S. 169-189; Plister S. $10-20$.

b) Ausg.: Prister S. 1-5.

6) Ausg.: Pfister S. 6-9. - Eine saggenliafte Jugendgesch. Al.s d. Gr. s PFister, Berl. philol. Wochenschr. 36 (1916), $447 \mathrm{f}$.

7) ZARNCKE. Sächs. Ges d. Wiss 1877, $57 \mathrm{ff}$.

5) Ausg. von F. A. W. MÖLDENER, Göttingen 1859; WiLH. Tolscher, Ueber die Alexandreis des Ulrich v. Eschenbach, Wiener SB. 97 (1880), 311 ff.; vgl. ZaCher, ZfdPh. 11, 404 ff.

9) ERNst Neuling, Beitr. 10,315-383; FrIEDR. PFISTER, Historia de preliis und Al.epos des Quilichinus, Münch. Museun 1 (1911), 249-301; Paul Lehmann, Berl. philol. Wochensclır. 1918, 812-815. 
Als eine der großen historischen Persönlichkeiten, als Stifter eines Weltreichs hat Al. auch in der Weltgeschichtsschreibung seinen gebührenden Platz gefunden, so in Ekkehards von Aura Weltchronik, um 1110 (nach der Bamberger Hs. der Historia); ${ }^{1}$ ) in Gotfrids von Viterbo Pantheon (um 1185), in Vincenz' von Beauvais ( $\dagger$ 1264) Speculum historiale.2)

So war Al. der gefeiertste Held der Weltliteratur des MA.s und so ziemlich jedes literarische Volk besaß eine oder mehrere Al.dichtungen. ${ }^{3}$ ) Besonders im Orient lebte und lebt noch jetzt Al. in Sage und Literatur weiter, wobei ebenfalls der griechische Roman des Pseudokallisthenes Vermittler war. Und so besaß auch Deutschland eine reiche Al.literatur.4) Schon Otfrid erhöht den Ruhm der Franken dadurch, daß er ihre Verwandtschaft mit dem Welteroberer Al. hervorhebt. ${ }^{5}$ ) Auf dieselbe Sage spielt das Annolied an in der historischen Einleitung 321-334 ( $=$ Kchr. 325-334); hier auch Al.s Eroberungszug, sein Ende in Babylon und die darauf folgende Diadochenherrschaft. An der anderen Stelle, 207-236 (= Kchr. 536-564), ist Al. historisch gefaßt als Gründer des dritten Weltreiches, dargestellt aber als der sagenhafte Wundermann.6) Mit Lampr. beginnt die Reihe der selbständigen Al.dichtungen. ${ }^{7}$ )

In höfischem Geiste waren die, verlorenen, uns nur durch Rudolfs v. Ems Nachricht bekannten Al.romane des Berthold v. Herbolzheim (bei Freiburg, um 1210) und des Biterolf, ${ }^{8}$ ) seines Freundes, gehalten. Rudolfs Alexander (um 1230-40, s. oben S. 240) hat, der gelehrten Richtung des Verfassers entsprechend, stark historisch-chronikalischen und moralisch-didaktischen Gehalt. Einen fein höfischen Al.roman dichtete Ulrich v. Eschenbach für den König Wenzel v. Böhmen (um 1280). Im 14. Jh. (um 1352) schrieb Seifrid, ${ }^{9}$ ) ein sonst unbekannter Dichter, einen Al., und nach 1390 entstand der große Alexander, der Alexander magnus (Wernigeroder Hs.), eine Übersetzung dẻs Quilichinus. Dann treten im 15. Jh. an Stelle der Versübersetzungen die Al.prosen mit lehrhafter, historischer und moralisierender Absicht: die viel gelesene Al.chronik des Meister Babiloth ${ }^{10}$ ) und das in einer größeren Anzahl von Drucken verbreitete Al.buch des Vielschreibers Johann Hartlieb (erster Druck 1472), dieses speziell mit der Bestimmung als Fürstenspiegel.11)

1) Ausfeld, ZfdPh. 18, 385-405; Werner, WSB S. $82 \mathrm{ff}$.

2) Paul Meyer 2, 330-34.

3) Die Al.sage war der erste antike Stoff, der in eine der abendländ. Volkssprachen aufgenommen wurde, und zwar zuerst im Französisclıen, in Alberichs v. Besançon Werk.

4) ZINGERLE S. 3 ff.; STrauch, Enikel S. $360 \mathrm{ff}$.

5) OTFR. 1, 1, 87-92, nach Fredegar, vgl. ERdmann, Ausgabe S. $341 \mathrm{f}$.

6) Siehe MASSMANN, Kchr. 3, 464. $477 \mathrm{ff}$; WILMANNS, Ueber d. Annol. S. $21-24$. $30 \mathrm{ff}$; ZACHER, ZfdPh. 10. $108 \mathrm{ff}$; KinZel ebda 15, 222-229; CHRISTENSEN, Beitr. S. 8; ZINGERLE S. 5 ; Strauch S. 360.368 .
7) Ueber die mhd. Al.literatur s. Bd. II, 2.

8) ZACHER, ZfdPh. 10,93-112; JuNK, Beitr. 29, $460 \mathrm{ff}$.

9) F. WOLF, Wiener SB. 1832, Anzeigebl. S. 19 ff.; V. KARAJAN, ZfdA. 4, 248; HERTZ S. $123-25$.

10) Herzog, Die Alexanderchr. des Meister Babiloth, Progr. Stuttgart 1896-97, wo die übrige Literatur angegeben ist.

ii) SIEGM. HIRSCH. Das Alexanderbuch Joh. Hartliebs, Pal 82; Hans POPPEN, Das Alexanderbuch Johann Hartliebs u. seine Quelle, Heidelberg. Diss. 1914; EugEN TRAVN1K.Ueber eine Raaber Hs. des Hartliebschen Alexanderbuches. Münch. Mus. 2, 211-221. 
Als Stück der Weltliteratur ging die Geschichte Al.s auch in mhd. Geschichtswerke über: ein Fortsetzer von Rudolfs v. Ems Weltchronik hat diesem Werke den Zug nach dem Paradies, die Meer- und Luftfahrt und die Sonnenbäume angefügt; die gleiche Fassung enthält der Basler Al. 4131 ff., Enikels Weltchronik 18945-19658 und die aus Rudolf entstandene prosaische Historienbibel. ${ }^{1}$ ) Endlich der sog. niederdeutsche Al. (Prosa) ist ein Ausschnitt aus dem sehr verbreiteten Seelentrost, einer Tugendlehre nach den zehn Geboten (vor 1358): bei dem zehnten Gebot wird die Al.geschichte kurz in schlicht volkstümlichem Tone erzählt als abschreckendes Beispiel gegen die Habsucht. ${ }^{2}$ ) So ist mit der Popularisierung der Literatur vom 14. Jh. an auch die Kenntnis der Geschichte Al.s weiter ins Volk gedrungen und schließlich wurde er zum Helden von Fastnachtspielen: in Lübeck wurde von den Patriziern im Jahr 1446 'Alexander und Anteloe', im Jahr 1467 'Alexander und die Könige von Morland', im Jahr 1473 'Alexander wollte das Paradies gewinnen' aufgeführt; ${ }^{3}$ ) und 1558 verfaßte Hans Sachs Ein tragedi vom großen Alexander. ${ }^{4}$ )

Und so gehört denn Al. zu den Autoritäten des MA.s, deren Persönlichkeit und Taten als typisch für Beispielsfälle angeführt werden.5) Das Wunderbare in seiner Geschichte dient zum Vergleich, die Luftfahrt: Ulrich v. Liechtensteins Frauendienst 387, 2 ff. (der edel wundercere), Reinmar v. Zweter Spruch 162 (Roethe S. 492) (wunderlîchiu wunder), im jüng. Titurel (PIPER, Höf. Epik 2, 520 f.); die Meerfahrt: Konrads v. Würzburg Trojanerkrieg 14072-81 (daz wilde wunder 14077, vgl. 14072) im jüng. Titurel (PIPER aaO.); Wunderfahrten im allgemeinen: Konrads Engelhard 838-842 (der künic Alexander fuor durch wunder in diu lant); der Wunderstein, bloB in seiner materiellen Kostbarkeit alle andern Edelsteine übertreffend: Rother 4952 ff. (HERTZ S. 101-103), und Al. als Steinkundiger: Wolframs Parz. 773, 23 (s. Martins Ausg. Bd. 2, 506); dagegen in seiner symbolischen Bedeutung: Frauenlob Spr. 167 (EtTMÜller S. 115 f., vgl. Hertz S. 119), Boners Fabeln Nr. 87 (HERTZ S. 123). Die Lehre von der Welt Eitelkeit, die ihr Ende findet in einem Grab von sieben Fuß Länge, wird oft einzeln herangezogen und auch als Beispiel in Predigten verwendet. ${ }^{6}$ ) Al. der Weltbezwinger wird von der Minne bezwungen: Ulrich v. Gutenburg, MSF. 73, 7

1) TH. MERzDorf, Die deutschen Historienbibeln des MA.s 2, 543-552; vgl. ZACHER, ZfdPh. 10,105-112; HERTZS. 117 f.; STRAUCH, Enikel aaO.

$\left.{ }^{2}\right)$ Abgedruckt bei P. J. BRUNS, Romant. u. andere Gedichte in altplattd. Sprache, 1798, S. 337-366; vgl. HeRTZ S. 115 f.; HeInR. FucHS, Giessener Gymnasialprogr. 1907; StRECKER, Anz. 33, 96; BURDACH, Ackermann S. 270. - Ein Al.gedicht in einer Gleinker (jetzt Linzer) Hs. s. JuNk, Beitr. 29, 456-4こ9.

3) C. WeHrManN, Nd. Jahrb. 6 (1880). 1-5; zu Al. und der Zwergkönig Antlloye s. HeRTZ S. 95 f. Dic Könige v. Morland bedeuten die
Episode von Al. und der Königin Candacis, KINZEL v. $5511 \mathrm{ff}$.

4) Hirsch S 133 (nacli Hartlieb).

5) ZINGERLE S. 1 ff., wo noch einige andere Stellen angegeben sind, auch S. 121. Ueber das Charakiterbild Al.s in Rudolfs Al.s siehe Ehrismann, Heidelberg. SB. 1919, 9. Ablıdl. S. 79 ff, 103. $109 \mathrm{f}$.

6) In der lat. Disciplina Clericalis des spanischen getauften Juden Petrus Alfonsi, einer Sammlıng lehrhafter Erzahlungen (um 1110), s. Hulka, Samml m.alterl. Texte I, $48 \mathrm{f}$; daraus in dic Gesta Roma:ırum übergegangen (Kap. 31). Ueber den Wunderstein s, unten. 
Anspielung auf die Candacis-Episode, vgl. Anm. Vogts in MSF.; Frauenlob Spr. 141 (EtrmÜller S. 102).1) Das Giftmädchen: Frauenlob Spr. 46 (EтTMÜLLER S. 54). Als Vorbild für Tapferkeit wird Al. zitiert im Rolandslied 141, 10 (BARTSCH 3974-76); StRICKERS Karl 4902-4 (= Rolandslied); Virginal 868, 10 ff. 936, 9 ff.; Heidin, GSA. 1, 419, 34 f. (Pfannmơlleer 1134 f.); für Freigebigkeit: von Hartmann im Erec 2821, von Walther v. d. Vogelweide 17, 9 f., in der Erzählung vom Junker und dem treuen Heinrich, GSA. 3, 221, 922 (KınZELS Ausgabe dieses Ged. S. 64, 922); für Fürstentugend: Frauenlob Spr. 329, 17 f. (ETTMÜLler S. 189); als Muster für junge Ritter: von Thomasin im Wälschen Gast 1050; hier auch für die Pflicht, daß man Gelehrte und weise Männer ehren soll 6413-17.6493-99, ähnlich 9209-16. Als Muster für letztere Lebre stellt ihn auch Hugo v. Trimberg in seinem Renner hin 16413 ff.; aber in der Strafpredigt, die er der Welt hält, ist Al.s Macht, Reichtum, Ehre, Kühnheit nur ein vergängliches Nichts 'gegen die Armut des Petrus oder gegen die wahre Liebe 1441. 19001. $19082 \mathrm{ff} .19647 \mathrm{ff}$. 21021 ; und lieber wollen die Leute von weltlichen Rittern und Recken erzählen hören, auch von Wundern Al.s, als von Gott 16198. Selbst Al.s angeblicher Vater, der zauberkundige Betrüger Nectanebus, hat es zu hohen Ehren gebracht: der Dichter der Minneburg (um 1350) preist Neptanaus als der hohsten meister ein..., der künste ein kern für alle die da lebendic wern, der ihm allein die allegorische Auslegung der Wunder in der Minneburg geben konnte. ${ }^{2}$ )

Malerei und Plastik, die im MA. so eng mit der Literatur verbunden waren, fanden auch in der Al.sage dankbare Gegenstände sowohl für geistliche Symbolik als für weltlichen Schmuck. ${ }^{3}$ )

An die Al.literatur schließen sich die dem Aristoteles zugeschriebenen Secreta Secretorum oder De regimine principum an. ${ }^{4}$ )

Der Stricker hat in der Einleitung zu seinem Ritterroman Daniel von Blumental 7-14 mit wörtlichen Anklängen an 13-18 V Meister Albrich von Bisenze als Verfasser seiner französischen Quelle vorgetäuscht, um seiner frei erfundenen Erzählung stärkere Glaubwürdigkeit und ein höheres Ansehen zu verleihen. ${ }^{5}$ )

Beziehungen zu andern Dichtungen. Der Dichter des Rolandslieds hat das Al.lied gekannt, und zwar im ganzen Umfang von V und S. Das geht aus mehreren anklingenden Stellen hervor, in denen ersichtlich der

3) HERTZ aaO. S. 156-277 u. dessen Spielmanns-Buch S. 293 f.; ROETHE, Reinmar S. 243 Anm. 301; Hugos RENNER 1456514599: K. JaNiCKE, Archiv 32, 172.

2) Minneburg Kap. II, vgl. Ehrismann, Beilt. 22, 304 .

3, A. L. Meissner, Arch. 68, 177-190; Panzer, N. Jahrb. 7 (1904), 140; Ders., Der roman. Bilderfries am südl. Choreingang des Freiburger Münsters u. seine Deutung, Freib.
Miinsterbl. 2. Jahrg. H. 1; V. D. Leyen, Abhandl. z. deutschen LG. FRANZ MUNCKER dargebr., SA. S. 1-20; ZINGERLE S. 5 f.

4) Siehe LG. II, 2. - Aristoteles war die vulgäre Form des Namens im MA. In der Kirchenliteratur wurde Aristoteles kurzweg Philosophus oder Magister genannt.

5) Holtzmann, Germ. 2, 29 f.; Rosenhagen, Unlersuchungen üb. Daniel v. Blühenden Tal vom Stricker, S. 47 ff.; WILHELM, Beitr. 33, 336. 
Pfaffe Konrad der Entlehnende ist. $\left.{ }^{1}\right)$ Somit steht das Al.lied an der Spitze der neuen, von Geistlichen gepflegten weltlichen Epik.

Der vorhöfische Straßburger Al. ist dann ein Verbindungsglied zu der höfischen Dichtung, Veldeke hat ihn wohl gekannt und stilistisch von ihm gelernt: viele Stellen in seiner Eneide sind ihm nachgebildet. ${ }^{2}$ ) Auch in Eilhards Tristrant finden sich Parallelen. ${ }^{3}$ )

Der ethische Gehalt. Das Al.lied in seiner ganzen Ausdehnung $(\mathrm{V}+\mathrm{S})$ ist ein biographischer Roman, der das Leben des Helden von der Geburt bis zum Tode umfaßt. Diese Lebensgeschichte zerfällt in drei Perioden: Al.s Jugend bis zum Tod seines Vaters Philippus (71 V--558 V); seine Eroberungszüge, Schlachten, bis zum Tode des Porus (559 V-4761 S); seine Reisen in die Wunderländer des Orients und sein Ende (4762 S-7278 S).

Schon die griechische Al.überlieferung besteht zugleich aus Geschichte und aus Volks- und Länderkunde, der Pseudokallisthenes ist ein historischer und zugleich geographischer Roman. ${ }^{4}$ ) Al. dem Großen ist somit ein doppelter Wirkungskreis zuerkannt, er ist nicht nur Eroberer, sondern auch Entdecker. ${ }^{5}$ ) Innerhalb dieser beiden Gebiete, Krieg und Wunderwelt, spielen sich ebenso im m.alterlichen Al.epos die orientalischen Begebenheiten ab.

In der altdeutschen Literatur hat $\mathrm{Al}$. und seine Geschichte eine große kulturelle Bedeutung erlangt: der Stoff trug schon in sich in hohem Maße die beiden Eigenschaften der Dichtkunst, zu unterhalten und zu belehren, denn er bestand aus einer Mischung von Fabelei und Wirklichkeit. Die heldenhaften Taten, die Wunder der fremdartigen morgenländischen Welt, die seltsamen Abenteuerlichkeiten ergötzten die Phantasie: wounderlîch (admirabilis) wunderbar, Wunderbares schaffend wird Al. oft genannt, schon im Annolied 326. Geschichte und Länderkunde, dazu vor allem Moral konnte man lernen, denn die großen historischen Ereignisse und die Schilderungen fremder Länder und Menschen bereicherten die Kenntnisse in jenen Wissenschaften und der mit allen Fürstentugenden ausgestattete König gab ein treffliches Musterbild ab für hohe Herren.

') Vgl. dazu und über die Priorität des Al.liedes: SCHERER, QF. 7, 62 f. 12, 79. 81; Rödiger, Anz. 1, 87. 13, 115; KINZEl, Einl. S. LVIl tf.; SCHRÖDER, ZfdA. 27, $70 \mathrm{ff}$., DLZ. 1885, 784-787, Kchr. S 57; WilmanNs, ZfdA. 50, 137-145; V. BAHDER, Germ. 20, 393 f. (Al. u. Kaiserchron, Al. u. Rother), KINZEL, Anm. zu 1403 (S. 448); Linzer, Apollonius v. Tyrus S. 223 (Al. u. Apollonius v. Tyrus); OTtMANN, Einl. S. XVIl ff.

2) BEHAGHel, Eneide, S CLXXX-CLXXXV; SChERER, QF. 7, 60; RÖDIGER, Anz 1,78; HARCZYK S. 29 f.; KINZEL, ZfdPł1. 14, 1-18.

$\left.{ }^{8}\right)$ LiCHTENSTEIN, Eilhart v. Oberge S CLIVf.; Ders., ZfdA. 26, 13-16; WiLMANNS, ZfdGymn. wesen 36, 708, ZfdA. 27, 294-298; KINZEL, ZfdPh. 14,111; SCHRÖDER, DLZ. 1882, 568 -
571. 1883, 155); Gierach. Sprache Eilharts S. 253. Beziehungen zwisclien Al.roman und Lanzelet: WILMANNS, ZfdA. 45, 245-248; Al. u. Nibel.lied: Droege, ZfdA. 51, $199 \mathrm{f}$.

4) ROHDE aaO ; SCHWARTZ aaO.

5) Schwartz S. 76 ff. 90 f.; Waltek Otto, Marburger akadem. Reden Nr. 34, Marburg 1916, S. $11 \mathrm{ff}$; Der Charakter Al.s in Pseudokall.: AUSFELD, Griech. Al roman S. 235-237; Kampers an verschiedenen Orten. - Die beiden Gebiete waren von jeher in der roman. hafien Geschichtschreibung der Griechen vereinigh, schon die homerischen Epen scheiden sich nach den beiden Stoffkreisen: die llias mit ihrenKämpfen alsl leldenepos, die Odyssee mit ilıren wunderbaren Lăndern und deren Bewolinern als Reiseroman. 
In erster Linie ist das deutsche Al.lied ein Heldenepos und die kriegerischen Darstellungen überwiegen trotz der vielseitigen Stoffelemente die andern Interessen. Die Kämpfe sind im m.alterlichen Sinne aufgefaßt und dem Stil der französischen Chansons de geste angepaßt.1) Der Charakter des im griechischen Roman und in den darauffolgenden lat. Quellen gezeichneten Hel fen ist im deutschen Liede nicht in den Grundlinien geändert. $\left.{ }^{2}\right)$ Macht und Größe ist hier wie dort der Zentralbegriff seiner Persönlichkeit. Ein Wunder ist der Siegeszug dieses jugendlichen Eroberers, der im dreiunddreißigsten Jahre seines Lebens, im dreizehnten seiner Regierung (7238-7270) verschied, nachdem er die Welt umgestaltet hatte. In der stehenden Bezeichnung der wunderlîche Alexander ist das Staunen ausgedrückt, das seine glänzende Erscheinung hervorrief: ein titanischer Held, der Wunder vollbracht hat, unerhörte Taten als Gründer eines Weltreiches, der Wunder geschaut hat, die jedem anderen verschlossen waren. Seine vor allen hervorgehobenen Eigenschaften sind Tapferkeit, die durch Ritterlichkeit und Edelmut den Helden verehrenswert macht (1091 ff. $2547 \mathrm{ff} .2772 \mathrm{ff}$. 2817. 2824 ff. 2896 ff. 2915 ff. 2978 ff.); Klugheit (1105 ff. 2063 ff.), die als Schlauheit (2944 ff. 4386 ff.) die zum Ziel führenden praktischen Mittel auffindet, aber auch in hohem sittlichen Sinne als Weisheit, die die Bedeutung des menschlichen Lebens und seiner Aufgaben erkennt (bes. 4873 ff.). Aber diesen Merkmalen des Übermenschen sind rein menschliche Empfindungen beigegeben, die dem überragenden Geist ein schönés Gemütsleben verleihen: Mitleid mit dem Unglücklichen (3575 ff. 3769 ff.), Kindesliebe (401 ff. 529 ff. 2079 ff. 4899 ff.), Verehrung für den alten Lehrer (4899 ff.).

Doch fehlen diesem harten Kriegerleben nicht die zarten Freuden der Liebe. Candace, eine zweite Circe, fesselt den Weltbeherrscher in die Bande der Minne: Ebenso ist das liebliche Natur- und Seelenbild von den Blumenmädchen antiken Ursprungs: wie die Blumen in der sengenden Sonnenglut welken müssen, so vergeht Frauenschönheit und Liebesglück. Doch macht sich in dér Auffassung der Frau auch die spezifisch m.alterliche Empfindungsweise geltend: beim Fortsetzer zeigen sich Spuren der gesellschaftlichen Stellung, die die Frau später im höfischen Minnewesen einnahm, vgl. 2753-71. 2788 f. $6235-6260$ (tougen minne); $\left.{ }^{3}\right) 2918$ f. (wîben dienen); 3362-69 (amîs-trît).

Ist nun das Charakterbild des Helden auch im MA. in seinen Grundzügen bewahrt geblieben, so ist doch der antike Stoff in der Anschauungsweise des MA.s aufgefaßt, wie das immer bei der Übertragung fremder

1) Durch Beiziehung der Schlacht auf dem Wolfenwerde (Wulpinwerde S) aus der Hildesage (1321-1328) wird dem schwersten Kampf, den Al. zu t estehen hatte, ein nationaler Zug beigemischt, der das Interesse der Hörer noch besonders verstärken mußte, vgl. ERDMANN, ZfdPh. 17,223-226; WOLFGANG MEYER, Beitr. 16,523ff.; SCHRÖDER, ZfdA. 43, 303 f.; PANZER,
Hilde-Gudrun S. 184 ff. 426 Anm.; DROEGE, ZfdA. 54, 159 ff.; MarTin, Kudrun Einl. XLIIXLIV; SYmons, Kudrun, 2. Aufl. S. XLIff., wo weitere Lit.; BAESECKE, ZfdPh. 48, $135 \mathrm{f}$.

2) Gervinus S. 323 ff.; Alw. Schmidt S. 31 -82; HAMPE S. 100-102, dazu AUSFELD, Lit.-Bl. 1892 S. 6.

3) Vgl. Zingerle, Germ. 17, 306-309. 
Werke im Mhd. der Fall ist. So wurden Anlagen, die in der antiken A.sage vorhanden waren, benutzt, um ein m.alterliches Fürstenideal aufzustellen. Das Al.lied ist ein Fürstenspiegel. Schon im Prolog spricht Lampr. seinem Al. die beiden Grundeigenschaften eines Königs zu: er war weise und ein Held (er gewann viele Reiche $7 \mathrm{f}$. in V, entsprechend der Charakterisierung, die Alberich von ihm gegeben hatte; vgl. feruer 35-60, spez. 54. 57. 165. 167, auch 223. 563. Von zwei moralisierenden Partien ist das ganze Gedicht umrahmt: am Eingang steht die Erziehung $\mathrm{Al} . \mathrm{s}^{\mathbf{1}}$ ) als eines vornehmen Jünglings, die ihn für seine hohe gesellschaftliche Stellung vorbereitet. Er wird in den sieben Künsten unterrichtet, im Trivium 171-176 und im Quadrivium 177-196, dann in der Waffenkunst 197-214 und in der Rechtskunde 215-220 (die Quelle Jul. Valerius hat nur eine trockene Namenaufzählung). In eine Regentenlehre im Anschluß an die Deutung des Wundersteins läuft das Gedicht aus 7153-7246: 1. Zwei Warnungen werden gegeben, vor der Hoffart 7159-62 (vgl. 3839 ff. 6176-86. 6613 ff. 6913 ff.), vor der Habgier (d.i. der unersättliche Ehrgeiz) 7163-78 (vgl.6667-84); und eine Mahnung: der Vergänglichkeit des Irdischen (vanitas) zu gedenken 7179-7201. 2. Pflichten der Untertanen 7207-7234 und die Pflichten des guten Fürsten 7235-46. - 3. Die Ausübung dieser Pflichten durch den guten Fürsten 7247-69, Al. befolgt die Lehren des jüdischen Weisen: er erfüllt seine Pflicht gegen die Untertanen (nicht tyrannisieren) 7258 f., ist bereit $z u$ allem Guten 7260-62, er hielt die mâze ein 7263, gab Krieg und Habgier auf 7264 f., er war hochgemut mit Sitten (mit zuhten gemüt) 7266. Das Thema des Epilogs 7279-7302 wiederholt die Warnung vor der Habsucht und schließt mit einer Aufforderung zur Buße.

So hat der Weltbezwinger eine Läıterung in christlichem Sinne durchgemacht. Ehrgeiz und Ruhmsucht haben ihn bis zu den Pforten des Paradieses getrieben, und der Fortsetzer Lampr.s nennt den gefeierten Heldenkönig einen tobenden Wüterich, der in seiner Gier der Hölle gleiche, dem unersättlichen Loche 6667-84. Aber er hat die Lehre des alten Weisen in sich aufgenommen und pflog fortan gûter mâzen 7263 (vgl. 3436 ff. 4871 f.). Hier wird zum erstenmal in der ritterlichen Morallehre die mâze als Grundwert des sittlichen Verhaltens aufgestellt, die Kardinaltugend der

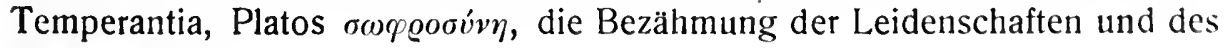
Eigenwillens.

Am Anfang und am Schluß ist die Geschichte des antiken Helden unter den Eindruck der herrschenden m.alterlichen Weltstimmung gestellt, das ist der mönchische Geist der Weltverneinung. ${ }^{2}$ ) Mit vanitas vanitatum vanitas

1) Hertz, Aristoteles als Lehrer Al.s, Ges. Abh. S. 1-33; ALw. SCHMIDT S. 6 f.

2) Die vereinzelten geisllich gelelırten liemerkungen in $\mathrm{V}$ sind Erklärungen im Predigerstii, eine religiöse Stimmung erwecken sie nicht (in V: 473 ff. 601 f. 693 f. 696 1015 ff. $1262-64.1396$ ff. 1461 f. $1470-72$ : in S: $2305-7$ und gewichtiger $4024-57$. 2987-97. Vgl. HAKCZYK S. 21 f ; KINZF:L ZfdPh. 10, 53; Reblin S. 35 f.: Hampe S. $58 \mathrm{f}$ 
beginnt Alberich sein Heldenlied, 19-24 V, und der deutsche Dichter schließt mit der Erkenntnis, daß auch der Weltbeherrscher ein sterblicher Mensch ist, der am Ende nichts sein eigen nennt als sieben FuB Erde im Grab 7274-7278.1)

Diese Ethik der Entsagung, die Warnung vor dem Übermaß und die Mahnung an die Vergänglichkeit, gehört nicht zur ursprünglich heroischklassischen Auffassung des historischen Al., sie wurde erst durch orientalischen, semitischen und indischen, Einfluß hineingetragen.

Die Quelle für den Zug nach dem Paradies und für den Wunderstein²) ist das Iter ad Paradisum, die Sage ist hebräischen, talmudisch-rabbinischen Ursprungs. Es ist auch die Weisheit, welche dem Welteroberer die Brahmanen entgegen halten, die indischen Büsser in dem Lande Occidratis 4762-4889.3) In jenen heiligen Männern Indiens ist das Ideal des kynischen Weisen gezeichnet, die kynische Askese in ihrer Verachtung aller menschlichen Bedürfnisse. $\left.{ }^{4}\right)$ Der kyniische Philosoph des Altertums aber ist nach dem Untergang des Heidentums in dem christlichen Mönche wiedererstanden, auch dieser findet seine Lebensaufgabe und seine Seelenharmonie in der Loslösung von der Welt, im Verzicht auf die irdischen Güter. ${ }^{5}$ ) Der philosophisch gerichtete griechische Geist erblickt also in der weltgeschichtlichen Erscheinung Al.s den mächtigen, zugleich nach Weisheit strebenden König; in dem bettelarmen indischen Büßer den diese Weisheit besitzenden Kyniker. Sind dies nicht auch die Grundlagen des theologischen Geschichtsbildes im christlichen MA.? Hier als Herrscher des Weltstaates der gute Fürst, der aber doch immer in den Banden des Vergänglichen befangen ist, dort der erdenflüchtige Mönch, der heilige Bürger des Gottesstaates? Auch hier also eine christliche Idee, vorbereitet im Altertum, stark geworden in der Spätkultur des Hellenismus. Und hier auch die beiden Pole der menschlichen Willensbeschaffenheit: das in rastlosem Handeln ringende Streben und das im Quietismus sich beseeligt fühlende Beharren.

In der äußeren Einkleidung trägt auch noch das deutsche Al.lied das ursprüngliche Gewand, das dem Roman in der hellenistischen Zeit verliehen wurde, durch die vielen eingeschalteten Briefe, besonders in dem langen

3) Das Grab als letzter Besitz des Menschen: 6437-52. 7191-96. 7233 f. $7274-78$; vgl LiEBRECHT, Das Grab und seine Länge, Germ. 4, 374 f.; R. KÖHLER, ebda 5, 64-66 u. Kl. Schr. 2, 24-27; ZiNGERLE S. 4; BURDACH, Ackermann S. 270.

2) KINZEl, Ausg. S. XLVIII--LI; STrauch S. 361 Anm. 5; HERTZ, Aristoteles und der Wunderstein, Ges. Abh. S. 73-130.

s) Oxidraces. Ueber sie berichtet schon Onesikritos, ein Begleiter des Königs, in seinem nur in wenigen Bruchstücken erhaltenen philosoph.-hist.Al.roman. - Die gleiche weltverachtende Lebensauffassung wie hier ist, viel ausführlicher, in dem Briefwechsel zwischen Al. u. d. Brahmanenkönig Dindymus und in den diesen verwandten Schriften niedergelegt, im Pseudokall. vgl. AUSFELD, griech. Al.roman S. $88 \mathrm{f}$, auch S. 9 und 89 Anm., WEISMANN 2, 154-188; Jul. Val. III, 10 ff. (KÜBLer S. 119 ff.), III, 44 (S. 151 f.); Hist. de prel. BM III, 4-6 (LANDGRaF S 106 -108), erweitert $\$ 90-102$ (ZINGERLE S. 214 -236); Pfister aaO.; HeINR. Becker, Die Brahmanen in der Al.Sage. Progr. Königsb. 1889

4) SCHWARTZ S. 82-85, s. auch S. 42-45; REITZENSTEIN S. 43.

5) AD. HARNACK, Das Mönchtum, 7. Aufl. 1907 , bes. S. $19 \mathrm{ff}$. 
Schreiben Al.s an seine Mutter und seinen Lehrer, das in Ich- (Wir-) Erzählung abgefaßt ist. ${ }^{1}$ )

Die Metrik s. oben unter den einzelnen Hss. V, S, B. ${ }^{2}$ )

$\$ 78$. Das Rolandslied des Pfaffen Konrad.

PIPER, Spielm. D. 2, 14-91, Höf. Ep. 3, 712 f., Nachtr. S. 244. - Ausg.: SCHILTER, Thesaurus II; W.GRIMM, Ruolàndes Liet, Gött.1838 (Heidelbg. Hs. P mit den Varianten der Straßburg. Hs. A und der Bruchst. S u. W); BaRTsCH, Brockhaus-Ausg., Leipz. 1874 (nach Hs. A), dazu Germ. 19,385-418. - Übersetzungen: OtTMANN, Reclams Univers.-Bibl. Nr.2745-2748(1892); Christian Stecher, Deutsche Dichtung f. christl. Familie u. Schule 1, Graz 1880. - W. Grimm, Der Epilog zum R.lied, ZfdA. 3, 281-288 u. K1. Schr. 3, 200-207; HAUPT, ZfdA. 15, 256-258; Gaston Paris, Hist. poétique de Charlemagne, Paris 1865, S. 120-122; Scherer, ZfdA. 18, 298 ff., QF. 12, 81-83; SteinmeYER, ADB. 16, 638; Wilh. WaLD, Über Konrad den Dichter des deutsch. R.liedes, Halle 1879, dazu Steinmeyer, Anz. 5, 430 f.; Golther, Das R.lied des Pf. Konr., München 1887, dazu SchröDer, Anz. 13, 114 f.; J. J. AMMANN, Das Verhältn. von Strickers Karl zum R.lied, Progr. Krumau 1886-97 u. als Buch 1905; Bruno Baumgarten, Stilist. Untersuchungen zum deutsch. R.licde, Halle 1899, dazu ZwIERZINA, DLZ. 1901, 1627 -1629, LC. 1899, 1233 f.; Holthausen, Germ. 31, 120; Leitzmann, Beitr. 43, 26-47.

Hss.: $\left.{ }^{3}\right)$ A. Straßburger Hs., in der ehemaligen Johanniterbibliothek, 1870 beim Brande der Bibliotliek untergegangen, Perg., Ende des 12. Jhs., mit Bildern, ${ }^{4}$ ) enthielt in 7 Bruchstücken etwa die Hälfte des Gedichtes, 4621 Zeilen. Der Dialekt ${ }^{5}$ ) ist mittelfrk. mit bair. Einzelheiten.

P. Heidelberger Hs., Cod. pal. germ. 112, Perg., Ende des 12. Jhs., von zwei Schreibern geschrieben, mit 39 Bildern. Der Dialekt ${ }^{6}$ ) ist bei beiden Schreibern bair. mit mittelfrk. bezw. niederfrk. Einzelheiten (in $\mathrm{Pa}$ ist das Bairische stärker ausgeprägt).

S. Schweriner Bruchstücke, Regierungsbibl. zu Schwerin, Perg., 12. Jh., 8 Bl., abgedruckt von Lisch, Jahrb. des mecklenburg. Vereins für Gesch. u. Altertumsk. 1 (1836), 157-172. Ein Doppelblatt derselben Hs., abgedruckt von Grotefend, Quartalbericht d. Vereins f. mecklenburg. Gesch. LVIl, 3 (1892) S. 4-10.7) Desgl. ein Doppelblatt, gefunden von Wilhelm Teske, abgedruckt von SCHRÖDER, ZfdA. 50, 382-385. Dialekt obd. mit md. Spuren.

W. Stuttgarter (Kauslersches) Bruchstuck, Pergamentbl. Dialekt ähnlich P.

E. Erfurter Bruchstück, Pergamentbl. der Amplonianischen Bibliothek zu Erfurt, um 1200 geschrieben, abgedruckt von C. LIERSCH, ZfdPh. 10, 485-488. Dialekt mittelfrk.

Arn. Arnstädter (Einertsches) Bruchstück, durchschnittenes Pergamentb!., gefunden im ehemal. Archiv zu Arnstadt von E. Einert, abgedruckt von P. WALTHER mit Erläuterungen von BEHAGHEL, Germ. 35, 385-388 (für die Textkritik kaum von Bedeutung).

Die handschriftliche Uberlieferung ist so gut wie wir sie selten für ein ad. Gedicht besitzen, da P, das in dem ursprïnglichen Dialekt des Gedichtes, dem bainischen, geschrieben ist, durch seine Sorgfalt eine vorzügliche Grundlage bildet, der $\mathrm{A}$ und $\mathrm{S}$ an Wert wenlg nachsteher. ${ }^{8}$ )

1) ROHDE S. 200 ff.; SCHWARTZ S. 97 ff.; AUSFELD, Griech. Al.roman S. $231 \mathrm{f}$.

2) W. GRIMM, ZGdR., KI.Schr 4. Reg. S.333; KINZEL, Ausg. S. LXVIII-LXXX; HOLTZMANN, Germ. 2, $36 \mathrm{ff}$.: Schade, Decas S. 48 57; Amelung, ZfdPh. 3, 269 ff.; RöDiger, Anz. 1, 78 ff. 11, 280 f.; KinZEL, Beitr. für Zacher S. 27 ff.; KuHNT aaO.

3) HOFFMANN, Fundgr. 1, $211 \mathrm{f} ;$ W. GRIMM S. I-XXX; MSD. II', Einl. S. XXV-XXIX; BARTSCH S.XX-XXII u. Germ. 19, 385-418; BARTSCH, Katal. Nr. 69.

4) Zu den Bildern s. W. GRIMm S. XXIVXXIX; ZfdA. 3, 283 u. KI. Schr. 3, 202.

s) Zum Dialekt der Hss.: W. GRIMM S. IXXIV; MSD. I XXV.XXIX. XXXI; SCHRÖDER,
Kchr., Einl. S. 52- 56; Johannes JaCOBI, Ueb. die Bezeichnung der verschobenen Verschlußund Reibelaute in den Hss. des R.liedes, Bonner Diss. 1904.

6) Heinr. Schứer, Die Sprache der Hs. P des R.liedes, Progr. Komolau 1887., daz.. BARTSCH, Germ. 33, 234 f.

7) Vgl. O GlÖDE, Germ. 37, 367.

8) BARTSCH, Germ. 19, 385-390; BARTSCH, Ucber Karlmeinet S 87-208, bes. S. $201-$ 208; SCHrÖDER, ZfdA. 50, 383, Kchr. S. 52 ff.; BARTSCH, der den Dichter noch für einen Rheinfranken hielt, hat selne Ausgabe, den Spraclıformen voll $A$ folgend, im ind. Dialckt hergestellt, während W. Grimms Abdruck von P den ursprünglichen bair. Charakter bewahrt liat. 
Der Dichter ist der Pfaffe Konrad von Regensburg, der auch die Kaiserchronik verfaßt hat, Zeit der Entstehung: bald nach 1131 .

Inhalt. - Das Rolandslied ist eine poetische Verherrlichung Karls des Großen und seiner Ritter im Feldzug gegen die spanischen Mauren. Im Mittelpunkt steht die gewaitige Gestalt des Kaisers, der Dichter selbst kündigt ihn im Prolog, nach der Anrufung Gottes, als Helden seines Werkes an und verkörpert in ihm den geistlichen Grundgedanken, der alle Handlung bewegt: er hat das Gottesreich errungen, weil er die Heiden uberwand und das Christentum zum Ruhm brachte. In kurzen Sätzen wird im Prolog $(1-30)$ der Ertrag seines Lebens zusammengefaßt: . Ehre und Vorteil hat er erworben, denn er hat die grimmigen Heiden zum wahren Lichte bekehrt, daß sie ihren Schöpfer erkannten, und ist von der Jugend bis zum Alter in steter Vervollkommnung fortgeschritten, bis ihn Gott in sein Reich, in die ewigen Wohnungen aufnahın. Eine Stufe in diesem ununterbrochenen Streben zu Gott ist die Bekehrung der Heiden in Spanien.

In Karl ist das Idealbild des christlichen Herrschers dargestellt:') er ist kräftig und zugleich milde, ein gerechter Richter, fromm, demütig, gehorsam (697-708. 1154 ff. 1354 ff. 1404 ff. 1487 ff. 1534 ff. 3133 ff. 3216 ff.). $E r$ steht im besonderen Schutz des Herrn, Engel wachen über ihm (7080), erscheinen ihm (52 ff. 7000 ff. 7443. 7477), in Träumen läßt ihn Gott die Zukunft voraus ahnen (3030-3082. 7084-7127). An seinem Hofe herrscht ein glänzendes Leben. Im Lager gibt es große Lustbarkeiten, da sind Tierkämpfe, Fechtübungen und Waffendienst, Singen, Sagen und Saitenklang, Falkenbeize und schöngeschmückte Frauen, viel Weltwonne und die größte Herrscherpracht seit Salomo. Der Kaiser aber sitzt still beim Schachspiel. Sein Antlitz war wonnesam, seine Augen leuchteten wie der. Morgenstern; man kannte ihn von ferne, die fremden Gesandten brauchten niemand zu fragen, wer der Kaiser sei, denn keiner war ilım gleich, ein strahlender Glanz ging von ihm aus, die Augen der Anschauenden blendend wie die Sonne am hohen Mittag (641-696). - Als engere Vertraute hat er um sich die zwölf Pairs, die weisesten im Rate und Führer des Heeres. Sie sind geschmückt mit den Tugenden christlichen Rittertums: sie sind treffliche Helden, keusch und rein, freudig geben sie den Leib hin um die Seele, ihr höchstes Sehnen ist, für Gott zu sterben und als Märtyrer das Himmelreich zu erwerben (65 ff.). Die angesehensten unter ihnen sind Karls Neffe Roland, dessen Blutsfreund Olivier, der Erzbischof Turpin, Typen dreifachen Heldentums, der Kampfleidenschaft, der besonnenen Tapferkeit, des geistlichen Kriegertums. Einer der Paladine aber wird zum Verräter, Genelun.

Der Grundplan des Gedichtes trägt ein architektonisches Gepräge, er

1) Oboedientia, humilitas, justitia sind die wichligsten Fürstentugenden nach der von Auguslin begründeten Lehre von der weltl. Obrigkeit. Karls Krieg ist ein bellum justum, vgl. BERNHEIM, M.alterl. Zeitanschauungen, und die Greifsw. Diss. von Krôger 1910, Hammler 1912, Frederich 1914, HerzFeld 1914, Fiebach 1914, Tiralla 1916. 
üst symmetrisch angelegt: auf der einen Seite stehen die Gesinnungen und Taten der Christen, auf der andern die der Heiden; hier Wahrhaftigkeit und Heldensinn, dort List und Trug, hier rechte Demut und Glaube, dort Hochmut und Götzendienst, hier der himmlische Lohn, dort die Verdammnis. Die Heiden sind verworfene Söhne des Teufels, aber doch nicht unrettbar verloren, auch werden sie nicht mit wildem Fanatismus verfolgt. $\mathrm{Ha}$ B besteht nur so lange gegen sie, als sie Feinde des Christentums sind, und lieber schreitet man zur Taufe als zur Vertilgung.

I. Prolog 1-30:') Anrufung Gottes; Karls Lebensaufgabe; Bekehrung der Heidcn.

11. Hauptteil 31-9016 besteht aus Beratungen (A) und Kämpfen (B).

A. Die politischen Verhandlungen 31-3240: a) Beratungen Karls und seiner Paladine 31-272. b) Die ersten Kämpfe mit den Heiden 273-384. c) Beratung der Heiden 385-624 unter ihrem König Marsilie und ge'eitet von dem alten Blanscandiz. d) Beratung der Christen 625-1749. e) Genelun als Gesandter bei den Heiden, sein Verrat 1750-2760.

In Genelun ist ein seelisches Problem entworfen, alle andern Personen sind feste Typen, er allein macht eine Entwicklung durch. Er ist ein schillernder, ein zwiespältiger Charakter. Er ist nicht absolut schlecht. Er ist ein glänzender Ritter von großer Schönheit, er besitzt weiche Gemütseigenschaften, er liebt seine Frau, seinen kleinen Solnn, seine Mannen hängen mit rührender Treue an ihm; er ist tapfer (2018 ff. $2071 \mathrm{ff}$.); aber als ihm die unheilvolle Botschaft aufgetragen wird, verliert er in der Sorge um Weib und Kind allen Mut, Furcht befällt ihn, er erbleicht (1382), er läßt den dargereichten Handschulı zitternd zur Erde fallen (1430 ff.), er wirft in der Erregung den Mantel zu Boden (1453), er weint heftig (1458). Er ist charakterlos von Natur, in ihm ist der Ungetreue gezeichnet, der die oberste Pflicht und Tugend des Vasallen verletzt, die Mannentreue. Damit ist er der moralische Widerpart des Getreuen, Rolands. Der erste Beweggrund zu seinem Abfall sst der $\mathrm{HaB}$ gegen Roland, des weiteren wird er dazu verführt durch die Bestechung der Heiden, die seine Habsucht rege macht; an diesen beiden Lastern packt ihn der Teufel (1979, vgl. 2365). Er ist ein Judas geworden (1925 ff., vgl. 2375 ff. 6103) und bald ist der letzte sittliche Halt, die Verehrung, die selbst er auch in seiner inneren Zerrüttung noch dem Kaiser zollte, geschwunden. Jetzt ist sein Gewissen so abgestumpit, daß er es ruhig hinnimmt, wenn der Kaiser vor Leid über den Verlust seiner verratenen Helden sterben wird (2471-2476).

B. Die Kämpfe 3241-8672. Held dieses Vernichtungskampfes ist das fränkische Heer, allen voran Roland, ihm zur Seite Olivier und Turpin. Antithetische Parallelgruppierung and Wiederholung sind auch hier die technischen Mittel, durch welche der an sich gleichförmige Stoff zu großem Umfang gedehnt wird.

a) Dîe Vorbereitungen 3241-4016. Beschreibung der Ausrïstung; der sittliche Gegensatz zwischen Christen und Heiden: Demut mit Gottesdienst und Beichte - Hoffart mit Tanz und Saitenspiel und Götzendienst 3361-3367. 3393-3530. Das gleiche Kontrastmittel wird abertsagen auf die beiderseitigen Heerführer: die Heiden 3531-3844, die Clrristen 3845-4016. Die Gefahr naht, Olivier, fordert Roland auf, Karl durch den Hornschall zu Gilfe zu rufen, aber er weigert sich zu blasen, denn den Heiden ist vor Gott ihr Urtell gesprochen, aber die Gottes Märtyrer werden mit Blut entsiilnt.".) Diese himmlische Zuversicht fuhrt das Christenheer ins irdische Verderben.

b) Die Schlacht bei Runzeval 4017-6949, nahezu 3000 Verse umfassend, zerfält, da das heidnisclie Heer dreimal vernichtet wird (5190. 5423. 5630) in 4 Abschnitte: 1. 4017-5190 (Zweikämpfe, Herausforderung, gelpf; ${ }^{3}$ ) der eigenti. Kampf ist inmmer kutz, der

1) Die Zeilenziffern nach der Ausg. von BARTSCH, in der die Seitenzalılen der Ausg. won W. GRIMM am Rande notiert sind.

Deutsclie LIteraturgeschichte. II.
2) Vgl. G. PARIS aaO. S. 122.

3) LG. I, Reg. S. 459 unter Gelf. 
Heide wird erschlagen, dann folgt oft noch ein allgemeiner Kampf); 2. 5191 - 5423, 3. 54245630, 4. 5631-5968: allgemeines Kampfgetümmel, dazwischen Ansprachen der Feldherren. Die Schar der Christen schwindet zusammen, von überirdischer Kraft beseelt halten die drei Heergesellen Roland, Olivier, Turpin die Wehr um die ringsum sinkenden Getreuen bis zum sieghaften Ende, dem Märtyrertod. Das ganze interesse drängt nun auf den Abschluß zu, den Heldentod der drei Gewaltigen 5969-6949, hier steigert sich die Darstellung zu großer dichterischer Kraft und erreicht ihren Höhepunkt im Ende Rolands. In der höchsten Gefahr setzt er das Horn Olivant an den Mund, weit gellt es in die Lande und der Kaiser hört den Notschrei seiner letzten Getreuen, aber es ist zu spät. Olivier erhält den todbringenden Schlag, bitterlich weint Roland um den liebsten Gesellen, zur Erde. sich werfend spricht jener sein letztes Gebet, für den Kaiser, für Roland, für die süßen Karlinge. Auch der Bischof bricht tot zusammen, Roland ist allein noch übrig, an einem Felsen will er sein Schwert zerschmettern, es bleibt fest. Dann spricht er sein Gebet, neigt sein Haupt und stirbt. Da geschahen Zeichen wie beim Tod Christi, es war als ob die Welt untergehen und Gott zum Gericht kommen sollte.

c. Die Paliganschlacht 6950-8672. Der Kaiser eilt zurück, er findet keinen Lebenden mehr, überwältigt von Schmerz bricht er in die Totenklage aus 6950-7127. Neuer Krieg: der Perserkönig Paligan kommt Marsilie zu Hilfe 7128-7442, die Racheschlacht beschließt den spanischen Feldzug 7623-8672. Karl erschlägt den Paligan (8439-8570), Marsilie fällt vor Leid tot nieder (8595 f.); seine Frau, die Königin Brechmunda, läßt sich taufen (8617-8630).

C. Das Nachspiel, Geneluns Bestrafung 8673-9016. Die Geschichte Rolands ist abgeschlossen, jetzt findet die Geneluns ihre Entscheidung. Hoftag zu Aachen. Alda, Oliviers Schwester, Rolands Verlobte, fällt auf die Nachricht von dessen Tod leblos zu Boden (8685-8728). Uber Genelun wird das Gottesgericht gehalten (8729): im Zweikampf besiegt der junge Tirrich, Rolands nächster Verwandter, den starken Binabel aus Geneluns Sippe, wie David den Goliath. Genelun wird von wilden Rossen zerrissen. Ende des Liedes (9016).

III. Epilog 9017-9094. Im Eingang und Ausgang des frommen Liedes richten sich die Gedanken nach der Ewigkeit. Das Schlußwort ist dem Seelenheil des Veranlassers und des Dichters gewidmet. Danach zerfällt es in zwei Teile: a) die Fürbitte für den Veranlasser 9017-9076, zugleich eine Verherrlichung desselben als Urheber des Gedichtes (9017-9038) und als tugendhafter Herrscher (9039-9076); b) die Fürbitte für den Dichter 9077-9394. Dabei ergeben sich folgende literarisch-historische Tatsachen über die beiden Persönlichkeiten und über das Werk: Herzog Heinrich hat die Vorlage (daz buoh), die in Frankreich (ze den Karlingen) geschrieben ist, herbeigeschafft, die edle Herzogin, eines mächtigen Königs Kind, hat es gewünscht (9020-9025); sie haben veranlaßt, daß es in deutscher Sprache herausgegeben wurde (9031-9033). Der Dichter heiBt der pliaffe Kuonrât, er hat den französischen Text zuerst ins Lat. übertragen und dann ins Deutsche, er hat nichts dazu getan und nichts übergangen (9077-9085). Der Herzog Heinrich ist Heinrich der Stolze von Baiern (1126-1139), seine Gemahlin, di edele herzoginne, eines rîchen kuninges barn, Gertrud, die Tochter Kaisers Lothar.

Als frühster Termin für die Abfassungs zeit'1) (terminus a quo) ergibt sich somit das Jahr 1127, in welchem die Vermählung der beiden stattfand; als End-

1) W.GRIMM S.XXXI-XXXIV; MASSMANN, Eraclius S. 559-561 (dazu W. GRIMM, ZfdA. 3, 281-288) u. GIESEBRECHr, Gesch. 4, 499, hielten Heinrich den Löwen für den in dem Gedichte erwähnten Herzog, also ca. 11701180 für die Zeit der Entstehung, aber die Sprache und die Verskunst setzen ein höheres Alter voraus. Mit Recht erhob GoEDEKE, D. Dicht. im MA. 1854 S. 683 (2. Ausg. 1871)
Widerspruch gegen diese frühe Datierung (s. auch GoEDEKES Grdr. Bd. 1, 1. Aufl. 1862, S. 22, 2. Aufl. 1884. S. 65); eingehendere u. für Heinrich den Stolzen beweisende Untersuchungen brachten dann SCHADE, Decas S. 63 - 66: MÜLLENHOFF in MSD. ${ }^{2}$, S. XXXV, 3. Aufl. IS. XXXIX; BARTSCH; Ausg. S. Xl f.; SCHERER. D. Stud. 1, 13 f., ZfdA. 18, 303-305; WALD S. 1 ff.; SCHRÖDER, ZfdA. 27, 70 - 82 u. Kchr. 
punkt das Jahr 1133, da Lothar noch König tituliert wird, am 4. Juni 1133 aber wurde er zum Kaiser gekrönt. Im Jahr 1131 machte Heinrich eine Reise nach Frankreich und es ist möglich, daß er bei dieser Gelegenheit das franz. Rolandslied kennen gelernt hat. Somit wäre bald nach 1131 das Gedicht abgefaßt. Der Dichter stand offenbar mit Heinrich in näheren Beziehungen: vielleicht war er auf jener Reise nach Paris in des Herzogs Begleitung. Eine Vorliebe für die Baiern spricht aus dem Gedichte: sie zeichnen sich im Kampfe besonders aus, ihr Herzog Naimes wird auffallend bevorzugt, unter den Personennamen finden sich mehrere bairische Geschlechter, Regensburg ${ }^{1}$ ) speziell wird genannt bei der Schilderung von Naimes' kostbarem Schwert: der Schmied hieß Madelger, der es in der Stadt Regensburg verfertigte (1583-1609). Die Sprache stimmt zu den in dem Gedichte gegebenen bairischen Anhaltspunkten, damit ist Konrad näher als "Regensburger" Geistlicher zu bestimmen.2) Der Umweg bei der Übertragung, indem er die franz. Verse zuerst ins Lat. übersetzte, $\left.{ }^{3}\right) \mathrm{d}$. h. in lat. Prosa, war doch eine Erleichterung für den Dichter, da die unmittelbare Umgießung franz. Verse in deutsche große Schwierigkeiten bot, während die Übertragung sowohl des Franz. ins Lat. wie auch die der lat. Prosa in deutsche Verse ihm, dem lat. geschulten Geistlichen, leicht fallen mußte. Einigemale sind ihm Mißverständnisse begegnet, besonders in Eigennamen. ${ }^{4}$ )

Quelle des deutschen Gedichtes ist das altfrz. Rolandslied,,$^{5}$ die Chanson de Roland. Dieses kostbarste Denkmal der altfrz. nationalen

S. 51; Kraus, D. Ged. S. 116 Anm.; WILMANNS, ZfdA. 50, 137-145 (das R.lied setzt den Straßburger Al. voraus); OTTMANN, Al.lied S. XIX-XXIII. - WELZHOFERS Hinweis auf HEINRICH JASOMIRGOTT, Untersuchungen über d. Kchr. S. $57-66$, hat mit Recht nirgends Anklang gefunden. - V. 9046 wird Heinrich als Heidenbekehrer gefeiert (die haiden sint von ime bekêret). Darunter sind doch wohl die Normannen Unteritaliens zu verstehen, die auch Kchr. 17149 gerade bei dem Kriege Lothars und Heinrichs gegen Roger II von Sizilien haiden genannt werden. Mit Heiden konnte dieser Feind des rechtmäBigen Papstes, gegen den der heilige Bernlard zum Kriege aufforderte und der als $A b$ trünniger und Ungläubiger geschmäht wurde (GiESEBRECHT S. 116), wohl bezeichnet werden. So klagt in der Kchr. 15860 ff. der Papst, daß die Mailänder, seine Anhänger, Christen lingen und wie Heiden mit ihnen verfiihren. Dann würde diese Stelle, 9039-9049, den Normannenkrieg 1136 und 1137 voraussetzen (vgl. Scherer, ZídA. 18, 304 f.) und erst nach dieser Zeit in den Epilog eingeftigt scin, zugleich damit wohl auch 9062-9076, denn nach dem ze gerichte er im [Gott] nu stât 9070 (W. GRIMM 309, 33) muB Heinrich bel der Abfassung dieser Stelle schon gestorben gewesen sein, vgl. W. Grimm, ZfdA.
aaO. Durch den Ruhmestitel* eines Heidenbekehrers bringt der Dichter seinen Gönner Heinrich mit dem Inhalt seines Gedichtes und dessen Helden Karl in nähere Beziehung: wie der mächtige Kaiser Karl, so hat auch dieser Herzog Heinrich die Heidenscliaft überwunden, wie jener ist er ein Gottesstreiter. Auch er ist damit ausdrücklich zum christlichen Ritter gestempelt und in die Reihe der Kreuzritter gestellt.

1) WilhelM, Die Namen von Regensburg (Kchr. 671-689), Münch. Mus. 3, 232.

2) SCHRÖDER, Die Heimat des deutschen R.liedes, ZfdA. 27, 70-82, Kchr. Einl.S 5256; LEITZMANN, R.studien, Beitr. 43, 26-35, dagegen SCHRöDER, Gött. Nachr: 1918, 427 Anm. Der Pfaffe Konrad zugleich Verfasser der Kchr: s. unten.

3) Vgl.Baumgarten, Stilist.Untersucliungen S. 99 .

4) Wald S. XIll f.; Golther S. $143-145$.

5) GRÖBERS Grundr. II, 1, 463-465 u. Rcg. S. 1280: VORETZSCH, Einftilirung s. Reg. Bearbeitung der Sage: W. GRIMM S. XXXIVCVII. CXVI-CXXVIIl; W. MASING, Balt Monatsschr. 53 (1902), 299-329; AMMANN, Strickers Karl u. R.lled.; TH. EıCKE, Zurneneren LG. der R.sagge In Deutsclil. u Frankr., Leipz. 1891, dazu H. VARNHAGEN, DL.Z. 1892, 1615 f., LC. 1892,882 . 
Dichtung, das altfrz. Volksepos im eigentlichsten Sinne, ist das Werk eines unbekannten Volksdichters aus der Isle de France oder der Normandie und wurde nach der Eroberung Englands durch die Normannen, also nach 1066, wahrscheinlich erst um 1100, in einreimigen Tiraden, ungleichen Strophen, in denen ein und derselbe Reim assonierend durchgeht, abgefaßt. In ursprünglicher Form ist uns das altfrz. Epos nicht erhalten und auch der auf uns gekommene älteste in Assonanzen abgefaßte Text (Anglonormannisch, Oxforder Hs. O, um 1170, und weniger wertvoll und später, ca. 1240, die Venetianer Hs.V4) stellt nicht die Fassung dar, die der Pfaffe Konrad gekannt hat, denn seine Bearbeitung enthält manche sicher ursprüngliche Züge, die sich in der auf uns gekommenen franz. Überlieferung nicht finden.1) Manches Altertümliche aus der altfrz. Sage hat die isländische Prosaübertragung in der Karlmagnussage (13. Jh.) bewahrt.

In Deutschland war die Erinnerung an Kail den Großen als einen mächtigen und gerechten Herrscher nie erloschen, seine überragende politische und kriegerische Bedeutung befestigte seinen Ruhm für alle Zukunft. Aber diese Überlieferung pflanzte sich mehr auf gelehrtem Wege fort, im Volke bewahrt wurden nur spärliche Sagensplitter. ${ }^{2}$ ) Den Westfranken dagegen wurde Karl, der große Kaiser, zum Nationalhelden, zum Herrn des heroischen Zeitalters. Die zu reicher Entfaltung gelangte franz. Karlssage ging dann durch die Dichtung in die deutsche Literatur über. Das älteste ist hier das deutsche Rolandslied. Das höfische 13. Jh. aber hat Karl unter die großen Menschen eingereiht, denen die verehrungssüchtige Ritterschaft huldigte. "Er, der vil scelige man, hat eine Gemeinde von Freunden gewonnen. Alle die, welche ein eigenes Urteil haben, tragen ihm holde Gesinnung, denn er war recht und gut in allen seinen Dingen. Das höchste Ziel hat er erreicht, das einem Laien vorbehalten ist er hat der Welt Ruhm erlangt und seine Seele hat das Himmelreich erworben ". ${ }^{3}$ )

Der geschichtliche Ursprung der Rolandssage liegt in dem Kriege Karls des Großen gegen die Araber in Spanien. Als der Kaiser im Jahre 777

1) Das Verhältnis des deutschen Gedichtes zu der altfranz. Ueberlieferung behandelt GOLTHER aaO.

2) Vgl. LG. I, 91; Golther S. 146 f. Ueber die Bemerkung der Kclır. 15072 Karl hât ouch enderiu liet S. SCHADE, Decas S. $65 \mathrm{f}$.; SCHRÖDER, ZfdA. 27, 79, Kchr. S. 50. 55; JOHN MEIER, Beitr. 16, 85. 100 f. Karls Persönlichlikeit als Fürstenideal s. SCHERER QF. $12,83 \mathrm{f}$. und unten bei Kchr. - Ueber die Karlssage s. die altfrz. Literaturgesch., bes. GRÖBERS Grundr. II, 1, 447 ff. 535 ff. 792 ff.; VORETZSCH, Einführung 1 S. 106 f. 108-136. 205 ff. 220 ff.; HIPER S. 14-16; J. KIRCHHOFF, Zur Gesch. d. Karlssage in der engl Lit. des MA.s, Marburger Diss. 1916; SEELMANN, Verhandl. d. 48. Philol.-Vers. in Leipzig 1905; MASING, Balt. Monatsschr. aaO.; FRANZ KAM-
PERS, Die Mär von der Bestattung Karls đ. Gr., Köln 1918; G. RAuSCHEN, Die Leg. Karls d. Gr. im 11. u. 12. Jh., Leipz. 1890, dazu SCHRÖDER, Anz.20,251-255; A.DÖRRWÄCHTER, Die Gesta Caroli Magni der Regensburger Schottenlegende, Bonn 1897, dazu SCHRöDER, Anz. 26, 256-258; O. FreitaG, Die sog. Chron. v. Weihenstephan, Hermaea I, 1906. - Kulturgeschichtliches: A.M. WEISS, Die Entwicklung des christl. Rittertums im R.lied, Hist. Jahrb. d. Görresgesellsch.1 (1880), 107-140; BRESSLAU, Rechtsaltertümer im R.liede, Archiv 48, 291 ff., Mitteil. d Vereins f. thüring. u. sächs. Landeskunde IV, 1, 172; F. E. MANN, Das R.lied als Geschichtsquelle u. d. Entstehung der R.säulen. 3) Strickers Karl d. Gr., Prol. 41 ff. (BARTSCHS Ausg. von Strickers Karl S. 2). 
das Maifest in Paderborn abhielt, erschienen vor ihm arabische Gesandte, um ihn gegen die Herrschaft des Emirs Abderrhaman, den letzten Sprößling der Kalifen, zu Hilfe zu rufen. Karl drang bis zum Ebro vor (788), die mohammedanischen Fürsten stellten ihm Geiseln, er eroberte Spanien bis an den Ebro (die spanische Mark). Da wurde er plötzlich in seinem Siegeszug unterbrochen durch einen Aufstand der Sachsen, der ihn zur Umkehr zwang. Auf dem Rückmarsch durch die Engpässe der Pyrenäen wurde seine Nachhut von räuberischen Basken (Wascones, Gascogner), die sich auf den bewaldeten Bergen in Hinterhalt gelegt hatten (positis insidiis), überfallen und bis auf den letzten Mann vernichtet. In diesem Kampfe fielen Eggihard, des Königs Truchsess, Anshelm der Pfalzgraf und Hruodland, der Statthalter der britannischen Grenzmark (das ist $=$ Markgraf der Bretagne). ${ }^{1}$ ) Von Eggihard ist eine poetische Grabschrift erhalten, wonach er am 15. Aug. starb. Demnach wäre der 15. August 778 der Tag der Schlacht gewesen. ${ }^{2}$ )

Dieser Vernichtungskampf ist der Kern der Sage und einer der gefallenen Führer, Roland, wurde ihr Held. ${ }^{3}$ ) Sie ist rasch zum Nationalgut geworden. Schon vor der Mitte des 9. Jhs. waren die Namen der Gefeierten so bekannt, daß ein Biograph Ludwigs des Frommen, der sog. Astronomus Limosinus, nicht für nötig hielt, sie zu nennen. In epischen Liedern wurde bald, wohl unmittelbar nach dem Ereignis, die Heldentat verherrlicht, und diese, die in mündlicher Überlieferung manchfache Wandlungen durchmachten, auch neue, verwandte Züge aufnahmen, wurden später zu größeren Epen erweitert. Aus solchen Chansons de Geste schöpfte in ersten Drittel des 12. Jhs. die Chronik des Pseudoturpin, die dem im Jahre 800 gestorbenen Erzbischof Turpin von Rheims zugeschriebene Historia Caroli Magni, ihre Erzählung von Karls Zug nach Spanien (Cap. 21-30).

\footnotetext{
1) In quo proelio Eggihardus regiae mensae praepositus, Anshelmus comes palatii [et Hruodlandus Brittannici limitis praefectus] cum aliis conpluribus interficiuntur, berichtet Einhard in seiner Blographie Karls, der Vita Karoli Imperatoris Kap.9. Vielleicht ist Hruodlandus allerdings erst aus der Sage in Einhards Grundtext hineingekommen, da die ihn betreffenden Worte in einer Klasse der Hss. fehlen, aber auch diese Hss. reichen bis ins 9. Jh. zurlick, so daß sie doch eine unmittelbar auf die Begebnisse zurückgehende Ueberlieferung voraussetzen.

2) Hgb. von E. DÚmMLER, ZfdA. 16, 279 f. 1. 436 .

3) Das tragische Ende macht die Begebenhelt zu einem echt volkstümlichen Stoff. Der Untergang des Helden durch Hinterlist und Verrat ist ein beliebtes poetisches Motiv in den Volkssagen (SigFrID, Die Burgunden), bes. aber in den Verräterepen der franz. Heldendichtung, wie denn aucl die wirkliche Geschichte der Volkerwanderung voll von Taten der Untreue ist. Aehnliches erzähit
}

Einhard im 13. Kap. seiner Biographie von dem Ende des Herzogs Erich von Friaul in Karls Avarenkrieg: Duo tantum ex proceribus Francorum eo bello perierunt, Ericus dux Forojulianus in Liburnia juxta Tharsaticam maritimam civitatem insidiis oppidanoruns interceptus usw. Den Tod jenes Herzogs Erich beklagt ein lat. Gedicht (DU MÉRIL, Poésies pop. lat. ant. XII.s S. 241-244), das gewiß niclıt viel später entstand. Es ist aber sehr wahrscheinlich, daß Einlard aus dem Grund gerade jene Helden, Hruodlandus und seine Gefährten und ebenso den Ericus, mit Namen anfïhrte, weil sie durclı Lieder beriblumt waren. Die Gestalt des Verräters gehört schon der frühen Ueberlieferung an: nach einer Urkunde Karls d. Kalılen v. J. 845 leitete Herzog Lupus v. Aquitanien den Ueberfall der Wasconen und wurde zur Strafe dafitr hingerichtet. Der Name Genelun kehrt wieder in den des Erzbischofs Wenilo v. Sens, der in J. 859 von Karl d. Kalılen wegen Abfalls zum Tode verurteilt wurde. 
Mit dem Nationalgesang der Helden von Ronceval wird die Entscheidungsschlacht bei Hastings (1066) eröffnet: Taillefer, dem Heere des Normannenherzogs Wilhelm voranreitend, sang sehr schön von Karl dem Großen, von Roland und von Olivier und von den Rittern, die bei Ronceval fielen.1) Spärlich sind diese Erwähnungen von dem Fortleben der Rolanddichtung bis zu dem auf uns gekommenen Epos, aber sie bezeugen doch die Verehrung, die diese Reckengestalten in der Volksseele gefunden hatten.

Behandlung der Quelle. Mit der Versicherung, er habe zu seiner Quelle (daz buoch $9080,{ }^{2}$ ) nichts hinzugefügt und nichts weggelassen, will der Dichter das Vertrauen in die Zuverlässigkeit seiner Arbeit verstärken, denn eine Übersetzung soll nach den Anforderungen des Mittelalters den Stoff wahrheitsgetreu wiedergeben, das heißt so wie ihn die Vorlage überliefert. Dabei ist aber dem Bearbeiter ein weiter Spielraum gelassen, er darf zwar die bedingenden Tatsachen nicht ändern, aber er kann sie unter Umständen sehr frei stilisieren. In letzterem Sinne hat der Pfaffe Konrad seine Quelle behandelt. ${ }^{3}$ ) Er hat trotz seiner gegenteiligen Behauptung manches übergangen, und, besonders in der ersten Hälfte, noch sehr viel mehr hinzugetan, so daß der Umfang des deutschen Gedichtes den des uns erhaltenen altfrz. fast um das Doppelte übertrifft. Aber er folgt damit nur der üblichen mhd. Übersetzungsmethode; er erweitert die knappere Erzählungsweise seiner Vorlage zum breiten Epenstil. Nebendinge scheut er sich nicht wegzulassen, wie etwa kurze Situationsschilderungen; Naturbilder, die als Orts- und Zeitangaben dem landschaftlichen Hintergrund Farbe verleihen, läßt er weniger zur Geltung kommen;4) allzu leidenschaftliche Affektausbrüche werden gemäßigt oder ganz unterdrückt. Dagegen dehnt er oft erheblicí die Reden, die Schilderungen von Kämpfen und Gewändern, die Beschreibungen von Personen und Charakteren, Stimmungsszenen wie Abschieds- und Totenklagen. Diese Änderungen sind immer noch mehr formaler, stiltechnischer Art, bloße Erweiterungen schon vorhandener Stoffteile. Aber er hat durch starke Hervorhebung der inneren Vorgänge und durch unablässige, alle Einzelheiten durchdringende $\mathrm{Be}$ tonung des religiösen Elementes dem geistigen Gehalt eine andere Richtung verliehen, das ist nicht mehr eine stoffliche, sondern eine ethische Umwandlung und darin liegt der Wesensunterschied zwischen den beiden Gedichten. Tapferkeit und Mannestreue, die sittlichen Grundbedingungen

\footnotetext{
1) So berichtet der normannische Trouvère Wace in seiner historischen Dichtung, der 'Rou' genannten Normannenchronik (um $1160-1170$ ), zur Schlacht bei Hastings. Die Szene hat Uhland seiner bekannten Ballade zugrunde gelegt, vgl. dazu UHLANDS Schriften 4,352 f. Jener Bericht über den Gesang Taillefers beweist nur für das Fortleben der Sage in Liedern und setzt nicht unbedingt eine Stufe der uns erhaltenen Chan-
}

son de Geste voraus.

2) Vgl. W. GrIm M, Ausg. S. XXXI; Golther aaO.; OTtManN, Al.lied S. XIX; WilmanNS, ZfdA. $50,137 \mathrm{ff}$.

3) Siehe GolTHER aaO., bes. Kap. I. II. 111.

4) Landschaftszitate bei Konrad sind $z$. B. 1168. 1669. 1919 f. 2178 , dazu 2411-2414. 2918; ferner 66.643 f. 891. 2985. 2987. 3334. 3341. 3962; etwas ausführlicher $393-400$; vgl. Golther S. 142 f. 
für den Feudalritter, sind die selbstverständlichen Vasallentugenden im deutschen wie im französischen Rolandsliede, aber die treibenden Ideen sind verschieden: die franz. Helden, fromm in dem Bewußtsein, für das Christentum zu kämpfen, sind doch am stärksten erfüllt von der Liebe zum Vaterlande, dem süßen Frankreich, la doulce France. Diesen nationalen Zug hat der Pfaffe Konrad zurückgedrängt, seine Recken sehnen sich nach der himmlischen, nicht nach der irdischen Heimat; in ihnen herrschen als ideale Mächte nur Tapferkeit und Frömmigkeit, nicht auch die Liebe zur Heimat. Der franz. Roland ist der Nationalheld, in dem Gottes- und Vaterlandsliebe zusammenwirken, der deutsche ist ausschließlich der christliche Ritter, aus dem volkstümlichen Epos ist ein christliches geworden, ${ }^{1}$ ) die Sinnenwelt hat die Bedeutung eines Symbols angenommen. Diese Entwicklung zum geistlichen Typus hat der Stoff schon vor Konrad in Frankreich selbst genommen, in Pseudoturpins Chronik. Auch mit dieser Umwendung der Idee hat Konrad nicht gegen seine Behauptung, wahrheitsgetreu übersetzt $z \mathfrak{u}$ haben, verstoßen, da er nicht die eigentliche Handlung des Stückes angegriffen hat.

Mit allem Nachdruck hat der deutsche Dichter in der Anlegung des Stoffes kund getan, daß er sein Werk zur religiösen Begeisterung bestimmt hat. Dieses Programm entwickelt er in der Vorgeschichte (17-360), ${ }^{2}$ )

1) Vom modernen Standpunkt aus wird oft das franz. Gedicht wegen dieser glïhenden Vaterlandsliebe höher geschätzt als das deutsche. Dieses Urteil mag subjektiv berechtigt sein, ist aber unhistorisch, als Vorwurf gegen den Verfasser jedenfalls unbegrïndef; denn der deutsche Geistliche konnte doch die Vaterlandsliebe nicht bestimmend mitwirken lassen, da sie sich ja auf das fremde Frankenreich bezog.

2) Golther S. 114-119. Die vier Ansprachen in dieser Beratung, die von Karl $87-106$. 181-221, Roland 146-156, Turpin $243-272$, sind Kreuzreden und haben die typischen Grundgedanken derselben, vgl. dazu G. Wolfram, Kreuzpredigt und Kreuzlied, ZfdA. 30, 89-132; Wolframs Willehalm 297, 5-299, 30.303, 1-30; Thomasin Welsch. Gast 11347-11830. Die werbende ldee ist dic Verheißung des Lohnes im Himmel, also der Grundsat $z$ des jenseitigen Eudaimonismus, welcher das WertmaB der christlichen Ethik bildet. Ein Musterbeispiel einer Kreuzrede ist dic Karls an das Heer 181221: sie enthält die üblichen Motive Lohn, Schandtaten der Heiden (vgl. Bernhards v. Clairvaux Epist. 322, Wolframs Willehalm 297, 14 ff.; Thomasin 11356 ff.), Pflichten der Krenzfalırer. Turpin hält, seinem geistlichen Stande entsprechend, eine ausgesprochene Kreuzpredigt, schon die formelhafte Anrede an die Ciemeinde mine vile lieben liute 260 ist dementsprechend gewählt. Der
Gegenstand dieser Predigt ist das heilige Kreuz und die Nachfolge Christi (die Erinnerung an den Kreuzestod Christi auch Willeh. 303, 17 ff.; Thomasin $11607 \mathrm{ff}$.), sie schlicBt, wie auch die vorgenannte Rede Karls, mit einer Ermahnung zu christlichen Pflichten. Die geforderten Tugenden gehören zu dem Bestand der Vorschriften für Kreuzfahrer: weset deumute 216 humiliato spiritu WOLFRAM, Kreuzpred. u. Kreuzl. S. 104; mit guoten werken 271 bonis operibus adornatus ebda; sêle und lip sind als der bessere u. schlechtere Teil einander gegenübergestelit $268 \mathrm{f}$. = des libes tôt, der sêle ein iemerleben WOLFR. S. 107, vgl. cum enim abnegatis desideriis carnis ebda S. 104; inwer spîse sî gemeine $265=$ et tam in victu quam in vestitu mediocritatem servantes ebda; daz herze machet reine 266 puro corde ebda S. 104 Anm. 1, darunter ist die Reinigung von Siinden durch die Beichte verstanden. Die Pflichten, die der Pfaffe Konrad für die Ḱreuzritter aufzählt, sind zusammengefaßt speziell Mönchsgebote und sind in der Benediktinerregel enthalten. Der Geistliche kann sich die stttliche Vollkommenheit nur als mönchisch denken, aber auch der Mönch ist ein Kämpfer, ein Streiter für Christus mit den Waffen des Gelıorsams (Ben. Reg. Prolog), Demut und Gehorsam (weset inwer meisterscefte untertân 218) sind Grundgebote der Ben. Reg., zuht mit gnote 215 ist die l.ebensweise der Klosterleute; etwas willehlichen tuon $213=$ cum 
die die Chanson nicht enthält, mag er auch Andeutungen der Art in einer franz. Vorlage gefunden haben. Zum Kreuzz.ug hat den Heidenkrieg erst Konrad gestempelt (167. 246ff. 3447f. 4979f.), im franz. Liede findet sich nichts davon. In der Vorgeschichte (17ff.) ist der Grundton für die ethische Stimmung des deutschen Gedichtes angeschlagen.

Ein gutes Beispiel für die Arbeitsweise Konrads bietet die Behandlung der Botschafe des Blanscandiz (709-838), wo er gegenüber den 35 Fünftaktern der Chanson (122-156) 130 Reimverse braucht. ${ }^{1}$ ) Klar und kräftig legt die franz. Chanson die Friedensbedingungen dar: Tributzahlung 127-133, Huldigung 136. 151-154, Geißelstellung 147-150, Annahmedes Christentums 155, dafür Karl das Land verlassen soll $134 \mathrm{f}$. Der eine Vers aber von der Christwerdung (155) ist im deutschen Lied zum Grundgedanken der Verhandlung, der politische Vertrag ist $z \mathfrak{u}$ einer Heidentaufe geworden.

Überall wird das Tempo der Erzählung verlangsamt. Auf 3 Versammlungen wird die Beratung über das Verhalten gegen Marsilie ausgedehnt, ${ }^{2}$ ) (Lied $891-1537=$ Chanson 168-341); eine neue Person, der greise Bischof Johannes, wird zur Verstärkung des religiösen Elementes eingeführt; alle Edelsteine an den Gewändern von Geneluns Rittern werden aufgezählt, seine Ausrüstung unfaß̧t in der Chanson 6 Verse (343-348), im Lied 68 (15681634, 1648 f.), sein Abschied (1668-1749) 82 gegen 17 in der Chanson (349-365).

In der darauffolgenden Szene von Geneluns Verrat $(1750-2760)$ hat der deutsche Dichter die Methode der Verbreiterung auf die Vorgänge des inneren Lebens angewendet (sog. "psychologische Vertiefung ${ }^{a}$ ). Er hat sich zu entscheiden zur Treue oder zus

bono animo Ben. Reg. Kap. V; mit guoten werken $271=$ ebda Kap. IV; wir sculen ime allez nâh varen, Christus nachfolgen $256=$ ut sequatur Christum ebda Kap. IV. Aus dem Mönchsleben stammt auch die Aufforderung, die 7 Tagzeiten $z u$ halten $260-264$, Ben. Reg. bes. Kap. XVI, wo der 'propheta' als Autorität zitiert wird: Septies in die laudem dixi tibi, das ist Ps. 118, 164, und darauf zielt der Dichter 262. Dagegen wird nicht die sündentilgende Wirkung der Kreuzfahrt verheißen, die sonst hervorgehoben wird, z. B. Bernh. v. Clairvaux aaO.; Thomasin $11613 \mathrm{ff}$; ; Wolfr. aaO. S. $101 \mathrm{ff}$; auch im Ludwigslied $13-18$ ist der Kampf gegen die heidnischen Normannen ein verdienstliches Werk. Miles Dei: vgl. BuRdACH, Ackermann S. $213-217$.

1) Dieser geistliche Zusatz hat den Inhalt des Taufritus: Blanscandiz, der zu taufende Heide, leistet das Bekenntnis des Christenglaubens (confessio, vgl. LG. I Reg. S. 458) (714-721) und bittet um Aufnahme in das Christentum (722-730); Karl, der hier die Stelle des Priesters vertritt, spricht ein Dankgebet und nimmt die Meldung zur Aufnahme an (775-782); Taufe bewirkt Reinigung von Sünden (778); der Täufling soll die Heidengötter verwerfen, was der abrenuntiatio entspricht (801-811), und soll dagegen an Christus glauben (812-814); in den Schlußworten Karls (820-838) klingt die Entlassung mit dem Segenswunsche des Friedens an (vade in pace, durh got sculet ir vride hân 834, Dominus sit tecum, got lâze iuh sine hulde gewinnen 838).
2) In einfachem ubersichtlichen Plane und in kräftigen Zügen entwickelt sich der Verlauf der Beratung in der Chanson, das deutsche Gedicht dagegen ist umständlich und ermüdend durch die weitläufigen Reden und Wiederholungen ${ }^{\circ}$ und durch die ZerreiBung in drei Teile: in der Chanson ist die Beratung nur ein politischer Akt über die gegen. Marsilie $z u$ ergreifenden Maßnahmen, das Lied dagegen macht das weltliche Geschäft $\mathrm{zu}$ einem religiösen Bekenntnis und nähert den Verkehrston dem einer geistlichen Synode. Dort schließt Karl seine Eröffnungsrede mit dem Mißtrauen gegen die Heiden (Ch. d. Rol. 191), hier mit dem Zielstreben, Gottes Huld zu gewinnen (908-910); Rolands Ergebnis ist dort Aufforderung zur Rache (Chans. 210 213), hier die Erringung des Seelenheils durch Gottesdienst (934-.-936). Turpin hält eine Predigt iber das Thema von den Arbeitern im Weinberg (Matth. 20, 1-16), die den Text für den Sonntag Septuagesimae bildet, nach. Gregors Homilie 19: die Kreuzfahrer sind Arbeiter im Weinberg des Herrn, die als Lohn das Himmelreich erwerben, vgl. Operarii in vinea sudantes sunt omnes electi in Ecclesia bona operantes Honorius Aug. Spec. Eccl., Dom. in Sept., Migne 172, 858), vgl. auch SchönBaCH, Ad. Pred. 2, 47-50. 3, 44 f.; Grieshaber, D. Pred. 2, 45-51; K. Roth, D. Pred. S. 37 f. - Mit den Waffen des heil. Geistes will Turpin die Heiden bekehren durch die Lehren der Propheten des alter. Testaments (dieselbe Beweisführung wie in der Silvesterdisputation der Kchr.). 
Untreue. Der franz. Volksdichter läßt in schlichter, aber kraftvoller Erzählung auch lier allein die Tatsachen sprechen, der deutsche Geistliche führt sie auf die entsprechenden Seelenbewegungen zurïck, er findet für den Verrat auch den inneren Grund. Es ist die Naturnotwendigkeit: Untreue ist eine Wesenseigenschaft Geneluns, denn in sineme geiste newas nehein triuwe..., er muose sine nâtûre begân, darum mußte er sie begehen (1953 ff. 1962 ff.). In seinem Charakter aber liegen bereit als sündhafte Anlagen die Hauptlaster $\mathrm{HaB}$ und Habsucht: sie sind die unmittelbaren Ursachen für seinen Treubruch und sind

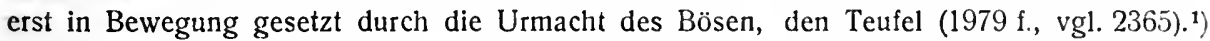
In Predigtweise sind Stellen aus der Bibel beigezogen, die das Laster des Verrats brandmarken: Genelun ist gleich Judas (1924-1943), von ihm geiten die Worte Davids im Psalm 108 (2382 ff.). ${ }^{2}$ ) Der folgende Abschnitt, Gencluns Rückkehr (2761-3240), ist von Konrad mit den gleichen Mitteln erweitert. Das Bild Karls als des christlichen Herrschers hat hier den ausgeprägten Zug crhalten, er ist jetzt der deınütige Büßer, der entronnene Knecht Gottes, und das imperium beugt sich vor dem sacerdotium, denn dem Bischof Egidius muß der Kaiser beichtend seine große Schuld bekennen, damit er Gottes Huld wieder erwerbe $\left.^{3}\right)(2994-3025$. 3048-3065).

Schon das franz. Gedicht hat in verwirrender Fülle und häufiger eintöniger Wiederholung die stärksten Mittel angewendet, um die Riescnmassen anmarschieren zu lassen, bis endlich die Katastrophe das übermenschliche Ringen auflöst. Die hicr sclon ins Maßlose gehäuften Einzelmotive wurden aber von Konrad, wie das der erweiternde Stil verlangte, noch wiederholt oder ins Breite gezogen, pedantisch, ohne Erfindungsgabe. Dabei sind diese franz. Schilderungen von einem idealen Glanz durchleuchtet, denn die Liebe zum Vaterlande ist es, die die Herzen der Helden erfült, sie treten für ihr Volk ein, während Konrad seine stereotypen Kampfmodelle nicht mit dem hohen Geist seines Werkes, der Hingabe für das Gottesreich, zu durchtränken verstand; denn nur vereinzelt kommen hier religiöse Stellen vor, etwa wenı Christus oder Petrus und Mahmet einander gegenübergestellt werden, oder in den V. 4719-4722. Aber die Technik der Kampfschilderung war in der deutschen Heldendichtung doch so kräftig entwickelt, so reich an lebensvollen, ja großartigen Bildern, ${ }^{4}$ ) daß auch der Geistliche, aus diesem Born der Poesie schöpfend, sein Werk mit künstlerischen Treffpunkten ausstatten konnte. In den letzten Kämpfen der drei christllchen Helden, von der Verwundung Olivicrs bis zum Ende Rolands (6372-6949), hat Konrad wenig hinzugefügt ( $=$ Chanson $1940-2396$ ), und hier hat er den richtigen Ton getroffen. Nach aller Zerstörung des Lebens bringt der nahende Tod die Versöhnung, der Feindeshaß wird überstrahlt durch die Freundesliebe, in zarter Herzenswärme sorgen die drei letzten lieben Gesellen umeinander, ihr Scheidegedanke ist Gott und der Kaiser Karl. Im letzten Teil, in der Paliganschlacht und der Bestrafung Geneluns (6950-9016), hat Konrad den Versbestand seiner Vorlage nicht erheblich überschritten, den geistlichen Charakter hat er aber auch hier verstärkt..5) Bezeichnend ist, wie er die bciden einzigen Frauengestalten des Gedichtes, die sonst nur nebensächlich genannt sind, hier am Sclıluß hervortreten läßt: mit ihnen will er Beispiele weibliclıen Glaubenseifers geben, und so ist Breclımunda der Typus der getauften Heidenkönigin, die zu einer Bekennerin des Christentums wird (8617-8630. 8645-8656), Alda, Rolands Braut, dic Jungfratı, die mit rein bewahrtem Magdtum die Erde verläßt (8685-8728).

Nach dieser Gegenüberstellung der beiden Gedichte bedeutet die Umarbeitung des Nationalepos in die Märtyrerlegende künstlerisch eine Ab-

1) Zwei Mäclite bestimmen hier den Willen des Menschen, die angeborene böse Natur (vgl. ScHÜT, Thomaslexikon ${ }^{2}$ S. 514: natura in se recurva est) und der Tenfel.

2) Judis und der 108 . Psalm sind typische Stellen fïr Verrat und Verleumdung, vgl.
Augustins Psalmenkommentar zu Ps. 108.

3) Vgl. Kchr. 15015-15068.

4) Golther S. 131-136; Baumgarten S. $28 \mathrm{ff}$.

5) Golther S. 108. 
schwächung. Die Verringerung des poetischen Wertes liegt nicht in der Verschiebung der Idee, in der Umgestaltung des Todesopfers für das Vaterland zu dem für den Glauben, sondern im Stil. Die erweiternde Stilisierung zersprengte die festen Umrisse, die monumentale Kraft, die dramatische Bewegung, die vorbrechende Leidenschaft sind in weiten Strecken gehemmt durch geistliche Rhetorik. Denn die Kunstform des franz. Gedichtes ist gedrungene Architektonik, die Tiraden sind in sich geschlossene Einheiten, jede ein Glied für sich. Oft haben mehrere hintereinander den gleichen Inhalt. Diese "Paralleltiraden" fallen ebenfalls unter das Prinzip der Erweiterung und die beiden Gedichte stellen zwei Arten dieser epischen Stufe dar: in der Chanson wird der gleiche Gedanke mit leichter Änderung, oft unter gleichen Ausdrücken, in mehreren Tiraden wieder gesagt, die Erweiterung geschieht also durch wiederholende Nebeneinanderreihung des gleichen Stoffteils, das deutsche Lied erreicht demgegenüber den größeren Umfang durch Ausdehnung des betreffenden Stoffteils zu einem einzigen umfangreichen Abschnitt. Dort ist das Gefüge aufgelöst in plastische Einzelformen, hier breitet es sich aus in langgezogenen Linien. Jene Stilart ist der unmittelbare Ausdruck markigen Reckentums, diese entspricht der geistlichen Auffassung vom Rittertum.

Die Formung der Sprache²) war für den Verfasser der christlichen Heldendichtung vorgezeichnet: es ist der herrschende Spielmannsstiel, in den aber mit der religiösen Färbung des Stoffes geistliche Bestandteile eindrangen, Einzelheiten im Ausdruck, in Formeln und auch in größeren predigtmäßigen Partien. Es kommen also alle Eigenschaften der zeitgemäßen epischen Sprache zur Geltung: typische Epitheta, Doppelglieder, Parallelismus und Antithese, Metaphern und Bilder, Hyperbel. In parataktischem Satzbau bewegt sich die einfache Ausdrucksweise, zuweilen belebt durch rhetorische Fragen und Ausrufe. Vom Stil des franz. Gedichtes ist das deutsche wenig beeinflußt. Der ganzen Stimmung entsprechend ist auch das Temperament der sprachlichen Darstellung gemäßigter, die kräftigen franz. Beschimpfungen sind nicht wiedergegeben. Auffallend gering ist die Zahl der lat. Wörter. $\left.{ }^{3}\right)$

Rhythmisch gehört das Rl. zum ungleichen Typus, da kürzere und längere Verse wechseln, die A sson a nzen bewegen sich in mäßigen Grenzen.")

Unter den Beziehungen zu andern Gedichten sind die zur Kchr., die ja den gleichen Verfasser hat, außerordentlich eng, die zum Alexanderliede von besonderer literarischer Bedeutung (s. oben S. 250 f.). Anklänge, die zum Teil auf unmittelbarer Entlehnung beruhen, finden sich ferner an

1) GOLTHER S. 140 ff.

2) Thamhayn, Hallenser Diss. 1884; GolTHER S. 124 ff.; BAUMGARTEN aaO.; PNIOWIR, ZfdA. 33, 80-97; Leo WOLF, Der groteske u. hyperbol. Stil, Pal. 25, 8 f. u. ö.; BeHAGHel, Beitr. 30, $431 \mathrm{ff}$.; ferner die unten bei d. Spielmannsdichtung angeführten Abhandlungen.

3) Wald S. XIII; GRÜNEWALD S. 33 f.
4) FRANZ SPENCKER, Zur Metrik des deutsch. R.liedes, Rostocker Diss. 1889; ERNST OPPERMANN, Die Versschlüsse der Form: $\dot{x} \dot{x}(\dot{x})$ im deutschen R.lied, Greifsw. Diss. 1913; MSD. II ${ }^{3}, 160 ;$ ZWIERZINA, ZfdA. 44, 43 Anm. u. $94.45,38.281$; SCHRÖDER, Gött. Nachr. 1918 S. 426.427. 
das Annol, an das Lob Solomons, auch an das Ezzolied, an Arnolds Siebenzahl, an das himmlische Jerusalem, Laudate Dominum, den heil. Veit. ${ }^{\text {) }}$ Manche Züge aus Konrads Dichtung hat Wolfram für seinen Willehalm entlehnt, der ja den gleichen Inhalt hat, den Kampf der Christen gegen die maurischen Heiden. ${ }^{2}$ )

\section{$\$ 79$. Die Kaiserchronik vom Pfaffen Konrad.}

Kelle 2, 103-105. 306 f.; PIPER, Spielm. D. 2, 182-272, Nachtr. S. 244, Höf. Ep. 3, 714 . Ausg.: Massmann, Der keiser und der kunige buoch oder die sogenannte Kchr., 3 Teile, Quedlinb. u. Leipz. 1849. 1854; DiEMER, Die Kchr. nach der ältesten Hs. des Stiftes Vorau. Th. I, Urtext, Wien 1849 (Vor. Hs.); EDw. ScHRÖDER, Dic Kchr. eines Regensburger Gejstlichen, Mon. Germ. hist., Deutsche Chroniken I. Bd. I. Abt., Hannover 1892 (die grundlegendo Ausgabe), dazu Vogt, ZfdPh. 26, 550-562, John MEIER, Lit.Bl. 1895, 257-262, LC. 1893, 972 f. - Scherer, Rolandslied, Kchr., Rother, ZfdA. 18, 298-306; Ders., D. Stud. 1, 13 f.; Ders., QF.7,30-42. 12,83-87; GiesEbreCHT 4, 376. 398-400; HEINR. Welzhofer, Untersuchungen üb. d. deutsche Kchr., München 1874, dazu Scherer, ZfdA. 18, 298 ff., W. BERnHARDI, Jenaer Lit.Z.1875 Nr.5; WatTenBaCh, DG. s. Reg.; Felix Debo, Uber die Einhelt der Kchr., Diss Graz 1877; R. NeberT, Die Abfassungszeit der Kchr., Festschrift, Halle 1894; Carl Röhrschejdt, Stud. zur Kchr., Gött. Diss. 1907; Stephan Teubert, Crescentia-Studien, Hall. Diss. 1915.

Hss. ${ }^{3}$ ) Das ursprüngliche, frühmhd. Werk ist zweimal umgearbeitet worden, es bestehen also drei Fassungen:

A. Der alte Text, geht bis z. J. 1147. Von ihm sind 7 Hss. vollständig erhalten und 8 fragmentarisch. Sie zerfallen in 2 Klassen, X (bair.-österreichische Gruppe) und Y (rheinischnorddeutsche Gruppe), an deren Spitze die Vorauer Hs. und die Heidelberger Hs., Cod. pal. germ. 361 (Perg.), 13. Jh., mittelfr., stehen.

B. Der jüngere Text, ${ }^{4}$ ) die Uberarbeitung bezw. Umreimung des alten Textes, vom Anfang des 13. Jhs., 3 vollständige Hss. und 9 Bruchstücke. Reime und Versbau sind gebessert, aber die Bearbeitung ist roh und verständnislos, durch Fortlassungen und Zusammenziehungen, um etwa 1600 Verse gekuirzt.

C. Der jüngste Text, in 3 Hss, und 5 Bruchstücken überliefert, mit selbständiger Einleitung und Fortsetzung, eine völlige Glättung des alten Textes A in Versbau und Reim. An die Stelle der Einleitung des alten Textes ist eine neue von 64 Versen (MassMANN 2, 588 ff.) getreten. Die Fortsetzung, 800 Verse, ist geführt bis zum Tode Friedrichs II 1250 (SCHRÖDER, Ausg. S. 393-408), abgefaßt ist die ganze Umarbeitung um 1260 von einem Baiern (erste, bairische Fortsetzung). Der Stil ist ungewandt, ist, besonders in der Einleitung, RuDOLFS vON EMS Weltchronik nachgeahmt, die Darstellung oberflächlich, die Verskunst regelmäBig. - In einer der Hss., in Schloß Zeil im südlichen Württenberg (Ende des 15. Js.), ist von einem schwäbischen Diclıter eine $z$ weite, schwäbisclıe Fortsetzung, vom Ende des 13. Jhs. (1281?), erhalten, die Reminiscenzen an die höfische Epik, besonders an WOLFRAM vON EsCHENBaCH, zeigt.

1) SCHRÖDER, Kchr. S. 56-58. Anz. 13,115; GolTHER S. 148-154; BAUMGARTEN S. 2; MSD. zum Lob Salomons 1, 5. 16, $8=\mathrm{II}^{3}$, 223. 230, zum Laudate Dominum $1^{3}, 270$; KINZEL, Lamprechts AI. S. LIX - LXIII; RÖDIGER, Annol. S. 86 f.; Kraus. D. Ged., Reg. S. 280; Wilmanns, ZfdA. 50, 137-145. - Anspielungen auf d.deutscheHeldensage: SCHRÖDER, ZfdA. 27, 70-82; GOLTHER S. 147; auf die Salomosage: Singer, ZfdA. $35,184 \mathrm{f}$.

2) S. A. BACON, The source of Wolfram's Willehalm, Sprache ı. Dichtung IV, Tübingen 1910; SinGER, Wolframs Willehalm, Bern 1918,
S. 1 ı. ö. Beziehuugen zum Nibelungenlied: Droege, ZfdA. 51, 200 f.; PAlgen. Willehalm, R.lied u. Eneide, Beitr. 44, 191-241.

3) MASSMANN 3, 221-244: SCHRÖDER S. 7 -39 11. S. 438 f.; SCHrÖdER, ZfdA., 26, 224-240; Angabe der Veröffentlichungen der Bruchstückfunde s. in den Anm. zu ScriRöDERS Alisgabe S. 5 f. 7 -26. 438 f.; Scineli.. Festgabe an K. Weinhold, Berl. 1896, S. 41; PIPER, Höf. Ep. 3, 714.

4) A. JUNEMANN, Eine literaturgeschichitl. Untersuchung iber die Fortsetz. der lichr., Straßburger Diss. 1909. 
Die Grundlage für die Herstellung des Textes bildet die Vor. Hs., die das Ursprüngliche ziemlich treu bewahrt hat; neben $\mathrm{V}$ tritt die Heidelberger Hs., die zwar viel fehlerhafter ist, aber auf eine gute Vorlage zurückgeht. Die Hss. der Bearbeitungen B und C kommen für die Kritik nicht in Betracht.

Über den Verfasser, den Pfaffen Konrad, der auch das Rolandslied dichtete, ferner über Zeit, Heimat, Dialekt s. unten.

Inhalt. Prolog 1-42, Anrede an die Hörer bezw. Leser. Bitte um gute, wohlanständige Aufnahme des Gedichtes, gegen die tumben 1-14. Ein deutsches Bucl ist gedichtet, das uns vom römischen Reich berichtet, cronica genannt, von den Päpsten und Königen bis auf den heutigen Tag; ich will erzählen nach meinen besten Kräften 15-26.1) Gegen die Lügenerzählungen der Spielleute 27-42.

A. Die römischen Kaiser $43-14281$.

I. Die lieidnischen Kaiser von Rom 43-7805.

1. Vorgeschichte 43-246, Gründung Roms. 2. Julius Caesar 247-602, zumeist aus d. Annolied u. aus Arnolds Siebenzahl (s. S. 70-74). 3. Augustus 603-670, ebenf. zumeist aus d. Annolied. 4. Tiberius 671-1114, Veronicalegende (s. S. 129). 5. Gajus (d. 1. Caligula) 1115-1218, die Erzählung von Marcus Curtius (Livius V!I, 6), der hier Jovinus heißt. 6. Faustinianus 1219-4082, Gesch. von der unschuldigen Königin und die Simon MagusSage (Trennung und Wiederfindung der Eltern und Kinder, Disputation Petrus mit dem Gaukler Simon). 7. Nero 4083-4300, seine Schandtaten, Hinrichtung von Petrus und Paulus. 8. Tarquinius (Superbus) 4301-4834, Gesch. der Lucretia, Gespräch über die Minne zwischen Totila u. Almenia. 9. Galba 4835-46. 10. Otto (so!) 4847-57. 11. Vitellus (so!) 48585098, Gesch. von Mucius Scaevola (hier Odnatus). 12. Vespasianus 5099-5364, Besiegung der Heiden von Babylon. 13. Titus 5365-5556, seine Gerechtigkeit. 14. Domitianus 5557 -5682, Christenverfolgung, Marter des Ev. Johannes. 15. Nerva 5683-5838, die Sage vom Stier des Perillus (Phalaris, Massmann 3, 748; Ovid, Ars amat. 1, 653 ff.; Valer. Maximus 9, 2. 9). 16. Trajanus 5839-6096, Erzählung von Tr. und der Witwe, Legende vom Papst Gregorius. 17. Philippus 6097-6114, erster christlicher Kaiser. 18. Decius 6115-6450 Christenverfolgung, Märtyrerlegenden, die 7 Schläfer. 19. Diocletianus u. Maximianus 6451-6621, Christenverfolgung. 20. Severus 6622--7135, Erzählung vom Baiernherzog Adelger, Fabel vom Hirschherzen. 21. Helius (= Helvius) Pertinax 7136-7211, tritt als Gladiator auf. 22. Helius Adrianus (= Älius Hadr.) 7212-43, baut Jerusalem wieder auf. 23. Lucius Accommodus (= Lucius A[ntoninus] Commodus) 7244-7425, der Gegenkönig Alaricus zerstört Rom. 24. Achilleus 7426-51. 25. Gallienus, mit dem Arzt Galenus verwechselt 7452-7603, Sage von dem in den Tiber geworfenen Giftkasten. 26. Constantius (= Const. Chlorus) 76047805, Gemahl der Helena, Vater Constantins.

II. Die christlichen Kaiser von Rom 7806-14281. 27. Constantinus 7806-10633, Silvesterlegende (7806-10400): C. wird vom Aussatz befallen, er kann durch das Blut unschuldiger Kinder geheilt werden, auf welches Opfer er aber verzichtet. Der Papst Silvester tauft ihn, darauf wird er gesund. Er führt das Christentum ein. Siegreiche Disputation Silvesters mit 12 jüdischen Gelehrten, ob das Christentum oder das Judentum die wahre Religion sei; S. erweckt als Wahrheitsbeweis einen toten Stier. Helena findet das heil. Kreuz, sendet den heil. Rock und andere Reliquien nach Trier. C. gründet Constantinopel. 28. Julianus 10634-11137, ihn macht der Teufel zum König von Rom. 29. Heraclius 11 138-351, erobert das heil. Kreuz von dem Heidenkönig Cosdras. 30. Narcissus 11352 -12812 , Crescentialegende (die unschuldig verleumdete Frau, vgl. die Faustinanussage).

1) Die V. 15-26 gehören offenbar nicht dem ursprüngl. Prolog an. Der Interpolator von 15-26 sagt, das Buch, die Chronik, sei gedichtet, er wolle es vor zellen. Die Kchr. bricht am Schluß 17284 mitten im Satz ab, der Verf. hat das Werk nicht zum endguiltigen
Abschluß gebracht und nicht veröffentlicht. Der Interpolator ist wohl der "Herausgeber" (vgl. SCHRÖDER, Einl. S. 42-45), er will den der Oeffentlichkeit noch nicht erzăhlten Inhalt jetzt mitteilen. 
31. Justinianus 12813-13066, seine Frau Tharsilla lehrt ihn, anstatt Furcht zu erwecken Liebe zu gewinnen. 32. Theodosius 13067-660, Astrolabius' Liebe zu der Venusstatue; Erwachen der 7 Schläfer. 33. Constantinus Leo (Leo III) 13661-824, ist hier mit seinem Sohn C. Kopronymus zusammengefallen. 34. Zeno 13825-14193, bei dem die Taten Dietrichs (Theoderichs d. Gr.) erzählt werden. 35. Constantius (Constantin VI. Porphyrogenetos) $14194-281$. Von da ist das Rümische Rejch von Griechenland geschieden.

B. Die deutschen Kaiser 14282-17283. Das Reich steht leer bis auf 1. Karl d. Gr., 14282-15091. Er und Papst Leo sind Brüder, der Papst, von den Römern vertrieben, flieht zu Karl, wird von ilım wieder eingesetzt. Karl richtet das Recht ein. 2. Ludwig d. Fromme 15092-235. 3. Lothar 15236-317. 4. Ludwig d. Deutsche 15318-99. 5. Kail (der Dicke) 15400-517, Gesch. von der unschuldigen Königin. 6. Arnulf 15518-81, Gründung von S. Emmeram. 7. Ludwig d. Kind 15582-651. 8. Konrad 1. 15652-759, die aufständischen Herzoge Erchenger u. Perhtolt werden enthauptet. 9. Heinrich I. 15760-849. 10. Otto I. 15850-973, Schlacht auf d. Lechfeld. 11. Otto Il. 15974-16063. 12. Otto III. 16064-141. 13. Heinrich 11. 16142-253, Gründung des Bistums Bamberg. 14. Konrad II. 16254-375. 15. Heinrich III. 16376-531. 16. Heinrich IV. 16532-847, sein zügelloses Leben; Kreuzzug Gotfrids (v. Bouillon). 17. Heinrich V. 16848-941. 18. Lothar II. 16942 -17 181, Preis Heinrichs (des Stolzen) von Bayern. 19. Konrad III. 17182-283, Bernhard v. Clairvaux mahnt zum Kreuzzug.

Aus der Inhaltsübersicht ergibt sich die Komposition der Kchr. Es ist die erste eigentliche und große Geschichtsquelle in deutscher Sprache. Sie besteht aus einer fortlaufenden Reihe von Kaiserbiographien, die in einen römischen (A) und in einen deutschen (B) Teil zerfallen.

Entstehung der römischen Kaisergeschichte (A). Die m.alterl. Weltgeschichtschreibung ist in ihrem Grundschema Chronologie der Regenten. Diese christliche Chronographie wurde festgelegt in der uns verlorenen, bis auf Constantin reichenden gricchischen Chronik des Bischofs Eusebius von Caesarea (265-340). Die Grundlage für alle folgenden Compendien aber ist die lat. Übersetzung des Eusebius durch Hieronymus (380]81). Diese Weltgeschichte ist eine Zcittafel, in welcher der Reihe nach die Fürsten der verschiedenen Reiche, der Assyrer, Juden, Ägypter, Griechen (Sicyonier, Argiver, Mycener, Athenienser), Römer, mit, meist spärlichen, Notizen einzelner Ereignisse synchronistisch zusammengestellt sind. Die übrigen Dynastien gehen nacheinander in dem römischen Weltreich auf, so daß dieses schließlich, von der Zerstörung Jerusalems durch Vespasian an, allein die Geschichte ausmacht. Hieronymus hört mit dem Tode des Kaisers Valens (378) auf. Er zählt der römischen Zeitrechnung entsprechend nach den Regierungsjahren der Kaiser.

Die Chronik des Hieronymus ist in ihrer knappen Aufzeichnung rein äußerer historischer Tatsachen annalistisch, dagegen hat Augustinus in seinem Buche vom Gottesstaat $\left.{ }^{1}\right)$ die geistige Auffassung der Weitgeschichte geschaffen, indem er sie als Entwicklung des göttlichen Erlösungswerkes auffaßt. (Buch 11-22.) Die Geschichte beginnt mit der Weltschöpfung und endet mit der jenseitigen Ewigkeit, sie spielt sich ab in den zwei entgegengesetzten Staaten, dem Gottesstaat und dem Weltstaat, der civitas coelestis und der civitas terrena. Der Ursprung der beiden Staaten liegt schon in der Verschiedenheit der Engel, im Fall Lucifers ist die civitas diaboli begrtindet. Durch den Sündenfall entsteht die civitas terrena, das Reich der Sünde, das Reich des Teufels auf Erden; mit Kain und Abel tritt der Gegensatz unter den Menschen auf, zwischen den Gottlosen und den Frommen, den Kindern der Welt oder des Teufels und den Kindern Gottes. Die Augustinische Geschiclitsentwicklung vollzieht sich im Rahmen des Alten Testamentes und ist gegliedert in sechs Weltalter: 1. von Adam bis zur Sündflut (Buch 15), 2. von Noc bis Abraham, 3. von Abraham bis David (Buch 16), 4. von David bis zur Babylonischen Ge-

1) Siche oben Einleitung S. 3. 
fangenschait (Buch 17), 5. von da bis auf die Cieburt Christi; im sechsten findet die Ausbreitung des Christentums statt. In den Gottgehorsamen, den Patriarchen und Propheten, lebt die civitas Dei auf Erden weiter. Die civitas terrena wird gebildet von den heidnischen Staaten, den verschiedenen Weltreichen, deren ältestes das der Assyrer und jüngstes das der Römer ist. Ihre Geschichte, beginnend mit Ninus, zur Zeit Abrahams, ist kurz in die des Judentums eingeflochten (bes. Buch 18); der Stoff dieser Partie entspricht in allgemeinen Zügen der Chronik des Hieronymus. Die letzten Bücher Augustins, Buch 19-22, behandeln die Fragen des ewigen Lebens.

Das deutsche Kaisertum ist dem MA. die Fortsetzung des Imperium romanum, in der Kchr. ist die Geschichte dieses römischen Reiches entfaltet bis auf die Gegenwart, d.h. bis auf die Zeit des Verfassers. Seit Suetons (ca. 75-150 n. Chr.) Kaiserbiographien ist die Geschichte des Reichs eine Geschichte der Regenten. Die einzelne Persönlichkeit stand im Mittelpunkt der Ereignisse. Die römische Geschichtschreibung hatte eine stark epische Färbung. Schon ihr Begründer, Livius, der die Kunst lebendiger Veranschaulichung in hohem Maße besaß, wirkt gerade dadurch so fesselnd, daß er eigenartige und bedeutende Ereignisse in einzelnen abgeschlossenen Bildern plastisch und kräftig heraus gearbeitet hat. Diese novellistische Erzählungsweise überwucherte aber in der Historiographie der Kaiserzeit ganz die Tatsachen der Wirklichkeit, der Hauptzweck war, zu unterhalten, zu ergötzen durch Anekdoten, durch interessante und pikante Histörchen. Die Geschichte besteht in Geschichten-Erzählung.

In dieser spätrömischen, fabulierenden Gestalt hat das MA. die römische Kaisergeschichte uiberkommen, ein solches, uns aber verlorenes, Werk war auch Hauptquelle für den römischen Teil der deutschen Kchr. Diese Sagen gehören zum Teil zu den beliebtesten Erzählungsstoffen des MA.s, $\left.{ }^{1}\right)$ manche finden sich außerordentlich häufig in Erzählungsbüchern mit Geschichten anderer Herkunft zusammen. Die reichhaltigste derartige Sammlung ist die weitverbreitete der Gesta Romanorum aus dem Anfang des 14. Jhs. Die Kchr. ist in ihrem ersten Teile (A) weniger ein Geschichtsbuch als ein Geschichtenbuch. Geschichte ist hier nicht die Wiedergabe der Wirklichkeit, sondern eine Sammlung von Sagen, Novellen, Legenden, Anekdoten. Wahrheit und Dichtung verflechten sich in buntestem Wechsel, unbeschränkt schaltet die Phantasie, aber ihr leichtes Spiel wird für Ernst gehalten. Was daz buoch, daz liet, saget, die lateinische Quelle, das ist gewiß wahr, und je abenteuerlicher es ist, um so lieber wird es geglaubt.

\section{A. Die römischen Kaiser.}

Die Gliederung der einzelnen Stücke. Der Eingang der Kaiserbiographien enthält die Nennung des Namens, gewöhnlich in der Formel Daz buoch kundet uns sus, daz rîche besaz dô $7 y$ bêrîus $671 \mathrm{f}$. , desgl. Gajus 1115, entsprechend ferner ein Reim auf lat. Nom. us: 1219. 4301. 5099. 5557. 5839. 6097. 6622. 7426. 7452. 7604. 10634. 11138. 11352. 12813. 13067. 14194, vgl. auch 6451.7212; im Reim auf lat. Nom. ô: daz rîche besaz dô Galbâ unde Pîsô 4835, ferner 4847. 13825, stärker abweichend 4083. 4861. 7136; dem Inhalt entnommene Einsätze sind seltener: 603. 5365. 6115. 7244. 7806. Nach dem Eingang folgt nicht selten eine kurze Charakteristik des betreffenden Herrschers wie z. B. bei Tiberius: der gewan Rômceren michel êre, die wîsen redent, er behielte die sêle 673f., vgl. Heraclius 11140f., oder Nero: der was der aller wirste man der von muoter in dise werlt ie bekom 4085f., vgl. Tarquinius $4303 \mathrm{f}$., oder kürzer:

') Siehe Massmann 3, 395 ff.; Schröder, Einl. S. 58 ff. und in den Anm. zum Texte. 
der verworfen Ottô 4848, Domîtîânus, der was ain gotes widerwarte $5558 \mathrm{f}$. Den Schluß bildet die chronikalische Notiz: Regierungszeit des Herrschers, z. B. bei Gajus: driu jâr er des rîches phlac unt zehen mânode mêre $1216 \mathrm{f}$., bei Faustinianus: daz rîche hêt er vur wâr rehte driuzehen jâr und ehte mânode mêre $4079 \mathrm{ff}$,, dabei auch oft der Tod des Regenten, z. B. bei Tiberius: do vergâben si ouh dem hêrren 1114, vgl. 4082. 7425; bei Tarquinius: alsô resluoc in der hêrre 4834; bei Titus: von der werlte versciet der hêrre 5556; bei Domitian: die tievel wîzent sin sêle 5674, $=$ Decius 6450, Julianus 11137; bei Dieterich: die engele ladeten sine sêle 12812, = Theodosius 13650, vgl. 10510.1) Das von formelhaftem Eingang und Schluß umrahmte Mittelstück enthält Taten des betreffenden Kaisers und Ereignisse unter seiner Regierung. Der Umfang dieser Hauptteile ist sehr verschieden. ${ }^{2}$ ) Am kürzesten sind die Stücke über Galba mit zwölf und Otto mit elf Versen; hier ist die Darstellung von annalistischer Knappheit. Diese kurzen Biographien fallen aus dem epischen Tone der Gesamtdichtung heraus, in welcher sich die einzelnen Bilder teilweise zwar nur in Hauptzügen, oft aber in reicher Detailausführung entfalten, so daß z. B. die Abschnitte über Faustinian 1219-4082, Constantin 7806-10633, Narcissus 11352-12812 mit ihren 3864, 2828, 1461 Versen zu ausführlicheren, in sich selbständigen Gedichten abgerundet sind. Man kann in der epischen Darstellung unterscheiden zwischen historischen und fabulistischen Partien. Rein historisch sind nur wenige Stücke, Vespasianus und Lucius Accomodus. Bloße Fabel und Sage ohne geschichtliche Verknüpfungen wird erzählt von Gajus, Faustinianus, Tarquinius, Nerva, Severus, Narcissus. Die übrigen Biographien endlich, die Mehrzahl von allen, enthalten sowohl historische als fabulistische Bestandteile. In die Erzählung sind öfter lehrhafte Partien verwoben, worunter die Disputationen im Faustinian und im Silvester am umfangreichsten sind. Mit dem Maßstab des Historikers darf man an diese römische Kaisergeschichte nicht herantreten; es fehlt hier der Begriff des historischen Urteils. Die chronologische Folge der Kaiser ist der lat. Quelle entnommen, sie ist aber willkürlich verändert. ${ }^{3}$ ) Zwar die Reihenfolge von Augustus bis Trajan ist in Ordnung, dann aber wird auf Philippus (a. 244-249), Decius (a. 249-251), Diocletian (a. 284-305) übergegangen, darauf kommen der frühere Severus (a. 193-211) und dessen Vorgänger Pertinax (a. 193) und weiter in der Zeitenfolge rückwärts Hadrian (a. 117-138) und Commodus (a. 180-192), wonach auf Gallienus (a. 260-268) übergesprungen wird. Durcheinander geworfen sind dann auch die Byzantiner, indem Heraclius (a. 610-641) vor Justinian (a. 527-565) steht, worauf dann erst der viel frühere Theodosius (a. 379-395) folgt, usw. Viele Kaiser, darunter auch bedeutende, fehlen,

7) MASSMANN 3, 338-341. 353.

2) Zur Gruppierung nach dem Stoff vgl. KetTNER, ZfdPh. 9, 284-296.

3) Massmann 3, 331-334. Die Charaktere der Kaiser ebda $335-338$. 
umgekehrt sind nicht dazu gehörige Persönlichkeiten unhistorisch aufgenommen: Tarquinius aus der altrömischen Königsreihe, Faustinianus aus der nachklassischen Sage (s. unten); ferner Achilleus, Narcissus;1) Gallienus ist mit dem Arzt Galenus verwechselt; Alarich zerstört Rom unter Commodus (Accommodus), sein Feldherr ist Wilhelm v. Apulien (7361. 7391), der gegen den Antoninus (Antonius) Pius, einen Feldherrn des Commodus, kämpft; ein Totila kommt unter Tarquinius Superbus vor. Verhältnismäßig wahrheitsgetreu angegeben ist die Anzahl der Regierungsjahre, oft ganz, oft annähernd richtig, selten völlig falsch. Die aufgeführten geschichtlichen Ereignisse beschränken sich im wesentlichen auf Kriege und dem Interesse der Zeit entsprechend benutzt der Dichter gern die durch den Stoff gebotene Gelegenheit zu Schlachtschilderungen. $\mathrm{Zu}$ den geschichtlichen Teilen gehören auch die Christenverfolgungen (Domitian, Decius, Diocletian und Maximian, Gallienus, Justinian) und Synoden (Constantinus, Theodosius).

Die Hauptmasse des Werkes bilden die fabulistischen Partien, die Erzählungen. Sie sind verschiedenen Ursprungs: der Geschichte am nächsten schließen sich an römische Kaiserfabeln: Nero, Titus, Trajanus, Pertinax, Helius Adrianus, Gallienus, Julianus, Justinianus, Constantinus (Porphyrog.); entfernter stehen antike Sagen, altrömische: Gajus (Marcus Curtius), Tarquinius (Lucretia), Vitellius (Mucius Scaevola), spätere: Faustinian (Clementin. Recognitionen), Nerva (Perillus); und deutsche: Severus (Adelger), Zeno (Dietrich von Bern);2) wiederum aus der Zeitgeschichte unmittelbar hervorgegangen sind die Legenden bei Tiberius, Faustinianus, Nero, Domitianus, Trajanus, Philippus, Decius, Diocletianus, Constantinus (Chlorus), Constantinus, Julianus, Heraclius, Narcissus, Theodosius, Constantinus Leo.

Die Grundlage, die der Verfasser für die römische Kaisergeschichte benutzte, läßt sich nur vermutungsweise erschließen. Es wird eine lat. Chronik gewesen sein, welche stark fabulistisch das Leben der Kaiser in den Hauptzügen behandelte, mit den Regierungsjahren, dem Tod und einigen kurz erzählten Taten und Ereignissen, unter ständiger Bezugnahme auf die Päpste und das Christentum. Die erzählenden Partien, alte und spätere Kaiserfabeln wie bei Nero, Titus, Trajanus, Pertinax, Gallienus, Justinianus, hat der deutsche Verfasser reicher ausgearbeitet und vor allem hat er selbst Sagen, Novellen und Legenden eingeschoben; für letztere mag ihm teilweise ebenfalls eine Sammlung, ein Legendar, vorgelegen haben. ${ }^{3}$ ) Die

1) Achilleus, der Ursurpator Ägyptens unter Diocletian, begegnet bei Hieronymus (Migne 27, 660), in Ekkehards Chronik aaO. S. 110, 41. 111, 1. Narcissus ist ein in der römischen Geschichte mehrfach vorkommender Name, vgl. MASSMANN 3.896f.; SCHRÖDER, Anm.zu 11352 . Odnatus (4905ff.) = Odenatus ist bekannt als einer der dreißig Tyrannen, Kaiser des Ostens (a. 267, vgl MASSMANN 3, 730 f.; SCHRÖDER, Anm. zu 4905).

2) W. GRIMM, DH. ${ }^{3}$ S. 43. 224 (Anm.) 227.
421 Anm. Vgl. Georg Matthali, ZfdA. 46, $6 \mathrm{ff.;}$ JAC. BLEYER, Beitr. 31, $496 \mathrm{f}$.

3) Ueber die Herkunft und Verbreitung der einzelnen Sagen - auch im deutschen Teile s. MASSMANN 3, 395-1179. 1185-1192 "Sagenerörterungen "; SCHRÖDER in den Anm.; JELlineK, Anz. 16, 139 f.; SchöNHOFF, ZfdA. 49, 353-355, dazu ScHRöDER ebda S. 362; Verhältnis zu dem Legendar des 12 . Jhs. (oben - \$ 41) s. SCHERER, QF. 7, $39 \mathrm{ff}$.; BUSCH, ZfdPh. 10, 440. 11, 16 f. 32.45 u. ö. - Zur Grün- 
Veronica-1) und die Silvesterlegende, ${ }^{2}$ ) die überhaupt schon die Tradition an Tiberius und Constantin knïpfte, werden zum hauptsächlichen Inhalt in der Geschichte dieser Kaiser. Der vorbildlichen Bedeutung wegen wurden die Novellen von $\mathrm{Lucretia}^{3}$ ). und von $\mathrm{Crescentia}^{4}$ ) aufgenommen, wodurch der König Tarquinius in die Reihe der Kaiser kam, und im Narcissus eigens ein solcher ersonnen und dem vorhergehenden Heraclius als Bruder beigesellt wurde. ${ }^{5}$ ) Die Faustinianus-Legende ${ }^{6}$ ) nahm der Verfasser auf wegen der Lebensgeschichte des Apostels Petrus und seines Schülers Clemens, die als Gründer des römischen Christentums und als erster Papst am Eingang der Kirchengeschichte stehen. Damit wurde Faustinianus zum Kaiser gemacht und zum Bruder des Claudius, denn bei diesem mußte die Legende eingeschaltet werden, weil die Ereignisse unter seiner Regierung stattfanden. Die altlat. Sagen von Marcus Curtius und Mucius Scaevola (Odnatus) ${ }^{7}$ ) schöpfte er wohl aus derselben lateinischen Sammlung, die auch die Lucretia enthielt, alle drei stehen nahe zusammen ziemlich am Anfang des Werkes. Mit der deutschen Sage von Adelger, die er wahrscheinlich einem Spielmannsgedicht entnahm und willkürlich unter den Kaiser Severus einschob, huldigte er seinen bairischen Landsleuten und deren Fürstenhaus. ${ }^{8}$ ) Die aus lat. Quellen entnommenen Erzählungen sind vom Dichter selbst ohne deutsche Vorlagen unmittelbar aus der betr. lat. Quelle in den Text hineingearbeitet worden. Adelger ${ }^{9}$ ) hat noch manches vom Charakter des zugrunde liegenden deutschen Liedes bewahrt, die Crescentialegende aber, die sich durch ebeneren Rhythmus und sorgfältigere Reime, auch durch häufige Verlängerung der Strophenschlüsse, von dem Eigentum des Dichters abhebt, ${ }^{10}$ ) ist ein ursprünglich deutsches selbständiges Gedicht gewesen, das ohne große Änderungen eingeschoben wurde.

dung von Regensburg 687-689; WILHELM, Die Namen von Regensburg, Münch. Mus. 3,232 .

1) Siehe oben S. $128 \mathrm{ff}$.

2) Siehe oben S. 152 f.; SCHERER, QF. 7, 33. 38 f.; RÖDIGER, ZfdA. 22, 181-209; VOGT, ZfdPh. 27, 145-148; RÖHRSCHEIDT S. 65-81; Prochnow, Mhd. Silvesterlegenden u. ihre Quellen, ZfdPh.33, 145-212; BURDACH, Vom MA. zur Ref. 1, $217 \mathrm{ff}$

8) Scherer, D. Stud. 1, 61 u. QF. 12, 86; Schröder, Einl. S. $63 \mathrm{f}$.

4) SChERER, QF. 12, 86; SchröDER, Einl. S. 52.58f.; RÖHRSCHEIDT S.82-111; TEUBERT, Crescentia-Studien; Hilka, Archiv 133, 135141; Panzer, Sigfrid S. $37 \mathrm{ff}$.

b) Bei den unecliten Kaisern Fanstinianus und Narcissus sind, abweichend von der ublichen Teclınik, keine Regierungszahlen angegeben, bei Tarquinius sind sie falsch, bei Áchilleus natiirliclı erdiclitet.

6) MASSMANN 3,635 ff.; Scherer, QF. 7, 33 fi.; SCHRÖdER, Einl. S. 63; RÖHRSCHEIDT S. 1-64; TeuBERT S. 1-24. - Quelle ist Deutsche Literalurgeschlchte. II. der von Rufinus $(\uparrow 410)$ lat. bearbeitete, uns verlorene spät griech. Roman „Recognitiones Clementis" mit dem eclit hellenistischen Motiv der Trennung und Wiedervereinigung sicl nahestehender Personen. Die Abenteuererzählung ist zugleiclı die poetische Einkleidung fiir kirchengeschichtliche und theologische Themata. Ueber das Verhältnis von der Crescentia zum Faustinianus s. TEUBERT aaO.

7) JELLINEK, Anz. 16, $139 \mathrm{f}$

8) Die historisclien Volkslieder werden demnach nicht als "Liigen" betraclitet wie dic alten Heldensagen.

9) SCHERER, ZföG. 21 (1870), 41 ff. II. Kl. Sclir. 1, $181 \mathrm{ff}$.

10) Siche Laclumann, Kl. Schr. S. 465; Schade, Crescentia, Berlin 1853. Geistl. Ged. S. LIII-LXXV (Scli. sucht den Text der Crescentia, des Adelger, von Julian und der Witwe, Justinian und Tharsilla in 6 zeilige Stropluen Zu bringen); SCHERER. QF. 7, 31 f. 38; DEBO S. 8-14, dazu ScuröDER, Einl. S. 5 u. 43; RÖHRSCHEIDT S. $93 \mathrm{ff}$; SCHRÖDER, Gött. Nachr. 1918 , 126 f.; SARAN S. 265. 
Eine von der Kchr. unabhängige Fassung ist erhalten in der Kolmarer Crescentia, ${ }^{1}$ ) ebenfalls aus der Mitte des 12. Jhs. ${ }^{2}$ ) Als sichere Entlehnungen lassen sich nur die Stücke aus dem Annolied ${ }^{3}$ ) und aus Priester Arnolds Siebenzahl nachweisen, weil hierfür die Quellen unmittelbar vorliegen, und die Crescéntia, denn das Kolmarer Gedicht setzt eine gemeinsame Vorlage mit der Episode in der Kaiserchronik voraus. ${ }^{4}$ )

Innerhalb des römischen Reiches entwickelt sich die christliche Kirche, mit der Geschichte des Kaisertums geht Hand in Hand die des Papsttums, die Einleitung selbst betont, daß das Buch uns chundet von den bâbesen unt von den chunigen $18 \mathrm{f}$; die politische Geschichte ist also verbunden mit der Kirchengeschichte. Sie beginnt mit dem Erlösungstode Christi, dem Bilde der Veronica und dem Fall Jerusalems unter Tiberius (Veronicalegende 690-1104). Petrus ist der erste Apologet des Christentums in der Disputation mit dem Magier Simon, dem goukelore 2058-2590. Unter des Claudius (Faustinianus) Regierung kommt Petrus nach Rom 4035; Clemens ist der erste Papst 1320; durch Nero erleiden Petrus und Paulus den Märtyrertod 4155-4264; Domitian ist der erste Verfolger der Christenheit 5561; Philippus, bezw. sein Sohn, getauft vom Papst Sixtus, ist der erste christliche Kaiser, Papst und König arbeiten für das Gottesreich 6097 ff.; unter Decius, Diocletian und Maximian häufen sich die Christenverfolgungen mit Märtyrertaten, auch Gallienus ist Christenfeind $7458 \mathrm{ff}$. Aber mit einem Mal ist die Macht des Heidentums gebrochen: Constantin, von schwerer Krankheit genesen, läßt sich durch den Papst Silvester taufen 7938 ff., die Einführung des Christentums durch den frommgläubigen Kaiser und der Preis des heiligen Papstes Silvester ist der Höhepunkt in der Geschiche der römischen Herrscher, ein neues Reich beginnt. Julianus ist der letzte Gottesfeind; sein Nachfolger Heraclius gewinnt das heilige Kreuz zurück; unter dem frommen Theodosius werden die Anhänger des Irrlehrers Arius bekehrt $13479 \mathrm{ff}$. Christentum und Heidentum stehen im Kampfe, die Märtyrer sind die Sieger, auch wenn sie den Todesqualen erliegen, denn sie haben die Krone und heißen Könige, während ihre Peiniger der immerwährenden Not verfallen sind 6408-6416. Die Christen haben die sittliche Macht, sie sind die Trauten Gottes, die Heiden sind Feinde Gottes und Söhne des Teufels. Der Dualismus zwischen Christentum und Heidentum ist die stärkste ethische Idee des Gedichtes (jâ sint die haiden von.den

1) Bruchstücke des 12. Jhs. im Bezirksarchiv zu Kolmar i. E., hgb. von MarTiN, ZfdA. 40, 305-331, dazu Collation von SChröDER, ZfdA. 41, 92 f.; LeItZMANN, Kl. geis1l Ged. S. 3-5. 30. Ueber die Urcrescentia vgl. RÖHRSCHEIDT u. TEUBERT.

2) Eine minderwertige Umarbeitung der alten Legende ist das mhd. Gedicht vom Ende des 13 Jhs. in der Heidelberger Hs. 341 u. dem Koloczaer Kodex, s. SCHRÖDER, Einl. S. 26; RÖHRSCHEIDT S. 82-111.
3) Ueber das Verhältnis der Kchr. zum Annolied s. oben S. 147 f.

4) Außer der Crescentia hat sich bis jetzt kein selbständiges, in ursprünglicher Form erhaltenes Lied mit Sicherheit aus dem umgebenden Text ausscheiden lassen. $\mathrm{Zu}$ den Versuchen von RöDIGER, ZfdA 18, 157-159 (dazu SCHERER, QF. 7, 32 f.) und SCHRÖDER, Einl. S. 62, vgl. VoGt, ZfdPh. 26, 554-560; s. ferner WELZHOFER S. 19 f., dazu SCHRÖDER, Einl. S. 67. 
christen gescaiden $6045 \mathrm{f}$.), aber sie durchzieht nicht, sie beherrscht nicht das Ganze. ${ }^{1)}$ Die Menschheit ist nicht so einfach gespalten, daß nur die Gläubigen auch trefflich, dic Heiden verabscheuungswürdig sind. Denn auch heidnische Kaiser können tüchtig und moralisch gut sein: Tiberius, Titus, Nerva, Trajan, dessen Seele später durch den Papst Gregorius erlöst wurde 6019-6082; böse aber sind unter allen Umständen die Christenverfolger.

Überhaupt ist in den Biographien ein besonderes Gewicht auf die sittliche Persönlichkeit gelegt, die Könige werden in gute und böse unterschieden: von den chunigen, baidiu guoten unt ubelen berichtet das Gedicht $19 \mathrm{f}$. In ihren Handlungen offenbart sich ihr moralischer Wert, aber auch unmittelbar charakterisiert sie der Dichter durch Epitheta oder kurze Bemerkungen. Besonders ausgeschmückt mit ehrenden Bezeichnungen werden Titus 5367. 90. 416. 51. 93. 549-52; Nerva 5685. 93. 705. 55.79. 96. 837; Trajan 5859 f. 69. 6091 ; Constantin 7638. 809. 41. 8306. 474. 9854. 10477; Tiberius vereinigt Weltruhm und Seelenheil 673f., vgl. $13 \mathrm{f} .5681 \mathrm{f}$. und ebenso Constantin $11140 \mathrm{f}$. Auch für die bösen Fürsten, besonders für die Christenverfolger, hat der Dichter allgemeine Merkmale: Domitianus ist ain gotes widerwarte 5559, der grimmige man 5576, der verworhte 5647; Decius der grimmige man 6151, der vil grimme 6171, ain fraislich man 6115, vgl.6249.52; Diocletian und Maximian : die grimmigen wuoterîche 6612, die ubelen wuotgrimmen 6453; vgl. ferner Gallienus 7458, Julian 10637. 938. 11000 , des laiden vâlandes man 10813. Mit besonderer Heftigkeit wird Dietrich v. Bern angegriffen: der ubel wuotgrimme, den Papst stieß er von St. Peters Stuhl und legte die Christgesinnten in den Kerker; dafür warfen ihn die Teufel in den Vulkan (Vesuv), wo er bis zum jüngsten Tage brennt 14154 ff. : das ist das Bild, das die Kirche von dem Nationalhelden, dem Liebling des Volkes, aufgestellt hat gegenüber der Verherrlichung der Spielleute, die für Lüge erklärt wird 14187 (vgl. 27 ff.). ${ }^{2}$ )

Charakteristisch sind auch die Todesarten. Die meisten Herrscher werden erschlagen: Gajus, Tarquinius, Galba und Piso, Otto, Philippus, Gallienus, Decius, Diocletian, Pertinax, Adrian, Accomodus, Achilleus, Gallienus, Justinian, Constantinus (Porph.), in der Schlacht fallen Severus und Julianus, vergiftet werden Augustus, Tiberius, Claudius, Alarich, Vitellius wird lebendig begraben, Domitian ertrinkt, den unchristlichsten Tod, den Selbstmord, tun sich an Nero und Maximian. Nur wenige sterben eines natürlichen Todes an Krankheit: Vespasian, Titus, Nerva, Trajan, Constanti(n)us (Chlorus), Constantinus Leo, Zeno, es sind besonders die "guten" Kaiser, Nerva und Trajan erhalten noch außerdem den elirenden Zusatz, daß sie beklagt wurden. Besonders hervorgehoben aber wird der Gegensatz zwischen Gotteskindern und Teufelsdienern, indem Nero, Domitian, Decius und Julian von den Tenfeln geholt

1) Die augustinische Trennung der Menschheit in elne civitas Dei und eine civitas terrena ist nicht der geistige Leltgedanke in den von Hieronymus ausgehendeu Chroniken.

2) Vgl. Vogt, Breslauer Festschr. S. 513 f. 
und gepeinigt werden, während die Seelen Constantins, des Narcissus, Theodosius von den Engeln in Empfang genommen werden.

Weisheit lehren ist das hohe Ziel des Gedichtes: zuîstuom unt êre werden die Hörer davon haben und ihrer Seele wird es zum Nutzen sein, so lautet das Programm des Verfassers in den Eingangszeilen (13); Wahrheit wird hier geboten, nicht Lüge, wie sie die Spielleute erdichten, daß davon die Seelen in der Hölle brennen werden. ${ }^{1}$ ) Die Novellen, Fabeleien, Abenteuerlichkeiten, an die selbst die blühende Phantasie der Spielleute nicht heranreicht, hier sind sie bare Wahrheit, sie sind, wenn sie auch auf die Unterhaltungslust berechnet sein mögen, doch im Hauptgrunde zu dem höheren Zweck der Belehrung und Erbauung bestimmt als Beispiele für die Einrichtung eines sittlichen Lebens, sie stellen im Bilde dar, wie man haṇdeln und wie man nicht handeln soll. Der Dichter selbst will seine Gestalten als Vorbilder aufgefaßt wissen, ${ }^{2}$ ) er sagt von Trajan: Nû suln alle werltkunige dâ bî nemen pilede, wi der edel kaiser Trajân dise genâde umbe got gewan 6083-6086, umgekehtt Domitian als abschreckendes Beispiel: von diu suln alle kunige bî im iemer nemen pilede, behuoten ir sêle, behalten ouh werltlîch êre 5679-5682. In Trajan wird ein weltliches Fürstenideal gezeichnet: er ist der gerechte Richter, ein Beispiel dafür ist die Erzählung von Trajan und der Witwe 5841 -5872. 5887-5996, ${ }^{3}$ ) der im gerechten Kampfe tapfere Krieger 5873-5884. 5997-6006, und der Friedensfürst 6013-6018. Theodosius ist, wie Constantin, der Typus des frommen Herrschers (Tugendlehre 13601-625) mit dem Lohn der himmlischen Krone. Der Gegensatz zwischen dem christlichen und dem heidnischen Regenten ist dargestellt an Philippus und Decius $6133 \mathrm{ff}$. Die Pflicht gegen die Untertanien lehrt Tharsilla ihren Gemahl Justinianus 12825-12998, vgl. auch 13672-13682. Grundsätze der Jugenderziehung entwickelt Faustinianus 1375-1403.4) Beispiele für opferfreudige Glaubensstärke geben die Helden der Märtyrerlegenden, weibliche Tugend verherrlichen die moralischen Erzählungen von den keuschen Frauen, die demütig und geduldig in allen Leiden ihre Ehre bewahren, Mähthilt in der Faustinianuslegende, Lucretia, Crescentia.

Alle diese Lehren und Erzählungen sind Zeugnisse praktischer Moral. Aber meistens äußert sich der didaktische Charakter des Werkes in der Aufnahme theologischer Spekulation. Die Silvesterl egen de ist eine Apologie des Christentums in der Form einer Disputation, eingekleidet in novellistisches Gewand, ihr Inhalt ist die Glaubenslehre und der Sieg des Christentums über das Heidentum. Widerlegt werden 12 jüdische Einwände. Diese

1) Vgl. Ekkehards Chron. aaO. S. 99, 4 ff. Conradus Hirsaugiensis bestimmt in seinem Dialogus (12. Jh.) den Unterschied $z$ wischen einem historiografus und einem poeta dahin, daB jener ein Schreiber von gesehenen Tatsachen sei, dieser ein Erdichter, der für Wahres Falsches sagt und dem Falschen zuweilen Wahres beimischt (ed. SCHEPSS S. 24 f.); vgl. auch IsIDors Etymol. I, 40, 1.

2) Siehe SCHRÖDER, Anm. zu 5889; BURDACH, Vom MA. zur Ref. 1, 68 ff.

3) Massmann 3, 349-353. 366-371.

4) Die Fürstenlehren, „Fürstenspiegel “, bllden einen wichtigen Teil in der m.alierlichen Elhik und Pädagogik, vgl. die oben S. 256 Anm. 1 angeführten Arbeiten. 
Sătze zusammen bilden eine Heilslehre, die Silvesterdisputation ist eine Summa Theologiae. Im Plan des Gedichtes bildet die christliche Lehre mit ihrer Spitze, der Taufe, den Mittelpunkt, sie ist an den Anfang der christlichrömischen Weltmonarchie gesetzt und enthält die religiösen Grundforderungen für das Reich, in dem nunmehr das Christentum zur Herrschaft über das Heidentum gelangt ist. Aber die Silvesterlegende birgt in sich eine tiefe sittliche Wahtheit, die Selbstentsagung, die Aufgabe des Eigenwillens, die Năchstenliebe, die christliche Charitas: der aussätzige Kaiser will nicht um das Blutopfer unschuldiger Kinder seine Gesundheit erkaufen, besser ist es, daß ich allein sterbe, als daß so viele Menschen um meinetwillen verderben $7838 \mathrm{f}$. Aber wiederum genugt diese innere Umwandlung, die reine Menschlichkeit, nicht zur Erlösung vom Leiden, sondern den Entscheid gibt abermals die Glaubenssatzung, das Dogma: Heilung bringt dem Kranken erst die Taufe, die mystische Kraft des Sakraments. ${ }^{1}$ )

In der Besprechung zwischen Faustinianus und seinen Söhnen werden die Fragen um das Fatum (wîlscelde) und um den freien Willen behandelt ${ }^{2}$ ) 3063-3892. Ebenfalls in der Faustinianuslegende findet die Disputation zwischen Petrus und dem Magier Simon statt 2058-2590. Apostel und Gaukler stehen sich gegenüber als Vertreter des Spiritualismus und des Sensualismus 2425-2450, des Christentums und des Heidentums und ihrer beiderseitigen gegensätzlichen Lebenszustände des Friedens und des Krieges 2156-2233.3)

\section{B. Die deutschen Kaiser.}

Der Umfang der einzelnen Stücke bewegt sich in mäßigen Grenzen, nur das Leben Karls des Großen, dem der Verfasser ganz besondere Verehrung zollt, übertrifft mit 783 Versen an Ausdehnung weit die andern, die, außer Heinrich IV. mit 315 Versen und Lothar II. mit 240 Versen, sich zwischen ca. 60 und ca. 150 Versen halten. Die Anlage ist die gleiche wie bei den römischen Kaisergeschichten: Eingangs- und Schlußformel, in der Mitte die Regierungstaten. Der Wortlaut der Eingangsformeln weicht ab, weil hier keine bequem reimenden Namen vorkommen wie dort die auf - us: sus, -ô: dô. Zweierlei Typen werden verwendet: bei der Erbfolge, wenn der verstorbene Kaiser einen Sohn hinterläßt (der dann die Zustimmung der Fürsten erhält), wird weitergefahren mit der Formel z. B.: Alse Ludevîch von der werlte versciet, ainen tiurlichen sun er liez (Lothar) 15236, desgl. bei Karl d. Dicken 15394, Ludwig d. Kinde 15582, Otto I., Il. und llI. 15850. 15974. 16064, Heinrich Ill. 16376 und ganz ăhnlich bei Ludwig d. Frommen 15092. Im Falle einer Wahl dagegen wird, von Arnold an, gesagt, daB die Fürsten auf einen König rieten oder ihn wählten: bei Arnold 15521 ff. (hier nur

1) W. GRIMM, Konrads v. Wurzburg Silvester S. XIII ff.; BURDACH, Vom MA. zur Ref. $1,217 \mathrm{ff}$.
2) RÖHRSCHEIDT S. 44 ff.

3) Pax und discordla sind die Aeußerungsformen der Civitas Dei und der civitas diaboli. 
angedeutet), Heinrich I. 15760 ff., Heinrich II. 16142 ff., auch Heinrich IV. 16532 ff. und 16848 ff., und Lothar II. 16942 ff.; bei den drei Konraden ist der Reim bestimmt durch den Namen: si kômen alle ze râte, si griffen an ainen Chuonrâten 15656 ff. 16256 ff. 17182 ff. Die Abschlüsse sind bezeichnet durch die Zahl der Regierungsjahre, die oft bis auf Monate, ja auf Tage genau, und meist auch richtig, berechnet sind. Die Todesarten brauchten bei den deutschen Kaisern, die alle ein natürliches Ende gefunden haben, nicht angegeben zu werden. Bezeichnend aber für etwaige besondere Wertschätzung, in der ein oder der andere Herrscher bei dem Verfasser und seinen Gesinnungsgenossen stand, sind die gleichsam die moralische Persönlichkeit zusammenfassenden Kundgebungen der Sympathie am Schlusse der Biographien, so bei Karl dem Großen die Aufzählung seiner Fürstentugenden mit dem Schlusse: Karlen lobete man pillîche in Rômiscen rîchen vor allen werltkunigen: er habete di aller maisten tugende 15069-15087;') ferner bei Ludwig dem Frommen 15224-15231, Heinrich dem Heiligen 1624616253, Heinrich III. 16522-16527, Lothar II. 17165-17181; Totenklage bei Heinrich I. 15849, Otto I. 15973, Heinrich II. 16254 f., Konrad II. 16375.

Die erzählenden Hauptstücke in der Mitte enthalten fast durchweg historische Bezüge, nur die Regierung Karls des Dicken, über die der Dichter nichts zu sagen wußte, ist ausgefüllt durch eine Novelle, denn "Richgards Feuerprobe" $15400-15517$ ist wiederum die Geschichte von der unschuldig verleumdeten Königin.

In großen Zügen entfaltet sich die Reichsgeschichte an den Taten der Herrscher. Der Typus des christlichen Regenten, der rex Christianus, ist das Urbild, an dem diese gemessen werden. Unter drei Gesichtspunkte ist die Tätigkeit eines mittelalterlichen Fürsten zu stellen: sein Verhältnis zum Papst, zum Krieg, zum Frieden; die oberste sittliche Anforderung ist "fromm sein". Seine Beziehungen zum Papst, das Verhältnis zwischen Imperium und Sacerdotium, sind die beherrschenden Linien für die Weltlage, sie bedeuten die Wahrung oder die Verletzung der Grundidee der Weltgeschichte, das ist die politische Verwirklichung des Gottesstaates auf Erden. Das Ideal des frommen und gerechten Fürsten, der die Einheit des Gottesreiches und des Weltreiches, des Papsttums mit dem Kaisertum, durchführt, ist verkörpert in Karl dem Großen, er habete di aller maisten tugende 15087. Symbolisch ist diese Einheit dargestellt darin, daß Karl und Leo, der Kaiser und der Papst, Brüder sind. Der von den Feinden mißhandelte Papst flieht zum Kaiser, damit ist ausgesprochen, daß dieser der weltliche Schutzherr (voget 14533) der Kirche ist. Karl ist der siegreiche Kriegsfürst, aber in gerechten Kriegen, der gotes dienestman 14909, ain wârer gotes wîgant 15073, er führt den Kampf des Christentums gegen das Heidentum: mit dem swerte sol ich di christenhait bescirmen 14537; er gründet das Bistum

1) Vgl. Schade, Decas S. 65 f.; Schröder, ZfdA. 27,79 f. 
Bremen $14873 \mathrm{ff}$; ; er ist zugleich der Friedensfürst, denn er hat das unverletzliche, beschworene Recht gegeben für alle Zeiten $14757 \mathrm{ff} .{ }^{1}$ ), durch Erneuerung des Constantinischen Vertrags (vgl. 8073 ff.) schützt er das Kirchengut gegen die Fürsten 14779-14787 und bestimmt die Kleidung der Bauern unter Verhängung der härtesten Strafen gegen die, die das Schwert tragen statt des Treibsteckens und der Heu- oder Mistgabel 14783-14814. Von demütiger Frömmigkeit ist jede seiner Handlungen durchdrungen, bußfertig unterwirft sich der Nachfolger der Imperatoren einer noch stärkeren Macht, jener über das Menschengemüt, der Beichte 15015-15068. BarfuB fleht er in den Kirchen Roms zu Gott und ihm wird die höchste Gnade zuteil, die einem Laien bestimmt ist: die Ehre der Welt und zugleich doch das Heil der Seele $14366 \mathrm{f}$.

Das Reich Ludwigs des Frommen ist eine Erfüllung der Gründung des großen Karl. Nach einer rasch erledigten Störung herrscht ungetrübtes Völkerglück. Im Gottesfrieden (15140) ruhen die Lande, Bî̀ des chuniges Ludewîges zîten (15202, vgl. 15164. 78), in der guten alten Zeit, da freute sich die Christenheit 15203. Es war das goldene Zeitalter. ${ }^{2}$ )

In scharfem Gegensatz zu dem Walten der Gerechtigkeit unter dem frommen Ludwig besteht der Bericht über des "guten Helden" Lothar Regierung in der Erzählung einer Vasallenfehde, die vom Dichter klärlich nur aus Mangel an historischem Stoff hereingebracht ist. Ludwig der Deutsche vollends ist verwickelt in die schlimmste $Z$ wietracht, in den Bruderkrieg, und hier bewährt sich die Geistlichkeit und an ihrer Spitze der Papst als Hort des Friedens. Mit Karl dem Dicken ist die Reihe der Karolinger abgeschlossen. Von Taten war bei ihm wenig $z u$ berichten, dafür schaltet der Verfasser sein Lieblingsmotiv von der erprobten Gattentreue ein, in dem sich durch die Entscheidung des Ordals die Gerechtigkeit Gottes offenbart.

Die Aufgabe der folgenden Herrscher - es sind Arnulf, Ludwig das Kind, Konrad l., Heinrich I. - ist die Verteidigung des Vaterlandes gegen den Ansturm der Heiden, besonders der Ungarn oder der Hunnen, auch die Niederwerfung aufrührerischer Vasallen. Durch Ottos I. Sieg auf dem Lechfeld, der durch das Gebet des heiligen Ulrich von Gott erfleht ist, wird den Ungarneinfällen ein Ende gemacht 15932-15962. Die imperialistische Reichspolitik Ottos I. und seines Sohnes Ottos II. findet ihren Ausdruck in den italienischen Kriegszügen, kriegerisch ist auch der Bericht über O tto III. Mit Heinrich II., dem heiligen Kaiser, ersteht wieder, seit dem frommen Ludwig, ein ldealherrscher in Milde und Güte und großer Demut $16148 \mathrm{f}$., ain wârer gotes dienestman 16166 mit den Tugenden der Barmherzigkeit und Friedfertigkeit, Freigebigkeit und Gottesliebe 16157-16167, in tapferen Kämpfen ein Bekehrer der Heiden und ein Befestiger der Christenheit durch

\footnotetext{
1) Siehe Bd. I, 91. 146 ,

$\left.{ }^{2}\right)$ Ueber die "aurea tempora* vgl. Kari.

Gol.D,Chronologie Ekkehards v.Aura, Greifsw. Diss. 1916 S. $29 \mathrm{f}$.
} 
Gründung des Bistums Bamberg. Nach der kampferfallten Zeit Konrads II. folgt sein Sohn, der guote Hainrîch 16378, dessen Macht sich erweist in siegreichen Kriegen und noch mehr in der friedlichen Lösung des Streites um den heiligen Stuhl. Damit ist die Machtfrage zwischen Kaisertum und Papsttum eröffnet und dieser Gegensatz bedingt die politische Stellung des. Dichters. Im Sinne seiner, der klerikalen, Partei ist Hein rich IV. der rex iniquus, der tirannus: die Reichsfürsten behandelt er rücksichtslos, die Edeln höhnisch, er ist unklug und unkeusch, begünstigt Räubereien, ist frivol, er liegt dem Spiel ob statt seinen Regierungspflichten 16548-16560.1) Die Schuld trägt sein Ratgeber, der Erzbischof von Bremen, ${ }^{2}$ ) die Folge ist der Sachsenkrieg. Im Gegensatz zu den ungerechten Kriegen des Kaisers steht der Zug des Herzogs Gotfrid zum heiligen Grab, dem wâren gote zêren 16622, der erste Kreuzzug 16618-16789. Dem entsprechend erhäit Gotfrid auch den höchsten Laienpreis; er hat die Ehre der Welt und die Gnade der Seele, sein Leib ruht beim heiligen Grab, die Seele ist heilig, während Heinrich durch den einzigen Sohn aus seiner Herrschaft verstoßen wird und ruhmlos endet. Zwietracht stört das Reich und die Christenheit auch unter seinem Sohn Heinrich V., dessen Herrschaft aus dem Streit mit dem Vater geboren war, Fehde zwischen Laien und Pfaffen, 16860 f., zwischen Kaiser und Papst. Ein neuer Zwiespalt bestimmt die Zeit der beiden letzten Kaiser, das Ringen um die weltliche Oberherrschaft zwischen Lothar und den Hohenstaufen, zwischen dem Welfen Heinrich dem Stolzen und dem Staufer Konrad III. Diese Ereignisse hat der Dichter nun selbst mit erlebt und seiner Parteistellung gibt er deutlichen Ausdruck. Dem "guten" Lothar 16952, der sich demütig weigert, die Krone anzunehmen, bringt er persönliche Verehrung entgegen, er fordert auf für sein Seelenheil zu beten, er ist ihm der Inbegriff der Herrschertugenden, ihm und der seligzupreisenden Königin bringt er das Fürstenlob dar wie vorher dem großen Karl, dem frommen Ludwig, dem heiligen Heinrich und dem guten Heinrich (III.): er war der Friedenskönig; berichtet wird allerdings nur von Kriegstaten. - Auch dem Schwiegersolin des verehrten Kaisers, dem Baiernherzog Heinrich dem Stolzen, bringt der Dichter seine Huldigung dar, aber der Ton des Lobes hält sich in gebührendem Abstand: nicht einzelne christliche Trefflichkeiten werden hervorgehoben, sondern nur im allgemeinen wird gerühmt, daß er in hohen Ehren stand, ein sehr erhabener Fürst war, gnädig seinen Untertanen, als Schwiegersohn des Kaisers einer der vornehmsten Laien und viele gute Tugenden besaß 17097-17104.

Mit der Vorbereitung zum zweiten Kreuzzug bricht das monumentale Werk ab, mitten im Satze hat der Dichter die Feder aus der Hand gelegt. Hat sie ihm der Tod entrissen? Haben ihn äußere Umstände verhindert,

1) Aus Ekkehards Chronik aaO. S. 199, vgl. SCHRÖDER, Einl. S. 69.

2) Ueber den bösen Ratgeber in der Auf- fassung der Kirche vgl. HerzfeldS Diss. S. $25.55 \mathrm{ff}$. 
den historischen Faden weiter zu spinnen? Wie auch immer, an einem gewaltigen Moment der Weltgeschichte hat er Halt gemacht: die Predigt des heiligen Bernhard, ') die süße Lehre des Abtes entflammt das Gemüt der Christenheit, treibt die mächtigsten Könige zu folgenschweren Unternehmungen. Das Mönchtum hat seine höchste Macht erlangt, die Glut der Gottbegeisterung ist nun in der Tat der stärkste politische Faktor geworden, reif sind die Pläne Gregors VII., ein einzelner, ein Gotterwählter, macht sie zur Wirklichkeit, denn er besitzt die Macht mystischer Suggestion und die ist die stärkste in der Ideenwelt des Christentums. Diese Auffassung hat allerdings der deutsche Dichter nicht in seine schlichten Worte hineingelegt, er besitzt nicht die Ergriffenheit weltgeschichtlicher Stimmung, er fühlt sich nicht ein in die Seele der Zeit, er stattet nur Bericht ab über die äußeren Erscheinungen. Er kennt auch nicht die politischen Triebe, die die Geschichte der Menschen mit Naturnotwendigkeit lenken, der Name Gregors VII. wird nicht einmal genannt, vom Investiturstreit ist bei den Kämpfen Heinrichs V. mit dem Papste nicht die Rede. Oft begegnen tatsächliche Irrtümer, auch Mißverständnisse und Verwirrungen. ${ }^{2}$ ) Vorherrscht die Freude am Stofflichen, Geschichte ist dem Dichter immer nur die bunte Fülle von außerordentlichen Begebenheiten, auch in dem deutschen Teile, wobei er zwischen Wirklichkeit und Fabel keinen Unterschied macht. Seinen reichen Stoff entnahm er zum Teil auch hier historischen Quellen, ${ }^{3}$ ) wobei er besonders der Weltchronik Ekkehards folgte; auch wohl aus mündlicher Überlieferung schöpfte er und für die letzten Jahrzehnte aus seinem eignen Gedächtnis. Noch aber bestand auch die alte, germanische Form geschichtlicher Tradition, das Lied, die Sage. ${ }^{4}$ ) In Balladen, epischen Liedern, wurde die Erinnerung an gefeierte Helden, besonders von den Spielleuten, durch die Jahrhunderte weitergetragen. Stark sagenhaft ist die Biographie Karls des Großen (z. B. die Papstgeschichte 14308 ff. 14412. ff.; das Vorstreitrecht der Schwaben 14597-14628; die Belagerung von Arles $14885 \mathrm{ff}$; das Mädchenheer $14930 \mathrm{ff}$. ; $^{5}$ ) Karls Beichte 15015 ff.). Mit Vorliebe wird bis zur Zeit Ottos III. von Vasallenaufständen ${ }^{6}$ ) berichtet, von unbändigen Großen, die eigenwillig dem Reichsoberhaupt trotzen, den gewählten König nicht anerkennen, ihr stolzes Selbstgefühl nicht beugen (15116 ff. $15244 \mathrm{ff} .15612 \mathrm{ff} .15754 \mathrm{f} .16078 \mathrm{ff}$.): so ist der in der Volksdichtung so beliebte Typus des Recken, der sich gegen die bestehende Macht oder Rechtsordnung erhebt, der im Herzog Ernst wiederkehrt und in den mit den Reichsfürsten und Städten in Felıde liegenden Rittern (vgl. die historischen Balladen in Uhlands Volksliedern), so auch im Götz von Berlichingen, weiterlebt.

1) Siehe besonders Bernlaards Kreuzzugsbrief an Klerus und Voik des östlichien Frankens und Baierns, Epistola 322.

$\left.{ }^{2}\right)$,Leichtfertige Arbeitsweise ", SCHRÖDER, Einl. S. 72.

$\left.{ }^{3}\right)$ Ueber die Quellen vgl. Wel.ZHOFER aaO.;
SCHRÖDER, Eini. S. $68-73$.

4) LG. I, $17 \mathrm{f}$.

5) Vgl. Singer, Karl unter den Weibern, Schweiz. Archiv f. Volkskunde 22, 112-114.

6) Vgi. dazu SCHRÖDER, Einl. S. 71. 
Ganz besonders tritt der Anteil der Baiern an den Schicksalen des Reichs hervor. Naturgemäß sind sie die berufenen Verteidiger gegen die Einfälle der Ungarn; ausführlich werden bairische Sagen erzählt, so die vom Herzog Adelger schon im römischen Teile; dann die Geschichte von Herzog Otto und seinem treuen Vasallen Hermann, welche zur Ausfüllung der Regierungszeit Lothars I. dient; die abenteuerliche Heirat der Herzogin Agnes $16600 \mathrm{ff}$. und $17248 \mathrm{ff}$. Mehr als alle andern deutschen Städte wird Regensburg, die Hauptstadt 16822, erwähnt, besonders als Sitz für Hoftage 15243. 16152. 16822 f. 16864. 17200. Dieses überwiegende, zum Teil speziell lokal gefärbte Interesse für Baiern, 1 ) in höherem Maße aber noch dazu seine politische Stellung, die in der sympathischen Auffassung Lothars II. und Heinrichs des Stolzen den entsprechenden Ausdruck findet, sind untrügliche Zeichen dafür, daß der Verfasser ein Baier war, und zwar genauer: ein Regensburger Geistlicher. Unmittelbar auf die Persönlichkeit führt die Beobachtung der dichterischen Sprache: das Vorkommen zahlreicher gleicher Verse in der Kchr. und im R.lied, zumeist in den Kampfschilderungen, und die Art ihrer Verwendung setzt einen gemeinsamen Urheber voraus, Dialekt, ${ }^{2}$ ) Versbau und Reim stimmen ebenfalls zusammen, demnach hat der Dichter des Rolandsliedes, der Pfaffe Konrad, auch die Kaiserchronik verfaßt. ${ }^{3}$ ) Die Kchr. ist das spätere der beiden Werke. Erschienen ist sie bald nach 1147 , die zuletzt erzählten Ereignisse, die Vorbereitungen zum zweiten Kreuzzug, fallen in dieses Jahr. ${ }^{4}$ ).

Ein vielgestaltiges Leben entfaltet sich in dieser Geschichtensammlung. Die mit Personen und Handlungen reicher ausgestatteten Novellen sind Kulturausschnitte, die die Sitten der Zeit widerspiegeln.5) Das Leben der Ritter und der Frauen ist anschaulich dargestellt in der Erzählung von der Lucretia: die Frau ist liebreich, züchtig und demütig, treu und tugendhaft, sie verschönert das Leben des Mannes und hält im Haushalt auf feine Formen; der Mann dagegen verbringt seine Zeit auf Kriegsfahrten oder am Hofe mit renommistischen Kameraden und hat rauhe Sitten. Doch auch er trägt große Liebe zu seinem Weibe im Herzen, und wenn sie einem Frevler zum Opfer fällt, ist sein einziger Gedanke die Rache. Der Sinn für Luxus und schöne

1) SCHRÖDER, Einl. S. $45-50$.

2) Dialekt: SCHRÖDER, Einleit. S. 52 ff.; ZWIERZINA, ZfdA. 45, 33. 38. Metrik: W.GRIMM, ZGdR., KI. Schr. 4, Reg. S. 332; SARAN S. 253; s. oben S. 273 Anm. 10.

3) WELZHOFER S. 57-66; SCHERER, ZfdA. 18, 302; SCHRÖDER, Anz. 7, 191, ebda 13, 115, ZfdA. 27, 78; Kchr. Einl. S. 5. 50-59, bes. $55 \mathrm{f}$., Nachtr. S. $440 \mathrm{f}$. und häufig in den Anmerkungen zum Text; KraUs, D. Ged., Reg. S. 273 u. 280 (unter Ruland); LEITZMANN lehnt Konrad als Verfasser der Kchr. ab, Beitr. 43, 26-35, dagegen ScHRÖDER, Gött. Nachr. 1918, 427.SCHRÖDER hält Konrad nicht für den alleinigen Verfasser, sondern ein älterer Regensburger Geistlicher habe das Ganze angelegt und die Einleitung, Tiberius und Constantin-Silvester gedichtet, Konrad habe dabei mitgearbeitet und vom AbschluB der Geschichte des Constantin und Silvester das Werk weiter geführt (Einl. S. 5. 42-45. 59-64. 67 f. u. 439).

4) Zeit und Ort der Abfassung: SCHRÖDER, Einl. S. 39-50. 67 f.; GiesEbRECHT aaO.; WELZHOFER S. 16 ff.; SCHERER, D. Stud. 1, 15, ZfdA. 18, 298 ff.; Kraus, D. Ged. S. 116 Anm. 1; NEBERT aaO.

5) Scherer, QF. 12, 86 f.; E. Henrici, Zur Gesch. d. mhd. Lyrik S. 36 ff.; NEBERT S. 13. 
Lebensführung ist rege. Nicht allein ans Kriegshandwerk denken die Männer, an Hunde, Pferde, Falken 4415 ff., sondern sie sind auch empfänglich für die Schönheit und Tugend der Frau. Eine höfische Sitte besteht und eine, allerdings nicht in Sprödigkeit befangene Galanterie entwickelt sich zwischen den Geschlechtern. Man unterhält sich darüber, ob Frauengunst dem Manne höher zu schätzen sei oder Kampf mit einem kühnen Gegner, und es knüpft sich daran eine Lehre über die Minne, in der diese für die höchste irdische Gewalt erklärt wird; und schon hier, und hier zum erstenmal, wird die Minne als eine sittigende Macht gepriesen, die dem Mann Höfischheit und Kühnheit verleiht, also feine Sitte in der Gesellschaft und Tapferkeit im Kriege, die beiden Gebote ritterlicher Lebensbetätigung 4575 ff. Ein fürstlicher Hofhalt bildet die Umgebung in der Crescentia 11896-12358: der Fischer, der seinen Fang zu Hofe bringt, der Ammann, die Mägde, die gütige Herzogin, die Demut der kaiserlichen Frau und die Rohheit des Viztums - auch hier ist das Weib die edlere Natur. Das Gefühlsleben ist am stärksten in der Faustinianlegende ausgeprägt: Abschied, Verlust der Kinder oder der Gattin, Hülflosigkeit in der Einöde rufen Klaggebärden und Schmerzensausbrüche hervor 1300.72 .1445 .87 f. $1512-27.51-65.1624-27.1704$. 31. 2663-700. 39-41. 98-802. 913-18. 3830-36. 4013 f. Auch freudige Ereignisse bewirken Steigerung der Stimmung 3908-18. Aber die christlichen Glieder der Familie wissen die Kardinaltugend der MäBigung, die

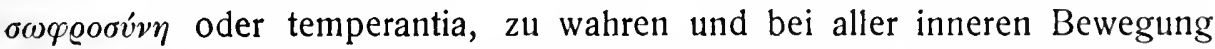
die Affekte zu meistern 2823-2842. 2957-2960. 3919-3931. Doch ist die feine, auf Selbstbeherrschung beruhende höfische Lebensgestaltung, zuht, mâze, noch nicht zur selbstverständlichen Bewegungsform der aristokratischen Gesellschaft geworden. 'Die Bildung ist noch unausgeglichen. Neben Zügen von großer Innigkeit stehen andere von erschreckender Brutalität: wie zart ist die Liebe des Faustinianus zu seiner Frau 1339-1344. 1352 f. 1528-1539. 1631-1636! wie rücksichtsvoll überhaupt das Benehmen der Menschen gegeneinander in dieser Erzählung, der noch von ihrer Entstehung aus dem hellenistischen Roman eine gewisse Weichheit und Sentimentalität eigen ist! wie heimtückisch und roh mißhandelt dagegen der bösartige Viztum die demütige Crescentia, da sie seinen Gelüsten nicht zu Willen ist! Und selbst kaiserliclie Ehegatten traktieren ihre Frauen mit Faustschlägen (Justinian 12846-48, Karl d. Dicke · 15443-47.).

Die Erzählungsweise ist schlicht und schmucklos, ohne Pathos und Rhetorik, manchmal durch eingeworfene Ausrufe belebt, und bewegt sich in einfachen Satzformen mit den gewöhnlichen stilistischen Mitteh. Sehr häufig sind die gleichen Ausdrücke, Sätze, Verse verwendet und solche Wiederholungen finden sich oft in kurzen Abständen.1) Gewohnhcitsmäßig haben sich zweigliedrige Ausdrücke und typische Formeln eingestellt, besonders

i) E. Kettner, ZfdPlı. 9, 285-288. 299. Zum Stil vgl. SCHERER, QF. 12, 86; BeIIAGHEL,
Beitr. 30, 431 ff.; Teurert S. 3 ff. $23 ; 33-41$; ZWIERZINA, ZfdA. 45, 281. 
Berufungen auf daz (diu) buoch, daz liet.1) $\mathrm{Zu}$ dramatischer Lebendigkeit aber steigert sich die Sprache in den Kampfschilderungen. Diese Technik, in der Volkspoesie ausgebildet, war längst Gemeingut auch der geistlichen Dichter geworden und der Pfaffe Konrad hatte ja schon in den zahlreichen Kämpfen des R.liedes häufig Gelegenheit, sie in Anwendung zu bringen. Anklänge an andere frühmhd. Dichtungen finden sich zerstreut und bezeugen ihrerseits ebenfalls Kenntnis der einschlägigen Literatur. $\left.{ }^{2}\right)$ Gegen die äußere Form ist der Verfasser gleichgültig, auch auf die Metrik ${ }^{3}$ ) hat er keine Sorgfalt verwendet, so wenig als auf den Stil. Im Bau der Verse, die sich zwischen Kürze und Überlänge bewegen, und im Reimgebrauch herrscht große Freiheit. Reimnot veranlaßt oftmalige Wiederholung gleicher Verse.4)

Der Verfasser hat mit seiner Chronik die Anschauungen der Zeit gut getroffen. Wie eifrig sie gelesen wurde, das beweist die große Anzahl von Hss.; rasch wurde sie in Baiern und Österreich, dann in Mittel- und Niederdeutschland, nicht aber in Alemannien, verbreitet. Ritterliche Dichter schöpften aus ihr historische Kenntnisse, Heinrich v. Veldeke, der Verfasser des Moritz v. Craon, Meister Otte. Das Buch behielt seine Bedeutung und seinen Reiz auch in veränderten Kulturverhältnissen, nach einem Jahrhundert wurde es ihnen nur äußerlich angepaßt in der jüngeren und jüngsten Bearbeitung; es wurde vorbildlich für die umfangreichen Weltchroniken des Jansen Enikel (nach 1277) und Heinrichs v. München (um 1350) und von beiden stark benutzt, die Sächsische Weltchronik entnahm der Kchr. fabulöse Züge und im 14. Jh. entstand eine Mischredaktion aus der Kchr. und der sächsischen Chronik. Noch im 14. Jh. wụrde die Kchr. in Prosa übertragen (Buoch der künege niuwer $\hat{e}$ ) und noch von Chronikschreibern des 15. u. 16. Jhs. wurden gewisse Teile weiter überliefert. ${ }^{5}$ )

Der Verfasser der Kaiserchronik ist dem Bedürfnis und den Bildungsanforderungen der Zeit gerecht geworden. Ein schöpferischer Geist war er nicht, dem Stoff steht er unselbständig gegenüber und in der Formgebung ist er abhängig von dem allgemein gültigen Typus, aber er war ein geschickter Sammler und Ordner und ein nicht ungewandter Erzähler.

\section{b) Das Spielmannsepos.}

Literatur über die Spielleute s. Bd. I, 62-69. 69-71. 89-95. 128-131 u. Reg. unter Spielmann ff., dazu (bes. für die mhd. Zeit): LachmanN, Kl. Schr. S. 468 ff.; UHLANDS Schriften 1, 271-279; Wilmanns, Walther 1. Aufl. S. 3 ff. 32-35. 39-42 u. Anm., 2. Aufl. von Michels S. 1-4. 16-18. 63-67 u. Anm.; BurdaCH, Reinmar, Reg. S. 231 (Fahrende);

1) Massmann 3, 380-387; Debo S. 1517. 25 f. 27.

2) SCHRÖDER, Einl. S. 56-58; Parallelen aus dem Annol., dem Lob Salomons, Arnolds Siebenzahl, dem himml. Jerusalem, dem heil. Veit kommen auch im R.lied vor, was ebenfalls für die Einpersönlichkeit der beiden Dichter spricht, s. SCHRÖDER ebda; KRAUS, D. Ged., Reg. S. 273; Kelle S. 105. 306 f.
3) W. GRIMm, ZGdR., K1. Schr. 4, Reg.S.332; SCHERER, QF. 7, 30-38; DEBO S. 8-14. 17. 31 f.; SCHRÖDER, Einl. S. 5. 38. 43. 58.75, Gött. Nachr. 1918, 426 f.; VogT, ZfdPh. 26, 559 f. Zur Metrik der Crescentia s. oben S. 273. 4) DEBO S. $15 \mathrm{ff}$.

b) "Fortleben der Kchr.": MassmanN 3, 244-261; Verbreitung und Nachwirkung: SCHRÖDER, Einl. S. 73-78. 
JÄNICKE D.Heldenb. IV, Einl. S. XLVI ff.; Vogt, Salman, Einl. S. CXXIl ff.; Berger, Orendel S. C-CXV; Stosch, Der Hofdienst der Spielleute im deutschen MA., Berliner Diss. 1881; SeEmƠller, Wiener SB. 102 (1882), 612 f.; SchÖNBACH, Wiener SB. 142 (1900), VII, 56-96; PANzER, Erzbischof Albero von Trier und die deutschen Spielmannsepen, Germanist. Abh. H. PAUL dargebr., S. 303-332; HAMPE, Die fahrenden Leute, Leipz. 19C2; EDMOND FAREL, Les jongleurs en France au Moyen Age, Paris 1910; Friedr. KaUfFManN, D. Altertumskunde, S. 314; Schwietering, Gemeit, ZfdA. 56, 125 ff.; Burdach, Berliner AK. 1918 S. 10201022, Deutsche Abende S. 13; Roethe, Deutsches Heldentum, Kaisergeburtstagsrede, Berlin 1906; VoGT, Das Königs- $u$. Kaiserideal in der deutschen Dichtung des MA.s, Kaisergeburtstagsrede, Marburg 1908; BehaGHEL, Der Krieg im ad. Epos, Westerm. Monatsh. 118 (1915) Il, 669-676; Petsch, Germ. Heldentum, Preuß. Jahrb. 164 (1916), 303-318; Roethe, Vom Altert. zur Gegenwart, 1919 S. 152 ff. Weitere Lit. s. Bd. II, 2 unter Heldenepos.

Die empfindlichste Lücke in der Beschreibung unserer älteren deutschen Literatur besteht in der Unkenntnis unserer Volksdichtung. Gerade diejenigen Schöpfungen, in denen sich das deutsche Geistesleben am unmittelbarsten ausgesprochen haben mochte, die volkstümlichen Gedichte, sind verschollen. Zwischen dem einzigen Rest unserer althochdeutschen Skopfdichtung, dem Hildebrandslied, und dem zeitlich demnächst uns erhaltenen frühmittelhochdeutschen Spielmannsepos vom König Rother liegen dreiundeinhalb Jahrhunderte, liegt die große Wandlung der Verskunst - vom Stabreim zum Endreim -, der technischen Gattung — vom Lied zum Epos -, vom germanischen Skop zum mittelalterlichen Spielmann.

Spielmann war im Grunde jeder, der ein Spiel zur Unterhaltung anderer und um Lohn betrieb. Darum waren die Geschäfte der Spielleute' ${ }^{1}$ manchfaltigster Art und bewegten sich in sehr verschiedenen Sphären menschlicher Tätigkeit. Man kann zwei Rangstufen unter den Spielleuten unterscheiden, die sich aber nicht streng trennen lassen, eine niedere und eine höhere Zunft. $\mathrm{Zu}$ jener gehörten die „unehrlichen Leute“, 2) Marktschreier und Possenreißer jeglicher Art, Gaukler, Tänzer und Springer und Kunstreiter und Tierbändiger, Mimen und Puppenspieler, die sich im Land herumtrieben und auf den Straßen und Plätzen oder in den Wirtshäusern ihre Kunst der Menge zum Besten gaben; Musikanten, Fiedler ınd Pfeifer, die unter der Linde oder in der Schenke zum Tanze aufspielten. $\mathrm{Zu}$ Volksfesten, Kirchweihen, Jahrmärkten, Hochzeiten strömten sie zusammen oder zogen im Troß dem Heere auf dem Marsche nach. Bei Erecs Hochzeit waren es mehr als dreitausend (Hartmanns Erec 2158 ff.), dem Heere des Heidenkönigs Ymelot folgtcn wohl

1) Die varnden, varnde liute, varndiu diet, varndez vole, als einzelner ein varnder man; die gernden (Gehrenden Bettelnden), gernde liute, dit gernde diet. Der Possenreißer ist der gumpelman (mhd. gumpel Springerei, Possengetrieb, verb. gumpeln), hovegumpelman Possenrelßer bel Hole; spilman, spilliute, spilwip, tanzer, springer, singer, gîger, videler, pfifer, vloitierer, harpfare, rottore, tamburare, vgl. LG. I, 63-69; PIPER, Spielm. D. 1, 11; SchöNBACH aaO. Instrumente:
Alw. Schultz, Hof. Leben 12, 551 ff.; Fleischer, Pauls Grundr. II, 22, 313; Piper, S. 11, Höf. Ep. 3, 710. - Spielmanusnamen: Piper S. 29-31; Múllenhoff, ZfdA. 7, 530 f., Zur Runenlelure S. 54, Z. Gescli. d. Nibelunge Not S. 19.71; Ludw. SCHÖNACH, ZfdA. 31, 171-185; Alfr. SchaER, Die ad. Fechter u. Spiclleute S. 105-108. 131 ff.; WALLNER, Belir. 33, 540-546.

2) LG. I, 86. 
hundert Spielmänner (Rother $4293 \mathrm{ff}$.). Die fahrenden Leute wurden von den Herren zu mancherlei Diensten verwendet, als Boten, Kundschafter, Kuppler, oder um in Verkleidung listige Anschläge auszuführen. Gerade die folgenden Spielmannsepen eröffnen lehrreiche Einblicke in das Leben und Treiben der fahrenden Leute, denn mit naiver Eitelkeit und selbstgefälligem Behagen messen die Verfasser ihrem Stande und auch den niederen unter ihren Zunftgenossen eine besondere Wichtigkeit bei.

Die Geschichte des Spielmannswesens ist bedingt durch die kulturellen und politischen Wandlungen. Solange die nationale Sitte herrschte, war der Sänger ein angesehener Mann am Fürstenhofe, ein geehrtes und gefeiertes Glied unter der Gefolgschaft. Aber als die Kirche die Volksbildung klerikalisierte und die Verehrung der heimischén Heldengestalten zusammt dem Schicksalsglauben $z \mathbf{u}$ verdrängen begann durch die Lehre vom dreieinigen Gott und dem leidenden Erlöser, als die Literatur sich spaltete in einen höheren, geistlichen und einen niederen, weltlichen Teil, da verlor auch der Volkssänger seine bevorzugte Stellung, - er war ja nicht mehr der Träger der geistigen Werte und Ideale -, und näherte sich dem rö mischen Mimus, ${ }^{1}$ ) der schon seit der Völkerwanderungszeit die Höfe mit leichterer, auch leichtfertigerer Kunst ergötzte. Die abgünstige Stimmung der Kirche gegen die Spielleute findet auch in der frühmhd. Zeit in manchen polemischen Worten, mit denen geistliche Verfasser auf ihre lügenhaften Geschichten anspielen, kräftigen Ausdruck. ${ }^{2}$ )

Höheres Ansehen als jene vor dem Volke auftretenden Straßenkünstler genossen die bei den Höfen zugelassenen Sänger. Die Liebe zur alten Heldensage war im Volke noch lebendig, ${ }^{3}$ ) mehr noch auf den Burgen des Adels vor den vornehmen Herren und Damen wurde von den Riesenund Drachenkämpfen Dietrichs von Bern oder von dem Untergang der Nibelunge gesungen; wie ehedem in früheren Jahren so war es auch jetzt noch die Aufgabe der Hofdichter, die Gesellschaft $z \mathbf{u}$ unterhalten und $\mathbf{z u}$ belustigen, besonders bei den Gelagen. ${ }^{4}$ ) Neben der nationalen wurde hier, wie im Volke, auch die lehrhafte Poesie gepflegt und die Spruchdichter waren als Bewahrer alter Volksweisheit Lehrer sittlicher Grundsätze und praktischer Klugheitsregeln. Vor allem war es auch ihnen um die Gnade der Herren zu tun und sie entfalteten eine rege Tätigkeit in Preissprüchen, mit denen sie den Ruhm der freigebigen Gönner verbreiteten.

Auch diese Hofdichter betrieben ihre Kunst als Handwerk, sie nahmen Belohnung für das Lob, das sie den Herren sangen, ${ }^{5}$ ) kostbare, atch ge-

1) Ueber den Mimus s. LG. I, Reg. S. 464.

2) SCHERER, QF. 12, $17 \mathrm{ff}$.

3) Quedlinburger Annalen, LG. I, 90.

4) Von Hofsängern berichten zwei Erzăhlungen des dänischen Geschichtschreibers Saxo Grammaticus (um 1200, zu den Jahren 1131 u. 1157, Saxo ed. Holder S. 427 f. 490 , vgl. W. GRIMM, DH. ${ }^{3}$ S. 53 f.; MUlLENHOFF, ZfdA. 12,335-337; KÖGEL, LG. 1, 2, 195 f.

5) Guot umb êre nemen, s. bes. BURDACH, Reinmar S. 132. - Musik war aber auch Herrenkunst: Ruodlieb (SEILER IX, 30 ff.) und Rother (s. unten) spielten die Harfe. Der Typus des ritterlichen Spielmanns ist ver- 
tragene Kleider, ein Pferd, Geld. Auch sie entstammten allerlei sozialen Kreisen, viele mochten schon von Herkunft der wandernden Gesellschaft angehört haben, ihnen lag die Künstlerbohème im Blut, manche kamen, die ihren Beruf verfehlt hatten, verbummelte Scholaren, entlaufene Kleriker, Vaganten; es waren aber auch ernst strebende Männer darunter, die durchdrungen waren von den hohen ldealen ihrer Zeit, der Kirche und des Rittertums.

Die Stoffe der Spielmannsepik lagen in dem allgemein überlieferten Schatz von Geschichten, Märchen, Schwänken, Anekdoten, von biblischen Erzählungen und Legenden bereit, dazu fanden merkwürdige Taten und Begebenheiten der Gegenwart als niuwiu more begierig Aufnahme. Die Kreuzzüge, die dem Abendlande eine neue Welt erschlossen, lieferten neue Stoffe, vor allem aber gaben sie einen veränderten Schauplatz ab, und zwar einen solchen, auf dem die fesselndsten Ereignisse der Zeitgeschichte spielten, wobei nunmehr die Spieler und Gegenspieler sich teilten in Christen und Heiden. Der beliebteste Gegenstand war die Entführung der Braut, $\left.{ }^{1}\right)$ jenes alte, in Geschichte und Literatur weit verbreitete Thema, wie der Mann sich das Weib erringt durch List oder Gewalt oder durch beides, das auch aus der Frühzeit der Griechen und der Römer überliefert ist (Raub der Helena, der Sabinerinnen) und seine Wurzel in der wirklichen Geschichte, in den sozialen Zuständen primitiver Kulturen hat. In diese Form ist in der Spielmannsdichtung das Liebesbegehren vom Mann zur Frau gekleidet, es ist nicht Minne, eine das ganze Gefühlsleben ergreifende Leidenschaft, das süße Geheimnis von Wonne und Weh, sondern es handelt sich um die Ehe, das heißt meist um einen politischen Akt, zu dem Zweck die Nachfolge $\mathrm{zu}$ sichern.

Der ethische Ton der"Spielmannsdichtung ist charakterisiert durch einen humoristischen Einschlag und darin liegt der Unterschied gegen die nationale Heldensage, die in ihrem erhabenen Pathos der sittliche Ausdruck einer Welt-

treten durch Volker im Nibelungenlied, durch Horant in der Kudrun. Spielleute im Gefolge der Hersen: W. GRIMm, DH ${ }^{3}, 423-425$.

1) Werbung, Entfiuhrung oder Brautraub bildet das Grundmotiv im Walthariuslied (eine Werbung auch im Ruodlieb, LG. I, $393 \mathrm{ff} .400 \mathrm{ff}$.), Rother, Salman, Oswald, Orendel, Nibelungelied, Kudrun, Ortnit, Hugdietrich (Werbung auch in der Exodus [Isaac], im Ged. Von d. Hochzeit), oft in der Thidrekssaga. Literaturangaben s. bei den folgenden Spielmannsged., ferner in den Werken uber die deutsche Heldensage: W. Grimm, W. MÓller, SYMONS, V. D. Leyen; PANzer, Hilde-Gudrun; Ders., Sigfrid; BAEsecke, Miinch. Osw., bes. S. $266 \mathrm{ff}$; SCHNEIDER, Wolfdictr.; HeINZEL, Ueber d. Walthersage S. $66 \mathrm{ff}$; BURDACH, Verl. der 44. Plıilol.-Vers, in Dresden 1897 S. 29; VoRETZsCH, Epische Stud. 1, 189 ff. 337 ff.; Ders., Philol. Stud. für Sievers S 87 ff.; Wecissler,
ZfromPh. 25, 449-471; DEUTSCHBEıN, Studien S. 274 ff.; VoGT, ZfdPh. 23, 496; SiNGER, ZfdA. 35, 177 ff.; Heusler, Germ. Abh. für Herm. Paul S. 12 ff. Il. ö.; Ders., Hoops Real-Lex. 1, 376; V. UNWERTH, Beitr. 38, 280 ff.; WolfSkehl, Germ. Werbungssagen; FR. R. SCHRÖDER, Germ.-5om. Monatsschr. 1920 , 288; Dorsch, Zur Herbortsage, Hall. Diss. 1902; TARDEL, Unters. zur mhd. Spiclm.poesie, bes. S. $33 \mathrm{ff}$; SchMEING, Fluclit- t. Werbungssagen in der Legende, Miinst. Diss. 1911; THIEN, Uebereinstimmende Motive; Büririg, Sage vom K. Rother; SCHOEPIERLE, Tristan and lsolt, 1913, S. 188 If.; EDWIN Sidney HaRTiand, The Legend of Persens. - Häufige Nebenmotive siud: Verkleidung (Gestaltenwechsel), Träume; typische Personen: der werbende lleld, der die Tochter versagende Vater, die unworbene Prinzessin, die günstig gesinnte Mutter, der hilfreiclic Dämon. 
anschauung ist. Der germanische Nationalsänger ist ein Lehrer, ein Seher und Verkündiger der hohen Wahrheiten, die den geistigen Kulturbesitz seines Volkes ausmachen, der Spielmann will unterhalten und ergötzen. Das GroteskKomische ist sein Element, Überlistungen, Verkleidungen, Prügeleien sind stehende Motive seines Spielplanes und in dieser niederern Richtung offenbart sich seine Verwandtschaft mit dem Mimus.

Die germanische Form für die erzählende Dichtung war das epische Lied, die Ballade. Eine bedeutende Änderung im Vortrag und in der ganzen Anlage erfuhr diese kürzere Gattung des Liedes durch die Erweiterung zum Leseepos. $\left.{ }^{1}\right)$ Dies geschah unter dem Einfluß der weltlichen Literatur der Geistlichen, des Alexander- und des Rolandsliedes. Das Lied wurde mit stark musikalischem, rezitativischem Ausdruck, wohl mit begleitendem Instrument, vorgetragen, das Epos dagegen mehr in einfachem Sprechton, ohne Musikbegleitung.

Das Epos besteht aus einer bedeutend größeren Anzahl von Motiven. Den Zentralpunkt bildet das Kernmotiv, das Sagenthema. Dieses wird bestimmt durch die Hauptmotive, das sind die notwendigen, unentbehrlichen Bestandteile, in denen sich das betr. Thema darstellt, die planbauenden (konstruktiven) Elemente. Der aus diesen Hauptmotiven bestehende Grundstock wird erweitert durch den Anschluß einer kleineren oder größeren Anzahl von Nebenmotiven, die für den Inhalt mehr oder weniger bedeutsam sind und darum wieder in Nebenmotive ersten und zweiten Grades geteilt werden können. Eine genaue Scheidung zwischen diesen beiden Wertgruppen läßt sich nicht machen: die bedeutenderen Nebenmotive sind solche, welche die Handlung fortführen durch erzählenden, fabulierenden Inhalt, während die minder wichtigen Nebenmotive bloß zur Erweiterung, Dehnung, Anschwellung dienen. Sie können dabei ebenfalls Erzählung enthalten, fügen aber dann der Handlung kein bestimmendes Moment hinzu, sondern vermehren nur die Anzahl oder den Umfang der die Handlung fortführenden

1) Von der "liedhaften Knappheit" zur "epischen Breite": Heusler, Lied u. Epos in germanischer Sagendichtung, Dortmund 1905, S. 21 f., dazu PANZER, DLZ. 1908, 133 -139; HeUSLER, Dialog in der altgerman. erzählenden Dichtung, ZfdA. 46, 189-284; Ders., Das Nibelungenlied u. die Epenfrage, Internat. Monatschr. 13. 97 ff. 225 ff.; Ders., Nib.sage u. Nib.lied, Dortmund 1921; Ders., Einl. zu Genzmers Uebersetzuug d. Edda I u. II; Ders., Heliand, Liedstil u. Epenstil, ZfdA. 57, 1 -48; Ders., Anz. 31, 115 f.; Ders., Berl. Ak. 1918 S. 153; PANZER, Das ad. Volksepos, Halle a. S. 1903; JOHN MEIER, Werden und Leben des Volksepos, Halle a. S. 1909, dazu Heusler, Anz. 33, 129-136; W. P. KER, Epic und Romance, London 1908; NECKEL, Beiträge zur Eddaforscluung mit Exkursen zur Heldensage, Dortmund 1908; Ders., Die
Nibelungenballaden, Aufs. f. Braune S. 85 ff.; HELM. DE BOOR, Die färöischen Lieder des Nibelungenzyklus S. $8 \mathrm{ff}$.; BAESECKE, Deutsche Philologie, Wissenschaftl. Forschungsberichte III, 1919, S. 84 ff.; Jos. KöRnER, Die Klage u. d. Nibelungenlied S. 31 ff.; SCHNEIDER, ZfdA. 58, 97 ff.; LG. I, 128 f. - Die kurze Form der Enlführungsballade hat auch neben dem umfänglichen Epos weiter bestanden, aber iiberliefert sind uns epische Lieder dieses Inhalts erst seit dem Wiedererblithen des Volksliedes; ein Beispiel ist das Lied vom Ulinger mit seinen verschiedenen Abarten (Uhlands Volkslieder Nr. 74), vgl. LG. I, 65. 241. - Zur Entstehung des Volksepos ferner Axel Olrik, ZfdA. 51, l ff.; K. KROHN ebda $13 \mathrm{ff}$; ERICH BeTHE, Homer. Dichtung und Sage, 1914. 
Motive (Häufung, Wiederholung). Oder sie bestehen in einer Ausmalung des Kostüms und haben nur ornamentale, dekorative Wirkung: das sind Schilderungen und Beschreibungen von Kämpfen und Heeresaufgeboten, von Kleidern und Rüstungen, Festen, Empfängen. ${ }^{1}$ ) Die technische Aufgabe bei der Verarbeitung eines Liedtextes oder Liedstoffes zu einem Epos bestand im Grunde einfach in der Verlängerung des Umfangs, d. h. in der Erweiterung durch die Nebenmotive.

Die Überlieferung der Spielmannsgedichte war sehr frei. Mochten auch die Fahrenden geschriebene Texte besitzen, Büchlein²) oder Einzelblätter, in der Hauptsache trugen sie ihre Stoffe gedächnismäßig vor. Bei der Art der Verbreitung war natürlich der ursprüngliche Typus starken Veränderungen ausgesetzt und die Vortragenden verfuhren sehr willkürlich mit ihren Quellen, sie änderten den Wortlaut, machten Zusätze, kürzten nach Belieben. Demzufolge weichen auch noch unsere Handschriften vielfach voneinander ab.

Die Heimat dieser Spielmannsgedichte waren die Rheinlande, ${ }^{3}$ ) dahin weist der mittelfränkische Dialekt der uns erhaltenen Stücke. Die alten fränkischen Kulturlande um Köln, Trier, Aachen sind von jeher in naher Beziehung zu der westlichen Bildung gestanden, dort auch entwickelte sich zuerst jene in der Lebensauffassung und im Stil eigenartige spielmännische Literatur, deren erste Anzeichen uns in den geistlichen Balladen vom Lob Salomons, den drei Jünglingen und der älteren Judith überliefert sind. Die rheinischen Spielleute fanden besonders in Bayern gastliche Aufnahme und verbreiteten dort ihre Erzählungskunst und ilıre neuen Stoffe.

Literatur über den Stil der Spielmannsdichtung: J. Grimm, D. Rechtsaltert. S. 1 ff.; Heinzel, Ueber d. Stil d. altgerm. Poesic, QF. 10; R. M. MeYer, Die altgerm. Poesic nach ihren formelhaiten Elementen 1889; OTTo HofFMANN, Reimformeln im Westgerm., Freib. Diss. 1885. - Für das Ahd. u. As. s. die in Braunes LB. unter 'Literar. Nachw.' angeführten Arbeiten: für den Heliand: Sievers Ausg. S. 391-495, dazu RöDiger, Anz. 5, 267-277; Paschaly, Behaghel (Hel. u. as. Ges.), Pauls; für Otfrid: Paul Schütze; NauMann, Boethius S. $86 \mathrm{ff}$ - - Für das Frülımhd.: Behaghel, Germ. 24, 167 ff.; Ders. Beitr. 30, 431 ff.; Schröder, Anegenge S. 24 ff.; Kraus, D. Ged. in den Anm. S. 71 ff. u. Reg.

i) RUD. Fischer, Zu den Kunstformen des m.alterl. Epos, Wien u. Leipz. 1899.

2) Erhalten ist uns nichts dergleichen, aber die Ueberlieferung vom Lob Salomons und der damit verbundenen geistlichen Spielmannsballaden deutet auf eine solche SammelHs., s. oben S. 6 f. Vgl. VoGT, ZfdPlı. 22, 487.

3) Vgl. bes. John Meier, Stud. zur Sprachu. Literaturgesch. der Rheinlande, Beitr. 16, $64 \mathrm{ff}$. (speziell 79 ff. 92 ff.); VoGT, Gött. gel. Anz. 1912, 243-251; Gierach, Sprache Eilharts S. 259; BAESECKE, Die Westinark 1, 363-368. - Bezichungen zwischen der deutschen und französisclien Spielmannskunst haben bestanden und der Einfluß der Jongleure auf dic deutsclse Spielmannsdichtung ist anch in Einzelleiten ersichtlich, vgl. SCHERER, QF. 12, 22 f.; HFnNing, Nibelungenstudien, QF. 31, 19 ff.; HEINZEL, Ostgot.Helden-

Deutsche Lileraturgeschichte. II. sage S. $68 \mathrm{ff} .77 \mathrm{ff}$; PNIOWER, ZfdA. 33, 73 ff.; die Abhandlungen von SINGER ïber Apollonius und Tardel s. unten bei Orendel; LEO WOLF, Der groteske u. hyperbolische Stil, Palaestra 25, 8 f.; Singer, Neujalirsblätter der literar. Gesellsch. Zu Bern 1917; Ders. MA. u. Renaiss. S. 52 f. Ueber germ. (altfränk.) Elemente im a franz. Heldenepos: Voretzsch, Einführung Kap. Il \$ 4 u. Ep. Stud. 1; PIo Rajna, Le origini dell' epopea francese, Turin 1884; (iUst. BRockstedt, Floovent-Studien, 1907, dazı Blötte, Anz. 34. $49-52$ i. Brockstent, Das a.franz. Siegfridlied, 1908, dazu BıötT, Anz. 34, 53-55: BURIACH, Deutsclie Abende 1H. 4 S. 13; Heusier, Aufsätze fïr Braune S. 79 ff., Nib.sage 11. Nib.lied S. 33. 88; Voretzsci, Zur Gesclı. d. Nibelungensage in Frankreich u. Dentschland. ZfdA. 51, 39-59. 
passim; ZWierzina, ZfdA. 45, 262 f. 264. 267. 281 ff.; Ehrismann, ZfdW. 1, 129 ff. Lachmann, S. u. S., Kl. Schr. S. 461 ff.; Schwietering, Singen u. Sagen, 1908; Thurau, Singen u. Sagen, 1912; HeuSler, Anz. 31, 113-115. Für Gen. u. Ex.: Weller, Bulthaupt, KossMANN, PNiower (ZfdA. 33, 80 ff.); Hartmanns Rede v. Gl.: v. D. Leyen; Wernhers Marienl.: BRUINIER; Al.lied: KInZEls Ausg. in den Anm.; R.lied: BAUMgarten. Für die Spielmannsdicht.: PIPER, Spielm. D. 1, 57-74; Einl. zu den 5 Bden des deutschen Heldenbuchs hgb. von MÚllenhoff usw.; Walther Vogt, Germ. Abh. 20, dazu Behaghel, Lit.Bl. 1905 S. 6, Panzer, ZfdPh. 38, 551 ff.; Hellwig, Giess. Diss. 1898; Held, Pal. 31; Leo Wolf, Pal. 25; DicKhoff, Pal. 45; Herchenbach, Pal. 104; Friedr. WahnschafFe, Pal. 132; LaCKNer, Greifsw. Diss. 1903; Hawel ebda 1908; Bernatzky ebda 1909; Bode ebda 1909; KotZenberG, Berl. Beitr. Heft 23 (1907). Böckel, Deutsche Volkslieder aus Oberhessen 1885; DAUR, Das alte deutsche Volksl., 1909; Kracke, Giess. Diss. 1911; Lindemann, Bresl. Diss. 1914; Salomon, Gött. Diss. 1919; Ehrismann, ZfdW. 2, 145-159. - Zum Rother: ThiEn, SchmeDES, Wiegand. Zum Salman: Vogrs Ausg. S. CXVIIl ff.; Walther Vogt aaO. Zum Oswald: Baeseckes Ausgaben passim, Ehrismann, Anz. 32, 184-193; E. H. Meyer, ZfdA. 12, 394 f.); Rödiger, Anz. 2, 258; Walther Vogt aaO. Zum Orendel: Bergers Ausg. S. CXIV f.; Vogt, ZfdPh. 22, 476 ff.; WAlther Vogt aaO. Zu Ortnit und Wolfdietrich: AmElung u. Jänicke im Deutschen Heldenbuch Bd. 3 S. LXV ff. u. Bd. 4 S. XLVI; LeHNERDT, Germ. Abh. 36. Zur Virginal: v. Kraus, ZfdA. 50, 1-123. Zu Eilhart: Lichtensteins Ausg. S. CL ff. Zum Gr. Rudolf: BETHMANN, Pal.30. Formeln mit "sprechen " und Redeeinleitung: DWb. 9, 2805.2812 ff.; Heusler, ZfdA. 46, 189-284; ScmwartzkopfF, Pal. 74, däzu LunZer, Anz. 35, 131-140. — Ferner Hơnnerkopf, Heidelbg. Diss. 1914, Trautmann, Gött. Diss. 1917, Droege, ZfdA. 58, 19 ff. Weiter folgen dann die stilist. Abhandlungen zum Nibelungenlied u. zur Kudrun.

Unter den vier älteren Spielmannsepen ist der Rother das vornehmste. Es ist für hohe aristokratische Kreise in Bayern verfaßt und spiegelt den Geist der ritterlichen Gesellschaft um die Mitte des 12. Jhs. wieder. Die innere Auffassung ist stark heroisch abgetönt, Salman und Morolf und auch, mehr geistlich gefärbt, Orendel und Oswald sind viel volkstümlicher gehalten und für breitere Kreise gearbeitet. Der Rother stellt eine ältere, vorhöfische Stufe ritterlicher Epik dar, die drei andern haben den reinen Spielmannston, am stärksten der Salman. Der Rother trägt besonders durch die Dienstmannensage und das Reckenmotiv den Charakter eines nationalen Epos, Oswald und noch mehr Orendel haben von vornherein keinen nationalen sondern legendarischen Stoff, und im Salman und Morolf ist ursprünglich byzantinisch-orientalische Sage am wenigsten mit mittelalterlich feudaler Anschauung durchtränkt.

Aus ahd. Zeit ist uns nur ein Heldengedicht erhalten, das Hildebrandslied (s. LG. I, 115-131), das nächstfolgende volkstümliche Epos ist das Spielmannsgedicht vom König Rother.

\section{$\$ 80$. König Rother.}

Kelle 2, 219-223. 389; PiPer, Sp. 1, 75-108, Nachtr. S. 243, Höf. Ep. 3, 711. - Ausg.: v. D. HAgen u. BÜsChing, D. Ged. d. MA. 1. Bd., XII, 64 S. (nach einer Abschrift von TIECK, vgl. Haupt, ZfdA. 15, 264), dazu J. Grimm, Heidelberg. Jahrb. 1809, 2, 156-164 u. K1. Schr. 4, 28-34, Hoffmann, Fundgr. 1, 215-219; Massmann, D.Ged. S. 157 f. 162-234; Heinr. RÜCKERT, Deutsche Dichtungen des MA.s (Brockhaus) 1. Bd., 1872, dazu LAMBEL, ZföG. 24 (1873), 168-181; v. BAHDER, Ad. Textbibl. Nr. 6, Halle 1884, dazu RöDiger, Anz. 11, 109116, VoGT, Lit.B1. 1885, 315-317, LC. 1885, 612 f. - Neubearbeitungen: G. L. KLEE, Gütersloh 1880; Emil Taubert, Berlin 1884; Hans Zimmer, Hendels Bibl. 352. - Scherer, QF. 12, 
92 f. u. ZfdA. 18, 305 f.; EdZARDI, Untersuchungen über König Rother, Leipz. Diss. 1874 u. Germ. 18, 385-453. 20, 403-421; v. BAHDER, Germ. 29,229-243. 257-300; J. THIEN, Uebereinstimmende und verwandte Motive in den deutschen Spielmannsepen, im Anschluß an „König Rother", Progr., Hamburg 1882; Heinr. BÜhrig, Die Sage vom König Rother, Gött. Diss. 1889; LudW. Singer, Zur Rothersage, Progr. des akad. Gymn. zu Wien 1889; Jul. Wiegand, Stilist. Untersuch. zum K. R., Germ. Abh. 22, dazu A. Bernt, Anz. 32, 171-174; FranZ Pogatscher, Zur Entstehungsgesch. des mhd. Ged. vom K. R., Halle 1913, dazu BAESECKE, DLZ. 1914, 1062-1064; ARN. PieritZ, Die Stellung des Verbums im K. R. usw., Greifsw. Diss. 1912; GotThaRd Berndt, Die Reime im K. R., Greifsw. Diss. 1912; OtTo WeisLEDER, Die Sprache der Heidelb. Hs. des K. R. (Lautlehre), Greifsw. Diss. 1914; SCHRöDER, ZfdA. 48, 363 f.; Leitzmann, Beitr. 42, 512-516; Jan DE VRIEs, Het epos van Koning Rother, Tijdschr. v. Nederland. Taal-en Letterk. 38 (1921) Nr. 1 ff.; Heusler, Hoops Real-Lex. 3, 533 f., wo weitere Lit. - Siehe auch PANZER, Hilde-Gudrun, Reg. S. 451; BAESECKE, Münch. Osw., Reg. S. 443; SchneIder, Wolfdietrich, Reg. S. 417 (dazu BAESECKe, Anz. 38, 42-51); Heusler, Nib.sage u. Nib.lied, Reg. S. 235.

Die Uberlieferung. ${ }^{1}$ ) Die einzig vollständige Hs. ist $\mathrm{H}$, die Heidelberg. $\mathrm{Hs}^{2}{ }^{2}$ Cod. pal. germ. 390, perg., noch im 12. Jh. von zwci Schreibern geschrieben. ${ }^{3}$ ) Die Sprache ist nicht einheitlich, streng mfrk. Mundartlichkeiten wechseln mit gemein-md. Formen ab. Eine Mischung mag schon in der ursprünglichen Fassung bestanden haben, auch mögen spätere Schreiber noch daran beteiligt gewesen sein. ${ }^{4}$ ) Die mfrk. Bestandteile tragen einen etwas jüngeren Sprachcharakter als der aus den Reimen zu erschließende Originaltext. Der Text von $\mathrm{H}$ ist schlecht, entstellt durch zahlreiche Lese- und Schreibfehler.

Münchener Bruchstücke, $\left.{ }^{5}\right)$; Cgm. 5249, 1, Querstreifen Anf. des 13. Jlıs., entlält die V. 4062-4080. 4099-4148, aaO. 4584-4604. 4621-4640. Die Sprache ist vom Schreiber aus dem $M d$. ins rein Obd. (Bairische) umgesetzt. In der Textfassung steht $M$ dem Original unter allen Hss. am nächsten. Sie enthält nicht die Verse $4107 \mathrm{f}$. und $4115-4142$.

A. Das v. Arnswaldische (Hannoversche) Bruchstück, ${ }^{6}$ ) in Berlin, Ms. germ. fol. Nr. 923 (Fragmenteamappe). Es enthält den Schluß des Gedichtes von 5140 an mit zwei Lücken. Die Sprache ist etwas mehr obd. gefärbt als die von H. A ist eine Umarbeitung des Grundtextes mit Herstellung reiner Reime.

Die folgenden mit B bezw. E bezeichneten Bruchstücke gehören ein und dersclben Hs. an. B. Badener Bruchstück, ${ }^{7}$ ) aus Baden, Kant. Aargau, im Germ. Museum zu Nürnberg Nr. 27744, ein Perg.streifen, 13. Ji., V. 1002-1054.

E. Ermlitzer Bruchstück, $\left.{ }^{8}\right) 2$ Perg.-Doppelbl., in Privatbesitz zu Ermlitz. Es entspricht den Versen 1387-1815.

Die Hs. BE ist eine stark veränderte Bearbeitung des Grundtextes, die aber auf eine gute Vorlage zurückgeht. Es ist eine Umschreibung ins Obd. mit Tilgung veralteter (bairischer) Worte, die den Versbau regelmäßiger macht und die ungenauen Reime zum Teil beseitigt (etwas uber ein Drittel der Assonanzen ist in genaue Reime verwandelt worden). Auch enthält sie Einschiebungen, die in $\mathrm{H}$ nicht stchen.

1) LAMBEL aaO.; EDZARDI, Germ. 18 u. 20 aaO.; v. BAHDER, Germ. 29, 265 Anm. u. 275 f.; SCHRÖDER, ZfdA. 35, 419 Anm. u. 42,111 .

2) BARTsCH, Katal. Nr. 212; Sprache von H: EDZARDI, Germ. 18, 403-420. 450-453; v. BAHDER, Germ. 29, 257-276 แ. Ausg. S. 6 f. $11-14$; Weisleder aaO.

3) Dic Versziffern bezlehen sich auf die Ausg. von V. BAHDER.

4) Die $t$-Verschiebung in Ausl. ist noch nicht ganz durchgedrungen z. B. scat, liet, vôt neben denen hd. scaz, liez, vuoz, ähnlich ist $g o t t$ alte mfrk. Dialektform, $g \hat{t} t$ md. sclırift- sprachl., guot lid. Ueber die Verschiebung der nd. Spracligrenze im Mfrk.: WREDE, Zflıd. Mundarten 14, 3 ff.; Frings, Beitr. 39, 362 ff. 40. 348 ff. 41,193 ff. 42,177 ff.; DLZ. 1915, $2269 \mathrm{ff}$.

5) Keinz, Münclı. SB. 1869, 2, 307 ff.

6) Abgedr. bei Massmann S. 232-234, dazu S. 158; s. EDZARDI, Germ. 20, 421: SCHEEL, Festgabe an Karl Weinliold (1896) S. 48 .

7) Abgedr. in GirafFs Diut. 2, 376-378; EDZARDI, Germ. 20, 419-421.

8) Abgedr. von v. Bahlder, Giermi. 29, 229 $-243$ 
Demnach hatte die Münchener Hs. den Versbestand am ursprünglichsten bewahrt, während IH schon erweitert hat. A und E B sind Reim und Vers glättende Umarbeitungen, in denen der alte Text sehr stark verändert ist.

Die Überlieferung des Gedichtes ist, da die einzige vollständige Hs. $\mathrm{H}$ sehr fehlerhaft st und die Bruchstücke viel geändert haben, recht ungünstig.

Der Diale kt des Gedichtes ist, wie sich aus den Reimen ergibt, mittelfrk. ${ }^{1}$ ) Der Verfasser war ein Spielmann, er dichtete aber für den bairischen Adel.

Für die Bestimmung der Abfassungs zeit stehen nur allgemeine Gesichtspunkte zu Gebote: die Erwähnung des Meraner Herzogtitels und die Beschaffenheit der Verstechnik weisen etwa auf das Jahrzehnt von 1150 bis 1160.1)

Der Inhalt des Gedichtes beruht auf einer Wiederholung des Grundmotivs, er besteht also aus zwei Werbungsgeschichten.

A. Erste Werbungsgeschichte $1-2942$. 1. Rothers Werbungsplan 1-429. Die Hofgenossen raten dem jungen König zur Heirat. R.s Boten, Söhne seines vertrauten Ratgebers Berchter, werben die Botschaft bei Konstantin in Konstantinopel, aber der läßt sie ins Gefängnis werfen. Trauer Rothers um die treuen Boten. II. Rothers Reckenfahrt 430-1908. R. zieht in Verkleidung als verbannter Recke unter dem Namen Dietrich mit Heer nach Konstantinopel, darunter die Riesen Asprian und Widolt. Ill. Die Liebesszene 1909-2322. R., in das Gemach der Prinzessin gebeten, legt ihr als Geschenk zwei kostbare Schuhe an und gibt sich ihr dabei als König R. zu erkennen. IV. Freigabe der giefangenen Boten 2323-2562. Auf Bitten R.s werden durch Vermittlung der Prinzessin die Gefangenen aus dem Kerker zur Mahlzeit geführt. An einem Harfenlied, das R. hinter einem Vorliang spielt, erkennen sie ihren Herrn. Große Freude des Wiedersehens. V. Die Entführung 2563-2942. Der Heidenkönig Ymelot fällt ins Land. Bei der kriegerischen Verwirrung lockt R. die Prinzessin auf sein Schiff und entflieht mit ihr in seine Heimat.

B. $Z$ weite Werbungsgeschichte 2943-4995. I. Die Rü ckentführung 2943-3268. Ein Spielmann als Kaufmann verkleidet lockt durch seine kostbaren Waren die Gemahlin R.s auf sein Schiff und bringt sie ihrem Vater zurück. II. Das Wiedergewinnungsabenteuer 3269-4757. R. zieht mit Heer nach Konstantinopel. Er kommt in Verkleidung gerade zur Vermällungsfeier seiner Frau mit Basilistium, dem Sohn Ymelots. Er wird entdeckt, zum Galgen geführt, aber durch sein Heer und das des befreundeten Grafen Arnoli befreit. III. Di e H eim k eh r 4758-4995. Als Sieger kehrt er mit seiner Frau nach Bari zurück; ihr Sohn ist Pippin, der Vater Karls des Großen. Belohnung der getreuen Mannen.

C. Anhang 4996-5201 Pippins Schwertleite. R. und seine Frau und Berchter ziehen sich ins Kloster zurück.

Die Entführungsepen haben auch ihre bestimmte in nere Form, die Auffassung der Personen und Handlungen ist ty isch. Die Personen zerfallen in zwei Gruppen: der werbende Held mit seinen Mannen, dabei ein oder mehrere starke Helfer;2) diesen gegenüber die Familie der Braut: der unerbittliche Vater, die Jungfrau und ihre Mutter, die der Werbung günstiggestimmt sind. ${ }^{3}$ )

Unser Gedicht stellt einen Höhepunkt der spielmännischen Erzählungskunst dar in seiner Frische und unmittelbaren Lebensempfindung. Un-

1) SCHERER aaO.; RÜCKERT S. LV ff.; EDZARDI, Germ. 18, 388 ff.; V. BAHDER, Germ. 29, 278. 293 f.; Vogt, Salman S. CVI ff.

i) Im Rother die Riesen, im Oswald der Rabe, im Orendel (der indessen nicht auf einer Entführungssage beruht) der Fischer Ise, im Salman der brüderliche Diener Mo- rolf. Diese hilfreichen Personen sind besondere Lieblingsfiguren der Spielmannsepen.

$\left.{ }^{3}\right)$ Die humoristisch-ironische Färbung des Eheverhältnisses, in dem die Frau die klügere Hälfte ist, besteht auch bei Attila und Ospirin in Ekkehards Waltharius, s. LG. I, $388 \mathrm{f}$. 
gehemmt schreitet die Handlung in der Fülle der Szenen vorwärts, die alle nach dem einen Ziele, der Entführung, streben, anschaulich sind die Situationen gezeichnet, scharf sind die Charaktere in ihren Sondereigenschaften abgestuft, der Wechsel zwischen Ernst und Scherz belebt die Stimmung in dieser Intrigengeschichte. Der Grundton aber ist ein wohlbehaglicher Humor mit dem Optimismus eines Märchens.

Die Osanctrix-Sage. Der 1. Teil der Erzählung des Gedichtes, Rothers Werbung und Brautfahrt, ist noch in zweiter Fassung überliefert, in einer Episode der Thidrekssag a Kap. 29-38. Die Thidrekssage, ${ }^{1}$ ) früher meist Wilkina Saga genannt, ist eine umfangreiche Sammlung von Heldengeschichten, die von einem Isländer veranstaltet, aber im zweiten Teil, der von einem Norweger herrührt, stark umgearbeitet ist (um 1230-1250). Die Quellen sind deutsche Erzählungen und Gedichte, die Gewährsmänner waren Niederdeutsche, vielleicht hanseatische Kaufleute, die nach Skandinavien Handel trieben. Speziell für die in der Kompilation inbegriffene Nibelungensage beruft sich der Sammler auf Männer von Soest, Bremen und Münster. Also nur die Sprache der Thidrekssaga ist altnordisch, der Inhalt besteht aus der deutschen Heldensage, wie sie im 13. Jh. in Liedern und Erzählungen in Nordwestdeutschland verbreitet war. Die meisten uns aus der mhd. Lit. bekannten Heldensagen sind hier zu einem außerordentlich reichhaltigen Cyklus zusammengestellt, in dessen Mittelpunkt die Reckengestalt Dietrichs von Bern gestellt ist. Es will aber das Sammelwerk zugleich eine Darstellung der Vorzeit sein, eine Geschichte der großen Reiche von Wilkinaland (Land der Wilzen, der Slaven zwischen Elbe und Oder), Rußland, Hunnenland, Italien. Es ist als eine historische Chronik aufgefaßt, wie etwa die ebenso aus Sagen und Liedern entstandenen dänischen Geschichten des Saxo Grammaticus. Diese historische Tendenz, mit der natürlich die Absicht $\mathrm{zu}$ unterhalten wohl vereinbar war, hat auf die Einzelbehandlung eingewirkt. Die Kämpfe der Fürsten und ihre Unternehmungen sind nicht bloß persönliche Heldentaten, sondern zugleich politische Handlungen. Sie werden zu ihren Leistungen nicht allein angespornt durch Ehrgeiz und Ruhm, sondern noch dazu durch den Trieb, ihre Kraft $z \mathfrak{u}$ bezeugen. Ein Kampf ist dann

1) Literatur der Thidrekssage, die für die Rothersage in Betracht kommt: W. GRIMM, DH. ${ }^{3}$, Reg. unter Vilkina Saga. Ausg.: C. R. UNGER, Christiania 1853; HENRIK BERTELSEN, Kopenhagen 1905-1911. Uebersetzungen: F. H. v. D. HAGEN, Ad. u. a.nord. Heldensagen, 2. Aufl., Wilkina- $u$. Niflunga-Saga, 2 Bde., Breslau 1855; AUG. RASZMANN, Die deutsche Heldensage, Bd 2, Hann. 1858, 2.Aufl. 1863. - FinNUR JóNSSON, Den oldnorske og oldislandske Litteralurs Historie 11, 2, Kopenhagen 191, S. 847-863; ElaRd Hugo MEYer, Germ. Mythologic S. $46 \mathrm{f}$; Symons, Heldensage, PaulsGrundr "2 II, 1, 636 (SA. S. 31); O. KıоскHOFF, Studier öfver pidrekssaga, Upsala 1880; HolTHaUsen, Beitr. 9, 451-503; PAUL, Die piđtrekssiga und das Nibelungenlied, Mincli. SB. 1900 S. $297-338$ (bes. S. 310-314); MOGK, Gesch. d. norweg.-isländ. Lit., PAULS Grundr. ${ }^{2}$ S. 859 -864 (SA. S. 305--310); R. C. BOER, Die Sagen von Ermanerich u. Dietr. v. Bern, Germ. Handbibl. X, Halte 1910; Heusler, Berl. Ak. 1914, 1129; Hans Friese. Pal. 128; Wald. Haupt, Pal. 129, dazu GolTher, Lit.BI. 1917, 73-77; J. J. A. A. FrantzEN. Neophilologus 1, 196-209. 267-282; WolfG. STAMMLER, Hans. Gesch.bl. 1919, 38. Weitere Literatur findet man in den hier angefiihrten Werken. 
nicht nur eine Tapferkeitsprobe, sondern es geht um die Herrschaft. Ehre ist Ruhm der Tapferkeit, Ehre ist aber auch Macht. Damit tritt die Machtfrage als ein die Vorgänge der Erzählung mit bestimmender Gesichtspunkt in das technische Gefüge der bewegenden Momente. Ein solcher Kraftmensch, in dem das Zentralgefühl herrscht, wer ist der stärkere (Kap. 52), ist Osanctrix, der Held der in die Thridekssaga eingeschalteten, hier in Betracht kommenden Episode. Gegenüber der hochdeutschen Fassung der Sage, die im Gedichte vom König Rother vorliegt, stellt die Erzählung der Thidrekssaga die niederdeutsche Gestaltung dar.

In halt dieser niederdeutschen Version:

König Osanctrix von Wilkinaland will nach dem Tod seiner ersten Gattin Juliana sich wieder vermählen. Melias, der König von Hunaland, hat eine schöne Tochter, Oda, die er aber niemand zur Frau geben will. O. sendet zwölf Boten mit einem Werbungsschreiben an Melias, worin er ihm im Falle der Weigerung mit seiner Macht droht. Melias läßt die zwölf Ritter ins Gefängnis werfen. O. beruft die Ratsversammlung, er will durch einen Kriegszug diesen Schimpf rächen, aber der Rat schlägt ihm vor, würdigere Boten, seine Neffen Hertnid und Osid, zu senden. Diese iiberbringen einen Werbungsbrief an Melias zugleich mit der Forderung, die Gefangenen freizugeben, im Weigerungsfalle $\mathrm{O}$. Rache nehmen werde. Hertnid überbringt die Botschaft mit wohlgesetzter Rede und zugleich kostbare Geschenke. Aber Melias lehnt sie höhnisch ab und läßt auch diese zweite Gesandtschaft gefangen setzen. O. zieht mit Zustimmung der Räte ins Hunnenland. Er entbietet dazu den König Aspilian von Seeland und seine 3 Riesenbrüder, worunter Widolf mit der Stange, dem seine Eisenstange und eine Kelte, an die er wegen seiner Wildheit gefesselt werden muß, überall nachgetragen wird. $O$. läßt sich von seinen Mannen Friedrich nennen, zieht friedlich im Hunnenland ein und macht sich durch seine Freigiebigkeit beim Volk beliebt. Melias traut dem Friedrich, der als Vasall in seine Dienste treten will, nicht und nimmt ihn trotz Bitten seiner Tochter Oda nicht auf. Widolf stampft, zornig über die Demütigung seines kniefällig bittenden Herrn, mit beiden Füßen bis über die Knöchel in die Erde und Aspilian schlăgt Melias an das Ohr, daß er besinnungslos niederfällt. Der Kampf bricht los, Widolf erschlägt alles Lebendige in der Burg, die gefangenen Boten sprengen das Gefängnis, Melias entflieht. Oda übergibt sich in Friedrichs Gewalt, er aber setzt sie auf sein Knie und zieht ihr einen silbernen und einen goldenen Schuh an den Fuß. Da sagt die Königstochter: "Wann werde ich den Tag erleben, daß ich so meinen Fuß auf des Königs O. Thron setzen werde?" Und er antwortet: „Heute ist der Tag, daß du deinen Fuß auf den Hochsitz des O. strecken magst." Da erkennt sie ihn. Er führt sie mit sich heim und söhnt sich mit Melias aus. O.s und Odas Tochter ist Erka (die später Attilas Gemahlin wurde).

Vergleich der Rother-mit der Osan ctrix-Sage. Beide haben Sondermerkmale gegenüber andern Werbungssagen gemein, worin ${ }^{1}$ ) ihre enge $\mathrm{Zu}$ sammengehörigkeit beruht: die Riesen als Helfer, die sogar die gleichen Namen haben: Asprian-Aspilian, Widolt-Widolf (Widolt mit der stangen Roth. $2165=$ Vidolfr mittumstangi Thidr.-Saga); der Freier übernimmt selbst

1) W. GRimm, DH. ${ }^{3}$, Register unt. Oserich, Ruther; MÜLlENHOFF, ZfdA. 6, 446. 10,171. 12, 340-343. 348; Wilh. MÜller, Mythol. S. 190 ff. u. Reg. unt. Osantrix, Rother; EL. H. MEyer, Mythol., Reg. unt. Rother; Symons, Heldensage ${ }^{2}$ S.620.720f.; JiRICZEK,D Heldens. 1, 174 ff.; HeInzEI., Rez. von Schriften Kirpičnikovs zur deutschen Heldensage, Anz. 9,
241 ff.; PAUL, Münch.SB.aaO., bes.S.310-314; BÜHRIG, Thien; PANZER, Hilde-Gudr., Reg. unt. Rother; Ders., Germanist. Abhandl., H. Paul dargebr.S. $315 \mathrm{ff}$; BAEsECKe, Münch. Oswald, Reg. unt. Osantrix, Rother; SCHNEIDER, Wolfdietr., Reg. unt. Osangtrix, Rother; V.D.LEYEN, Die d. Heldensagen, D. Sagenb. 2. Teil, S. 218 -228; SymoNs, Kudrun ${ }^{2}$ S. XI-LXXII. 
in verstellter Person die Werbung; die Schuhprobe. Besonders charakteristisch für die Gleichheit der Rother- und Osanctrixsage ist die Vereinigung der Werbungssage mit der Dienstmannensage (s. S. 298).

Die grundlegenden Hauptpunkte sind in den beiden Versionen zum Teil verschieden gruppiert, ihr Zusammenwirken und die ganze Tendenz ist anders gewendet. In O. geschieht die Entscheidung durch Kampf: die Eingekerkerten werden durch eine Schlacht befreit, die Königstochter wird gefangen genommen und als Beute mit fortgeführt; in R. durch List: die Prinzessin erbittet die Gefangenen, sie wird durch Falschmeldung Rothers auf ein Schiff gelockt. In O. entwickelt sich die Handlung folgerichtig als Mannenbefreiungssage und Brautraub durch Kampf, aber die Schuhprobe paßt nicht hinein, eine Erkennungsszene ist überflüssig, da Osanctrix die Braut ja schon als Sieger in seiner Gewalt hat. Die Entführungsgeschichte am Schluß ist in O. nur äußerlich mit der Dienstmannengeschichte verbunden. Die Handlung in R. dagegen ist ein typischer, durch List geleiteter Brautraub, die mit der Dienstmannengeschichte geschickt verarbeitet ist, indem die Befreiung der Getreuen ein motivierendes Glied in der Werbehandlung bildet. R. hat die ursprüngliche Werbungssage hinter allen Erweiterungen besser erhaiten als O., am Schluß aber geändert: mit Ymelot wird eine dem ursprünglichen Sagentypus fremde Figur hineingebracht ${ }^{1}$ ) und an Stelle Konstantins gesetzt, denn der Schlußkampf muß zwischen dem Werber und dem Brautvater stattfinden; und zwar $\mathrm{nach}$ der Entführung, während er hier vor dieselbe verlegt ist und die List zur Flucht auf das Schiff begründet. O. steht trotz scheinbarer Einfachheit und Regelmäßigkeit doch der ursprünglichen Quelle ferner und zwar deshalb, weil die alte Werbungssage stark unter dem Einfluß des Machtmotivs steht. Das Interesse an der Werbung und an den gefangenen Boten ${ }^{2}$ ) tritt zurück. Das Zusammentreffen der beiden Herren, Osanctrix und Melias, wird erzählt wie ein historisches Ereignis, zuerst werden Verhandlungen über die Aufnahme in die Vasallität gepflogen, als diese sich zerschlagen, kommt es zum Kampfe, der mit dem Siege der fremden Eindringlinge und der Gefangennahme der Königstochter endet und einen dem Sieger günstigen Staatsvertrag zur Folge hat. In diesem Verlauf wird die Werbungssage mit den dazu gehörigen Motiven - die Verkleidung als vertriebener Vasall, das Zureden der Oda und vollends die Schuhprobe - nicht mehr recht verständlich.

Diese äußern Unterschiede der beiden Sagenfassungen sind begrïndet in den Stilgattungen, denen sie angehören, also in der Verschiedenheit, die besteht zwischen der Anschauungsform der niederd. Heldensagen und der hochd. Spielmannsdichtung. Die Scheidung zwischen beiden liegt im

1) Ymelot als „abgewiesener Freier und Nebenbuliler Rothers" S. PANZER, Hilde-Gudrun S. $343 \mathrm{f}$.

$\left.{ }^{2}\right)$ Die Gefangennahme der Gesandten und der damit verbundene Briefwechsel hat Aehulichkeit mit der Erzăhlung von Samson und Elsung, Thidrekssaga Kap. 11. 
tiefsten Grunde im Ethos, in der Auffassung und Wertung des Menschenwesens. Ernst, herb, hart ist die Stimmung, die sich um die Person des Osanctrix breitet, viel milder, weicher die in der Rothersage. Herrisch und unerbittlich ist Melias, „der stolzeste aller Männer"; durch Besiegung des Vaters, durch Kampf wird Oda gewaltsam das Eigentum des Werbenden, Rother dagegen gewinnt die Braut durch List. An gekränktem Ehrgeiz, weil seine Werbung abgewiesen wurde, zieht Osanctrix, um diesen Schimpf zu rächen, gegen Melias. Rother will das Schicksal seiner Mannen erfahren, aus Treue entschließt er sich $z \mathfrak{u}$ dem gefahrvollen Abenteuer; für jenen ist das Unternehmen eine Machtfrage, für diesen eine Sache des Gemüts. Besonders charakteristisch für die Verschiedenheit der moralischen Anschauungen in den beiden Fassungen sind die Mittel, welche die Menschen zur Erreichung ihres Zweckes aufwenden: Kraft, Heldentum entscheidet in der Osanctrix-Handlung, im Rother wird bei aller Tapferkeit doch das Meiste durch List erreicht. Damit ist schließlich der literarisch-historische Unterschied auf eine Formel gebracht: die niederd. Darstellung der Thidrekssage ist heroisch-episch im Geiste der nationalen, germanischen Heldensagen, der Stil der hochd. Erzählung ist spielmännisch.

Ursprung der Rothersage. In seiner Langobardengeschichte erzählt Paulus Diaconus (Hist. Langobard. III, 30): der König Authari (584-590) schickte Gesandte nach Baiern und ließ durch sie um die Tochter König Garibalds, Theudelinde, für sich werben. Garibald nahm sie freundlich auf und versprach dem Langobardenkönig seine Tochter zu geben. Da kam Authari das Verlangen, seine Braut mit eigenen Augen zu sehen und er zog mit wenigen auserlesenen Mannen, darunter sein getreuer Vertrauter, gen Baiern. Beim Empfang spricht er zum Baiernkönig, als ob er der Abgesandte Autharis wäre, der seinem Herrn über die Gestalt der Braut berichten solle. Da ihm ihre Schönheit wohl gefiel, erklärt er, daß die Langobarden sie zu ihrer Königin wünschten, und erbat einen Becher Weins aus ihrer Hand entgegennehmen zu dürfen. Als Theudelinde ihm den Becher reichte und er diesen nach dem Trunke ihr zurückgab, berührte er, ohne daß es jemand bemerkte, ihre Hand mit dem Finger und strich ihr mit seiner Rechten über Stirn, Nase und Wangen. Schamroth erzählte Theudelinde den Vorfall ihrer Amme, diese aber sagte: „Wenn dieser Mann nicht selbst der König und Dein Verlobter wäre, so hätte er auf keinen Fall Dich zù berühren gewagt. Indessen wollen wir stille sein, damit Dein Vater nichts davon erfährt. Denn wahrlich es ist ein Mann, der es wohl verdiente, König zu sein und mit Dir vermählt zu werden." $\left.{ }^{1}\right)$ Nach einiger Zeit floh Theudelinde vor dem Anzug der Franken aus Baiern-(anno 589), worauf in Verona die Vermählung gefeiert wurde. In dieser langobardischen Erzählung liegt, wie man mit großer Wahrscheinlichkeit annehmen darf, der Ursprung der Rother-

\footnotetext{
1) Uebersetzung von O. ABEL, Geschichtschreiber d. d. Vorz., 8. Jh. Bd. IV, 2. Aufl. von R. JACOBI S. $66 \mathrm{ff}$.
} 
sage, denn die den Höhepunkt der Ereignisse bildende Szene enthält beide Male das gleiche Motiv: ein Fürst, der für sich selbst, als sein eigener Abgesandter, unerkannt, um die Braut wirbt, und sich ihr durch eine heimliche, vertrauliche Handiung zu erkennen gibt, dabei die Mitwirkung der Amme. $\left.{ }^{1}\right)$ Speziell auf langobardische Verhältnisse weist der Name des Helden, Ruother, der dem langobard. Rothari entspricht. Die Sage wurde von Authari auf den späteren König Rothari übertragen (636-652), der als Gesetzgeber (Edictus Rothari) ${ }^{2}$ ) und als Eroberer hohen Ruhm in seinem Volke besaß und dessen Name durch sein Gesetzbuch fortlebte.

Entwicklungsgeschichte des Epos vom König Rother. Die Rothersage kam von den Langobarden zu den nördlich benachbarten Baiern und wurde dann durch fahrende Sänger nach Niederdeutschland gebracht, wo sie auf den dort bekannten Sagenhelden Osanctrix übertragen wurde. ${ }^{3}$ )

Die Entwicklung, die die Rothersage bis zu der uns erhaltenen Fassung, dem mhd. Gedichte, durchmachte, hat verschiedene Stufen durchlaufen, ${ }^{4}$ ) deren älteste Form, die Autharisage, in der Aufzeichnung des Paulus Diaconus erhalten ist. Zugrunde liegt ihr ein verlorenes Gedicht, ein Heldenlied in Stabreimen und germanisch-epischem Stil, vorgetragen vom Volkssänger, dem Skop (I). Die Kunstform ändert sich, an Stelle des Stabreims tritt der Endreim, das ernste, getragene Heldenlied wird verdrängt durch das leichte, zum

1) Auch die Riesen scheinen schon einer langobard. Fassung der Rothersage angehört zu haben. Asprian und besonders Widolt gleichen in ihrer Wildheit Berserkern und dieser Kriegertypus ist außer im Norden nur bei den Langobarden nachzuweisen, vgl. Paulus Diac. I, 11 (HeINZEL, Anz. 9, 248-253; KÖGEL, LG. 1, 1, 118, SYMONS, Heldensage ${ }^{2}$ S. $115 \mathrm{f}$; vgl. auch HerM. GÜNTERT, Ueber alte inländische Berserker-Geschichten, Beil. z. Jahresber. d. Heidelberger Gymn. 1912. In der Nacligeschichte der Erzählung des Paulus Diaconus liegt noch eine, allerdings woh! zufällige, Aehnlichkeit mit der Sage: Theudelinde flieht vor einem in das Land ihres Vaters einfallenden Feinde $z u$ ihrem Geliebten, wie Konstantins Tochter nach dem vermeintlichen Sieg Ymelots zu Rother. Auch darin, daß Rother in dem mhd. Gedicht König von Rom ist, könnte noch eine alte Erinnerung an den langobard. Rothari nachklingen, in dem man Lamparten und Rom als ein Reich auffaBte, so wie auch Ortnit „der Lamparte" Herr über Rôme und Laterân war (Ortn. Str. 6, Wolfdietr. D III Str. 47), s. Holthnusen, Beitr. 9, 476; Wald. Haupt S. $166 \mathrm{f}$. - Aus langob. Sage kann endlich auch die Geschichte von der Tötung des königlichen Löwen durclı Asprian stammen: einen ähnlichen in Konstantinopel vorgekommenen Fall berichtet Paulus Diac. 11, 30: Peredeo, ein ungemeln starker Mann, tötete in einem Kampfspiel zu Konstantinopel vor dem Volke und dem Kaiser einen Löwen von wunderbarer Größe. Ueber historische Lieder der Langobarden s. KöGEL, LG. 1, 1, $115-122$.

2) Einige Paragraphen dieses Gesetzbuches handeln von gewaltsamer Ehe, Ehe gegen den Willen der Eltern, Raub von Verlobten, s. CARL MEyer, Sprache und Sprachdenkmäler der Langobarden S. 28 f.

3) Der Name der entfijhrten Prinzessin war ursprïnglich nicht Helche-Erka, sondern wie im Walthariusliede Ôspirin, vgl. MÜLLENHOFF, ZfdA. 10, 171 f., D.AK. IV, 668 ff. ; I.AISTNER, ZfdA. 38, 132; KÖGEL, LG. I, 2, 288; WILMANNS, Gött. Abh. VII, 2, 16; Althof, Waltharii Poesis 2, 53 f.; WALD. Haupr S. 91. Im Biterolf wird Helche, Etzels Gemahlin, Oseriches kint genannt, V. 1962, und vorher wird auf ihre Wegfülırung durch Etzels Gesandte angespielt, v. 341 ff. $367-386$. Diesen Bericht schöpfte der Dichter des Biterolf aus seiner Kenntnis d. nd. Sage, vgl. WaLD. HaUP' S.91. 162.-Zum Nannen Osanctrix s. MÜLLENHOFF, ZfdA. 10, 171 f., D.AK. IV, 668 ff.; HeInzel, Anz. 9, 249; Wrede, Spraclie d. Ostgoten S. 111-113; LAISTNER, ZfdA. 38, 132 f. ; Schatz ebda 43, 39 f.; HeUsLer ebda 52,101 u. Hoops Real-Lex.1, 138, s. auch Intern. Monatssclir. 1918, 103 ff.; M. SCHÖNFELD, Wörterbuch d. altgerm. Personen. u. Völkernanuen S. $178 \mathrm{f}$.

4) Vgl. KIRPIČNikov bei HeinzeL aaO; $V$. 1). LEYEN aaO. 
Komischen neigende Spielmannslied der Fahrenden, dessen Inhalt etwa aus jenen Grundzügen bestanden haben mochte, die für R. unten zusammengestellt sind (II). In dieser Gestalt mochte die Oserichsage (s. vorige Seite Anm. 3) nach Niederdeutschland gekommen sein, wo sie zur Osanctrix-Version umgebildet wurde. Das "singbare Lied" wird zum "Leseepos" ") durch Aufnahme neuer Züge und technischer Erweiterungen (III). Dieses waren die typischen Hauptentwicklungsstufen, die indes nicht regelmäßig periodisch aufeinander folgten, vielmehr mag sich das Spielmannslied noch lange neben dem umfangreichen Spielmannsepos erhalten haben. Bei der wandelbaren Überlieferung der Volksliteratur waren aber verschiedenartige Bearbeitungen dieser Typen im Umlauf, indem die Texte den strenger werdenden Kunstforderungen angepaßt wurden durch Verbesserung des Ausdrucks und Regelung der metrischen Form, oder indem der Verfasser besondere Tendenzen bevorzugte. Auch das Bedürfnis, den Umfang zu vergrößern, konnte bei solchen Änderungen mitgewirkt haben.

Die den festen Grundstock erweiternden Bestandteile wurden dem allgemeinen Motivenschat $z^{2}$ ) entnommen. Schon früh, wohl im Spielmannslied, ist der ursprüngliche Inhalt durch die Erzählung von den gefangenen Dienstmannen bereichert worden. Sie stammt aus der fränkischen Wolfdietrichsage, deren Mittelpunkt sie bildet, ${ }^{3}$ ) und Berchter von Meran, der Ratgeber Rothers und Vater der Gefangenen, ist der Berchtung von Meran in den Wolfdietrichepen. ${ }^{4}$ ) Den stärksten Zuwachs hat der Stoff naturgemäß beim Übergang vom Lied zum erzählenden Gedicht (III) erfahren. Der 2. Teil, die Wiederholung der Brautfahrt, wird zugefügt. ${ }^{5}$ ) Er beruht ganz auf Entlehnungen aus der Salomosage:6) die Verlockung auf das Schiff zur Besichtigung der Waren durch vorgebliche Kaufleute, der Spielmann als Entführer; Lagerung des Heeres vor der Stadt, der Held geht ohne Heer in die

1) Vogt, ZfdPh. 22, 480 ff. und in Vogt u. Koch, Gesch. d. d. Lit. ${ }^{4}$ S. 91.

2) Für den mhd. Rother s. THIEN aaO.

3) EinfluB d. Wolfdietrichsage auf K. R.: MOULLENHOFF, ZfdA. 6, $447 \mathrm{ff}$.; RÜ CKERT S.Xff. XXXII ff. XLIX ff.; LAMBEL S. 171 f.; HeINZEL, Ostgot. Heldensage S. 66 ff.; BüHRIG S. $21-$ 53; THIEN S. 53; SCHNEIDER, Wolfdietr. S.215f. 361 ff. 391, dazu BAESECKE, Anz. 38, 42-51; VORETzSCH, Ep. Stud. S. 289; vgl. ferner FrZ. SETTEGAST, Quellenstudien z. gallo-roman. Epik, Leipzig 1905 S. 325 ff. 336 ff.; JAN DE VRIES, Rother en Wolfdietrich, Neophilologus 4, 121-129. - Rother u. Alexander: v. BAHDER, Germ. 30, 394 ff.; Rother u. Nibelungen: Droege, ZfdA. 51, 197-199. 54, 166. Rother u. Hildesage: Symons, Kudrun ${ }^{2}$ S. LXIX. Rother u. Herzog Ernst: HAupt, ZfdA. 7, 262. 289; BARTSCH, H. Ernst S. CLXIX. Rother u. Boevesage: Deutschbein, Studien zur Sagengeschichte Englands S. 34-39. 4755. 83 f. 254.

4) MÜllenhoff, ZfdA. 6, 447 f.; RÜCKerT S. XLVI ff.; D. Heldenb. IV S. XXXIX; THIEN S. 5 f. $10 \mathrm{ff}$. s) Vgl. MüllenhofF, D.AK. 1, 39; D. Heldenb. III S. LXIV.

6) WiLMANNS, Anz. 7, 283 f.; BÜHRIG S. 21 -53; Singer, Anz. 22, 46 f.; PANZER, HildeGudr. S. 268 f. $368-370$; PANZER, Germ. Abh. für Paul S. 321 ff.

2) Literatur s. bei THIEN S. 2 f. 27; vgl. auch die Heimkehrsage: UHLANDS Schriften 4, 286 ff. 8, 397-399. 419 ff.; BARTSCH, H. Ernst S. CXIVff.; ERwin RoHDE. Der griechische Roman' S. 182; VoGT, Beitr. 12, 431 ff.; BERGER, Orendel S. LXXX ff.; BEER, Beitr. 13, 35 ff.; SPLETTSTÖSSER, Der heimkehrende Gatte u. sein Weib in d. Weltliteratur, Berlin 1899; Walther Seehausen, Michel Wyssenherre, bes. S. 73 ff.; DEuTsChBEIN, S. 39-47. 51 ff.; A. Hilka, Die Inclusa, Mitteil. d. Schles. Gesellsch. f. Volkskunde 19, 29 ff.; MATHILDE EBERLE, Die Baqueville-Leg.,Berner Diss.1917; BOLTE-PoLívKANr. 218, 3, 517 ff.; s. auch unten bei Orendel. - Ein Motiv aus der Sage vom heimgekehrten Gatten ist es wenn Rother gerade zum Hochzeitsgelage seiner wiedervermählten Frau eintrifft und sich durch einen in den Becher geworfenen Ring zu erkennen gibt. 
Burg, Begegnung mit einer Person vor der Stadt; Erkennung des zu der entführten Frau eingeschlichenen und verborgenen Helden, er soll gehängt werden; Szene unter dem Galgen, Hornsignal, Befreiung durch die hervorbrechenden Getreuen.

Die Auffassung des Sagenstoffes ist bedingt durch den Geist der Zeit. Die Kreuzzüge haben dem abendländischen Menschen eine neue Welt erschlossen, ein Wunderland hat sich im Osten aufgetan, ein günstiges Feld für Märchenphantastik. Wenn der Spielmann vom Orient erzählte, konnte er mit Sicherheit auf das Wohlgefallen seiner Hörer rechnen. Es war interessant, wenn ein deutscher Fürst die Tochter des griechischen Kaisers entführte. Es war etwas Neues. Diesen Schritt tat der Spielmann, der den Liedstoff zum Epos umgedichtet hat, er verlegte den Schauplatz nach Konstantinopel. Ein lokal und historisch bestimmter Hintergrund ist gegeben. Rother ist als römischer Kaiser gedacht und als solcher auch Gebieter über Deutschland. Er schiffte sich in Bari ein, dem gewöhnlichsten Hafenort deutscher Kreuzfahrer. $\left.{ }^{1}\right)$ Konstantinopel war in der Zeit des ersten Kreuzzuges ein politischer Interessepunkt. Man hat sogar Ähnlichkeiten in dem Charakter Konstantins mit dem unzuverlässigen und feigen Kaiser Alexius Komnenus (1081-1118) gefunden. ${ }^{2}$ ) Die Kaiserburg, Poderamush of 893. 2156. 4586, ist der Hippodromus. Unter den Gewalttaten, die die Pilger auf der Kreuzfahrt 1101 in Konstantinopel verübten - auch deutsche Herren wie Herzog Welf IV. von Bayern nahmen an diesem Zuge teil - hatte die Tötung eines zahmen kaiserlichen Löwen Aufsehen erregt: eine Erinnerung an dieses Stücklein mag noch in der Kraftprobe Asprians 1146 ff. enthalten sein. ${ }^{3}$ ) Das Spielmannsepos vom König Rother setzt also den ersten Kreuzzug voraus.

Die Grundlage des uns erhaltenen Textes wird um die Mitte des 12. Jhs., etwa 1140-1150, entstanden sein. ${ }^{4}$ ) Unsere Heidelb. Fassung war von jenem Original durch verschiedene $Z$ wischenglieder getrennt und sowohl der Wortlaut im einzelnen als der Umfang hat jenem gegenüber nicht unbeträchtliche Änderungen durcligemacht. ${ }^{5}$ ) Wie frei die Schreiber mit ihrer Vorlage

3) MÜllenhoff, ZfdA. 6, 446; Scherer, ebda 18, 305 u. QF. 12, 93 (vgl. dazu Kchr. 17087-17096 u. SCHRÖDERS Anm. in den Varianten seiner Ausgabe S 389, dazı auch 17142 s. auch $16600 \mathrm{ff}$.); EDZARDI, Germ. 18 S. 402; Wald. HAUPT S. $166 \mathrm{f}$.

$\left.{ }^{2}\right)$ EDzARDI, Germ. 18,389f.; NECKEL, Germ.rom. Monatsschr. 1921, 281.

3) Leonem domilum, qui erat gratissimus in palatio Imperatoris, Albertus . Aq. VIII, 4, s. WiLkEN, Gesch. d. Kreuzzïge 2, 124. Die Tötung des Löwen durch Peredeo (s. oben S. 297 Anm. 1) kann als altes Moliv der langobardischen Sage angehört haben und durch dieses neue Ereignis wieder belebt worden sein, vgl. SymoNs S. 116.

1) Der cinzige bestimuntere historische Anhaltspunkt ist die Benenumng Berchters als
Herzogs (Grafen) von Meran, die um 1150 nachzuweisen ist (s. unten). Fitr die Zeit un 1140 wiirde auch die Spraclie unseres Gedichles passen. Daß sclion vorher, etwa von 1120 an, der Uebergang vom Lied zum Leseepos gemaclıt wurde, ist möglich. Heınzeı, Anz. 9, 245, nimmt als Enlstehungszcit den Beginn des 12. Jhs. an, als die Lieder die Form des literarischen Epos anzunehnen begannen ". Siehe ferwer RÖ́cKERT S. LV-LIX L.XV f.; Scherer, QF. 12, 92 f.; Edzardi, Germ. 18, 388 ff.; v. BAHDER, Germ. 29, 278. 293 f.; Scııröder, Ḱclır. S. 440; VOGT, ZfdPh. $22,480 \mathrm{ff}$.

5) LAMBEI. S. 188 ff.; EDZARDI, Germ. 18, $428-453$; V. BAIIDER, Germ. 29, 276-288; WIEgand S. $165-203$; POgitscher S. 1 ff. 
verfuhren, zeigen jene uns erhaltenen Bruchstücke, die regelmäßigere Formen durchzusetzten suchten, und der Heidelb. Text selbst befindet sich geradezu im Flusse dieser Entwicklung, denn im allmählichen Übergange treten hier gewisse stilistische Eigentümlichkeiten ein, vor allem auch wird der Bau der Verse sorgfältiger. Aber nicht nur der Wortlaut des überlieferten Textes hat Änderungen erfahren, viel mehr fallen die nicht geringen Erweiterungen des Stoffes ins Gewicht, die in den vorauszusetzenden $Z$ wischengliedern zwischen der Grundlage des Heidelb. Textes und der Heidelb. Hs. stattgefunden haben. Auch für die willkürliche Behandlung des Versbestandes geben die Bruchstücke verschiedene Beispiele. Es sind Interpolationen,1) die in $\mathrm{H}$. von bestimmten Grundsätzen eingegeben sind. Darunter treten besonders zwei Gruppen so stark hervor, daß durch sie der Vorstellungsgehalt des ganzen Gedichtes beeinflußt wird, das sind die bairischen und die religiösen Bestandteile. Bairische Namen tragen die Großen des Reiches, die zu der engeren Ungebung Rothers gehören, sein alter vertrauter Ratgeber, Berchter, der Vater der zwölf Getreuen, Lupolts, Erewins und der anderen, die für ihren Herrn die gefahrvolle Botschaft übernehmen, ist herzoge, auch grâve von Merân. Dieser Titel war im 12. Jh. an das Dynastengeschlecht der Grafen von Dachau geknüpft. ${ }^{2}$ ) Auch hat mit dem Namen dieser Helden der Dichter einen alten Sagenzug aufgenommen: im Wolfdietrich heißt der Vater der treuen Gefangenen Berchtung von Meran. Amelger von Tengelingen (Tengeling in Oberbayern) ist in Abwesenheit Rothers Reichsverwalter (740 ff.). Sein Sohn ist Wolfrat, "der jegliche Ehre verdient hat", nie kamen von einem Geschlecht so viele Helden (u. a. 2954-2966. 43334352). Auf politische Vorgänge in Bayern scheint der Dichter anzuspielen mit dem Aufstand Hademars von Diezen, eines einem den Tenglingern benachbarten Geschlecht angehörenden Großen, der in der Abwesenheit R.s nach Amelgers Tod sich zum Gegenkönig erhebt (2942 ff.). Auf das ganze Volk der Bayern dehnte der Verfasser seinen Preis aus, indem er den Glanz ihres äußeren Auftretens, die Pracht ihrer Gewänder rühmt (3562-3585). Diese bayerischen Bestandteile gehören wohl der Grundlage von $\mathrm{H}$. an. Der rheinische Spielmann um die Mitte des 12. Jhs. dichtete für bayrische Adelshöfe und brachte ihnen mit diesen lokalpatriotischen Übermalungen seine Huldigung dar. ${ }^{3}$ )

\footnotetext{
1) Interpolationen: RÜCKERT S. LXI ff.; LAMBEL S. 173-176; EdZARDI, Germ. 18, 4 $\angle 8-453$; v. BAHDER, Germ. 29, 276-288; Wiegand S. 169-203; Pogatscher aaO.; C. A. Turrell, A contribution to the study of König Rother, Modern Language Notes $18,2,35-38$.

2) Seit 1152 nachgewiesen (MOLLLENHOFF, ZfdA. 6, 447 ff. 455; EDZARDI, Germ. 18, 431 f.; HeInzel, Ostgot. Heldensage S. 66 f.). Nach deren Aussterben 1181 wurde der Titel von den Grafen von Andechs übernommen.
}

Verstanden wurde unter Meran die oströmische Provinz Maronia, d. i. Dalmatien u. Kroatien, die für das Stammland der Goten gehalten wurde, s. EDZARDI S. 391; KIRPIČNiKOV bei Heinzel, Anz. 9, 252; Heinzel, Ostgotische Heldensage S. 9 ff.; V. BAHDER, Germ. 29, 276 f.; SCHRÖDER, Kchr. S. 441.

3) Mólennoff, ZfdA. 6, 446 ff.; HaupT ebda 7, 262; SCHERER ebda 18, 305 u. QF. aaO.; RÜCKERT S. XLVI-LII. LX f,; EDZARDI, Germ. 18, 402 f. 432 ff.; v. BAHDER, Germ. 29, $276 \mathrm{ff}$.; SCHRÖDER, Kchr., Einl. S. 66. 70. 74. 
Speziell für unsern, durch die Heidelb. Hs. vertretenen Rother sind die religiösen Interpolationen charakteristisch, die besonders gegen den Schluß, von ca. V. 4000 an, mit vordringlicher Häufigkeit auftreten. Als nachträgliche Einschübe heben sie sich manchmal schon durch die äußerlich glättere Form von der Umgebung ab. ${ }^{1}$ ) Äußerungen frommer Gesinnung gehören zum Stil eines Spielmannsepos und somit auch zu dem unseres Gedichtes, darum widerspricht der fromme Ausgang des kraftvollen Heldendaseins auch nicht der Stimmung des Spielmannsmärchers. Auch andere Helden der Spielmannsdichtung, Oswald, Orendel, Wolfdietrich, gehen nach vollbrachter Lebensarbeit ins Kloster. Ein solcher Lebensabschluß ist zudem nicht nur eine poetische, nur in der Phantasie ersonnene Fiktion, sondern stellt eine nicht seltene Erscheinung der Wirklichkeit dar. ${ }^{2}$ ) Aber der letzte Bearbeiter hatte geradezu die Tendenz, dem Werk einen religiösen Charakter $\mathrm{zu}$ verleihen. Er hat die heroische Wertung des Lebens mit ihren kräftigen Diesseitsforderungen verkehrt in die mönchische, nach himmlischem Lohne trachtende Weltentsagung. Er breitet die Stimmung der Kreuzzüge über die Spielmannsburleske. Die Riesen raten in der Besprechung über das Schicksal, das die Sieger dem Konstantin und seiner Stadt angedeilen lassen sollen, zur Schonung um Gottes Willen, ${ }^{3}$ ) Asprian spricht eine erbauliche Rede über das heilige Kreuz und über die Macht Gottes, Widolt vorchte den heilant und demütigt sich in einer Sündenklage 4397-4509. Die Königin hält ihrem Mann eine Predigt über das Hauptlaster, den Übermut, und über den Teufel 4549-4568. Auch Konstantin macht fromme Redensarten 973-976. Der Aufmarsch der Leute Rothers gegen Ymelot ist als ein Religionskrieg aufgefaßt, als der Kampf der Christen gegen die Heiden. Die Christen sind Kreuzritter. Die beiden Ansprachen des Grafen Arnold 4067-.. 4080 und 41234-41424) sind Aufforderungen zum Kreuzzug in Geiste der Kreuzzugspredigten. Ganz ungeschickt angebracht ist die Rede Berchters über die Gnade Gottes in dem Augenblick, als R. bei dem Festmahl entdeckt wird 3932-3954. Stark erweitert ist die Mönchwerdung 5080-5189. Die ausgesprochen theologische Stilisierung dieser Interpolationen macht es höchst wahrscheinlich, daß ihr Verfasser ein Geistlicher gewesen ist.

Wie religiöse, so sind auch historische Tendenzen in das Gedicht hineingetragen, die nicht dem ursprünglichen Sagenbestand angehörten und sich ebenfalls besonders am Ende geltend machen. Rother wird mit der Königstochter aus Konstantinopel Vater Pippins, der mit Berta Karl und die heilige Gertrud zeugte 4765-4795. Der Schluß handelt ganz von der Geschichte des jungen Pippin und des alten Rother 4996-5079, von Pippins Schwertleite auf dem Hoffest zu Aachen, 5080-5190, worauf noch ein Aus-

1) EDZARDI, Germ. 18, 428-432; v. BAHDER, Germ. 29, 287 f.; WiEgand S. 177-187. $201-203$.

2) EDZARDt, Germ. 18, 431 f.

3) Eine Parallele dazı im Wolfdietrich B
925 ff., s. Enzardi, Germ. 18, 429 f.

4) In M fehlt diese Stelle, die lnterpolationsfrage ist hier wie in vielen andern Fillen nicht geklärt; vgl. v. 13AHDER, Germ. 29, 280f.; Pogatscher S. $11 \mathrm{f}$. 
blick auf die Regierung Karls des Großen 5191-5196 folgt.1) Damit ist Rother, der die römische Krone trug, als Vorgänger Karls des Großen gleichsam in die Chronik der deutschen Kaiser hineinversetzt. 2)

Der Grund für diese Verbindung der Sage mit der Geschichte liegt in der Bedeutung, die der historische Gehalt in der frühmhd. Epik hat: das Annolied, das Alexander- und das Rolandslied, die Kaiserchronik, Oswald, Orendel und Herzog Ernst handeln von Personen und Ereignissen der Geschichte, sie werden in ihrer Grundlage als geschichtliche Vorgänge aufgefaßt. Und so verstärkt auch die Übertragung der Heldenrollen auf bayerische Geschlechter das geschichtliche Moment mit dem allem geschichtlichen Leben anhaftenden Persönlichkeitswerte.

Die Verehrung der am Niederrhein gefeierten Heiligen, des sante Gilje, Aegidius, 3952, und der guten sancte Gêrdrût von Nivelle 3486 ff., ${ }^{3}$ ) die mit der Familiengeschichte Pippins ${ }^{4}$ ) und Karls des Großen verbunden ist, deutet, wie die Sprache des Gedichtes, auf einen mittelfränkischen Verfasser.

Der ethische Gehalt. Der in nere Gehalt der Entführungsgeschichte beruht auf einem doppelten Ethos, ${ }^{5}$ ) auf der heroisch-ritterlichen und der spielmännischen Lebensauffassung. Die beiden Gegensätze sind zusammengefaßt in den beiden Eigenschaften des im Mittelpunkt stehenden Helden, der Tapferkeit und der Schlauheit, und sie äußern sich in den Mitteln, die er zur Erringung der Braut anwendet, Kampf und List. Das heroisch-ritterliche Moment wird im ersten Teil noch verstärkt durch die Bedeutung, die der Treue in der Dienstmannensage zukommt.

Im ethischen Gehalt liegt der tiefgehendste Unterschied zwischen den beiden Hälften $A$ und $B$ : im 1. Teil herrscht das ritterliche Wesen vor, er ist mehr von nationalem, germanisch-ethischen Geist getragen (die Sage von den treuen Dienstmannen, die Beratungen des Fürsten mit den Vornehmen, Dietrich-Rother tritt als Recke in Konstantinopel auf). Der 2. Teil hat mehr Spielmannsart, entsprechend seinem Zusammenhang mit der stark spielmännischen Salomosage (der Spielmann als Entführer, die Volksbilder bei dieser Entführung, Rother erscheint in der Hofburg zu Konstantinopel nicht als Krieger, sondern als Pilger, er wird zu gemeinem Galgen verurteilt). Der 1 . Teil betrifft also höhere, der 2. niederere Lebens- bezw. Gesellschaftsformen.

1) Der Verfasser der genealogischen Stellen über Pippin 3480-3491 und 4765-4795 hat die ausgesprochene Absicht, einen geschichtlichen Beitrag zu liefern und stellt das Lied, d. h. diese Abschnitte, als historische Wahrheit andern Liedern (oder den andern Teilen des Rother?) gegenüber 3490 f. $4792-4795$, er macht also einen Unterschied $z$ wischen der Auffassung eines historiografus, der ein Lied schreibt, das viel Tatsächliches enthält (recht), woraus ihm Glaubwïrdigkeit entsteht (4794 f.); und einem poeta, dessen liet von lugenen gedichtet ist (3490 f.), der Wahres

mit Falschem vermischt (vgl. ConRadi HIRS. Dialogus ed. Schepss S. 24). Ueber die Quelle, buoch, liet, tichtêre, vgl. W GRIMM, $\mathrm{DH}^{3}$ S. 57; SCHERER, QF. 12,92; RÜCKERT S. LXI -LXVl; EDZardi, Germ 18, 420 f.; v. BaHDER, Germ. 29, 278 ff.; WiEGAND S. 146 f. 188; VoGT, Breslauer Festschr. 1911 S. 513.

2) SCHERER, ZfdA. 18, 305.

3) SCHRÖDER, ZfdA. 39, 144.

4) Auch die Verkleinerung Pipinchis mâder 3483 ist mfrk.

亏) Vgl. LG. I, 391. 
Der zwiefache Zug, die Mischung altepischer und spielmännischer Geistesart, bezeichnet das Innenleben der Menschen in der spielmännischen Auffassung. Darum sind zwei fast gegensätzliche Eigenschaften die Triebkräfte für die Entwicklung der Handlung im König Rother, Treue und Schlauheit, Zuverlässigkeit und Überlistung, jene die sittliche Grundbedingung in der Dienstmannensage, diese in der Entführungsgeschichte.

Treue ist die Grundlage des sittlichen Lebens im germanischen Heldentum, das soziale Band, das den Fürsten mit seinen Gefolgsmannen vereint, ${ }^{1}$ ) die stärkste Gemütsmacht, die schicksalsgleich die Wege des Daseins bestimmt. Treue ist die eigenartige Form der Handlungen, welche in dem Verhältnis zwischen Herrn und Untertanen sich abspielen, auf der Treue beruht die Existenz sowohl des Fürsten als der Vasallen. In diesem Betracht ist das Gedicht durchdrungen von tiefem sittlichem Ernste, ein Denkmal für die Macht der Treue im germanischen Volksbewußtsein. Groß ist die Sorge R.s um seine verschollenen Gefährten, da Jahr und Tag umgeht und sie nicht zurückkommen. Sehr trauerte er um die guten Boten, er rang die Hände, auf einem Steine $s a ß$ er drei Tage und drei Nächte, ohne mit jemanden zu sprechen. Zwölf Söhne hatte der alte Berchter, einer ist für seinen Herrn im Kampf gegen die Heiden gefallen, sieben sind für ihn auf die Brautfahrt gegangen und kehren nicht zurück 430-497. Die Reckenfahrt unternimmt Rother, um das Schicksal seiner Getreuen zu erfahren, nicht um des ursprünglichen Zwecks, der Brautwerbung, willen (die Dienstmannensage hat hier die Entführungssage in den Hintergrund gedrängt). Diese Treuszenen gehören $z u$ den schönsten Stellen des Gedichtes. In ihnen offenbart sich ein reiches, tiefes Gemütsleben, wie die Gefangenen von ferne ihren alten Vater schauen 2467-84, wie sie an dem Harfenspiel ihren lieben Herrn erkennen 2507-29. Und noch eine zweite Treuprobe hat R. $z u$ bestehen. Als die junge Königin durch den Spielmann entführt wurde, fürchteten die Bürger von Bari den Zorn ihres Herrn, doch Lupolt nimmt die Schuld auf sich und bietet Rother sein Leben dar. Aber Rother dem das Herzeleid geschehen war, ergriff Lupolts Hand und küßte ihn auf den Mund und verzeiht ihm, denn er hat ja dritthalb Jahre bei den Griechen im Kerker für ihn gelegen. An diesem Tag hat seine Trene die ihm vom Vater ererbte Selbstzucht aufs neue erwiesen 3269-3369. Die erste Stelle unter den Mannen nimmt der Herzog Berchter ein, der alte getreue Ratgeber, ${ }^{2}$ ) den Rother in allen Angelegenheiten befragt, zô deme er allen sînen rât nam 459. Der treueste der Getreuen ist Berchters Sohn Lupolt, der Fülırer der gefangenen Gesandten, darnu1 trägt er auch die Bezeichnung der getrûze man, der aller getrûiste man 55 (163). 2713. 2973. 3297. 3538. 3553. 3615. 3697. 4460. 4885, denin er hat die Botschaft aufs allertreueste geworben 99.121, hê ist gruntveste allir troutwe 4206. Und

1) Slehe LG. I, 13.

2) Der historische Typus des trenen Be- raters: s. KaUfFmann, Philol. Sudien, Festg für Sievers S. 156 ff.; Heusler, Anz. 35, 178 
das letzte Wort der Mannen, als sie von Rother Abschied zur Heimfahrt nehmen, ist das Versprechen der Treue 4918-26 (treues Zusammenhalten der Sippeverwandten 3412-35). Aber triuwe ist nicht nur ein ideales Gemütsverhältnis, sondern eine habhafte Forderung der Wirklichkeit, eine Verpflichtung zu realen Leistungen, ein Vertrag zwischen dem Herrn und dem Mann. ${ }^{1}$ ) Der Vasall war zu Hoffahrt (zu Beratungen, Gerichtstagen, Festlichkeiten) und Heerfahrt verpflichtet, der Herr gewährte ihm dafür den Rechtsschutz, belohnte ihn mit Ländereien, Grundbesitz und Gerechtsamen und mußte überhaupt seine Dienste lohnen durch Geschenke, Schatzspenden, Anteil an der Kriegsbeute u. dergl. So war das Verhältnis zwischen dem Fürsten und seinen Lehensmannen fest eingefügt in die materiellen Lebensbedürfnisse durch die Wechselwerte von Dienst und Lohn, doch verinnerlicht und poetisch verklärt durch die tief sittliche Gemütsmacht der Treue.

Darum war aber auch bei der Treue die Freigiebigkeit, diu milte, eine so unerläßliche wie gepriesene Fürstentugend und Rother übt sie im weitesten Umfang (lîhen=belehnen, geben, lônen 146-148, vgl.3726 f. 190197. 498 f. 623. 4796-4896 (lônen-dienen 4824 f. 4842) 4981-89. Auch Konstantin gibt und lohnt 3042-58. 4712-35; dienen=lônen $4734 \mathrm{f}$.

In den vorliegenden Fällen war milte germanische Fürstentugend. Aber in der Entführungsgeschichte Rothers ist altheimische und spielmännische Art vermischt, und so gibt es auch eine spielmännische Freigebigkeit. Sie ist schon im Stoff des Gedichtes begründet und ist eines jener Listmotive, durch die der Held seinen Zweck, die Braut zu gewinnen, erreicht: Rother nimmt großen Reichtum an Schätzen, Gold und kostbaren Gewändern auf seine Reckenfahrt mit und dazu Goldschmiede 596-607. 616-619. 785801. Ausschiffung des Gutes 1031-40; Kleidung und Speisung der Armen und dürftiger Ritter 1291-1522. 3719-43. Beschenkung des Grafen Arnolt 1291-1522; der gefügigen Kammerfrau Herlint 1934-36. 2033 f. 2053 f.; eines Kaufmanns für Bewachung des gelandeten Schiffes 206-17. Die Fahrenden werden beschenkt, ein armer Spielmann erhält einen Mantel 1882-1895. Mit besonderer Vorliebe verweilt der Dichter bei solchen Belohnungen. Sie gehören zum stehenden Inventar der Spielmannsdichtungen. In derartigen Schilderungen ungemessener Verschwendung stellten die Dichter ihren Gönnern rühmenswerte Beispiele zur Nachahmung vor.

List und Treue lassen sich in der Spielmannsdichtung wohl vereinigen.

1) Der Herr, hêrre (dominus, senior), nimmt den man (homo, fidelis, miles, vassallus) in seinen Schutz, sein Schutzrecht, munt stm.f. (mundium), auf durch die hulde, Huldigung (commendatio). Der Akt der Huldigung, einem hulde, manschaft tuon, swern, bestand in Treueid (fidelitas) und der Handreichung (homagium), hende valten, hantslac (GRIMM, RA. S. 139 f.), auch durch KuB (vgl. nam hê Lûpolde mit der hant unde kuste en vor den munt $\sin 3330$ f.). Durch die Huldigung wird der Untergebene zum man, dienstman, holde. - Hulde, ahd. huldî, ist eigentlich die Verneigung. Die Neigung des Körpers oder des Hauptes ist ein symbolisches Zeichen und geschieht sowohl von seiten des Herrn zum Diener (herablassend, gnädig, Gnadebezeugung, vgl. der koninc sich in zô vôzin bôt 4807) als vom Diener zum Herrn (treu, gehorsam, gewärtig, Ergebenheitsbezeugung). 
In der germanischen Heldensage ist List $^{1}$ ) nicht eigentlich ein charakterisierender Zug des Kriegers, obwohl sie bei der Wahl der Mittel nicht als unrühmlich galt;2) Hinterlist allerdings war unter allen Umständen schmachvoll. Der Spielmannsheld dagegen sucht sein Ziel mehŕ durch List als durch Tapferkeit $\mathrm{zu}$ erreichen und wird darin von der begehrten Braut unterstützt. Wir môzen mit gôtin listin unser lîb gevirstin 816 f. (vgl. 3032 f.) ist der Grundsatz, mit dem Rother die Reise in das fremde Land unternimmt, da er den Mannen seine Umwandlung in den Recken Dietrich vorträgt 813-822. Darum wird er bei dem Meisterstück seiner Schlauheit, bei der Schuhprobe, der listige $\operatorname{man}^{3}$ ) genannt 2128. 2201, vgl. 2290, ebenso später, als die heimliche Abfahrt vorbereitet wird 2823. 2836. 2877, und schließlich bei der Entdeckung des ganzen Listgewebes 2906. 3003. Listichlîche spricht die Königstochter 2336, Herlint die Kammerfrau ist daz listigez wîph 1950, der Spielmann, der Rothers Weib entführt, war ein listiger vâlant 3113. List hat aber im Mhd. überhaupt noch nicht einen ausgesprochen moralischen $\mathrm{Ge}$ halt wie heutzutage, die bezzere list 512 hat noch die ursprüngliche Bedeutung „das bessere Wissen, die bessere Weisheit", Sachkenntnis, Verständnis, Rat, wie z. B. 729. In diesem Sinne wird Lupolt, der keine Untreue hatte, ein vile listiger man' genannt 161-163. Die list, die Weisheit, sich mit voller Einsicht in die der Tatsachen in schwierigen Lebenslagen zurecht zu finden, wird an Rother gerülımt $2274 \mathrm{f}$.

Das kriegerische Element tritt in der durch die List geleiteten Entführungsgeschichte zurück. Jeder der beiden Teile hat nur eine Schlachtszene, kurz vor dem Schluß: I. 2563-2750 (der eigentliche Kampf 27352750), Il. 4030 - 4352. Die Kampfschilderungen sind dem Verfasser nicht besonders gelungen, es fehlt ihnen an Kraft und Gedrungenheit, es kommt nicht zu spannenden Einzelkämpfen mit regelrecht geführten Stichen und Schlägen, unter den Gegnern tritt überhaupt keine einzelne Person hervor und auch Rother selbst greift kaum in die Schlacht ein. Im ersten Teil ist der Kampf überhaupt kurz abgetan 2735-2750. Die Darstellung des zweiten Kampfes (Teil II) dehnt sich lang hin, sie ist verworren, fällt auseinander und wird durch andere Ereignisse unterbrochen. Als Kämpfer treten die Riesen auf, im zweiten Teil auch Erwin und besonders Wolfrat 4259-4261. 4333-4352, denn mit dem Preis seiner Tapferkeit soll den Grafen von Tengelingen, deren Ahnherr er ist, eine Huldigung dargebracht werden. Diese Aristeia des bairischen Helden steht außerhalb des Zusanmenhangs, sie ist erst nach abgeschlossenem Kampfe angebracht. ${ }^{4}$ )

$\hat{E}$ re ist nur ein äußerlicher Wertbegriff, das Ansehen, das ein vornehmer

1) Vgl. Lit.Gesch. I, 94.

2) Verstellung der Person gehört ja schon der Grundfabel von Authari an.

$\left.{ }^{3}\right)$ LACKNER, Das schmückende Beiwort S. 27.

4) Wolfrâtis zorn 4337 ist kräftiger gehoben als die sonstigen Kampfschilderungen

Deutsche Lileralurgeschichle. II. in dem Gedichte. Wolirât (Wolfhart, s. EDZARDI, Germ. 18, 436 ff.; WIEGAND S. 171 ff.) hat den kampfgierigen Cliarakter wie sein Namensverwandter in den späteren Dietriclısepen. 
Mann genießt durch Macht und Reichtum, Stand, hohe Stellung. Einem solchen gebührt Ehrung, er ist aber durch diese Vorzüge auch verpflichtet, standesgemäß aufzutreten. Ehre umfaßt also die mit der Ehrenstellung verbundene aristokratische Lebensführung. Die Hofsitte verlangt, daß der Fürst nâch êren, standesgemäß in der von dem Hofzeremoniell vorgeschriebenen Weise auftritt, die Hofetikette bewahrt, seine Vasallen würdig behandelt und reich ausstattet (mit êren, mit allin, grôzen êren) 125. $132 \mathrm{f}$. 555. 559 f. 667.896 f. 937 f. 1279 f. $1520.1545-64.1763 .2985$ f. 3058. 3590. 3723. 4618. 4988. 4994. In allen diesen Fällen bezieht sich êre auf die äußeren Lebensformen, zur sittlichen Bedeutung des Ehrgefühls, der Achtung, die einer vor sich selbst hat und von andern für sich verlangt, ist êre vertieft in der Kemenatenszene, wo die Prinzessin Rother zu sich. bitten läßt: hier muß zuerst der Ehrenpunkt überwunden werden, Rother kann den Schritt nur tun, wenn ihr beider Ehre nicht verletzt wird 1932. 1943 f. 1961. 1997. 2004. 2042. 2189. 2314, vgl. 1534. Pflicht ist es, den Fremden zu helfen, die im Unglück sind 1250, den Verwandten beizustehen 3413; Ritterehre 2942,1) königliche Ehre 3677, königliche Macht 4757, dem König Ehre erbieten 4682.

Die Spielmannsdichtung hat demnach einen andern, einen weniger idealen Ehrbegriff als die ritterliche Dichtung. Ere ist nicht jener hohe sittliche Trieb, der die starke Persönlichkeit bildet, eine Kraft, die den ganzen Mann erfüllt und zu großen Taten begeistert, die Tugend des Kriegers, dem der Ruhm als höchstes Ziel vorschwebt. Ere ist überhaupt nicht eine Tugend, ${ }^{2}$ ) eine die Handlungen der Personen bestimmende sittliche Eigenschaft, sie ist vielmehr nur eine äußere Lebensform und gehört in das Gebiet der Sitte. Mit den Beschreibungen von Kleidern, Festen, Aufzügen, Empfängen und Abschied bildet sie die höfische Umwelt, innerhalb derer sich die Personen der ritterlichen Gesellschaft gezogenlîche bewegen. Große.Pracht wird entfaltet bei den Aufzügen und Hoffesten. Nicht genug kann sich der Dichter tun mit der Schilderung kostbarer Gewänder, glänzender Rüstungen, schöner Pferde, zierlichen Schmuckes, z. B. 150-160. 221-249. 386-429. 785-801. 863-875. 1105-1127. 1566-1615. 1820-1841. 1842-1879. 3562-3585. 4585-4606. 4932-4960; das Staunen, das solch großartiges Auftreten erregt: 243 -249. 250-269. 277-287.386-393.827-831.11171127. 1523-1530. In Glanz und Herrlichkeit erscheint das Leben der Vornehmen. Derartige Schilderungen gehören zum technischen Apparat der mittelalterlichen Romane, aber in unserm Gedichte hat das Gepränge Dietrichs auch einen sachlichen Grund, indem er dadurch die Aufmerksamkeit der umworbenen Jungfrau auf sich lenkt und sie und ihre Mutter günstig fär

1) Die V. 2941 f. sind ein Abschiedssegen für einen Ritter. Der Wunsch für Behütung der weltlichen Ehre gehört zu den formelhaften Bestandteilen der ritterlichen "Ausfahrtssegen", vgl. MSD. 13, 183, 48. 188, 76.
2) Vgl. Ehrismann, ZfdA. 56, $155 \mathrm{ff}$. - Der Unterschied $z$ wischen dem spielmännischen und dem ritterlichen Ehrbegriff kann z. B. bei einer Vergleichung $z$ wischen Rother und dem Rolandsliede beobachtet werden. 
sich stimmt, da sie aus dem Reichtum des Vasallen, als den Dietrich sich ausgiebt, schließen, daß sein Herr, der König Rother, ein ungeheuer mächtiger Herrscher sein müsse.

Das hö fische Le ben ist nach der Sitte geregelt, es hat feste, verbindliche Formen und berıht auf gegenseitiger Höflichkeit. Das ist die zuht (gezogenlîche), die gute Erziehung, das feine Benehmen. ${ }^{1}$ ) Bei jeder Gelegenheit gesellschaftlichen Verkehrs wird auch die schöne Lebensart hervorgehoben: Erziehung 52. 989. 2263-70; Empfang, Begrüßung, Abschied 102-6. 240. 71. 73. 75. 906. 8. 15-17. 1096. 3355. 4648-55. 4738-41. 4927-29; Sprechen 107. 4630. 73; Gangart 2004 f. (Sprichwort), 2089-95. Die alte gute Sitte wird gepriesen, die alde zucht, die jeder Dienstmann gegen seinen Herrn haben sollte 3654-3659, die alde zucht und êre verlangt, $\mathrm{daB}$ man Beleidigungen um Gottes willen übersieht 4616-4627; beide Male ist mit diesem Lob der guten alten Zeit ein religiöser Beigeschmack verbunden.

Alle diese Beispiele artigen Benehmens betreffen nur die äußere Umgangsform. Aber doch verpflichtet dieser ungeschriebene Sittenkodex die Gesellschaft zugleich zu Anstand und Würde und unterbindet Roheit und verletzende Ausbrüche von Leidenschaft, ohne daß indessen die Gefühlsregungen unterdrückt würden. ${ }^{2}$ ) Vielmehr dürfen sich Freud und Leid ungehemmt aussprechen, und unmittelbar ergeht sich das Gefühl in Weinen und Klaggebärden (Händeringen, hantslagin 2883). Damit kommt das Innenleben $z \mathfrak{u}$ seinem Rechte und die Personen treten uns menschlich näher, das Gemuit erschließt sich und die dramatisch bewegte Handlung gewinnt einen sentimentalen Ton. Besonders sind es gewisse traurige Ereignisse, die von einem starken Gefühlswert getragen sind: das Leiden der Gefangenen, der Schmerz des treuen Herrn, des alten Vaters sind ergreifend und wirkungsvoll dargestellt. In zwei Szenen werden diese Seelenleiden vorgeführt, bei der Gefangennahme der Boten 341-385. 430-497, und bei ihrer Befreiung 2413-2484. Rührend auch ist der Schmerz der getrennten Gatten 3820-22. 3827-33, darauf die Freude der Frau über die nahende Rettung und ihr unheilverkündendes Lachen 388085. 3896-99; Schreien und Weinen der Frauen und Bürger über Rothers Not 4014-42; rascher Wechsel von Jammer und Freude 2881-2942 (vgl. 2855). Die Ausdrücke der Freude sind seltener (lachen 2483. 2937 f. 3882. 86, halsen und küssen 3259 f.). Gewaltig ist die Erschütterung Konstantins, als er die Flucht seiner Tochter erfährt, er weint, quält sich ab, fällt in Ohnmacht 3013-23. 3042. Derartige Überwältigung durch die Leidenschaft, daß einer von Sinnen kommt, ist unmännlich, und im Gegensatz zu Konstantin bewahrt Rother, als ihm seine Frau geraubt wird, seine Würde. Er bleibt gefaßt und gerät nicht in zorn 3272. 3339. 46. 53, ja gerade im Unglück zeigt er sich groß und edelmütig. Zornig werden gehört

1) Ueber die Anredeformen im Rother s. ZfdWortforsch. 2, 145-151.

2) Ausdruck des Gefühls: WiEgand S. $139 \mathrm{ff}$. 
nicht zum guten Ton (Konstantin 325, Asprian 1030, Widolt 2706; in Kampfzorn gerät Wolfrat 4337). Aber doch bricht bei starker Erregung die Leidenschaft ungehemmt los und Auslassungen gerechten Zornes werden nicht als eine Verletzung der guten Sitte empfunden. In solchem überwallenden Elementargefühl versetzt der sonst so besonnene Berchter in der Ratsversammlung einem alten Herzog, dem er den berechtigten Vorwurf der Feigheit macht, unter dem Beifall seiner Mannen einen Faustschlag, daß ihm das Blut aus dem Halse fährt, und er drei Tage besinnungslos liegt 566-577.

Ere und zuht, die Forderungen der guten Sitte, regeln das sittliche Leben, noch ist nicht die mâze, die durch Stärkung des sittlichen Willens erreichte Selbstbeherrschung, als ethisches Prinzip ausgesprochen. Auch der hôhe muot, das gehobene Selbstbewußtsein, das von dem Streben nach sittlichen Idealen erzeugt wird, befindet sich nicht unter den moralischen Werten dieses Ritterlebens, auch nicht die salde, das Glücksgefühl reichen irdischen Besitzes und Erfolges, selten nur erwähnt wird die stcete, die Charakterfestigkeit. Und die Frömmigkeit, die im Verlauf der Erzählung in ein weitschweifiges Moralisieren ausläuft, ist meist nur äußerlich aufgetragen als Zubehör des spielmännischen Milieus; doch mit Maß gebraucht verleiht die fromme Gesinnung der betreffenden Stelle einen warmen Gemultston, z. B. $186-189.320-323.360-364.2940-2942$. Und noch fehlt in dieser sittlichen Erziehung der Einfluß der Frau. Sie hat nicht die überragende Bedeutung wie bald darauf in der höfischen Kultur. Der Mann begegnet ihr mit Achtung, ja schon mit einer gewissen Courtoisie, es ist zuht sie zu ehren 4630-4641. Sie vertritt die Würde des Hauses gegenüber den Gästen 272-275. 905-908. Gehobene Töne werden angeschlagen beim Preis der Frauenschönheit 70-79. 1820-1841. Aber die Frau ist nicht ein vergöttertes Wesen wie in dem galanten Spiel des höfischen Minnedienstes, sie wirbt um den Mann und ist ihm in einfacher Herzensneigung zugetan 1917 - 1920. 1955-1964. Treue verbindet die Gatten, und um das geraubte Weib wieder $z u$ erlangen, wagt Rother sein Leben. In wenigen schlichten Worten ist das große Glück der Ehegatten ausgesprochen, Freud und Leid zu teilen: sint gewan sie mit deme helede manige werltwunne unde ouch trûbe dar under 1922-1924 (vgl. 320-323).

Im Rother entfaltet sich ein lebensvolles Bild der älteren mhd. Hofgesellschaft. Der Dichter stellt in dem Helden die ideale Gestalt eines Fürsten dar 3719-3793: er pflegt grôzir êrin 3723, alle Fürsten sind ihm hold, Arm und Reich, wegen seiner Freigebigkeit 3725-3742, er ist gnädig und gütig 3748f., alle Tugenden hat er 3754, er ist milte 3755-3759, ein mächtiger Gefolgsherr 3760-3763, hilfreich in Kriegsnöten 3764-3766, ein Sieger über die Heiden 3767-3771, durch Mühen und Höflichkeit hat er sein Weib erworben $3782 \mathrm{f}$, ein tuginthafter man 3790.

Es ist noch ein einfacherer Bildungstyp. Die Schranken der Sitte haben sich noch nicht zu jener geistigen Freiheit erweitert, in der sich die gebil- 
deten Kreise zur Blütezeit der ritterlichen Kultur bewegten. Einfacher sind die geistigen Ansprüche in dieser Spielmannsgeschichte gegenüber dem reichen, phantasievollen Leben in der höfischen Dichtung, das durch Poesie und Frauenverehrung eine romantische Verklärung fand. Welcher Unterschied z. B. in dem Minnewerben! Rother sucht eine Frau aus praktischen Staatsgründen, Sigfrid im Nibelungenlied hört von der Schönheit Kriemhildens und ihrer hohen Gesinnung, er wirbt um sie, denn sein Herz hat große Liebe zu ihr (Nibel. Lachm. 46,1. 48,1.49,2. 50,2.53,3.1) Im höfischen Epos endlich ist das Werben ein ritterliches Abenteuer (Hartmanns Erec und Enite, Iwein und Laudine, Wolframs Parzival und Kondwiramurs, Gawans Liebesaffären).

Das doppelte Ethos des Gedichtes, die Mischung von nationaler und spielmännischer Tonart, befaßt zugleich einen Gegensatz in der Stimmung zwischen Ernst und Scherz, zwischen heroischem Pa tho s und spielmännischer Komik. Am stärksten kommt dieser zwiefache Rhythmus zum Ausdruck in dem Kontrast zwischen der zuht der höfischen Gesellschaft und der Unsitte der Riese n. Sie sind die Träger der ausgesprochenen Spielmannsburleske, durch das ganze Gedicht hindurch und bei jeder Gelegenheit spielen sie die unfreiwilligen Spaßmacher, ihr groteskes Benehmen, ihre plumpen Gewalttaten, ihre Prahlereien bilden den Gipfel der niederen, derben Komik, an welcher sich das Publikum der Spielmannsdichtung ergötzte. Schon ihr Äußeres ist aufsehenerregend. Zu Fuß im Staub, nicht auf ritterlichem Rosse, denn keines konnte ihn tragen, kommt Asprian an, ein wunderlîcher man; er trägt eine stählerne.Stange (Keule), vierundzwanzig Ellen lang. Geißeln haben sie mit eisernen Ketten und großen Knöpfen 632-639. 652-703.2) Noch grimmiger ist sein Mann Widolt. Den mußte man bewachen wegen seiner Wildheit, gefesselt ging er wie ein Löwe, wenn man ihn von der Kette los ließ, schlug er jeden tot, der seinen Ärger erregte 756-773. 1659-1665. 1732 f. 2751 f., vgl. 891 - 900. Er reibt Feuer aus Stein 10481050, er beißt in seine Stange, daß die Flammen herausfahren 4658-4669. 4679-4681; er war der zornigste Mann seit Adams Zeiten 2706-2712. In drei Kraftstïcken gipfeln die Leistungen der Riesen: wie Asprian im Ärger über Rother-Dietrichs Demut den Fuß bis über den Knöchel in die Erde stampft $942 \mathrm{f}$., wie er den Löwen an die Saalwand wirft 1146-1152, die Prügelei 1616-1773.

Stellt die Riesengroteske eine niedere Komik mit der Übertreibung ins Possenhafte dar, so ist der griechische König Konstantin mehr in einer feineren, humoristisch-ironischen Auffassung gezeichnet. Ein nuächtiger Herrscher, anmaßend und feig, schwach und kopflos. Er wirft die fremden Gesandten ohne weiteres in den Kerker, prahlerisch rïhnt er sich dieses leichten Sieges über Rother und entschuldigt dann seine kecke Rede, als

1) Neben dieser seelisch tieferen Auffassung vom Verhăltnis der Geschlechler stehen im Nibelungenlied noch die Motive des alten Brautwerbungstypus: der Rat der Mannen Str. 49, 1-3; dic Jungfrau geziemt dem werbenden Fürsten wegen ihres Reichtunis Sir. 49, 3. 50, 3. 4; die Gefahr der Werbung wegen der feindseligen Hallung der Verwandten der Jungfran Str. 52-62.

") Vigl. Droege, ZfdA. 51, 198. 
Asprian aufbegehrt, mit Trunkenheit 987--1029: dieses Gebaren war richt kuninclîche getân 1089-91. Mehr aus Furcht denn aus Güte hatte er Rother aufgenommen 961-986. 1075 f. Ferner sein Verhalten bei der Verprügelung der Hofbeamten 1779-94. 1811 - 13; beim Einfall Ymelots 258792. 2601-20; beim Siege Rothers 4520-42; sein Geiz 1119-27; sein Hochmut 4549-68. $2590 \mathrm{f}$. So ist Konstantin das Abbild eines Fürsten, wie er nicht sein soll, in dieser Hinsicht ein Gegenstück zu dem gerechten Herrscher, Rother. Aber einen menschlich sympathischen Zug hat dieser schwankende Tyrann doch, das ist die abgöttische Liebe zu seiner Tochter, vgl. 2363. 74, auch 1554-64; 3013-42. 3256-60. 3886-89. Von der humoristischen Seite ist auch das eheliche Verhältnis zwischen Konstantin und seiner Frau aufgefaßt. Mit ihr bespricht er die wichtigsten Staatsangelegenheiten, die durch das Auftreten der Fremden und dann durch den Einmarsch Ymelots eine heikle Wendung genommen haben. Sie hat einen viel klareren Einblick in die Sachlage. Von vornherein war sie für die Werbung Rothers, 'er aber hat durch seine Starrköpfigkeit den Reichskarren verfahren. Wo er nicht mehr weiter kann, sucht er bei ihr Rat und dann macht sie ihm, nicht ohne Schadenfreude, berechtigte Vorwürfe 1060-91.1172 -1222. 1463-71. 1795-1813, vgl. auch 3046-3059. 4543-68. 4672-87.

Die höfisch aristokratische Literatur bewegt sich nur in den Höhen der Gesellschaft, der Spielmann aber ist der Mann aus dem Volke. So geht er auch mit Vorliebe auf volkstümliche Interessen ein. Im Rother spielen weite Kreise des Volkes mit, eine Unterschicht neben der in êren hochstehenden Hofaristokratie. Eigentlich gehören auch die Riesen zu diesen niederen Leuten. Es sind Typen der gemeinen Soldaten, die zu Fuß gehen und mit Stangen oder Spießen bewaffnet sind, im Gegensatz $z u$ den berittenen, mit dem Schwert ausgerüsteten Rittern.

Ein reges Volksleben entfaltet sich in einer dramatisch bewegten Szene, als der Spielmannskaufmann seinen Kram auftut, Bürger und Ritter strömen zusammen und feilschen um Schmuck und feine Stoffe und um wundertätige Kieselsteine 3108-3224. Pilger (Rother und seine zwei Getreuen) ziehen auf der Landstraße zur Stadt und sprechen mit einem begegnenden Ritter über die jüngsten Neuigkeiten 3694-3827. Am liebsten ergeht sich des Spielmanns Phantasie in der Vorstellung guter Belohnung. Er gehört ja zu den Gehrenden. Wer recht viel schenkt, wird am meisten gepriesen. Solches Lob ist darauf berechnet, das zuhörende Publikum zur Nachahmung $\mathrm{zu}$ reizen und $\mathrm{ihm}$ den Beutel $\mathrm{zu}$ öffnen. 230 Verse werden verwendet, um die unerhörte Freigebigkeit Rothers gegen die Bedürftigen, gegen Arme, Kranke, Nackte und Bettler in ihrer ganzen GroBartigkeit darzustellen 12911522. In naiver Selbstbespiegelung schiebt sich der Spielmann ${ }^{1}$ ) gern in den Vordergrund. List ist seine Hauptkunst. Einer seines Standes ist es, dem das große Werk gelingt, die entflohene Königstochter ihrem betrübten

1) RǗCKERT S. LXVI f.; EDZARDI, Germ. 18, 422 f.; THIEN S. 28. 
Vater wieder zurückzubringen. Einen solchen verdienten Mann behandelt sogar der Herrscher von Griechenland - nach der prahlerischen Darstellung des spielmännischen Autors - als Seinesgleichen: mit ehrenden Worten redet er ihn an: Genâdhe hêre, trûtgeselle 3083. 85. Und der verbannte Recke Dietrich verneigt sich dem fahrenden Volke, als er an der Hoffeier zu Pfingsten die Festgaben austeilt 1880-95. Mit Selbstironie erzählt der Dichter, wie Spielleute von den Riesen mißhandelt werden; mit GenuP aber die Prügelung des Kämmerers 1616 ff., denn zwischen den fahrenden Leuten und den Hofbeamten bestand begreiflicherweise ein gespanntes Verhältnis. Spielleute als Überbringer neuester Nachrichten 1710-32. 42934328 (Motivwiederholung), vgl. 2579-2600. Asprian wird der riesen spileman genannt, weil er Akrobatenkunststiucke macht $2169 \mathrm{f}$; damit werden die Riesen ohne weiteres in die Klasse der Gaukler und Springer versetzt 2165 - 76. Der höchste Stolz aber für den Verfasser des König Rother ist es, daß sein Held gleichsam selbst zur Zunft gehört: er ist ein königlicher Harfenspieler 2526.

Der Stil. Der Rother ist ein typisches Denkmal der frühmhd. ritterlichen Epik. Auch dem sprachlichen Ausdruck') nach gehört er zu jener höheren Gattung, die durch das Alexanderlied, das Rolandslied, die Kaiserchronik vertreten ist, und hebt sich durch eine ausgebildetere Technik von dem niederen, nachlässigeren Spielmannsstil des Oswald, Orendel, Salman ab. Die Ausdrucksweise steht nicht wie in jenen Dichtungen unter der Herrschaft des Formelwesens und von der Wiederholung gleicher Wendungen wird nur maßvoll Gebrauch gemacht. Ein zweiter sehr merklicher Unterschied zwischen diesem frühmhd. ritterlich epischen Stil und dem eigentlichen Spielmannsstil besteht in der architektonischen Gliederung. In den drei genannten Spielmannsgedichten sind die Verse paarweise geordnet, so da $B$ je zwei oder vier oder sechs eine Einheit bilden (so können vierund sechszeilige Strophen entstehen), der Sinneseinschnitt fällt also mit dem Schluß eines Reimpaares zusammen (mhd. rime samenen). Im Rother herrscht dieses Paarungsprinzip nicht so merksam vor, hier zerteilt oft die Inhaltsgrenze ein Reimpaar (Brechung des Reimpaares, mhd. rime brechen). Die symmetrische Grundform des Spielmannstypus bedingt in sich einen Versparallelismus, dem weiterhin parataktischer Satzbau entspricht. Das germanische Stilmittel der Variation ist zwar auch im Rother bewahrt, auch herrscht die Parataxe durchaus vor, aber doch ist gegenüber dem starren Gliederungsprinzip der Spielmannstechnik das Formgerüste hier freier, beweglicher, Sätze und Verse sind nicht so ausgesprochen parallel geordnet, die monotonere Reihenbildung wird eher durch manchfaltigere Übergänge durchbrochen.

3) Ueber Sprache u. Stil: RÜCKERT S. LVII; EDZARDI, Germ. 18, 423-428. 447-450; Vogt, Salm. u. Mor. S. CXVIII ff.; Schmedes, Pieritz, Wiegand aaO.; Bimaghei., Beitr. 30 ,
431 ff.; ZWIERZINA, ZfdA. 45, 79. 282. 335; ferner die oben S 289 f. angegebene Literatur. - 1,atein. Einschiebsel s. bei GRUNEWALD S. 36. 
Besondere Ausdrucksmittel des epischen Stils wie die verschiedenartigen Formeln, Eingang, Übergang, Quellenberufung, Wahrheitsbeteuerung, Zahlen, Alliteration, Paarbegriffe, Epitheta, Hyperbeln, Metaphern sind maßvoll verwendet, öfter finden sich Vergleiche. Belebt wird die Erzählung durch Ausrufe mit wie, hei wie, owît, owî wie, wie waz, eiâ, wol bei Gemütsbewegung, Verwunderung etc. 195. 247. 253. 349. 355. 379. 449. 471. 486 f. 1065. 1153. 1182. 1466. 1555. 1707. 1779. 2071. 2083. 2336. 2528 u. ö., zum Ausdruck rascher Handlung 182. 2026. 2094. 2318. 2492. 2512 u. ö. Der Dichter läßt die Menschen nach Grundsätzen handeln. Gern stellt er den einzelnen Fall unter moralische Wertung und knüpft daran einen Erfahrungssatz, z. B. 500-504. 617-619. 1551-1553. 1971. 2004 f. 2035 f. 3057 f. 3322-3324. 3415-3417. 3418-3421. 3654-3659. 3712-3717. $4383 \mathrm{f}$. 4524-4526. $4559-4562.4640$ f. 5124-5127. 5151-5156. 5161-5163. Er läßt sprichwörtliche Redensarten einfließen, z. B. 1085 f. 1474. 3138.

Die Reime und der Vers ba ${ }^{1}$ ) entsprechen der um 1130-1160 üblichen Technik. Die Verse sind infolge der Freiheit der Senkungsfüllungen von ungleicher Länge, jedoch ist ein gewisses Mittelmaß zwischen den Extremen Regel.

Das Fortleben des Gedichtes. Das Gedicht muß auch noch im dreizehnten Jahrhundert recht beliebt gewesen sein, da es in mehreren Hss. dieses Jahrhunderts auf uns gekommen ist und einer Modernisierung nach den Anforderungen eben jener Zeit unterzogen wurde (Hs. A). Der Marner2) und ihm folgend Hugo v. Trimberg im Renner ${ }^{3}$ ) zählen den König Rother unter den Stoffen auf, nach denen von dem ungelehrten Publikum ihrer Zeit am meisten verlangt wurde, ${ }^{4}$ ) und öfter werden in Dichtungen des 13. Jhs. die Riesen Asprian, Widolt, als besondere Kraftkerle zitiert. ${ }^{5}$ ) Und als durch die wundersüchtige Geistesströmung der Romantik der Sinn für das Mittelalter wieder erweckt worden war, da schrieb Tieck bei seinem Aufenthalt in Rom im Jahr 1805 die palatinische, damals im Vatikan aufbewahrte Handschrift ab. In dem auf Tiecks Abschrift beruhenden Drucke von der Hagens (1808) lernte Goethe das Gedicht kennen und las es mit andern altdeutschen Denkmälern dem auserwählten Kreise seiner Mittwochsgesellschaft vor (Annalen 1809). Er auch hat der ewigen Lebensfrische und Gemütsinnigkeit des Gedichtes die treffendste und schönste Erläuterung gegeben in den sechs Strophen des romantischen Maskenzuges von 1810 (Jubil.-Ausg. Bd. 9, 328 f. 441 f.), deren beide ersten er 'als Stammbuch-

1) Metrik: Amelung, ZfdPh. 2, 253-305; RÜCKERT S. LXXXII ff.; LAMBEL S. 177-179; EDZARDI, Germ. 18, 391 ff.; v.BAHDER, Germ. 29, 257 ff. 288-296; VoGT, Salman XCVII ff.; Berger, Orendel S. LXI; HerTel, Marburg. Diss. 1908; BERNT, Diss. aaO.; SCHRÖDER, Gött. Nachr. 1918, 425. Sechszeil. Strophen: SCHADE, Cresc. S. 54 ff., Geistl. Ged. S. LXXV -CII; achtzeilige Strophen: POGATSCHER S. 37 ff. - SARAN, Reg. S. 352; ZWIERZINA,
ZfdA. 44, 43. $94 \mathrm{f}$.

2) Ausg. von Strauch S. 125 u.Anm.S. 180; DROEGE, ZfdA. 5I, 215.

3) Ausg. d. Lit.Ver. V. 1223 u. 16197.

4) W. GRIMM, DH ${ }^{3}$ S. 179 f. 191; RUCCKERT S. V-IX; LAMBEL S. 171; EDZARDI, Germ. 18, $388 \mathrm{f}$. - Der Name lautet in späteren Hss. oft Rücker, s. die Varianten zu den Stellen des Marner u. des Renner in den betr. Ausgaben.

5) W. GRIMM, Reg. S. 500 unt. Asprian. 
verse für Frau v. Spiegel 1824 wiederholte (Bd. 3, 20). Und den Reichtum an plastischen Szenen erkannte mit geschärftem Künstlerblick, heimatlich romantisches Empfinden mit klassischem Schönheitssinne verbindend, Eduard Mörike. ${ }^{1}$ )

\section{$\$ 81$. Salman und Morolf.}

1. Das Spielmannsgedicht von Salman und Morolf.

Kelle 2, 216. 388; PIPER, Spielm. D. 1, 196-229; Höf. Ep. 3, 711. - Ausg.: v. D. HaGeN in v. D. Hagen u. Büsching, D. Ged. d. MA. I. Bd. Einl. S. IV-XXIV, Text (nach E): Spielmannsged. S. 1-43 Anm. S. 65-91, Spruchged. S. 44-64 Anm. S. 91-99, dazu J. GriMm, Heidelb. Jalıb. 1809, 2, 151-154. 249-255 u. KI. Schr. 4, 25--27. 44-49; FRIEDR. VoGT, Salman und Morolf, Halle 1880, dazu Wilmanns, Anz. 7, 274-301, LC. 1880, 1333, RödiGer, DLZ. 1881, 1038, PAul, Lit.Bl. 1881, 9-11. - Siehe auch PANZer, Hilde-Gudr., Reg. S. 451; BAESECKE, Müncl. Oswald, Reg. S. 442. 443; SCHnEIder, Wolfdietr., Reg. S. 417.

Hss.:2) E. Eschenburgs Hs. v. J. 1479, ehemals im Besitz Eschenburgs (in Braunschweig), dann in Berlin, jetzt verschollen. Über v. D. Hagens Mskpt. s. VogT S. 165.

S. Stuttgart, vorher dem Kloster Weingarten gehörig, mit Bildern (12 sind erhalten), 14./15. Jh.; Dialekt: südl. Rheinfrk.

Dresdener Hs., ${ }^{3}$ ) Bruchstücke (12 Blättchen), Mitte 15. Jh., enthielt ebenfalls Bilder. - Eine Hs. v. J. 1476 der elemal. Straßburger Johanniterbibl. ist mit der Stadtbibliothek 1870 verbrannt.

d. Druck, Straßburg 1499, mit Holzschnitten.

$\mathrm{S}$ und $\mathrm{d}$ haben eine gemeinsame, ziemlich fehlerhafte Vorlage (Y), d ist ganz unzuverlässig durch Lücken, Entstellungen, Änderungen und Interpolationen; Dresden steht am nächsten $z u d$. E ist weit nachlässiger und willkürlicher als $\mathrm{S}$, welches demnach den alten Text am besten bewahrt hat. Die Quelle von Sd-E (X) ist nicht der Originaltext selbst, sondern eine im Laufe des 13. und Anfang des 14. Jhs. durch Entstellungen, Interpolationen und Strophenerweiterungen zustande gekommene Version. Das ursprüngliche Gedicht ist am Ende des 12. Jhs. von einem Dichter des südlichen Rheinfranken verfabt. ${ }^{4}$ )

Inhalt.5) Einleitung Str. 1-21. Salman, König von Jerusalem, hat die Tochter des Heidenkönigs Cyprian von Endian über das Meer entführt und getauft. Sie heißt Salme. Ihre Schönheit, Kleidung; Kircligang am Pfingstfest.

A. Salme und Fore Str. $21-597$.

1. Salmes erste Entführung durch den Heidenkönig Fore Str. 21-158. Seine Herren schlagen Fore die Christenkönigin in Jerusalem, Salmans Getnahlin, zur Frau vor. Er zielst gegen Salman, wird in der Schlacht gefangen genommen, der Salme zur Bewachung übergeben. Er schenkt ilhr einen zauberkräftigen Ring, der sie zur Liebe zwingt. Sie hilft ihm zur Flucht. Ein Spielmann Fores gibt Salme ein Zauberkraut, das sie scheintot macht. Sie wird begraben, vom Spielmann, der den Sarg erbricht, enffülrt. - II. Morolfs Kundschaft Str. 159-345. Um als Kundschafter unkenntlich zu sein, ersticlit Morolf einen alten Juden und steckt sich in dessen Haut. Als Pilger zieht er nach der Königin ans. Einen Heiden, der ihm ihren Aufenthaltsort angibt, ersticht er, 11 m niclit von ilım verraten zu werden. Beim Kirchgang erzäblt er der Königin bettelnd von Salman und der Flucht der Salme. Darauf von thr zum Schachspiel geladen verrät er sich, indem er eine ilır bekannte Weise singt, wird gefangen, entflieht dadurch daß er die Wächter trunken macht, wonlach er itıen Platten scheert. Wieder gefangen, befreit er sich auf die gleiche Weise. Er gelit zu Hofe und spielt den Kaplanen Fores und diesem selbst eincn lächerlichen Streich: cr betäubt alle durch

1) Vgl. Hans WolfG. Rath, Bricfwechsel zw. Ed. Mörike u. Mor. v. Sclıwind S. 48. 202 -208 u. Reg. S. 211. - Ueb. Rother in R. Wagners dramat. Entwurf 'Wieland der Schmied' s. Roethe, Berl. Ak. 1919, 693.699. - In der Zs. f. Einsiedler: SCHERER, J. Grimm S. 65.
2) V. D. HAGEN u. BÚSCHiNG, liter. Girnndr. 1812 S. 207 f.; Vogr, Einl. S. $1-X X$ u. S. 165.

3) L.UDW. SCHMIDT, Beitr. 30, $571 \mathrm{f}$.

4) Vogt S. CVII--CXVIII; WILMANNS aaO. 5) Vogt, Einl. S. XXI-XXXlll. 
einen Schlaftrunk und legt sie auf einen Haufen an die Wand, den König steckt er in die Kutte eines Kaplans, legt den König an die Wand und den Kaplan ins Bett zu Salme; dem König scheert er eine Platte. Dann entflieht er und kehrt zu Salman zurück. - III. Salmans Kundschaft Str. 346-480. Mit einem Heer zieht Salman zur Burg Fores, als Pilger verkleidet wird er erkannt, von Salme mit Hohn behandelt, von Fore zum Galgen verurteilt. Fores Schwester tröstet ihn im Gefängnis. - IV. Salmans Rettung, Wiedergewinnung der Salme Str. 481-551. Am Galgen bläst er dreimal in sein Horn, sein Heer eilt herbei und befreit ihn, die Heiden werden besiegt, Fore gehängt. - V. Anhang Str. 552-597. Besiegung König Isolts, Fores Neffen. Rückkehr nach Jerusalem mit Salme. Fores Schwester wird getauft.

B. Salme und Princian Str. 598-783.

I. Salmes zweite Entführung durch Princian Str. 598-610. Princian, als Pilger verkleidet, gewinnt Salmes Liebe durch einen Zauberring und entführt sie. - II. Morolfs $z$ weite Kundschaft Str. 611-712, in verschiedenen Verkleidungen (als Krüppel, Pilger, Spielmann, Metzger, Krämer). - 1II. Z weite Wiedergewinnung der Salme Str. 713783. Morolf erstattet Salman Bericht, zieht dann mit Heer gegen Princian. Mit Hilfe von Zwergen gelingt es ihm, Princian gefangen zu nehmen. Dieser entflieht, wird aber dann in der Schlacht von Morolf erschlagen. Salme wird zurückgebracht. Im Bad läBt sie Morolf zur Ader, er drückt sie dabei so leise, daß ihr die Seele ausgeht. Salman nimmt Fores Schwester zur Frau.

Komposition.1) Die Geschichte vom Raub und der Wiedergewinnung der Frau Salmans wird zweimal erzählt, demnach zerfällt der Grundplan in zwei Hauptteile: A Salme und Fore und B Salme und Princian, das System beruht auf Wiederholung des Hauptmotivs. Aufgebaut ist jeder der beiden Teile in drei Stufen: I. Entführung der Salme durch einen überseeischen Heidenkönig; II. Kundschaft Morolfs, Erspähung des Aufenthaltsorts der treulosen Königin unter mancherlei Abenteuern; III. Wiedergewinnung der Salme durch Besiegung des Heidenkönigs.

Sage. ${ }^{2}$ ) Dem MA. war Salomo in seiner Macht und Weisheit das Ideal eines irdischen Königs. Sein Name bedeutet Friede, er ist der Friedenskönig, sein Reich bedeutet das Reich Christi, seine Liebe zu Sulamith den Bund Christi mit der Kirche, seine Lehre stellt das richtige Verhältnis zwischen Mensch und Gott auf: Gott fürchten und die Welt verachten, Gottesfurcht ist der Weisheit Anfang (principium sapientiae timor Domini Prov. 1, 7.

1) VoGT S. XXXIII-XLI.

2) Zur Sage s. Vogt S. XLI-CXVIII, dazu Wilmanns aaO.; v. D. Hagens Einleitung; J. GRIMM aaO.; J. M. Kemble, The Dialogue of Salomon and Saturnus, London 1848; ARTH. v. VINCENTI, Drei altenglische Dialoge von Salomon und Saturn, Münch. Diss. 1904 u. Münch. Beiträge zur roman. u. engl. Philologie H. 31 : BENFEY, Pantschatantra 1, 436 ff. KOnR. Hofmann, Münch. SB. 101 (1872), 415 -448; Ders., Amis und Amiles und Jourdain de Blaivies, 2. Aufl., Erlangen 1882, Einl. S. XL f.; Symons, Kudrun, 1. u. 2. Aufl. an verschiedenen Stellen der Einleitung: L. BEER, Der Stoff des Spielmannsgedichtes Orendel, Beitr. 13, 99 ff.; JoH. v. ANTONIEWICZ, Anz. 14, 244 ff.; Singer, Salomosagen in Deutschland, ZfdA. 35, 177-187; HerM. TARDEL,
Untersuchungen zur mhd. Spielmannspoesie, Rostocker Diss. 1894 S. 33-72, dazu SINGER, Anz. 22, 43 ff.; PANZER, Germ. Abh. Herm. PAUL dargebr., S. 303-332; BURDACH, Archiv 108 (1902), 131 f.; BURDACH, Ackermann S. 260-262 (mit vielen Literaturangaben); DeutschbeIn, Studien zur Sagengesch. Englands 1,31 ff. u.ö.; JAGIC, Arch. f. slav. Phil. 1, 82 ff.; WESELOFSKY ebda 6, 393 ff. 548 ff.; HEINZEL, Anz. 9, 241 ff. (s. auch VoGT S.XLIAnm.2); FRANZ KaMPERS, Das Lichtland der Seelen und der heilige Gral, Görres-Gesellschaft, 2. Vereinsschrift 1916 (Salomosage u. Gralsage, mit reichen Literaturangaben); KAMPERS, Mitteil. d. Schles. Gesellsch. f. Volkskunde 19 (1917), 72-139; WesSELOFSKY, Mélusine 4, $269 \mathrm{ff}$. 
9, 10), es ist Alles eitel (vanitas vanitatum et omnia vanitas, Eccles. 1, 2).1) Gott gab ihm die höchste Weisheit, die je ein Mensch besaß (III. Reg. 4, 29). Aber ungetrübt ist auch dieses Menschenbild nicht, auch er, der weiseste auf Erden (ebda 4,31), mußte der Menschenart seinen Tribut zahlen: er liebte viele ausländische Weiber, und da er alt war, neigten seine Weiber sein Herz fremden Göttern nach (III. Reg. 11, 1.4). Doch hat diese Schwäche der Verehrung des weisen Königs im Mittelalter keinen Abbruch getan, nur Nachklänge hat sie, besonders in der weltlichen Literatur, hinterlassen. Als Beispiel für die Allgewalt der Minne zitiert ihn Veldeke: "Diu Minne twanc ê Salomône: der was der aller wîste man, der ie getrüege küneges krône MSF. 66, 16-18;2) vgl. auch Parz. 289, 16 f. Dieser weltliche Salomo nun ist der Mittelpunkt unserer beiden Gedichte, des Spielmannsepos und des Gesprächs. In der ritterlichen Dichtung ist er, wie in den eben zitierten Versen Veldekes, ein Vertreter des höfischen Frauenkultes.

Salo m osage. Beide Dichtungen gehen in ihrer Grundlage auf hebräische Tradition zurück. Im Andenken seines Volkes lebte Salomo in reicher Sagenbildung fort. Das Idealbild des weisen und mächtigen Herrschers, als welchen ihn das alte Testament verherrlicht, nahm in talmudischen und kabbalistischen Schriften und in salomonischen Apokryphen (das Testament des Salomo) Züge aus der niederen Volksvorstellung an, aus dem Zauber- und Geisterglauben. Er besaß einen geheimniskräftigen Sicgelring, vermöge dessen er Gewalt hatte über die Geschöpfe der Erde und des Dämonenreiches. Sein gefährlichster Feind ist der Geisterfürst Aschmedai (Asmodaeus), der seinen Siegelring und dadurch die Macht über ihn erlangt. Von Aschmedai, der seine Gestalt angenommen, verstoßen, seines Reiches und seiner Frauen beraubt, irrt er wie ein Bettler umher, bis er nach Entlarvung und Bewältigung des Aschmedai wieder in die Herrschaft eingesetzt wird. In dieser hebräischen Sage liegt der Keim für das mhd. Spielmannsgedicht: ein feindlicher König (Fore) beraubt durch einen zauberkräftigen Ring Salomo seiner Frau. Dazu kommen noch andere Ähnlichkeiten: Salomo gelangt unter die Gewalt des Aschmedai: Salman in die Gefangenschaft Fores; der Ausgang ist beidemal der gleiche: Aschmedai und Fore werden überwältigt, SalomoSalman erlangt die Herrschaft wicder. Unmittelbar an den Bericht der Bibel, daß Salomo heidnische Frauen hatte - seine oberste Gattin war die Tochter des Pharao (der Name 'Pharao' hat sich in 'Fore' erhalten) - , erinnert die Einleitung des Spielmannsgedichtes (Str. 2 ff.), wonach Salnan seine Fran einem lıeidnişchen Fürsten entführt hat. Die jüdische Sage verbreitete sich in das byzantinische Reich, ${ }^{3}$ ) wo vermutlich unter starken Wandlungen die

1) Mit dem ersten der beiden Leitsätze beginnt Freidank, mit dem zweiten, der Salomonischen Weisireit, das alte Al.lied (s. S. 253 f.).

2) Vgl. MSF. Anm. zur Stelle; Behagilel, Eneide Einl. S. CLXXIl ff.; Singer, Salomo- sagen S. 182 f.; BURDACH, Ackermann S. 262 -266, Vom MA. zur Ref. S 87 Anm. 1.

$\left.{ }^{3}\right)$ Sie war odurch die Tradition der Jerusalempilger bereits seit dem 4. Jahrhundert n. Chr. in das gesamte Aisendland verbreitet", BURDACH, Ackermanu S. 260 f. 
für die Folgezeit gültige Sagengestalt in den Hauptpunkten festgelegt wurde. Aus solchen griechischen Fassungen entwickelte sich die russische (wohl ursprünglich serbisch-bulgarische) und die deutsche Überlieferung. Sehr wichtig ist die russische, in Volksballaden und Prosaerzählungen erhaltene Version. Sie hat mit dem deutschen Epos nicht nur die Gesamtanlage, sondern auch viele einzelne Stoffteile gemein; die Handlung aber verläuft einheitlich ohne Wiederholung und Häufung von Szenen.

Auch für die Entwicklung der deutschen Salomo-Entführungssage ist eine in knapper Form gehaltene Ursage vorauszusetzen. Für diese ergibt sich aus dem Vergleich des Spielmannsepos mit dem russischen Liede nahezu der gleiche Grundplan, wie er oben in der Inhaltsangabe für A aufgestellt ist, außer daß Morolfs Kundschaft wegfällt, der überhaupt in der ursprünglichen Sagenform weniger hervortritt.

Diese Gestalt der ältesten deutschen und der russischen Sage, demnach im wesentlichen auch ihrer byzantinischen Grundlage, ist aus lauter bekannten Zügen zusammengestellt. Die Salomo-Aschmedai-Sage lieferte nur das Thema, den Kern, zur epischen Ausführung wurde die Erzählung von der ungetreuen Gattin (die Rasosage) verwendet, die in vielen Versionen verbreitet war. ${ }^{1}$ ) Ihr sind die meisten Einzelszenen, vor allem von der Ausreise Salomos an, entnommen. Wenn man diese Wendung der Entführungssage spezieller nach dem Inhalt bezeichnen will, so muß man sie zu dem Kreis der Sagen von der ungetreuen Gattin rechnen. Diese ursprünglichste Sagenform hat im Deutschen eine bedeutende Verstärkung durch die Einführung Morolfs erfahren. Er gehört der Sage von der ungetreuen Gattin an, denn in manchen Versionen derselben steht dem gefährdeten Helden, wie Morolf dem Salman, ein Helfer zur Seite, meistens der Sohn. ${ }^{2}$ ) An dessen Stelle ist im Deutschen Morolf getreten und damit ist die einfache Salomosage zur erweiterten Salomo-Morolfsage geworden. Er entspricht zugleich einer Lieblingsfigur der deutschen Entführungsgeschichten, dem hilfreichen Dämon. Entnommen wurde er dem Dialog Sal. u. Mark., denn schon hier war Markolf als schlauer Partner mit Salomo verbunden. ${ }^{3}$ )

1) VogT S. LXV ff. u. Beitr. 8, 313-323; WESELOFSKY aaO. 6, $393 \mathrm{ff}$.; LIEBRECHT, Germ. $5,56-58.11,172$ f. $25,33-40$. Zu Rudolf v. Schlüsselberg s. bes. SсHÖNBACH, Wiener SB. 145 (1902) Nr. VI. In der lat. Erzählung des Gualterus Mapes ist der betrogene Gatte ein Ritter namens Raso.

2) Bei Gualterus Mapes, in dér Erzählung von dem Ritter R. v. Schlüsselberg, im frz. Bastars de Buillon und in der portugiesischen Ueberlieferung, vgl. VoGT, Beitr. 8, $313 \mathrm{ff}$. Als Bruder Salomos wird Morolf erwähnt im ags. Salomon und Saturnus (VogT S. LV).

s) Vgl. Liebrecht, Germ. 25, 40. - Schon der Charakter und das Benehmen Morolfs zeigt seine Abstammung aus dem Markolf, er ist der spottere Mark. 1373. 76 (vgl. Spielmannsged. Str. 131. 138. 142), der mit dem König seine Possen treibt, so daß er vom Hof verjagt wird 1425 ff. (Spielmannsged. Str. 134. 137); er verkehrt die Worte Salmes ins Gegenteil Str. 534-536; der unflätige Witz im Ofen $1486 \mathrm{ff}$. ist ins Spielmannsged. Str. 138 ff. übernommen worden. Natürlich muß dann die Quelle ein älteres Spruchgedicht als das uns erhaltene, vielleicht ein lat., gewesen sein; möglicherweise aber stammt die possenhafte Natur des Morolf überhaupt unmittelbar aus der Volksüberlieferung, da ja Markolf eine allgemein bekannte Figur war (vgl. VoGT S. CXXI). 
Entstehung des deutschen Spielmannsepos. Die erste Stufe dieser Salomo-Morolfsage ist enthalten in dem Anhang zum Spruchgedicht (v. D. Hagen S. $62-64$ V. 1605-1848). Hier ist der Stoff noch nicht durch Häufungen und Ausmalungen erweitert, das Thema nicht durch den zweiten Teil, Salme und Princian, fortgesponnen.1) Der Anhang hat mit dem um 1190 anzusetzenden kürzeren Spielmannsepos (dem Original, von dem das uns erhaltene Gedicht $\mathrm{X}$ abgegangen ist) dieselbe Grundlage, der Inhalt war nahezu der gleiche, jedoch ist auch hier das Original der SalomoMorolfdichtung nicht rein erhalten, vielmehr sind Änderungen und Kürzungen vorgenommen, denn es fehlen wichtige $Z$ wischenglieder. Somit ist der Motivengehalt und der Umfang der Originaldichtung auch aus dem Anhang des Spruchgedichtes nicht genau zu ersehen.

Der gedrängte Sagenstoff jener ursprünglichen Fassung von ca. 1190 wurde in dem uns erhaltenen Spielmannsgedicht (X, um 1300) zum umfangreichen Epos erweitert und gerade mit Morolf war eine für die Technik sehr dehnungsfähige Figur gewonnen, da die listigen Streiche und Verkleidungen des Schalkes beliebig vermehrt werden konnten. Anschwellung durch Wiederholung bezw. Häufung: von Fores Spielmann ist zweimal die Rede: Str. 109 wird er angekündigt, Str. 119 erscheint er; zweimal läßt Fore Salman durch Boten Fehde ansagen 40 und 51 ; zweimal wählt der Dichter als Lokal für das Auftreten der Salme den Gang zur Messe, 10 und $121 \mathrm{ff}$. (vgl. 191); die Messe dauert zu lange 124 und 201; zum Zweck seines Kundschafterganges bringt Morolf zuerst den Juden Berman, dann einen Heiden um $159 \mathrm{ff}$. und $179 \mathrm{ff}$; die zweimalige Auskundung, zuerst durch Morolf, dann durch Salman; dreimalige Fluchtversuche Morolfs; dreimaliges Trunkenmachen und Glatzenscheeren $286 \mathrm{ff} ., 311 \mathrm{f}$. und $323 \mathrm{ff} .{ }^{2}$ ) Die Schlacht mit Isolt hat nur den Zweck, den Umfang zu dehnen. Schildernde Partien, Beschreibungen von Personen (Salme), Kämpfen, Rüstungen, Kirchgängen, bringen nicht erheblichen Zuwachs.

Nicht nur einzelne Stoffteile innerhalb des abgeschlossenen Ganzen werden wiederholt, sondern der Roman selbst ist auf zwei Teile angelegt, dessen zweiter wie im Rother nur eine Variation des ersten ist. Die alte Schablone wird mit geringen Änderungen wiederholt. Der Schwerpunkt liegt in den Verkleidungen Morolfs, die in der Ökonomie dieses Teiles den größten Raum einnehmen (611-712), wie denn Morolf fast durchaus der Träger der Handlung ist, während Salman ganz zurlicktritt. Eingeschoben ist das Motiv von den hilfreichen Zwergen, welthes sofort den günstigen Ausgang, die Besiegung Princians und die Wiedergewinnung Salmes, entsclieidet. Der Schluß, die Bestrafung der Salme 775 ff., bringt erst den endgültigen

1) Vielleicht war doch diese Fortsetzung dem Verfasser des Anhangs bekannt. Dafür würde der gleiche SchluB sprechen: Salme wird nicht, wie in der internationalen Sagenform und in dem ersten Teil des Spielmanns- gedichtes, sofort mit dem Entfihhrer, sondern erst zu Hause umgebracht (vgl. WhislanNs, Anz. 278 f.).

2) VogT S. CXX, ebda die häufigen Verkleidungen. 
Ausgang des ganzen Romans, denn am Ende des ersten Teiles muß Salme mit dem Leben davonkommen, da sie ja im zweiten wieder mitzuspielen hat. $\left.{ }^{1}\right)$

Stil. $\left.{ }^{2}\right)$ Die Gliederung des Gedankenstoffs ist bedingt durch den strophischen Bau des Gedichtes. Die durch diese spezielle Form gegebene Inhaltseinheit ist die Strophe von fünf vierhebigen Zeilen, die Unterabteilung ist der Satz. Meistens zerfällt die Strophe in zwei Gedankeneinheiten. Nach der Anzahl von Zeilen, die die beiden Sätze jeweils umfassen, gibt es zwei Typen: a) die beiden Sätze stehen im Verhältnis von zwei Zeilen zu drei Zeilen, oder b) umgekehrt; z. B. a) der häufigere der beiden Typen Str. 3. 7. 10. 11. 12. 13. 14. 15. 19. 22. 24. 27; b) Str. 6. 8. 9. 18. 23. 29.34. 36. 38. Nicht in allen Strophen ist die Zweiteilung in gleicher Weise merkbar, in andern, besonders in redehaltigen Strophen, läßt sie sich überhaupt nicht durchführen, z. B. Str. 26.28. 33. 35. 37. 41. 88. 114. Die Strophen sind immer in sich abgeschlossen und gehen inhaltlich nur sehr selten ineinander über.

Mit dieser Eingrenzung des Sprachstoffes in die Strophenform ist auch schon der Satzbau bestimmt: er kann sich nicht in längeren Perioden entfalten, er kann nur parataktisch sein.

Das Charakteristische des Spielmannsstils beruht in der Wiederholung3) von Sprachgliedern, dem bequemsten Mittel zur stilistischen Formgebung. Gleicher Inhalt ruft gleichen Ausdruck hervor, die bei einer Situation gebrauchten Worte kehren bei einer ähnlichen wieder. Aber die Parallelen werden nicht mechanisch wörtlich wiederholt, sondern jeweils der veränderten Sachlage angepaßt. Drei Könige versprechen in der Ratsversammlung Fore ihrem Herren Unterstützung 32-39: sie tun es mit fast den gleichen Worten, aber doch hat der Dichter durch geringe Abformungen die drei Redner unterschieden, und zwar durch das Kunstmittel der Steigerung: der erste, Cyprian, sendet vier, der zweite, Duscan, fünf, der dritte, Priscian, sechstausend Helden; Priscian, der mächtigste, rühmt außerdem seine große Vasallenschaft, die aber doch hinter der des Großkönigs Fore zurücksteht (23). Eine ganz leichte Abwechslung ist sogar in die Wortwahl gelegt mit der Folge der Verba senden $33,3.34,1$, dann füeren $35,3.36$, 1, dann wieder senden 37, 3. 39, 1. Die beiden ersten Könige beklagen am Schluß ihrer Reden das Schicksal der Salme, daß sie in der Christenheit ist, der erste als Vater (34), der zweite nur als Untertan (36), der dritte aber schließt diese ganze Verhandlung ab, nicht mit einer Klage, sondern mit Siegeszuversicht (39). Durch solche kleine Züge erhalten die drèi Fürsten eine gewisse individuelle Note. Auch formal im Aufbau der Szene besteht ein gewisser Plan, die Strophen

1) Auch die Sage von der ungetreuen Gattin in der Ueberlieferung des Gualterus Mapes zerfällt in zwei Teile: zweimal zieht der betrogene Mann auf Kundschaft aus, beim ersten Kampf wird seine Frau gerettet, erst beim zweiten wird sie durch den Sohn er- schlagen.

2) Siehe die vorbildliche Darstellung bei VoGT S. CXXXIII ff. u. Anm. S. 165 ff. ; ZWIERZINA, ZfdA. 45, 36. 282.

3) VOGT S. CXXXIV-CXXXVII. 
sind symmetrisch verteilt, auf den ersten und den dritten König fallen je drei, auf den mittleren zwei. Überhaupt beziehen sich in der ganzen Ratsversammlung Str. 24-40 die Strophen durch Parallelen aufeinander: 25, $3-5$ u. 26,3-5 u. $29,3-5 ; 27,1.2$ u. $30,1.2 ; 27,5$ u. 29,1 u. 34,$3 ; 30,3-5$ u. 39, 4 f.; $28,3-5$ u. 34,1 f. u. 36,1 f. u. 39,1 f. u. $40,3-5$. - Sehr zahlreich sind die eigentlichen Formeln, besonders als bedeutungslose Ausfüllungen des Vers- oder Strophengefüges, also Berufungen auf die Quelle, z. B. alsô kundet uns daz liet, Wahrheitsbeteuerungen, z. B. daz ist wâr, Aufforderungen zur Aufmerksamkeit bezw. Übergangsformeln, z. B. nu horent wie, Hindeutungen auf ein böses Ende, z. B. ez gât in allen an daz leben. Ausrufe und Fragen, z. B. wie balde...! wie nu. .?, beleben die Mimik des Vortrags.

Alles ist auf Handlung angelegt, daher die Fülle von Begebenheiten. Das Tempo der Erzählung ist lebhaft, Schilderungen außer von Schlachten (67-78. 516-527. 555-574. 757-771) sind selten: Salmes Schönheit und Kleidung 5-18, zuerst Aufzählung der Einzelheiten, dann indirekte Schilderung: die Ritter vergessen vor Staunen beim Mahle zu essen und zu trinken. Erzählung und Rede sind ebenmäßig verteilt, das strophische Epos ist schon durch seine Zertrennung in einzelne Gesätze langen Reden nicht günstig.

Das Spielmannsgedicht von Salman und Morolf stelit unter den verwandten Dichtungen die spielmännische Art am reinsten dar. Hier ist der niedere, volksmäßigere Geschmack am besten getroffen. Ergötzt und belustigt will dieses Publikum') werden, es hat seine Freude an derberer Kost. Ohne Unterbrechung in unterhaltender Abwechslung folgen sich hier die Abenteuer und Schwänke, die Schelmenstücke und Betrügereien, immer wird der Hörer wieder in neue Spannung versetzt, wie Morolf sich aus seinen ungemütlichen Situationen herauslisten mag; dann wird das Mitleid erregt für den schönen, betrogenen König, am Ende aber triumphiert doch die Gerechtigkeit über die Bosheit. In einzelnen keck entworfenen Genrebildern entfaltet sich das Leben der kleinen Leute. Man beobachtet das Volk auf der Landstraße: der Pilger zieht mit rauhem Bart, in grobem Rock, einen Palmzweig auf dem Rücken, den Stab in der Hand, durch das Land (362. 666. $677 \mathrm{ff}$.). Geckenhaft schreitet der stolze spilman einher (687 ff.), in rotseidenem Gewande und höfisch anstehender Kleidung, die Harfe in der Hand; auf der Straße beginnt er süß zu spielen, daß laut der Ton erklingt, die Leute setzen sich zu ihm, sie vergessen ihre Arbeit, den ganzen Tag bis in den Abend hinein schlingen sie den Reigen; aber der Spielmann muß endlich weiter, denn er ist zu einer Festlichkeit bestellt; wohl belohnt und bedankt zieht er von dannen. Dann sieht man den Metzger im grauen Rock

1) Damit ist nicht gesagt, daß das Gedicht nur für niedere Kreise, fiir die Leute auf den Straßen oder auf Jahrmärkten, bestimmt gewesen sei. Der Ton ist vorhöfisch und unn- höfisch und bestand auf den Burgen des Adels als Unterströmung jedenfalls auch in den Zeiten der feinen romanisclien Bildung, vgl. Wilmanns, Anz. 7, $300 \mathrm{f}$. 
und großen Schuhen, das Messer am breiten Gürtel, sein Handwerk treiben (701 ff.), den Hausierer seinen Kram mit Nadeln, Gürteln, Bändeln, Beuteln richten (709 ff.). Naiv stellt sich das Volk den Verkehr mit den Fürsten dar, wie im Märchen: der bettelnde Krüppel, der auf allen Vieren rutscht, läßt durch den Torwächter den König aus der Burg holen und der Herrscher erscheint, von seinen Rittern umgeben, auf den Wunsch des Armseligen, beschenkt ihn reichlich, hebt ihn eigenhändig auf seinen Esel und hilft ihm, da er herabfällt, wieder hinauf (639 ff.). Das sind freilich Idealzustände für Bettler, aber doch ist diese phantasievolle Ausschmückung ein sprechendes Beispiel für die auf dem Gebote der Nächstenliebe beruhende Pflege der Armen und Kranken im Mittelalter, ein Bild für diese schönste soziale Tugend des Christentums, für ihre Erfüllung durch den gütigen Fürsten, zugleich aber auch für ihren Mißbrauch durch das bettelnde Volk.

Lediglich nach dem materiellen Vorteil schätzen die Fahrenden, die guot durch êre nehmen und wohl wissen, daß sie ein unfrommes Handwerk treiben, die Menschen ein: wer am meisten gibt, der wird am lautesten gepriesen. Von den Gönnern hängt ihre Existenz ab, darum wird ihnen geschmeichelt, sie werden als Muster von Milde und Freigebigkeit hingestellt (Princian 639 ff.); auf dem Kriegsfuß dagegen stehen sie mit den Dienern, denn die sind ihnen aufsässig, behandeln sie schlecht und suchen die $\mathrm{Zu}$ dringlichen mit Schlägen vom $\mathrm{Hof} \mathrm{zu}$ vertreiben. Solche Prügelszenen gehören zu den besonderen Ergötzlichkeiten der Spielmannsdichtung (192194. 363-369. 645-652, vgl. 312 f. 317). Derbe Komik ist die Würze der Spielmannspoesie, aber einige Unflätigkeiten Morolfs gehen darüber hinaus und verraten seine Herkunft aus der niederen Sphäre des Spruchgedichtes.

Morolf ist der eigentliche Held der Erzählung. Entsprechend seiner Entstehung aus dem helfenden Verwandten der Rasosage und dem Schelmen des Spruchgedichtes hat er eine doppelte Natur: einerseits ist er ein vornehmer Ritter, andrerseits ein Possenreißer. Als Mitglied der Feudalgesellschaft ist er der liebe bruoder Salmans, der zu seiner Seite sitzt (55, 4 f.); sein Vertrauter (Salmânes drût 185, 1.); sein getrûtwer dienstman $(351,5)$, der tugenthafte dinstman $(208,5)$; sein Ratgeber und getreuer Gefolgsmann, der sich für ihn in Lebensgefahr begibt und ihn vom Tode errettet; der Heerführer und Bannerträger; ein kühner Held (ritter edele, ritter lobesam, der stolze ritter balt, der werde helt guot, der degen hêre, der $\hat{u} z e r w e l t e$ degen, der stolze degen, der kuone man, der dugenthafte man); er ist jung und noch bartlos $(127,1.259,4)$; hat blondes, gelocktes Haar $(261,4)$, spiegelklare Augen und zierliche Brauen (673); selbst im Bettlergewand verleugnet er nicht, daß er von hôher art geborn ist (195). Wie Ganelun, als er zur Botschaft unter die Feinde gesandt wurde (oben S. 264 f.), so sorgt auch Morolf um sein Kind und übergibt es, mit Herzeleid scheidend, in den Schutz seines Königs (176 f.). Das ist der Morolf der höfischen und ritterlichen Partien. Sein eigentliches Fach aber ist die Abenteuerkomik und 
diese Rolle ist ihm vom Dialog her überkommen. In diesem Kostüm ist er die ergötzliche Person, der Held des Volkshumors, das Urbild des Fahrenden, schlau und verschlagen (der listige man), begehrlich aufs Trinken und auf Geschenke und eitel auf Ehrung, der geriebene Kundschafter, der lustige Possenreißer, auch der rohe Cyniker, in seinen Künsten ein erfinderischer Komödiant.oder auch ein dämonischer Zauberer.

Im Romanbild nimmt Morolf das größte Interesse in Anspruch, er ist der Erreger und zumeist auch der Ausführer der Handlung, er ist auch der Hauptträger der Grundstimmung, nämlich der Komik. Salman ist mehr passive Figur.

Salman ist christlicher König von Jerusalem, Fürst über alles Christenvolk 1,3, seine Mannen sind Tempelherren. Von dem biblischen Salomo hat er die Weisheit 1, 5. 101, 3. 155, 1. 381, $1 \mathrm{f}$, die ihm aber nur traditionell zugeschrieben wird und in dem Gedicht selbst nicht in die Erscheinung tritt. Stärker betont wird seine Schönheit: sie kann sich auch unter dem Pilgergewand nicht verbergen 398,3 , sein Antlitz ist so wonnesam, daß die junge Heidin von dem ersten Blick an sich nicht mehr von ihm trennen kann 401 , er ist der allerschönste Mann, den jemals eine Frau gewann, es funkeln ihm die Augen sehr schön in seinem Haupt gleich einem wilden jungen Falken, zierlich stehen ihm die Brauen 404, 5 405. 406. 423, 5. 424, 1-3. Er ist eine hoheitsvolle Gestalt. Edelmütig verzeiht er seinem betrügerischen Weibe; dem Feind, den er in der Hand hat, schenkt er das Leben; er will lieber den Tod leiden, als das Mädchen, das ilın befreien will, in Gefahr bringen; er könnte sein Leben retten, wenn er klug sich verteidigte, aber sein Stolz läßt es ihm nicht zu $(438,1)$. Aber er ist allzu vertrauenseelig und überläßt der leicht $z u$ verführenden Frau den gefangenen Nebenbuhler zur Bewachung. - Die ihm beigelegten Epitheta sind nur stilistischer Schmuck und sagen nichts Bestimmtes über ihn aus; er ist wîse, der edele, der rîche, edeler kunig lobelîch, keiser lobesam.

Das Intrigenspiel wird zwischen Salme und Morolf geführt, sie sind die eigentlichen Gegner im Stück. Sie weiß genau, daß Morolf ihr gefälılichster Feind ist (101, 3-5, ferner 104. 105. 407. 411. 448, $4 \mathrm{f}$.). Morolf dafür durchschaut alle ihre Ränke, unbarmherzig arbeitet er auf ihr Verderben und am Ende gewinnt er das Spiel. Sie ist berückend schön und gänzlich herzlos, ein dämonisches Weib: den ersten Mann, der sie so sehr liebt, verrăt sie und will ihn an den Galgen bringen, dem zweiten macht sie es nicht besser: als sie mit ihm zusammen vom Schicksal ereilt wird, lädt sie um sich zu retten feige die Schuld auf ihn und gibt ihn preis, daB er gehängt werde (415, 449. $496 \mathrm{f}$.). Der stärkste Flıch trifft sie, der der Treulosigkeit: vor Gott klagt sie Salman an waz mag grôzer untrîuen an der kuniginne sîn! 420, 4 f. 412, 1; sie ist daz ungetrîze wîp 531. 545, das verchungetrûwe wîp 262, 4. 533, 3, das mortgrimme wîp 421, 3. Diesen charakterisierenden Beiwörtern gegenüber stehen, dem formelhaften Stil des 
Volksepos entsprechend, auch allgemein ehrende Bezeichnungen, edele kunigîn, ein kuniginne hêr, schône frouwe, frouwe wolgetân, schône frouwe wolgeslacht, daz wunderschône wîp.

Offen und ehrlich stehen sich $\mathrm{Christen}$ und Heiden gegenüber. Fore will Salmans Weib haben, darum überzieht er ihn mit Krieg, rechtmäßig wird er gefangen und nun hat er nach seiner Auffassung auch das Recht, das Weib des Feindes zu entführen: diesen Standpunkt verteidigt er in der von Salman gegen ihn angestrengten Rechtsfrage (438-448). Ein Unterschied in der moralischen Wertung zwischen Christen und Heiden wird kaum gemacht, Fore ist großmüiig (425. 435. 439. 441. 446. 458 f.), seine Schwester barmherzig, Princian menschenfreundlich (639ff.), mutig sind sie alle. Es wird fast ganz vergessen, die Heiden als Glaubensfeinde zu betrachten, in naiver Unbefangenheit werden ihnen christliche Gebräuche zugeschrieben (die Messe 196. 201 f.; Hofkaplane 322 ff. 410; der Witz des Glatzenscheerens hat nur unter Voraussetzung christlicher Verhältnisse den richtigen Sinn). Das religiöse Empfinden tritt bei den Heidenkämpfen nur einmal hervor, bei der Rüstung gegen Fore (71-73): Morolf stärkt die gegen die ubelen heiden ausziehenden Krieger im Vertrauen auf Christus und läßt in das Banner ein goldenes Heiligenbild wirken. Hier klingt Kreuzzugsstimmung an, aber als eine Kreuzfahrt ist dieser Krieg doch nicht aufgefaßt, sonst würde das Kreuz als Bannerzeichen erwähnt sein. Das Merkmal, das Christen und Heiden trennt, ist die Taufe: Salme wird getauft 4.34. 36, Fores Schwester 433. 579-592.

Wie alle Spielmannsgedichte, so hat auch der Salman einen religiösen Einschlag, aber die frommen Beziehungen sind nur gering und verleihen dem geistigen Leben nicht einen besonderen Gehalt wie im Oswald und Orendel. Die die Stimmung des Gedichtes beherrschende Komik hat selbst keine Scheu vor geistlichen Einrichtungen: die Schwester Fores ist für die Patin ein zu schwerer Täufling, und Salman braucht überhaupt aus gewissen Gründen bei dem Akt nicht zuzusehen (589. 590); unehrerbietig sind die Scherze, die Morolf mit den trunken gemachten Kaplanen Fores treibt; Kirchgang (10 ff. $196 \mathrm{ff}$.) und Almosengeben (164 ff. $639 \mathrm{ff}$.) sind äußerlich werktätige Handlungen. Konventionell, aber immerhin Ausdrücke des augenblicklichen Empfindens, sind die Gebete Morolfs vor dem Kampf (71. 485), in Lebensgefahr (769f.). Salman aber kommen die frommen Gedanken unmittelbar aus innerem Erlebnis: aus Trauer über den vermeintlichen Tod seines getreuen Morolf und aus Schmerz über den Verlust seiner Frau will er sein Leben Gott ergeben (357), ferner 165. 395. 420. 473. 495. 500. 505-510. Von geistlichen Klängen ist das Gedicht umrahmt: es beginnt wie ein volkstümliches Weihnachtslied und schließt mit der Huld Gottes.

Kein anderes mhd. Epos gibt ein so umfassendes Kulturbild wie der Salman, denn er bewegt sich nicht nur in den hohen, sondern auch in den niederen Gesellschaftskreisen, zu welchen sonst die Dichter nicht herab- 
steigen. Den stärksten Unterhaltungsstoff bilden die volkstümlichen Szenen, aber auch das höfisch-ritterliche Element wirkt in der Darstellung des Gesamtlebens mit. Unerläßlich sind in einem mhd. Epos die Kampfschilderungen, doch dienen die Schlachten hier nicht zur Charakterisierung und Hebung der Helden, Salmans und Morolfs, sie sind nicht Selbstzweck, sondern nur herkömmliche epische Motive zur Ausfüllung und Ornamentation. Der aristokratische Verkehr ist in gewölnlicher Weise stilisiert, tugentlîche, gezogenlîche, schône ist das Benehmen, feine Kleider, goldene Kostbarkeiten werden $z \mathbf{u}$ dekorativer Wirkung aufgeführt. Der Verkehr mit den Frauen besteht nicht in galanter Huldigung, doch ist diese Sitte dem Dichter nicht fremd gewesen (164-166). Aber die höfischen Bestandteile beschränken sich doch fast nur auf gelegentliche Erwähnung, stark ist das Interesse für das vornehme Leben nicht geäußert, eingehendere Schilderungen von Gewändern, Waffen, Festen, Turnieren liegen schon nicht im Stil des Gedichtes.

Das innere Spiel ist bewegt, stark sind die Menschen in Haß und Liebe, leicht ist die Leidenschaft erweckt, das Gefühl wird nicht zurlickgehalten. Salman weint über den vermeintlichen Tod Morolfs, er küßt ihn von jêmerlîchen freuden, als er ihn wohlbehalten vor sich stehen sieht (354-360); er weint bei Morolfs Abschied (619); ferner 128, 5. 148, 2. 612, 1. 779, 2; 18, 4 f. (Freude); Morolf: 398, 1. 654, 1 (geheuchelte Bettlertränen); Fores Schwester 476, 4. 544, 4. Sie alle weinen aus Liebe und Leid, Salme aber weint aus Zorn und Angst (513), und heiß weinend setzt sie sich vor ihrem Hofgesinde auf die Erde, aus Wut, daß Morolf entronnen (299. 300 u. Anm.). Häufig sind Äußerungen der Freude: Salmân wart der rede frô $(499,4)$, (Morolf) wart unmâzlî̀chen frô $(687,6)$; Alsô Môrolf die rede vernam, er wart ein freudenrîcher man $(488,1)$., des gewan er freudenrî̀chen muot $(289,5)$, dô schiet er frôlîchen dan $(659,5)$, Salmân lachen dô began 537, 1. 550, 1. 720,1 u. a. Typisch ist die Haltung des Hauptes je nach den Gefühlen der Lust und Unlust: der kunig (Fore) von zorne (Unmut) nider sach $(27,2)$, der kunig von freuden $\hat{u} f$ sach $(30,2)$. Die innere Kultur ist unausgeglichen. Die Empfindsamkeit bei seelischen Leiden, die Barmherzigkeit gegen die Armen sind Beweise eines weichen Gemütslebens. Am rührendsten ist das Mitleid der Schwester Fores mit Salman (400-482), dem unglücklichen König, als er zum Galgen geführt wird: die Jungfrau neben ihm ritt, mit ihrem bunten Mantel sie ihm den Schweiß abrieb: Du bist ein Fürst an Ehren reich, deine Fạrbe ist nicht verblichen, du bist den Rosen gleich (482). Daneben die Roheit einer barbarischen Zeit in Morolfs Grausamkeit (159 ff. 179 ff. 291 ff.) und erbatmungslosem Hohn (772. 778. 780. 781).

Das Grundmotiv der Handlung und ebenso der sittlichen Forderungen ist die Untreue der Gattin. Damit ist das innere Spiel ein Widerstreit zwischen Treue und Untreue, und unter diesem ethischen Gesichtspunkt gruppieren sich auch die Personen nach Gegensätzen: Salman, Morolf und 
die Schwester sind die Getreuen, Salme ist die Ungetreue. Salman und Morolf verkörpern die Treue zwischen Brüdern, zugleich zwischen Mann und Mann, in Salman und Salme stehen sich der treue Gatte und die treulose Gattin gegenuber, in der Schwester und Salme das treue und das ungetreue Weib, Morolf gegen Salme fuhrt den Kampf der Treue gegen die Untreue.

In unserm mhd. Volksepos ist die Treue „Urquell und Inbegriff der edelsten Tugenden". ${ }^{\text {) }}$ Auch im Spielmannsgedicht von Salman ist die Treue im Grunde die Macht, die das sittliche Leben bedingt, aber sie ist nicht auch in Wirklichkeit die belebende Kraft, die die Menschen in ihrem Tun leitet. Eine solch ernste Lebensauffassung liegt nicht in der Stimmung eines Gedichtes, dessen Ausdruck burleske Komik ist. Der sittliche Kern wird überwuchert vom Spaßhaften. Der novellistische Stoff trägt in sich die Anlagen $z \mathfrak{u}$ einer großartigen Tragödie, der getreue Vasall führt den Vernichtungskampf gegen das haßerfüllte Weib, das seinen Herrn verderben will, Morolf gegen Salme, daz mortgrimme wîp, wie Hagen gegen die vâlandinne Kriemhilt.

In der Vermischung von Ernst und Scherz besteht gerade die Spielmannsart. Zwischen einer Fülle von Witz und Lächerlichkeit tauchen zuweilen unerwartet große Schönheiten auf. An solchen Stellen herrscht eine andere und zartere Empfindung, das ist echt volkstümliche, nicht spielmännische Weise. Wie abgerundete Lieder heben sich die zwei Kemenatenszenen aus der Umgebung hervor, die beide das Motiv des Zaubergesanges) enthalten: Morolf singt vor der Königin besser als irgendein Mann. Alles ward freudenreich, wer die Töne von ihm vernahm ... Ich kam nach Gilest in die Hauptstadt, wo die Sonne ihren Ruhesitz hat, dabei liegt ein Land, heißt Endian, da lernte ich die Weise schön und wonnesam usw. (251-258). Die Jungfrau, Fores Schwester, führte Salman in eine Kemenate, sie saß zu ihm auf eine Matte und tröstete ihn mit großem Fleiß . . Er nahm eine Harfe, gar wohl kannte er den Engelgriff, die Töne waren wonniglich: „ich veriraue meinen Engeln in dem Walde (es sind seine rettenden Helden gemeint), daß sie mich nicht verlassen; nun schweig, mir tun deine Tränen weh!" (461-476). In eine mystische Vision gekleidet ist die Auslegung der drei rettenden Heere Salmans, die im Walde unter Morolfs Führung verborgen sind. Die Jungfrau blickte gegen den Wald hinaus, sie sprach: "Ein Herr, der reitet in einem schwarzen Mantel, wenn der Wind den aufbläst, so ist sein Harnisch weiß wie Hermelin." Salman sprach: "Siehst du eine schwarze Schar? das sind alles Teufel; siehst du eine bleiche Schar? die sind unsers Herren Verwandte $\left.;^{3}\right)$ siehst du eine weiße Schar? das sind alles Engel und

1) UHLANDS Schriften 1, 303.

2) Gesang als Liebeszauber ist altgerm. Volksglaube, der Gegenstand dieser beiden liedartigen Episoden ist also alt-volkstümlich und in der Volkspoesie sehr beliebt, vgl.
PANZER, Hilde-Gudr. S. 227-231 (bes. S. 231 Anm.) u. S. 301-307.

3) Die Strophe scheint entstellt zu sein, s. VoGTS Anm. S. 193. Unsers hêrren mâge sind d. gerecht. Menschen, deren Seelen erlöst sind. 
nehmen meiner Seele wahr..." „Salman, das mag wohl geschehen; du hast deine Engel hehr mit dir hergeführt aus der guten Stadt Jerusalem: das sind deine Mannen, sie wollen dich nicht in Nöten lassen, sie kommen dir zu Hilfe vor dem Walde" (504-511).

II. Das Spruchgedicht von Salomon und Markolf.

Ausg.: v. D. Hagen aaO., dazu v. D. Hagen, Narrenbuch, Halle 1811, S. 498-513; W. SChaumberg, Beitr. 2, 1-63; Walt. Benary, Salomon et Marcolfus, Samml. m.latein. Texte H. 8, Heidelberg 1914. - Hans Walther, Das Streitgedicht in der lat. Lit. d. MA., Berliner Diss. 1914, S. $20 \mathrm{f}$.

Hss.: E. Eschenburgs Hs., s. oben. Das Spruchgedicht folgt auf das Spielmannsgedicht.

D. Darmstadt, 15. Jh.

H. Heidelberg, Cod. pal. germ. 154 v. J. 1474, BARTSChS Kat. Nr. 95.

B. Berlin, s. Braune, Beitr. 2, 63 (Nachtr.).

Verhältnis: E-DH, E steht dem Original näher. B ist noch nicht untersucht.

Der Dialekt ist mittelfrk. Die in den Hss. enthaltene Überlieferung ist wohl im 14. Jh. entstanden.

Im Prolog $(1-18)$ und im Epilog $(1849-1874)$ berichtet der Dichter, daß er seinen deutschen Text aus einem lat. Buch übersetzt habe, und entschuldigt sich wegen der vielen unhöfischen Stellen. Das ganze Gedicht zerfällt in zwei Teile, von denen nur der 1. das Spruchgedicht enthält 201604, während der 2. 1605-1876, der Anhang, ein Auszug aus einer alten Fassung des Spielmannsgedichtes ist. Das Spruchgedicht besteht wieder aus zwei Teilen, dem eigentlichen Dialog oder der Disputation, 20-604 (A), und der Schwanksammlung, 605--1604 (B).

A 20-604. Eines Tages kamen zwei Menschen an Salomos Hof, ein Mann und eine Frau, die unmäßig wunderlich mißgestaltet waren, wahre Schcusale an Häßlichkeit, der Baner Morolf und sein Weib (19-64). Salomo fordert Morolf' ${ }^{1}$ zu einer Disputation auf. In Rede und Antwort zu meist in je 2, seltener in 4 Versen, bezw. 1 oder 2 Reimpaaren, führen die beiden miteinander ein Wechselgespräch und zwar in der Art, daß Salomo eine allgemeine Sentenz aufstellt, auf die Morolf mit einer gegenteiligen erwidert. Die Thesen Salomos sind Sprichwörtcr, Lehren, Erfahrungssätze, Morolf antwortet in Parodien, obszönen und zotigen Verdrehungen, durch die er Salomos Lebensweisheit ins Platte und Gemeine herunterzieht. Zwei Menschennaturen und Bildungsstufen sind in zwei Typen einander gegeniibergestellt: der weise, hochgesinnte König und der plumppfiffige, ordinäre Bauer. Sie vertreten den Widerstreit zwischen formender Gejstigkeit und roher Materie, zwisclıen dem Idealismus, der die Welt glaubt nach sittlichen Grundsătzen einrichten zu können, und dem verneinenden, brutalen Naturalismus, der für dieses löhere Streben wur Spott und Verhöhnung hat. Und das Gemeine behält die Oberhand in diesem Wetistreit mit der Morallehre. Salomo kann in diesem nicdrigen Tone nicht verkehren, Morolf triumphiert und erhält den Slegerlohn, Rock und Scluhe (583-604). Die Sprïche erstrecken siclı ungeordnet auf die verschiedensten Lebensgebiete, einige der weniger anstöbigen mögen hier als Beispicle angefülıt sein: Sal.: Ein gut wip und schone, die ist ires mannes krone, Mor.: Einen duppen (Topf) mit milch vol sal man huden vor den katzen wol 188-191; Sal.: Ein gut wip sanfte gemut, die ist gut uber allez gul, Mor.: Beginnet sie dich schelden, du salt sie loben selden 192-195; Sal.: Win brenget unkuscheit, wer drunken ist, der

1) Der richtige Name des Gegenspielers im Spruchgedicht ist Markolf, nach dem lat. Marcolfus. Dic Hss. haben Morolf, nach dem
Spielmanusgedicht. Darum iiberschreibt die Hs. E das Spruchgedicht der ander Morolff, V. D. HAGEN S. 44. 
stiftet leit, Mor.: Den armen machet rich der win, des sulde er alle zit drunken sin 242-245; Sal.: Du salt in guter maze slafen, darumb enmag dich niman strafen, Mor.: Mich weckent dicke die miuse mit kratzen und ouch die liuse 469-472.

B 605-1604. Auch in den Schwankgeschichten liegt die Orientierung in der Verhöhnung Salomos durch den gumpelman (Possenteißer 609), der dem weisen König Streiche spielt und mit Narreteidingen Belehrungen gibt. Sie sind, während die Disputation aus einer Aneinanderreihung einzelner Gnomen besteht, zu einer fortlaufenden Erzählung zusammengefaßt. 1.605-680 Sechs schwankhafte Rätselfragen. 2. 681-716 Der Schwank vom Kuhfladen. 3. 717-1016 Fünf allgemeine Behauptungen, für deren Gültigkeit Morolf dem König tatsächliche Beweise vorführt, z. B. er stellt ein Gefäß mit Milch an eine finstere Stelle, an der Salomo vorbeigehen muß. Das Erwartete erfüllt sich, Salomo tritt in die Milch und Morolf beschwichtigt seinen Ärger mit der Entschuldigung: „du hast gesagt, Milch sei weißer als der Tag, nun kann man aber die Wahrheit sehen, daß der Tag heller ist als die Milch." Schließlich werden die Frechheiten Morolfs dem König zu bunt und er jagt ihn vom Hofe weg, aber er kehrt wieder zurück. 4. 1017-1084 Der kahlköpfige Ritter. 5. 1085-1460 Das salomonische Urteil und seine Folgen. 6. 1461-1560 Morolf im Ofen (er foppt den König auf höchst unwürdige Weise). 7. 1561-1604 Morolfs letzter Betrug. Er soll im Walde aufgehängt werden, weiß aber seine Henker solange herumzuziehen, bis sie ihn laufen lassen.

Der Ursprungi) der Salomo-Dialoge liegt letzten Endes in den Salomo zugeschriebenen Büchern des alten Testamentes, denn seine Weisheit ist hier eben in Sprüchen niedergelegt. Die dialogische Form dieser Didaktik wird erwähnt bei dem Besuch der Königin von Saba, denn sie kam ihn zu versuchen in Rätseln (3. Reg. 10,1). In den talmudischen und sonstigen orientalischen Überlieferungen ist es ein häufig vorkommender Zug, daß Salomo mit Dämonen gelehrte Gespräche führt. Die Zahl und Benennung dieser Geister ist groß. Ein dem lat. Marcolfus entsprechender Name kommt in den uns erhaitenen orientalischen und griechischen Unterredungen nicht vor, aber es gab einen hebräischen Abgott Marcolis, der aus dem lat. Mercurius entstanden war, und dieser MarcolisMercurius ist der Held des lat. Dialogs, Marcolfus, deutsch Markolf. Zur Ausbildung des humoristisch-satirischen Charakters, der den ursprünglichen Gesprächen Salomos mit den Geistern nicht eigen ist, haben Züge der Aesopsage mitgewirkt: Aesops niederer Stand als Sklave, seine Häßlichkeit, sein schlagfertiger Witz, seine Erfahrenheit in Rätseln und Schwänken, all diese Eigenschaften, die die griechische Vita Aesopi (verfaßt vor dem 10. Jh.) erzählt, kommen auch dem lat. Marcolfus zu.

Ein lat. Salomo-Dialog wird am frühesten erwähnt in dem Decretum Gelasii, das dem Papst Gelasius (492-496) zugeschrieben wird, wo eine Contradictio Salomonis unter den apokryphen Büchern aufgezählt ist, die rechtgläubige Christen nicht lesen sollten. Ein Zeugnis für die Bekanntschaft eines lat. Marcolfus-Dialogs in Deutschland gibt Notker in seiner Psalmenübersetzung Ps. 118, 85 (PIPER, Notker 2, 522, $19 \mathrm{ff}$.), wo er auf nichtige Fabeleien, die bloß ergötzliche Wortübungen sind, anspielt: Vuaz ist ioh anderes daz man marcholfum saget sih éllenon unider prouerbiis

1) Schaumberg S. 29 ff.; Vogt S. Lil ff. 
salomonis? "Ist es denn etwas anderes, das man von Markolf erzählt, daß er gegen die Sprüche Salomos wettstreite? Das sind nur schöne Worte ohne Wahrheit." Dieser ältere lat. Dialog hatte nicht den pöpelhaften Inhalt wie das mhd. Spruchgedicht. ${ }^{1}$ )

Unter Salomos Namen gingen - jetzt verlorene - Spruchgedichte verschicdener Art. Die älteren hatten ernstlehrhaften Inhalt, erst später kam die groteske Parodie. ${ }^{2}$ ) Auf diese, wahrscheinlich den lat. Marcolfus, geht der Spruch im Freidank 81,3 ff.: Salmôn wîsheit lêrte, Marolt daz verkêrte; den site hânt noch hiute leider manege liute, mit der darauffolgenden Rechtfertigung des verspotteten Weisen: Salmôn hât doch wâr geseit, diu werlt sî gar ein üppekeit.

Die $Q \mathfrak{u}$ elle für das deutsche Spruchgedicht ist, nach seiner eigenen Angabe, der lat. Salomon et Marcolfus, ${ }^{3}$ ) der den Dialog und die Schwankgeschichten enthält und in vielen Handschriften und alten Drucken verbreitet war.

Der älteste in einer m.alterlichen Volkssprache abgefaßte Salomo-Dialog ist der in zwei Teile zerfallende ags. Salomon and Saturnus, ${ }^{4}$ ) ein ernstes $Z$ wiegespräch über theologlsche und das menschliche Schicksal betreffende Fragen, das mit dem deutschen Markolf nichts $z u$ tun hat.

Aus Frankreich sind zwei unter sich völlig verschiedene Marcolfdialoge bekannt (Ende des 12. und Anf. des 13. Jhs.), die ebenfalls mit der deutschen Fassung nicht verwandt sind.

In Italien ist Bertoldo, der italienische Markolf, seit dem 16. Jh. eine burlesk-volkstümliche Gestait geworden.

Metrik. ${ }^{5}$ ) Das Gedicht ist in Strophen abgefaßt. Die Strophe besteht aus 4 paarweise gereimten, vierhebigen, stumpf ausgehenden Versen; zwischen dem 3. und 4. Verse steht eine reimlose Zeile (Waise) von meist 3 Hebungen und meist klingendem Ausgang. Das Schema ist also: 4 a 4 a 4 b $3 \times 4$ b. Der Rhythmus ist sprechmetrisch. Die Senkungen sind laäufig zweisilbig, auch überlange Verse sind nicht selten. Zuweilen wird dem zweiten Vers ein reimloser Vers (Waise) vorgeschoben, so daß dann die Strophe in zwei gleiche Hälften zerfällt $(\mathrm{ax}+\mathrm{a} \mathrm{bx}+\mathrm{b})$. Die Anzahl der Assonanzen ist sehr bedeutend, sie beträgt ca. 40 Prozent. Groß ist auch die Reimarmut.

Das Gedicht von Salman und Morolf stellt die höchst erreichte Stufe der niederen Spielmannsepik dar. Der Vorzug dieser Gattung besteht in der Frische und Lebendigkeit der Erzählung, aber mit der Manier des flotten

1) Der Papst Gelasius wtirde solche niedrigc Literatur überhaupt bei einer Aufstellung der in die Kirche aufzunehmenden Werke (dc libris recipiendis et non recipiendis) nicht erwähnt haben, und Notker hätte die Sprache nicht schön genannt, vgl. SCHAUMBERG S. $32 \mathrm{f}$.

2) Eine kurze Notiz iiber im Volke gehende Erzählungen von Marcolfus' Zwiegespräch mit Salomo entlält auch die in der zweiten Hälte des 12. Jhs. abgefaßte Clironik des Wilhelm von Tyrus XIII Kap. 1.

8) Ausg.: Benary aaO.; v. D. Hagen S. V
-XII; Schaumberg S. 1-10; vgl. Ernst SCHAUBACH, Gregor Hayden's Salomon und Marcolf, Leipz. Diss. 1881.

4) Ausg.; Kenble 1848; Arth. V. Vincenti aaO. SChAUMBERG S. 29 ff.; VOGt S. $1.11 \mathrm{ff}$.

5) VOGT S. LXXVIII-CXII; J. Grimm hat den Strophenban crkannt, kil. Schrr. 4, 25; Lacumann, S. u. S., Kl. Schr. S. 176-478: BARTsCh, Germ. 2, 285 f.; Scherer, D. Stud. 1, 1 ff.; WILMANNS aaO. S. 298 ff. ; HARKENSEE, Orendel S. 53-55; SARAN S. 294. 298. 
Hinwerfens hängt andrerseits zusammen ein Mangel an Sorgfalt der Behandlung von Stoff und Form: Komposition, Sprache und Verskunst sind nachlässig. Das Dichten ist Handwerk, berechnet auf den Geschmack der Masse, oder überhaupt auf einen massiveren Bildungsgrad.1) Innerhalb der Spielmannsdichtung bedeutet der Salman einen Höhepunkt. Die Salom osage ist von bedeutendem EinfluB auf die Ausgestaltung der Entführungsgeschichten gewesen, die ganze Anlage und eine Reihe einzelner Motive kehren in den entsprechenden mhd. Dichtungen immer wieder. ${ }^{2}$ )

In der schwankfrohen Zeit des 15. u. 16. Jhs. war die Eulenspiegelei des Markolf auch in Deutschland ein beliebter Unterhaltungsstoff. Um die Mitte des 15. Jh. hat ein sonst nicht bekannter Autor, Gregor Hayden, ${ }^{3}$ ) für den bairischen Landgrafen Friedrich von Leuchtenberg († 1487) eine Rezension der lat. Prosa in deutsche Reime gebracht. Viel verbreitet war das ebenfalls aus der lat. Prosa übersetzte deutsche Volksbuch ${ }^{4}$ ) "Frag und antwort Salomons und marcoifi", schon 1487 in Nürnberg erschienen, dann bis ins 17 . Jh. oft wiederholt, auch ins Niederdeutsche und Dänische übertragen. Aus dem Volksbuch schöpften dann Hans Folz (Ein Spil von konig Salomon und Markolfo) ${ }^{5}$ ) und Hains Sachs (1. Das Judicium Salomonis, 2. Von Joseph und Melisso, auch König Salomon) den Stoff für ihre Fastnachtspiele.

$\$ 82$. Sanct: Oswald.

Kelle 2, 216 f. 388; PIPER, Spielm. D. 1; 146-170, Nachtr. S. 243, Höf. Ep. 3,711. - Ausg.: Ettmüller 1835 (Schaflh. Hs.), dazu Mone, Anz. f. Kunde d. d. Vorz. 4, 414 ff., Schmeller, Münch. Gel. Anz. 1836 Nr. 122-124; Krit. Ausg. von Georg Baesecke, Der Münch. Oswald, Germ. Abh. 28, 1907, dazu Wilmanns, Gött. gel. Anz. 1909, 108-127, EhrismanN, Anz. 32, 174-193. 33, 123, BAEsecke, ZfdA. 53, 384-395; BAESECKE, Der Wiener Oswald, Germ. Bibl. 2, 1912 (vgl. Verh. d. 51. Phil.-Vers. in Posen 1911 S. 103 f.), dazu KeIM, Anz. 36, 240-251, v. UNWERTH, DLZ. 1913, 1513-1516, HelM, Lit.Bl. 1915, 258-261; GERTR. Fuchs, D. W. Osw., Germ. Abh. 52, 1920. - J. V. Zingerle, Die Oswaldlegende und ihre Beziehung zur deutschen Mythol. 1856, dazu Anz. f. Kunde d. d. Vorz. 1857, 381-388; BarTsCH, Germ. 5, 129-174; E. H. MeYer, ZfdA. 12, 387-395; Jos. Strobl, Wiener SB. 64 (1870), 457-504; ANT. EdZARDI, Untersuchungen üb. d. Ged. von St. Osw. 1876, dazu RöDiger, Anz. 2, 245-262; Berger, Beitr. 11, 365-469; Siegmar Schultze, Hall. Diss. 1888; Keim, Bonn. Diss. 1912, dazu v. Unwerth aaO., Helm aaO.; Helm, Beitr. 40, 1-47; Schneider, Wolfdietr., Reg. S. 416; BAESECKE, Anz. 38, 49 f.

Die Legende vom heil. Oswald ist im Deutschen in drei verschiedenen, mit einander in Beziehung stehenden Fassungen erhalten:

1) Ueber d. Verhältnis zu Rother, Orendel, Oswald s. oben S. 290.

$\left.{ }^{2}\right)$ Siehe bes. die oben angeführten Werke von PANZER, BAESECKE, SCHNEIDER, TARDEL.

3) Hgb. von BOBERTAG, Narrenbuch, Kürschners D. National-Litt. Bd. 11, 293-361; SCHAU$\mathrm{BACH}$ aaO.

4) v. D. Hagen S.XIVf.; Goedekes Grundr. $1^{2}, 347$ f. 467 ; BENARY S. XXV-XXVIII; BoBERTAG, Geschichte des Romans, I. Abt. 1.Bd. S. 186 ff.; dazu SCHERER, QF. 21, 25. 34; BoBERTAG, Narrenbuch S.296ff.; Jos.GöRRES,

Die teutschen Volksbücher, Heidelb. 1807, S. 188 ; neu abgedr. in V. D. HAGENS Narrenbuch S. 215-268, dazu S. 498-513; H. W. Fischer, S. u. M. nach d. Ausg. v. d. Hagens neu hgb., Leipz. 1907; J. J. A. A. FRANTZEN und A. Hulshoff, Drei Kölner Schwankbücher aus d. XV. Jh., Utrecht 1920, dazu SCHRÖDER, Anz. 40, 93 f.; vgl. Neophilologus $\mathrm{V}$ H. 2.

5) V. D. HAGEN S. XV-XVII; ADELBERT Keller, Fastnachtspiele Bd. 2, 523-540 u. Reg. Bd. 3, $1580^{b}$. 


\section{Der Münchener Oswald MS. ${ }^{1}$ )}

Hss. $M^{2}$ ) München, Cgm. 719, 15. Jh. (vor 1444), bair.

I Innsbruck, ${ }^{3}$ ) Mus. Ferdinandeum 1114, 2. Hälfte des 15. Jhs., von zwei Händen $I_{1}$ und $I_{2}$ geschrieben, $I_{1}$ ist bair., $I_{2}$ schwäb.

S Bibl. zu Schaffhausen, ${ }^{4}$ ) 2. Hälfte des 15. Jhs., schwäb.

Mk München, Cgm. 5377, 15. Jh., bair., enthält die V. 668-682.

$M$ ist die Haupths., $M$ und I haben eine gemeinsame Vorlage gegenuber dem sehr unzuverlässigen $S$. $M$ gibt den ursprünglichen Text am treuesten wieder, darum diese Version als 'Münchener' Oswald bezeichnet wird.

\section{Prosaauflösungen.}

s Stuttgatt, ${ }^{5}$ ) Kgl. Bibl., Cod. theol. et phil. 81, aus dem Kloster Reute, um 1480 geschrieben, schwäb., ist eine Prosaauflösung von MIS, mit enger Anlehnung an diesc Fassung.

b Berlin, ${ }^{6}$ ) Mscr. Germ. Oct. 288, 15. Jh., bair., Prosaauflösung von MS mit starker Abweichung.

u Budapest, Ungar. Nationalmuseum Cod. 31, v. J. 1471, bair., verwandt mit b.

\section{Die Prosa $z n .^{7}$ )}

$\left.z^{8}\right)$ ist im Sommerteil des Lebens der Heiligen in vielen Hss. des 15. Jhs. und in Drucken (seit 1471) erhalten.

$\left.\mathrm{n},{ }^{9}\right)$ eine nordische Bearbeitung von $z, 16$. Jh.

zn hat mit MS eine gemeinsame Quelle $M z$.

\section{II. Der Wiener Oswald WO. ${ }^{10}$ )}

Hss.: W Wien, ${ }^{11}$ ) Nr. 3007 , v. J. 1472, schlesisch.

O Olmütz, ${ }^{12}$ ) Metropolitankapitel, 15. Jh. (um 1450), böhm.-mährisclı.

D Dessau, $\left.{ }^{13}\right)$ 2. Hälfte des 15 . Jhs., obersächs.

Verhältnis: W-DO; $\mathrm{W}$ ist die Haupths.

Die 3 Bearbeitungen ${ }^{14}$ ) $M S+z n+W O$ stammen von einem gemeinsamen Original, $* O$, $a b$, einem Gedichte, das von einem mittelfrk. Spielmann (etwa in Aachen) um 1170'5) verfaßt war. $M S+z n(=M z)$ setzen wieder unter sich eine bair.-österreich. Vorlage $\left.{ }^{16}\right)$ von Ende des 12. Jhs. voraus. ${ }^{17}$ ) WO ist die Bearbeitung eines md. Geistlichen in der 1 . Hälfte des 14 . Jhs. ${ }^{18}$ )

Die Legende. ${ }^{19}$ ) Der heilige Oswald war König der Northumbrier

1) Die Hss. S. bei BAESEcke, Münch. Osw. S. $169-200$.

2) BARTSCH, Germ. 5, 142 ff.

3) ZINGERLE, ZfdPh. 6, 377-404, auch Anz.

f. K. d. d. Vorz. 1856, 271 ff. 301 ff.

4) Hgb. von ETTMÜLler s. oben.

5) ZiNGERLE, Anz. f. Kunde d. d. Vorz. 1857, 38-40; hgb. von EdZard, Germ. 20, 190206. $21,171-193$.

6) Hgb. von Haupt, ZfdA. 13, 466-491.

7) BAESECKE, Münch. Osw. S. 221-228. 238-261. 310-389.

6) Hgb. von Zingerle, Die Oswaldlcgende aaO. S. 41-69 nach 2 Innsbrucker Hss. des 15. Jhs.; ein Bruchstiick des böhm. Mus. in Prag, hgb. von MOUREK, SB. d. bölım. Ges. d. Wissensch. 1890, 280-282, dazu HEINZEL, Anz. 17, 95.

9) Hgb. von Jón Sigurdsson, Annaler for nord. oldkynd. 1854, S. 15 ff., dazu O. KLOCKHOFF, Om Osvalds saga, Sinå bidrag til nord. Literaturhistorien, Upsala 1880; EDZARDI, Untersuchungen S. 3 ff.

$\left.{ }^{10}\right)$ Dle Hss. s. bel BAEsecke, Wien. Osw.,
Einleitung; Müncli. Osw. S. 229-261. 310 -389 ; Fuchs S. XIII ff.

11) Zum erstenmal hgb. von Franz PFeiffer, ZfdA. 2, 92-130, dann BAESECKE, neuestens FUCHS aaO.

12) BARrsCh, Anz. f. Kunde d. d.Vorz. 1861, $391-393$.

$\left.{ }^{13}\right)$ Helm, Beitr. 40, 1-47; Fuchs, Ausg.

14) Zum Verhältnis d. 3 Fassungen s. BERGER S. 367-408; BAESECKE, Miincl.. Osw. S. 169 -389, Wien. Osw. S. XClX ff.; KelM aaO.; ferner EDZARDI, Untersuchungen S. $2-53$; S. Schultze S. 5-30; ïber das Alter s. auch E.H. Meyer, ZfdA. 12, 387-395; VogT, ZfdA. $22,476 \mathrm{ff}$.

15) Vgl. dazı Keıı, Anz. aaO.

16) Vgl. ZWIERZINA, ZfdA. 44, 263-265.

17) Zil diesem von BAESECKE aufgestellten Hs.verhăltnis s. KEIM S. 243 f.

18) Nach BAESECKE, Wien. Osw. LXXXVIl ff. : schlesisclı, von einem Mönche des Ḱlosters Heinriclaan am Anfang des 14. Jhs.; vgl. dazu KE1M aAO. S. 244 f. 250 f.

19) BERGER S. 409-459; BAESECKE, Müch. 
(635-642), die er zum Christentum bekehrte. Wir besitzen zwei Überlieferungen von seinem Leben, die zwei Stufen in der Entwicklung des geschichtlichen bezw. sagenhaften Stoffes darstellen. Die wichtigsten historischen Tatsachen hat Beda (672-735) mitgeteilt in seiner Historia ecclesiastica gentis Anglorum II, 5. 20. III, 1.3.6 f. 9-13, von denen folgende noch als grundhafte Züge in dem deutschen Spielmannsgedichte vorkommen: Osw. war fromm und demütig, freigebig, beschenkte reichlich die Armen, speiste sie von seinem Tische and zerteilte die Stücke seines silbernen Bechers unter sie, kämpfte mit heidnischen Königen, wirkte für das Christentum durch Heidenbekehrung und veranlaßte einen heidnischen König (Kynegils von Wessex) zur Taufe, stand dabei Pate (a.635) und heiratete dessen Tochter (Kyneburg). Er stirbt nach kurzer Regierung. In das Bild, das Beda von dem frommen König, der nur ein Menschenalter vor seiner Geburt gestorben war, entworfen hat, sind schon übernatürliche Ereignisse verwoben (Wunder bei seinem Tode, an seinem Grabe u. a.), die erste ausgebildete Legende aber, die wir besitzen, ist die Vita S. Oswaldi regis et martyris des englischen Mönches Reginald ${ }^{1}$ ) v. J. 1165 . Hier treten ebenfalls einige im Spielmannsgedicht wiederkehrende Züge auf: die Vorausverkündigung von Oswalds Tod, das keusche Eheleben, die Wunderquelle, hier auch erscheint ein rabenähnlicher Vogel, wohl das Urbild des Raben in der deutschen Sage.

Schon zu Bedas Zeiten waren Wundererzählungen von Oswald auf das Festland $z u$ den heidnischen Franken und Friesen gelangt, die Überführung von Reliquien im 8. Jh. nach Westfalen, im 11. Jh. nach Bergues in Flandern und seine Verehrung im 12. Jh. in Echternach bezeugen für jene Gegenden einen ausgesprochenen Kult des Heiligen. ${ }^{2}$ ) Im 13. Jh. war seine Verehrung auch in Oberdeutschland verbreitet, heutzutage wird er besonders in den Alpenländern gefeiert, wo ihm viele Kirchen geweiht sind und eine Reihe von Orten seinen Namen tragen. Er ist einer der vierzehn Nothelfer, Patron des Wetters und heilkräftiger Quellen, Helfer in Krankheiten, einer jener heiligen Männer, die im frommen Volksgemüte lebendig bleiben. Und auch die kirchliche Kunst hat in Wechelbeziehungen zur volkstümlichen Sage das Bild des königlichen Gottesmannes, meist mit dem Raben als Attribut, der dann wohl einen Ring im Schnabel trägt, in zahlreichen Darstellungen verbreitet. Seltener ist in der bildenden Kunst der Heilige als Speiser der Armen nach der von Beda überlieferten offiziellen Kirchenlegende anzutreffen.

Zum Spielmannsthema wurde die historische Legende dadurch, daß der

Osw. S. 261-309; ZINGERLE, Oswaldlegende S. 70-103, Anz. f. Kunde d. d. Vorz. 1857, 381-388; S. SCHULTZE S. 30-60; KEIM, Diss. S. 7 ff. ZINGERLES mythologische Deutung, wonach die Oswaldsage die Umbildung eines Wodanmythus wäre, stand eine Zeitlang in Geltung (SIMROCK, Mythol.4, Reg. S. 632; WilH. MÛ́LLER, Mythol. S. 241 ff.; vgl. auch E. H. Meyer, Germ. Mythol. Reg. S. 337).

Nahe Beziehungen zu einer Salomosage weist SINGER nach ZfdA. $35,177 \mathrm{ff}$.

1) Hgb.von TH. ARnOLd, Symeonis monachi opera omnia, London 1882, tom. I, 326-385.

2) Seine Vita ist aufgenommen in die Acta Sanctorum Bollandorum Aug. II, $83 \mathrm{ff}$. - - Das Fest des Heiligen fällt auf den 5. August. 
Verfasser des ursprünglichen Gedichtes von ca. 1170 die Heirat Oswalds mit der Tochter des getauften Heidenkönigs (Kynegils) in die Form einer Brautraubgeschichte kleidete. $\left.{ }^{1}\right)$ Der Grundplan dieser Spielmannslegende oder spielmännischen Legende lautete also: A. Der "fromme und mildtätige König Osw. von England, der für die Verbreitung des Christentums wirkt, will heiraten. Es wird ihm geraten, jene heidnische, aber dem Christenglauben geneigte Königstochter jenseits des Meeres zur Frau zu nehmen, deren Vater alle Freier umbringt. B. Er sendet seinen Werber, einen Raben, zu ihr. Nach ihrer Zusage fährt er selbst in ihr Land, entführt sie durch List, besiegt und tauft ihren Vater und dessen heidnisches Heer. - Dieses Gerüste wurde von dem Dichter des Originals ausgefüllt und erweitert durch Sonderzüge nach dem gewöhnlichen spielmännischen Kompositionsverfahren.

Die Textgestalt der Vorlage der drei Fassungen, d. i. eben das für uns erreichbare Originalgedicht, kann nicht wiederhergestellt werden, da jene drei Abzweigungen sowohl den Stoff als den Wortlaut $z u$ selbständig geändert haben. ${ }^{2}$ ) Positive Zeugnisse für altes Gut sind die Übereinstimmungen zwischen allen drei Hss. MS, zn, WO oder die zwischen MS und zn bezw. WO, jedoch ist gemeinsames Nichtvorhandensein im Texte von zn und WO für den Versbestand des Originals nicht unbedingt beweiskräftig, da diese beiden Bearbeitungen unabhängig voneinander Kürzungen vorgenommen haben. Demnach enthielt das ursprüngliche Gedicht schon Neben- und Doppelmotive, ${ }^{3}$ ) z. B. den ehrenvollen Empfang des Pilgers durch Osw. (Münch. Osw. 209-211, Wien. Osw. 61-64); das höfische Benehmen des Raben beim Enpfang durch den Heidenkönig (MS 833 f. 837 f., WO 210 f. $270 \mathrm{ff}$ ); der vergoldete Hirsch, der als zweiter Helfer an Stelle des Raben getreten ist (MS $2457 \mathrm{f}$., WO $1064 \mathrm{f}$.); ;) eine ausführliche Darstellung des Hornblasens, wodurch der Heidenkönig seine Mannen zusammenruft (MS 2692 ff., WO 1155 ff. ${ }^{5}$ ) Die religiöse Auffassung kam auch in der Vorlage schon in Gebeten zum Ausdruck: die Aufbetung des Tors (MS 2533-2570, WO 1104-1123); das Gebet Osw.s un Rettung gegen die verfolgenden Heiden mit dem Gelübde (MS 2787-2804, WO 1198-1219). Damit sind auch schon Unebenheiten für die Vorlage nachgewiesen, denn dicses Gebet ist, obgleich es erhört wird, doch überflüssig, da die Heiden gleich darauf doch Osw. und sein Heer einholen. Auch das Vorkommen formellafter Wendungen im Original wird durch Übereinstimmung von MS und WO bewiesen. Demnach beschränkte sich das Urgedicht nicht auf die notwendigen Grundzaige des Sagenthemas, sondern es war ein durch inlialtliche und formale Bestandteile erweitertes Epos. ${ }^{6}$ )

1) Siehe BAEsecke, Münch. Osw. S. $266 \mathrm{ff}$. und die oben S. 287 angegebene Literatur.

$\left.{ }^{2}\right)$ BAESECKE (Münch. Osw., hinten unter Abh. S. 169 ff. an verschiedenen Stellen, vgl. auch Wien. Osw., Einl.) suclit durch inialtliche und metrische Beweismittel und unter Beizlehung von $\mathrm{zn}$ und WO das Original und die Anteile von sechs Bearbeitern aus dem Text von MS zil sondern. WILMANnS erkennt die Möglichkeit solch genaucr Scheidung nicht an, weist aber auf einige Störungen hin, die durch jlingere Weiterbildungen veranlaßt seien; vgl. auch EHRISMANN aaO. und KeIM, Diss.

3) Diesc Gleichungen zwischen MS und WO s. BAESECKE, Mlinch Osw. S. 230-232; s. ferner S. 349 ff. und Wien. Osw. S. LXXVIIl ff. 4) $Z_{11}$ der weitverbreiteten Hirsclisage vgl. CARL Pschmadt, Die Sage von der verfolgten Hinde, Greifswalder Diss. 1911, bes. S. $126 \mathrm{ff}$.

${ }^{5}$ Auch die $z$ wei Wunder bei der Heidentaufe: WO hat zwar nur die Auferstehumg der Toten, aber gerade das Quellwunder wird als ursprünglich für die Legende erwiesen durch das Vorkommen bej Reginald. Die Wiedererweckung der Toten kann aus der Hildesage stammen.

6) Da wir uns das Original nur in solch allgemeinen Umrissen vorstellen kömuen, ist es uns unmöglicls, die Tätlgkeit der drei Bearbeiter zu durchschauen. Uber Vermutungen kommen wir nicht hinaus. 


\section{Die drei Fassungen.}

\section{Der Münchener Oswald (MS).}

Inhalt. A. Die Werbung 1-1424. Osw. bittet Gott um Rat zu einer Frau, ein Engel empfiehlt ihm, eine heidnische Prinzessin zu nehmen. Seine Landesherren wissen keine, der Pilger Warmunt verweist ihn an Pamige, die heimlich dem Christenglauben hold ist; aber ihr Vater Aron schlägt jedem Freier den Kopf ab. Auf Rat des Pilgers sendet Osw. einen mit menschlicher Stimme begabten Raben als Boten. Unterwegs von wilden Meerweibern gefangen, entfliegt er durch List. Aron läßt ihn in den Kerker werfen; von der Prinzessin losgebeten, richtet er ihr seine Botschaft aus. Sie nimmt den Antrag an. Auf der Rückkehr wieder ein Hindernis: der Ring entfällt ihm ins Meer, wird ihm auf eines Einsiedlers Gebet durch einen Fisch wieder erstattet. - B. Die Entführung 1425-3209. Osw. zieht mit Heer übers Meer. Er und 12 Gefährten gehen als Goldschmiede verkleidet in die Heidenburg. Durch die List mit dem Hirschen (ein von ihnen mit Gold und Silber geschmückter Hirsch lockt Aron und sein Gesinde zur Jagd) gelingt es der Prinzessin zu Osw.s Schiffen zu kommen. Der Heide verfolgt die Fliehenden. In einer Schlacht auf einer Insel besiegt, läßt er sich, durch Wundertaten Osw.s bestimmt, taufen. - C. SchluB. Die Versuchung durch den bettelnden Heiland 3210-3547. Ein Bettler heischt von dem frommen König beim Mahle Gabe auf Gabe, zuletzt sein Land und sein Weib. Alles gibt Osw. widerspruchslos hin. Da gibt sich der Bettler zu erkennen. Es ist der lebendige Gott. Er gibt ihm alles Geschenkte zurück. König und Königin führen ein keusches Leben. Nach zwei Jahren holen die himmlischen Heerscharen ihre Seelen ins Himmelreich.

Die Bearbeitung MS rührt von einem Verfasser her, denn es besteht durchgängig die gleiche Ausdrucksweise. ${ }^{1}$ ) Unter den drei Fassungen hat MS die alte Oswalddichung am besten bewahrt. Zwar ist der Stoff durch neue Züge und durch die umfängliche Darstellung (vielleicht nicht unbedeutend) erweitert, der sprachliche Text auch frei behandelt worden, aber das ursprüngliche Bild ist nicht wesentlich verändert. ${ }^{2}$ ) Die neu hinzugekommenen Sonderzüge (inhaltliche Erweiterung) - sie sind geschickt in dem Bau der Vorlage eingefügt - und lassen sich kaum mit völliger Sicherheit ausscheiden. ${ }^{3}$ )

Reich an Bildern und Gestalten ist diese Fassung der Osw.sage und mit beredtem Vergnügen, doch nicht ermüdend, erzählt der Spielmann von dem, was ihn und sein Publikum interessiert, von Essen und Trinken, wohl-

1) BAESECKE nimmt vier an der Bearbeitung von MS beteiligte Personen an, vgl. dazu WILMANNS, EHRISMANN und KEIM aaO.

2) Die Bearbẹtung MS steht hinsichtlich des Umfangs und demnach in der Brejte der Darstellung auf dem Standpunkt vom Orendel, es ist also anzunehmen, daß um 1170 dies die herrschende Erzählungsart der Spielleute gewesen ist. Dies vorausgesetzt dürfte in MS das Original *O (Vorlage von MS, zn, WO) nicht allzu stark erweitert sein. Uebrigens muß diese in MS vorliegende Umarbeitung von $* 0$ ebenfalls einem Mittelfranken zum Verfasser gehabt haben, da die mfrk. Formen durch die 3 Hss. des Münch. Osw. durchgehen. Erst darauf kam der bair. Bearbeiter, durch den dann wohl die sprachliche Fassung von $* \mathrm{O}$ ein verändertes Gepräge erhalten haben mag. Es ist also zwischen *O und $M S$, bezw. genauer $M z$, noch eine Mittelstufe $M S_{1}$, einzusetzen, so daß die Reihe geht $* \mathrm{O}, \mathrm{MS}_{1}, \mathrm{MS}_{2}$.

3) Etwaige Interpolationen werden sich am ehesten unter den Motivenhäufungen finden, z. B. die in drei Bilder zerfallende nächtliche Szene des Heiratsentschlusses $35-42$. 4358. 59-74; die Verwirrung bei der Sendung des Raben 362-393; die Hindernisse bei seiner Hin- und Rückreise 650-771. 11971286 (650 ff. ist das Märchenthema von den Wassergeistern, die Menschen in ihr Reich ziehen. Die Klage der Meerfrau ist die Klage der Verlassenen wie im Falkenlied des Kürenbergers); die dreimalige Friedensversicherung $900-932$; bes. werden unter den geistlichen Stellen sich etwaige Zusätze des Bearbeiters befinden. 
bestellten Mahlzeiten und von gleißendem Schmuck, vom täglichen Leben und vom Hofe, von hochfahrenden Hofbeamten, den hofeschälken, die den kleinen Mann und ihn, den Fahrenden, schikanieren, von einfachen Leuten, vom "edeln" Pilger, der so ehrenvoll vom König behandelt wird, von Dienern, Torwärtern, Schiffsknechten, Goldschmieden. An Überlistungen und täuschenden Verkleidungen hat diese Gesellschaft ihre Freude, an Scherzen wie der Durchprügelung der Hofdiener, der buoben und schintvezzel, durch Oswald 3308; oder wenn die Königstochter ihrem Vater mit einem Spielmann durchzugehen droht, falls er ihren Willen nicht erfüllt $1045 \mathrm{ff}$.; wenn ihre Mutter, die Heidenkönigin, ihren Gatten lachend empfängt mit der Kunde, die Tochter sei mit den Goldschmieden ausgerissen $2671 \mathrm{ff}$; wenn die Prinzessin Kopfweh vorschützt, um sich heimlich entfernen zu können $2492 \mathrm{ff}$. In naiver Auffassung stellt sich das Volk den Verkehr am Hofe so vor, wie es ihn in seinen eigenen Lebensformen gewohnt ist.

Die äußeren Vorgänge werden mit dem Innenleben verknüpft, das Geschehende wird, gemäß der ausführlichen Erzählungsart des Gedichtes, gern in seinem ganzen Verlauf vorgefühtt, oft wird zuvor, ehe es zur Handlung kommt, die in Gedanken gepflogene Überlegung des zur Entscheidung Gedrängten verwertet und bei neu eintretenden Ereignissen wird häufig ein kurzer Blick in die Seele der Menschen geworfen, in ihre Stimmung, ob Freud oder Leid. Aber diese meist nur stilisierenden Bestandteile verleihen dem Gefühlsleben keinen tieferen Gehalt, dieses wird völlig ausgefüllt vom religiösen Empfinden.

Der Weltsinn ist nicht ausgeschaltet, im Gegenteil, Machtfülle ist auch die Grundbedingung für den christlichen Herrscher, und der Reichsgewalt des rîchen und milten Osw. unterstehn viele Könige, Herzoge, Grafen und Fürsten. In höheren gesellschaftlichen Formen bewegt sich das Leben, feine Sitte wird beobachtet, glänzend ist der Hoftag und die Festtafel, dazu die Landesherren berufen werden 7-18. 91-98, ehrenvoll wird der Pilger in das fürstliche Privatgemach geführt 210, mit feinsten Manieren stellt sich der Rabe als königlicher Gesandter den heidnischen Herrschaften vor. Doch erreicht das gesittete Benehmen nicht die Höfischheit im Sinne der französischen courtoisie. Das Minnewesen spielt gar keine Rolle in einem Verhältnis, wo Mann und Frau sich zur Ausbreitung des christlichen Glaubens verbinden $67 \mathrm{f}$. Das eigentliche Ritterideal aber, das Heldentum, findet eine Stelle auch in dieser Heiligenlegende, und der Dichter entwirft in dem herkömmlichen Schlachtenstil ein kräftiges Bild von Osw.s Kampf mit den Heiden 2835-2938.

Die Spielmannslegende ist eine Mischung von Sclierz und Ernst, von Weltgenuß und Frömmigkeit, sie will nicht nur ergötzen, sondern auch Moral lehren, den Glauben stärken. Die Fabel, der Erzälllungsstoff, ist die Grundlage für die Idee, den religi ösen Gehalt, der das Ganze mit einem tieferen Gemätsleben erfüllt. Jede Gelegenheit benutzt der glaubenseifrige Spiel- 
mann, um in Gebeten und religiösen Wendungen die Gottergebenheit der Christen, voran seines Helden, zur Geltung zu bringen. Die größte Wirkung aber erreicht er durch den Reiz des Wunderbaren, in die Umgebung des Alltags greift der Märchenzauber ein und das Wunder göttlicher Gnade. Denn dieses Christentum ist primitiver Volks- und Wunderglaube. Wie im Märchen der Ruf an die gütige Fee oder den sçhützenden Geist die Erfüllung des Wunsches herbeizaubert, so erfolgt hier auf das Gebet auch sofort die Erfüllung durch die Gnade Gottes: der Einsiedel betet, im Augenblick bringt ein Fisch den ins Meer entfallenen Ring $1255 \mathrm{ff}$.; Osw. und sein Heer beten in ihrer Not zum Fürsten des Himmels, sofort steht ein Engel in Bereitschaft 1752 ff.; der Rabe sitzt unerreichbar auf dem Turme, beim Gedanken an die Gnade Gottes kommt er auch schon herabgeflogen 372 ff., u. a. Das seltsamste Wunder ist eben der Rabe selbst, die Lieblingsfigur des Dichters, ja auf lange Strecken hin der Held der Geschichte, der Lockvogel des abenteuerlustigen Publikums. Er ist selbst eine Märchengestalt, er stammt aus dem Reich der sprechenden und der dem Menschen hilfreichen Tiere. Und doch ist dieses Geschöpf der Phantasie ganz der Wirklichkeit angepaßt. Er trägt die ausgesprochenen Züge eines Spielmanns, in ihm hat der Dichter seinen eigenen Stand abgebildet, schmeichelnd, zugleich mit ungewollter Ironie: als Königsbote hat er die erforderliche Schlauheit für sein Amt, er ist listic 738. 909. 921. 2010; er kennt alle Sprachen 389 ; er kann sich fein höfisch benehmen $827-842$, er kann auch grob sein 849-856. Er ist als fahrender Mann aufs Materielle aus, aufs Essen und Trinken') 686-702. 815 ff. 863-875. 1077-1085. 1345. 1834-1857. 1960-1967; er ist eitel und anspruchsvoll $430 \mathrm{ff}$., ehrgeizig und empfindlich $1794 \mathrm{ff} .1826 \mathrm{ff} .1973 \mathrm{ff}$., eifersüchtig auf Nebenbuhler $1816 \mathrm{ff}$. Er ist eine gewichtige Persönlichkeit bei Hofe, denn ohne ihn kann das Unternehmen seines Herrn nicht gelingen, er ist der eigentliche Leiter seiner Geschichte 1176. 1404. 1815. 1828. 2745. Natürlich ist auch er ein frommer Christ $602.825 \mathrm{f}$.

In alter Volksvorstellung lebt das Bild von dem Botschaft überbringenden . Vogel. ${ }^{2}$ ) In einer schwedischen und $z$ wei dänischen Balladen sendet eine gefangene junge Frau einen am Turme vorbeifliegenden Raben zu den lhrigen, die sie auf diese Kunde hin befreien. ${ }^{3}$ ) Mit der Oswaldsage näher verwandt sind das schottische und das deutsche Volkslied.4) Düster ist in der nordischen Ballade die Stimmung, aus der Todesnot der gefangenen

1) Auch im deutschen u. im schwedischen Volkslied wird dem Vogel Bier und Wein gereicht.

2) Der Vogel als Bote zu der heidnischen Prinzessin von Saba, ihre Bekehrung und Heirat mit Salomo s. SINGER aaO.

3) UHLAND, Abhandlung $z u$ den Volksliedern, Schriften 3, 100. 109-120. 170-173;
Anmerkungen ebda 4, 22 f. - Eine sprechende Dohle als Bote: Ruodlieb XI, 71 ff. (SEILER); vgl. GANZENMÖLLER, Das Naturgefühl im MA. S. 154 f.; WALLNER, ZfdA. 40, 290 ff. 50, $206 \mathrm{ff}$.

4) Uhland, Volkslieder Nr. 16 u. Anm. Im deutschen Lied und im ersten Teil des schottischen ist die Form der Werbungsballade erhalten. 
Frau trägt der hilfreiche Rabe den Rettungsschrei in die Heimat; eine heitere Liebesbotschaft bringt der Falke im schottischen, die liebe Frau Nachtigall im deutschen Liede $z \mathfrak{u}$ dem fernen Mädchen. ${ }^{1}$ )

Das Personal des Gedichtes besteht aus den typischen Gestalten der Entführungssage, dem freienden König, der umworbenen Prinzessin, dem widerspenstigen Vater, der Mutter, dem Brautwerber. Individuelle Zuige gewinnen sie durch die Eigenart des legendaren Gehalts. So ist der werbende Spielmann zu einem Raben geworden in Anlehnung an das Vorkommen eines solchen in der Legende. Osw. ist der Typus des christlichen Königs, barmherzig gegen die Armen und ein tapferer Kämpfer für das Christentum erringt er den höchsten Grad der Heiligung durch die Askese: selbst als weltlicher Herrscher führt er ein Leben der Enthaltsamkeit und bewährt die Mönchstugenden Armut, Keuschheit, Gehorsam in der Prüfung durch den Bettlerheiland. Aber die Legende ist verkettet mit der Spielmannssage und die hat eine andere Moral, sie verlangt für das Gelingen des Unternehmens nicht Frömmigkeit, sondern List, ein klein wenig Betrug. Der Dichter kann Osw. der literarischen Überlieferung nicht entziehen, er muß ihn sich verkleiden lassen, aber er löst den $Z$ wiespalt leicht durch ein Gebet, in dem der Goldschmied-König zur Beruhigung seines Gewissens Gott um Verzeihung für die Lüge bittet 22872293. Nicht der Held, der heilige König, ist Leiter der Intrige, sie fällt dem Raben und der Prinzessin zu. Typisch stilisiert sind alle Personen, die Christen sind fromm, die Heiden 'wild', aber eine strenge Scheidung zwischen gut und böse wird nicht gemacht. Aron ist 'wild', wie sein Volk, er gerät rasch in Zorn, doch hat er dabei etwas Brummig-Gutmütiges, stachlige Witze hat er zur Verfügung 1057-1060. 3035-3040 (der ernste Oswald treibt keine Späße), er ist leicht $z u$ betören und voll köstlichen Humors ist die Szene, da die Tochter, sein Liebling, ihm durch Drohen und Schmeicheln den gefangenen Raben ablistet 997-1072.

Die einzelnen Motive werden mit epischer Breite vorgeführt. Diese aber geht zuweilen über das Maß hinaus, z. B. wenn die Anfertigung des Geschmeides für den Raben 130 Verse einnimmt 430-559: der selbstbewußte Königsbote muß̣ die Gründe für seine Schmückung angeben, der Kämmerer muß geholt werden, um den Auftrag dem Goldschmied zu überbringen, lange Besprechungen müssen gelıalten werden. Ähnliche Schwel-

1) Im Plan der Entführungssage spielt der Rabe eine doppelte Rolle, die des Brautwerbers, wie Lupolt im König Rother, Werbel und Swemmel im Nibelungenlied, Horant in der Kudrun, und die des dämonischen Helfers, wie Ise im Orendel, Wate in der Kudrun, Alberich im Ortnit (BAESECKE S. 268. 292 f. 380 f.; Dämonen u. Tiere als Helfer: PANZER, Hilde-Gudr. S. 250 ff.). - Das schottische ${ }^{\prime}$. das deutsche Lied enthalten nur den ersten Teil der Brautraubsage, die Werbung, die Entführung dagegen felılt, denn was in dem schottischen Lied dieser entspricht, beruht auf einem ganz andern Motiv, beweist also nichts fiir cinen engeren Zusammenhang mit dem deutschen Oswaldgedicht und für die Annahme, die Einfügung der Entführung in die Oswaldlegende sei sclon in England vor sich gegangen (vgl. BERGER S. $456 \mathrm{f}$, BAESECKE S. 294). Die Verbindung zwischen Brautfahrt und legende ist, wie im Orendel, sicher erst eine Fiffindung des deutschen Spielmanns. - Vgl. KÉIM, Diss. S. 7 ff. 
lungen bedeutungsarmer Partien sind 139-151. 1690-1715. 1776-1882. 2090-2138; besonders bei Mahlzeiten: 685-702. 815-826. 1077-1086.

Eine rein formale Erweiterung ist die Anfällung mit inhaltleerem oder inhaltlosem Sprachstoff, das sind die wörtlichen Wiederholungen, Flickformeln und Flickverse. ${ }^{1}$ ) So wird die Aufzählung der Landesherren 7-18 bei ähnlichen Gelegenheiten gleichsam automatisch wieder hergesagt 88-98. 943-952; ebenso $1842-1857=1953-1967.1149-1176=1377-1404$. In Übergängen, Einleitungen von Reden oder bei Aufträgen dient oft eine schleppende Wendung wie diu wîle werte niht lange, der kameræere quam gegangen, dô er den hêrren an sach 462-464; dô er in die stat was bekomen, alse wir ez sider hân vernomen, an der selben stunde einen meister er an sehen begunde ... 476 - 479, ebenso 500-503, und ähnliche umständliche Verse 98-103. 394-399. 822-825. 871-879. 1499-1503. 1690-1698. 1900-1904. 2020-2023. 2613-2619 u. ö.

Das geistliche Element, das im Rother nur einzelheitlich vertreten war, ist in der Oswalddichtung zu einem Wesensbestandteil geworden. Die Entführungssage ist in den Dienst der kirchlichen Idee gestellt, sie ist zu einem Bilde geworden für den Sieg des Christentums über das Heidentum, sie ist in den großen Zeitinhalt eingefügt und die Heerfahrt übers Meer hat die Form eines Kreuzzugs angenommen.

Metrik. ${ }^{2}$ ) Die Verse des Münch. Oswald haben ungleichen Bau, doch sind Kurzverse seltener, während die Eigenart des Rhythmus durch die große Zahl langer Verse bestimmt wird. Die unreinen Reime treten im Ganzen zurück.

\section{Die Prosa (zn).}

zn ist eine völlige Umarbeitung und starke Kürzung der Fassung $M z$, an deren Text sich noch einige Anklänge erhalten haben. ${ }^{3}$ ) In einfach volkstümlichem Legendenton wird die heilige Sage erzählt, ohne Abscliweifung in schlichter Aufeinanderfolge der Hauptzüge. Das Spielmännische und das Alltägliche ist ausgeschaltet. Wiederholungen von Wendungen und Motiven sind nicht ganz vermieden, andrerseits entstehen manchmal Unklarheiten durch zuweitgehende Kürzung. Eingang und Schluß weichen von MS ganz ab. In der Einleitung wird die Vorgeschichte des Raben erzähit: er wưrde

\footnotetext{
1) Der Text ist förmlich zusammengesetzt aus gleichen Wendungen, vgl.EDZARDI, Untersuchungen $\mathrm{S}$. 2 ff.; BAESECKE an verschiedenen Stellen, bes. S. 310 ff.; EHRISMANN, Anz. 32, 184-193; WALTHER VogT, Wortwiederholung. - Parallelen zu Oswald: Droege, ZfdA. 51, 202; KeIM, Anz. 36, 249 f. - Anderes: ZWIERZINA, s. Anz. 26, Reg. S. 353. 27, Reg. S. 348.

$\left.{ }^{2}\right)$ BAESECKE, Münch. Osw. S. 201-213. $310-362$, nimmt für das ursprüngliche Gedicht vierzeilige Strophen an, auch Wien. Osw. S. XIX - XXIll. XXXV-LXll (vgl. aber Berger S. $460-469$, EhrismanN S. $180-$
}

183, LG. I, 227); Schade, Cresc. S. 60-63 stellt sechszeilige Strophen her, SIMROCK, Uebersetzung des Orendel S. XXIII f. (vgl. auch Die Nibelungenstrophe und ihr Ursprung S. 73-78), die fünfzeilige Morolfstrophe, ebenso E. H. MEYer, ZfdA. 12, 392 f., STROBL aaO. und EDZARDI, Untersuchungen S. 54107 (dagegen RöDIGER aaO.). Zu den Reimen s. auch BARTSCH, Germ. 5, 131-142, dazu RöDIGER aaO. S. 252 ff. - Heusler, ZfdA. $58,1 \mathrm{ff}$.

3) BAEsecke, Münch. Osw. S. 221-228. 238-261; BERGER S. 405 ff. 427 f. 
vom Himmel gesandt, um Osw. bei der Königskrönung das Salböl (crisem, zoi $i \mu a)$ zu bringen, da es an solchem gebrach. Der Schluß von Osw.s Leben ist Beda entnommen, nach dessen Bericht wird die Speisung der Armen, ohne die Gehorsamsprobe durch den Heiland, erzählt und der mit dem Tode des Heiligen endende Kampf gegen die heidnischen Könige Englands. Als Anhang folgen, wie es in Legenden üblich ist, Wunderzeichen, die an seiner Grabstätte geschahen.

\section{Der Wiener Oswald (WO).}

WO ist ein ganz anderes Werk als $M S,{ }^{1}$ ) eine völlige Umarbeitung des ursprünglichen Gedichtes " $\mathrm{O}$, wichtige Bestandteile sind ausgelassen, einiges Neue ist hinzugekommen, der spielmännische Charakter ist verwischt, das Possenhafte ausgeschieden, dafür herrscht der Geist der Frömmigkeit. In steigendem Maße tritt das geistliche Element in den Vordergrund: erst mit 390-396 kommt es eigentlich zur Geltung, wo auch der Grundgedanke des Gesamtgehaltes ausgesprochen ist: geloubet an den waren got . . und lat uch toufen vil balde, um dann gegen den Schluß, etwa von 930 an, immer stärker hervorzutreten. Gebete, die Vision von Hölle und Himmel 1260-1305 und am Ende die Heidentaufe nehmen hier über die Hälfte der Verse ein.

Die Darstellung ist mager und dürftig, ein trockener Bericht ohne inneres Leben, ohne ausmalende Ornamentik und ohne Schmuck der Sprache. Die einfache Umgangssprache des Alltags ist mühsam in Reime gezwängt, vereinzelt ragen aus der Tradition spielmännische Formeln herein. An Stelle der Spielmannsart ist die einfach volkstümliche Anschauung getreten, die zuweilen doch auch sich zu poetischer Auffassung erhebt, in Gebeten, in den poetischen Marienbildern eines Liebesgrußes $411-418$, in der Segensformel des lebenschützenden Ringes 540-553.

Umgewandt wie die sprachliche Ausdrucksweise ist die Versbildung, ${ }^{2}$ ) wenn auch regelmäßige Verse erstrebt sind, so fehlt doch das rhythmische Gefühl. Die Reime sind oft unrein.

Als Spielmannslegende ist Oswald am nächsten verwandt mit

$\$ 83$. Orendel.

Kelle 2, 217-219.388; PIPER, Spielm. D. 1, 170-196, Nachtr. S. 243, Höf. Ep. 3,711.734. Ausg.: v. D. HAGEN, Der ungenăhte graue Rock Christi, Berl. 1844; Ludw. ETTMÖ́leER, Or. u. Brîde, Zürich 1858, dazu Bartsch, Germ. 5, 109-120; krit. Ausg.: ARn. E. Berger, Orendel, Bonn 1888, dazu Vogt, ZfdPh. 22, 468-491, Singer, ZföG. 39 (1888), 753-755, LC. 1889, 582-584, RoETHE, Lit.BI. 1891, 329-333. Übersetzung: SIMROCK, 1845. - MÜLLENHOFF, DAK. 1, 32-46; E. H. MEyer, ZfdA. 12, 387-395; Heinr. Harkensee, Kieler Diss. 1879; L. BEer, Beitr. 13, 1-120, dazu ZfdPh. 23, 493-496 u. Vogt ebda 496 f.; Heinzel, Wien. SB. 126 (1892) Nr. I, dazu Vogt, ZfdPl. 26, 406-415; E.MIL. KettNer ebda 449-451; E. H. Meyer, ZfdA. 37, 321-356; TARDEL, Rostocker Diss. 1894 S. 1-32 (s. oben S. 314 Anm. 2), dazu Singer, Anz. 22, 43 ff., Alllgrimm, ZfdPli. 28, 535-537, Vogt, Archiv 96, 205 f.; Laistner,

1) Interpolationen in WO s. BAESEckE, Wlen. Osw.S. XXVIIff. - Einfluß des Orendel: Berger, Beitr. 11, 375 ff., Orendel, Ausg.

Deutsche Literaturgeschichte. It.

\section{S. LXI f.}

2) BAESECKE, Wien. Osw. S. XIX-XXIII. XXXV-1.XII. 
ZfdA. 38, 113-135; EmIL Benezé, Or., Wilh. v. Orense und Robert d. Teufel, Halle 1897; s. auch PANZER, Hilde-Gudr., Reg. S. 450, BAESEcke, Münch. Oswald, Reg. S. 442, SchNeider, Wolfdietr., Reg. S. 415, THIEN, Úbereinstimmende Motive.

Hss. $\left.{ }^{1}\right)$ H Straßburger Hs., vom J. 1477, ehemals Johanniterbibl. (Stadtbibl.), 1870 mit dieser verbrannt. Der Dialekt ist unterelsässisch. Es fehlen Verse.

D Druck, Augsburg 1512 bei Hanns Froschauer, mit 32 Holzschnitten. Erhalten sind zwei Exemplare, in den Bibliotheken zu München und Berlin. Der Dialekt iet Augsburgisch. $D$ hat einen besseren Text als $H$. Beide, $H$ und $D$, streben nach Glättung der Reime. $H$ ändert viel häufiger als $D$.

P Prosa, wie D im Jahr 1512 in Augsburg gedruckt bei Hanns Othmar, mit 6 Holzschnitten. Der Dialekt ist Augsburgisch.

$D$ und $P$ sind aus Anlaß der Auffindung des heiligen Rockes zu Trier abgefaßt. P ist Prosaauflösung eines Gedichtes, wie die durchschimmernden Reime erkennen lassen. ${ }^{2}$ )

$\mathrm{H}$ und $\mathrm{D}$ hatten eine gemeinsame, ebenfalls mit Bildern geschmückte Quelle (U), die schon vielfach verderbt war. $\mathrm{HD}(=\mathrm{U})$ stehen gegenseitig in engerer Beziehung gegenüber der Prosa $P$, deren Quelle einen echteren Text hatte als $U$, so daß auch $P$ Wert für die Kritik besitzt. Bei der äußerst mangelhaften Überlieferung kann das Original des Gedichtes (O) nicht erreicht werden, Aufgabe der Textkritik ${ }^{3}$ ) konnte nur sein, unter Zugrundelegung von $\mathrm{D}$ und Beiziehung von $\mathrm{H}$ deren gemeinsame Vorlage $U$ herzustellen, wobei $P$ zuweilen Ausblicke auf das Originalgedicht $O$ gestattete. Die Fassung $U$ muß schon stärkere Wandlungen durchgemacht haben, denn es stehen ältere und jüngere sprachliche und stilistische Formen nebeneinander; auch die zahlreichen Textstörungen und Verwirrungen deuten darauf hin. ${ }^{4}$ )

Das ursprüngliche Gedicht $(\mathrm{O})$ wird gegen Ende des 12. Jhs. en tstanden sein, nach 1190, und zwar wohl in Trier, wohin das Interesse an dem heiligen Rock weist. Die Sprache paßt zu dieser Ortsbestimmung, sie ist mittelfränkisch. ${ }^{5}$ )

Inhalt. $\left.{ }^{6}\right)$ Einleitung 1-18 Gebet zu Christus. ${ }^{7}$ )

1. Vorgeschichte des heiligen Rocks 19-154: Maria hat ihn gesponnen, Helena gewebt, Christus hat ihn getragen während der 40tägigen Fasten und bei seinem Martertode. Ein alter Jude erhält ihn von Herodes. Da er die Blutflecken nicht herauswaschen kann, versenkt er ihn in einem steinernen Sarg ins Meer. Ein Siren erbricht den Sarg und vergräbt den Rock 9 Klafter tief im Sande. Im neunten Jahre kommt der Rock wieder an die Oberfläche der Erde. Da findet ihn der Pilger Traugemund, er kann die Blutflecken nicht tilgen, erkennt ihn als den Rock des Herrn und wirft ihn wieder ins Meer. Ein Walfisch verschlingt ihn.

Il. Orendels Ausfahrt, Schiffbruch und Knechtschaft bei dem Fischer Ise 155-813. Or. ist Sohn des Königs Oügel von Trier. Sein Vater rät ihm, Bride, die Königin von Jerusalem und vom heiligen Grab, zur Frau zu nehmen. Er fährt dahin mit 72 Schiffen. Sle werden vom Sturm überfallen, nur Or. rettet sich nackt auf eine Insel. Der Fischer Ise

1) WACKERNAGeL in Hoffmanns Fundgr. 1, 213-215; HARKENSEE aaO.S. 1 -30; BERGER S. III-XXXVIII.

2) Ein kurzer Bericht ist in der prosaischen Vorrede des Heldenbuches des 15. Jhs. unter eigenen Zutaten des Verfassers aus dem deutschen Gedichte ausgezogen, v. D. HAGEN, Heldenbuch S. CXI.

3) Nach diesen Grundsätzen hat BERGER seine Ausgabe bearbeitet.

4) VoGT, ZfdPh. 22, 487.

5) Heimat (Sprache) und Abfassungszeit:
BERGer S. I-XXXVIII. L-LXII; HARKENSEe S. 58-79; VogT, Salman S. CVI ff., ZfdPh. 22,476 ff.; E. H. MEYER, ZfdA. 12 aaO. u. ebda 37, 341 ff. 354. - Veranlassung zur Abfassung des ursprüngl. Gedichtes gab die Ueberführung des heil. Rockes aus dem Nikolausaltar im Dom zu Trier nach dem Hauptaltar 1196.

6) Vgl. Heinzel S. 2-10.

7) Die ersten Verse $1-4$ sind Nachahmung von Salm. u. Mor. 1--10, doch ins Religiöse umgedeutet. 
nimmt ihn als Knecht an. Im Bauche eines Walfisches findet er den grauen Rock. In diesem Gewande, wonach er selbst fortan 'der graue Rock' genannt wird, zieht er mit Urlaub vom Fischer zum heiligen Grab.

III. Orendel erlangt Bride zur Frau und damit die Herrschaft über das heilige Grab 814-3201. Ise wird zum Herzog erhoben. Kämpfe mit Heiden. Rückkehr mit Bride nach Trier. Das heilige Grab fällt in die Hände der Heiden. Sie ziehen ins heilige Land zurück.

IV. Wiedergewinnung des heiligen Grabes 3202-3863. Erste Gefangenschaft der Bride, sie wird von Or. und Ise mit Hilfe des Pförtners Achille befreit 3202-3763. Zweite Gefangenschaft der Bride, sie wird von einem ihrer Diener befreit. Or. erobert das heilige Grab wieder.

V. Schlu B 3864-3891. Or., Bride, Ise und Achille gehen ins Kloster.

Ursprung des Stoffes. Der Name Orentil, Orendil, Orandil (aus Orwendil), 8. Jh. auch Aurendil, ist in früheren ahd., bair. u. fränk., Urkunden vom 8. bis 11. Jh. nicht selten, auch langobard. belegt: Auriwandalus; ags. als Appellativum éarendel, jubar, Morgenstern; an. Orvandill, nach dem ein Sternbild die Bezeichnung Orvandils tá, Orendels Zehe, trug. Or. muß demnach, da nach ihm ein glänzender Stern benannt wurde, bei den germ. Stämmen ein berühmter Heros gewesen sein.

Die Erklärung für diese Benennung gibt ein an. Märchen in der prosaischen Edda, Skáldskaparmál Kap. 17: Thor hat Ǫrv. aus der Eiswelt der Riesen in einem Korbe heimwärts getragen. Eine aus dem Korbe herausragende erfrorene Zehe des Ǫrv. warf er an den Himmel und schuf daraus das betr. Sternbild. ${ }^{1}$ ) Ein Bericht des Saxo Grammaticus von Horwendillus, dem Vater des Amlethus (Hamlet), ist davon ganz verschieden und hat nur geringen Sagengehalt.

1) Die erste wissenschaftliche Begründung der Orendelsage hat Mül.LENHOFF (aaO., vgl. auch UHLANDS Schriften 6, $29 \mathrm{ff}$.) gegeben: der Kern ist nach ihm ein Jahreszeitmythus: Orvandill kehrt aus der Eiswelt, dem Winter, zurïck zu Groa (zu dem Verbum gróa grünen, Wachstum), das ist die junge, grünende Saat, der sprossende Frühling: Orendel wäre also demnach ein Licht- oder Frühlingswesen. MOLLENHOFF bringt den Jahreszeitmythus in Verbindung mit der weitverbreiteten Heimkehrsage und demnach mit dem Odysseusmythus; VoGT, ZfdPh. 22, 475. 23, 496 f. 26, 415, weist Zusammenhang mit der Heimkehrsage ab, desgl. Symons, PAuls Grundr. 2, 732 f. Der Apolloniusroman, Quelle für den Orendel: BERGER S. XC; SYMONS aaO.; E. H. MEYER, ZfdA. 37, 321 ff.; BuRDACH, Verhandl. d. 44. Philol.-Vers. in Dresden 1897 S. 28-31; TARDEL aaO.; SINGER, Apoll. v. Tyrus, Halle 1895 , S. $3-15$, dazu E. H. Meyer, Anz. 23, 197 f., Golther, ZfdPl. 29, $547 \mathrm{f}$. (s. auch Singer, Aufsätze u. Vortr. S. 79-103 u. Anz. 24, 372 f.); BAESECKE, Münch. Osw., Reg. S. 439; SCHNEIDER, Wolfdietr., Reg. S. 408; BuRDACH, Berl. Ak. 1918 S. 1016; v. UNWERTH, Beitr. 38, 280-313.
LAISTNER aAO. u.PANZER, Hilde-Gudr. S. $250 \mathrm{ff}$., bes. S. 264 f. Anm., s. auch Reg. S. 449 u. PANzer, Beowulf passim, gehen auf die Märchengruppe vom Eisenhans bezw. vom Goldener zurück, (GRIMms Märchen Nr. 136), auf dem auch der Apollonius beruhe, vgl. auch BENEZÉ an versch. Stellen, HeUSLER, Hoops Real-Lex. 3, 373 f. HeINZEL nimmt eine Sonderstellung ein, indem er in dem Orendelstoff eine Uebertragung der Legende von der Kreuzerfindung der heil. Helena sieht (vgl. auch Anz. 9, 256). - Zur mytholog. Bedeutung Orendels s. aucls J. Grim M, Mythol. S.310-312.603, Bd.3,211 f.;SIMROCK,Mythol., Reg.S.632; WiLH. MÜLLER, Mythol., Reg.S.259, ders., Zur Mythol.d.griech.u.deutschenHeldensage S. 147-177; E. H. MEYER, Germ. Mythol., Reg. S. 336; Symons, Paul.s Grundr. $2^{2}$, Reg. S. 135; Golther. Mythol. S. 269 f. - Ueber den N a me u vgl. J. Grimm, Mythol. ${ }^{4}$ S. 310 ff.; MOLlenHOFF aAO.; BEER S. 21. 23; BERGER S. LXXXV. XCIV; W. MÖller, Zur Mythol. usw. S. $160 \mathrm{ff}$; ' LAISTNER S. 123. $133 \mathrm{f.}$; HeINZEl S. 14 f.; Singer, Apollonius S. 3 f.; KLugk, Urgermaniscli, PAULS Grundr. $1^{3}$, 230; Much, Wörter u. Sachen 4, 169-173; Kluge, Etym. Wb. unter Ostern; HeUSLer aaO. 
Beide Sagen haben mit dem Inhalt des deutschen Gedichtes nichts gemein. Dagegen läßt sich dessen Stoff bis in Einzelheiten hinein mit dem spätgriechischen Roman A pollon ius v on Tyrus ${ }^{1}$ ) und seiner altfranz. Nachahmung, dem Jourdain de Blaivies, vergleichen. Der deusche Spielmann hat also eine franz. Fassung des Apollonius gekannt und dieser seine Erzählung nachgebildet. Gewiß hat es eine deutsche Orendelsage gegeben, nur läßt sie sich nicht aus der Vergleichung mit den ganz unverwandten Sagen der Edda und Saxos wiederherstellen. Um die ursprüngliche deutsche Sage zu erschließen, muß man nach einer Form suchen, die in der deutschen Literatur beglaubigt und mit dem Apolloniusstoff soweit verwandt ist, daB sich die Entstehung des Orendel-Apolloniusromans aus ihr erklären läßt. Die Grundzüge dieser deutschen Orendelsage lauteten: a) Ein Königssohn (Orendel) zieht aus und gerät in niedere Knechtschaft (Ise). b) Er erhält ein unverwundbar machendes Gewand (der graue Rock). c) Er verläßt seinen Meister und erringt durch Heldentaten (Orendels Kämpfe) eine Königstochter und ein Reich (das heilige Grab). ${ }^{2}$ ) Dieses Schema ist der Kern in einem weitverbreiteten Typus - ein junger Mensch niederer Herkunft, oder auch einer von edler Geburt, der aber in niedere Verhältnisse kommt, macht sein Glück -, zu dem das bekannte Märchen vom Eisenhans (auch Goldenermärchen genannt) ${ }^{3}$ ) und auch die Geschichte von Sigfrids Jugend gehören. Letztere besteht aus folgenden Motiven: a) Sigfrid, ein Königssohn, zieht aus und gerät in die Dienste eines Schmiedes. b) Er verläßt ihn und erlangt eine unverwundbar machende Hülle (die Hornhaut). c) Er erringt durch Heldenmut einen Schatz und ein walkürisches Weib.4) Eine derartige Orendelsage mag dem Dichter mit im Bewußtsein vorgeschwebt haben. Ihr entlehnte er den Namen des Helden. ${ }^{5}$ )

Bei der Beurteilung der Entstehungsgeschichte des mhd. Orendelgedichtes ist auszugehen von der Absicht seines Verfassers und von der Aufgabe, die er sich stellte: er beginnt die Erzählung mit der Bezeichnung des Inhalts: Nun wil ich... von dem heiligen grâwen rocke singen $19 \mathrm{f}$.,

1) Im deutsclien Orendel entsprechendem Apolloniusroman: Schiffbruch,Aufnahme beim Fischer, Knechtsdienste (in verwandten Fassungen des griech. Romans), Mantelkauf (im Apollonius Teilung des Rockes), Gang zur Stadt, Auszeichnung durch hervorragende Taten (Turnier, Kämpfe; im Apollonius besteht die Leistung in einem Ballspiel, im Jourdain in einem Schirmgefecht), Besiegung der Freier (Merzian und Sudan), Sendung des Boten (Schiltwin), Gewinnung der Gattin, Ausstattung mit Gewändern bezw. Rüstung, Verleugnung (Verschweigung) des Namens, Belohnung des Fischers durch Geld und Standeserhöhung, Rückreise zum Schutz des Vaters, Trennung der Gatten, wobei stärkere Abweichungen vom Apolloniusthema (entspricht teilweise den Schicksalen der Tochter im Apollonius), Wiedervereinigung nach vielen Abenteuern.

2) Diese Grundform geht bis zur Erringung der Braut, also bis ca. 1798 .

3) Siehe Laistner, Panzer, BenezE Anm. 1 der vorigenSeite.-Das charakteristischeMerkmal der Eisenhans-Goldener-Gruppe besteht in dem schützenden Dämon. Im Spielmannsgedicht vertritt diese Stelle der Fischer Ise.

4) Diese Vorgeschichte Sigfrids ist erst nachträglich durch Zusammenfassung ursprünglich verschiedener Lieder zu einer einheitlichen Erzählung geworden, s. LG. II, 2.

5) Von Bedeutung für die Ausführung des Stoffes war die hier vorausgesetzte Orendelsage nicht, sie hat keine Leitzüge gellefert, die nicht auch der Apollonius bezw. der Jourdain enthalten hätte. 
er will also die Legende vom heiligen Rock darstellen und verbindet dainit Verlust und Wiedereroberung des heiligen Grabes. Dazu benutzte er den Apolloniusroman, der sich für das beliebte Spielmannsthema von der Brautfahrt leicht darbot und ohne starke Änderungen verwendet werden konnte, ${ }^{1}$ ) auch in dem Mantel, den der Fischer dem Schiffbrüchigen gibt, sogar einen Berührungspunkt mit der Zentralvorstellung der Legende, dem grauen Rock, enthielt. Zur Erweiterung und Ausschmückung dienten dann noch leicht und passend sich einfügende Einzelzüge aus der Heldensage ${ }^{2}$ ) (wobei auch Erinnerung an die alte Orendelsage mit nachklingen mochte), aus der Spielmannsdichtung (besonders aus Salman) und aus eigener Erfindung.

Aber Sage und Märchen und Abenteuer waren dem Dichter schließlich nur poetische Mittel, um die wunderbaren Schicksale des heiligen Rockes mit erhöhten Reizen auszumalen. Denn eine Legende wollte er machen, der griechische Seefahrer ist zum christlichen Ritter, zum Helden des heiligen Rockes und zum Streiter des heiligen Grabes geworden, der Liebesroman zu einer Kreuzzugsgeschichte. Was er von dem Rock erzählt, ist eigentlich doch nur äußerlich an- und eingeschoben: die Einleitung des Gedichtes gibt die Vorgeschichte des Heiligtums 113-154, die Fortsetzung folgt 564 ff.: 8 Jahre (154) sind vergangen, da fängt Or. den Walfisch, der den Rock verschlungen hatte. Auf diese Weise kommt er in den Besitz Or.s, schützt diesen in seinen Kämpfen und gelangt durch ihn auf himmlischen Befehl nach Trier, wo er in einem Steinsarg vermauert aufbewahrt wird (3162-3177). Wechselvolle Vorgeschichte, letzter Besitzer, endgültige Niederlegung, das sind die drei Stufen, in denen sich das Schicksal der Reliquie abspielt. Nur die Benennung der Grâwe roc erinnert das ganze Gedicht hindurch an den Legendengehalt, und diese Kennzeichnung ${ }^{3}$ ) trägt der Held auch dann weiter, nachdem er den Rock in Trier zurückgelassen hat und um das heilige Grab kämpft.

Was hier als Legende vom Rock Christi erzählt wird, hat gar keine Gewähr in der geschichtlichen Überlieferung.4) Denn nach dieser

1) Das Gepräge einer Brautfahrtgeschichte erhielt das Gedicht erst dadurch, daß Orendels Schicksale durch den Heiratsplan und den Rat des Vaters eingeleitet wurden. Bei der Brautfahrt aber ist es geblieben und es ist nicht zur Entführung gekommen: dadurcl unterscheidet sich der Orendel von den verwandten Spielmannsromanen.

2) Ein Beispiel für Stilisierung im Geiste der Heldensage ist die Auffassung der Bride als Walküre (vgl. HEINZEL S. 54. 78; TARDEL S. 20-22; VOGT, ZfdPh. 23, 496 f.; KETTNER aaO.). 'Sie faht als ein man' 2076, sie reitet mit Brünne und Helm, mit Schwert und Stahlstange in den Kampf und haut ihren Gatten aus den Getümmel heraus, so daß er den Sieg erkämpft 2039-2130 (vgl. ferner 3711 ff. 3832 ff.). So Ist Brünhild Sieghelferin, helfender Schutzgeist (Edda: Lied von Sigrdrifa
Str. 2 f., Brynhilds Todesfahrt Str. 8; Swáwa im Lied von Helgi Hjorwardssohn Str. 9). so Sigrún (I. Lied von Helgi dem Hundingstöter Str. 55); wie Bride dem Orendel ihre Hand (und das Reich) anbietet, so Sigrún dem Helgi (ebda Str. 57; II. Lied Str. 14); und wie Bride dem Orendel das siegverleihende Schwert ihres Vaters David schenkt, das eine Reliquie des heil. Pancratius in sich birgt und in die Erde vergraben ist, mit dem er dann seinen Gegner tötet, so weist Swáwa dem Helgi ein durch Zauber gefeites Schwert an, das auf der Sigarsinsel versenkt ist und mit dem er seinen Feind erschlägt (Lied von I lelgi Hjorw. Str.8ff.).

3) Zur Namengebung vgl. PANZER, HildeGudr. S. 307 ff., Sigfrid S. 87. 199, Seifr. v. Ardemont S. IC. CV, Beowulf S. 72.215 ff.

$\left.{ }^{4}\right)$ Glldemeister und r. SYrbe, Der heil. Rock von Trier und die zwanzig andern lieil. 
befand sich der ungenähte Rock Christi einst in einer Stadt Galatiens oder Palästinas in einer hölzernen oder marmornen Kiste. Die h. Helena war es, die ihn mit andern Reliquien des Herrn nach Trier sandte.1) Im dortigen Dom wurde er, nachdem schon in der 2. Hälfte des 11. Jhs. ein Gerücht ihn daselbst lokalisierte, a. 1121 im Nikolausaltar, 1196 im Hauptaltar niedergelegt und blieb hier verschlossen bis zur ersten öffentlichen Ausstellung 1512, durch welche dann die beiden Augsburger Drucke D u. P veranlaßt wurden.

Die offizielle kirchliche Fassung hat es in der Frühgeschichte des Rockes und seiner Verbringung durch Helena nach Trier nur zu Ansätzen einer Legende gebracht, im deutschen Gedichte aber ist eine solche zu völliger Ausbildung gelangt. Die Auffindung und Überführung des Rockes durch Or. ist persönliche Erfindung des Spielmanns. ${ }^{2}$ ) Entgegen der historischen Beglaubigung schreibt er statt der Königin Helena, die so viele verehrenswerte Schätze nach Trier gebracht, einem sagenhaften einheimischen König. den Ruhm zu, den kostbaren Besitz seiner Vaterstadt verschafft zu haben, überträgt dagegen, in völliger Ụnkenntnis der Chronologie, auf jene Heilige die Webung des Rockes. ${ }^{3}$ ) Von gelehrter Seite wurde denn auch das tractatel oder büchelin von einem künig genannt Orendel - gemeint ist eine der zur Ausstellung des Rockes a. 1512 erschienenen Schriften - als falsche Erdichtung und gewinnbringende Spekulation gebrandmarkt.4)

Der durchaus herrschende Ton in dieser Spielmannsdichtung ist der einer ganz populären Frömmigkeit. Das Religiöse ist in grobsinnlichen Vorstellungen aufgefaßt. Kommt Or. in eine schwierige Lebenslage, so wird ein Wunder aushelfen, nichts vollbringt er selbständig aus eigener Kraft, seine Handlungen sind nicht Ergebnisse eigener, innerer Sittlichkeit, sondern sie werden gelenkt durch das unmittelbare Eingreifen der himmlischen Barmherzigkeit: er spricht ein kurzes Gebet zu Gott um Hilfe, und es wird erfüllt; oder Maria richtet ihre Fürbitte an den Sohn, Christus sendet einen Engel, der den Befehl ausführt; das ist der gewöhnliche Verlauf, wie ein Wunder eingeleitet wird. In der Gefahr selbst ist er der tapferste Held, furchtlos und stets siegreich in den schwersten Kämpfen gegen die Heiden, ein unbezwinglicher Verbreiter des Christentums (Heidentaufe 2506. $2828 \mathrm{ff}$. 3114 ff. 3243 ff.). Der legendarische Geist kommt noch viel mehr zum Ausdruck als im Oswald. Dort ein königlicher Heiliger, mit Szepter und Krone an der Spitze einer Schar hochgeborener Vasallen, hier ein demütiger Mönch in einen groben Mantel gehüllt, als ob er eben einem Kloster.

ungenähten Röcke, 1. Aufl. Düsseldorf 1845; CreizenaCh, Beitr. 1, 98; BERGER S. C ff.; HEINZELS. 48-51. ' ) Vgl.Kchr. 10387-10389.

2) Die Vorgeschichte des Gedichtes kann alte Sage enthalten: Herodes gibt den Mantel einem Juden, der ihn wegen der untilgbaren Blutflecken in eine Steinkiste (vgl. HEINZEL S. 51) vermauert (so fand ihn Helena). Im Spielmannsgedicht wiederholt sich der gleiche Vorgang dreimal: der Jude, der Siren, der
Pilger haben den Rock und werfen ihn wieder weg, erst der vierte Besitzer, Or., kann ihn, durch göttliche Gnade, tragen. Aber auch er muß ihn später an seinen richtigen Ort abliefern, an die geweihte Stätte in Trier.

3) Wie willkuirlich die profanen Verfasser mit heiligen Dingen umsprangen, zeigt der mittelniederl. Roman Seghelijn vanJherusalem, wo der Held die Marterreliquien Christi gewinnt, HEINZEL S. 53. 4) BERGER S. CI. 
entronnen wäre 1983. Was für ein König mag das sein? fragen seine neuen Untertanen 1978. Einem Fischer, einem rohen Heiden, folgt er willig als Knecht, aber er befreit das Grab des Erlösers von den Ungläubigen und wird Herr des Landes, wo der Gottessohn wandelte und litt. Es ist wie in der Märchenwelt und ist doch ein Stück Menschheitsgeschichte: es ist die verkörperte Idee des Mönchtums, die Weltherrschaft der Weltentsagenden. ${ }_{n}$ Nun schaut, wie er dort her reitet auf meinem hohen Rosse! Er führt nichts anders fürwahr als einen grauen Pilgersrock. ${ }^{1}$ ) Er ist ein Kernheld, dieser Mann, vor ihm kann niemand lebendig bestehen" 1275-1280; er ist ein schlichter Ritter, nichts anderes hat er an als einen grauen Rock, aber er kämpft in unwiderstehlichem Wüten; in Seide und kostbares Pelzwerk sollte er gekleidet sein wie ein König 1108-1118. Er, der einst mißachtete Bettler, ist zum angestaunten Helden geworden. Karl der Große, Roland, Olivier tragen die Zuge des christlichen Ritters, Oswald tut mit der Ertötung irdischen Begehrens, mit dem Gelübde der Keuschheit und dem Verzicht auf allen Besitz, den Schritt zur Askese, Orendel endlich ist völlig der mönchi sche Ritter, er hat eine noch höhere Stufe der Selbstentsagung erreicht, von der Demut vor Gott ist er zur Erniedrigung vor den Menschen gelangt.

Eine viel kräftigere Persönlichkeit als Orendel ist seine Frau, die Königin von Jerusalem, die Heldin des Gedichtes und die Trägerin der Handlung im 2. Teile, frouwe Brîde, die schonste ob allen wîben 220 f. u. ö. Auch ihr Tun ist begründet in frommer Gläubigkeit; weiß sie ihren Gatten in Gefahr, so bittet sie den himmlischen Herm um Hilfe für ihn $1750 \mathrm{ff} .1890 \mathrm{ff}$. 2041 ff. 2375 ff.; um Schutz ihrer bedrohten Ehre 3264 ff.; an geweihter Stätte vor dem Grab des Herrn verrichtet sie ihr Gebet $1750 \mathrm{ff} .1890 \mathrm{ff}$. 3779 ff., aber ihr Glaube ist der eines naiven Kindes: wenn Gott nicht hilft, so droht sie mit der Zerstörung seines Heiligtums $2375 \mathrm{ff}$. Sie ist keine asketisch veranlagte Natur, sie entsagt nicht der weltlichen Ehre, sie hât ouch weltlichen ruom 217, sie bleibt in aller Demut die königliche Frau, entschlossen und lebensmutig baut sie ihr Geschick, sie wählt sich selbst den Mann, dem sie hold ist, und nimmt ihn trotz seiner Armut zum Gatten, da sie in ihm den geeigneten Schützer ihres Landes erkennt;2) sie ist ihm treu in allen Anfechtungen, sie könnte ihr Leben retten, wenn sie die Werbung eines großen Heidenherrschers annähme, aber sie läßt sich lieber im Kerker geißeln, daß ihr das rote Blut über den Leib rinnt, ehe sie den Mann aufgibt, den sie zuerst auf Erden lieb gewann 3220-3267. 3584-3619. In glänzender Rüstung sprengt sie ins Schlachtgetümmel, sie kämpft an seiner Seite und rettet ihm das Leben 2039 ff. (vgl. 3711 ff. 3832), eine Heroine, zugleich Walküre und Märtyreriı. ${ }^{1}$ )

Zwei große Aufgaben sind in der Anlage des Gedichtes bedingt, einmal die Verbringung des grauen Rockes nach Trier: sie fällt Or. zu und ist

1) Einen guoten roc grawe, guot hat die Bedeutung wie in "gllot man" für Pilger, 
abgeschlossen mit der Niederlegung der Reliquie in einer steinernen Kiste daselbst 3164-3178; und die Wiedereroberung des heiligen Grabes, die Bride aufgetragen wird 3154-3159 und ihr nach großen Gefahren und Leiden (3206 ff. $3764 \mathrm{ff}$.) auch gelingt $3852 \mathrm{f}$.

Mit dem Verlust des Grabes an die Heiden aber ist eine historische Tatsache berührt, die Einnahme Jerusalems durch Saladin a. 1187. Und so erinnert denn überhaupt die politische Lage im Reich der Bride an die Zustände im Königreich Jerusalem zwischen 1180 und 1190: der französische Ritter Guido von Lusignan, der aus dem Abendland (Frankreich) gekommen war, gewann die Hand der Sibylla, der Schwester Balduins IV., Königs von Jerusalem a. 1183 und wurde von ihr a. 1186 zum König gekrönt. Zu dieser Zeit bestand ein friedlicher Verkehr zwischen Christen und Heiden in dem Lande, viele Große aber, besonders die Templer, waren dem heraufgekommenen Fremden feindselig gesinnt. ${ }^{2}$ ) Wenn nun die Darstellung des Gedichtes auch nicht eine unmittelbare Poetisierung der geschichtlichen Wirklichkeit ist, wenn Or. nicht Guido, Bride nicht Sibylle ist, so gibt doch die Erzählung, in deren Mittelpunkt ein so hervorstechendes Ereignis wie der Verlust des heiligen Grabes steht, ein Abbild der tatsächlichen Verhältnisse, und die Abenteuer des Spielmannsromans umhüllen Wendungen der Zeitgeschichte, die die ganze Christenheit mächtig bewegten. Jedenfalls haben die Erfindungen des fahrenden Mannes einen bedeutsamen historischen Hintergrund und die Idee des Gedichtes, der Sieg des Christentums über das Heidentum, steht in greifbarer geschichtlicher Beleuchtung.

Der Stil des Inhalts und der der Sprache gehören in eine niedere soziale Schicht. Die ganze Auffassung ist volksmäßiger als im Oswald. Die Personen stehen der Umgebung des Volkes näher: ein Knecht, Mönchsritter, Abenteurer, der König wird; eine Königin, die wie ein Mann ficht, ohne Stegreif in den Sattel springt, mit der Stahlstange, der Waffe der Riesen oder gemeinen Soldaten, kämpft und eine weite Straße durch die Feinde bahnt 2045-2080 und einem Türhüter den Kopf abschlägt 3846 f., ein Fischer, der zum Herzog gemacht wird und seiner Frau einen guten Mantel nach Hause bringt 2223-2248. Auf gesellschaftliche Form wird nicht wie im Oswald Gewicht gelegt, Prügelszenen sind häufiger als dort, auch in der Hofgesellschaft: die Königin haut ihren Kammerdiener, reißt ihn bei den Haaren zu Boden und tritt ihn mit Füßen 1613 ff., vgl. ferner $1481-1493 .{ }^{1)} 2439$ ff. $\left.{ }^{2}\right) 2611$ ff. 2664 ff. 2989 ff. Leidenschaftlich äußern sich die Gemütsbewegungen: Or. rauft sich in seinem Elend das Haar aus 669,

1) Die Szene mit dem Heidenkönig Minold enthält die Grundzüge einer Märtyrerlegende: ein heidnischer Fürst nimmt eine Jungfrau, die sich Gott ergeben hat, gefangen und wirbt um ihre Liebe unter großen Versprechungen, aber sie will ihn nur erhören, wenn er Christ wird. Durch Marterıng will er sie nun $z u$ seinem Willen $z$ wingen, aber sie bleibt Gott treu und erträgt standhaft alle Peinigungen $3220-3267$, dazu $3616-3619$.

2) E. H. MEYER, ZfdA. 12 u. 37 aaO.; HARKENSEE S. 63-68; BeRgER S. LIX-LXI; BENEZÉ S. $1 \mathrm{ff}$. 
Bride versteigt sich zu Drohungen gegen den himmlischen Herrn 2379 ff. Für Spott und Geschimpfe ist Gelegenheit gegeben in den Kampfreden (gelpf) 1283-1300. 1323. 1333-1340, s. auch 928 ff. 1084-1099.

Also burlesk und grobkomisch tritt der Spielmann auf, aber nicht so dreist wie im Salman. Einen eigenen Spielmannstypus wie Morolf oder Oswalds Raben zeichnet der Dichter nicht, doch sind die besonderen Interessen seiner Gattung, leckere Mahlzeiten und reiche Beschenkung, auch ihm angenehme Unterhaltungsgegenstände 1530 - 1539. 1799 f. 2791.3598 f. 3606 f. 3744 ff. 3864 f.; $1169-1176.2195-2200.2221-2248.3033-3040$. $3055 \mathrm{f}$. Ungemein lebensvoll und mit packendem Scherze schildert der Dichter das sorglose Treiben der fahrenden Leute, die unser Herrgott immer versorgt, wie sie lärmend heraneilen, um den gefangenen Riesen, den ihnen Or. überläßt, zu begucken, ihn seiner kostbaren Gewandung entledigen, sofort zum Weine laufen und die ganze Herrlichkeit vertrinken, mit einem dankenden Vergeltsgott für den edlen Spender 1345-1368.

Der Stil der Sprache ist starr und ungelenk, herb und trocken und ganz einförmig. Er besteht noch viel mehr als der im Oswald aus Formeln ${ }^{3}$ ) und Allgemeinplätzen und wiederkehrenden gleichen Wendungen. Ist von Bride die Rede, so heißt es stereotyp: frou Brîde, die schonste ob allen wîben; tritt der Fischer auf, so wird er eingeführt: meister Îse, ein fischer rîch und wîse; Orendel ist der grâwe Roc der wîtgant mit Reim auf spranc, twanc etc., oder der grâwe Roc der helt guot: huop, sluoc etc., oder sehr häufig der grâwe Roc mit Reim auf got, auch auf tempelhof.

Die Komposition des Gedichtes ist ungleichmäßig. Die beiden ersten Hauptzüge, Ausfahrt des Helden, Knechtschaft mit Gewinnung des Mantels, sind ziemlich einheitlich und geradlinig entwickelt 155-813, der dritte Zug dagegen, die Gewinnung der Bride und des heiligen Grabes, zersplittert sich in eine Reihe von Episoden (814 bis Schluß). Die Stoffmasse bilden Rüstungen und Kämpfe, Gefangennahmen und Befreiungen. Auch in der Kunstübung steht der Dichter des Or. weit hinter dem des Oswald zurück, sowohl in der Beherrschung des Ausdrucks als in der Anordnung des Stoffes.

Metrik. ${ }^{4}$ ) Wie die Behandlung der Sprache, so ist auch die der Verse mit den vielen, z. T. rohen Assonanzen u. überlangen Zeilen unsorgfältig. ${ }^{5}$ )

1) Vgl. Droege, ZfdA. 51, 202.

2) Der Zwerg Albân: LüTJen, Der Zwerg S. 28 ff. u. Reg. S. 112118 ; s. auch NeCKEL, Aufs. f. Braune S. 112 f.

3) ZWIERZINA, ZfdA. 45, 282.

4) Piper S. 175 f.; Harkensee S. 30-58. 59-62; Vogt, Salman S. XCVII ff. CVI ff. BERGER S. XXXIX-XIIX. L-LXII. VOGT, $\mathrm{ZfdPh} .22,476$ ff. $486 \mathrm{f}$.

5) Strophen von 6 Zeilen nimmt an SCHADE, Cresc. S. 56-60; von 4 Zeilen EtTMÜLler, Ausgabe S. $105 \mathrm{f}$; von 5 Zeilen (Morolf- strophe): BARTSCH, Germ. 5, 109-120, E. H. Meyer, ZfdA. 12, 392 f., Strobl, Wiener SB. 64 (1870), 474; auch, neben andern Strophenformen, HARKENSEE S. 30-58. SiMROCK sprach sich in seiner Uebersetzung S. XXVI-XXVIII für die Morolfstrophe aus, nahm diese Ansicht aber wieder zuriuck in seiner Sclırift Die Nibelungenstrophe und ihr Ursprung S. 73-7S; BERGER erkennt ebenfalls eine Anzahl urspringlicher Morolfstrophen an, S. XLIII-XLIX; dagegen VOGT, ZfdPlı. 22, 486 f. 


\section{Zeittafel.}

Um 1060 Ezzos Gesang.

1065 Williram.

1070 Wiener Genesis.

" Memento mori.

Z"weite Hälfte des 11.Jhs. Ält. Physiologus.

ca. 1080-1110 Annolied.

um 1090 Merigarto.

ca. 1110-1130 Milstäter Sündenklage.

, $"$ Rheinauer Paulus.

um 1120 Wien-Milstäter Exodus.

vor 1127 Ava.

ca. 1120-1130 Lamprechts Tobias.

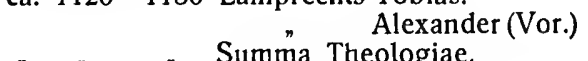

$" \quad " \quad$ " Friedberger Christ u. Antichrist.

, " Priester Adelbrecht.

Erstes" Drittel "des 12.Jhs. Lob Salomons, drei Jünglinge, ält. Judith.

ca. 1120-1140 Von Christi Geburt.

um 1130 Priester Arnold.

" Baumgartenberger Joh. Baptista.

ca. $1130--1140$ Vorauer Bücher Mosis.

nach 1131 Rolandslied.

ca. 1130-1150 Vom Rechte.

" " Die Hochzeit.

" " Mfrk. Legendar.

" " Gereimter Physiologus.

ca. 1135-1145 Paternoster.

um 1140 Jüng. Judith.

" Melker Marienlied.

" " Himml. Jerusalem.

$n$ Babylon. Gefangenschaft.

nach 1147 Kaiserchronik.

Mitte des 12. Jhs. Vorauer u. Milstäter Hs.

ca. 1140-1150 Hartmanns Rede vom Glauben.

Hamburger jüngstes Gericht.

1145-1155 Siebenzahl.

1150 St. Trudperter H.Lied.

" Heinrich v. Melk.

n Vorauer Sündenklage. ca. 1150 Visio S. Pauli.

" "Cantilena de convers. S. Pauli.

" " Arnsteiner Marienlied.

" S. Brandan.

" " Der Scopf von dem lône.

$"$ " Die Wahrheit.

" Upsalaer gereimte Beichte.

Erste Hälfte des 12. Jhs. Sprüche der Väter.

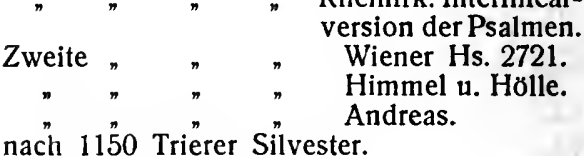

nach 1150 Trierer Silvester.

ca. 1150-1160 Rother.

" Mariensequenz aus St.Lambrecht.

um 1160 Straßburger Alexander.

, " Jüng. Anegenge.

" $\quad$ Trierer Aegidius.

" " Patricius.

" " Makkabäer.

" $\quad$ Deutung der MeBgebräuche.

ca. 1160-1170 Heinrichs Litanei.

, , hl. Margarete.

um 1170 Priester Wernhers 3 Lieder von der Jungfrau.

,$\quad$ Albers Tnugdalus.

" " Linzer Antichrist.

" $"$ S. Veit.

$"$ " Oswald.

ca. $1170-1180$ Wernher v. Niederrhein. Der wilde Mann.

Pilatus.

um 1180 Trost in Verzweiflung. Vom Himmelreich.

, 1187 Straßburg-Molsheimer Hs.

" 1190 Albanus.

" "Salman u. Morolf.

$"$ " Orendel.

Ende des 12. Jhs. Mariensequenz aus Muri.

n , Messegesang.

$n \quad " \quad$ Christus u. Pilatus.

$n$, , Esau u. Jakob.

Ortstafel.

(Heimat bezw. Mundart der Denkmäler.)

I. Alemannisch.

Schweiz: Memento mori, Rheinauer Paulus, Rhein. Sündenklage, Mariensequenz aus Muri. Elsaß: Deutung der Meßgebräuche. Alem. ohne nähere Bestimmung: Aelt. Physiologus, Milst. Sündenklage, St. Trudperter H.Lied, Scopf v. d. lône, Cantilena de conversione S. Pauli, Patricius, Evangelienübersetzung, Linzer Antichrist (?).

\section{Il. Bairisch-österreichisch.}

Kärnten, Steiermark: Wienèr Genesis, Exodus, Vor. Bücher Mosis, Priester Adelbrecht, Vom Rechte, Die Hochzeit, Paternoster, Vor. u. Wien-Milst. Hs., Himml. Jerusalem, Sequenz aus St. Lambrecht, Heinrichs Litanei. Donautal: Ava, Melker Marienlied, Heinr. v. Melk, Baumgartenberger Joh. Baptista. Österreich, ohne nähere Bestimmung: Priester Arnold, Gereimter Physiologus, Jüng. Judith, Babylon. Gefangenschaft, Siebenzahl, Vorauer Sünden- 
klage, Die Wahrheit, Jüng. Anegenge, Heil. Margarete. - Bair.: Regensburg: Pfaffe Konrad; Windberg: Albers Tnugdalus, Vom Himmelreich. Bair. ohne nähere Bestimmung: Priester Wernhers Marienlieder, Trost in Verzweiflung, Messegesang; bair. od. alem.: S. Veit.

\section{Ostfränkisch.}

Ezzos Gesang, Williram, Merigarto, Himmel u. Hölle.

\section{Rheinfränkisch.}

Südl. Rheinfränk.: Makkabäer, Straßburg-Molsh. Hs. Hessisch, Wetterau: Friedberger Christ u. Antichr., Arnsteiner Marienlied, Pilatus. Rheinfränk. ohne nähere Bestimmung: Summa Theologiae, Lob Salomons, 3 Jünglinge, Aelt. Judith, Hamburger jüngst. Gericht, Upsalaer gereimte Beichte, Interlinearversion der Psalmen, Trierer Silvester, Trierer Aegidius, Straßburger Alexander, Salman u. Morolf. Rheinfrk. od. moselfrk.: Sprüche der Väter.

\section{Mittelfränkisch.}

Annolied, Lamprechts (Vor.) Alexander, Von Christi Geburt, Mfrk. Legendar, Hartmanns Rede vom Glauben, Rother, Oswald, Wernherv. Niederrhein, Der wilde Mann, Albanus, Orendel.

\section{Thüringisch.}

Christus u. Pilatus.

VII. Obd. bzw. md.

Ohne nähere Bestimmung: obd.: Jüng. Physiologus; md.: Visio S. Pauli, St. Brandan Andreas, Esau u. Jakob.

\section{Nachträge.}

(Die hinter dem Komma stehenden Ziffern beziehen sich auf die Anmerkungen.)

S. 1,1 MaURICE DE WUlf, Gesch. d. m.alterl. Philosophie, übersetzt von EISLER, 1913. Wolf v. Unwerth u. Theod. Siebs, Gesch. d. d. Lit. bis zur Mitte des 11. Jhs., Grundr. d. d. Lit.gesch. I, 1920. Friedr. Vogt, Gesch. d. mhd. Lit. I. Teil Frühmhd. Zeit. Blütezeit I. Das höf. Epos bis auf Gottfr. v. Straßburg, dritte, umgearbeitete Aufl., Grundr d. d. Lit.gesch. 2, 1922. S. 11, zur Metrik: Holz, Saran u. Bernoull, Die Jenaer Liederhs, 2 Bde. 1901. S. 13, 1 BuRDACH, Reinmar u. Walther S. 139. 174 ff. S. 20, zu Williram. Hss.: Catalogus Bibl. Monacensis Tom. V pars 1, 1920, beschrieben von ERICH PETZET, S. 17 ff. 68 f. 126 ff. S. 106, 2 Mon. Germ. Poet. lat. IV, 11, 1, 459 ff. S. 113, 2 SchröDER, Gött. Nachr. 1917, 162. S. 132, zu Linzer Antichrist: SchiffmanN, ZfdA. 59, 163f. S. 140, zu 'Vom Himmelreich': Schröder, ZfdA. 58, 216, Jellinek ebda 217-221. S. 144, Lit. d. Annol.: SCHröder, Zur Kritik d. Annoliedes, ZfdA. 58, 92-95. S. 143, 1 M. v. Wulf, Heilige u. Heiligenverehrung in d. ersten christl. Jahrhunderten, 1910. S. 147, 7 hinter ${ }_{n}$ Schröder, Kchr. S. 65“ setze: u. 468. S. 151, zum mfrk. Legendar: SchatZ, Eine Reimbibel des 12. Jhs., ZfdA. 59, 1-22 (neu aufgefundene Bruchstücke, das Werk kein Legendar, sondern eine bibl. Gesch. des alten u. neuen Bundes). S. 159 hinter "Aulesius" erg. der heidnische Freier. 160, 4 O. MAUSZER, Eine Fahrt durch die Reiche des Jenseits, Walhalla 6, 200-271. S. 162, zu Patricius: A. C. L. Brown, Iwain, Stıdies and Notes in Philol. and Lit. VIIl (1903), 122f. S. 162, zu Tundalus: Amelung, ZfdPh. 3, 269 ff. (Versbau); van Hamel Neophilol. 4, 152-165. S. 164, 5 W. Grimm, ZGdR., Kl. Schr. 4, Reg. S. 330. S. 165, zu Brandan: BRown S. 86 ff.; LÜTJENS, Der Zwerg S. 15-18. S. 165, 2 BROWN S. 36 ff.; GERTR. SCHÖPPERLE, Tristan and Isolt, 1913, S. 326 ff. S. 184, zu Memento mori, Lit.: MÖller, Anz. 41, 111. S. 187, zu H. v. Melk: BaunaCK, ZfdA. 58, 239f. S. 200, zu 'Die Hochzeit': Rödiger, ZfdA. 36, 254-266. S. 206, 3 Paul Kớchenthal, Die Mutter Gottes in d. ad. schönen Litt. bis z. Ende des 13. Jhs., Gött. Diss. 1898. S. 212, zum Arnsteiner Marienl.: LISBETH JöRSS, Das Arnsteiner Mariengebet u. die Sequenzen des MA.s, Marburg. Diss. 1920. S.227, 5 Turteltaube: Domanig, Parzivalstudien 2, 91 ; W. HerTz, Parzival Anmerk. 22; BuRdaGH, Ackermann S. 185-194. 298. 387. S. 239 f. Kampfschilderungen: Neckel, Walhall S.9. S. 249, 5 BURdach, Ackermann S. 265. S. 247, 1 Friedr. Pfister, Der Alexanderroman des Archipresb. Leo, hgb., 1913. S. 262 f. Vogt, Franz. u. deutscher Nationalgeist im Rolandslied u. im Nibelungenlied, Marburger Akadem. Reden Nr. 40, 1922. S. 265, 4 NECKEL, Walhall S. 9. S. 267, zu Kaiserchr., Hss.: Catalogus Bibl. Monacensis aaO. S. 63 f. 357 f. S. 268, Constantin: BuRdACH, Vom MA. zur Ref. 11,1 S. 213 ff. S. 276, 3 Burdach, ebda S. 68 f. S. 289 Lit. üb. d. Stil d. Spielmannsd.: Panzer, Das ad. Volksepos, 1903; Ders., Märchen, Sage u. Dichtıng, 1905. S. 293, 1; HơnNERKopf, Die Rothersage in d. Thidrekssaga, Beitr. 45, 291-297. S. 329, 13 KEIM, Anz. 41, 82 f.

\section{Berichtigungen.}

S. 54, 2 v. oben 1. 12. Jhs. S. 97,2 11. 22 1. Balaanl. S. 160, 4 1. Walahfrld. S. 237, 2 1. Zacher. S. 250,4 1. Aristotiles war. S. 251, 1 1. Singer, Apollonius. S. 2531 . mit zuhten gemeit. S. 298: Anm. 7 gehört zu "Entfïhrer" in der vorletzten Zeile des Textes. 


\section{Re $\mathrm{g}$ is t e r.}

(Die hinler dem Komma stehenden Ziffern beziehen sich auf die Anmerkungen. Verzeichnel sind diese nur dann, wenn das Registerwort sich nicht schon unmillelbar aus dem laufenden Text ergibt.)

Aarons Stab 96. 96, 2. 209.214.

Abälard 4. 5. 56, 1; Trinitätsformel $7,2.32$. 54. 58. 59 . 92. 119. 134, 3. 197, 3 .

Abecedarius 176. 247.

Abel und Joseph $=$ innocens und justus 76 .

Abgarus, Leg. 129.

Abiatar, jüd. Bischof 218.

Abra 104.

Abraham = ewige Ruhe 82 ; Abr.'s Schob 200.

Abschied 84. 89. 262. 307.

Abschiedssegen 89. 306, 1 . acedia 186,4 .

Ackermann aus Böhmen 160,4 193, 2. 241, 5. 249, 2. 254, 1. $263,2.315,2.3$.

Acta S. Judae Quiriaci 152.

Acta Sanctorum 154. 155, 5 $330,2$.

Adam erster Menscl 204; Ad. - Christus 60. 209.

Adam v. Bremen 232, 4.

Adelbero, Bisch. v. Würzburg 233.

Adelbrecht, Priester, Johannes Baptista 72 . $123 \mathrm{f}$.

Adelger, Herzog, Lied 268. 272. 273.

Adonischer Vers 216.

Adso, Liber de Antichristo 132.

Adventlicd 208.

Aegidius, heil. 302; Leg. 144. 153-155; Egidius 174.

Aegyptische Plagen $=$ Sünden 94.

Aelian Irei $\zeta \omega \omega \nu, 225$.

Aesop 246, 1. 326.

Aethiop. Physiologus 226, 1.

Aetiologische Sage 100, 7.

Afra, heil. 63.

Agatha, heil. 35 .

Agnes, heil. 35. 174; Königin 44.

Aktives und kontemplatives Leben 76. 86.

Akzentuationssystem (Notker) 20.

al, Attribut 138, 1.

Alanus, Anticlaudianus 127, 1 ; Pred. 198, 1; Summa de arte praedic. 90,1. 197, 1 . 199, 1.

Alba, Gründung 147, 2.

Albân, Zwerg 345, 2.

A l b a nu s, Leg.144.155-157.

Alber, Tnugdalus 163 f.; s. Vision des Tundalus.

Alberich, Zwergkönig 335, 1.

Alberich v. Besançon 238255.

Albertus Magnus, Physica 227.

Albinus, heil. 156, 1 .

Alcimus Avitus 80.

Alcuin, Traktat de virtutibus et vitiis $77 f$.; Komment. z. H. Lied 28; de Trinitate $103,1$.

Alemannisch, Merkmale177, 4 .

Alexanderlied vom Pfaffen Lamprecht 90.184, 4. 235-255. 262, 2. 266. 288. 298, 3. 302. 311. 315 , 1, s. 110-114; StraBburger Al.258, 1; Al.dichtung 9; Al. sage 147; Orientfahrt 165; Al. u. Anteloe 249; der wunterliche Al. 145; afrz. 238; s. Tobias (s. Nachtr.). Alexius Komnenus 299.

Allegorie, allegorische, typologische Auslegungsweise, Tropologie 8. 18-29. 67 . 71. 77. 82. 90. 92. 95. 96. 97. 98. 100. 101. 115. 119. 122. 127. 139. 201. 202 . 204. 205. 208 f. 211. 225. 247 ; s. Symbolik, bezeichenen.

Alleluja, Depositio 115.

Allerheiligen, Pred. 75, 4; Litanei 173.

Alliteration 50. 57. 120, 137, 2. 142. 312; All.dichtung 11. $138,2$.

Altfranzösisch: Alexanderlied 238; Amis u. Amiles 314, 2; Bastars de Buillon 316, 2; Chansons de geste 252.261; Epos 260. 261, 3. 289, 3; Physiologus 226; Rol.lied $259 \mathrm{ff}$.

Altmann, Bisch. v. Passau 42 $-45.53$.

Altnordisch: Heldensage 105, 1. $293 \mathrm{f}$;; Nib.sage 105, 1; s. Atlakvipa, Brynhilds Todesfahrt, Edda, Gudrun, Helgi Hjorwards Sohn, isländ. Physiologus, Saxo Grammaticus, Sigrdrifa, Skáldskaparmál, Thidrekssaga, Wîlkîna Saga.

Amalarius 87, 4.

Amazonen 237.

Ambrosius, Hymnus 208; Phy- siologus 225. 226; Tobias 114; Engelchöre 92, 3; Marienverehrung 206.

Aminadabs Wagen 127.

Amis u. Amiles 314, 2.

Anapher 87. 127. 183.192. 213.

Andreas, heil.143; Leg.155.

Andreas Kurzmann 156, 1.

Das Anegenge $48,5.50,1$. 3. 58-62. 118, 1.2. 178, 9. 179. 179, 2. 4. 193,6 . 199 , 1. 201,$1 ;=$ Schöpfung 33 . 50. 53; s. Ezzos Gesang 40-53.

Anfortas, Gralskönig 164.

Angelsächsisch: Beowulf 105, 2. 341, 3; Physiologus 226; Salomon and Saturnus 314, 2. 316, 2. 327; Wulfstân; altengl. Physiolog. 226.

Angelomus 28.

Anna, heil. 218-224

Annolied 72, 7. 112. 138, 4. 144-151 (s. Nachtr.). 156,3. 231, 3. 248. 251. 267. 268. 274. 284, 2. 302; Anno, Erzbisch. s. 42.

Anonymus Leidensis 232, 4. Anredeformen und -formeln 186. 191. 194. 195. 243, 2. 307,1

Anselm v. Canterbury 5. 56, 1; Gebet 169. 170. 171.181. 182.

Anshelm, Pfalzgraf 261.

Anthropologie 80.

Antichrist 81.93; s. Ava, Friedberger Christ und Antichr., Linzer Antichr.

Antiphone 208. 212, 8.

antiquitas, Altertumsstudien $239,3$.

Apokalypse Johannis 17. 67. 70. 132. 135. 136. 139. 140. apokalyptische Dichtung 132 -142 .

Apokryphen: Evangelien 9. 208.219-221; Himmelfahrt Mose 95; salomonische Ap. 315.

Apollonius, Roman 9. 251. 289, 3. $339 \mathrm{ff}$.

Apostel, Schicksale151.151,5.

Apulejus, Arzneibuch 234.

Araber in Spanien $260 \mathrm{f}$.

Arabisch: . Evangelium infantiae 219, 3; Physiologus 226.

Arator 152. 
Arbeitsweise 109. 125. 152. 230, 1. 239. 281, 2.

Aretalogie 9. 143.

Aristoteles 24; Naturwissenschaft 225; Psychologie 54; Lehrer Alexanders 253, 1. 255; Brief Alexanders an A. 247; Wunderstein 249. 254, 2; Secreta Secretorum 250 ; s. Berichtig. S. 347.

Arles 154.

Arme - Reiche 129. 185191. 196-206.

Armenien 243; Physiologus 226.

Arnold, Priester, Juliane 70. 72, 3. 144. 159 f. (s. Naclitr.); VonderSiebenzah170-74; s.138, 4.147, 7 . 267. 268. 274. 284, 2.

Arnsteiner Marienlied 212 f. (s. Nachtr.).

Arrian, Anabasis 247.

Artusepen 164.

Arzneibücher $67,1.234$.

Aschmedai 315.

Askese, Weltflucht 1 f. 33. 42. 63. 64. 87. 123. 137. 167. 177. 185. 190. 191. 193. 195. 206. 253 f. 301 . 335. 343 ; s. Memento mori.

Assonanzentypus, jüngerer 159,4 . 164,6 .

Astronomie 71.

Asyndetische Reihe 234.

Athen 154.

Atlakviba 105, 1. 2.

Attila $42,3.105,1.292,3$ s. Etzel.

Augsburg, Gründung 147, 2.

Augustinus 47. 61. 182, 8; De catech. rud. 48, 2. 197, 1 ; De cura pro mortuis 114 ; De civ. Dei 3. 44, 4. 48, 2. 54. 92, 3. 136. 147. 190. 269. 275, 1 (s. Gottesstaat); De doctr. christ. 15, 3. 47, 4; Enchiridion 92, 3; De Genesi ad Litt. 160, 4; De lib. arbitrio 59,2 ; De symbolo 7; Predigterr 124, 3. 182, 7 ; Psalmenkomment. 27. 265, 2; Mariendogma 206; miraculum 44,4; weltl. Obrigkeit 256, 1; Siebenzahl 67. 68; Trinitătsformel 7, 2. 32. 54. 93. 134, 3; benutzt Physiologus 226 .

Augustus, Kaiser 145. 147, 7. 218. $268 \mathrm{ff}$

Ausfahrtssegen 306, b.

Aussatz 128.

Authari, König $296 \mathrm{f}$.

Autorenbescheidenheit 140,5.
Autoritäten 133. 193.

Ava 53. 160, 4; die Gedichte der A. 116-121; Leben Jesu 72. 123; Joh. Bapt. 124; sieben Gaben 70; jüngstes Gericht 137, 2.

Ave Maria, Englischer Gruß 207; Verse 171; lat. 214, 3 . Ave praeclara, Sequenz 214. $215 \mathrm{f}$.

Ave maris stella, Hymnus 208.

Babiloth, Meister 245, 5. 248.

Babylon, Gründung 147, 2.

Babylonische Gefangen. schaft (Ged.) 114 f. 123; babylon. Reich 112.3; Turmbau 112

B a l a a m 96-98 (Vor. Moses). 193; s. Bileams Eselin.

Balduin IV., König von Jerusalem 344

Ballade s. Lied.

Bamberg 1. 18, 1. 19. 40-53; Gründung des Bistums 269.

BambergerGlaube und Beichte 42. 134-138. 161. 185, 2 . 194, 3.

Basilius d. Gr. 225.

Basken 261.

Bastard de Buillon 316, 2.

Baukunst, gotische 4 .

Baum gartenberger Johannes Baptista 123,6 . 124.

Bec, Kloster 4.

Beda 132. 193; De temporum ratione 71,4 ; Kirchengesch. $160,4.330$. 337; Komment. z. H. Lied 28; Tobias $113 \mathrm{f}$; Zahlensymbolik 67, 2.

Beichte 81. 82. 94. 99. 123. 134. 138,1.175-184. 202 f. 279. 281; Beichtformeln u. -formulare 81. 123. 168.175. 179, 1. 183; Beichtgebetc 175; dic drei Beichten 201. 202 ; s. Bamberger Glaube u. Beichte, Poenitentialgedichte.

Bele, Frau 126.

Benedikt, heil. 1. 2. 36. 42.

Benediktbeurer Gebet. sammlung 170. 172.

Benediktbeurer gercimtes MeBgebct (Messegesang) 171, 3. 172; s. Salzburger MeBgebet.

Benediktbeuser Ludus paschalis $120,5,125$.

Benediktbcurer Weilınachtsspiel 120,5 .

Benediktinerregel 1. 2. $36 \mathrm{f}$ 189. $263,2$.
Beowulf 105, 2. 341, 3 .

Bernhard v.Clairvaux,De Christo et eccl.205; Epist. 263,2 ; Marienfeste 207; De modo bene vivendi $39.76,1$; Mystik 2. 56. 67. 117, 1; Predigten 115. 119, 2. 182.5. 199, 1. 208. 281; Salve caput 170,5 .

Berserker 297, 1.

Berta, Mutter Karls d. Gr. 301.

Berthold v. Herbolzheim 248

Berthold v. Regensburg 207, 2.

Bethania (Bethulia) 104.

bezeichenen, bezeichenunge 28.81.127. 139.228; diuten 139; daz meinet 135 .

Bibelübersetzungen, prosaische $142 \mathrm{f}$.

Bilderhandschriften 9. 10. 15 . 16. 116. 217. 224. 226, 2. 227. 230. 255.

Bileams Eselin 131. 187, 6; s. Balaam.

biograph. Roman 251.

Bischof Bonus, Leg. 139, 4.

Bischofsstadt (burch) 104107.

Biterolf,mhd.Ged.105,1.297,3.

Biterolf, Verfasser eines verlorenenAlexanderliedes 248 .

Bittgebet 88. 167-175. 206 -217 ; s. Gebet.

St. Blasien 43.

Blasius, heil. 174 .

Blumenmädchen 237. 245. 252.

Boevesage 298, 3 .

Bonaventura,Planctus de Christo 49 .

Bonaventura Vulcanius 144.

Boners Fabeln 249

Botanik 80.

Botewart, Zwerg 165.

Brahınanen 247. 254, 3 .

Sanct Brandan, Ged. 165 -167 .

Braut u. Bräutigam, Allegorie 18-29. 29-39. 200-206.

Brautgesang $200 \mathrm{f}$

Brautkleid 110. 200.

Brautnahl 105.

Brautwerbung, Brautfahrt, Brautraub, Entführung 9. 83 f. 92.200 f. $284-345$.

S. Brendauns 166 .

Breviarium Romanum 182,7.8.

Bricf 247. 254. 254. 3. 255.

Bruno, Erzbisch. v. Köln 2. 3,1.

brittachen 110, 2.

Brynhilds Todesfahrt 341,2 .

Buch der Rügen 187, 6.

Buoch der Kínege nluwer ê 284.

buochiet 192, 1. 
bürgerliche Dichter (Namen) 128.1.

Buße 24. 54. 80. 87. 94. 115. 134. 156. 183. $184-206$.

biißende Frauen 117. 118.

Bußprediger 123. 133. 184206.

Bußpredigt 123.182.184-206.

Bußpsalmen 167, 3. 176, 1 . $184,1$.

Byzantin. Sage 290; Salomosage 316 .

Cäcilia, heil. 35. 174.

Cambridger Hs. 48. 92, 1.

Candacis (Candace), Königin 237. 245. 249, 3. 250, 252.

Cantica canticorum 18-29. $29-39$; s. Hohes Lied.

Canticum trium puerorum 73,5 .

Cantilena de conversione Sancti Pauli 181 -183 .

Carmina Burana 92, 1. 120, 5 . 125,4 . 137, 2. 190, 2.

Cäsar, Julius 145. 147. 147, 7. 149. 150. 157.

Cäsarius v. Arles 141.

Cassiodor, Psalmenkomment. 27. $232,1$.

Chansons de geste 252. 261.

Charitas 197. 198, 1. 277.

Choralgesang 13. 52.

Chorgesang 210.

Chorherren 45. 52.

Von Christi Geburt $122 \mathrm{f}$.

Christi Höllenfahrt, Spiele $160,4$.

Christi Leib der Köder für den Leviathan 122.

Christl. Ritter 74. 235. 256267. 343 ; s. Gottesstreiter

Christophoruslegende 159,4 .

Christusbild 128. 129,1. 157,4.

Christus der Lichtbringer 46. 122.

Christus u. Pilatus 120,5 . $125 \mathrm{f}$.

Chrodegang v. Metz 42.

Chronicon Reicherspergense 152.

Chrysostomus (Physiologus) 225 f. 231

Cicero 15.

Circe 252.

Cirenberg, Bürgermstr. 144, 3.

Cistercienser 2. 207. 210.

Citeaux 2.

ClementinischeRecognitionen 272. 273,6 .

Clugny. Cluniacenser $1-3$. 26. 42. 43. 137. 185.

Coloman, heil. 173, 2. 174 .

Colonia Agrippina 147, 2.
Columban, heil. 173, 2. 174, 1 . Computus 71, 4 .

Conradus Hirsaugiensis 42, 1 . $302,1$.

Constantin, Kaiser 153. 267 -277; s. Nachtr.

Contradictio Salomonis 326 .

Cormac, König 164.

Crescentia,Leg.(Kaiserchron.). 268. 273. 273, 10. 274. 276; mhd. Ged. 274, 2

Curtius, römischer Historiker 238, 2. 245. 247.

dâ (anaphorisch) 135.

Dachau, Grafen 300.

Daktylen 213, 3. 215. 216.

Dämon, hilfreicher287,1.335,1.

Daniel, Traum 147; D. und die Priester 187, 6. 189.

Dänische Balladen 334.

Dankgebet 168, 1; s. Gebete.

Dante 161.

David und Goliath 258; D. und Urias 193.

Decretum Gelasianum 226; s. Gelasius.

Dedicatio ecclesiae 45,2. 101,4. $139,2$.

Democrit, Arzneibuch 234.

De utung der MeBgebräuch e 74 f. 199,1. 204,1.

Dialektik 3. 4. 7.

Dialektiker 5. 22.

Dicta Chrysostomi 226. 231; s. Pseudo-Chrysostomus.

Dicuil 232, 4. 233, 3.

Dienstmannensage 290-313.

Dietmar v. Eist 221.

Dietrich v. Bern 269. 271. 272. 275. 293.

Dindimus, König der Brahmanen 247. 254, 3.

Diocletian 155; s. auch Kaiserchron. $267 \mathrm{ff}$.

Dionysius Areopagita 92, 3 .

Dioscorides 234.

Dipodischer Versbau 223, 1. diuten 139 , s. bezeichenen.

De Diuite et Paupere, lat. Ged. 108.

dô, bes. anaphorisch 90.93 96. 107.111. 120.15C. 241,1 243.

Dominikaner 187, 6 .

Donati 187,6

Drama s.Spiel; lat. Drama 125.

Dreireime 57.88.97. 107. 124 . 160. 172. 178. 193. 194, 6 . 195.

Drogo 67, 2.

drûtscaft 135, 1.

Ebersberg, Kloster 18-29.
Ebersberger Chronik 19.

Ecclesia u. Synagoga 23-29. $76,2$.

Echu, König 160, 4. 162.

Edda 51, 3. 288, 1. 339. 340 . $341,2$.

Edelmann, Typus 86.

Edelsteine 134 f. 139. 145. 226. 234. 249; s. Lapidarien.

Edictus Rothari 297.

Eduard Mörike 313.

Egen v. Bamberg 158, 2.

Eggihard, Truchseß 261.

Ehe 196 f. 198

Eilhards Tristrant 251

ein, auszeichnendes 184, 4.

Einhard, Vita Karoli imp. 261, 1. 3 .

Einhorn $=$ Christus $228 \mathrm{f}$.

Einsiedler 63. 64. 154.

Eisen, das heiße 167. 206; s. Gottesgericht.

Eisenhans,Märchen 339,1.340.

Ekkehard 1., Waltharius 105, 1.

Ekkehard 1V. 18, 1.

Ekkehard v. Aura, Chronik 248. 272,1 . 276, 1. 279, 2. 280, 1. 281.

Elemente, vier 54. 119.

Eliachim, Hoherpriester 104.

Elias und Enoch 132.

Empfang 83,5. 85. 89. 289. 307 .

Engelbrecht, Abt 173.

Engelberger Gebete 170.

Engelchöre 79. 92, 3.

Englische Sagengeschichte 260, 2. 287, 1. 298, 3. 314, 2.

Epischer Stil 89. 95. 97, 1. 101 f. 105. 109. 110. 115 f. 284.

Episches Lied s. Lied.

Epiphanius (Physiologus) 225.

Epithalamium 27, 2.

Epitheta 86. 87. 93. 95. 102. 103. 107. 131. 138. 185. 266. 275. $312.321 .321 \mathrm{f}$.

Ere 305-308.

Erich, Herzog v. Friaul 261, 3.

Eriugena, Scotus 56,1. 145, 2.

Erkenfried, Abt 187.

Ernst, Herzog, Ged. 9. 165. 232, 2. 281. 298, 3. 302.

Esau und Jakob 75-77. 80.86

Eschatologie 132-142.

Ethik 276, 4.

Ethnographie 80.

Etzel 84,2. 297, 3; s. Attila.

Eucherius 67, 2.

Eugen, Papst 208.

Eusebius, Chronik 269.

Eva - Maria 60. 209. 211.

Evangelien, die vier 41,1 .

Evangelienüberset $z$ ung, alemann. $142 \mathrm{f}$. 
Evang. Nicodemi 116.

Evang. Thomae 219, 3.

Die vier êwangeljon (Ezzos Gesang) 41.

Ex od u s 78-91. 110. 235 287,1 ; s. Genesis u. Exodus.

Ezzos Gesang 14.18.4053. 55. 56. 57.58. 59. 62.66 . 120. 122. 123. 124. 127.179. 179, 4. 184. 186. 211. 267.

Fahrende s. Spielleute.

Falke 335.

Falkenlied 221. 332, 3.

Fär-Öer 232,4; Lieder 288, 1.

Fastenzeit 115. 167,3; s. Septuagesimae, Vorfastenzeit.

Fastnachtspiele 249. 328 .

Fatum 277.

Faust und Moses 95, 2.

Faustinian-Legende $271-276$. 283.

Fegfeuer 161. 162. 188.

Flecke, Flore 84, 1 .

Flickverse, Flickformeln 117,4. 120. 125. 152. 164. 239. 240. 242. 244. 336.

St Florianer Steinbuch 172.

Floyris, Trierer 153.

Formeln, formelhaft 62.69 . 72. 87. 90.93 .94 f. 96.97 (bes. 97, 1). 101. 103. 107. 111,2 . 113. 115. 118. 120. 121. 122. 123. 124. 125. 127. 131. 132. 133. 147, 7. 149,1. 150. 152. 158. 167. 168.174 . 191. 194. 194, 4. 200. 213, 2 . 217. 222. 230. 231. $233 \mathrm{f}$. 240. 243, 3. 266. 270 f. 283. 311.312. 319. 321. 331. 337. 345.

Fragmenta Burana 210, 1.

Franciscus Junius 21.

Franziskaner 187, 6.

Frater conversus 187,6 .

Frau, höfischer Einfluß 308.

Frauenlegenden, Typus 158.

Frauenlob 206, 3. 249. 250.

Frauenverehrung 2. 190. 193. 309. 315.

Fredegar 248, 5 .

Freidank 172. 227. 315,1. 327.

Freising 1.

Freisinger Paternoster 68, 1 .

Friedberger Christ und Antichrist 121f.123.132,1.

Friedrich v. Leuchtenberg 328 .

Fulda 1. 18, 1. 19.

Fün Sinne 202, 1.

Fünfzehn Zeichen vor d. jüngsten Tag 121.132.160, 4.

Fürst, der gute, Fürstenideal, Fürstenspiegel,der gerechte. christliche, Herrscher77.146,
198.235-255.256.258. 260 . 265. 276. 276, 4. 278. 279. 280. 308. 310.314. 315; der ungerechte F. 280 ; s. De regimine principum.

Gabriel, Erzengel 169. 218. Gabriel Rollenhagen 166, 2. St. Gallen 1.

St. Gangolph in Bamberg 45. Garibald, Baiernkönig 296.

Gattentreue, erprobte 279 .

Gattin, untreue $316.323 \mathrm{f}$.

Gebete 103, 1. 104. 109. 143 176. 218. 258. 322. 331. 334 . 337. 342. 343: Gebetliteratur 167-175; Mariengebete $169-175 ; 212-214$; Benediktbeurer $\mathbf{1 7 0}$; Engelberger 170. 171 ; Klagenfurter 171. 184; St. Lambrechter 159 . 169; Muri 167,3. 170. 171. 215. Vatikan. $170 ; Z$ üri cher 170. 171; Upsalaer Frauengebete 171. 184; Frauengebet der Vora uer Hs. 169; s. Bittgebet, Dankgebet.

Gebetsformel 91.

Geblümte Rede $108,1.158$.

Gelasius, Papst 226. 327, 1.

gelf, gelpf 105. 257. 345.

Daz gemeine leben 187. 188.

Genesis, typologische Auslegung 77.

Genesis und Exodus 78 -91. 235.

Geographie 71, 4. 231-234.

Geographischer Roman 251.

Gerechte (justi), drei Arten 203.

Gerhard Atze 184, 4.

Gerhoch v. Reichersperg 192.

Germanen, Kämpfe 149.

Gertrud, heil. $301 \mathrm{f}$.

Gertrud, Tocliter Kaiser Lothars 258.

gesach in Got 30.

Gesangsvortrag 11-15. 213.

Geschlechtsnamen 128, 1.

Gesta Romanorum 249,6. 270.

Gesta Trevirorum 112,3. 147. $147,7$.

Giftmädchen, Sage 246, 1 .

Von der Girlieit, vom wilden Mann 126-132.

Gîsel, Klosterfrau 163.

Glaubensbekenntnis 207; athanas. 7,2 ; nicän.-const.63. 65.

Goethe 312 .

Goldener, Märchen 339,1 340.

Goldschmied 200. 332. 333. 335.

Goldschmuck $200 \mathrm{f}$.
Goten, Stammland 300, 2 .

Gotfrid v. Straßburg 38, 1 .

Gotfrid v. Viterbo 248.

Gottesgericht 197. 206. 218. 258.

Gottesstaat 3. 16. 143. 143 -151. 190. 235. 254. 269. $275,1.277,3$; s. Augustin.

Gottesstadt $134-142$.

Gottesstreiter, Gottesritter 90. 200. 203. 222; s. christl. Ritter.

Gotthard Vögelin 20.

Gottschalk, Miserere 176

Götz v. Berlichingen 281.

Göttweih 43, 4. 44.

Grab, heil. $337 \mathrm{ff}$.

Grab und seine Länge 237. 249. 254.

Grabschrift 19. 261

Graf Rudolf 11, 1 .

Gral 164. 314, 2.

Grammatik 4.

Grates usiae, Sequenz 48.

Gregor d. Gr. 46. 47.61. 193; Dial. 160, 4; Hom. 264, 2; Moralia 172. 184, 4.

Gregor, heil. 174.

Gregor VII. 42. 88. 198, 2. 281.

Gregor Hayden 327, 3. 328.

Gregorianischer Gesang 13,1. $52,1$.

Gregorius, Leg. 156, 1. 157. 268.

Greifen 241 f.

Griechische Kirchenlehrer $145,2$.

Griechischer Physiologus $103,1.225$.

Griechischer Roman 246, 1. 273, 6. 298, 7 ; s. Hellenismus.

Griechische Wundererzählungen s. Aretalogie.

Der große Alexander, mhd. Ged. 245, 5. 248.

Gualterus de Castellione 247.

Gualterus Mapes $316,1.2$. $318,1$.

Gudrun 105, 1; s. Atlakvipa.

Guido v. Lusignan 344.

Guillaume le Clerc de Normandic 114 .

Guntherv. Bamberg 1. 40-46.

Guot umb (durdi) êre nemen 286, 5. 320 .

Hademar v. Diezen 300.

Haimo v. Halberstadt, Kom1uent. z. H. Lied $27 \mathrm{f}$.

Hakensti] 179.

Hamburger jungstes Gericlit 133 f. 137,1 .

Hamlet 339. 
Hanns Froschauer 338.

Hanns Othmar 338.

Hans Folz 328.

Hans Sachs 249. 328.

Harfe, Harfenspiel 286, 5. 303. 311. 319. 324.

Hartmann, Mönch in St. Gallen 173,6 .

Hartmann v. Aue 160, 4; Armer Heinrich 195, 3; Büchlein 195, 3; Erec 84, 1. 250. 285. 309; Gregorius 195, 3. Iwein 309. 343, 2.

Hartmanns Rede v. Glauben (Credo) 48, 5. 62-65. $117,3.184$. 190, 1. 191, 2.

Hastings, Schlacht 262, 1.

Heidin, mhd. Ged. 250.

Heilka, Klosterfrau 163.

Heilsmittel 167-206.

Heimkehrsage 298, 7. 339, 1.

Heinrich Il. 42. 279 f.

Heinrich llI. 19. 42. 44. 280.

Heinrich IV. 19. 42. 146. 233. 280.

Heinrich der Löwe 258, 1.

Heinrich der Stolze 258f. 280.

Heinrich v. Melk 117, 3 . $160,4.173,2$. 174, 2 . 185. 186-194. 199, 6. 206, 1 . (s. Nachtr.).

Heinrich v. München 284.

Heinrich v. Veldeke 193, 5. 267, 2. 284. 315 .

Heinrichau, Kloster $329,18$.

Heinrichs Litanei 121. 123, 6. 159. 169. 172-175. 179 . 182,4 ; s. Litanei.

Heldenbuch $338,2$.

Heldenepos, -sage, -sang 42. 74.89. 105,1.116.252.267,1; s. Spielmannsepos.

Henrich, Schreiber 126.

Helena, heil.153.268.338.342.

Helena, Raub 287.

Helgi Hjorwardssohn 341, 2;

Helgi Hundingsbana 341, 2.

Hellenismus 254; hellenist. Roman 283.

Heptaden s. Siebenzahl.

Heraclius und Cosdras 151. 152. 268. 274.

Herborts Trojanerkrieg 132,1.

Herder 150, 1.

Hermannus Contractus 3,2 . $137,1.214,4$.

'Herren' als Anrede 120.

Herr und Knecht 190. 196198.

Herodes 157.

Herodot 225.

Herrad, Aebtissin 30, 8.

Hester u. Mardocheus, lat.Ged. 108.
Hexameter 142, 2. 163, 8 .

Hieronymus 132. 133; Bibelübersetzung 219; Weltchron. $112,3.147,2.269$ f. $272,1$. 275, 1; Engelchöre 92, 3 ; Psalmenkommentar $226 \mathrm{f}$;; benutzt Physiologus 226; angerufen in d. Litanei 174 .

Hieronymus v. Kardia 101.

Hildebertus 226, 3; Moralis philos. 198,1; Sermones 115. 197, 1. 205.

Hildebrandslied 104, 1. 285. 290.

Hildegard, heil., Gebetbuch 215.

Hildesage 252,1. 298, 3. 331, 5; s. Kudrun.

Himmel und Hölle 42. 117. 120. 134-138. 141. 161. 188; s. Die Wahrheit $194,1$.

Vom Himmelreich 140 142 (s. Nachtr.).

Himmelszeichen 71, 4.

Himmlisches Jerusalem = Himmelreich 100. 115; die himmlische Stadt 139. 201 f; s. Jerusalem.

Himmlisches Jerusalem, Ged. 138-140. 267. 284, 2.

Hinde, verfolgte, Sage 331, 4.

Hiob, Kürze des Lebens 189.

Hippocrates 234.

Hirsaul, Kloster 1. 2. 43.

Hirschherzen, Fabel vom 268.

Historia de preliis $239,4$. 245 ff., s. Leo, Archipresb.

Historienbibeln 249, 1.

Hochzeit 32. 112. 200-206.

Die Hochzeit 31, 2. 74. 200-206 (s. Nachtr.); vgl. 196-200. 227. 287, 1 .

Höfisches Leben, Kunst 85. 156. 158. 187, 6. 189 f. 190. 193. 195, 3. 235. 248. 251. 252. 283. $306-310$. $319,1$. 320. 323. 325. 333.

Hohenburg, Kloster 30, 8.

Hohes Lied 204 f. 209; s. Cantica canticorum, Williram, S. Trudperter HL.

Holofernes 103-108.

Honigfluß 161.

Horaz 191, 1.

Horen 73.

Honorius Augustodunerisis 5. 47. 55. 192; De imagine mundi 71,4 . $72,4.112,3$. 232, 1. 2; Elucidarium 72, 4. 203, 1. 205, 1; Expositio in cant. 24.1 . $27,4.100,3.5$. 127, 1. 203, 1. 205; Gemma animae 72,4 . 124, 3; Sacrament. 115; Spec. eccl. 14 . $25,1.45,2.48 .50 .54,4.72,4$. 75, 4. 76, 1. 100, 5. 103; 1 . 106. 114. 115. 124, 3. 136 . 137. 151,5 . 179, 2 . 185,3 . 197, 1. 199. 205. 211. 222, 4 . $264,2$.

Hrabanus Maurus 114. 127, 1 ; Aeterne rerum cond. 49, 6; De cler. inst. $14,3.15,3$. 156, 2; De laudibus S. Crucis 44, 4. 47, 2. 49; De Universo 80; Computus 71, 4 ; Komm. z. Gen. 80; zum Matth.67,2; Litanei 173,6 .

Hrotsvitha, Ev. Pseudo-Matth. $219,3$.

Hugdietrich 287, 1.

Hugo v. Folieto 139.

Hugo v. Langenstein, Martina 227.

Hugo v. St. Viktor 5. 6. 34. 56. 117, 1; De quinque sept. 67, 2. 119; De sacr. 61. 76. 198; Summa sent. 61; Tobias 113f.; Tugenden 119, 2. - Appendix 76, 1; PseudoHugo 76, 3; De claustro animae 139,2 ; De fructibus carnis $198,1$.

Hugo v. Trimberg, Renner 114. 187,6 . 227. 233, 1. 250. 312. hulde $304,1$.

humilitas, Fürstentugend 256,1 .

Hymnen 11, 1. 41, 3. 44, 4. 48. 49 . 55,2 . 56. $57,2.72$. 73. 74. 90. 99, 4. 136. 139, 2 . 143. 170,5. 182,7. 206-217. Hyperbel 102. 105. 266. 312.

Jacobus, Apostel, Schutzpatron 184.

Jacobus a Voragine, Legenda aurea 182,7 .

Jahreszeitmythus 339, 1.

Jakob, Erzvater, = Anschauung Gottes 82 ; der fromme Hirtenknabe 93; Segen 93; Tod 82; Totenklage 85.

St. Jakobskloster in Regensburg 163, 6 .

Jansen Enikel, Weltchron. 78. 129,1 . 157, 4. 241, 4. 248, 4 . 249. 284.

ldsteiner Sprüche der Väter 78.

Jenseitsvisionen 9. 160-167; s. Nachtr.

Jerusalem, = Babylon 136. 137; Königreich 344 ; Zerstörung 128. 151.

Imperfecti $203,1$. 
Imperlum sacerdotium 265 . 278.

Imrama 165 f. (s. Nachtr.).

Inclusa 117. 298, 7.

Indien, Wunder 237. 247. 254.

Innsbrucker Arzneibuch $67,1.234$.

Innsbrucker Kräuterbuch 67, 1. 234.

Insel der Seligen 165.

Instrumente $285,1.288$.

Interlinearversion $142 \mathrm{f}$.

Interpunktion 137, 4. 140, 2.

Joachim und Anna 218-224

Johann Hartlieb, Alexander 245, 5.248; Brendanus 166,2.

Johannes Eremita 208.

Johannes Evangelist 152.174; Reimgebet 171 .

Johannes Rothe, Passion $157,4$.

Johannes d. Täufer, Leg. 151 $151,5.152$; Reimgebet 171 ; vornehmster Heiliger 123, 6 . $169 ;$ s. Priester Adelbrecht Ava, Baumgartenberger Joh. Bapt.

Jongleur 289,3 .

Jordansegen 95, 2.

Joseph in d. Wiener Gen. 79 83. 84. 85 f.; Vor. Gen. 93. 97. $98 ;=$ Unschuld 76 . Joseph Năhrvater 217-224. Josua 70; Josua - Jesus 95, 2. Jourdain de Blaivies 314, 2 . 340.

Iris 140 .

Irische Literatur 160-167.

Irische Volksmärchen vom Totenreich 164 .

Isaak $=$ Freude 82; Segen 91 . Isidor, Etymol. 67, 2. 80. 92, 3 . 227. 231. 232. 232, 1. 2. 233. lsland, Zustănde 232. 233.

Isländ. Physiol. 226.

Itala 108.

Italien. Markolf 327

Iter ad Paradisum 247.

Itinearium Alexandri 247.

Judas $165.180,182,8,193$; Judas Ischariot, Sage 156, 1 .

Das Jüdel 17.

Judith, ältere 103-108. 140 , 1. 289.

Judith, jungere 108-110.

Jugurtha 129.

Juliane, Leg., s.PriesterArnold.

Julii Valerii Epitome 246.

Julius Valerius $245 \mathrm{ff}$.

Jungfräul. Geburt 206-224.

Die drei Jinglinge in

Feuer of en 73.102 f. 177,6 .

178. $179,2.180,5$.

Jüngstes Gericht 65.81 .
116-121. $121 \mathrm{f} .132 .133 \mathrm{f}$. 160,4 . 177. 179. 181. 182. 201. 202. 202, 2. 3. 4. 203. 218 ; s. Ava, Friedberger Christ u. Antichr., Hamburger jüngst. Gericht.

Jünyster Tag 76. 204.

Der Junker u. d. treue Heinrich 250.

Justi 203, 1.

Justitia, Fürstentugend 256, 1 . Justinian u. Tharsilla 269. 273, 10. 276. 283.

Justinus, Chronik 147. 247. Juvenal 191, 1.

Kabbalistische Schriften 315.

Kain - Seth = Kinder des Teufels - Kinder Gottes 81 .

Kaiserchronikvom Pfaffen Konrad 9. 65, 3. 72, 7 . 124. $138,4.139 .145,1$. 147,7 . 153. 155. 184, 4 . 231, 3. 248, 6. 251, 1. 255, 8 . 266. 267-284. 302. 311 . 342 ; s. Rolandslied (s. Nachtr.).

Kaisergeschichte, römische $u$. deutsche 236.

Kallisthenes 246; s. Pseudokallisthenes.

Kaltschmicde 83

Kampfschilderungen 109. 149 f. $239,5.240 .243 .244$ f. 258. 265. 272. 282.284. 305. 319. 323. 333.

Kanon der bibl. Schriften 47, 4 . Kanoniker 42-45. 52.

Karl d. Gr. 22. 255-267 (Rol.lied). 269. $277-281$. 292 . 301. 302. 343

Karl d. Kahle 261, 3 .

Karlmeinet 255, 8.

Karthäuser 2.

S. Katharinen Marter 17.

Keronische Glossen 231, 3. Kerzenweihe 170

Kirchenlied, lat. 210. 213, 3.

Kirchweihe s. Dedicatio ecclesiae.

Klage 84. 86; am Kreuz 118 119; klagen 175, 2; s. Sündenklagen, Totenklage. Klagenfurter Gebete 171 . 184.

Klciderluxus 194, 3.

Kloster Bergen bei Neuburg $30,8$.

Klosterleben 36-39. 42.

Kiosterschtiler 140, 5 .

Kola 137, 2. 138. 192.

Köln 144-151; Lirbauung 112.

Konrad, Pfaffe s. Rolandslied, Kaiserclıronik.
Konrad v. Fussesbrunnen, Kindheit Jesu 17.217. 222,6.

Konrad v. Göttweih 44.

Konrad v. Heimesfurt, Urstende 17

Konrad v. Megenberg 227.

Konrad v. Windberg 163.

Konrad v. Würzburg, Engelhard 249; goldene Schmiede 9, 1. 209, 1; Silvester 277, 1; Troj. Krieg 249.

Koptisches Evang. De nativitate Mariae 219, 3.

Kosmologie $140 \mathrm{f}$; s. Merigarto.

Kräuterbücher 234

Kreuz, die 4 Enden 127.

Kreuzauffindung 151. 152. 268. 339,1 .

Kreuzesdichtung 49, 1 .

Kreuzesholz, Leg. 151, 5.

Kreuzeshymnus 49.

Kreuzesklagen 120 .

Kreuzfahrt (a. 1064) 44-46.

Kreuzreden 263, 2.

Kreuzpredigt 263, 2. 301.

Kreuzritter 90. 258, 1. 263, 2. 301.

Kreuzzüge, Pilgerfahrt 43-46. 106. 165. 235. 264. 269. 282. 299. 301. 322. 336. 341 .

Kreuzzugsepik 90.

Kriembild 84, 2.

Kritiker, übelwollende 108 .

Kudrun 85, 3. 105, 1. 252, 1. 286 , 5. 294, 1. 295, 1. 298, 6 . 314,1 . 335, 1. 339, 1. 341, 3.

Kudrunstrophe 216.

Kunst, bildende 9. 46. 124, 3 . 227 f. 250. 330; roman. Kunststil 51 ; s. Bilderhss.

Kürenberger 221. 332, 3 .

Kynegils, König v.Wessex 330 .

Kyniker 9. 254.

Kyrieleison 173. 174.

Lactanz, De opificio Dei $\varepsilon 0$.

Laienbruder 187, 6 .

Laieninvestitur 83.88.

Laienpredigt $72,1$.

Lambert v. Hersfeld 148. 148, 2.

St. Lambrechter Gebcte 169 f. 172; s. Mariensequenz.

Lamentatio, lamentum 175, 2. 176.

Lamm $=$ Sanftmut 146.

Lampreclit, Pfaffe s.Alexanderlied, Tobias.

Land der Verheißnng 166.

Landleben 86.

Länderkunde 251.

Lanfranc 4. 19. 22.

Langobarden, Geschiclite $296 \mathrm{ff}$.; histor. Lleder 297, 1 . 
Lapidarien 139. 226. 234; s. Edelsteine, Prüler Steinbuch. Lasterkatalog 177.

Lateinische Wörter, Sätze, Zitate 50. 51. 57. 63. 66 . 73 f. 87. 91. 93, 3. 95. 101 . 102. 103. 107. 110, 3. 115, 2 . 120. 122. 123. 125. 127 . 131. 132 f. 139.142 .152 . 153. $155,1.4 .162 .163$. 164, 4. 174. 178. 179. 181 . 186. 192. 193. 194. 195. 200. 204, 1. 211. 213. 214 . 217, 1. 222. 241, 1. 243. 244. 266. 311, 1 .

Laudate Dominum 70-74. 267.

Laurentius, leil. 174.

Lazarus, armer 151. 177, 6.

Lea u. Rahel 76.

Lebermeer 165. 232. 232, 2. 4. Legendar, mfrk. 129, 1 . 143. 151 f. (s. Nachtr.). 272,3

Legenden 18. 108. 114. 123. 143-160. 208. 268. 270. 290. 344, 1; LegendenstilForm 123. 155; Technik 121,4 ; s. Aegidius, Albanus, Andreas, Anno, Bonus, Brandan, Christophorus, Faustinianus, Gregorius, Juliane, Kreuzesholz, Margarete, Mariae transitus, Orendel, Oswald, Patricius, Petrus, Pilatus, heil. Rock, Scliottenlegende, Servatius, Sieben Schläfer, Silvester, Thomasleg., Tobias, Veit, Vergogna, Veronica, Veronilla; s. Märtyrerleg., Mönchsleg.

Leich 213.

Leichenpredigt $85.190,2$.

Lektionen 87

Leoninische Hexameter 20. 226.

Leo, Archipresbyter 239, 3. $246 \mathrm{f}$; s s. Hist. de preliis.

Leseepos 235. 288. 298.

Leviathan 47. 122.

Liebesgruß 337.

Liebeslieder 193.

Liebeszauber 324, 2.

Lied, Volkslied, Ballade 104. 106. 184, 4. 188. 192. 193. 217-224 (bes. 219, 2); episches Lied 101. 105. $107 \mathrm{f}$. 108. 110. 234. 273. 274, 4 . 281. 284-290. 297. 298. 334 f.; geistl. Spielmannslied 104 .

Linzer (Gleinker) Antichrist $132 \mathrm{f}$.
List 305.

Litanei 14.173. 173,6; s. Heinrichs Lit.

Liturgie 65. 75. 167, 2. 171 . 173. 182, 8; liturg. Vortrag $11-15$. 51, 5. 52. 182, 7 . Livius 270

Das Lob Salomons 99-102. 102. 103. 267. 284, 2. 289. 289, 2.

Lobgebet 168,1 ; s. Gebete.

Logik 3.

Lothar, Kaiser 258. 278. 280.

Lothringen 1.

Löwe $=$ Kraft 146; $=$ Christus 228.

Lucan 150.

Lucia, heil. 35.

Lucidarius, deutsch $71,4$. 203, 1. 205, 1.

Lucifers Fall 76. $79.81,91$. 92. 200-206.

Ludwig v. Arnstein, Graf. 212.

Ludwig Tieck 312 .

Ludwigslied 263, 2.

Lupus v. Aquitanien, Herzog 261,3 .

Madelger, Schmied 259.

Magdalena, heil. 63. 118. 120. 171. 174. 184.

Magnetberg 165

Makkabäer 115 f.

Manigolt, Priester 219.

Manna $=$ Leib Christi 94.

Marbod v. Rennes, Edelsteine 139; Oratio poenit. 177.

Marcellus, Petrus- u. Paulusakten 152 .

Märchen 108. 154. 287. 332, 3. 334.339;vom Eisenhans 340; von Salomo u. d. Drachen 108; vom Schlaraffenland 160,4 .

Marcus, Frater $163 \mathrm{f}$.

Margaretha, heil. 144. 174; Leg. 158 f.; S. Marg. Marter, püechlein, Passie 159, 5

Maria v. Aegypten 63. 179, 2. Maria u. Martha 37. 76. 118.

Mariä, 7 Schmerzen 67.

Mariae transitus, Leg. 151.

Marienantiphone 208.

Mariendichtung 206-224; Maria in Gebeten 167175.

Marienfeste 206 f. 208. 213. 214. 222.

Mariengebet in höf. Stil 171.

Marienideal 180.

Marienkultus 206, 3

Marienlob, Ged. 95. 96, 2. 98. 99. $216 \mathrm{f}$.

Marienlob, Versgebet 171.
Mariensequenz 14

Mariensequenz von $S t$. Lambrecht 213-215.

Mariensequenz von Muri 170. $215 \mathrm{f}$.

Mariensymbolik 9, 1.98. $209 \mathrm{ff}$. Marner 312

Maronia $300,2$.

Marquard Freher 20. 21.

Martin, heil. 66. 174.

Martin Opitz 144.

Märtyrerlegende 102. 103.123. 123, 6. $142-160$. 265. 268. 344,1 .

Mathaeus Vindocinensis 114. Maximian 155 ; s. Diocletian. mâze 253.

Medizin. Literatur 234.

Meginhart, Bisch. v. Würzburg 233.

Melito 152

Melk, Kloster 116 f.; Annalen 116 f.; Necrologium 117; s. Heinrich v. Melk.

Melker Marienlied 120. 123. 210-212.

Memento mori $2.3,2.188$. 189.190; Ged.14.184-186; s. Askese.

Menrad Molther 21

Menschenalter 71 .

Menschheitsgeschichte 46. 65 . 99. 145 . 146.

Meran 298--300.

Mercurius 326

Merigarto 231-234.

Messe 74 f. 82. 167-175. 193; Meßgebete $171 \mathrm{f}$. ; Meßopfer 41, 3. 94. 188 f.; s. Deutung der Meßgebräuche.

Messegesang $170.171,3$. 172.

Metrik 11 f. u. Nachtr., sowie bei den einzelnen Denkmälern.

Michael, heil. 63. 165. 169. 171.

Michel Wyssenherre 298, 7 .

Michelsberg b. Bamberg 44 .

Milstäter Sündenklage 72. $162,1.177$ f. 180 f.

milte 304.

Mimus 286. 288.

Mineralogie 139.

Minne 252. 268. 283. 287. 308. 309. 315. 333.

Minneburg, mhd. Ged. 250.

Minnesang 39. 92. 171. 193 206, 3. 221.

Miracula $44 \mathrm{f}$

Mischprosa 20-29.

Miserere 167, 3. 176. 181. 185.

Mittelvokal 138, 4.

Mittwoch, krummer 72, 2. 
Modus qui et Carelmanninc 48.

Mönchslegende 143.

Mönchsorden 1-3. 210.

Mönchspredigt 195.

MonopodischerVersbau 223,1.

Moraliter et spiritaliter 92, 2.

Morgensegen, Morgengebet 167, 3. 169. 170.

Moritz v. Craon 284.

Moritz v. Schwind 313, 1.

Morolfstrophe 345, 4.

Moses, Himmelfahrt 95; M.s Stab $=$ Kreuz 94.

movere, flectere(Rhetorik)186, 2. 191.

munt 304, 1.

Muri, Kloster 170; s. Mariensequenz.

Muri-Gries, Kloster 170.

Muri, Gebetbuch 170.

Muri-Engelberger Mariengebet 171 .

Musik $13 \mathrm{f} .210 .216 .217$. 286,5 . 288; s. Harfe, Instrumente.

Muspilli 136. 141, 7. 185, 3. Mystik 4. 6. 7. 22. 27. 28. 29-39. 47. 56. 67. 76. 90. 92. $117,1.119 .139$.

Mythologie 247. 339, 1.

Nabuchodonosor 102-110.

Nachtigall, Frau 335.

Naturlehre s. Kosmologie.

Naturwissens chaft 224 234.

Neumen 14.

Negative Veranschaulichung 90.

Nektanebus 241. 245. 247, 2. 250.

Nestorianischer Streit 206.

Nibelungenlied und Sage 84 , 2. 3. $105,1.116 .149,1$. 251,3 . $261,3.267,2$. 286, 5. 287,1 . 288,1 . 289,3 . 293. 298, 3. 309, 1. 324 . 335,1 . 336,2 . 345,5 .

Nicolaus, heil. 174. 212.

nidare 108.

Niederd. Sprachgrenze 291, 4.

Nîmes 154 .

Nimrot 112,3 .

Ninive, Gründung 112. 147,2.

Ninus 112. 145. 147. 149. 270.

Noker 184.

Nonnen 29-39.

Norbert, hell. 2. 77, 2.

Noten 210.

Notker Balbulıs, Lilanel173, 6 .

Notker Labeo 4. 5. 20. 27. 29. 184; Boethius 231, 4.

232. 3. 4; Psalmen $226 \mathrm{f}$. 326. 327,1 .
Novelle 143. 156. 270. 273. 276. 278 .

Oblati 187, 6 .

Oboedientia 256, 1

Occidratis (Oxidraces) 237. 254.

Ochsenhausen, Kloster 40. 43

Odilienberg, Kloster 30, 8.

Odilo v. Clugny 1.

Odo v. Clugny 1.

Odyssee 167. 251, 5 .

Oedipussage 156.

Officium b. Mariae 207. 208. 209, 2. 212, 8 .

Onesikritos 254,3 .

ordenunge 197, 2; ordo 197.

Ordnungen des menschl. Lebens 196.198.

Orendel 287, 1. 289, 3. 290. 301 f. $311.312,1$. $314,2$. 327,5 . 332,2 . 335,1 . 336 , 2. $337-345$.

Origenes 27.225

Orosius 147. 245. 245, 5. 247.

Ortnit 287, 1. 297, 1. 335, 1 .

Osanctrix $293 \mathrm{ff}$

Ospirin 292, 3. 297, 3.

Ostgot. Heldensage 300,2 ; Sprache 297, 3 .

Oswald 160,4. 162,2. 287, 1. $290.294,1.301$ f. 311 . 328-337. 344. 345 .

Otegebe, Klosterfrau 163.

Otfrid 11. 11, 2. 44, 4. 133, 4. 136. 141. 141, 4. 149. 248. Otloh 5. 79, 4. 80, 4 .

Otte, Meister 284.

Otto v. Bamberg 2.

Otto v. Freising 3, 1.

Ovid, Ars amatoria 268.

oŵे 111; owê 191 .

Ozias, jüd. Fürst 105.

Pädagogik 276, 4.

Padua, Gründung 147, 2.

Palladius 247.

Pancratius, heil. $341,2$.

Pantler $=$ Cristus $228 \mathrm{f}$

Pantschatantra $314,1$.

Parabel 196-206.

Paradies, vier Flüsse 40. 161 ; Garten 80,1 ; irdisches 237 -255 .

Paschasius Radbertus 206.

Passional, mhd. 162, 3; nd. 166, 2.

Passionsspiel s. Benedictbeurer Ludus pasch.

Das Paternoster66-69.70.

Patricius, Leg. 160, 4. 162 (s. Nachtr.). 164; Purgatorium 161 .

S. Patrick 162
Paul Gerhardt 170, 5

Paul Heyse 238, 2.

Paulinus v. Aquileja 176.

S. Paul, Kloster in Regensburg 163; in Sieiermark $43,2$.

Paulus. Apostel, Bekehrung (Fest) $182.182,7$; s. Cantilena de conversione S.P., Rheinauer P., Visio S.P.

Paulusapokalypse 160.

Paulus Diaconus, Hist. Lang. $296 \mathrm{f}$.

Paulus Merula 20. 21.

Pax u. discordia 277, 3.

Pelikan = Christus $229 \mathrm{f}$.

Peredeo 297, 1. 299, 3.

Perfecti 203, 1.

Perikopen 47, 2.

Petrus, Leg. 151.

Petrusapokalypse 135. 160.

Petrus-, Paulusakten 152.

Petrus Alfonsi, Discipl. cler. $249,6$.

Petrus Damiani 3, 2. 136. 177. 207 f. 209 f.

Petrus Lombardus 5. 55.

Petrus, Zöllner 63.

Pfaffendirnen 189. 192.

Pflicht $196 \mathrm{ff}$.

Pharmazeut. Pflanzen 234.

Philo v. Alexandrien 8,1 .

Philosophen - Theologen 5. $64,5,239,4$.

Phönix 201. 227. 230.

Physiologus 9. 10.46.139. 204, 3. 224-231.

Pilatus, Leg. 144. 157 f. s. Christus u. P.

Pippin, Vater Karls d. Gr. 292. 301. 302, 1.

Placidus 234.

Plato 24. 253

Plinius d. j. 225. 234.

Plural, kollektiver 49, 9. 57. 120. 131. 171, 3.

Poctik 9, 2. 11, 1 .

Pompeji 150.

Pönitenzgedichte $176 \mathrm{f}$.

Portugies. Sage 316, 2.

Prämonstratenser 2.77,2. 163. 207. 210. 212.

Prediger 92. 97. 129. 253, 2 ; s. BuBprediger.

Predigt 14. 18. 24. 25. 39. 50 $52,3.61,1.72,1.74 .75$. 82, 3. 85. 86. 87. 113. 115 . 133. 137.141.143. 146.151,5. $179,2.182,1.5 .7 .184-206$ 208. 211. 222, 4. 227, 4. 230. 249. 263, 2. 264, 2. 281; gereinte Pr. $75 ;$ s. Bußpredigt.

Predlgtstil 83. 87. 90. 95. 113 . 
133. 155. 186. 192. 194. 230. 253, 2. 265. 266.

Priesterleben von Heinrich v. Melk 186-194.

Priesterkleidung 74, 3 .

Protevangelium Jacobi 219, 3 .

Provenzal. Physiologus 226.

Prozessionen 173.

Prudentius 41, 3. 44, 4. 48.

Prìler Kräuterbuch 234.

Priiler Steinbuch 234.

Psalmenübersetzungen $142 \mathrm{f}$.; $\mathrm{s}$. Windberger Ps.

Pseudo-Abdias 152. 155.

Pseudo-aristotel.Schriften 234.

Pseudo-augustin. Predigten 141.

Pseudo-Chrysostomus 133, 3 . 228 f.; s. Dicta Chrysostomi.

Pseudo-Evangelium Matthaei 219-221.

Pseudokallisthenes 241, 3 . $246 \mathrm{ff}$.

Pseudoturpin 261. 263.

Psychologie 34 f. 56; psycholog. Vertiefung 82, 3. 264.

Purgatorium S. Patricii 162.

Putzsucht 194, 3.

Pythagoras 24.

Quedlinburger Annalen 286,3.

Querela 175, 2.

Quilchinus v. Spoleto 247. 248.

\section{Raab 95.}

Rasosage 316. 320 .

rât 194, 3 .

Räte des heil. Geistes 63.

Ratgeber, treuer 298.303.320.

Ratpert v. St. Gallen $173,6$.

Realist. Stilisierung $82-84$. 86.

Recht 74 f. 185 . 196-206. 269. 279; mhd. reht 196. $198,1$.

Vom Rechte $74.75,1.83$. 177,2 . 185, 3. 196-200. $227,2$.

Refrain 210.

Regensburg 44. 163.259. 272, 3. 282.

De regimine principum 250 .

Reginald, Vita Oswaldi 330 . 331,5 .

Reginpreht, Pfaffe 232.

Reiche s. Arme.

Reichenau, Kloster 1.

Reim, dreifacher, s. Dreireim.

Reimbrechung 237, 2. 240, 2.

Reimgebete $167-175$.

Reimlektionen 87, 6.

Reimprosa 11, 2. 137, 2.
Reinmar v. Zweter 249 .

Reiseroman 251, 5.

Rekapitulierende Parenthese 124, 1.

Repgauische Chronik 236.

Responsorien 174.

Rezepte 234.

Rheinauer Paulus 177,6 . 178. 180 f. 181.

Rheinauer Sündenklage 183.

Rheinfränk. Interlinearversion d. Psalmen 142.

Rheinischer Spielmann 108. 300.

Rheinische Städte 147, 2.

Rheinlande, Literatur 289.

Rhetorik 15. 39. 266

Rhetor. Formeln 97, 1.

Rhythmik u. Methodik 11-15. $101,2.140,1$. 151, 1. 200, 1. 213. 216. $222,5.223,1$; s. Vortragsweise.

Richard Wagner $313,1$.

Richgards Feuerprobe 278.

Rilindis, Aebtissin 30, 8.

rime samenen - brechen 311 .

Ritterl. Morallehre 253.

Robert, Cistercienser 2.

Rock, heil. s. Orendel.

Rogationes s. Prozessionen.

Roger II. von Sizilien 258, 1.

Rolandslied vom Pfaffen Konrad 10. 65, 3. 72.89. 90. 102, 2. 106. 124. 162, 1 . 231,3 . 235. 237. $250 \mathrm{f}$. 255-267. 268. 282. 284 . 284,2 . 288. 302. 306, 2 . 311. 343 ; s. Kaiserchronik 267-284 (s. Nachtr.).

Rom, Gründung 147, 2.

Röm. Litanei 174, 1.

Rothari, Langobardenkönig 297.

Rother 249. 251, 1. 285. 286. $286,5.287,1$. 290-313. 335, 1 (s. Nachtr.).

Rudolf v. Ems 158,2. 200, 2 : Alexander 184, 4. 240. 245, 5. 247,1 . 248. 249, 5; Barlaam 187, 6; Weltchronik 3, 1. 112, 3. 232, 3. 236. 241, 4. 247, 1, 249. 267.

Rudolf v. Schlüsselberg 316 , 1. 2.

rüegen $175,2.177$.

Ruodlieb 286, 5. 287, 1. 334, 3.

Ruotger, Biograph Brunos 3, 1 .

Rupert, heil. $30,8$.

Rupert v. Deutz 7. 69. 99, 2; De div. officiis 87, 4; De Trinitate 93, 1. 94; ExodusKomment. 95, 2. 96.

Russische Salomosage 316 .
Saba, Königin 100. 101. 130. 326. 334, 2 .

Sachsen, Aufstand 261.

Sachsenspiegel 200, 2.

Sächs. Weltchronik 284.

Saladin 344.

Salmanassar 112.

Salman u. Morolf 100,8 . 287, 1. 290. 292, 1. 2. 311 . 312,1 . 313-328. 338, 7 . 345. 345,4 .

Salomo 99-108. 188. 225 . 239, 2. 267, 1. 298. 302 . 313-328.

Salomon et Marcolfus 325328.

Salomon u. Markolf 325 -328 .

Salve regina, Antiphone 208. 212,8 .

SalzburgerMeßgebet172.

Sammelhandschriften 15 $-17$.

Sandalen 110.

Saxo Grammaticus 286, 4. 293. 339. 340.

Schächer 63.

Schachspiel 256. 313.

Schatz, vergrabener 200,2 .

Schauen Gottes 136. 140.

Schauspiel, geistl. 120, 5; s. Benediktb. Ludus pasch., Benediktb.Weihnachtsspiel, Christi Höllenfahrt.

schîbe 127.

Schicksalsglaube 221. 286.

Schiffermärchen, irische $165 \mathrm{f}$.

Schlange, eherne $=$ Christus 94.

Scholasticus 47.

Scholastik 3-7. 235.

Schöne Seele 38.

Schottenklöster, Schottenmönche 163.

Schottenlegende, Regensburger 260, 2 .

Schottisches Volkslied $334 \mathrm{f}$.

Schreibernachschrift 126. 128. 184.

Schularbeit 140, 5 .

Schulgelehrsamkeit, -wissenschaft 1.5 .

Schwänke 287. 326.

Schwedische Ballade 334

Sedulius 48. 152. 208.

Seefahrtsgeschichte, irische $165 \mathrm{f}$.

Seele, Braut Gottes (Seelenbräutigam) $29-39.54 \mathrm{f}$. 56. 204 ; vgl. $200-206$.

Seelentrost 241, 5. 249.

Se elm es se, Anweisung 171.

Segen 234. 306, 1. 337; ad equum erræhet 104,1 ; $\mathrm{Ab}$ - 
schied $89.306,1$; Reise 169 ; Wurm 102; Jakobs 93. 98; Isaaks 91; Tobias' 72. 114.

Seghelijn van Jherusalem $342,3$.

Seifrieds Alexander 245,5. 248.

Semiramis $112,3.145 .147,2$.

Sennacherib 112.

Sententiae S. Patrum 78.

Sentimentalität, mittelalterl. 116.

Septuagesimae, Sonntag 264, 2 ; Septuagesimalzeit 87,4 . 115; s. Vorfastenzeit.

Sequenzen 99, 4. 210. 213. $213-217$.

Serbisch-bulgarische Salomosage 316.

Sermones ad status 185,3 . $197,1$.

Servatius, Wiener 139, 4 .

Servius, Komment. zur Aeneis 147.

Sibyllen, Weissagung 160, 4 .

Slebenzahlen 66-74.76 (Gebote).

Von der Siebenzah1 69 f.; s. Priester Arnold.

Sieben Bitten 67-69.

Die sieben Gaben des heil. Geistes 68-71. 95. 96, 2 . 117, 1. 118. 119. 216.

Sieben freien Künste 1.4,2.22. $64,5.71$. 233. 239, 4. 253 s. Trivium.

Die sieben Seligpreisungen 68. 119.

Siebenschläferlegende 268 .

Siegburg 148.

Sigebert v. Gembloux 27, 4 .

Sigfrid 261, 3. 309. 340.

Sigrdrifa $341,2$.

Silvester, Papst, Leg. $143 \mathrm{f}$. 152 f. 268. 273-277. 282, 3 ; lat. Vita 153 ;s. Trierer S.

Simonie 189.

Singen u. lesen 13, 2.

Singen $u$. sagen $13,2,57$.

Sinnbilder Mariens $209 \mathrm{ff}$.

Sirenen 165. 228. 338.

Skop 288 (Nationalsänger); 297 (Volkssänger); D e r Scopf von dem lône 65 f.; Skopidichtung 285; schopfpuch 231, 1 .

Skáldskaparmál 339.

sô, anaphorisch 120 .

Sokrates 24.

Sonntag 40, 52, 4 .

Speculum ecclesiae ed. Kelle 74. 115. 123,6. 133, 1. 134 197, 1. 222,4 .

Speculum humanae salvatlonis 137,2 .
Spervogelstrople 216.

Spielmann, Spielleute, Fahrende, Spielmannsdichtung 65. 66. 99-108. 110.128, 1 . 130 f. 149. 201. 206. 234. 235. 273. 275. 276. 281. 284-345 (311. 321); s. Volksepos.

Sponsusparabel 203, 1.

spottere 108 .

Sprichwort 192

Spruchdichtung 66 .

Stabreim 297.

Städtegriundung 145. 147, 2.7; s. 272,3 .

Stämme, deutsche 145. 147.

Stände, Entstehung 80; Unterschied 197.

Standesbezeichnungen, ritterl. 109.

Steinbiicher s. Lapidarien.

Stephanus, Märtyrer 174.

Stiftshütte, allegor. 94. 95. 96. 98.

Stil s. bei den einzelnen Denkmälern.

Stilarten, die drei, 15.

Stricker, Daniel 250; Karl 250. 259, 5. 260, 3 .

Ströme des Paradieses 40.

Sucton 270.

Summa Theologiae, theolog. Sunime 7. 22.60 .61 . 277.

Summa Theologiae 48,5 . 53. 53-58. 72. 102. 120 . 186. $198,1$.

Summarium Heinrici 232, 2 .

Sünden, Tugenden, s. die cinzelnen geistl. Denkmäler.

Sündenklagen 14.63. 171. 172. 175-184. 301

Susanna 169. 193.

Symbolik 8. 9. 45, 2. 46. 48 . 49. 54. 66-74 (Zalılen). 74. 76 81.94. 98. 101. 103, 1 . 114. 121. 127. 129. 168. 183. 198 (Zahl). 200 f. 203. 218. 225. 227. 249. 250. 263. 278; s. Allegorie.

Symeon monachus 330,1 .

Synagoga s. Ecclesia u. Syn.

Synode; Epliesus 206; Paris 207: Roin 88

Syrischer Pliysiologus 226.

$\boldsymbol{t}$-Versclicbung 291, 4 .

Tageszeiten, liturg. 167, 3.

Taglölınerinnen 192.

Talıudisclı-rabbin. Sage 100. 247. 254

Tänzer von Kölbigk 104, 1 .

Taufritus 264, 1 .

Tengeling 300 .
Terra repromissionis 166 .

Tertullian 226.

Theobaldus, Physiologus 226.

Theopliilus 63 .

Theudelinde 296.

Thidrekssaga 287, 1. 293 if.

Thomas v. Aquino, Summa Theol. 198, 1.

Thomas v. Cantimpré 227.

Thomasin, Wälscher Gast 250. 263, 2 .

Thomaslegende 160, 4 .

Thule 232, 3. 4 .

Tiber 157.

Tiberius 129 f. $268 \mathrm{ff}$.

Tiergeschichte, Tierdichtung 224-234.

Tiermenschen 165 .

Tiraden, afr. 238. 260. 266.

Titurel, jüng. 249 .

Titus 128. 268. 272. 275

Tobias vom Pfaffen Lamprecht 110-114. 238; Anrufung 169; s. Alexanderlied.

Tobiassegen 72. 114.

Töchter Gottes, vier 59, 2. 60. $198,1$.

Toskana 233.

Tote begraben 114 .

Totenklage 83. 85. 89. 90. 92. 123. 258. 262.

Totenreich 166.

Trajan u. die Witwe 268. 276; s. Nachtr.

Transitus S. Mariae von Melito 152.

Transmundus, Vita S. Albani 157

Traugemund, Pilger 338.

Treue, trinwe 47. $303 \mathrm{f}$.

Trier, Gründung 112. 147, 7 ; lieil. Rock $337-345$

TriererAegidius $153-\mathbf{- 1 5 5}$.

Tricrer Psalmen 143.

Trierer Silvester $\mathbf{1 5 2} \mathbf{f}$; s. Silvester.

Trierer Teufelsspruch 172.

Trinität, Trin.-formcl, Dreieinigkeit 7 f. 32.34 .54 .55 . 58. 59 f. 69. 71. 82, 92 f. 94. 95. 98. 99. 119. 134. 135. 168. 174. 177. 197, 3 .

Trivium, Quadrivium 1. 226. 253; s. Sicben freien Kiinste.

Troja, trojan. Kricg 147. 147, 2. 236.

TrostiuVerzweiflung 194 $-196$.

St.Trudperter Hoheslied 29-39. 127, 1; s. Hohes L. trittiet 193.

Tryphon 115.

Tundalus, Tuugdalus s. Die Vision des $\mathrm{T}$. 
Turpin, Erzbischof v. Rheims 261.

Turteltaubc $=$ Treue 227 (s. Nachtr.).

Uebersetzungsweise, geistl. 109. 239.

Ulixes 147.

Ulrich v. Eschenbach, Alexander $245,5.247,8$. 248.

Ulrich v. Gutenburg 249.

Ulrich v. Liechtenstein 249.

Ulrich v. Zazikhoven 164. 232,3 . $251,3$.

Unbefleckte Empfängnis 206.

Unschuldige Königin 268.269. 278.

Untreue 255-267.

Uolricus dictus Wildenmann $128,1$.

Upsalaer Beichte 183.

Upsalaer Frauengebete 171. 184.

Ursperger Chronik 112, 3.

Utrecht 44. 232.

Vanitas 236. 253.

Vatikanische Gebete 170.

Veit. heil. 124. 155.267. $284,2$.

Venantius Fortunatus 49. 208.

Vergogna-Leg. 156, 1.

Verlöbnis 84 .

Verlobungsgeschichte 206.

Verlobungsring 201.

Verlorener Sohn 177. 179.

Vermählungsgebräuche $2 \mathrm{CO}$ 206.

Veronica, Leg. 126-132. 151,4. 152. 157. 157,4. 268. 273. 274.

Veronilla, Leg. 151.

Versus de poenitentia $176 \mathrm{f}$.

Vespasianus 126 ff. 268. 269. 275.

Vienne 157.

Vierzahlen 127.

Vierzehn Nothelfer 330.

Vincenz v. Beauvais 227. 248.

Virgil, Aeneis 147. 150. 166.

Virginal 250.

Visionen 135, 2. 146. 160167. $190,1.324 .337$.

Visio Fulberti 160, 4.

Visio Lazari 161, 5 .

Visio S.Pauli 161f.181-183.

Die Vision des Tundalus 160 , 4. 161. 162-165 (s. Nachtr.); s.Alber,Tnugdalus.

Visio Wettini von Walahfrid Strabo $160,4$.

Vogel als Bote $334 \mathrm{f}$.

Volksbuch: Brandan 166; Salomon u. Marcolf 328 .
Volksdichtung s. Spielmannsepos; volkstüml. Stil,Volksepos 82-86. 91. 92. 131. 149. 150. 191. 194. $234 \mathrm{f}$. 243. 244. 249. 263. $310 \mathrm{f}$. Volkslied s. Lied.

Volksmedizin 234 .

volkwîc 245.

Vorau, Kloster 16. 43

Vorauer Bücher Mosis 91-99. 110. 120. 194, 1. 216; Vor. Genesis 53. 91-93. 97; Vor. Moses 88. 93-95. 96, 2. 97.

Vorauer Sündenklage 62. 171. 176. 177 f. $178-180$. 212,7 .

Vorfastenzeit 87,7 ; s. Fastenzeit.

Vortragsweise $11-15.214 \mathrm{f}$. 230. 288; s. Rhythmik und Melodik.

Wace, Rou 262, 1.

Die Wahrheit 53. 63, 1. 194.

Walahfrid Strabo, Komment. zur Genesis 80,2; s. Visio Wettini.

Walküre 340.344.

Waltharius 287,1.292,3.297,3.

Walther v. d. Vogelweide 44,4 . 49,5 . 184, 4. 197, 2. 250.

Wartburgkrieg 166, 2.

Wasser des Lebens 246, 1.

Wasserprobe 218.

Weißenburger Katechismus $68,1$.

Welf IV., Herzog 299.

Welt, die dritte = Mensch 145 .

Wcltalter 71. 145. 201. 269.

Weltgeschichte 8 . 71. 81. 82 . 112, 3. 144-150. 248. 269 . 281.

Weltordnung 197.

Weltreich 147. 160,4. 248. 252.

Weltstaat s. Gottesstaat.

Wenilo, Erzbisch.v. Sens261,3.

Wenzel v. Böhmen 248.

Werbung $105.200 \mathrm{ff} .284 \mathrm{ff}$.

Werner v. Elmendorf 198, 1 .

Wernher v.St.Blasien 72,4.205.

Priester Wernher, Drei Lieder von der Jung. frau 10. 217-224.

Wernher vom Niederrhein 126-132.

Wessobrunner Beichte I 161 $194,3$.

Wessobrunner Gebet 71, 4.

Wido von der Bretagne, Graf 77.

Wiederholung 87, 3. 103. 107. 133. 152. 186. 243, 2. 283 289. 311. 314. 317. 318. 336 .
Wieland der Schmied 313,1 .

Wien-Milstăter Genesis u Exodus 62. 78-91.91. 109. 110. 220.

Der wilde Alexander 128, 1. Der Wilde Mann 126-132. 151,4

Wilhelmv.Conches 71,4.141,1.

Wilhelm v. Hirsau 5. 43.

Wilhelm v. Tyrus 327, 2.

Wilkina Saga 293.

Wille, Mönch (Abt?) 41. 44. 45. 52.

Willirams Paraphrase des Hohen Liedes 4. 18-29. 42. 76, 2. 100, 3. 4. 127, 1. 205.

wîlscelde 277.

Windberg, Kloster 163; s. Konrad v. W., Windb. Psalmenübers.

Windberger Psalmenübersetzung 140. 142. 143. 163.

winescaft 135, 1.

diu wise 52.

Wodan, Mythus 329, 19; Wodans Tag 72, 2.

Wolbero, Abt 30,8 .

Wolfdietrich 294, 1. 298, 3. 300. 301.

Wolfenwerd 252, 1.

Wolfhart 305, 4.

Wolfram v. Eschenbach 110, 2. 158, 2; Parz. 164. 202, 1. 227, 5. 249. 309; Willeh. 263, 2. 267; s. Gral.

Wortspiele 192.

Wulfstân 48,5 .

wunderlich 251. 252.

Wurmbesegnungen 102.

Würzburg, Bischofsstreit 233.

Xanten, Gründung 147, 2.

Zahlensymbolik s. Symbolik.

Zaubergesang 324.

Von den Zehn Geboten 75-77.

Zeilenstil 51, 3.

Zeitangaben in d. Erzählung 120.

Zeitschrift für Einsiedler 313,1.

Zoologie 224-231.

zuht $307 \mathrm{f} .333$.

Von der $Z$ ukunft nach dem Tode 161 f. 205, 1.

Züricher Arznelbuch 234.

$Z$ üricher Gebet 170. 171.

Zweifel 195.

Zweigliedrige Ausdrücke

(Zwillingsformeln) 87. 90. 95. 102. 103. 127. 131. 150. 154. 158. 185. 222 . 243,3 . 266. 283. 312 . 


\section{Handbuch des deutschen Unterrichts}

begründet von Dr. Adolf Matthias, Wirklichem Geheimen Oberregierungsrat

I. Band:

1. Geschichte des deutschen Unterrichts von Wirkl. Geh. Oberregierungsrat Dr. Adolf Matthias. 1907. VIII, 446 S. Lex. $8^{\circ}$. Geh. M 98.-, geb: M 150.-

2. Der deutsche Aufsatz von Professor Dr. Paul Geyer. Zweite, verb. u. verm. Auflage. 1911. XI, 347 S. Lex. $8^{\circ}$. Geh. M 80.--, geb. M 130.-

3. Lesestücke und Schriftwerke im deutschen Unterricht von Gymnasialdirektor Dr. Paul Goldscheider. 1906. XIV, 496 S. Lex. $8^{\circ}$. (Vergriffen.)

11. Band:

1, 1. Einführung in das Gotische nebst Wörterverzeichnis von Professor Dr. von der Leyen. 1908. X, 181 S. Lex. $8^{\circ}$. Geh. M 50.-, geb. M 90.-

1, 2. Einführung in das Althochdeutsche nebst Wörterverzeichnis von Professor Dr. Georg Baes ecke. 1917. XI, 285 S. Lex. $8^{\circ}$. Geh. M 70.--, geb. M 115.-

1, 3. Einführung in das Mittelhochdeutsche nebst Wörterverzeichnis von Professor Dr. Friedrich von der Leyen. (In Vorbereitung.)

2. Grammatik der neuhochdeutschen Sprache von Professor Dr. Ludwig Sütterlin. Mit Anhang: Die deutsche Aussprache auf phonetischer Grundlage von Professor Dr. Theodor Siebs. (Erscheint 1922.)

III. Band

1. Deutsche Stilistik von Professor Dr. Richard M. Meyer. Zweite, verb. u. verm. Auflage. 1913. XI, 257 S. Lex. $8^{\circ}$. Geh. M 65.-, geb. M 110.--

2. Deutsche Poetik von Professor Dr. Rudolf Lehmann. Zweite, neubearb. Auflage. 1919. XII, 280 S. Lex. $8^{\circ}$. Geh. M 70.-, geb. M 115.--

3. Deutsche Verslehre von Professor Dr. Franz Saran. 1907. XV, 355 S. Lex. $8^{0}$. (Vergriffen.).

IV. Band:

1. Geschichte der deutschen Sprache von Professor Dr. Herman Hirt. 1919. XI, 301 S. Lex. $8^{\circ}$. Geh. M 80.-, geb. M 130.-

2. Etymologie der neuhochdeutschen Sprache. Eine Darstellung des deutschen Wortschatzes in seiner geschichtl. Entwicklung. Mit Index. Von Prof. Dr. Her man Hirt. Zweite, verm. Auflage. 1921. X, 438 S. Lex. $8^{\circ}$. Geh. M 98.-, geb. $M$ 150.-

3. Deutsche Sprichwörterkunde von Stud.-Dir. Dr. Friedrich Seiler. 1922. X, 457 Seiten Lex. $8^{\circ}$. Geh. M 110.-, geb. M 165.-. (Soeben ersdienen.)

V. Band:

1. Deutsche Altertumskunde von Professor Dr. Friedrich Kauffmann. I. Hälfte: Von der Urzeit bis zur Völkerwanderung. 1913. XV, 508 S. Lex. $8^{0}$ und 35 Tafeln. Geh. M 110.--, geb. M 170.-_- II. Hälfte: Von der Völkerwanderung bis zur Karolingerzeit. Mit 30 Tafeln. (Erstheint Sommer 1922.)

2. Religion und Mythologie von Professor Dr. Friedrich Kauffmann. (In Vorbereitung.)

3. Deutsche Heldensage von Professor Dr. Friedrich Panzer. (In Vorbereitung.)

VI. Band:

Geschichte der deutschen Literatur bis zum Ausgang des Mittelalters. Von Professor Dr. G. Ehrismann. I. Teil: Die althochdeutsche Literatur. 1918. X, 471 S. Lex. $8^{\circ}$. Geb. M 110. - geb. M 165. . - II. Teil: Die frïllmittellochdeutsche Literatur. (Soeben ersdhienen.)

C. H. Beck'sche Verlagsbuchhandlung Oskar Beck München 


\section{Einführung in das Althochdeutsche \\ nebst Wörterver-

GEORG BAESECKE, Geheftet M 70.-, gebunden M 115.-

"Mit diesem stattlichen Bande legt der Verfasser der Fachwelt eine gediegene, achtunggebietende und in lohem Maße anregende Leistung vor.... Das Werk baut sich auf Braunes ahd. Grammatik auf, aber es geht darüber hinaus, indem es nicht nur die tatsächlichen Spracherscheinungen verzeichnet, sondern vor allem den Zweck verfolgt, diese Erscheinungen $z u$ erläutern und $z u$ begründen, das Geschichtliche an ihnen zu verknüpfen, das neu Gewordene zu entwickeln." Monatsschrift für höhere Schulen.

\section{Deutsche Altertumskunde Von FR. KAUFFMANN. 1. Hallte: Von}

rung. Geheftet M 110.-, gebunden M 170.-. 2. Hälfte: Von der Völkerwanderung bis zur Karolingerzeit. Erscheint Sommer 1922.

„Der leitende Gedanke, wetcher der Darstellung zugrunde gelegt wurde, ist, eine zusammenlıängende, belebte Schilderung, die sich durch Form und Inhalt leicht einprägen läßt, und in reichlichen Anmerkungen die Literaturzitate und die nötigen Erläuterungen zu geben. Dem Verfasser ist es vorzüglich gelungen, durch seine von eingehendster Sachkenntnis und eigner Stellungnahme zeugende Darstellung zu fesseln, und es muß fast ein Genuß sein, sich durch solche Lektüre auf einen anregenden Unterricht vorzubereiten." Neue Jahrbücher für das klassische Altertum.

\section{Deutsche Sprichwörterkunde Von FRIEDR. SEILER. Geheftet} (Soeben erschienen.)

„Der gelehrte Verfasser des vorliegenden Buches trachtet in seinem großen Werk darnach, das Waclistum unserer Stoffsammlungen durch alle Jahrhunderte zu verfolgen und strebt nach einer erschöpfenden Bibliographie nach Art von Goedekes Grundriß.... Er bemüht sich erfolgreich, dem wichtigen Forschungsgebiet, dem er dient, sein früheres Anrecht auf die Schule wieder zu erobern. Das tut er, indem er den Hauptteil seines Buches auf Wesen und Wert des Sprichworts verwendet mit der Nebenabsicht, die tausendfachen Erscheinungsformen der Sprichwörter zu illıstrieren, wo die sprichwörtlichen Redensarten mit in den Kreis der Betrachtung treten. Eine solche Einführung in Sinn und Geist, auch in die Form der Sprichwörter weiß er belebend zu gestalten. Aus liebevoller Vertiefung in den Gegenstand hervorgegangen, wendet es sich hauptsächlich an alle Lehrer, denen es einleuchtet, welch reicher Arbeitsstoff für die Schule im Sprichwort liegt." Prof. Friedrich Kluge (Literarisches Echo).

\section{Etymologie der neuhochdeutschen Sprache ${ }_{\text {Dar- }}^{\text {Eine }}$}

stellung des deutschen Wortschatzes in seiner geschichtlichen Entwicklung. Mit Index. Von HERMAN HIRT. 2. vermehrte Auflage. Geheftet M 98.-, gebunden M 150.-

${ }_{n}$ Hirts Etymologie ist der erste umfassendere Versuch einer solchen Darstellung. Er glbt die wortgeschichtlichen Tatsachen nicht in Form eines etymologischen Wörterbuchs, sondern in zusammenhängendem Vortrag, so daß sein Buch vom Anfang bis zum Ende mit Spannung gelesen werden kann.... Ich möchte Hirts Werk in die Hand jedes für deutsche Sprache und deutschen Geist interessierten Gebildeten, insbesondere aber jedes Deutschlehrers und Deutschstudierenden wünschen als ein Buch, das mir in besonderem Maße geeignet scheint, den Sinn für die reizvollsten Probleme des Sprachlebens zu wecken und wachzuhalten. Prof. Frd. Ranke (Königsberg Hartung'sche Zeitung).

C. H. Beck'sche Verlagsbuchhandlung Oskar Beck München 
Erster Band: Zur Paläographie und Handschriftenkunde. Herausgegeben von Dr. PAUL LEHMANN. Mit biographischer Einleitung von Dr. Franz Boll. 1909. LXXV, 263 S. gr. $8^{0}$. Geheftet M 150.-. Zweiter Band: Einleitung in die mittellateinische Philologie. Herausgegeben von PAUL LEHMANN. 1911. 1X, 176 S. gr. 8a. Geheftet M 80.-. Dritter Band: Gesammelte kleine Schriften. Herausgegeben von S. BRANDT. XV,344 S. gr. $8^{\circ}$. Geheftet M 150.-

\section{Quellen und Untersuchungen zur lateinischen Philo- logie des Mittelalters Begrindet von LUDWIG TRAUBE, herausgegeben}

I. Bd., 1. Heft: S. Hellmann: Sedulitus Scottus. 1906. XV, 203 S. gr. 8*. M 85.-. 2. Heft: E. K. Rand: Johannes Scottus. 1906. XIV, 106 S. gr. $8^{\circ}$. M 60.-. 3. Heft: Heribert Plenkers: Untersuchungen zur Ubberlieferung der ältesten lateinischen Möndisregeln. 1906. Xl, $100 \mathrm{~S}$. gr. 80. M 70.-. II. Bd.: Ludwig Traube: Nomina sacra. Versuch einer Gesdidate der christlichen Karzung. Mit Traubes Porträt. 1907. X, 287 S. gr. 8. M 150.-. IlI. Bd., 1. Heft: Paul Lehmann: Franciscus Modius als Handschriftenforscher. 1908. XIII, 151 S. gr. 80. M 70.2. Heft: Joseph Becker: Textgeschichte Liudprands von Cremona. Mit zwei Tafeln. 1908. VIl, 46 S. gr. $8^{0}$. M 25.-. 3. Heft: E. A. Loew: Die ältesten Kalendarien aus Monte Cassino. Mit drei Tafeln. 1908. XVI, 84 S. gr. 8. M 60.-. 4. Heft: Karl Neff: Die Gedichte des Paulus Diaconus. Mit einer Tafel. 1908. XX, 23I S. gr. $8^{\circ}$. M 100.-. IV. Bd., 1. Heft: Paul Lehmann: Johannes Sichardus. 191I. X, 237 S. gr. $8^{0}$. M 100.-. 2. Heft: Charles H. Beeson: IsidorStudien. 1913. VIII, 174 S. gr. $8^{\circ}$. M 70.-. V. Bd., 1. Heft: Paul Lehmann: Vom Mittelalter und von der lateinischen Philologie des Mittelalters. 1914. III, 25 S. gr. $8^{0}$. Goswin Frenken: Die Exempla des Jakob von Vitry. Ein Beitrag zur Geschichte der Eirzählungsliteratur des Mittelalters. 1914. V, 154 S. gr. 80 . M 85.-. V. Bd.. 2. Heft: H. Walther: Das Streitgedidnt in der lateinischen Literatur des Mittelalters. 1920. IV, 256 S. gr. $8^{0}$. M 98.-

\section{Geschichte der lateinischen Literatur im Mittelalter}

Von Professor M. MANITIUS. I. Teil: Von Justinian bis zur Mitte des 10. Jahrhunderts. Mit Register. 1911. XIII, 776 S. gr. $8^{\circ}$. Geheftet M 170.-, gebunden M 230.-. II. Teil in Vorbereitung. (Müllers Handbuch der klassisdhen Altertumswissensdiaft IX. Band, 2. Abteilung.)

\section{Die deutschen Dichter des lateinischen Mittelalters}

in deutschen Versen von PAUL von WINTERFELD. Herausgegeben von HERMANN REICH. 3. Auflage. (Soeben erschienen.) Halbleinenband M 125.-, auf holzfreiem Papier in Halbpergament M 250.-.

„Dieses Buch kann sich rühmen, mit echt deutscher Gelehrten- und Dichtcrkraft Schätze der mittelalterlichen deutschen Frühızeit, die für das Allgemeinbewußtsein verschüttet waren, zu einer wahrhaft herrlichen und, will's Gott, dauernden Urstand gefihrt zu haben. Gestalten, die deutsch zu fühlen, aber nur lateinisch zu reden wußten, finden nach tausend Jahren auch die deutsche Sprache für ihre Leiden und Freuden, ihre Schmerzen und Scherze, ihr Erzählen und Fabulieren, ihr Sinnen und Trachten. Von einem Geiste, der in jahrelanger treuer Geistes- und Herzensarbeit zu innerlichstem, verstehendem Miterleben herangewachsen ist, neu belebt, ihrer fremdländischen Sprache entkleidet und mit sicherem Geschmack in eln modernes deutsches Gewand gehtillt, stelıen sic jetzt zugänglich und in Lebensgröße vor uns." Blätter für höheres Schulwesen. 
Deutsche Literaturgeschichte Von ALFRED BIESE. Erster Band: Zweiter Band: Von Goethe bis Mörike. - Dritter Band: Von Hebbel bis zur Gegenwart. Drei Bände mit vielen Bildnissen. 19. Auflage (80. bis 84 . Tausend). Soeben erschienen. Jeder Band in Halbleinen geb. M 150.-, in Halbfranz geb. M 300.-

„Eine so großzügige Darstcllung der gesanten deutschen Literatur, so umsichtig in der Auswahl und modern in der Auffassung, zugleich von so reifem, sicherem Urteil, so klar in den Umrissen, warm in den Farben und verständlich in allen Teilen, so aus einem GuB und mit siclıerer Gewalt über die Sprache geschrieben - ist bisher in dieser Art schwerlich geboten worden." Konservative Monatsschrift. - "Ein ganz ausgezeichnetes Buch! erfrischend von der ersten bis zur letzten Seite, ein Werk von edler und gebildeter Volkstümlichkeit." Neues Wiener Tagblatt.

\section{Deutsches Literaturlexikon}

Von H. ANDERS KRÜGER. Biographisches und bibliographisches Handbuch mit Motivübersichten und Quellennachweisen. VIII, 488 Seiten gr. ${ }^{\circ}$. Gebunden M 70.-

„Vortrefflich ist die Anlage, die sich nicht auf die Schriftstellernamen beschränkt, sondern mannigfache sachliche Gesichtspunkte fruchtbar macht und dem Benützer mancherlei zweckmäßige Hilfen stoffgeschichtlicher, motivischer, örtlicher Bestimmtheit an die Hand gibt. Uberall begegnet mạn sorgfältiger und gediegener Arbeit, von der ältesten bis zur neuesten Zeit. “ Prof. J. G. Sprengel (Frankfurter Zeitung).

Deutsches Sagenbuch In Verbindung mit anderen herausgegeben von
FRIEDRICH von der LEYEN. 1. Teil: Die Götter und Göttersagen der Germanen. Von Frdr. v. d. Leyen. 2., neubearb. Aufl. Geb. M 55.2. Teil: Die deutschen Heldensagen. Von Frdr. v. d. Leyen. Vergriffen. Neue Aufl. erscheint Sommer 1922. 3.Teil: Die deutschen Sagen des Mittelalters. Von Karl Wehrhan. 1. Hälfte: Kaiser und Herren. Geb. M 48.-. 2. Hälfte: Stämme und Landschaften. Ritter und Sänger. Geb. M 52.-. 4. Teil: Die deutschen Volkssagen. Von Friedrich Ranke. Vergriffen. Neue Auflage erscheint Sommer 1922.

„Eine ausgezeichnet gelungene kritische Erneuerung der unvergänglichen Schätze altgermanischer wie deutscher Sage. Nicht nur der Gelehrte findet dabei mannigfach selne Rechnung. Lehrer und Schüler können hier überall für ,das Deutsche' im weitesten Umfang anknüpfen, jung und alt sich an dem unerschöpflichen urzeitlichen Jungborn reich erquicken und ergötzen." Bayer. Zeitschrift für Realschulwesen.

\section{Studien zur germanischen Sagengeschichte Von FRIEDR.}

Erster Band: Beowulf. 1910. X, 409 Seiten gr. ${ }^{\circ}$. Geheftet M 120.-. - Zweiter Band: Sigfrid. 1912. X, 281 Seiten gr. $8^{\circ}$. Geheftet $M$ 80.-

\section{Die Gedichte und die Sage von Wolfdietrich untersuchungen $_{\text {ihre Ent- }}^{\text {ing }}$} stchungsgeschichte. VIII, 420 Seiten gr. $8^{\circ}$. Geheftet M 150.-

\section{Sankt Servatius oder Wie das erste Reis in deutscher} Zunge geimpft wurde Ein Beitrag zur Kenntnis des religiösen und literaZunge geimptt wurde rischen Lebens in Deutschland im 11. und 12. Jahrhundert. Von FRIEDRICH WILHELM. XV, XCVI, 321 Seiten gr. $8^{\circ}$ mit 2 Tafeln. Geheftet M 120.-

C. H. Beck'sche Verlagsbuchhandlung Oskar Beck München

C. H. Beck'sche Buchdruckerei in Nordlingen 

PLEASE do NOT REMOVE CARDS OR SLIPS FROM THIS POCKET

UNIVERSITY OF TORONTO LIBRARY 
